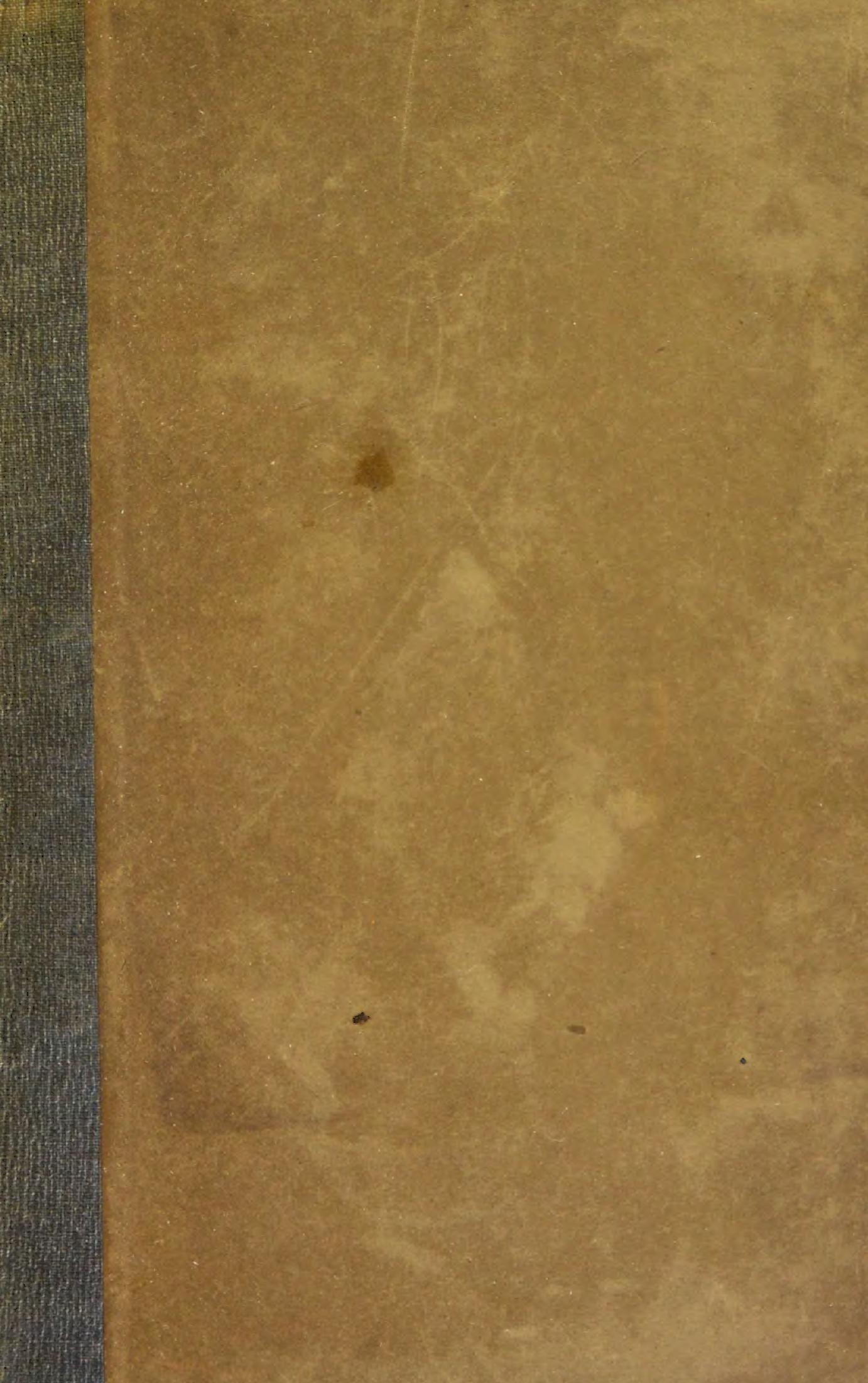




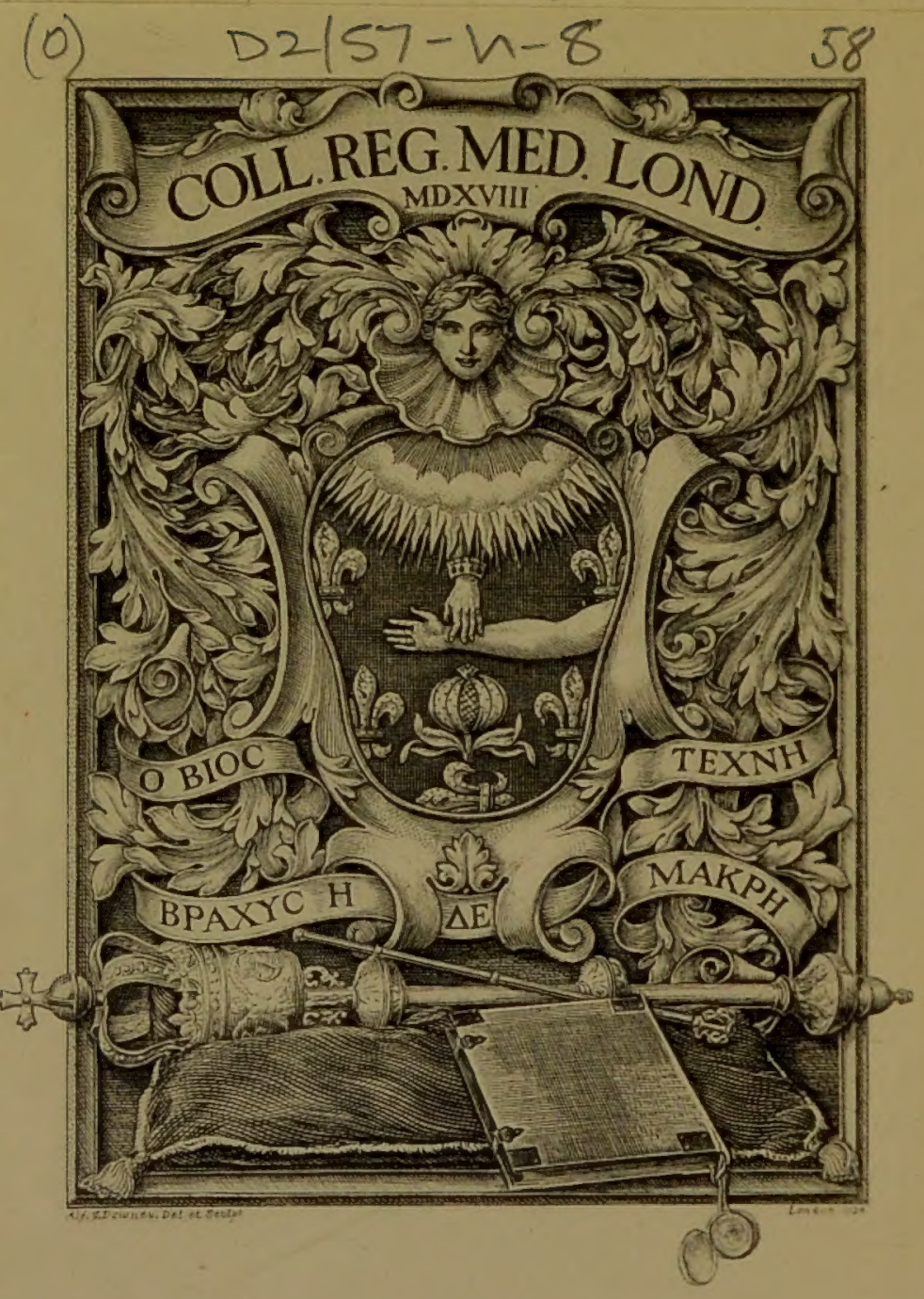




$\operatorname{lig}_{2}=$
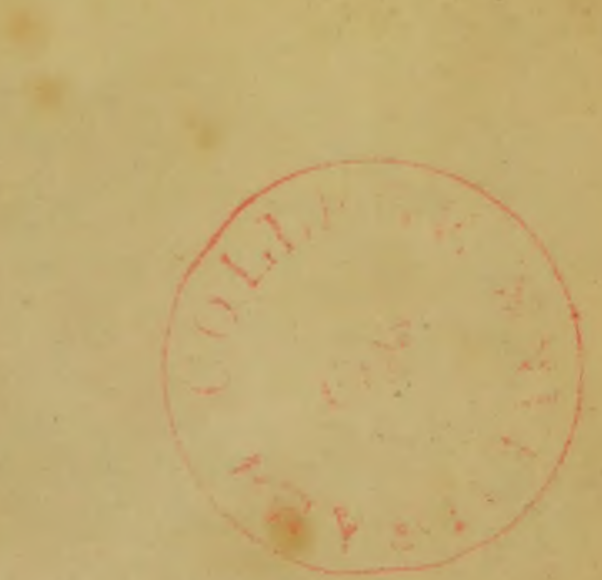

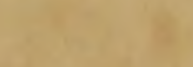




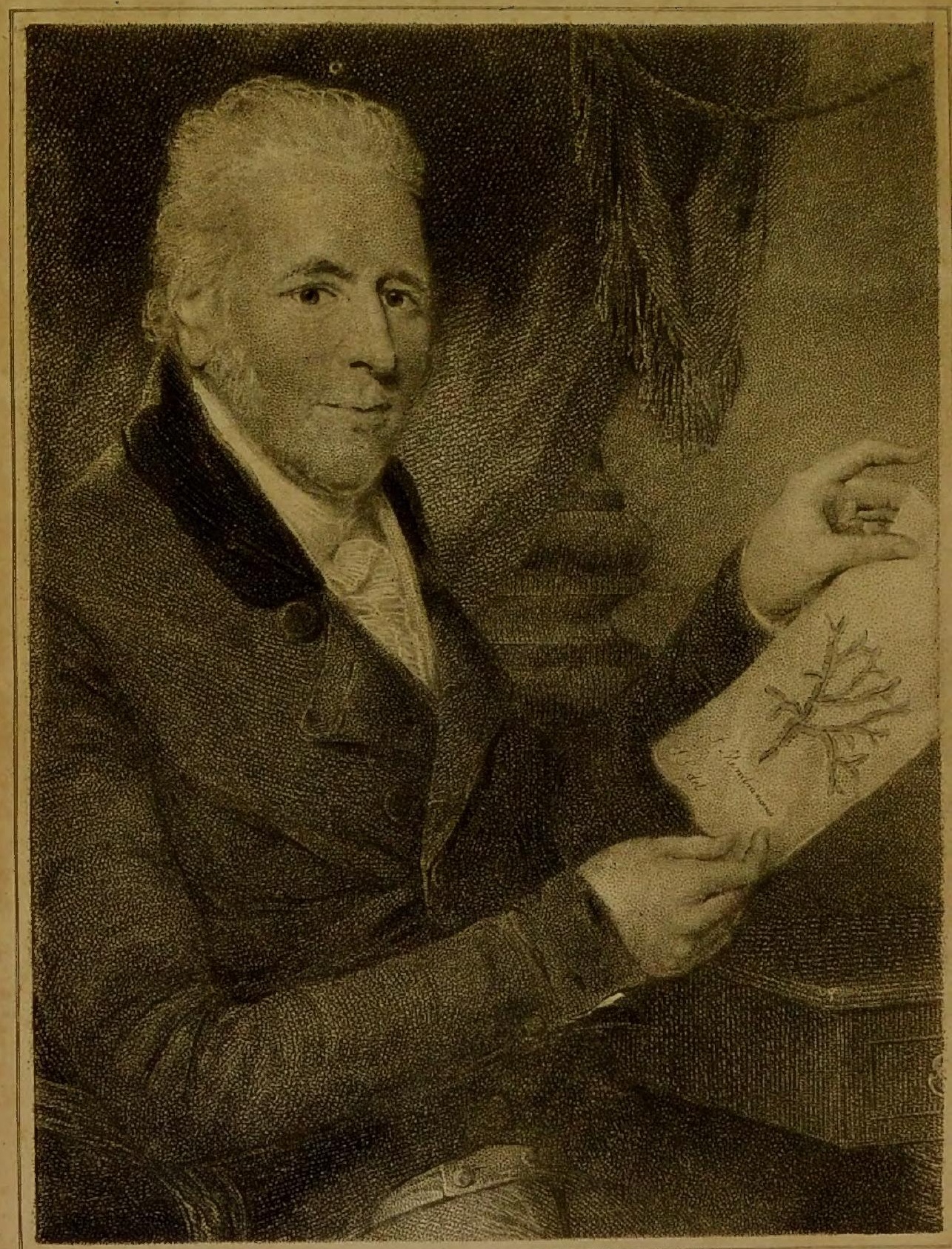




\title{
THEOPHRASTI ERESII
}

\author{
DE
}

\section{HISTORIA PLANTARUM}

\section{LIBRI DECEM,}

\author{
GRACE.
}

CUM

\section{SYLLABO GENERUM ET SPECIERUM,}

GLOSSARIO, ET NOTIS.

\section{CURANTE}

JOH. STACKHOUSE, Arm. Soc. Linn. S.

\section{OXONII,}

EXCUDEBAT S. COLLINGWOOD.

Prostant venales apud J. Parker, Oxonii; T. Parne, White et Cochrane, et J. Murray, Londini;

et J.Deighton, Cantabrigix. MDCcCxiII. 


\begin{tabular}{|c|c|}
\hline ROYAL & $\begin{array}{l}\text { LEGE OF PH } \\
\text { LIBRARY }\end{array}$ \\
\hline CLASS & 58 \\
\hline$A C C N$. & 12464 \\
\hline SOURCE & \\
\hline DATE & \\
\hline
\end{tabular}




\section{PRAFATIO.}

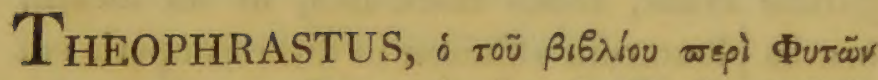

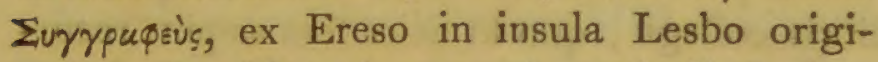
nem duxit. Platonis a teneris annis discipulus, post Aristotelis ; et, processu temporis, comes etiam et amicus, pallio defuncti, in LyCEO potitus est, tanta cum gloria sua, ut non modo $\mathrm{ab}$ Atheniensibus in deliciis habitus esset, sed a Cassandro et Ptolemere, Alexandri Magni successoribus, pari ac MagisTER IPSE veneratione persequebatur. Scripta ejus prodiere numero usque ad ducentum, ut a perhibent; ex quibus extant adhuc, plus minus, viginti : celebratissimi quidem, libri de-

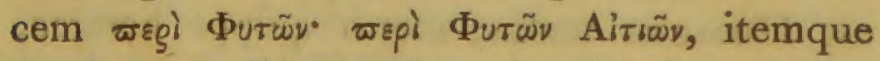
Xapáxтทৎєs. Centenario major, brevitatem vitæ humanæ deploravit; spatio, ut ait, longiori Cornici et Cervo, quam homini concesso. Antiquissimus hic rei herbariæ investigator, plantas circiter quadringentas, ut in variis peregri-

2 Diogenes Laertius vita.

a 2 
nationibus se forte ei obtulissent, enumeravit; paucas quidem obiter, utpote omnibus sui temporis notissimas, plurimas vero accuratissime : individuas illas sane, nulloque ordinis methodici vel Nomenclaturæ systematicæ respectu habito. Quotiescunque vel de habitu alicujus plantæ, vel de partibus ejus sermo erat; et præcipue quando vires medicæ quædam indagandæ erant, toties fasciculos, ut ita dicam, breves plantarum affinium in diversis operis sui libris collegit; quo fit ut eadem sæpius recurrat species. Hinc fastidium enatum Botanicis superioris sæculi, cui forsan addendæ sunt, cum ex lingua technica et insolita, tum ex textus corruptione ortæ difficultates.

THEOPHRASTI nimirum ubique textus corruptissimus; et, si codices MSS. litteris confluentibus exaratos, et vocum compendiis ubique scatentes, inspicias, minime mirum videbitur rem ita se habere ${ }^{b}$; præsertim si scientiæ Botanicæ ignaros omnino fuisse eorum exscriptores memineris. Omnium quidem ảxpı $6 \varepsilon_{\varepsilon}^{\prime} \alpha \tau 0 s$ est Homeri textus, metro quippe heroico,

b Operæ pretium erit transcribere quæ de hac re M. Camus, celeberrimus Aristotelis Historiæ Naturalis Editor, jampridem observavit: "Les abbréviations fort en usage dans les MSS: " Grecs; et les ligatures composées de plusieurs lettres, ont " donné lieu à bien des erreurs dans les éditions de ces livres, " soit à cause de la difficulté d'en deviner quelques unes, soit " à cause de leur ressemblance avec d'autres lettres."

Discours sur Aristotle, p. xxuxv. 


\section{PRIEFAIO.}

onnium auribus accommodato scriptus; adeo ut alienam vocem locum non suum occupare, salva soni concordia, vix possibile fuerit. At Botanico cuivis ThEOPHRASTI descriptiones assidue volventi, et plantas ipsas in agris simul investiganti (præcipue quibus contingat eas investigare in loco natali) simile quoddam, ni fallor, eveniet : specimen ipsum sub oculis erit textus commentarium, locisque corruptis, ut plurimum, medelam suppeditabit.

Singulare quoddan evenisse MSS. Aristotelis et Theophrast ex Strabone licet colligere; ita enim legimus: Nriseù rà' Aproro-

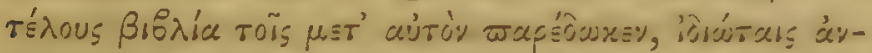

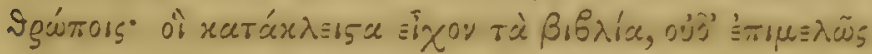

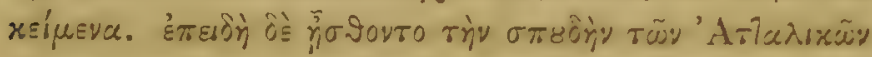

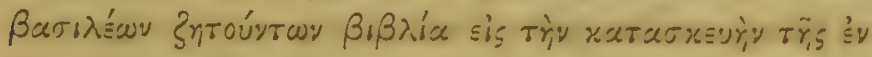

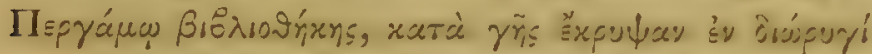

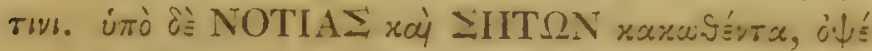

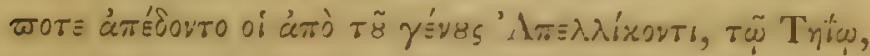

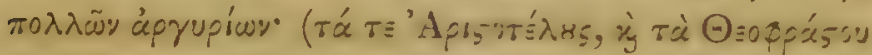

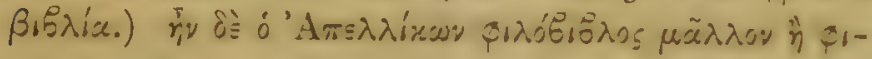

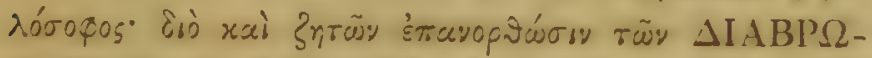

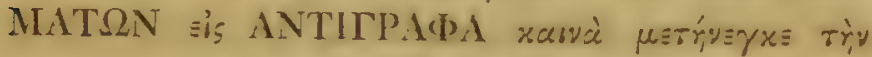

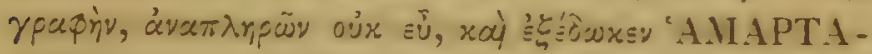

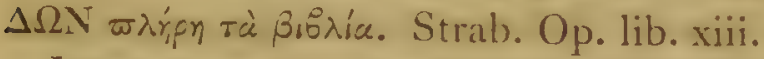

Inter errores innumeros libet exemplum depromere; ubi, speciminibus cum descriptione comparatis, ex meris tenebris vera eluccbit lectio. Generis 'Èăry Linn. duæ enunerantur

a 3 


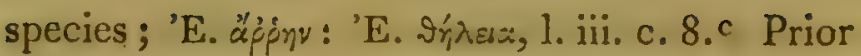
describitur "foliis magis pungentibus xà '̇ $\pi \varepsilon-$

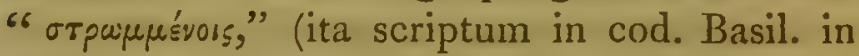

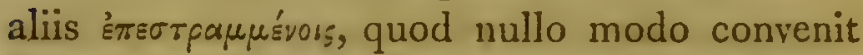
foliis Pinus:) quæ descriptio apte convenit P. Abieti Linn. ("Spruce Fir" nobis,) cujus folia coacervantur. Vid. Tab. fig. A. 'E $\lambda$ ár e contra, folium habet ws ๘tśpuyas (pinnas alæ)

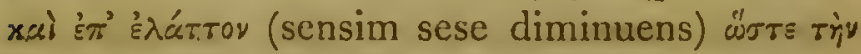

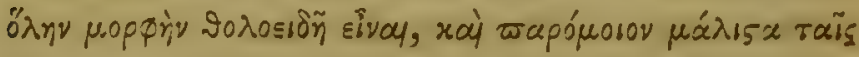
Boswtías xuv'sıs. (in marg. ed. Budxi legitur xúávors.) Locum hunc ita vertit TheоDORUs: " folium pinnatum, et in angustias tendens, " ut tota facies concamerata videatur, similis"que potissimum galeis Bootorum appareat." THEOPHRASTUM haud ita scripsisse facile quivis, ne dicam Botanicus, affirmabit; ThEoDORUM vero ignotum per ignotius Latine interpretari. Vox Tholus (Gr. @ónos) occurrit apud VARRONEM in describendo Ornithone Turdis servandis et saginandis constructo. VARR. 1. iii. c. 5. "Tholus camera interior "dense columnata; exterioribus lapideis, inte"rioribus ex Abiete tenuibus," sc. densis adco, ut parvulæ hæ aves minime transire queant. Ex structura Tholi clathrato-columnata, conjicere licet $\Theta$ ódov quoddam clathratum significare. Eśros, seu Cella penaria, Homer I Od. 
xxii. lignis crebris parallelis constructus videtur, quo aer facilius permect; sicut et $\Theta o ́$ xos, sive vaporarium in balneis. Hinc si ramulus, vel surculus extremus aliquis P. Picece L. cum foliis densissime ex opposito collocatis inspi-

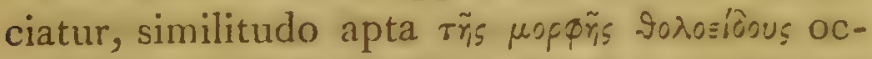
curret. (vid. Tab. fig. B.) Quod si vocem $x u-$ véaıs consideremus, nihil omıino cum ramo abietino commune habet. Substituo levi immutatione unius literæ vocem xтхуย́́

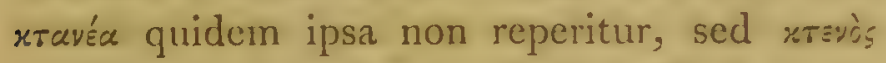
gen. a $x \tau=i i s$, pecten, est notissima, Dorice $x \tau x-$

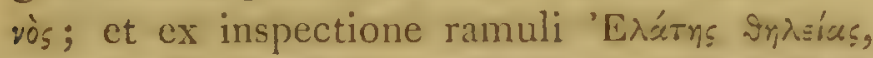
ceu Pinus Picex, cujus iconem exhibui, Tab. fig. B. licet conjicere xтаvéay Brwriay dentibus utrinque ex adverso instructam fuisse, ut in buxeis et eburneis nostris, Angl. " a double" toothed comb." Notandum etian est vocem ๘т́́puya pinnam alæe, xque ac alam significare; (vid. Hesych.) unde folium alutum superioris xvi Botanicorum, est folium pinnatum Linnei.

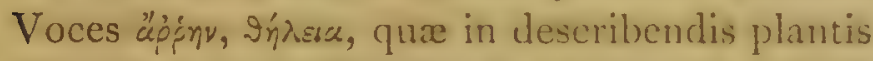
frequenter apud TirfopirRAsTum occurrunt, fertilitatem vel sterilitatem, habitumve plus vel minus robustum, indicare videntur, ut et vox i $i \pi 0$ s plantre nomini in compositione præfixus;

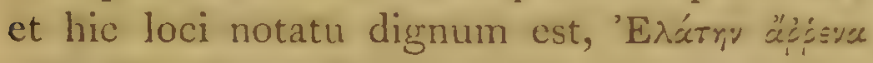
raro ante provectiorem retatis annum semina maturare. In aliis vero ejusdem auctoris locis distinctio hæc in Mares et Femineas $v . g$. in 
Palmis et Ficubus, clare indicatur. Methodum Palmas fœmineas polline masculo fœcundandi

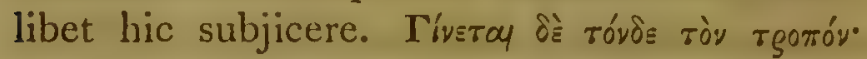

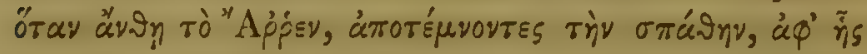

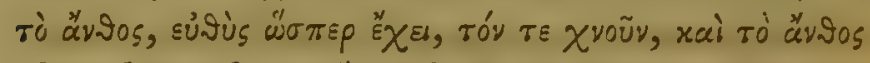

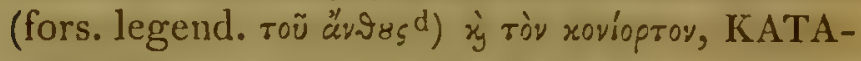

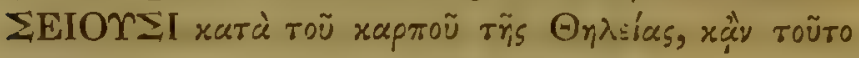

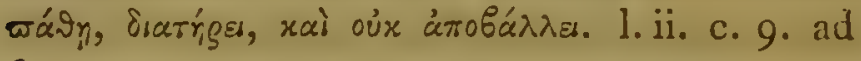
finem.

Nuperrime mihi in manus venit opusculum, cujus titulus "Tentamen in Historiam Planta"rum Trifophrasti, Auct. I. I. P. Molden"hawer, Hamburgi, 1791. Occasionem hujus "Auctoris libello, ut ipse ait, præbuit exem"plar editionis Aldinæ primæ, Historiæ Plan" tarum Theophrasti, et de Causis Plantarum, "variis lectionibus auctum, in Bibliótheca Re" gia Havniæ, una cum manuscriptis Alberti "Fabricii. In eo nempe cum occupatus fuerit, "ut utrumque opus commentario, notisque " criticis illustratum ederet, summo Theophrasti " acumine perculsus, et plura illum, quam vulgo "opinantur, vidisse perspiciens, Tentamen hoc, " ut specimen hujus instituti peritis tradit, ut "illorum suffultus judicio rationem operis " moderaretur." Quatuor tantummodo primi

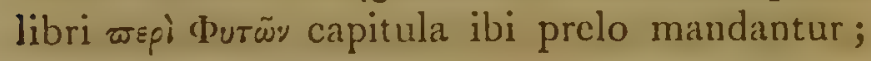
additis emendationibus textus, investigationi-

d Vid: voc: Xvoüs, Lex. Theophr. 
bus plantarum quæ in his continentur, et quæ de partibus plantarum, et de earum interna structura perspecta habuit THEOPHRASTUS. Apud nos etiam miscellaneo opere tractatus varios Historiæ Naturalis continente cel, vir Gul. Falconer, M.D. plantas Theophrasti et Dioscoridis, aliorumque scriptorum apud Græcos, additis Bauhini et Linnei synonymis, edidit, Cantabrigiæ, A. D. 1793. Ob variam sane Cl. scriptoris doctrinam, et inprimis summam Griecæ lingux peritiam, "Tabulam I'lan" tarum in priscis Scriptoribus Græcis maxime " repertarum," cuivis Naturæ inquisitori operæ pretium erit studiose perpendere; non tamen hujus instituti est discrepantia nomina plantarum Theophrasti et Dioscoridis, aliorumque in concordian redigere, sed tantummodo ex descriptionibus ejus in unum collatis Plantas Theorirasti clariores in lucem proferre.

Non autem tanquam Auctor systematicus, uti recte admonet LINNEUS, contemplandus est Theorhrastus, etsi inter l'hysicos vix magistro cjus Aristoteli sit posthabendus.

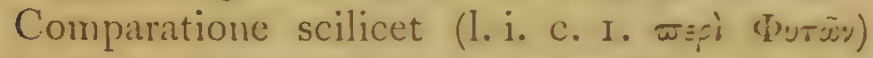
instituta inter animalia et vegetabilia, $\tau \dot{s} \mu \dot{s}, c r_{1}$,

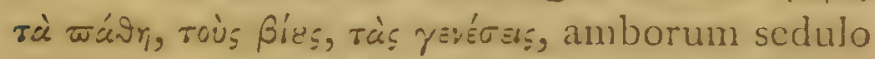
definit. Vires medicas etiam, et varias culturæ methodos incredibili fide ac cura persequitur, ut magis rem quotidiani usus legere videamur quam longinqua vetustate abditam. Cujus rei 
exempla pauca liceat hoc loco proferre: 1 . Methodum uvas sine acinis producendi. 2. Insita ex duobus Vitis, Viniferce L. varietatibus in unum conjungendi, ut albæ et nigræ in codem racemo inveniantur uvæ. 3. Luxuriem nimiam, fisso stipite, calculo interposito reprimendi. 4. Amygdalorum sterilitatem, ope fistulæ ferreæ in truncum circumactæ, quo succus nimius effluat, corrigendi. 5. In quamplurimis fructiferis arboribus corticem auferendo, vel circumscindendo: optime enim noverat vir acutissimus, quod quidem sæpius diserte monuit, fertilitatem ex debilitate, sterilitatem ex robore provenire.

Quod ad rationem hujus operis attinet, in animo habui illud quam minimæ molis edere, ut Botanicum comitetur in agro, et in itineribus suis longinquis; ut Glossarii solius ope, calci libri subjiciendi, TheOPHRAsti plantarum descriptiones cuivis litteris Græcis vel modice imbuto, perspicuas reddat. Hinc quoque minime desperandum, ut supra observavi, errores textus progressu temporis emendandos fore ex autopsia in loco natali.

Catalogus Plantarum exhibetur Græco-Latinus, itemque Latino-Grecus ordine alphabetico exaratus juxta nomenclaturam LINNEI.

Voces techuicæ, et minus usitatæ, asterisco notantur: harum explicatio in Glossario occurret. Voces uncis inclusæ non sunt Aucto- 
ris, sed ad supplendam miram ejus brevitatem additæ sunt; adeo enim nimia est, si ita dicam, ista brevitas, ut etiam ipsius Scaligeri, ut fatetur, persepe aciem eludat. Perspicuitas dictionis, præsertim in operibus didacticis, virtus est omnium maxime appetenda, nec incurrendum periculum obscuritatis, secundum Horationum illud,

\author{
Brevis esse laboro, \\ Olscurus fio.
}

P.S. Animadvertent queis in manus venerint "Illustrationes nostree," genera et species ibi designatas intervallo temporis, ex quo prodierunt, paullulum nomenclatura variare, quod studio in Theophrastum per biennium continuato præcipue tribuendum. 

Naturce curiosis hand inutilem mith videor navare Operam subjiciendo ex cel. Moldenhawer, recensionem Editiomum Theophrasti $\pi \equiv p i$ Фutũv; ut et Commentaria, et Traductiones, separatim editas, vel ineditas, et quarum usquam occurrit mentio.

\section{I.}

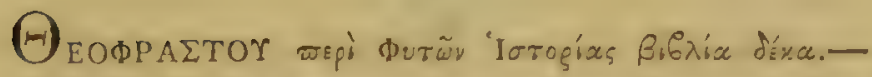
Subjectis Libris de caus. plant. et metaphy.s. Aristotelis problem. mechan. metaphys. Alexandri Aphrodis. problem. (omnia Griece.) Ad calcem: Exseriptum lenetiis in domo Aldi Manutii, Culendis Junii. MI. III D. fol. ut quartum tomum Aldine prime Aristotelis constituat. Sed hicce tomus sxpius in duo volumina divulsus, ita ut prius Ilistor. Pl. et libros de Caus. Pl. contineat: inde quibus hoc solummodo volumen contigit, recensent Aldinam sine (mno. Alii annum quo incepta (1495), alii quo finita (1498, hec Aristotelis et Theophrasti editio afferunt.

l'rafixa est Aldi Manutii ad Albertum Pium Principen epistola, qua se exemplaribus usum profitetur. Princeps hac editio et reliquarum omnium est fundus, quam Oporinus variis lectionibus et conjecturis auxit, Heinsius correxit, Bodæus suis aliorumque conjecturis cumulavit. 


\section{xiv}

II.

Theophrasti Opera, summo studio partim hinc inde conquisita, atgue in unum veluti corpus redacta: partim a multis, quibus etiam hactenus scatebant, mendis, doctorum virorum industria, ac meliorum exemplariun ope repurgata. (Græce) per Jo. Oporinum. Basilea 1541.

Contulit Oporinus Aldinie primæ textum cum versione Gazæ, emendatiouces inde haustas, et suas quasdam conjecturas margini addidit. In cextum recepit paucas, easque apertissimas.

III.

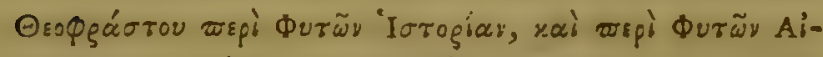

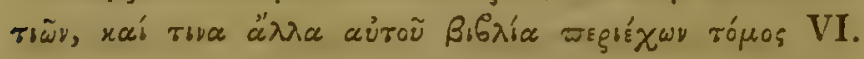
(post opera Aristotelis. Græce.) Ad calcem: Venetiis, apud Aldi filios. Expensis vero Nobilis viri Domini Federici de Turrisanis eorum avunculi. 1552. 8. Recusus Aldinæ primæ textus; obviis quibusdam correctionibus, parcissime licet interpositis ${ }^{2}$.

\section{IV.}

Theophrasti Eresii Grace et Latine Opera omnia. Daniel Heinsius textum Gracum locis infinitis partim ex ingenio partin e libris emendavit : hiulca supplevit, male concepta recensuit: interpretationem passim inter-

- Theophrasti de Historia Plantarum. De Caus. Plantarum ete. Gr. fol. Venet. Aldus. 1503. recenset Quesncl. Catal. Bibl. Thuan. P.II. p. 200. De qua dubito. Orta forsan ex Aldina prima, errore facili. Vid supra. 
polavit. Cum indice locupletissimo. Lugduni Batavorum, ex typographio Henrici ab Hastens. Impensis Jo. Orlers, And. Cloucq, et Jo. Maire. 1613. fol.

N. B. Ad MStum Heidelbergense et Aldinam primam variis lectionibus, locis Plinii parallelis, et conjecturis a viro quodam erudito auctam, textum corrigere conatus est. Cum vero nusquam innuat, manuscriptorum fide, an Plinium secutus, an conjectura inductus enendaverit; tenuis sane hujus editionis auctoritas. Gazæ versionem textui oppositam passim correxit ; licet quæe emendatrice manu plurimum egebant, omissa esse fatendum sit. Conf. Ezech. Spanh. obs. ad Aristoph. Plut. r. 1088. Moldenhawer.

\section{V.}

Theophrasti Eresii de Historia Plantarum libri decem, (omiss. Libri X. fragm.) Frr. et Lat. In quibus textum Gracum variis lectionilns, emendationibus, hiulcorum supplementis; Latinam Guze. versionem nova intcrpretatione ad margines: tolum opus absolutissimis cum notis tum commentariis: item rariorum plantarum iconibus illustravit J. Bodrus a Stapel. Cum indice Tocupletissimo. Apud Henricum Laurentium, Amstelod. 1644. fol.

Vix absoluto labore mortuus auctor, Egberto Bodro parenti vulgandum reliquit opus. Omnia effecit Bodæus, qua illa tempora, atque illa ætas ferre potuit. Plura in veterum scriptis ad restituendum explicandumque textum sparsa, vasta eruditione effudit. Conjectura ctiam acute usus, licet Plinio nimiun 


\section{xvi}

tribuat. In extricandis quoque plantis Theophrasteis sæpius felix. Sed obscura tum temporis Græciæ, finitimarumque regionum flora, adegit virum sane eruditum, ut ad plantas adeo Americanas anxius confugeret. Neque mirum, quæ de interna plantarum structura, vegetationis legibus, sexus mysterio Theophrasto perspecta, fugisse virum, ommibus quibus nos suffulcimur præsidiis destitutum. Textum Heinsianum recepit. Varias lectiones Aldine secundx, Basileensis, negligentius licet; tim suas, Scaligeri, Constantini, Salmasii conjecturas margini addidit: quarum non nullas in notis defendit vel refellit. Gazæ versionem ab Heinsio correctam, suis emendationibus in margine additis, textui opposuit. Scaligeri ac Constantini animadversiones suis præposuit. Icones obscuræe sane et incertæ, eadem magnitudine plantas maximas et minimas sistunt. Moldenhawer.

N. B. Icones hæe fere omnes ex Herbario Gerardi a Johnsono emendato. London. 1633.

\section{VI.}

VERSIONEM Historiæ Plantarum Latinam, Nicolai V. Pont. Max. nutu, exhibuit Theodorus Gaza. Quæ maguum sane hujus viri acumen, et linguæ utriusque facultatem demonstrat. Cum vero verborum adeo ordinem constructionemque assequi vult, spissus sæpius et parum Latinus. Quæ diuturna solum plantarum observatio evolvit, impedivisse virum; extatis illius rationem perpendenti minime mirum. In capitum distinctione, quam primus in- 


\section{xvii}

stituit, sæpius peccasse plures questi sunt. Uno. codice solum, et eo corrupto ${ }^{b}$; Aldinis tamen pra-. stantiore usus, ni omnia conjectura tribuenda ${ }^{c}$.

Tarvisi, per Bartholomcun Cunfalonerium de Salodio. 1483. fol. Cf. Braun. notit. hist. litt. P. II. p. 101.

\section{VII.}

Theophrasti Historia Pl. libr. IX. et decimi principium duntaxat, de Caus. Pl. libr. V. Theodoro Gaza interprete. (Absque ulla nota. Srec. XTT.) 8ro. 13ibl. Pinelliana pag. 258. Boehm. bibl, hist. nat. P. III. V.I.p. 91 .

Cum variis scriptis Aristotelis codem interprete, Venetiis, apud Aldum Manutium. 1501. fol. Qui

b Vid. ejus præfat. p. 110. Ald. 1.

c Ampla sane in hac versione ad restituendum textum Hist. Pl. et operis, prosertim de Causis Pl. materies. Ita de Caus.

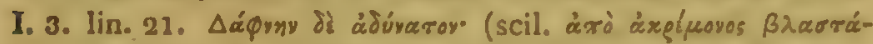

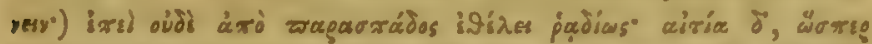

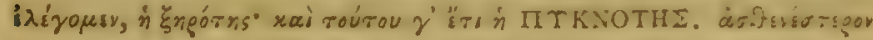

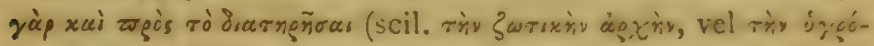

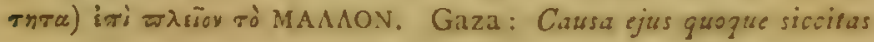
est atque rarilas; quod enim raro laxoque corpore est, infirmius est, quam ut humorem caloremgue scrvare diusius possis. Legebat

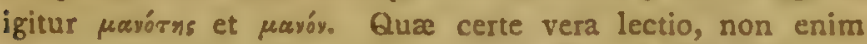

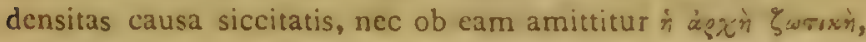
sed ob raritatem, ut sæpe tenet auctor. In proxime adeo se-

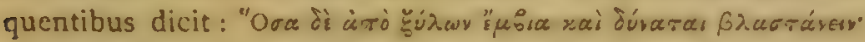

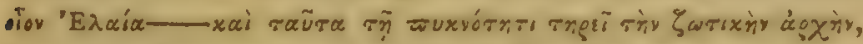

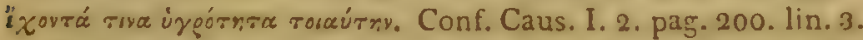

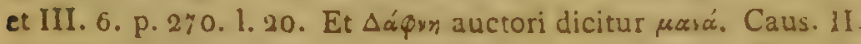
p. 25.1 .5$. 


\section{xviii}

eam cum Græcis exemplaribus contulit, et plura, vel omissa vel perperam impressa, emendavit, addidit.

\section{VIII.}

Repetita hæc editio, in œdibus Aldi, Venetiis, 1513. fol. ad Aldinam impressa, quæ prodiit cum libris de Caus. Plant. typis C. Wechel. Parisiis, apud Egidium Gourmonctum. 1529. 8vo. Cum iisdem et $\boldsymbol{A}_{\star}$ ristot. Hist. Anim. apud Crutandrum, Basilea. 1534. fol. et 1550. fol. Boehm. P. II. V. I. p. 7.

Iterum cura Jordani, qui corrupta quædam ab Aldo omissa restituit, apud Theobaldum Paganum, Lugduni. 1552.8vo. et apud Guil. Rovillium, ibid. eod. 8 vo. Utræque non nisi tituli plagula diversæ, et ad calcem appressuin : Excudebat Nic. Bacquenoius. 1552. Trew. Catal. Opp. Bot.

IX.

De Suffruticibus Herbisque ac Frugibus libri quatuor, (VI. ad IX.) Theodoro Gaza interprete, acc. Plinii Natur. Hist. L. XX. capita tria. Ad calcem: $A r-$ gentor. per Henr. Sybold, mense Augusto. 8vo. (sine anno.) Præfationem præfixit Henr. Sybold, qua his libris separatim edendis se fuisse auctorem testatur. Trew. Catal. Opp. Bot. (Cujus exemplari manu adscriptus erat annus 1528.) Bibl. Reg. Paris.

\section{$\mathbf{x}$.}

Libri tres priores ITALICE versi prodicre tit. Istoria delle Piante di Teofrasto Libri III. tradotti in Italiano da Mickel Agnolo Biondo. In Venezia. 1549. 


\section{xix}

8vo. Haym. Bibl. Ital. p. 200, 5. Conf. Tirabosch. Litter. Ital. T. VII. P.II. p. 98. et 19.

Commentaria qucedam et Ilustrationes separatim occurrentes.

I.

Primum Julius Casar Scaliger acute varia, sententiarum præcipue seriem eruit; licet inanibus sæpius disputationibus impediatur. Herbarum quoque cognitione nimis destitutus, quæ subtilius observavit auctor, perturbat primun, tum refellit atque castigat. Conjecturas quastam subtiles affert. Prodierunt ejus Animadversiones in Iistorias Thenphrasti apud Joannam Jac. Juntre F. Lugd. 1584. 8 vo.

Additæad calcem Roberti Constantini annotationes, qui pauca, ast ea acutissima attulit, et felicissimo plerumque successu textum emendat, Gazæe versionem corrigit. Verbis præterea aptus et pressus.

\section{II.}

Felicis Accoromboni cxplanatio sententiarum difficilium in Theophrasti libris de Plantis, (Hist. Pl. et de Caus. Pl.) Cum interpretatione obscuriorum locorum et sententiarum omnium operum Aristotelis. Romec, apud Sanctium et Soc, 1590. fol. Pag. 697-727.

In salebrosis impeditisque locis sententiarum or dinem felici sæpe successu indagat.

b 2 


\section{$\mathbf{x} \dot{x}$}

III.

In libros V. priores Solenandrum commentatum esse, Hallerus refert. Bibl. Bot. I. pag. 35.

\section{IV.}

Differentias plantarum Theophrasto observatas, ordine systematico disponere conatus est Conr. Gesnerus. Inscriptus liber : De stirpibus et e:trum partibus tabula, ex Theophrasti pracipue libris confecta. Ejusdem De stirpium collectione tabulis. Argertorati, 1553. 8vo. Recus. cum iisdem per Casn. Wolphium, Tiguri, 1587.8vo.

N. B. Mancum nimis tentamen.

V.

Theophrasti sparsas de Plantis sententias, in continuam seriem secundum litterarum ordinem dispositas, edidit Casar Odonus. Bononia, per Alexandrinum Benatium, 1556. et 1561. 4to. Bumald. Bibl. Bot. p. 27. Seguier. Bibl. Bot. p. 131. Bauer. Bibl. Libr. Rar. IV. p. 181. Boehn. Bibl. N. H. P. III. V.I. p. 94. Conf. 'Tiraboscb, Litterat. Ital. T. VII. P.II. p. 19.

\section{VI.}

Epitomen medicam de differentiis herbarum ex Hist. $P l$. Theophrasti composuit Ildefonsus Sorolla. Valentia, 1627. et 1642. 8vo. Seguier. Bibl. Bot. p. 185. Boehm. P. III. V. I. p. 95. 


\section{$\ddot{x} \times i$}

\section{VII.}

Animarversiones sive Observationes in Libros de Historia et de Causis Plantarum Theophrasti facto et observatce circa arbores, frutices, subfrutices, stirpes, plantas, et herbas, et ad nomen Italicum et vulgatum pro viribus redarta. Per Dominicum Vignam. Pisis, apud Sylv. Marchettum, et Cur. Massinum. 1625. 4to.

N. B. Plantas 'Theophrasteas, ordine alphabetico dispositas, determinat. C. Gesneri, Dodonxi, Delechampii, Clusii, rel. sententias compilat, nullis argumentis additis.

\section{VIII.}

Textus 'Theophrasti restitutio; et plurium, quae antiquitatem respiciunt, explicatio, a .Jo. Mearsio Sen. in Lectionum Theophrastenrum Libello. (ad calcem opusculi de scriptis Theoplurasti deperditis.) Luggl. Bat. ex off. Elsevir. 1640. 12mo. Recusa in Thesauro Gr. Gronov. Vol. X. et in Opp. Meursii ex recens. Jo. Lami, Vol. IV. p. 122-131.

\section{IX.}

Loca quxdam impedita, corrupta, salebrosa, felici sape successu corrigit, emendat, illustrat, Salmasius in Exercitatt. Plin. in Solin.

X.

Nonnulla explicare studuit Hieronymus :Mercurialis: Variaruin lectionum in medicince scriptoribus libr VI. apud Juntas, Venet. 1588. 4to. 


\section{xxii}

$\mathrm{XI}$.

Sosephus Scaliger: Animadversiones in Guilandini Commentarium in tria Plinii capita de Papyro. Opusc. Paris. 1610. 4to.

\section{XII.}

Plura revelavit Jac. Palmerius in Exercitationibus in optimos auctores Gracos. Lugd. Bat. 1668. 4to. pag. 582-603.

\section{XIII:}

Caput viii, lin. 17.-cap, xi. lin. 26. Libri IX.e duobus codicibus Sec. XIV. et XV. bibliothecæ Laurentianæ edidit Bandini. Catal. T. III. p. 431. seqq. Quæ valde, varia licet fortuna, a lectione vulgata recedunt.

\section{XIV.}

The Calendar of Flora by Theophrastus. At Athens. Latitude $37^{\circ} .25^{\prime}$. By Benj. Stillingflect. Published in his Miscellaneous Tracts relating to Natural History, Husbandry, and Physick. Lond.1762.8vo. p.319327.

Collegit plantas Græcas, quarum efflorescentiam Theophrastus tradidit; in quibus determinandis $J$. Rajum plerumque sequitur. Maximam longe partem omissam esse dolendum est.

\section{$\mathrm{XV}$.}

The literary Life and select Works of Benj. Stillingfleet, with unpublished Observations on some of the 


\section{xxiii}

Plants of Theophrastils. By W. Coxe, A.M. Archdeacon of Sarum. London, 1811.

\section{XVI.}

Variæ lectiones duorum codicum, illis quas editio Heinsiana exprimit omissis, prodierunt in programmate Abrah. Kallii, nonnulla de Theoplirasti ITistoria Plantarum bene merendn, subidia. Hurn. 1772. 8vo.

Accepit nempe Alb. Fabricius e bibliotheca Marq. Gudii Aldinam primam Hist. et de Cans. Pl. valiis lectionibus auctam, quæ cum MSS. Fabricianis delata est in bibliothecam Univers. Harn. Inspexi exemplat. Nec descripti nec nominati codices. Alterius codicis (quen H. 1. noto) lectiones in ora libri adscripsit Hermolaus Barbarus; alterius (quem H. 2. signo) ex Iermolai B. et Scipionis Carteromachi schedis excerpsit Marq. Gudius.

Priestantissimus ille, qui corruptelis inveteratis medelam inopinatam afferat, et accuratius collatus; hic minus vetus ac miuus prastans, et sparsin solummodo inspectus videtur. Tar. lect. in libr. de Caus. Pl. nondum promulgatæ sunt.

Commentaria inedita in Theophrastum, ot Observationes, quarum sparsim fit mentio.

Novam Hist. et libr. de Caus. Plant. editionem, versione nova et tela animadrersionum tali, qualem Casaubonus in Athenæum texuit, instructam, triginta annorum labore molitus est Casp. Hofmannus, Aristotelis, Galeni, Hippocratis, Athenæi, Diosco- 


\section{xxiv}

ridis, accurato studio, linguæ peritia, herbarum cog: nitione pro istis temporibus instructissimus; notisque praterea Dalechampii manuscr. a Jungermannio subministratis adjutus. Quæ anno demun 1643. ineunte absoluta, et prelum exspectans, post mortem auctoris transiit in bibliothecam Gothofredi Thomasii .

Scheferus etian medicus Francofurtensis emissurus erat utrumque 'Theophrasti de plantis opus, notis illustratum. Reines. Epist. XXXIII. p. 188. lin. 6.

- Adolphus quoque Vorstius in historia plantarum cum commentariis notisque criticis edenda, summo studio per plures annos elaboravit et fere absolvit opuse.

Petri Bellonii versionem Gallicam ineditam refert La Croix du Maine. Bibl. Gall. p. 385.

Benedictus Manzuolus episcopus postea Regiensis in Theophrasti de plantis operibus MStorum ope, et ingenio restituendis plurimum operæ posuit ${ }^{f}$.

- Castigationes Isanci Casauboni paucas, ad se olim

* Vid. Reinesii Epist XXXII1. p. 188.1.12. XXXIX.p.317. seq. XLII. p. 360.1.15. XLIV. p. 376.1.31. Hofm. Epist. ad J. C. Bauh. Richter. mantiss. I. p. 520 . seq. Baier Vita Medic. Altdorf. p. 65.

e Exspectabat collationem MSS. bibliothecæ Holsten. Petiit Th. Bartholinus ( 1660. ) post mortem auctoris a Joanne van Horne, ut urgeret apud hæredes editionem operis. Vid. Th. Bartholini Epist. medicinal. (ed. ann. 1740.) Cent. IV. Ep. LXVI. p. 352. et LXXIX. p. 407.

f Thuana p. 445. Il avoit toute sa vie travaillé sur Theo. 'phräste de Plantes, et lavoit restitue par l'dide des manusitrits, et par son esprit. 


\section{$X X V$}

missas, Dan. Heinsius C. Iofmanno per Richterum destinavit. 12 Jul. 1642. Vid, Richter. Epist. p. 158. Aninadversiones in libros de Caus. Pl. memorat Isauc Cusubonus in epistola ad Thuanum. A. 1598. Ep. CLV'JII. p. 81. ed. Almelov:

Renealmi Blesensis Medici emendationes ineditas in Theophrastum et Dioscoridem refert Ren. Moreau in epist. ad Hofmannum, p. 626.

Libros quoque de Cans. Pl. notis illustravit J. Bodeus, quas editurus erat Egbertus parens. Vid. edit. Hist. Pl. p. 1187.

g Scripsimus ea in Theophrasti libros de Causis Plantarum, quæ tibi posse probari non difficlimus. Nunquam putaveramus, divinum virum Cxsarem Scaligerum tantum spicilegium nobis reliquisse. 



\title{
CATALOGUS
}

\section{PLANTARUM THEOPHRASTI}

\author{
GRACO-LATINUS.
}

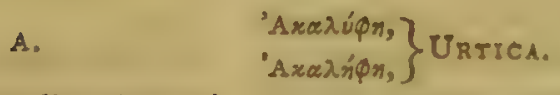

'ABgérovav, Santolina, Rosmari- "Axay\$os, Mimosa, Nilofica. nifolia.

"Axagve, Carduus, Acarna.

"Ayvos, Vitex, Agnus castus. 'Axóviroy, Aconitum, Lycocto-

"Ayperorss, Agrostis. num.

"A yXovora, Anchusa, tinctoria. "Aropos, Acorus, Calamus.

'Adínviav, Adiantum.

Aigeseos, Populus, nigra.

"Axrn', $\}$ Sambucus, nigra.

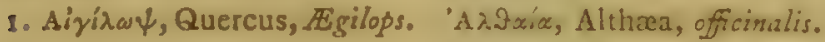

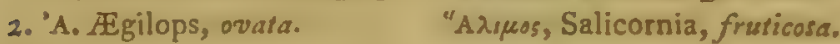

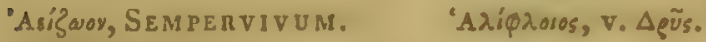

Airizugos, Cereale generis vi- 'Adwaírougos, Alopecurus. lioris, quasi hirco-triticum. I. 'Apá́saros, Origanum, $E$ -

Qu. de genere? sypriacum.

Aipúdoegs, ОRоваN СнЕ.

2. 'A. Asphodelus.

Aị $\alpha$, Lolium, iemulentum.

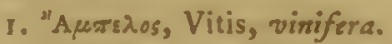

I. "Axayฟa, Atractylis, gummifera.

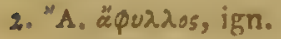

2. "A. "̈y ysa, v. Indica.

3. "A. 'Iscis, Vaccinium, $V_{7}$. tis, Idaa.

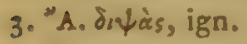

4. "A. 'Ivวิธหทे, V. n. I.

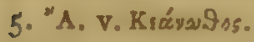

4. "A. ซáyrıa, Fuci species.

'A $\mu u ́ y \delta a \lambda$ os, $\}$ Amygdalus,

'A $\mu v y \delta \dot{\lambda} \lambda$, \} communis.

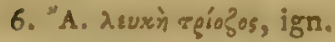

"Apeopes, AMOMUM.

7. "A. "H

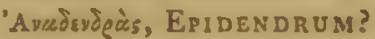

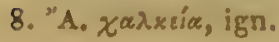

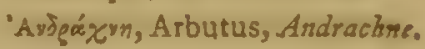




\section{XXViï CATALOGUS PLANTARUM THEOPHRASTI}

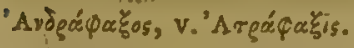

'Avieguaría, Andryala, integrifolia.

1. 'Avsеáry, AN в MONE.

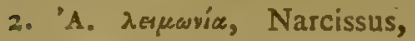
Pscudo-Narcissus.

"Avraloy, Anethum, horiense.

"Av9?ros, $\}$ ANTн EMIs.

'Ay:'ígeos, Asphodelus, Luteus.

'Ayqlópiryoy, 7 Antirrhinum ina-

'Ayríppiçor, $\}$ jus:

'Arapiry, Galiun, verrucosum. an Arctium, lappa?

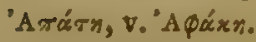

"Arros, Pyrus, Pyrus.

1. "A paxos, Vicia, cracca?

2. "A. "zpasos, Vicis?

'Apaxidva, Lathyrus, amphicarpus.

I. "A p̧ix, Quercus sp.

2. 'A. Cratagus, Aria.

'Agrrodoxia, ARIstoroch14.

"A prev\$os, Juniperus, communis.

'A próy aworoy, Plantago, major.

"A goy, Arum, Dracunculus.

'Arivn, an 'Arupivn?

'Arxior, LYcoperdoN.

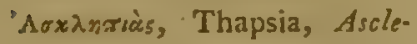
pissm.

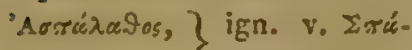

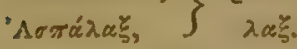

'Artrígexyos, $\{$ Asparagus, a'Arqúpayos, $\}$ phyllus.

"Adripionos, Aster, Atriciss.

"Arpóss.os, Asphodelus, ramo. sus.

'Arexyén, Clematis, Orientalis.

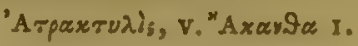

'A тǵá

1. 'A фárn, Lathyrus, Aphacis.

2. 'A. Heracium, vel LEONTODON.

'Aфágxn, Rhamnus, Alaternus. 'Apía, Caltha?

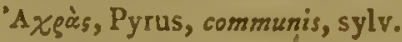
statu.

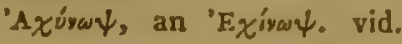
Kúvwభ. Flos ringens; fors. Antinrhinum, vel LinaR!A.

'A qivatov, Artemisia, absinthium.

\section{B.}

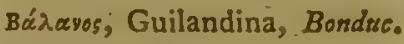
Bádrapos, Amyris, Gileadensis. N. B. Balsamus $B a$ lessan patrio sermone $\mathrm{a} \mathbf{D}$. Bruce vocatur.

Báros, Ru вus.

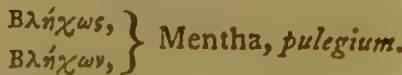
Bдіroy, ВцIтU м.

BodGorẃdın, Bulbocodium, vernum.

BorGivn, Scylla, unifolia.

I. Bòbòs, ign.

2. B. Eprópogos, Hyacinthus, Peruviamus?

Boúxęas, Ophrys, nidus avis. Boupsaía, Fraxinus, excelsior.

BoúxproTIS, BUPLEURUM.

Boúropes, Butomus, umbellatus? rectius Sparganii spec.

Béópes, Secale, cereale. 
$\Gamma$.

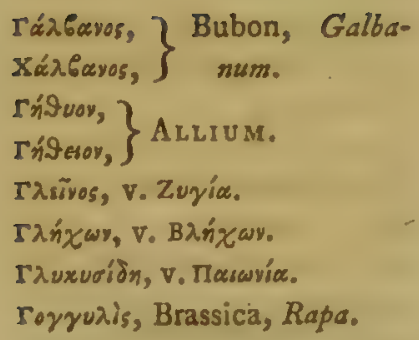

$\Delta$.

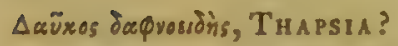

1. $\Delta a ́ \varphi v$, Laurus, nobilis.

2. $\Delta$. ày ģa, Viburnum, tinus An Lauro, Cerasus.

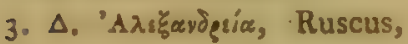
hypophyllum.

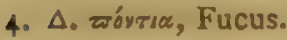

8. $\Delta$ íxтариos, Origanum, Dictamnics.

2. $\Delta . \psi v \delta_{0}, 0$. Egyptiacum. Siòs äy phyllus? Agrostemma? $\triangle$ dàs Báravos, Fagus, Castanea. Arórtugos, Diospyrus, Lorus. $\Delta$ ¿́duxos, Phaseolus, vulgaris. $\triangle$ óva , Arundo, Donax.

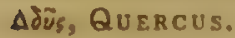
Aquxórviov, Arum, macslatum. $\Delta$ puris, ign.

E.

"Etrvos, Ebenus, Cretica. :Escía, Olea, Europea. 'Edaiarivos, Myrica, Gale. .
1. "Еле́ти, PINUs.

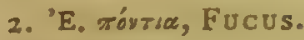

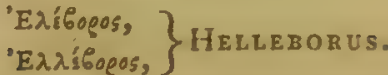

'Eגвbogivn, Serapias, Helleborine.

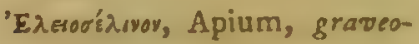
lens.

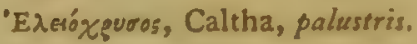

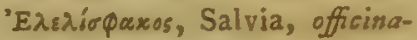
lis.

'Eגל̧iv, Fumaria, capreolata.

'Eגívroy, ign.

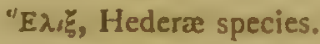

"Eגures, Panicum.

'Evisoúrixoy, Thymus, mastichina?

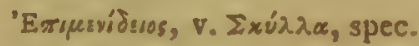
culta.

'Exírs sis?

'Egibuvas, Ervum, Lems.

'Egsixr, Erica.

'Egivsos, F. caprificus.

'Epropóga, Gossypium, arboreum.

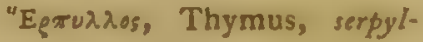
lum.

'Esuseravòs, Rubia, tinctoria.

'Eqúriuoy, Erysimum, officinale.

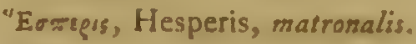
Eǚsuspos, Satureia, hortensis. Ейท่тагау, จ. Eręúxves.

Eủúnupus, Nerium, Oleander, iii. 17. 
z.

Z «⿳亠े, Triticum, monococcum. Zuria, Carpinus, Betulus.

H.

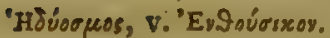

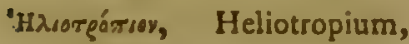
Europeum.

'Huíovos, Asplenium, Hemionitis.

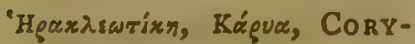
LUS.

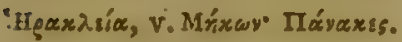

'Elergigar, Erigeron, graveolens.

$\Theta$.

అaభí, Thapsia? vel Seseli. Oígnos, Lupsnus.

Onduxgavia, Cornus, sanguinea.

lypieris.

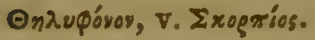

Onotioy, Rheum, Rhaponticum.

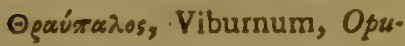
Ius.

1. Ogiðaxirn, $\}$ Lactuca, sa-

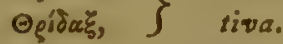

2. $\Theta_{\rho}$ dargia, L. sylvestris.

Opvardis, VERBASCUM.

Qvita, Thuya, aphylla.

Qúpbg, Thymbra.

1. Oúpes, Thymus, vulgaris.

2. Q. 2.9osidris, Corall.
I.

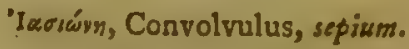
Aquilegia, vulgaris.

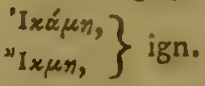

'I

'I Givn, Cardu us.

"Iov, Viola, odorafa.

'Irròy, $\}$ Equiv, $\}$ QUSETUM?

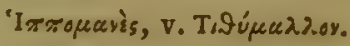

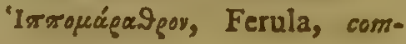
munis.

'Iт⿻上丨 satrum.

'Iтroధ'́ws, Dipsacus, Fullo-

'Irrápuov, $\}$ num.

'I gis, Iris, Florentina.

"Ioxaupes, Andropogon, ls. choemum.

'1бxàs, ign.

'Iria, Sazix.

"I

"I\&os, ign.

'Iw:ice, v. "Iov.

k.

Káxros, Cactus, Opuntia.

Karapiviq, v. Miv9a.

Ká $\alpha \mu$ os; ARUNDO.

$\mathrm{Ká} \pi \pi \alpha \rho$ 's, Capparis, spinosa.

Káģðapos, Sisymbrium, NasIurtium.

Ką̧а́реspe5, Amomurn, Cárdamomum. 
Kágue, Nucifera arbor. .

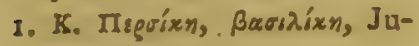
glans, regia.

2. K. "H ${ }^{2} \alpha x \lambda$ swrixn, Corylus.

Karia, Laurus, gracilis.

Kauradis, Caucalis.

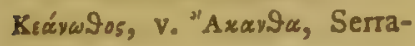
tula, arvensis.

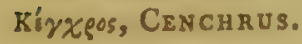

$\left.\begin{array}{l}\text { Kidpía, } \\ \text { Kedgis, }\end{array}\right\}$ Juniperus, Sabina.

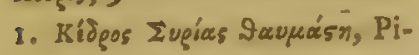
nus, Cedrus.

2. Kídeos, Juniperus, Oxycedrus.

Kıvтaúguy, Centauria, Centaurium.

Keyraugis rgígxss, ign.

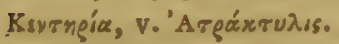

Kevreopevpopinn, Ruscus, aculcatus.

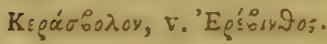

Kípacos, Prunus, Cerasus.

Kepxis, Cercis, siliguastrum.

1. Kıgavia, Ceratonia, siligua.

2. K. 'Tamarindus, Indica?

Kŕderogos, Celastrus.

Kńguvas, Cerinthe, aspera.

Kivrápeopes, Laurus, Cassia.

Kírros, Cistus.

KíTros, HEDERA.

Kixúģoy, Cichorium, Intybus.

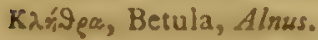

Kגúpesvas, Lathyrus, Clyme* num.

Krśwgoy, Daphne, Creorum.

Kviros, CNicus.

Koǐ̆, Coix, Lachryma Jobi.
Kósex os Kvísios, Capsicum, frustescens?

Koxxurpí, Rhus, Cotinus.

Koxxupriśc, Cordia, Myxa.

Koגoxíy In, Cucumis, Colocyrthis.

I. Koגouría, Colutea, arborescens.

2. K. Colutea, Emerus.

3. K. An Medicago?

$\left.\begin{array}{l}\text { Kópą̧os, } \\ \text { Kápagos, }\end{array}\right\}$ Arbutus, Unedo.

Kópn, Geropogon, glabrum.

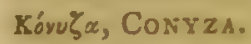

Kogíayyos, Coriandrum, sativนm.

Kogorótous, Plantago, Coronofus.

Kó xо९os, an Hieracium?

Kó qтos, Costus, Arabicus.

Kórivos, Olea, sylvesiris.

Kóques, V. Ké́raıros.

Kouxuopópos, Palma, Thebaica.

Kẹvsía, Cornus, mas.

Kéviray, Lycoperdon, bovista.

Kearaióyovos, Euphrasia, odon-

pitis.

Ķа́raryos, Y Cratægus, sormi-

Koxraryair, $\}$ nalis.

Kองทे, Hordeum, vulgare.

Kévas, Lilium, album.

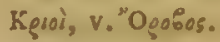

Kgóxos, Crocus.

K९́нpuvas, Aluiv.

Kpóray, Ricinus, Palma Chris-

ti.

I. Kúapos, Arum, Colocasia. 
2. Kúapo;, Vicia, Faba? Pisum, Sativum?

Kudúvios, Pyrus, Cydoxia.

Kúxas, Cycas, revoluta.

Kuxrápusyos, Cyclamen, Europeeum.

Kúpesyoy, Cuminon, Cyminum.

Kuvógodoy, v. 'Pódov.

Kuyóçaros, idem.

Kúva $\psi$, Plantago, Cynops.

Kuтágurros, Cupressus, sempervirens.

Kútę̧⿻上, Cyperus, longus.

1. Kúruos, Cytisus, Laburnum.

2. K. Medicago, arborea.

3. K. Cytisus, Maraula.

Kápaxos, MysusticA.

Kúyesav, Conium, maeulalum.

\section{$\Lambda$.}

Axं9ves, Lathyrus, sativus.

Aaxá9n, Prunus, Mahaleb?

súxa $\rho \alpha$, an idem ?

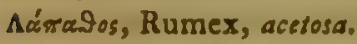

Aespavía, V. 'Avseúrn.

x. Atígior, NARCissu S.

2. ^. ign.

Aísva, Lemna, trisulca.

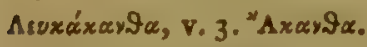

Asúxy, Populus, alba.

Acuxóöos, Leucoium, vernum.

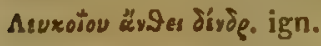

Aíavos, Juniperus, thurifera? An arb. Thurifera, Ger. cm.

1. Nbavaris, Rosmarinus, offcinalis.

2. A. Athamanta, libanoris.
Aívav, Linum, usitatissimum.

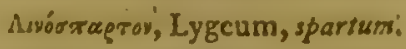

AvXvis, LYCHNIS.

I. Awròs, Celtis, australis.

2. ^. Nyniphaa, lotus.

3. A. Lotus, Melilatus.

M.

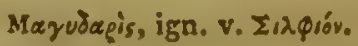

Madáxn, Malva, comrinis, an

M. Althrea ?

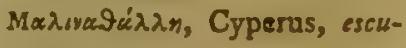
lentus.

Marferyógas, Atropa, Mandrageras.

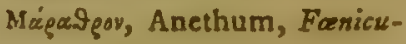
lum.

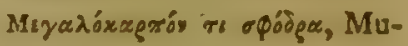
sa, Paradisiaca.

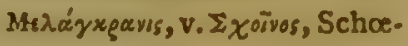
nus, mucronatus.

Mirépтugos; Melampyrum, arvense.

Mincéviov, v. "Iov.

1. Midía, Fraxinus, excelsior.

2. M. Fraxinus, Ornus, vel roturdifolia.

Midías Eitos, Polygonum, fagopyrum.

Mıdíaros, Trifolium, officinale.

Míduvos, Panicum, Italicum.

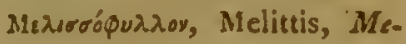
lissopliyllum.

Mıбrìn, Mespilus, Gorma. nica.

Mrdixn, Medica, sativa. 
Mи́xwV, PAPAver.

Mrií, Pyrus, Malus, culla.

1. M. ảy gia, sylvestr.

2. M. Mrduxh̀, Citrus, Medica.

3. M. Mrgouxǹ, Citrus, Aurantium.

Mŕ̀

Møvúav9s, Menyanthes, trifoliata.

Mínos, Taxus, baccata.

Mívar, Mentha, communis.

Mráoriov, Mnasium, Ensete?

Vid. Brucei Abyss. Append.

Muáxav\$os, incog.

Múdus, var. Quercus.

Múzrs, Agaricus.

Muóparov, incog.

Mugixn, Tamarix, Gallica.

Muppois, ign. v. Muppóivr.

Muppíry, Myrtus, communis.

Múgros, idem.

Miw̃e, Allium, Moly.

N.

Naịos, idem quod Náģos?

Nárv, Sinapi, nigrum.

Náęos, Andropagon, Nardus.

Nágar

Nagisnxuta, var. min.

Nágruros, Narcissus.

Nrrevals, Papaver oriestale; an succus Opium dict.?

Nvẹaí, Nymphra, alba.

$$
\text { 프. }
$$

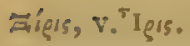

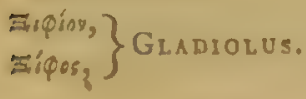

o.

Oün, $\}$ Sorbus, domestica.

1. Oixáv9n, Convallaria, majalis.

2. Oiváy In ảrgía, pl. scandens. 1. v. C. 10.

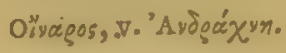

Oivoarńgo, ONAGRA?

3. Oigos, Ribes, Grossularia.

2. Öros, Salix, viminalis.

"Oxsкеs, Ocymum, Basilicum.

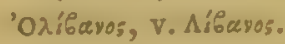

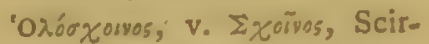
pus, Holoschenus.

'òvgณ, Hordeum, Zeocritum.

'Ovoxíx r.rs, Cichorium ?

'Ovesis, Ononis Antiquorum.

'Ožve, Fagus, sylvatica.

'OGućxcersa, Cratægus, Pyra-

cantha.

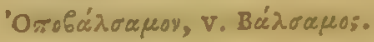

'Ogsno's svov, Athamanta, Oreo. selimum.

'Ogíravos, Origanum, Majorana.

1. "Oppusvay, Salvia, Horminum.

2. "O. ärgeroy, Salvia, Sclarea.

'Opobárzen, jgn.

"Osobos, Oronus.

'Opobiarior, Kgui? Cicer, Aris-

tinum.

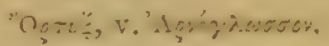

"O९̨usoy, Oryza, sativa.

"Oexis, Orchis.

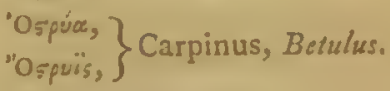

Oüryys, ign.

"Oxve, Pyrus, sylv. culla.

c 


\section{XXXiv CATALOGUS PLANTARUM THEOPHRAST}

$\Pi$.

Irádos, Prunus, Padus.

Maswivic, Pæonia, nobilis.

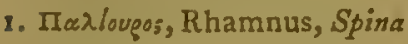
Christi.

2. II. V. Aẃros, n. I. $\left.\begin{array}{l}\text { Пúvarss, } \\ \text { Iávǎ́, }\end{array}\right\}$ LASERPITIUM.

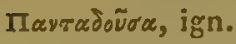

Па́тиоos, Cyperus, Papyrus.

IItiexivos, Coronilla, securidaca.

Iıт⿻а丿

1. Mร́rsgus, Piper, nigrum.

2. П. fruct. oblong. rubro. Capsicum, arnuиm.

Iigóixsov, Chondrilla, bulbosa? an Parietaria?

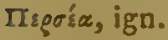

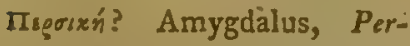
sica?

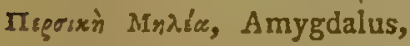
Persica.

Пigơixà Kapúu, v. Kąúx.

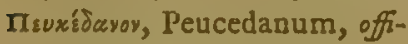
cinale.

x. IIเúxท, PiNus.

2. П. й

3. П. ảr ria, P. sylvestris.

4. II. '1daia, P. Cembra.

5. I. - арадias, P. Pinaster.

6. II. Kwropógos, P. Pinea.

7. П. $\varphi 9$ espoфópos, incert.

Ińravov, Ruta, graveolens.

Iixgis, PICRIS.

Mìos, Fungus, an Galla.
Mıois, Pisum, sativum.

חítus, PINus.

IIrviัy,, Ajuga, Chamapilys.

Forsan Cressa, erratica.

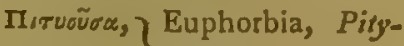

Miruisy, $\}$ u $a$.

IInáravos, Platanus, occidena talis.

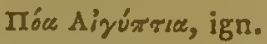

IÍגıvv, Teucrium, Creticum.

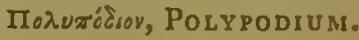

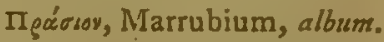

I. Iрáбoy, Allium, Porrum.

2. II. Tóvziov, Zostera, marina.

IIgivos, V. $\Delta$ pĩs.

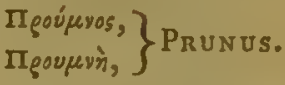

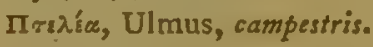

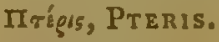

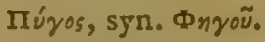

I. IIú̌̌s, Buxus, sempervirens.

2. $\pi$. FUNGUS?

חugòs, Triticum, estivum, et var.

P.

1. 'Pápyos, Rhamnus, Catharticus.

2. 'P. Hippophae, Rhamnoides. 'Paфavis, Rhaphanus, sativus.

1. 'Pápayos, Brassica, oleracea.

2. 'P. ócavòs, ign.

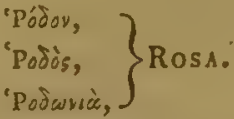

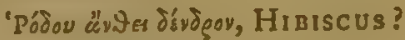

'Poì̀, Punica, granata.

'Poũs, Rhus, coriaria. 
'Púrgos, Carduus? an Echinops.

$\Sigma$

¿agi, Saccharum; Ravenna.

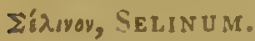

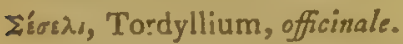

Inpữa, Betula, alba.

Eńrapov, Sesamum, Orientale.

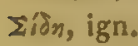

Eixúz, Cucuraita.

1. Iíxuos, Cucumis, sativa.

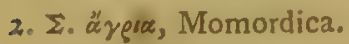

Sínథrov, Laserpitium. Ferula, Asa foctida?

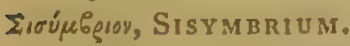

Eıvęirxıov, Iris, Sisyrinchium.

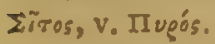

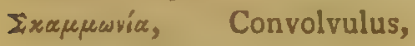
Scammonia.

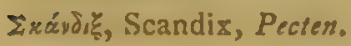

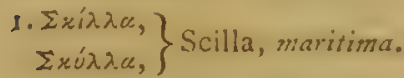

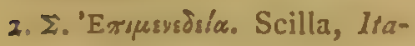
lica.

Exórvpes, Scolymus, Hispanicus.

¿̌xógodov, Allium, Scorodoprasum.

Exogrios, ULEX? an Genista Lusitanica?

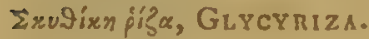

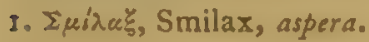

2. $\Sigma_{0} v_{0} \Delta \Delta_{\rho} \tilde{s}_{\text {s. }}$

Inúpya, Mimosa, Myrrhifera. Vid. Brucei Abyss. Append. żóyxas, Sonchus, oleraceus.

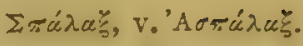

ETetgaic, SPIRÆA?

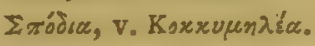

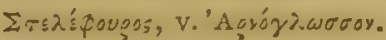

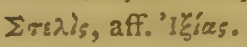

$\Sigma \tau o b$ nे, Centaurea, Sicebe.

I. Eтpoúasos, Pyrus, Cydonia, sylv. siatu.

2. $\Sigma$. CARDUUS?

¿rpúxyos, SULANUM.

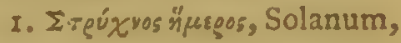
melongena.

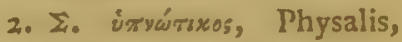
somnifera.

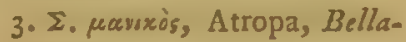
donna.

Erúp̧ø, Liquidambar, Styraciflua.

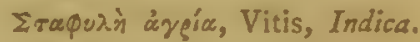

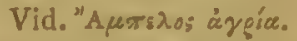

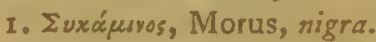

2. $\Sigma$. Airúxraa, Ficus, Sycamorus.

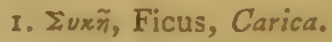

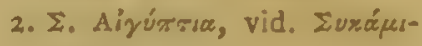
עos 2.

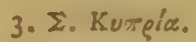

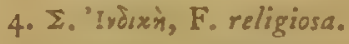

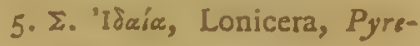
naica.

¿queréor, PEziza.

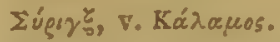

$\sum \phi a ́ x t \lambda 05$, Salvia, hortensis.

$\Sigma \varphi^{\prime} \dot{y} \delta a p u v o s, A c e r$, campestre.

$\Sigma$ Xivos, LENTISCUS.

I. ¿xö́ns, Scirpus. Juncus?

N. B. Apud Bod. spec. tres.

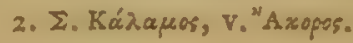

C 2 
T.

Trgfícuras, \} Pistacia, Terebin-

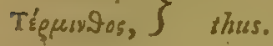

Trepeivaov "̈prosos, incog.

Terpacywis $\alpha$, Euonymus, Furopaus.

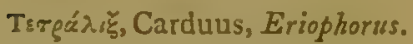

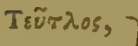

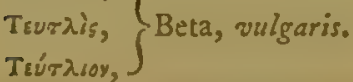

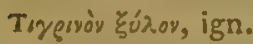

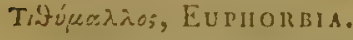

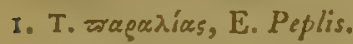

2. T. «̋pppy, E. Characias.

3. T. pueriris, E. myrsinitis.

Típn, Triticum, Spelia.

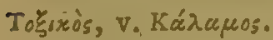

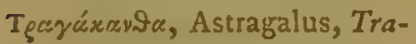
gacantha.

Tęryorẃywy, Tragopogon, $O$ rientale.

I. Tplboios, Tribulus, terrestris.

2. T. Trapa, natans.

Tẹráxııv, Aster, Tripolium?

Tęropecyès, Adiantum, Trichomanes.

Túzr, Trigonella, polycerata.

Túpn, Typha, latifolia.

\section{$\Upsilon$.}

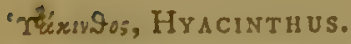

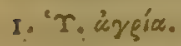

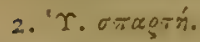

"

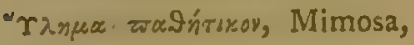
sensitiva.
'Troxospis, Hypocucrss? :

" $\Upsilon \varphi_{\varepsilon<}$, incog.

Ф.

1. Фáros, Ervum, sativum.

2. \$. spec. Indica.

Фérquavoy, Gladiolus. An

Iris, Xiphium.

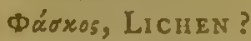

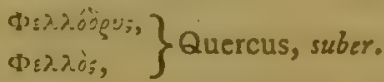

"ít, Dipsacus, Fullonum, vid.

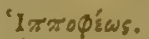

Фnyòs, V. $\Delta$ püs.

Фiravgo, 7 Phyllýrea, latifo-

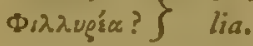

$\Phi i \lambda$ úxn, Rhamnus, Alaterrus? Фıи́́ga, Tilia, Europaca.

I. Ф. ฉ̈р’p’ry.

2. Ф. จทं่

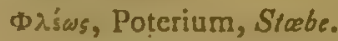
Dióyper, Erythronium, Dens

Canis?

Ф人ópos, VERBASCUM.

I. \$. $\mu\{\lambda a u v \alpha, V$. sinuatum.

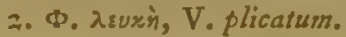

Ф人о̆, Agrostemma ?

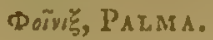

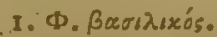

2. Ф. xúrģros.

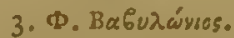

4. Ф. Aigúxтіов.

5. Ф. xúxas, Cycas, revoluta.

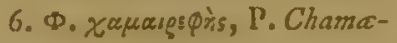
rops.

7. \$. xovriopógos, P. Cocos.

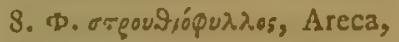
Cashecu. 
GRIECO-LATINUS.

xxxvii

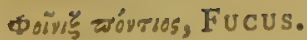

$\mathrm{x}$.

XarGáyn, Bubon, Galbanum. Xареале́фуя, Vinca, pervinca.

Xapaíģus,' Teucrium, Chamadrys.

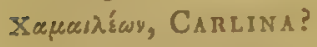

X. $\lambda$ evxòs, C. acaulis.

X. $\mu$ é $\lambda$ cs, Carthamus, corymbosus.

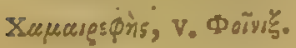

Ханаíbато5, v. Báros.

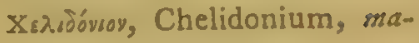

jus.

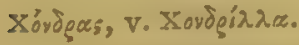

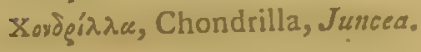

พ.

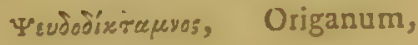
Egsptiacum.

$\Omega$.

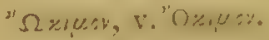

${ }^{7} \Omega$ хоร, Pisup, Oclirus.

c 3 


\section{QUAE IN REGNI ANIMALIS SEX CLASSI- BUS A THEOPHRASTO NOTANTUR.}

Classis prima, Mammalia.

$\Delta$ ọxàs, Capra, Dorcas.

"Eגapos, Cervus, Elaphus.

"Itros, Equus, Caballus.

Kvwेy, Canis, familiaris.

$\Lambda$ ayìs, Lepus, timidus.

$\Pi \tilde{\pi} \rho \dot{\delta} \alpha \lambda s s$, Felis, Pardus.

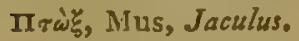

" $\Upsilon_{\xi}$, Sus, Scrofa.

\section{Classis secunda,}

\section{Aves.}

Astòs, Falco, Chrysaetos. Tì

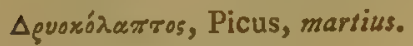

"Eто\%, Upupa, Epops.

'Iśęce F, Falco, gentilis.

'Ixtiv, Falco, Nisus?

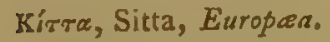

Kóxxư̆, Cuculus, canorus.

¿̇egoúasos, Struthio, Camelus.

' $\Upsilon$ rorwits, Curruca. N. B.

Motacillæ spec.

$\mathbf{X}$ çajģia, Columba, Oenas? vel var. $\beta$.
Classis tertia,
AмpнIBIA.

"EXss, Colvaer.

Kooxóduros, Lacerta, Crocodilius.

"Oфus, Coluber, Vipera?

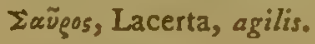

"rọos, Coluber, natrix.

Classis quarta,

Pisces.

Kagxagia, Squalus, Carcha. rias.

\section{Classis quinta,} InsECTA.

'Arríiabos, Attelabus. Genus Linn. Coleopterarum parvæ molis, frondibus vescens.

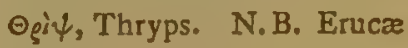
species minor.

Ká $\mu \pi \eta$, Eruca. Larva; vel primus Colcopterarum status.

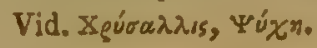




\section{[ $\operatorname{xxxix}]$}

Kav9agis, Curculio, granarius?

Kuvis, Ichneumon, Aphidum ?

Kврúбтrs, Insecti Coleopteri nomen generale.

Knфѝv, Vespa, wulgaris. An Apis mellifica, mas?

"I $\psi, \nabla, K y i \psi$.

Kriq, CYNIPs, an APHis?

Koxpirs as, Coccus, Aonidum.

'Ovíoxos, $\{$ Scolopendra,vel Ju-

'Ovívus, $\}$ lus. Species non descripta, Fucos habitans.

"Ovos, Oniscus, Asellus.

Iorúrove, an Scolopendra, V.

\section{Mollusca.}

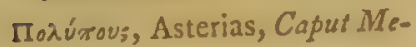
dusa.

Mecaruxovès, Cimex, prasinus. N. B. Hinc nomen $\Lambda$ ngl. "Lady cow."

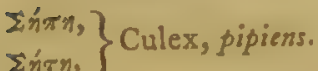

Ixodoria, Scolopendra, elecirica.

Zxogrias, Scorpio, Europaus.

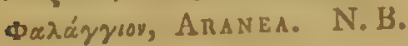

47 species.

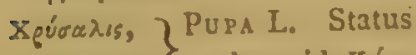

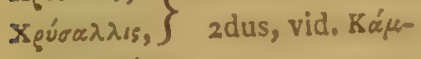
$\pi \eta, \Psi$ úxn.

צ'ǹ, Cynips, Psenes. 廿úxn, Imago L. Papilio, rel

Musca statu perfecto.

Classis sexta,

\section{Vermes, Mollusce.}

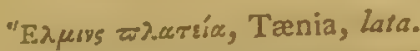

"Ives? Ascarides, vermiculares?

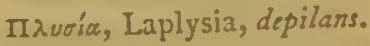

$\Sigma x \omega ́ \lambda$ r. LUMBRICUS ; forsan

ERUCA.

$\Sigma$ Qovdú $\lambda$, Larva quadam.

\section{Vermes, Testacea.}

Astàs, LEPAs.

Mogqúga, Murex.

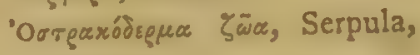
spirorbis.

Teprowv, Teredo, navalis.

Vermes, Lithophyta.

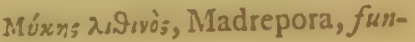
gites.

Vermes, Zoophyta.

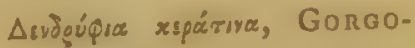
NIA: IsIs.

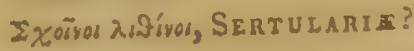





\section{CATALOGUS}

\section{PLANTARUM THEOPHRASTI}

\section{LATINO-GR ECUS.}

$\Lambda$.

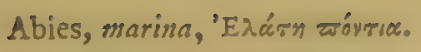
Acer, campestre, $\Sigma \varphi^{\prime}$ ídapeyos. Aconitum, Lycoctonum, 'Axóyıroy.

Acorus, Calamus, "Axogos.

Acrosticum, Thelypteris, $\Theta_{n-}$ 2urroģis.

ADIANTUM, 'Adíayray.

Adiantum, Trichomanes, T $\rho^{\prime-}$ xoucusés.

AEgilops, ovata, 1. Aigiraw. Egilops, Quercus spec. 2da:

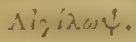

Agaricus, Múrns.

Agrostemma, Flos Jovis, Aiòs üyos, vid. Dianthus.

Agrostis, "Ayguoris.

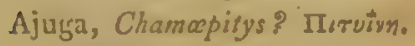

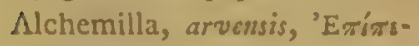
rอs.

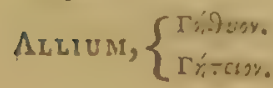

Allium, Cepa, Kৎ́́peruev.

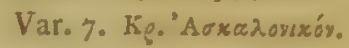

K与. Kvidióv.

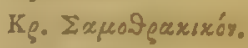

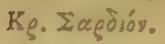

$\mathrm{K}_{\rho} . \Sigma_{\text {. }}$ ravisiay。

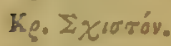

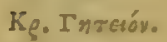

Allium, Moly, Mẽ̃v.

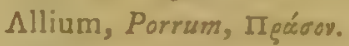

Allium, Scorodoprasum, इxógoo oy.

Alopecurus, 'Adartixougos.

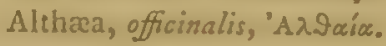

Amaranthus, Blitum, Bגíroy. Амоми м, "Анешноу.

Amomum, Cardamomum, Kagisuruaruav.

Amygdalus, conmunis, 'A $\delta \dot{\alpha} \lambda \gamma_{0}$

Amygdalus, Persica? IIsposxभ̆ Amyris, Gileadensis, Bádr.a. ros.

Anchusa, tinctoria, "A 
Andropogon, Ischromum, "Ioxaspos.

Andropogon, Nardus, Náęoos. Andryala, integrifolia, 'Avōgua $\lambda i \alpha$. Vid. Sonchus.

ANEMONE, 'AvEนény.

Anemone, pratensis, 'Avequwyn

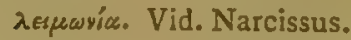

Anethum, hortense, "Avnsov. Anethum, farsiculum, NágenIpov.

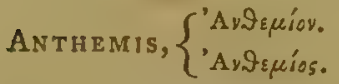

Antirrhinum? 'Avrippoyey.

Antirrhinum, majus, Kúva $\psi$, 'Axúvaw. Vid. Cynoglossum.

Apium, graveolens, 'Eגesors'rovov.

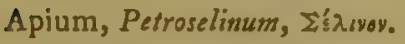
Aquilegia, vulgaris? 'Icercúvn. Vid. Convolvulus, Sepium.

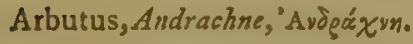
Arbutus, Unedo, Kó́papos. Arctium, Lappa?" Aragivy. Areca, Cathecus? Фoĩv" бrgou-

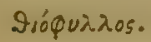

Aristolochis, 'Apisoloxia. Arum, Dracunculus," Agov. Arum, Colocasia, 1. Kúapuos. Arum, maculatum, $\Delta$ paxáyzroy. Arundo, Donaxe, $a_{\text {varúg. }}$ ARUNDO, Kárapeos.

Spec. 7. K. Aủanrixós.
K. Boperexias.
K. 'Errírsos.
K. $\triangle$ óva

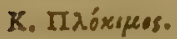

K. Tó̌ssros.

K. Xapaxias.

Artemisia, Absinthium, 'A $\psi$ iySoov.

Asclepias, Vincetoxicum ' Aroxixrias.

Asparagus, aphylius, 'Arrágasyos.

ASPHODELUS? 'Apágaros.

Asphodelus, ramosus, 'Arpidinos.

Asphodelus, luseus, 'Ay9' '́ruos. Asplenjum, Hemionitis, 'H $\mu$ '́oyos.

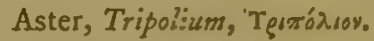
Aster, Atticus, 'Arrseírxos. Astragalus, Tragacantha, Tpa-

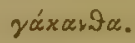

Athamanta, 2. Aitavírts. Spec. 2. A. xá

$$
\text { A. «xхета丿. }
$$

Athamanta, Oreoselinum, 'O $\mathrm{O}$ เ० orísııvov.

Atractylis, gummifera, "Axay $9 a$ 'Aręarrudis.

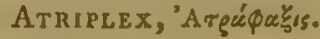

Atropa, Mandragoras, Mavdęayópas.

Atropa, Belladonna, Erৎ̧úxvos нúvirios.

Avena, fatua, Aigír $\psi$.

B.

- Balsamus, Balessan, Bruce, Abyss. Bároapos. Vid. Amyris.

Bambusa, arundinacea, Kádra-

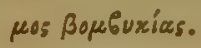




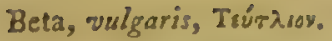

Betula, alba, Inpúda.

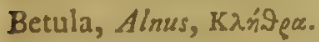

Brassica, oleracea, 'Pápayos.

Brassica, Rapa, Гoyrudís.

Bubon, Galbanum, Xaגßávn.

Bulbocodium, vernum, Boגßoxw์ôs\%.

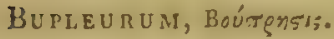

Butomus; umbellaius? Boúroros. Vid. Sparganium.

Buxus, sempervirens, Пǔ́̆os.

c.

Cactus, opuntia, Káxros.

Caltha, palustris, 'Edesóxqueos.

Capparis, spinosa, Kárragıs.

.Capsicum, frutescens, Kóxxos Kッ⿻̀ı́:

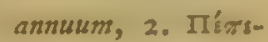
Łı! Vid. Piper, nigrum.

Carduus, Acarna, "Axagua.

CarduUs, specosex, "Aravar.

"ג. ¿े

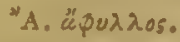

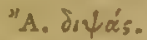

"A. '1

"A. xsáves?os.

"A. reióss.

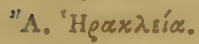

"A. xahxsiog.

Carduus, Eriophorus, Tsrgá-

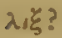

Carlina, acaulis, Xapaìźav

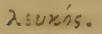

Carpinus, Betulus, 'Oorgéve.

Carthamus, corymbosus, $\mathbf{x} x=$

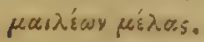

Caucalis, Kauradís.

Celastrus, Kŕrasp̧os.

Celtis, Australis, ^urós.

CEnchrus, K'́ryðos.

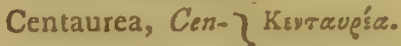

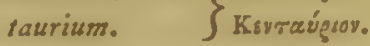

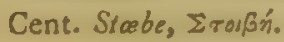

Ceratonia, siliqua, Kegavíc.

Cercis, siliquastrum, Ks

Cerinthe, aspera, Kńpusavov.

Teucrium, Chamapitys, $\Pi /-$ rúw.

Chamærops, Palma, Xagaupṕsprs.

Chelidonium, majus, Xsridsyov.

Chenopodium, bonus Henri-

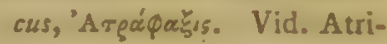
plex.

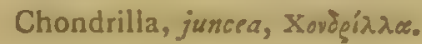
Chond. bulbosa, IIspdixsay. Vid. Parietaria.

Cicer, Arietinum, Kgori "OgoBicuios.

Cichorium, Intybus, Kıxápıor.

Cistus, Kívros.

Citrus, Medica, Mryouxyे Mr $\lambda$ ía.

Citrus, Aurantium, IIsgoixì Mndźa.

Clematis, Orientalis, Argarívn.

Clematis, Vitalba. An idem?

Creorum, Kúścogoy.

CNicus, Kuixos.

Cocos, nucifera? Kouxuфógos. Vid. Palma Theb.

Coix, Lachryma Jobi, Koǐ 


\section{xliv CATALOGUS PLANTARUM THEOPHRASTI}

CozuteA, Koגour'́ce.

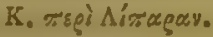

R. 'Isciice.

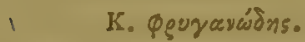

Conium, maculatum, Kévsroy.

Convallaria, majalis, Oivóv\$n.

Convolvulus, Scammonia,

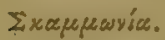

Convolvulus, sepium, 'I ariáyn. Vid. Aquilegia.

Conyza, Kóvuşa.

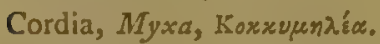

Coriandrum, sativum, Kogíayvov.

Cornus, mas, Kẹassia.

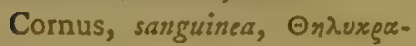
veía.

Coronilla, securidaca, Is $\lambda_{\varepsilon x i-}$ vos.

Corylus, Avellarsa, Kagúce 'H-

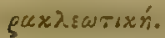

\section{K. ár pia. \\ K. й sespos.}

Costus, Arrabicus, Kóoros.

Cотura, 'Aváściay. Vid. $\Lambda \mathrm{n}$ themis.

Cratægus, Aria, 'A p̧ia.

Cratægus, torminalis, K९áralros.

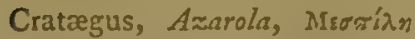

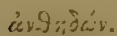

Cratægus, Oxyacantha, M. àySrousasori.

Cratægus, Pyracantha, 'O Ģuáxavia.

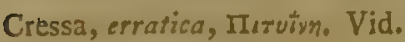
Chamxpitys.

Crocus, Kóros.
Crocus, $K$. ¿̨uพris.

K. भ̌ $\mu$ şos.

Cucumis, Colocynthis, Koגa xน์yง

Cucumis, sativa, इíxuos.

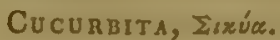

Cuminum, cyminum, Kúpuvay.

Cupressus, sempervirens, KVтúguтros.

Cycas, revoluta? Kúxas.

Cyclamen, Europaum, Ku-

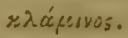

Cyperus, longus, Kúrzigos.

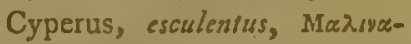

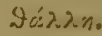

Cynoglossum, officinale, 'A ¿úyoษ. V. Antirrhinum.

Cytisus, Laburnum, I. Kúruoros, jerjowirns.

Cytisus, Maranta, 2. Kúroos.

D.

Daphne, Cncorum, Kvícugov. Vid. Cneorum.

Dianthus, Caryoplyyllus? Aròs äv905. Vid. Agrostemma.

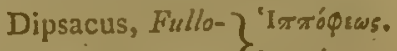
num, $\}$ 'Irróфuov.

Diospyrus, Lotus, $\Delta$ rórgrugos.

E.

Ebenus, Cretica, "Elryos.

Echinops, Ritro, Kúvoł. Vid. Antirrhinum, majus.

EPIDENDRUM, 'Ayeedsudgás.

EQuisitu: "1ray.

ERICA, 'Fęsixr. 
Erigeron, graveolens, 'Hęr'gasy.

Erythronium, Dens Canis,

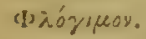

ERVUM, Фáxos.

Ф. orágroy.

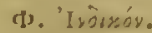

Ervum, Ervilia, "Ogobog. Vid.

Cicer.

Ervum, Lens, 'Egécivàos.

Erysimum, officinale, 'Eưúrs.

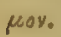

Euonymus, Europaus, Trregagavia.

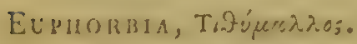

$$
\begin{aligned}
& \text { T. } \pi \alpha \rho \alpha \lambda i \alpha s . \\
& \text { T. «ррриу. }
\end{aligned}
$$

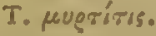

Euphorbia, Pithy- Tuтváy. usa,

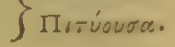

S nirúura.

F.

Fagus, Casianer, Diòs Pé̉axns.

Fagus, Sylvatica, 'Oร̌víd.

Ferula, communis, '1ттора⿱⺊口аIpoy.

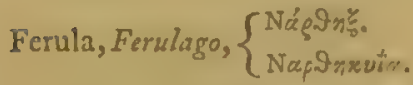

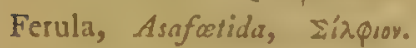
Vid. Laserpitium.

Ficus, Caprificus, 'Egivsos.

Ficus, Carica, इuxĩ.

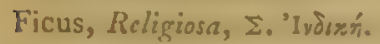

Ficus, Sycamorius, इuráperyos.

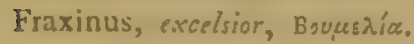
Mstíx.
Fraxinus, Ornus, Media. Forsan Fr. rotundifolia.

Fucus, Фข̃xos. N. B. Io spec. enumerantur.

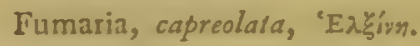
vid.Polygonum, Fagopyrum.

G.

Galivm, 'stagínn. vid. Arctium.

Genista, Lusitanica, Inogrios. Geropogon, glabrum, Kópen.

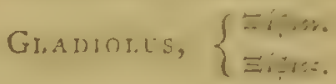

Glycyrrimiza, Exuation piלa.

Gossypium, arboreum, 'Eproo फेंक्षि.

Guilandina, Bonduc, Bádavos. Gypsophila, Struthium, 2. ziscointus.

H.

HEDERA, Kítros.

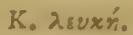

K. "ร

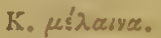

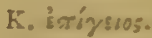

Hedera, Helix, "Eג

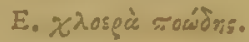

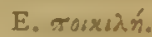

Hcliotropium, Europaum,

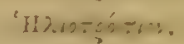

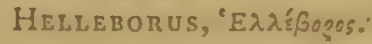

'E. $\lambda \varepsilon$ exós.

'E. $\mu \hat{I}^{\prime} \lambda \alpha_{5}$.

Heracleum, Panaces, Пuvà '11, $\because 3 \leq \cdots$ 


\section{XIvi CATALOGUS PLANTARUM THEOPHRASTI}

Hesperis, matronalis, "EFrzés.

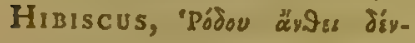
Soga?

Hieracium, Kóexogos.

Hippophae, Rhumnoides, 'PQ́pyos $\lambda$ Еuxท́.

Hippuris, 'Itróv. Vid. Equisetum.

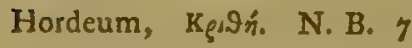
var, cult.

Hottonia, palustris, Nipevadis $\pi \%$

Hyacinthus, 'Táxiy:Tos.

Hyacinthus, Peruvianus? BoגBòs 'ęseq.ipos.

HYDN U M, " $T \delta$ Vvov.

HYPOCHERIS, 'TTOXougis.

\section{I.}

Iris, Florentina, ${ }^{\top} \mathrm{I}_{\text {gis. }}$.

Iris, - isyrinchium, इıvęirxsos.

Iris, Xiphium, Фáarayoy.

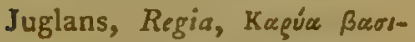

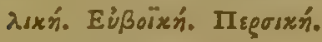

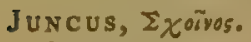

Juniperus, communis, "AgxrvSos.

Juniperus, Oxycedrus 2. Kร́Sos.

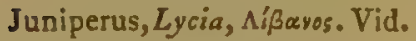

K. $\lambda u x i \alpha$, iii. $1 x$.

Juniperus, Sabina, Kodęis.

Ixia, bulbocodium, Borboxw' dov.

L.

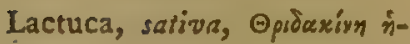
espis.
Var. $\Theta \varrho . \lambda$. $\varepsilon x \tilde{n}_{s}$.

I. $\pi \lambda a r u ́ x a v \lambda . o s$.

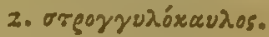

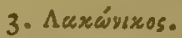

Var. $\Theta$. praxivas.

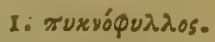

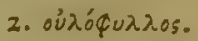

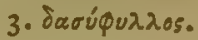

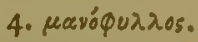

5. $\lambda \varepsilon v x a ́ x \propto v \lambda$ as.

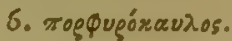

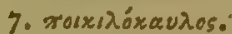

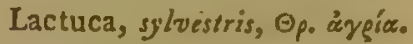

Laserpitium, Hévaxes.

Laserpitiun, latifolium, IídQrov. V. Ferula, Asa foetida.

Lathyrus, amphicarpus, "Apoxídya.

Lathyrus, Aphaca, 'Aфáxn.

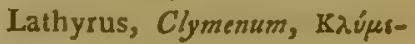
vov.

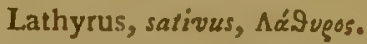

Laurus, nobilis, $\Delta \alpha \dot{\varphi} \varphi n$.

Laurus, gracilis, Karia.

Laurus, Cassia, Kivyápewpos.

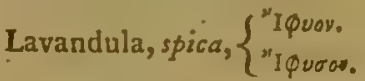

Lemna, trisulca, $\Lambda^{\prime} \mu v v$.

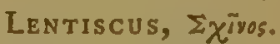

Leontodon, Taraxicum, 'Apáxท, 'A สа́тท.

Leucoïum, vernum, Аะvxóïoy.

Lichen, pulmonarius, $\Phi \dot{\alpha}^{\sigma} \sigma x 0 s$.

Lilium, album, Kgivov.

Linum, usitatissimum, Aívov.

Liquidambar, stiraciflua, Irú $\rho^{\alpha} \xi$.

Lolium, temulentum, Aịẹa. 


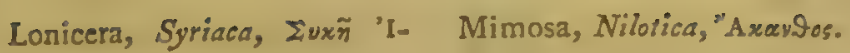
jaía.

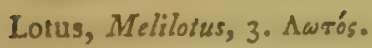

Lupinus, Oígreos.

LYCHNIS, Auxvís.

Lycium, Europeum, 'Pápvos,

Qu? Rhamnus, Catharticus.

Iycoperdon, 'Arxiov.

Lycoperdon, bovista, Kéáysoy.

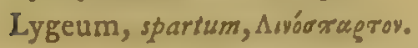

M.

Marva, Althra, Maráxy.

Mangifera, Indica ? Msyaxóxарто́у 7 . Vid. Musa.

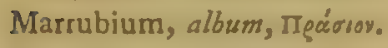

Marrubium, Pseudo-dictamnus, พ'svóodíx тарevos.

Matricaria? "Ayquruís.

Medica, sativa, Mทঠьะท́。

Mentha, communis? Mirasu.

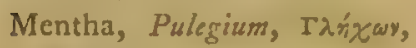
Binrican.

Menyanthes, trifoliata, $\mathrm{MI}$ -

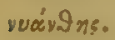

Menyanthes, Nymphesa, an id.

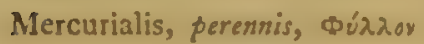
ró.

Spec. I. áṕṕs só rovov.

$$
\text { 2. Iniéryovov. }
$$

Mespilus, Germanica, Mrerí $\lambda \eta$. Vid. Cratægus.

Mruvas, Paradoxum, M'siyov. Vid. Panicum.

Mimosa, myrhhifera. Bruce,

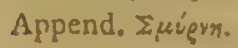

Mimosa, sensitiva, "Ү za9nтsxóv. Mnasium, Ensete? Bruce. Mráasoy.

Momordica, elaterium, 'Eגaríguv.

Morus, nigra, इuxápuvos.

Musa, Paradisiaca? Mtyarioxxęróy $\tau$.

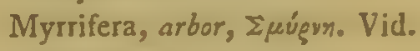
Mimosa.

Myristica, $\left\{\begin{array}{l}\text { Kópaços. } \\ \text { Kópacesos. }\end{array}\right.$

Myrtus, commu- Muppívn. nis, $\{$ Múgros.

N.

Narcissus, Nágxioros.

Narcissus, Pseudo-Narcissus,

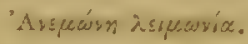

Narcissus, Poeticus, Atigroy "regar.

Narcissus, minor, vel Bulbocodum? BoגGoxẃdıcv. Vid. Bulbocodium.

Nerium, Olcander Eúwyues.

Nymphæa, alba, Nupquía.

Nymphaxa, Nelumbo, Idem.

Nymphæa, Lotus, 2. Awrós.

o.

Ocymum, Basilicum, "Oxıнsy.

Olea, Europica, "Eraía.

Olea, Sylvestris. Kótavos.

ONAGRA ? Oivoángex.

Ononis, Antiquorum, 'Ovavís. 


\section{xiviii CATALOGUS PLANTARUM THEOPHRASTI}

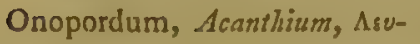
xúzerva.

Ophrys, ridus avis, Bouxígas.

Orchis, "O弓Xis.

Origanum, AEgyptiacum, พвv-

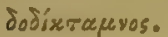

Origanum, Majorana, 'O gírevos.

Var. I. นเยxй.

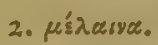

OrobaNCHE? Aipádógoy.

Orobus, Qu. an Erv, Ervilia, L. "Ogobos.

Oryza, sativa, "Oৎ̣కัos.

\section{P.}

PALME.

Phonix, Dactylifera.

Cycas, revoluta, Kúxas. Cocos, nucifera, KouxioQ́́gos.

Chamzerops, XapusipposQris.

PANICUM, "Fonpess:

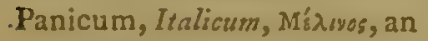
Milium, paradoxum.

Pæonia, nobilis, Ilaswyice.

Papaver, Mŕswv.

Parietaria, officinalis? Isporixuoy, Vid: Chondrilla, bulbosa.

Papyrus, Nilotica, Пúтขęos.

Peucedanum, officinale, Iive xídervoy.

Peziza, II ל’s.

Prallus, impudicus, Aidovordis rí.

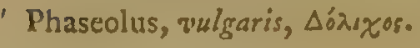

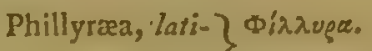

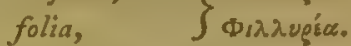

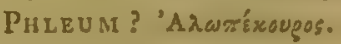

Phonix, Dactylifera, Фoivi

Var. \$. Baciluxós.

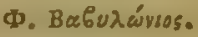

$$
\begin{aligned}
& \text { Ф. Kúrgsos: }
\end{aligned}
$$

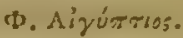

Phyllanthus, Emblica, Bárasvos. Vid. Guilandine.

Physalis; somrifera, $\Sigma r g u ́ x v o s$ ขंสขต์สเหอ5.

Plcris, Mixgis.

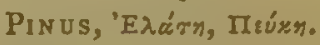

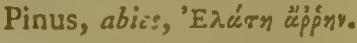

Pinus, Picea, 'E. Yทं $\lambda \varepsilon a$.

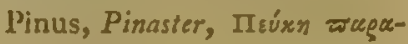
díx.

Pinus, Cembra, ПI. 'I $\delta$ aía.

Pinus, Pinea, ח. xcuroфópos.

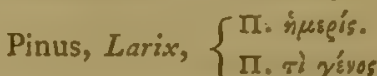

Pinus, $\Pi$, $\phi$ streopópos.

Pinus, Sylvestris, $\Pi$. àyia.

Pinus, Cedrus, I. Kédęos.

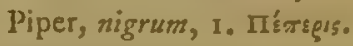

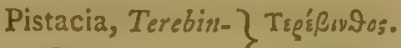
thus. \} Tร́

Pisun, sativrm, חIloos, Kúx= peos.

Pisum, Ochrus, " $\Omega$ xgos.

Plantago, major, 'Agyó y dworov.

Plantago, Coronopus, KoguvóTov5.

Plantago, Cynops, Kúvw $\psi$. Forsan P. Psyllium.

Plantanus, Orientalis, Пגárave;. 
Po1 ? Mók.

Polygonuin, Frgopyrum, M\&-

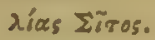

POLYPODIUM, Moגutódıy.

Populus, nigra, Ä̈yrupos.

Populus, alba, Asúxy.

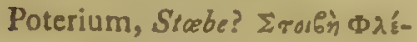
ws. Vid. Centaurea, Sicebe.

PRunus, II goupuń.

Prunus, Laurocerasus? $\triangle \alpha \dot{\varphi v}$ áypia. Vid. Viburnum, $T_{i-}$ nus.

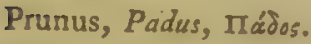

Prunus, Cerasus, Kíparos.

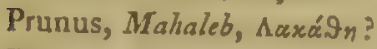

Pteris, חrígis.

Punica, granata, "Poiá.

Pyrus, communis, "Arsos.

Pyrus, sylv. statre, 'A xpós.

Pyrus, sylv. culia, "O Хyn.

Pyrus, malus, Mndía.

Pyrus, malus, sylv. statu, Mn-

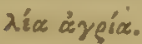

Pyrus, Cydonia, Kudários.

Pyrus, Cydonia. sylv. statu, 2. Ergoúlas.

\section{Q.}

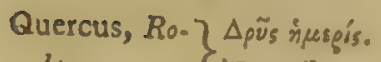
bur, $\}$ 'Eтupódģus.

Quercus, Egilops, I. Aiyi$\lambda \omega \psi$.

Quercus, Esculus, Фиүós.

Quercus, Cerris, "Orregis.

Quercus, Ilex, "Aגípdosos?

Quercus, Coccifera, II givos.

Quercus, Suber, $\Phi \varepsilon \lambda \lambda \dot{o s}_{s}, \Phi \varepsilon \lambda-$ גádgus.

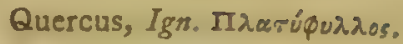
Quercus, incog. Múdıos.

R.

Raphanus, sativus, 'Paфavís.

Var. 'P. Kagsy'ía.

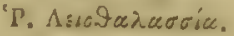

'P. Kiswria.

'P. Boswrixá.

Rhamnus, Catharticus, 'Pá $\mu$ -

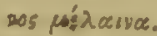

Rhamnus, Alalernus? 'A фágxn. Rhamnus, Paliurus, Пa入íou $\rho j$.

Rhamnus, Spina Chrisi, an Id. ?

Rheum, Rhaponticum, $\Theta$ r. бriov.

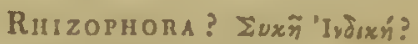

Vid. Ficus, Religiosa.

Rhus, Coriaria, 'Poüs.

Var. 'P. äp’pry.

$$
\text { 'P. จทं่ }
$$

Rhus, Cotinus, Kaxsurpia.

Ribes, Grossularia, I. Oïros.

Ricinus, Palma Christit, Kẹó$\tau \omega y$.

RosA, $\left\{\begin{array}{l}\text { 'Pódov. } \\ \text { 'Poduvix. }\end{array}\right.$

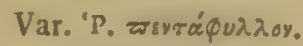

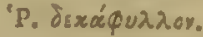

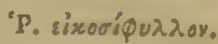

'P. ixazoyró

Rosmarinus, officinalis, $\Lambda \cdot 6 a-$ swris.

Ruвus, Báros.

Rubus, fruticosus, B. ą9oфúrs.

d 


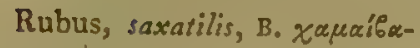
ros.

Rubus, Idaus, B. xuvóoberos.

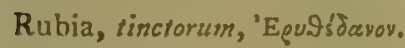

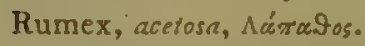

Ruscus, hypaphyllism, $\Delta x \dot{\alpha} \phi v$, 'A $\lambda \varepsilon \xi \xi \alpha v \delta \rho s i a$.

Ruscus, aculealus, Kevreoruppp̌ivn.

Ruta, graveolens, IIńyavav.

s.

Saccharum, Ravenna, Eág̣ ro.

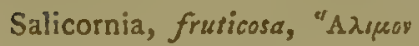
ró.

SALIX, 'IT'́e.

Salix, alba, 'I. дєvxท́.

Salix, nigra, "I. $\mu$ '́ìasve.

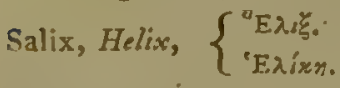

Salix, variegata, I. тouxid $\%$

Salix, viminalis, 2. Oiros.

Salvia, horninum, "Opperyoy.

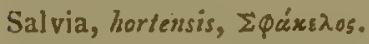

Salvia, officinalis, 'E $\lambda \varepsilon \lambda i \sigma \varphi \alpha-$ xos.

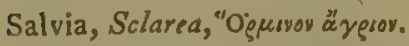

Sambucus, nigra, $\left\{\begin{array}{l}\text { "Axrn; } \\ \text { "Arrsos. }\end{array}\right.$

Santolina, Rosmarinifolia, 'AEgóravav.

Satureia, horiensis, Eü

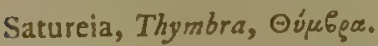

Satyrium, "Eגasoogivn. Vid.

Serapias.

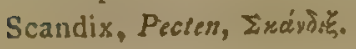

Schnenus, mariscus, $\Sigma$ Xaĩyos.

Schœnus, mucronatus? Mø$\lambda \dot{\alpha} \gamma$ xৎavis.

Scilla, uniffora, Boגeiyn?

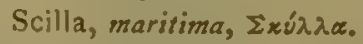

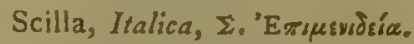

Scirpus, holoscheenus, 'Oגór Xotvos.

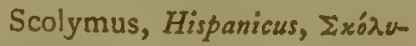
ros.

Secale, Cereale, Boópos.

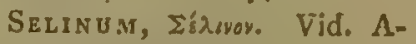
pium, petoselinum.

Sempervivum, 'Así̧wov.

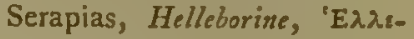

Bopiry. Vid. Satyrium.

Serratula, arvensis, 'Ax. Ksáy wa9\%.

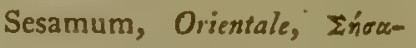
peor.

Sesell, Фałia. Vid. Thapsia.

Sinapi, nigrum, Nárv.

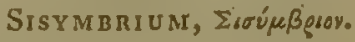

Sisymbrium, Nasturtium, Kóp-

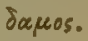

Smilax, aspera, I, $\Sigma \mu i ́ \lambda \alpha \xi$. Smyrnium, olusatrum, "Iтøo-

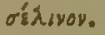

Solanum, melongena, vel lhy=

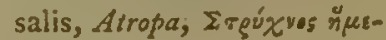
eos.

Sonchus, asper, 'Avôguaría.

Vid. Andryala.

Sonchus, oleraceus, Nórxos.

Sorbus, domestica, Оüท.

$$
\text { v. ¿̇ypia. }
$$

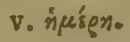


Sparganium, Boúropos. Vid.

Butomus.

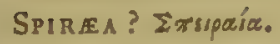

T.

'Tamarindus, Indica, 2. Kı९wyix?

Tamarix, Gallica, Muęirn.

Taxus, baccaia, Míxos.

Teucrium, Chamedrys, Xa-

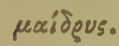

Teucrium, Creticum, חó̀ıov。 Thapsia, v. Seseli, @aұí。

Thapsia, Asclepium, 'A riks.

ТнумввА, v. Satureia, ๑úfeלgos.

Thymus, vulgaris, @upeós.

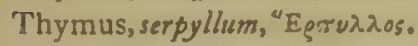
'Thymus, mastichina "Evasúoixoy,

Thuja, aphylla, @vita.

Thurifera, arbor Mibayos. V. Amyris.

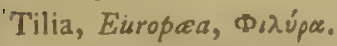

Tordillium, offcinale, Eiors.

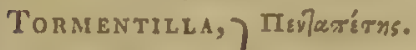
fors. Potentil- Пirrá $\phi u \lambda-$ la recta. $\int$ dov.

Tragopogon, Orientale, Tow. yоти́y̆u.

Trapa, natans, 2. Toíboros.

Tribulus, terrestris, 1. Tpibaגos.

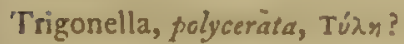

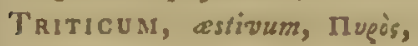
Eiron.

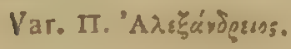

II. 'A arov́giog.

II. Kayxpwías.

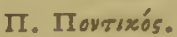

II. Aigurróos.

II. Eģaxurós.

II. Außuxós.

IT. $\Sigma(x \leq \lambda / x \not ́ s$.

Triticum, moroccum, Zsú.

Triticum, Spelta Típp.

Typha, latifolia, Túpr.

U.

ULEX ? Vid. Genista, Lusitanica, इrogrios.

Ulmus, $\Pi \tau \varepsilon \lambda \xi \alpha$.

Ulmus, var. 'О९̨ıтr\& $\lambda i \alpha$.

Ulva, Lactuca? Фथ̃xos Ţุidaxirn.

V.

Vaccinium, Vitis Idcea, " $A \mu$ $\pi \approx \lambda . s$ ' $^{\prime} \delta$ reía.

Verbascum, plicatum, $\$ \lambda$ ópos $^{\prime}$ $\lambda$ ¿ย́xห.

Verbascum, sinuatum, $\Phi \lambda_{\text {. }}$.

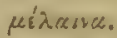

Verbascum? Ogvardís.

Veronica, Chamedrys ? X $\mathrm{X} \alpha$ -

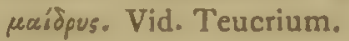

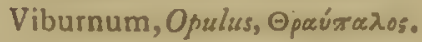

Viburnum, Lantana? $\Delta \alpha \dot{\varphi} \varphi v$ ảrẹia.

Viburnum, Tinus? An Idem.

Vicia, cracca " "A pares.

Vicia, Faba, an Pisum, Kúa-

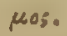

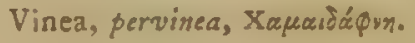




\section{lii CATALOGUS PLANTARUM THEOPHRASTI.}

Viola, odorala, "Iov.

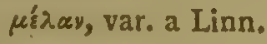
$\lambda \varepsilon u x o ́ v$.

Viscum, album, "I $\xi_{i c \alpha}$

Vitex, agnus castus, "A yyos.

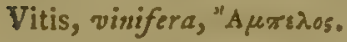

Var."A. $x \alpha \pi v^{\prime} \alpha$.

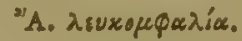

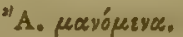

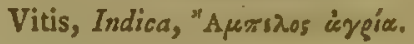

Z.

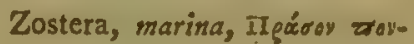
riw.

\section{CORRIGENDA.}

P. xxviii. Port Bádruyos, Guilandina, Bonduc add. vid. Phyllanthus, emblica.

P. xxxí. Lege 3. Kéógos Avxía, Juniperus, Lycia.

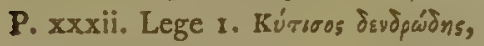

Ibid. Aibavos del. Juniperus, Thurifera g 


\section{E C T O R I.}

Peracta editione Theophrasti Historiæ Plantarum usque ad cap. I2. libri ix. Curtii Sprengel Historiam Rei Herbarix, Lut. Par. MDCCCVIII. benignissime mecum communicavit vir clarissimus, scientiarum omnium fautor eximius, Soc. Reg. Lond. Præses; quod opus, a me diu desideratum, flagrante magis indies bello, prene desperatum erat. In eruendis et distribuendis plantis a Philosopho, Botanicorum vere parente, memoratis, felici sudavit vir ille egregius successu; ita ut species circiter CCCLVI accurate discreverit, ceteris numero fere totidem silentio preteritis. Nupera tamen et accuratior plantarum Tineopurasti recensio, edita jam prima hujus operis parte, facta, plures cousque ignotas, monstravit, ut et nominibus quasdam ambiguis latentes, aliqua ex parte illustravit; ita enim se rem habere cel. Sprengel ipse fatetur. "No" mina ipsa ambigua sunt, nec certis legibus " definita, ipse cnim (Theophrastus) Hist. Pl.

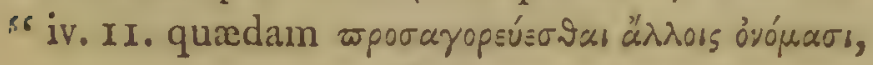




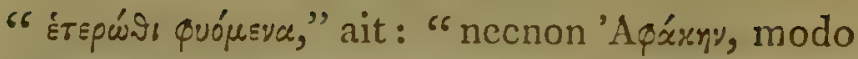
"Leontodon Taraxicum, wodo Lathyrum $A$ "phacam: 'Aragivnv modo Galium, Aparinen,

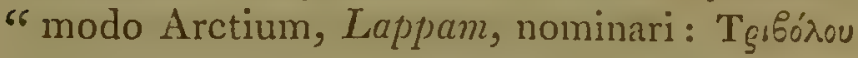
"quoque tria diversa genera occurrere; 'Av"Spáx p. 75 .

Plantarum harum nomina subjicio, ut cum Catalogo partis primæ conferantur, additis quoque Sprengelianis, quoties diversæ sint; notulis ad calcem, ubi minus placeant. Meminerit tamen Lector curas meas præcipuc adhuc versari in emendando textu TusoPHRASTr, atque ideo plantas non tam, ut omni ex parte perspectas, sisto, quam ut continua observatione, in solo cujusque natali habita, adhuc clarius eluceant, admissis libenter hunc ad finem omnibus omnium conjecturis. Sprengelio omnino assentior, "Omnem plantarum a "scriptoribus seriorum sæculorum cognitio" nem, a Theophrasto et Dioscoride "proficisci debere." Quantopere ergo dolendum est, nomina in corum scriptis occurrentia plantarum, de quibus adhuc parum constat, alienis prorsus, imo novi orbis indigenis temere imposita esse. Parvi quidem momenti est, neque impedimento habendum, quod genera, vel species ita denominatæe, frustra a Botanicis antiquioribus tentata sint: Græcarum enim 


\section{LECTORI.}

litterarum indies crescente studio, vix dubitandum est, quin voces technicæ (si ita dicam), et loquutiones difficiliores, ad rem herbariam pertinentes, textus emendationem ipsa adjuvante natura, quotidie expeditiores et planiores fierent. 



\title{
PLANTE OMISSE,
}

\section{IN CATALOGO PARTIS PRIMÆ,}

\section{VEL EMENDAT压。}

\author{
CUM NOTIS.
}

\section{A.}

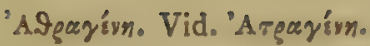

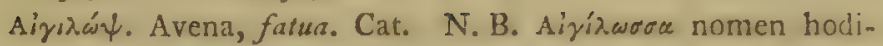
ernum Panici repertis. Videndum tamen an segetes infestat.

"Axav\$a Aírvтría. An pro 2. 'Axáv\$o ? Vid, infra.

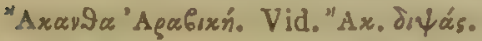

"Axay $9 \alpha$ dı $\psi$ ás. Nullibi inter synonyma. In calidis regionibus Syria et $\Lambda$ rabia spinosissima Echinopis occurrit species, in arena mobili in Deserto Kahiræ. Vid. Forskâl. Egypt. Ho-

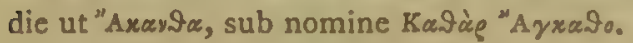

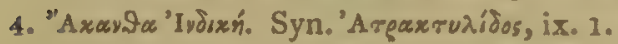

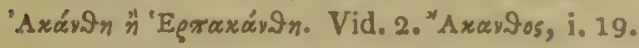

1. "Axay

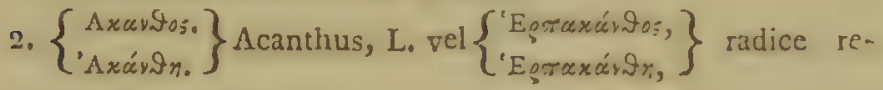
pente, i. 16 . ix. 21.

1. "Axayos, i. 4, 9, 13. Onopordum, Acanthium.

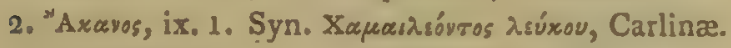

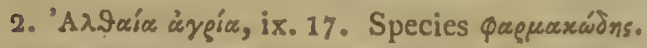

'Anwríxoupos. Phalaris, Paradoxa. Flor. Græc. Sin vero ex icone judicandum sit, Phleum, crinitum, ibid.

'Ayوgloxos. Omiss. Caucalis, Anthriscus, L.

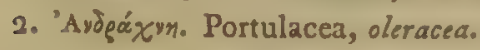

Aragria. Omiss. Pl, affinis Scabiosæ? vii. 9.

* E 3 


\section{IViii PLANTAE OMISSE, VEL EMENDATIF,}

2. 'Arráinn. Arctium, Lappa. N. B. 1. 'Ar. Galium, Aparine, non verrucosum.

2. "Agoy. An Arum, Colocasia? N. B. Radix cdulis, vii. 12.

'Agyórdworov. Plantago, major. Cat. Rectius Pl.minor, cujus vires ad saginanda pecora notæ, ut nomen hodiernum indicat Bourupóxogroy.

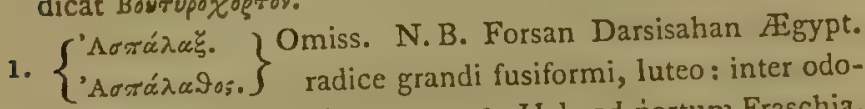
riferas. Prosp. Alp. Ægypt. Forsan Pancratium. Vid. not. p. 416.

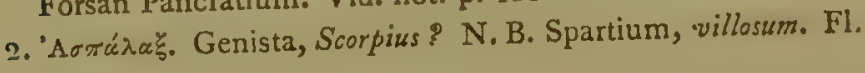
Græc.

1. 'Aręxrudis. Carlina, corymbosa.

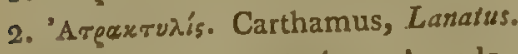

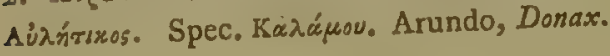

B.

Boupsaia. Vid. Cat. N. B. Sibthorpius solummodo enumerat Msdíay, Fraxinum, ornum, ut Græciæ indigenum; alibi tamen in Oriente, si Theophrasti fides, Fr. excelsior L. reperitur; 'sc. ad ripas Nili, p. 172.

Bגirov. Leg. Amaranthus, Blitum.

Bopbuxia. Bambusa, arundinacea.

Bęúọos. Pro Oẹúogos, ix. 13. Syn. Eręúxyou paxíxou.

\section{$\Gamma$.}

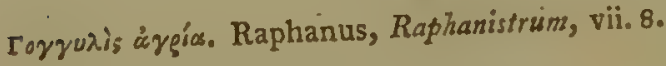

$\Delta$.

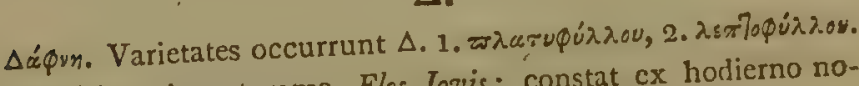
$\Delta$ iòs äy 905. Agrostemma, Flos Jovis; constat ex hodierno nomine Koxxoגı, quod adhuc apud nos obtinet: sc. "Cockle." $\Delta$ equis. Drypis, spinosa.

E.

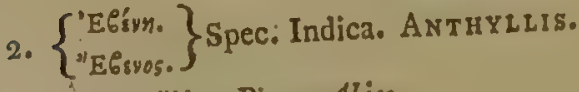

1. 'Eגárn üpppiny, Pinus Abiss. 


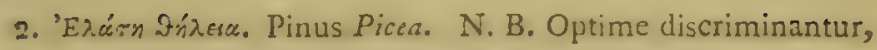
iii. 8 .

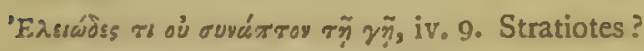

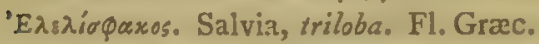

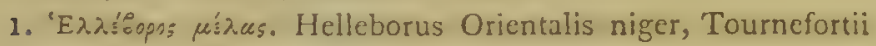
Annal. du Mus. t. velin. xi. 178.

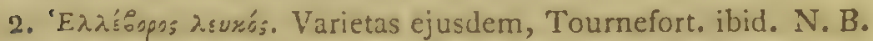

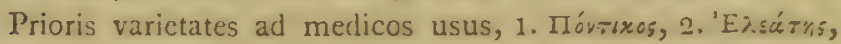

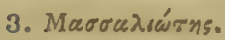

'Exízeros. Kárapos, Arundo, Epigeios.

Eü?sus\%. Corrige ex Plinio; Brassica, Eruca. De usu cjus vid. Plin.

'Epríregor p̈ŗ́ıy. Colchici, Lethalis, species, ix. 21.

\section{$Z$.}

Zıиiтrs. Kédupes. Arundo, Donax.

H.

'Hóvorpos. Mentha, gentilis.

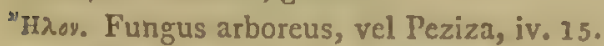

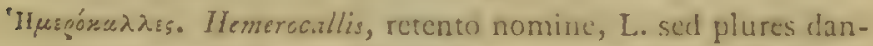
tur ephemeri flores. Plinius interpretatur, unius diei pulchritudo. Descriptio nulla.

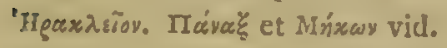

'Heíryov. Eryngium, campestre?

$\Theta$.

Enגépovov. Doronicum, Scorpioides.

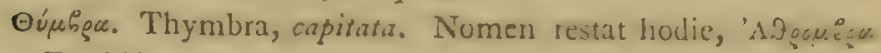
Forskal.

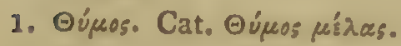

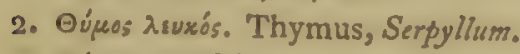

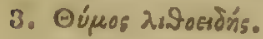

I.

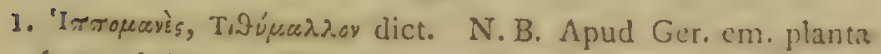
hre vel Stramonio, vel Papaveri spinoso, referenda. N. B. Longe alia Plinii mens de Hippomane crescente in fronte pulli equini. 


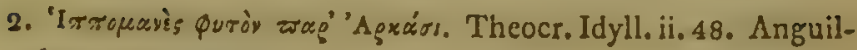
lara, 233-234.

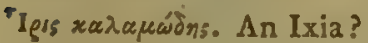

1. 'I

2. 'Iavía åypía. Viola, canina, vii. $\%$.

K.

Káxapes. Arundo. N. B. Vid. spec. Cat. Lat. p. xlii.

Kádacuos süoopos. Acorus, Calamus. N. B. Junco magis aff.

1. Karía. Laurus, Cassia.

2. Karia. Cassia fistula, ix.4.

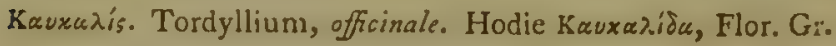

Kirxesos. Panicum. Vid. not. lib. viii.

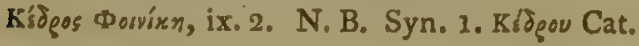

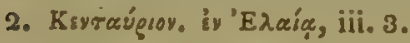

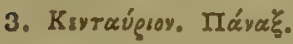

Kı̨ás. Nomen familiare rảdicis "Paф. ürģiou, ix. 7 .

Kígaros. Prunus, Cerasus. Var. $\lambda_{0} \mathbf{P}_{\mathrm{r}}$ Duracina dict.

3. Ksparía. Cassia, fistula, iv. 2. Vid. Karía.

1. Kioros äpppyy. Cistus, Creticus.

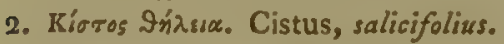

Kıvvópewpos. Laurus, Cinnamomus, ex insula Tapobrana. Antiquitus nota.

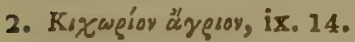

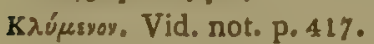

1. Kvixos. Xadxisios, an ex colore floris? vi. 4.

2. Kviros äresos sủqúxaudos. Carthamus, arborescens.

3. Kvíxos darsia. Carduus, mollis.

4. Kvixos ทั $\mu \varepsilon \rho a$. Carthamus, tinctorius,

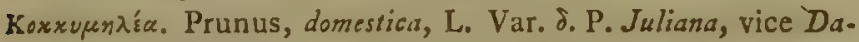
mascena. N. B. Nomen hodiernum Pro insititice, $\Delta \alpha \mu \alpha \sigma x \operatorname{vica}$. Vid. Flor. Græe. Sed certe sapor Pr. insititice minime cum domestica comparand. Consule Bauhinum super Pruno. N. B. Plin. ait Catoni genus Prunus ignotum esse, $\mathbf{x v} 13$.

1. Kóvȩ́a. Conyza, saxatilis.

2. Kóvv̧̧ $\alpha$. Inula, helenium.

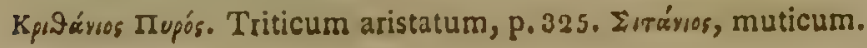


2. Kéxos súorpos, i. e. stigma, ut videtur, non corolla. Crocus, sativus. Forsan Crocus, aureus. Flor. Gr. Vid. varietates

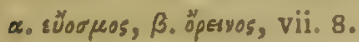

2. Kóxes ñ

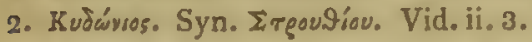

2. Kúreipss. Lacus Orchomeni, an species diversa, an syn. Acori, Cat. ix. 7 .

\section{$\Lambda$.}

1. NáraDos. Rumex, Parientia, vel species affinis. N.B. No-

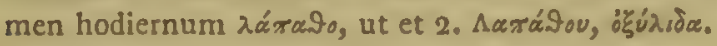

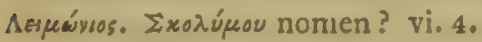

1. Asíguy. Lilium, candidum.

2. Asípray zạфugoũy. Lilium, bulbiferum. Var. $\delta$.

Aícavos. 2Amyris, Gileadensis, L. Balsamus olibanus Mecuárou divgen. $\}$ nobis. Vid.not. p. 425.

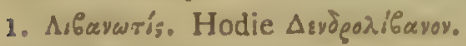

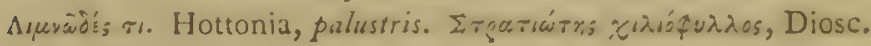
iv. 103. p. 174.

\section{M.}

Madwria. Syn. Nukpaía;, ix. 15. Nomen Egyptiacum.

1. Màáxy, i. 10. Lavatera, árborea.

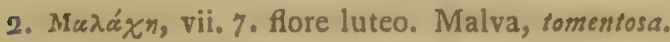

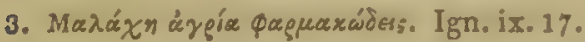

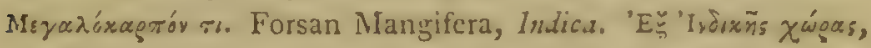
iv. 5 .

Mirágrẹuve. Schœnus, rigricans.

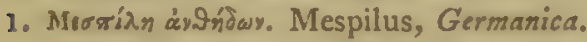

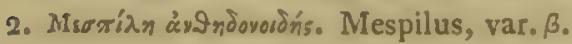

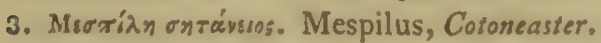

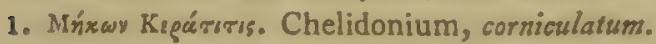

2. Mińxav 'Porás. Papaver, Rhcus.

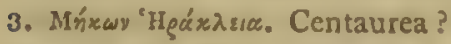

Mrrávioy. An Tithymalus, ix. 8. rel syn. Mŕxwvos? N. B. Succus Mrixwvos cum succo Tithymali et aliis venenosis mixtus. Múxrs. Agarlcus, campestris. 


\section{lXii PLANTE OMISSE, VEL EMENDATE,}

\section{N.}

Nágòo;. Apud nos falso "spikenard," quasi ex spica, non ra-

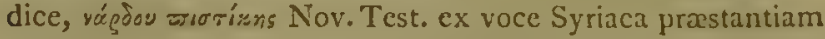
notante. Schleusner. Accurata descriptin occurrit Act. Reg. Lond. item in cel. opere Gallico Jardin de Cels dict. sub nomine Andropogon, Schoenanthus.

Napanruia. Ferula, meiodes.

Nñers. Vid. Nǟos. Forsan syn. Náģov.

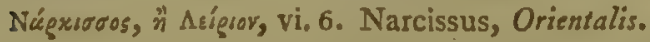

\section{O.}

Oiráran. Enanthe, pimpinelloides. Notand. an adsit odor vini.

1 2. Öros. Videndum an genus Ribes in calidioribus montanis reperiatur.

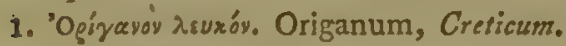

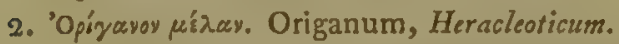

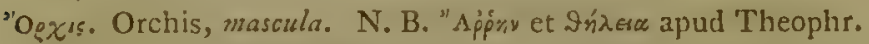
de bulbo majore et minore cjusdem plantæ; non, ut Linn. Sp. Pl. species diversæ.

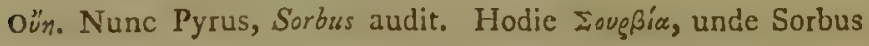
Lat.

oüiryos. Arabis, lypogaca.

\section{$\pi$ II.}

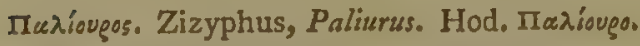

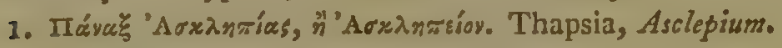

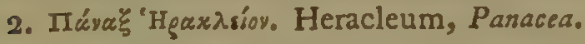

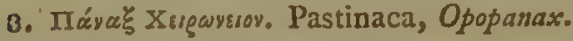

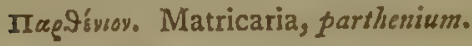

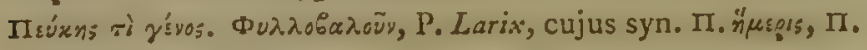
Q9ergopógos?

$\Pi$ Iregis. Picris, echioides.

Móas 'Apégaros. Lychnis, Chalcedonica.

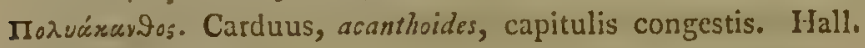
Helvet.

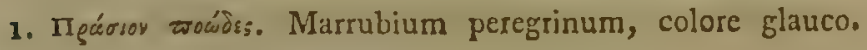
Bauhin, An Mar. vulgare. 


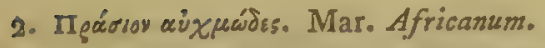

חugós. Distinctio sumitur inter aristatas et muticas species,

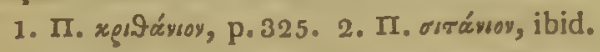

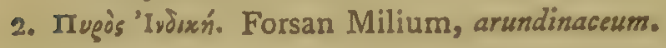

\section{'P.}

2. "Páфaros. äygios, vel öpervos. Vid. not. ix. 14.

3. 'Páфasos. Cochlearia, armoracea.

'Pı̧́iov ṣ́ńresov. Colchici lethale genus ad ripas Tanaidos fluvii. Species non descripta.

\section{$\Sigma$.}

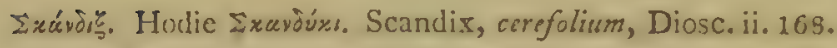

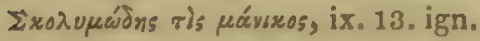

1. Exogriós. Genista, Lusitanica.

2. Exoprios. Spartium, Scorpius, vi. 1-3.

3. Exogrios. Radice contorta фąpaxádys, ix. 14. ign.

$\Sigma \mu i \lambda \alpha \xi$. Hodie $\Sigma \mu \iota \lambda \alpha \gamma \gamma \alpha$.

$\Sigma \mu u ́ p$. Vid. not. ix. 4.

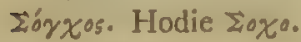

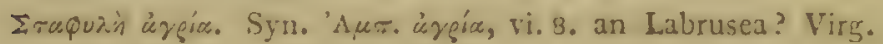
Delphinium, staphylina agria, $\mathrm{L}$.

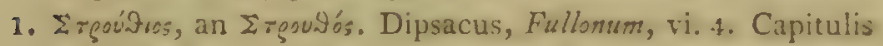

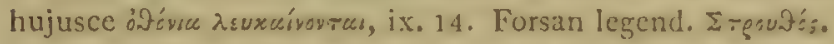

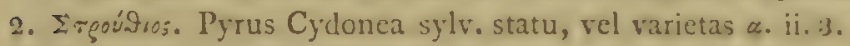

3. Ergoúdios. Lonicera, Peryclymenum, vi. 8. Vid. Athen.

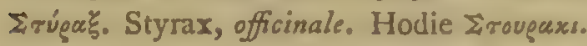

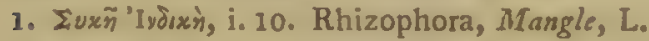

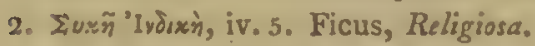

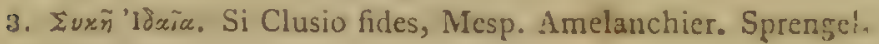

R. H. 99.

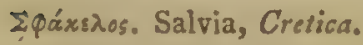

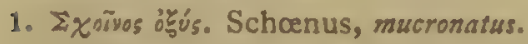

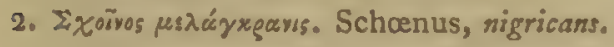

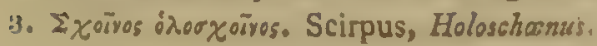


lxiv planta omis, \&c. in Cat. part, prim.

T.

TlQuov. Tussilago, farfara.

3. Tgiboros. Fagonia, Cretica.

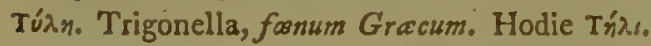

$\Upsilon$.

'Troxorgis. Hyoseris.

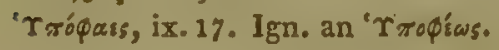

$\Phi$.

Фiरúgx. Nomen hodie $\Phi_{i} \lambda u g ̧ i x$.

2. $\Phi \lambda^{2}$ íss. Arundo, calamogrositis.

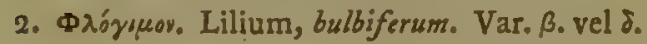

$\mathrm{X}$.

Xapaibaros. Rubus, casius.

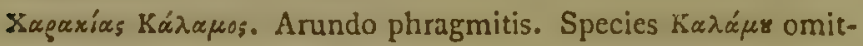
tuntur in Cat. Græco-Latino, Vid, Arundo 1. p. xlii. 


\title{
PLANTE SPRENGELIANE,
}

\author{
QUARUM \\ NOMENCLATURA A NOSTRIS DIVERSA:
}

CUM NOTIS.

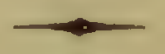

A.

"Ayguorts. Triticum, repens.

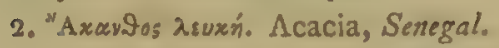

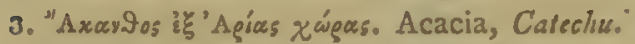

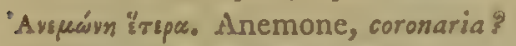

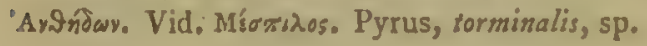

B.

Bádayos $\dot{\eta}$. Hyperanthera, Moringa.

Bódreos ípripeses, ix. 16. Colchicum, autumnale.

Bód Gos igóóøogos. Crinum, Asiaticum. Vid, not. p. 318.

Boúropes. Butomus, umbellatus.

Béás. Secale, Cereale. Vid, not. p. 358.

$\Gamma$.

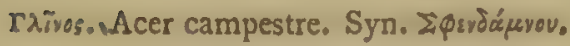

$\Delta$.

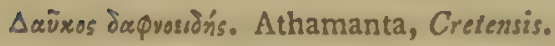

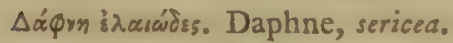

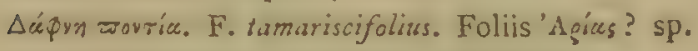

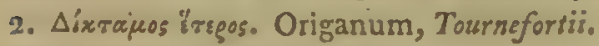

$\Delta \rho^{u} \tilde{u}_{s}$ অovtia, Fo membranifolius, sp. 


\section{E.}

'Enaíayvos. Salix, Babylonica.

'Eגiviov. Teucrium, Creticum.

'Elíxpurov: Graphalium, Stoechas.

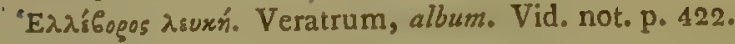

'Eтizirgov. Sedum, anacampseros.

'Epúourev. Alyssum, sativum. Vid. not. p. 354.

Eiávupos. Euonymus, Europacus. Vid. not. p. 144.

\section{H.}

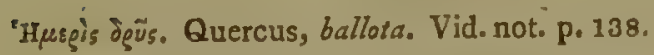

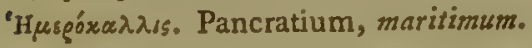

'Hgiryiav. Eryngium, planum.

\section{$\Theta$.}

Oaభice. Thapsia, Asclepium. Vid. not. p.416, 418.

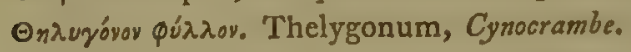

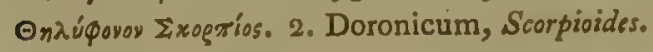

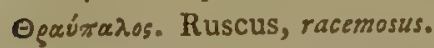

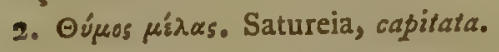

\section{I.}

"I gls ràapwìns, vii. 12. Iris, graminea.

'Iтvóy. Hippuris, vulgaris.

"I

K.

Kaдереiv9n. Melissa, Cretica, sp.

Kirxęs. Panicum, Italicum. Vid. not. p. 355.

Kєdgís. Juniperus, nana.

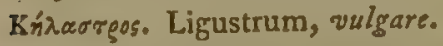

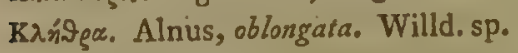

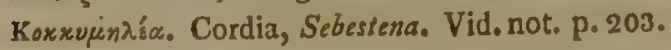

Koroxúrar. Cucumis, sativa. 


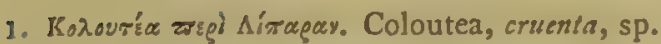

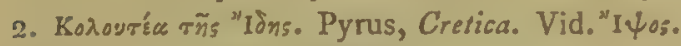

Kópxopos. Corchorus, olitorius.

Kouxiópogos. Cocos, nucifera. Vid. not. p. 203.

Kéávioy. Tuber, cibarium.

Kpárayos. Cratzgus, Azerola.

Kévov díev9:5. Narcissus, Calathinus.

Kpivou öposiss. Asclepias, procera, iv. 9.

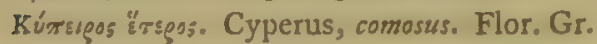

Kúxpos. Nelumbium, speciosum.

\section{$\Lambda$.}

\axáSn. Phillyrea, latifolia.

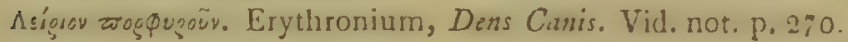

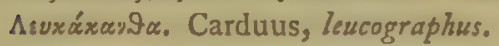

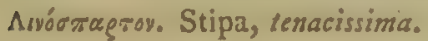

\section{M.}

2. Mayvidéís. Laserpitium. Vid. not. p. 267.

Mápatpov Moyriov. F. faniculaceus.

Mlasvoy. Panicum, Miliaceum, Vid, not, p. 355.

Mróoiov. Cyperus, esculenius.

Mw̃⿰v. Allium, nigrum.

\section{N.}

Norpaia. Nymphra, lutea, sp.

\section{o.}

Oivolńga. Epilobium, Alpesire.

2. OHoos. Lycium, barbarum.

'Oגóaxouvos. Cladium; Germanicum. Schrader.

'oגepa. Triticum, Spelta. Vid. not. p.

'ožún čyşia: Quercus, cerris.

'Ogrorísyov. Laserpitium, formosum, sp.

'Opobáryx. Cuscuta, Europaca.

Ogobos: Ervilia, Ervum. Vid, not. p. 354.

'Orrģúa. Ostrya, rulgaris. 
П.

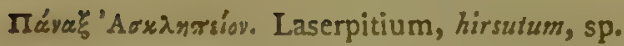

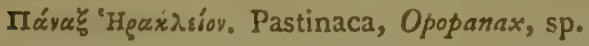

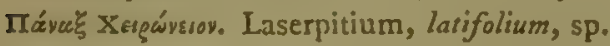

Irpdixsov. Polygonum, viviparum, vel divaricalum.

Iişota. Cordia, Myxa.

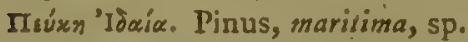

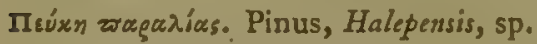

Mirvs, iii. 8. Pinus, Larix.

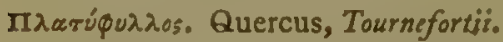

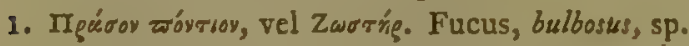

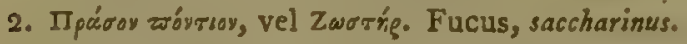

$\Pi$ givos. Quercus, coccifera.

Irígu乡. Acarna, cancellata?

\section{'P.}

1. 'Páuvos $\mu$ śdoes. Rhamnus, Lycioides, sp.

2. 'Pápvos גivxós. Zizyphus, vulgaris, sp.

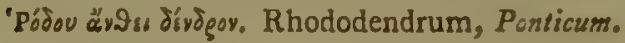

\section{$\Sigma$}

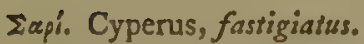

¿ín. Nymphra, alba.

$\Sigma i x$ vor. Cucurbita, Pepo.

Eíxuos. Cucumis, Melo.

Eis prov. Ferula, Tingirana.

Eraviplesov. Mentha, sylvestris.

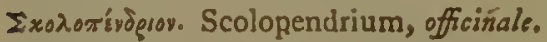

¿xódvpos. Scolymus, maculatus.

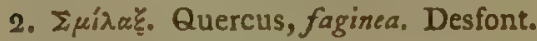

इórxos. Sonchus, maritimus.

Erooias. Prunus, insititia.

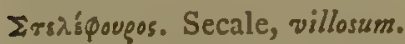

¿ridis. Loranthus, Europaus. De Caus. Pl.

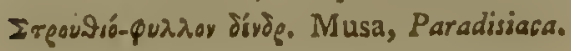




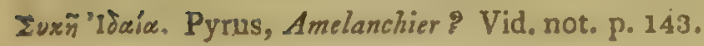

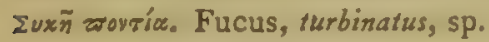

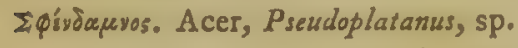

T.

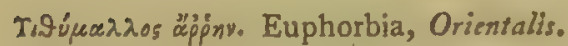
Tiфn. Secale, Cereale. Vid. not. p. 351.

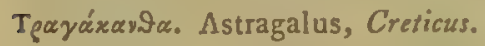

2. Tpibonos, iv. 11. Potamogeiton, serratus.

$\Upsilon$.

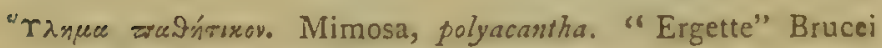
Append.

'rroxoụís, Hyoseris, lucida, sp.

\section{$\Phi$.}

Фáxos 'Ivơrý. Dolichos, Caltang, iv. 5.

$\Phi \lambda$ síws vel $\Phi \lambda^{2} \hat{w}_{5}$. Arundo, ampeiodesmus. Cyrilli Neapol.

Ф人óysuov. Lilium, Chalcedonicum. Vid. not. p. 270.

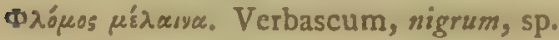

Фoivis. Phonix, dactylifera.

Фoivi छavrios. Fucus, Palmatus, sp.

Фũxos $\beta$ axroxóv. Fucus, cartilagincus.

$\mathrm{X}$.

Xapaidíwy píracs. Brotera, corymbosa. 


\section{NOT 瓜}

\section{IN PLANTAS SPRENGELIANAS.}

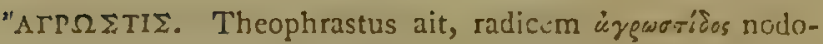

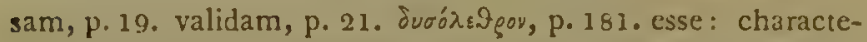
res magis proprii Tritici repentis quam $\Lambda$ grostidis, etsi spec. A. stolonifera dicta, maxime sit peculiaris.

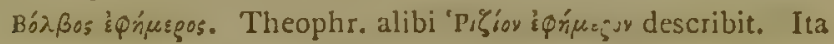
dict, quia infra dici spatium interimit: prope Tanaim nasci ait: certe divers, a Colch, auturnnali.

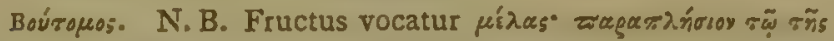
乏ions, i. e. globosus, p. 180. N. B. Sparganii char. evidens.

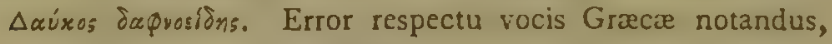
quæ non forma, sed colore refert Laurinum folium.

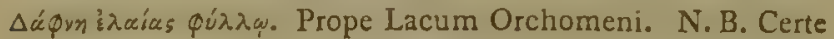
videtur Myricæ species.

$\Delta \tilde{y}^{2} ;$ ๘urria. Haud leviter rejicienda antiquorum opinio, apud quos F. serratus et vesiculosus, ut Quercus marina species enumerantur.

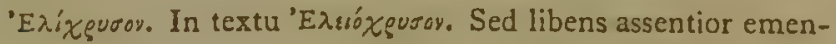
dationi Auctoris.

'Exízв gov. Ex parvitate floris Alchemillam nominavi.

'Eqúoupoy. N. B. Inter Alyssa Linn. Willd. A. satioum non occurrit.

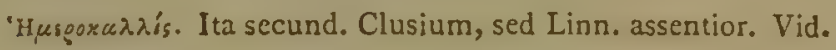
not. p. 266.

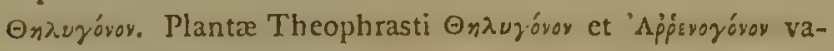
rietates Mercurialis, perennis, L. Spec. P1. 1411. Cynocrambi Camerar. et Ger. em. 332.

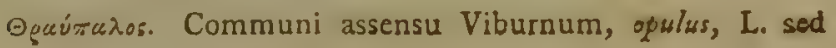
nulla descriptio apud auct. 
"I

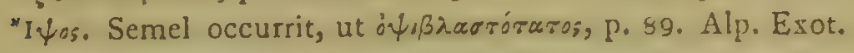

c. 2. citatur ab auctore,

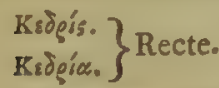

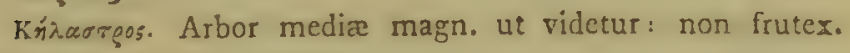
Recte apud Linn. Vid. Cat.

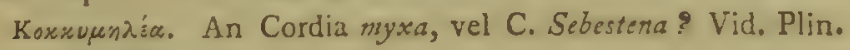
et not. p. 203.

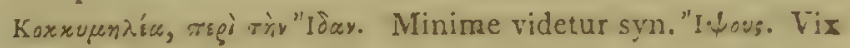
ulla desc.

Kodoxí:9n. Deceptus sono vocis, Colocynthida interpretatus sum. N. B. Vox hodierna Cucumeris Koגoxugía.

Koiroy dusy'šs. N. B. Vox indicat florem super florem; apte conveniens nectario in Narcisso.

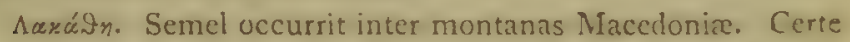
non Phyllirea latifolia, cujus nomen hodiernum idisxa per corruptionem a Фíduxa. Rhamnus, Alaternus. Cat.

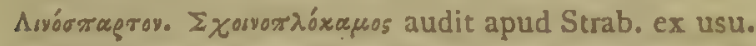

Mváosoy. Semel occurrit yox hac peregrina originis, termi-

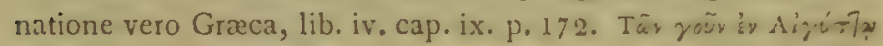

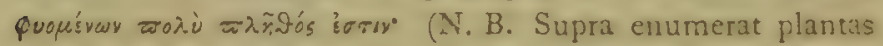

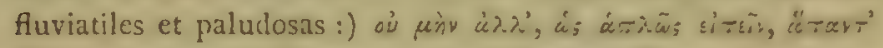

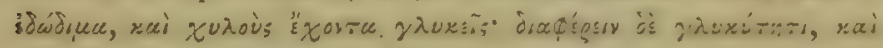

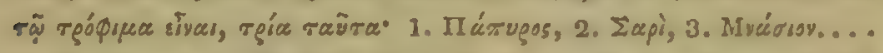

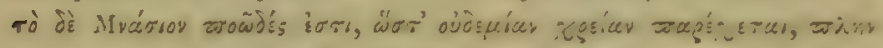

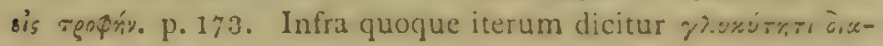
fígar rò Muéosoy.

Ex similitudine vocum MNAsI, ExsI, (rocibus, ut vijecur, Egsptiacis,) dempta utriusque terminatione haud inverisimile videtur plantam a Bruceo descriptam sub nomine ENSET eandem esse ac MNAsrum Theophrasti: Botanicus quivis ex icone et descriptione genus istud intermedium inter PALALs et MIUSAs in systemate collocaret. Iconem sisto magnitudine dimidiata. Vid. tab. ii. p.17\%. Fructus ENSET inedulis esse dicitur, bases foliorum aveniæ, tenerrimæ, usitatissimæ apud Ethiopas ad cibos. Brucei Append. p. 39. Respectu dulce-

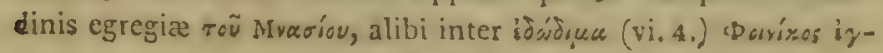

$$
\text { * } 2
$$




\section{Ixxii NOTE IN PLANTAS SPRENGELIANAS.}

xípàor recensetur. N. B. Arecæe oleraceæ medulla, si ita di$\mathrm{cam}$, in insulis Caribbeis adeo in deliciis, certe antiquitus ignota. Notandum tamen Phonicis dactyliferce (Cyclop. Britan.) cor prædulce et lactiftuum.

Nã̃u. Error Linn. ab auctore rite notatus, de quo vid. Joh. Bauhin.

2. Ollos. De Lycio minus constat: haud tamen afirmarem R. Grossulariam antiquis notam fuisse, nec in regionibus calidioribus sponte perveniri.

'Ožún úvģia. Mira, ut videtur, hallucinatio Auctoris, contra opinionem receptam ab omnibus. Textus sc. unius literae

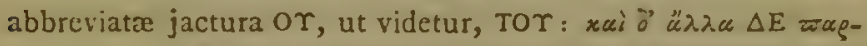

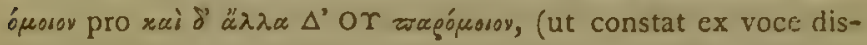
junctiva $\Delta E$,) contrarium sensum efficit. Folium distincte comparatur folio Pyri, sed largiori, i. e. apice elongato: $\delta v \sigma \chi i \delta$ is Bod. tenax, scindi difficilis; $\dot{a} \sigma x$ xö̀s al. i. e. sine lobis : išcuráy-

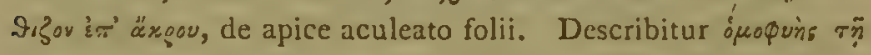

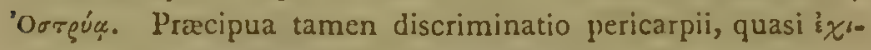

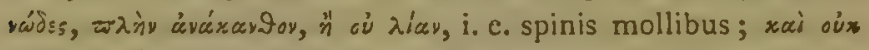

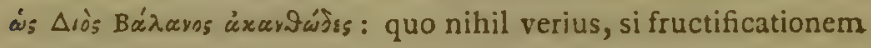
perspiciamus.

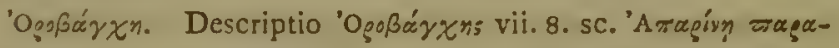

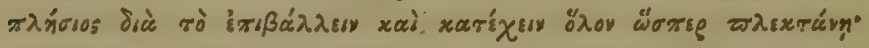
characteres Polygoni convoluti, Angl. "Bearbind," vel Fumariæ et Aparines proprii.

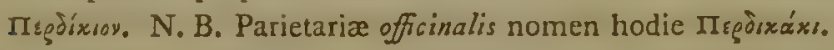
Flor, Græc.

$\Pi € \sigma^{\prime} \mathfrak{s}^{\alpha}$. Describitur ut similis Pyri habitu, foliis, floribus, iv. 2. Locus nutalis Nomus Thebaicus, Egypt. iv. 3. Plinius ait foliis deciduis, sed species sempervirens secundum Theophrastum. Vid. not. p. 202.

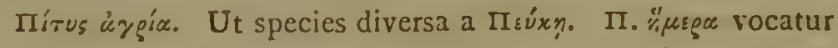

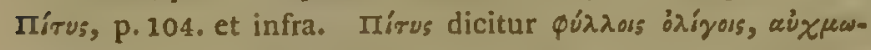

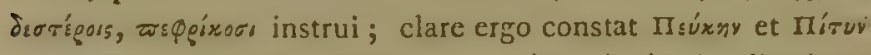
quodammodo synon. alibi quoque İśxns ri gívos implicatione

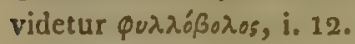

II rígviš. Semel in Hist. Pl. occurrit vox hæc, ut xaudios og̣ ò Kóxtov, vi. 4. Sed verior explicatio Sprengelii videtur. 


\section{NOTE IN PLANTAS SPRENGELIANAS, IXXiii}

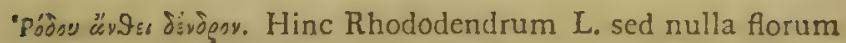
congestorum generis istius cum simplici Rosa, vel etiam $\dot{z}$.

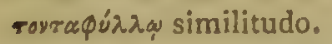

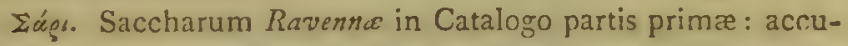
ratius tamen perpendenti mihi, vix ulla videtur dubitatio Saccharum, officinarum, L. vel saltem S. biforum, Forskâl. Egrypt. hic indicari, Quod ad S. offic. dicitur, "Culmos venales cir"cumferri, et crudos edi." p.15. Descriptio S. bifor: apud cundem: "Culmus homine altior ex aquis extat. .. in littore, "Nili limoso tanta crescit copia cum Arundine Donaci, ut "penetrari non possit bee sylva arundinacea, nisi incolec "parvos exscinderent tramites." Ibid. p. 16. Apud Theo-

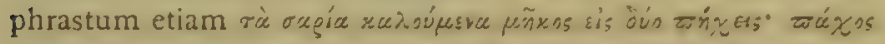

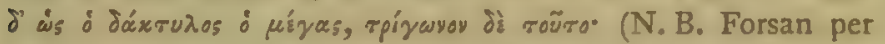

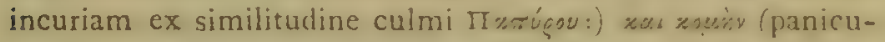

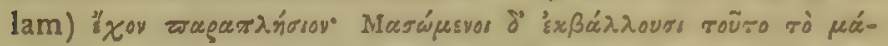
onpec, i. e. manducantes caulem exspunt crudam materiem. N. B. Antiquitus Sacchari, sul) nomine $\mu: \lambda .100$, mellis, ex arundinibus exsudantis mentin fit: ita Nearchus apud Stra-

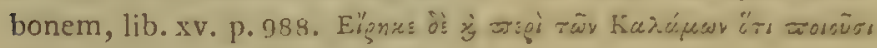

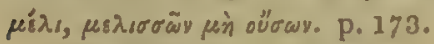

乏íon. Minuta, ct, ut vilectur, accuratissima descriptio. Pericarpium membranis cinctum albis: calyx 4-phylla: grana similia Punici granati non conveniunt Nymuhnas nostrati. Hab. Lac. Orchomeni. P. 180.

$\Sigma$ rodias. Ita nominata ex colore fructus, unde varietas facile eruenda in loco natali.

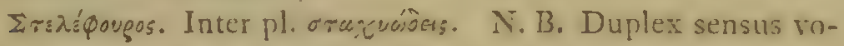

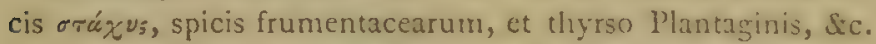

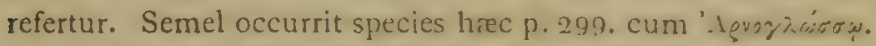

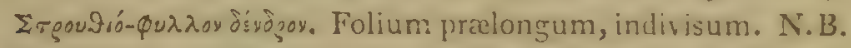
Musæ folium minime convenit plumæ Struthionis. Substituo Arecæ folium ex insula Tapobrana.

2. Teibsnos. Certe ex descriptione pericarpii Trapa natans L.

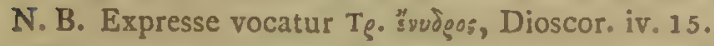

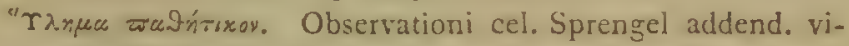
detur quod Forskâlius fabulose forsan narrat de Mimosa qua. dam arborea ramis demissis viatorum salutante. 


\section{lxxiv NOTE IN PLANTAS SPRENGELIANAS.}

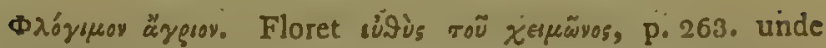
verisimilior conjectura Erythronii : item ex flammeo colore. Nulla habitus descriptio.

Фoìy.̆. Palma, Cat. N. B. Ordinis nomen ; cujus Phonir

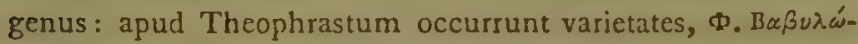

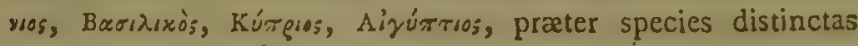

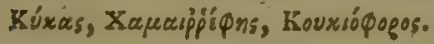




\section{NOMINA HODIERNA}

\section{PLANTARUM GRACIE.}

A.

Acanthus, spinosus. Moúrgeryo.

Achillea, pubescens. "Aygus 'A qivisa.

Aconitum, napellus. 'Axávirov.

Acorus, Calamus. "Arogos.

Adonis, autumnalis. Mapóxagroy.

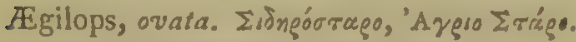

Agrimonia, Eupatoria. Dovóxogroy.

Agrostis, alba. "A $y \rho 10 \mathrm{IK} \alpha \lambda \alpha \mu \varepsilon \alpha$.

Agrostemma, Githago. Korrods.

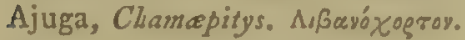

Alcea, rosea. $\Delta$ ivdęo Módoxa.

Alchemilla, alpina. Arovroróóov.

Alisma, plantıgo. $\Lambda a ́ r \pi \alpha$.

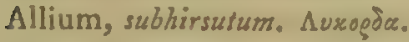

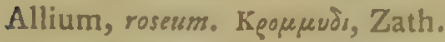

Alopecurus, utriculatus. 'A

Amaranthus, Blitum. Bגíroy.

Amaranthus, ruber. Bגiroy roxruvor.

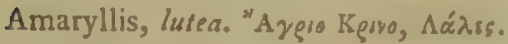

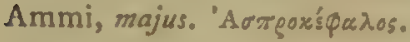

Amygdalus. 'A $\mu$ '́rdar.,

Amygdalus, Persica. 'Podáxuve.

Anagallis, arvensis. IIsodisoúd.

Anagyris, fretida. 'Avḑgaßáyo.

Anchusa, pariculala. Boudoy dwroov,

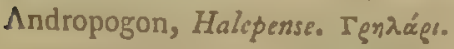

Ancmone, coronaria. Iatagoũvs. 


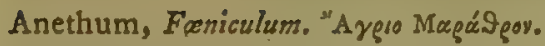

Anthemis, rosec. II $а$ roũys.

Anthyllis, vulneraria. Koxovóxogrov:

Apargia, tuberosa. "A qgesa "Pádiso.

Apium, Petroselinum. Mugódic.

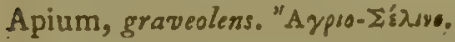

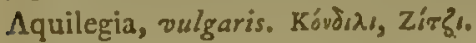

Arbutus; unedo. Kopapia.

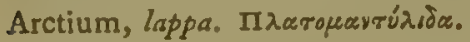

Arenaria, rubra, Midnyovov。

Artemisia, Absinthium. 'A భidise.

Artedia, muricata. 'A 's ryavo.

Arundo, Donax. Kérape. Vid. Phragmites, id.

Asarum, Europerum. 'Aóágo.

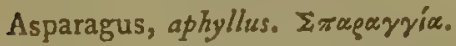

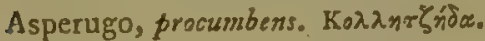

Asphodelus, ramosus. 'A póório.

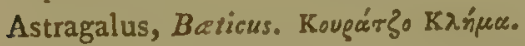

Astragalus, Monopessulanus. Ţuyovóxog̨rov,

Astragalus, arisfatus. T

Atropa, Mandragora. Mavidgayoú

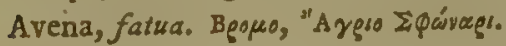

B.

Ballota, nigra. II

Bartsia, Trixago. "Argeio súxos.

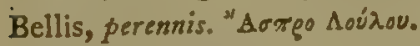

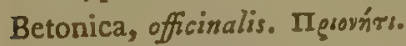

Betonica, alopecurus. Biтóusx.

Betula, Alnus. $\Sigma \times 1 \lambda i i_{\rho} \alpha$.

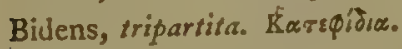

Borago, officinalis. 'A $\mu$ Tura, Bovgúrza.

Brassica, oleracea. Мazayay ró.

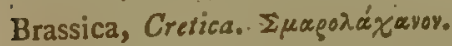

Brassica, Eruca. Eủz̧̄uarov.

Brassica, caulifolia, Kąyaßírı. Forskâl.

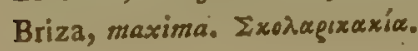


Briza, minor. Tל̌oyís.

Bromus, mollis. Auxávoga.

Bromus, sterilis. "A ypeo Béóre.

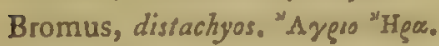

Bupleurum, glumaceum. Boגoxpixoy.

Bupthalmum, mäirimum. Xaproxadı

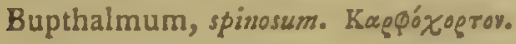

\section{C.}

Cachrys, Sicula. Iırgò Napa'ńxo.

Calendula, offcinalis. Xapeßovęrza.

Campanula, versicolor. Xapírsss.

Camparula, Speculum. "A ygro Toúdra.

Capparis, spinosa. 'Pspoviáģa, Kaxzagía.

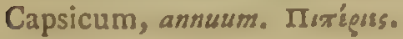

Carduus, n. go. "A yraito.

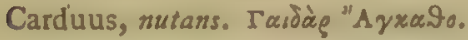

Carduus, marianus. Koúpo "A yra.9o.

Carduus, Acarna. "Arrgo "A yra9o.

Carduus, arvensis. Nígo "Ayrano.

Carduus, serratula. "Ayeso Zóxos.

Carlina, larrata. Kexx/y "A yxx98.

Carlina, corymbosa. "A zеasrúdido.

Carlina, rubra. Kóxxsy "A yxa.9o. Vid. Carlina, rubra.

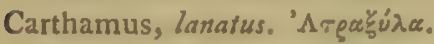

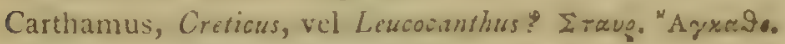

Caucalis, grandiflora. Kauxádida.

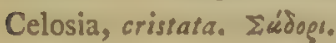

Celtis, australis. Tגuxvxorex, Muporéxrode.

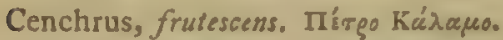

Centaurea, benedicia. Kádo "A yra.9.

Centaurea, calcitrapa. Kargir "A yra.9o.

Centaurea, Centauroides. इasr" "Ayxa9s.

Centaurea, comentosa. 'Argorspa.

Cerastium, lomentosum. Гаứ́xoproy.

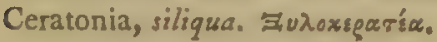

Cerinthe, amara. Exadus'ivax, 
Chara, vulgaris. Maxa.

Chelidonium, majus. Xirsoóviay.

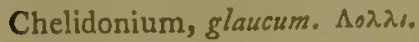

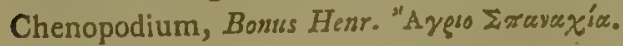

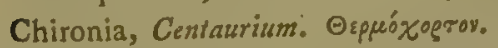

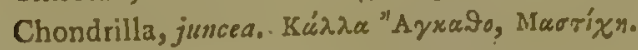

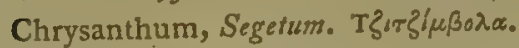

Cicer, arietinum. 'PE\&

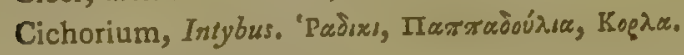

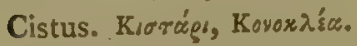

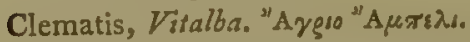

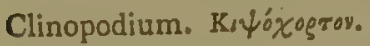

Cnicus, Acarna. "A ypro "A yxe20.

Cnicus, horridus. Mave "Ayxa:

Cochlearia, Draba. Magoudéxio

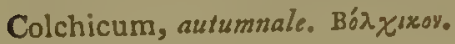

Conium, maculatum. B९онóxogrov。

Convallaria, Majalis. Magraẹıragía.

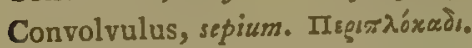

Convolvulus, arvensis. Idem.

Convolvulus, althaoides. "A

Convolvulus, tenuissimus. Kàroyspoxовтоу.

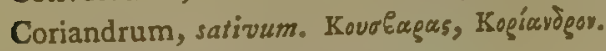

Cornus, sanguinea. Maupoßsegrsa.

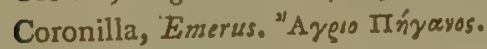

Corylus, avellana. Фouvroúxis.

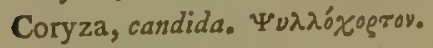

Cotyledon, umbilicus. $\Sigma \alpha \mu \beta$ ßovv。

Crepis, fuliginosa. "A y şo "Páoirra.

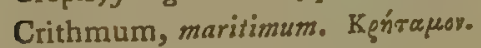

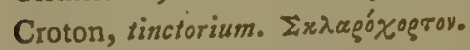

Cucumis, anguind. Ko

Cucurbita, Citrullus. Xspeóvixo.

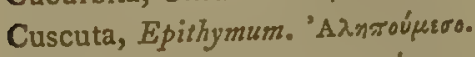

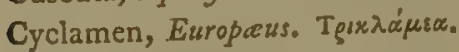

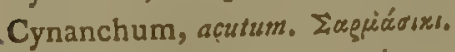

Cynara, Scolymus. "A yęo Kúvago.

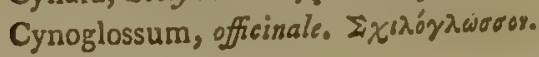


Cynosurus, phleodes. Kog̣wéss. Z.

Cyperus, longus, et rotundus. Kursiges.

Cyperus, esculentus. Kiтrgo.

Cytisus, hirsusus. ¿úvspo.

\section{D.}

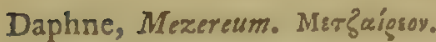

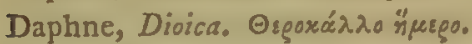

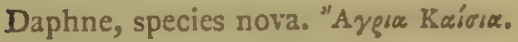

Datura, Stramonium. T\&́roùa.

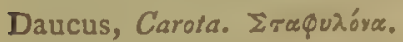

Delphinium, Ajacis. Karour ל̧'yo.

Delphinium, grandiffore. "A yęo Zovpeтoúrıe.

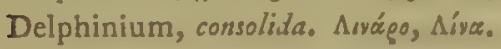

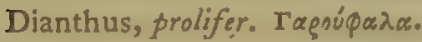

Dianthus, barbatus. Ovंronúßıa.

Digitalis, ferraginea. Kạóxọroy.

Doronicum, Pardalianches, $\Sigma$ xogriò.

\section{E.}

Echinops, sirigosus. Kaqùg "A yxa9.

Echium, flarragineum. Boudoy dworov.

Echium, Italicum. Mavoũy.

Erica, arborea. 'Píri, 'Pıítל̧.

Erica, verticillata. Turc. Фейугळ.

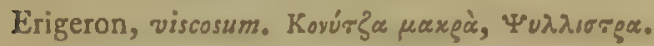

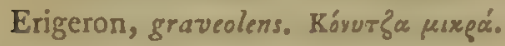

Erodium, Cicutarium. Kàóyıgo.

Erodium, moschatum. Mooxodáxavov.

Eryngium, campestre. 'Ayra9ta.

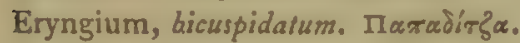

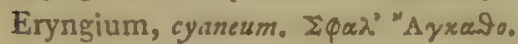

Erysimum, officinale. 'Aypra Móprxo.

Ervum, Ervilia. 'Póßı.

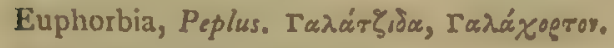

Euphorbia, Apios. Фخópuxs.

Euphorbia, spinosa, Koxxodoфávia. 
F.

Ferula, communis. 'Axćganx».

Festuca, uniglumis. "A ypu $\Sigma$ rágs.

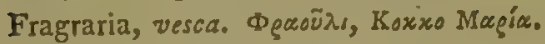

Fraxinus, Ornus. Mírıos.

Fumaria, officinalis. Kázuı.

Fumaria, capreolata. Karrióxoproy.

G.

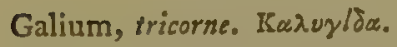

Galium, paschale. 'Pí̧ $\alpha$ ģ。

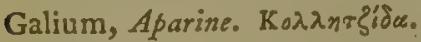

Geropogon, glaber. Kovę̧́́rтos.

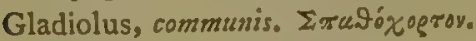

Glechoma, hederacea. Kúoros.

Globularia, Alyssoid. ¿irovgixi.

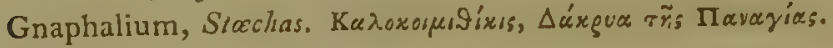

Gomphrena, globosa. Mevớsya.

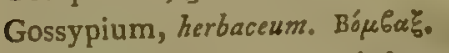

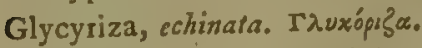

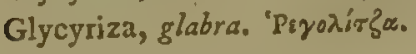

\section{H.}

Hedera, helix, Kioros, Kirz̧o.

Hedysarum, Crista Galli. Tpíßouג.

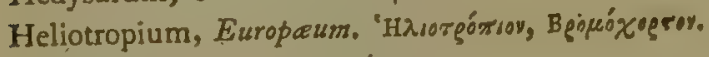

Helleborus, officinalis. $\Sigma x$ xúp̧ $\phi$.

Hieracium, bulbosum. Xミsavóx

Holcus, Halepensis. Kaдapex́yga.

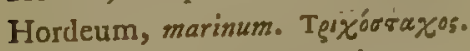

Hordeum, sativus. Kpla áps.

Hordeum, perversum. Koupóxogro.

Hyacinthus, comosus. BódBo.

Hyoseris, Cretica. Koגr\{̧ida.

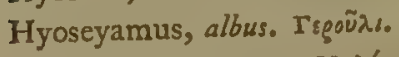

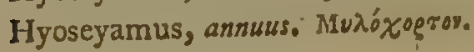




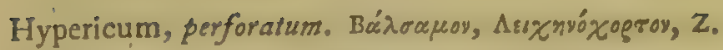

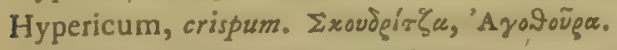

Hypericum, Olympicum. 'A yodovęa.

Hypericum, Coris. Bazoapivo.

\section{I.}

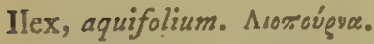

Iris, Germanica. Kéivo.

Iris, Pseudacorus. Nepéxpiyo.

Iris, Graminea. "Aygro Keivo.

Iris, Sisyrinchium. Idem.

Juncus. Boúpgro.

Ixia, Bulbocodium. Kárz̧a.

Juniperus, Oxycedrus. "Aypso $\Phi / \delta \alpha$.

L.

Lactuca, sinuata. $\Gamma \alpha \lambda \alpha \tau \zeta i \delta \alpha_{0}$

Lagœcia, cuminoides. 'A ypropíyavı.

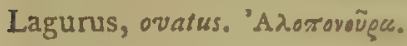

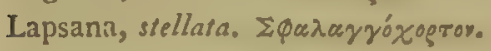

Lathyrus, Aphaca. 'Ayger Bábovds.

Lathyrus, sativus. Aáa Sovgs.

Lathyrus, minutus. "A y̧̧o Koúxo.

Laurus, nobilis. $\Delta a ́ \varphi v$.

Laurus, Indica. "Aypro $\Delta \alpha \dot{\varphi} \varphi$ y.

Lavandula, spica. Karoyspóxogrov.

Lavandula, Sicechus. Mavgoxs $\rho а \lambda$.

Leontice, leontopetalum. Boup̧arda.

Leontice, Taraxicum. "Aypro Magoúdsa.

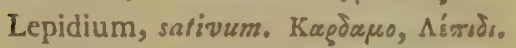

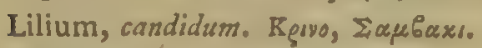

Linum, usitatissimum. Avág̨.

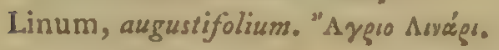

Linum, gallicum. Aíyo.

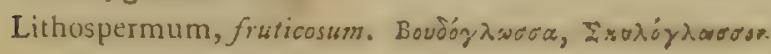

Lolium, temulentum. "II $a$.

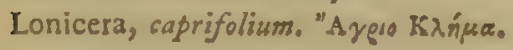




\section{Ixxxii}

\section{NOMINA HODIERNA}

Loranthus, Lonicera. "о

Lotus, tetragonolobus. Mayradia, z.

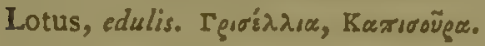

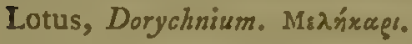

Lupinus, hirsutus. "Aygro Avrouvs.

Lupinus, pilosus. Аutrovv.

Lycopsis, variegata. $\Sigma x \alpha \rho \delta \alpha \beta_{i} \dot{z} \alpha$.

M.

Malva, rotundifolia. Móraxa.

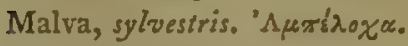

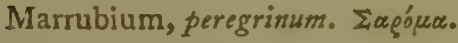

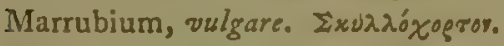

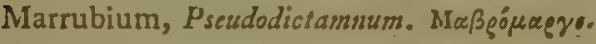

Matricaria, Chamomilla. хареони́d

Medicago, marina. 'A $\mu_{\mu \nu \rho l} \rho_{\rho} \alpha$.

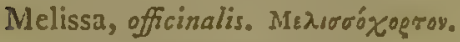

Melissa, grandiffora. Kóaroy.

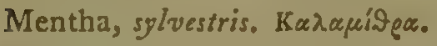

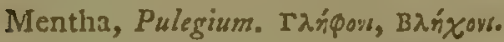

Mentha, spicata. "A yeso "Hovórpe.

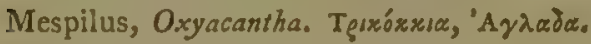

Milium, arındinaceum. Tęnáér.

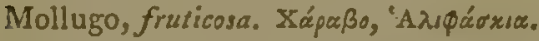

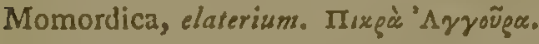

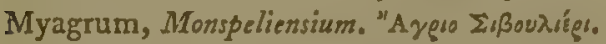

Myrtus. Múgro. Turc. Bę̧aírza, Muģarvav.

N.

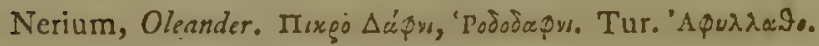

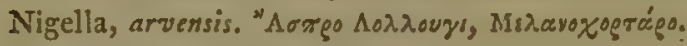

Nigella, Damascena. Maß̧óxoxo.

Nuphar, Nymphca. Nupupav.

Nymphrea, alba. Nę̧o Koxoxúvira.

\section{O.}

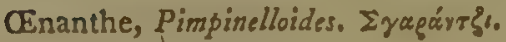

Olea, Europeca. 'Eגı⿰. 
Ononis, antiquorum. 'Avovsíja.

Onosma, Orientalis. Đuróąopubos.

Onosma, montana. Misíxogror.

Origanum, Dictamnus. इroparóxogroy, cap. 5.

Origanum, Creticum. 'A rgóóiyav.

Ornithogalum, Dictamnus?.Vid. supra.

Orobanche, major. Avxos.

Oxalis, corniculata. Mooxó

\section{P.}

Preonia, officinalis. Máxos.

Pancratium, maritimum. "Ay

Panicum, Crus Galli, Kéxęs.

Paricum, Dactylon. 'Arpíada.

Panicum, repens. 'A yí $\lambda \omega \sigma \sigma \alpha$.

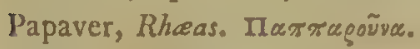

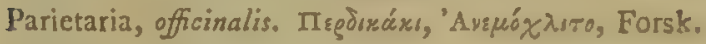

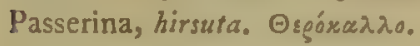

Pastinaca, Opopanax. 'A

Peganum, liarmala. Beproxugrágo.

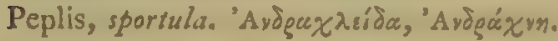

Periploca, Greca. Гuגá乡̌va.

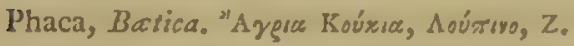

Phalaris, Canariensis. 'Avвpóxąтo, Koúxodo.

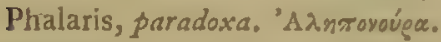

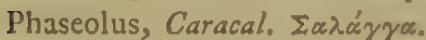

Phleum, felinum. Novoraxa Kar\}ovגiov.

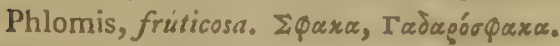

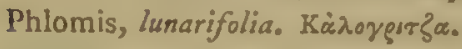

Phyllirea, larifolia. \$uגixk.

Phytolacca, dioica. 'A $\gamma$ groorá $\phi i \delta \alpha$.

Picris, echioides. Xergoßorávn.

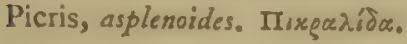

Picris, spinosa. Forsk. "A yrovgí̧a.

Pistacia, Terebinthus. Forsk. ¿rţivos.

Pistacia, Lentiscus, 引เฉoúdox.

Pisum, sativum. Aüxos. 


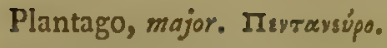

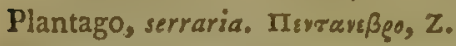

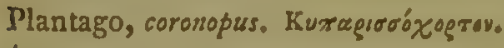

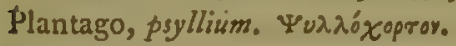

Plantago, Afra. Boveugóx cẹcov.

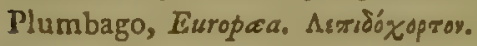

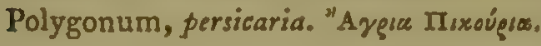

Portulaca, oleracea. 'A ygroorápióa.

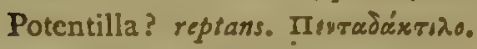

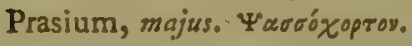

Prinanthus, viminea. Mapoúds äy

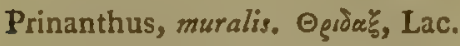

Prunella, vulgaris. Boyтuǵx́ọroy.

Prunus, laurocerasus. $\Delta a \varphi^{\prime o ́ s i d e s . ~}$

Prunus, Cerasus. Var. $\lambda_{0}$ "A ygice Keparík.

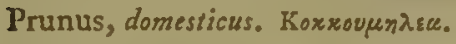

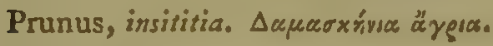

Prunus, spinòsa. Гộrzia.

Pteris, nom. gen. Фrsp̧i。

Punica, granała. 'Pódica.

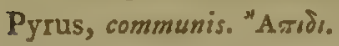

Pyrus, malus sylz. 'A ypropeńdisa.

Pyrus, cydonia. Kudúvico.

Pyrus, domestica. "Eoupgoos.

Pyrus, spinosa. 'Ayrougiza. Forsk.

\section{Q.}

Quercus, Cerris. Forsk. MEroi.

\section{R.}

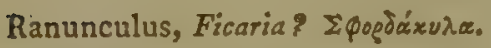
Reseda, luteola. 'Oxlerea.

Reseda, species nova. Forsk. Iráę $9 a \mu o$ ärg.

Rhamnus, Cathurticus. Asvxárxa:90.

Rhamnus, infectorius. Aads'ixsel.

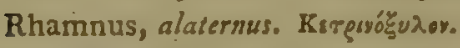

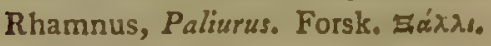

Rhus, Cotinus, Xguoúğuдov. 


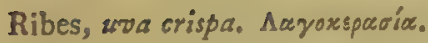

Rosa, non germinans. 'Póda.

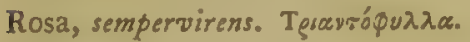

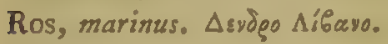

Rubia, tinctoria. 'P'? $\alpha \rho \circ, \Lambda i \xi a \rho$.

Rubia, peregrina. 'Pí̧ugo ä $\gamma p$.

Rubus, fruticosus. Báro.

Rumex; crispa. $\Lambda \alpha ́ \pi a 90$.

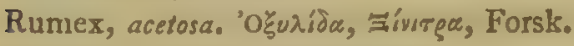

Rumex, lachanus. $\Lambda a ́ x a y o$, Forsk.

S.

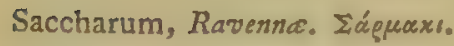

Salicornia, herbacea. Kgílquos.

Salvia, pomifera. Фжоконй $\lambda$ sa.

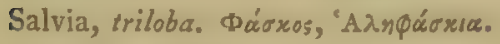

Salvia, ringens. Xríus.

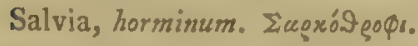

Salvia, verbenaca. Bourugóxogrov. "A yesso Baríluro, Forsk.

Sambucus, nigra. Kouф́ó̌ùov.

Sambucus, racemosa. 'Avdéúryos.

Sambucus, ebulus. 'A ßoútל̧ı.

Satureia, Juliana. "Trowro.

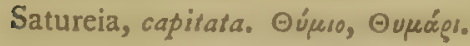

Satureia, hortensis, 'ASpipę̧re, Forsk.

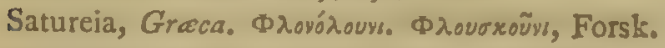

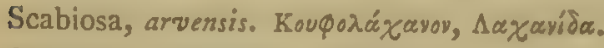

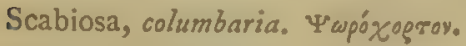

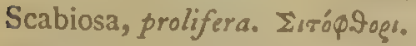

Scabiosa, Africana. $\Sigma x \alpha u \beta u ́\} a$.

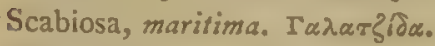

Scandix, Peclen. ¿xávduxt.

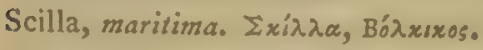

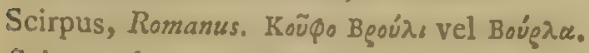

Scirpus, lacusiris. $\Sigma$ $\varphi \varkappa_{\text {. }}$

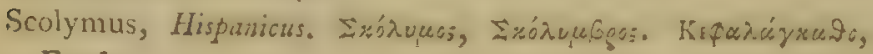

Forsk. 
Scorpiurus, sulcata. Mapyóxogroy.

Scorzonera, sulcata. Idem.

Scrophularia, peregrina. B९онóxoеgrov.

Scrophularia, canina. Ixogrtióóxogrov.

Serratula, spinosa. "1ota oroßia, Forsk.

Sherardia, arvensis. Пৎоßaróxoẹroy.

Sidum, Cepæa. Kрó

Sidum, Erịocarpon. 'Apćágavтo.

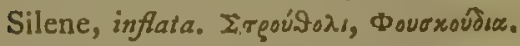

Silene, armeria. ^uxvosıss.

Sinapis, arvensis. $\Lambda a ́ \mu \psi$ uev.

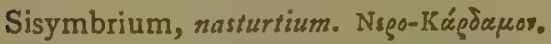

Sisymbrium, polyceratum. "A y

Sium, nodifforum. Nego $\Sigma \dot{\Sigma} \lambda$ svov.

Smilax, aspera. $\Sigma \mu i \lambda \alpha^{\prime} \gamma \gamma \alpha$.

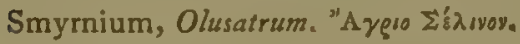

Solanum, Melongena. Msidirave.

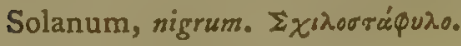

Sonchus, oleraceus. इóxos.

Sonchus, chondrylloides. Aaróbpopo.

Spartium, juncum. $\Sigma$ ráéro.

Spartium, scarpius. 'A фóvyo.

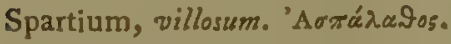

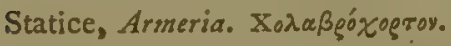

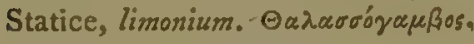

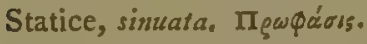

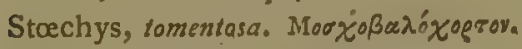

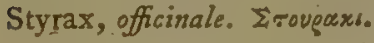

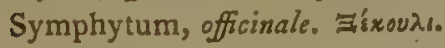

$\cdot$

$\mathrm{T}$.

Tamarix, Gallica. Movarnixse.

Tanacetum, Balsamita. Kó бđa.

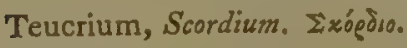

Teucrium, Chamadrys, Xapaişevu.

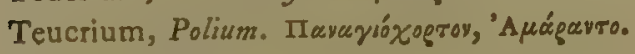

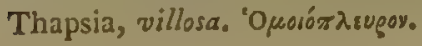


Thapsia, fatida. Moגúxsegrog.

Thapsia, Asclepium. "A

Thymus, Zygis. $\Sigma \mu x \rho s$.

Tilia, Europaca. Фıגou९́sa.

Tordyllium, officinale. Kavxanida.

Tragopogon, major. Aagoyevsía.

Tribulus, terrestris. Tęißods.

Trifolium, (nom. gen.) T фí $\varphi \lambda \lambda .$.

Trifolium, augustifolium. Гarzovoúgo.

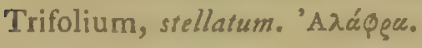

Trigonella, corniculata. Nixóxı.

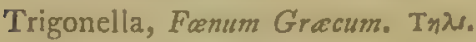

Triticum, repens. Aiga.

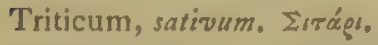

Tussilago, Farfara. Xapà $\lambda \varepsilon \dot{x}$

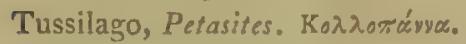

Typha, augustifolia. Túza̧̧。

U.

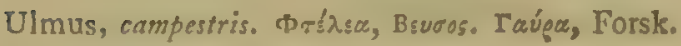

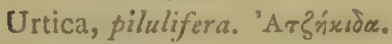

Urtica, dioica. 'Ar şárvidu.

\section{V.}

Valeriana, rubra. 'Аvádaros.

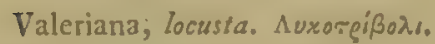

Veratrum, vigrum. ¿rúppi.

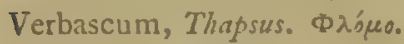

Verbascum, plicatum. Idem.

Verbascum, blattaria. ¿xúg.

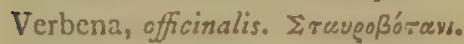

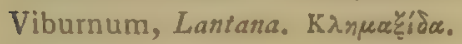

Vicia, sativa. Bйrex.

Vicia, hybriaa. "A Y̧oso Koúx.

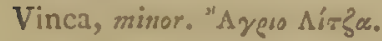

Viola, odorata. Bıдśt๘.

Viola, canina. "Aypro Bıdíra. 


\section{Ixxxviii NOMINA HODIERNA \&c.}

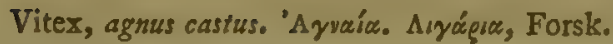

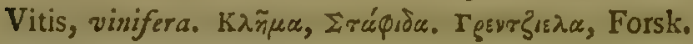

$$
\text { Z. }
$$

Zacintha, verrucosa. Kapaßidóxoẹtov.

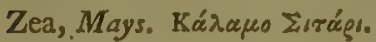

Zizyphus, Palizrus. Пaגíovpos.

Zostera, marina. Фuxía. 


\title{
$\Theta \mathrm{EO} \Phi \mathrm{PA} \Sigma \mathrm{TO} \Upsilon$
}

\section{IIEPI $\Phi \Upsilon T \Omega N$ I $\Sigma T O P I A \Sigma$}

\author{
TO $\mathbf{A}^{\prime}$.
}

\section{CAP. I.}

De Partibus Planturum, et Nofis inde sumendis.

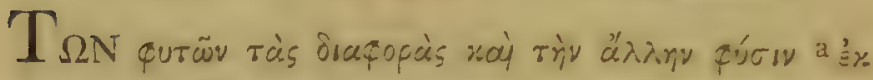

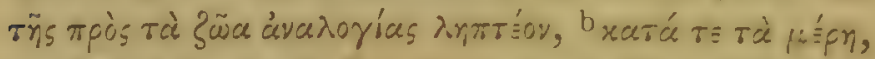

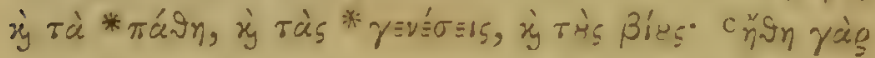

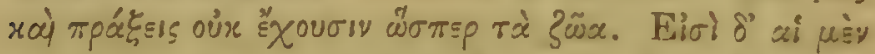

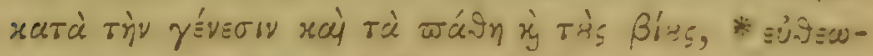

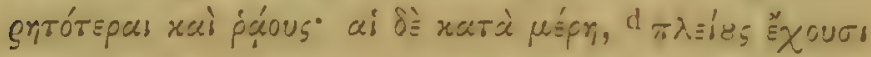

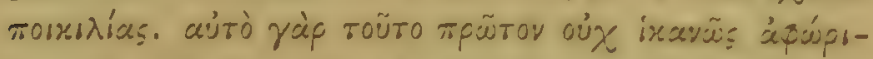

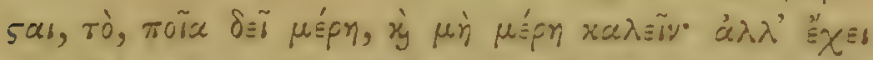

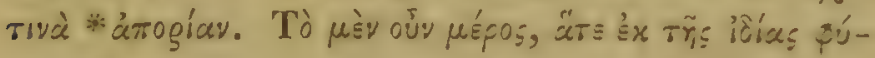

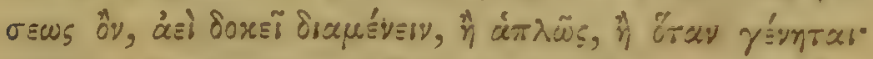

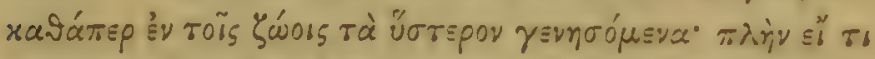

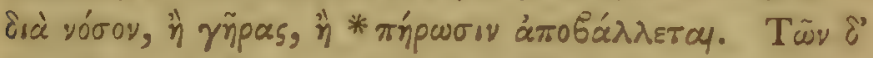

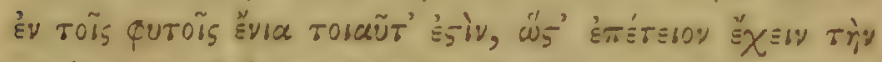

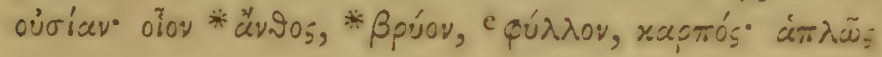

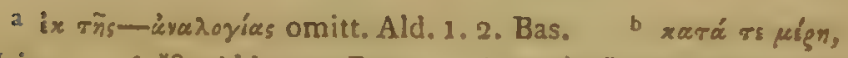
Heins. c "In Ald. 1.2. Bas. क चגeiss है Xovor Ald. 1.2.

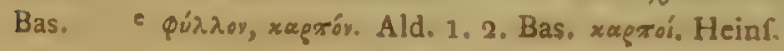




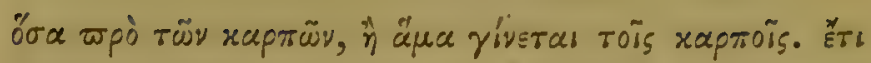

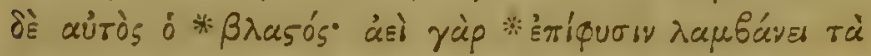

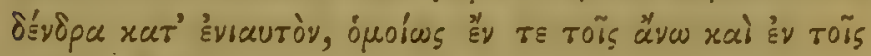

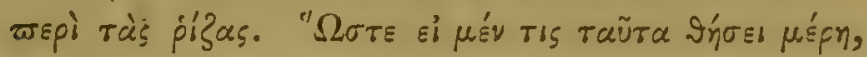

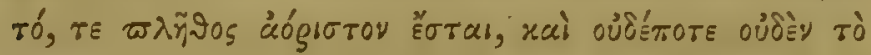

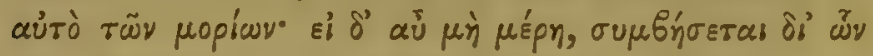

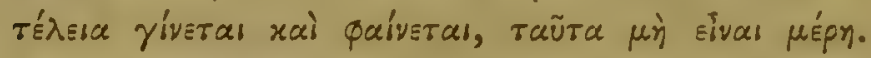

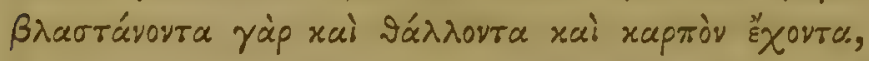

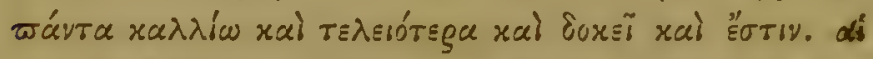

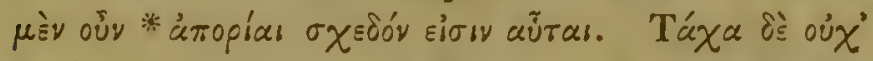

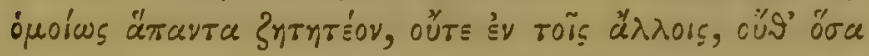

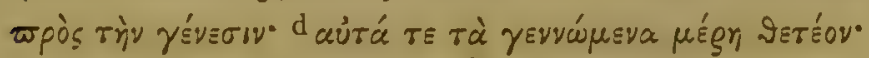

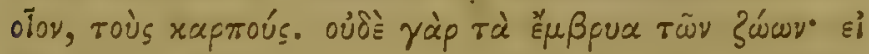

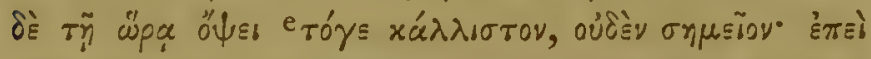

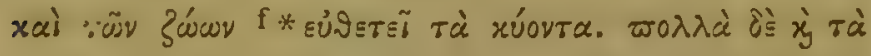

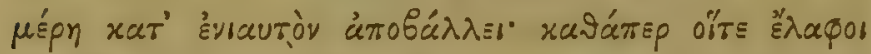

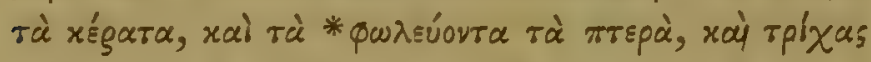

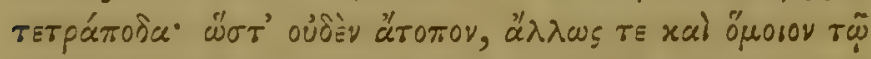

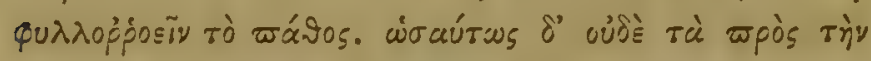

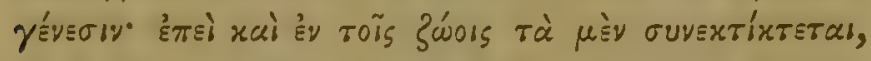

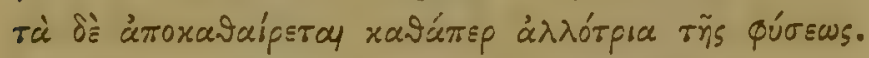

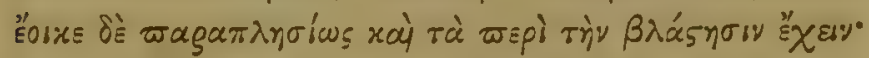

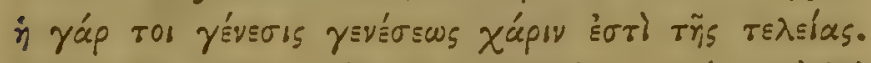

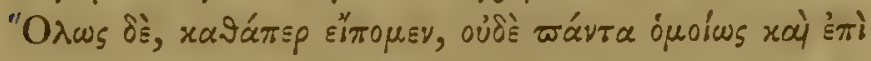

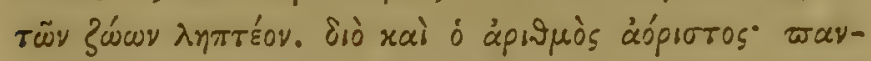

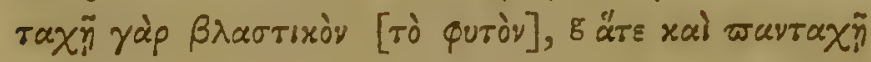

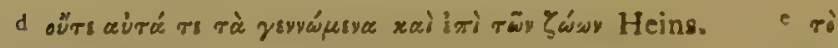

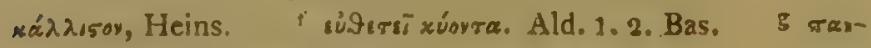

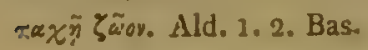




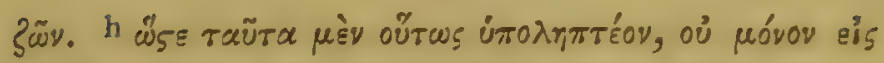

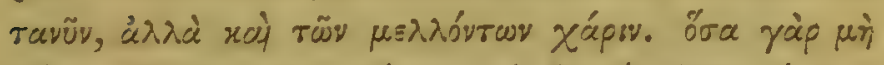

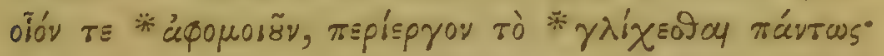

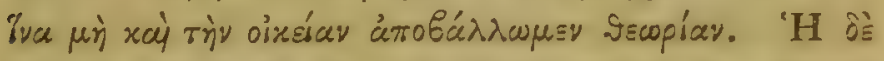

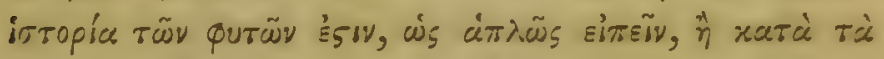

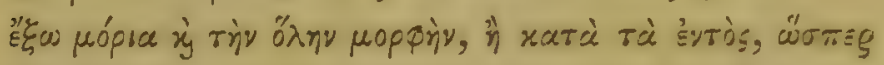

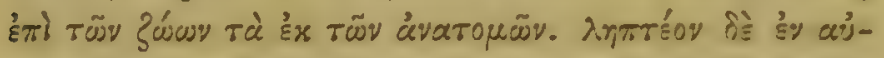

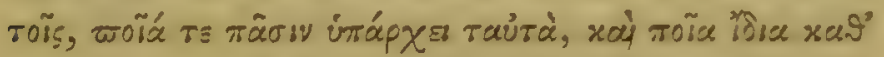

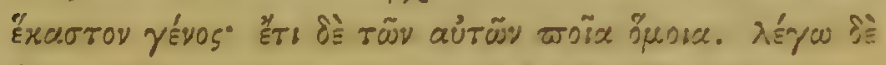

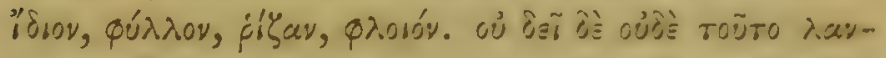

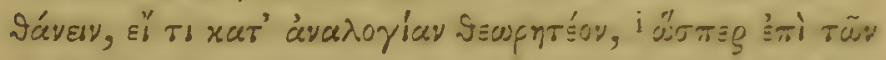

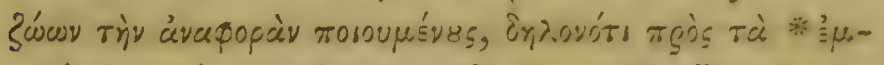

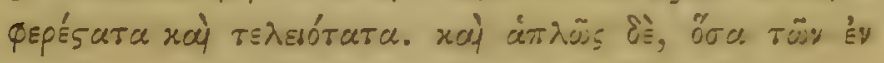

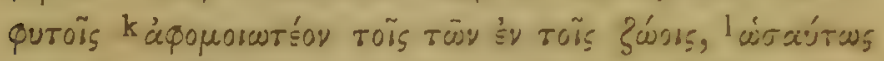

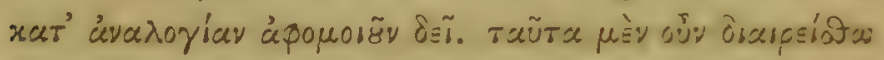

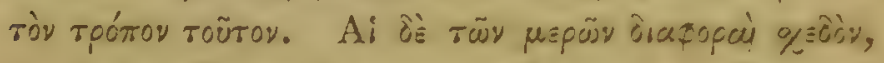

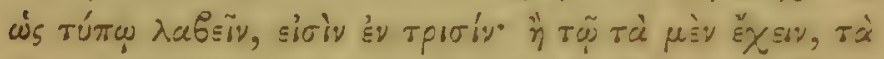

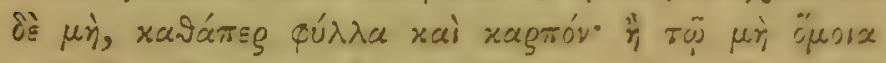

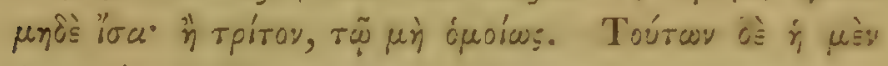

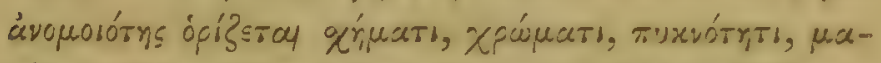

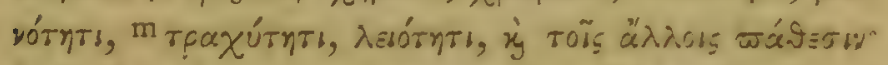

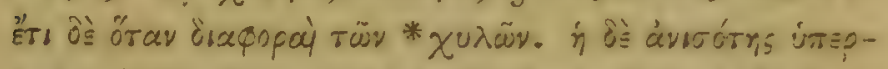

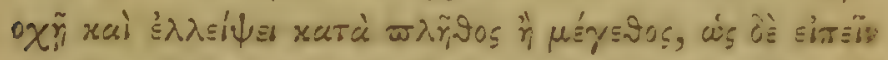

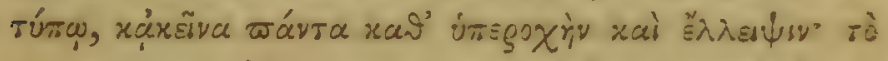

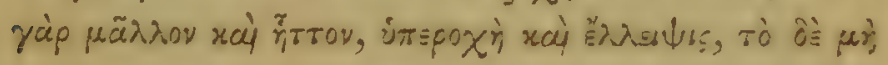

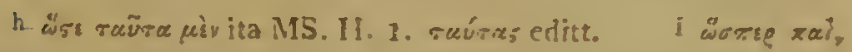

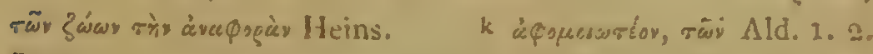

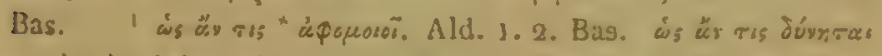

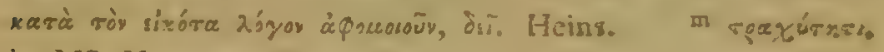
ita MS. H. l. $\approx \alpha x i r x_{r}$, editt. 


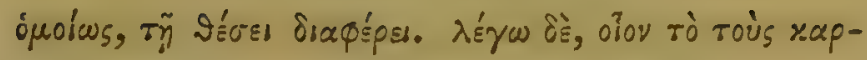

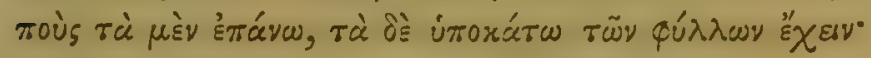

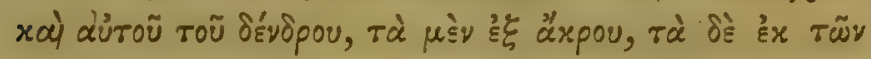

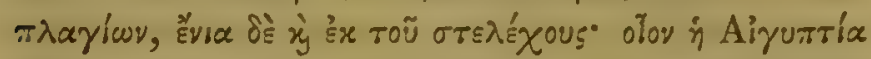

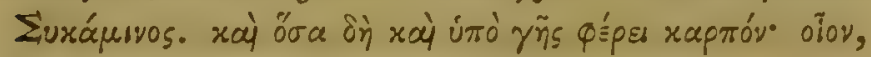

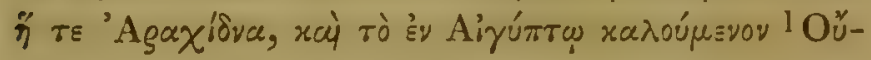

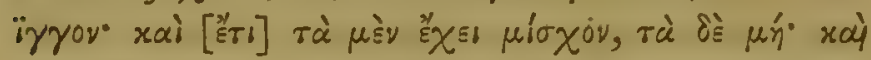

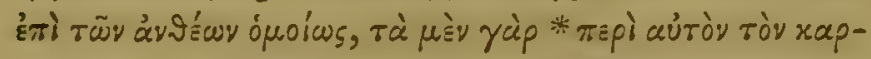

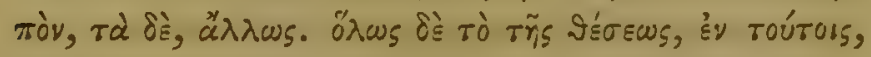

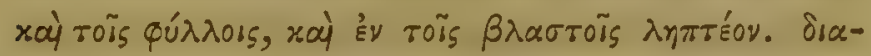

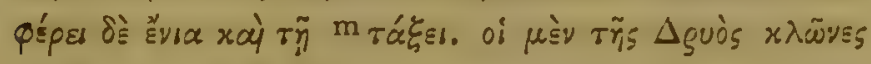

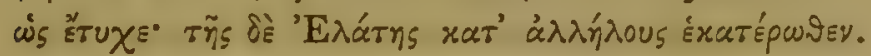

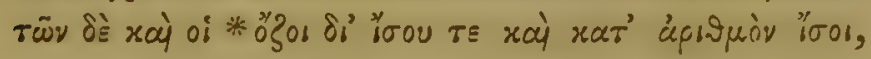

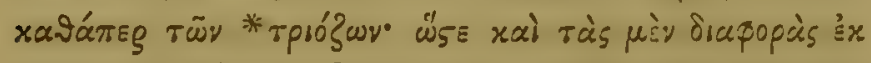

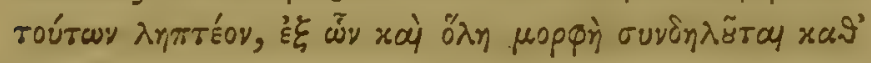
Exasor.

\section{CAP. II.}

Radix, Cortex, Medulla, Lignum, Caulis, Ramus, Fructus, Succus.

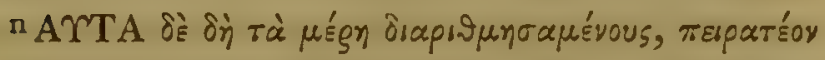

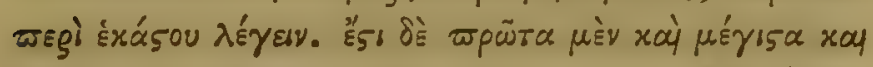

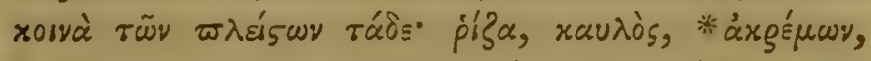

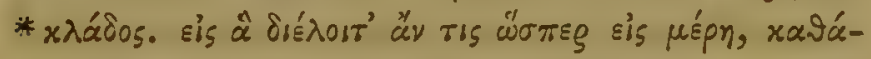

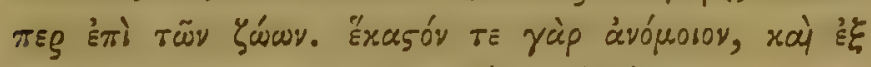
áта́

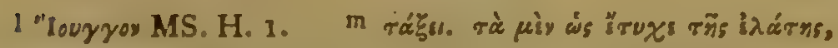

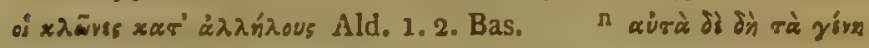

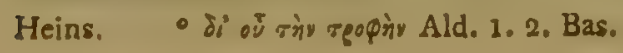




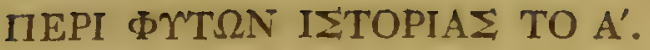

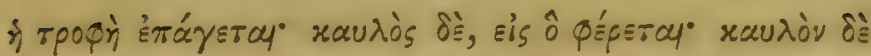

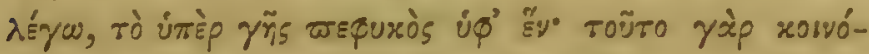

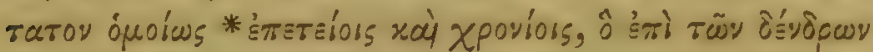

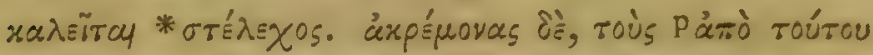

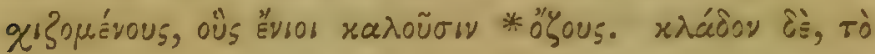

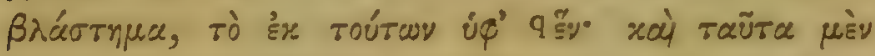

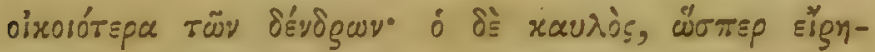

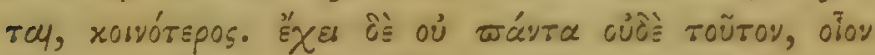

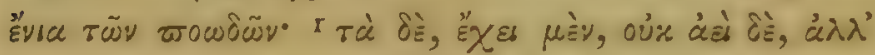

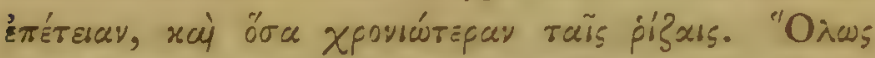

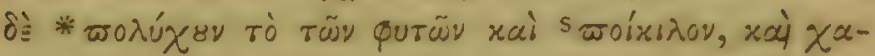
$\lambda$

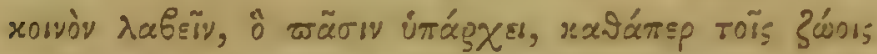

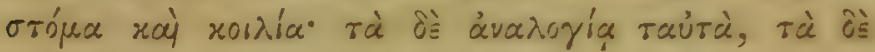

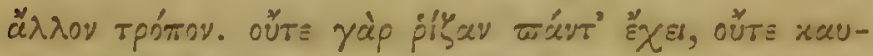

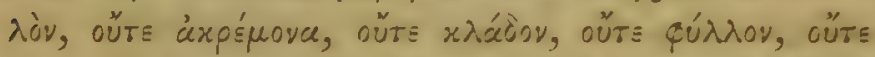

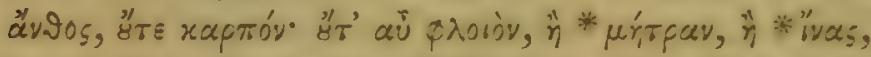

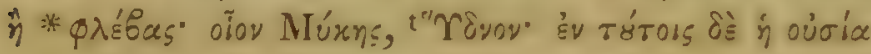

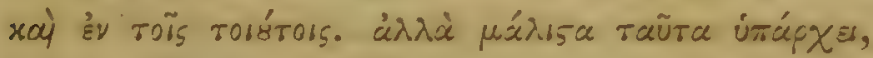

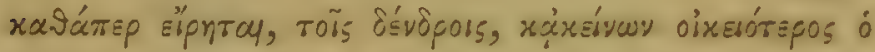

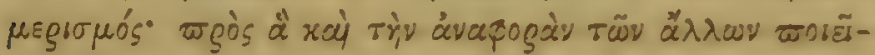

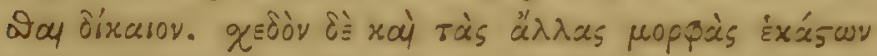

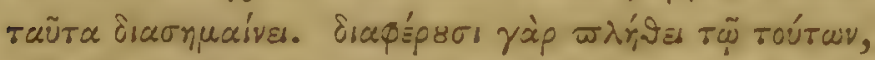

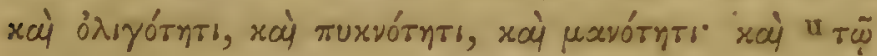

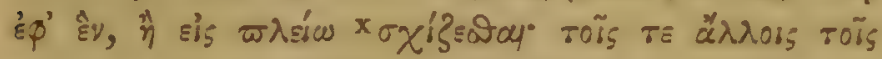

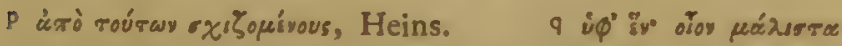

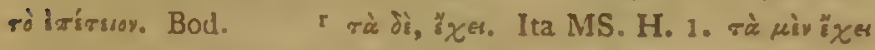

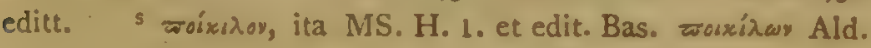
1.2. 'Oídvev. Ald. 1.2. Bas. "

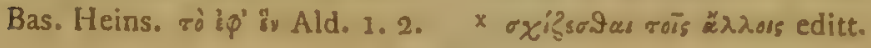




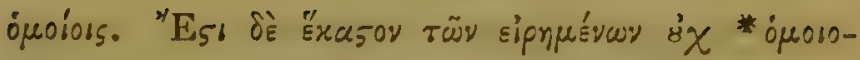

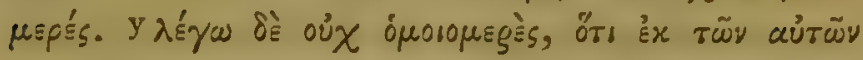

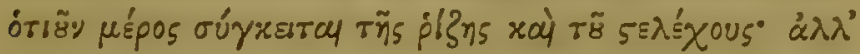

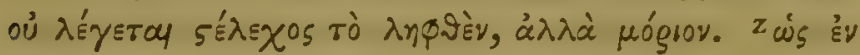

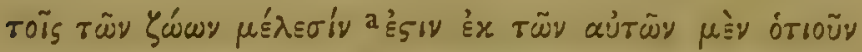

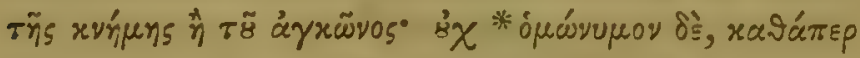

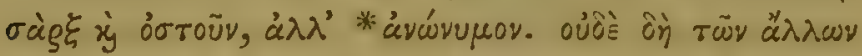

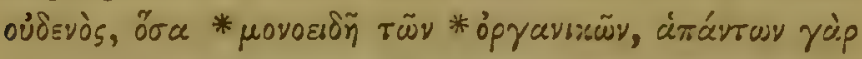

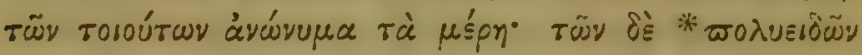

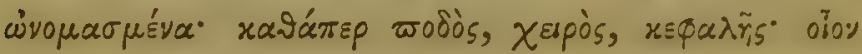

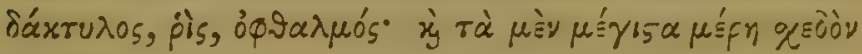

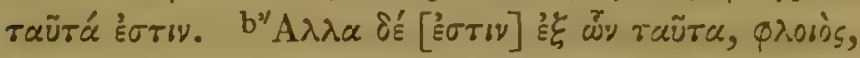

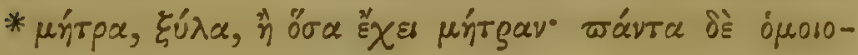

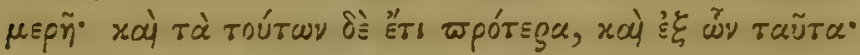

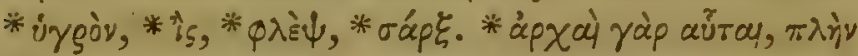

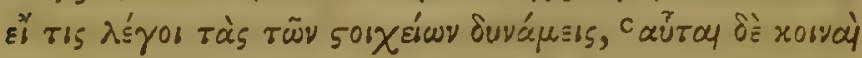

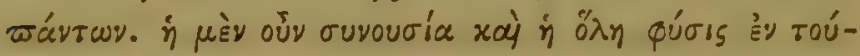

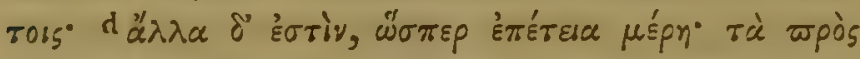

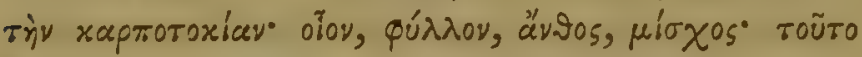

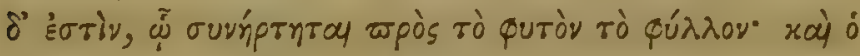

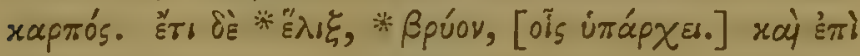

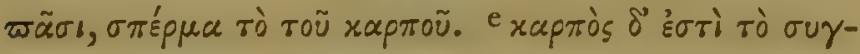

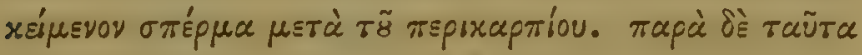

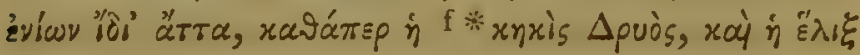

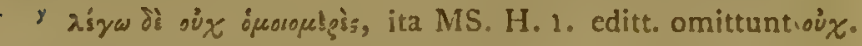

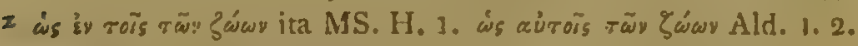

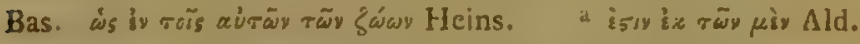

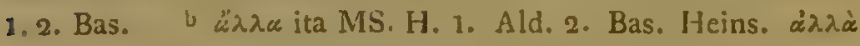

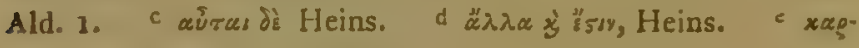

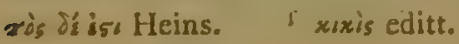




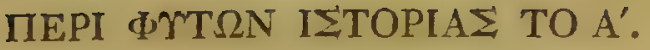

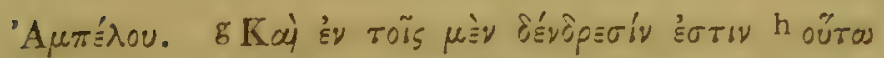

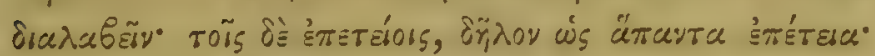

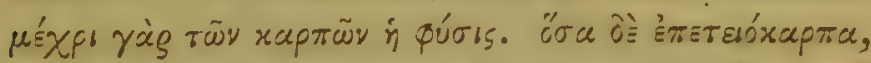

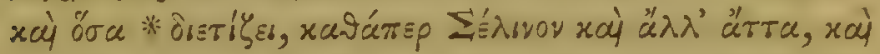

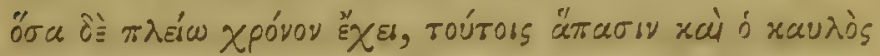

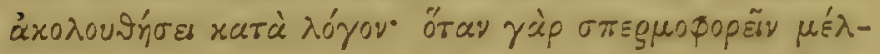

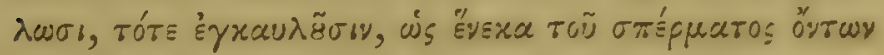

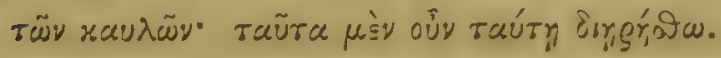

\section{CAP. III.}

Interna Plantarum Structura fusius revelatur.

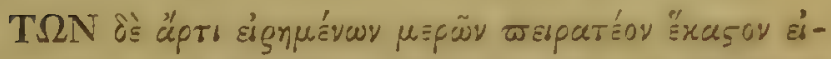
$\pi \tilde{\varepsilon}$

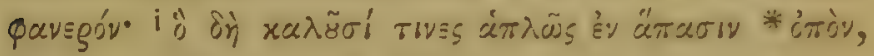

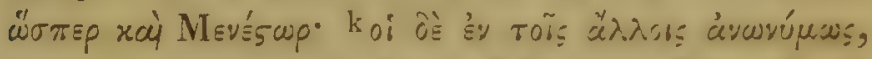

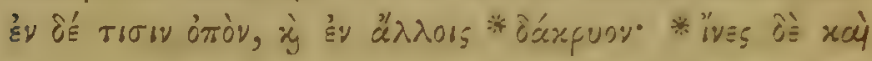

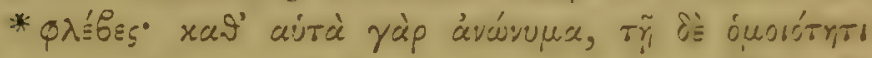

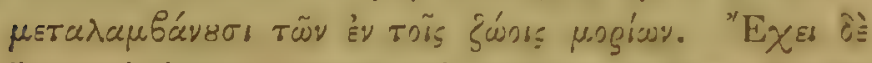

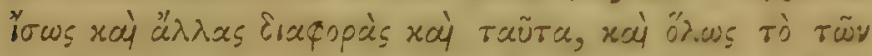

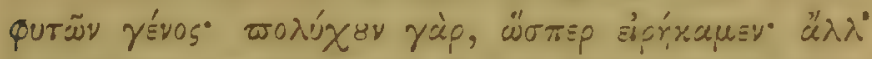

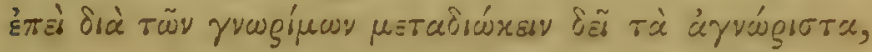

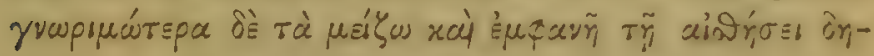

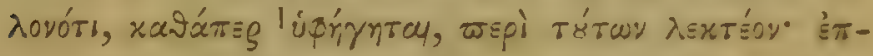

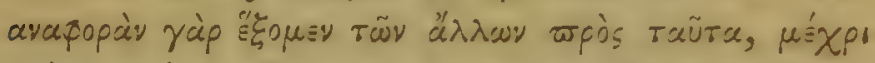

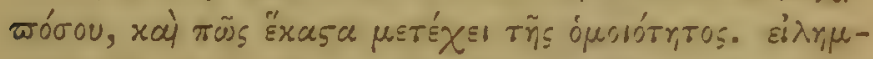

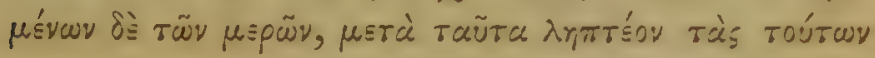

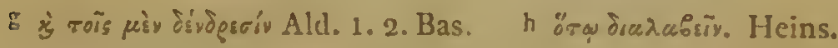

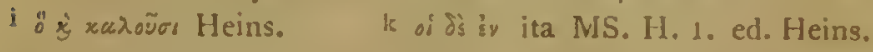

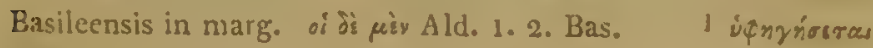
MS. H. I. 


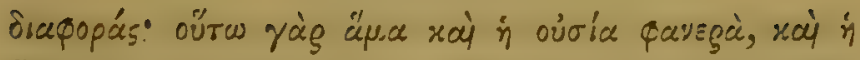

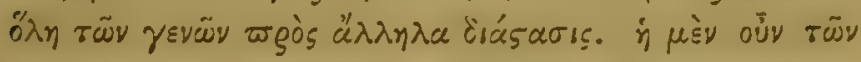

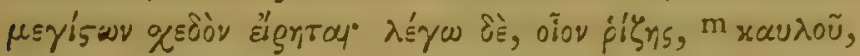

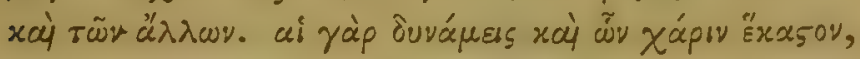

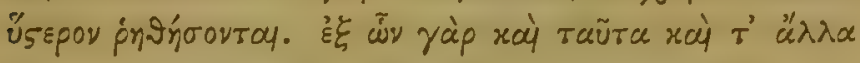

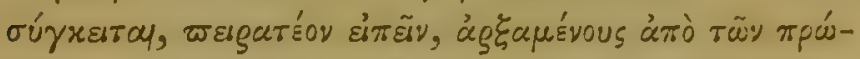

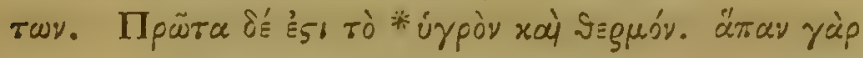

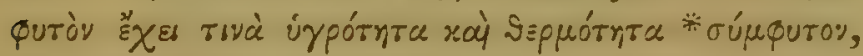

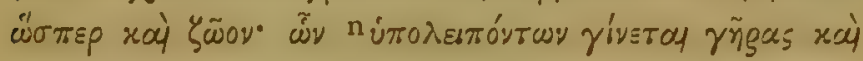

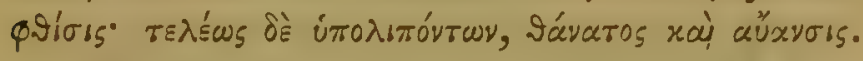

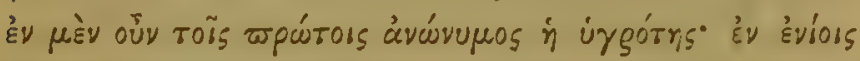

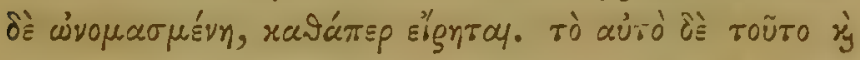

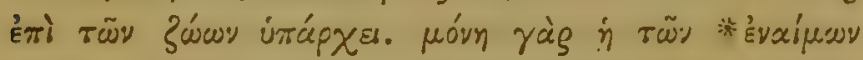

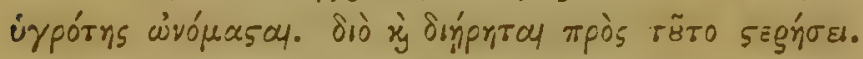

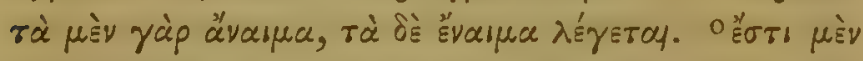

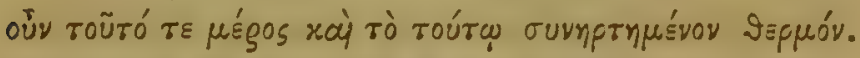

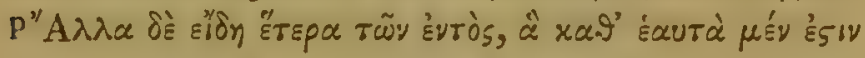

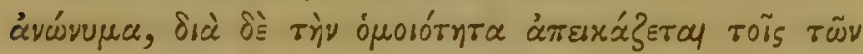

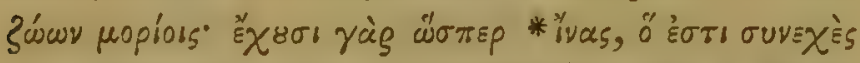

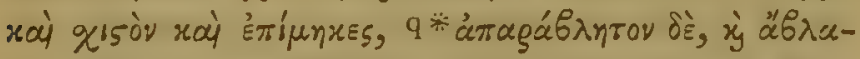

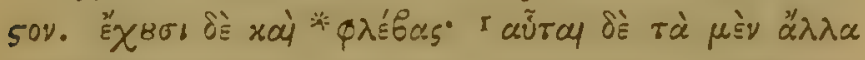

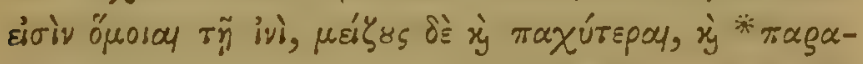

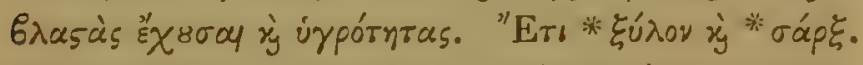

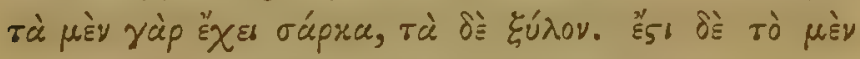

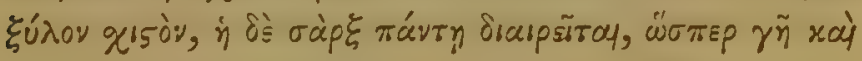

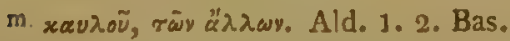

n wy izorstóntesy

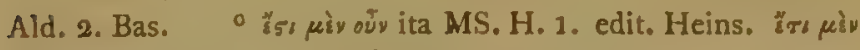

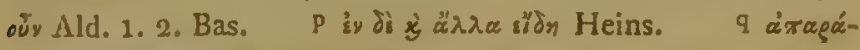

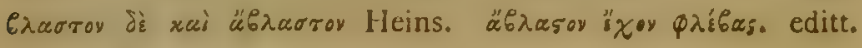
$\tau$ ณiัras di, rà Heins. 


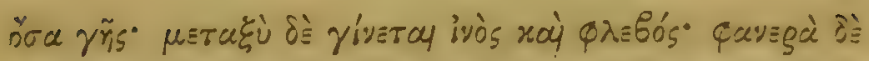

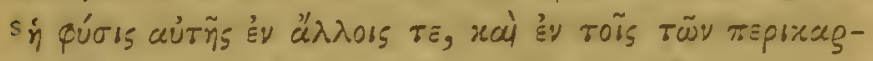

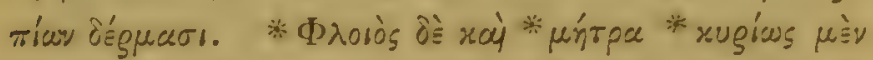

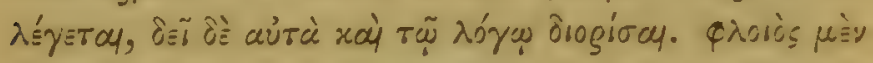

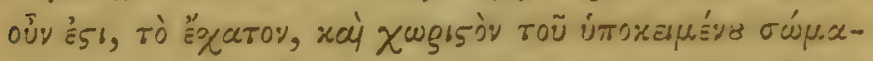

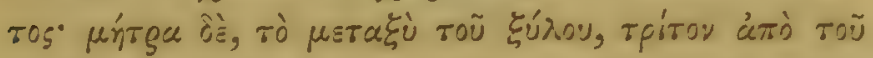

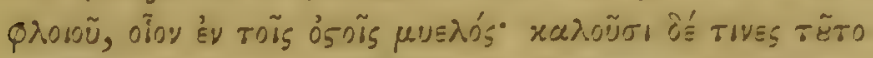

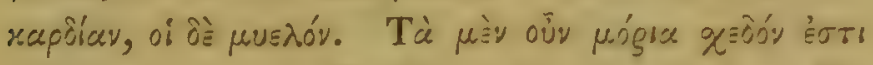

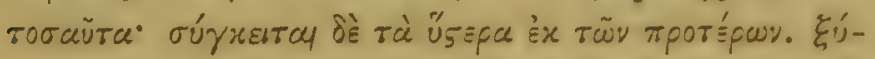

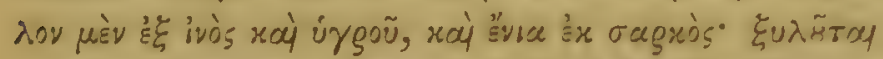

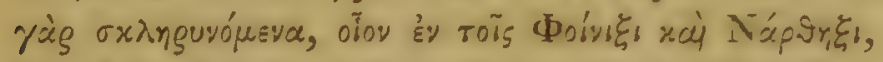

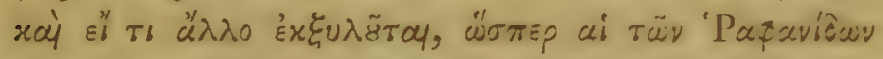

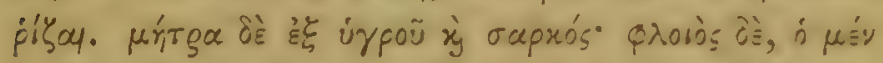

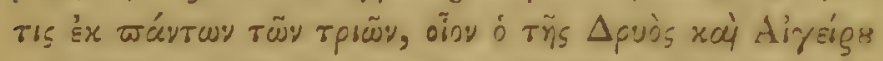

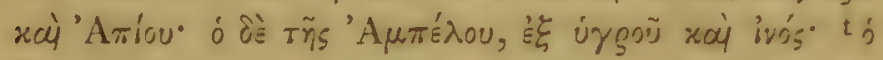

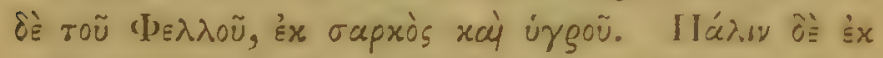

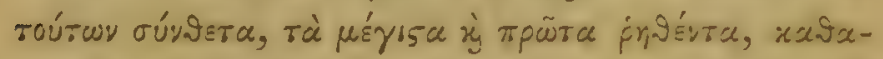

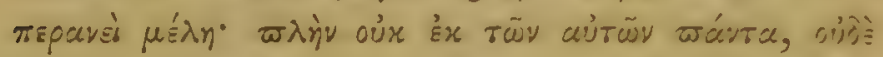

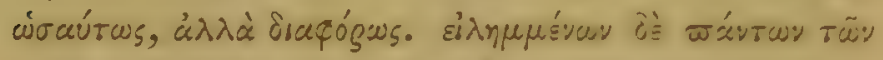

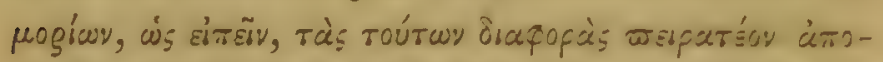

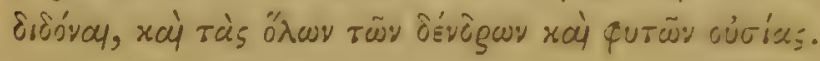

\section{CAP. IV.}

Quid Arbor, quid Frutex, quid Herba.

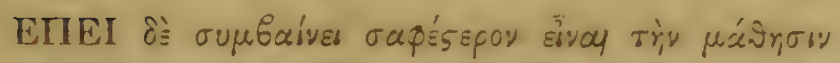

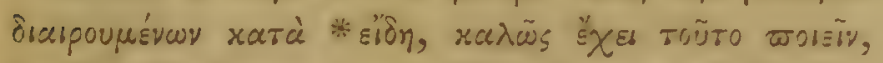

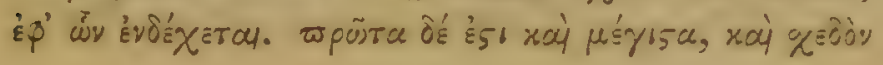

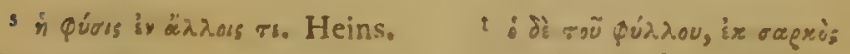
Ald. 1. 2. Bas. 


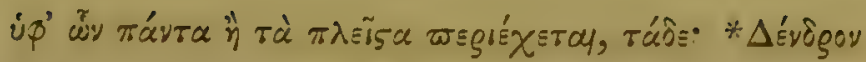

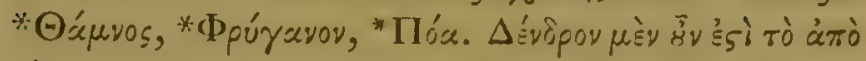

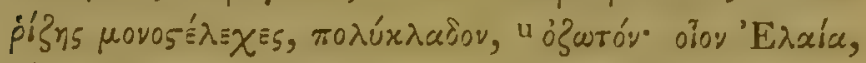

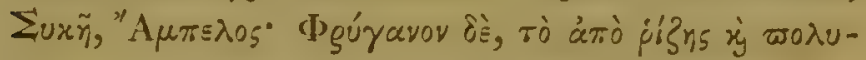

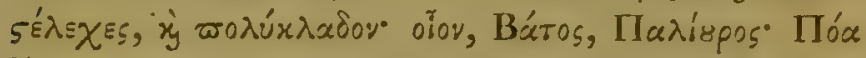

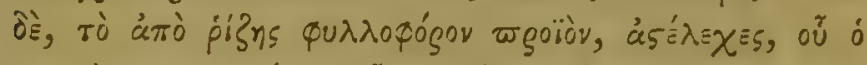

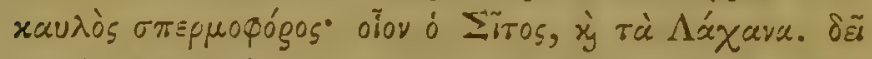

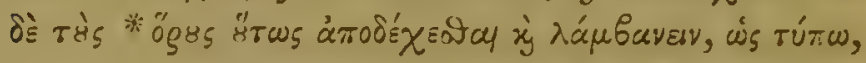

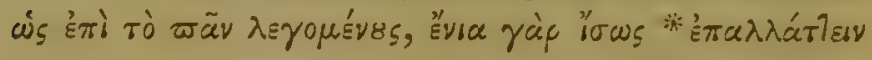

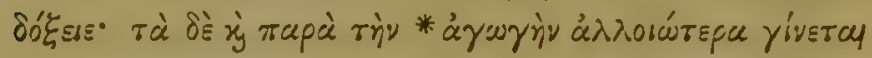

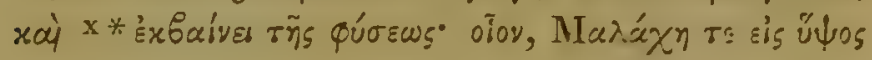
à

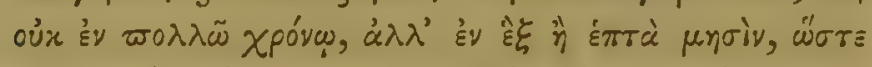

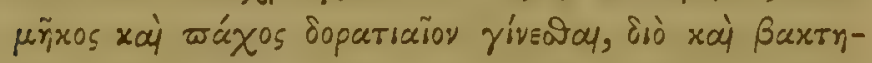

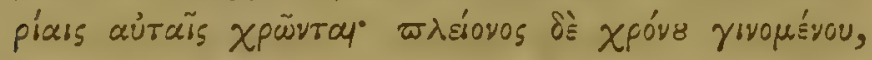

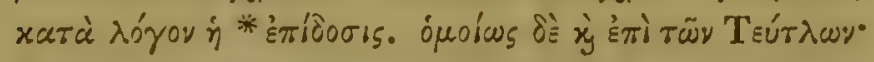

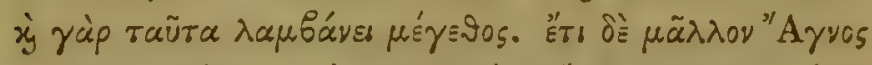

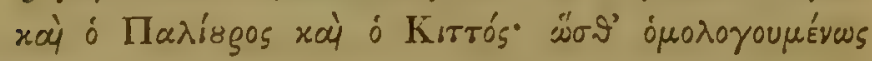

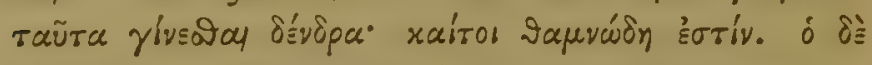

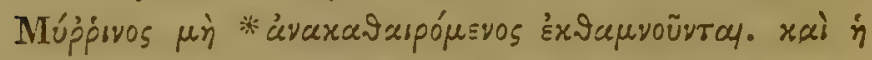

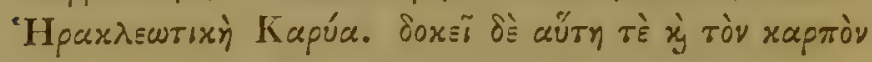

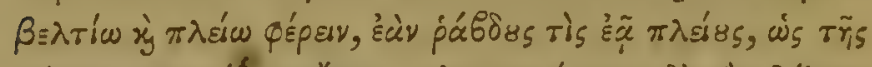

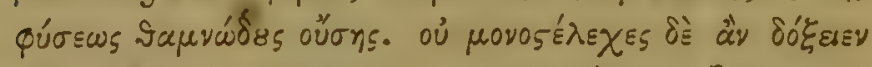

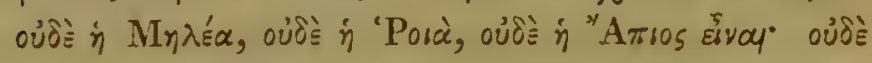

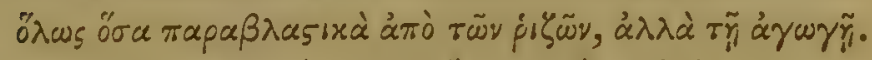

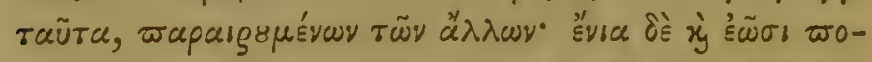

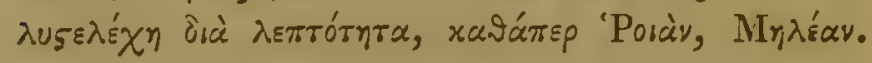

"u '̇̌s oioy Bod. $x$ ixeacivery Bod. 


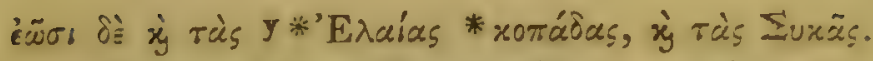

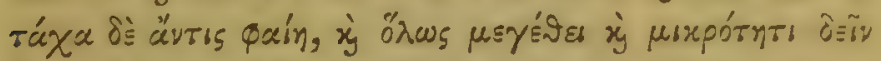

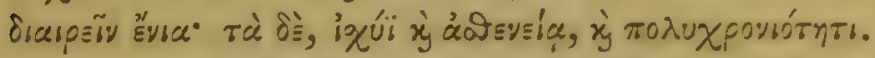

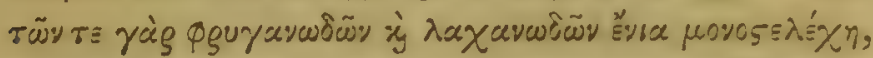

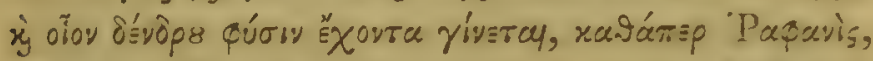

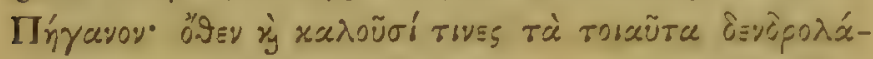

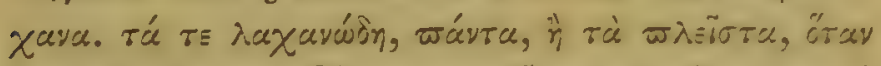

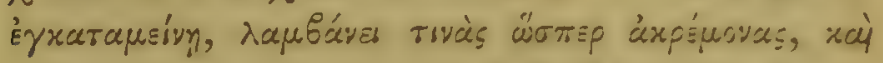

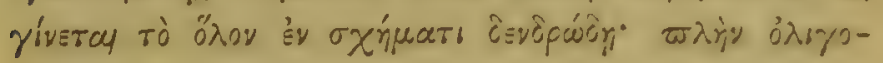
хроví́s Ера.

\section{CAP. V.}

Arborum alire culte, rulie sylestres; alia finctifier, alie steriles; alia florifera, alia flore carentes.

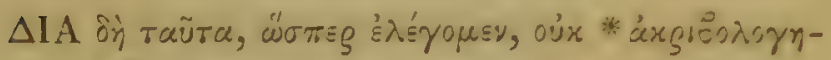

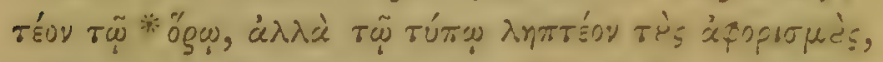

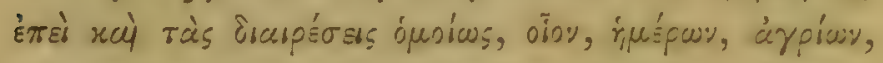

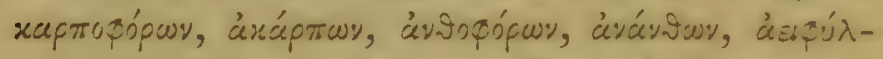

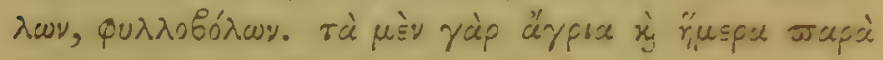

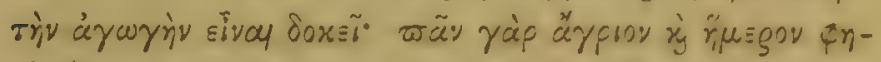

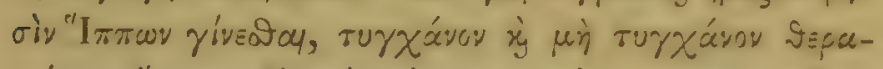

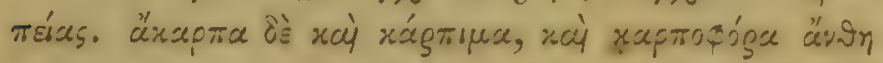

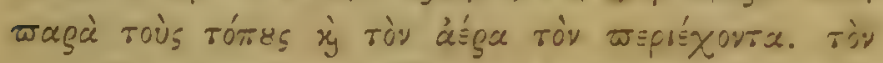

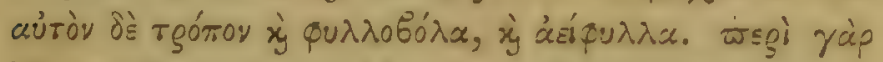

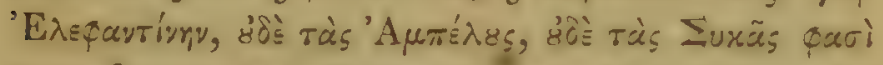

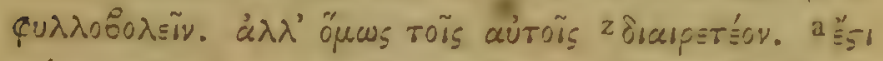

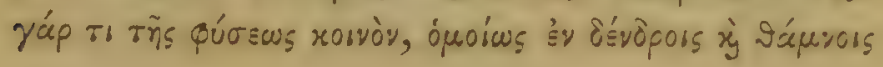

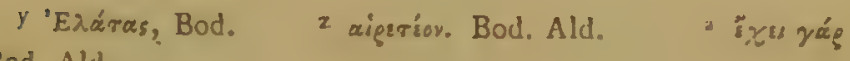
Bod. Ald.
} 


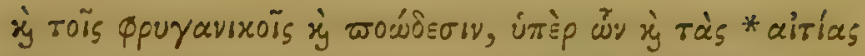

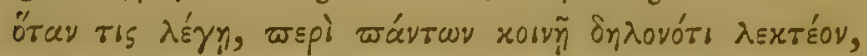

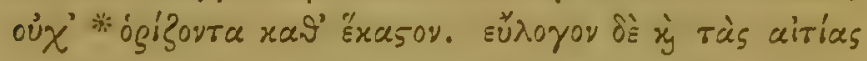

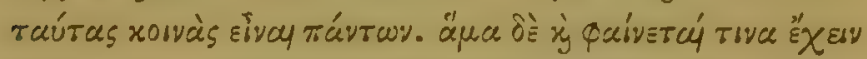

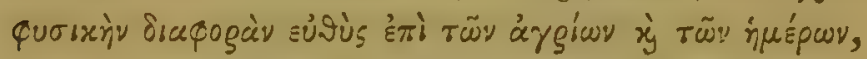

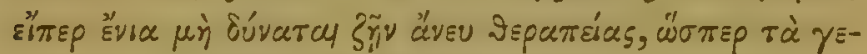

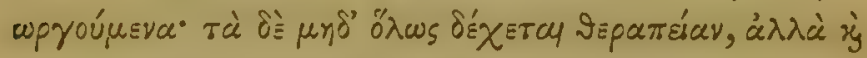

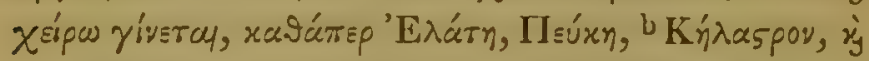

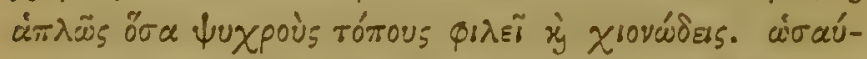

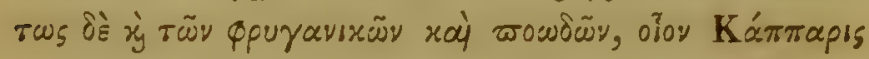

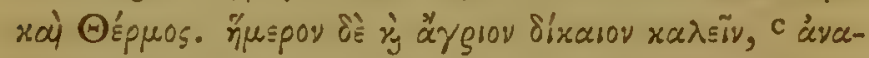

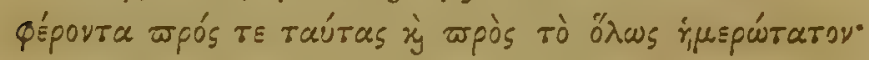

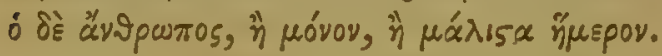

\section{CAP. VI.}

Formarum Differentia ; et quod alia terrestres, alia aquatiles; alice in Paludibus, alice in Lacubus; ulice in Fluviis, alice in Mari.

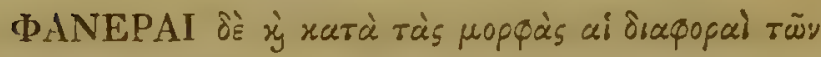

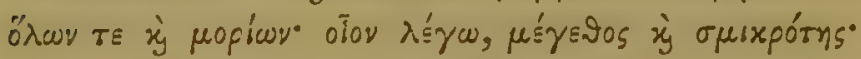

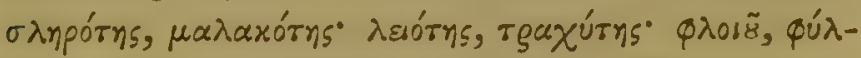

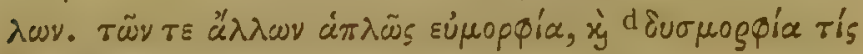

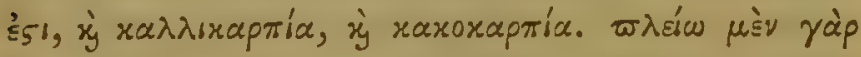

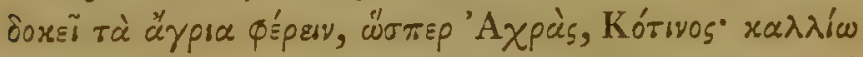

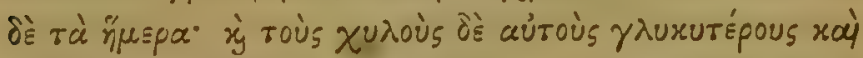

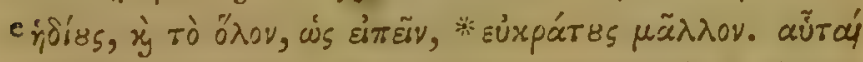

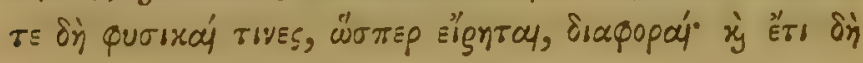

b $2 \alpha \dot{s}$ gov Bot. Ald.

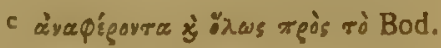
Ald. d rif iैं di Bod. Ald. e idiovs Ald. 


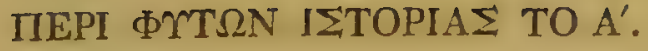

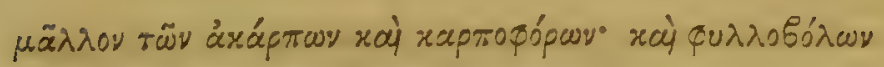

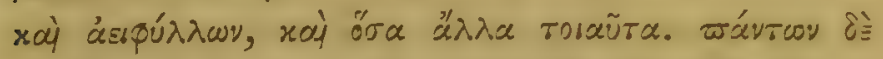

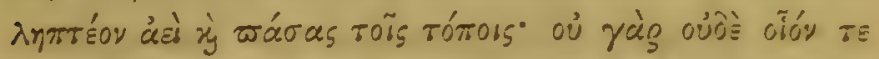

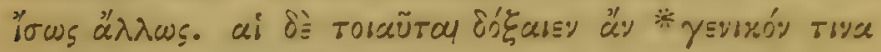

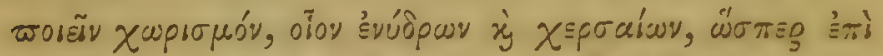

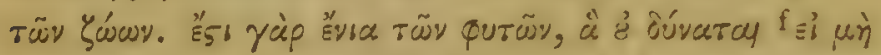

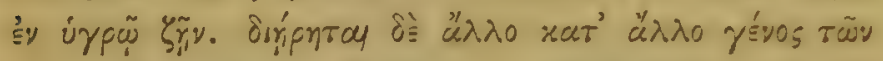

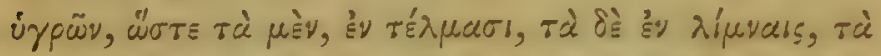

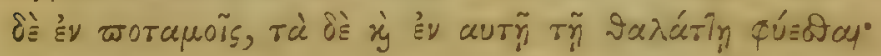

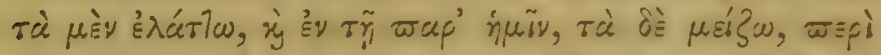

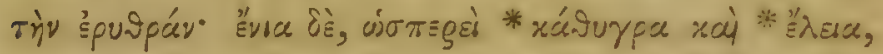

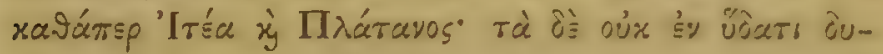

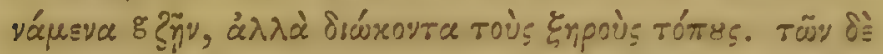

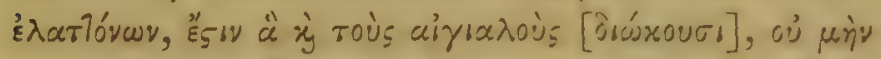

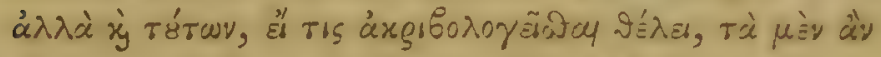

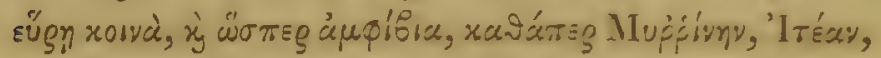

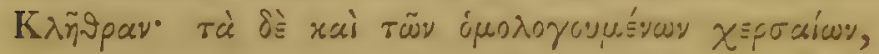

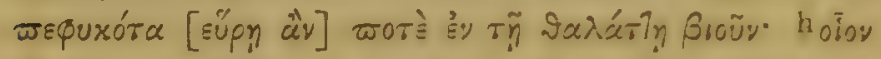

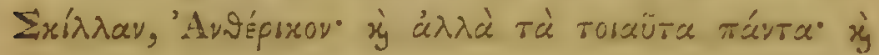

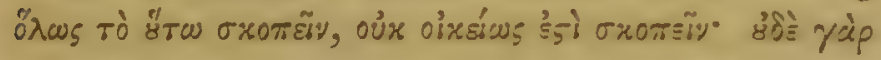

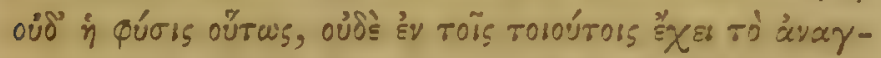

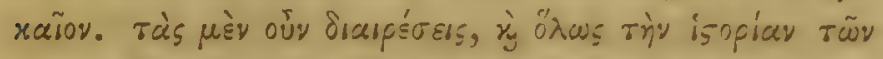

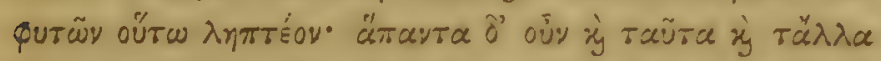

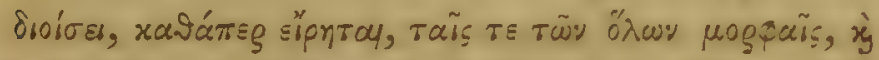

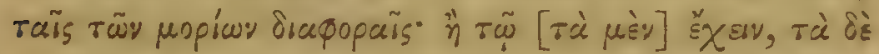

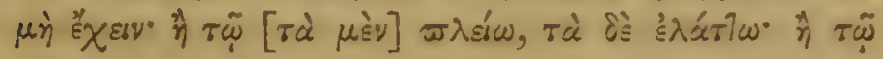

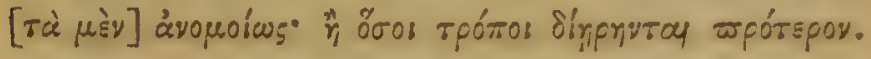

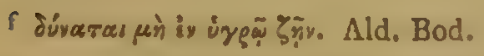

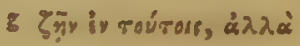

Bod. sioy $\Phi$ oívixa, $\Sigma x i \lambda \lambda \alpha y$, Bod. 


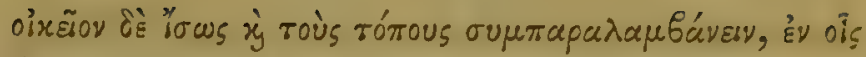

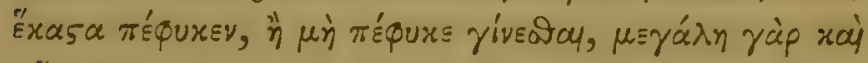

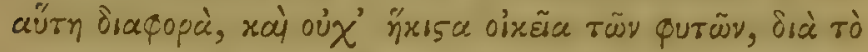

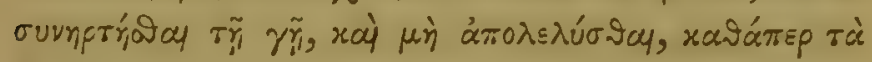

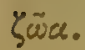

\section{CAP. VII.}

Differentir Planlarum. Habitus. Caudex. Cortex. Lignım.

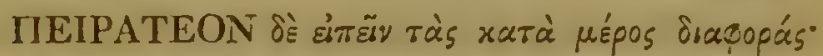

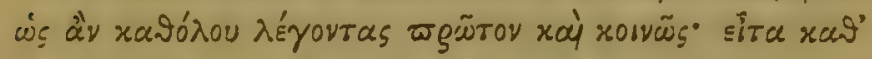

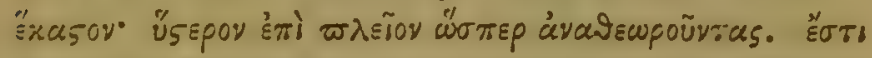

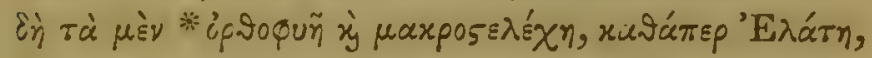

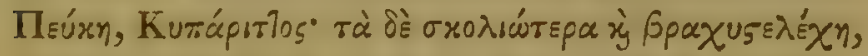

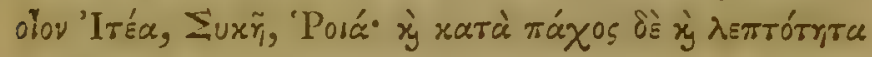

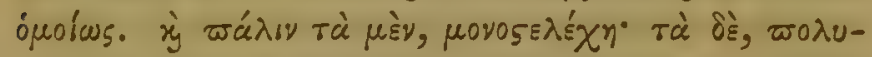

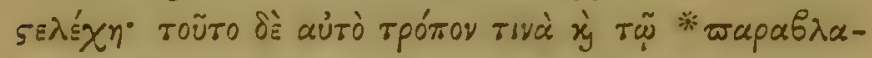

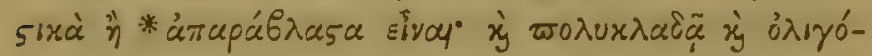

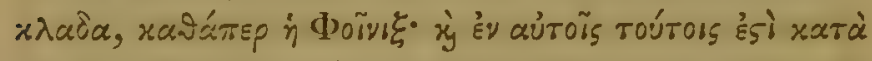

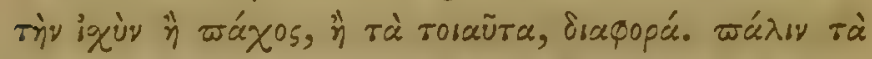

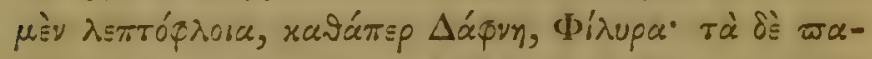

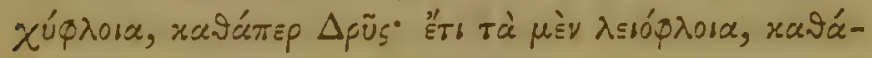

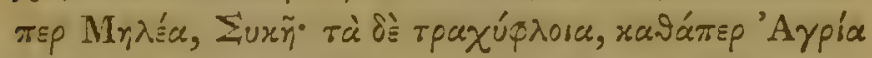

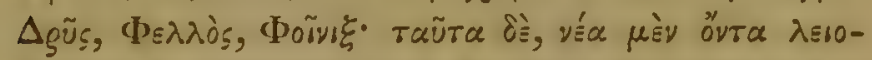

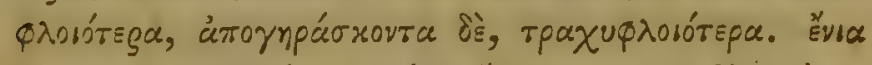

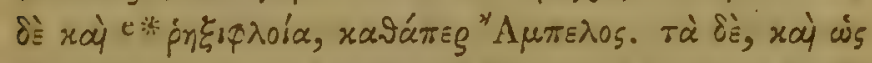

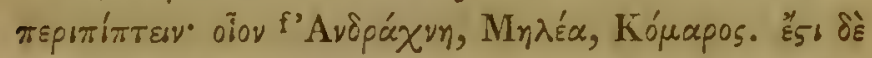

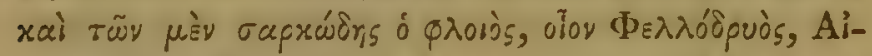

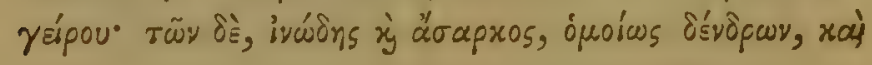

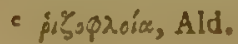

$$
\begin{aligned}
& \text { "Asgcáx"n, Ald. }
\end{aligned}
$$




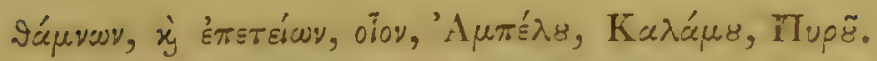

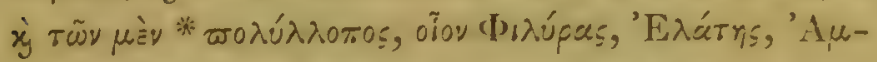

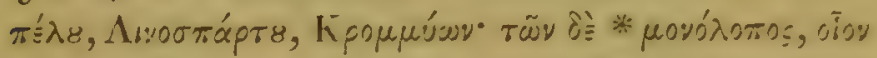

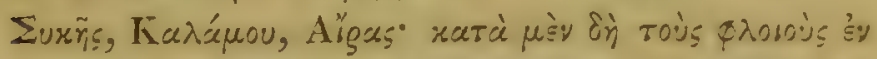

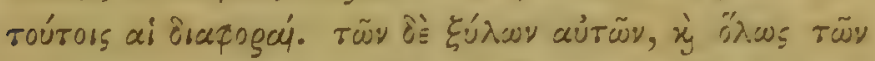

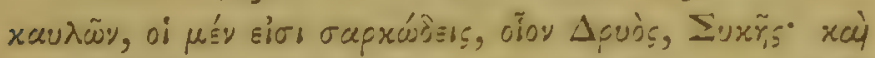

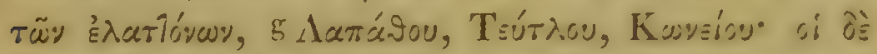

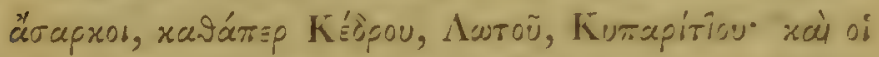

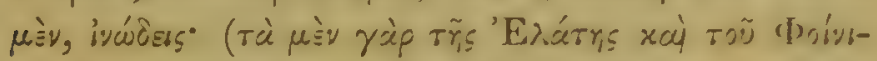

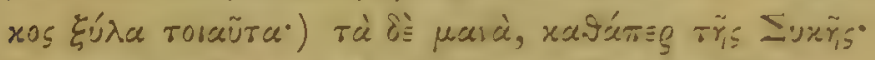

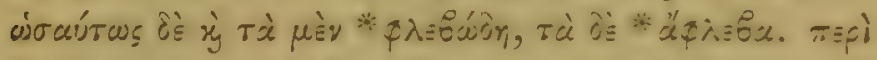

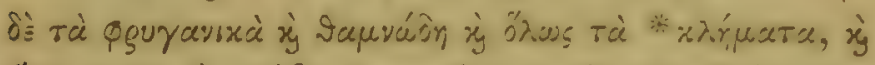

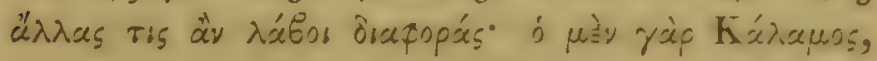

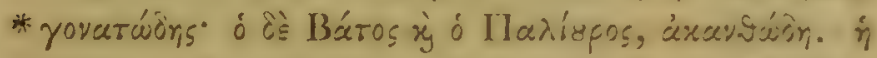

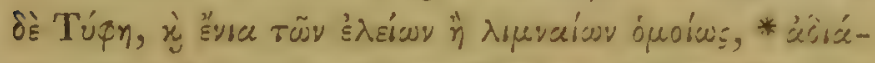

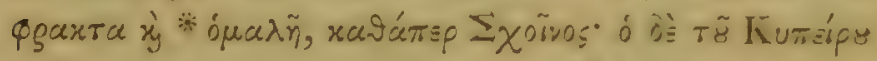

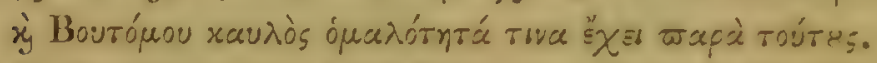

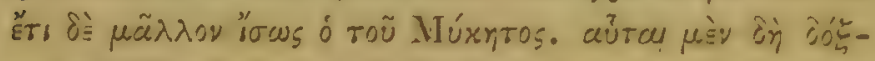

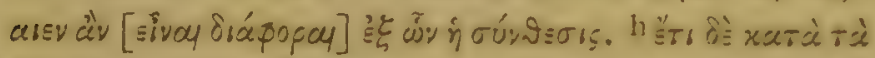

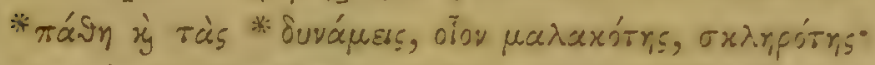

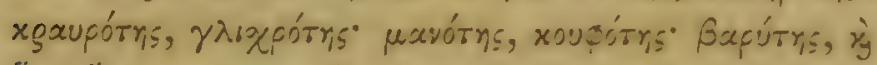

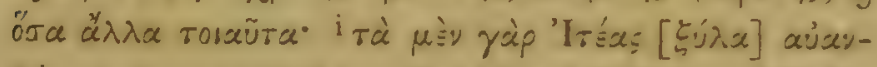

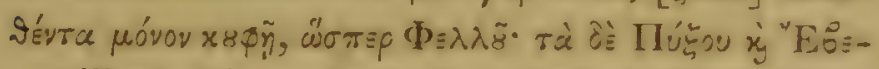

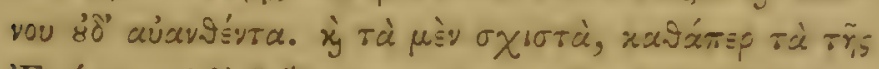

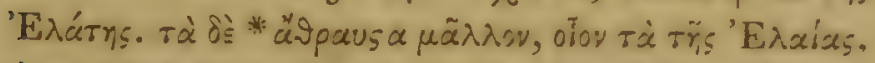

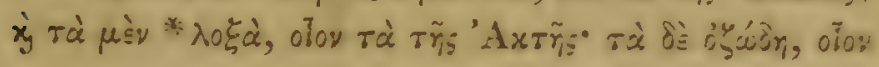

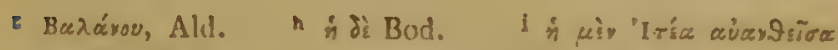

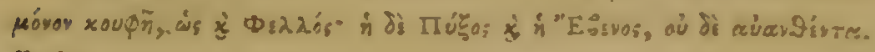
Bod. 


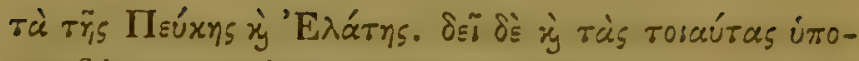

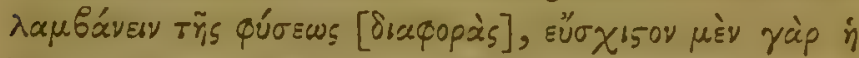

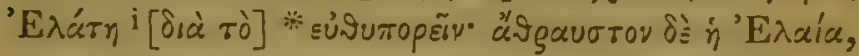

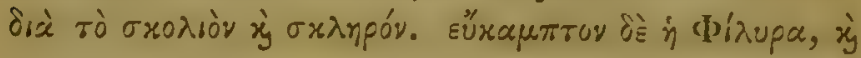

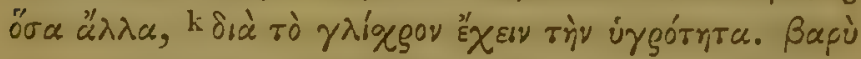

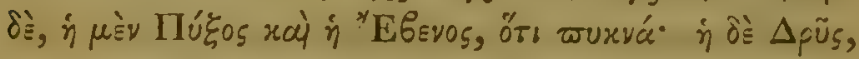

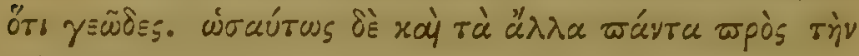

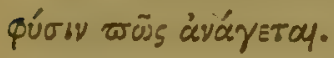

\section{CAP. VIII.}

Differentic Medullarum, Discrimina Radisum.

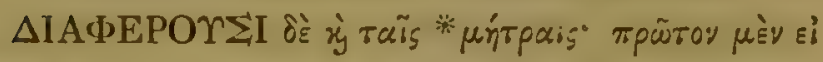

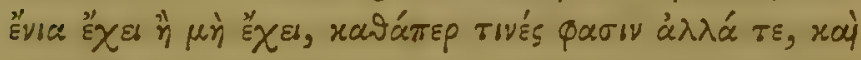

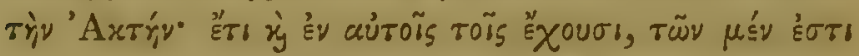

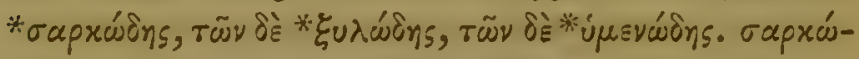

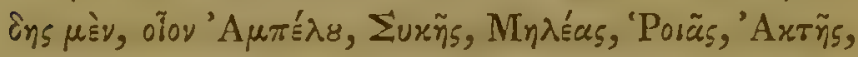

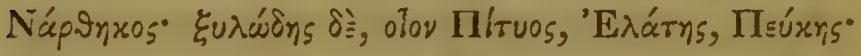

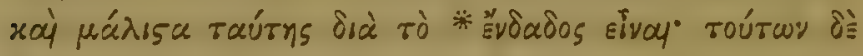

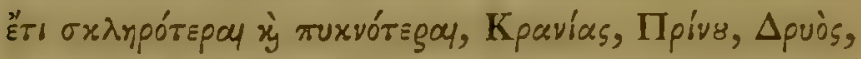

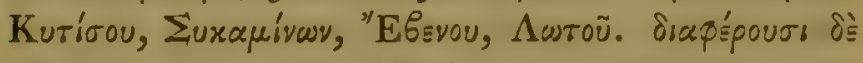

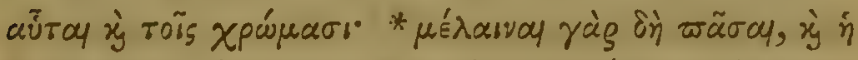

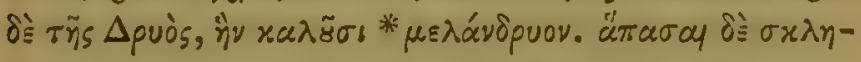

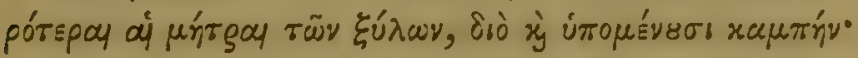

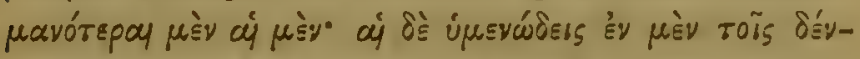

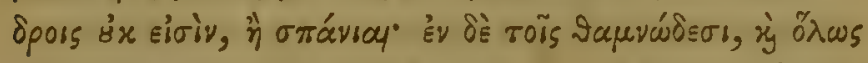

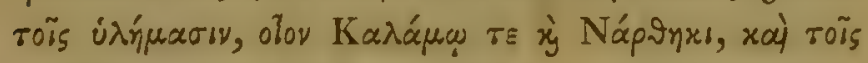

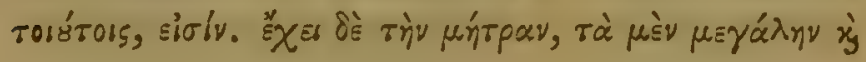

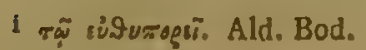
Thra. Bod.

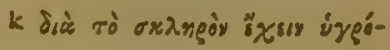




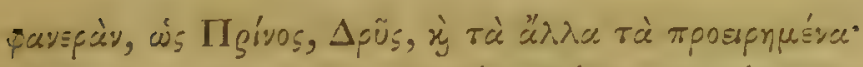

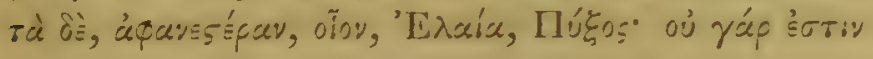

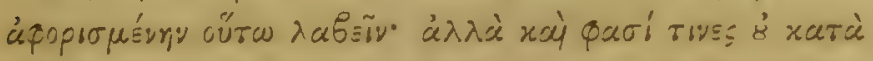

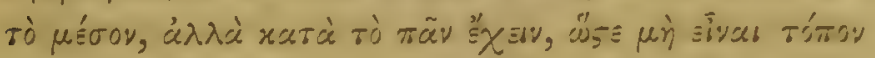

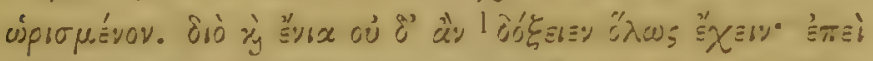

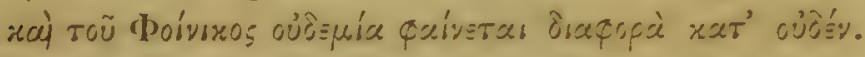

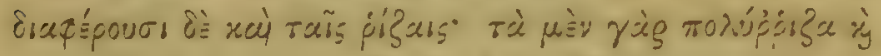

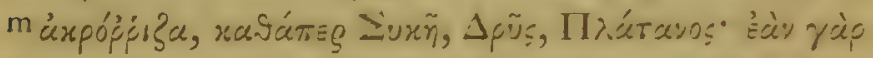

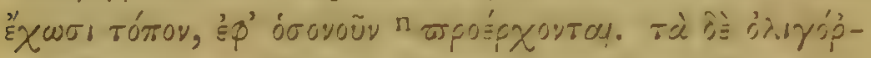

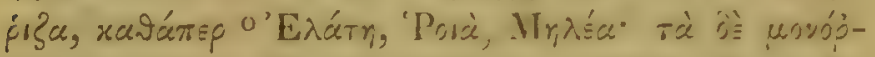

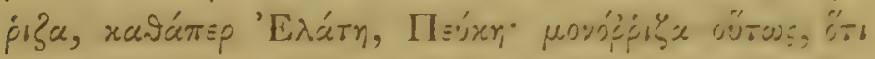

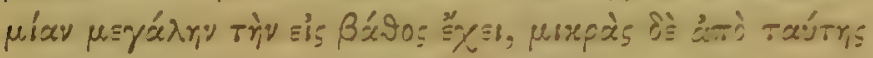

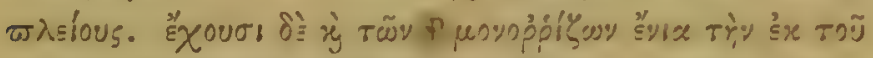

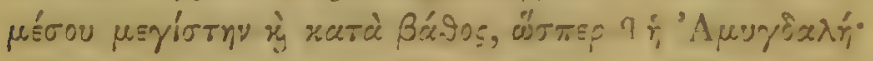

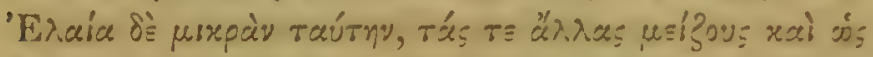

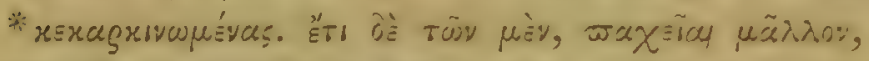

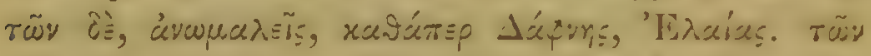

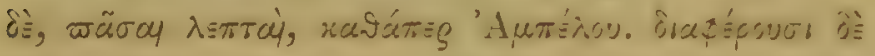

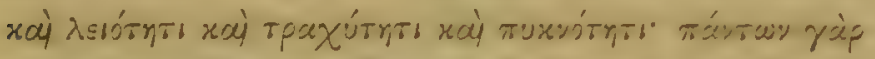

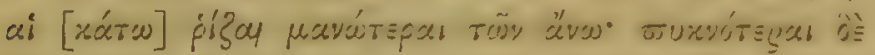

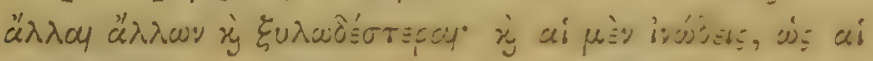

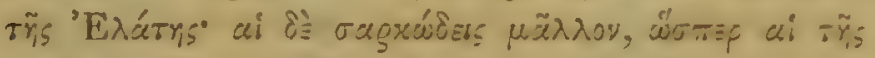

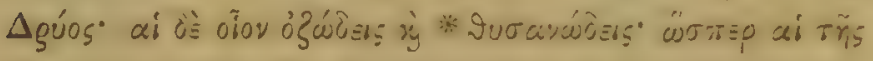

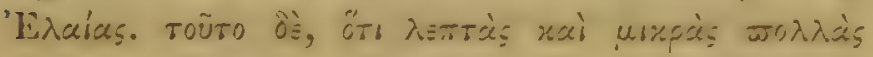

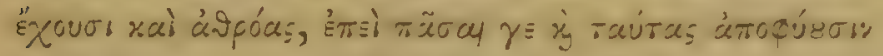

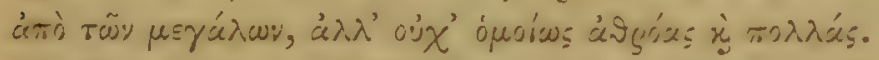

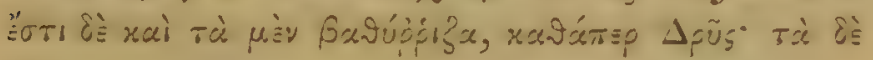

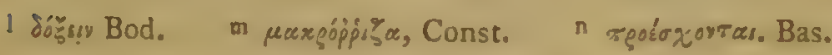

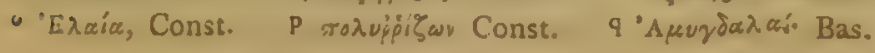




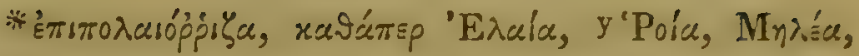

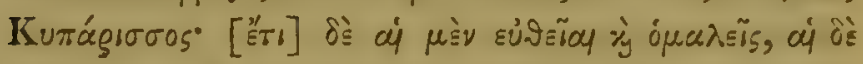

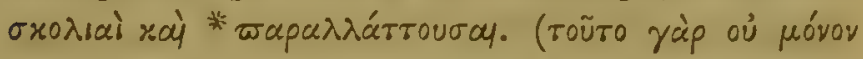

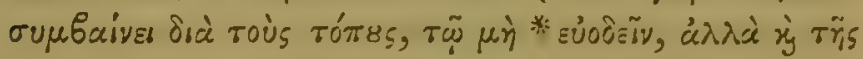

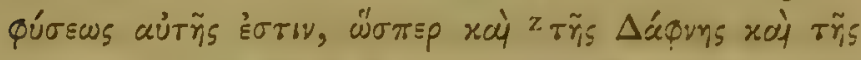

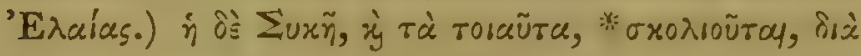

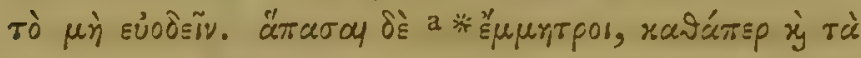

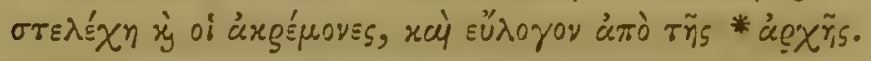

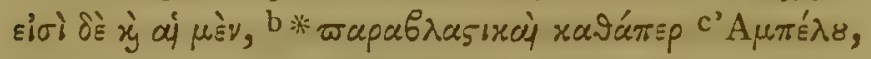

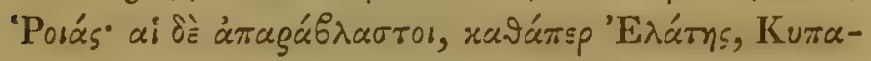

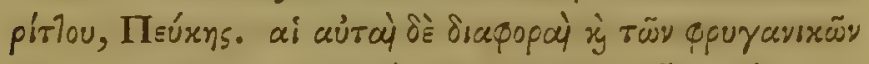

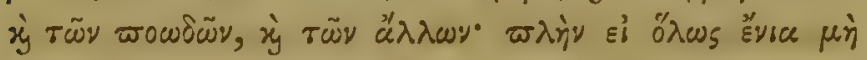

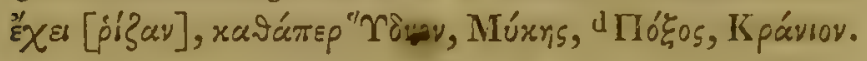

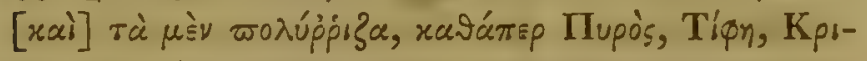

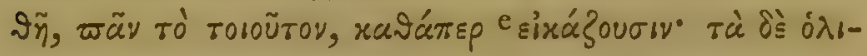

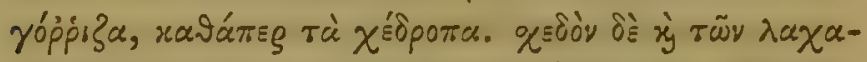

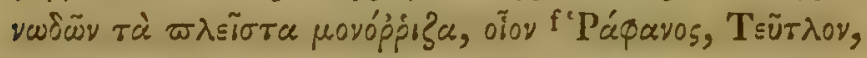

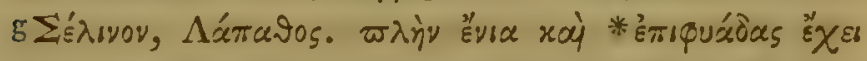

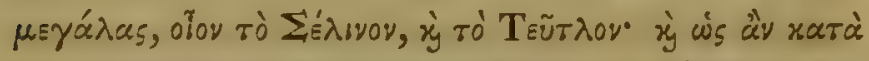

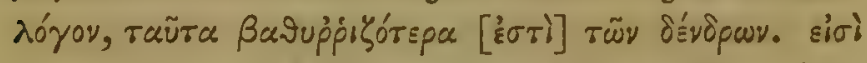

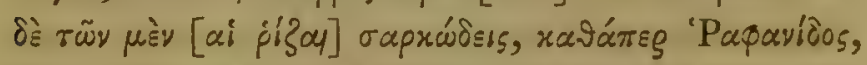

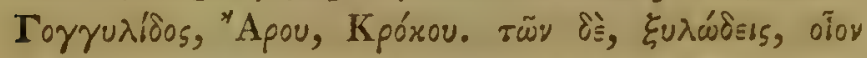

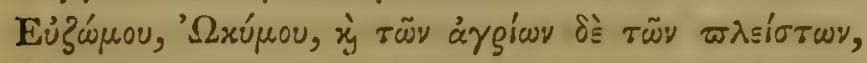

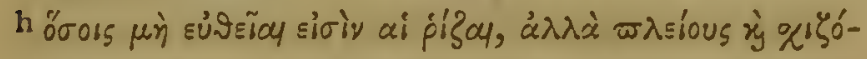

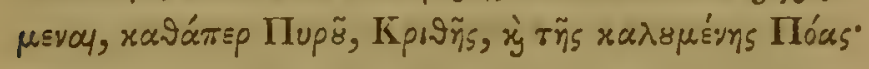

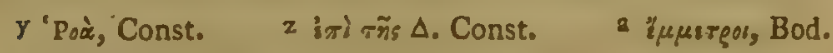

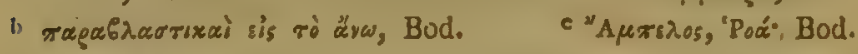

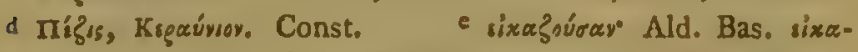

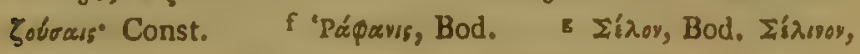

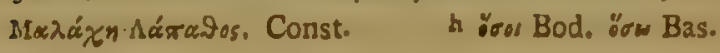




\section{MEPI ФMT INN ISTOPIAS TO A'.}

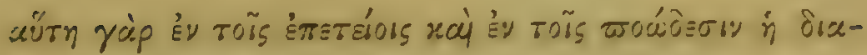

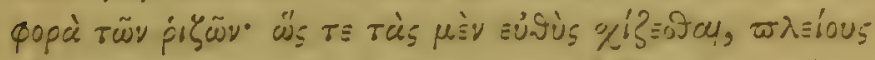

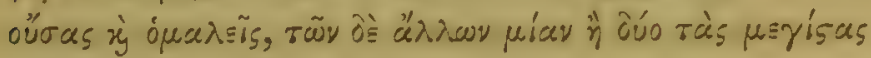

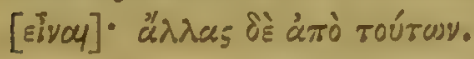

\section{CAP. IX.}

Radices bulbasc; Scilla, Cepre, Ari, Cyperi, \&.c.

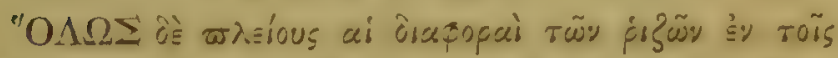

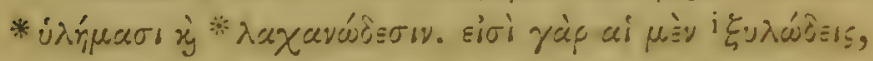

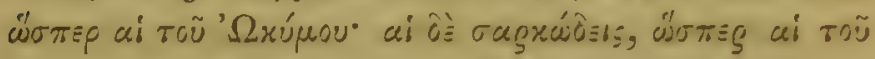

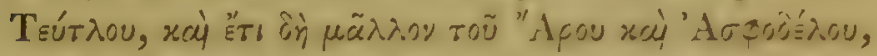

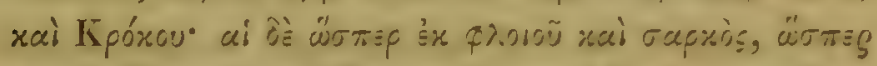

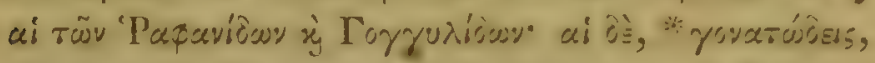

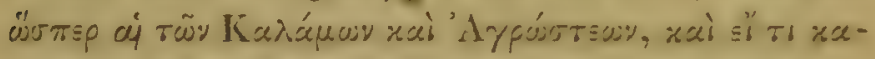

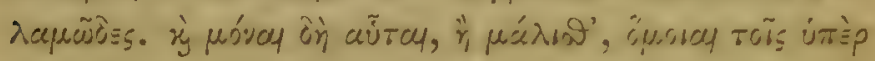

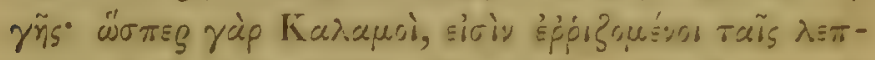

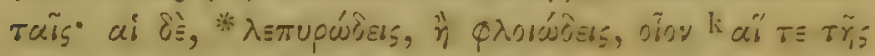

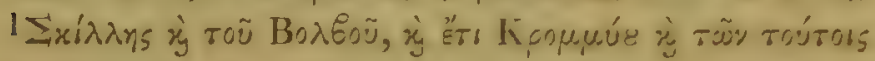

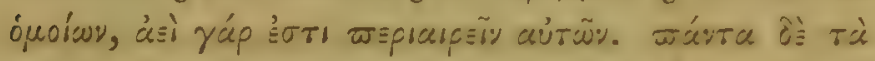

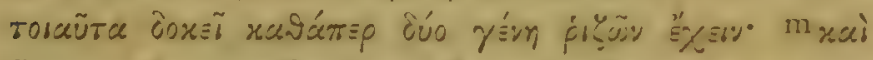

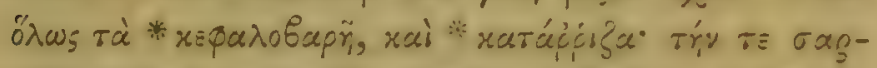

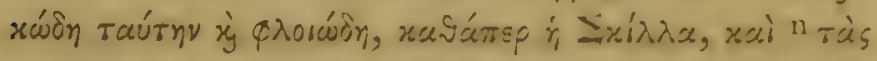

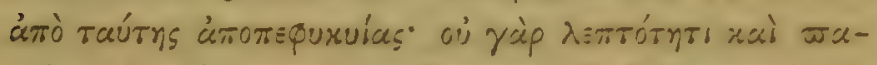

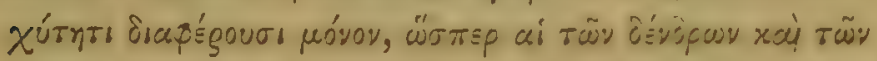

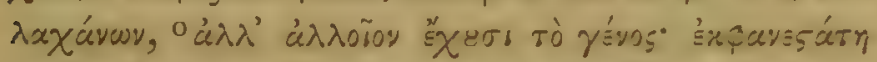

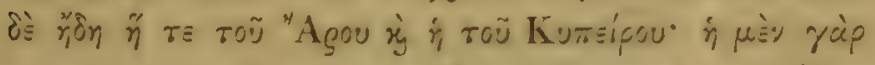

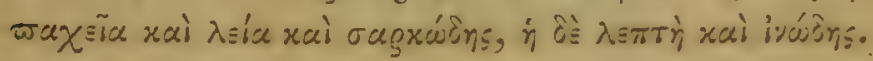

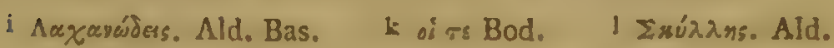

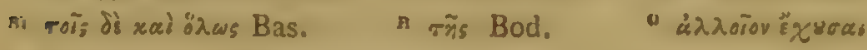
Bod. à $\lambda \lambda \dot{\alpha} \lambda \operatorname{siov}$ Ald. 


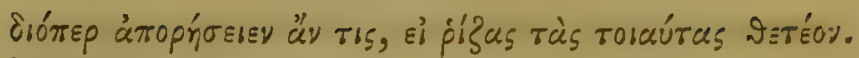

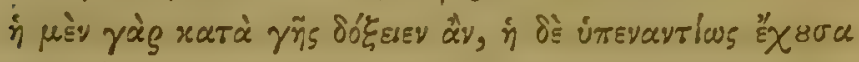

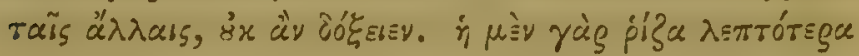

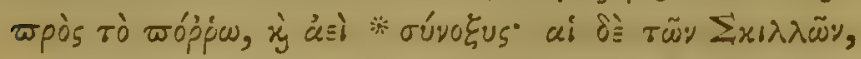

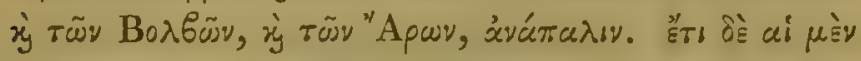

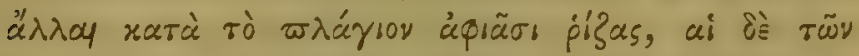

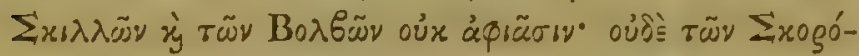

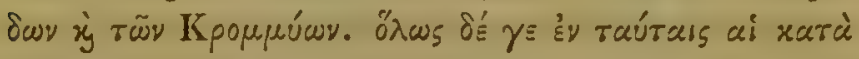

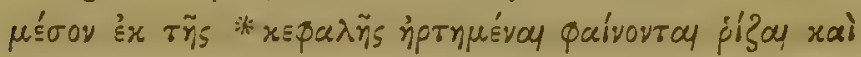

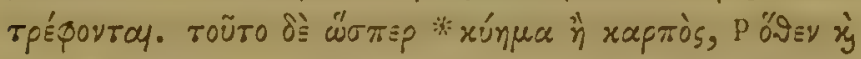

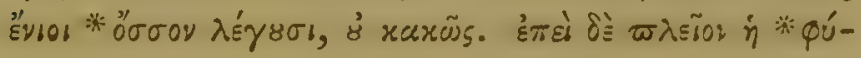

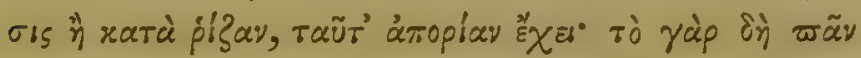

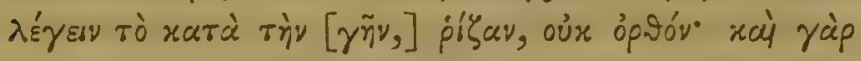

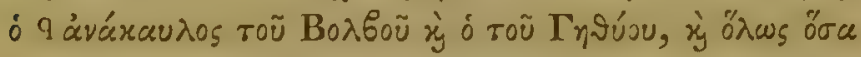

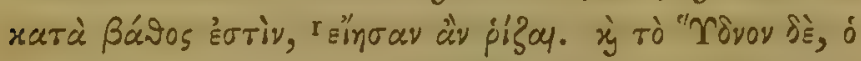

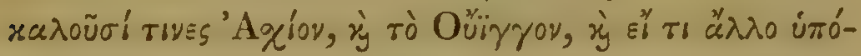

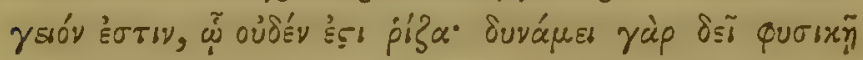

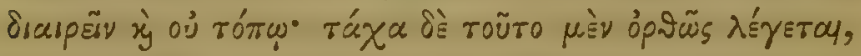

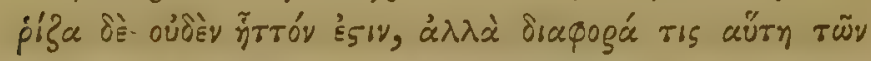

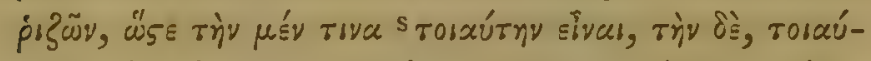

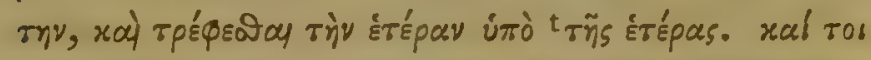

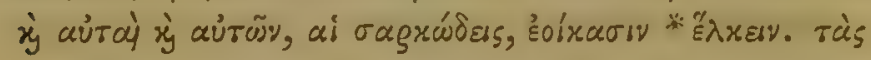

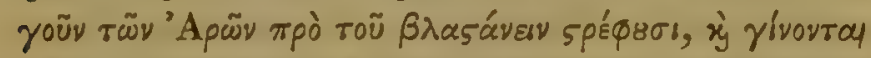

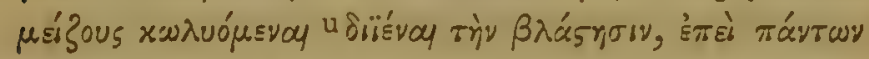

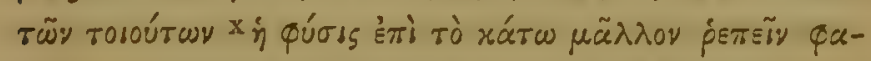

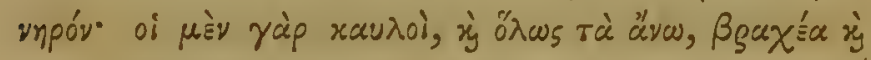

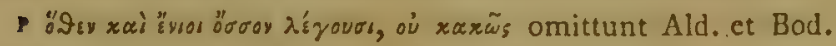

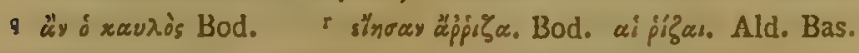

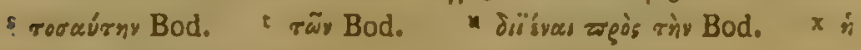

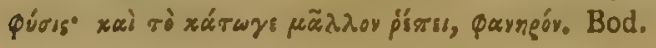




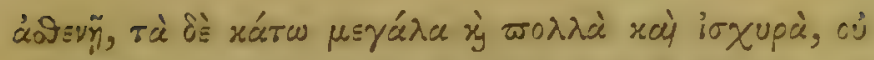

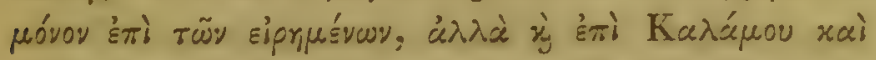

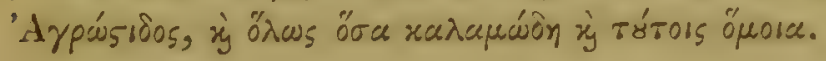

\section{CAP. X.}

Radices Craci, Laserpitii, et Plantarum quarundam in Egypto.

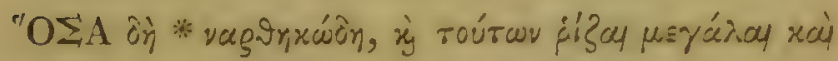

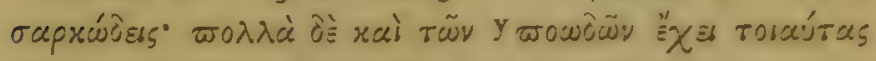

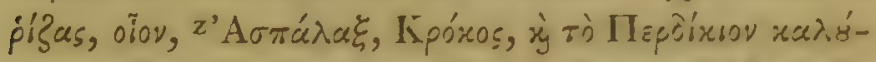

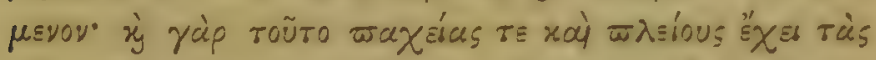

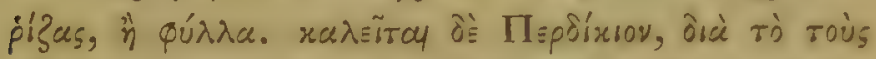

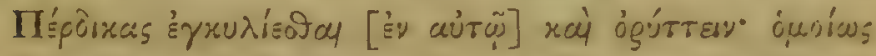

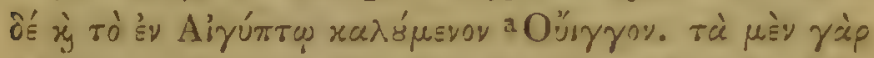

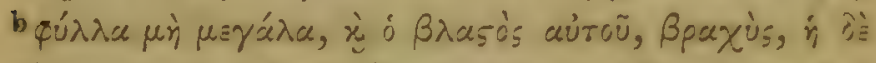

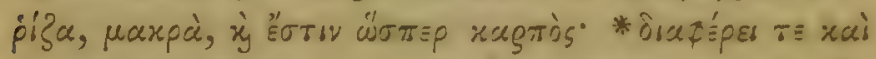

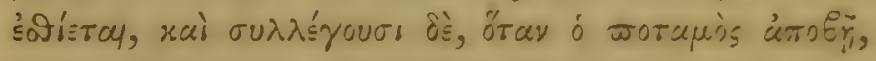

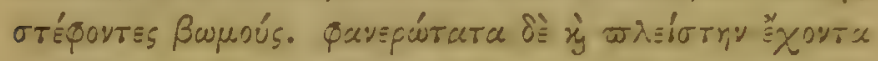

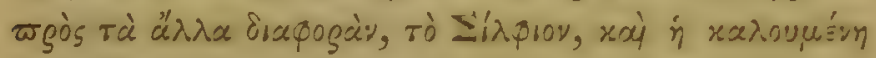

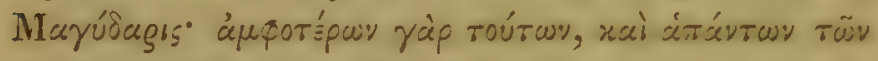

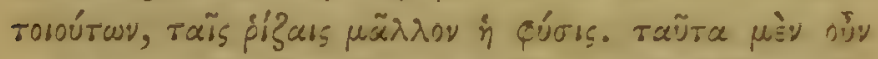

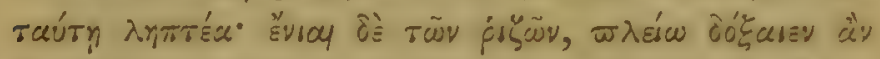

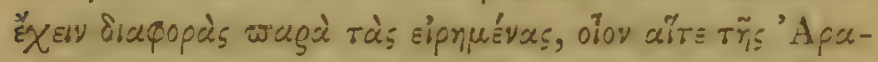

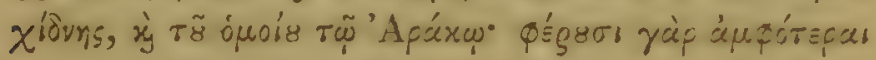

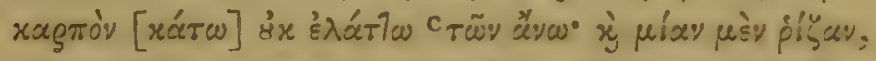

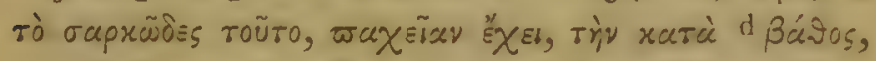

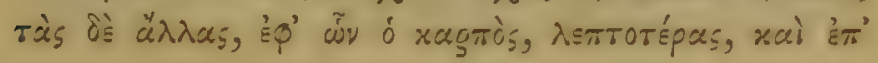

$y$ modũ Ald.

Hes. Ath. Plin. - Bágry, Ald.

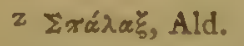

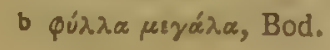

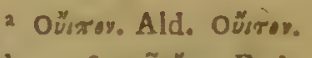

c 3 


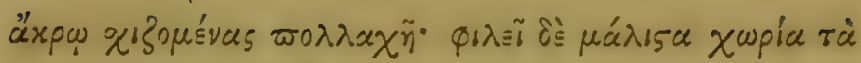

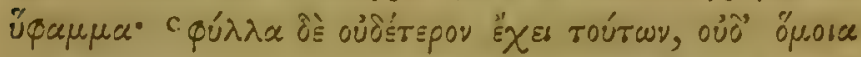

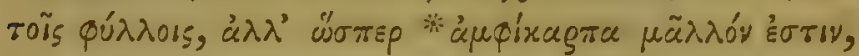

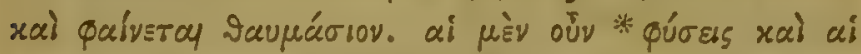

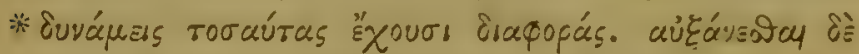

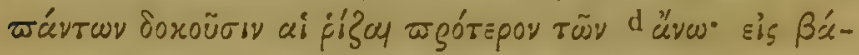

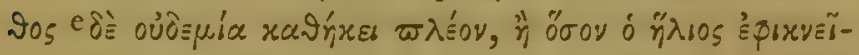

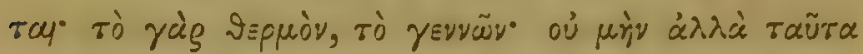

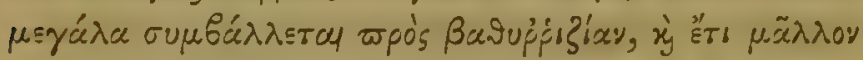

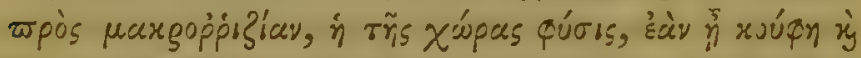

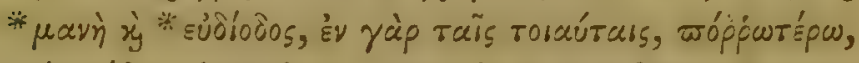

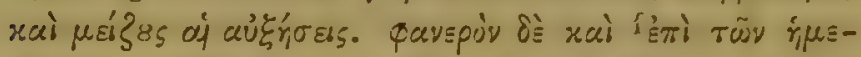

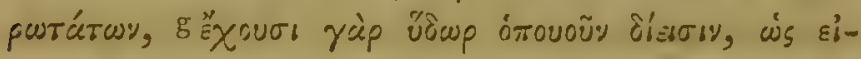

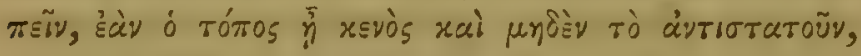

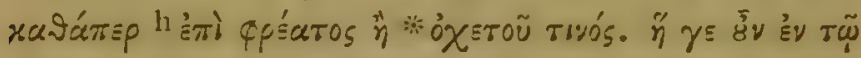

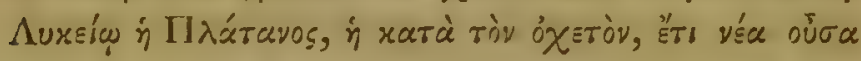

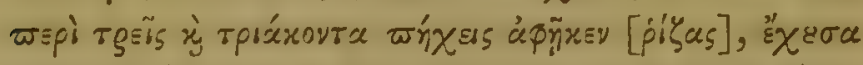

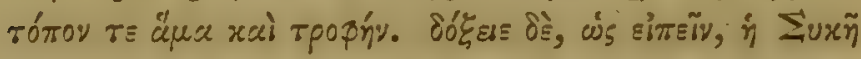

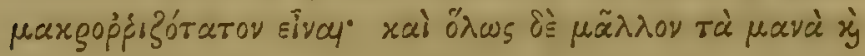
๕ủงúp่อ่

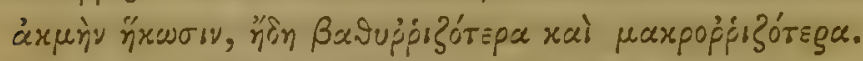

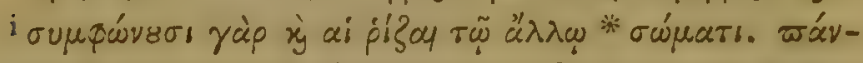

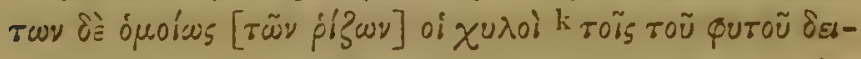

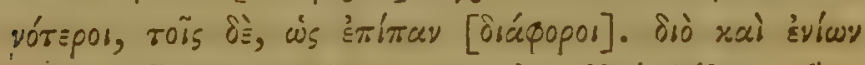

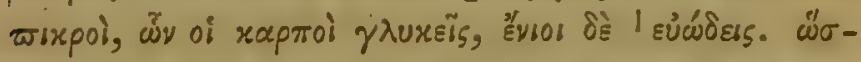

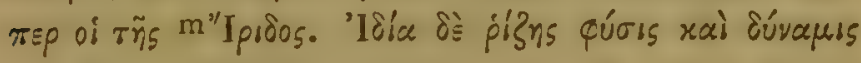

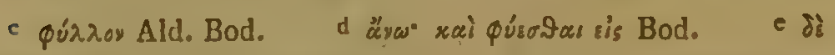
deest Ald. f

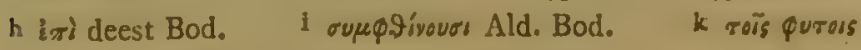
Bod. I Tuédess. Const. m "Igros. Bod. 


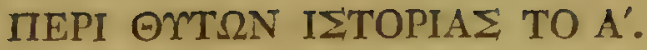

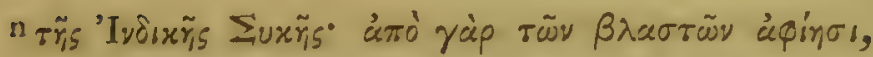

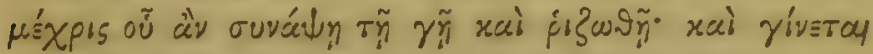

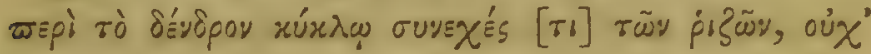

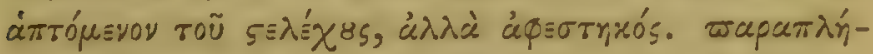

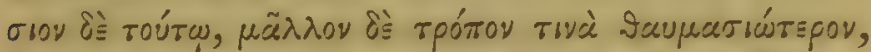

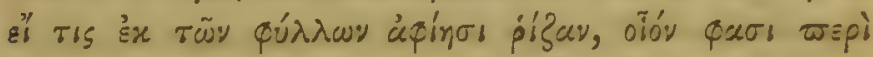

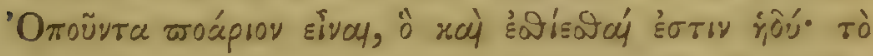

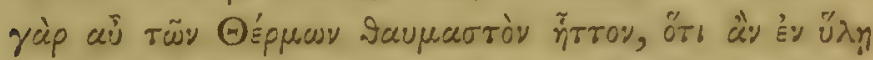

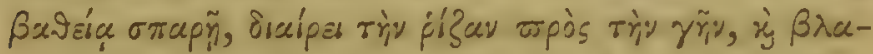

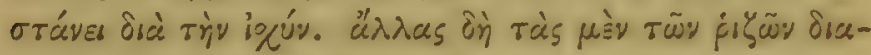

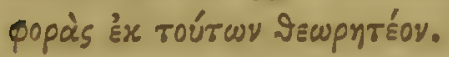

\section{CAP. XI.}

Ramorum Differentia; Nodi \&c. in Truncis.

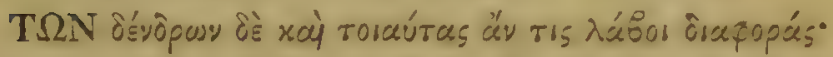

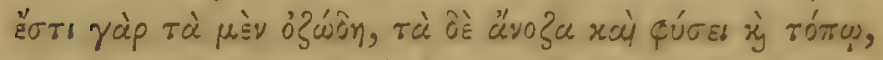

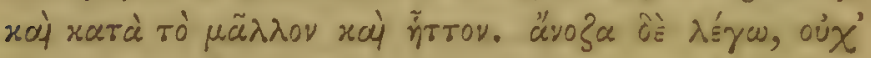

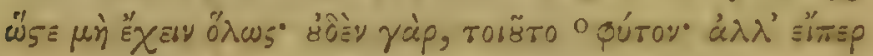

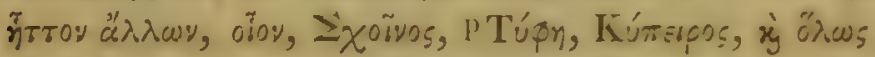

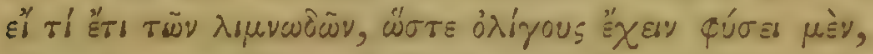

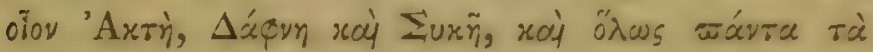

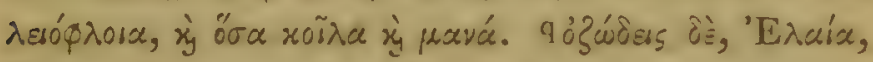

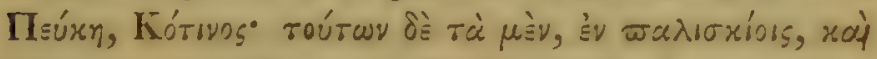
ขทvย́

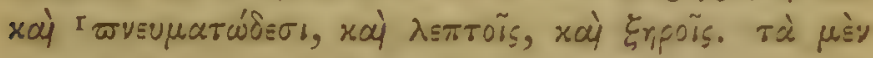

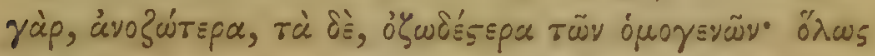

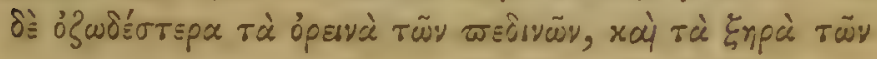

ก

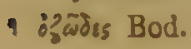

- Sivipor Ald. Bod.

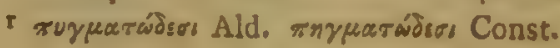




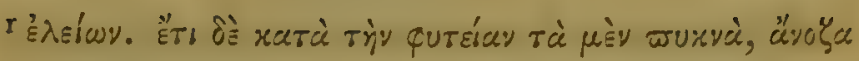

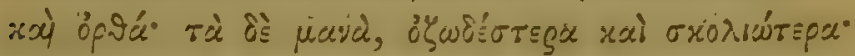

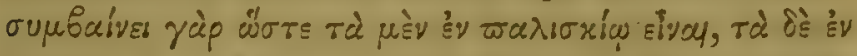

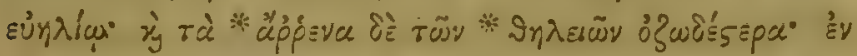

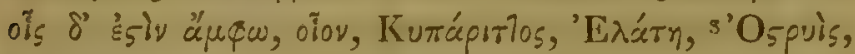

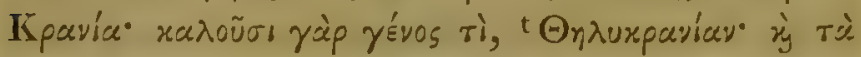

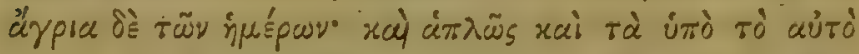

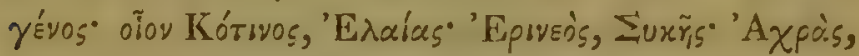

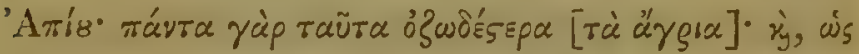

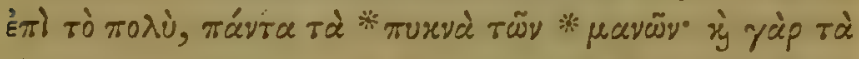

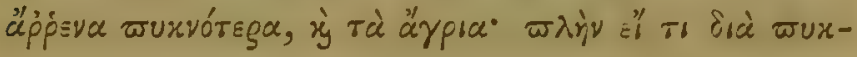

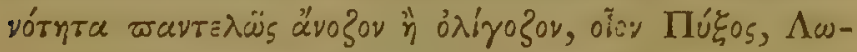

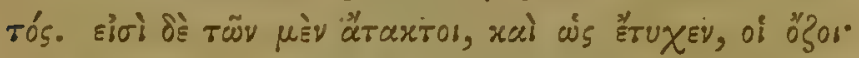

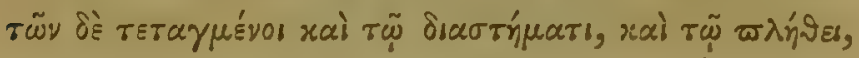

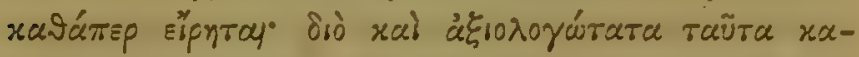

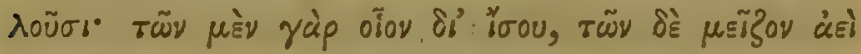

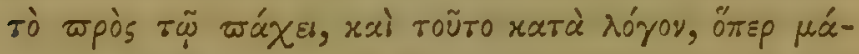

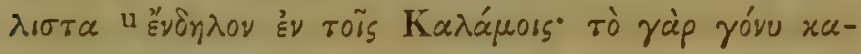

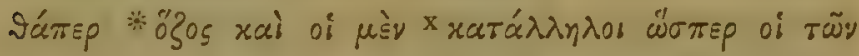

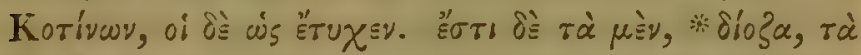

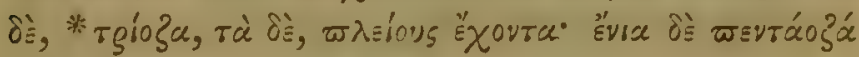

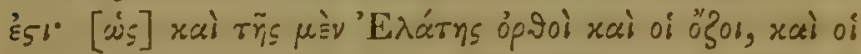

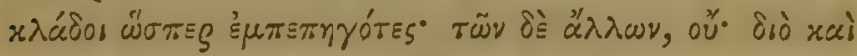

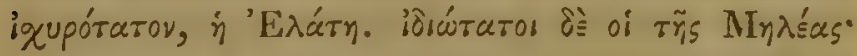

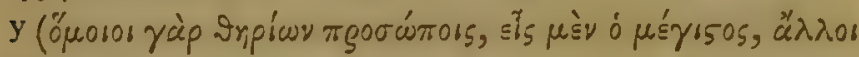

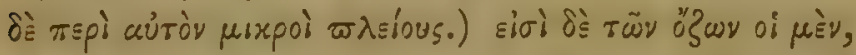

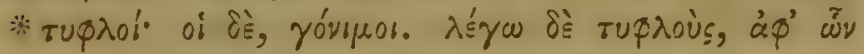

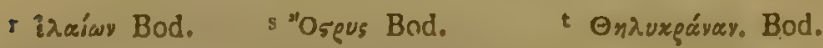

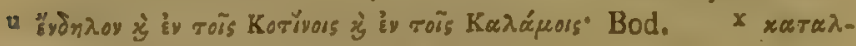

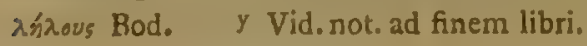




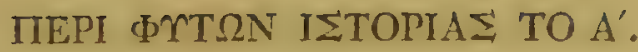

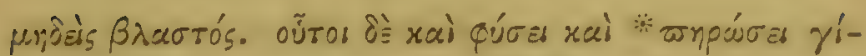

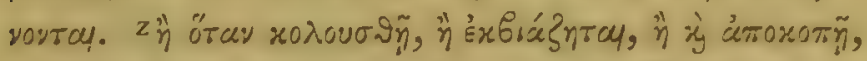

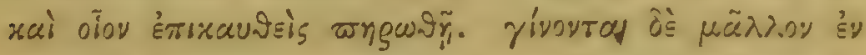

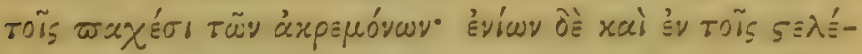

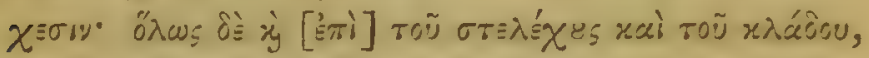

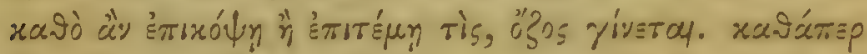

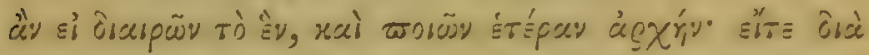

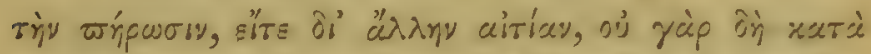

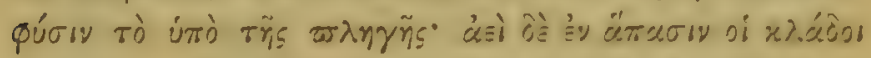

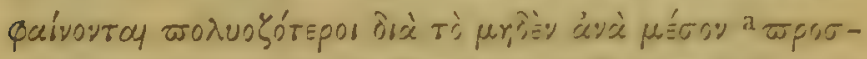

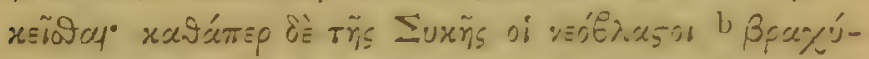

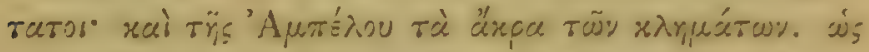

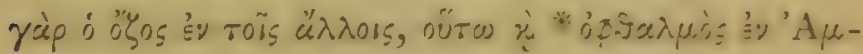

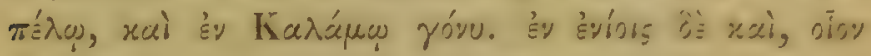

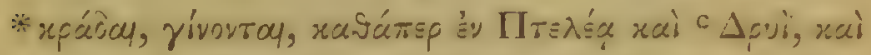

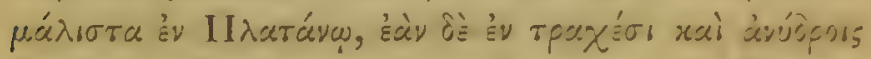

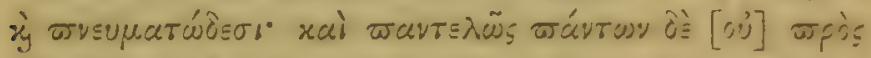

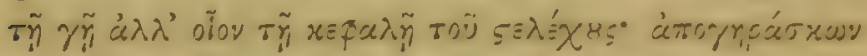

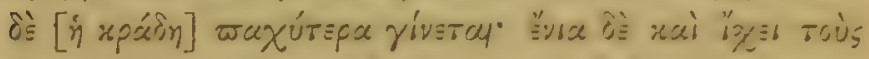

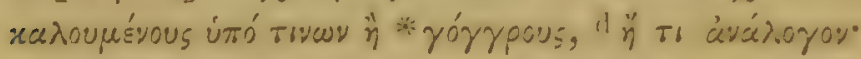

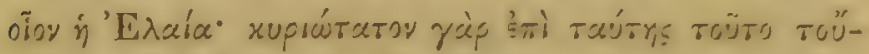

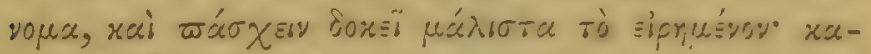

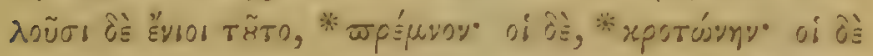

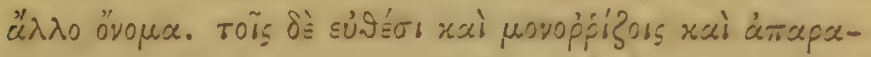

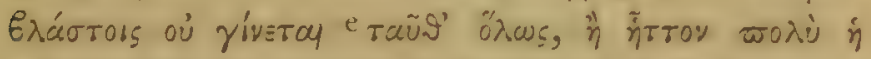

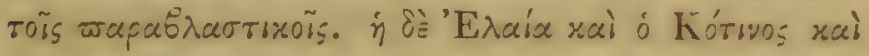

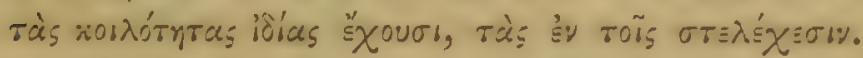

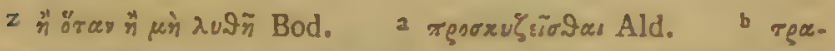

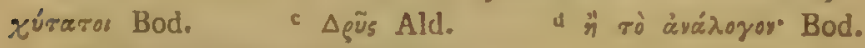

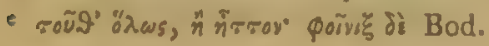




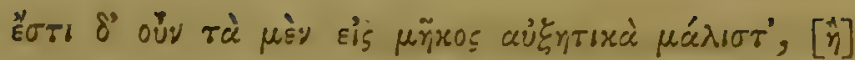

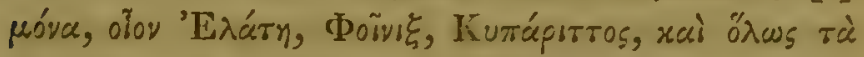

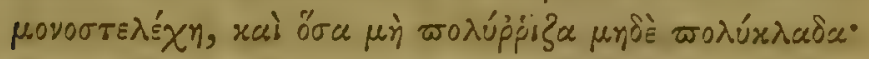

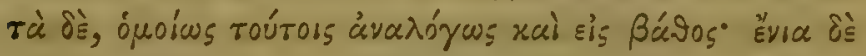

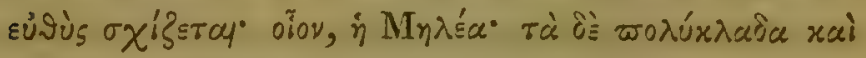

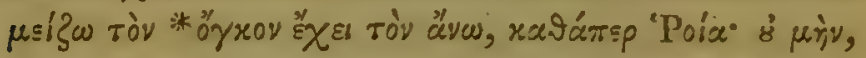

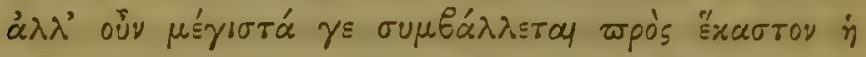

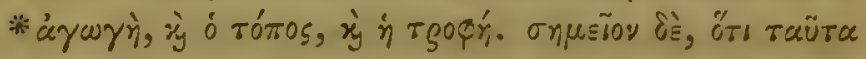

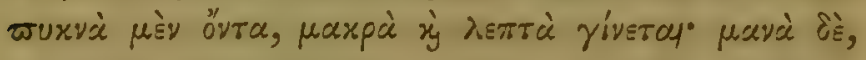

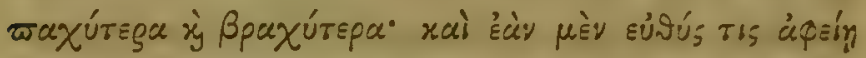

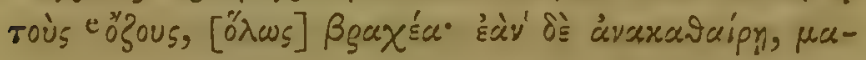

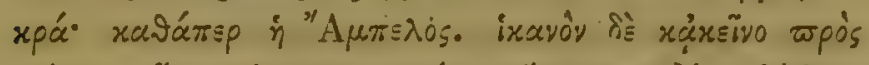

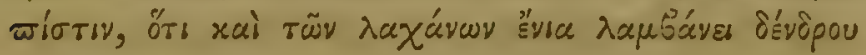

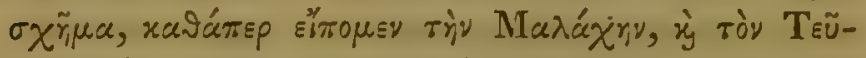

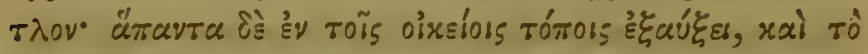

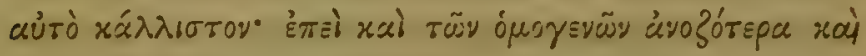

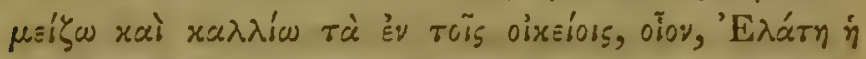

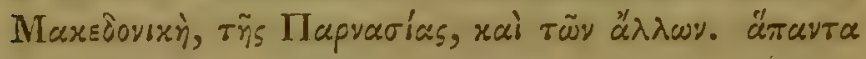

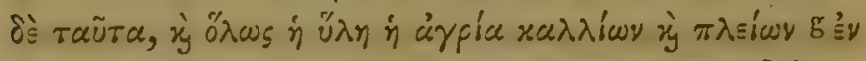

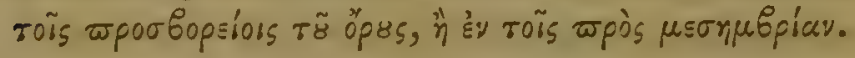

\section{CAP. XII.}

Foliorum Differentice : semper virentia, decidua. Anomala quadan.

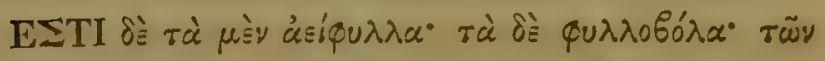

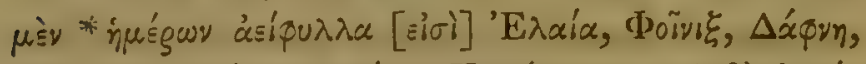

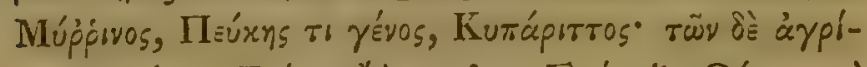

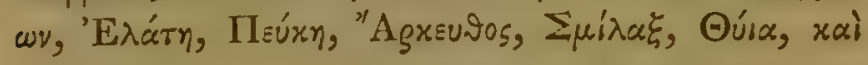

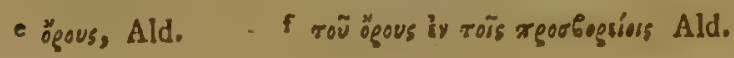




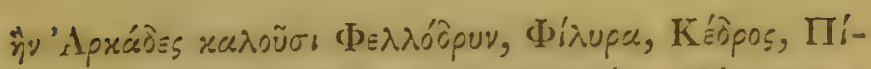

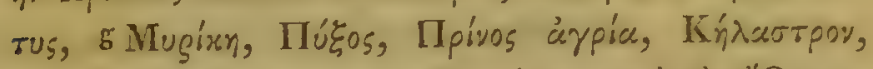

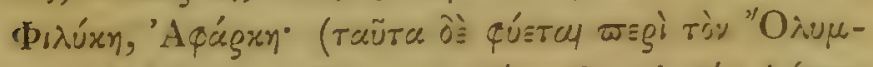

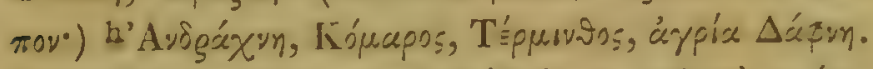

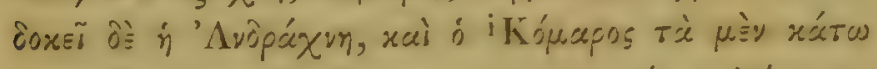

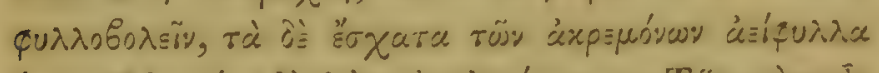

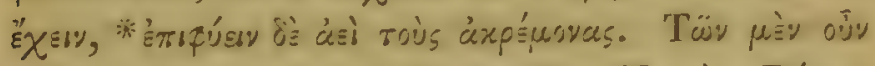

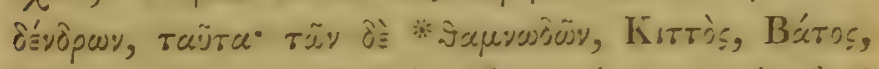

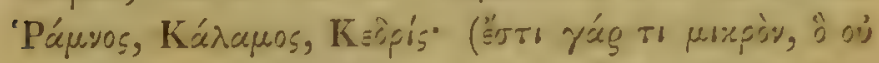

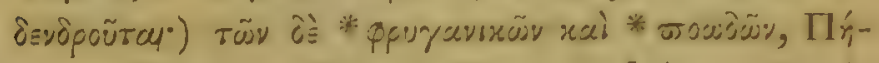

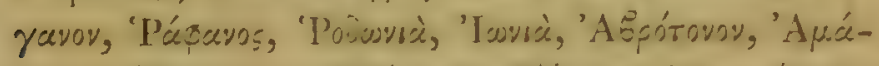
рахо\%, "Е

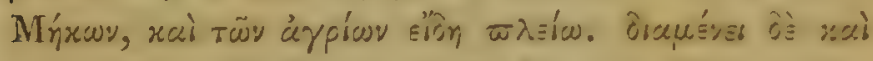

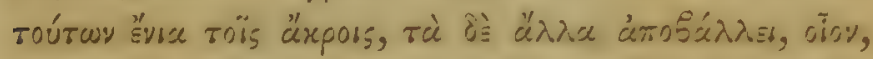

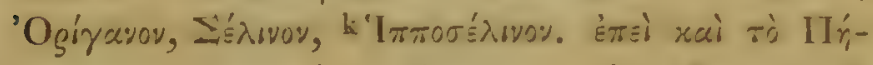

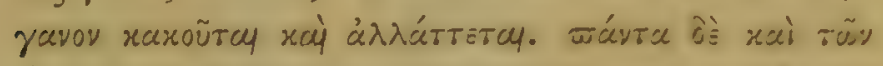

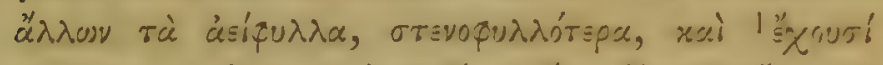

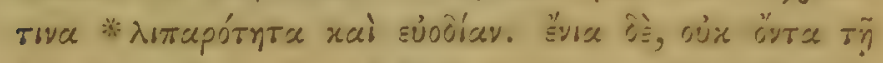

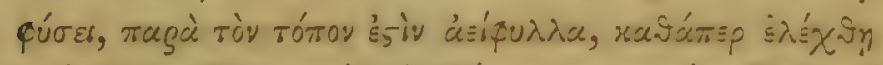

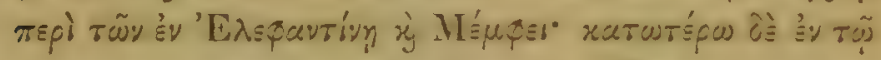

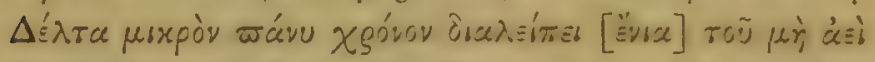

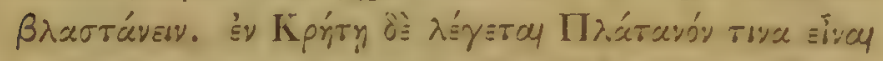

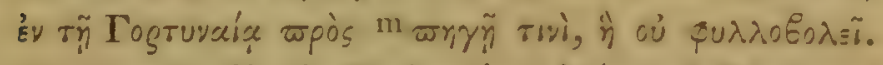
$\mu$ भง

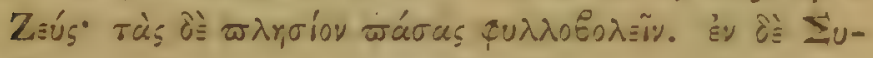

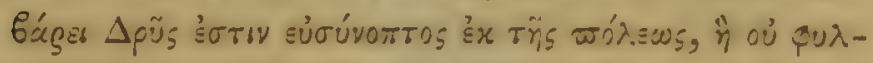

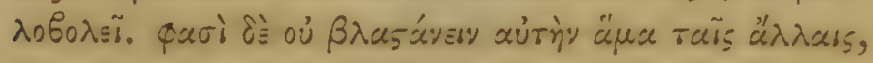

= Muppeixix, Bod. h 'Adęáxyn, Const. i öruẹos Bod.

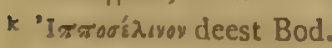
Bas. *ยูทข̃ Const.
1 " "xove Ald. Bod.

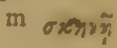
n imi raúry Bod. 


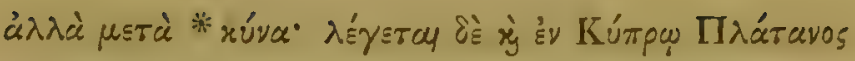

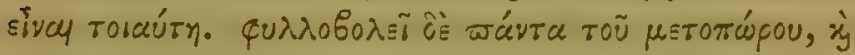

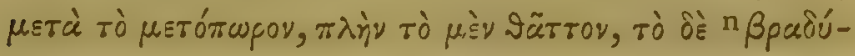

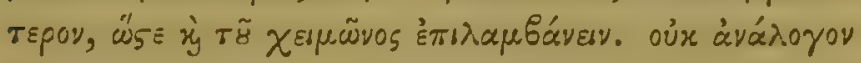

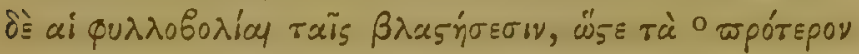

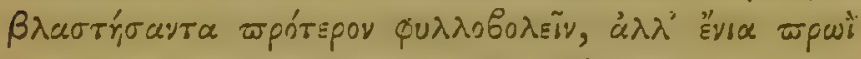

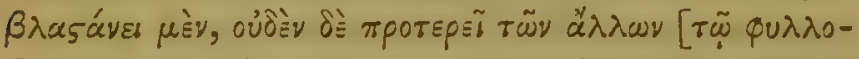

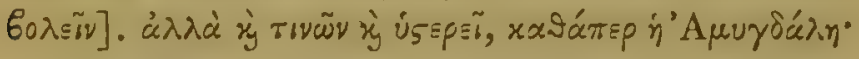

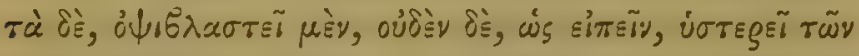

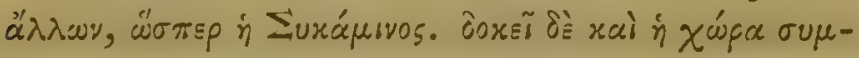

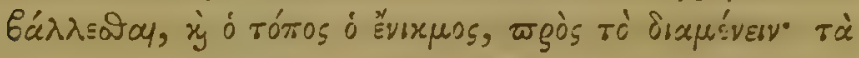

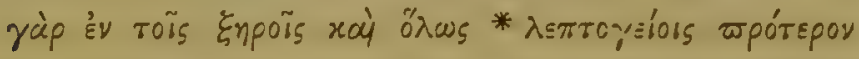

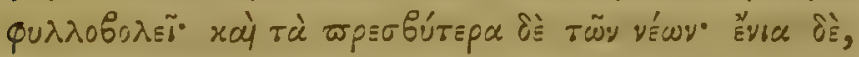

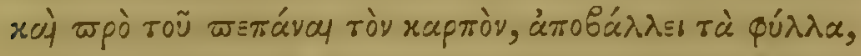

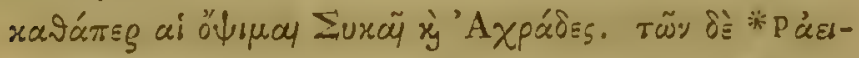

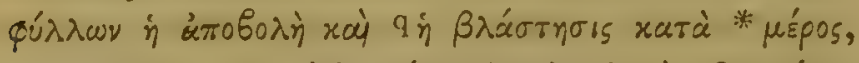

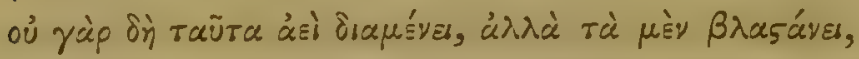

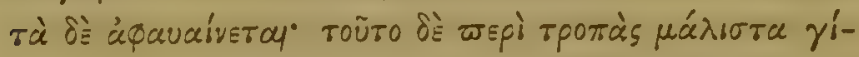

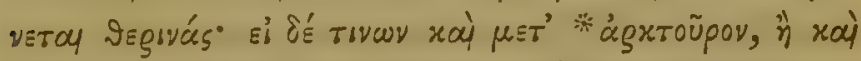

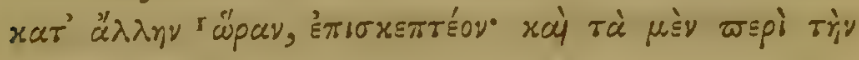

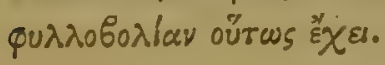

\section{CAP. XIII.}

Foliorum Differentic quoud Figuram. Succonum Varietates.

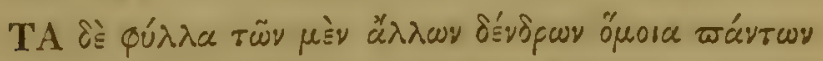

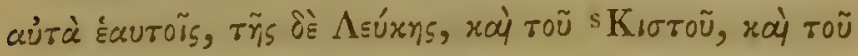

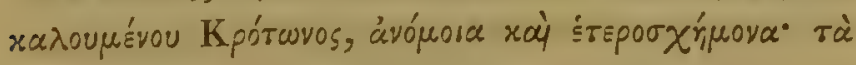

त B̧ádu Bod.

- चgérepar deest Ald.

P $\dot{\alpha} \varphi \dot{\imath} \lambda \lambda \omega \boldsymbol{y}$ Bod. $\mathrm{q}$ ทं aै้ alii. s Kırroũ, Ald. Bod. 


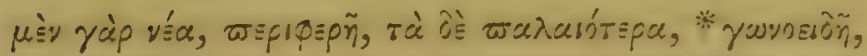

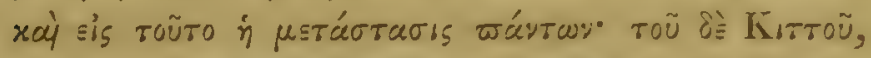

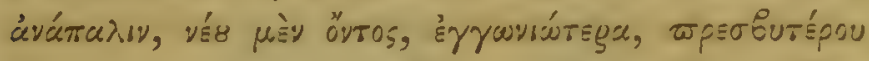

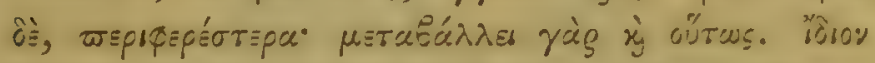

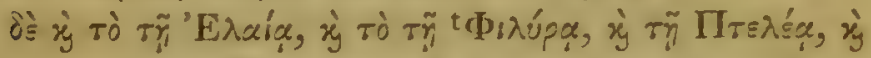

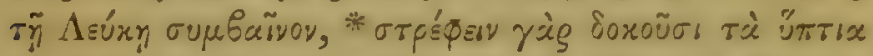

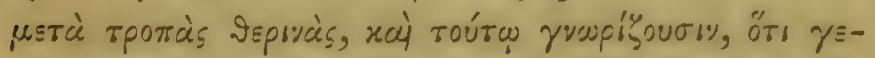

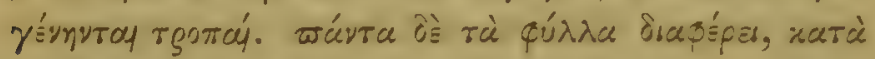

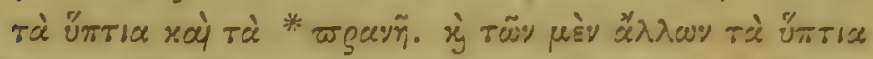

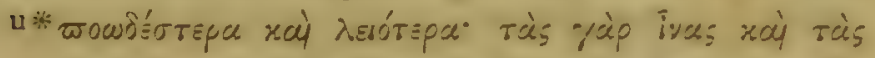

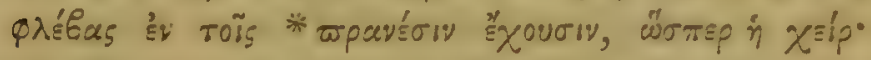

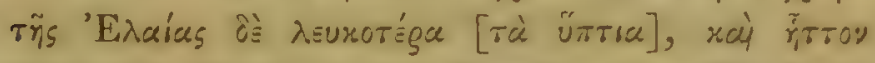

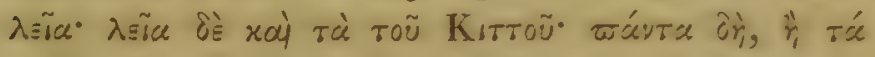

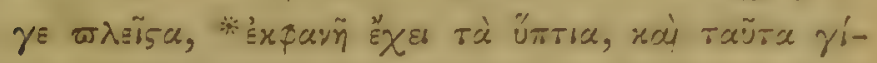

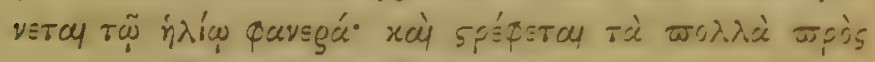

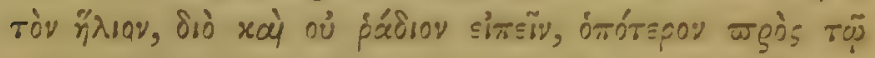

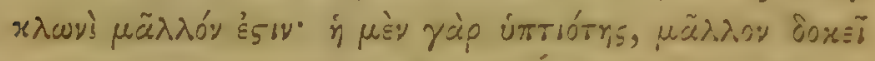

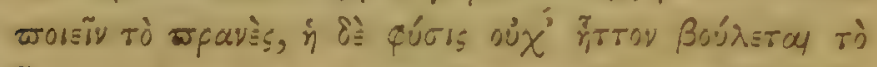

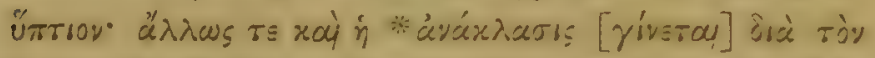

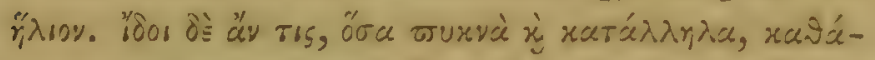

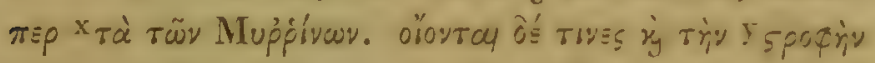

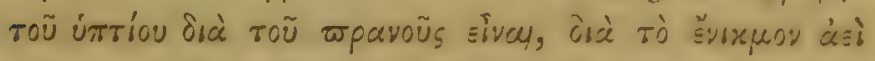

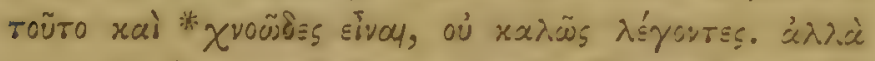

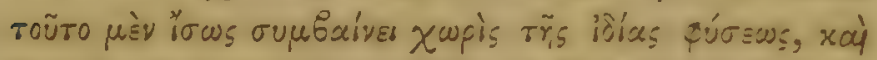

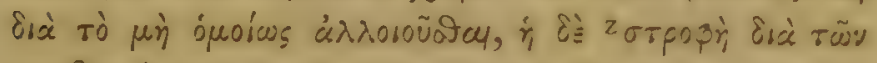

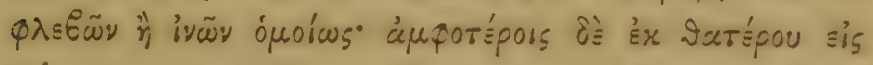

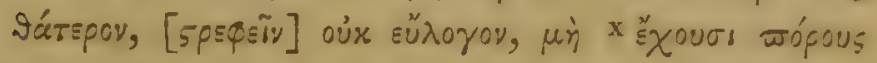

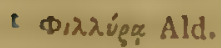
u ziadiotzęa Bas.
X ท่ rãy Mup่- firvar Bod. y rpopin Bod. $x$ reopiे Bod.

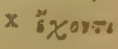

Bod. 


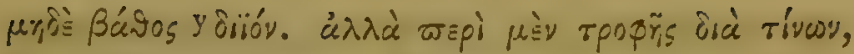

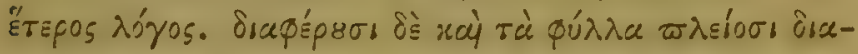

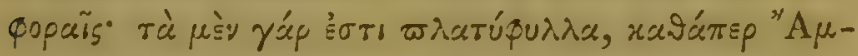

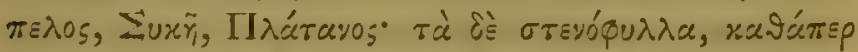

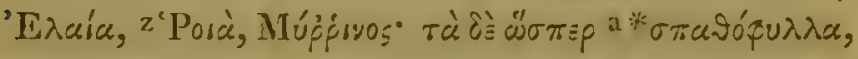

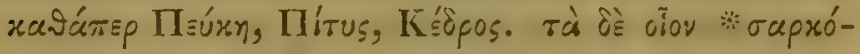

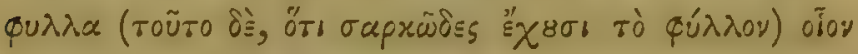

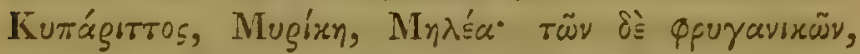

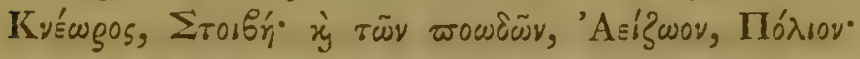

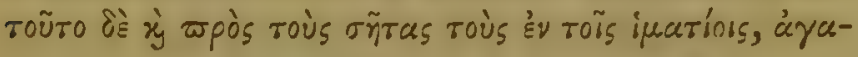

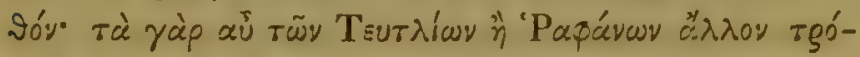

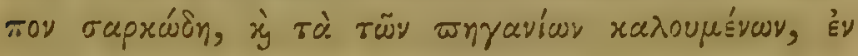

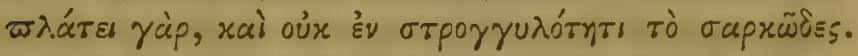

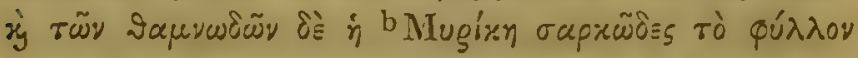

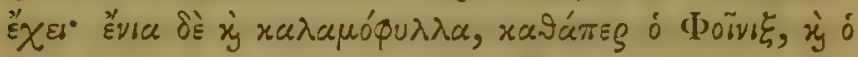

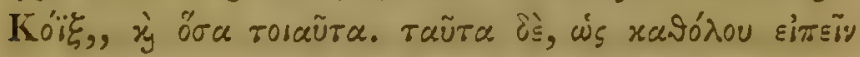

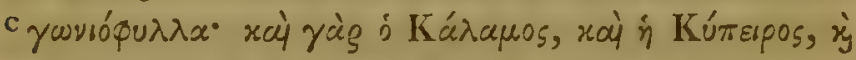

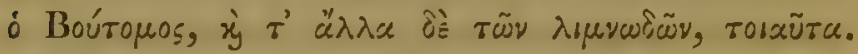

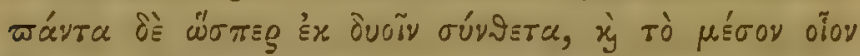

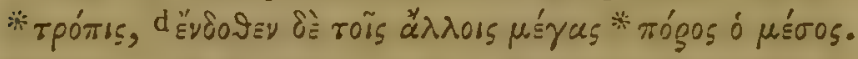

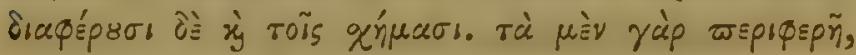

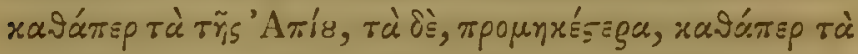

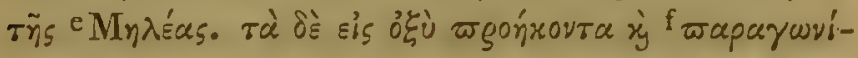

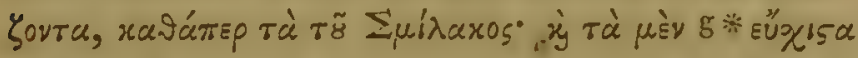

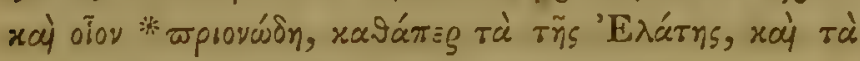

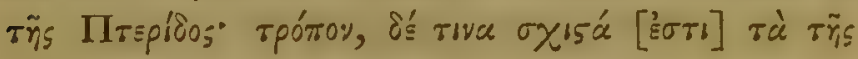

y diḯy. Ald.

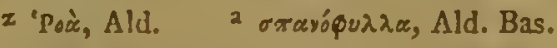
ᄂ 'Eg gixn Const.

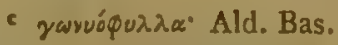

d อัดงเ รoĩ

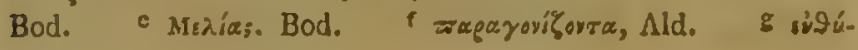
oxsora Const. 


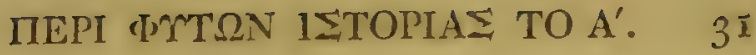

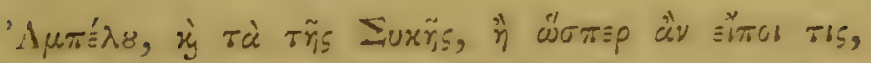
h

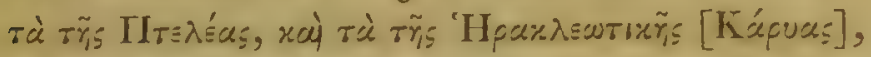

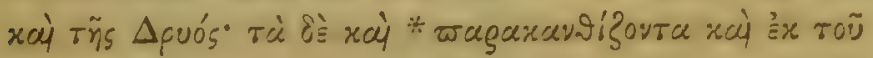

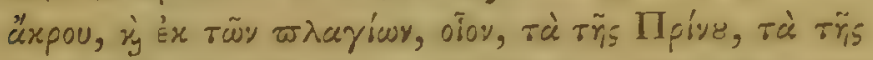

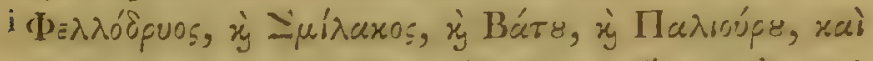

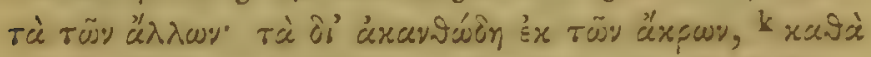

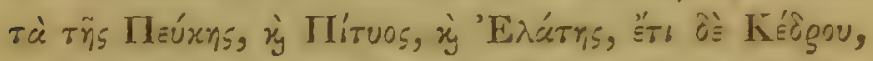

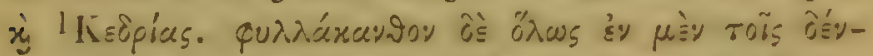

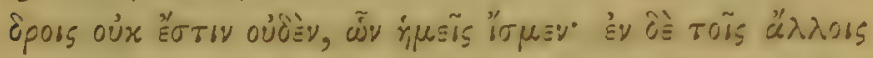

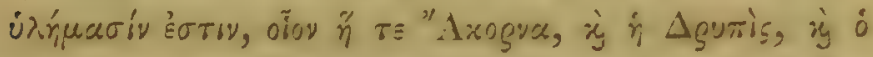

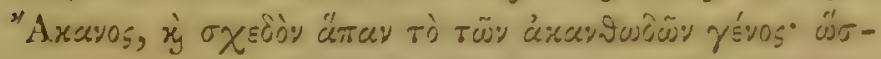

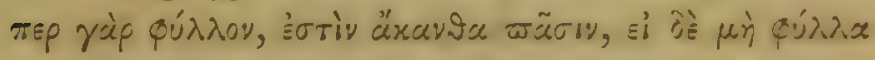

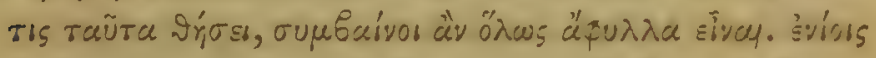

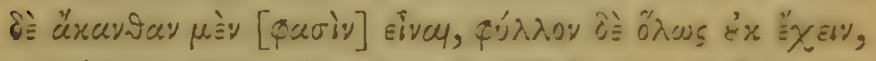

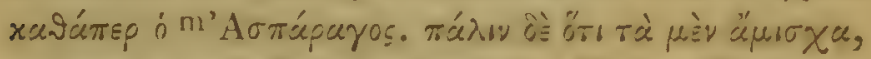

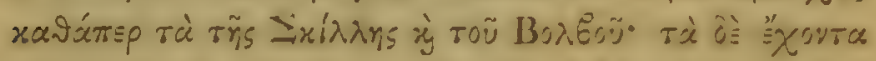

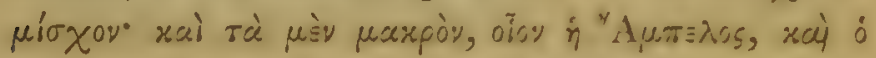

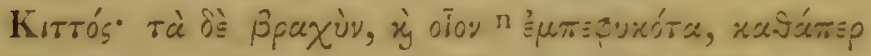

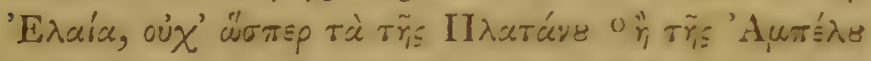

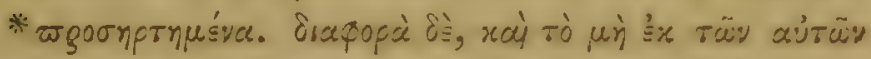

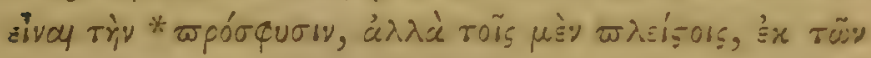

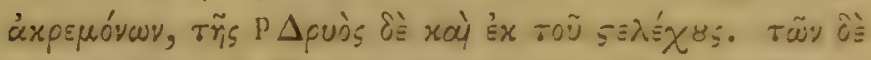

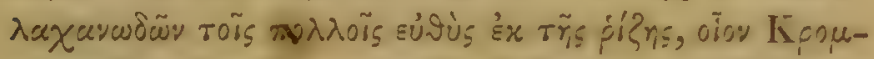

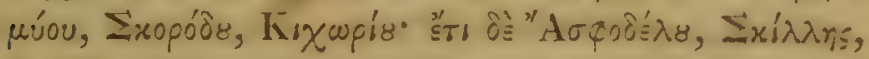

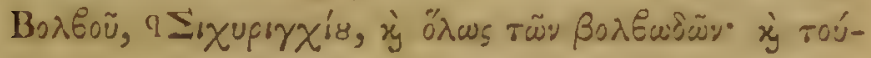

h xọwyotasíñ. Const. i

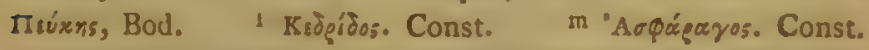

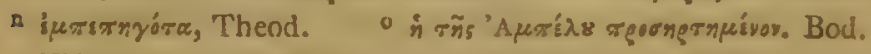

2Vid. nut. ad finem libri. Q 'Ifueryxiou, Ald. Bas. 


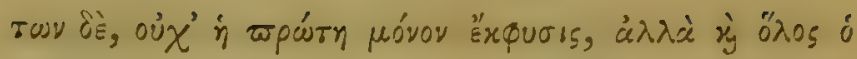

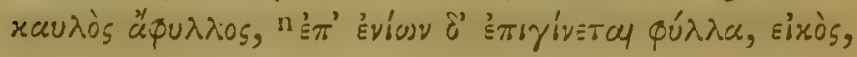

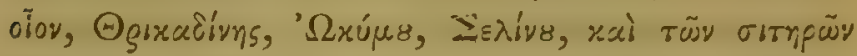

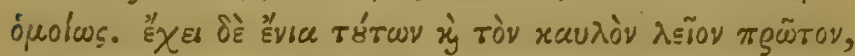

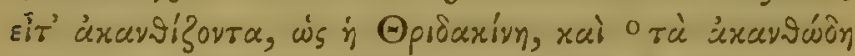

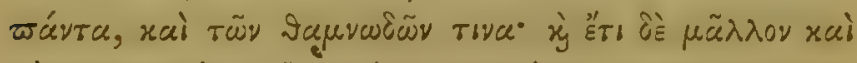

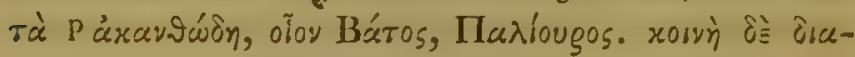

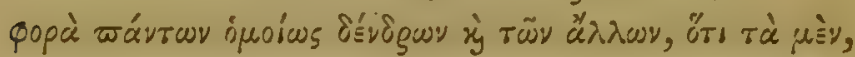

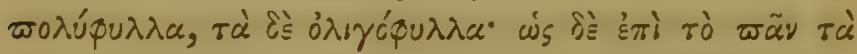

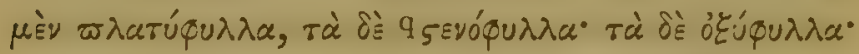

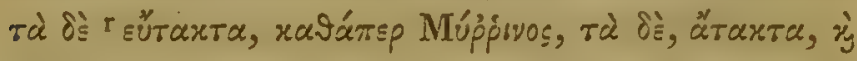

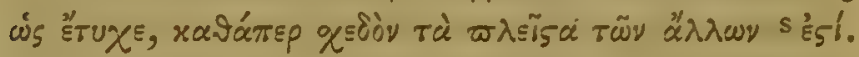

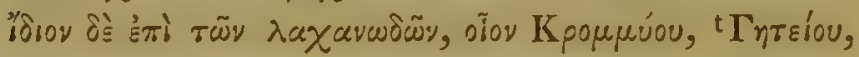

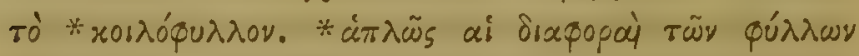

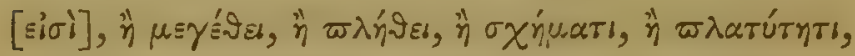

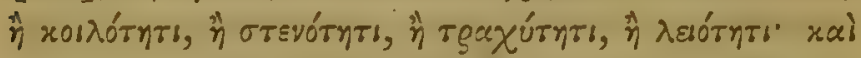

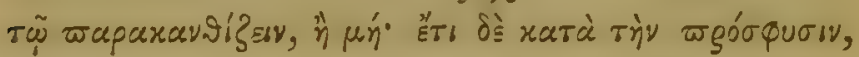

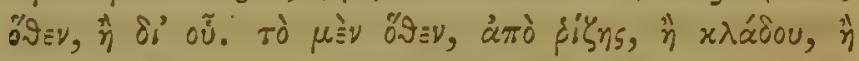

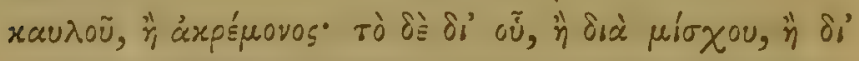

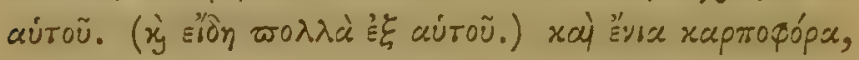

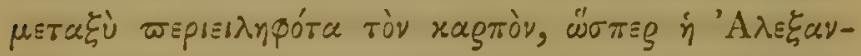

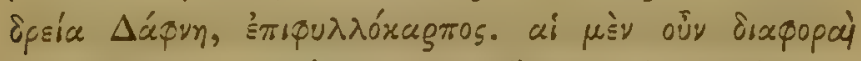

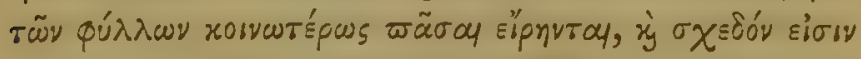

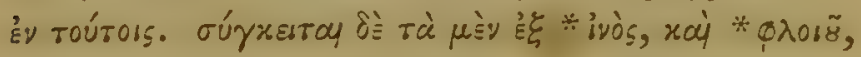

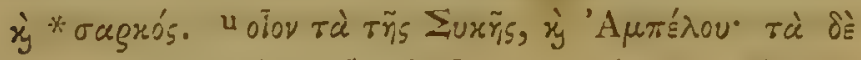

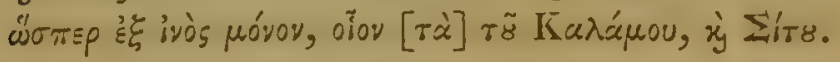

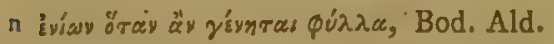
- $\tau \dot{\alpha} \varphi \dot{\alpha} \lambda \lambda \alpha$

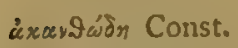
deest Ald. Bod. $\mathrm{p} \dot{\alpha} \times \alpha$ vấín deest Bod. q ระvópurace I ёँкахта, Bas. Ald. $s$ ที丶. Bod.

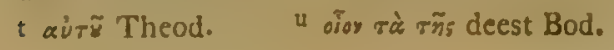




\section{CAP. XIV.}

Succus in variis Partibus; Foliis; Floribus ; Fructibus.

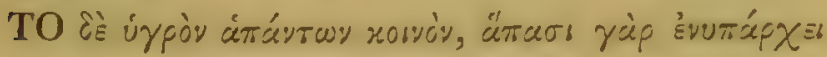

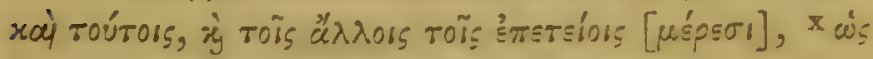

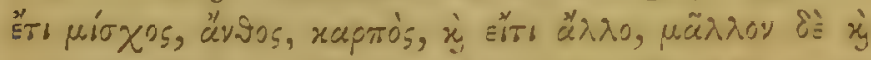

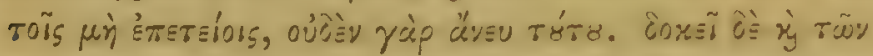

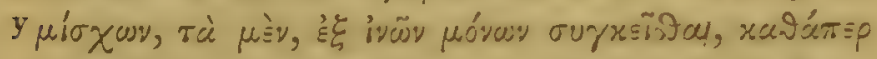

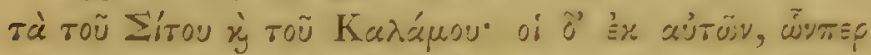

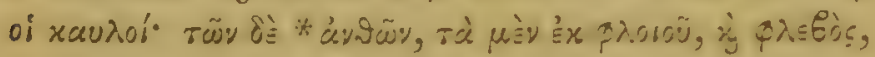

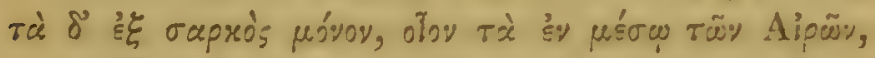

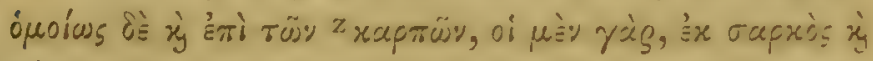

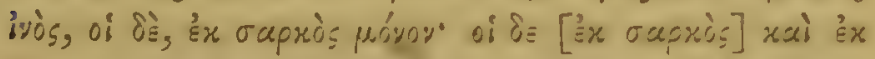

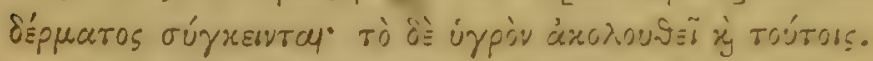

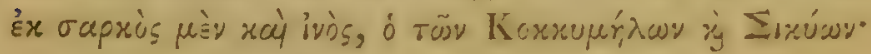

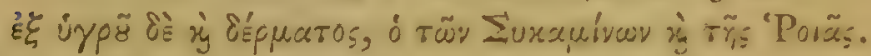

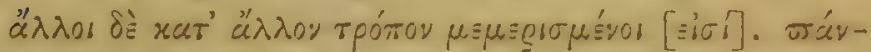

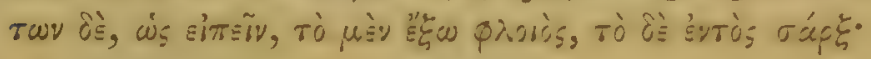

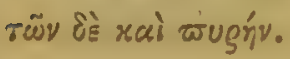

\section{CAP. XV.}

Semina Alborum : ce yue Simina congeste, ct quä discretu.

De Ficu EEgyptia.

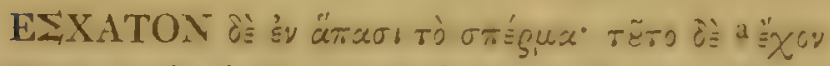

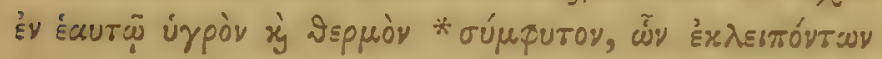

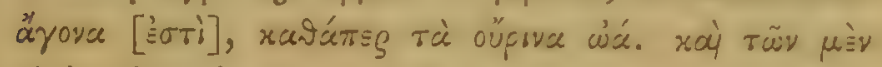

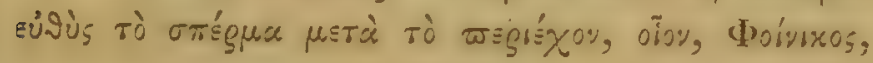

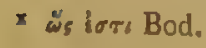

a "zu Const.

Y. apioxay, Const.

2 rapxäy, Bod. 


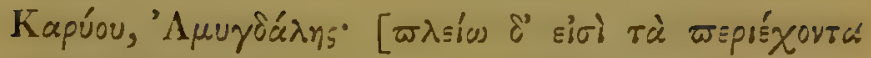

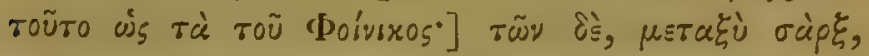

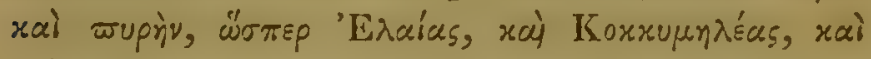

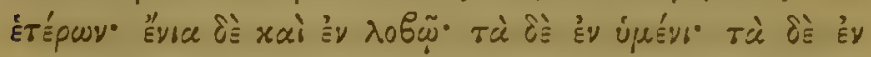

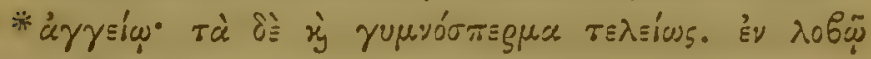

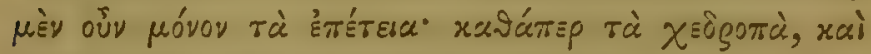

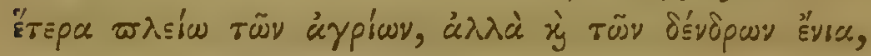

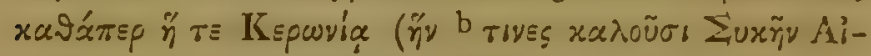

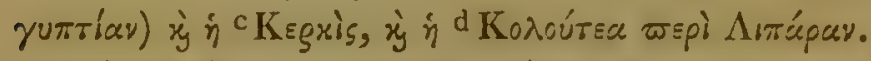

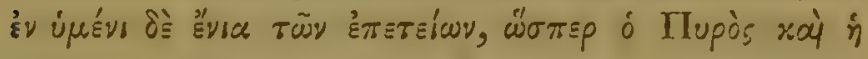

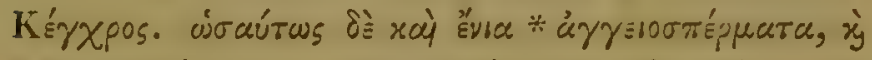

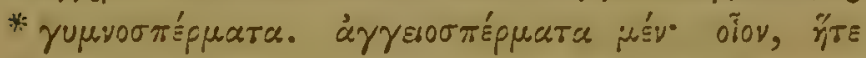

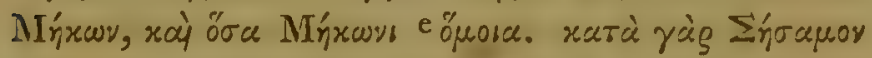

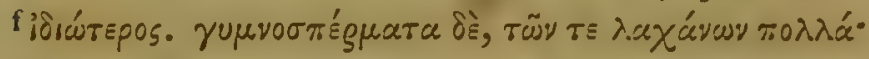

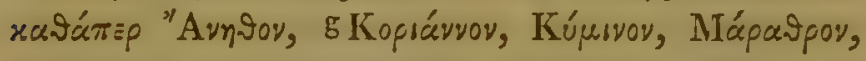

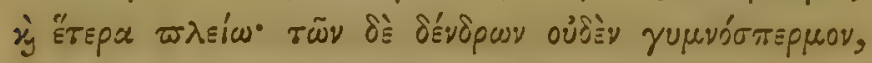

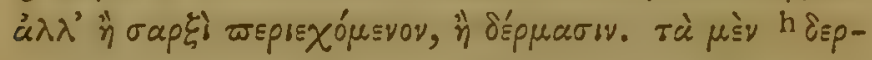
$\mu a \tau$ เхой,

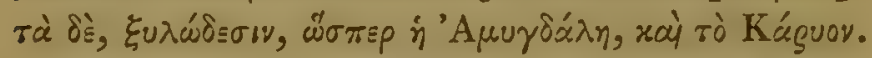

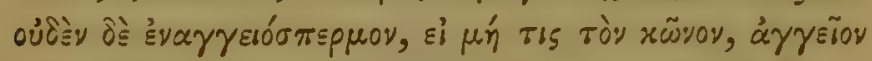

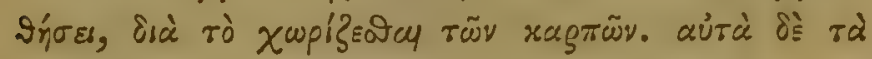

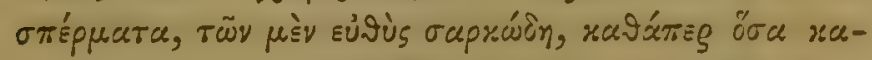

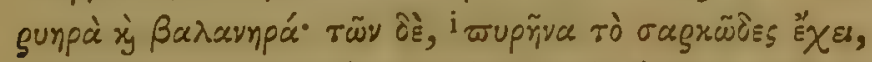

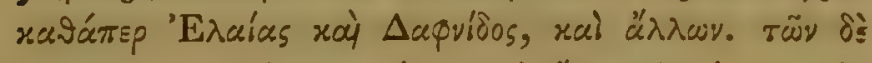

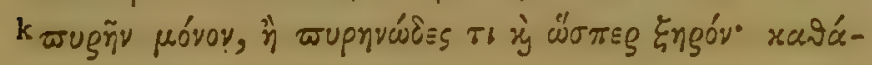

D Tave Bod. c Kixis, Bod. Krxis Ald. d Koroírse Bod. e "̈rosa deest Ald. Bas. - Kogiayyoy, "Avicoy, Const. h नrequertixoĩs, Ald. Bas.

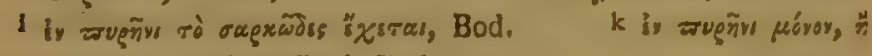

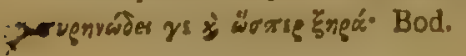




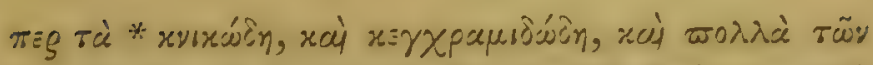

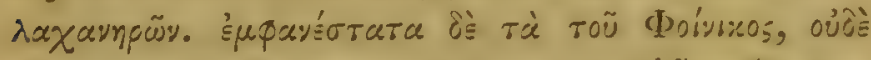

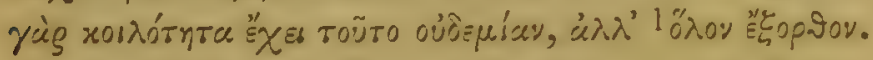

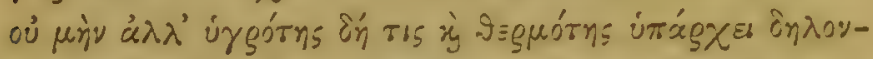

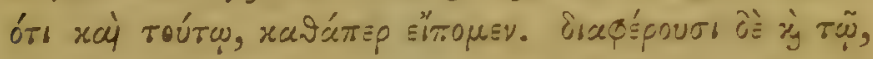

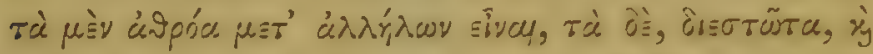

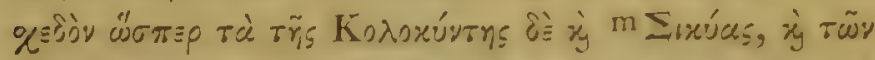

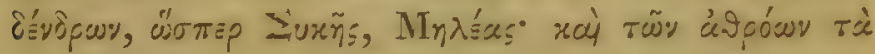

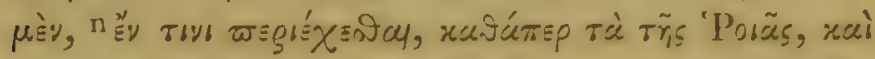

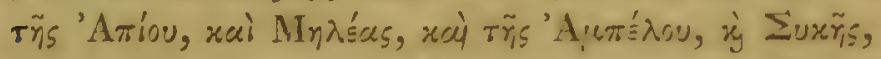

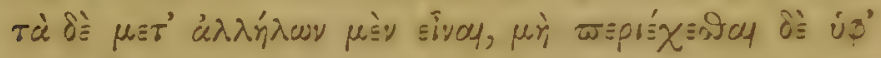

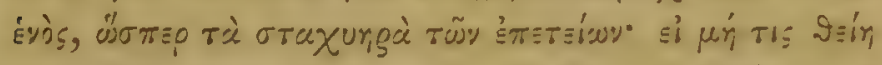

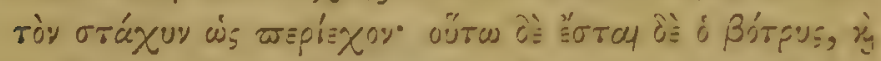

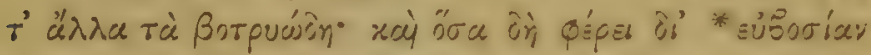

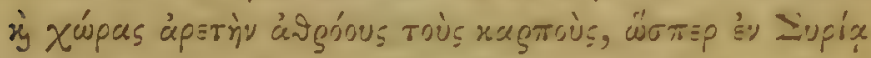

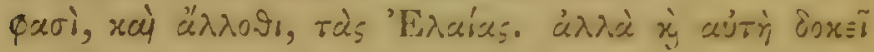

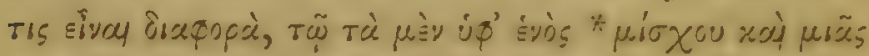

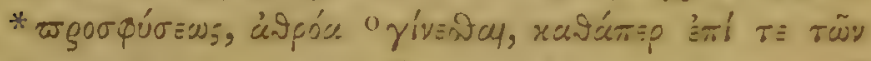

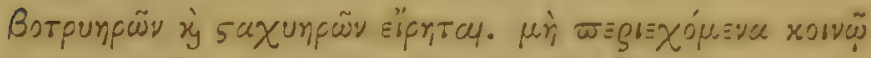

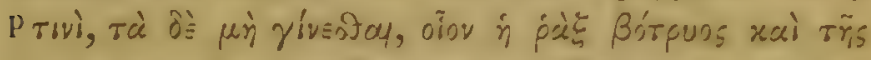

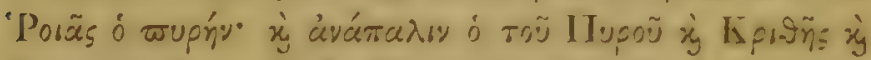

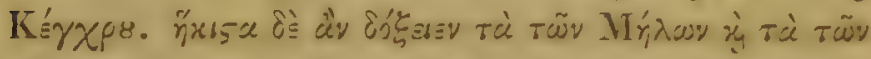

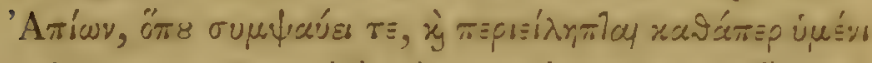

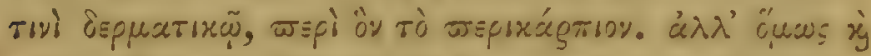

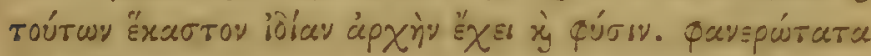

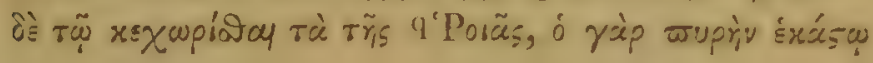

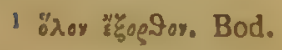

m Eıxúov, Const.

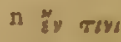

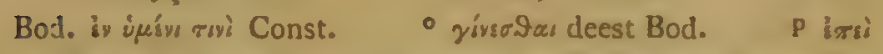

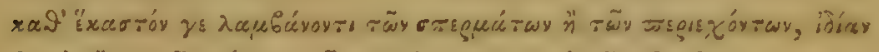

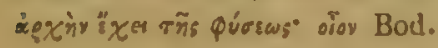

9 'Poös, Bod.

D 2 


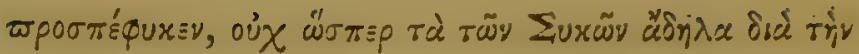

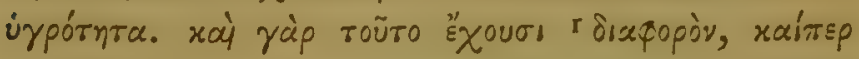

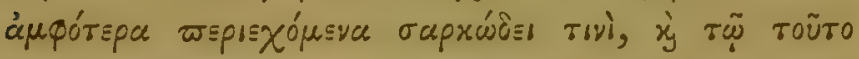

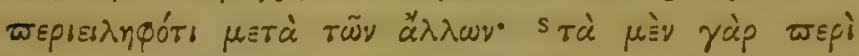

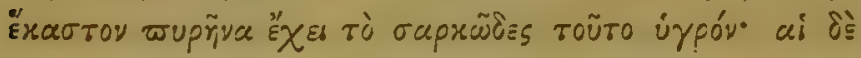

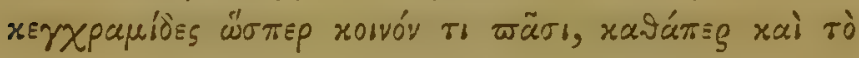

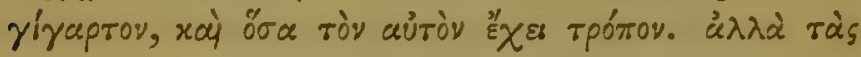

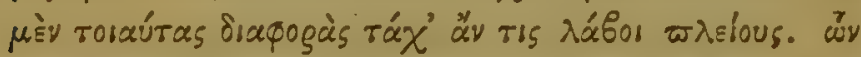

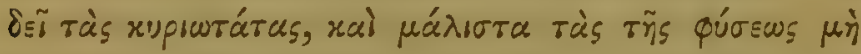

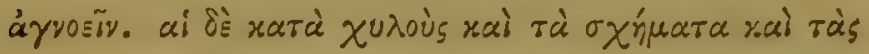

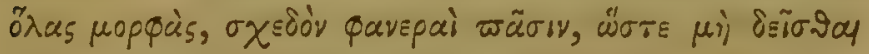

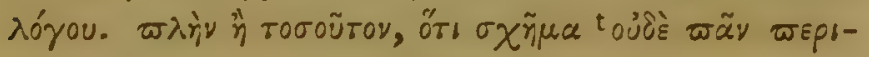

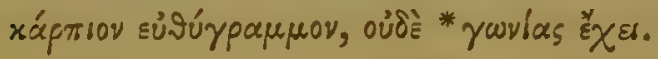

\section{CAP. XVI.}

De Succorum Odorumque Differentia.

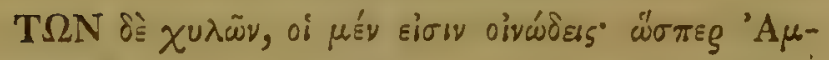

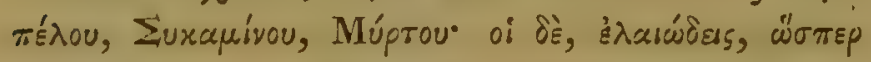

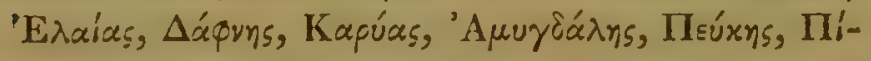

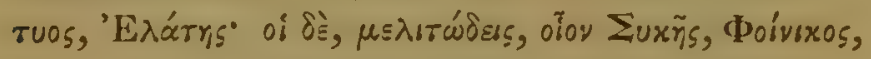

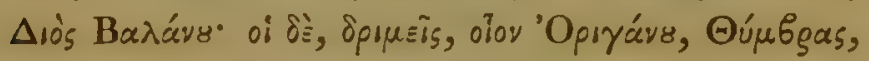

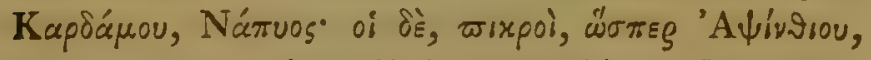

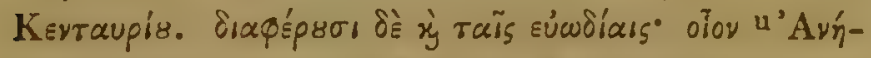

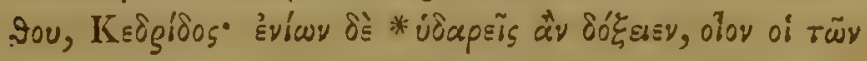

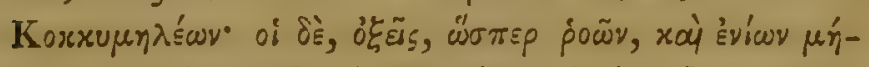

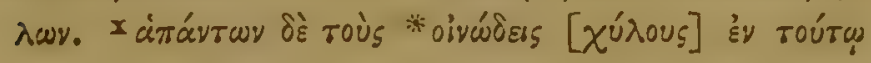

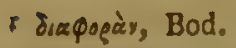

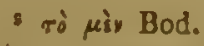

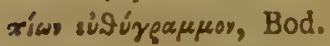
u' Arroov, Bas.

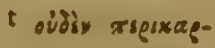
di civưous \&े trov̀s Bod. ivúdsus Ald.
} 


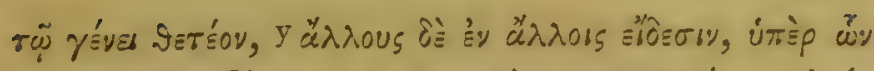

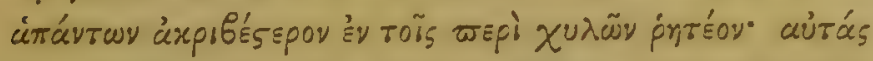

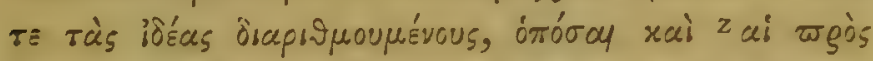

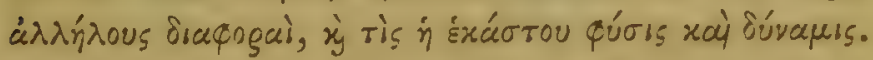

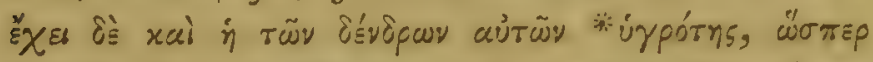

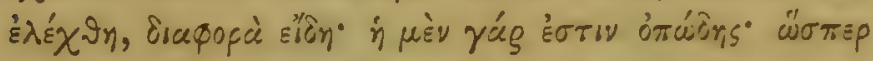

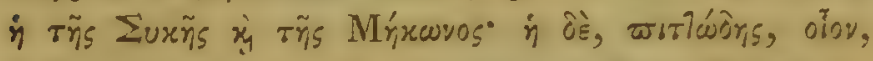

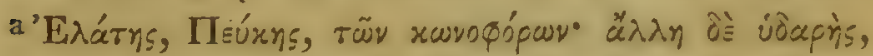

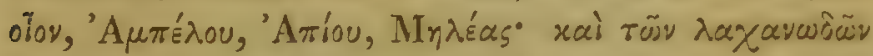

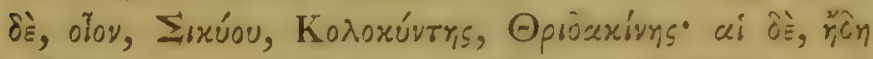

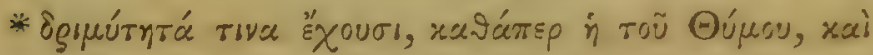

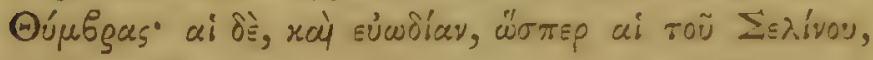

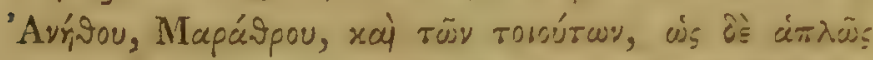

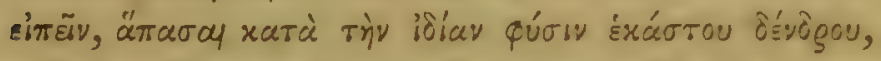

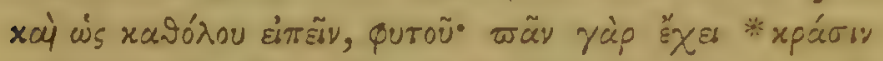

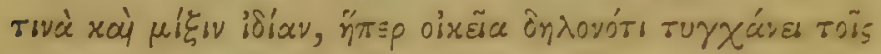

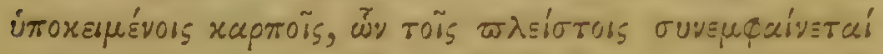

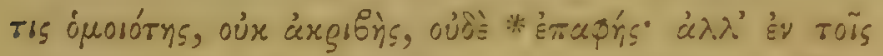

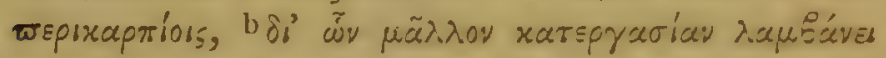

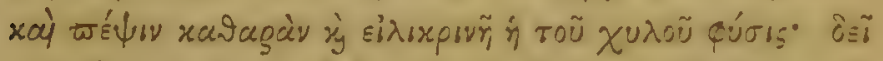

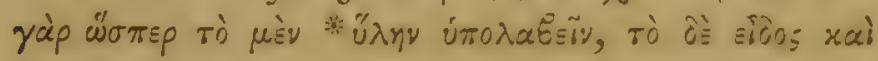

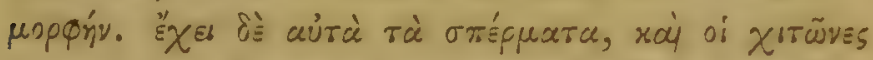

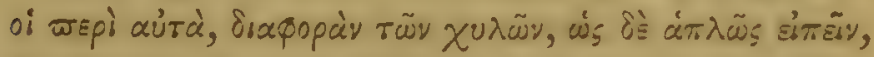

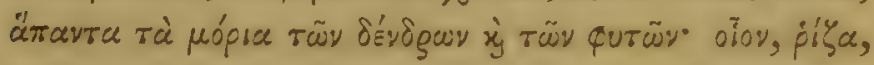

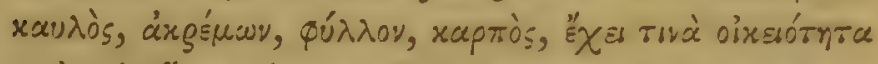

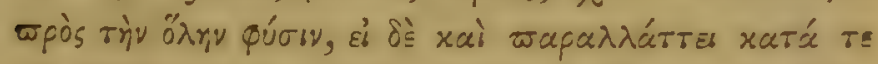

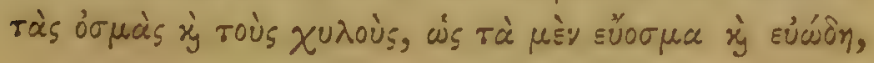

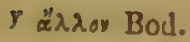

a. 'Eraias, Bod.

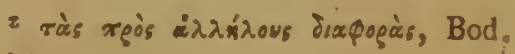

b siò Bod.
}

D 3 


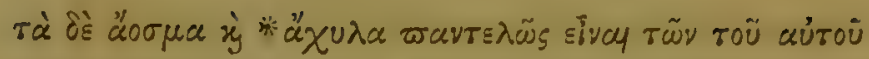

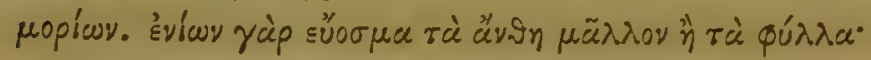

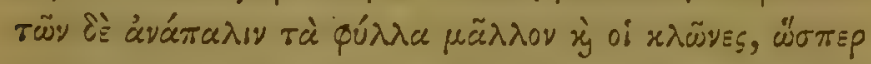

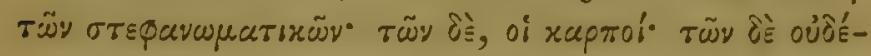

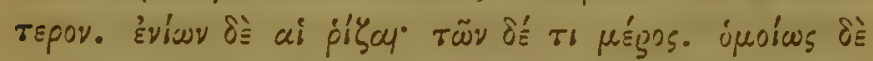

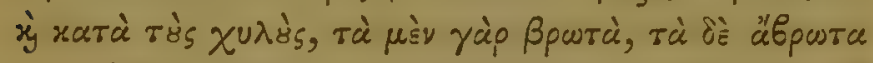

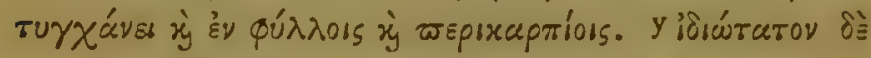

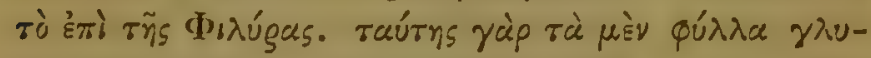

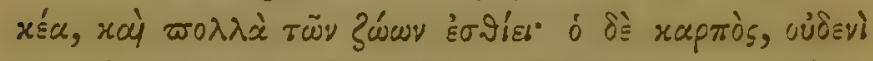
B

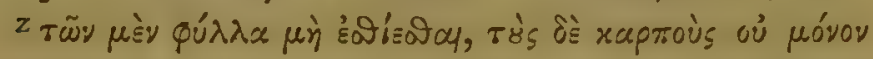

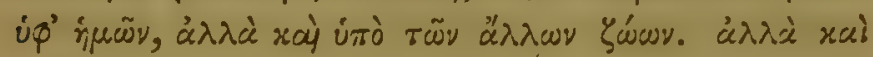

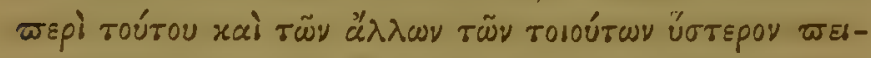

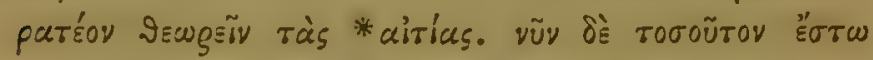

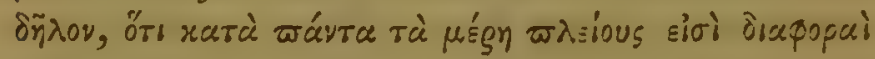

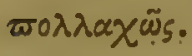

\section{CAP. XVII.}

\section{Florum Genera et Differentia.}

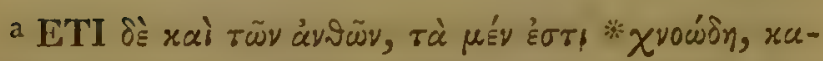

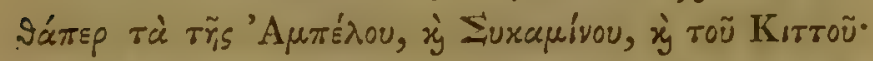

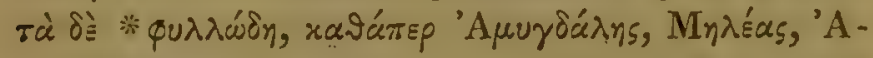

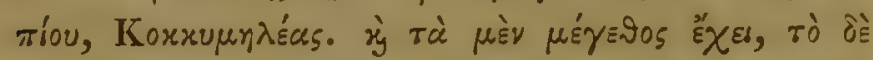

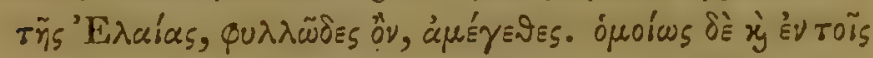

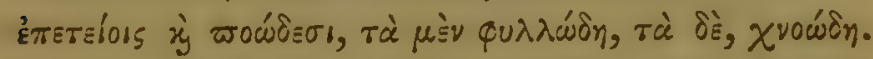

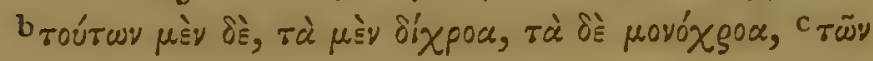

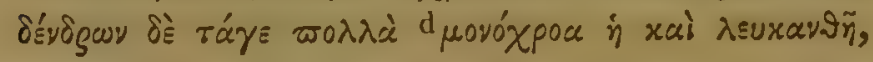

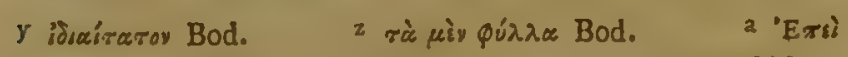
xxi Bod. b xáy

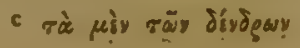

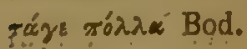

d povạsídx Conșt. 


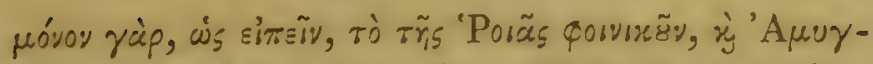

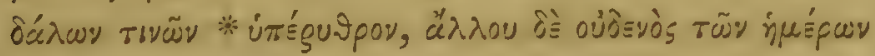

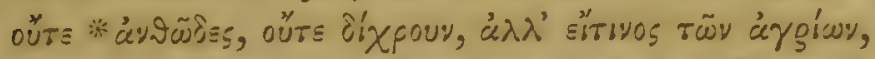

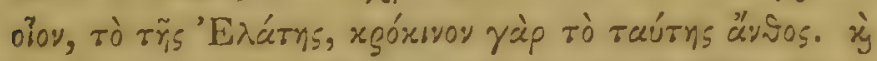

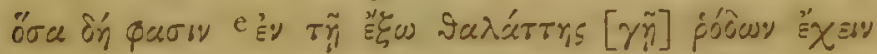

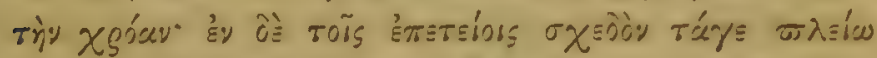

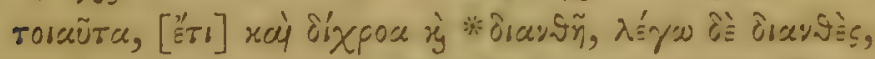

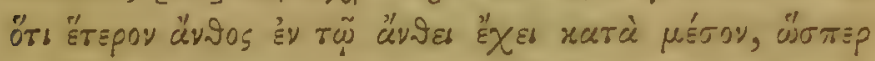

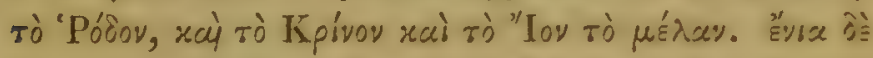

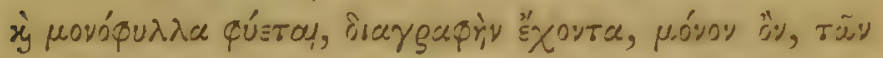

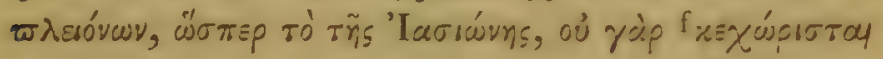

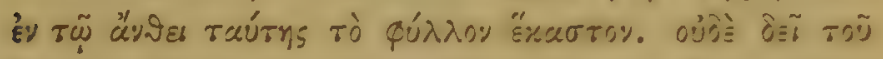

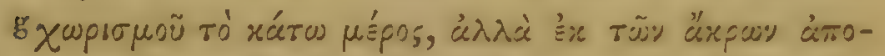

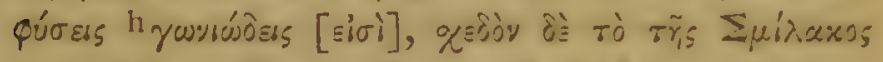

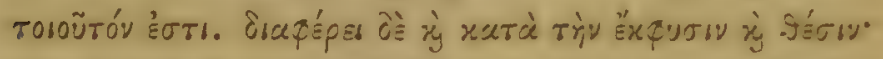

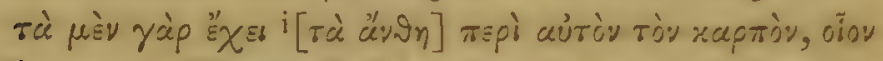

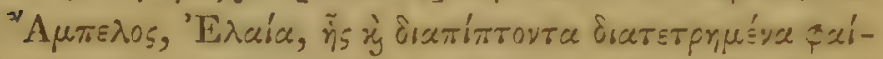

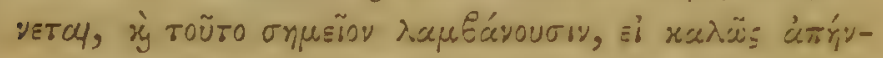

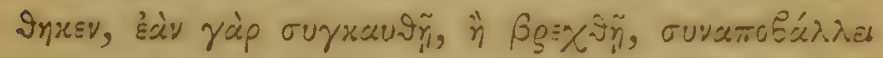

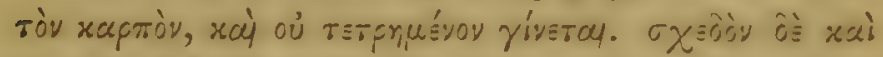

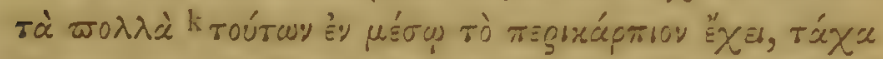

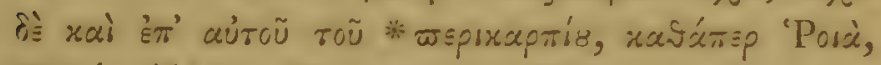

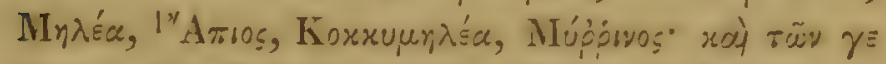

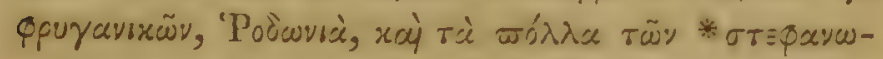

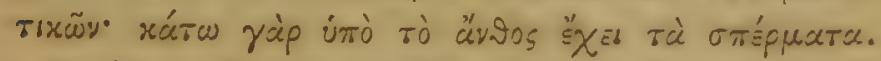

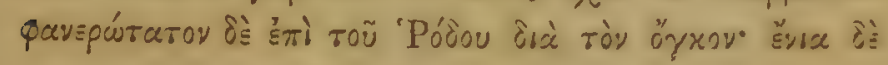

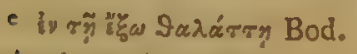

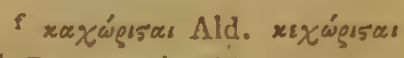

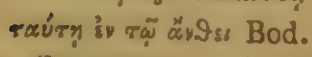

5 xugír Bod. $\chi$ sugis Ald. ${ }^{\mathrm{n}}$ yo-

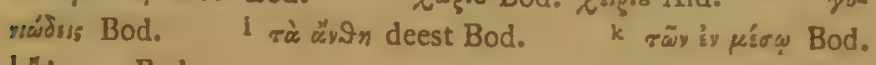
I"Ayvos, Bod.

D 4 


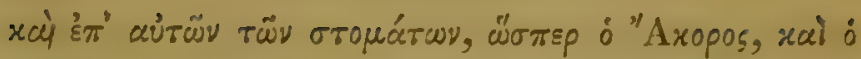

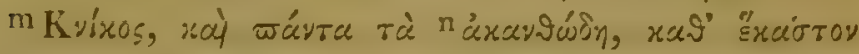

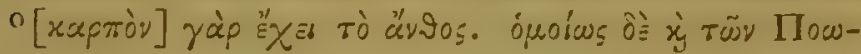

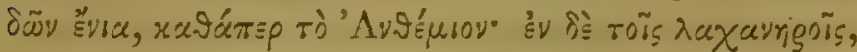

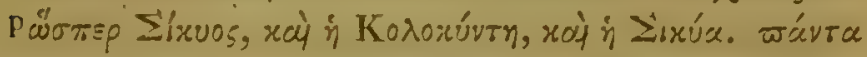

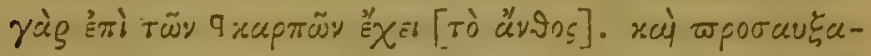

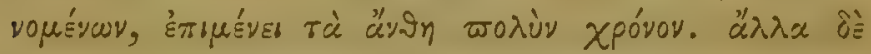

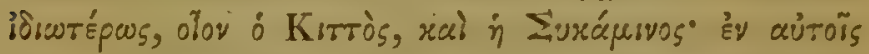

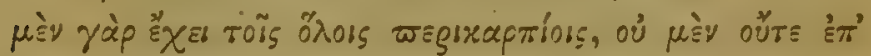

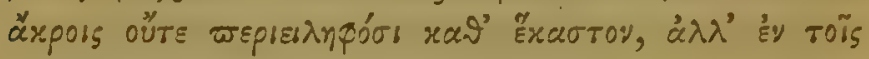

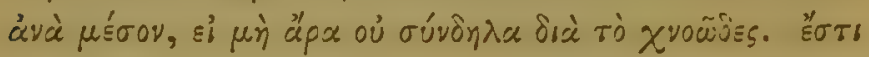

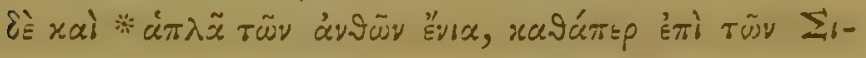

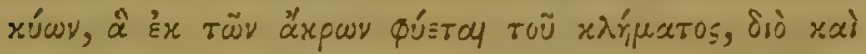

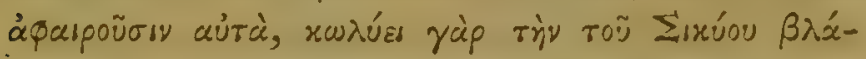

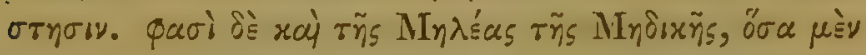

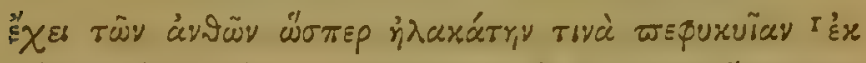

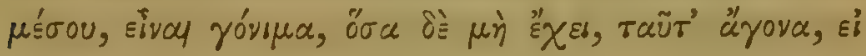

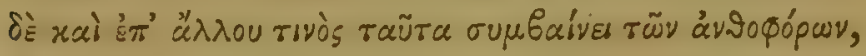

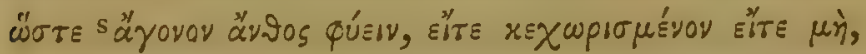

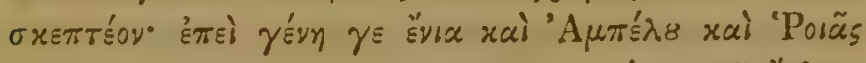

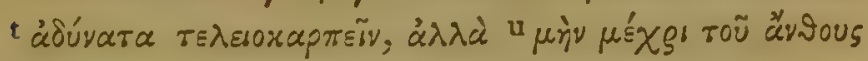

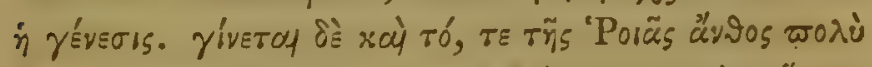

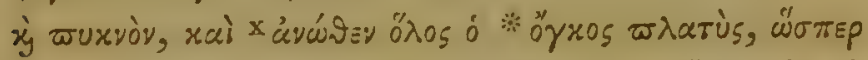

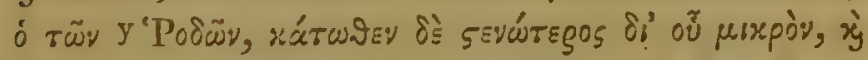

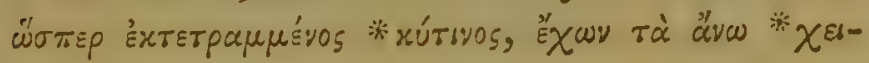
m Kvíxos, Const.

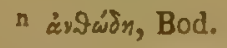

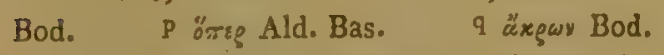
- xagroì deest

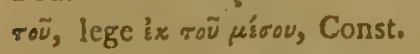
8 ärovey, Ald. Bas.

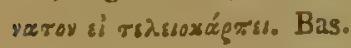 u $\mu \grave{n}$ Bod.
$x$ żyíaly deest Bod. y 'Poüy, Bod. 


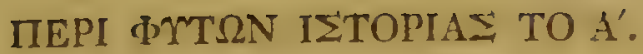

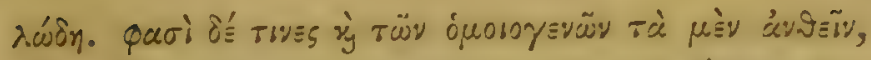

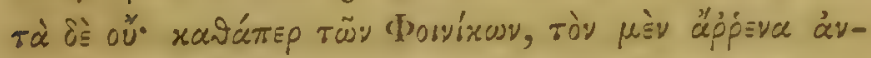

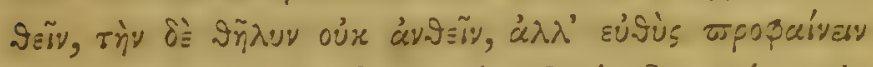

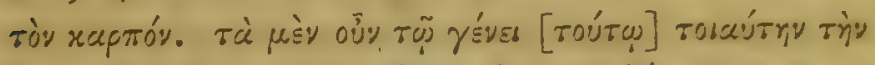

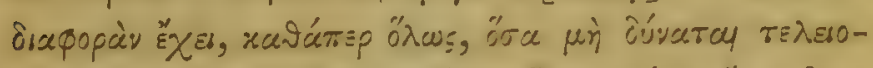

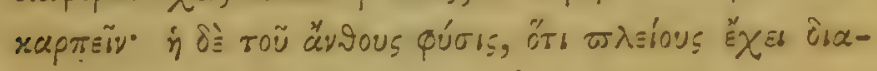

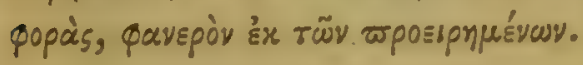

\section{CAP. XVIII.}

Quomodo distent in fructificando Arbores.

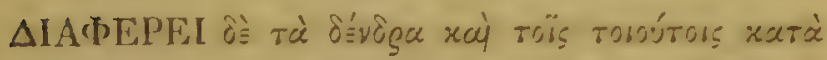

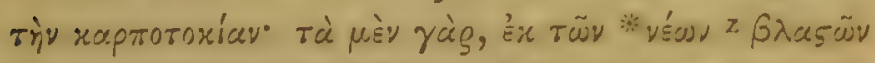

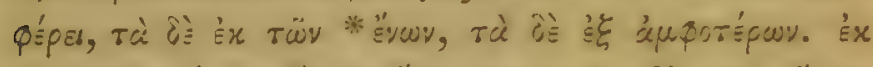

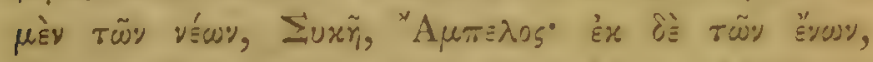

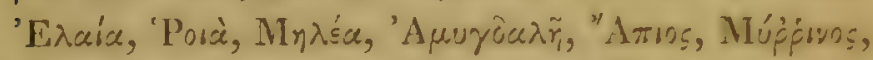

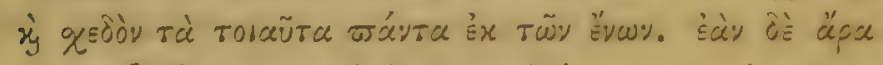

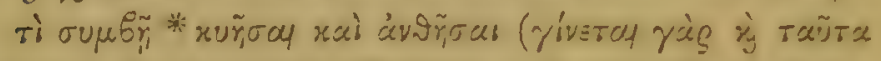

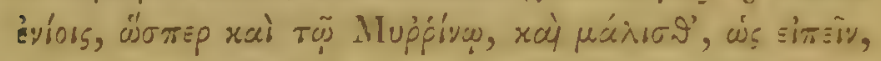

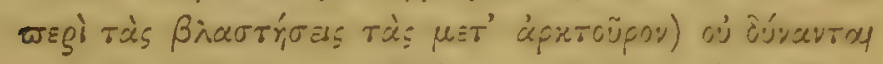

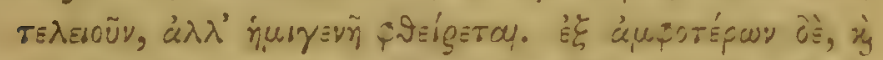

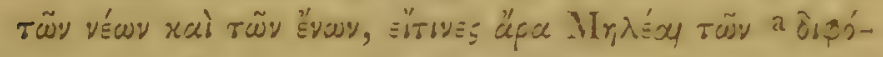

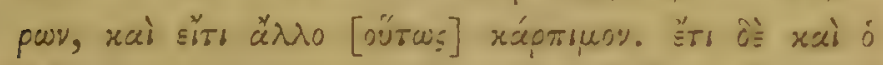

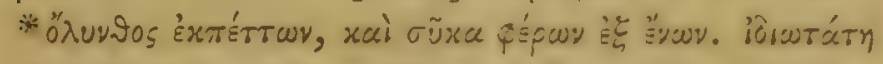

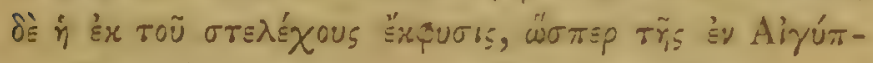

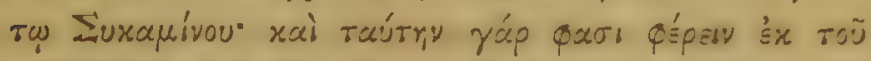

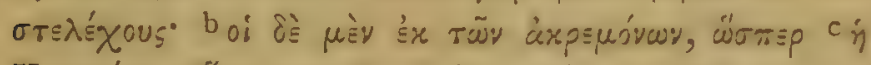

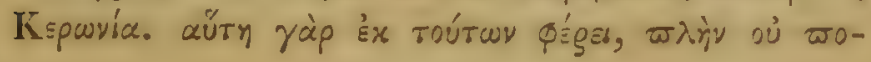

2 Bráeror Ald. Bas.

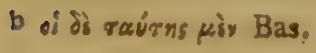

a Jaçópar Bod. Jipógary Const: c $\tau \tilde{n}$ s xepurias. Bod. 


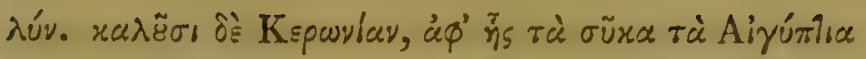

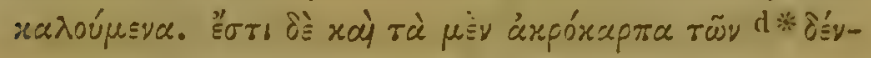

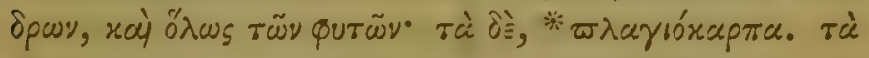

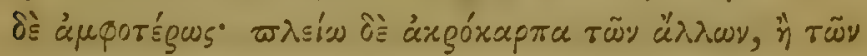

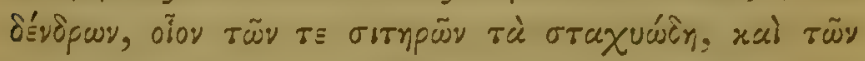

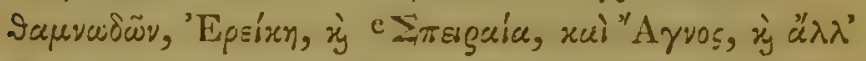

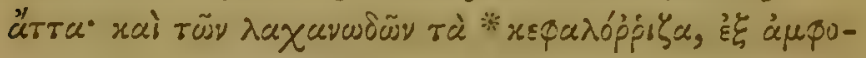

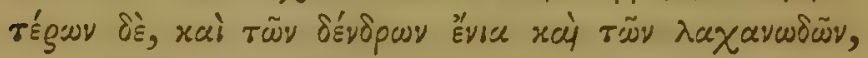

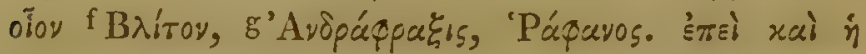

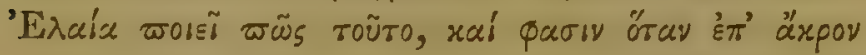

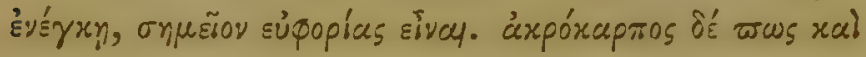

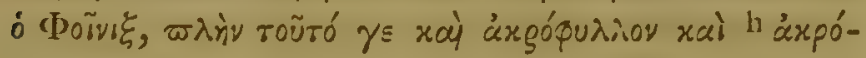

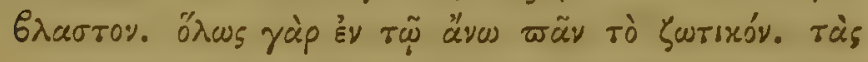

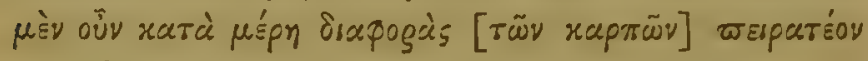

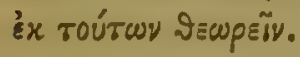

\section{CAP. XIX.}

Repetuntur Differentic Plantarum.

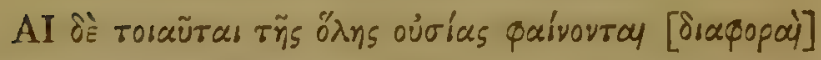

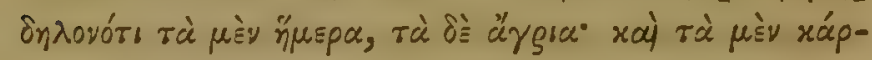

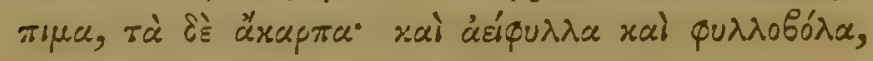

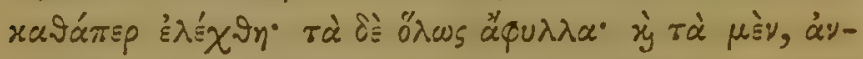

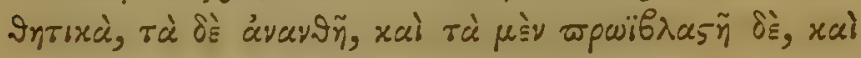

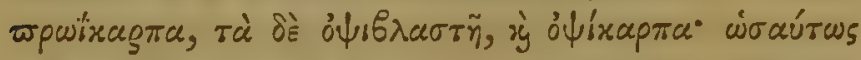

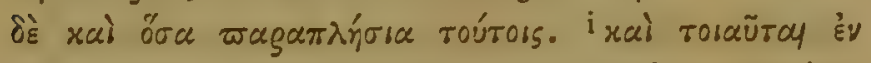

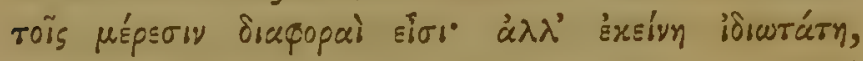

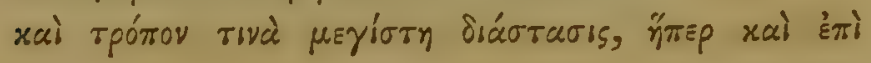
d dsvasuy, Bod.
e rugaia, Ald.
E Bairrav, Const.

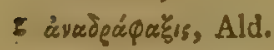
h áxp̧óezaray. Bod.
i rá $y^{3}$

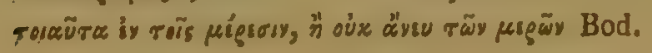




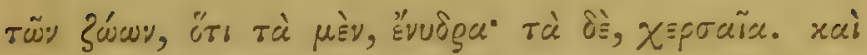

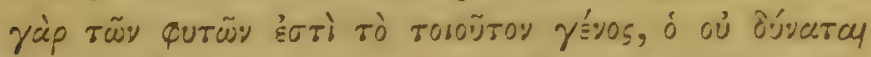

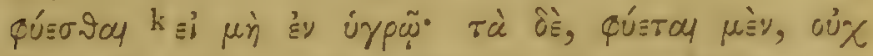

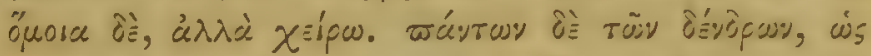

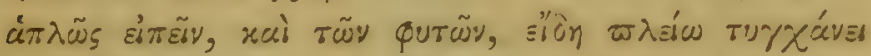

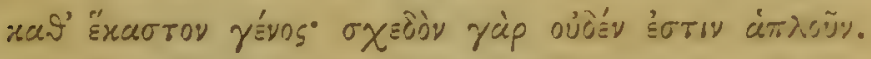

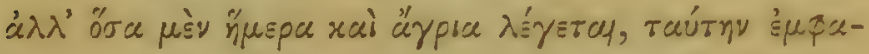

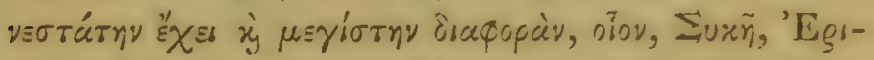

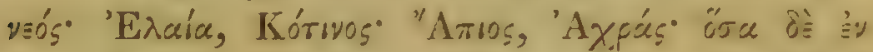

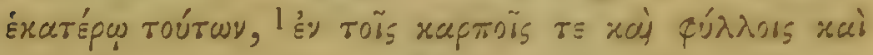

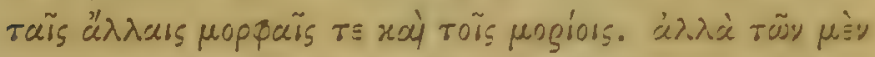

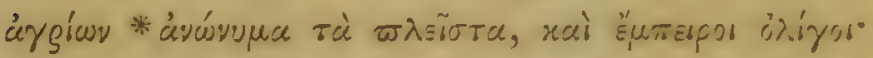

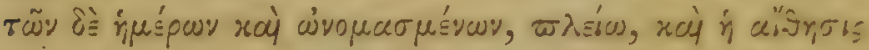

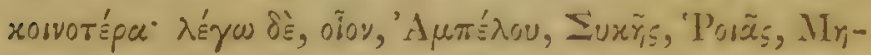

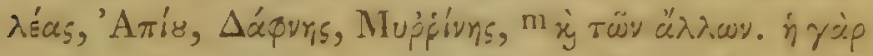

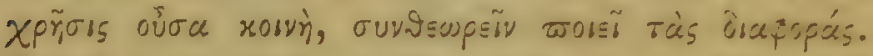

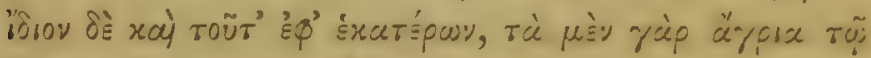

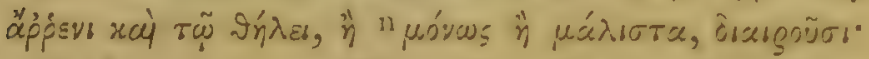

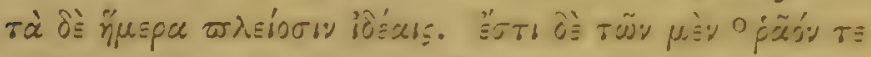

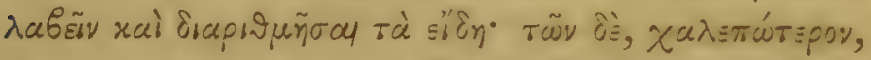

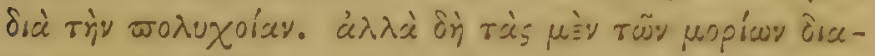

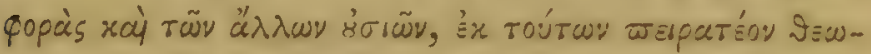

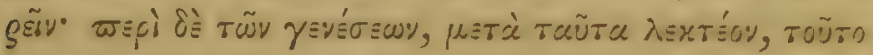

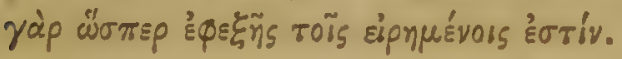

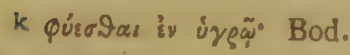

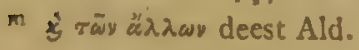

1 ì roïs xaproüs deest Ald. n peóvors Bod. $\quad$ jäsy rs Bod, 


\section{NOT}

\section{IN LIBRUM PIRIMUM.}

\section{Partes constituentes Plantarum.}

\section{CAP. 1.}

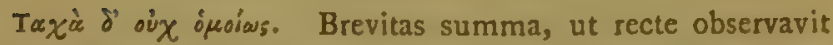
D. Moldenhawer, in comparatione Animalium cum Plantis ad finem capitis hujusce; de qua consulendus Aristoteles Hist. Anim. v. 3.

" $\Omega$ รt oủ $\delta$ sv äroxov. Vide super hac re Lib. de Caus. Plant. ii. $20,22,23$. v. 2 .

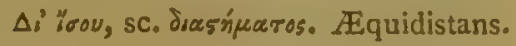

CAP. II.

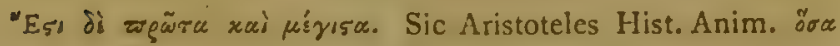

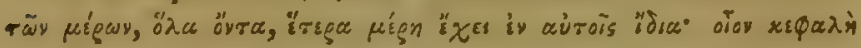
x. $\tau$. $\lambda$.

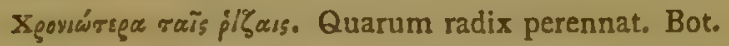

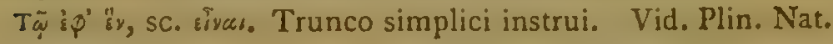
Hist. xiv. 1. 30.

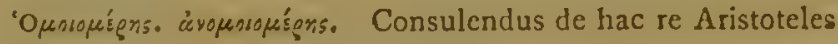
de Gen. Anim. i. 1. et Lex. Theophr.

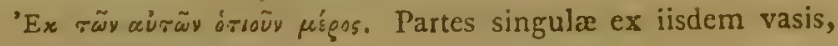
fibris, membranis, \&c.

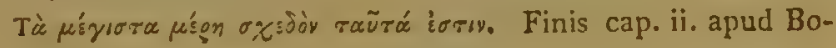
dæum.

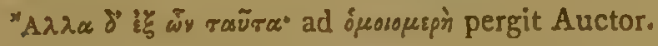

\section{A P. III.}

Msyísug. Rei Herbarix Auctor, cujus opera haud extant.

-Aywyúrews, simpliciter rò ù y̧ór.

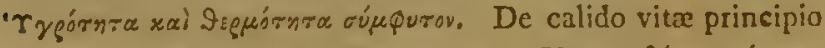

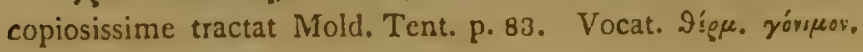


de Caus. Plant. i. 4. Confer item Galen. Ab Aristotele vocat, rò Sípper Qúosóv. ii. 3.

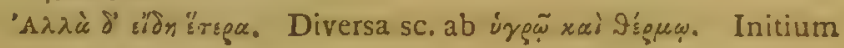
cap.iv. Bod.

'Ivàs- $\phi \lambda \_६ a ́$;. Mira sagacitas Auctoris in describendis te-

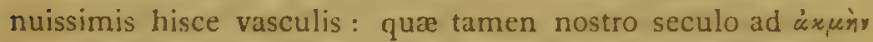
producta sunt. Copiosissime de hac re Mold. Tent. p. 31.

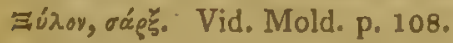

Mńrpe comparatur $\mu \nu \leq \lambda \tilde{y}$ हैy

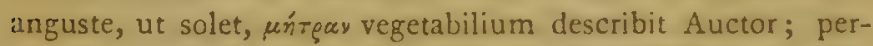
spicue tamen, si vim verborum perpendas. Alibi mentio fit, i. 9. iv. 2. De Caus. Plant. v. 6, 7, 24.

\section{A P. IV.}

'E $\phi^{\prime}$ wy $: y \delta$ ¿ $\chi \varepsilon \tau \alpha$. In is quz divisionem admittunt.

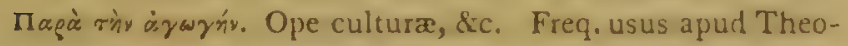
phrastum.

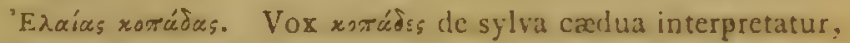
sed hic forsan de arbore decapitato.

\section{A P. VI.}

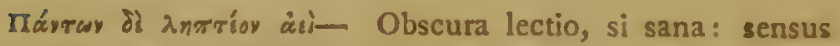

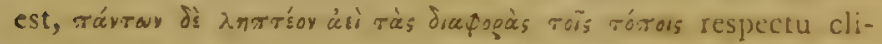
matis, \&c.

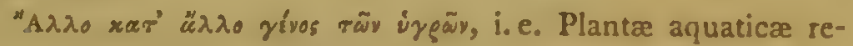
spectu rórqu inter se discrepant.

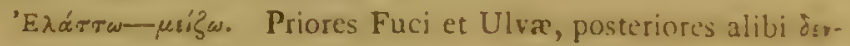
Séúpra vocati; Gorgoniæ, Corallinæ. Vid. iv. 8.

\section{CA P. VII.}

Ma $\chi^{\prime}$ s. Hic crassitiem vel molem trunci indicat. Oppo-

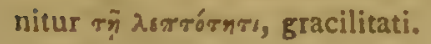

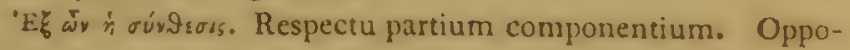

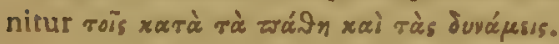

\section{A P. VIII.}

Mŕrgass. Vid, cap. iii. p. 9.1.6. N. B. Cap. IX. Bodæi.

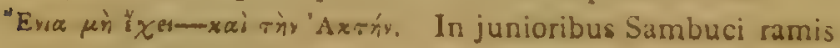
non inest medulla. 


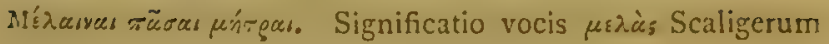
latuit. Vid. Bod. p. 24. et Lex. Theophr.

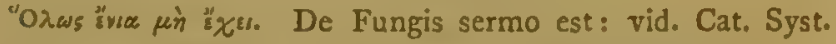
quorum nulla affinitas cum plantis aliis. Vid. Bod. p. 27.

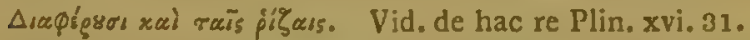

Quravádsrs. Fimbriati, Plin. sed alius sensus vocis qúravor, vittæ, fibrarum penicilli. Poll. Vid. Lex. Theophr.

$$
\text { C A P. IX. }
$$

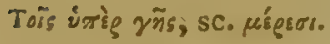

'H $\mu$ ì yà

$$
\text { C A P. X. }
$$

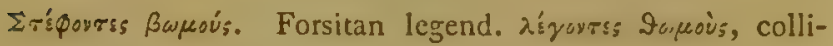
gentes acervos.

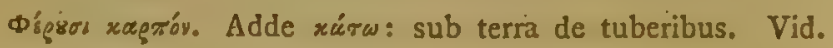
Icon. 'A

'O $x \alpha \rho \pi \delta$ 's, sc. tuber e radice.

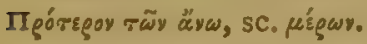

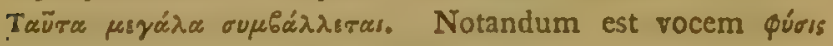
pluraliter sumendam.

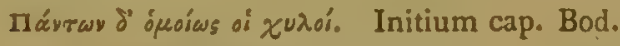

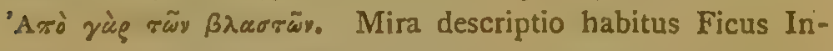
dicæ L. Angl. "The Banyan Tree."

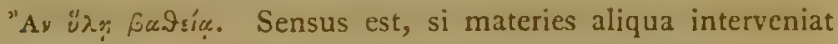

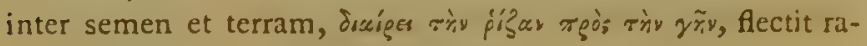
dicem versus terram donec attingat.

\section{A P. XI.}

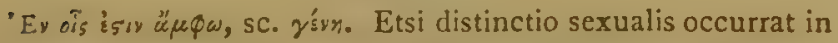
Palma, communiter tamen voces $\ddot{\mu p \rho p \eta v, ~} จ \tilde{n} \lambda v_{5}$ varietatibus specierum attribuuntur, utpote quar robustiores et infructiosiores, vel e contra observantur.

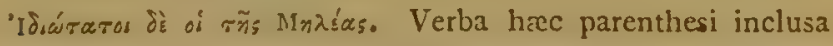
ex margine irrepserunt, ut suspicor, et descriptionem habitus

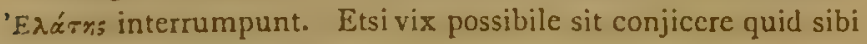

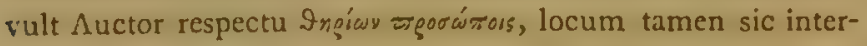
pretatur Plin. Nat. Hist. 1. xvi. c. 30. "Malis proprium genus 
"ramorum, ferarum enim rostra reddunt, adharentibus uni " maximo minoribus."

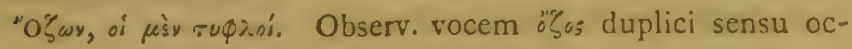
currere, ut ramus, et nodus in trunco.

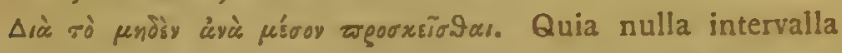
sunt. Scal.

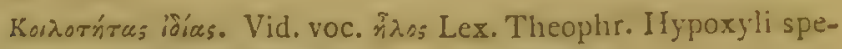
cies, ut suspicor. Vid. iv. 16.

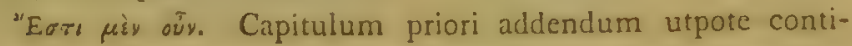
nuatio.

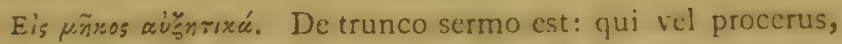

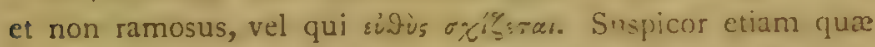

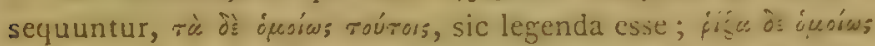
roúrols. Sic Virgilius: "Quantum vertice ad auras æethereas "tantum radice ad Tartara."

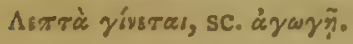

C A P. XII.

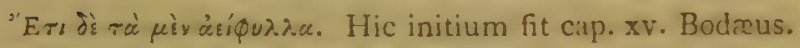

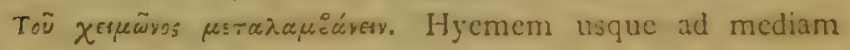
durare.

\section{A P: XIII.}

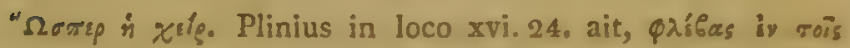
zęarésy, "incisuras subter," id est, lineas cavas, ut in palma manus.

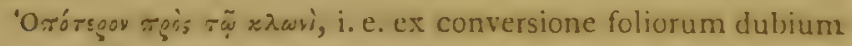

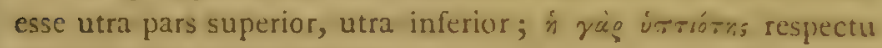
situs, diversa a folii natura.

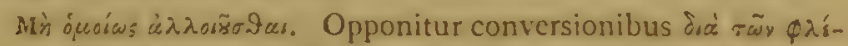
Cwy ทै ivãy, i. e. non modo constanti, regulari.

Bááos doïò interpretandum de crassitudine folii.

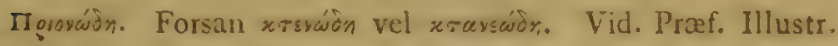
'Theophr. p.v. Item descr. 'E2а́zrs, 1. iii.

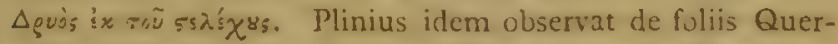
cus, Nat. Hist. xvi. 24. Bodæus ait se nunquam observasse. Suspicor errorem textus: legend. forsan kurgía. Vid, de

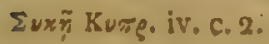




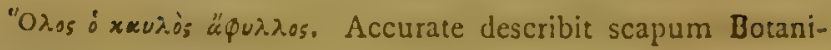
corum.

Ai aùroũ. Ex seipso: de folio sessili. Bot.

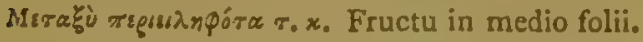

C A P. XIV.

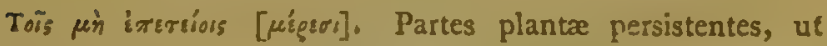

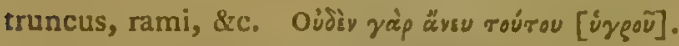

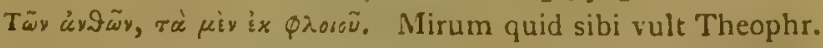
Flores ex cortice et nervis. Error certe textus, et legendum

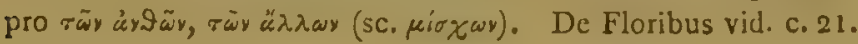
22.

\section{CA P. XV.}

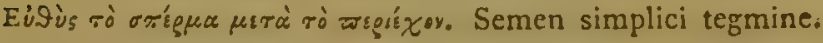
In hoc capite sex notantur seminum genera, quorum enumeratio confusa et pralonga. Hæc sunt 1. sem. simplicia

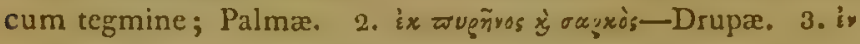

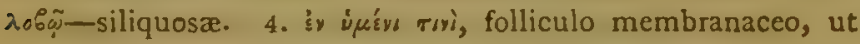

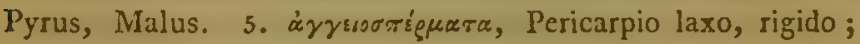

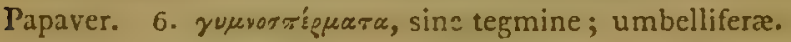

Oĩoy í $\dot{p} a \xi^{\prime}$. Hic loci textus corruptissimus. Distinctio

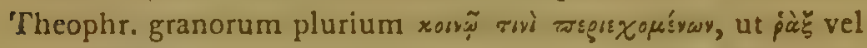
yírąrov in uva: itemque in semine. N. B. II ugñves Mali Granati opponuntur granis singulis Tritici \&c. " $\mathrm{H}$

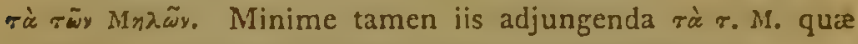
in parte interiore fructus membranis circumvolvuntur.

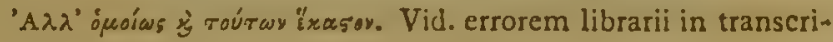

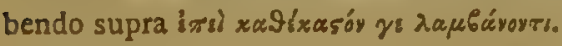

\section{CA P. XVI:}

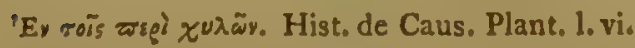

Oẹidaxivrs. Succus idáęns dicitur minus recte. Fors. efror textus, utpote supra pro izwóons de succo Ficus et Papaveris yaraxrúòns ponend.

"Hлє̨ oixwa. Sensus est, succum peculiarem cujusvis plantæ

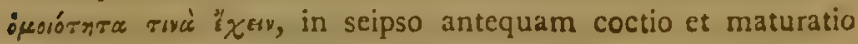
fiat in fructu quæ efficitur ope pericarpii. 
'Evisy süorper. Vid. fusius de odoribus Theophr. de Caus. Plant. 1. i. 6. ut et de succis.

\section{CAP. XVII.}

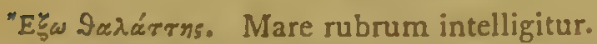

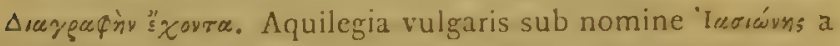
Botanicis plerisque indicatur; et descriptio, etsi intricata, mire

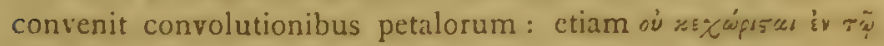
üvast.

N.B. Quibusdam forte magis arridebit Bodæi conjectura,

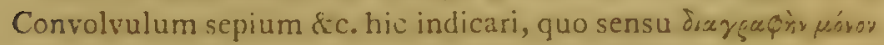

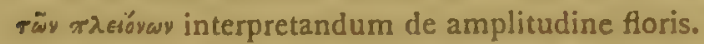

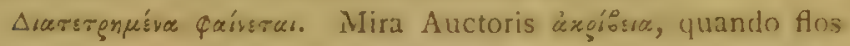
foratus, i.e. sine stigmate decidit, fructus incipiens manet;

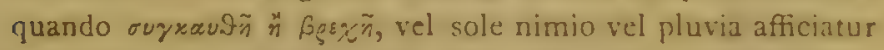

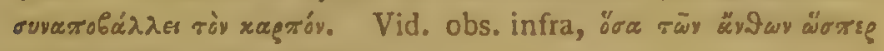

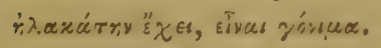

'Eт⿱一⿻上丨⿱⿰㇒一乂 orópe igitur receptaculum commune in hac classe.

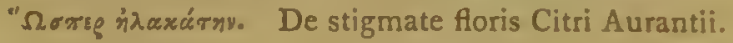

Eisì̀s reopaivesy ròy xagròv, i. e. sine flore vel petalis.

\section{CAP. XVIII.}

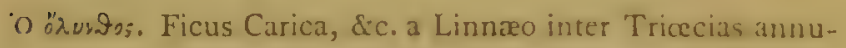

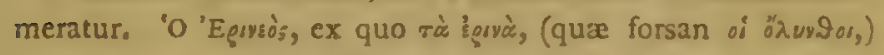

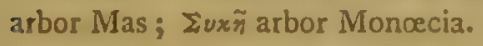

$$
\text { C A P. XIX. }
$$

Ai di rouṽ $r \alpha$. Summarium et recapitulatio libri hujus.

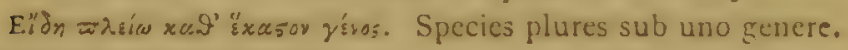
Distinctio vere Linnæana!

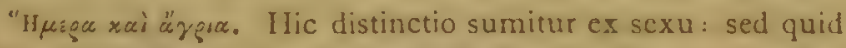
sibi vult? Plantas sylvestres sexu distingui, cultas vero räácon, idsaus; anne indicat varietates fructuum? 



\section{$\Theta \mathrm{EO} \Phi \mathrm{P} A \Sigma \mathrm{TO} \Upsilon$}

\section{IIEPI $\Phi \Upsilon T \Omega N$ I $\Sigma T O P I A \Sigma$}

TO B'.

CAP. 1 .

De Modo Generutionis Sutionisque in Arboribus.

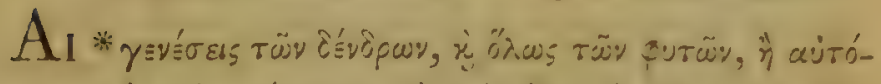

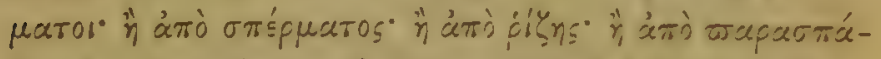

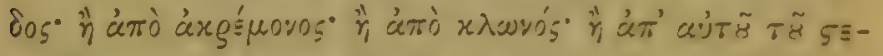

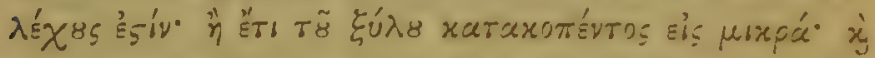

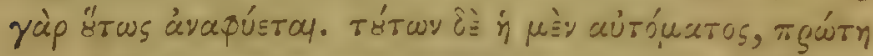
ті́弓

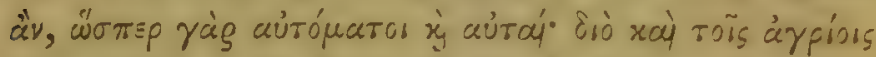

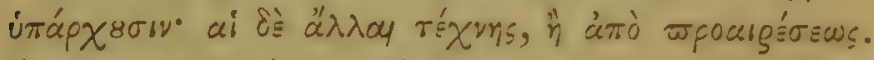

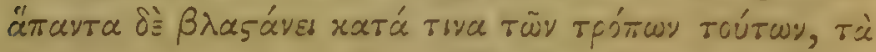

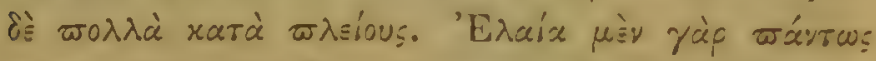

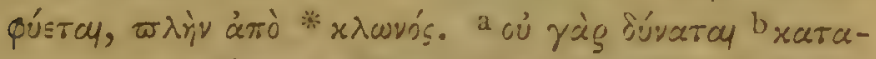

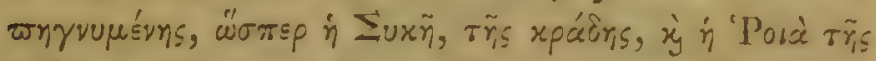

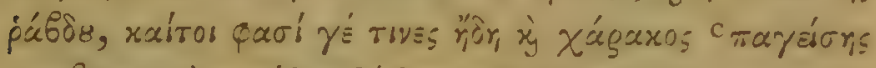

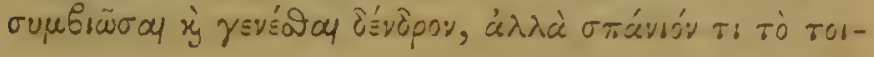
2 xai où Ald.

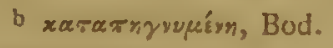
c $\pi$ agrifrs,

xai rģos rì Karròr cupliw̄oal Bod.

E. 2 


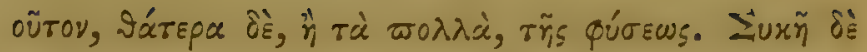

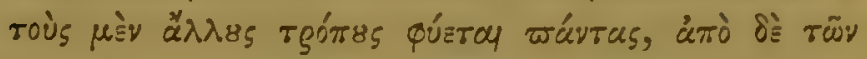

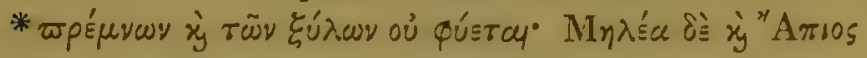

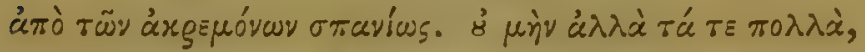

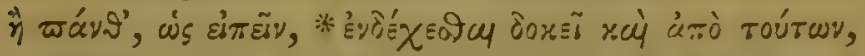

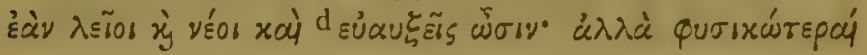

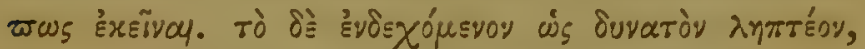

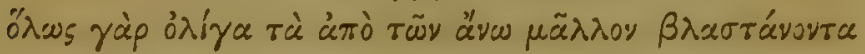

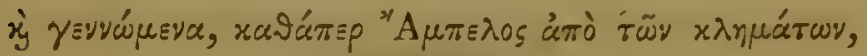

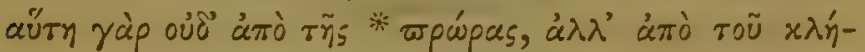

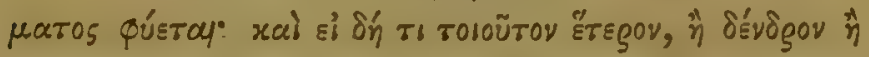

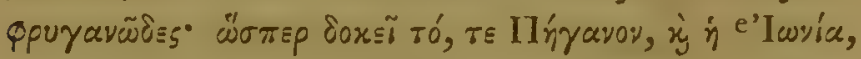

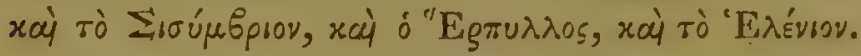

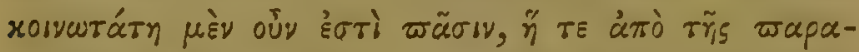

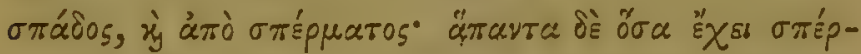

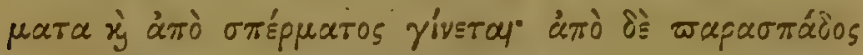

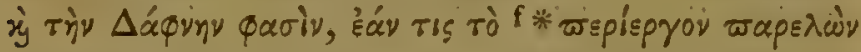

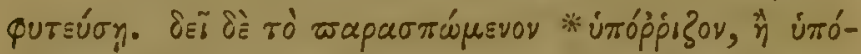

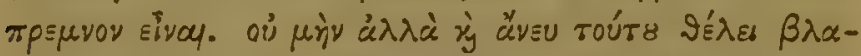

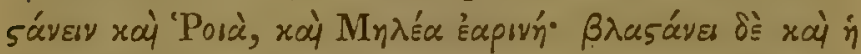

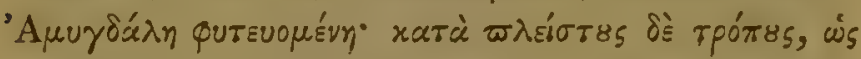

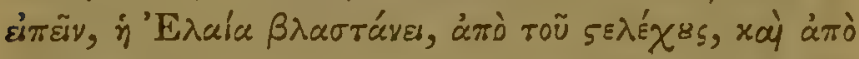

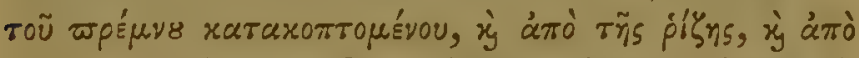

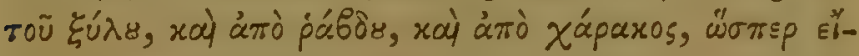

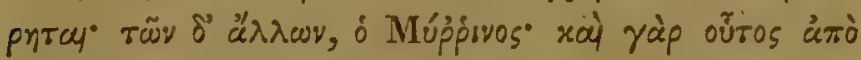

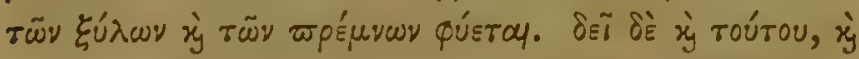

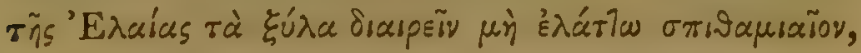

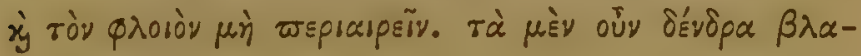
d aỉรูสั Bas.
- wivía, Bod.
f ròr xigixoura Ald. 


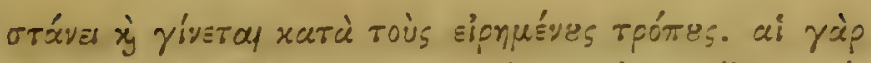

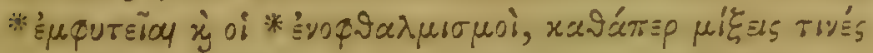
Ei

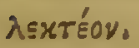

\section{CAP. II.}

Quomodo Suffrutices, et Herbce, itemine Arbores nuscantur.

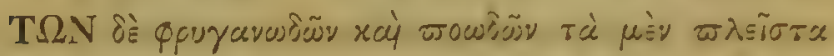

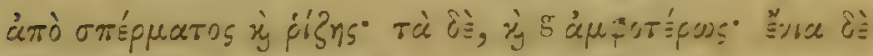

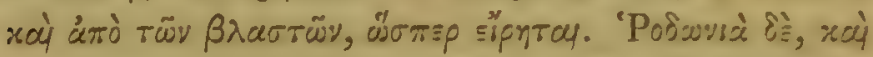

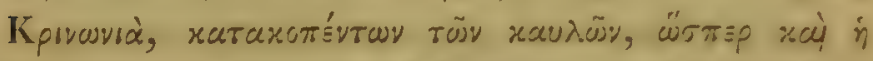

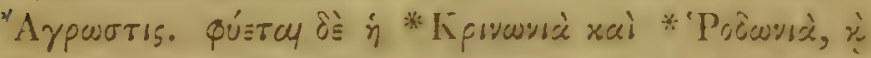

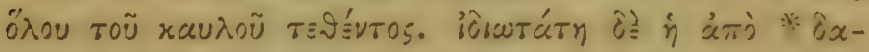

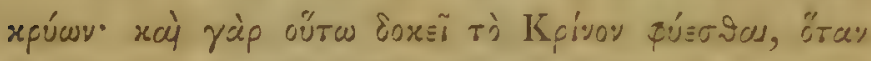

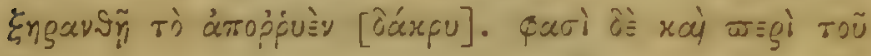

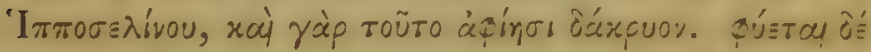

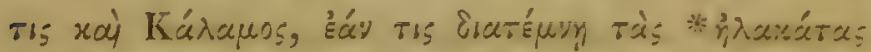

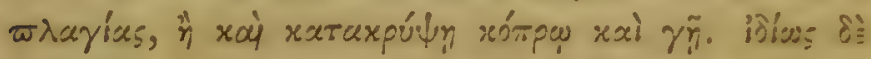

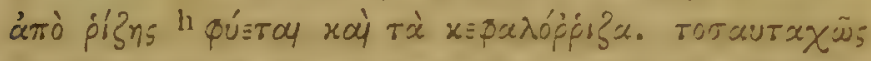

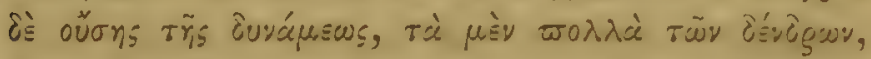

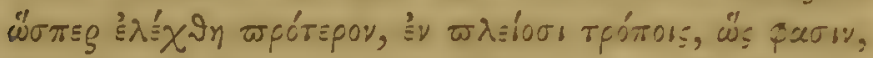

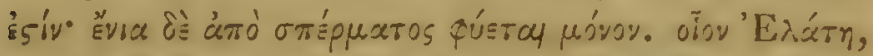

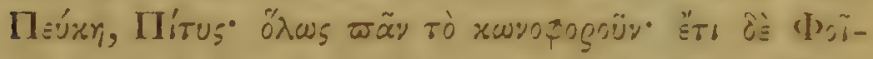

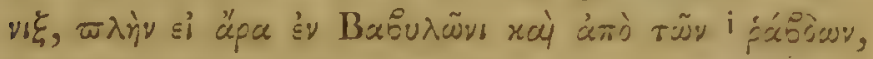

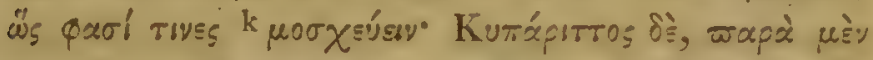

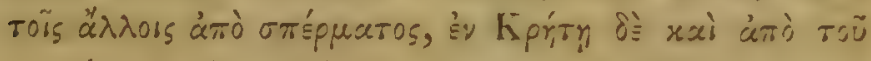

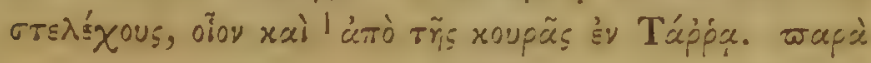

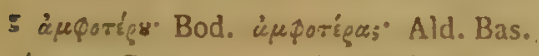

1 cúdras" Const. iogers Alk. Bas.

$k \mu \omega \lambda$ úcsy, Ald. Bas. h Fús-Tai Boil.

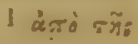




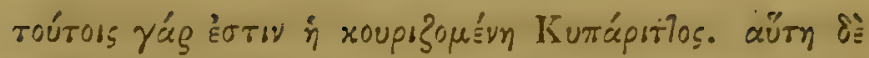

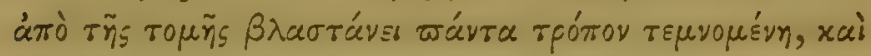

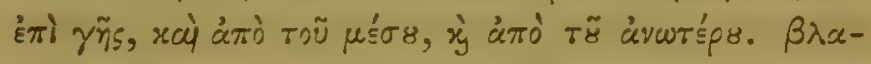

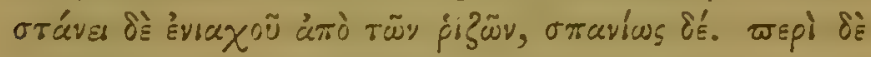

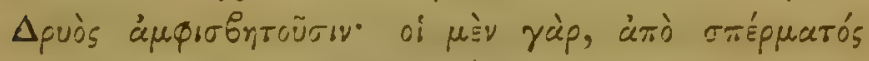

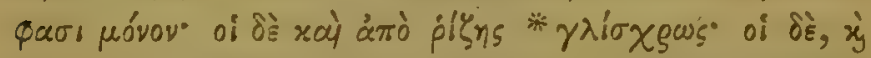

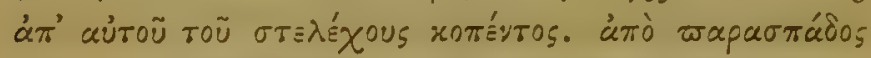

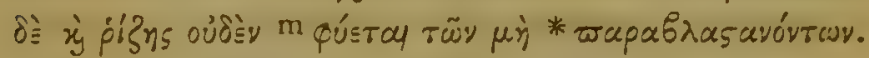
árर́์

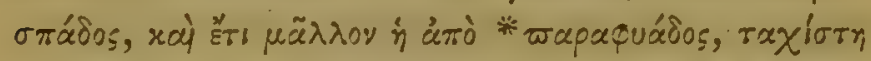

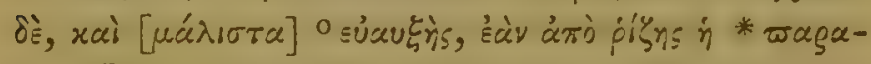
Quàs गु.

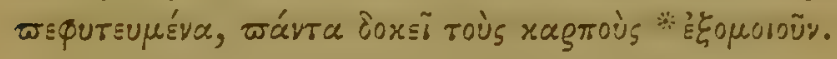

\section{CAP. III.}

Quamobrem degenerent aliquando Satu: qua non degenerant, sed meliore quoque fiunt, etiam in Arboribus.

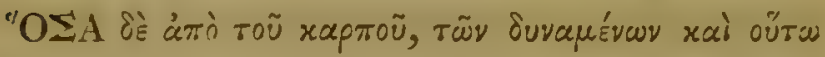

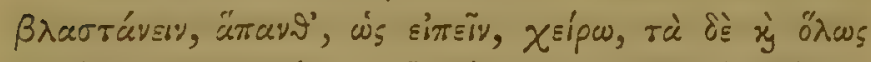

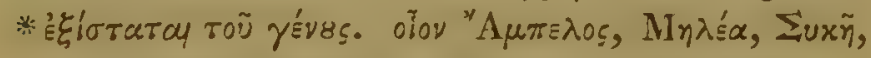

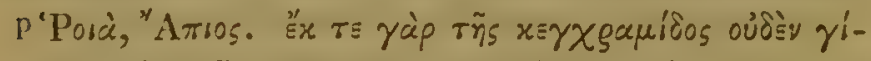

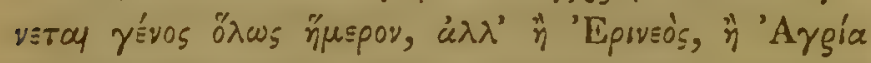

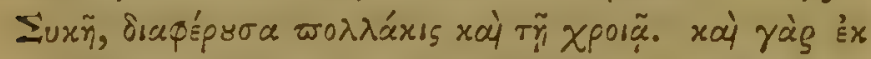

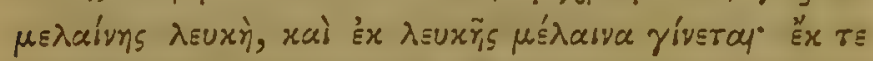

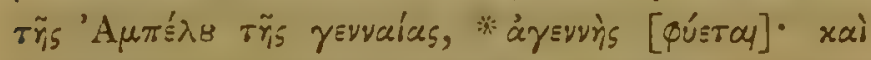

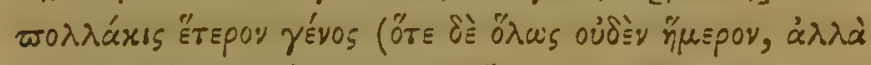

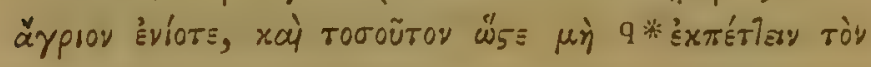

1 Qúsodal Bod.

P 'P pà̀, Const.

n ai Ald. Bas.

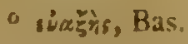

$q$ ixrixisuy Const. 


\section{MEPI TYTSN ISTOPIA TO B'.}

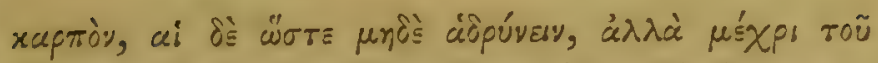

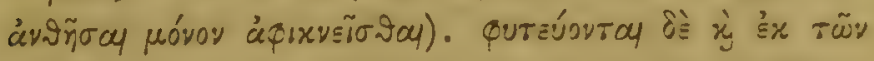

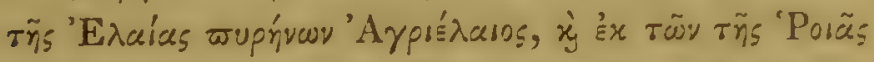

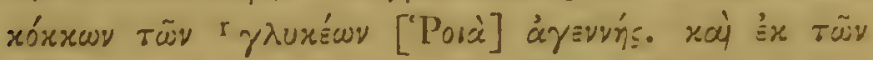

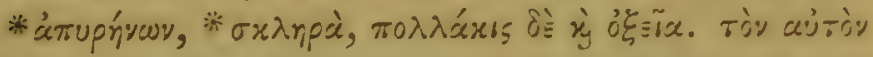

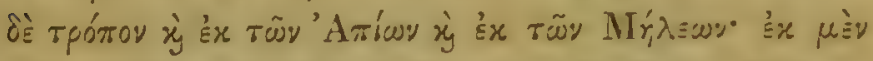

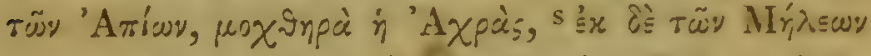

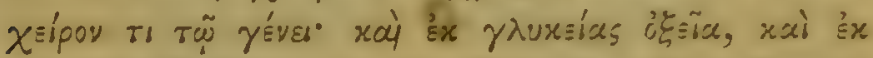

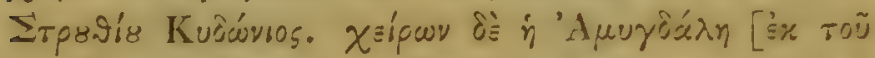

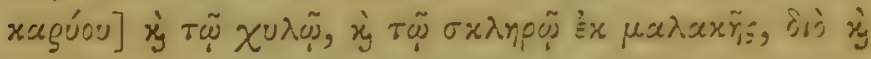

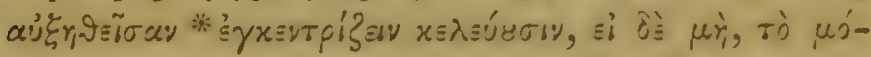

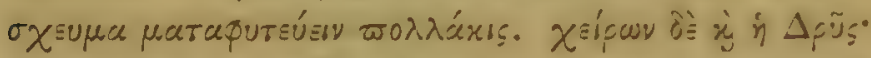

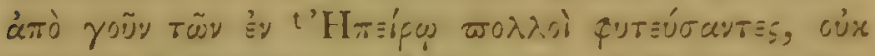

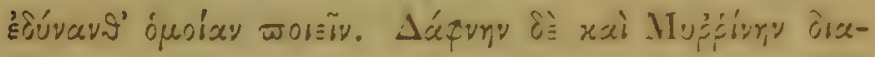

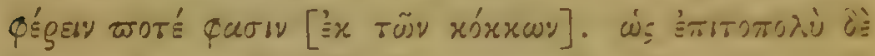

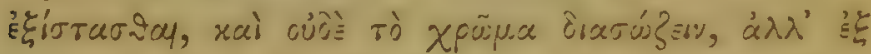
É

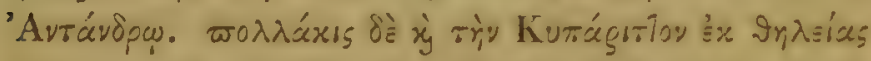

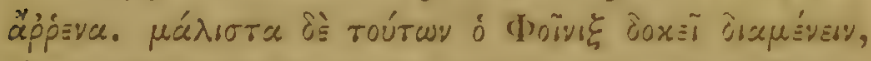

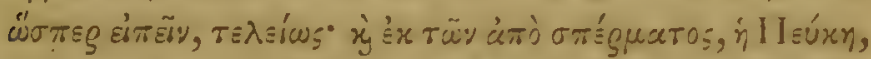

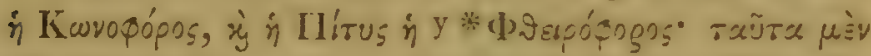

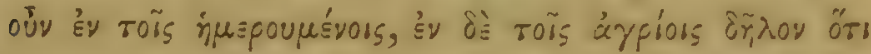

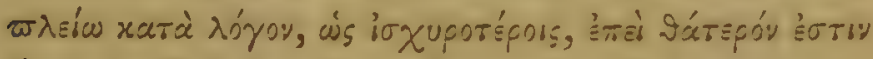

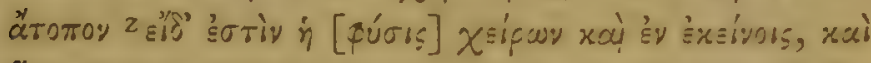

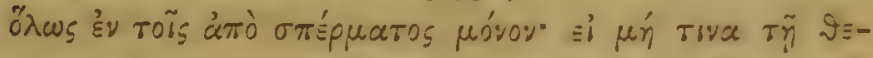

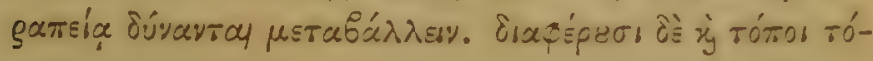

\&rauxeiw Ald. Bas.

- ITúppó Ald. Bas.

y posporoiós. Ald. Q9ligotoiós" Const.

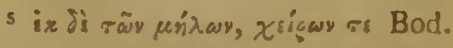

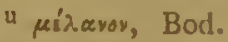

$x$ riv Bod. 2 "15 deest Bod.

E. 4 


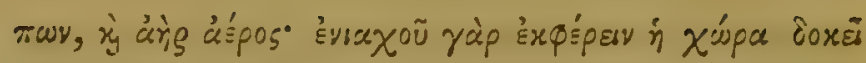

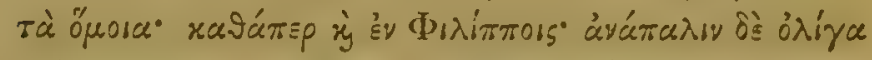

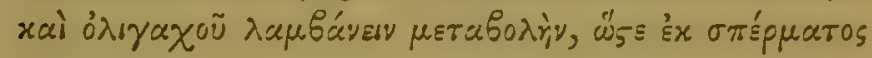

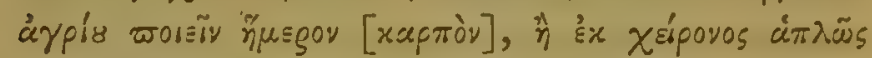

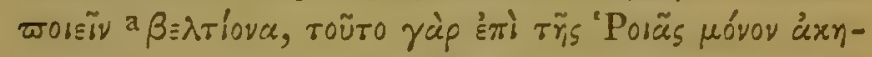

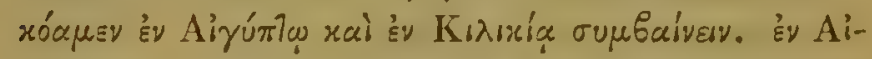

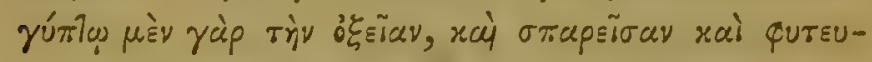

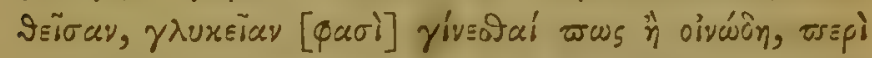

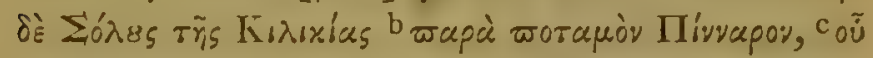

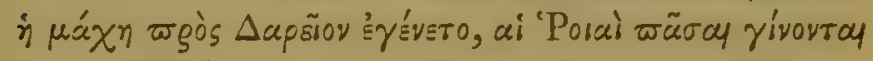

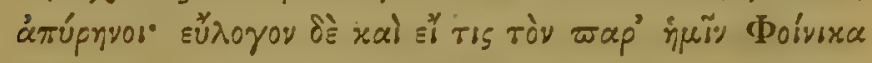

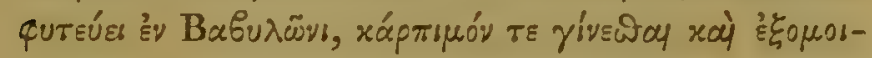

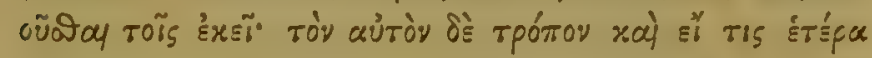

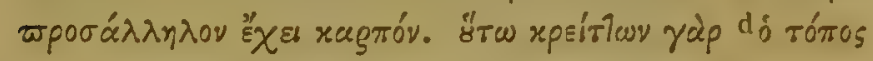

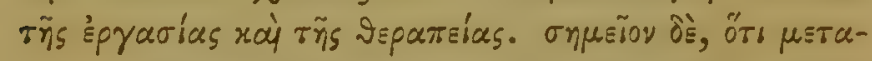

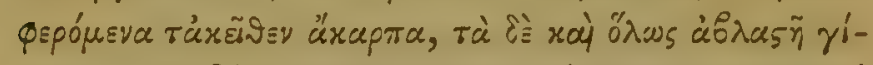

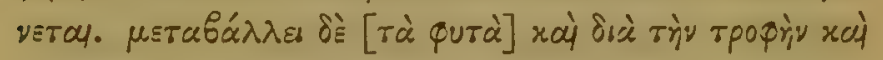

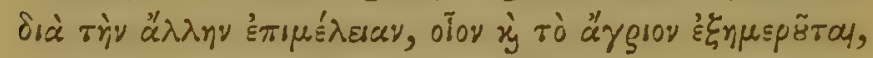

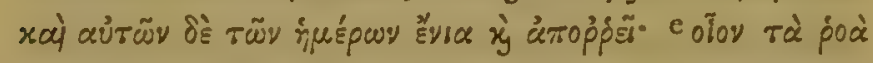

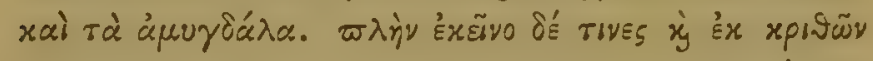

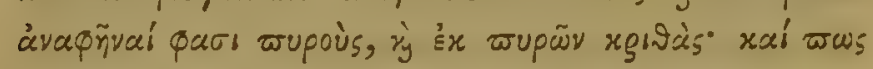

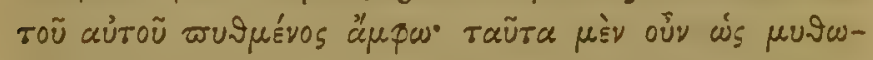

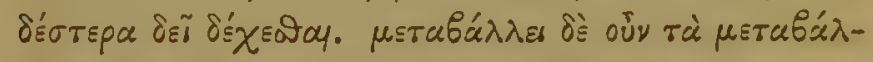

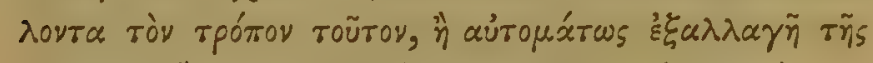

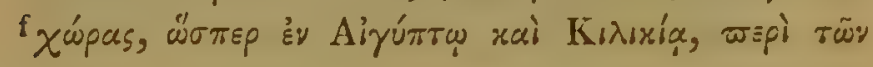

a Gínzioy, Ald. Bas.

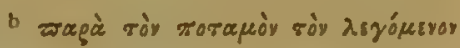

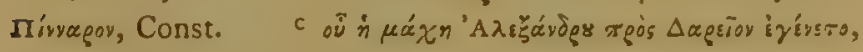

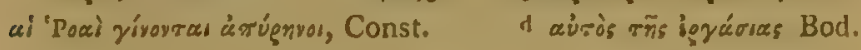

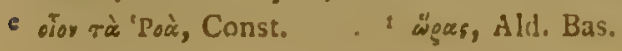




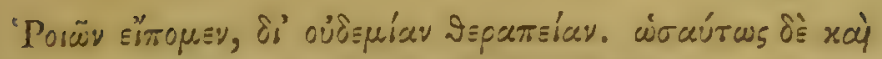

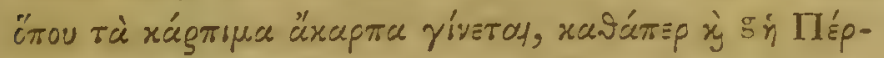

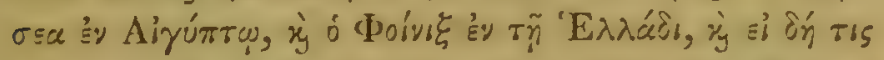

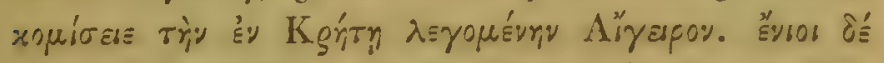

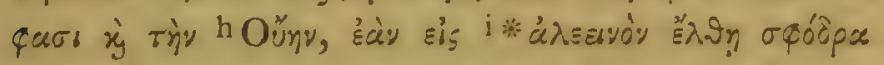

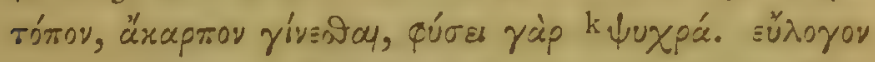

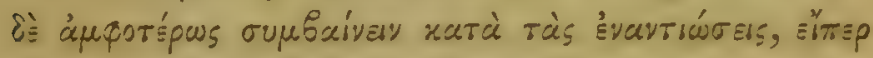

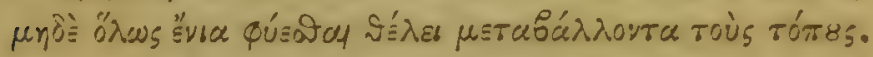

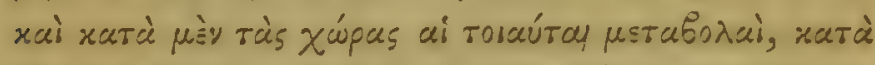

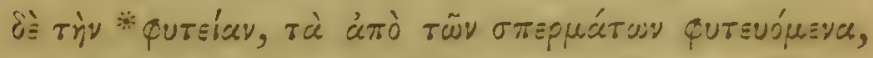

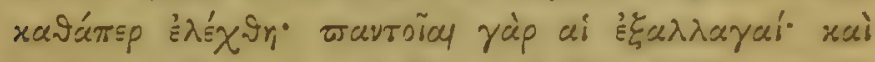

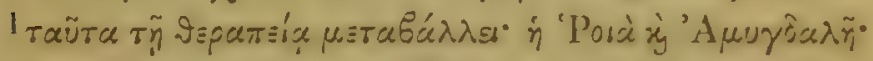

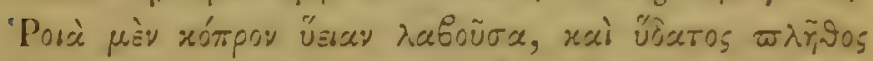

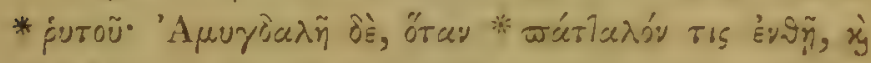

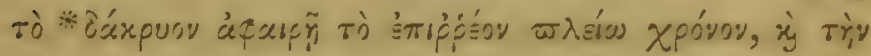

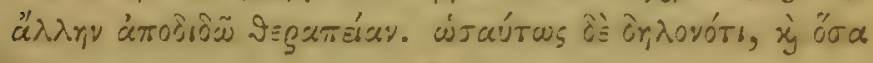

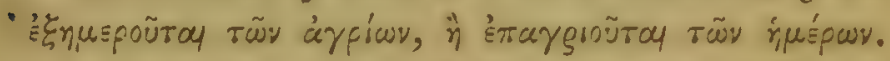

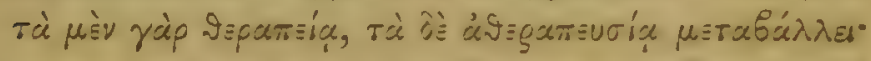

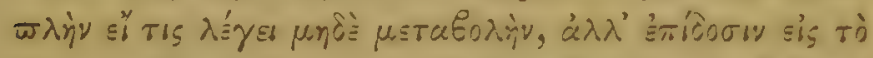

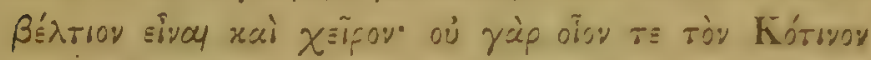

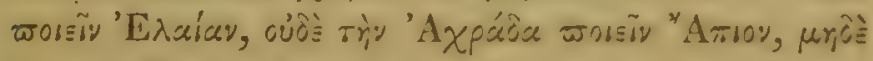

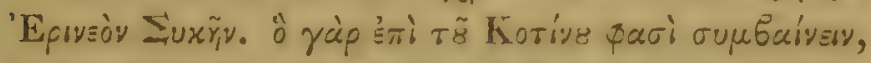

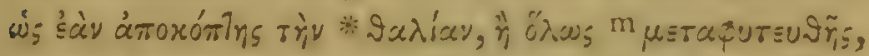

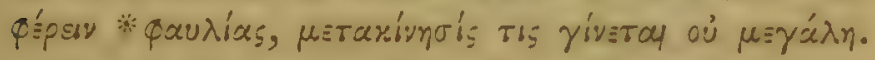

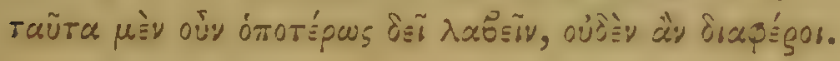

g tì Irégorov Bod.

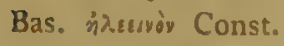

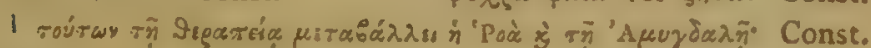

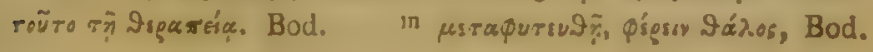




\section{CAP.TV. \\ Ostenta in Arboribus.}

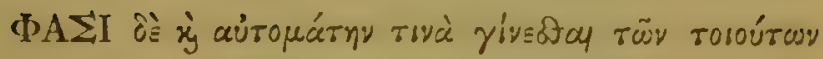

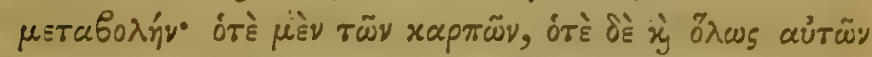

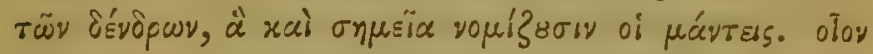

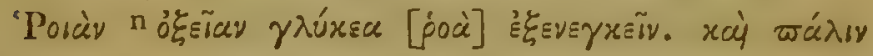

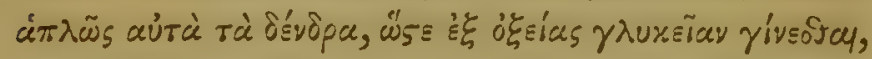

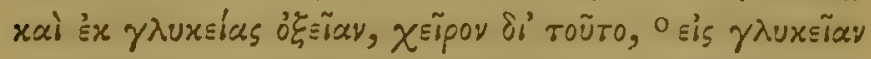

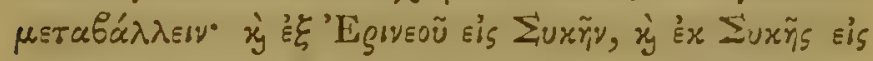

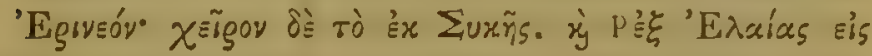

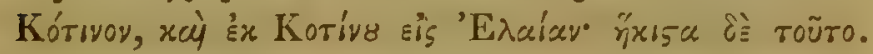

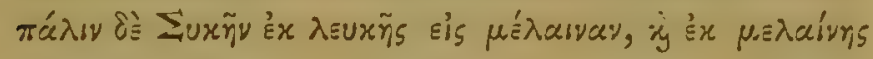

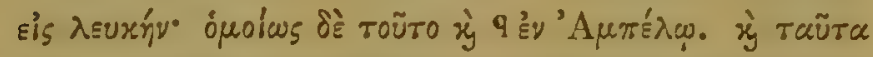

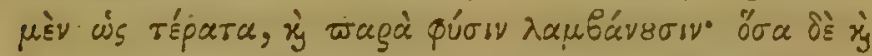

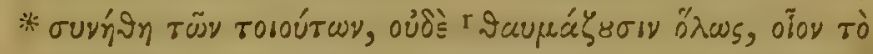

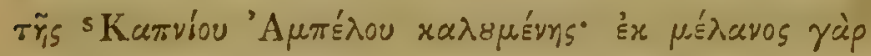

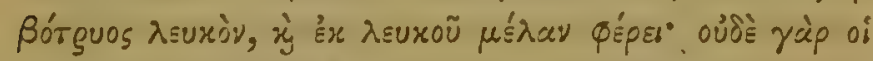

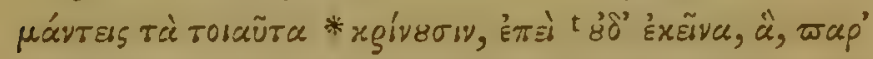

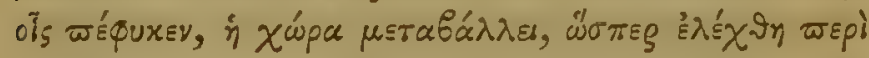

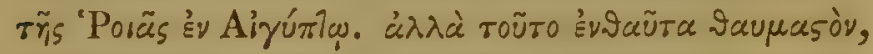

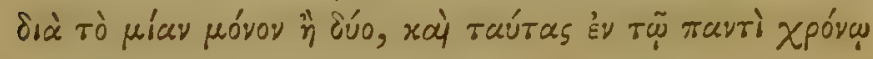

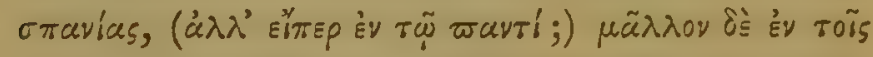

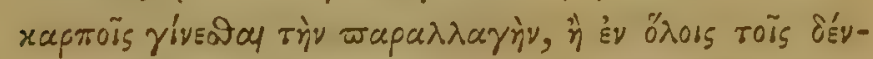

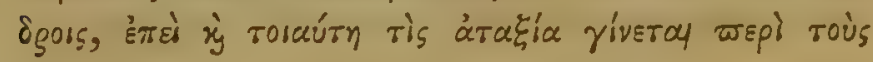

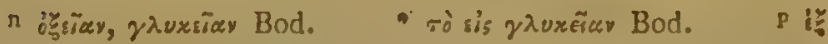

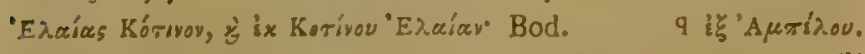

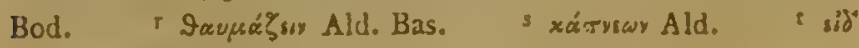
ixsive rag. or's Bod. 


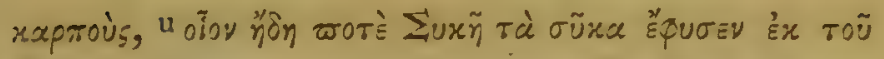

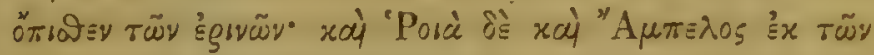

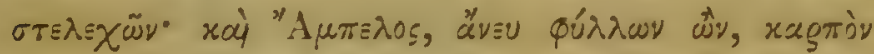

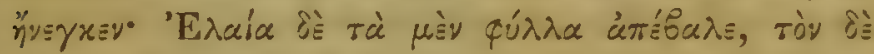

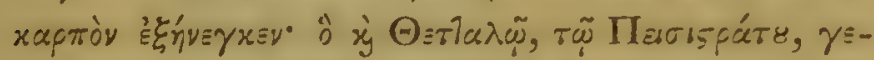

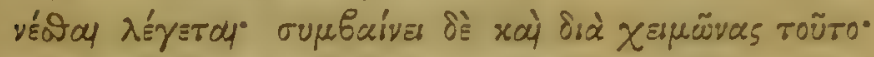

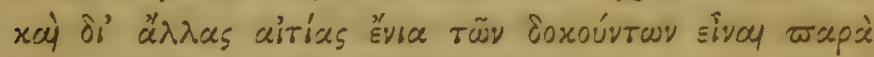

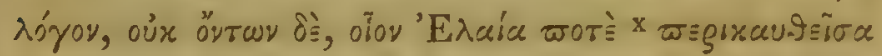

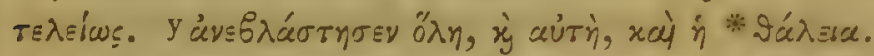

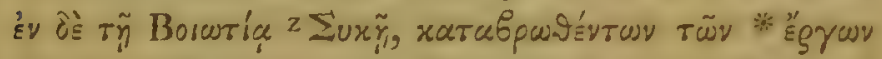

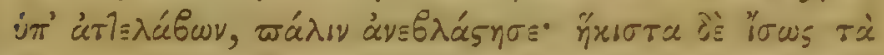

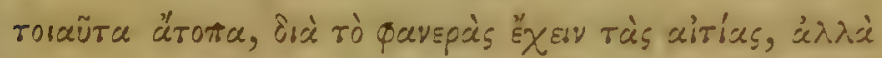

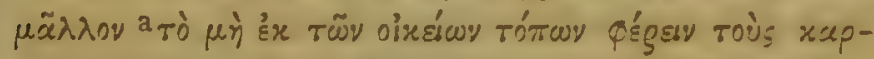

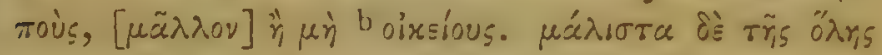

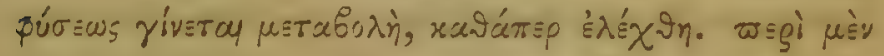

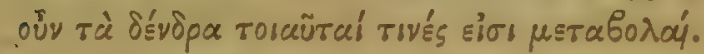

\section{CAP. V.}

Que Ilerba degenerent, melionescantic. Sisymbrium in Mentham; Triticum in Lolium. Legumina coctibilia et incoctibilia: et quo pacto crassescant.

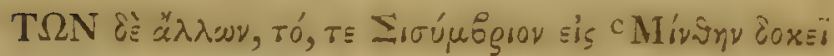

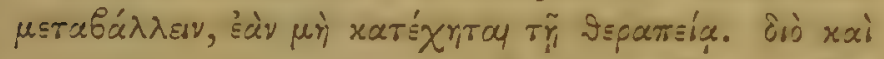

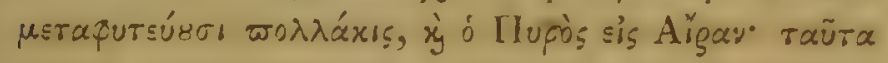

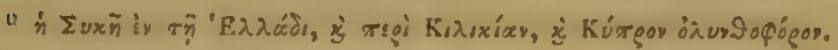

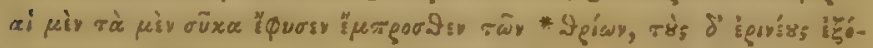

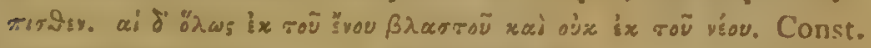

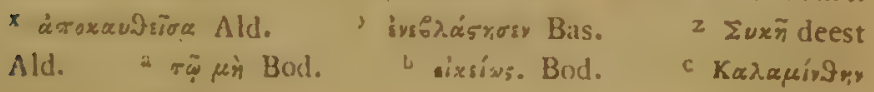
ex Plin. Const. 


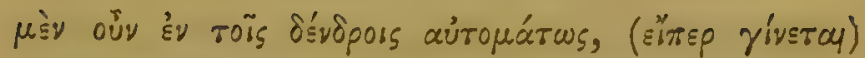

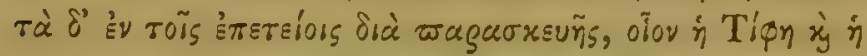

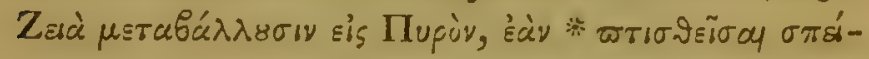

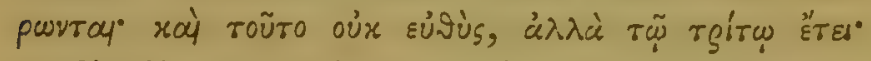

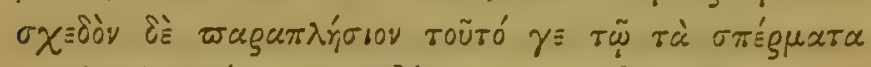

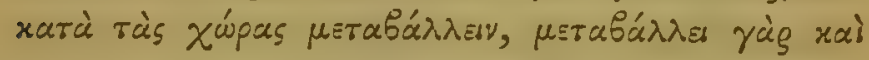

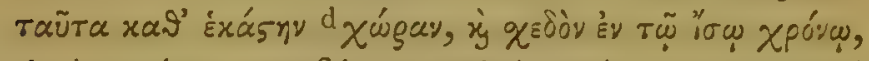

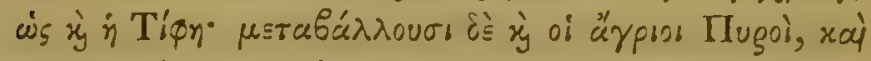

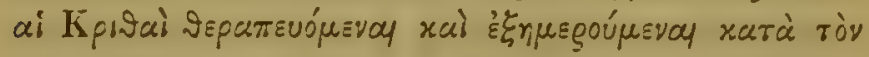

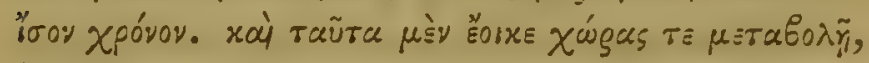

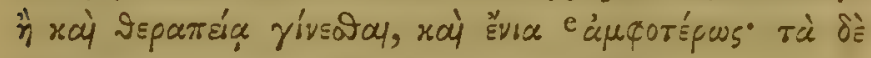

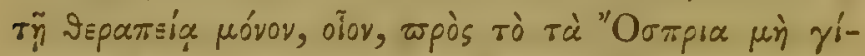

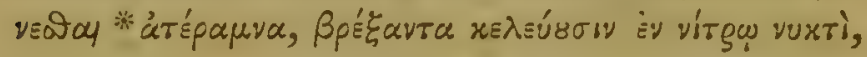

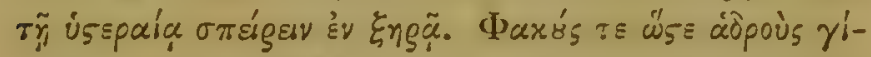

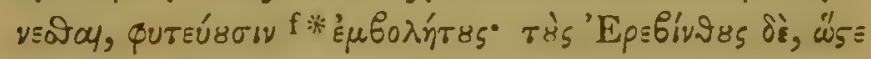

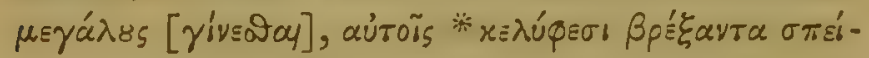

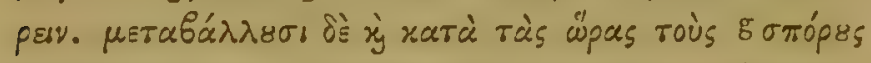

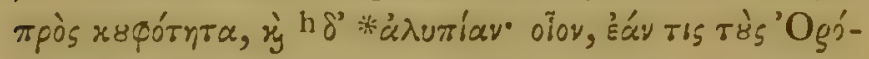

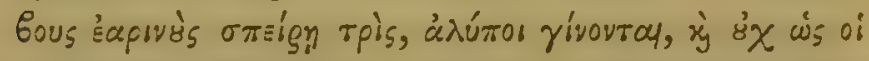

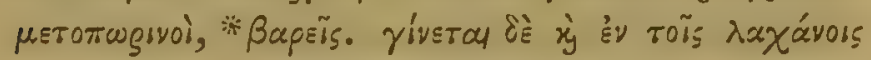

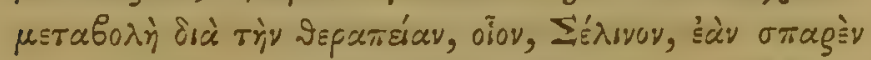

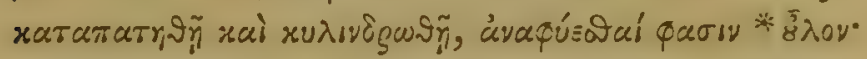

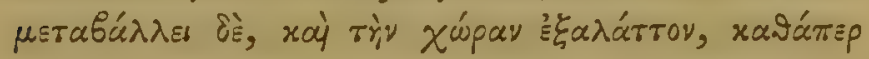

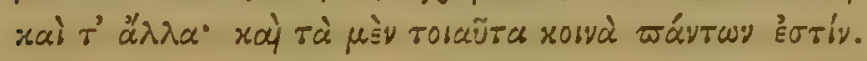

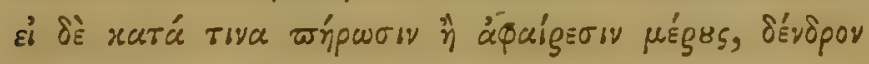

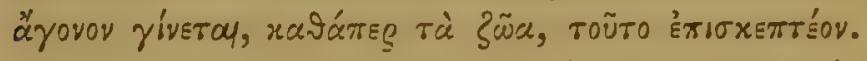

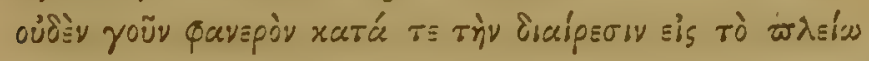
i) w̧axy, Bod.

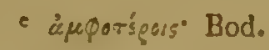

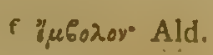

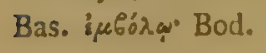 g. sógrs Ald. Bas. Bod.
b $\delta_{i} \dot{\alpha} \lambda v-$ rion. Bod. 


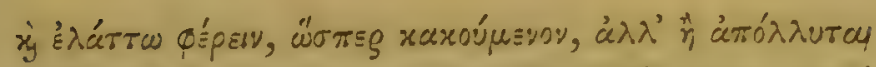

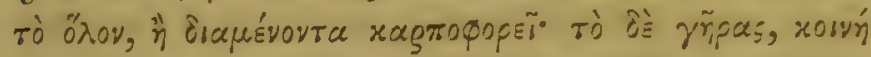

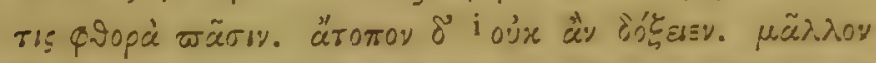

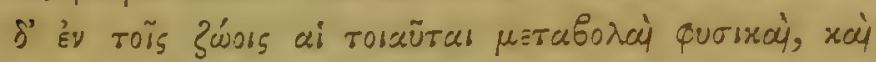

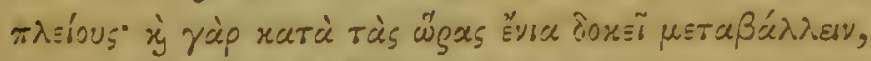

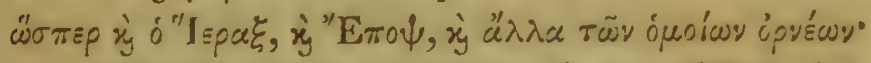

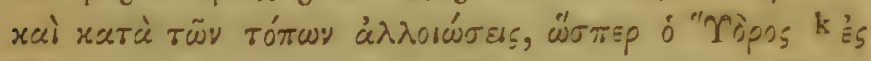

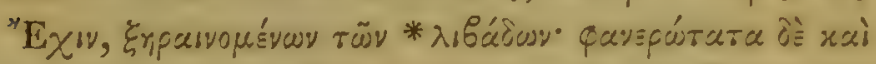

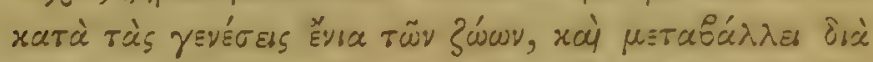

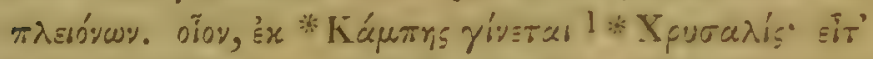

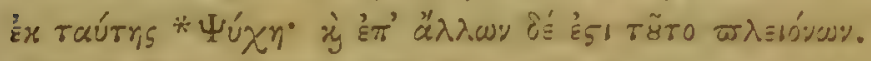

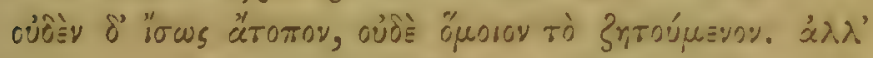

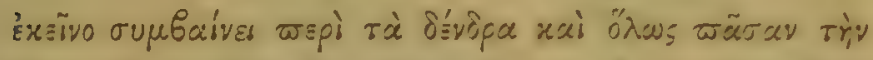

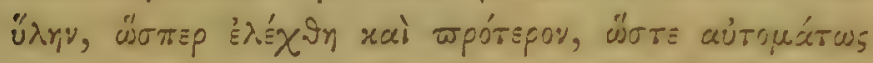

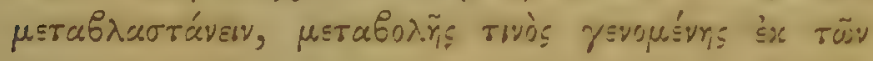

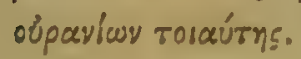

\section{CAP. VI.}

Propagationes Artorum er Semine. Stolonilus, Surculis; ilem per Insitionem.

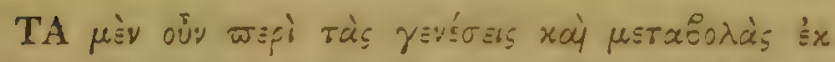

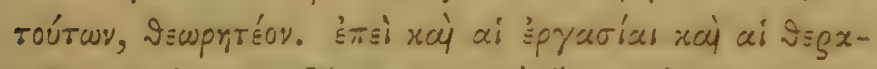

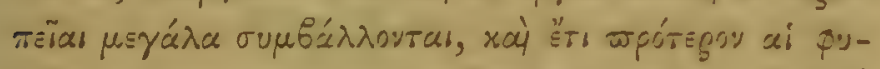

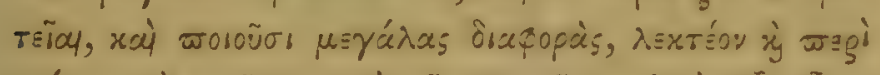

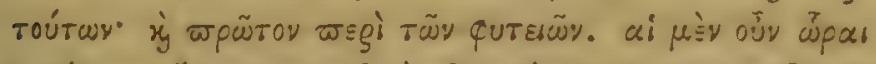

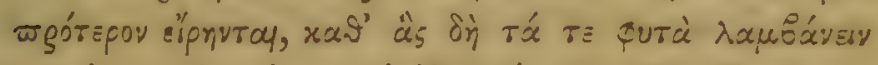

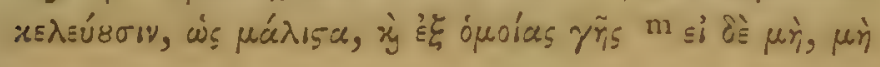

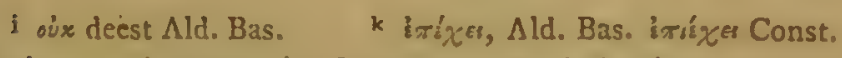

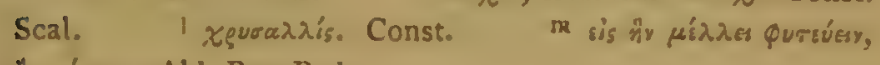

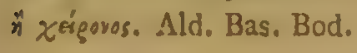




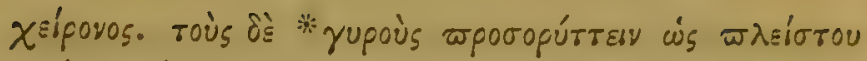

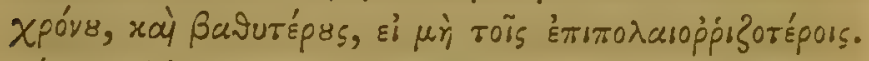

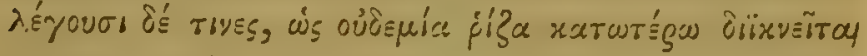

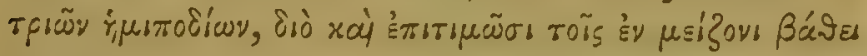

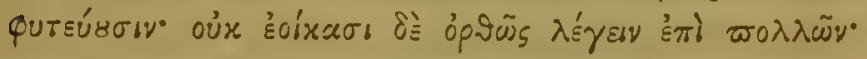

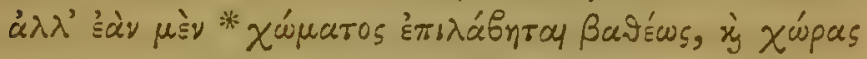

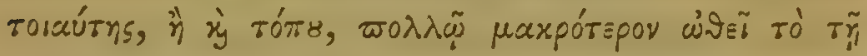

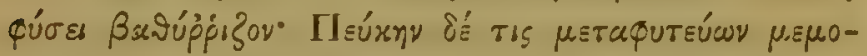

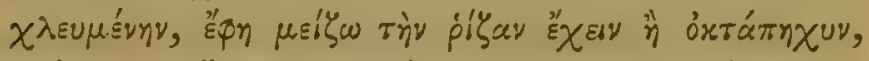

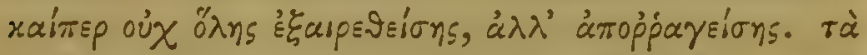

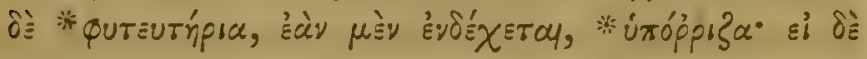
$\mu \grave{\eta}, \delta \approx \tilde{i} \mu \tilde{a} \lambda \lambda \circ v$ n

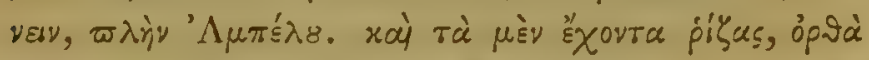

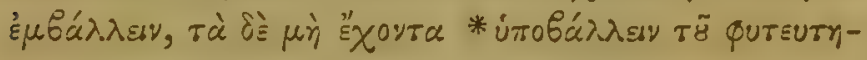

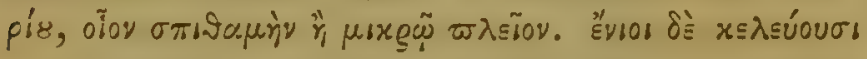

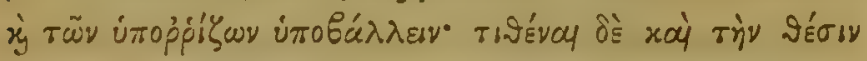

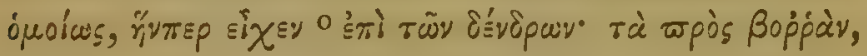

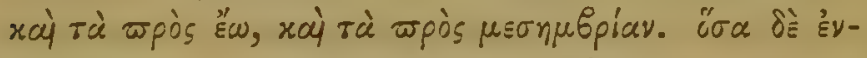

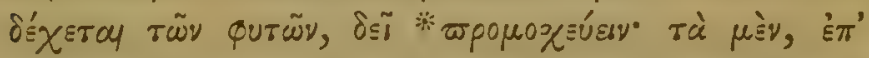

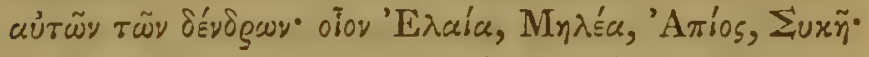

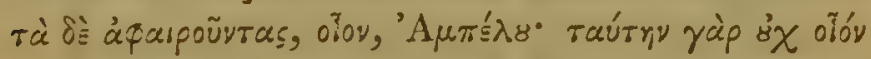

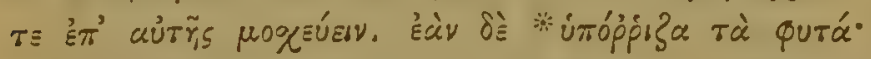

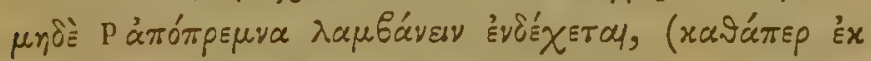

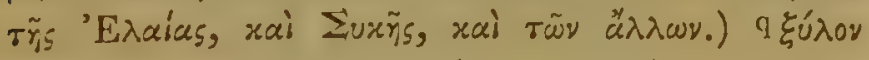

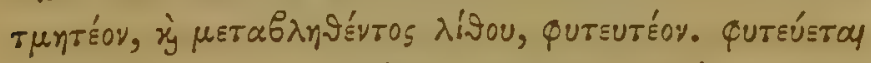

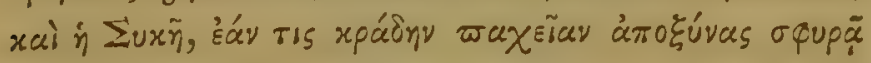

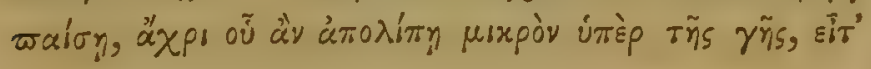

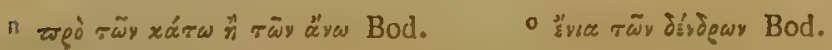

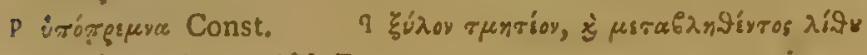
puriurioy omittunt Ald. Bas. 


\section{IIEPI IPT $\Omega N$ IITOPIAS TO B'.}

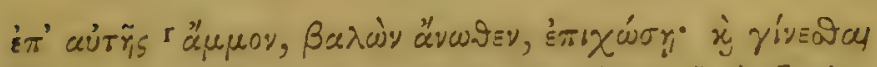

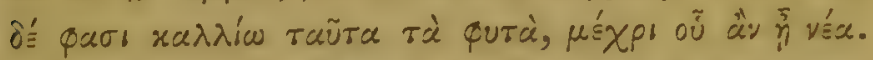

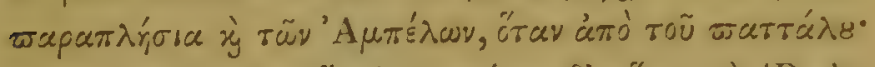

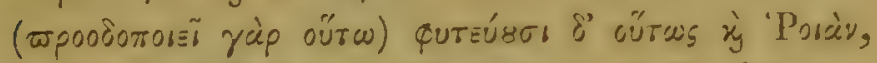

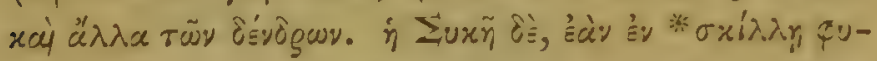

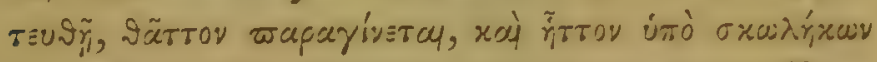

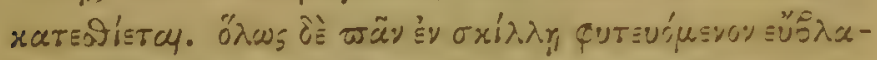

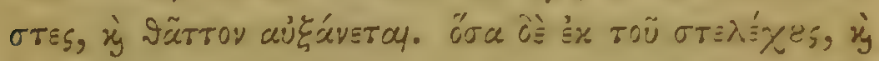

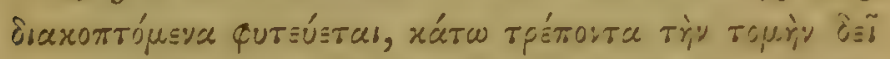

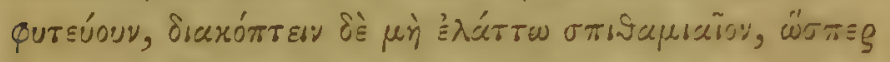

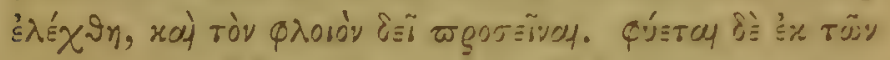

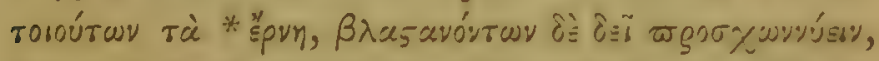

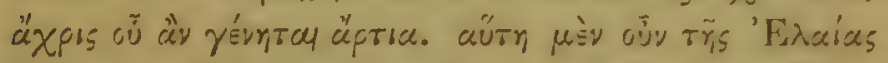

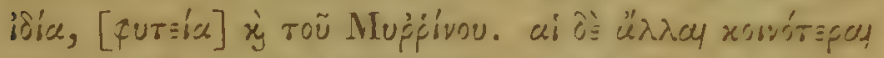

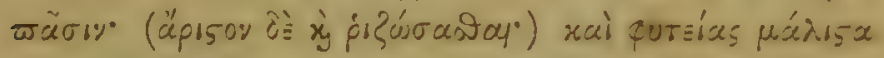

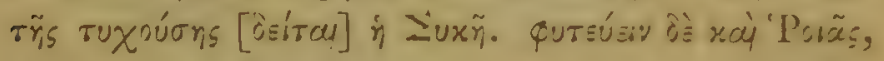

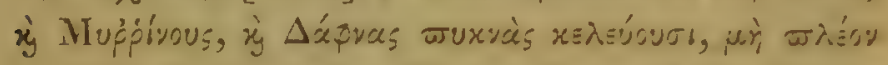

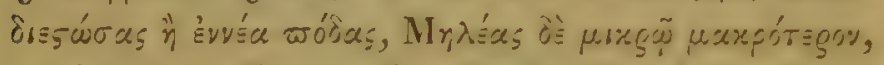

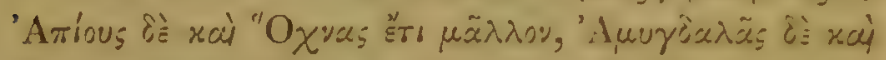

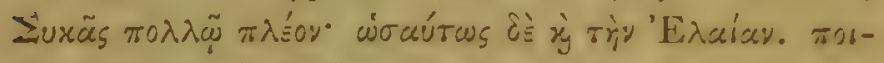

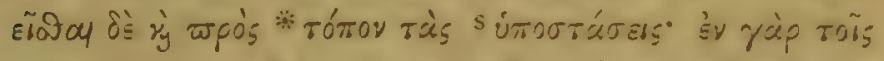

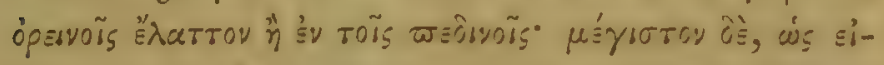

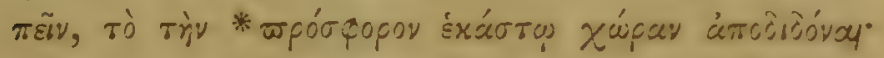

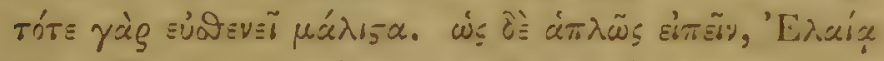

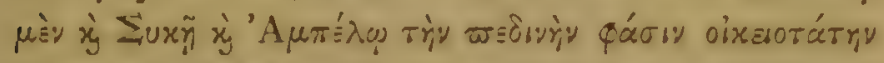

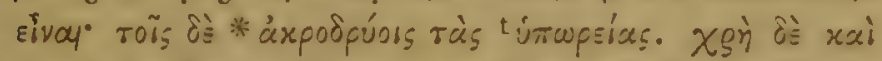

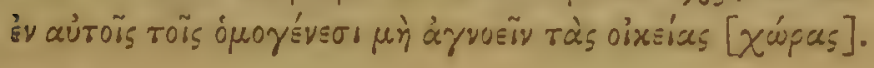

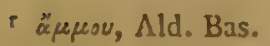

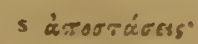

i ixw-

stías. Bod. óxápas. Const. 


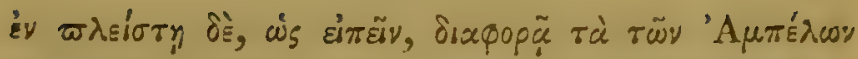

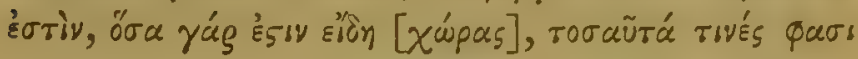

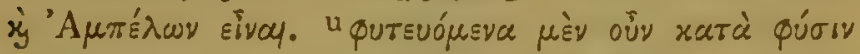

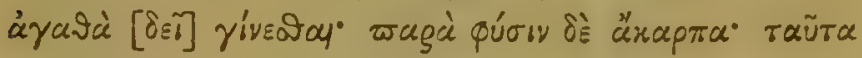

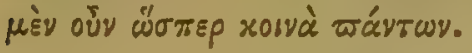

\section{CAP. VII.}

Phrnix, Dactylifera, \&c. et alia Species Pulmarunt.

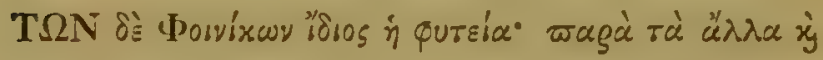

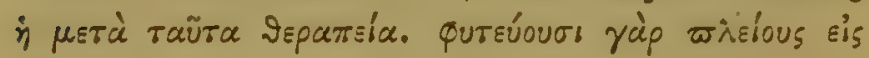

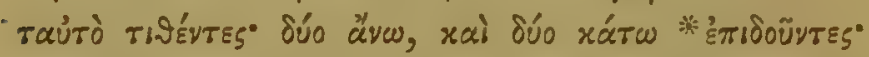

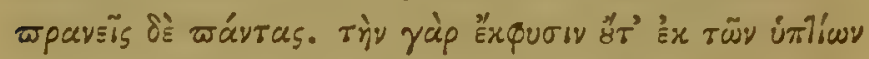

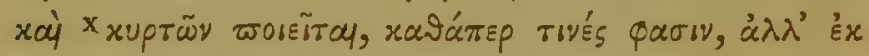

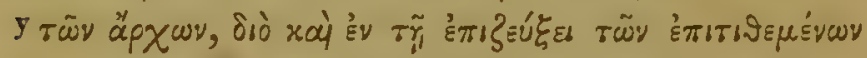

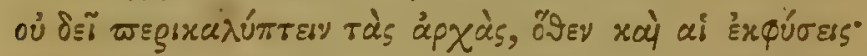

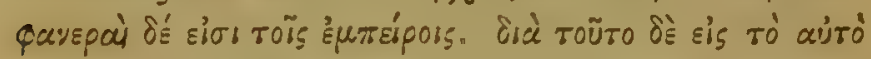

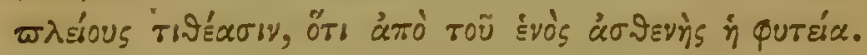

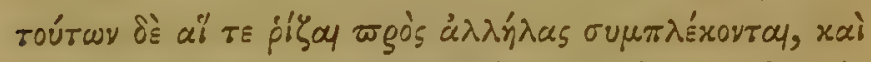

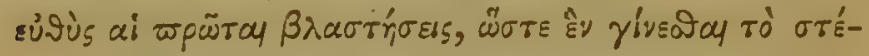
$\lambda \leqslant \chi 0$.

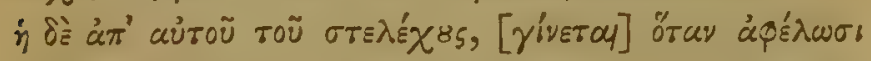

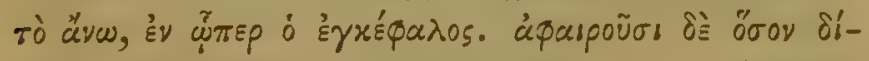

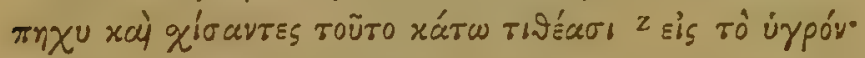

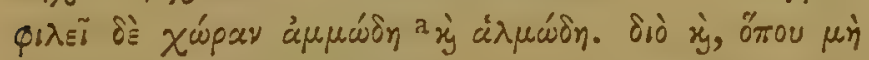

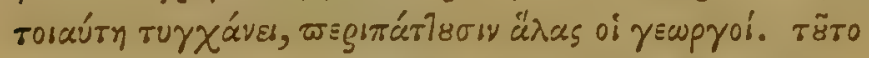

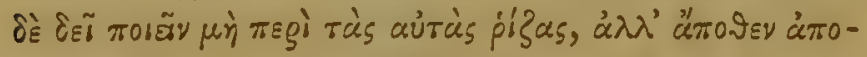

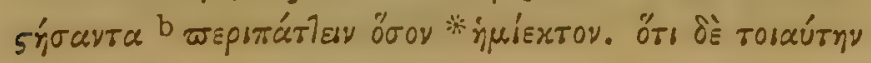

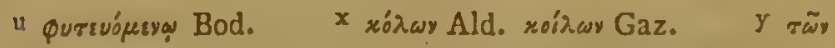
žyw, Bod. $\quad z$ tis deest Bod. a zaị ůr.péín deest Bod:

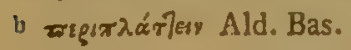




\section{MEPI $\Phi \Upsilon T \Omega N$ I}

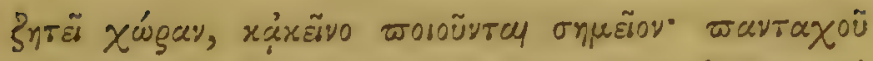

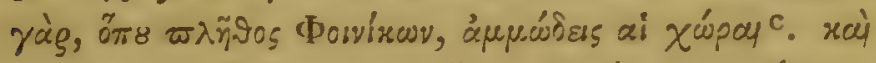

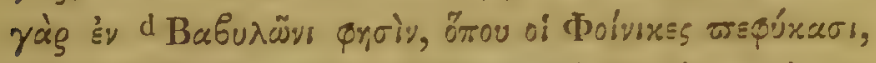

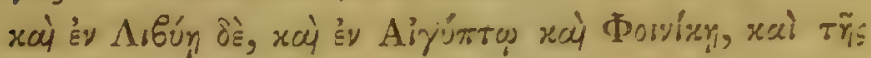

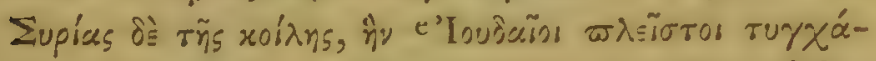

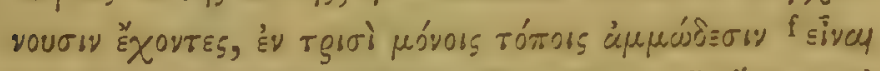

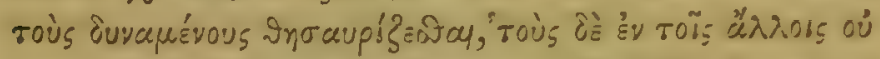

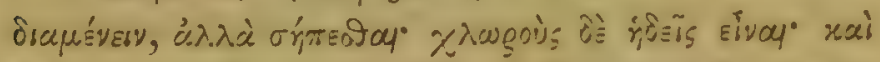

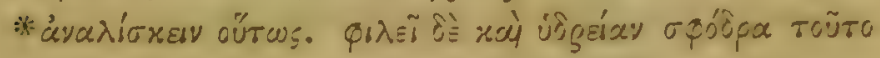

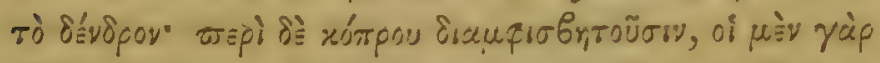

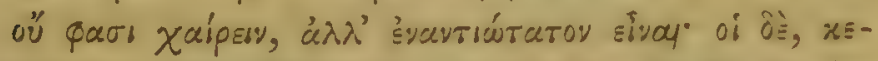

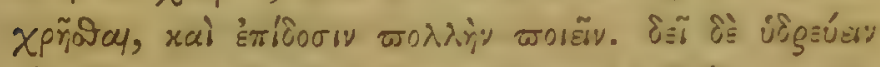

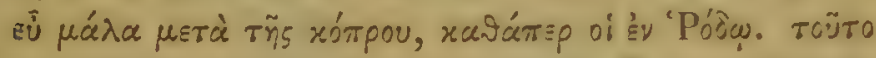

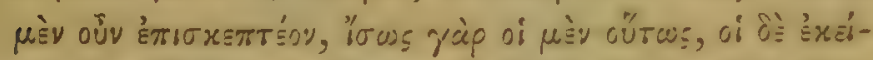

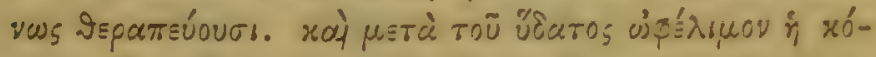

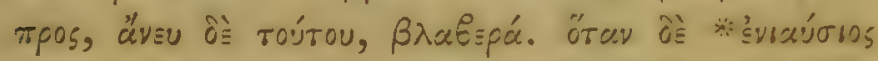

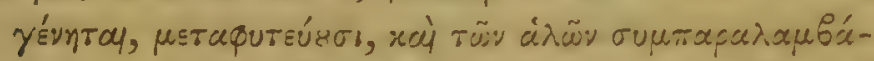

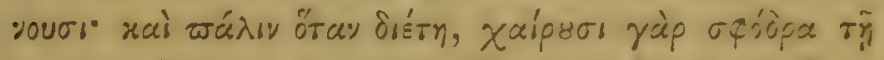
$\mu \leq \tau$

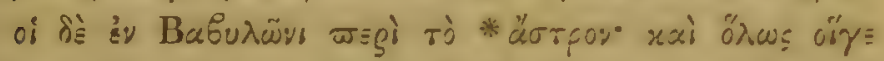

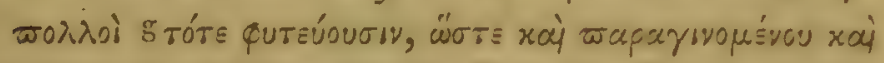

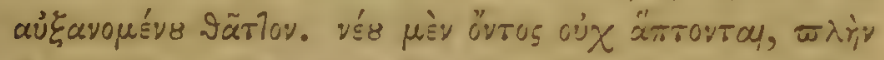

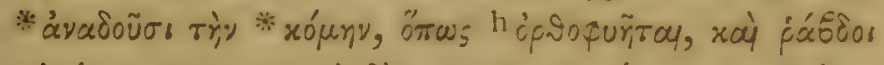

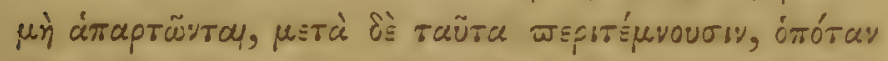

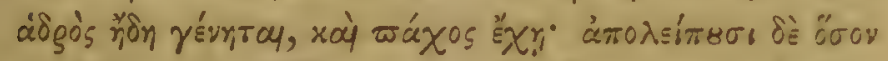

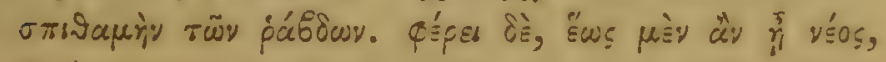

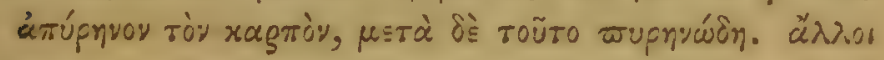

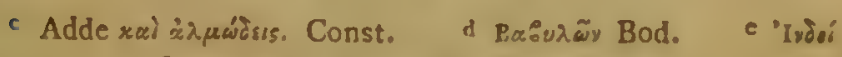

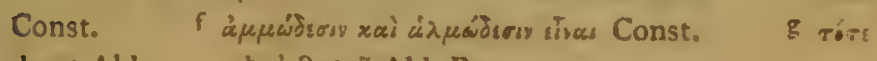
deest Ald. $\quad h$ ọ̧̀ợuñ Ald. Bas. 


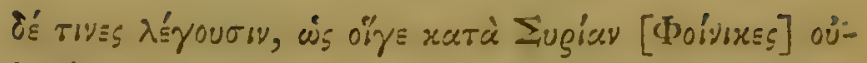

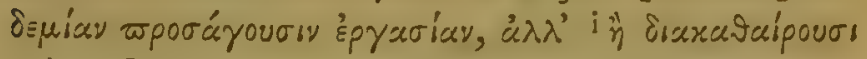

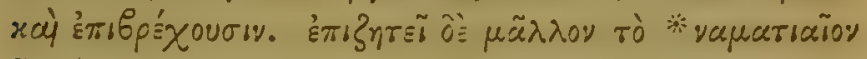

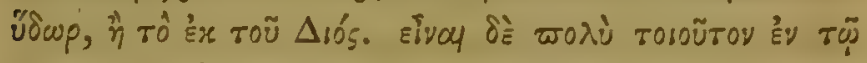

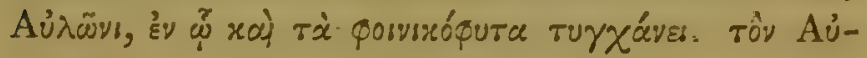

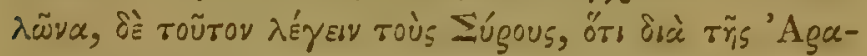

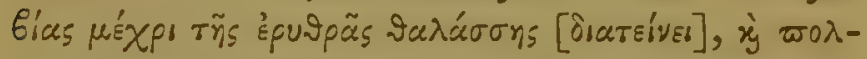

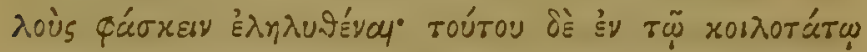

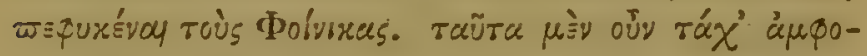

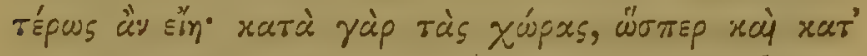

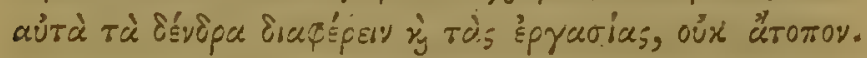

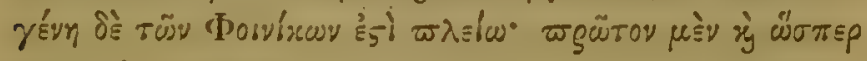
हैy $\mu \equiv \gamma^{\prime} \sigma \tau \eta \eta$

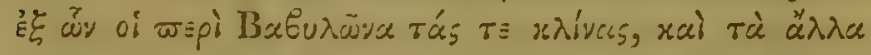

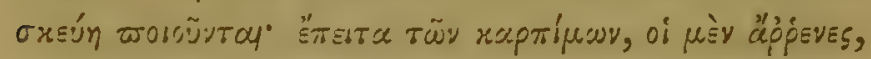

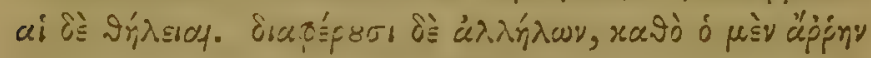

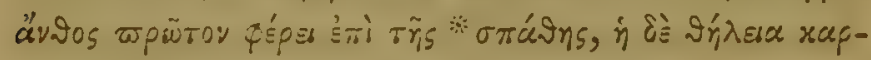

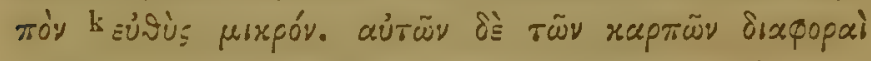

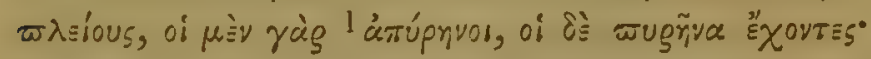

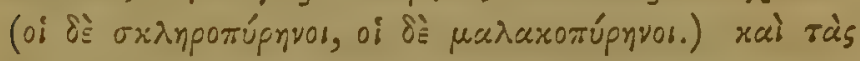

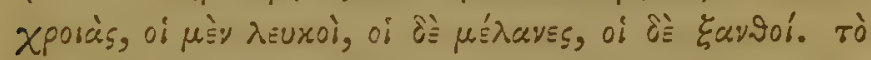

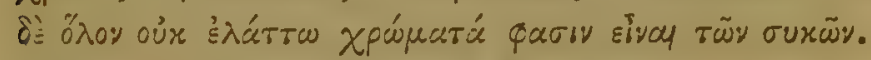

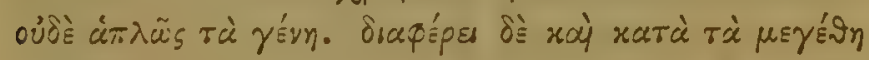

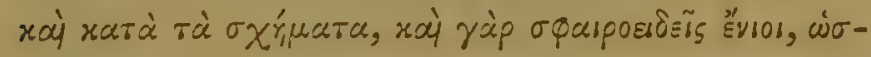

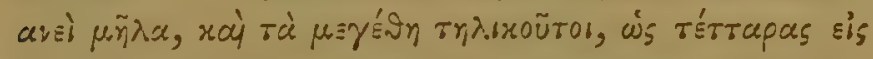

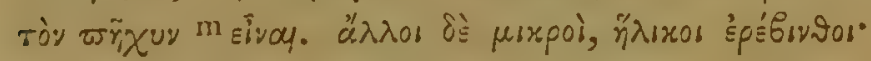

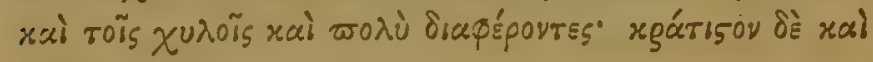

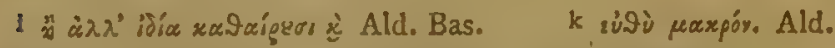

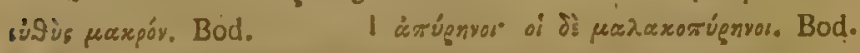

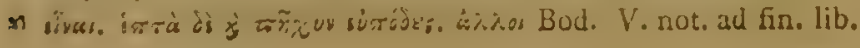




\section{ПEPI $\Phi M T \Omega N ~ I \Sigma T O P I A \subseteq ~ T O ~ 13^{\prime}$.}

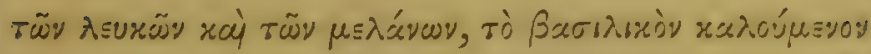

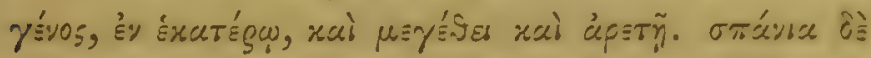

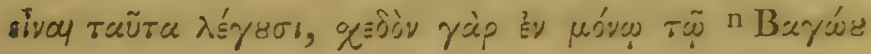

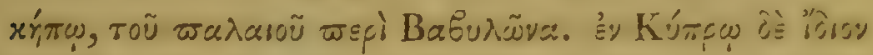

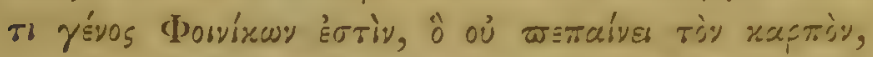

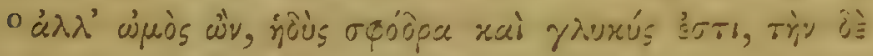

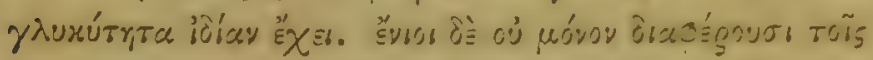

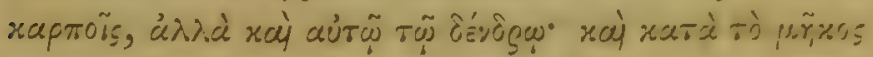

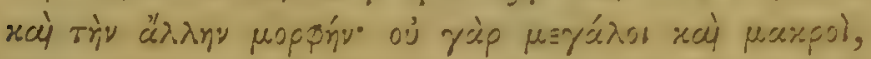

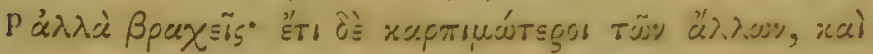

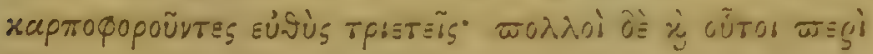

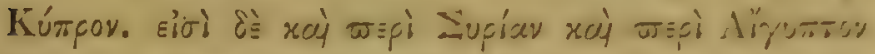

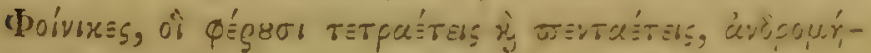

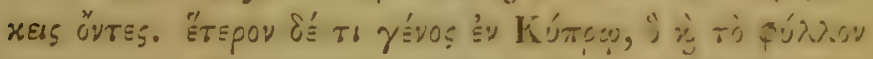

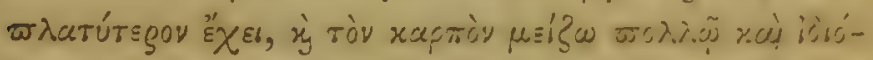

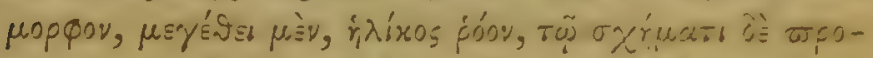

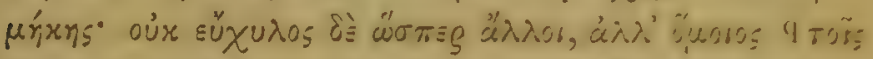

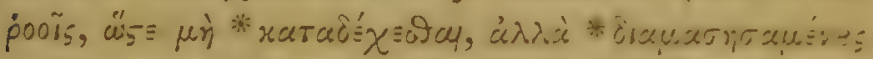

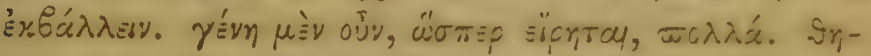

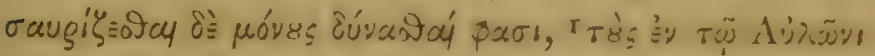

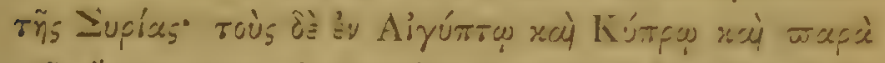

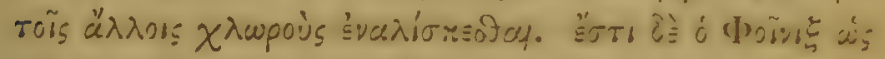

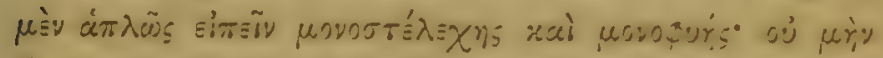

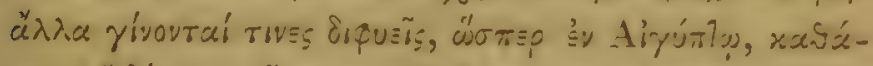

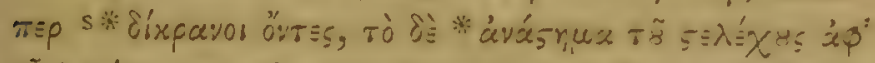

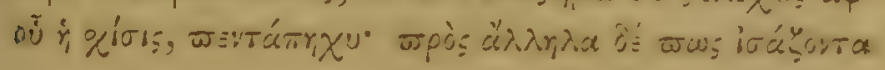

n Bárrov Bod,

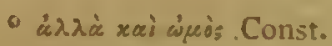

$P$ xarà:

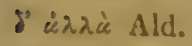

9 rai; piş⿻rs, Bod.

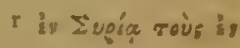

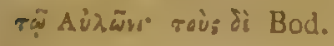

5 Sixgéay ixorrs;, Bod.

เ 2 


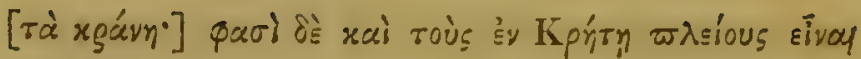

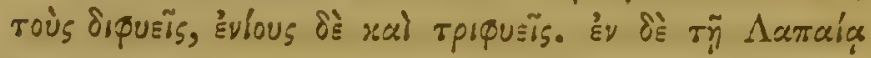

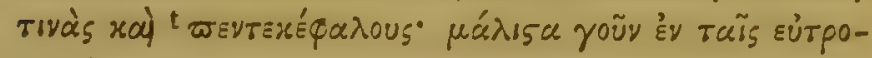

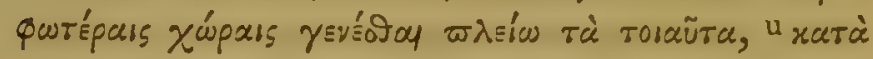

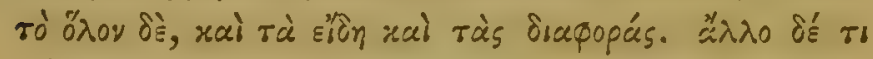

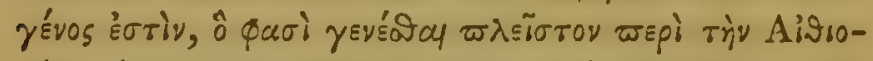

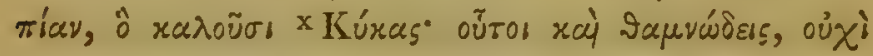

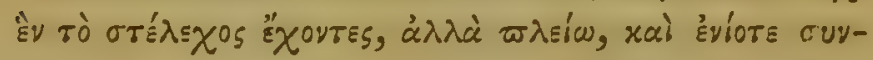

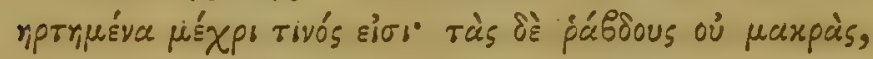

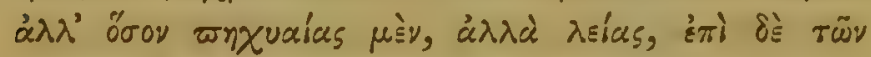
äxр

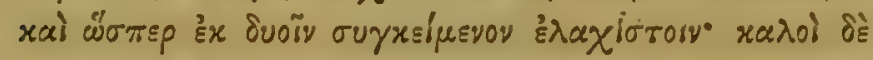

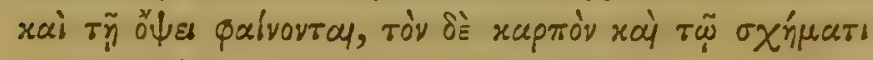

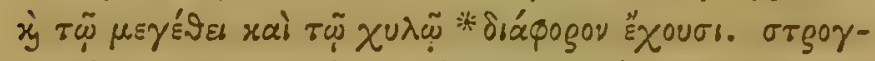

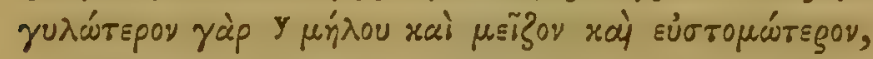

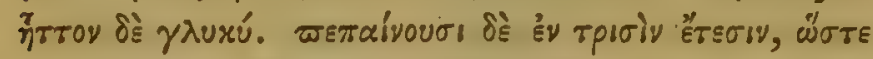

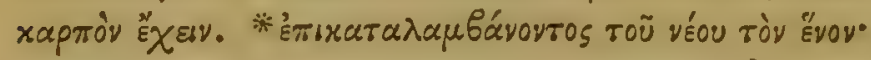

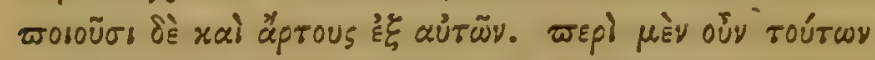

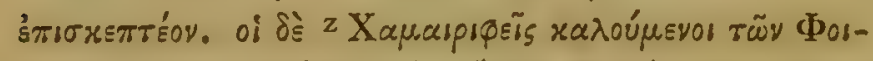

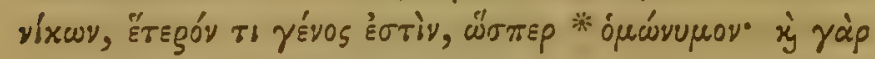

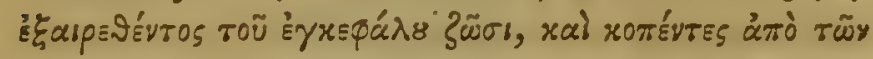

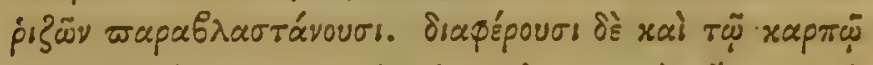

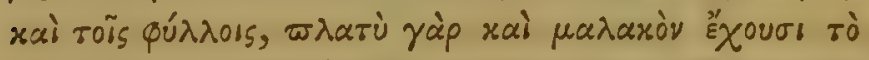

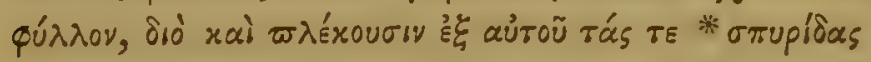

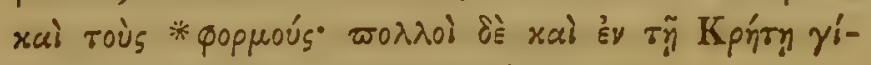

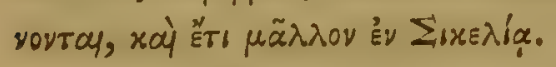

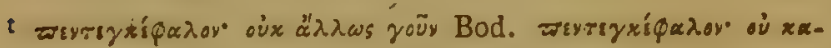

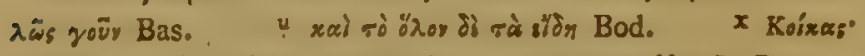

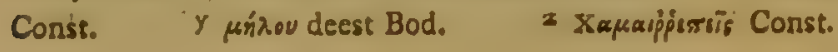




\section{CAP. VIII.}

De Plantatione et Cultura Arborum quarundan.

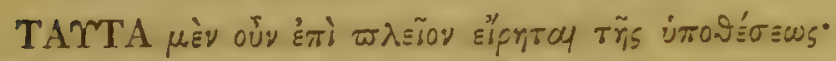
'ُy

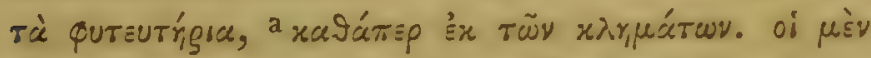

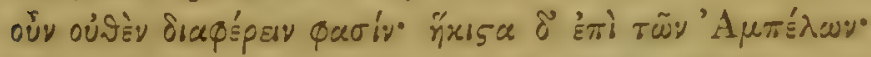

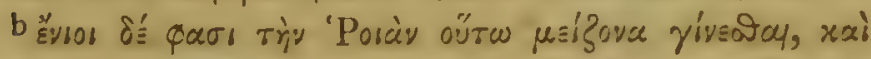

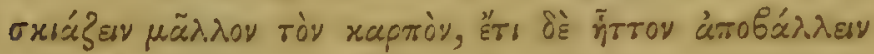

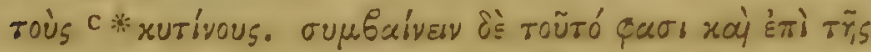

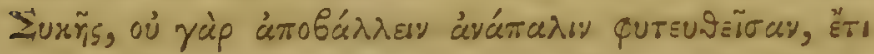

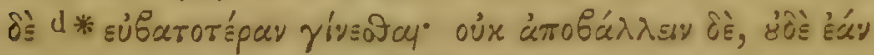

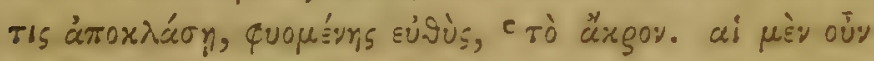

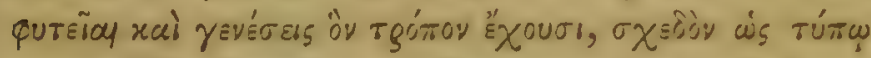

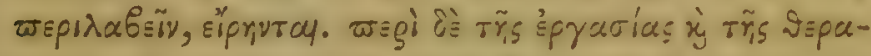

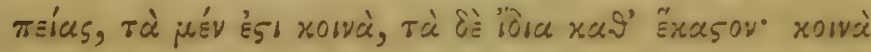

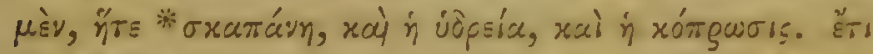

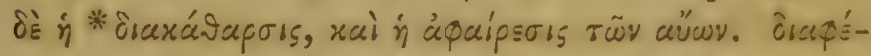

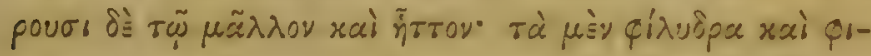

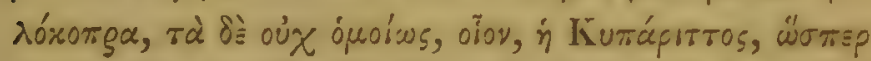

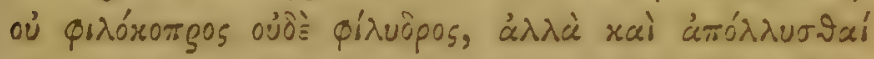

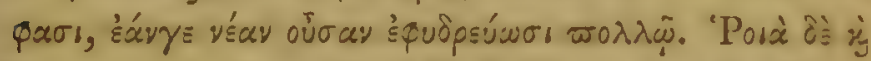

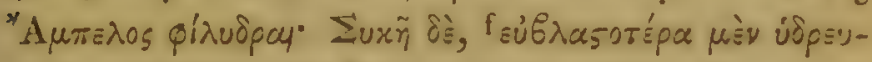

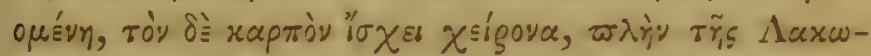

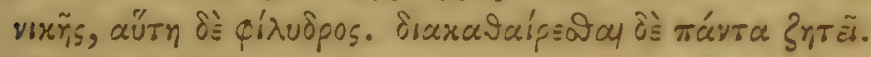

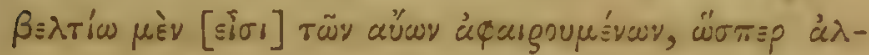

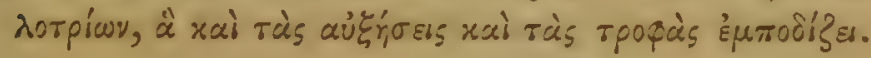

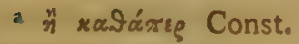

c xsxirvous. Bod.

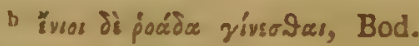
xúgrov. Bas. a ábaroripay Ald. Bas. f ábrøsoripa Ald. Bas. 


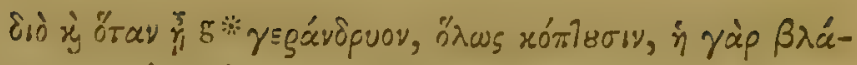

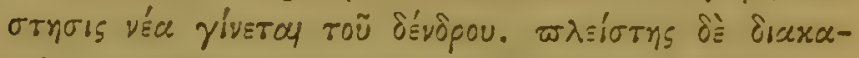

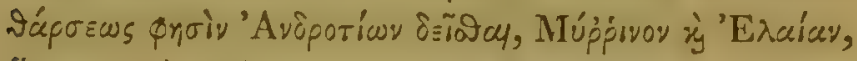

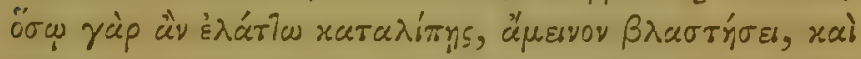

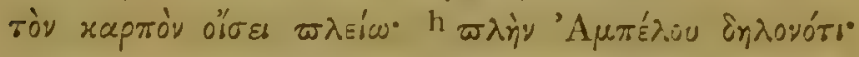

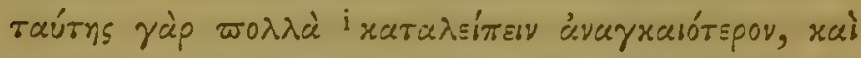

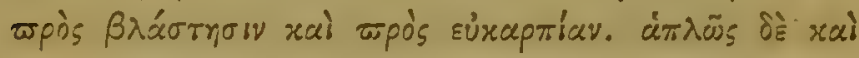

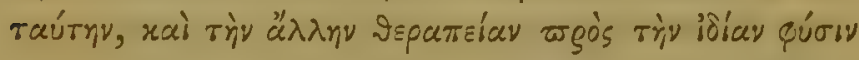

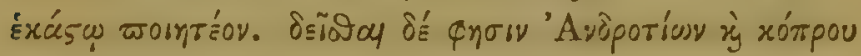

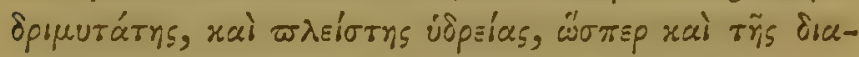

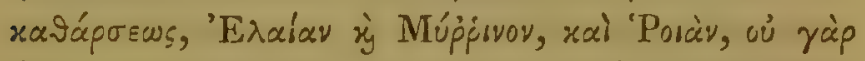

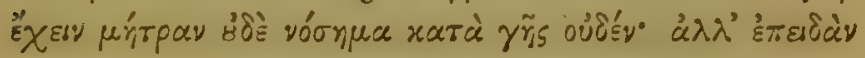

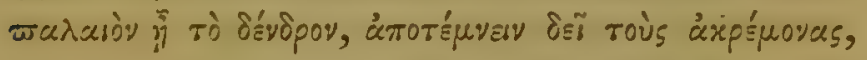

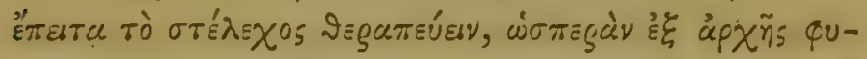

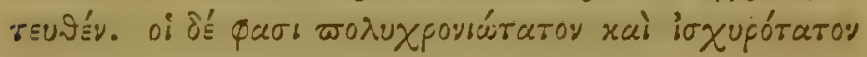

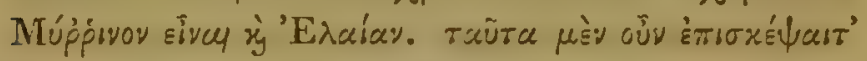

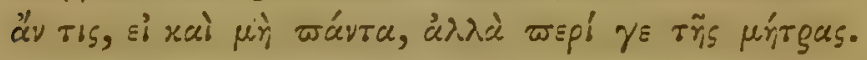

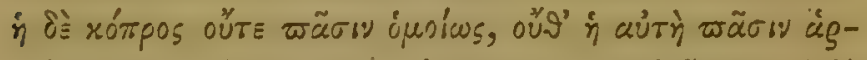

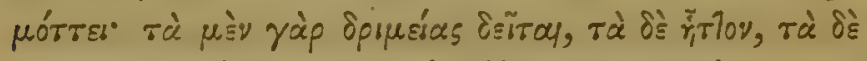

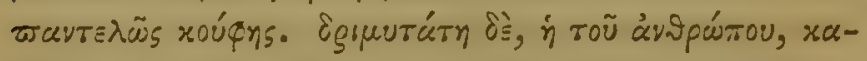

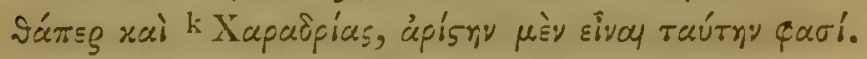

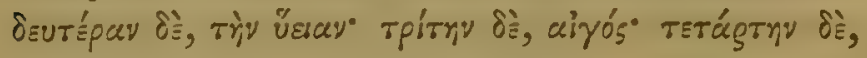

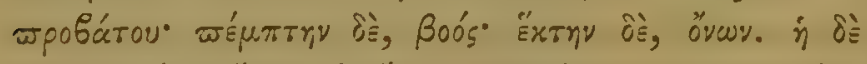

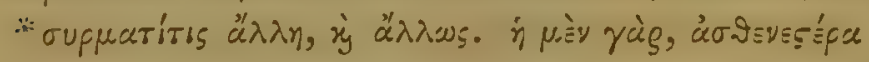

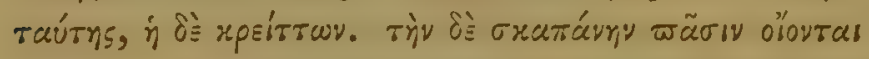

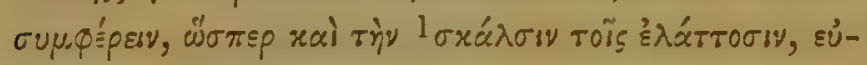

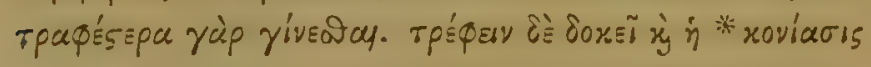

g regáyóguay, Bod.

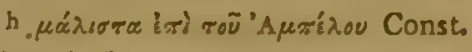

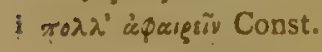

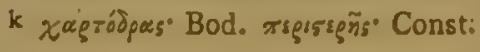
1 ơxadosy Ald. Bas. 


\section{MEPI TMTSN ISTOPIAS TO B'. 7 I}

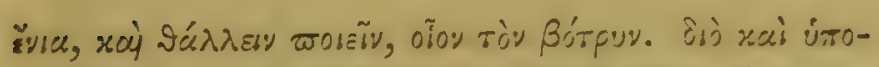

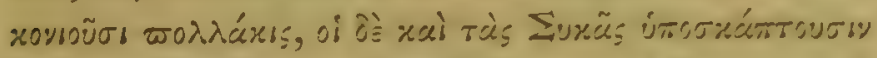

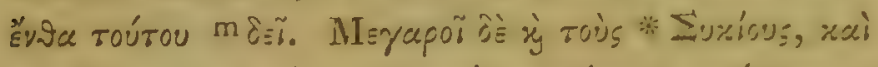

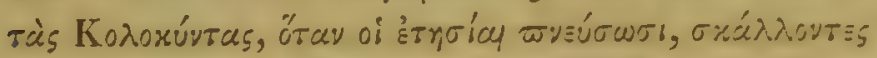

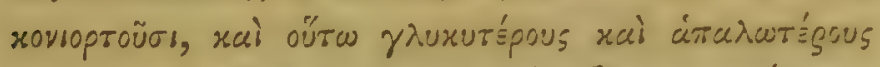

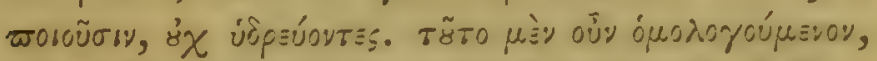

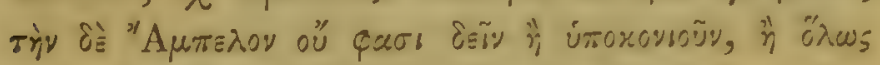

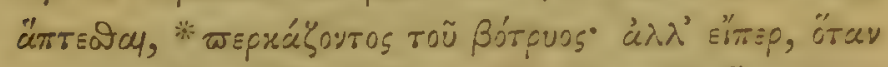

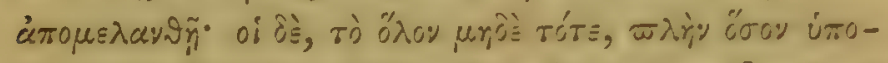

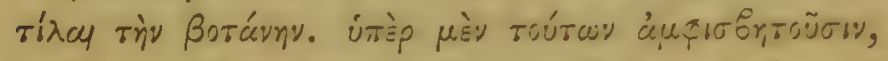

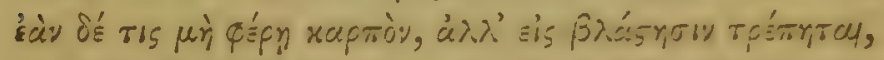

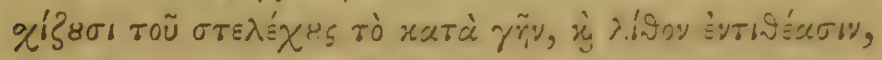

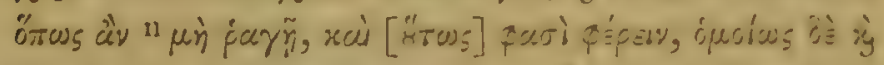

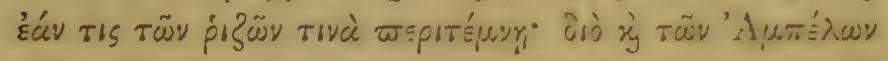

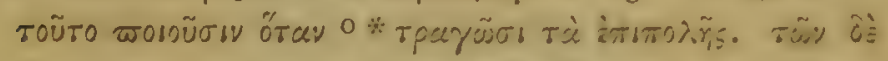

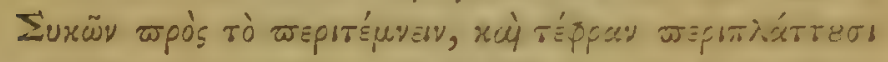
xai p.

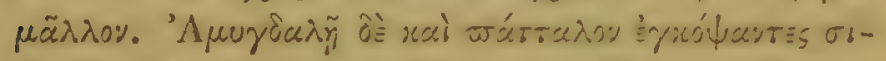

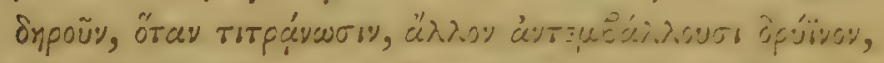

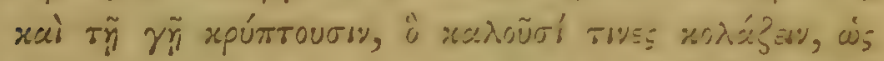

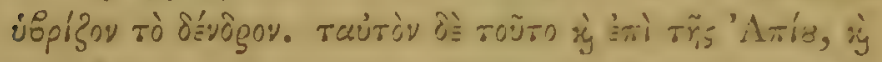

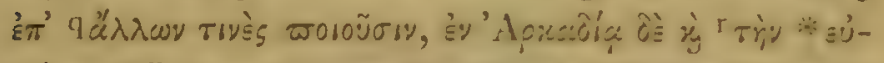

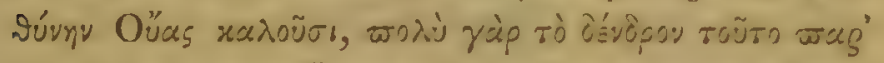

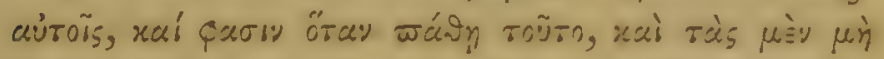

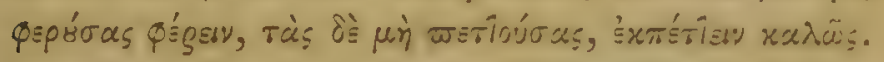

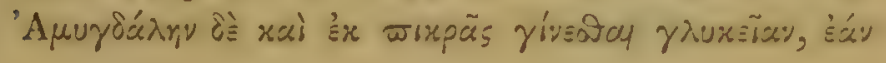

m öi deest Bas.

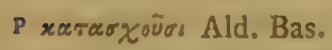

n $\mu \grave{n}$ deest Bod.

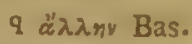

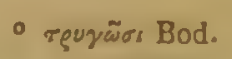

$x$ รท่̀ sisúvx.

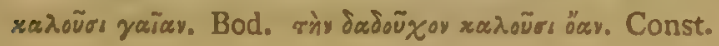

F 4 


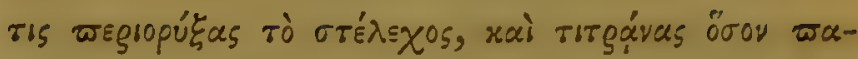

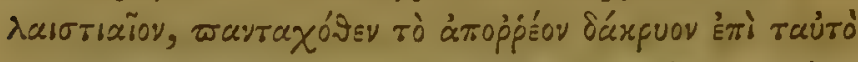

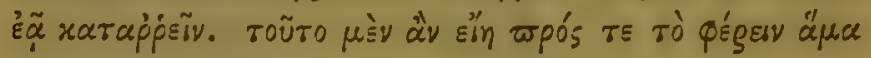

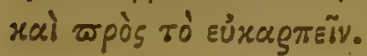

\section{CAP. IX.}

Fructificutiones abortiva; Caprificutio; Cynips, Psenes L. Facundatio Palmarum.

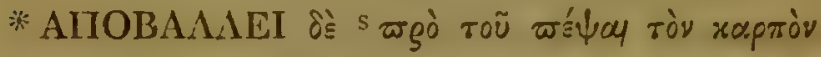
'A

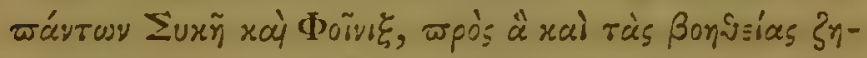

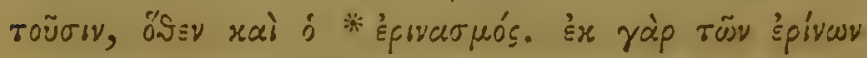

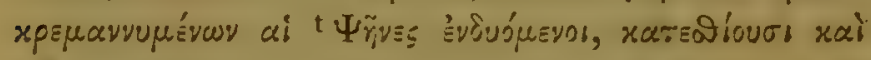

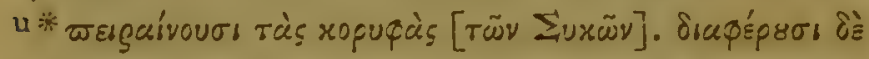

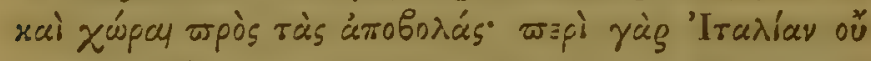

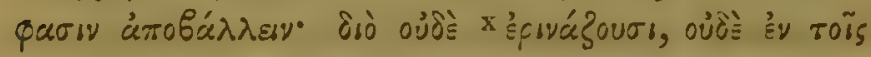

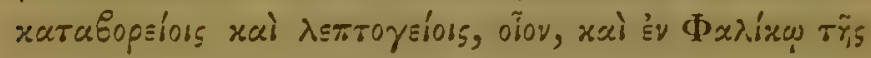

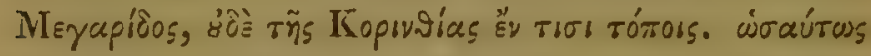

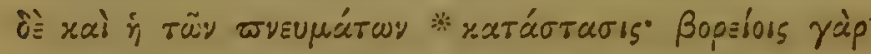

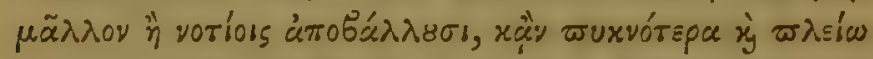

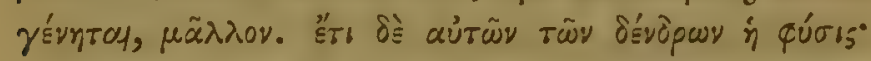

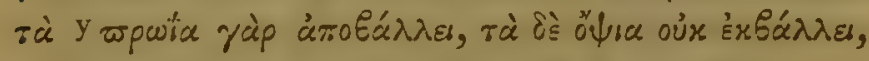

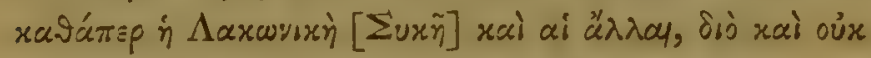

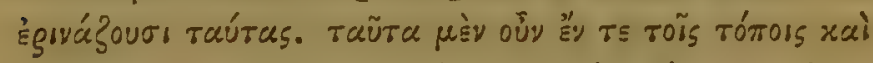

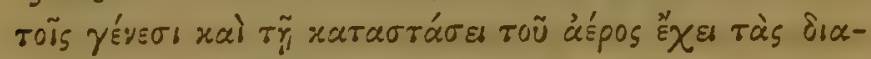

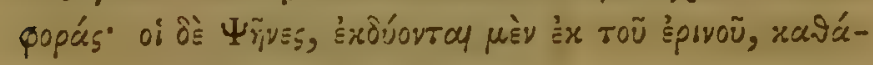

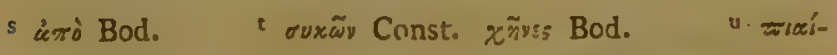

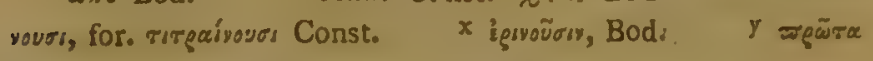
Bod. 


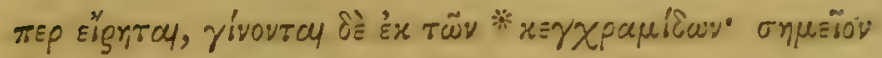

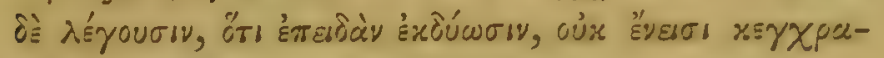

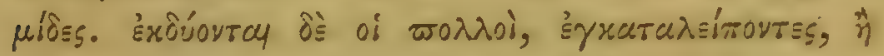

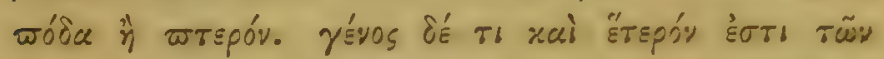

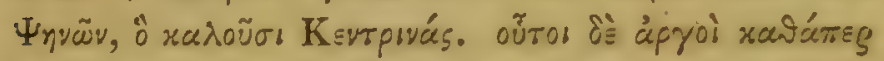

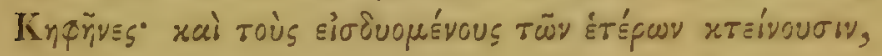

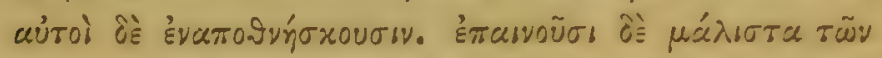

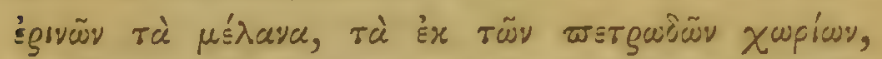

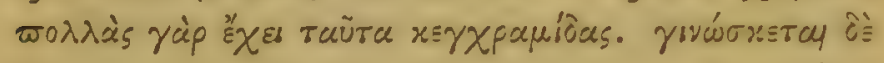

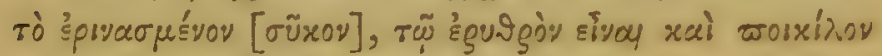

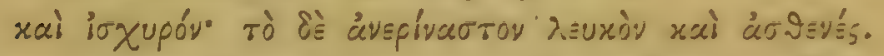

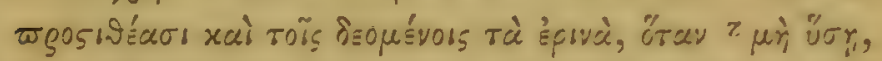

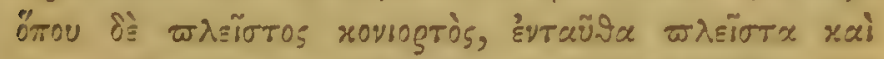

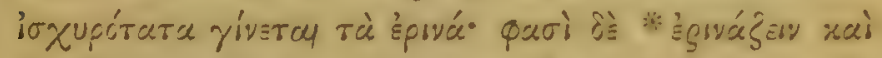

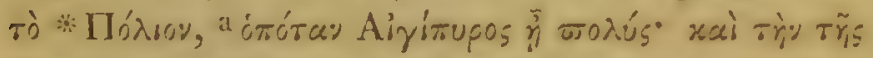

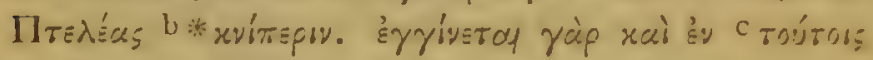

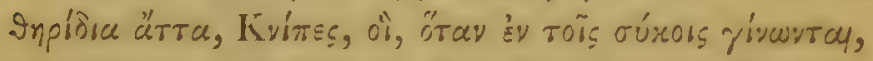

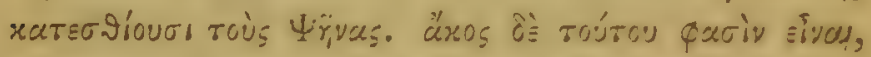

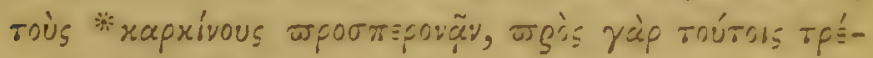
$\pi$ ooव

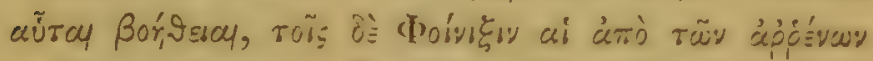

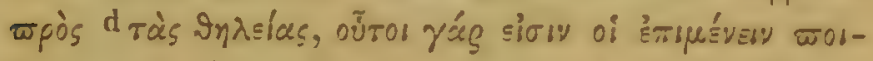

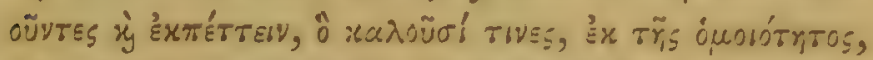

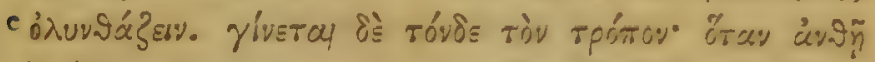

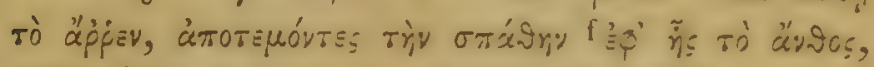

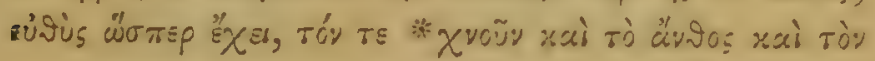
$z$ rì deest Bod.
b xúrรgly. Bod.

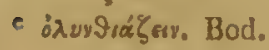
a "̈rov üy Const. Vid. not. ad fin. libri.
$c$ ró $\pi 0 u s$ Ald.

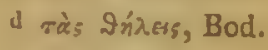

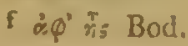




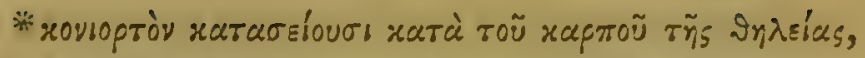

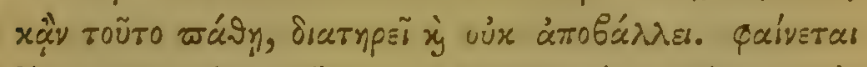

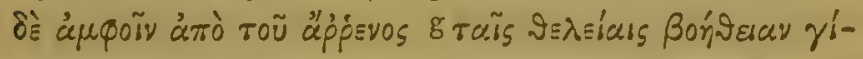

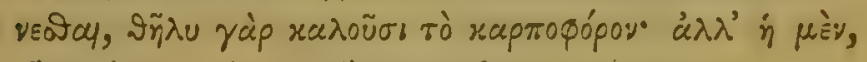

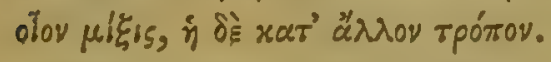

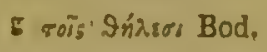




\section{NOT $Æ$}

\section{IN LIBRUM SECUNDUM.}

\section{A P. I.}

Ai zrúoer. Aristoteles libro primo partes constituentes Animalium, secundo generationes describit: ita Theophrastus respectu Plantarum.

Airóparos. Minus propric spontanea generatio arborum asseritur; etsi a Plinio recepta xvii. 16. Necnon a Virgilio in celebri loco Georg. ii.

Namque alia, nullis hominum cogentibus, ipsæ

Sponte sua veniunt.

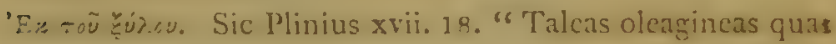
"in scrobe saturus eris, tripedaneas facito."

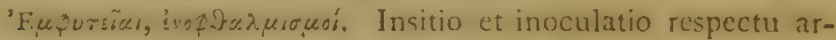
torum; Angl. "grafting and budding." Usus insitionis ex casu, ut ait Plinius xvii. 14. itemque Virgilius, scdulus naturac investigator:

Et sæpe alterius ramos impune ridemus

Vertere in alterius, mutatamque insita Mala

Ferre Pyrum, et Prunis lapidosa rubescere corna.

Idem de inoculatione:

Nunc modus inserere atque oculos imponere simples.

Nam qua se medio trudunt de cortice gemme,

Et tenues rumpunt tunicas, angustus in ipso

Fit nodo sinus, huc aliena ex arbore germen

Includunt, udoque docent inolescere libro.

\section{A P. 11.1}

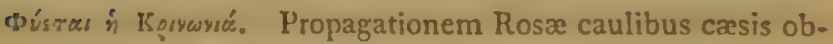
scrvarit Bodacus: sed vis rerborum mays indicat operationem flantam totam sub terra ponendi ; Angl. "making layers." 


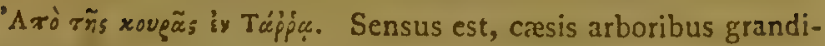
bus repullulant, et scse extendunt: ita Bellonius i. 17. Tarra oppidum Cretre.

\section{A P. III.}

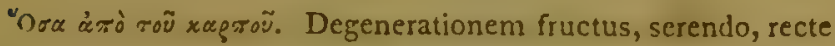
observat Auctor: notandum tamen vigorem in arboribus fructiferis obstare fertilitati, sed ex seminibus enasci, quod Botanici vocant varietates fructuum.

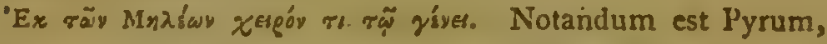
Malum L. sylvestri statu, Angl. "Crab Tree," non nominari

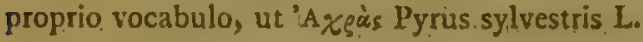

\section{A P. IV.}

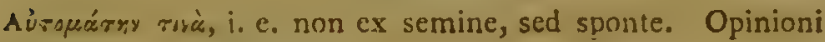
huic assentitur Plinius xvii. 25.

Kóżvay å $\mu \pi$. a Plinio et Columella, "Vitis helvola," ab

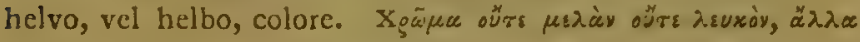
røтváòs, fumosus. De Caus. Plant. 1. iii. Fumosus, Columella.

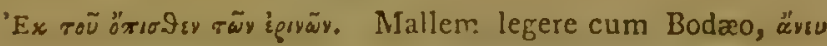
Zẹiwy, Tg̣isy enim folium ficulneum. Hesych. Vid. Bod. p. 81.

$$
\text { C A P. V. }
$$

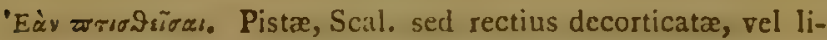
quore aliquo (an salino?) maceratæ.

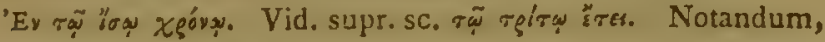
transformationes hasce plantarum a genere in genus ex defectu investigationis accuratæ oriri, quando sc. post messem Tritici, anno sequente oriatur Avenæ seges ex agro inculto. Hoc non fit ex granis Tritici, sed ex granis Avenæe prioris anni.

'O 'Íçą̧. Observatio accurata admodum; plumæe avium variant multum ætate. Vid. Buffon. et D. Montagu. Act. Linn. v. 9. p. 182.

"o "rogos. Mutatio generis fabulosa, ut supra memoravi.

Oía i̇ Ká $\mu x n s$. Triplex transformatio insectorum plurimosum. Vid. Linn. Syst. Nat. N. B. Hinc ұvxй Papilio, animæ humanæ apud antiquos typus. 
C'AP. VI.

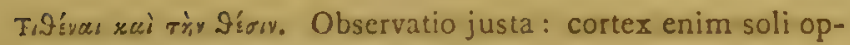
positus tenuior, versus Boream crassior.

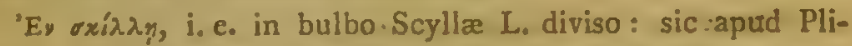
nium, "Si plantam Fici diviso Squillæ bulbo intersitam, "strictamque vinculis, collocemus." Nat. Hist. xvii. 11. Item Constant. Cæsar. de Agric. I. x.

CAP. VII.

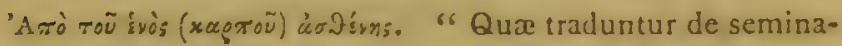
" tione Phoenicis mira admodum : sc. semina plura in unum "devincta sub terra condi; plantulasque inde enatas in unum "coalescere solita; sic tamen fieri ex experientia recentiorum "confirmatur." Bodæus in loco.

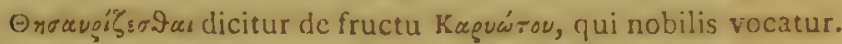
Fructus alterius xúosıos dict. parvi estimatur. Strab. 1. xvii。 Diosc. v. 4. Plin. xiv. 16.

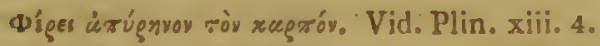

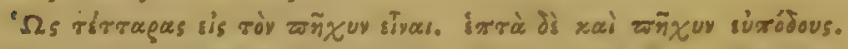
Sermo est de cubito minore, qui sesquipes. N. B. Pes Graeus continet sexdecim digitos: singuli fructus igitur longitudine

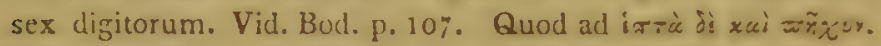
Verba hæc ex margine, ignorantia librarii, qui forsan notalit iis di ซríxus duò ródss.

Axтrai Cretæe oppidum, hodie Lapan. Scal.

\section{CAP. VIII.}

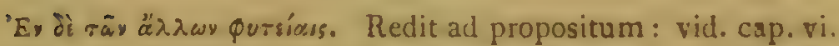

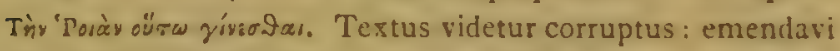
ex Cod. Ald. etsi poũs alibi morbus peculiaris vitis iv, 11 . dictus apud Gallos, "la couleur."

Xạadging. Xaoródęas Bod. Ita substitui, ut Avis apud antiquos nomen; an unquam Columba ita vocabatur? De stercore columbino antiquissima mentio in S. S. Vid. Columellam de stercore avium ii. 15. Ita Geopon. Auct. ii. 19. Bodaus

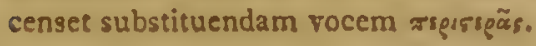




\section{CA.P. IX,}

'o ięrvarrós. Accuratisssime describitur modus caprificandi Ficum. Animalculi quod penetrat fructum Ficus mentio fit ab Aristotele v. 32. Animalculum hoc, Cynips, Psenes Linn. Mira etiam sagacitas Auctoris in detegendo Ichneumone K'vrg̨s dicto, qui larvam $\Psi$ nvòs necat. Vid. infra.

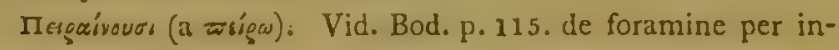
sectum.

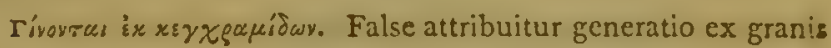
Ficus, quia post evolutionem non reperiuntur grana.

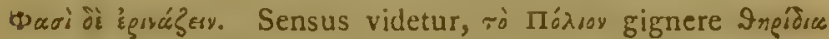
$\Psi$ צัy similia, ut Gaza vertit: sed textus proculdubio corruptus; et, ut vereor, insanabilis. Remedium ex appensione cancrorum etiam inverisimile. Observandum ctiam quod Kri $\psi$ hic dicitur devorare roùs $\Psi$ \%̆ves, etsi supra 1. vi. vocatur y'vos

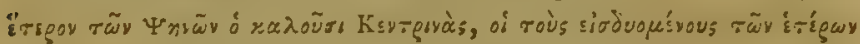

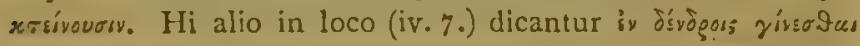

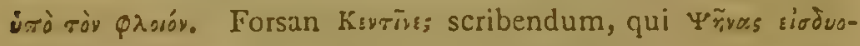
p'yous rrsivvovo. CEconomia haud absimilis inter minutiors Hist. Nat. observatu digna, respectu Tipulae, Tritici L. Act. Linn. v. 96 . et Ichneumonis cujusdam parvuli. 


\section{$\Theta$ EO $\Phi$ PA $\Sigma T O \Upsilon$}

\section{IIEPI $\Phi \Upsilon T \Omega N$ I $\Sigma T O P I A \Sigma$}

To $\Gamma^{\prime}$.

\section{CAP. I.}

De Generatione sylzestrinem Arburum: De Sulice, Platano, \& $:$.

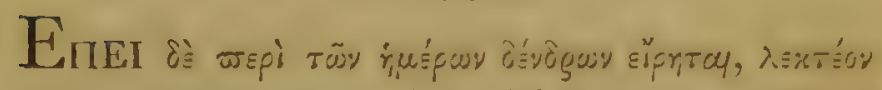

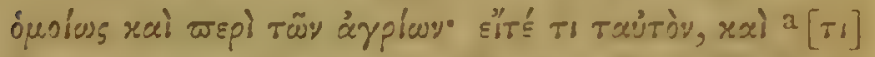

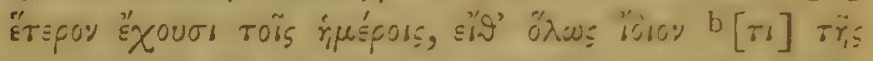

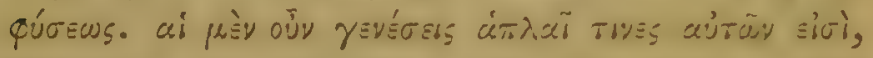

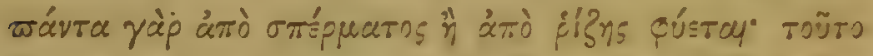

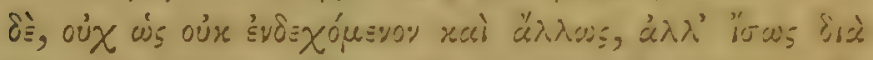

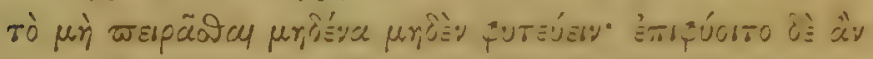

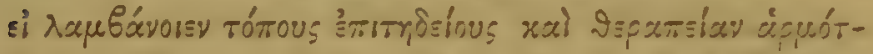

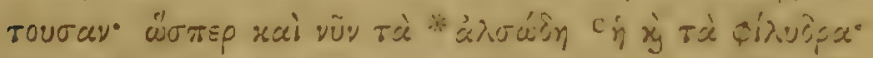

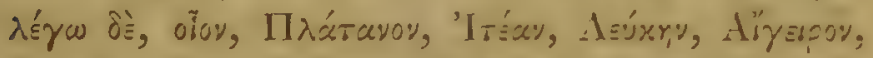

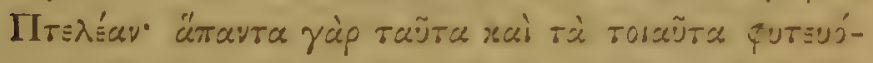

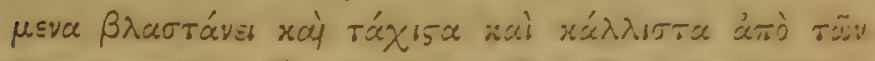

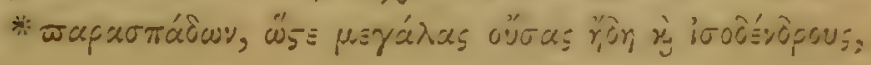
- ri leest Bod.
- ri deest Bod.
c $\dot{n}$ deest Bod. 


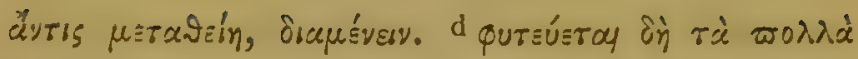

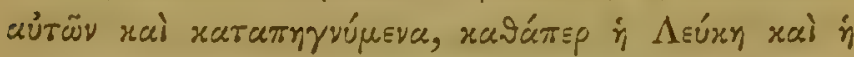

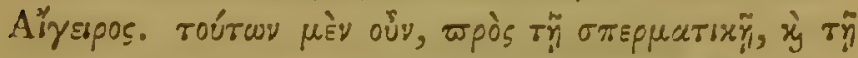

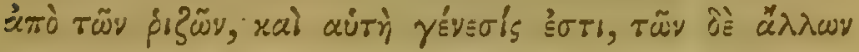

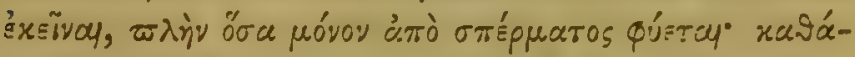

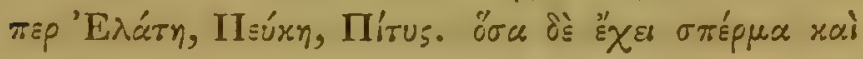

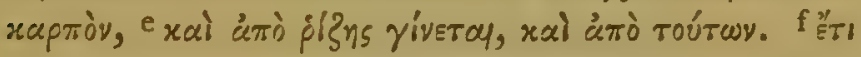

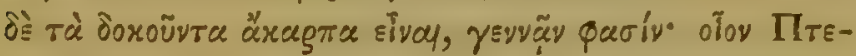

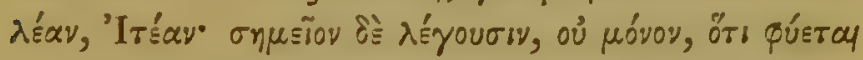

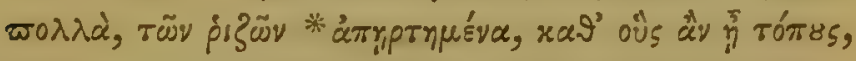

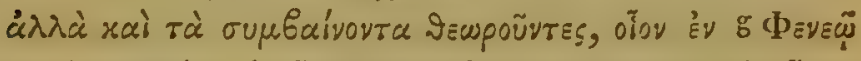

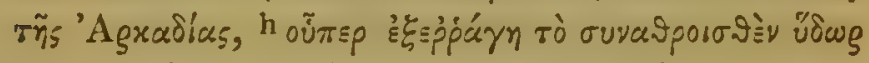

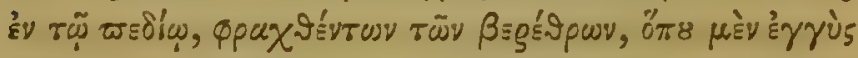

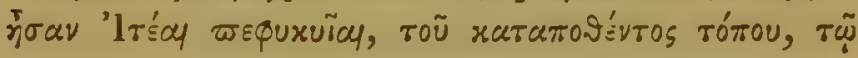

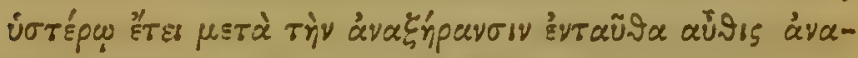

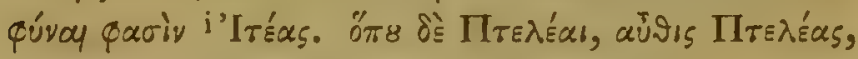

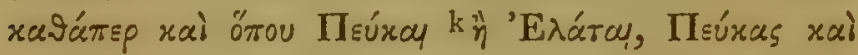

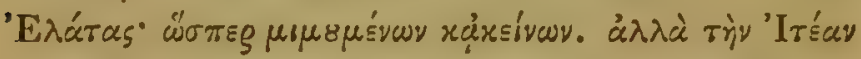

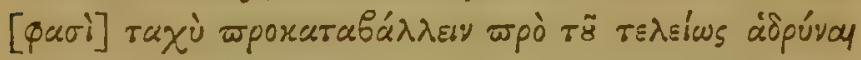

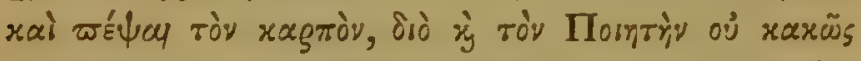

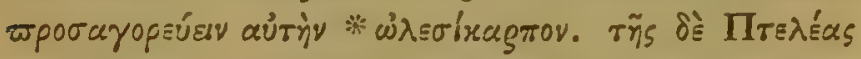

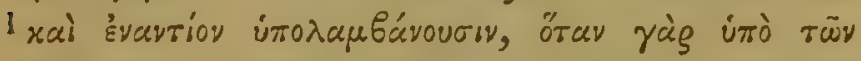

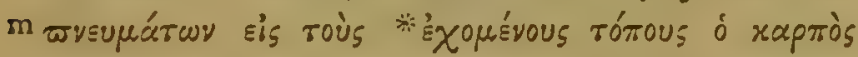

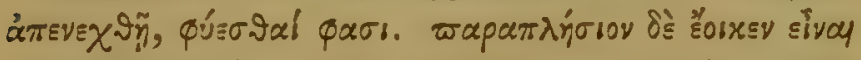

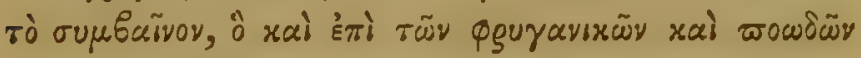

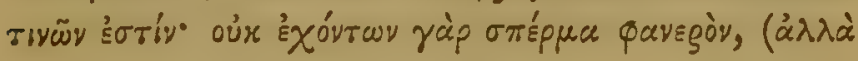

d Qústa, Const.

- Derveñ Ald. Bas.

- xxi deest Bod.

Sor Bod. xaixsivo onpsion Theod. c. $x$ axy Bod.

h ผँธrt? Bod.

f. iสil rai: Bod. 1 'Iríay" Bod.

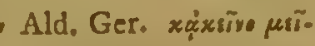

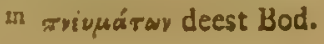




\section{MEPT TYTRN 1STOPIAS TO $\Gamma^{\prime} . \quad 8 I$}

-

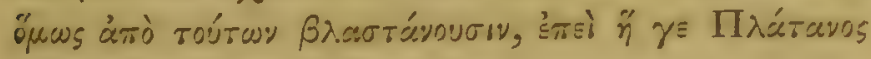

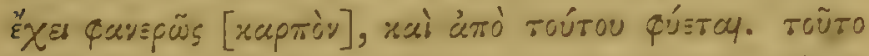

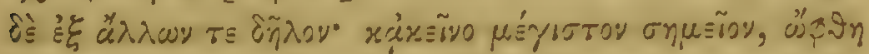

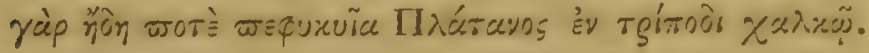

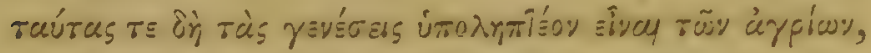

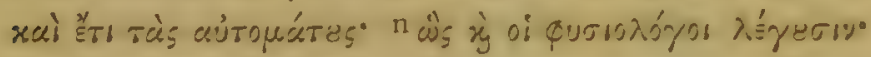

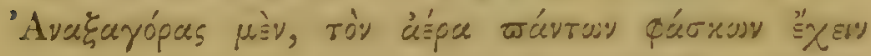

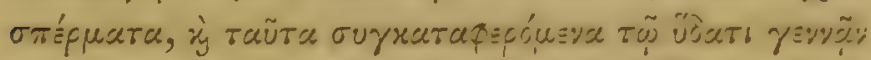

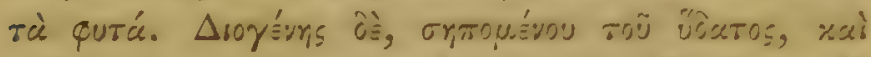

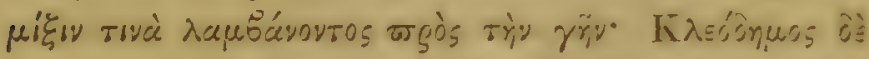

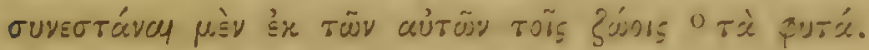

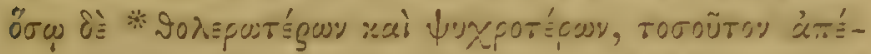

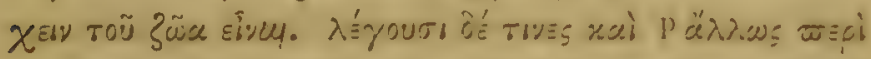

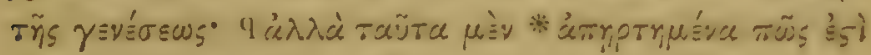

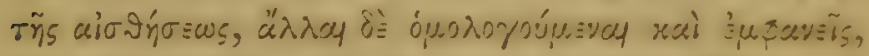

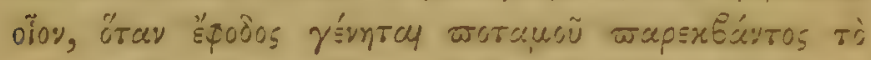

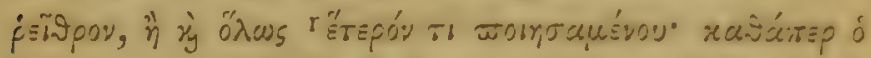

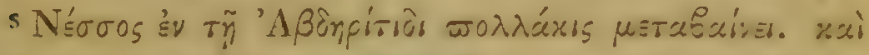

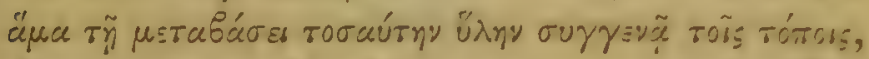

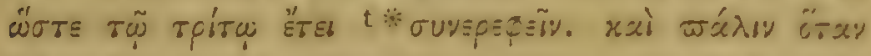

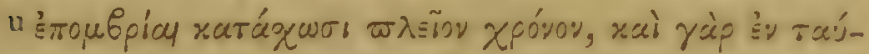

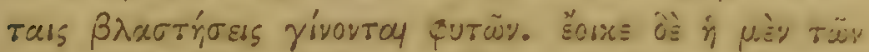

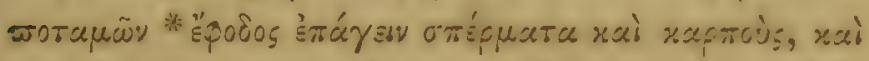

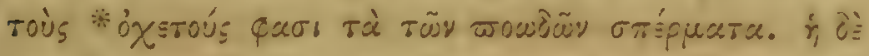

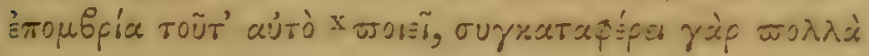

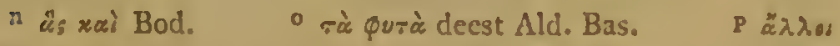

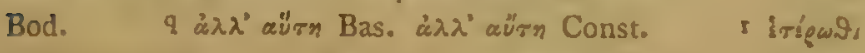

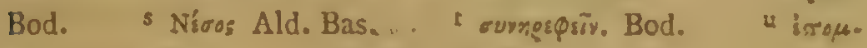

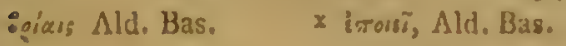




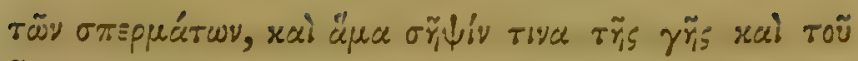

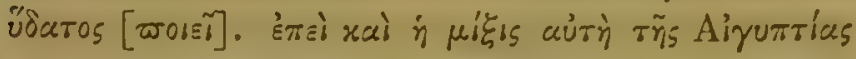

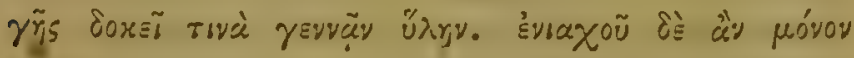

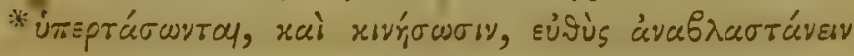

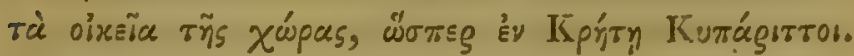

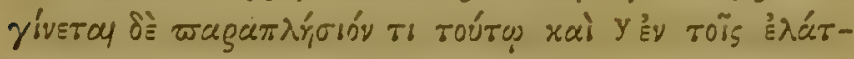

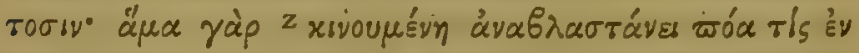

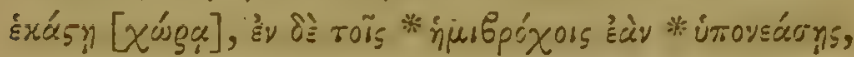

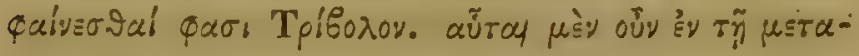

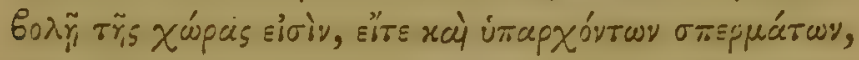

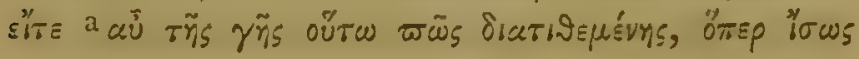

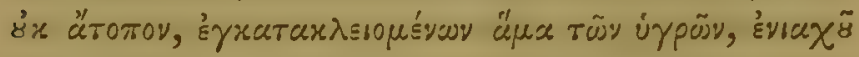

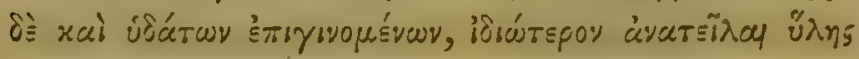

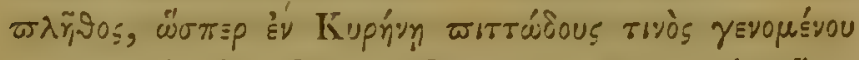

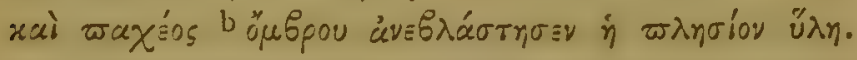

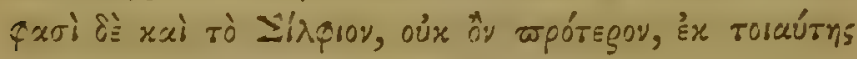

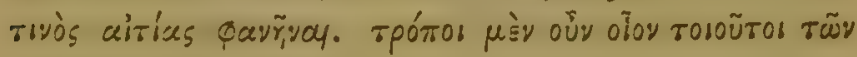

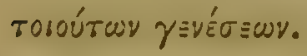

\section{CAP. II.}

De Arboribus fructiferis, viel stcrilibus ; et de Cultura Arborum.

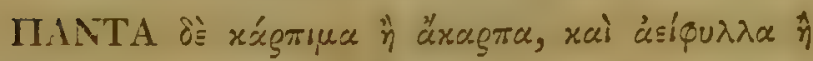

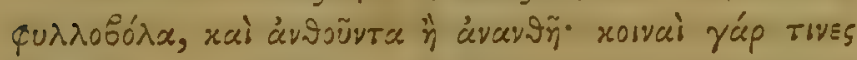

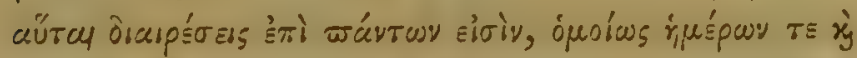

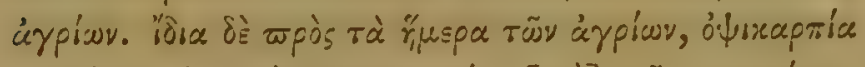

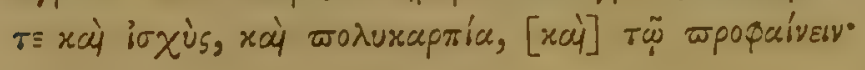

$y$ iy deest Bod.

2 rivoupiross Bod.

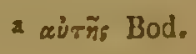

b "poposu deest Ald. Bod. 


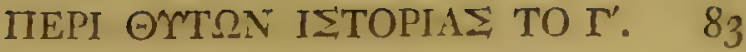

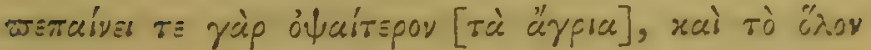

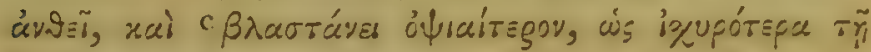

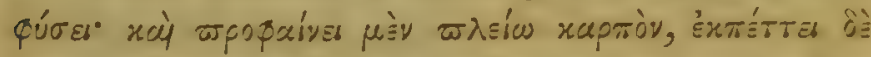

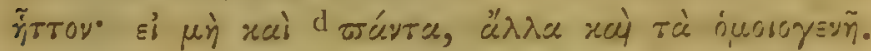
e oloy Kŕtrivos ri

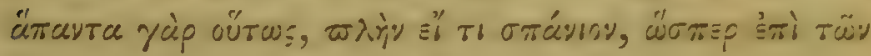

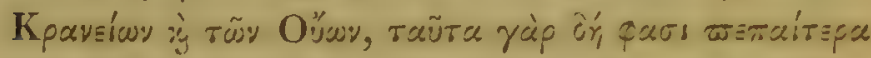

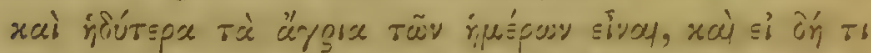

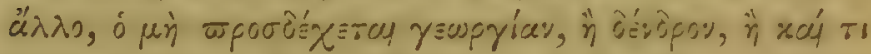

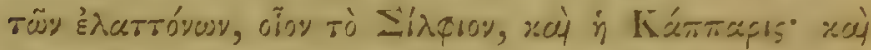

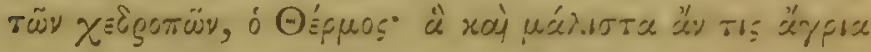

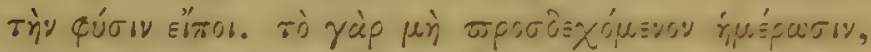

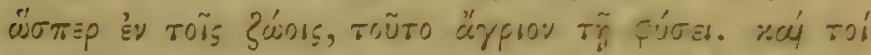

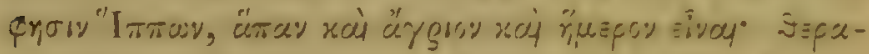

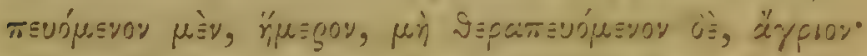

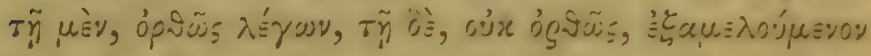

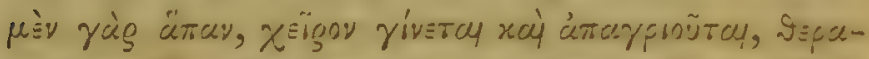

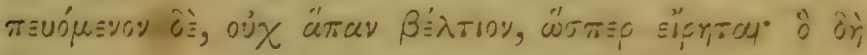

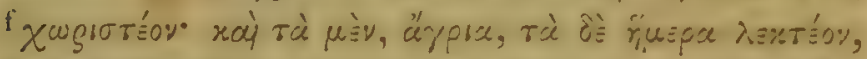

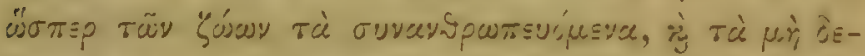

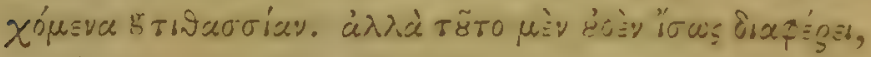

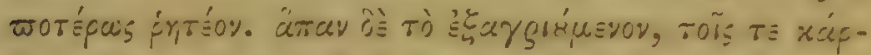

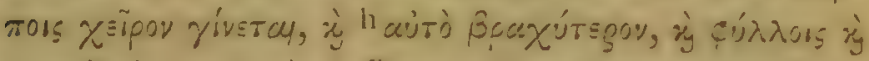

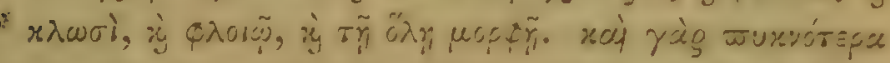

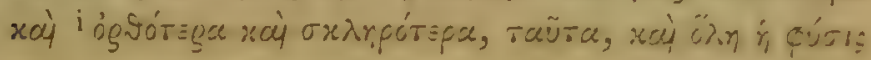

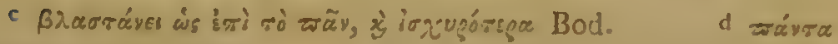

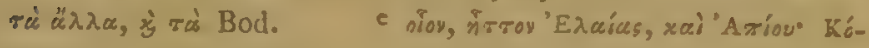

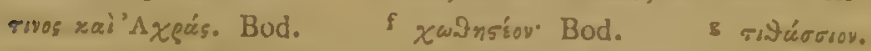

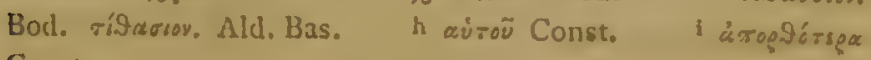
Const. 


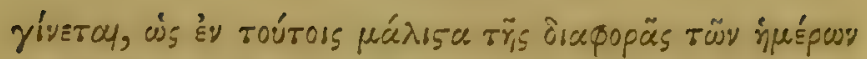

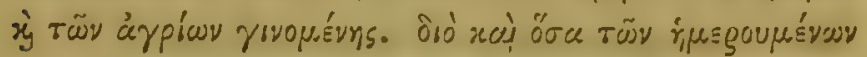

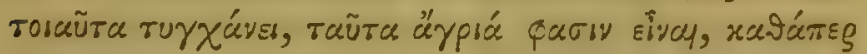

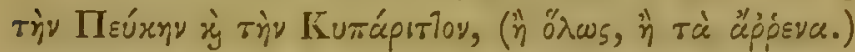

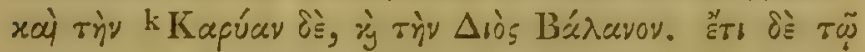

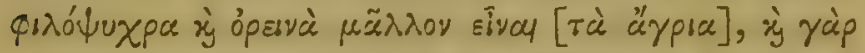

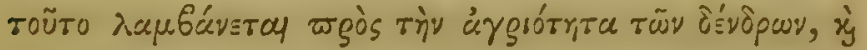
"̈̉

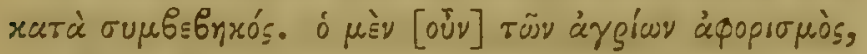

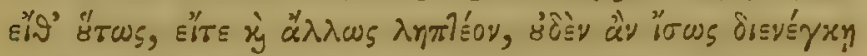

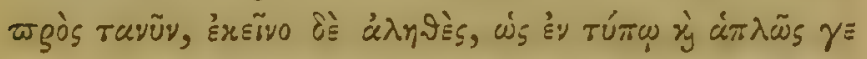

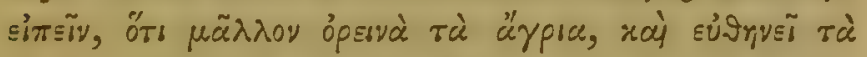

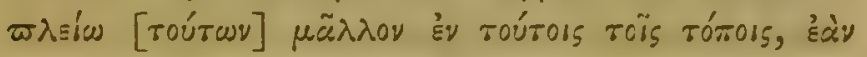

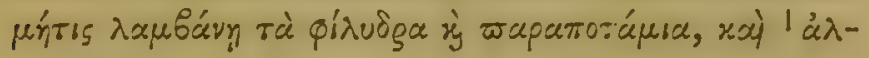

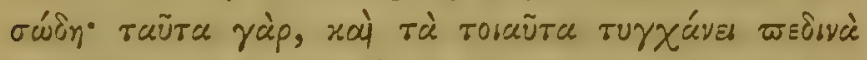

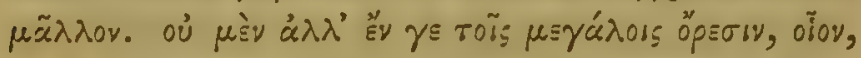

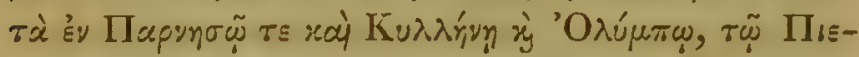

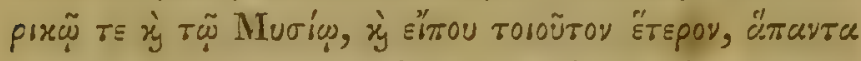

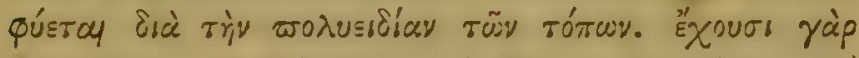

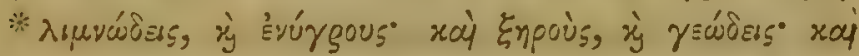

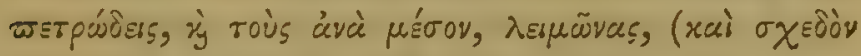

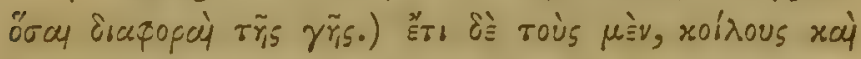

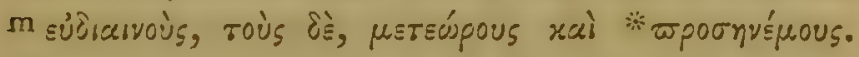

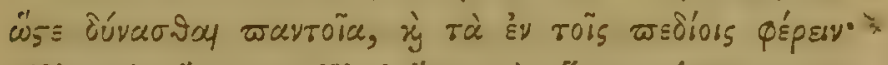

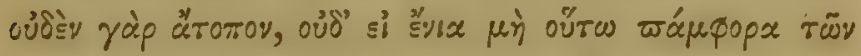

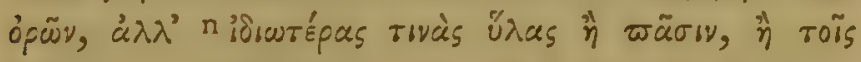

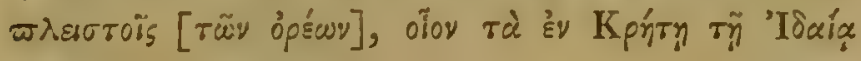

k Kagixy Ald. Bas.

1 árídr Bod.

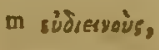
Bod.

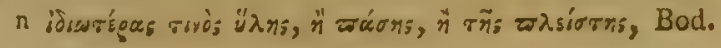




\section{MEPI TMTRN ISTOPIAS TO $\Gamma^{\prime} . \quad 85$}

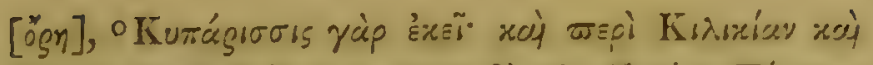

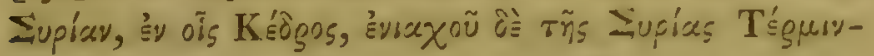

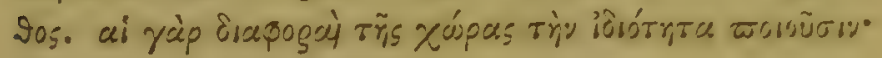

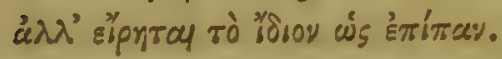

\section{CAP. III.}

Arbores montana et campestres. Tacedonic. De Climalunit

Differentiis in Arboribus.

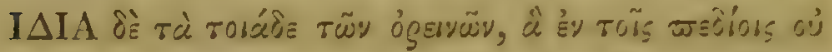

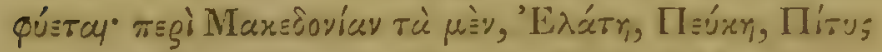

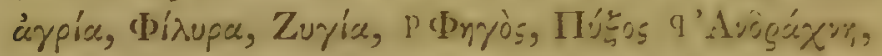

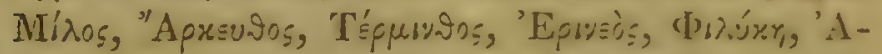

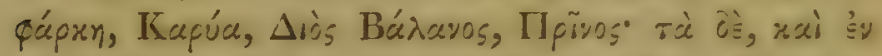

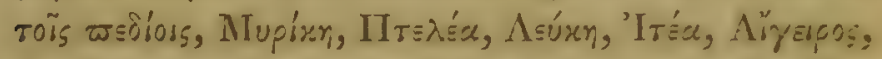

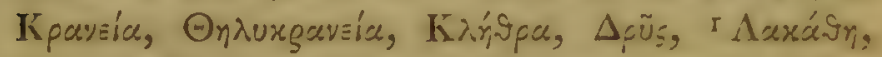

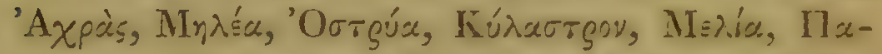

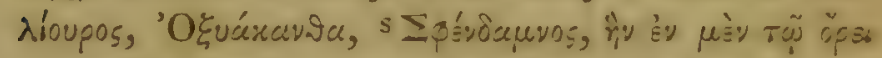

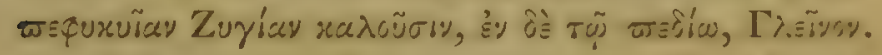

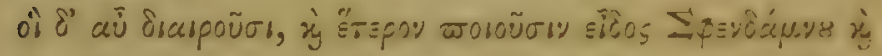

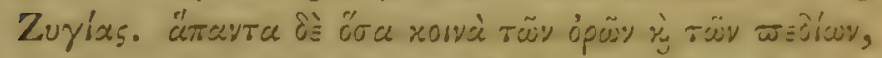

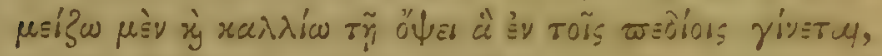

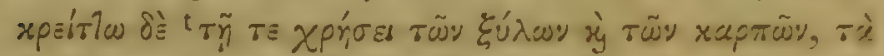

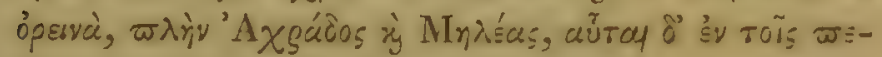

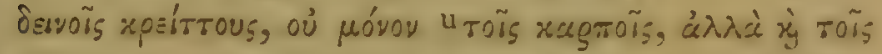

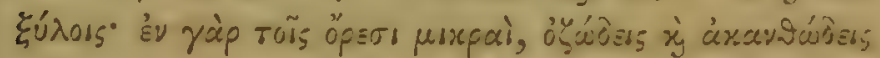

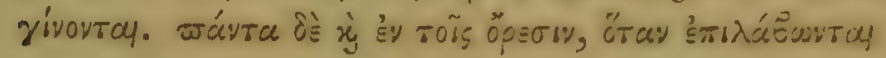

- Kuสáęrrres xai Bod.

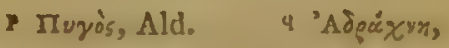

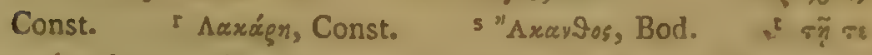
xgriver desunt Ald. Bas.

u' is roîs xaproîs, Ald. Bas.

G 3 


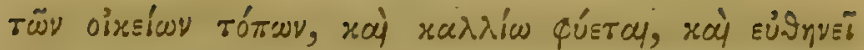

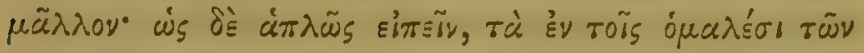

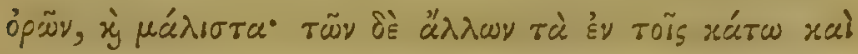

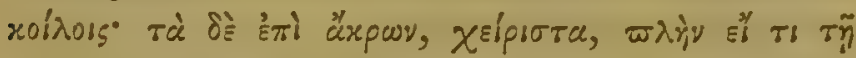

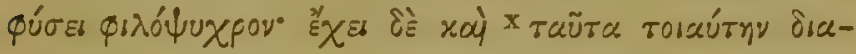

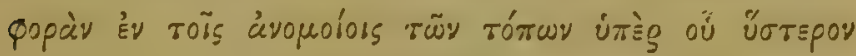

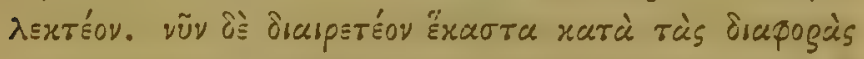

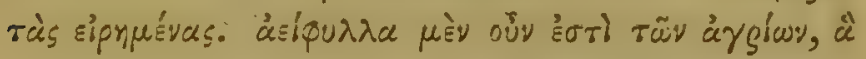

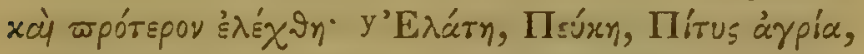

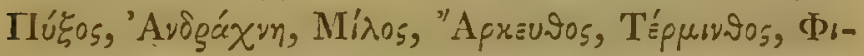

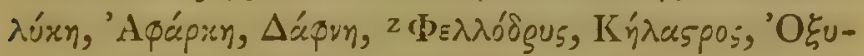

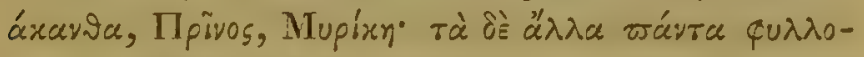

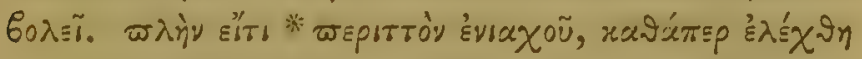

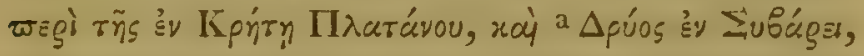

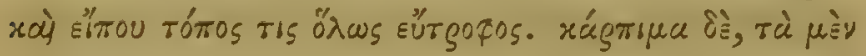

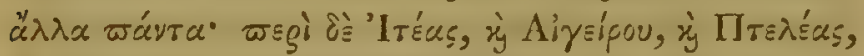

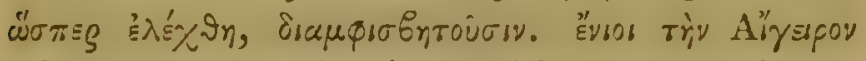

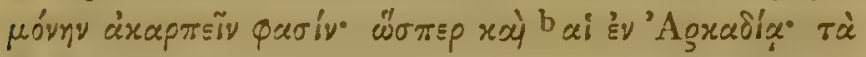

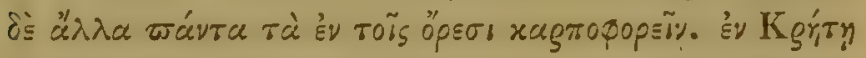

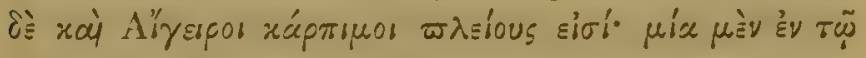

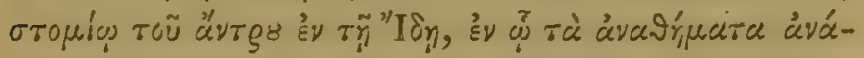

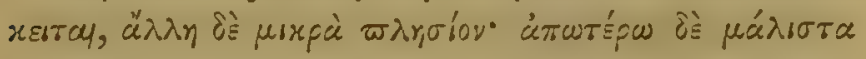

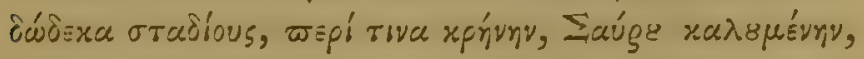

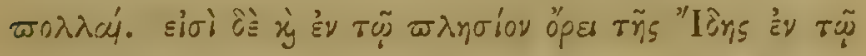

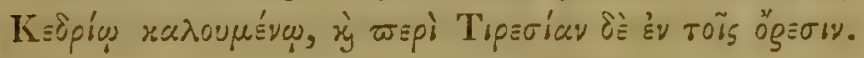

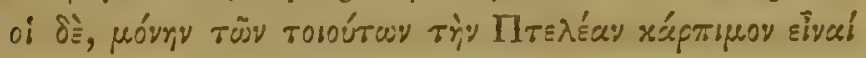

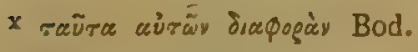

y 'Ex'árn deest Bod.

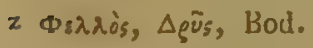

Const. b of Bod.

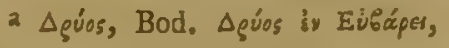




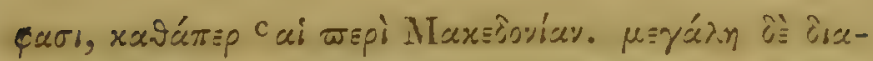

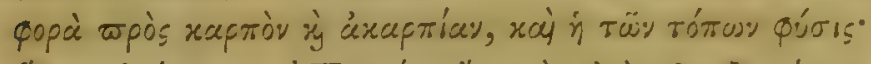

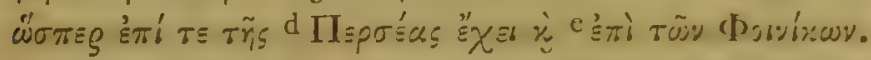

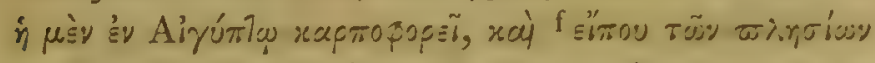

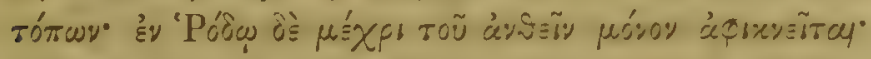

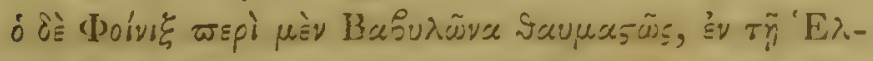

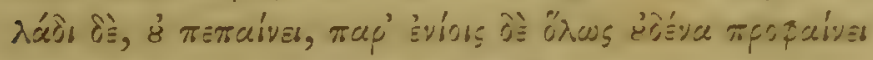

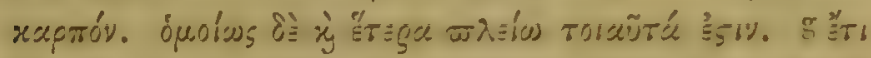

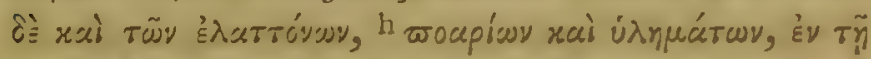

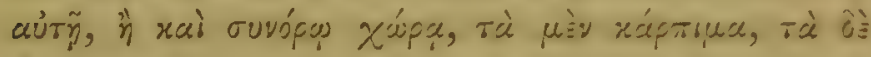

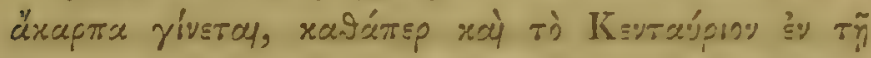

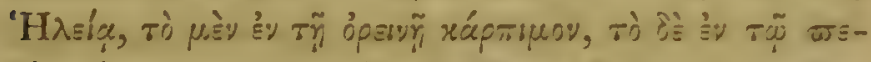

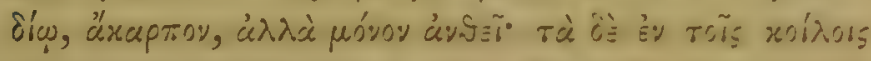

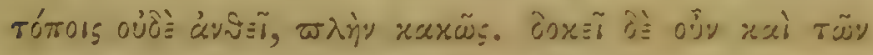

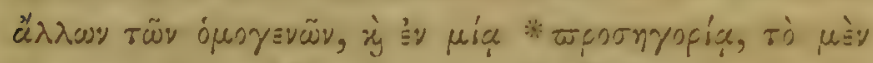

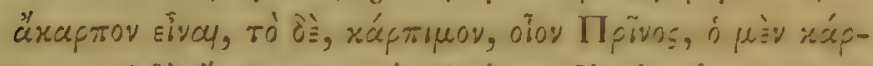

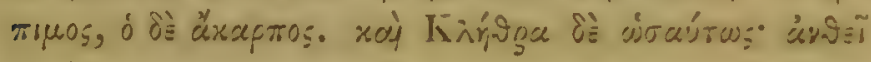

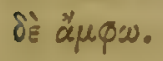

\section{CAP. IV.}

Arbores mares ct famina. (ierminatio primu, rel rerna. Galla et Purasita Quercus.

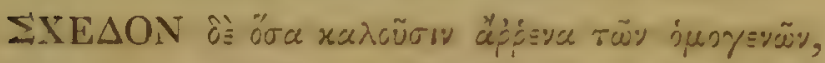

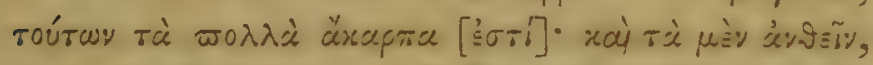

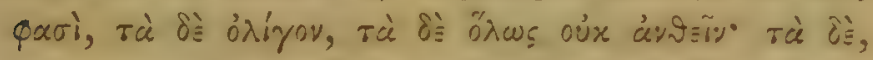

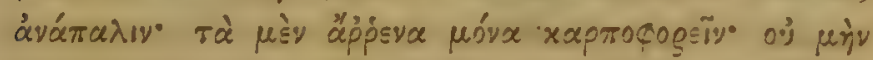

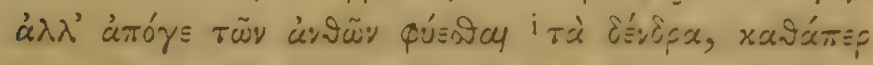

c oi Bod.

f เร้าเ $\approx 0$ Cี Const.

i rà divdga Bod. d IIggoines Bod.

' 'สя di Bod.

G 4 c isi deest Bod. b uregíar Ald. 


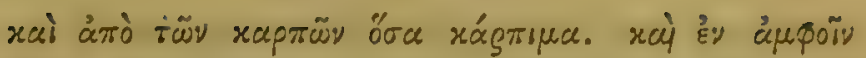

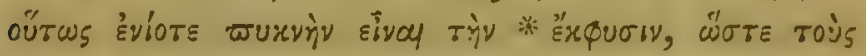

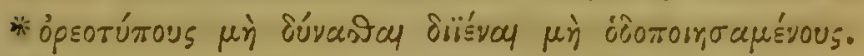

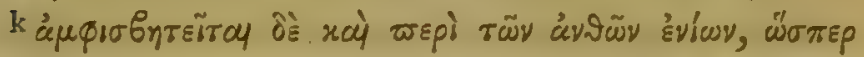

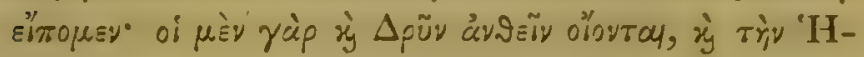

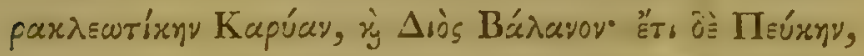

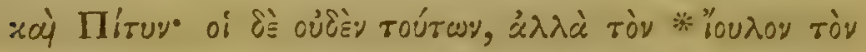

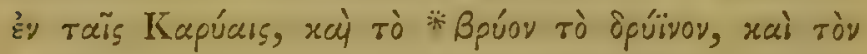

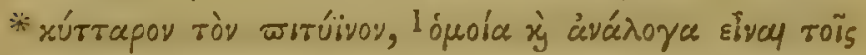

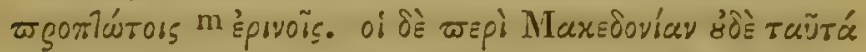

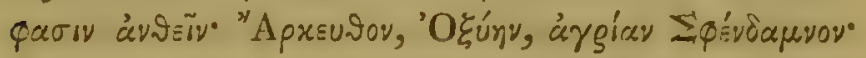

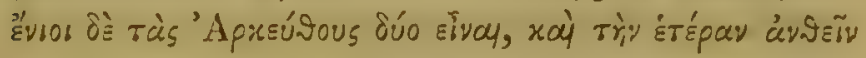

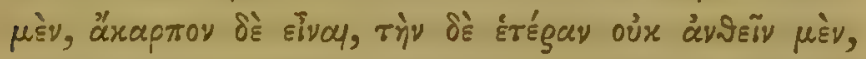

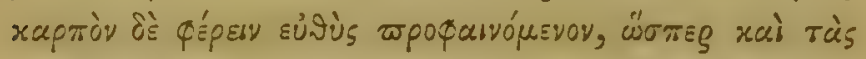

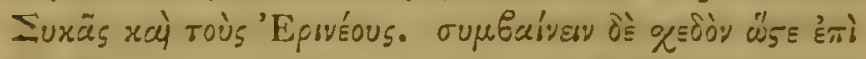

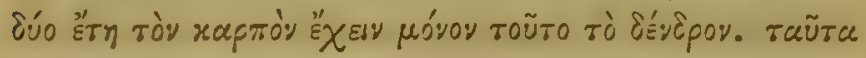

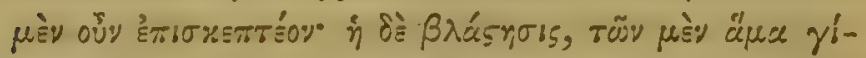

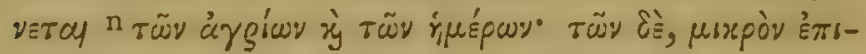

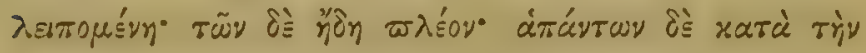

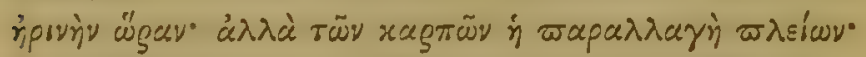

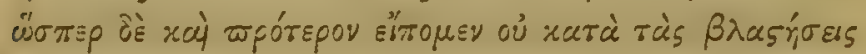

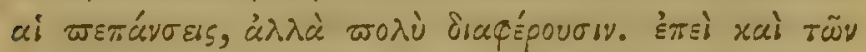

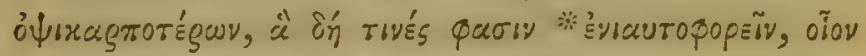

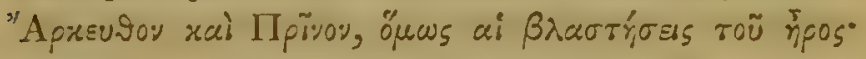

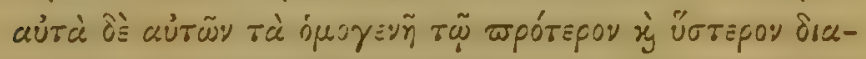

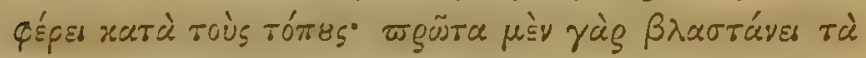

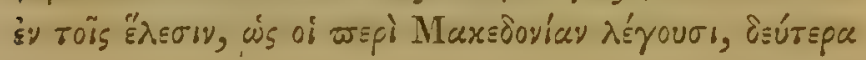

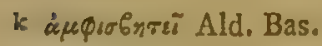

1 ¿́poiay xai àvádioyoy Bod. $m$ ig̨ıyois. Bod.

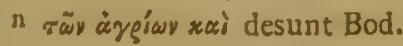




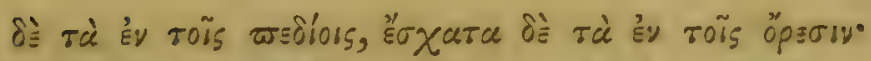

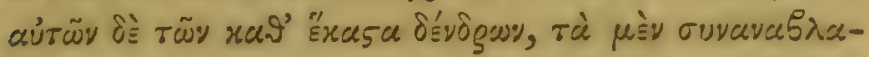

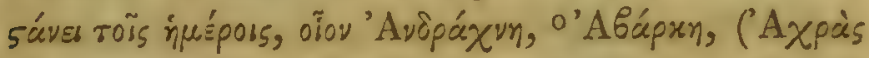

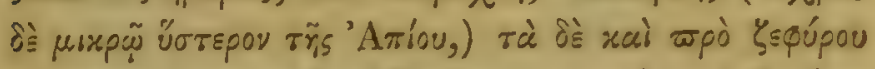

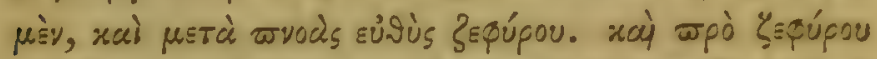

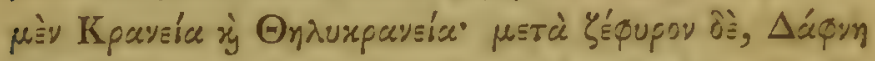

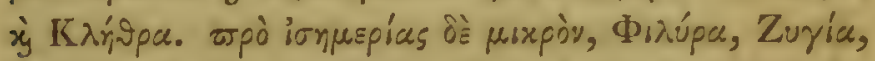

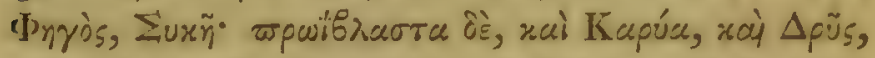

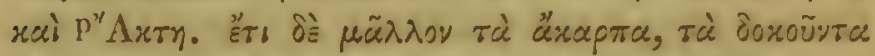

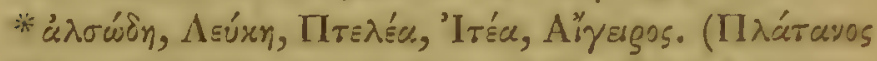

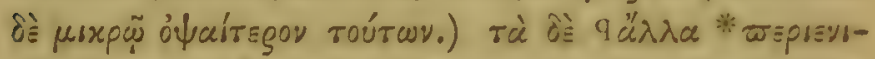

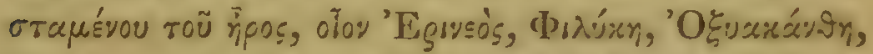

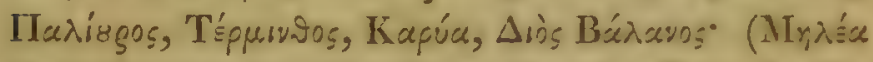

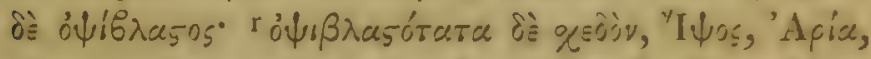

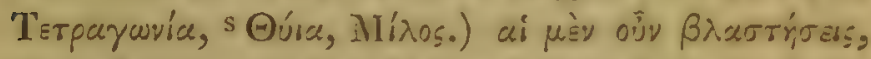

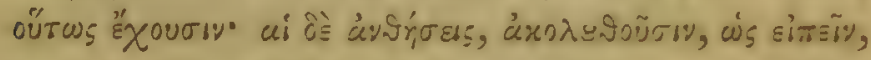

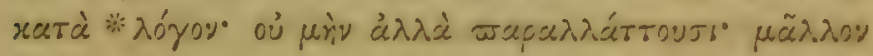

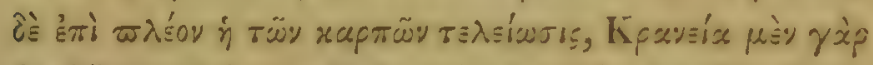

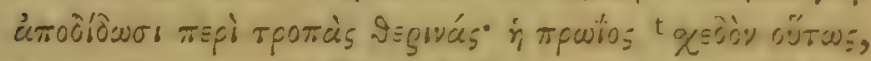

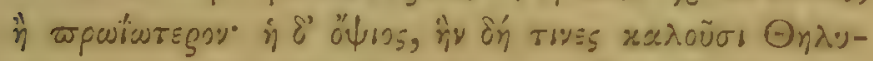

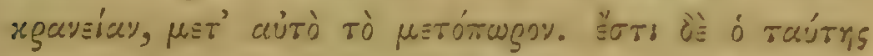

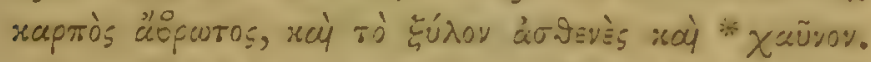

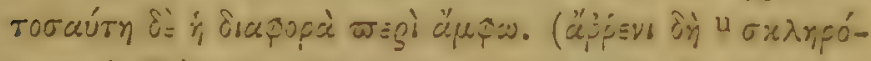

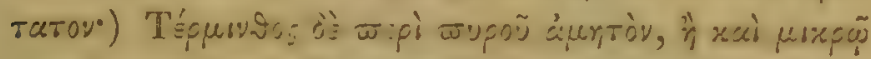

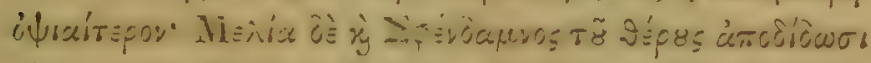

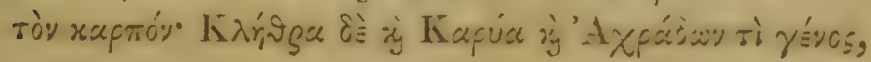

- ạ́ágxr, Const.

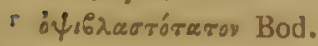

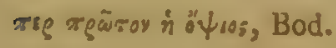
Const.

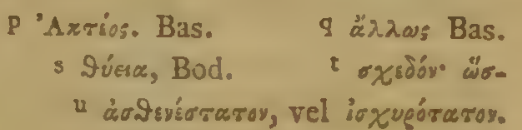




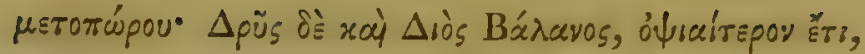

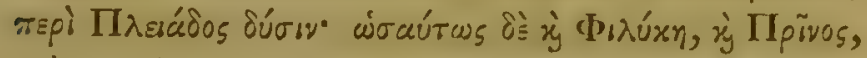

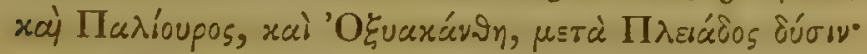

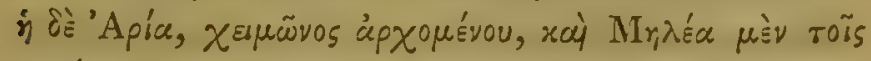

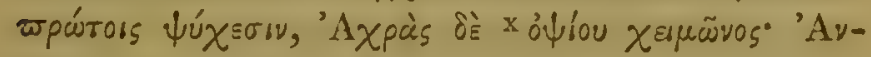

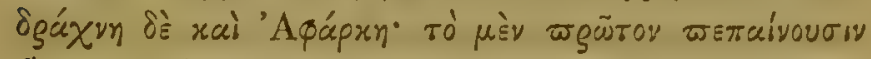

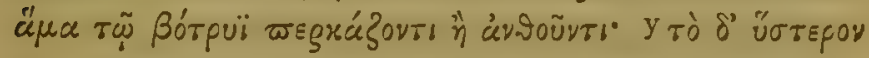

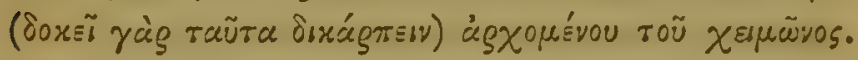

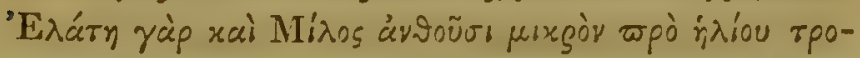

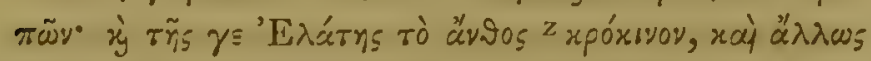

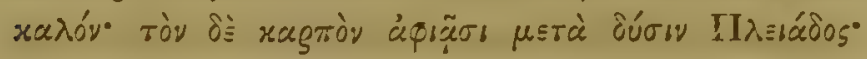

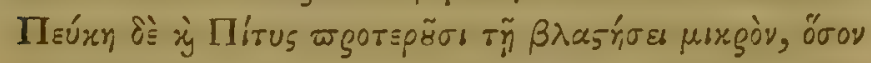

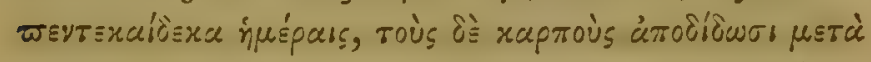

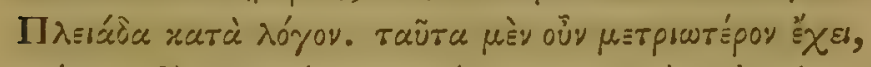

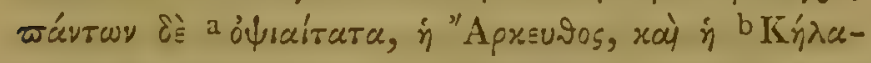

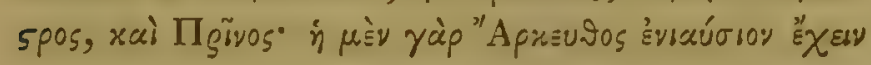

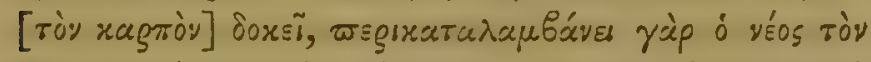

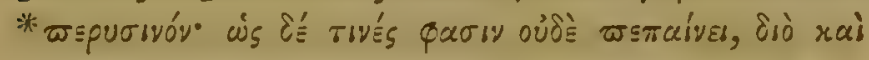

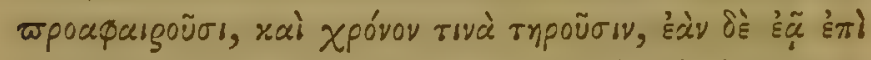

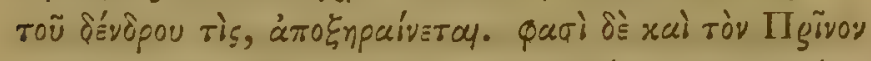

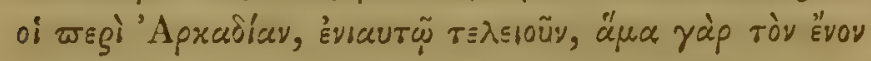

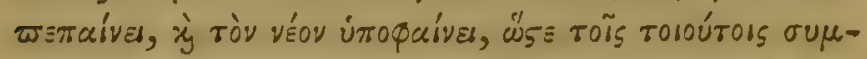

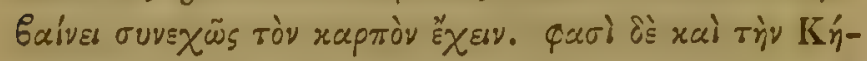

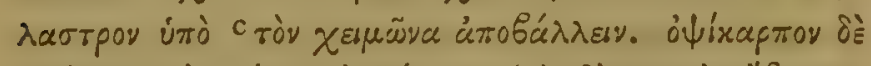

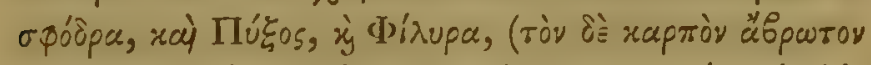

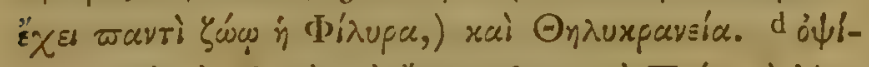

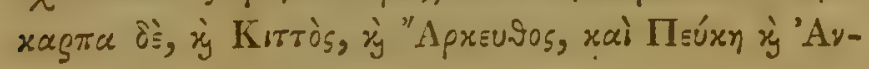

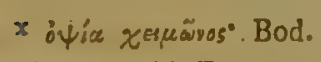
z xóxxavey, Ald. Bas.

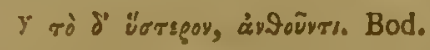

$$
\begin{aligned}
& \text { a } \pi \lambda \text { sífrny, Bod. } \\
& \text { b Kи́daбros, }
\end{aligned}
$$

Bod.

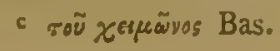




\section{MEPI TYTSN ISTOPIAS TO $\Gamma^{\prime} . \quad 9 \pi$}

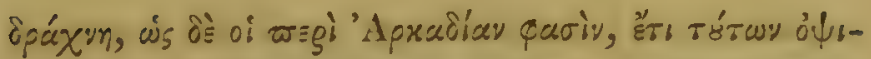

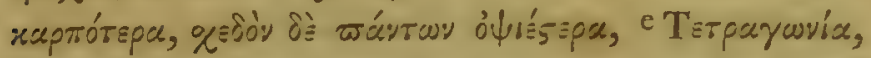

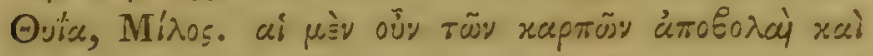

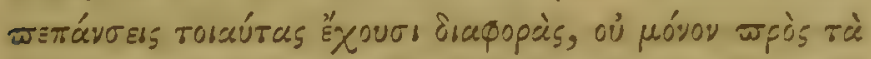

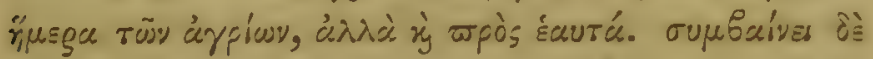

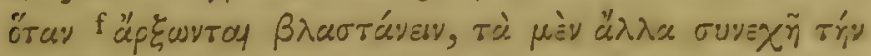

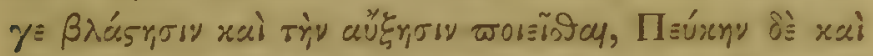

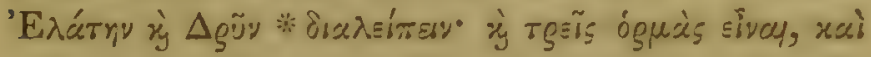

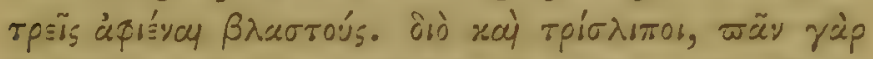

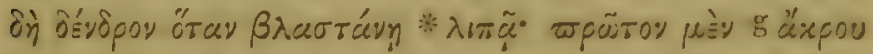

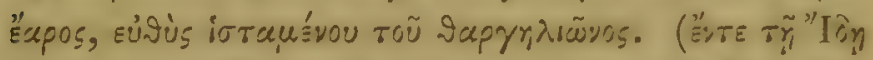

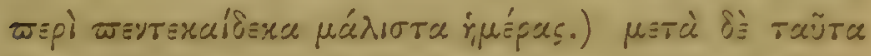

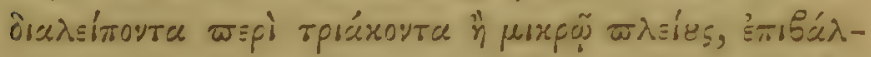

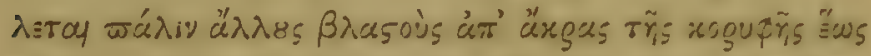

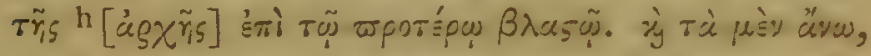

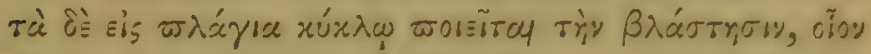

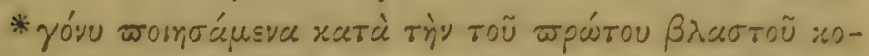

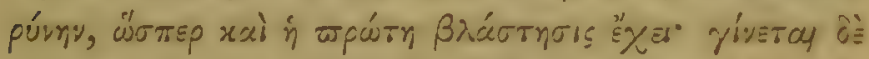

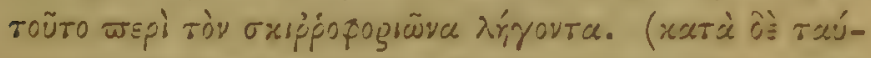

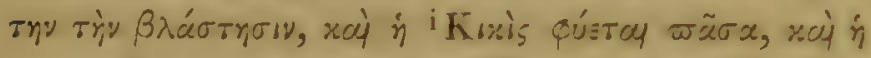

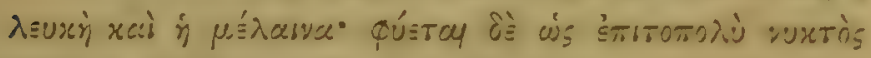

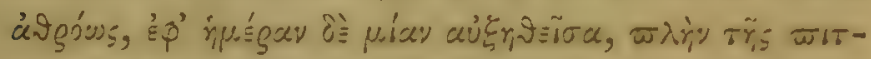

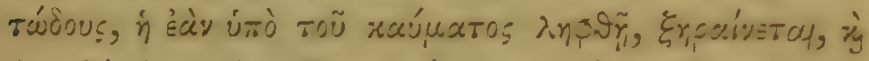

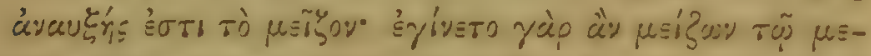

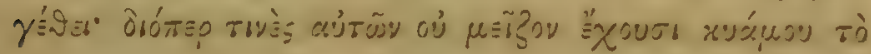

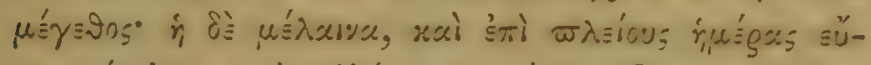

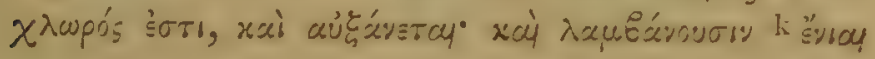
e rwvia, Bod.

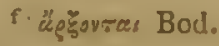
Const. Plin.
h $e_{\varrho} \chi \tilde{n} s$ deest Bod.

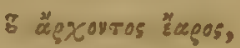
Vid, not. ad fin. libri.
k "ี้ $v$ ore Bod.
i Knxis Const. 


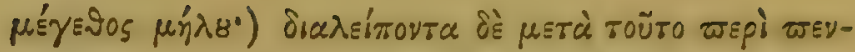

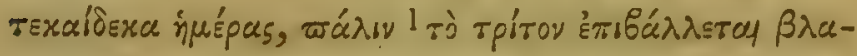

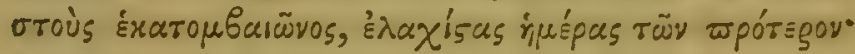

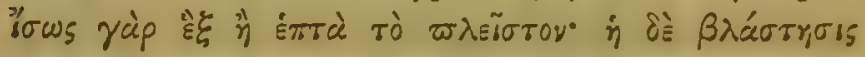

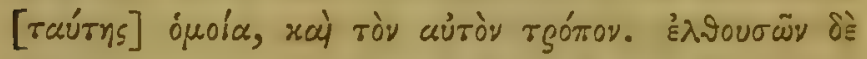

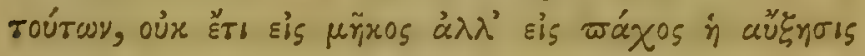

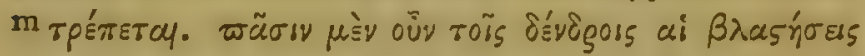

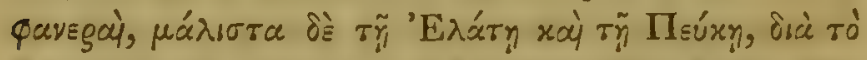

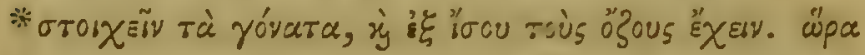

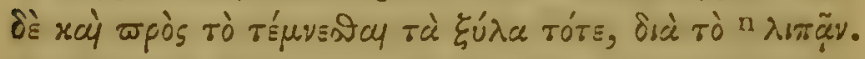

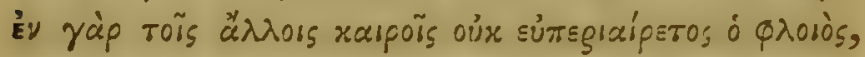

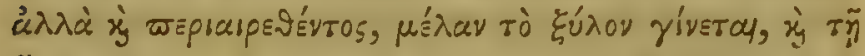

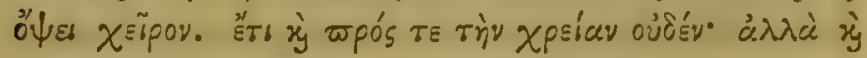

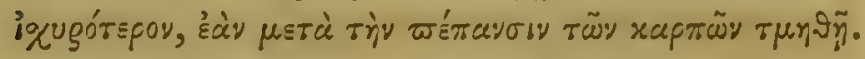

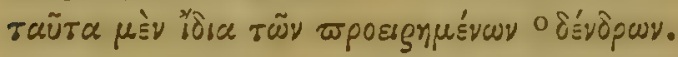

\section{CAP. V.}

Germinatio secunda, autumnalis. Amenta in Mronaciis. Radicum Differentia.

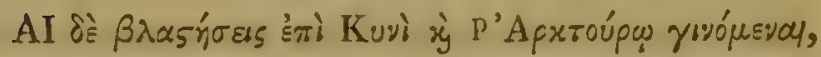

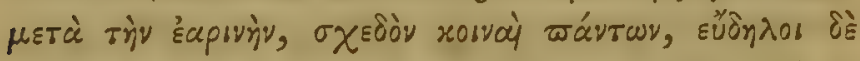

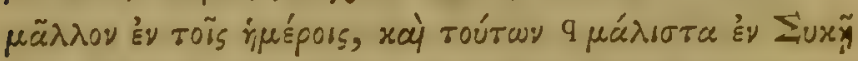

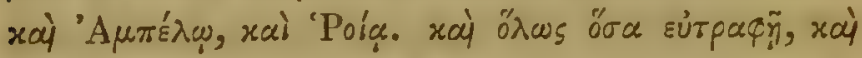

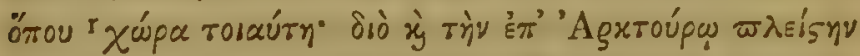

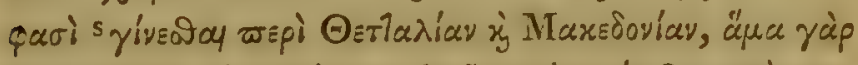

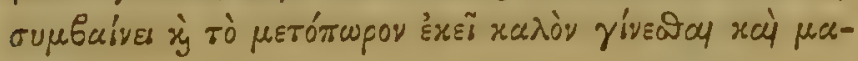

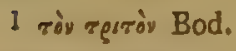

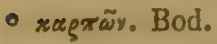

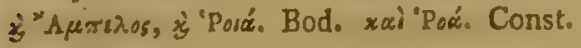

3 ysvigass Bod.

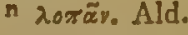

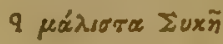
a wga. Const. 


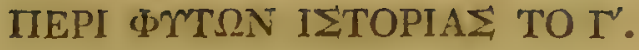

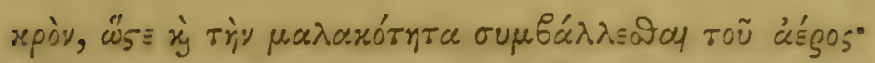

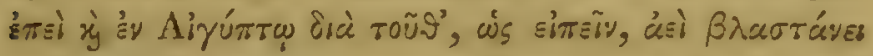

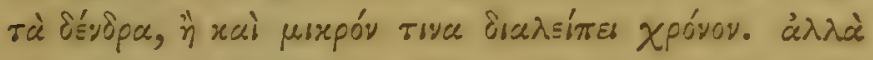

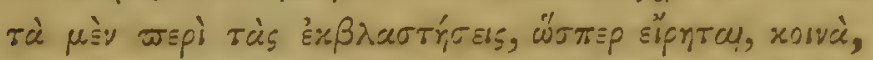

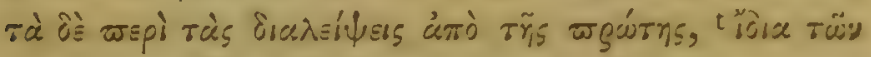

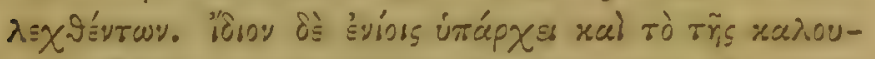

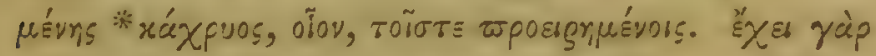

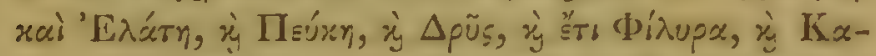

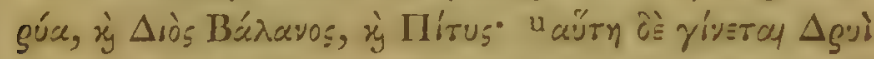

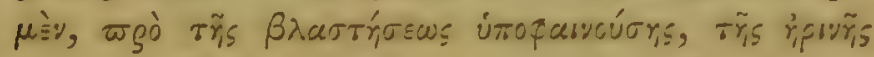

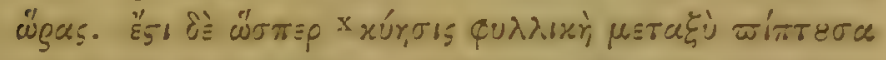

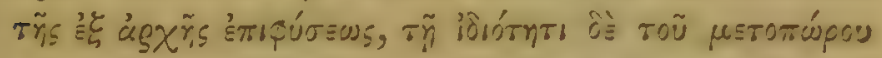

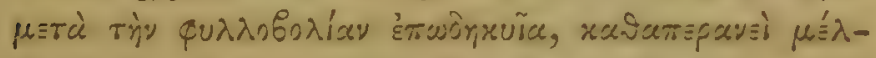

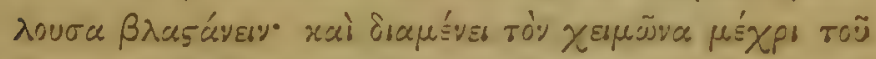

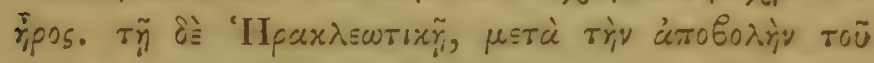

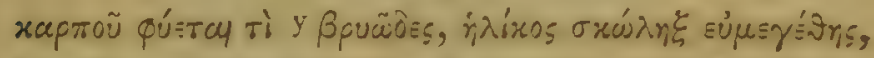

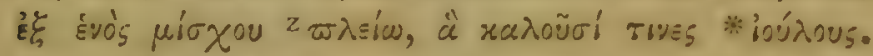

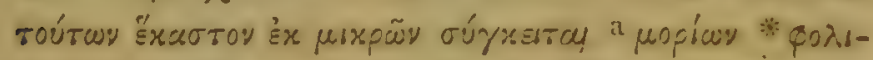

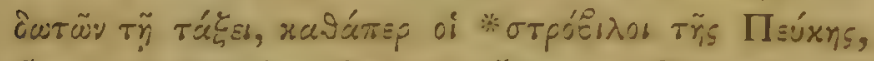

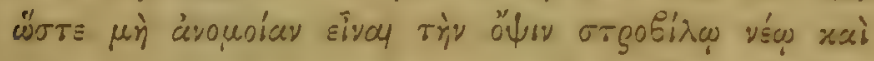

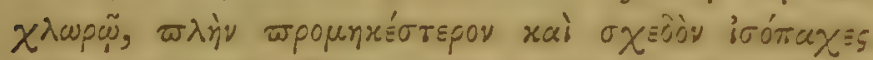

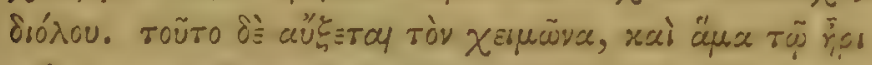

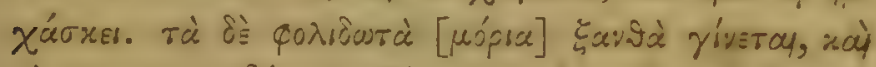

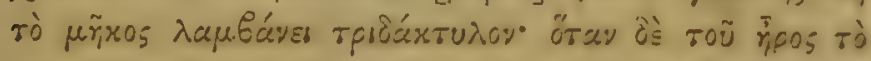

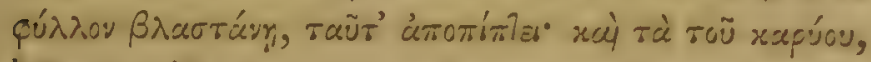

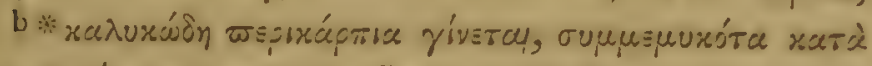

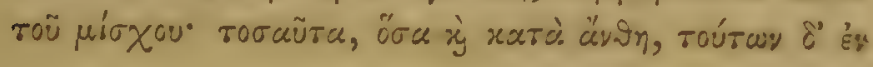

t sidy Const.

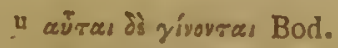

$x$ xúnois Qu.

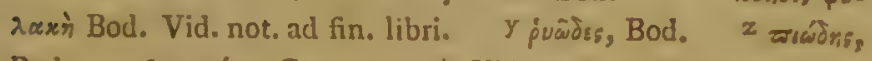

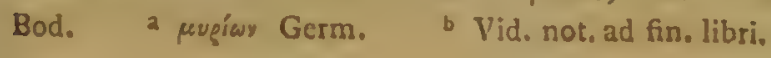




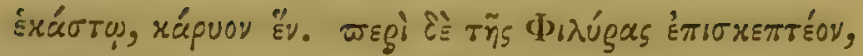

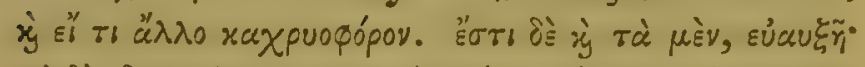

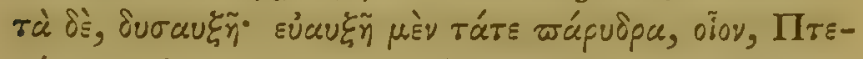

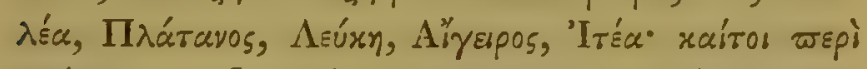

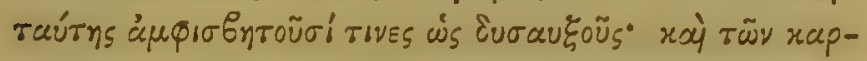

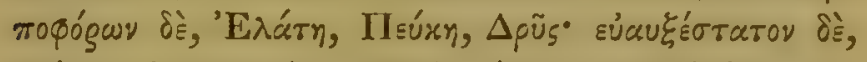

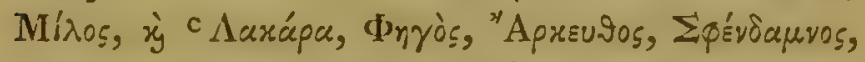

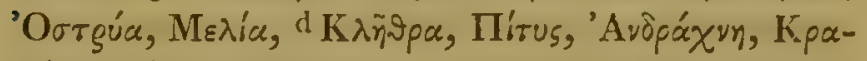

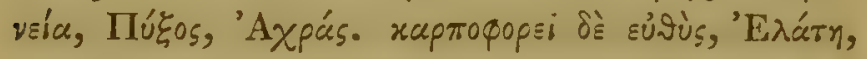

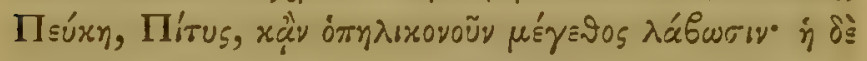

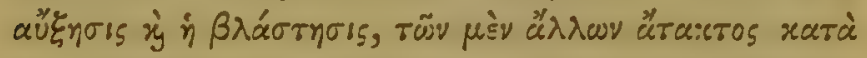

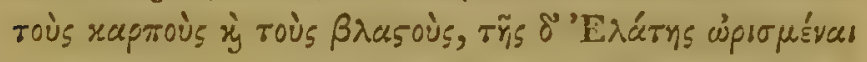

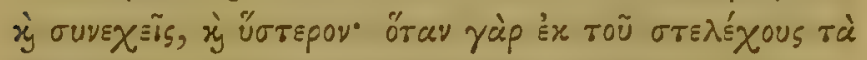

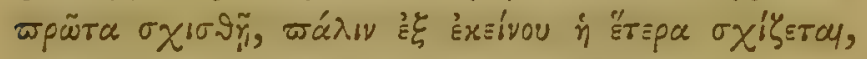

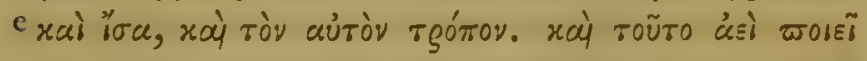

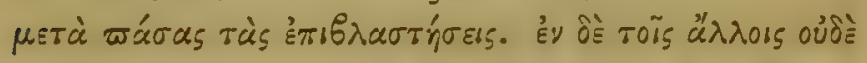

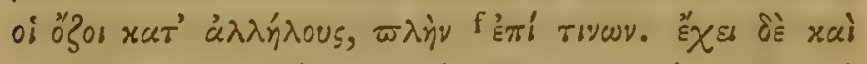

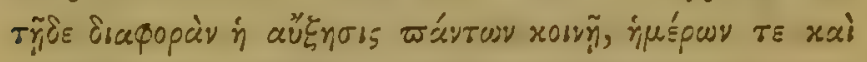

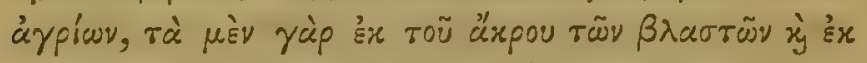

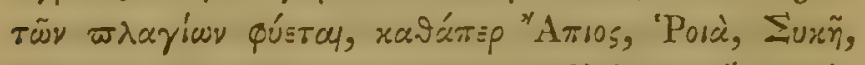

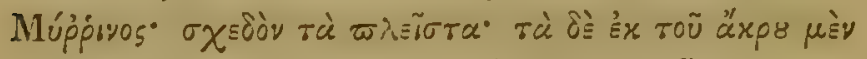

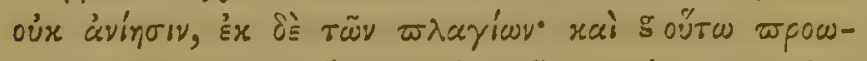

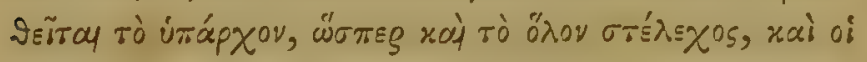

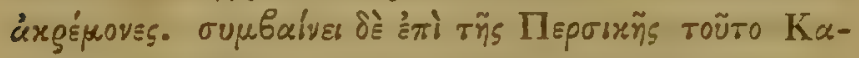

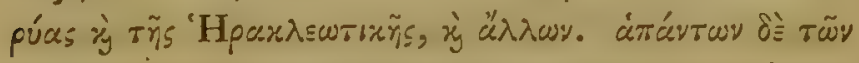

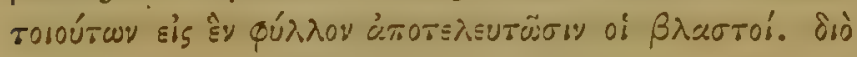

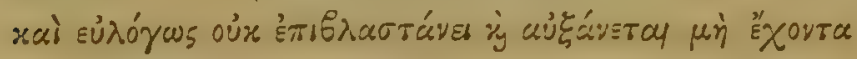

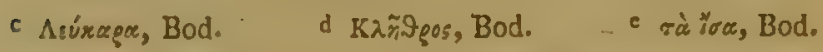

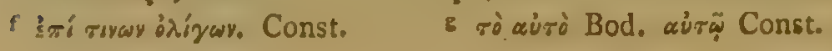




\section{MEPI $\Phi \Upsilon T \Omega N$ ISTOPIA}

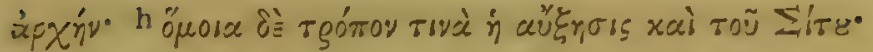

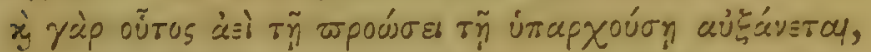

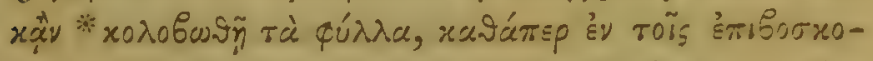

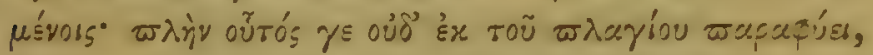

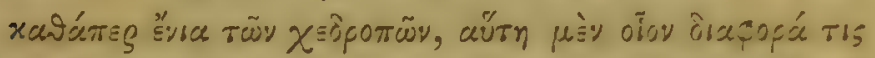

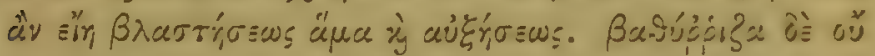

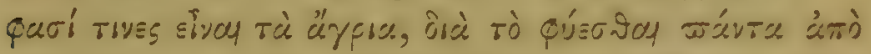

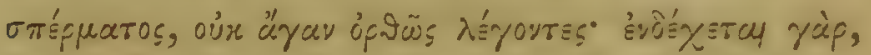

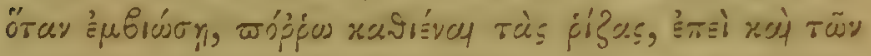

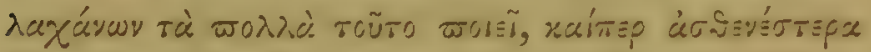

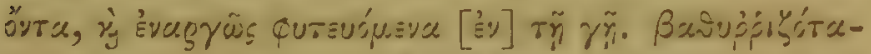

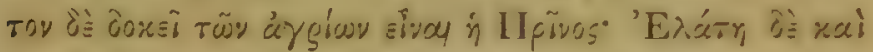

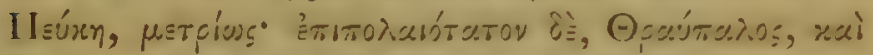

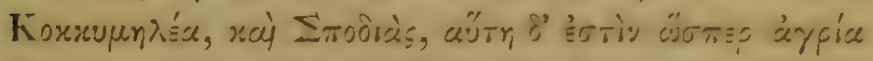

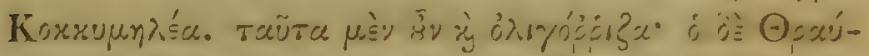

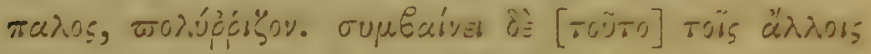

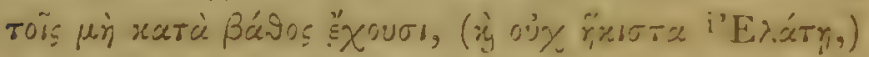

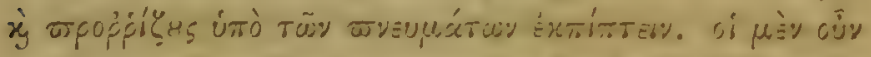

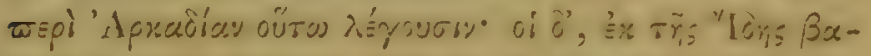

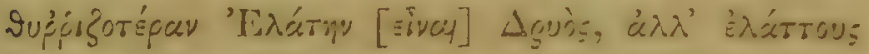

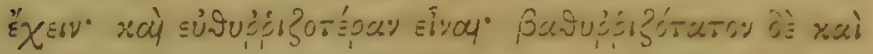

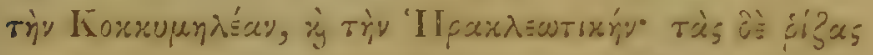

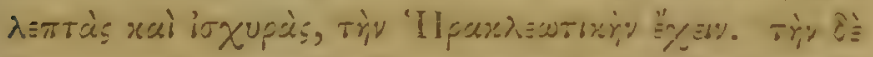

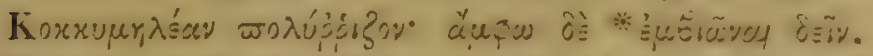

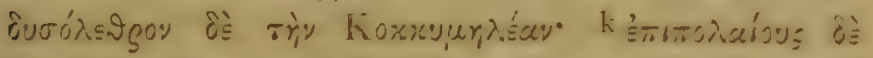

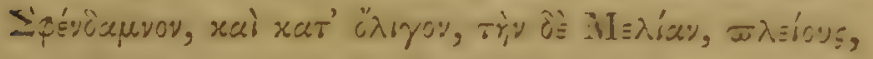

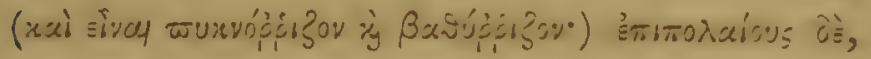

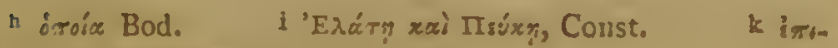

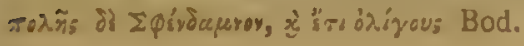




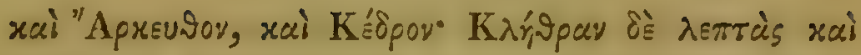

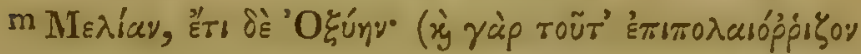

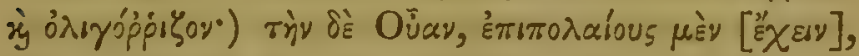

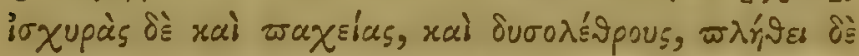

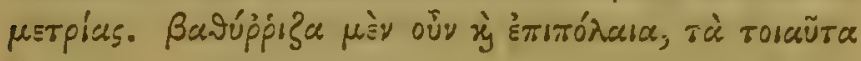
हैं

\section{CAP. VI.}

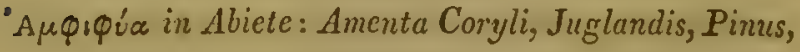
Quercus.

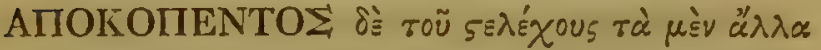

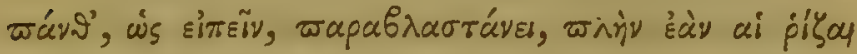

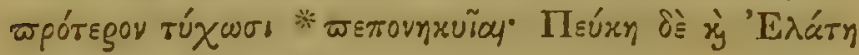

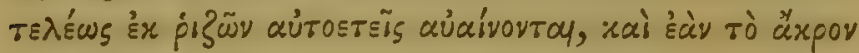

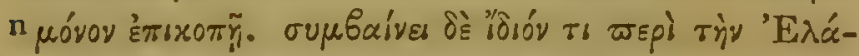
тท. ö

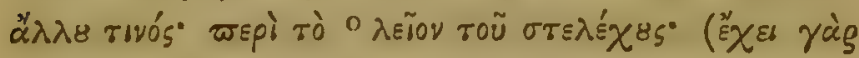

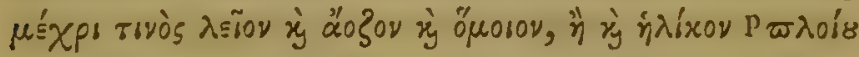

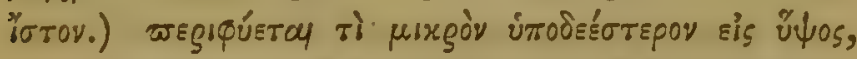

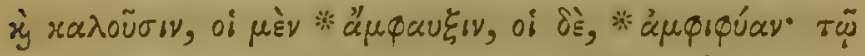

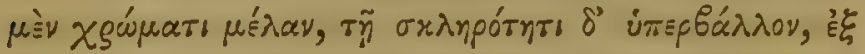

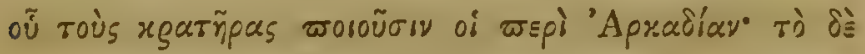

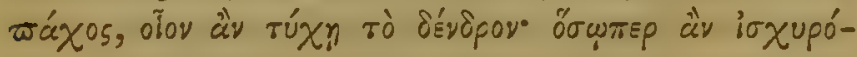

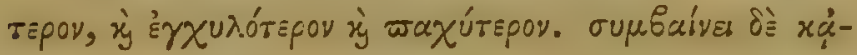

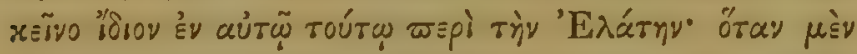

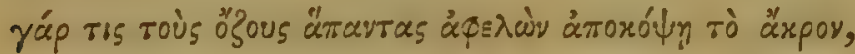

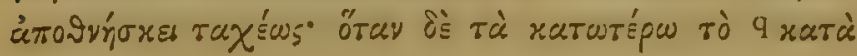

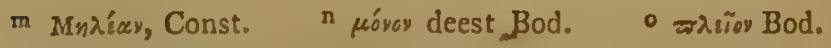

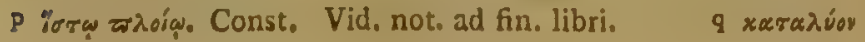
Bod. 


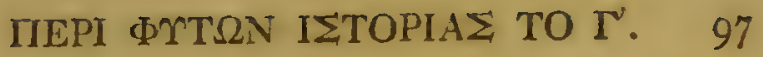

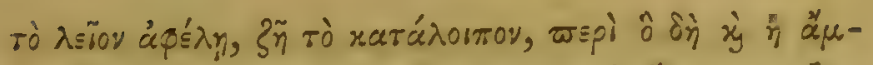

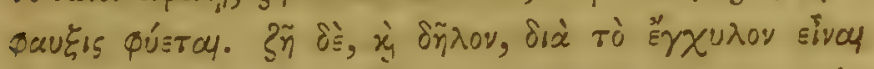

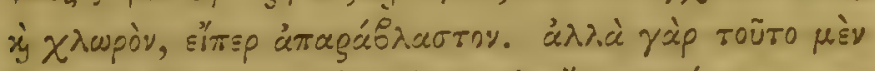

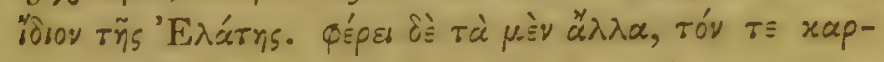

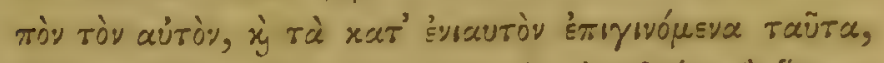

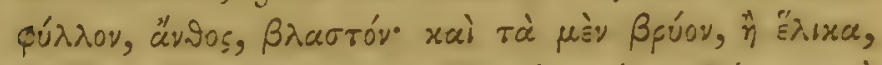

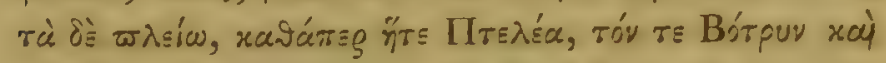

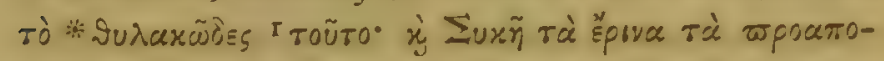

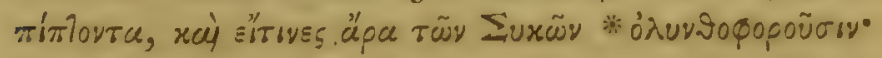

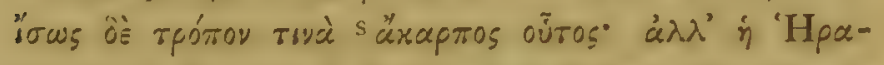

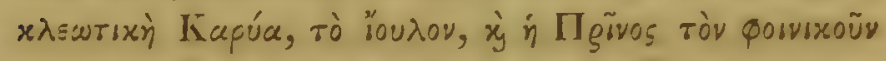

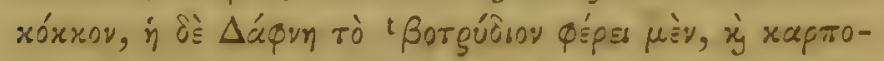

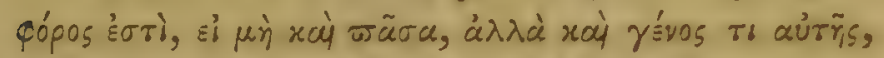

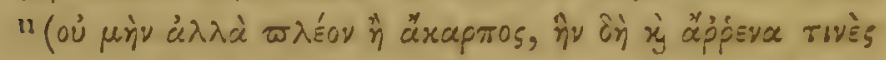

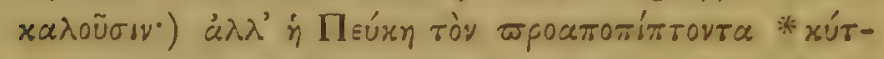

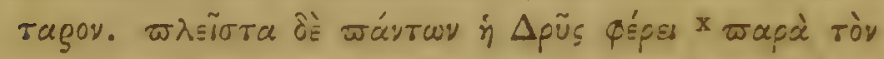

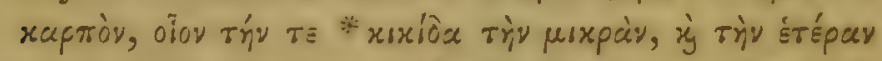

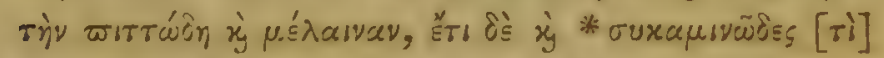

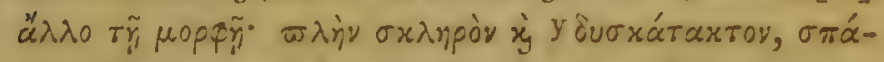

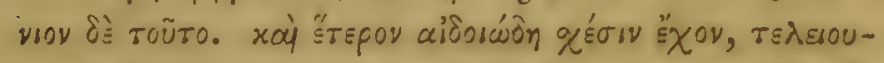

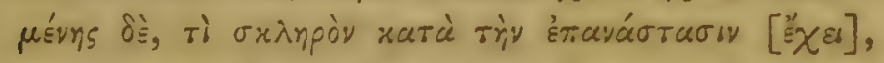

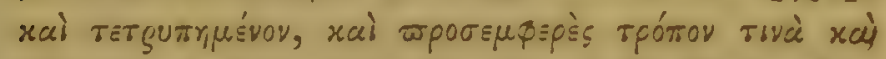

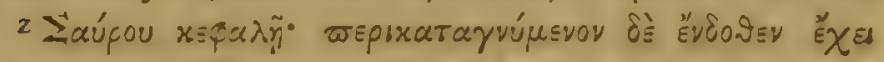

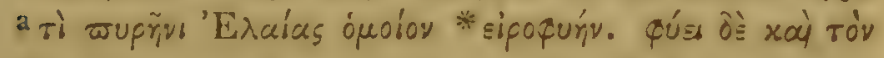

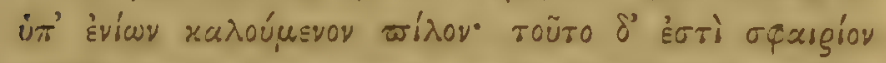
É

I oúrws" Const. s reẹrò̀s Const. 'Bórģuar Ald. u Vid.

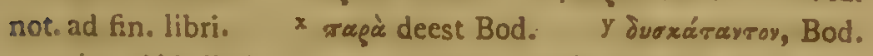

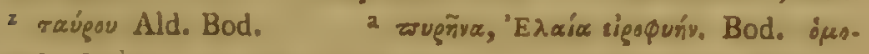

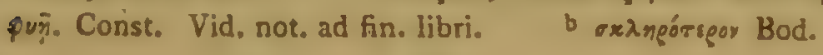




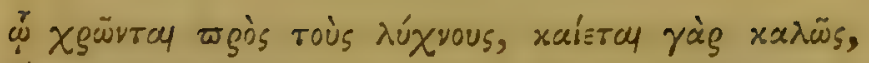

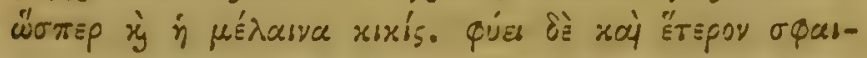

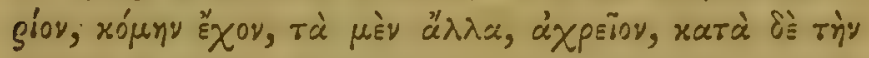

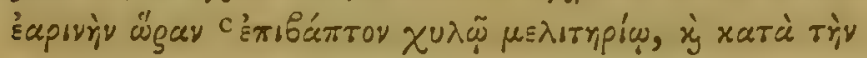

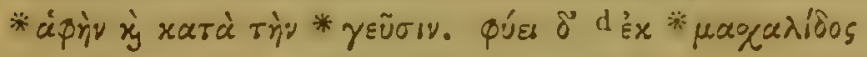

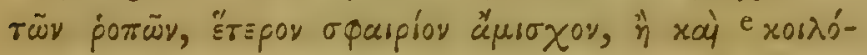

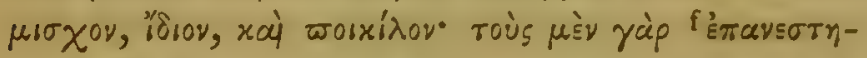

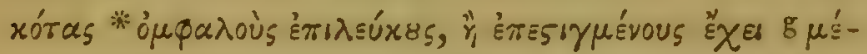

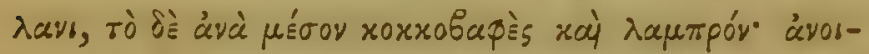

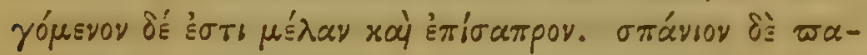

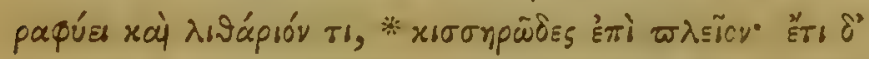

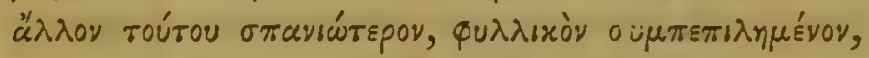

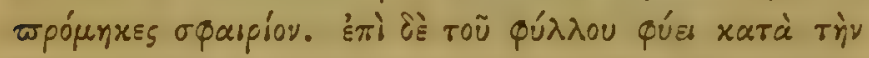

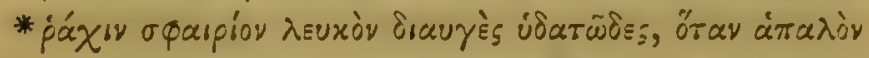

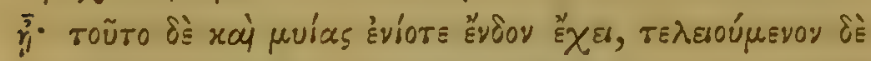

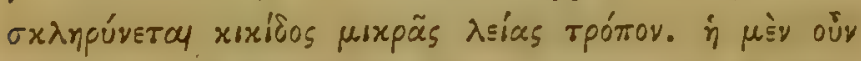

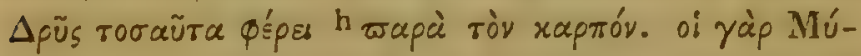

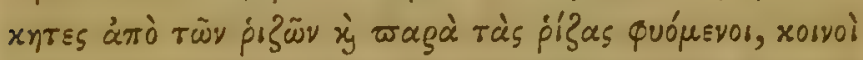

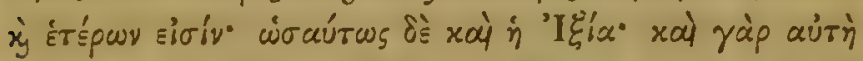

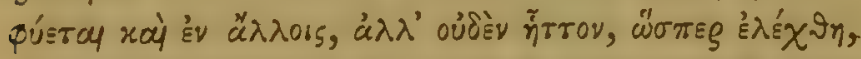

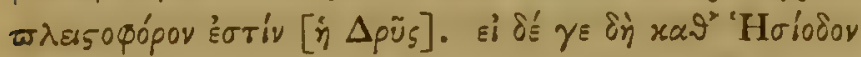

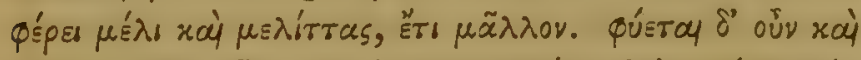

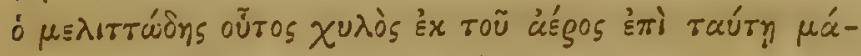

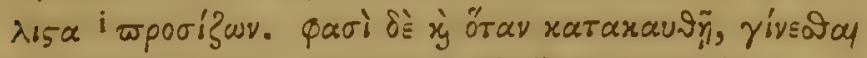

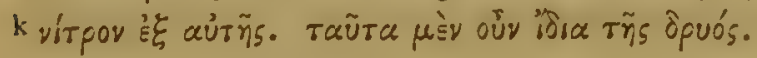

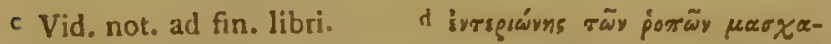

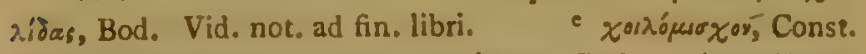

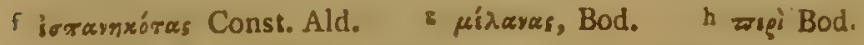

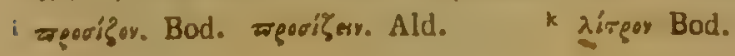




\section{CAP. VII.}

Mfas et füminu in Arboribus. De Roboris Generibus.

Differentice in Glandibus. De Gullis.

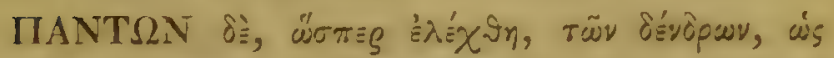

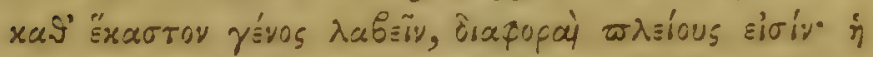

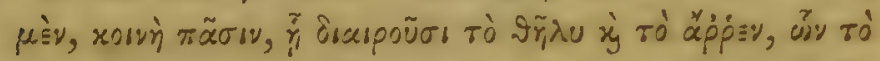

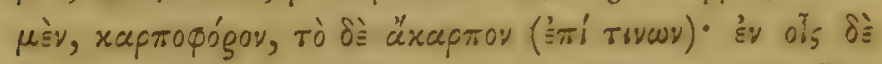

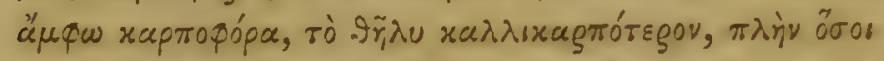

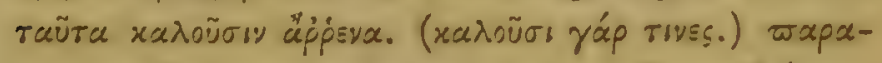
$\pi \lambda \dot{r}, \sigma s a, 1 \hat{n}$ ì

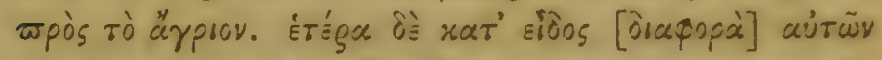

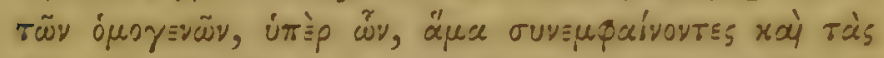

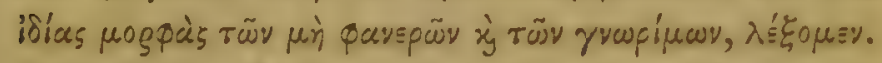

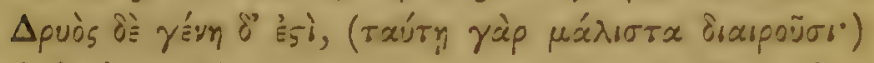

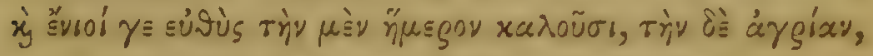

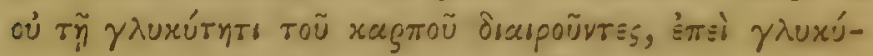

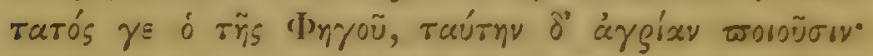

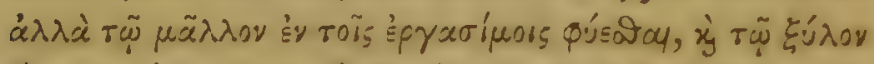

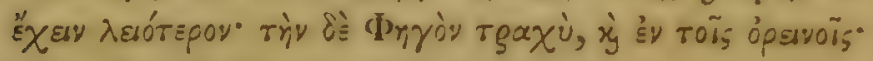

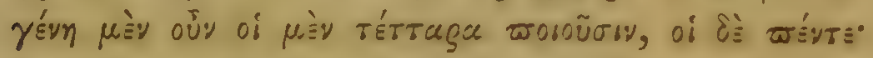

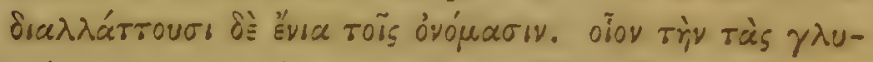

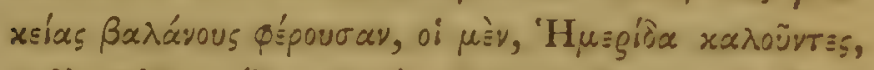

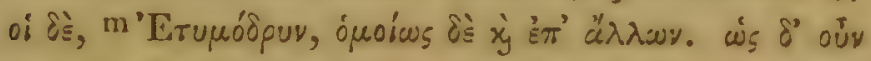

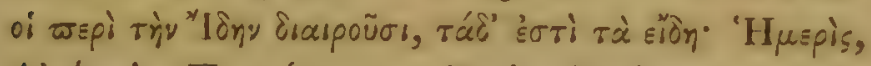
Airì

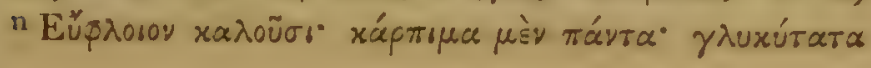

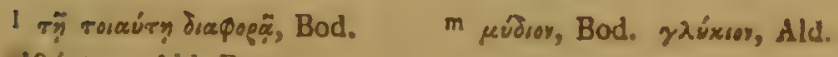
- sưqúqroor Ald. Bas. 


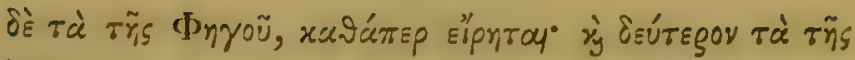

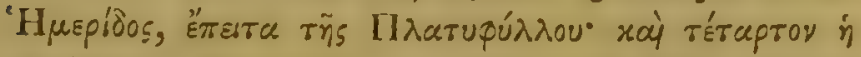

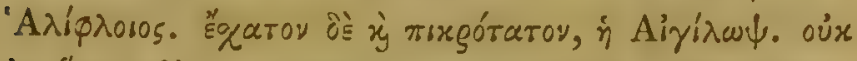

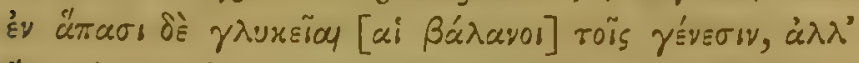

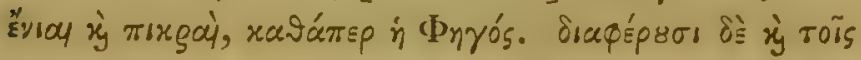

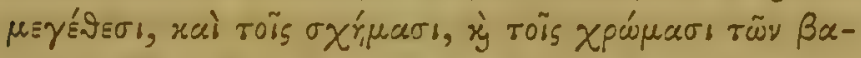

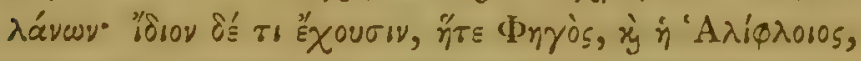

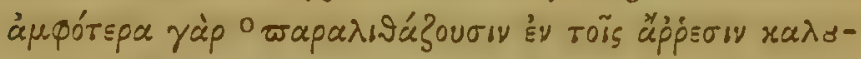

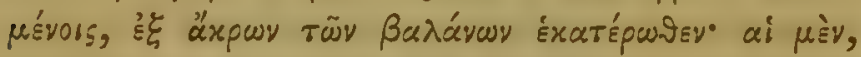

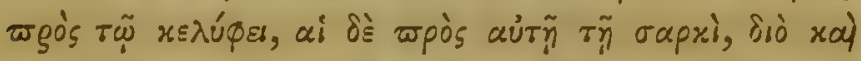

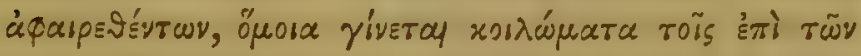

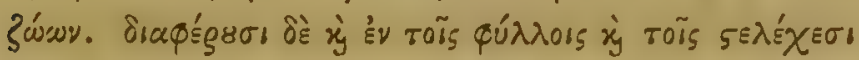

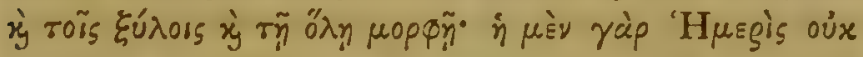

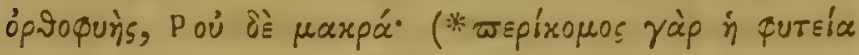

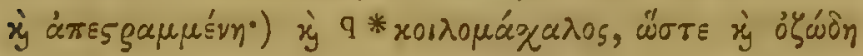

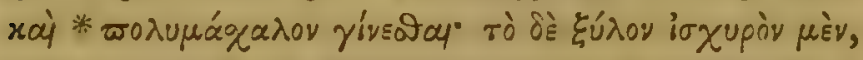

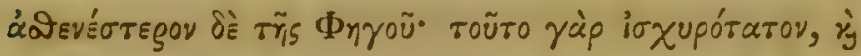

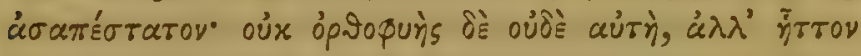

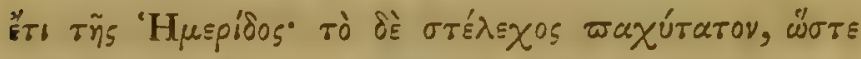

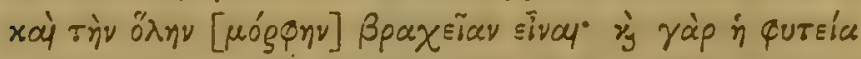

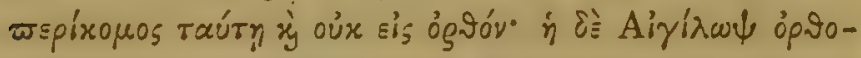

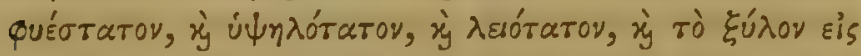

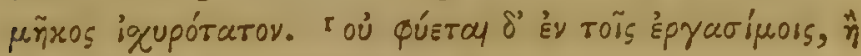

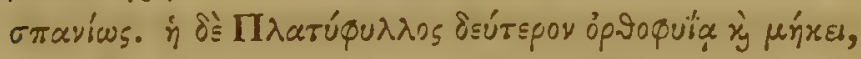

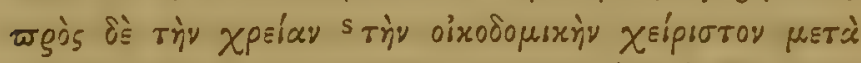

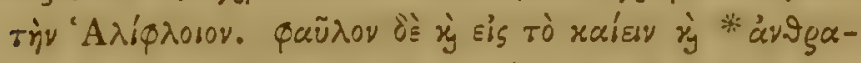
xะúav,

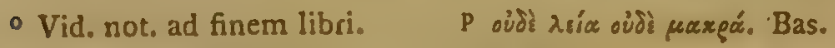

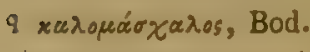
$r$ ou deest Bod. $s$ ชที่ ดixยBouisĩs Const. t. Sprowioratar Bod. 


\section{MEPI WMTSN ISTOPIA TO $\Gamma^{\prime} . \quad$ IOI}

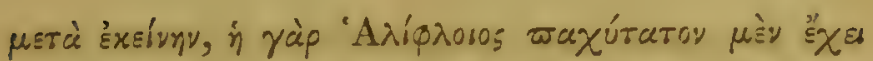

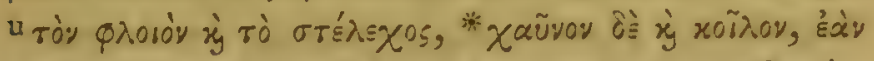

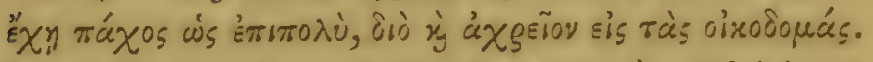

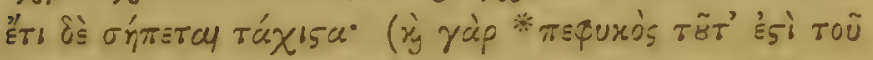

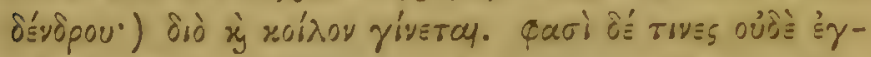

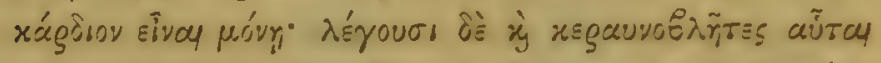

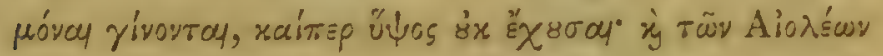

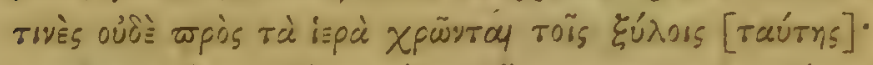

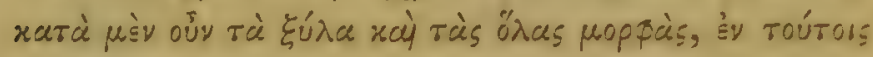

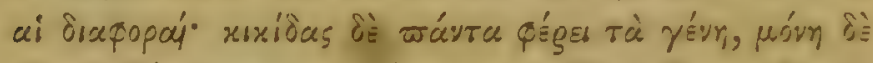

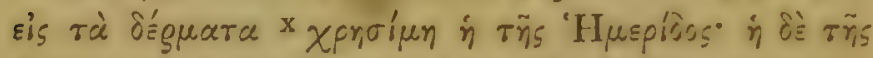
Airid

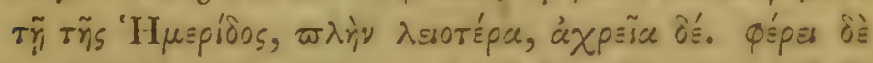

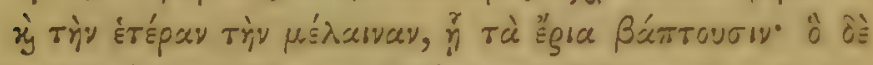

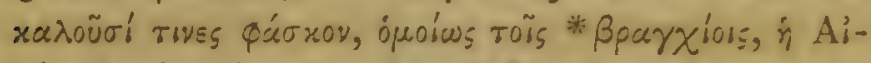

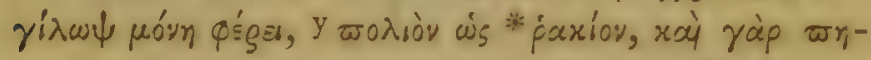

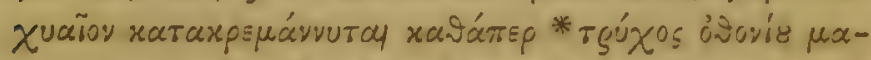

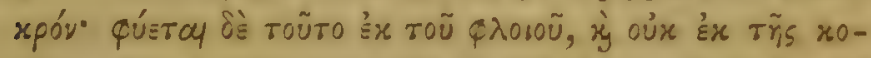
gúvทs, "̛̀ง

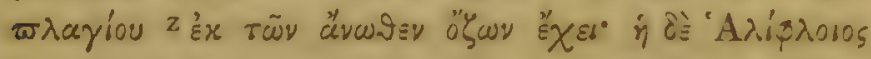

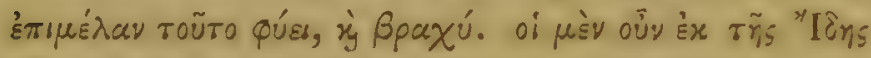

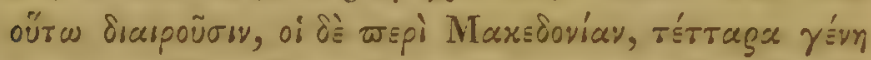

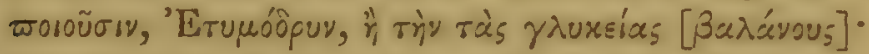

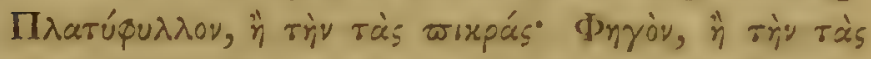

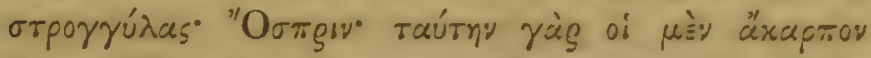

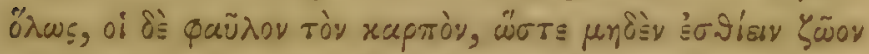

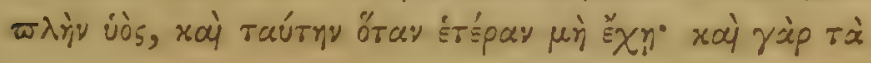

4 ròv proiò desunt Bod.

$Y$ zodiòy xai ß̧áxuav, Bod.

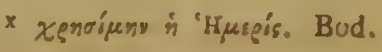

$z$ ix deest Bod.

H 3 


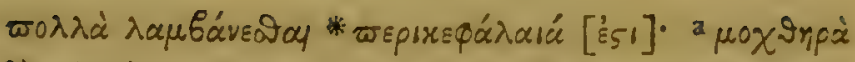

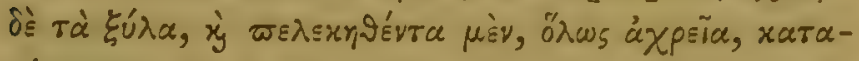

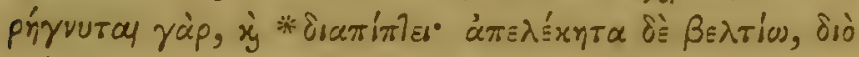

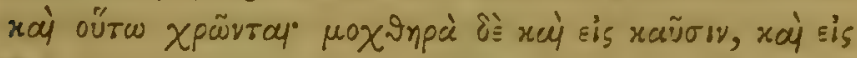

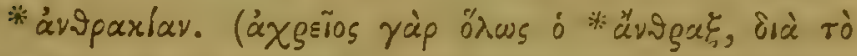

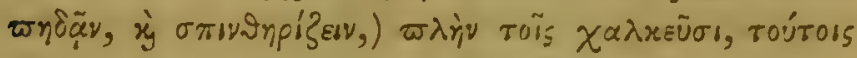

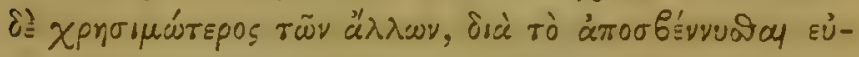

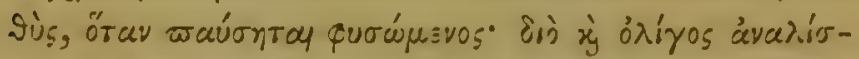

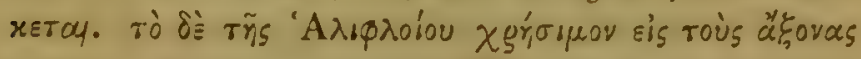

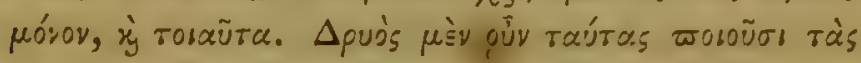

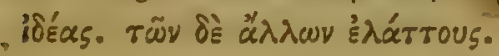

\section{CAP. VIII.}

Pinus sylzestris, P. Pinea rel Cembra? Pircu, Albies.

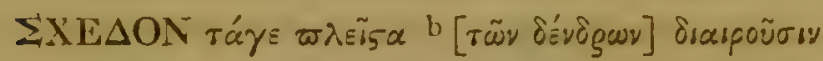

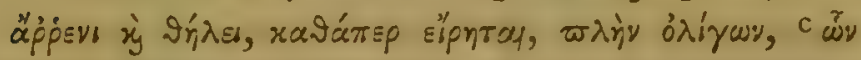

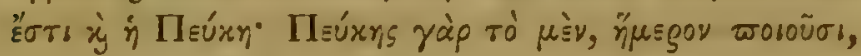

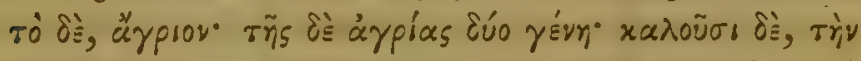

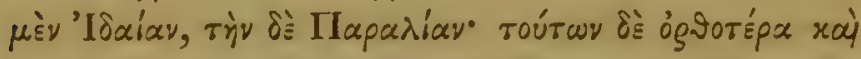

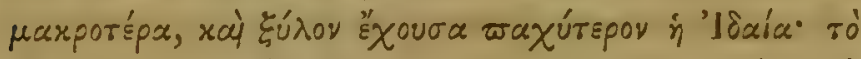

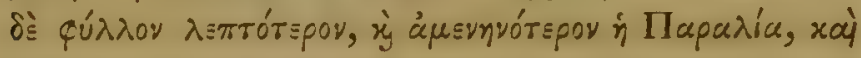

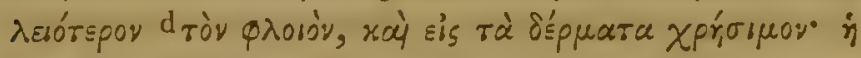

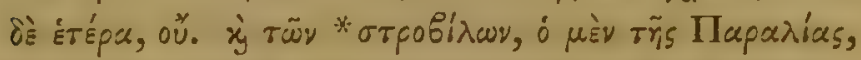

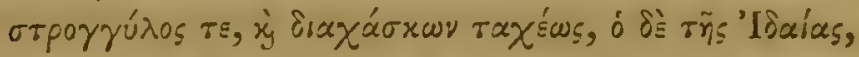

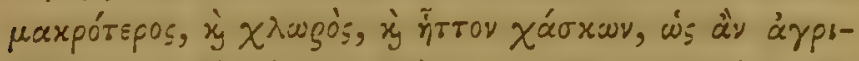

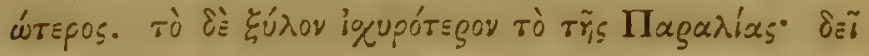

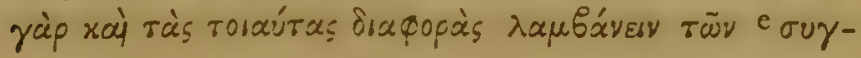

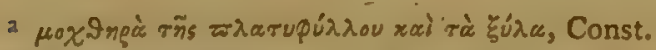

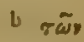
Jivegay desunt Bod.

$c$ wis Bod.

u rò prociòv, Bod.

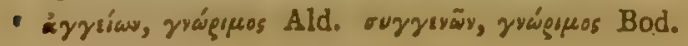




\section{MEPI TMTSN ISTOPIAভ TO $\Gamma^{\prime} \cdot 103$}

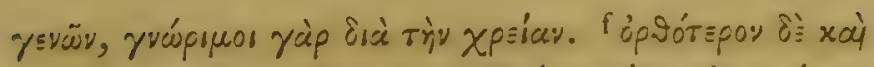

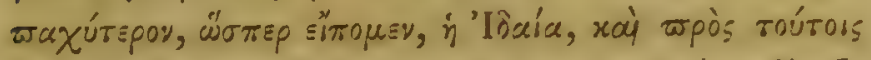

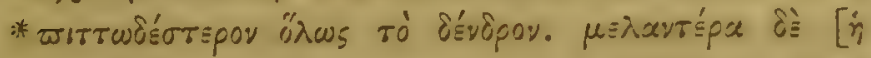

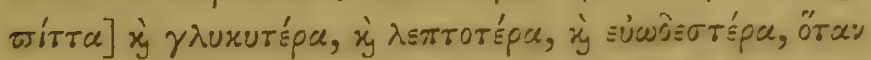

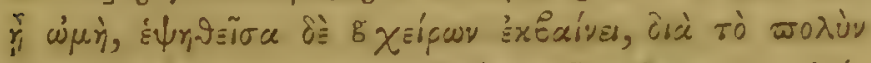

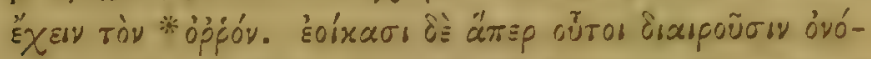

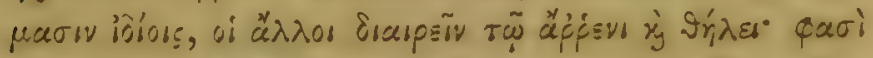

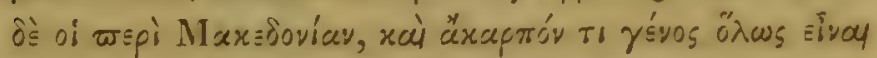

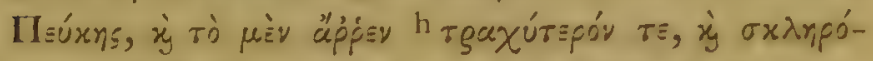

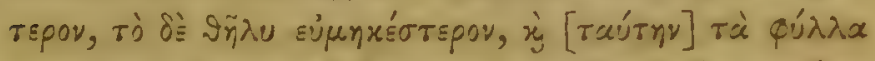

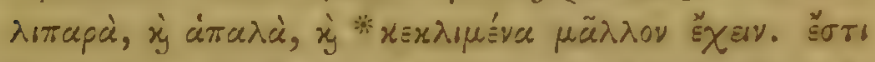

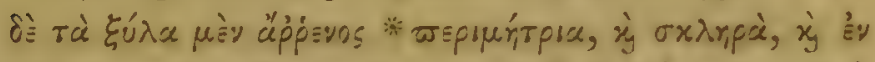

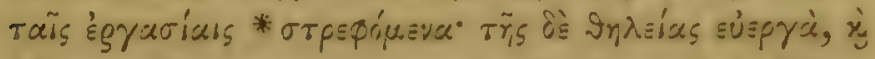

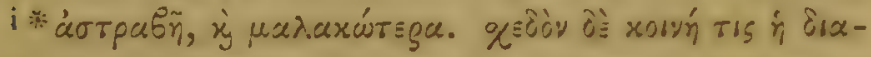

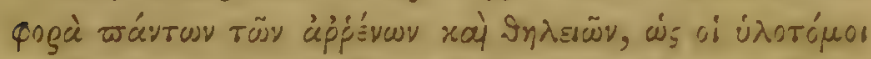

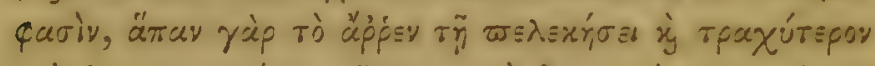

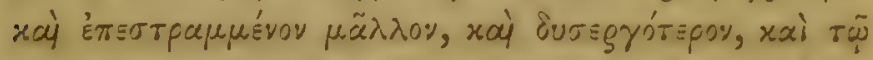

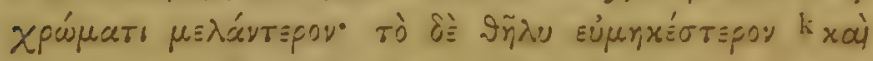

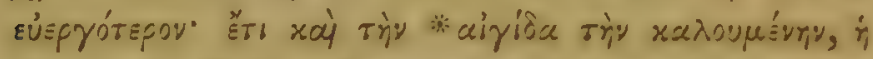

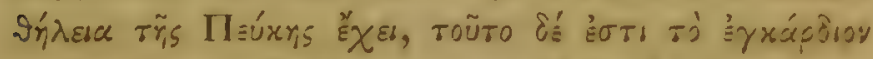

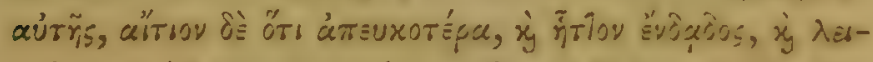

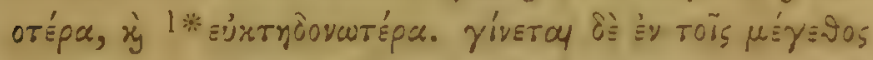

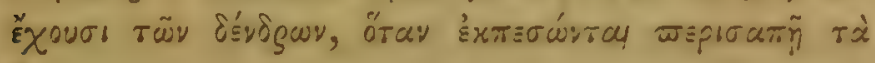

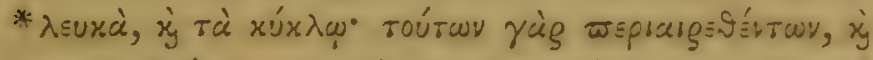

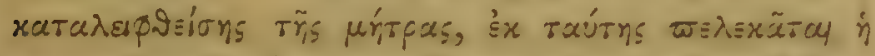

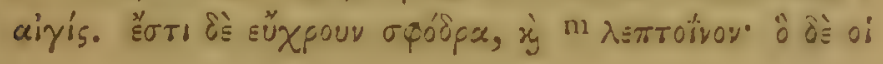

f ̇̌órsear Ald. Bas.

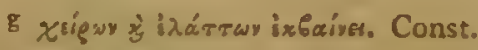

ho Bequxureger Bod. desunt Bod.

i sioręueñ, Bas.

$k$ xui sisogrórşar m ว.sтrive. Bod.

H 4 


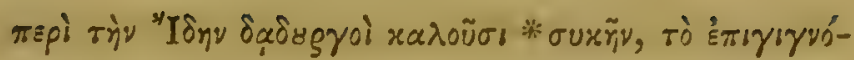

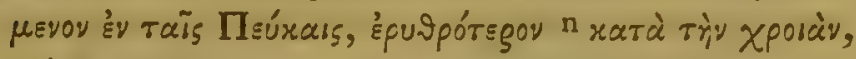

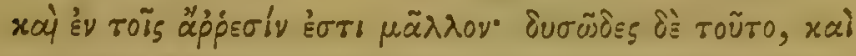
oủx ơ้

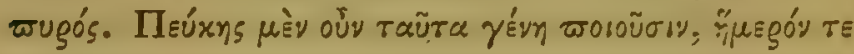

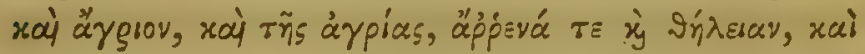

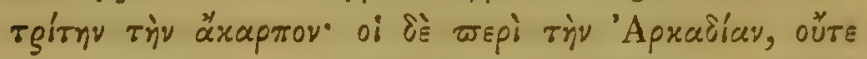

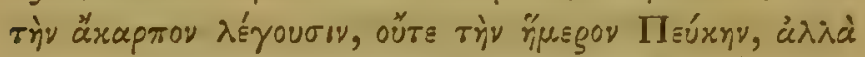

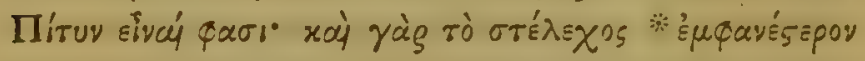

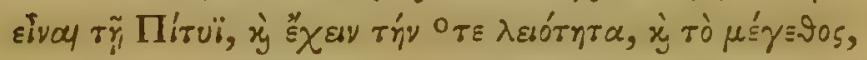

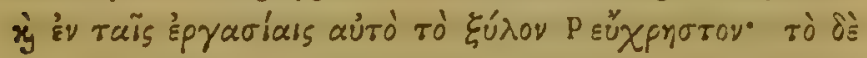

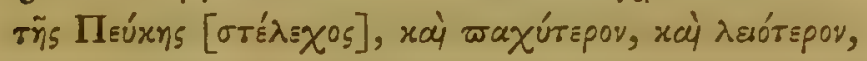

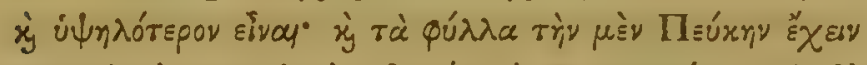

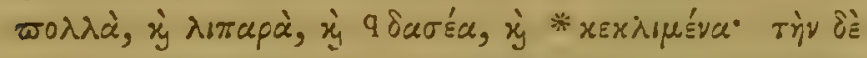

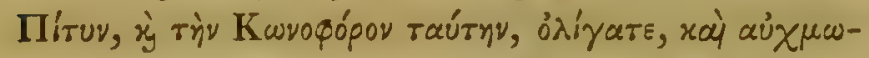

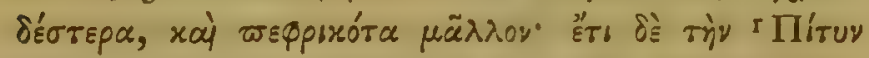

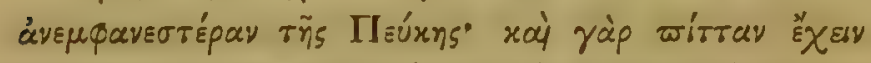

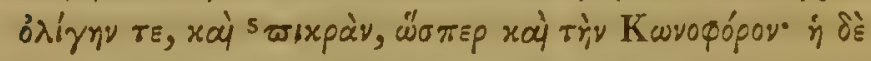

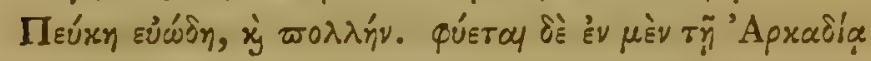

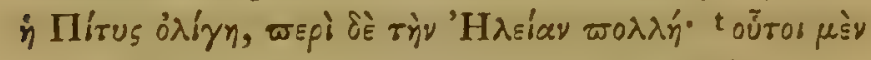

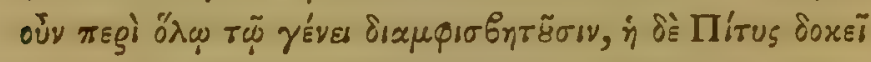

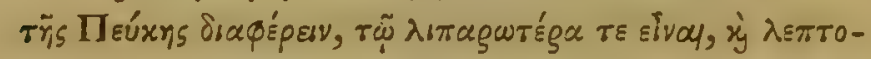

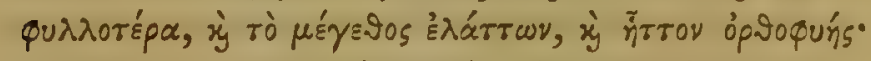

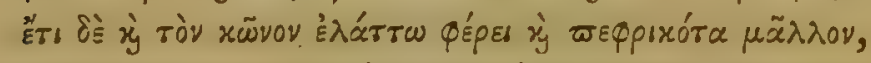

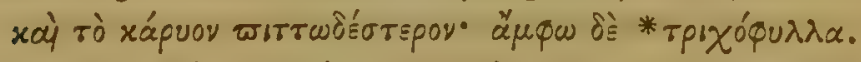

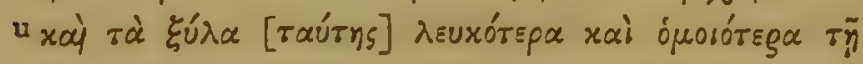

$\pi$ xaі รиे Bod.

deest Bod.

Const. q Bastix, Bod.

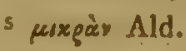
IIíruos Eúrie Const. 


\section{MEPI ФMT $\Omega N$ ISTOPIA TO T'. 105}

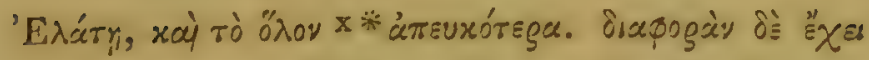

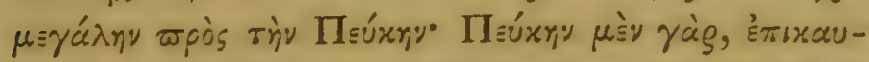

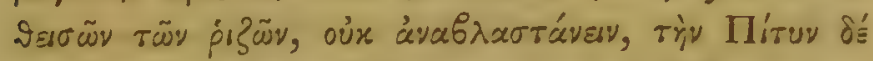

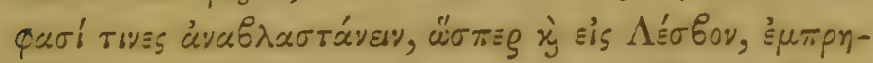

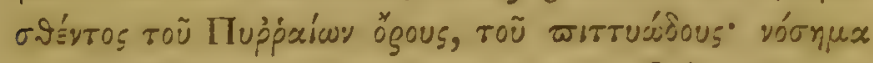

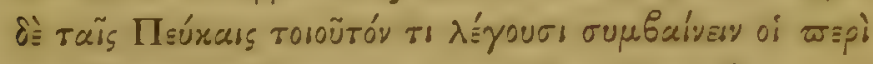

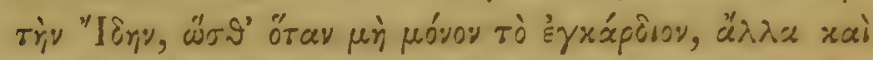

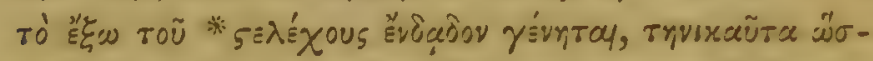

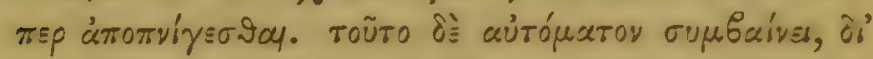

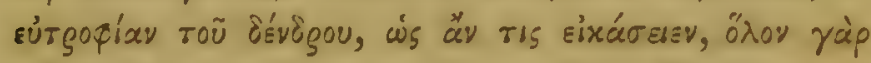

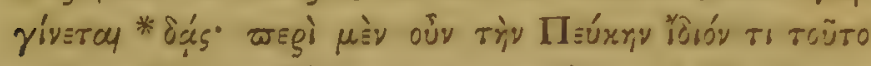

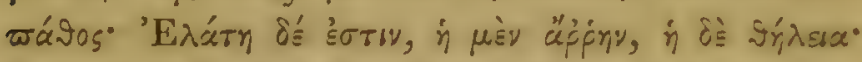

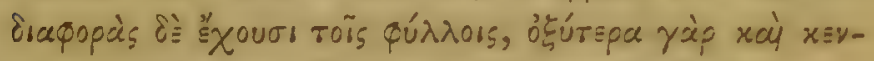

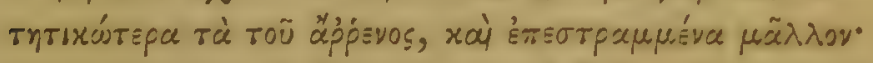

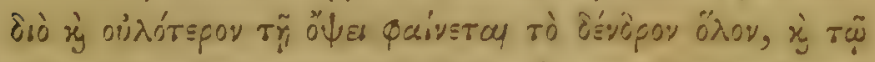

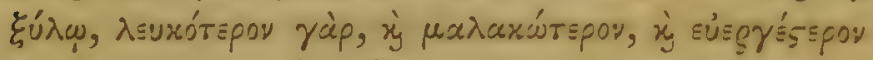

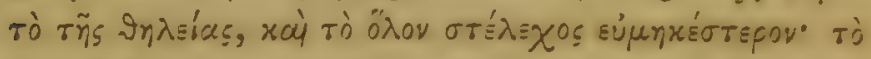

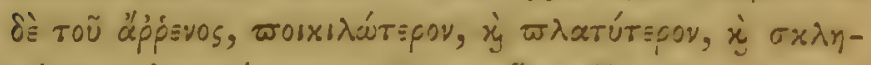

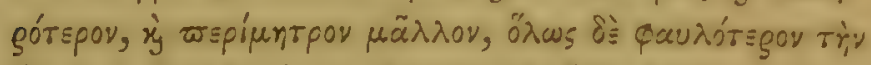

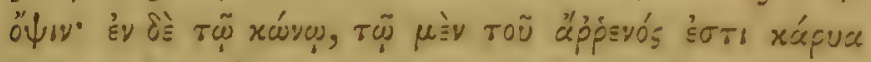

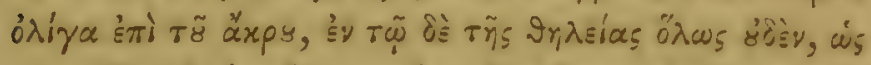

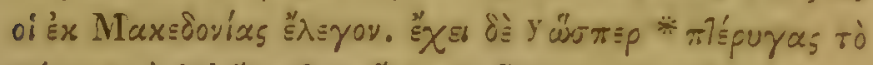

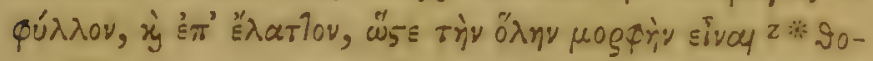

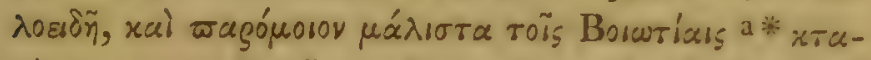

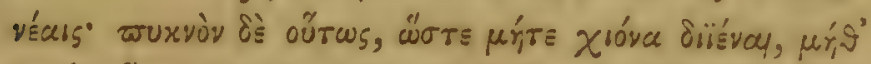

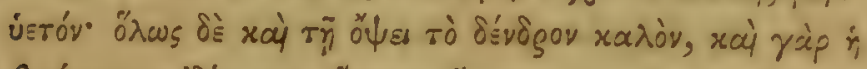

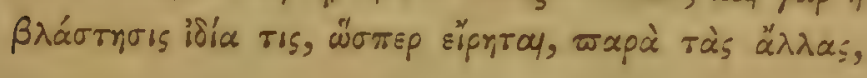

$x$ ämtuxa. Bod.

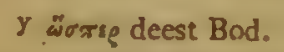

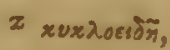

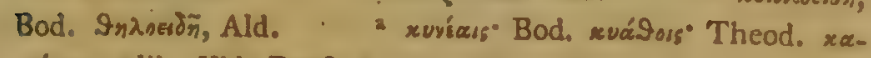
'ápars" alii. Vide Præe. et not. ad finem libri. 


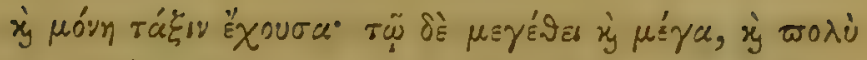

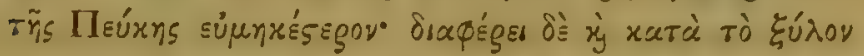

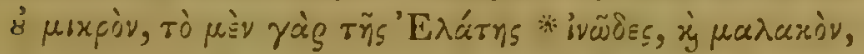

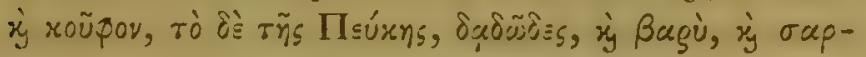

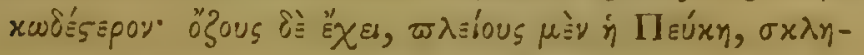

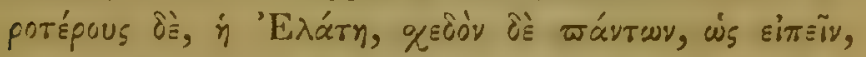

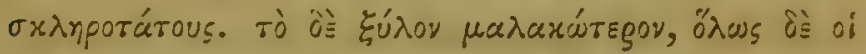

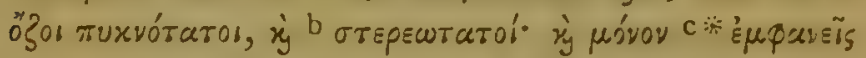

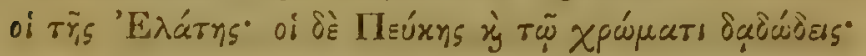

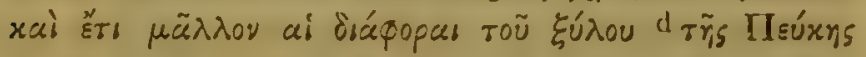

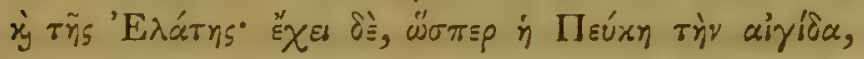

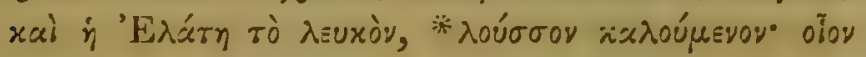

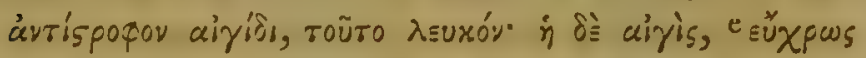

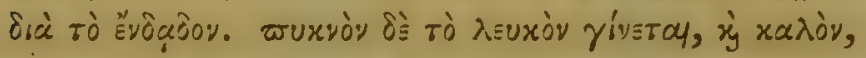

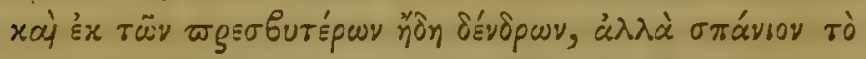

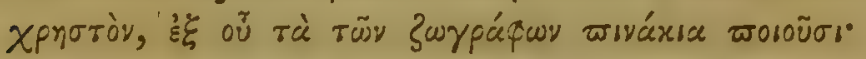

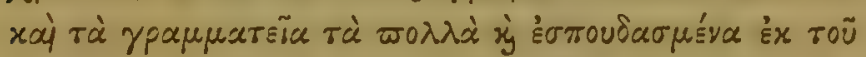

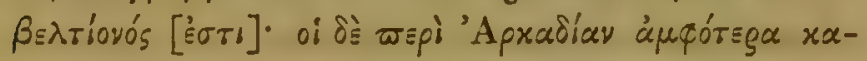

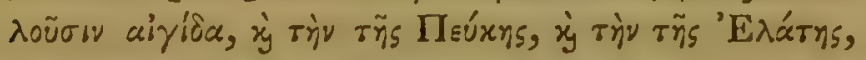

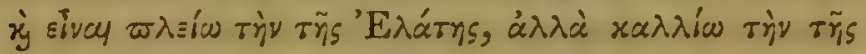

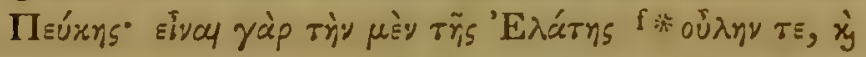

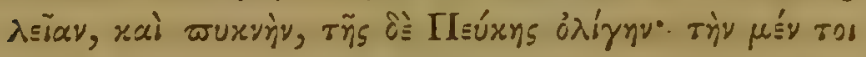

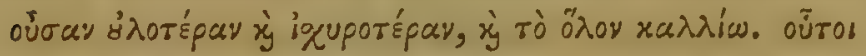

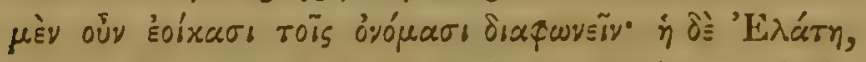

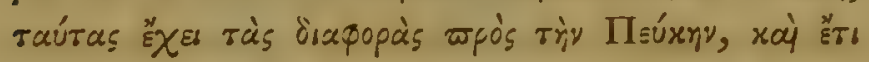

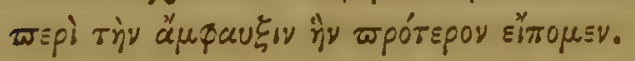

- arigurasixoi, Bod. Mrúrys desunt Bod. c Vid. not. ad fin. libri. ส รที 


\section{CAP. IX.}

Fugus sylratica; Tarus baccata; Carpinus, Ostrya; Tilia

\section{Europaca.}

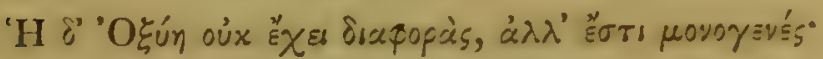
óp.

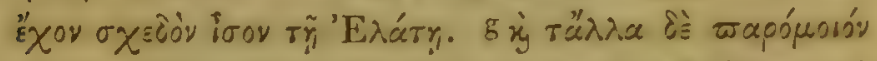

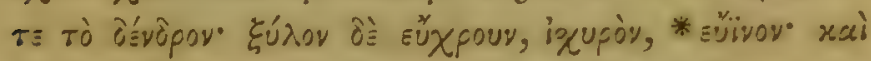

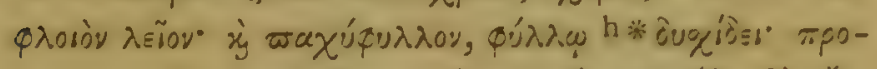

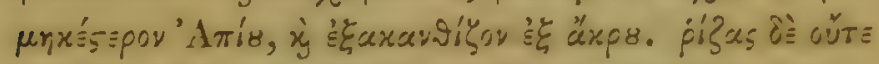

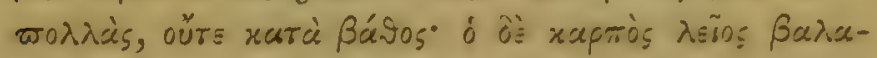

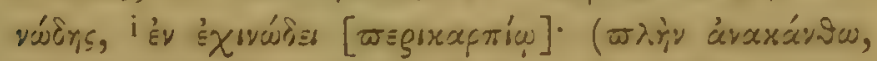

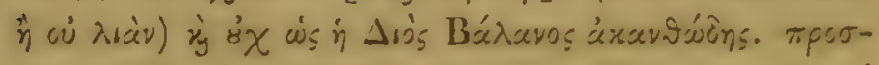

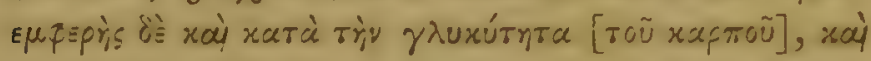

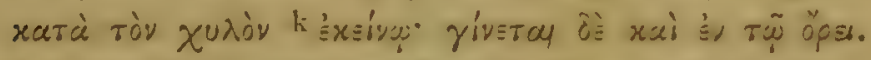

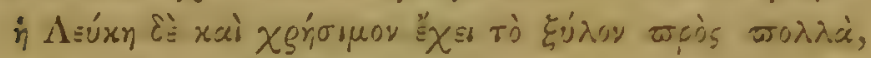

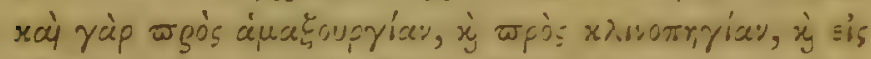

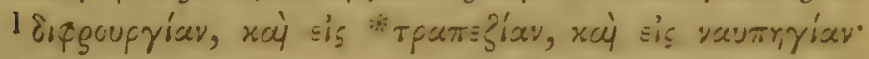

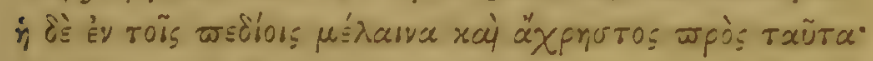

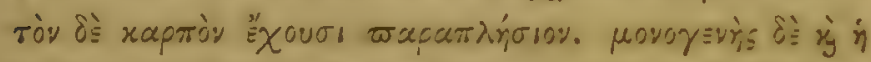

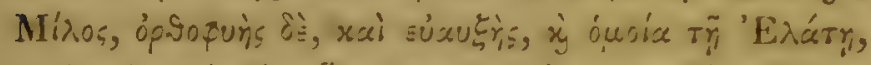

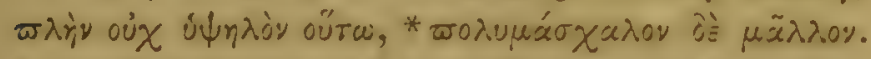
ö

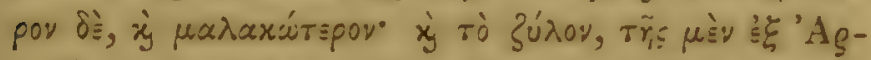

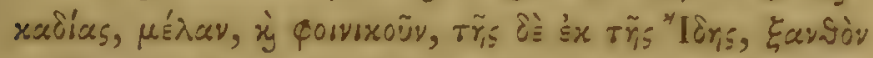

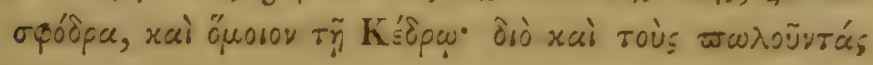

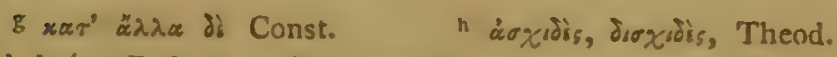

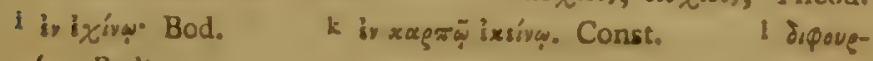
gian, Bod: 


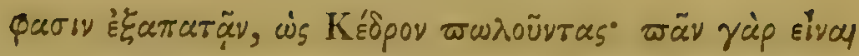

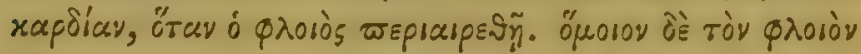

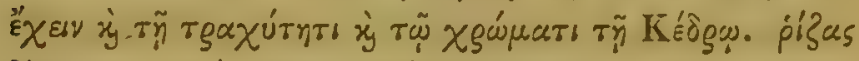

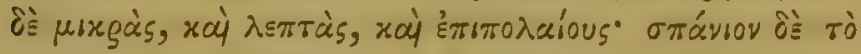

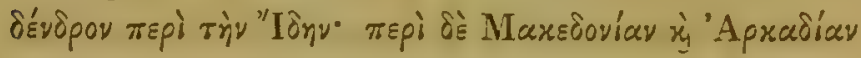

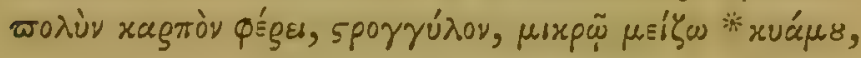

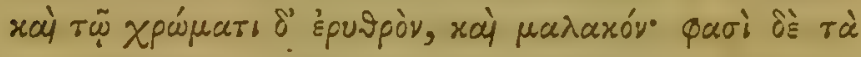

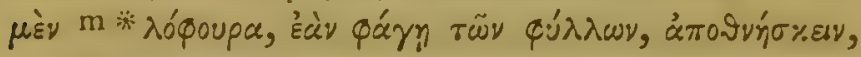

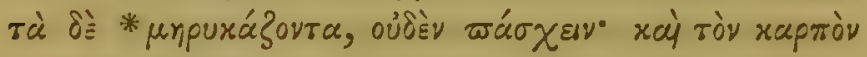

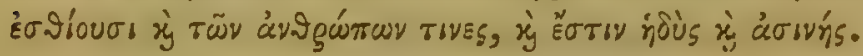

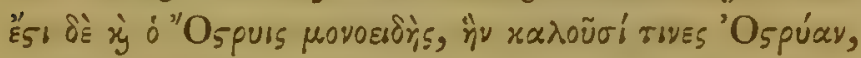
ó

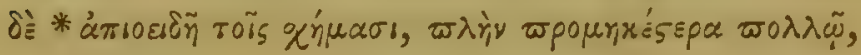

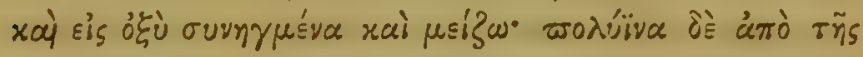

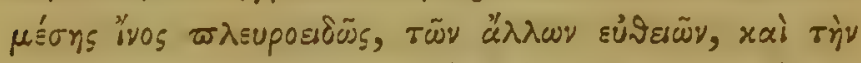

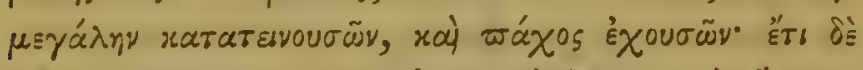

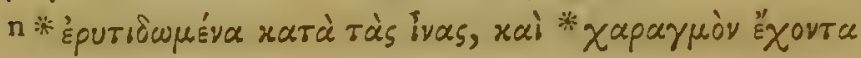

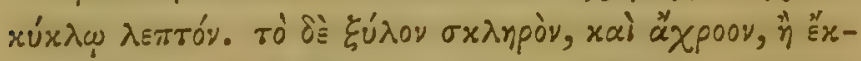

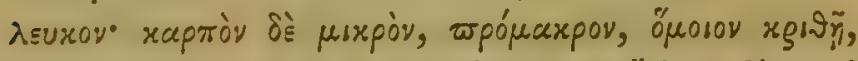

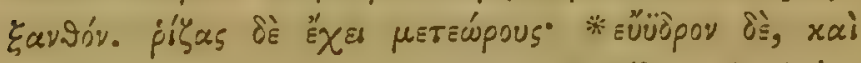

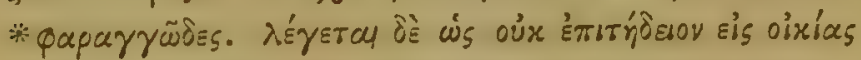

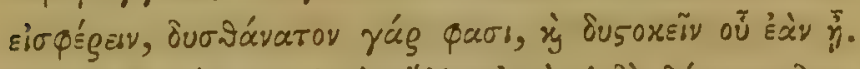

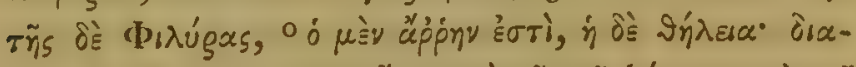

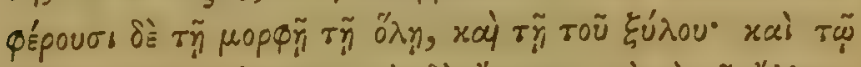

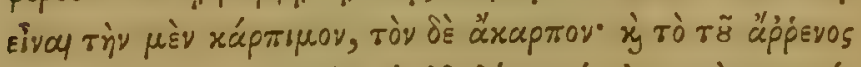

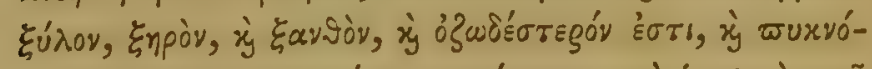

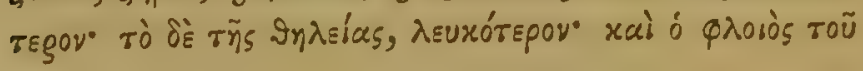

m xódópovęa, Const. ipropúsa, Bas.

n ippuriouplve Bod.

- is pir Bod. 


\section{MEPI $\Phi \Upsilon T \Omega N ~ I \Sigma T O P I A \Sigma T O \Gamma^{\prime} . \quad 109$}

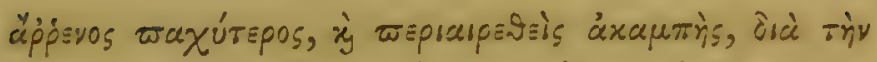

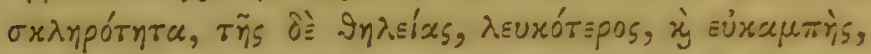

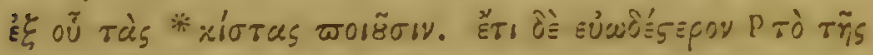

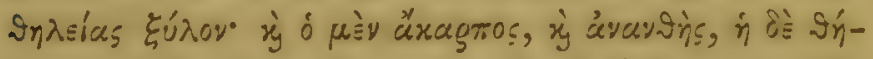

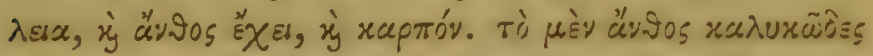

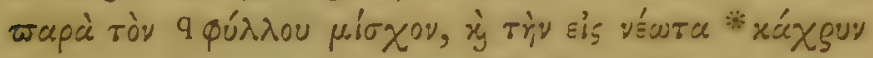

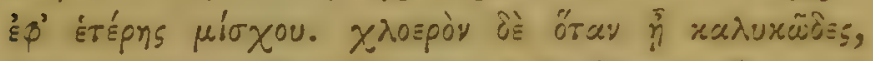

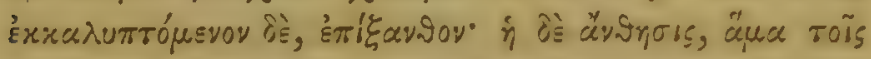

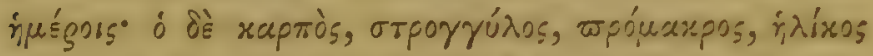

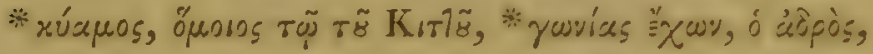

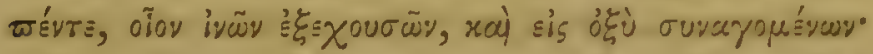

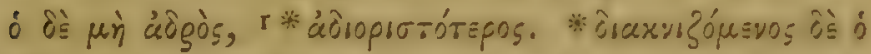

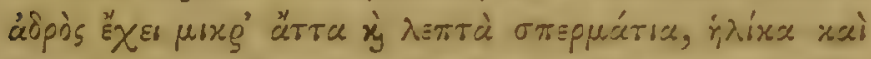

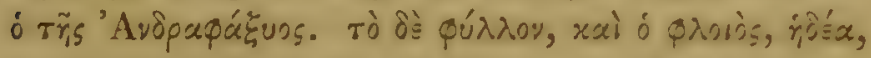

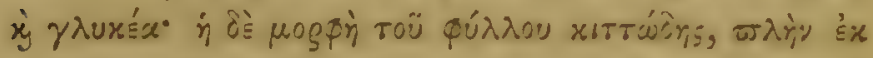

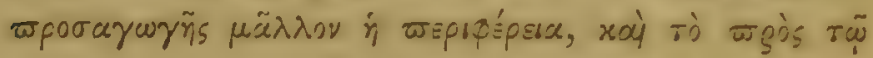

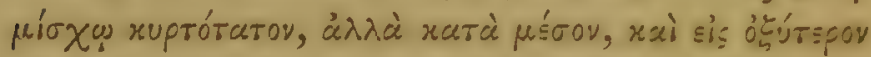

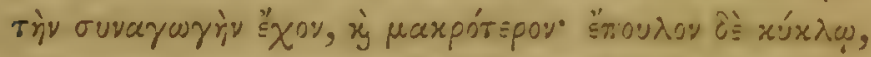

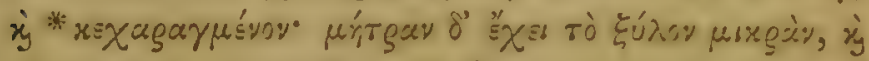

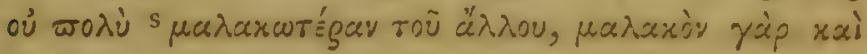

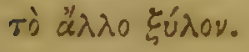

\section{CAP. X.}

Acer campestre, \&c. Fraxinus, excelsior; Fraximus, Orrus.

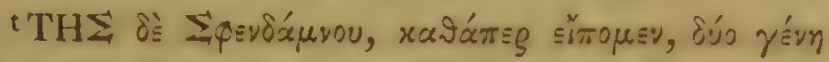

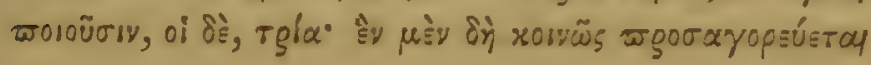

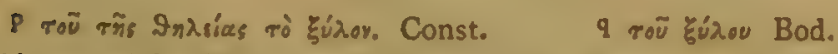

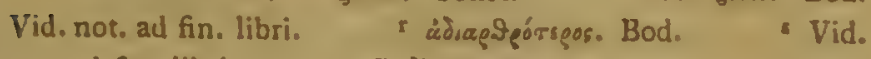

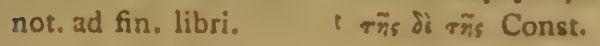




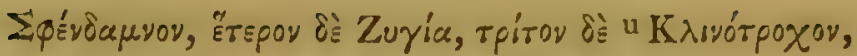

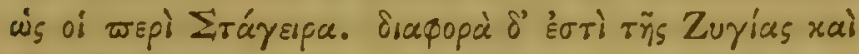

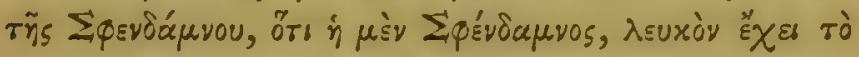

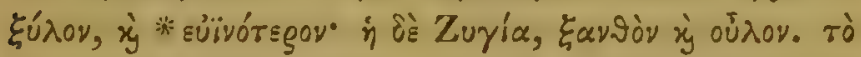

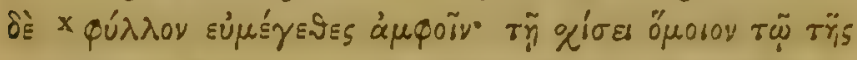

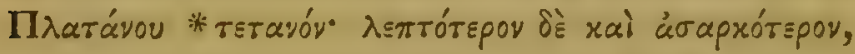

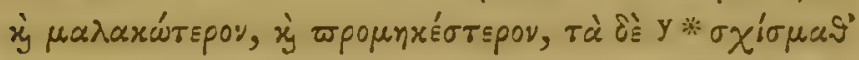

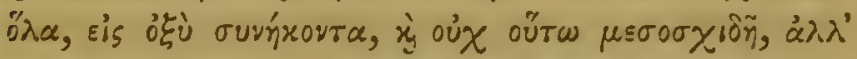

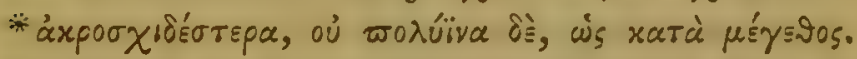

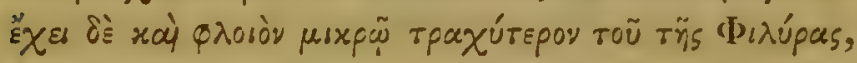

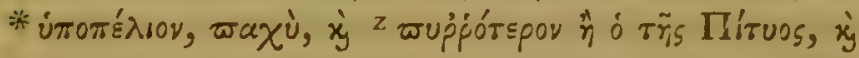

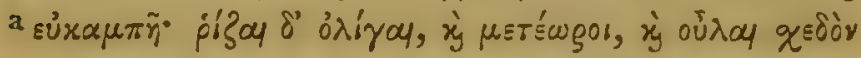

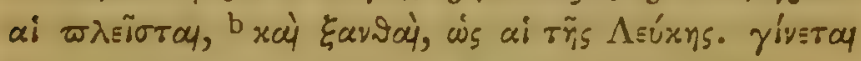

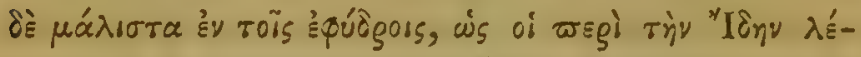

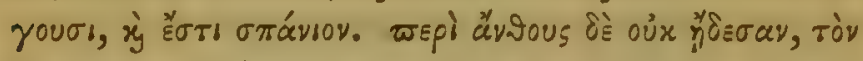

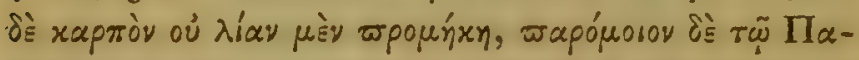

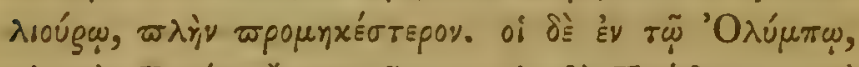

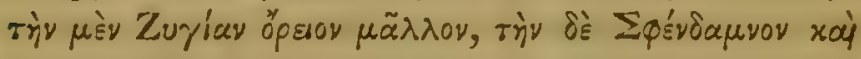

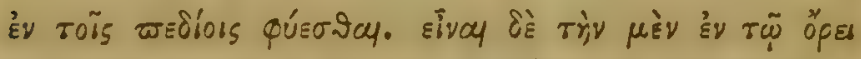

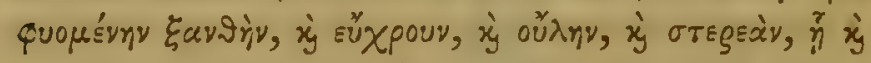

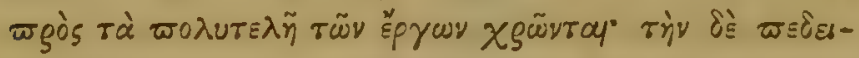

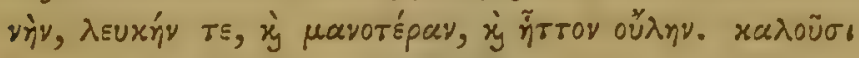

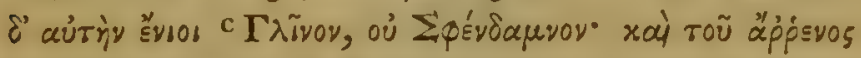

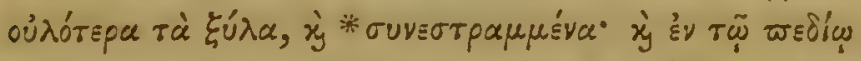

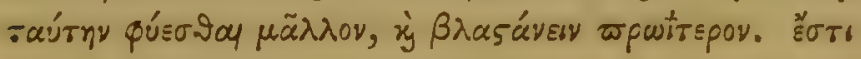

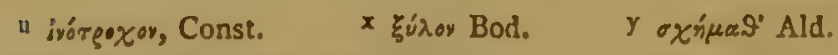

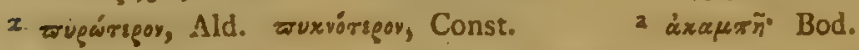

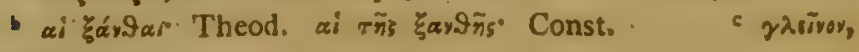
Const. 


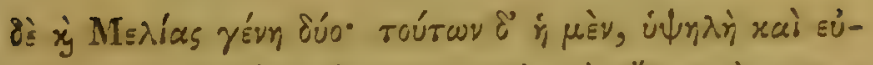

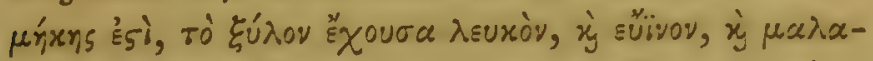
xúrs:pov, 艾 ávo

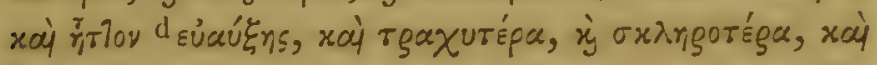

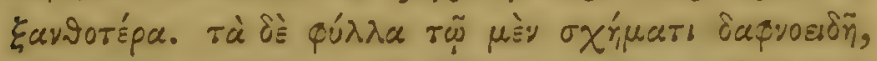

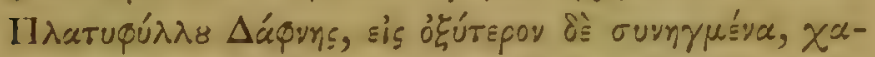

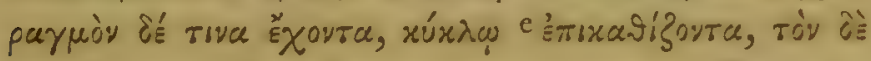

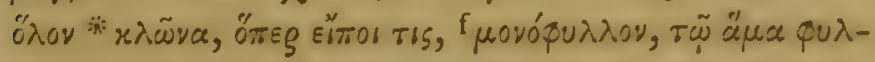

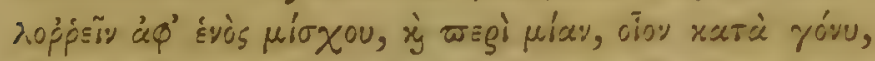

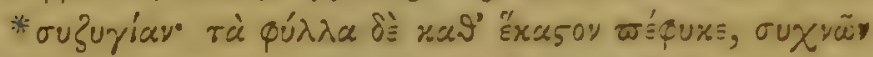

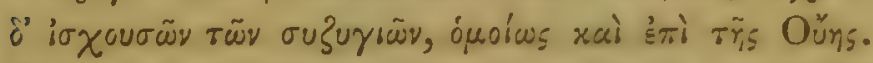

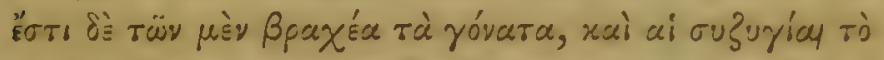

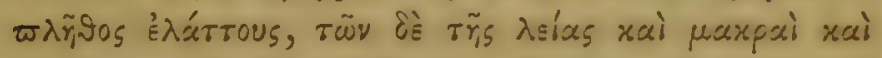

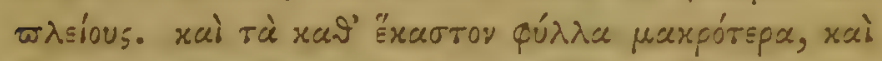

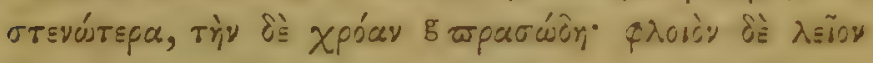

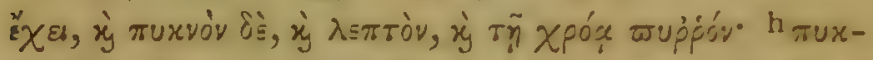

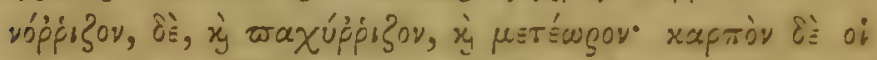

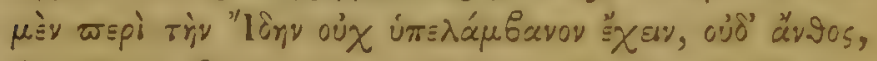

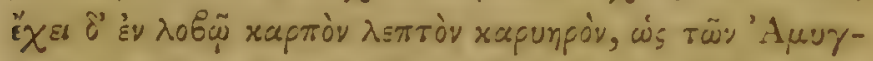

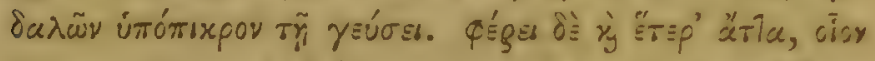

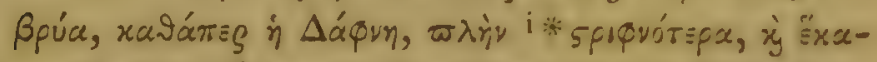

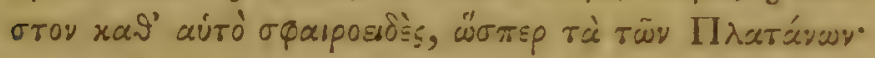

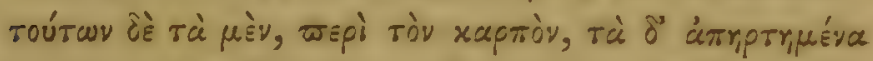

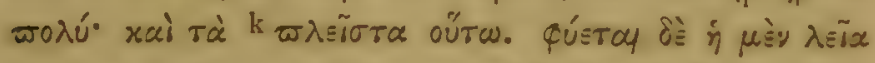

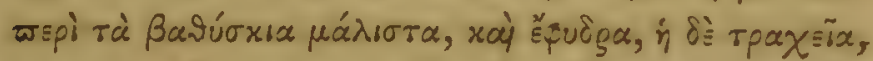

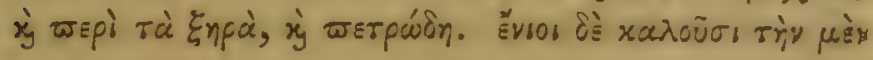

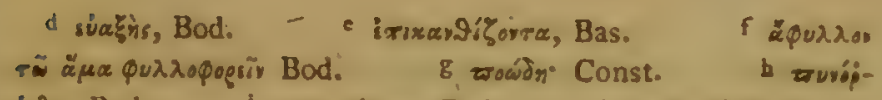

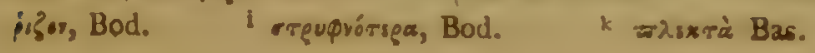




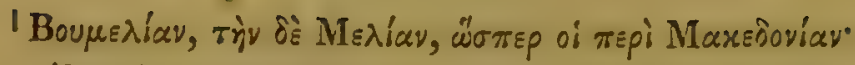

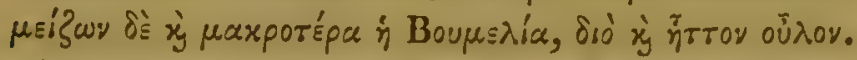

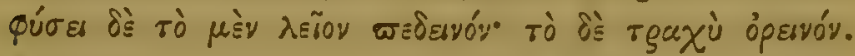

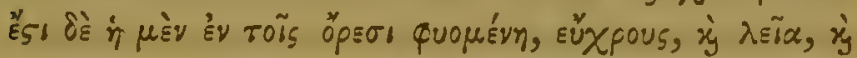

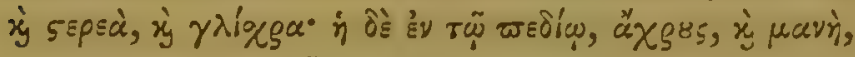

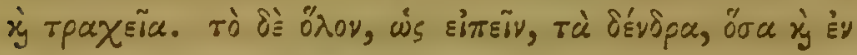

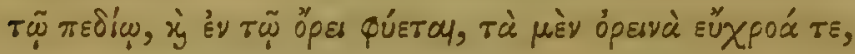

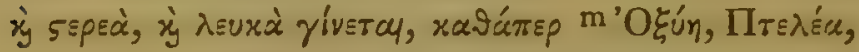

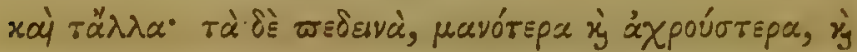

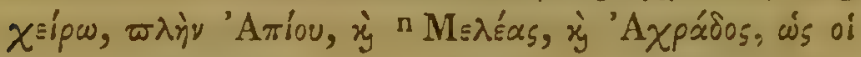

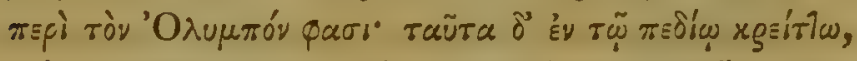

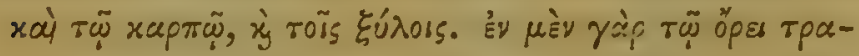

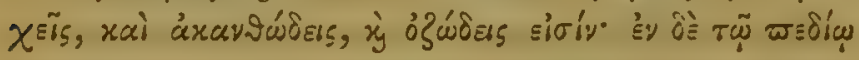

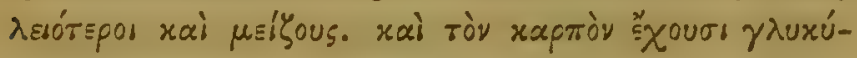

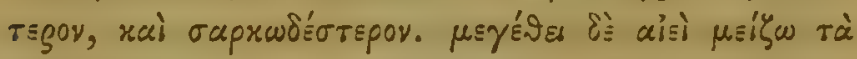

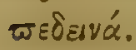

\section{CAP. XI.}

C'ornus mas. Corn. sanguincu. Juniperus, Oxycedrus, J.

Lycia \& J.communis. Mespilus, Germanica, Sorbus, domestica, \&c.

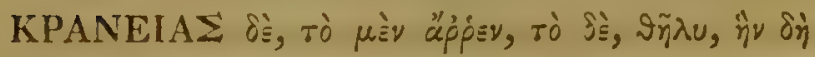

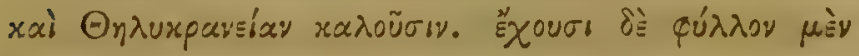

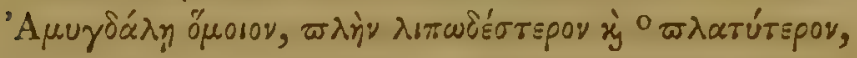

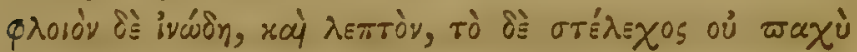

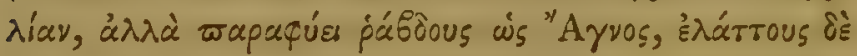

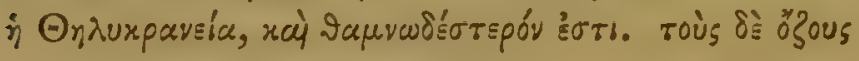

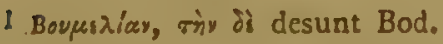
m 'oร̧urvidia, Bod.
in Merias, Bod.
- saxírşor, Bod. 


\section{MEPI W TSN I}

1.

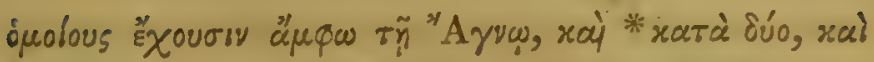

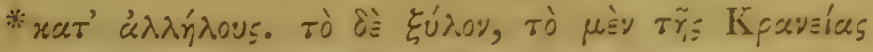

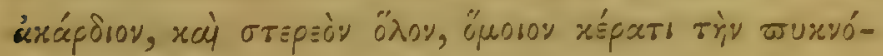

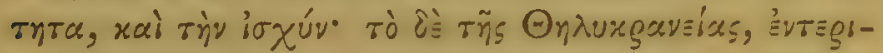

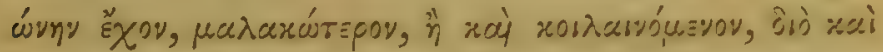

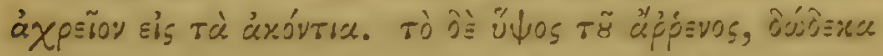

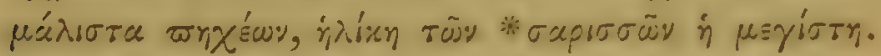

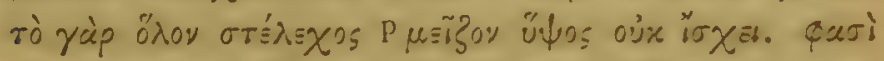

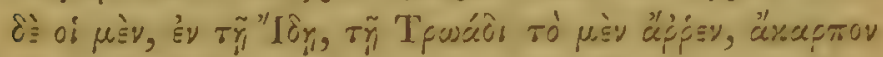

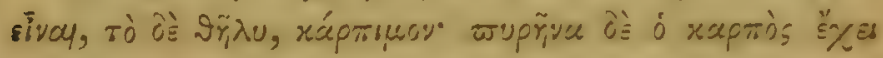

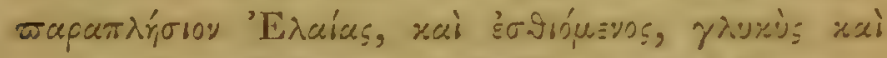

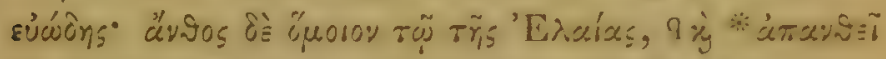

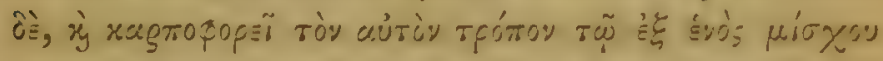

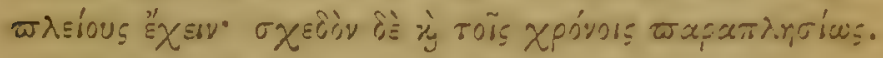

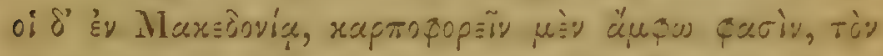

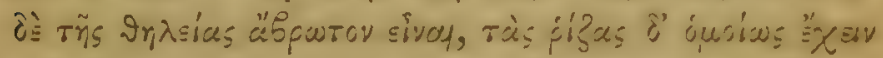

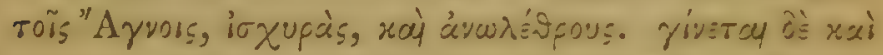

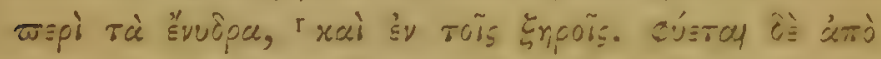

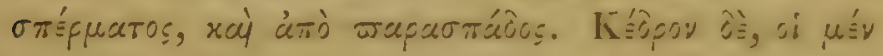

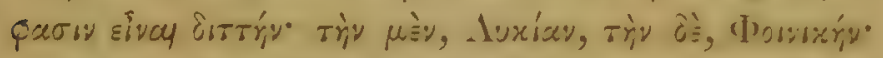

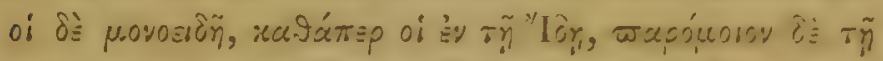

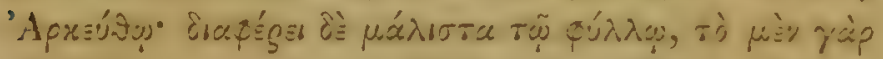

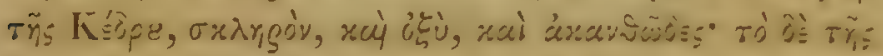
'А

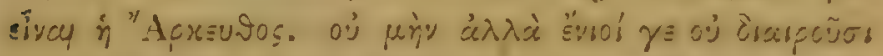

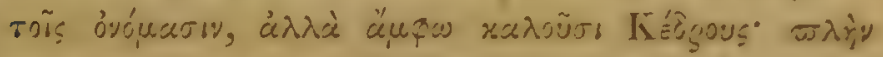

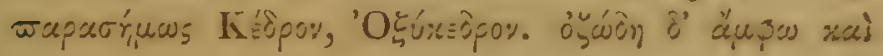

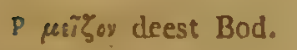

Q ณُvง

rai six iy rois క̆npoiss póvoy. Const. 


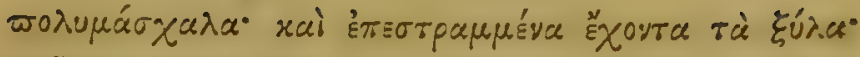

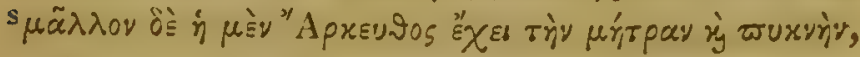

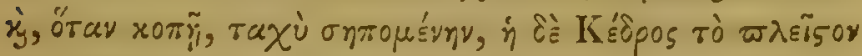

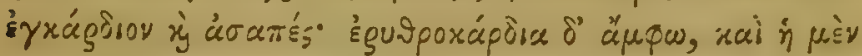

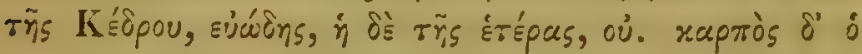

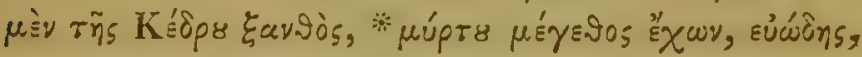

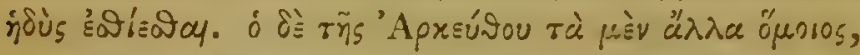

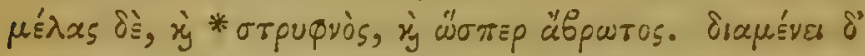

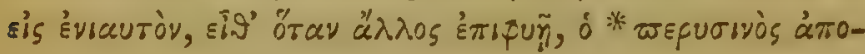

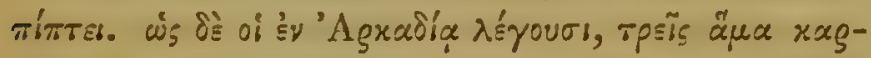

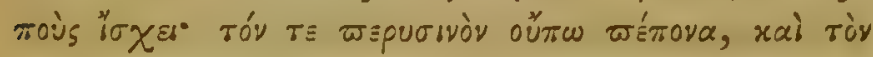

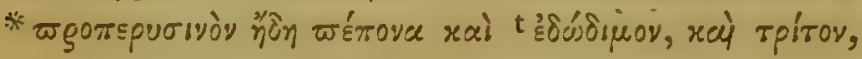

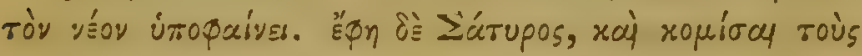

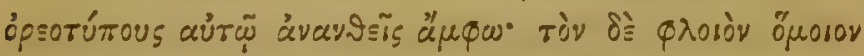

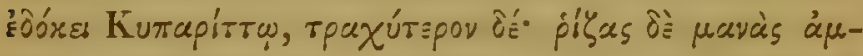

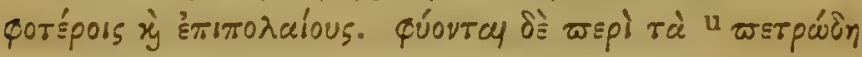

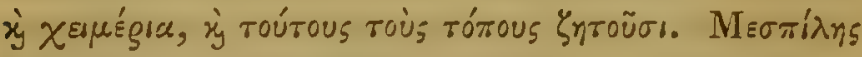

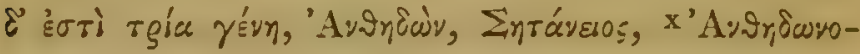

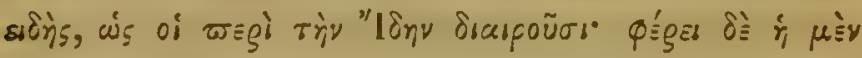

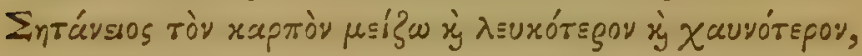

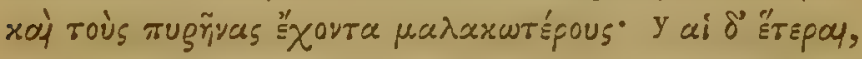

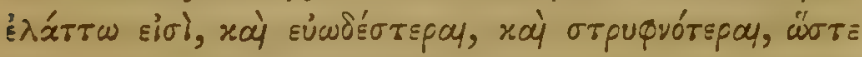

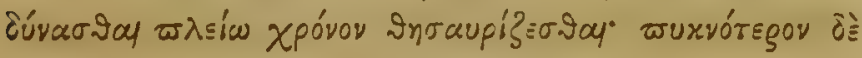

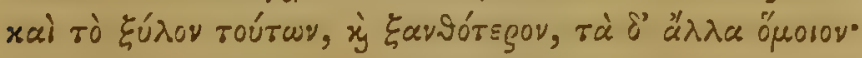

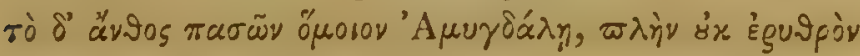

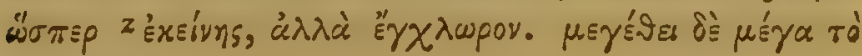

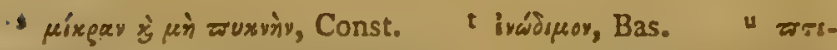
दuî̀n Bod. $x$ áy $z$ ixcive, Bod. 


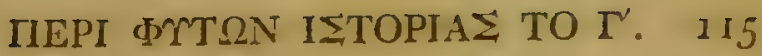

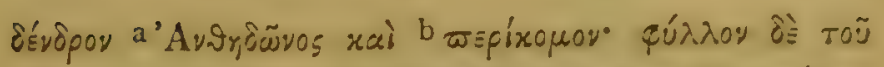

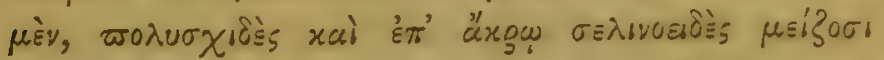

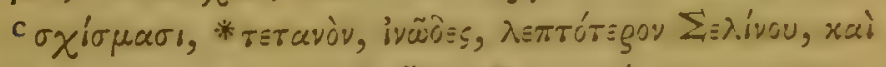

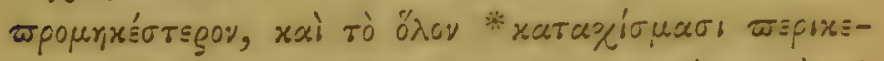

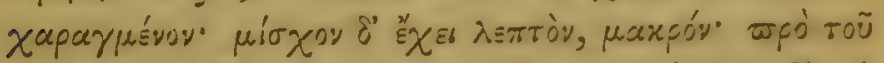

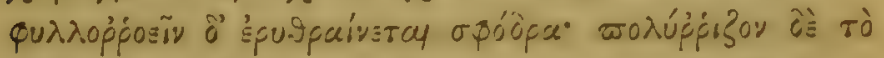

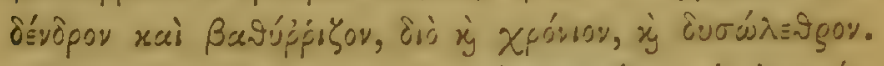

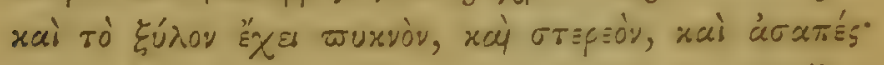

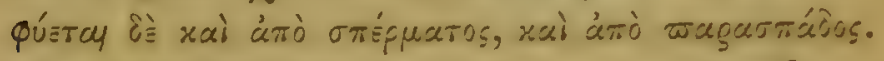

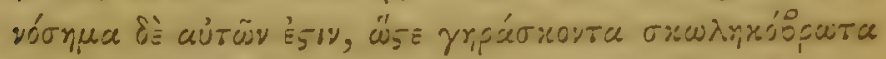

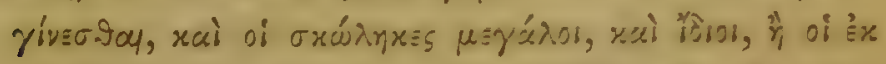

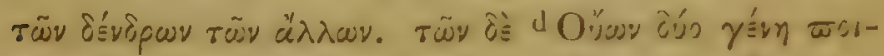

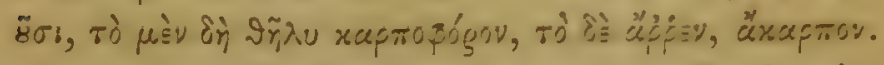

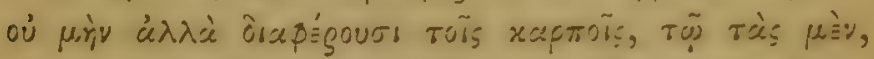

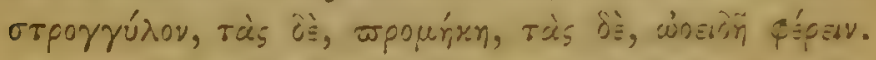

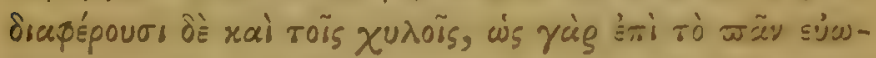

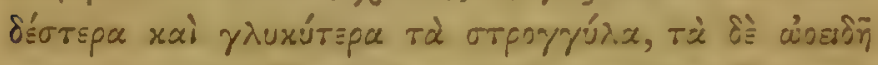

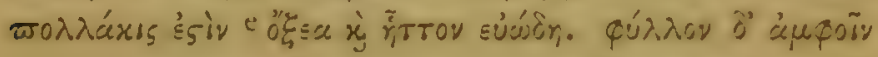

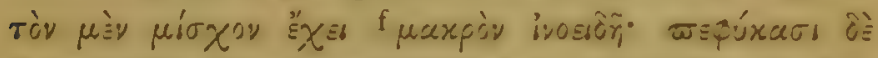

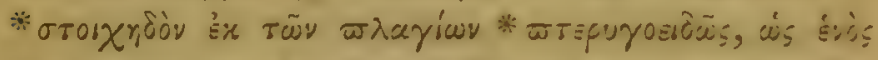

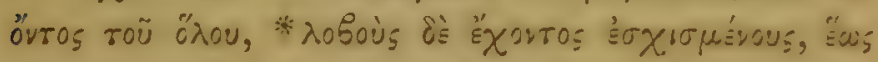

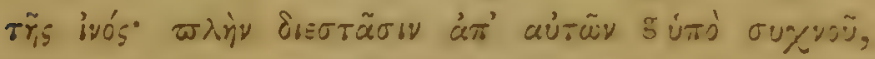

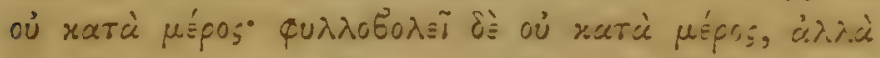

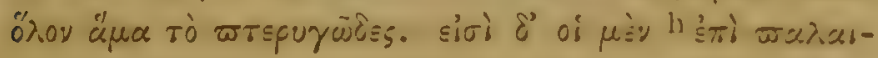

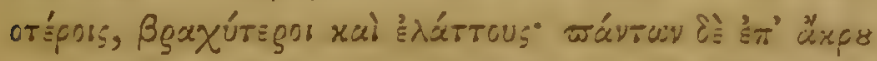

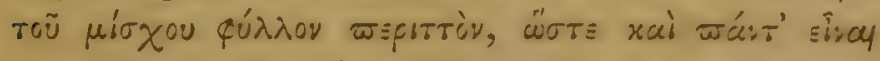

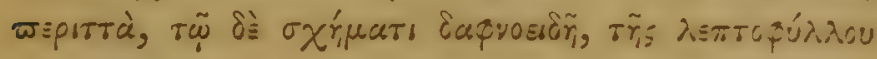
2 'Avandō̃os deest Bod.
b żุívoua Const.
c $\sigma: x^{r-}$ masi, Bod.
d "Owy Const.
C ל̧̧sia Bor.
if pixpòr

Fonst. I Vid. not. ad fin. libri. L, irtroda 


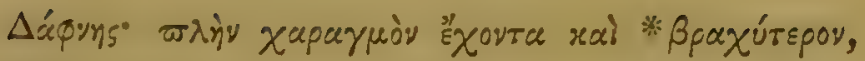

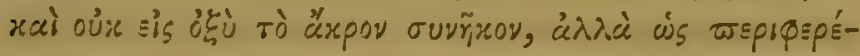

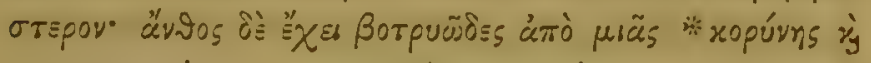

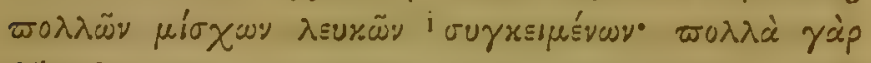

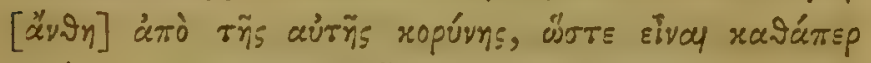

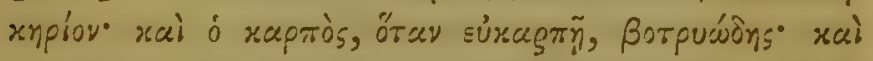

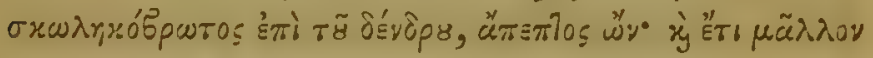

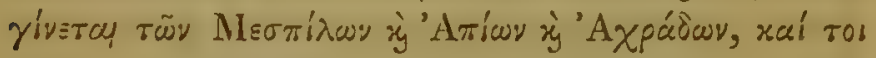

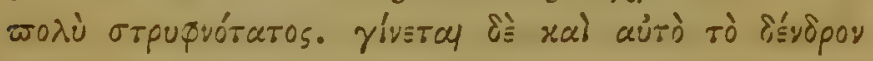

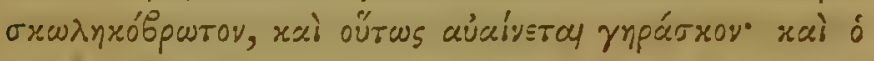

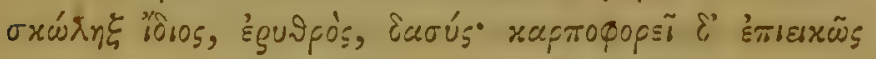

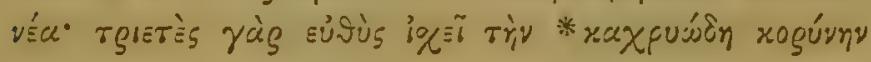

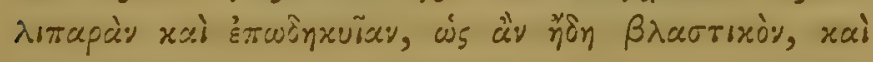

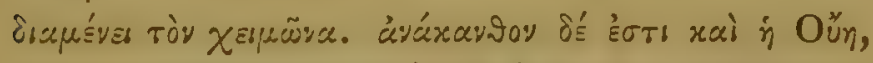

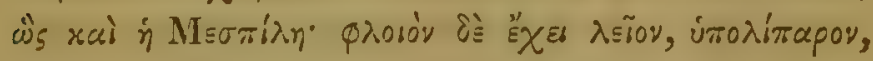

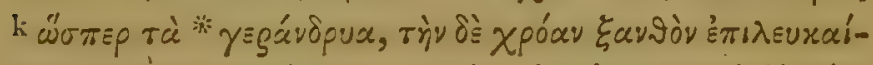

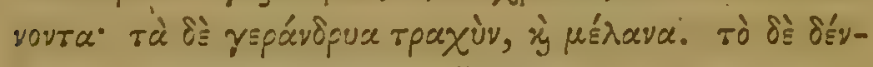

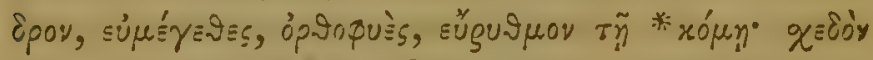

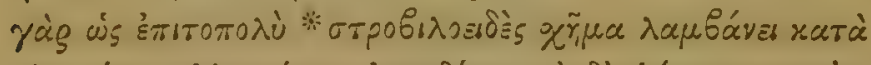

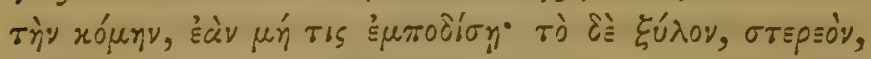

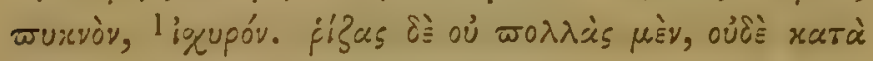

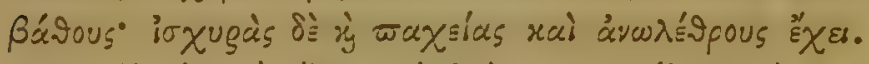

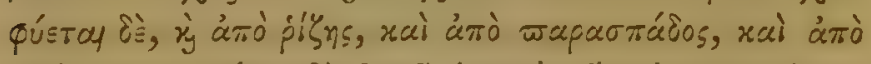

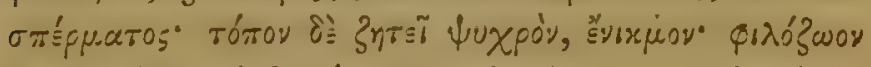

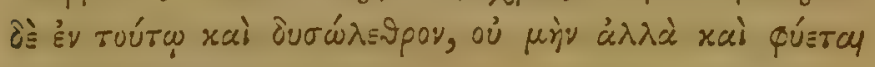

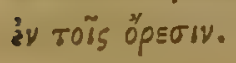

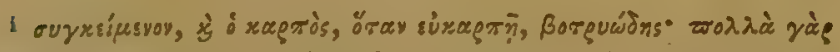

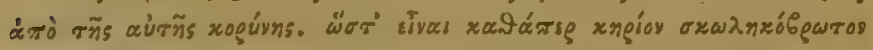

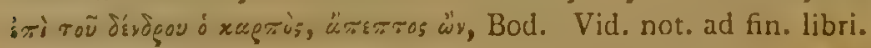

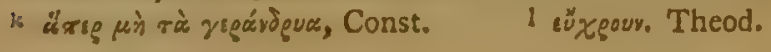




\section{CAP. XII.}

Prunus, Cerasus L. Sambucus nigra. Sulicis Specics.

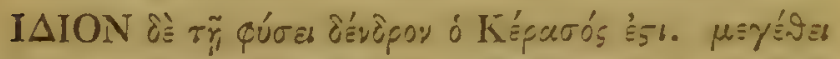

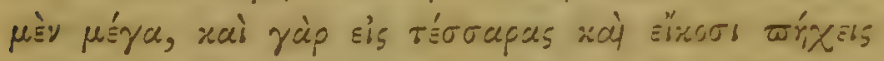

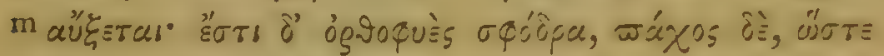

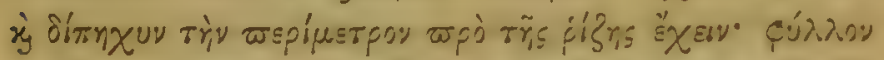

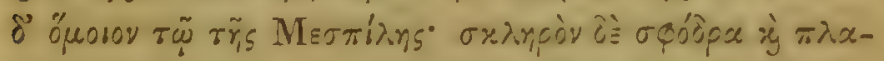

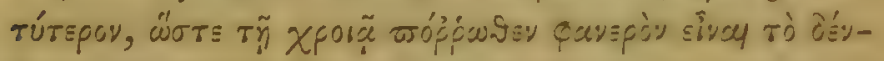
Epor" ${ }^{n}$ p

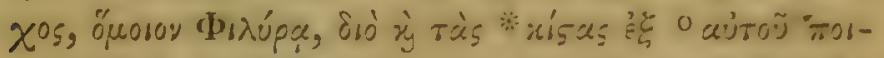

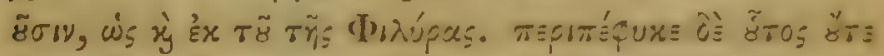

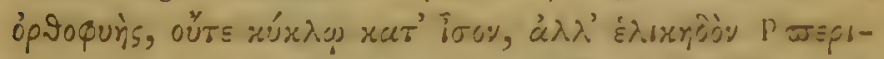

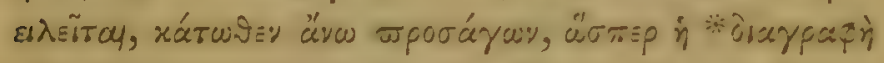

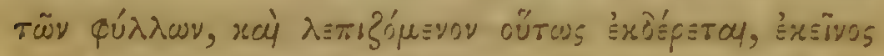

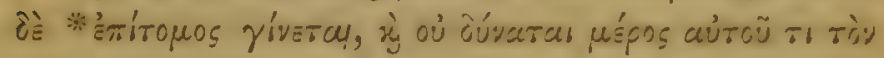

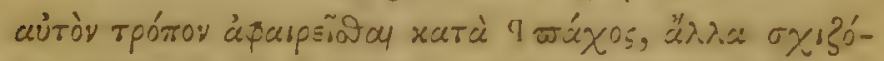

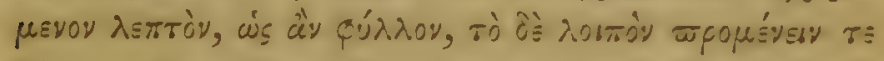

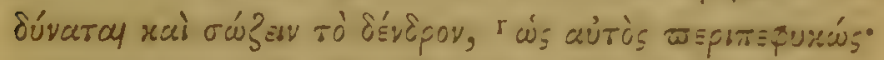

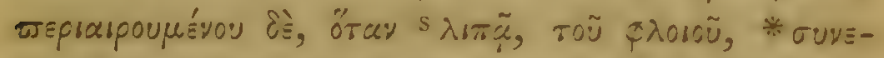

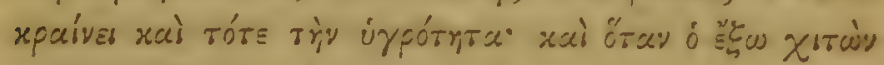

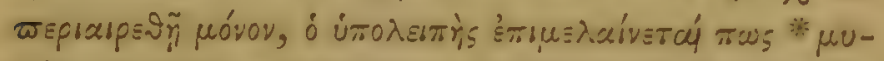

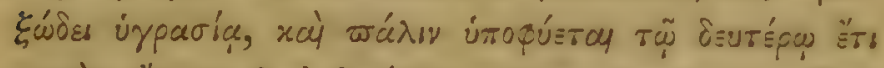

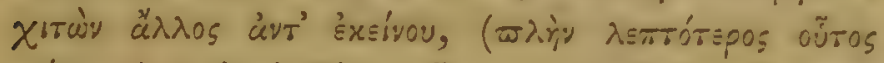

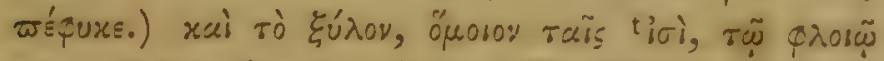

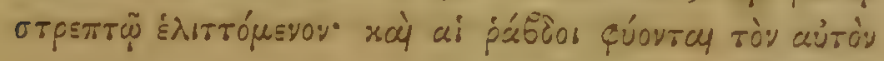

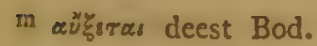

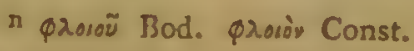

- avirã̃y Bod.

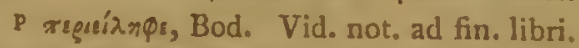

q ráx os, Const.

Ald. Bas.

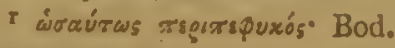

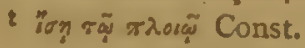

s $\lambda e s \pi \tilde{\alpha}$,

I 3 


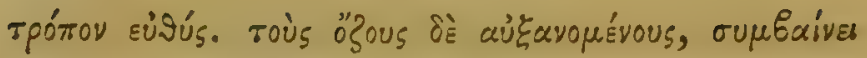

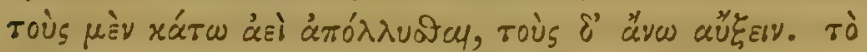

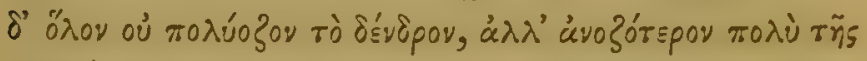

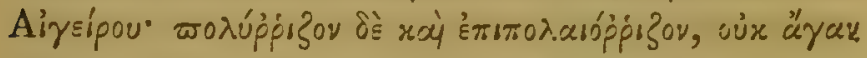

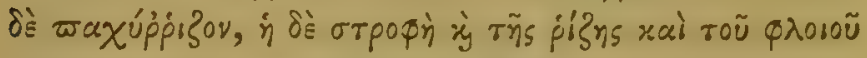

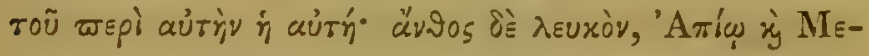

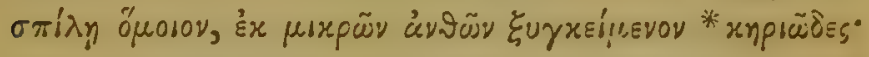

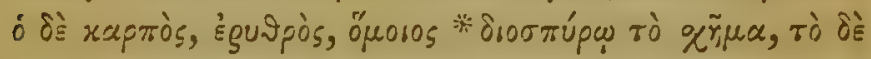

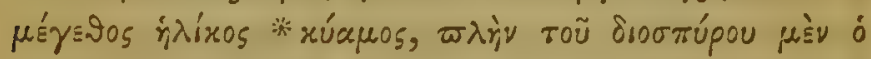

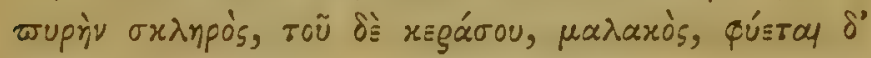

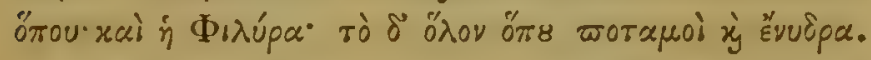

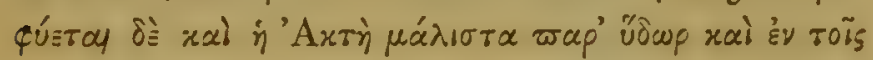

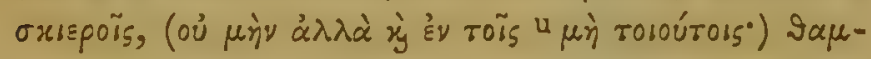

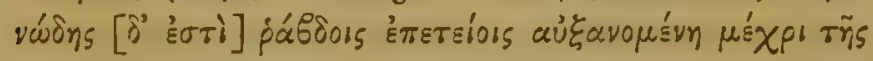

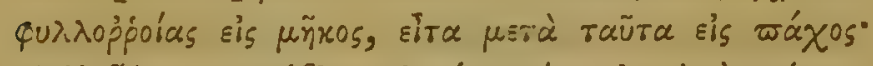

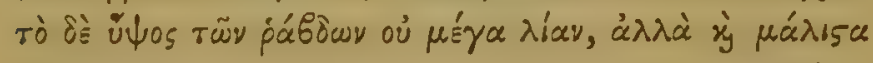

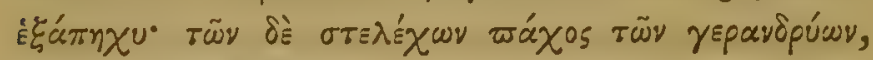

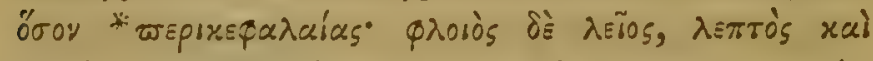

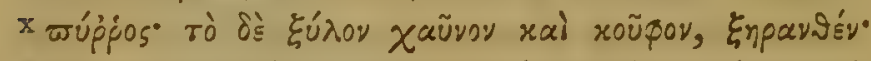

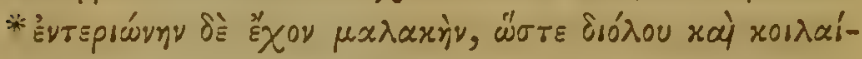

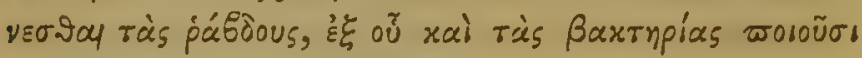

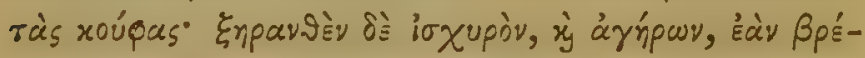

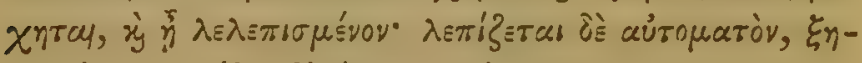

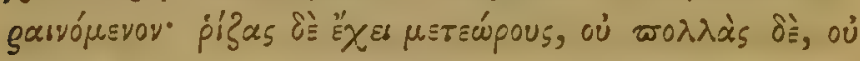

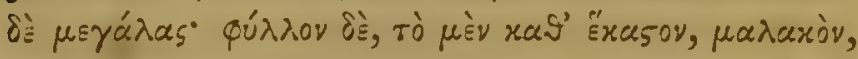

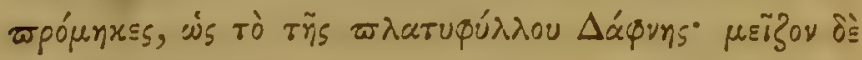

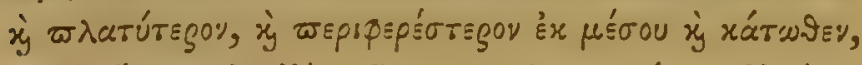

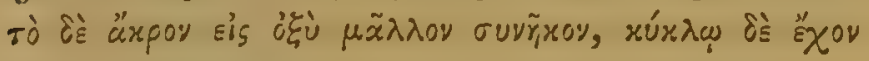

u $\mu$ ̀̀ deest Ald.

$x$ zuxyós" Bod. 


\section{MEPI TYT $\Omega N$ ISTOPIA TO F'. II}

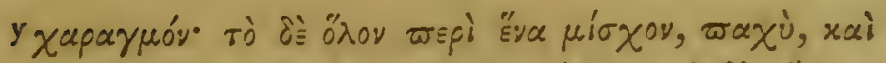

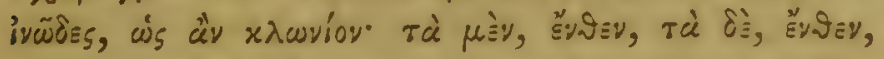

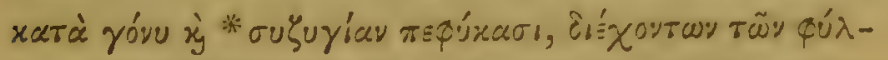

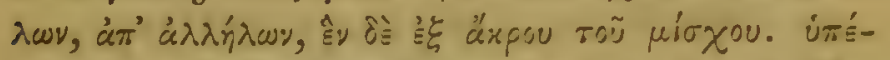

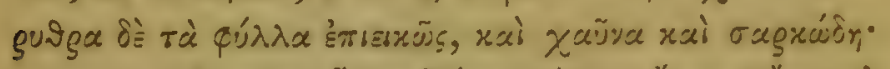

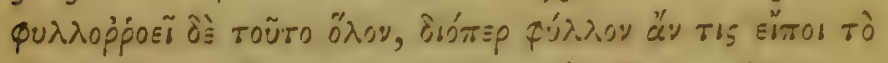

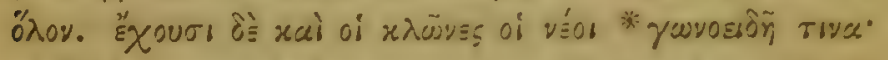

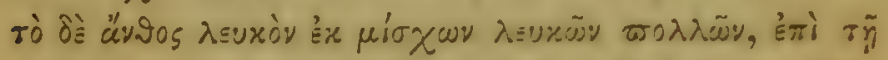

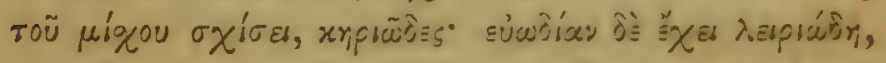

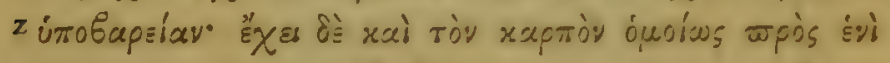

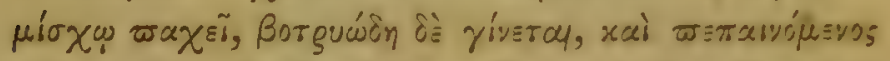

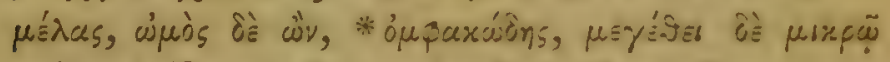

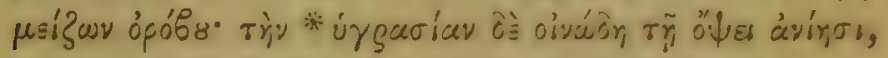

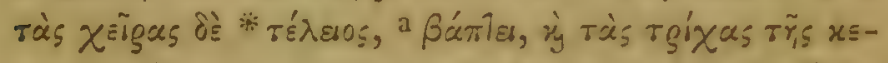

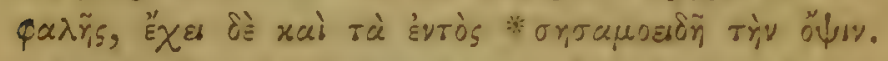

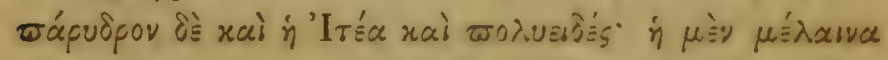

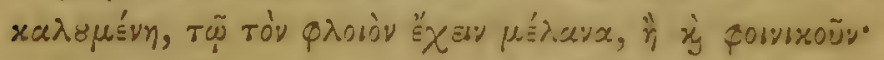

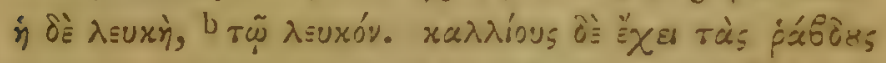

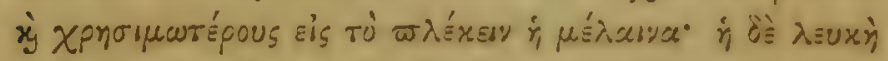

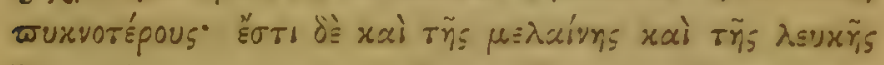

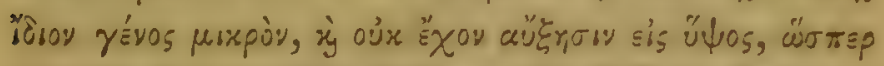

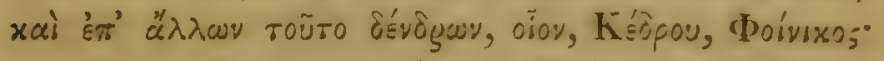

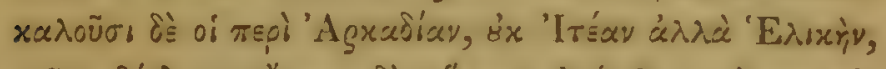

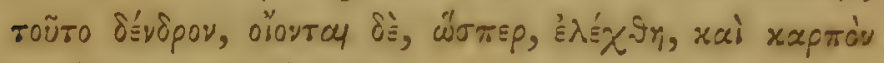

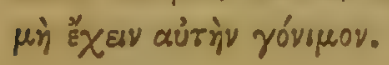

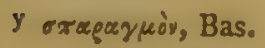
$\operatorname{sid} s \times s \varphi \alpha \lambda \alpha_{s}$. Const.

z izi Bagsíav, Bas.

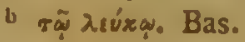

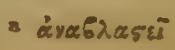




\section{CAP. XIII.}

Ulmus campestris L. Populus alba, et nigra ; Cercis, siliquastrum. Betula, Alnus; Betula alba.

E

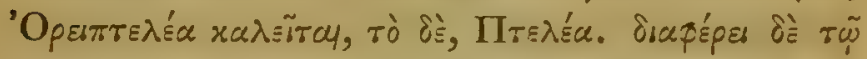

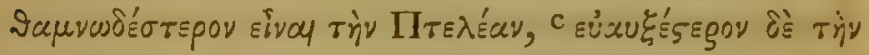

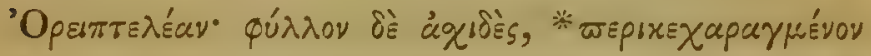
*

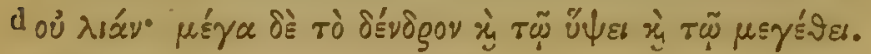

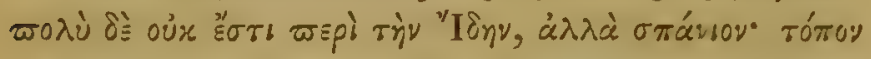

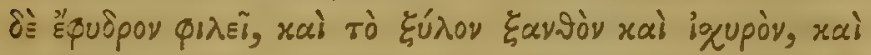

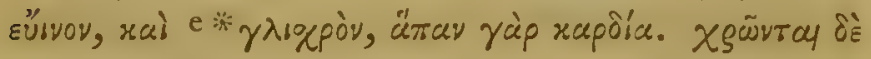

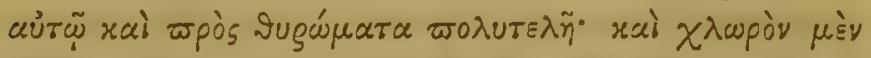

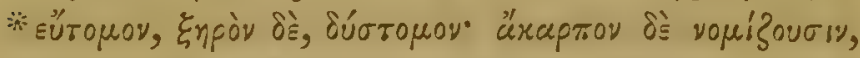

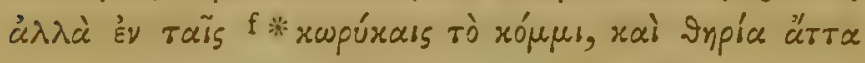

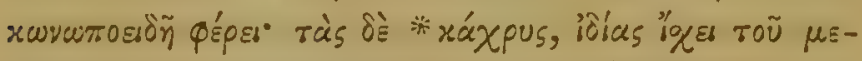

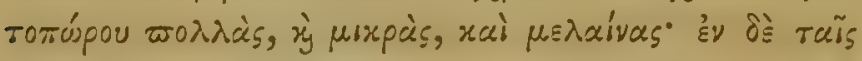

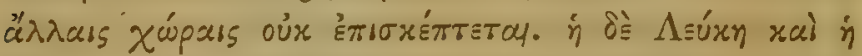

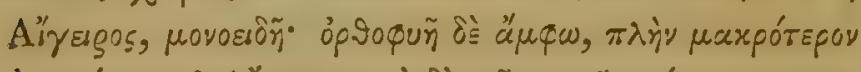

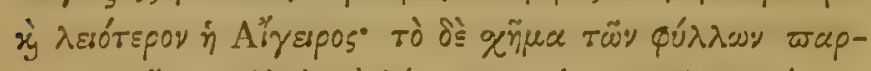

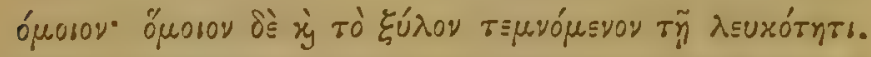

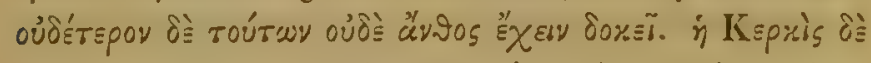

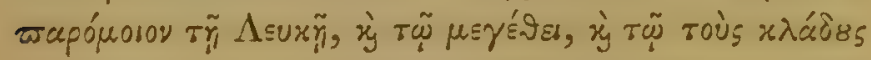

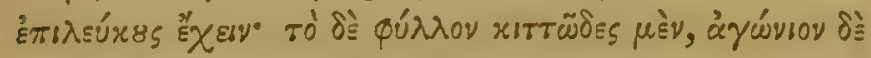

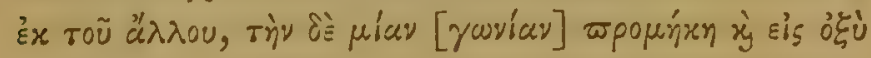

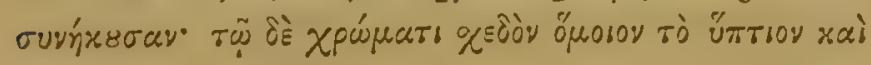

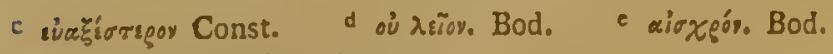
$f$ rewéxoí, Bod. xwẹuxoot, Bas. 


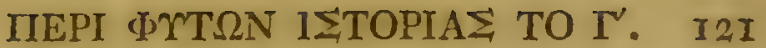

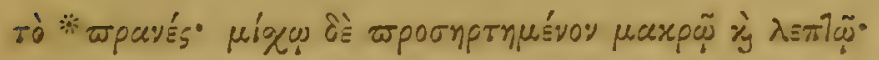

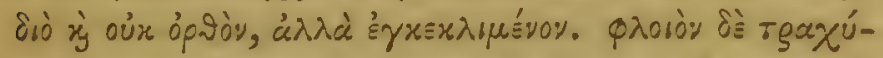

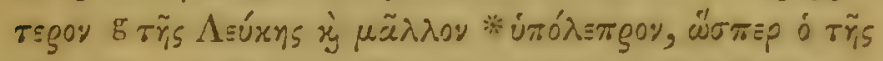

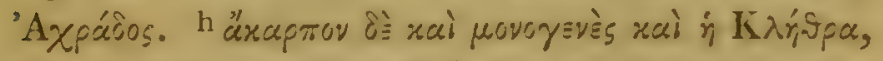

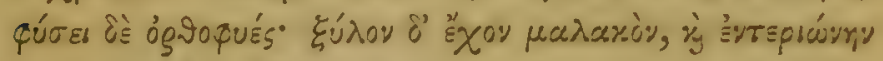

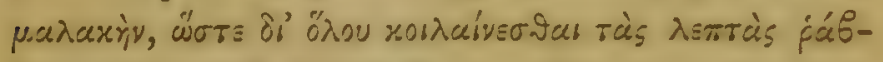

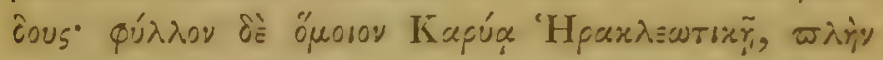

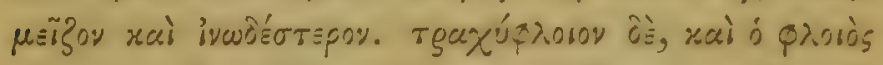
E้б

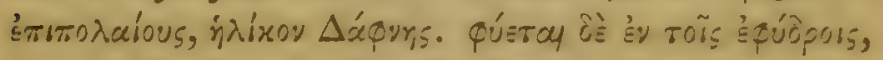

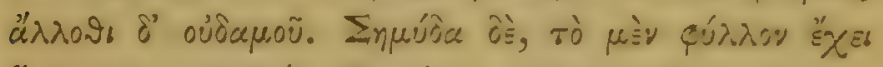

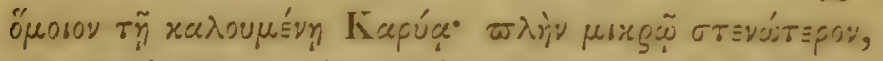

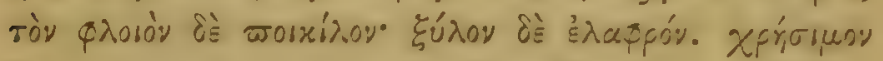

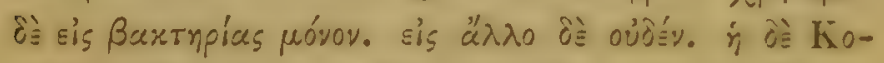

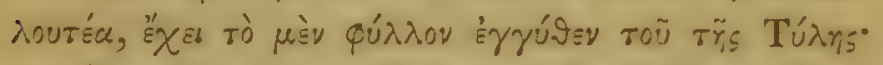

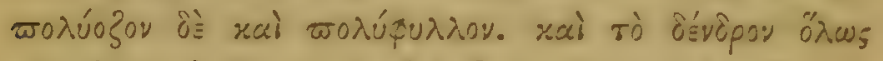

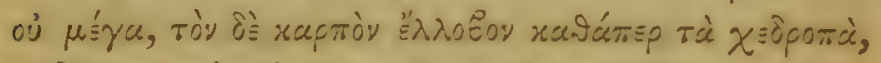

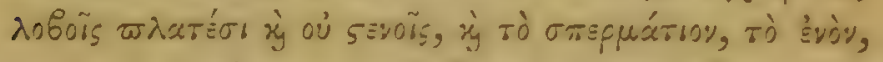

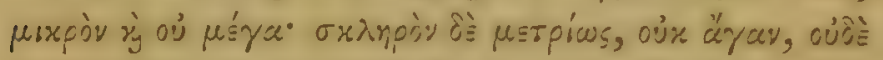

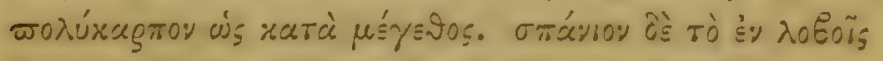

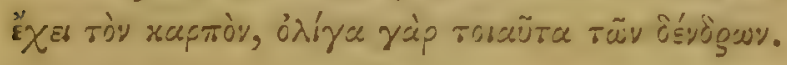

\section{CAP. XIV.}

Corylus, Avellenu, L. Pistncin, Tercbinthus. Burus sempercirens. Cratagus torminalis.

'H $\grave{a} \equiv$ 'I

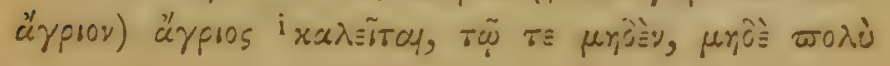

E ท́ Asúxทs Theod.

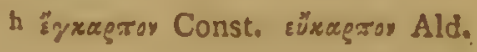

i калะгта deest Bod. 


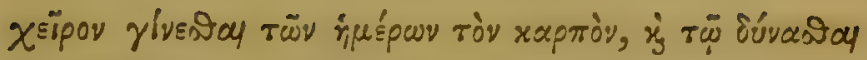

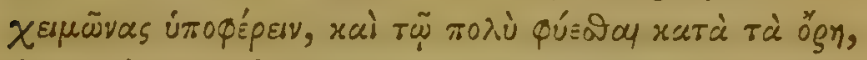

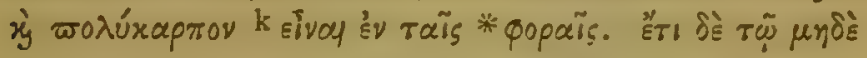

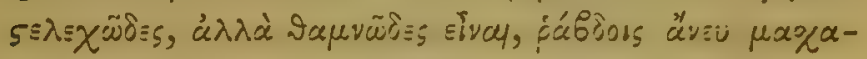

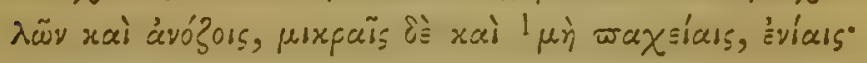

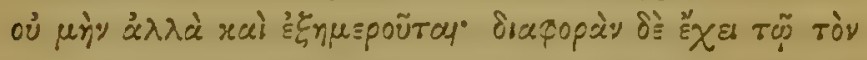

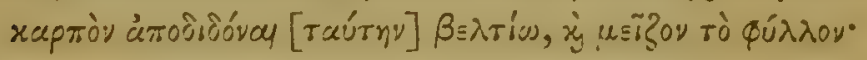

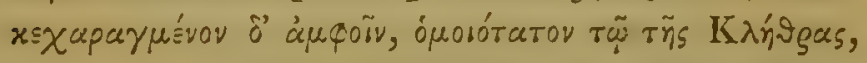

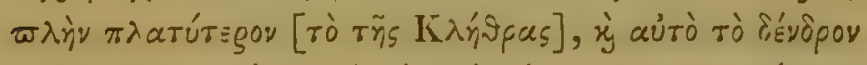
$\mu$

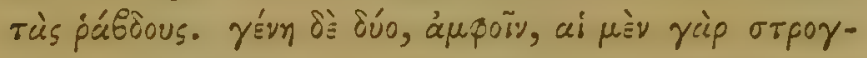

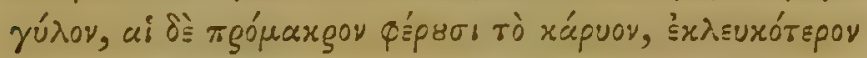

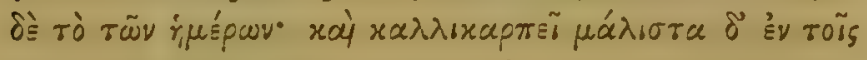

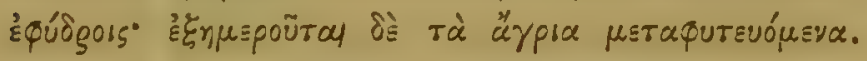

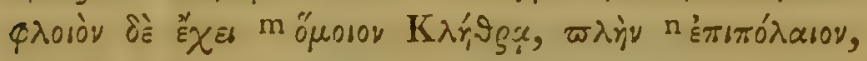

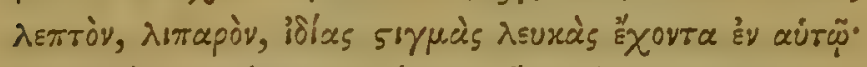

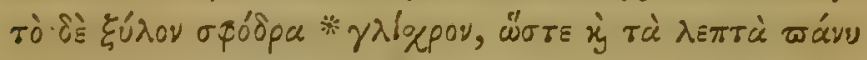

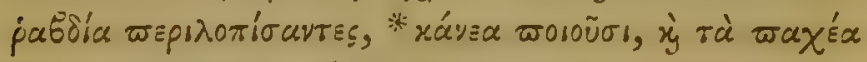

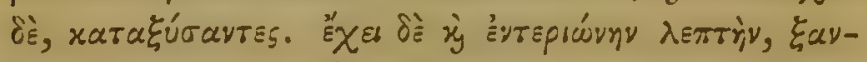

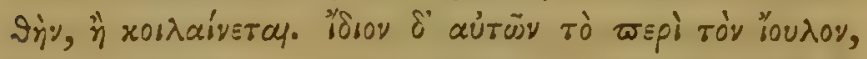

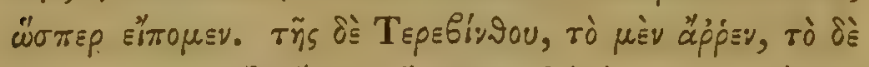

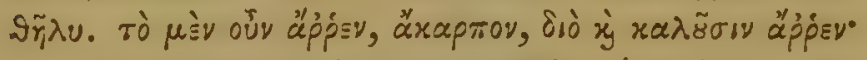

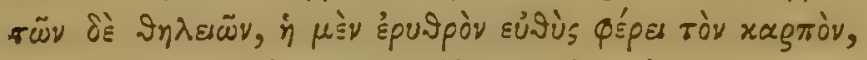

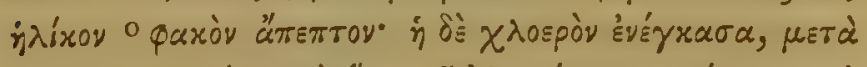

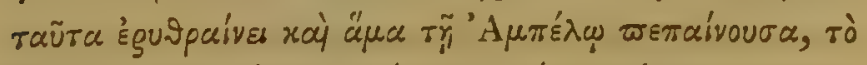

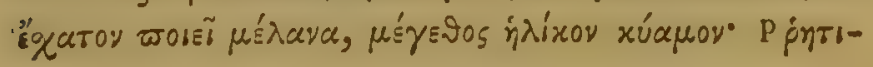

$k$ tivar deest Bod.

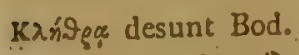
Bod.
1 н̀े deest Bod. Ald. n Forsan שoixidoy. in öposor - paxoss s purivádn, purivn, Bod. 


\section{MEPI TMTSN ISTOPIAS TO $\Gamma^{\prime}$.}

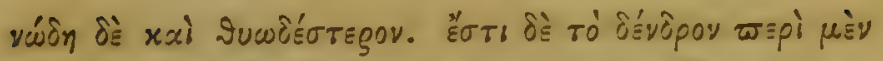

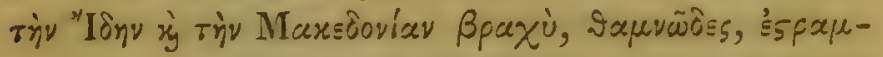

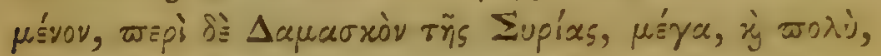

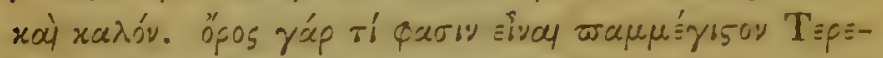
Eivง

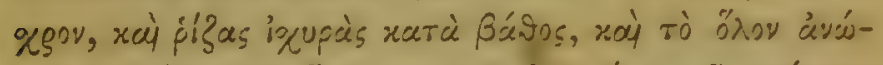

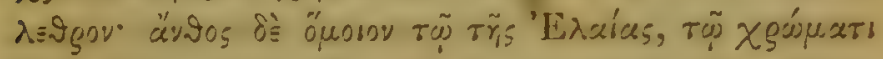

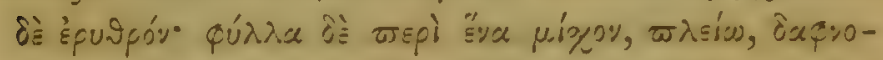

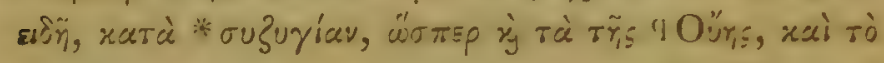

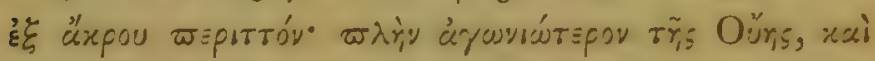

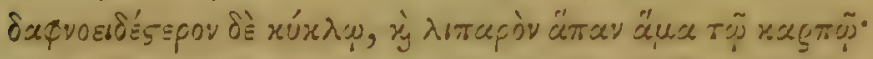

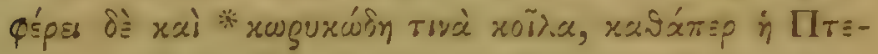

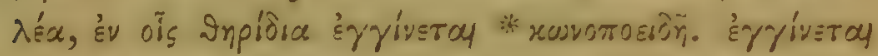

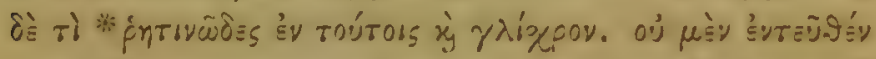

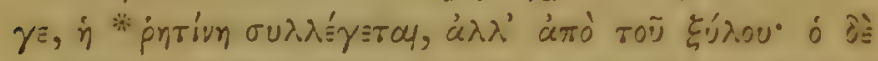

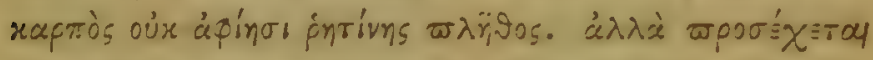

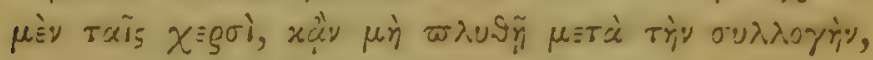

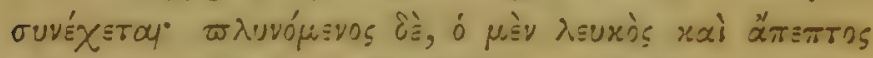

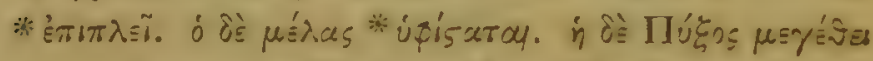

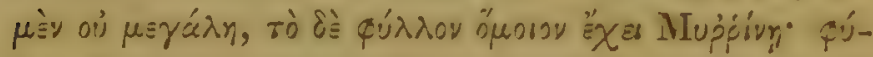

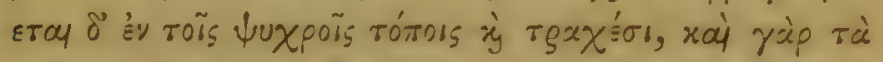

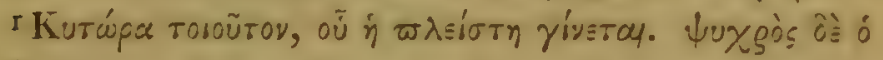

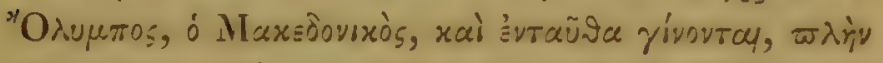

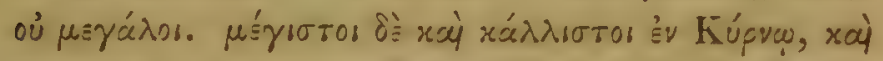

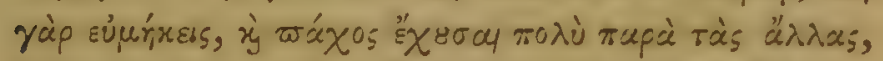

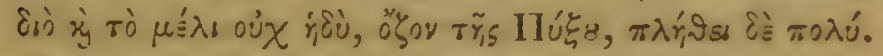

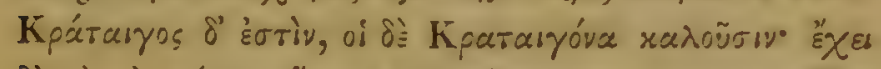

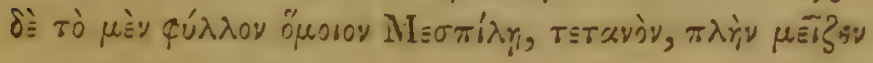

9. oins. Bod, "Ons. Const.

r Kúrz̨̧a Bod. 


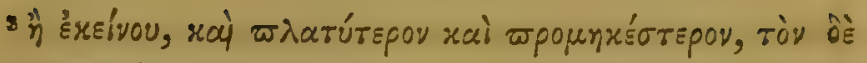

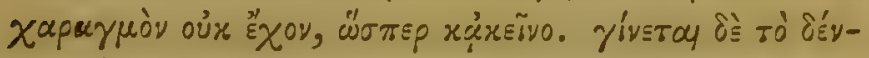

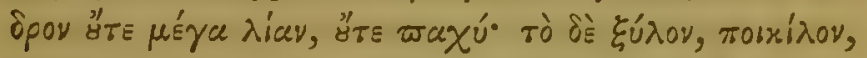

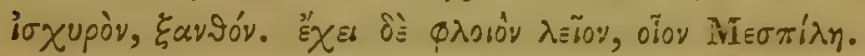

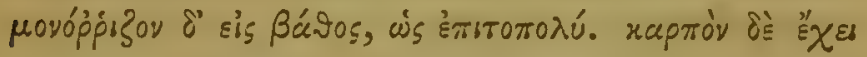

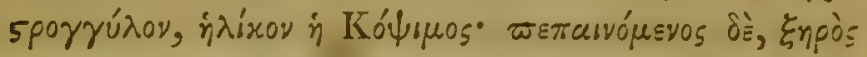

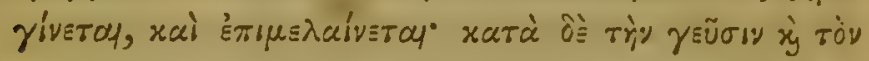

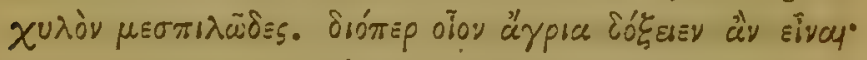

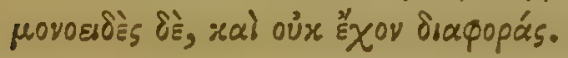

\section{CAP. XV.}

Quercus, Prinus. Ilex, Suber, et Varielutes. Viscum, album: Arbutus, unedo. A. Andrachne.

Rhus, Cotinus.

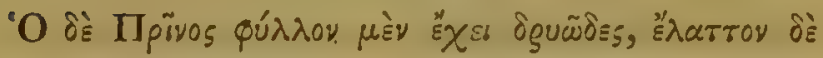

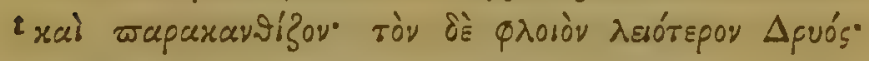

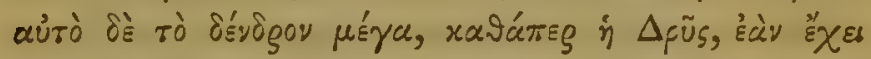

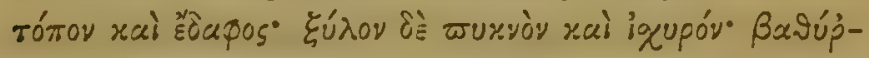

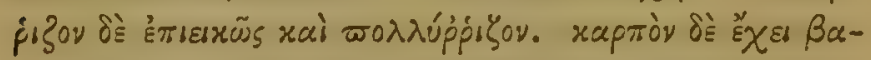

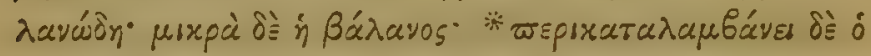

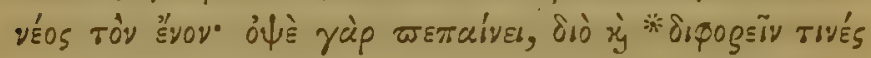

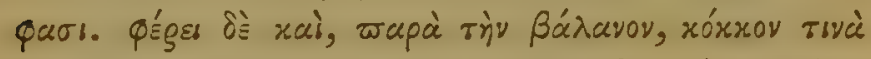

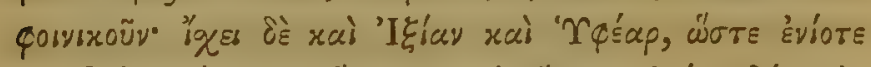

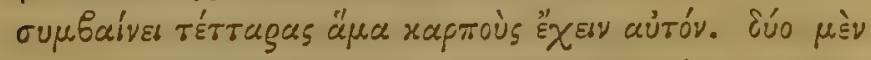

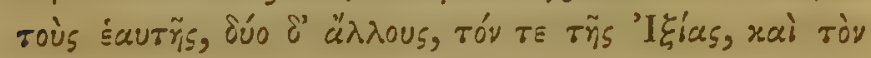

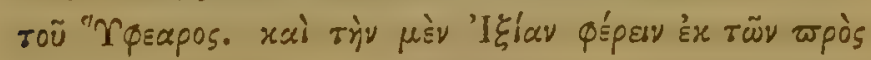

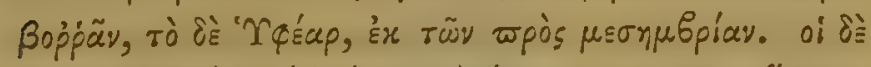

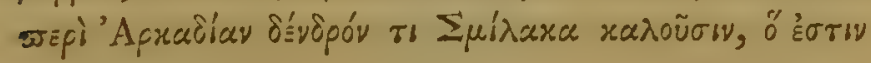

s मैं deest Bod.

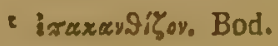




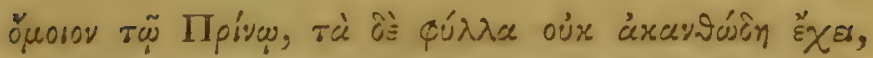

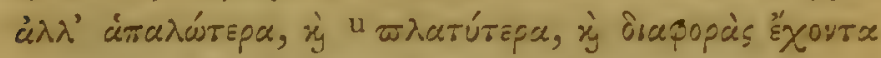

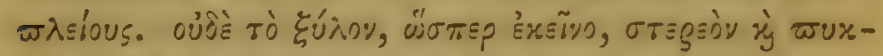

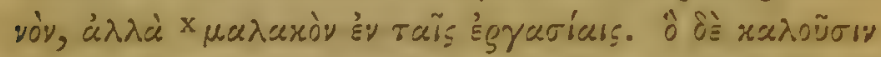

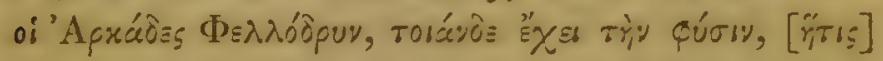

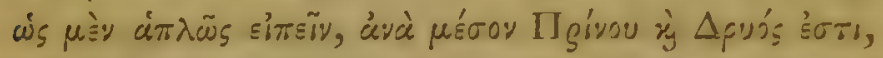

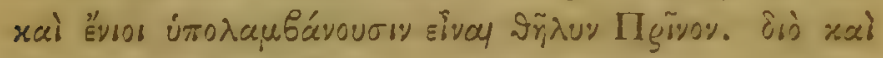

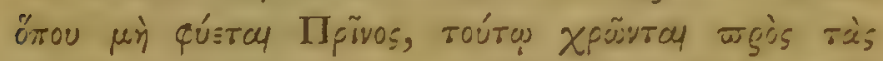

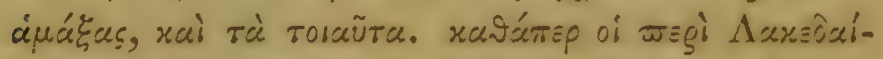

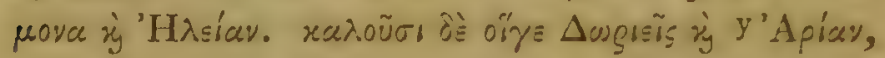

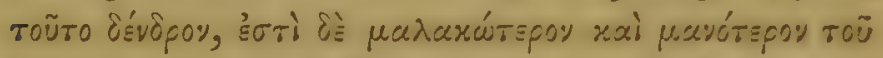

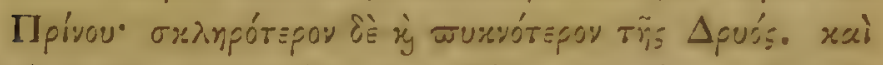

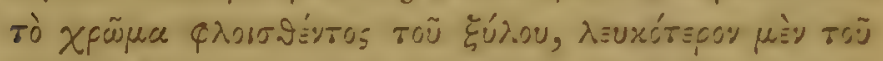

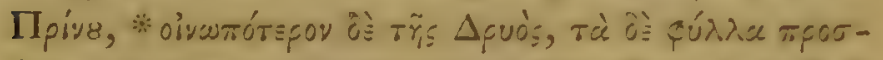

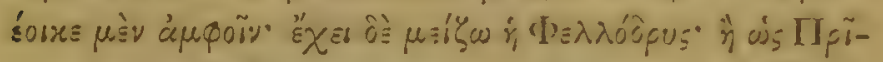

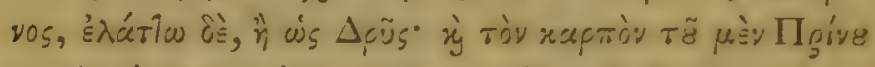

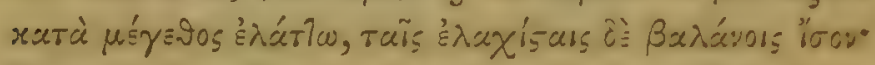

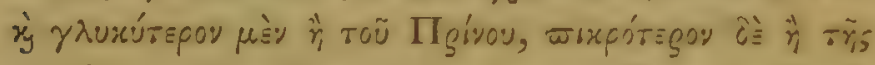

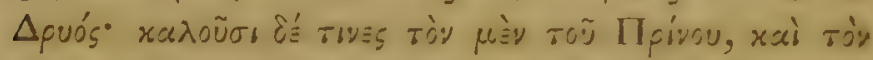

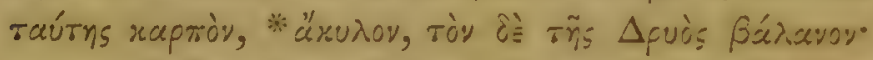

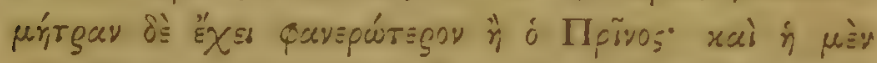

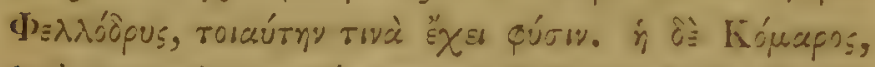

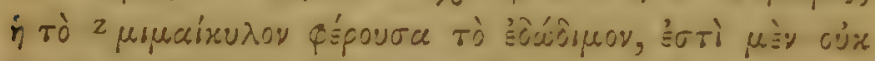

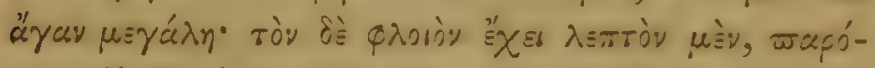

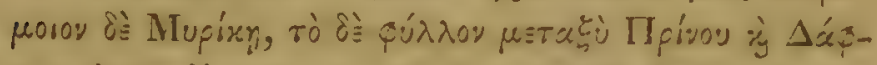

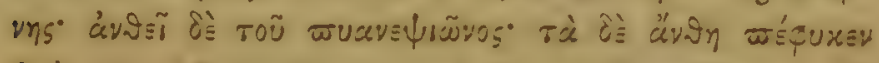

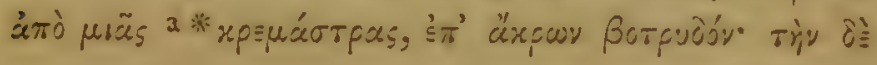

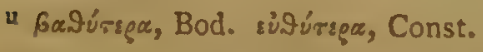

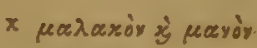

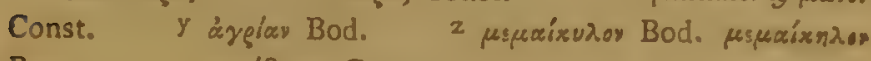
Bas. a xusús şas, Const. 


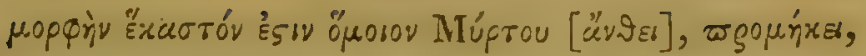

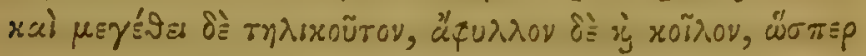

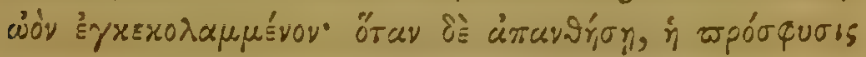

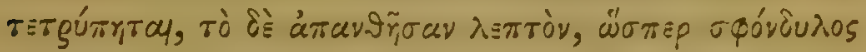

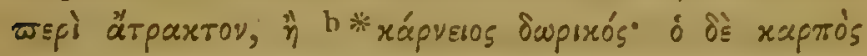

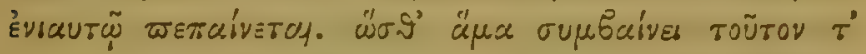

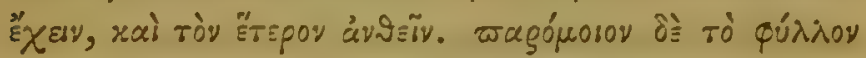

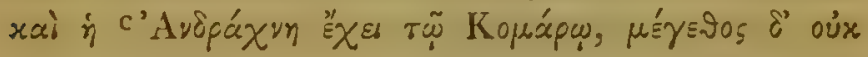

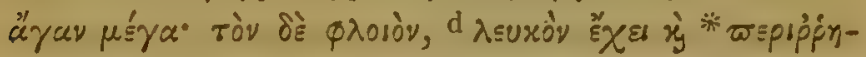

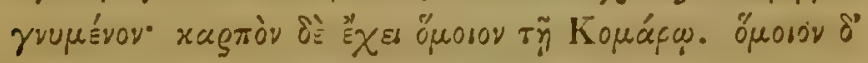

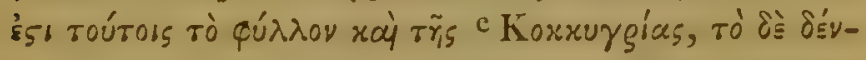

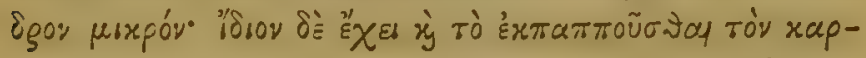

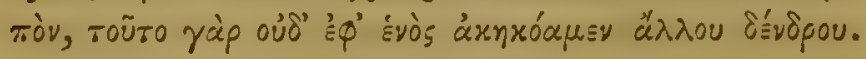

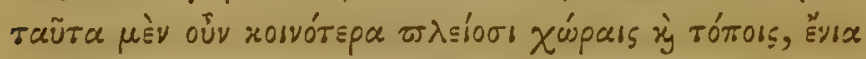
$\delta$ iôúw

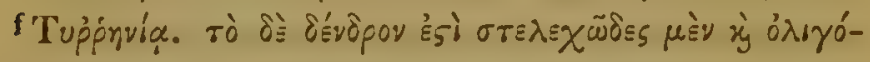

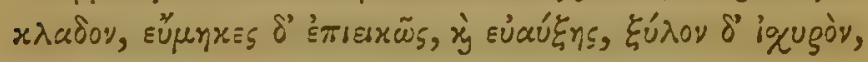

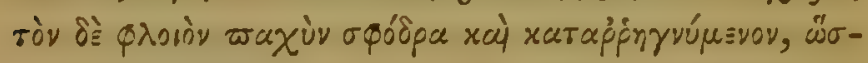

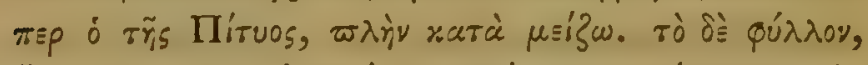

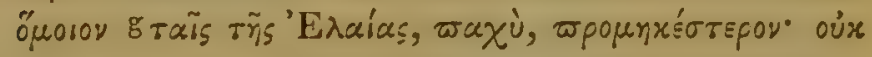
¿̇ं

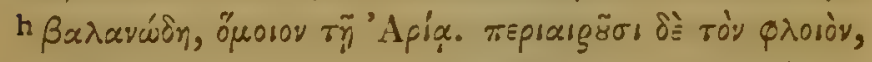

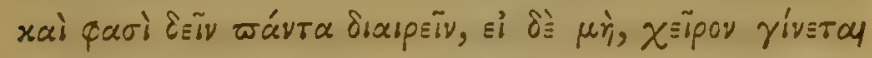

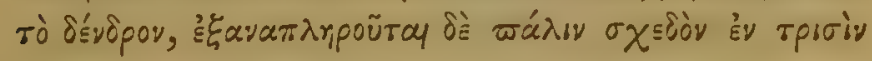

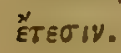

b xsoyóxpaxyy Const.

Plin.

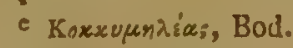

híass, Bod. Mndíass, Const. c 'Adgáxyn Const.

f Iupporyía. Bas.

h Baдarnфógov, Bod.

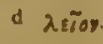

g $\mathrm{Mr}$ - 


\section{CAP. XVI.}

Colutea, arborescens I. Coronilla, Emerus? Ruscus hypophyllum, R. aculeutus. I'uccinium Vitis Idera. Lonicera

Pyrenaica. Rhumni Rhois, et Grossulurice rurictates, ut et Riubi $L$.

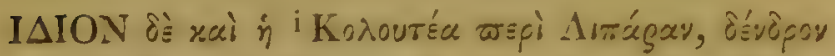

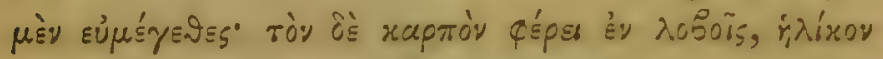

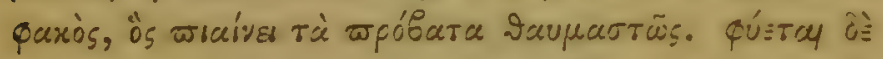

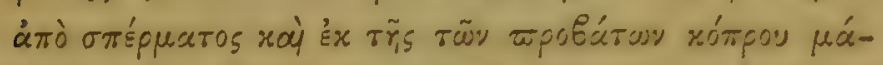

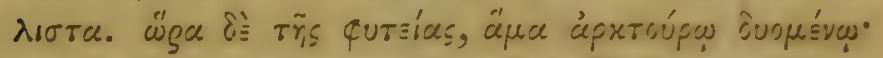

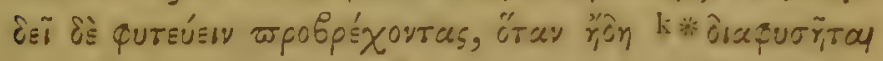

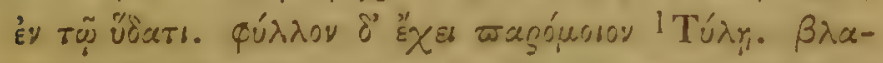

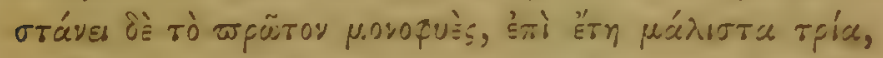

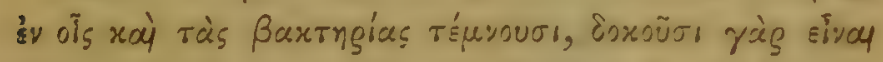

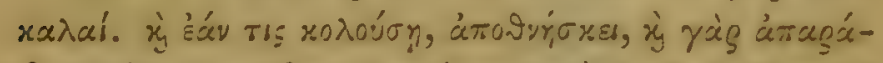

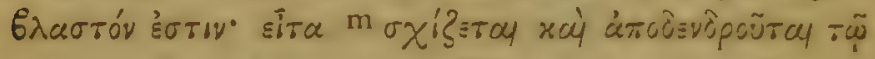

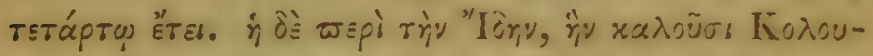

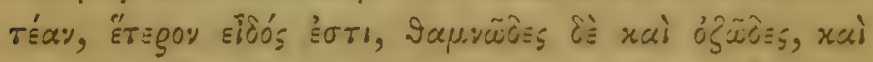

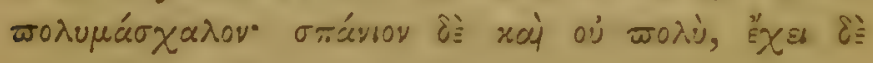

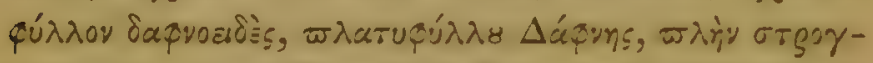

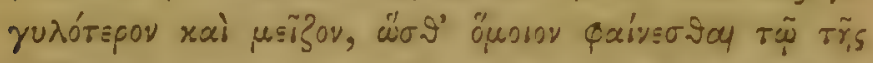

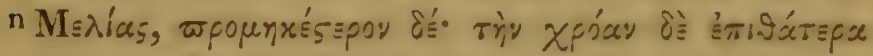

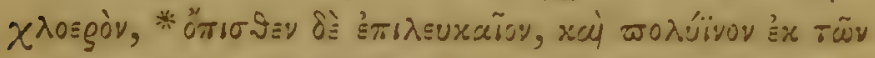
ö

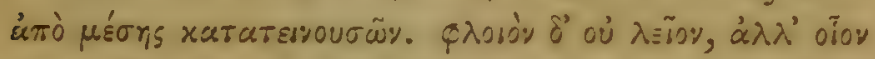

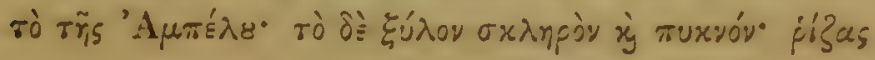

i Koגourí Const.

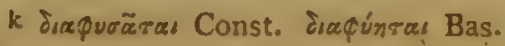
1 'Irí. Bod. Tŕגes. Const.

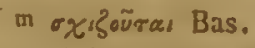

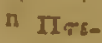

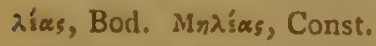

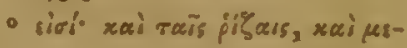
ra E $_{i}$ Bod. Vid. not. ad fin. libri. 


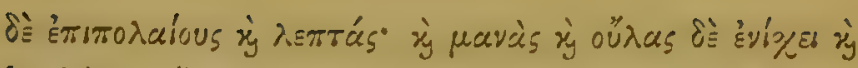

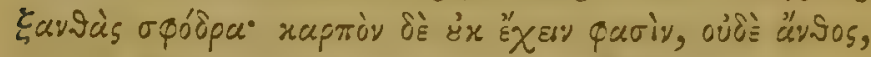

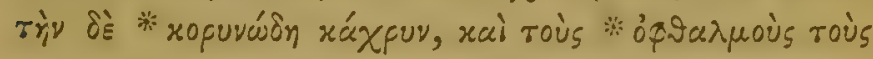

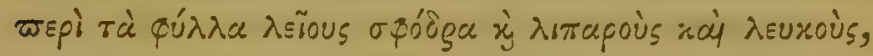

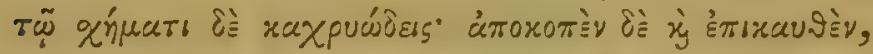

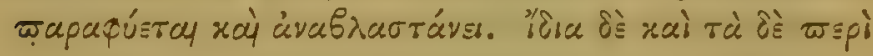

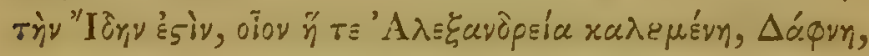

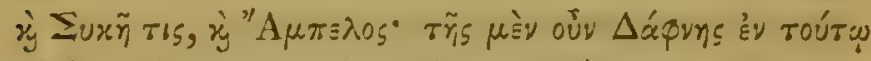

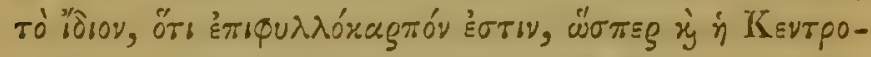

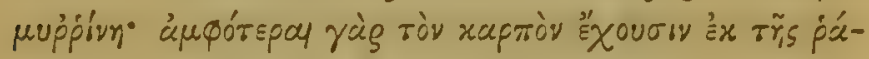

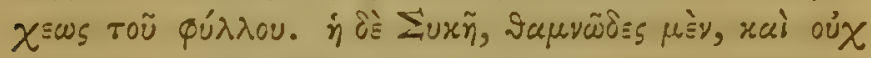

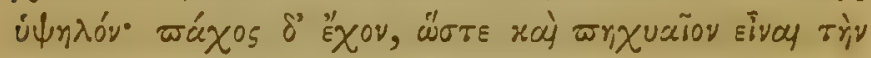

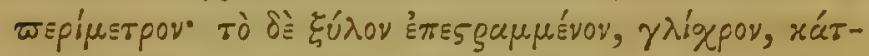

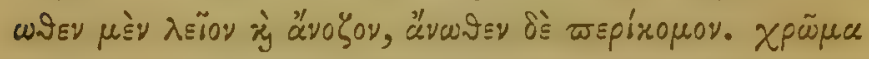

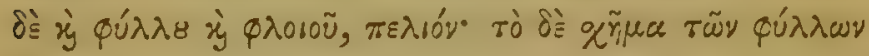

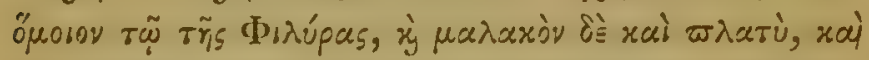

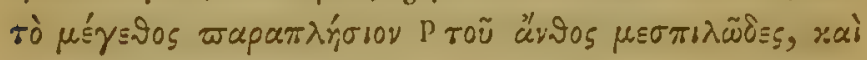

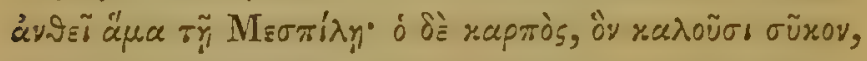

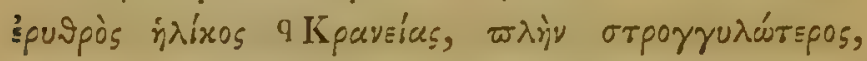

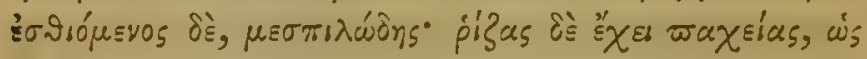

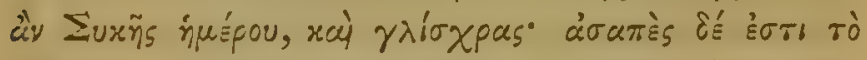

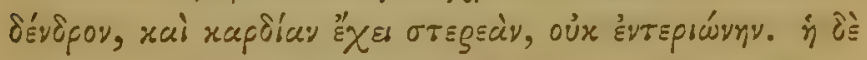

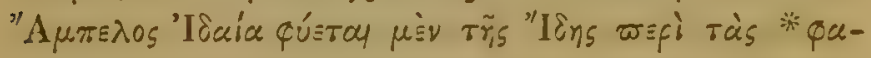

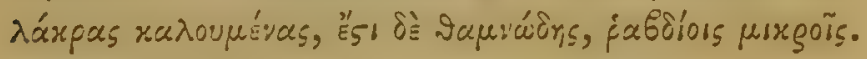

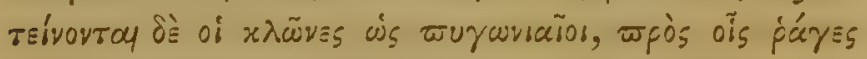

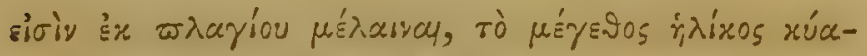

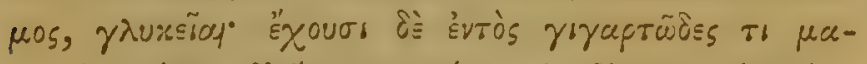

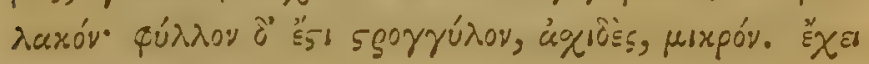

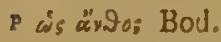

Q 'Eגaiks" Bod. 


\section{MEPI TMTSN ISTOPIAS TO $\Gamma^{\prime}$.}

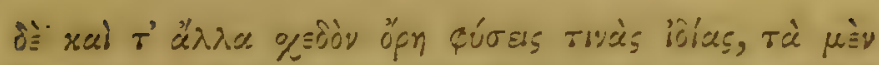

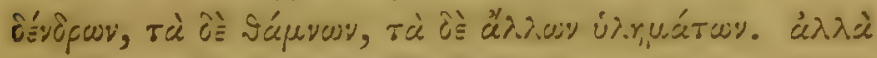

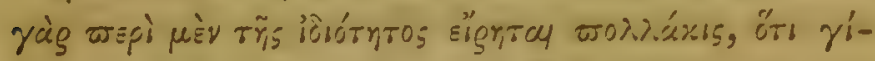

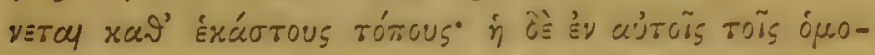

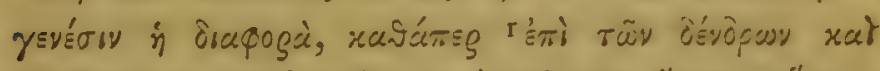

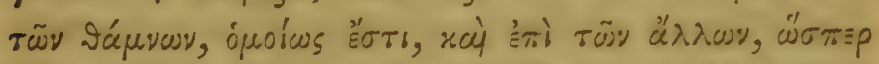

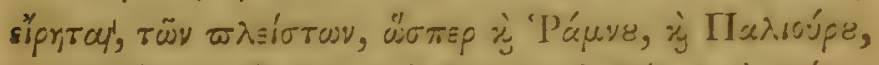

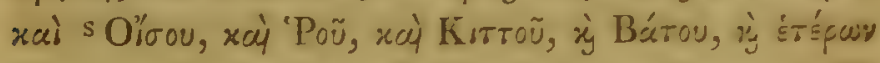

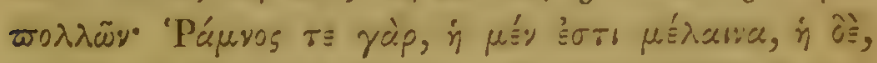

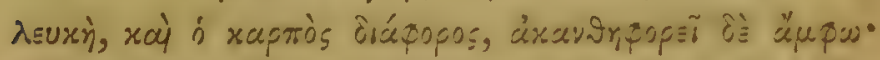

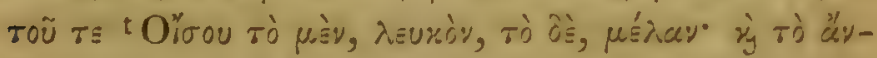

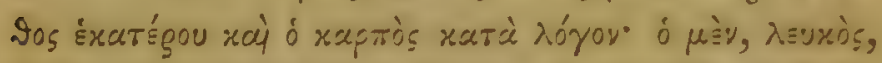

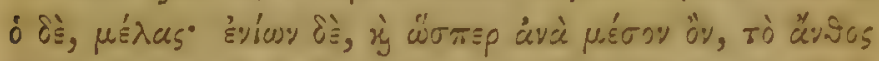

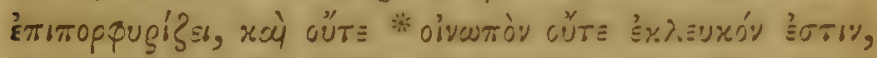

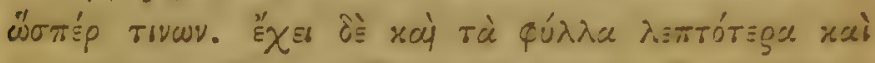

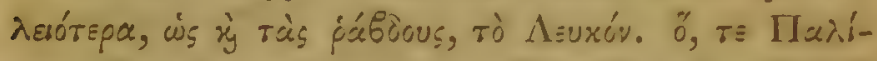

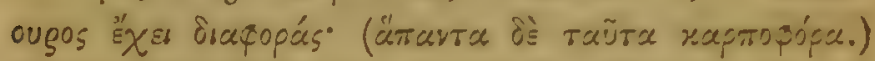

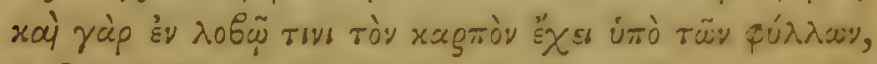

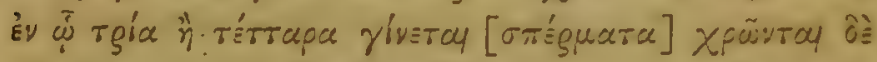

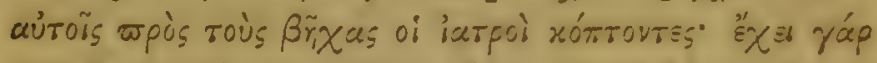

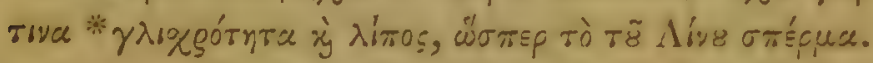

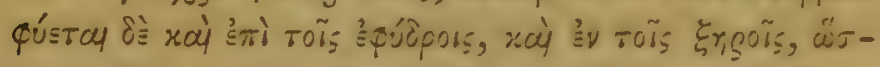

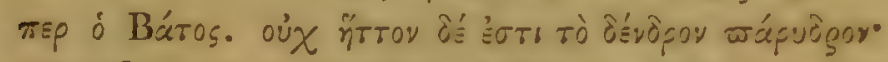

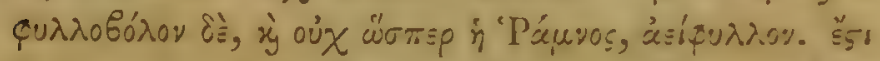

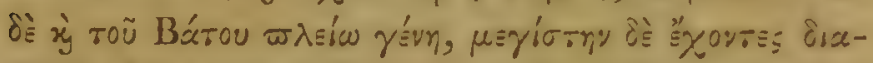

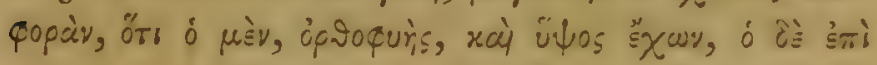

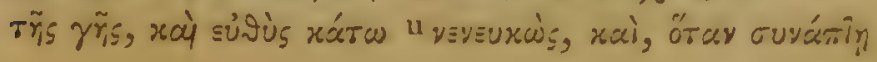

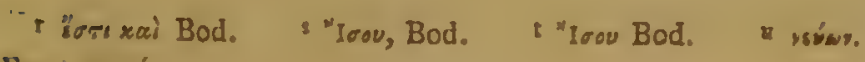
Bas. "ะuxẃs. 


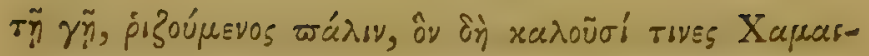

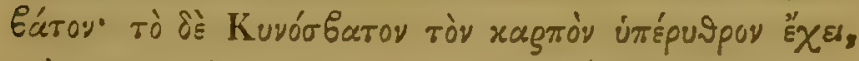

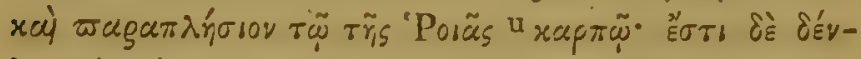

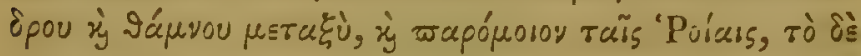

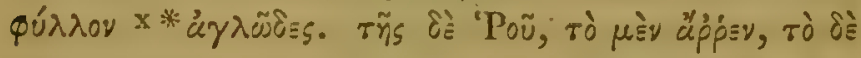

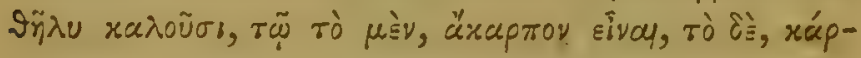

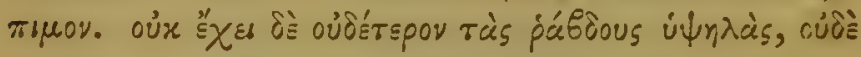

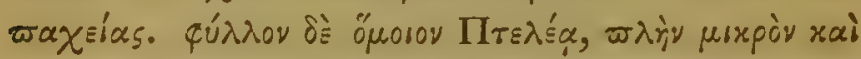

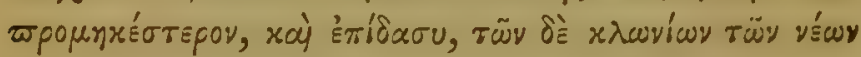

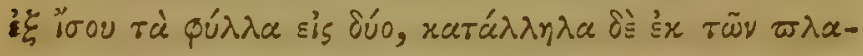

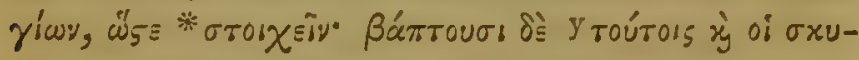

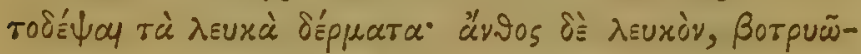

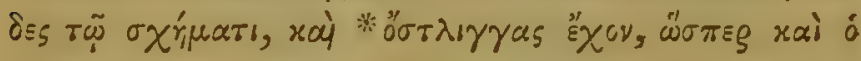

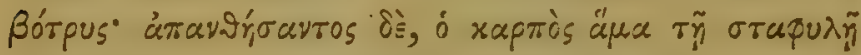

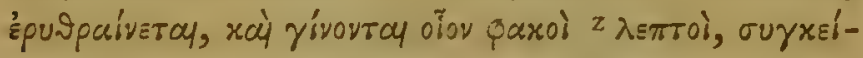

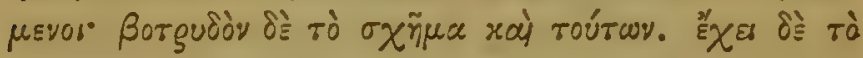

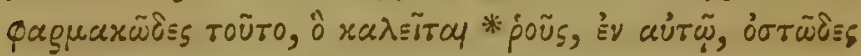

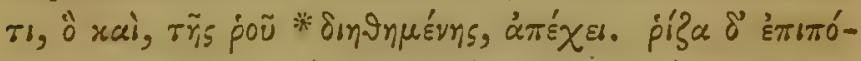

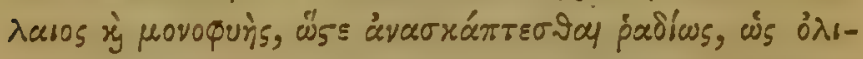

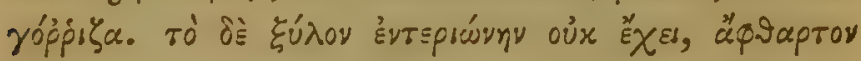

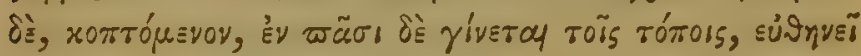

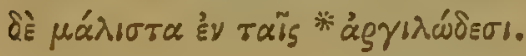

\section{CAP. XVII.}

Hedere Species. Smilar, aspera. Nerium, Oleander?

ПO

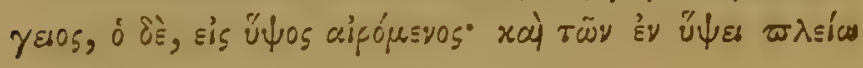

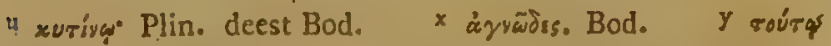
Bod. 2.rxtì Bod:

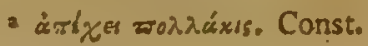




\section{ПEPI ФPTSN IITOPIA TO T. I3I}

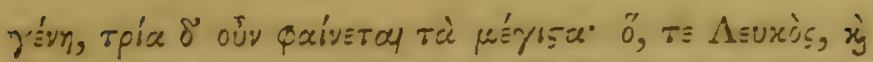

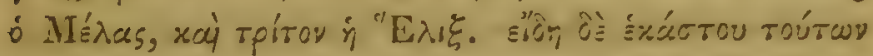

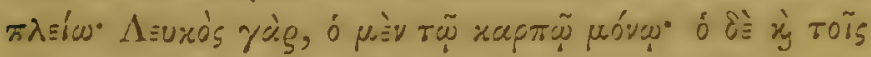

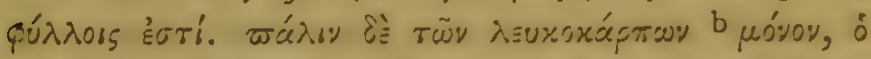

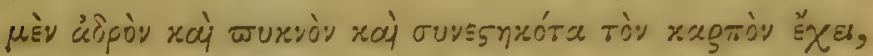

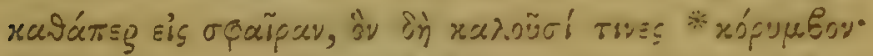

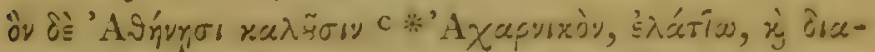

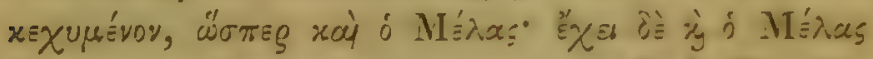

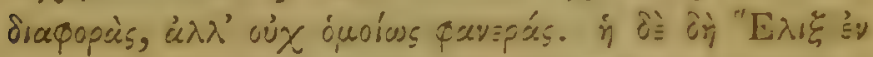

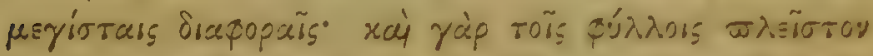

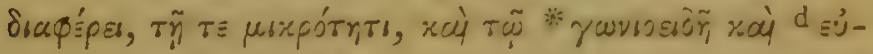

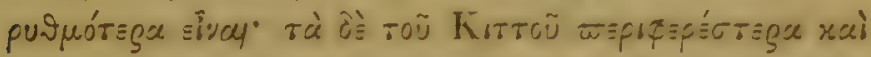

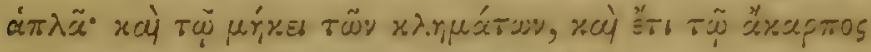

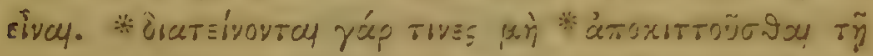

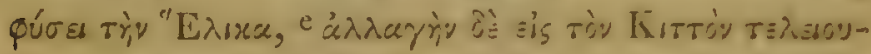

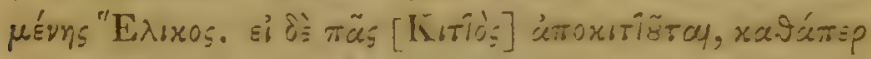

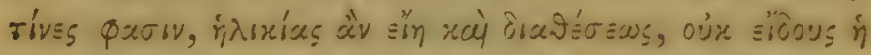

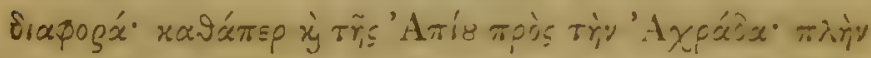

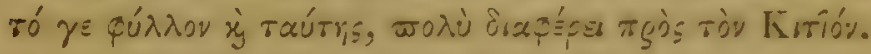

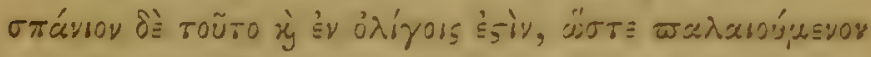

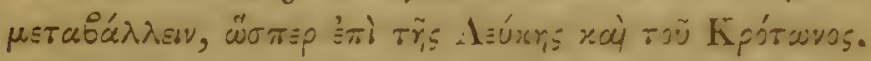

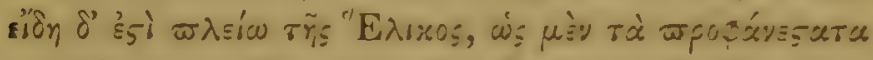

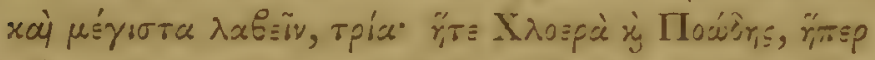

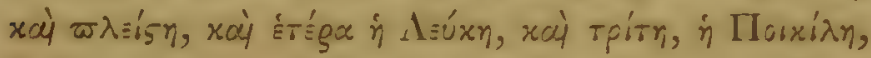

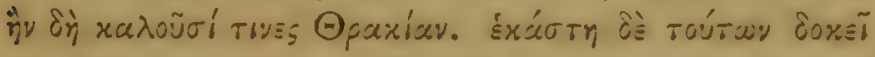

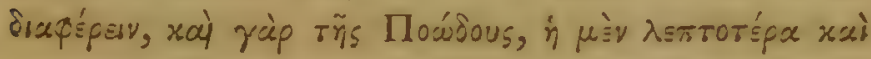

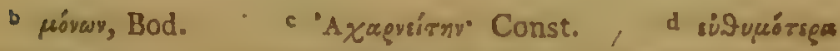

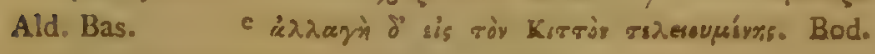

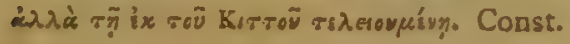

$$
\text { เ. } 2
$$


'

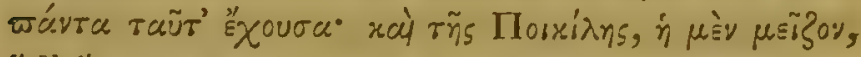

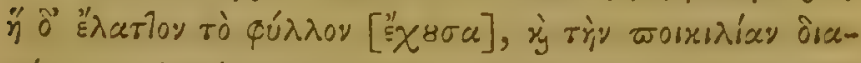

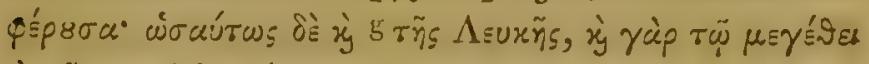

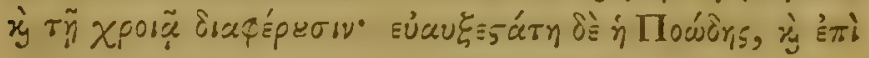

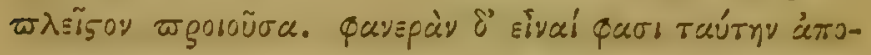

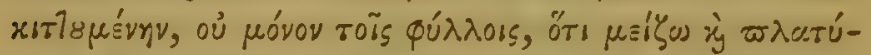

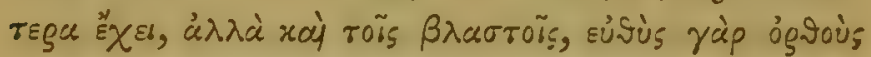

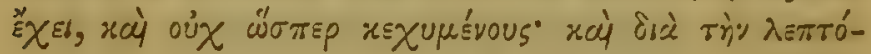

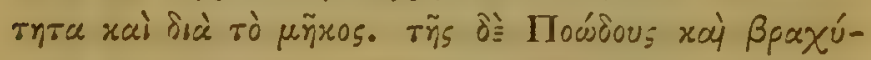

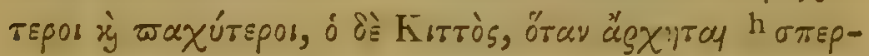

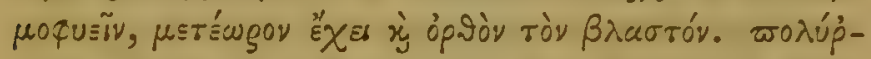

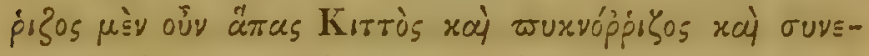

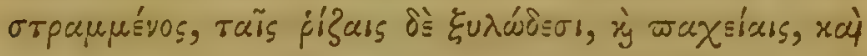

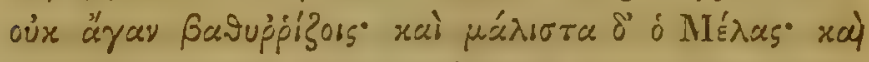

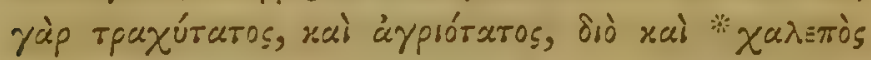

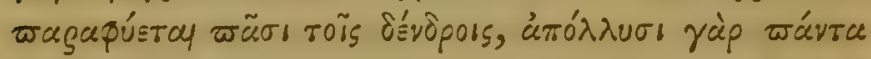

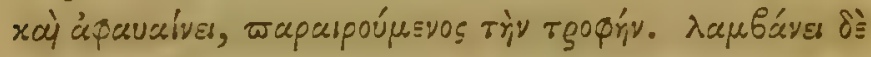

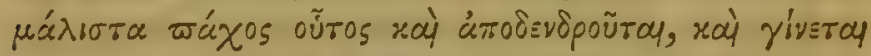

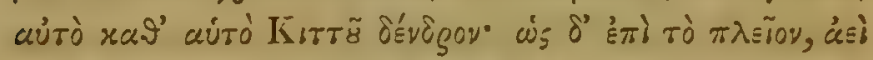

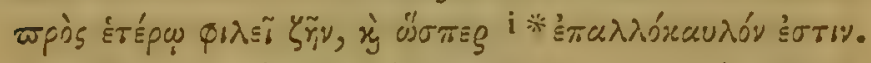

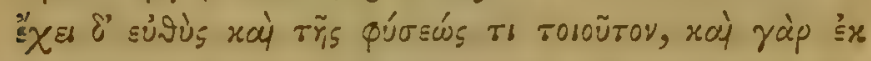

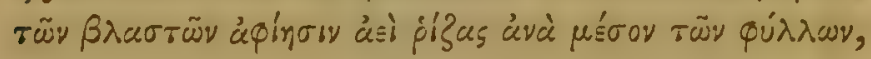

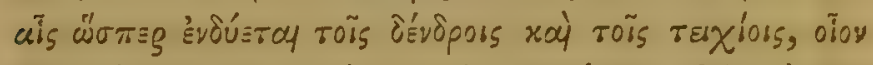

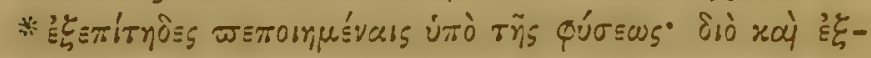

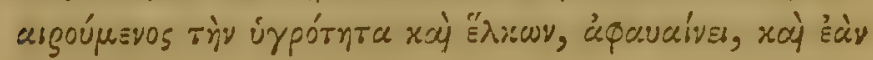

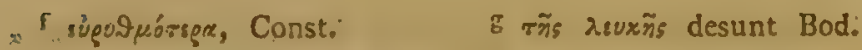

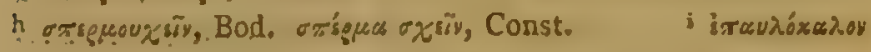
Bod.
} 


\section{MEPI WNTRN ISTOPIA TO T'. I33}

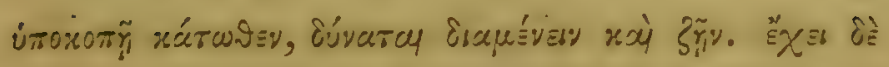

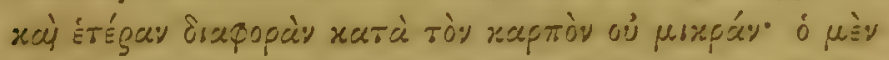

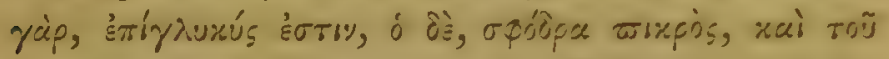

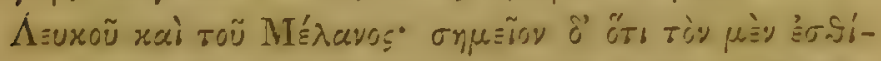

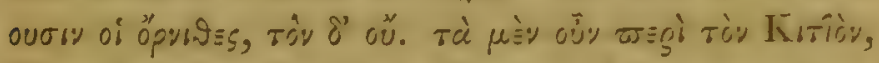

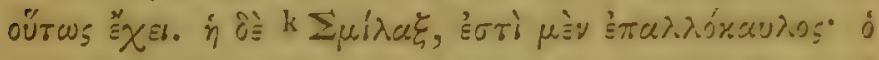

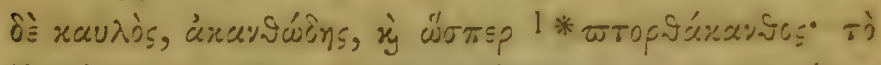

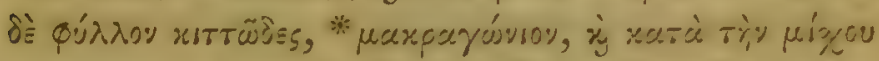

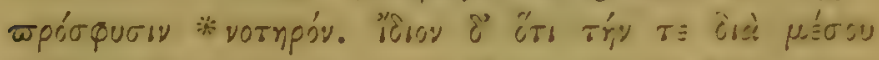

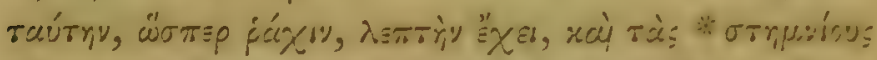

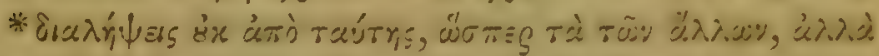

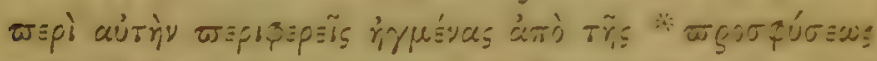

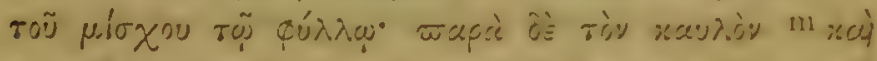

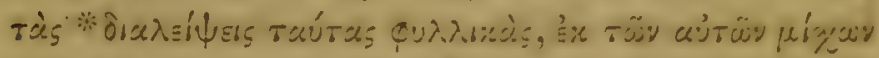

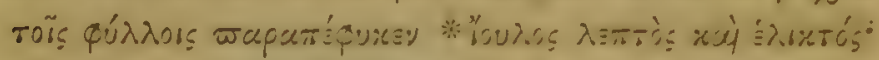

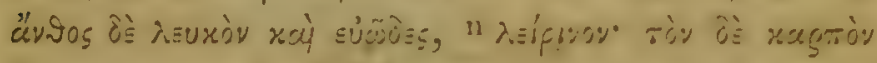

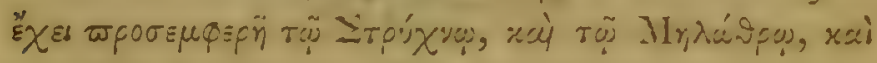
$\mu \mu_{\lambda}$

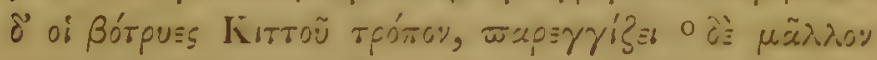

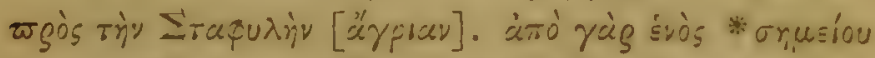

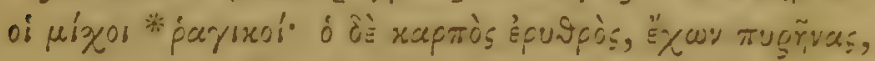

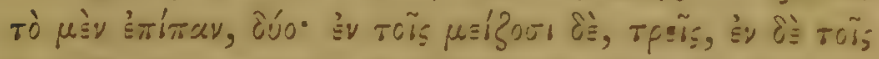

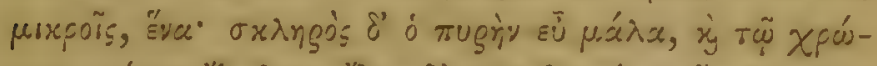

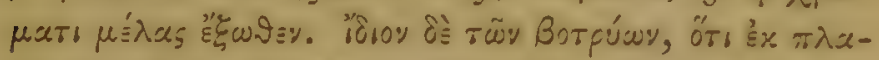

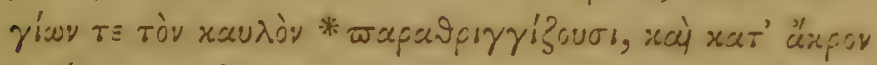

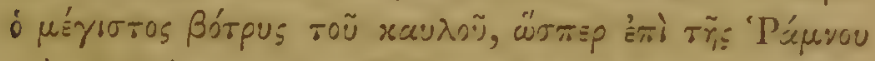

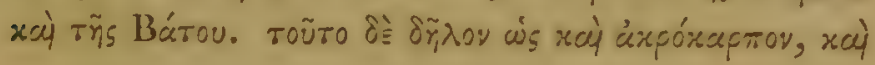

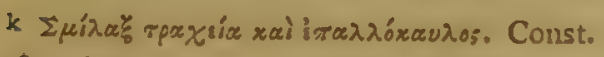
xжy90\%" Bod. mn ràv ärovey Bod.

- dis ás argòs Bod.

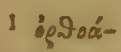
n nẹvarov Bod. 


\section{QEOФPA}

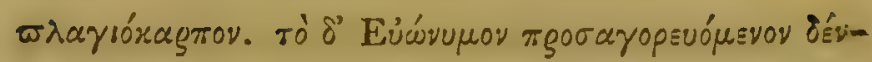

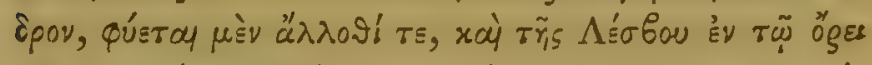

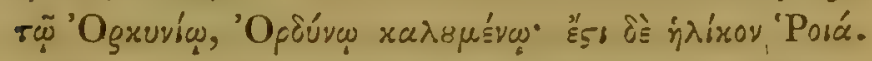

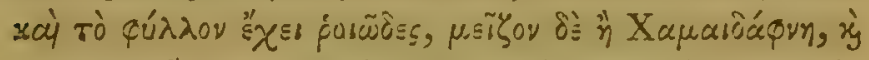

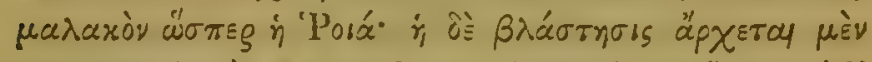

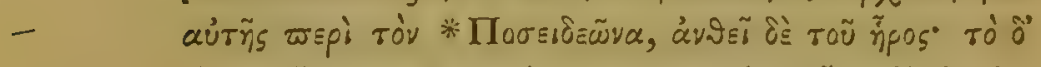

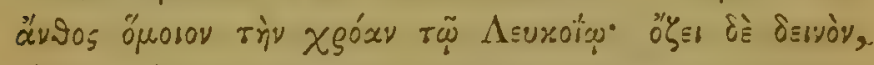

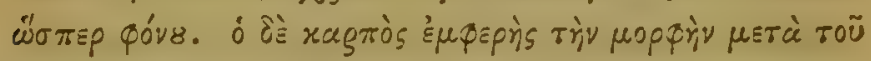

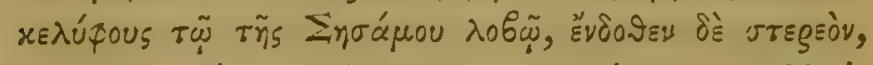

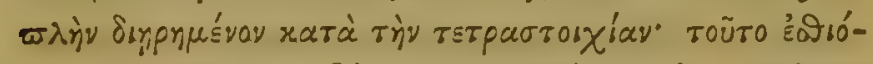

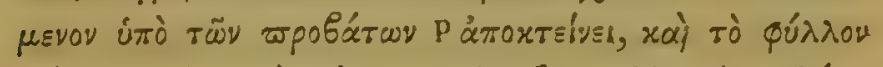

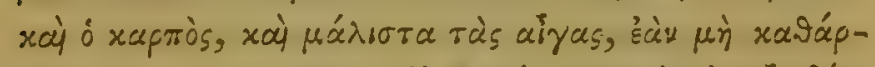

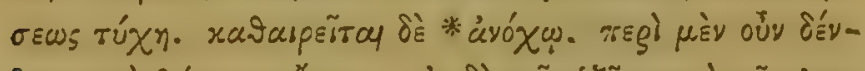

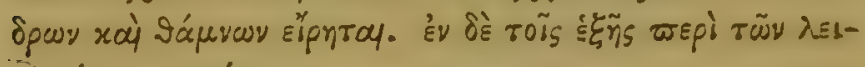

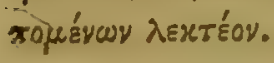

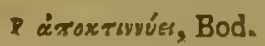




\section{NOT E}

\section{IN LIBRUM TERTIUM。}

\section{A P. I.}

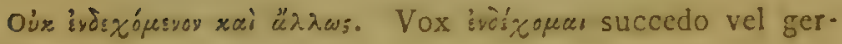
mino: Angl. " to strike."

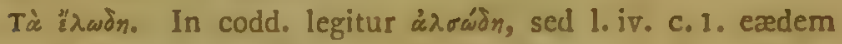

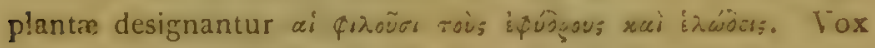

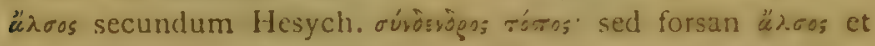
rímos apud Gracos differunt, utpote palustri, rel sicco loco crescentes.

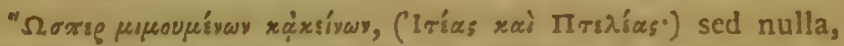
ut videtur, analogia; Abietes enim et Pinus ex seminibus in endem loco, ubi siti fuerint parentes, oriuntur. Salices vero et Ulmi ex seminibus in alium locum vi ventorum allatis.

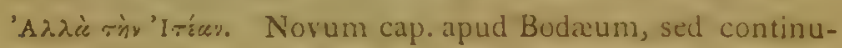
atio subjecti ejusdem.

' $\Omega \lambda$ soíragтay. Vid. Hom. Odys. $x x$. et alibi: vide etiam Obs. Plinii in hunc locum xvi. 16. et Illust. Theophr. p. 81. Alia et longe diversa interpretatio vocis apud Plin. Loc. cit.

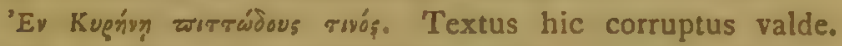
Sermo est de Laserpitio, celebri planta Cyrenensium, ut constat ex icone in nummo civitatis hujus; (vid. Bod. p.59s.) Vide etiam Prosp. Alpinum fuse de hac planta. Succus Laserpitii secundum Plin. xix. 3. pretii maximi apud Romanos. De ortu ex imbri piceo Plin. loc. cit. Item Theophr. de Caus.

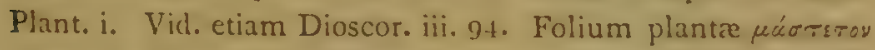
Grece; succ. apud Lat. Larser; vid. usus in medicina Galen. de Morb. Acut. iv. Recentiores radice utebantur. Conjicitur a quibusdam örav hunc esse Asam foetidam Pharm.

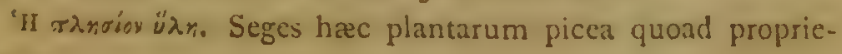
tates.

\section{K 4}




\section{A P. II.}

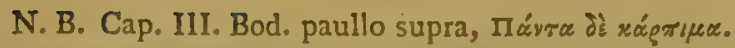

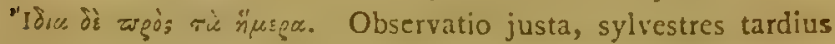
maturare fructus, et plus vigescere.

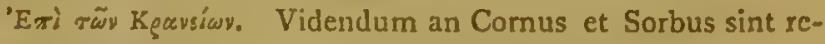
vera ùygíov $\varphi$ vó́ws, et non meliora fiant cultura.

\section{A P. III.}

'Iòa qoix́ô. Septemdecim species arborum in montibus Macedoniæ enumerantur; totidem in planis.

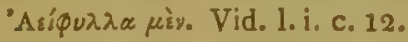

Aizsıgor xáęrтuss. Populus fomina rara admodum.

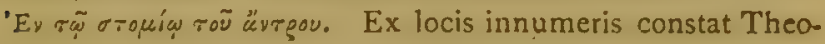
phrastum regiones ipsas herborisando investigasse.

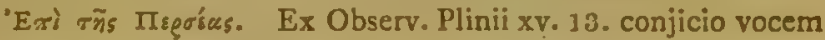

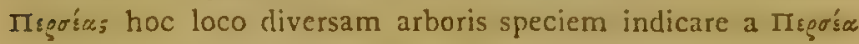
iv. 2. ibi enim, ut et apud Plin. distinctio sumitur inter Persicam et Perseam. Amygdalus Persica accuratissime describitur a Dodonæo A.D. 1640. Dioscorides etiam et Galenus, ut genera diversa, Persicam et Perseam describunt. Suspicor tamen Malum Persicum, vel saltem varietates ejus cultas, Plinii tempore Romanis ignotum fuisse; ita enim 1. xxiii. describitur, "Nec est alius eis pomis innocentior cibus; nus"quam minus saporis, succi plus."

\section{C.A P. IV.}

'Appp'va póva. Vox äp̧piny de vigore plantæ interpretanda, paucis locis exceptis.

'A pséúavos dúo. Observatio justa, spec. enim Diœcia Linn. Dubitatio occurrit supra de Quercu, Abiete, et aliis Monœciis,

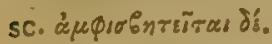

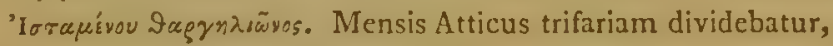

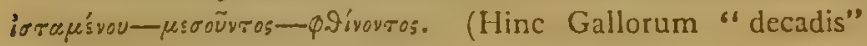
hodierni.) Initio Februarii nensis.

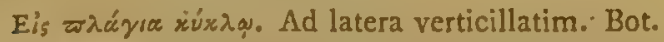

'II Kusis. Supervacaneum videtur ita accurate de Gallæ ortu et accremento disserere, quæ non planta, scd insectæ domici- 
Jium : suspicor tamen corruptionem textus: ut ut se res habet, parenthesi includend. qua de Kíniò, et verba dianairsovice di

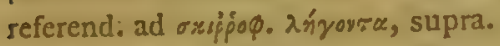

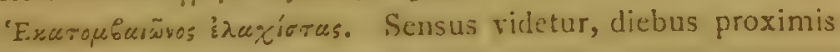
initio mensis Junii, quando sol in cancro. Const.

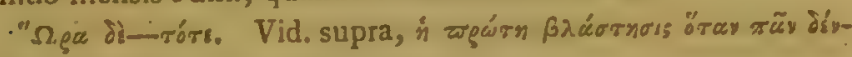
jopov $\lambda s \pi \tilde{u}_{0} \cdot$

\section{A P. V.}

N. B. Bodri Cap. VII.

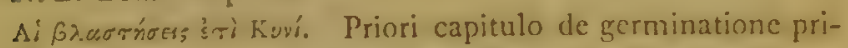
ina, vel rernali. Intermissiones her (ova $\lambda$ sítes; vocantur, et germinationes, qua post Canicula ortum producuntur; Anglice "Michaelmas shoots."

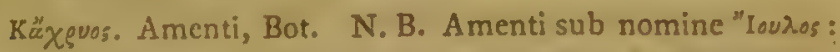
accuratissima occurrit descriptio in Corylo, Aveliana Linn. cap. sequente. Vid. Plin. xvi, 8.

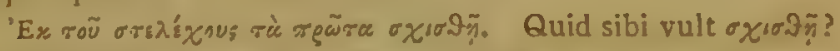
an actionem rumpendi corticem? Scal. ait surculos fissos, et disparatos. Bod. p. 1:39. Binis adversis coharentibus, subrecta divisura. Gaz.

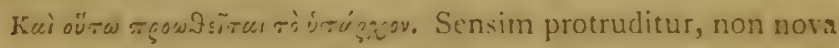
germinatione junioris ligni, ut in Abiete.

\section{CAP. YI.}

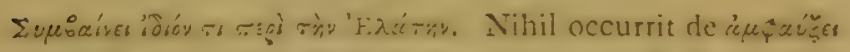
apud Bod, nec neminit Plin. in loco de decacuminatione Abietis xvi, 30. Ex significatione vocis Greca conjicerem aliquid enasci post cæsuram, ut nodi in aliis arboribus: superat hoc duritie lignum trunci, et differt colore; idcoque aptum poculis vel rasis faciendis.

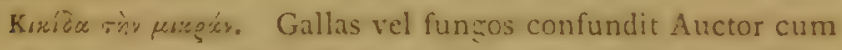
partibus constituentibus plantarum. Accurata adnodum desc. quarundam e classe cryptoganica plantarum crescentium super arboribus, çuas operæ pretium crit Botanicis investigare in regionibus ipsis. Vide qua notavi in Lex. Theophr.

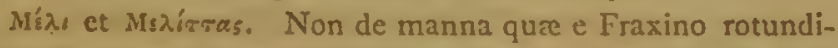
folio, L. pervenit, memorat $1 /$ esiodus, sed de alvearibus in cavis trunci. 


\author{
CAP. VII.
}

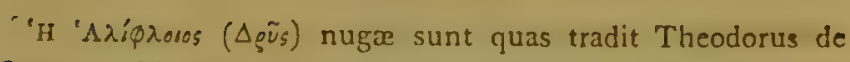
Quercu salsi-roricice; vox ú $\lambda$ is abundantiam, vel crassitudinem corticis indicat. Species quinque clare indicat Theophr. 1. $\Delta p$.

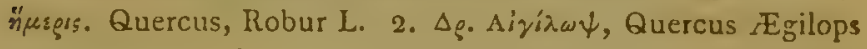

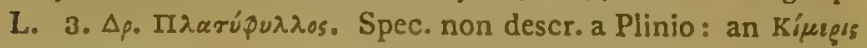

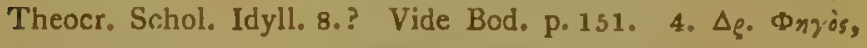

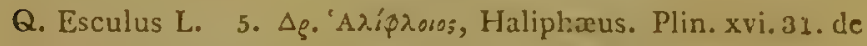
qua non constat nisi $Q$. Cerris, vel $Q$. Coccifera $\mathbf{L}$.

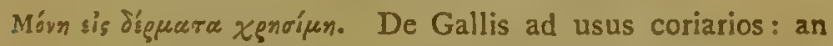
solæe Quercus íneş́óos utiles, videant Botanici ; sed quid de xuxidu $\mu$ saiva ad usum tinctorium. N. B. Lichenum quorundam vires tinctoriæ memorantur. Lich. Pulmonarius L. hic videtur innui.

\title{
C $\Lambda$ P. VIII.
}

Genus, Pinus L. hoc capite describitur. Species enumerata sunt, P. Sylvestris, P. Pinea, P. Cembra, P. Picea, P. Abies, et P. Larix. Vix aliquid certi reperitur super hac re apud antiquos scriptores. Quatuor apud Linn. Sp. Plant. 1418. P. sylv.

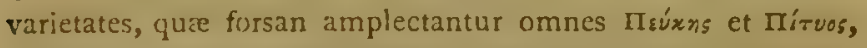
a Theophr. enumeratas specics, Larice, et P. Pinea, et Cembra exceptis, Respectu Laricis nulla occurrit desc. specifica: $\Pi$. rì gívos deciduum vocaturi. 13. et alibi. Mírus $\phi$ astoópopos occurrit

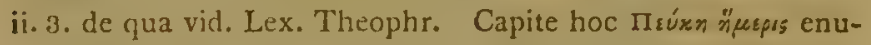

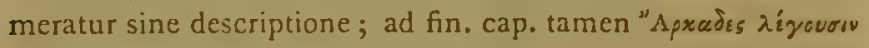

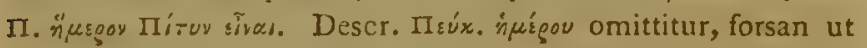
arbor notissima. ח. 'I $\delta$ céa, secundum Mathiol. Pinus maritima altera ; secundum Clus. Pinaster prior. Fuse tractat super liac re Bodæus, sed paullo ad.rem, p. 165. 2.

Tǹy aizid $\alpha$. Supra mentio fit a gidis apud antiquos ex nodis Pinus vel $\Delta$ bietis ad tabulas pictorias, vel scriptorias, \&c. Hic

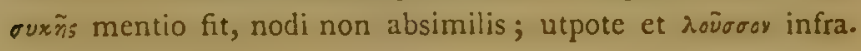
Vid. Lex. Theophr.

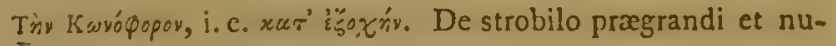
cibus edulibus P. Pinex, et Cembre.

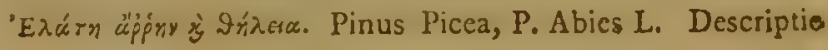


accuratissima, sed ex corruptione textus respectu voc. xux

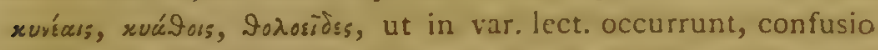
orta vix sanabilis. Vide de hac re Praf. ad Illustr. Theophr. p. iv.

O ${ }^{\ulcorner} \lambda y y$ \&े $\lambda$ síav. De ægide: an curvature venarum in ligno?

C A P. IX.

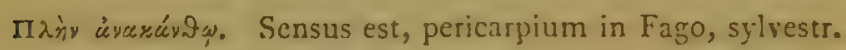
molliter spinosum esse, non rigide, ut in $\mathrm{F}$. Castanea.

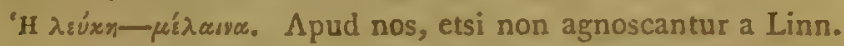
duæ occurrunt varietates ex colore ligni nominate, alba et nigra, quarum nigra duritie longe præcedit.

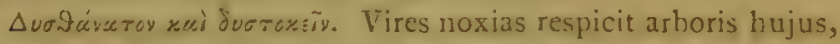
adeo ut mors habitantium in domibus ex ligno cjus construc. tis, æque ac parturitio difficilis : anilis fabula, ut videtur.

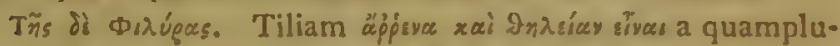
rimis superioris avi Botanicis, æulue ac a Theophr. asscritur: minus recte tamen. In classe Polyandria Linn. enumeratur Tilia, cujus in Spec. Plant. p. 733. occurrunt varictates quinque. Fors. var, $\alpha_{0}$ T. mas, var. $\gamma$. T. foemina.

"A:20s ruzuncoss. Explicatio loci hujus dificillimi, si textus sanus sit, ex inspectione fructificationis petenda, et hine forsan emendanda.

C A P. X.

Epindáuyou dúo gśrm. Plinius ait tria genera xvi. 15. "marem "ct forminam; tertium genus Zygiam, rubentem fissili ligno, "cortice livido et scabro: hoc alii generis proprii esse malunt, "et Latine Carpinum appellant." Sed Carpinus L. accurate describitur cap. priore sub nomine "Orapeirs. N. B. Bodreus icon. Aceris majoris et minoris Lobel. sistit, p. 183.

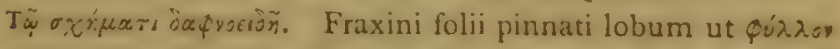
describit Thcophr. folium ipsum $\approx \lambda$. $\tilde{\omega}_{*} \approx$ vocat; attamen dicit,

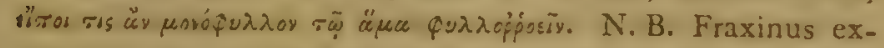

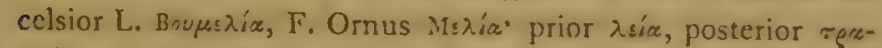

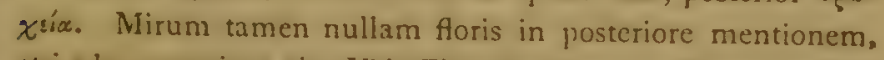
etsi adeo conspicua sit. Vide Flor. Gr. Fasc. 1. Racemus flor. Frax. excels. sic describitur, pį̧́ rà है"

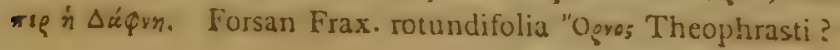




\section{A P. XI.}

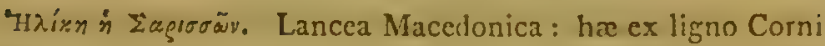
fiebant. Longitudo ejus eximia hic clare indicatur, sc, duodecim cubitos.

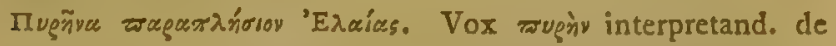
drupa tota, non de nucleo ejus. Fructum Corni eleganter describit Dioscor.i. c. 172.

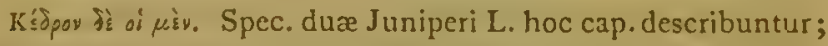
itemque Juniperus communis L. sub alio nomine "Aoxqu9.s. Nira hallucinatio Bod. qui Pinus Cedri L. iconem sistit, p. 197.

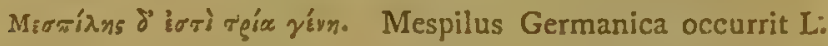
Sp. Plant. p. 684. cujus var. $\alpha$. et 6 . sed nulla mentio Setaniae vel Anthedonis. Quatuor species enumerantur Ger. em. 1453 . M. sativa prima, M. sativa altera, M. Aronia, M. chamemespilus. N. 13. Fructu Mespili inter delicias enumerato, var. forsan plurimæ interciderunt.

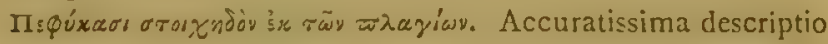
folii pennitti Sorbi. Textus forsan corruptus : conf. descr. folii Fraxini, cap. $x$.

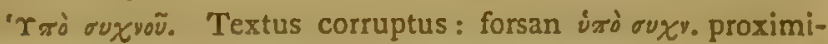
tatem loborum folii pennati indicat, et postea legend. жаi xarc $\mu$ śgos, per paria.

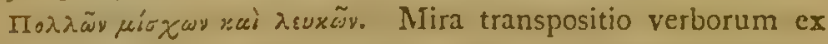
incuria librarii. Kag\%o hoc loco dicitur similis *ngis, sed um-

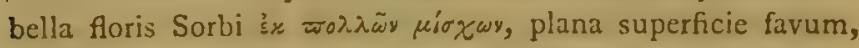
cellulis relictis vacuis, apprime refert. Suspicor etiam vocem

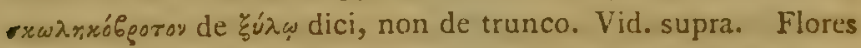

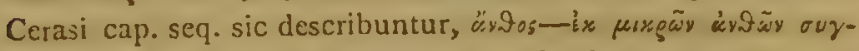

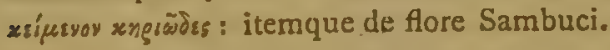

\section{A P. XII.}

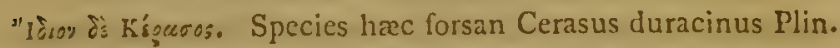
Cer. sylv. non cultus, ex quo tamen var. cultæ, cujus fructus in deliciis sub nomine Pruni Cerasi L. Secundum Constantinum Cer. sylv. "Gignier" vocatur Gallis. Cer. niger Ger. em. 2.505. Usus corticis singularis ad cistas facicndas, ut et decorticatio non transversim, sed linea spirali, si textus sanus. 
N. B. Cerasi sylv. in sepibus nostris forsan non indigenæ, sed ex nucleis, var. cult. in hortis nostris ab avibus et aliis, seminatis.

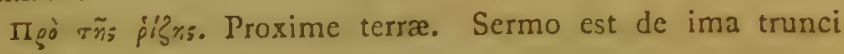
parte.

Kaì tò Ǧúrov "̈poso\%. Sc. fibras in ligno spirales esse, et similes fibris in cortice: sed certe aliter se res habet, et textus vel corruptus, vel obscurus.

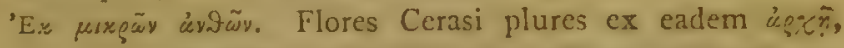
non tamen umbellati. N. B. Occurrit itcrum similitudo cavitatum in flore cellulis vacuis favi. Vid. Fraxinus, Sorbus, supra.

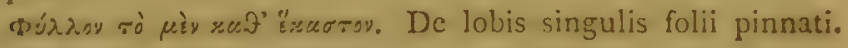
"Ey $\delta \mathrm{s}$ है

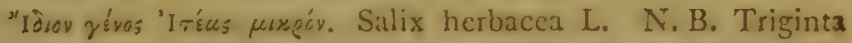
fere spec. Salicis occurrunt L. Spec. Plant. 1412. varietatibus apud nos ad infinitum multiplicatæ.

\section{A P. XIII.}

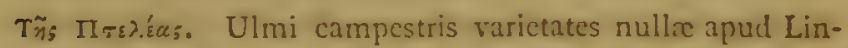

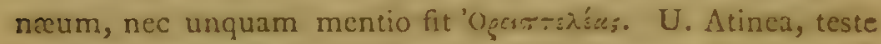
Plin. xvi. 17. excelsior; U. campestris fructicosior : "Atineæe " non ferunt Samara : ita vocatur ejus semen." Sed forsan Samara, quae apud Columellam " amara," fructificatio UImi primo vere, xapúxas xà̀ rò xópps Theophr.

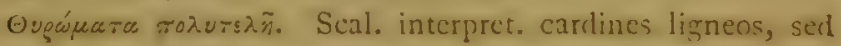
rectius opera fabrilia forarum valvas spectantia, qua antiquitus artificiose cælata.

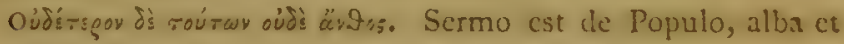
nigra L. Inter has $P$. foemina rarissima.

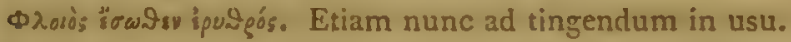

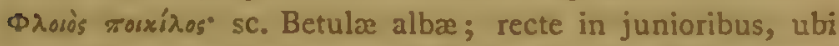

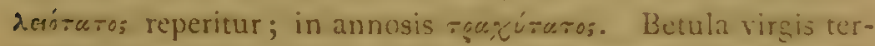
ribilis antiquitus, Batula, a batuendo (credendo) vocalbatur, teste Plinio.

Koגoviś $\alpha_{0}$ Interpretor Coluteam arborescentem L. sed ob. scura et nimium brevis descriptio. Plante hujus iterum fic mentio c. xvii. N. B. Pro 'Iria legend. Túdr, qque vox ibi ss- 
mel tantum occurrit, et a Bodaen vocatur Trigonella, fœnum Græcum L.

\section{A P. XIV.}

'H ò̀ 'H et C. colurna, a Theophrasto describuntur, ut sylvestris et culta satis accurate.

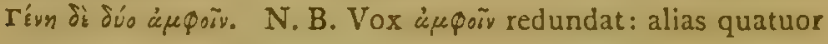
species.

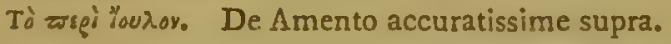

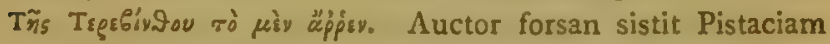
Terebinthum L. Pist. Lentiscus L. Egù gòn $\phi^{\prime}$ tacire nux exterius viridi-rubescens, nuclei cuticulis rubescit. Vide Plin. xiii. 6.

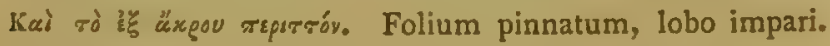
Vide Fraxinum supra.

'H $\delta \dot{s} \Pi$ úas. Recte vocatur Myrtifolius. Arbur frigoris amans, ut Taxus. Virg. Georg. Tæ̀ Kurága sc. öৎn. Sic Plinius: "Buxus Pyrenæis et Cytoro montibus plurima," xvi. 16. et

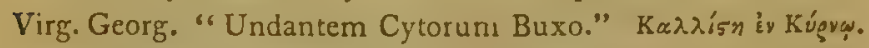
Crassissima in Corsica. "Flore non spernendo, qux causa " amaritudinis mellis." Plin. ibid.

\section{A P. XV.}

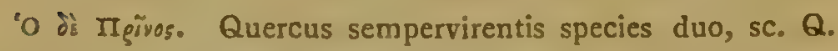
Ilex, L. var. a. et Q. Ilex var. $\beta$. (Q. Smilax Theophr.) has

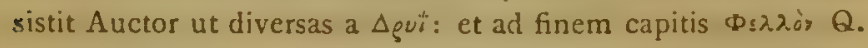
Suberem descr. Decorticatio exterioris corticis, et ejus reproductio memoratur. De usibus nulla mentio.

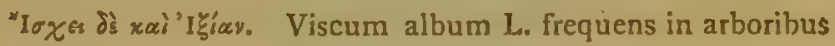
Parasita: rarissime in Ilice, si Clusio fides. Sed q.? ' $r$ ṕ̣ą ut species distincta? "A septentrione Viscum, a meridie Hy"phear." Plin. xvi. 30. Nulla tamen mentio apud synon. Linn.

4) égé bè rórxov. N. B. Quare species a Linn. coccifera vocatur diversa ab Ilice? Quod ad xóxzav parviraús; Vid. Clus. Granum puniceum nigricans, 1. i. c. 15. Coccus hic cst Galla species, insecti domicilium. 


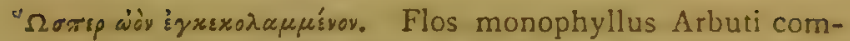

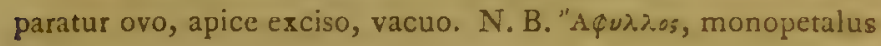
Bot. i.e. non petalis distinctis.

Koxruypia. Vide Plin. xv. 24. "Similis Andrachnes Coc" cygria proprietatem habet fructum emittendi cum Pappo, " quod nulli alii arbori evenit." Vid. Ic. Bod. 246. Tupppyigg. Tyrrhenia, vel Etruria.

\section{A P. XVI.}

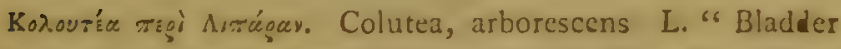

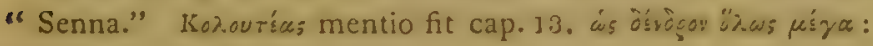
sed forsan legend. ou píga.

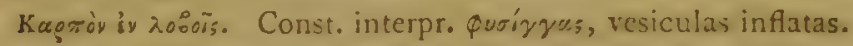

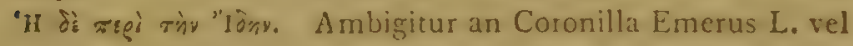
Anagyris fortida L. ex descriptione parum constat: quod ad

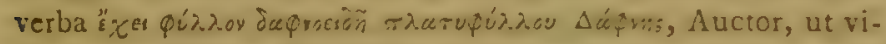
detur, simpliciter indicat folium pinnatum, iisdem cnim verbis utitur de folio Fraxini et Sambuci. Vid. cap. 10. Forsan corri-

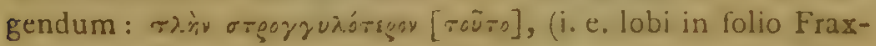

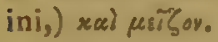

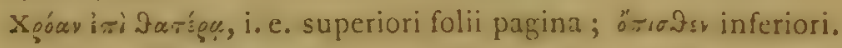

Taĩ i\%. Post hæc verba in textu Bodxi occurrunt voces raïs piscers: interpolatio certissima.

Tìv reguvaión xáx̧⿻y. Amentum Gaz. sed non datur in Diadelphis: anne crror in roce xá $\chi_{?}^{3} u_{5}$ ? Forsan apex rami gemmis intumescentibus indicatur.

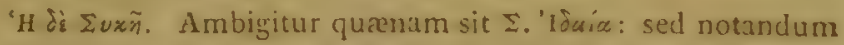
Theophrastum hic cursim tantum et obiter de plantis montis

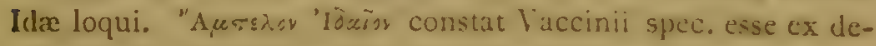
script. et $\Sigma_{0}{ }^{\prime} I \delta$. Lonicera Pyrenaica secundum Bodæum.

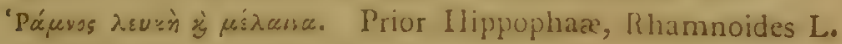
posterior Rh. Catharticus L.

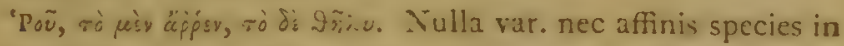
Rhoi Coriaria L. reperisur. Rhoen eleganter describit Theophr. Bod. p. 273. Vid. Dioscor. 1. i.c. 147. "Rhus Syria fomina "fertilis; masc. sterilis.". Plin. ziii,6. Alibi tria nominat genera, inter quæ spec, herbaceam xxiv. 11.

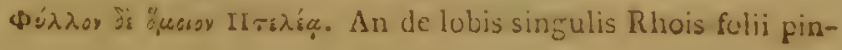


nati? Suspicor legend. Tú $\lambda$, Trigonella L. Vid. obs. ad cap. xiii. ubi Túrn apud Bod. in describendo Coluteæ folio occurrit, vice $\Pi r \varepsilon \lambda^{\prime} \alpha_{s}$ in margine.

$$
\text { C } \triangle \text { P. XVII. }
$$

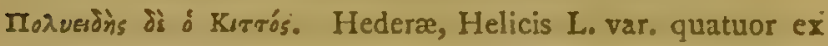
Bauhinc, ex quibus $\dot{a} \mu \varepsilon^{\prime} \omega_{5}$, Hedera arborea: de ceteris minus

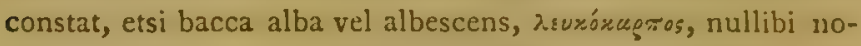
tetur. Hedera sape conspicitur foliis maxime variegatis, qua rosxín Theophr.

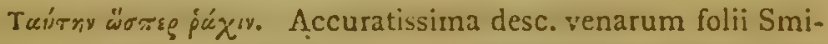
lacis, ubi venæ concentricæ, novemnerviæ, Gouan, apud Linn: Spec: Plant, 1458.

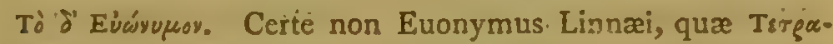
yovia Theophrasti. Bodæus conjicit Nerium L. indicari, vel Cncorum. Prior magis arridet, si detur var. Ner. Oleandri

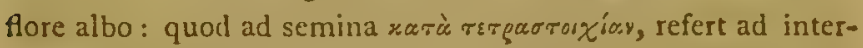
nam collocationem seminum in pericarpio quadrilocari, non. ad figuram internam pericarpii. Vid. Plin, xiii, 22. 


\section{$\Theta \mathrm{EO} \Phi \mathrm{PA} \Sigma \mathrm{TO} \Upsilon$}

\section{ПEPI $\Phi \Upsilon T \Omega N$ I $\Sigma T O P I A \Sigma$}

\section{TO $\Delta^{\prime}$ 。}

\section{CAP. I.}

Quibus Locis quaque Arbores gaudeant.

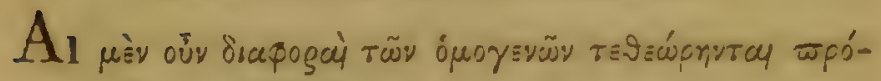

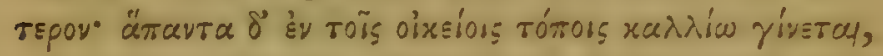

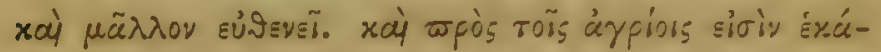

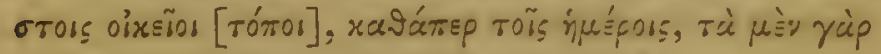

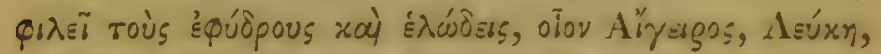

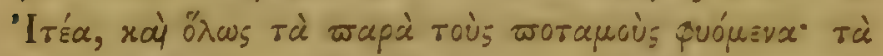

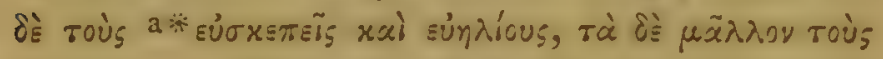

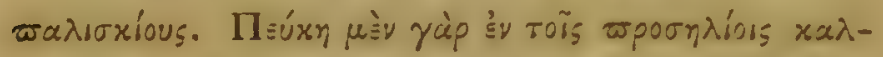

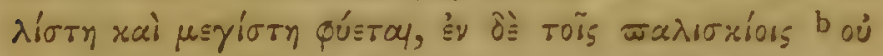

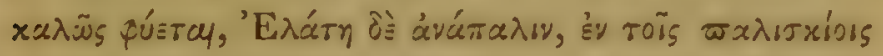

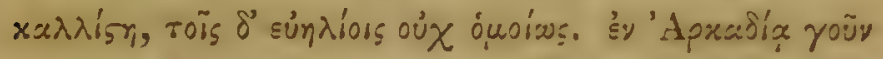

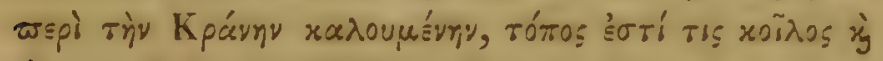

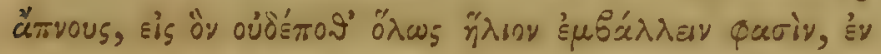

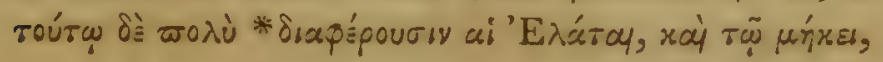

- doxtruís Theod.

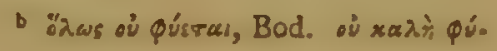
stณi, Const. 


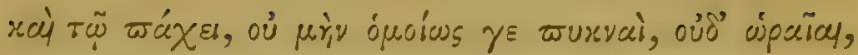

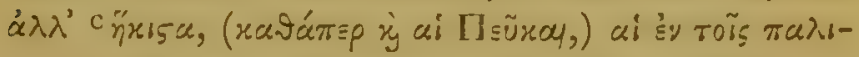

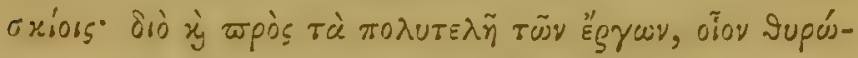

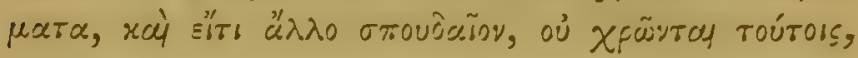

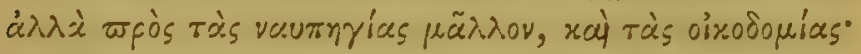

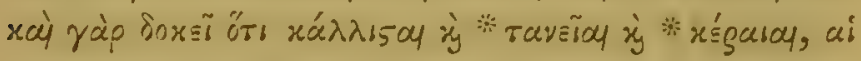

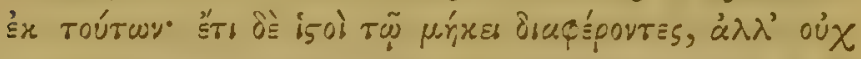

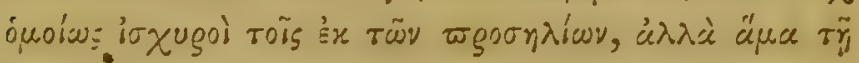

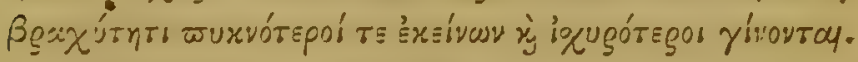

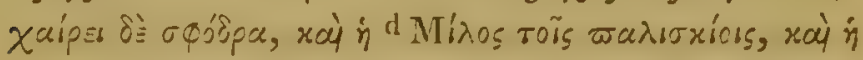

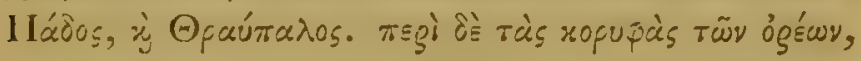

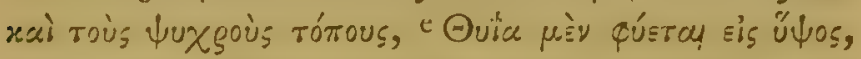

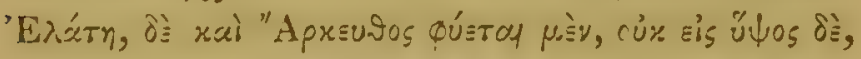

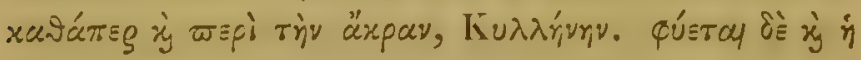

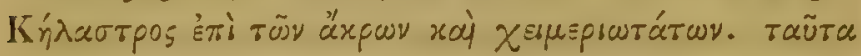

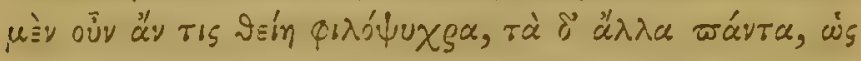

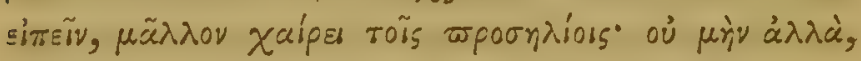

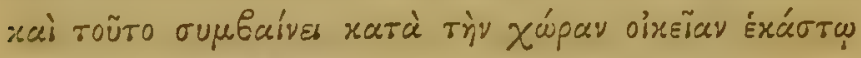

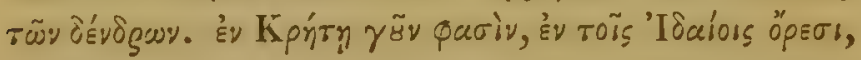

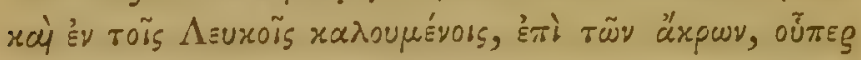

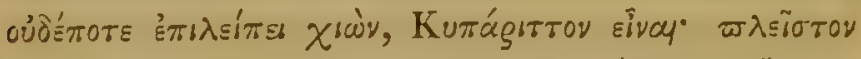

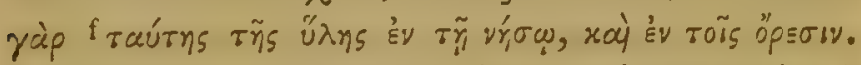

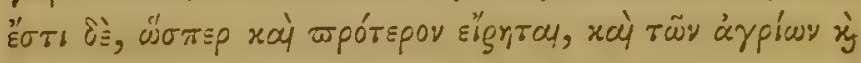

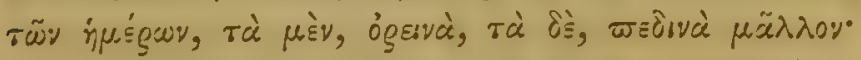

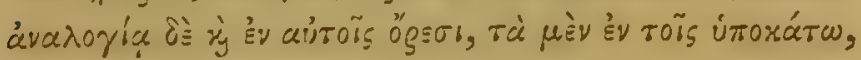

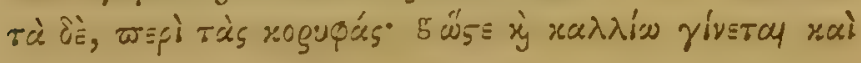

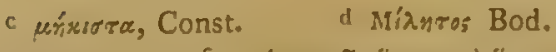

- Oría Bod.

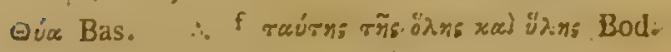
ह ผัสтร

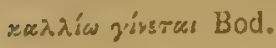




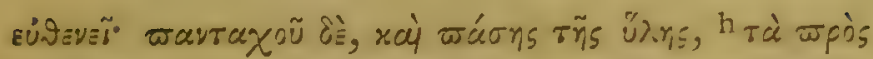

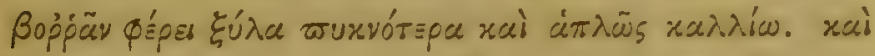

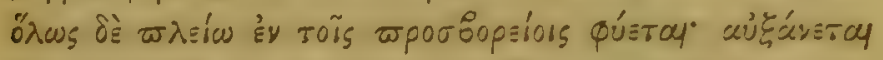

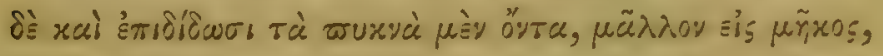

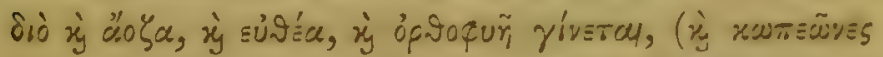

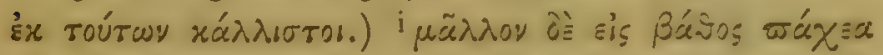

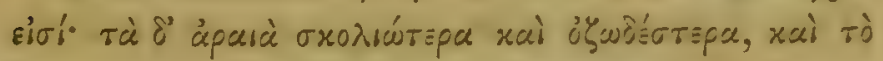

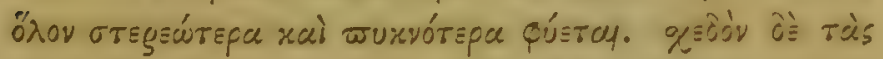

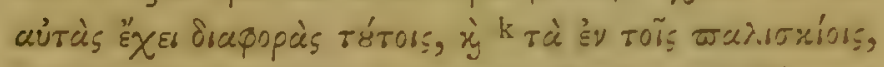

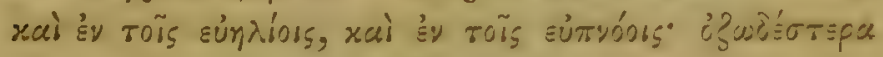

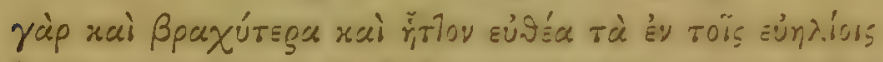

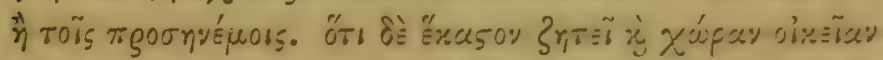

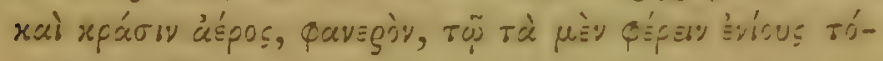

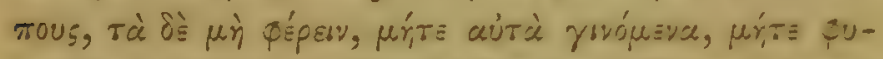

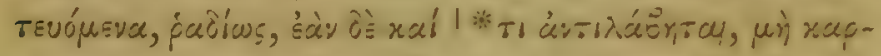

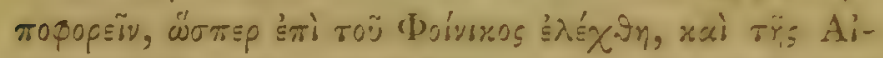

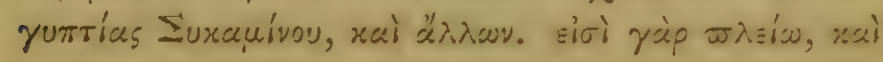

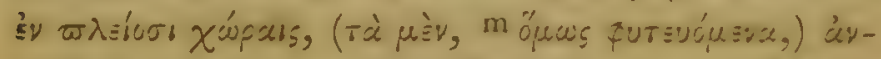

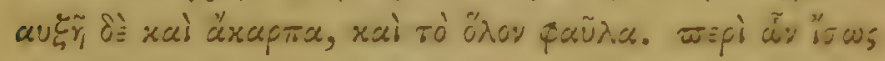

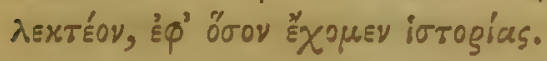

\section{CAP. II.}

Fous Sycomorus, et Cupria. Ceratomin, silinua? Persea? Guilandina, Bonduc. Cycas, circinulis.

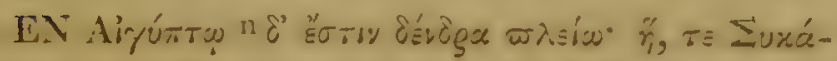

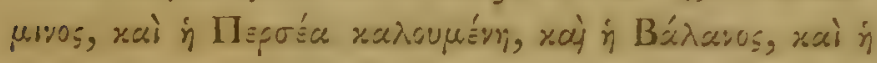

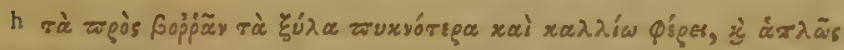

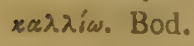

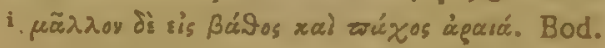
zà ápaíce. Scal. Vid. not. ad fin. libri. 1 ri decst Bod, m "ras Const. $k$ Tà deest Bod. jirọea Bod.

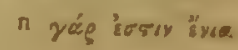

\section{2}




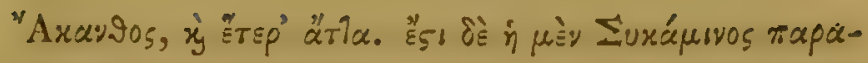

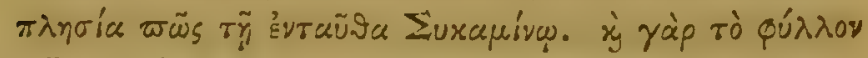

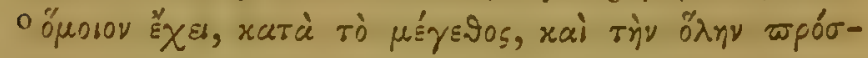

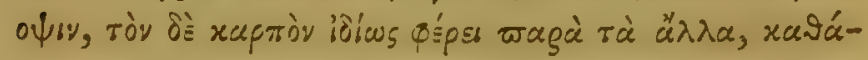

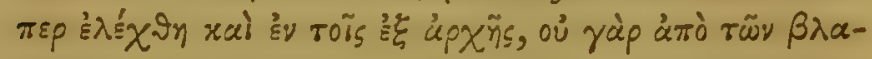

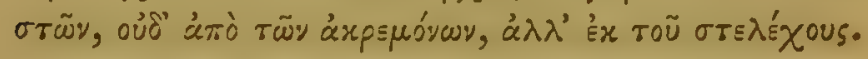

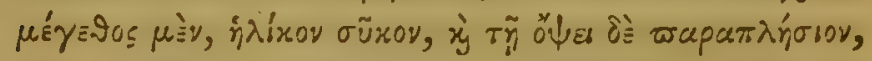

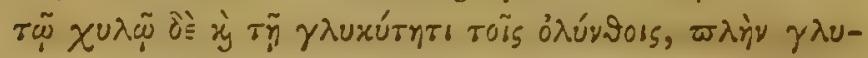

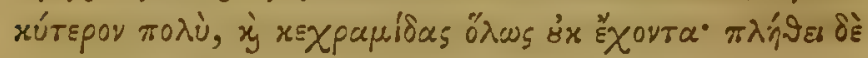

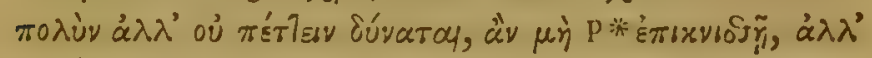

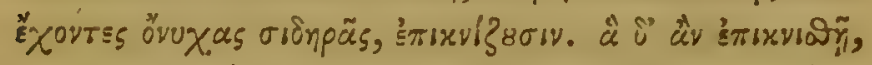

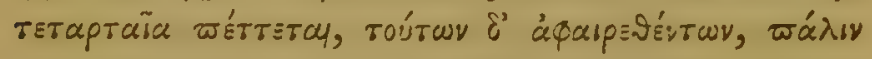

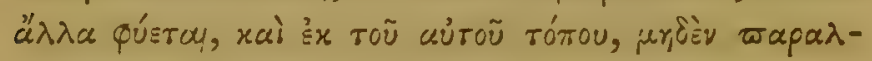

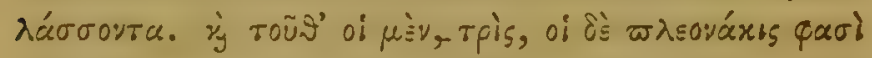

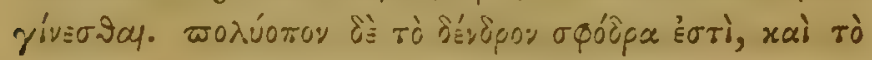

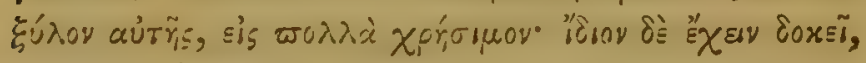

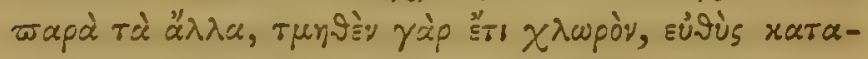

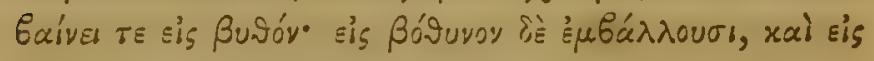

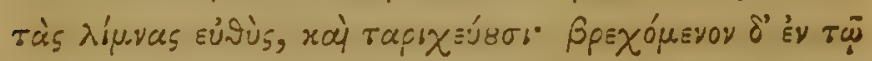

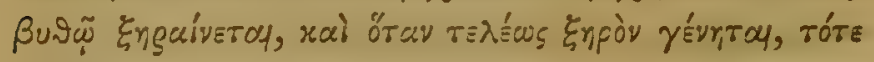

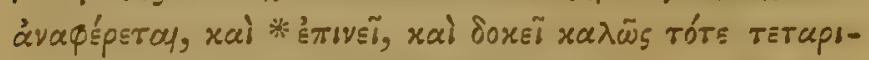

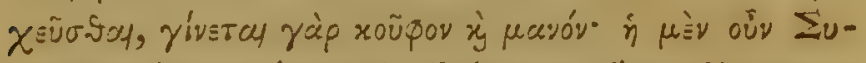

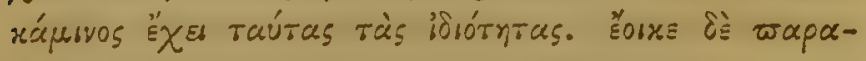

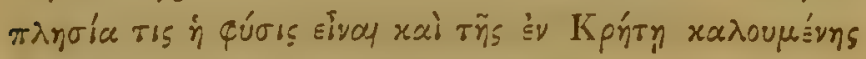

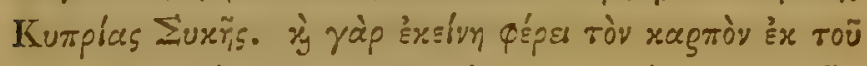

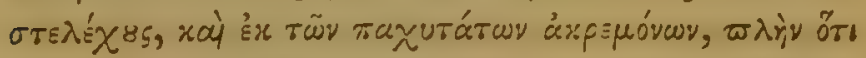

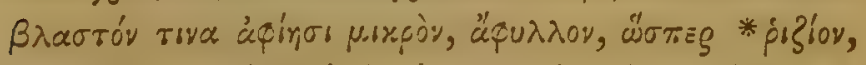

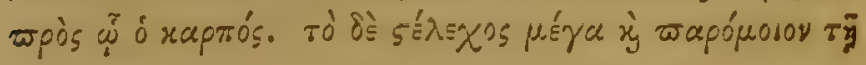

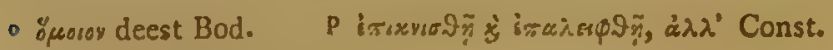
Vide Lib, de Caus, Planto i. 21. 


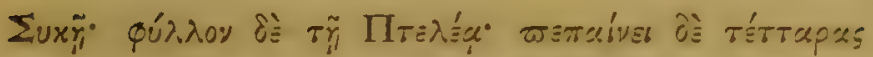

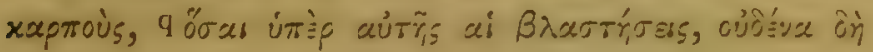

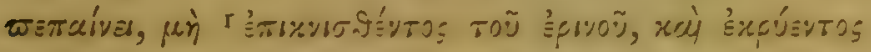

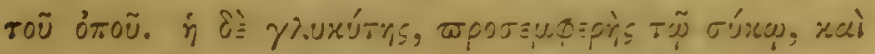

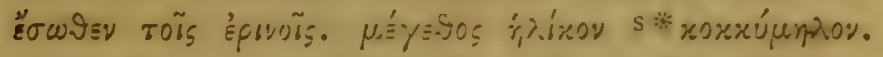

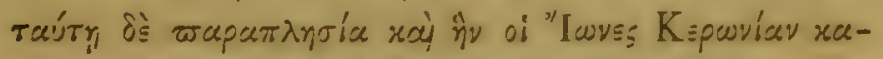

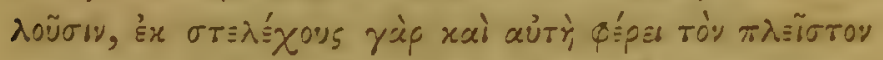

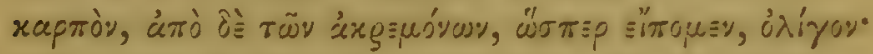

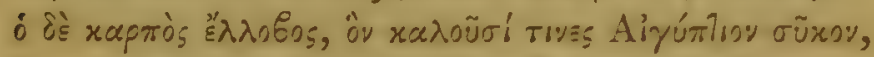

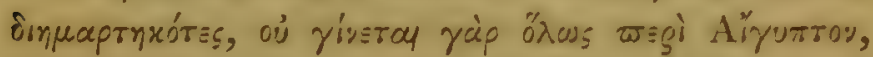

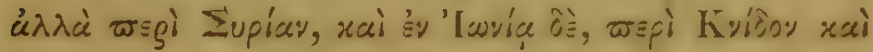

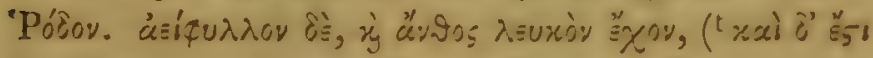

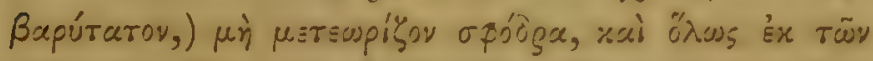

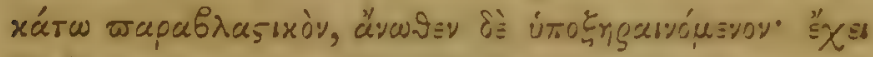

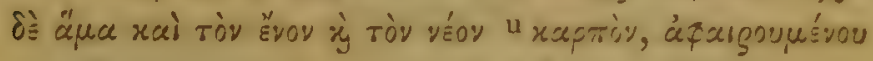

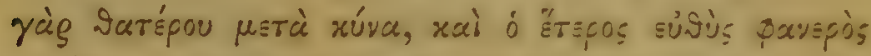

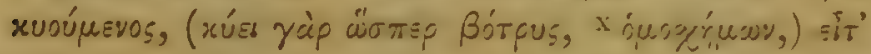

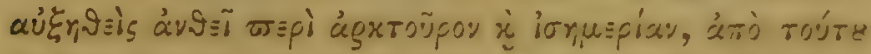

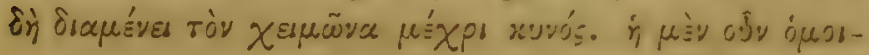

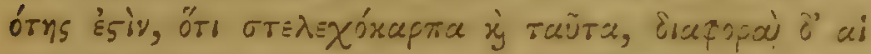

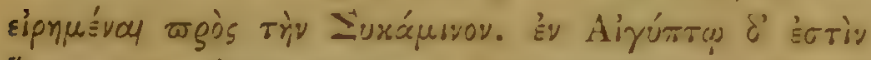

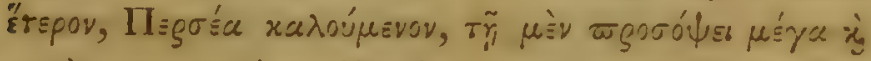

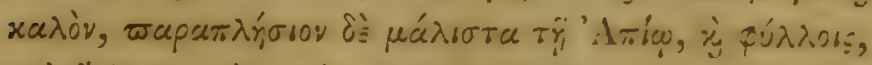

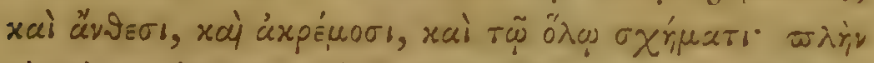

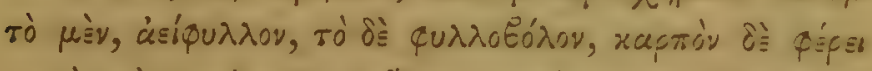

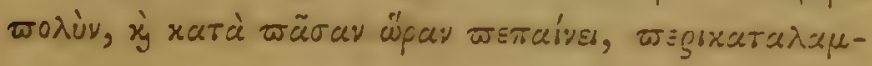

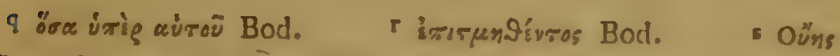

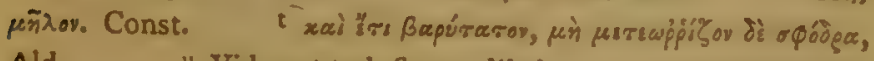
Ald. "Vid. not. ad finem libri. $x$ iprosor.xnipesv, Const. 


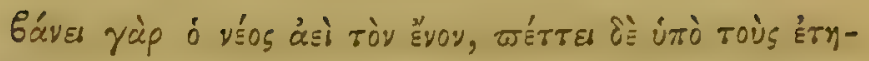

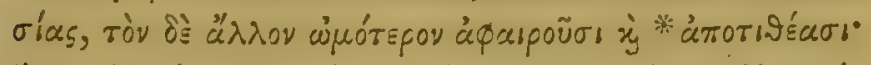

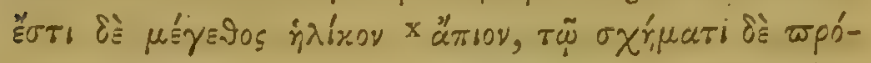

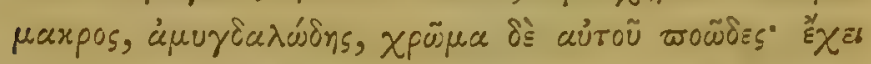

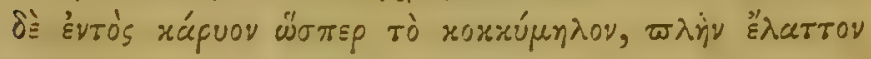

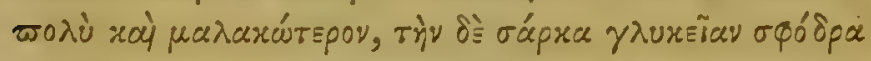

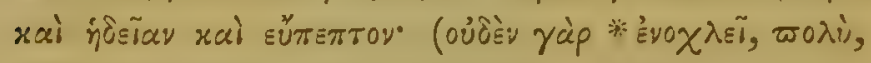

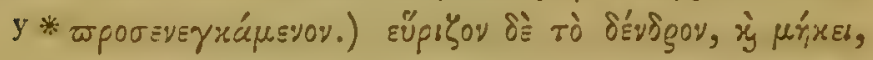

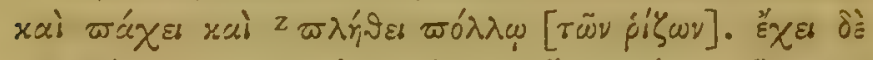

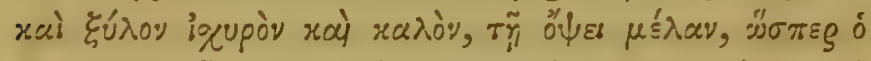

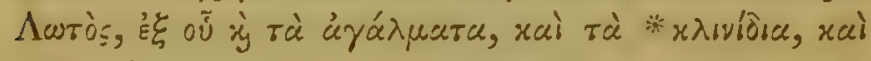

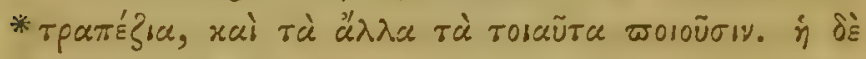

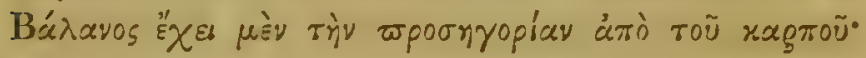

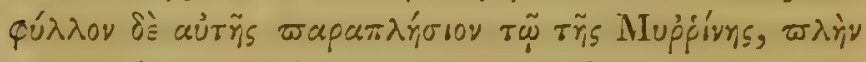

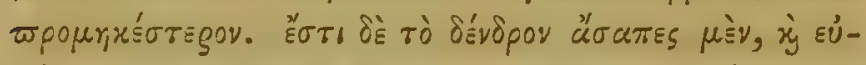

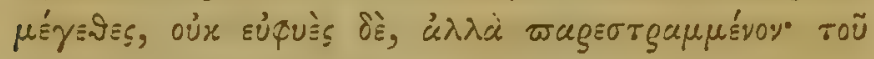

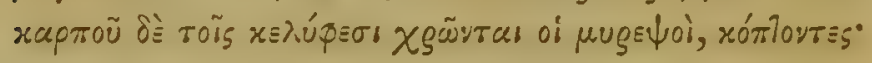

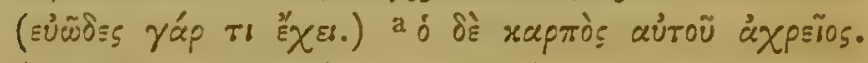

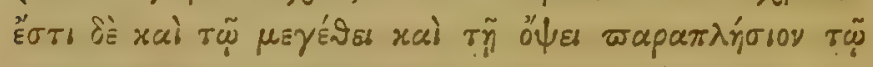

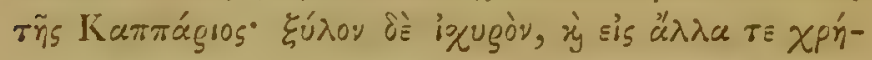

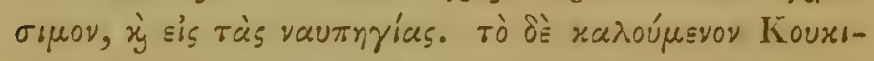

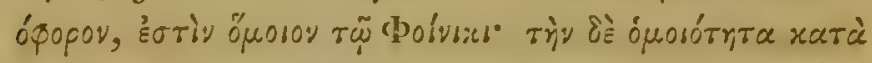

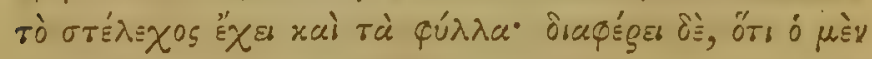

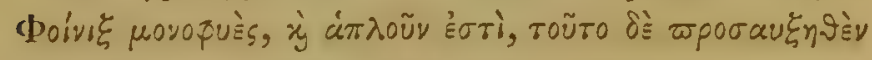

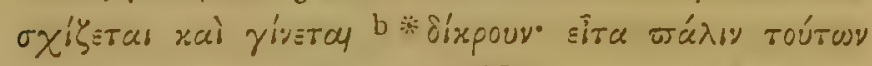

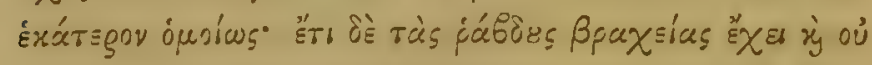

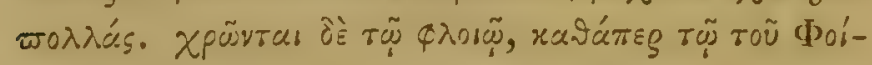
$x \ddot{a r r t o s, ~ B o d . ~}$

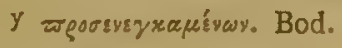

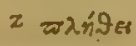
wori, " " ${ }^{\epsilon s}$ Bod.
a ròy ḋ̀ xąrò̀ aủroũ Boụ,
b ёxpoy:

Bod. 


\section{MEPI TMTSN ISTOPIAS TO $\Delta^{\prime}$.}

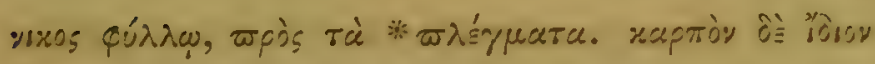

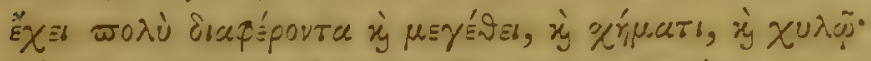

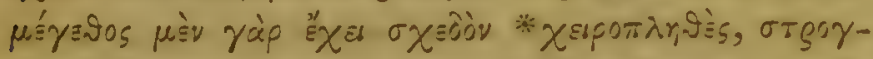

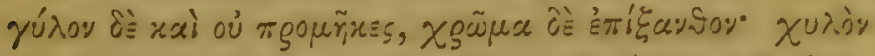

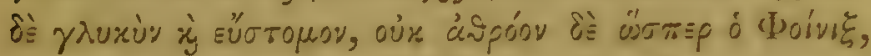

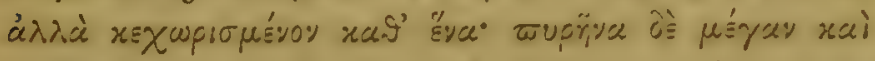

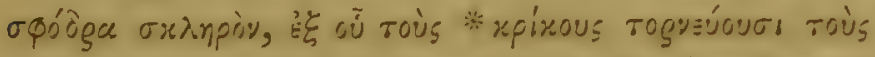

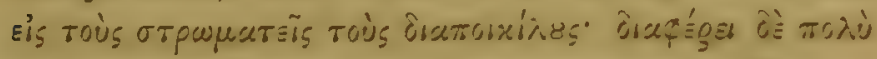

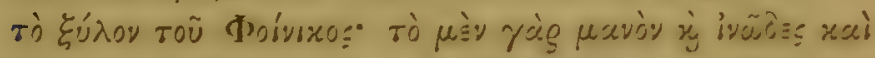

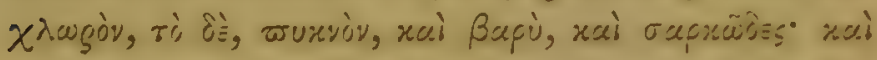

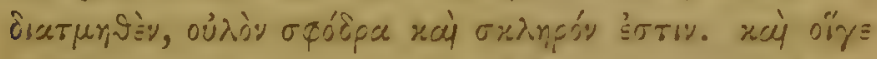

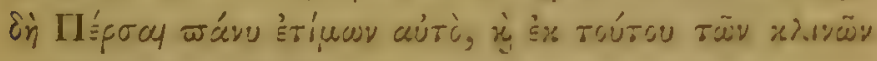

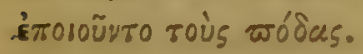

\section{CAP. III.}

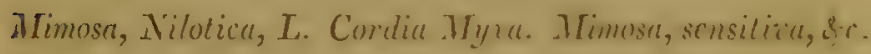

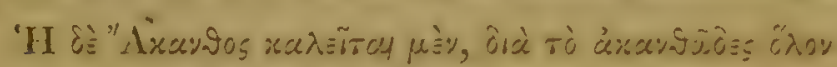

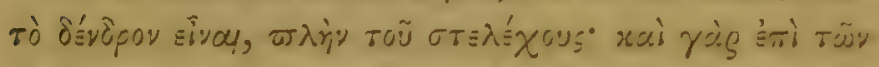

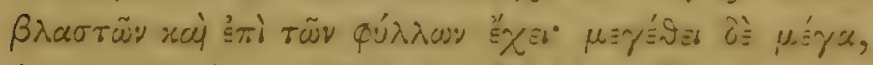

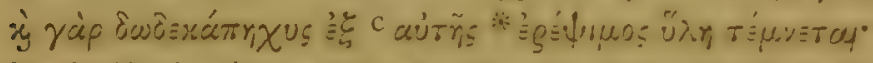

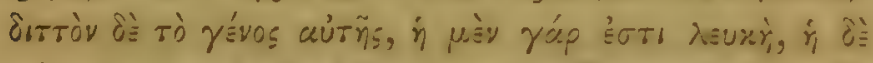

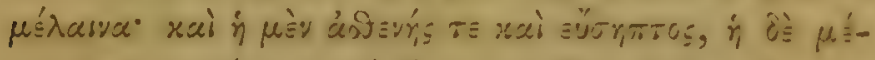

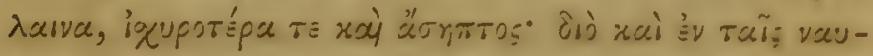

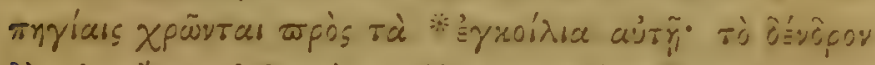

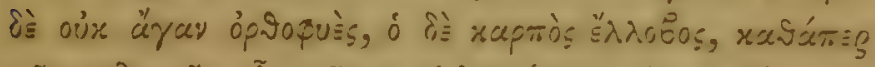

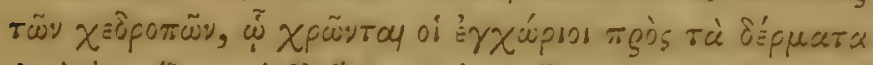

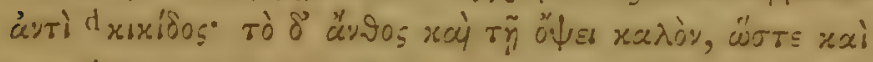

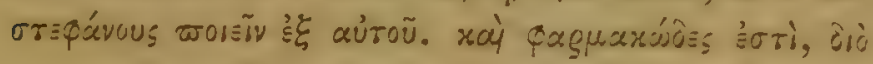

c airrãy Bod.

dx ríridas Const.

1. 4 


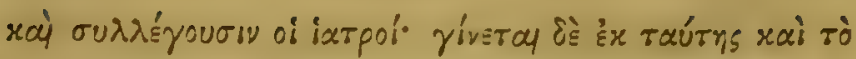

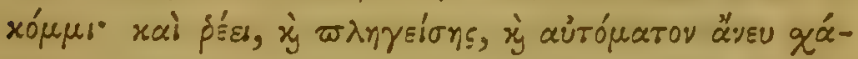

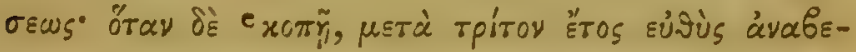

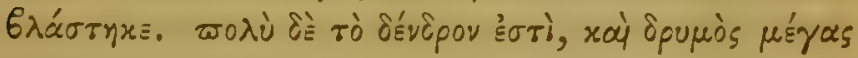

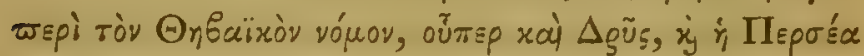

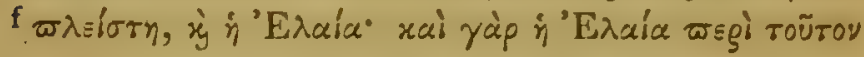

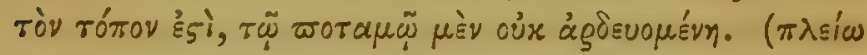

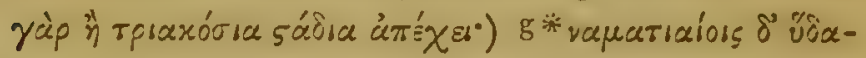

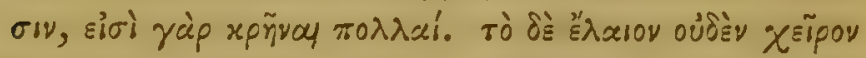

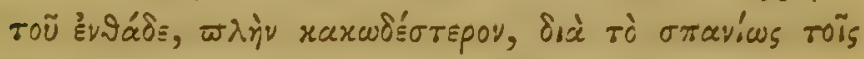

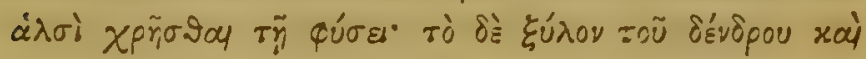

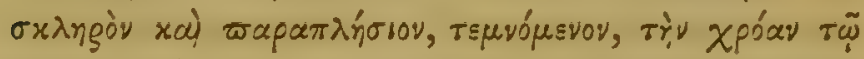

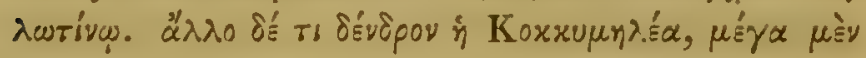

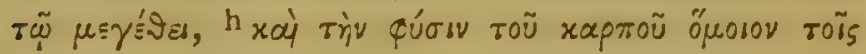

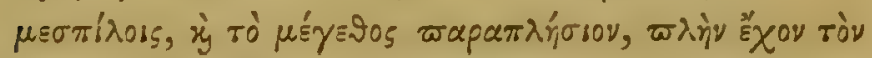

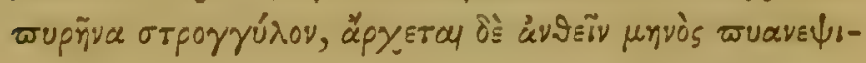

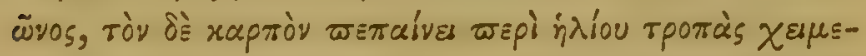

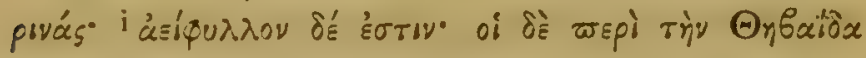

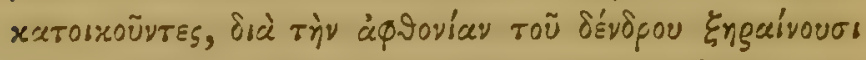

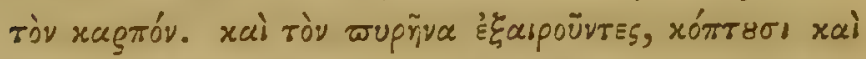

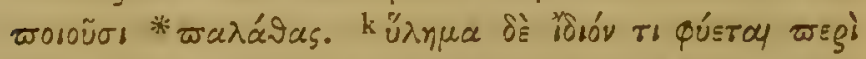

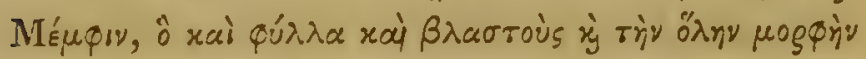

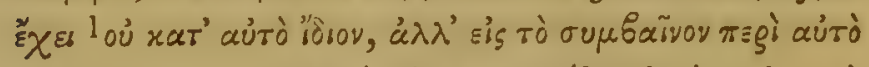

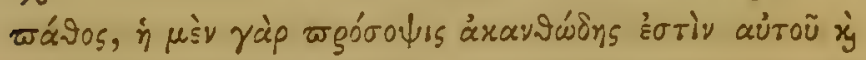

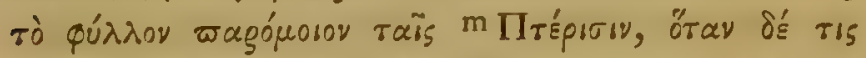

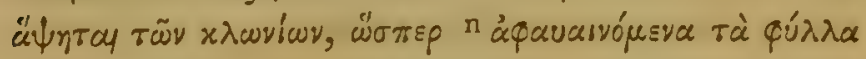

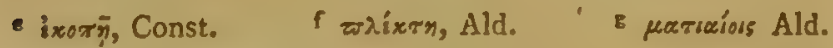

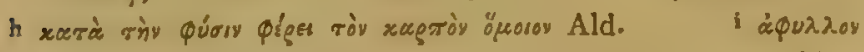

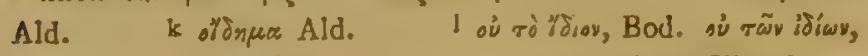

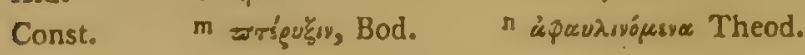




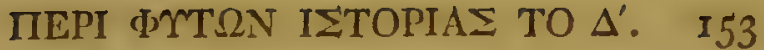

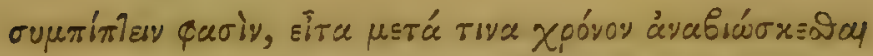

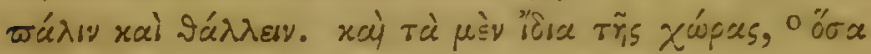

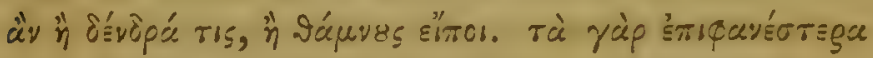

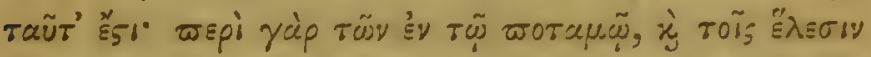

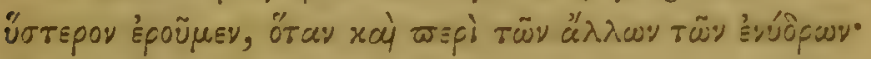

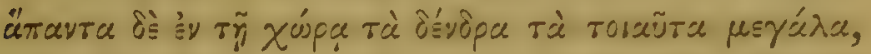

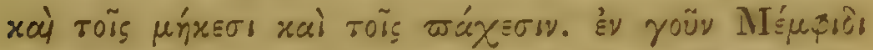

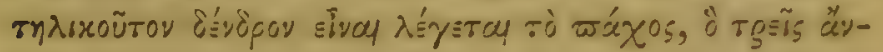

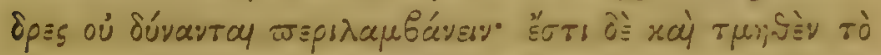

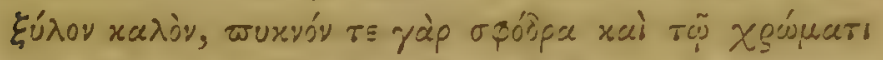

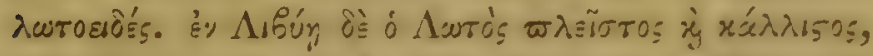

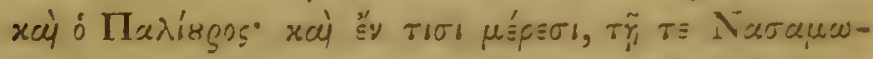

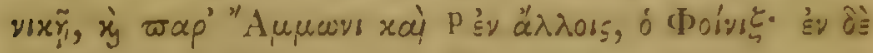

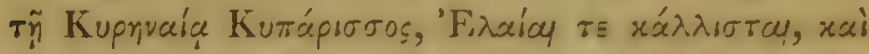

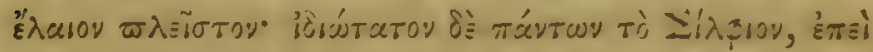

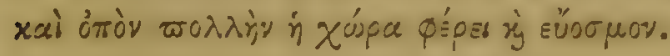

\section{CAP. IV.}

Celtis, australis, et Toti aftinis Plontu. Palma in Africa, \&c. Citrus, Aurantium, sylvestri statu, \& c. \& \&c.

E

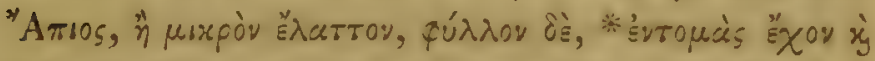
q

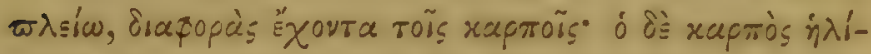

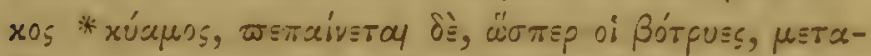

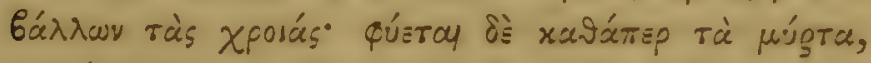

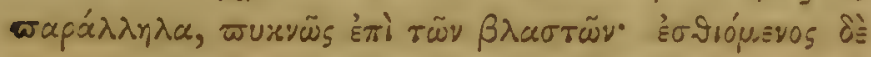

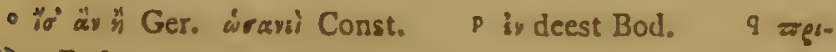
mã̀rs, Bod. 


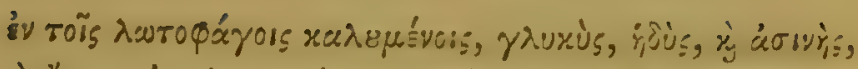

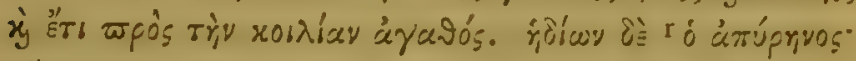

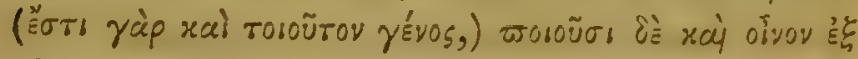

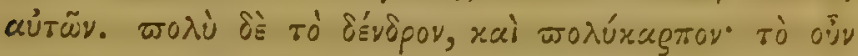

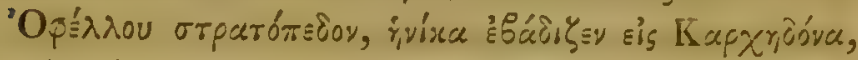

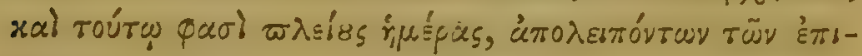

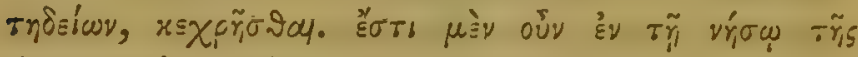

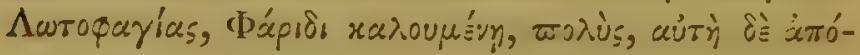

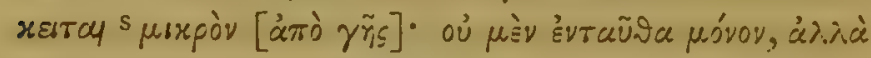

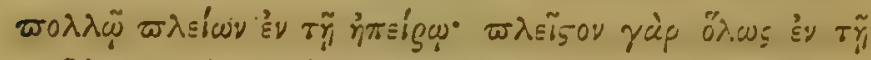

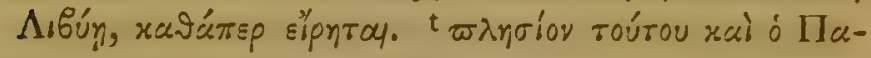

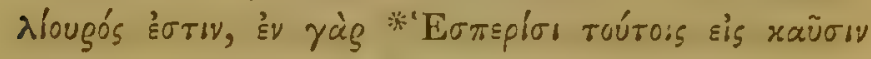

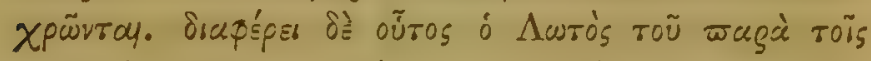

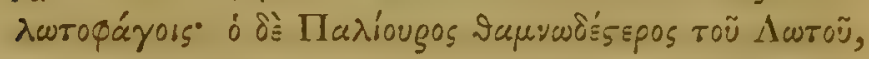

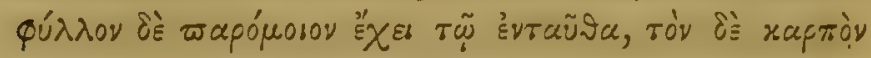

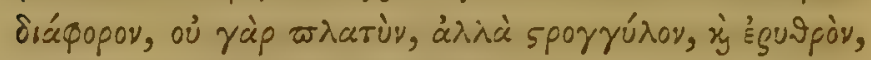

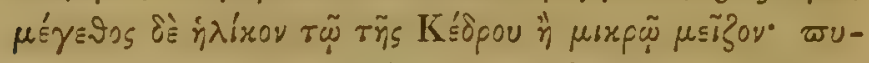

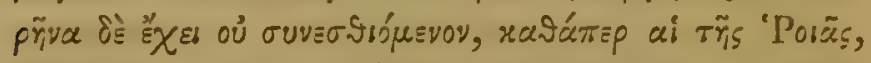

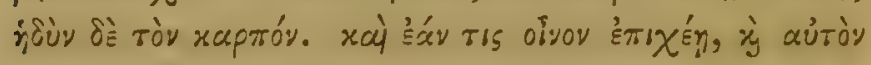

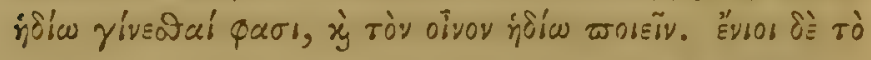

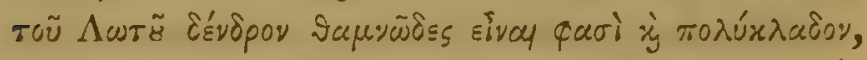

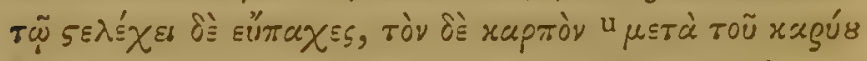

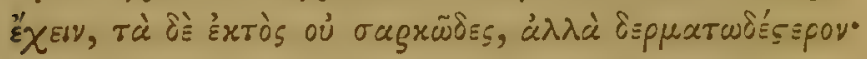

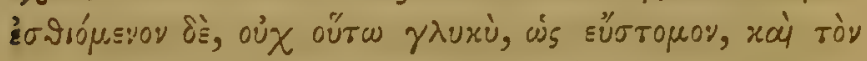

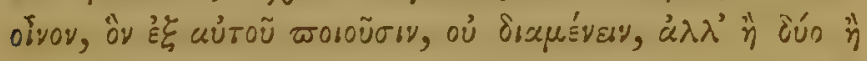

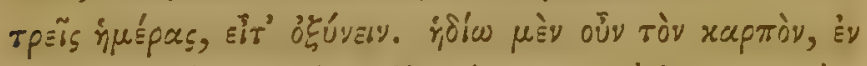

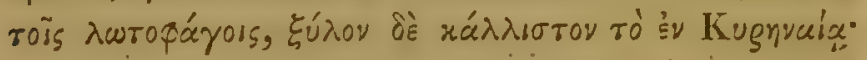

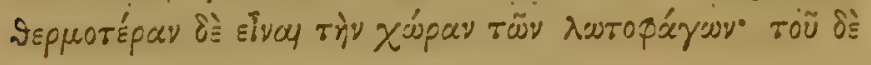

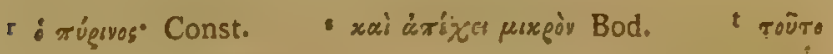
exi Bod. u $\mu$ íra Const. 


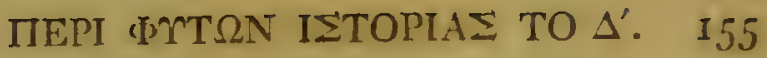

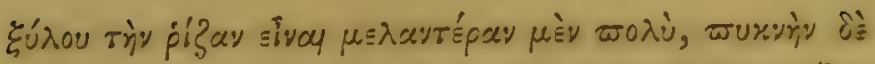

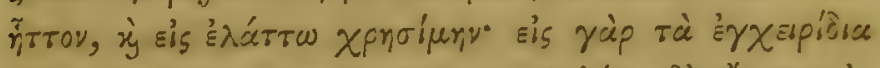

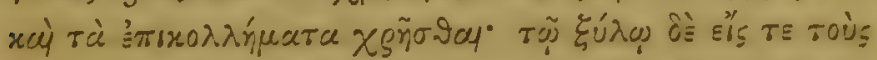

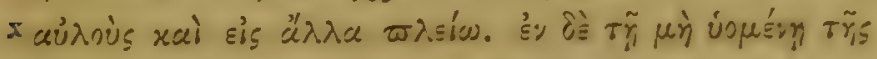

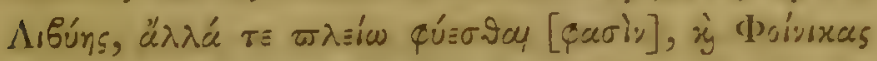

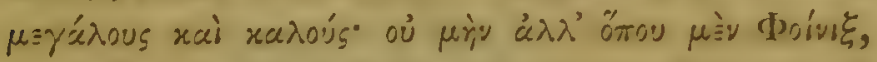

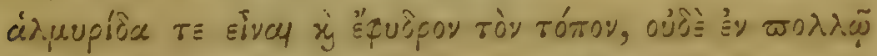

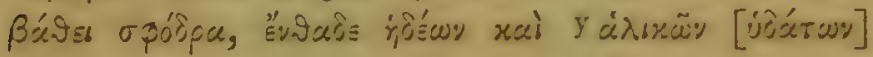

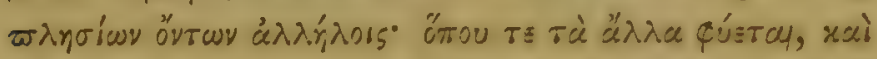

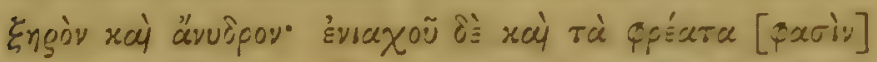

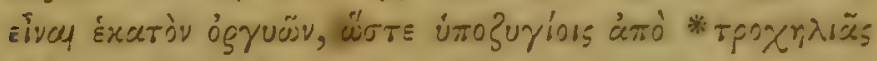

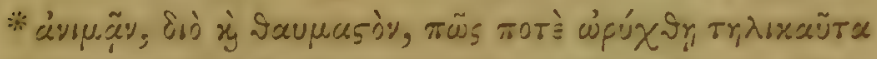

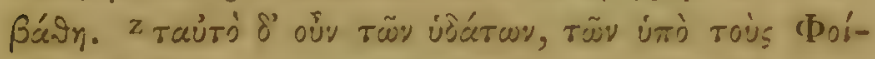

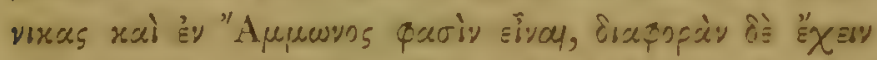

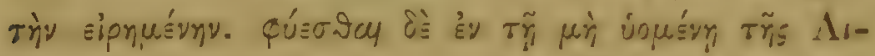

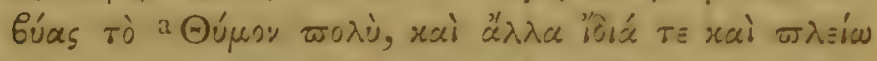

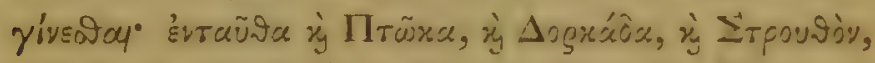

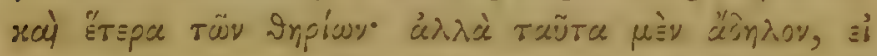

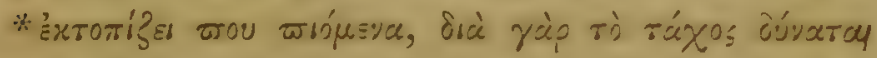

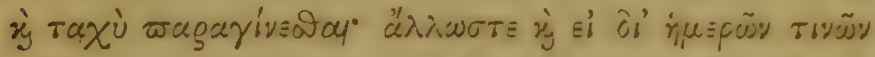

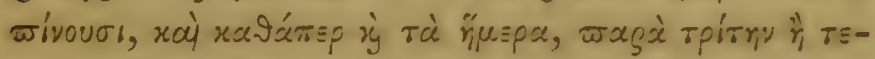

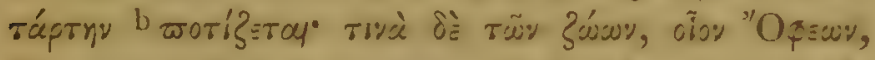

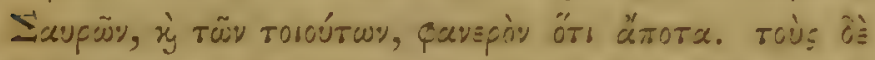

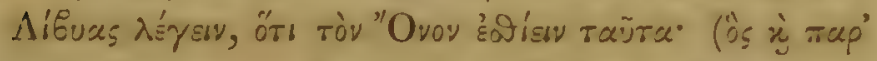

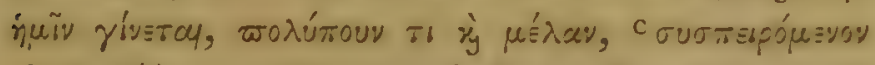

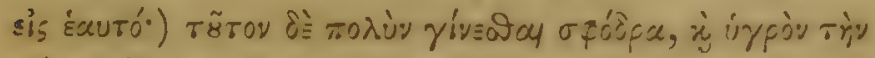

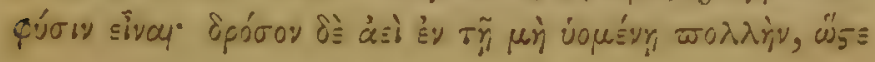

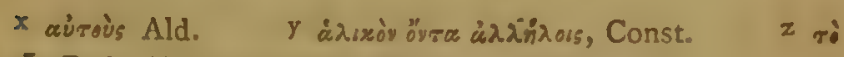
¿où Bod. Vid. not. ad fin. libri. a Tápvoy Bas. b тo

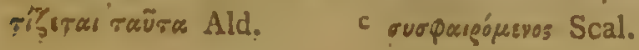




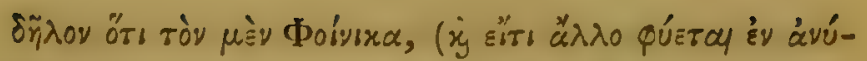

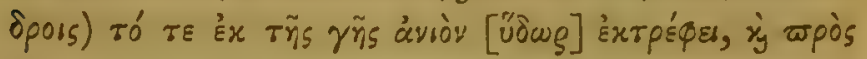

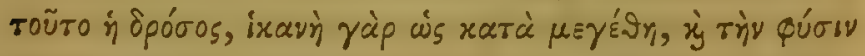

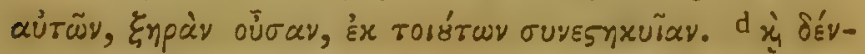

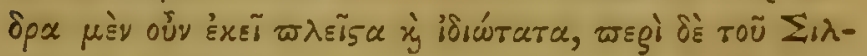

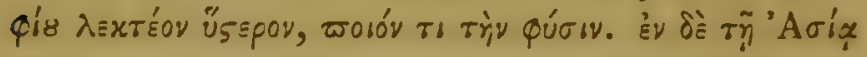

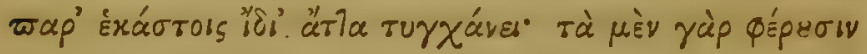

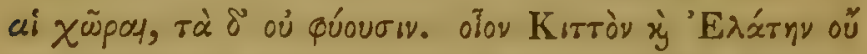

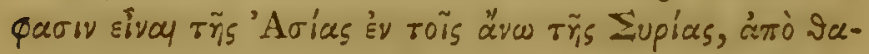

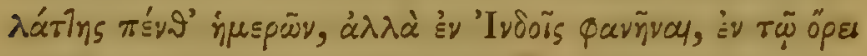

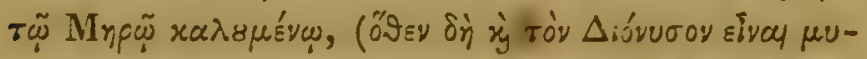

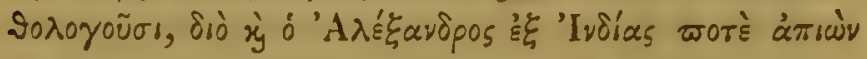

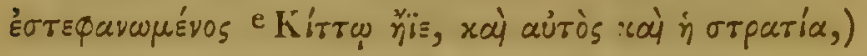

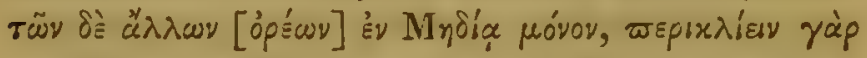

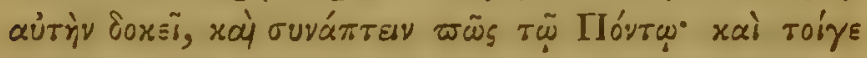

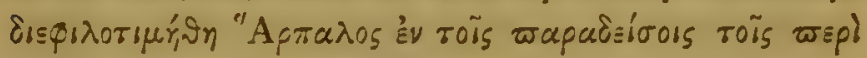

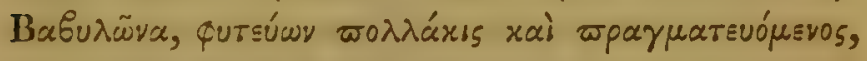

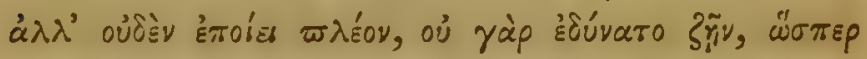

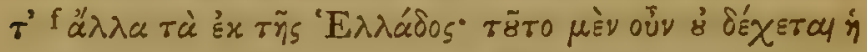

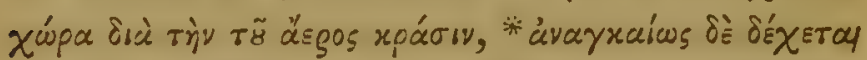

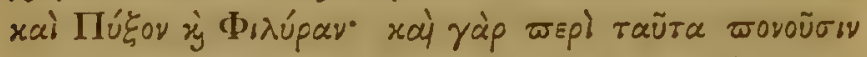

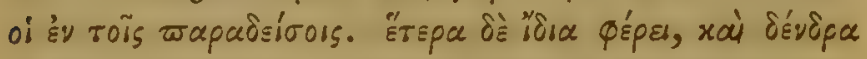

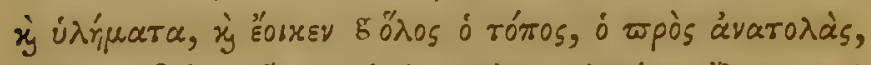

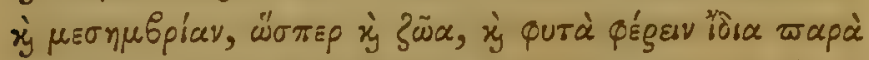

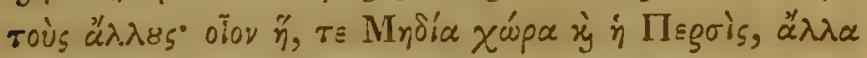

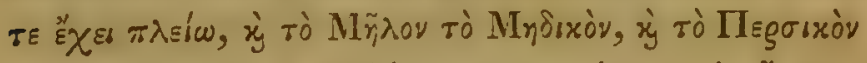

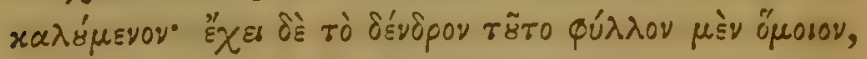

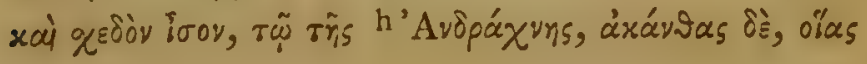

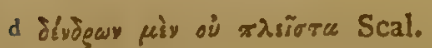

f ä $\lambda \lambda \approx$ rivà Const.

s "גws Bod.
- Kírry deest Bod. i $\Delta x \dot{\varphi}$ yrs, Const. 


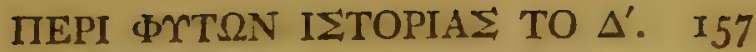

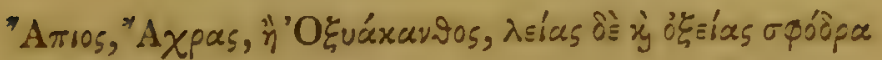

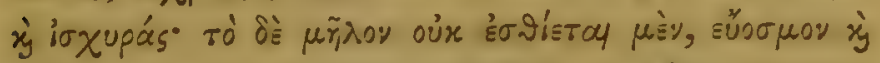

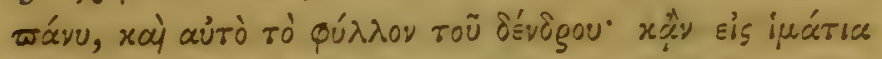

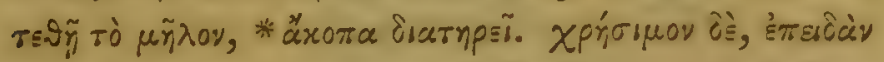

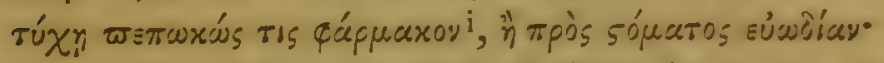

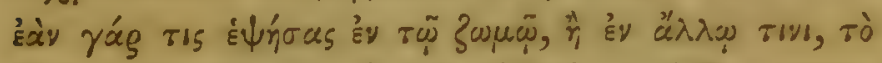

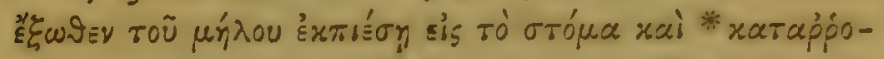

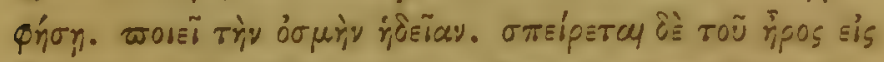

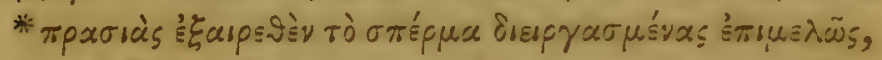

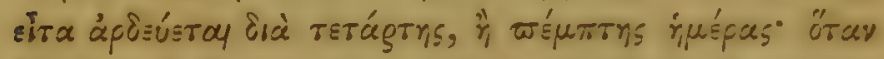

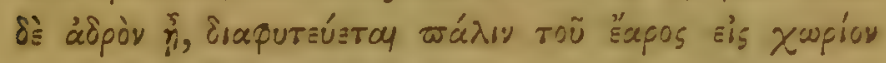

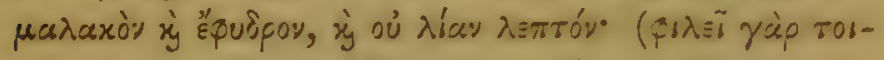

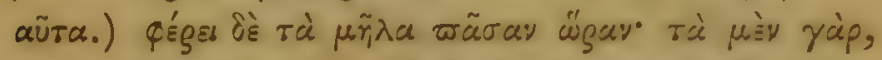

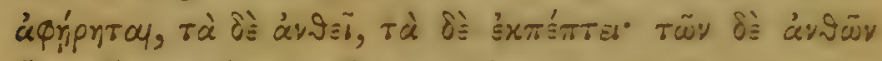

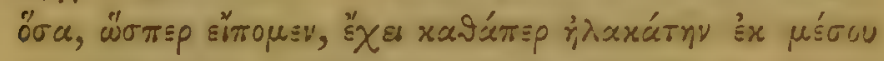

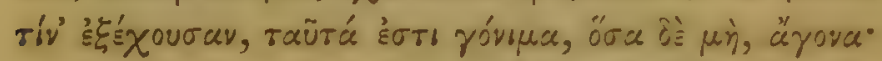

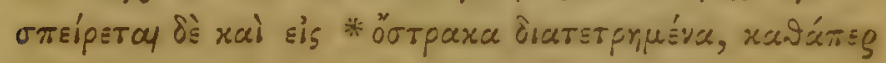

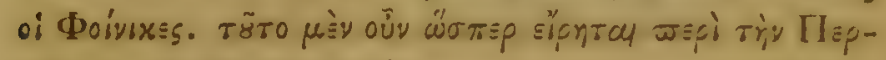

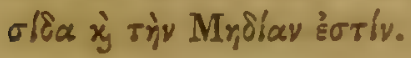

\section{CAP. V.}

Ficus, religiosa, L. Ebenus Craticu. Pistucia, Terebinthrs. Musu. Cerealia quadam ex Oriente.

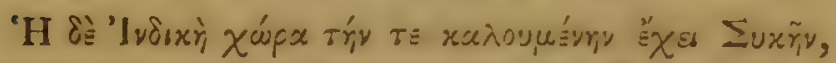

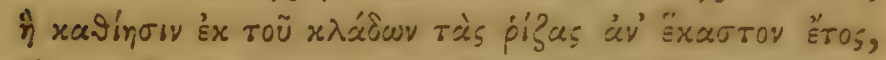

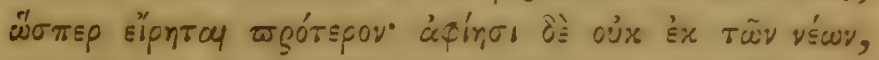

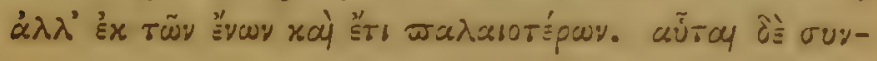

\section{Const.}

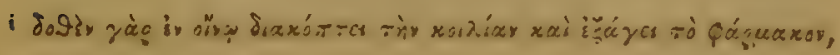




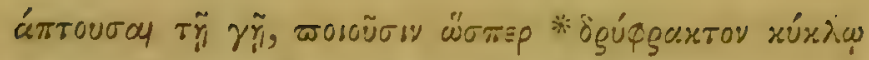

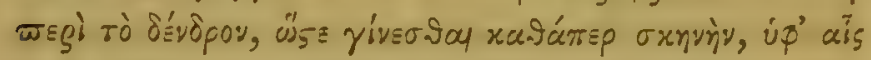

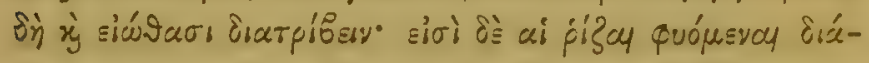

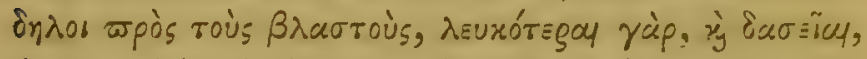

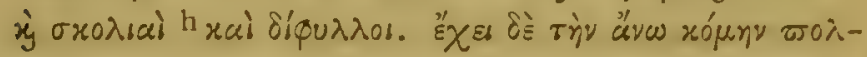

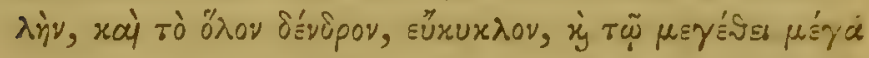

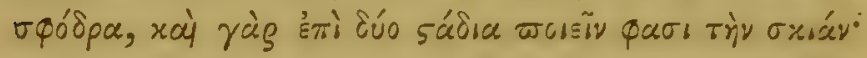

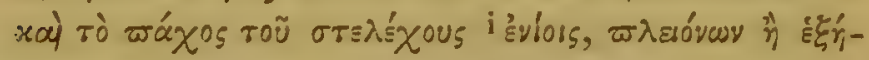

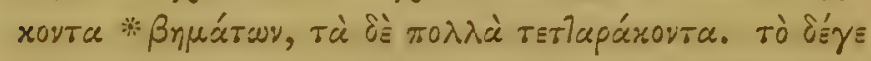

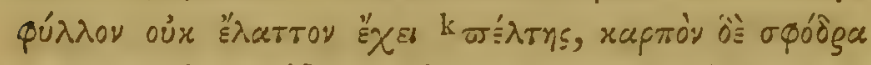

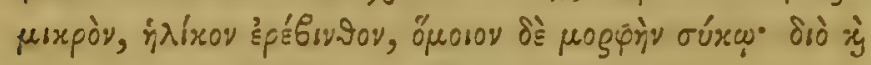

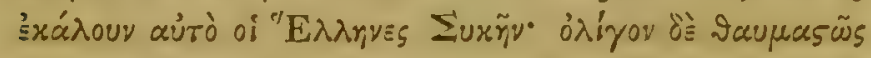

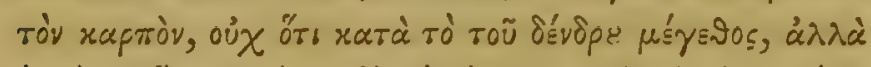

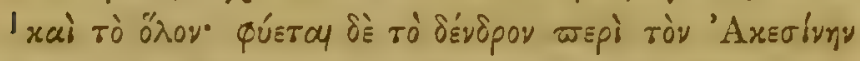

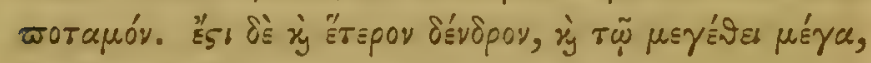

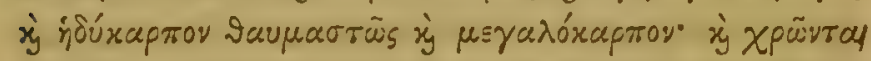

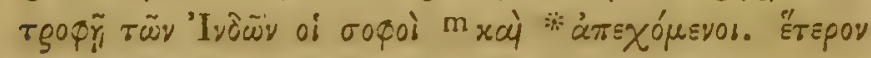

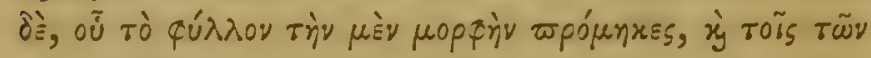

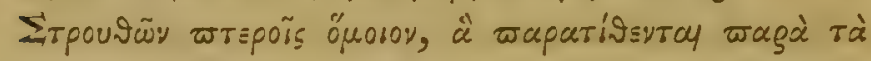

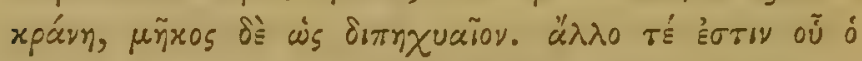

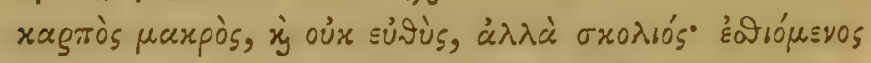

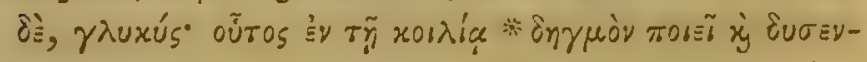

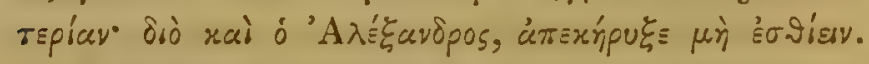

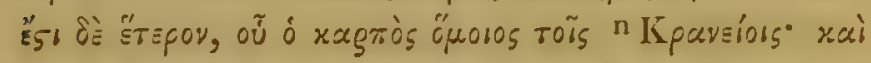

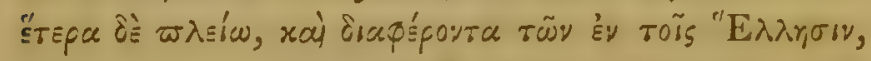

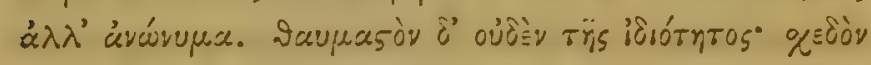

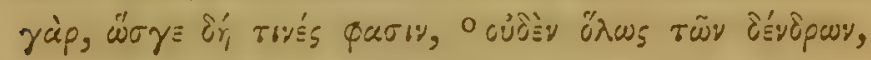
h rai deest Bod.
vเxйร, Const.

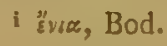
Xópsvg. Const.
1 zarč̀ rò "xiov" Const.
"xgavioss" Bod.

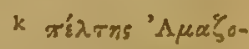

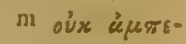
o oudi Bod. 


\section{ПEPI $\Psi \Upsilon T \Omega N$ I $\Omega$ TOPIA}

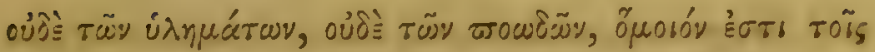

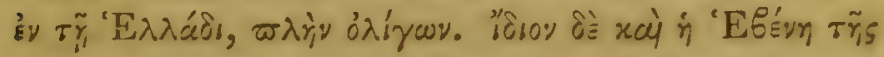

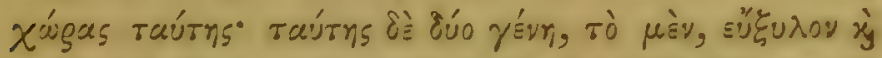

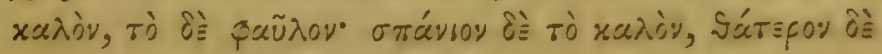

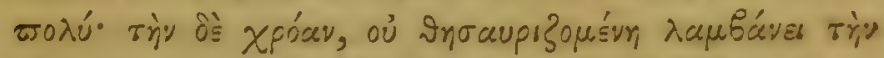

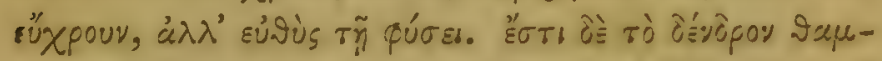

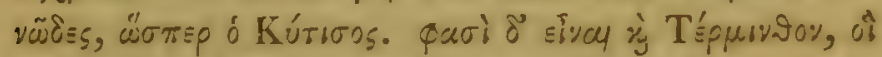

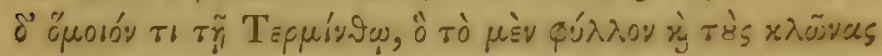

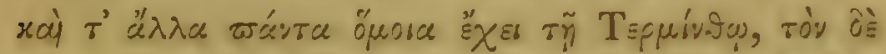

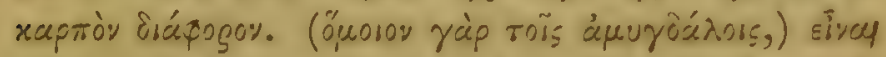

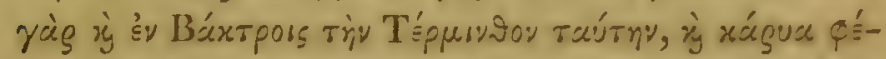

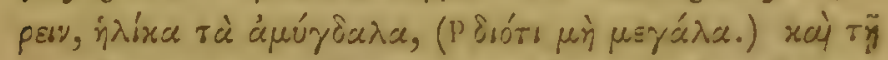

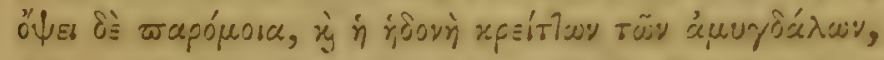

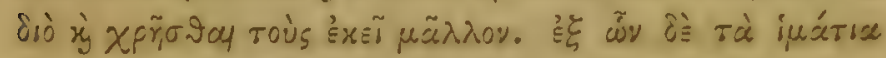

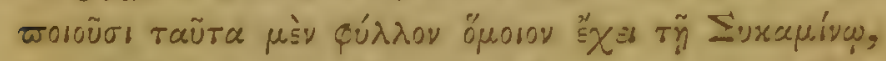

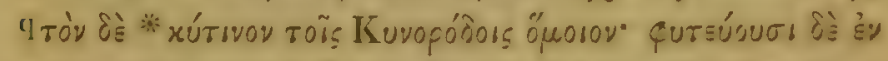

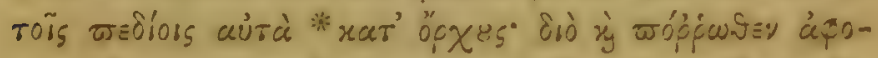
p

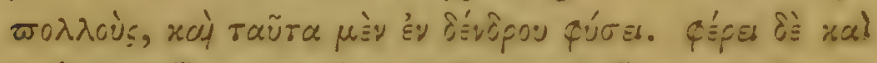

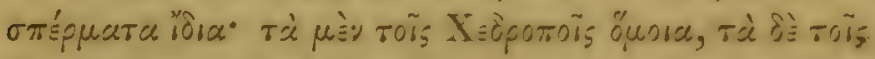

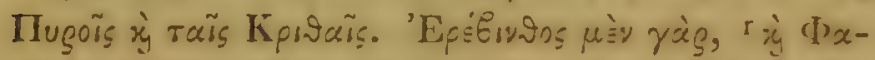

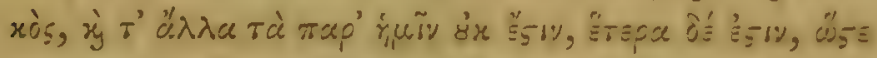

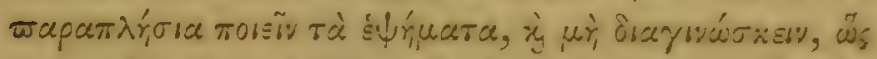

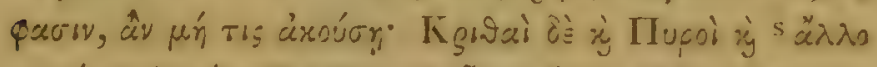

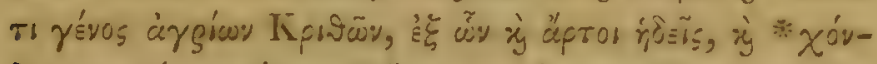

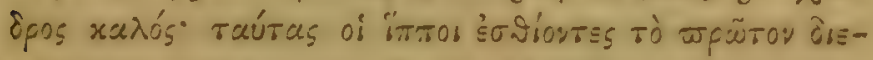

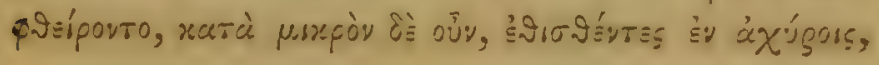

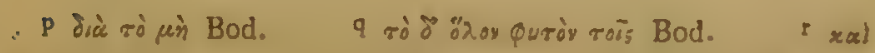

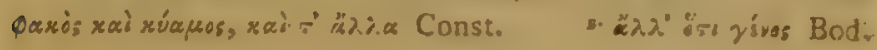




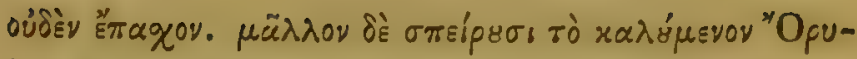

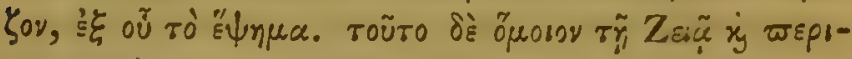

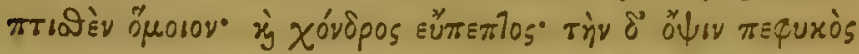

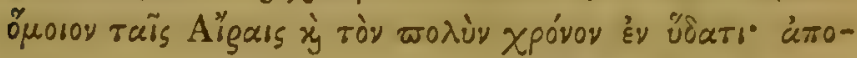

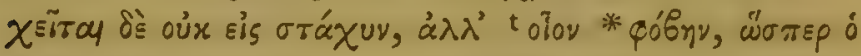

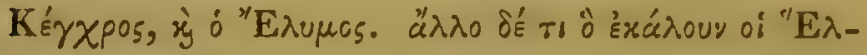

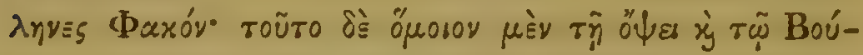

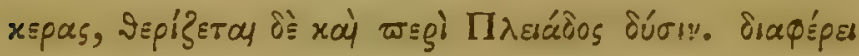

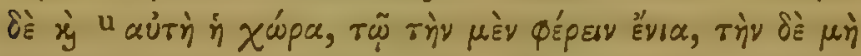
申́์

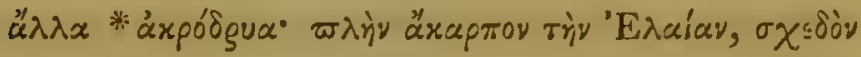

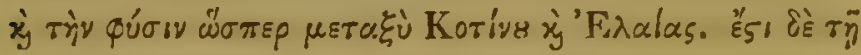

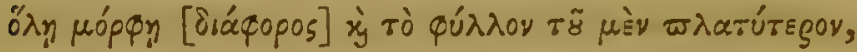

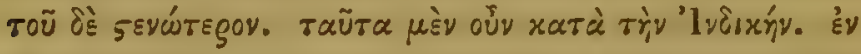

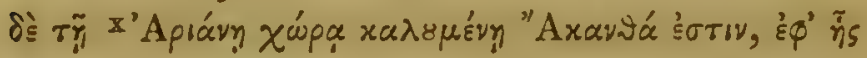

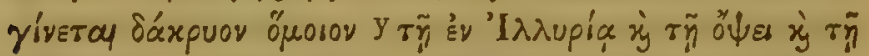

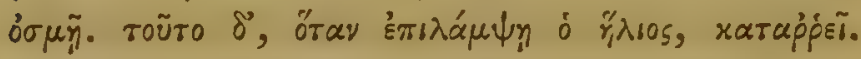

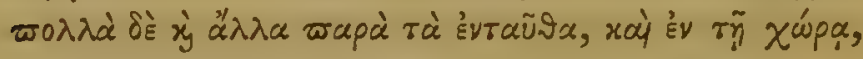

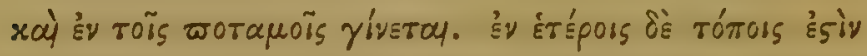

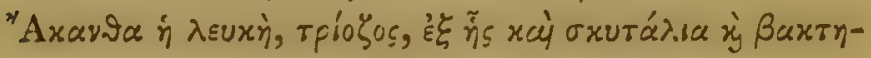

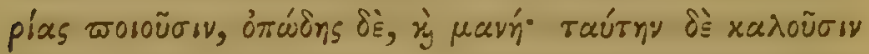

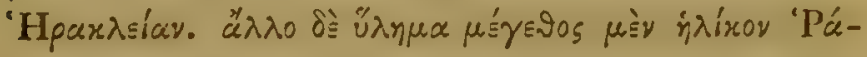

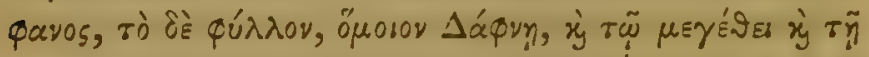

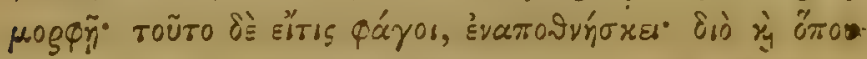

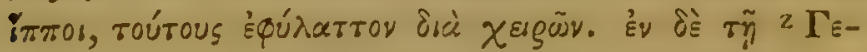

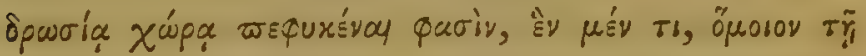

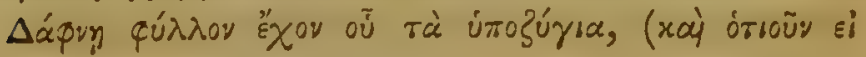
t ờy fóbry, Bod.

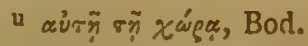 $x$ 'A pía,

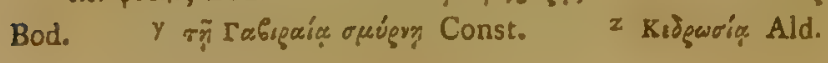




\section{MEPI $\Phi \Upsilon T \Omega N ~ 1 S T O P I A \Sigma T O \Delta^{\prime} . \quad$ I I I}

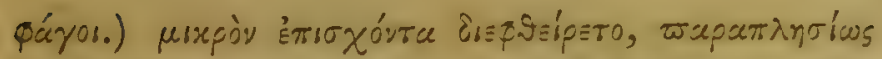

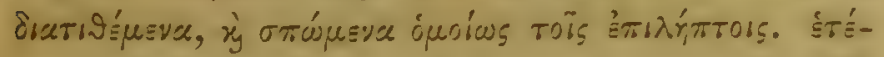

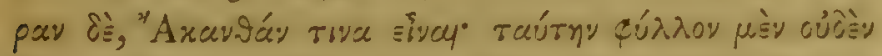

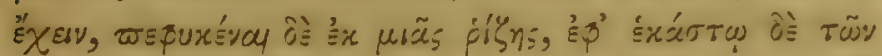

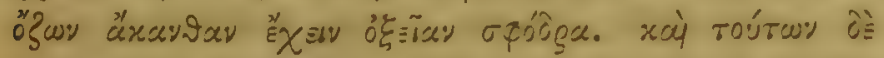

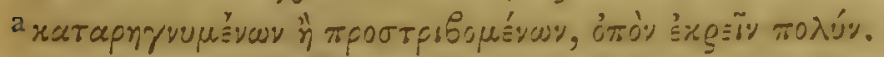

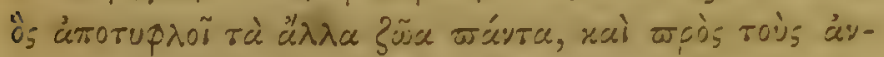

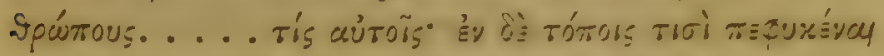

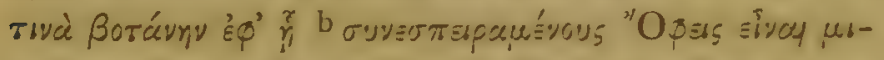

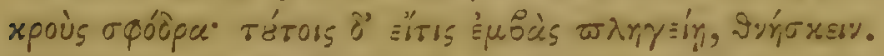

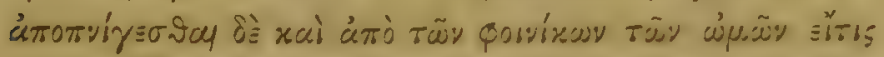

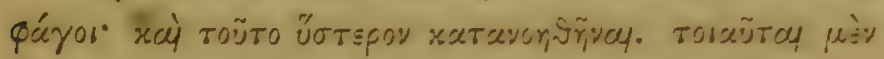

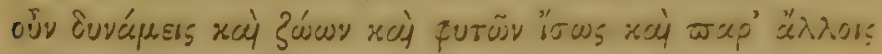
ยīl.

\section{CAP. VI.}

Arbures odorifera: Quemem drbme, Regrionuen dicersarum et Montium propric.

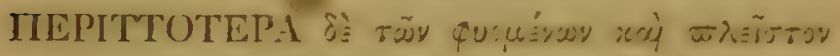

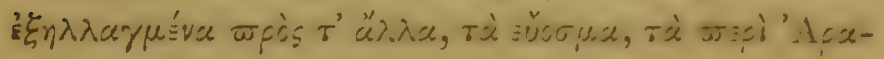

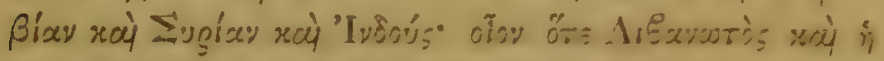

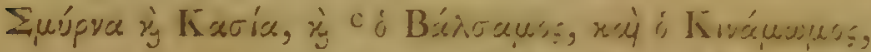
xaों गे

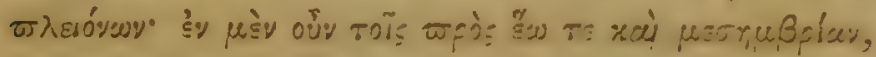

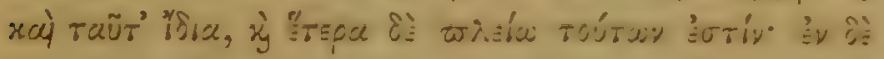

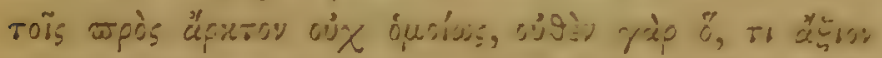

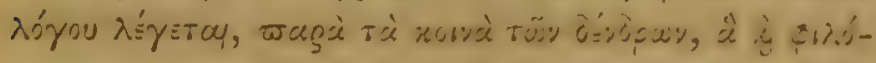

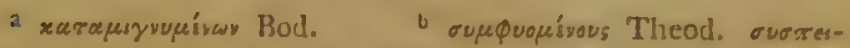
opelyou: Scal.

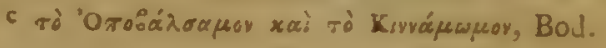
1 iv deest Bort. 


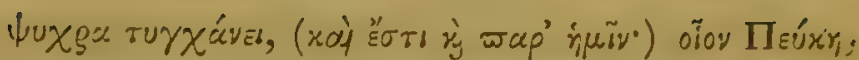

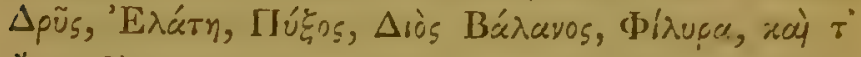

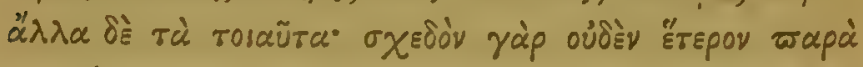

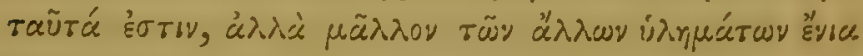

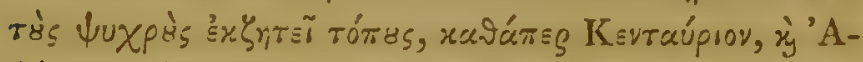

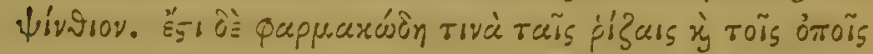

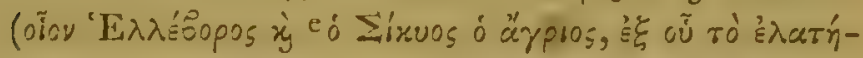

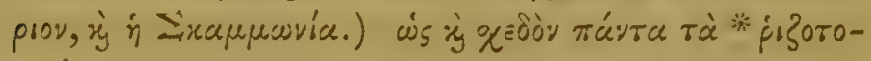

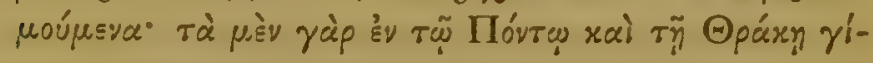

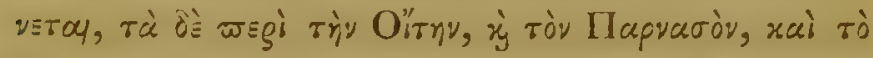

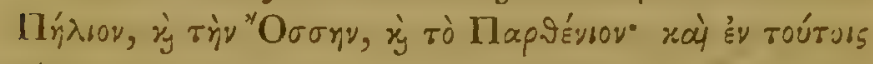

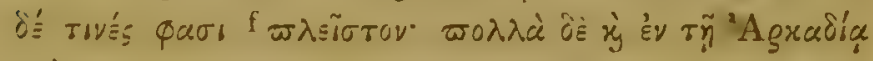

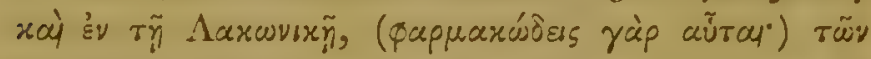

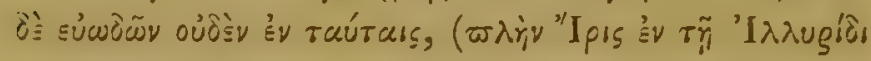

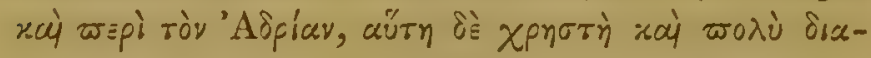

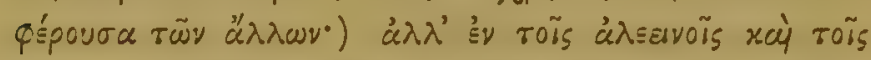

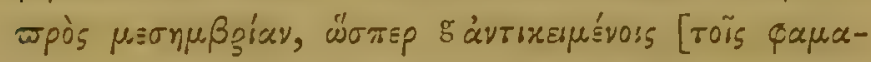

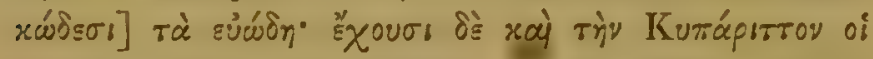

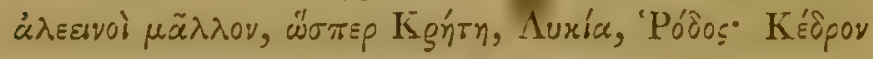

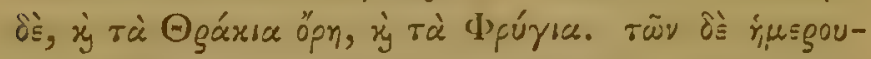

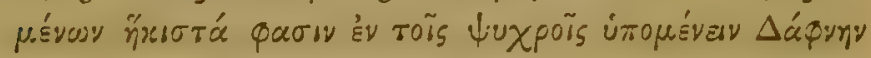

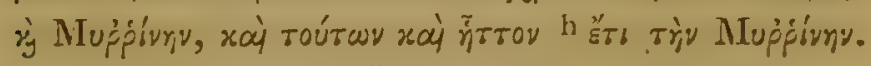

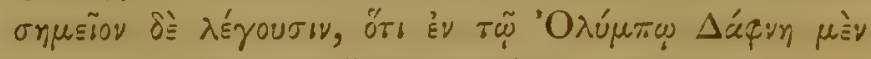

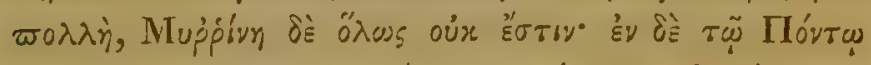

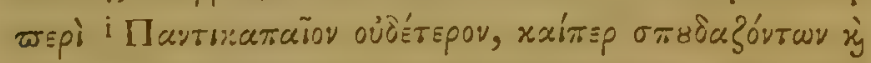

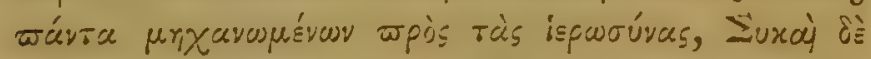

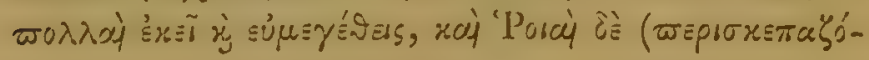

: ¿ Siruos o̊ aैy

f Qusrrór. Const.

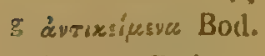

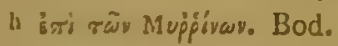

i ravri rài woĩoy, Bod. 
MEPI TMTSN ISTOPIA TO $\Delta^{\prime} . \quad$ I63

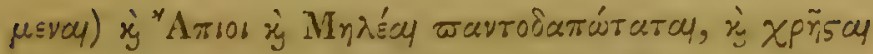

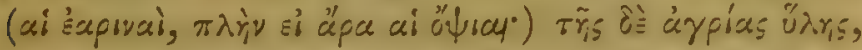

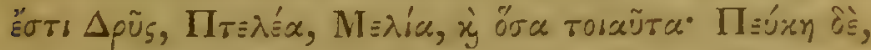

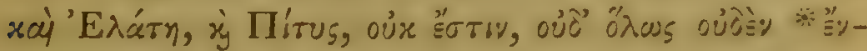

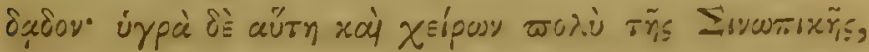

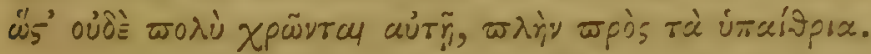

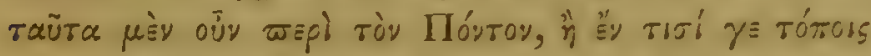

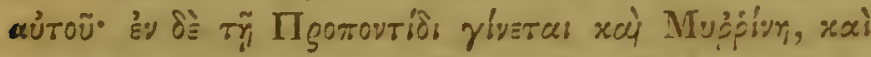

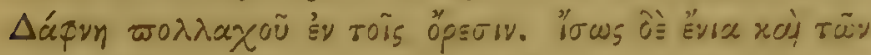

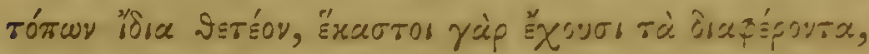

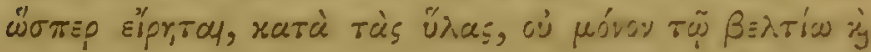

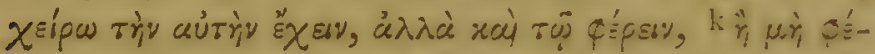

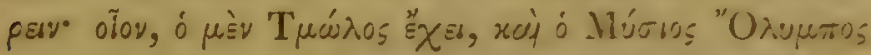

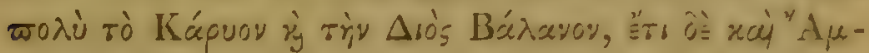

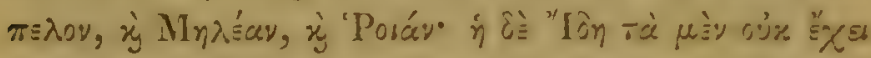

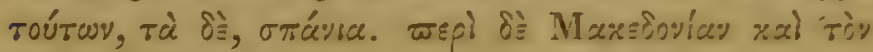

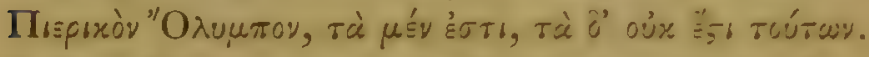

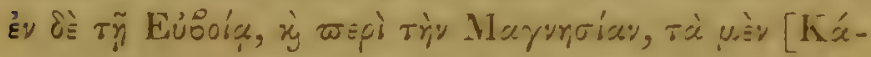

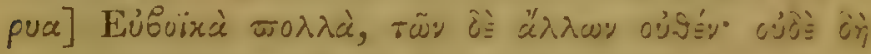

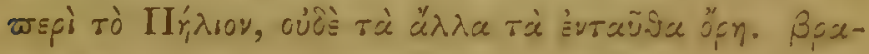

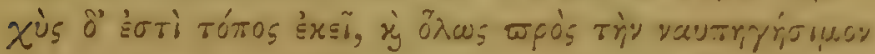

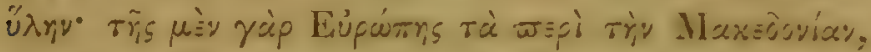

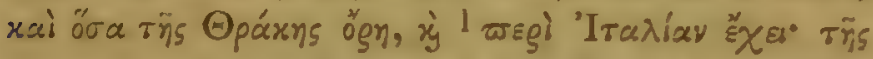

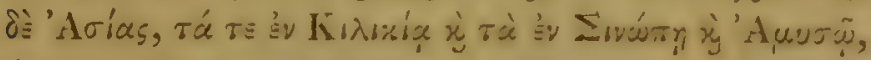

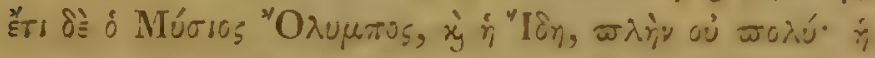

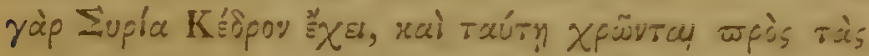

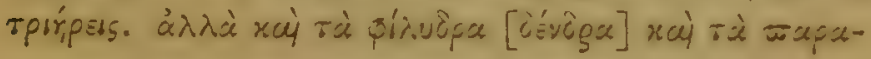

\section{Const.}

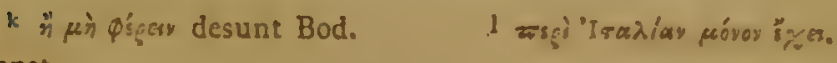




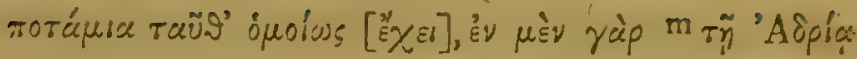

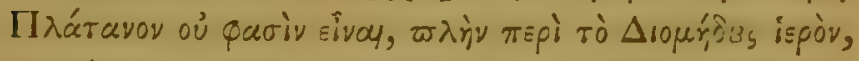

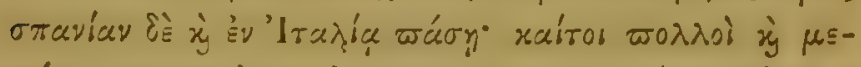

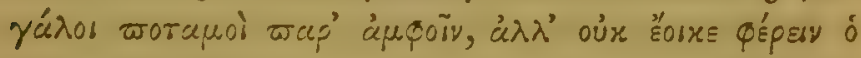

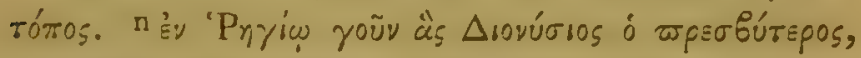

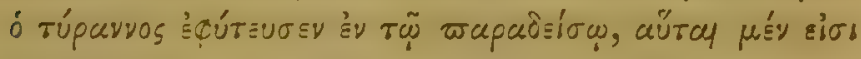

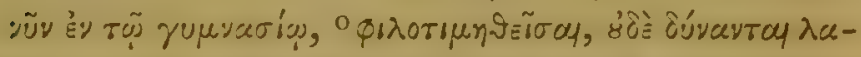

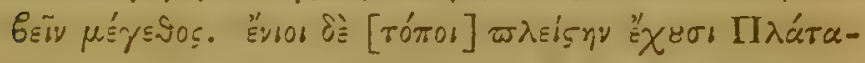

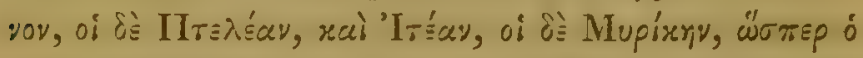

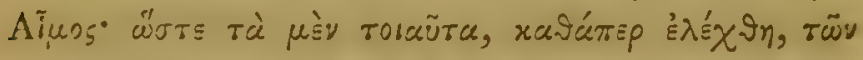

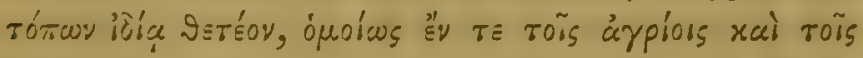

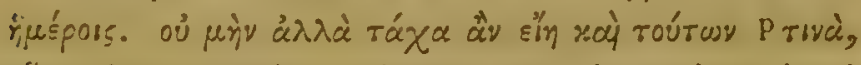

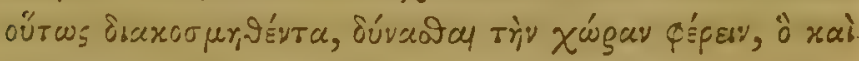

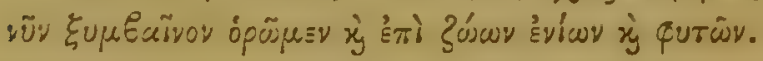

\section{CAP. VII.}

Alga marine, utriusque Maris.

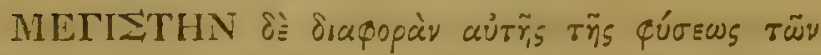

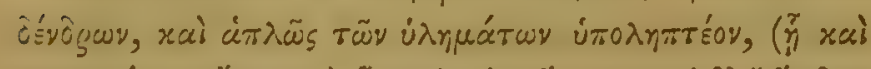

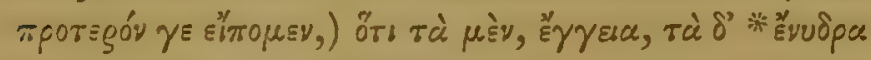

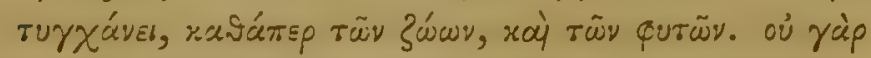

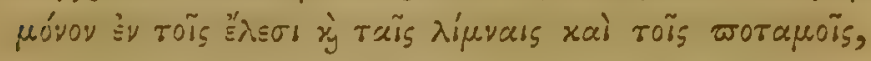

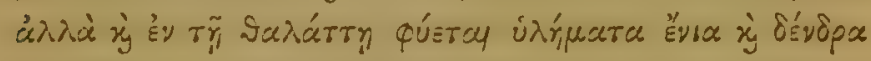

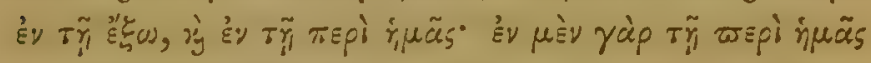

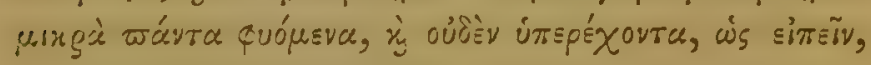

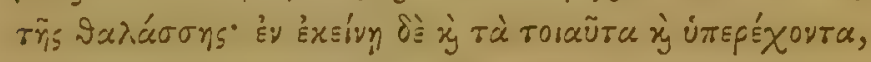

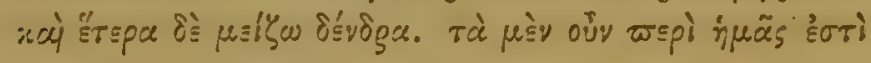

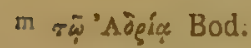

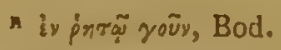

- Qirori$\mu$ inivis, Bod.

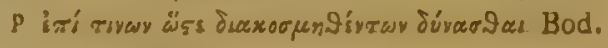




\section{MEPI OMTRN ISTOPIAS TO $\Delta^{\prime} . \quad 165$}

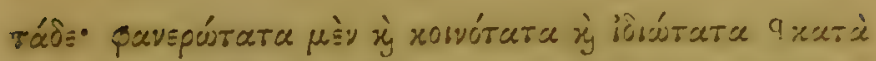

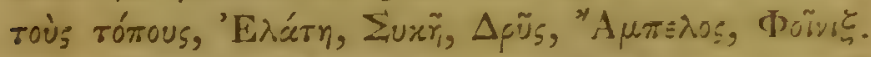

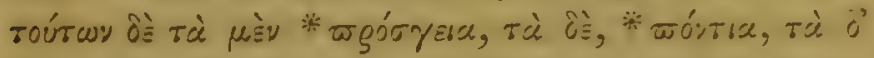

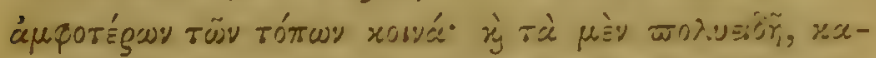

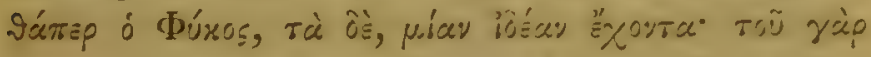

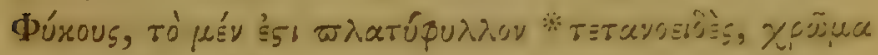

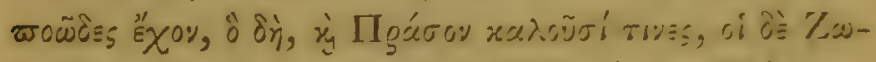

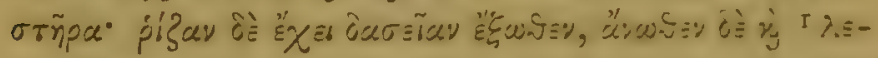

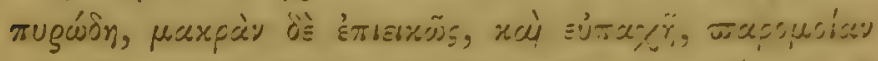

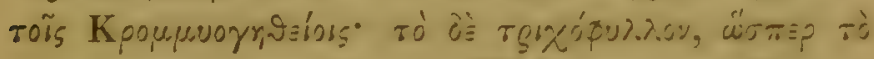

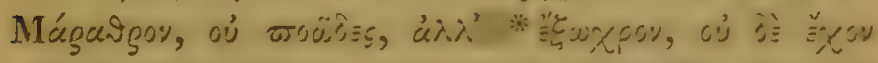

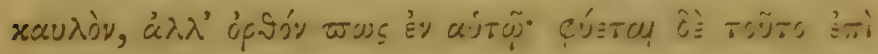

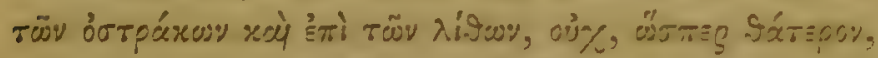

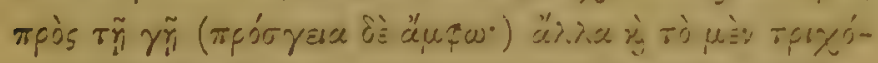

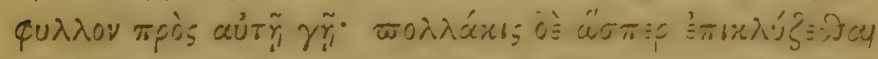

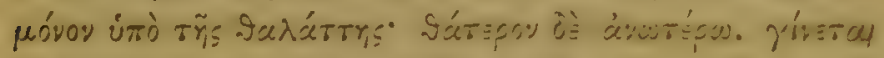

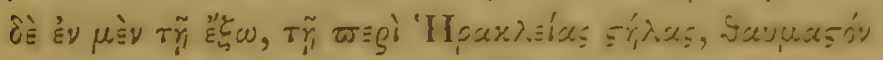

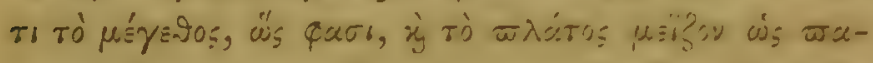

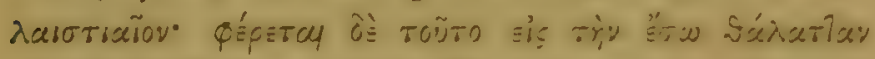

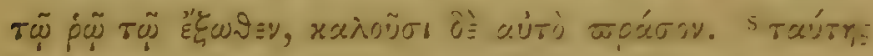

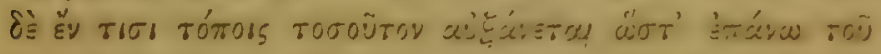

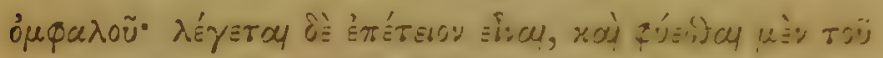

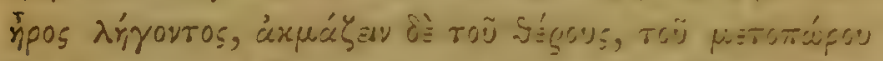

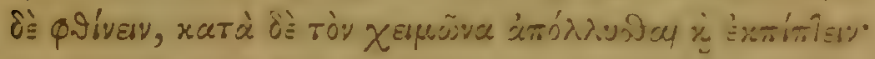

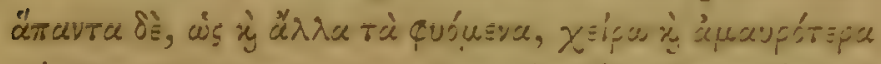

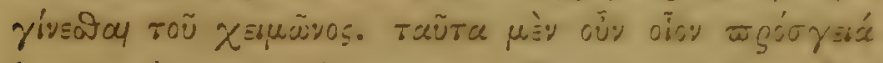

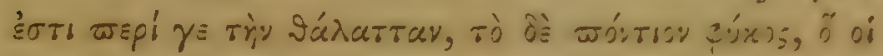

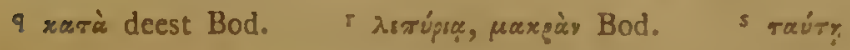
Bod. 


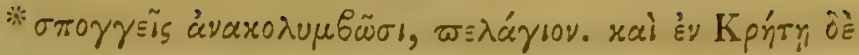

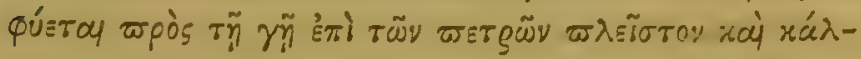

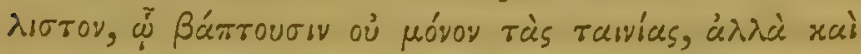

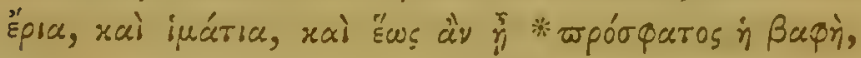

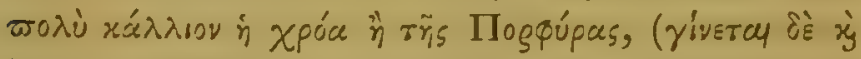

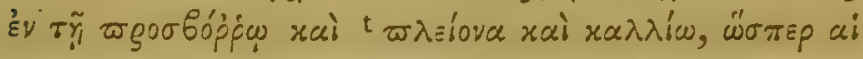

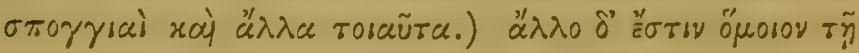

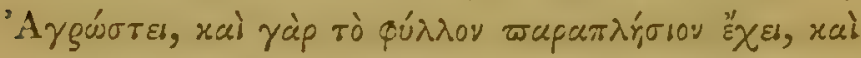

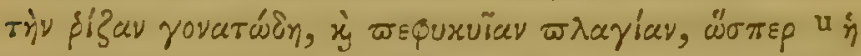

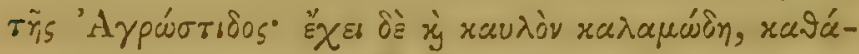

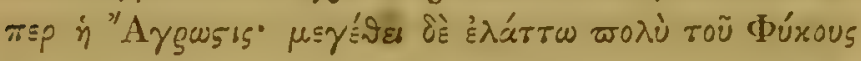

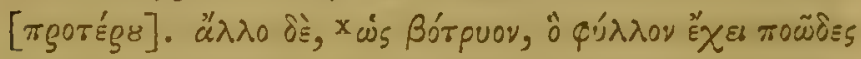

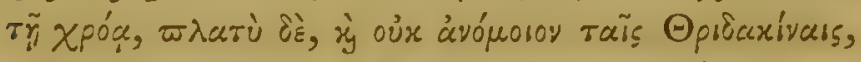

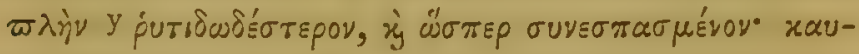

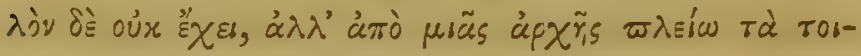

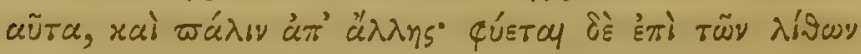

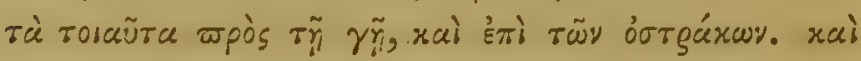

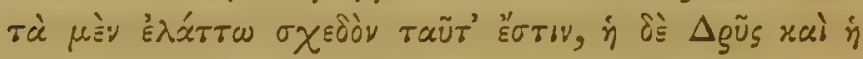

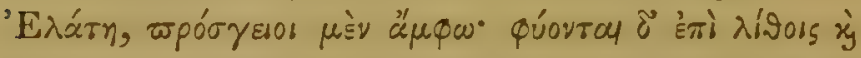

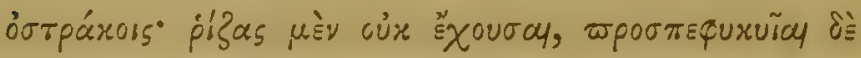

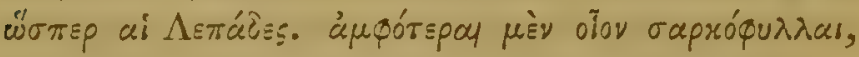

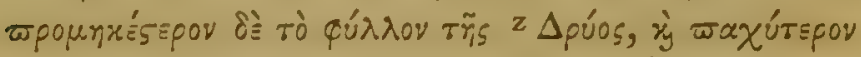

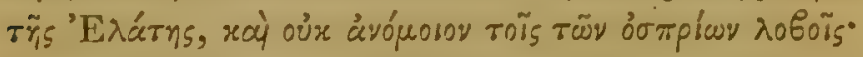

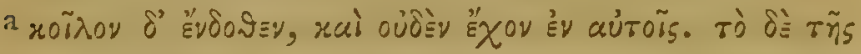

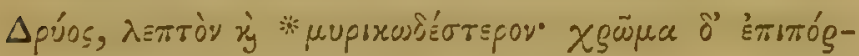

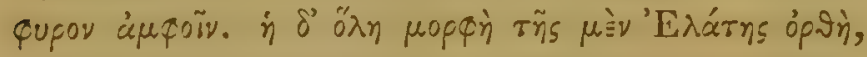

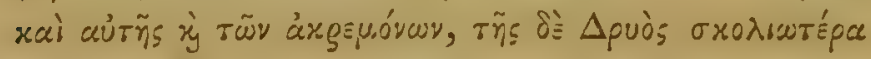

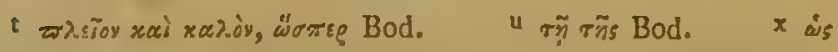

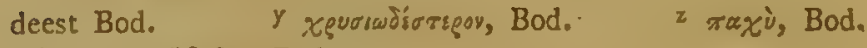

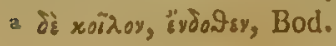




\section{MEPI $\Phi M T \Omega N ~ I \Sigma T O P I A \Sigma T O \Delta^{\prime} . \quad$ T 67}

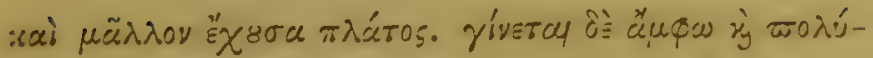

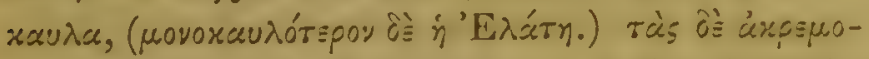

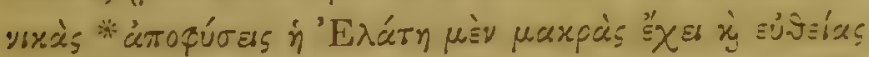

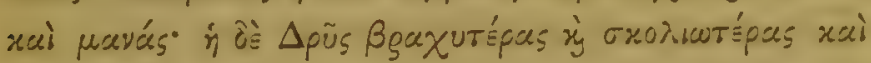

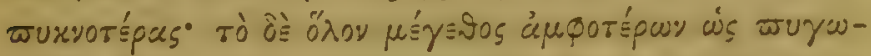

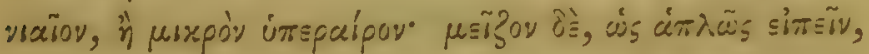

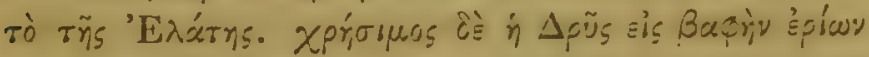

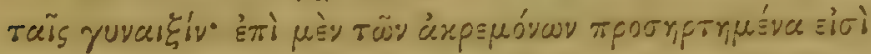

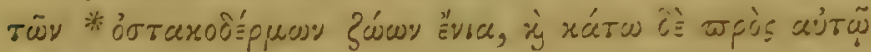

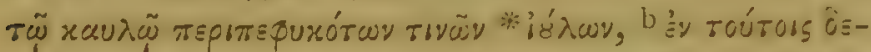

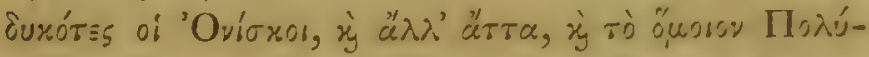

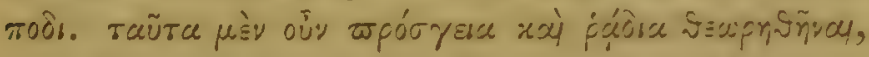

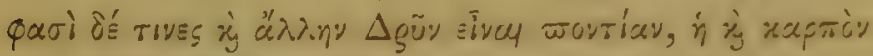

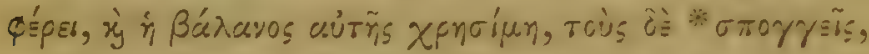

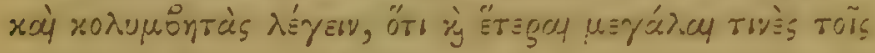

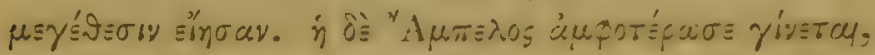

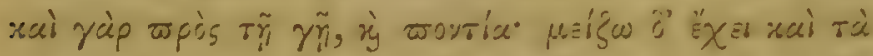

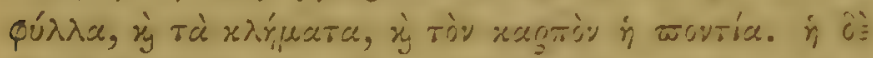

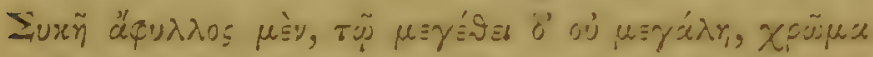

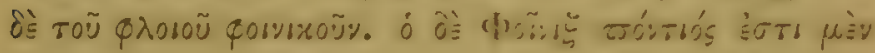

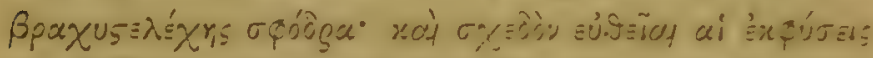

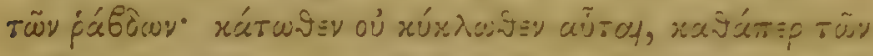
ṕá

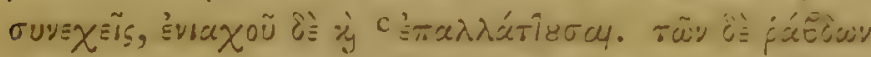

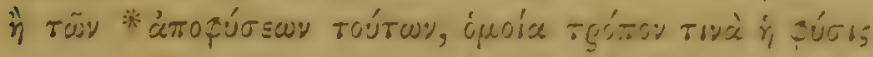

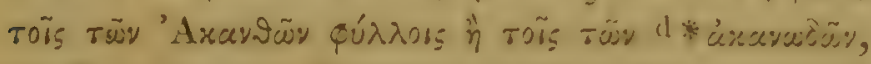

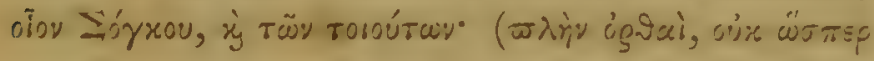

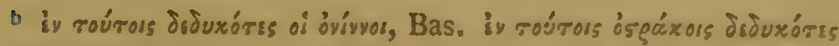

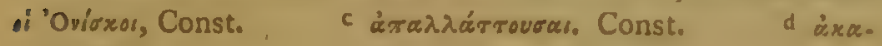
wxลัท, Bod. 
E่xEive. *

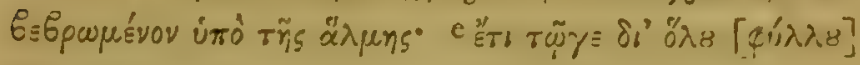
ท̆丶

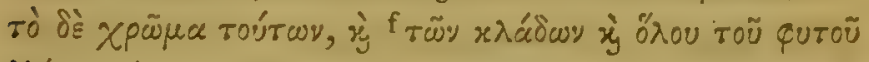

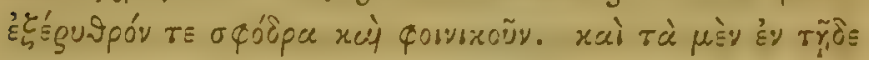

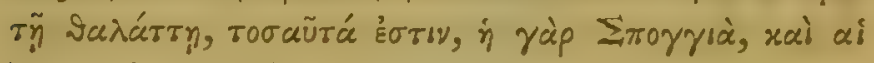

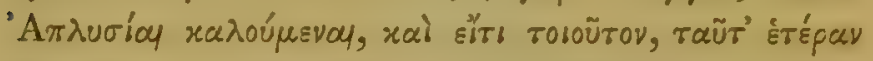

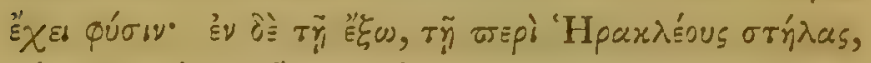

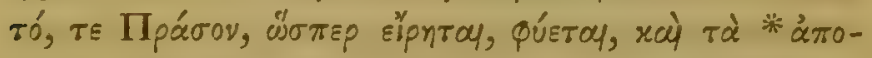

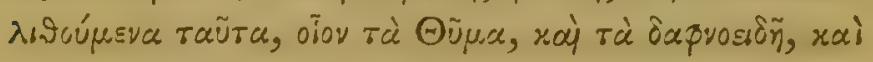
$\tau \dot{\alpha} \ddot{\alpha} \lambda \lambda \alpha$.

\section{CAP. VIII.}

Planta Arabica; et qua in Muri rubro occurrunt, Coralline, Gorgonia, \&c. \&c.

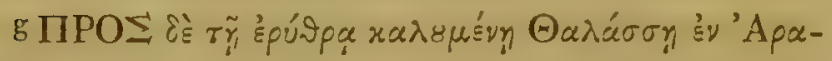

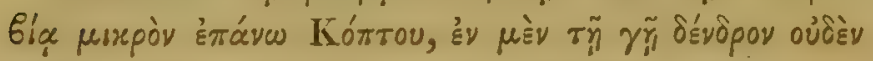

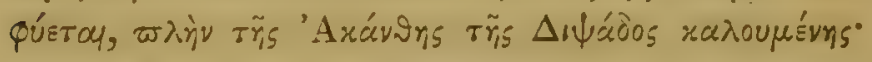

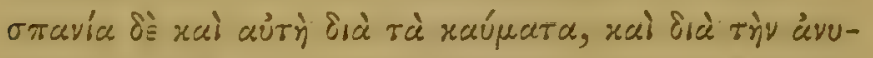

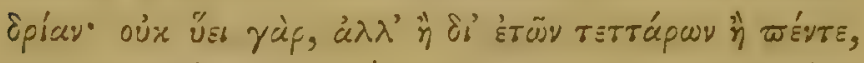

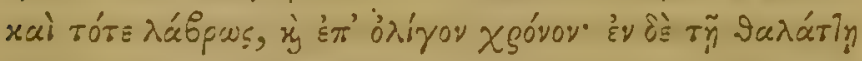

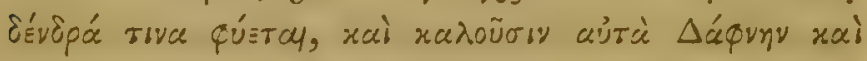

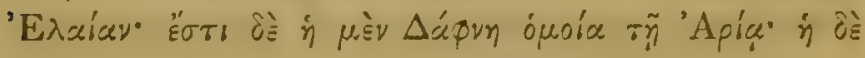

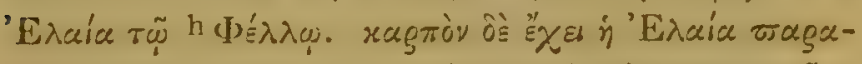

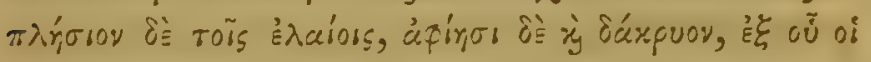

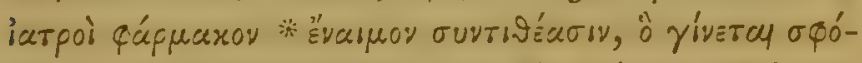

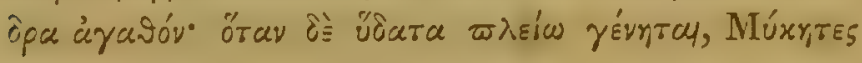

- imsi Bod.

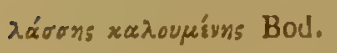

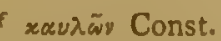

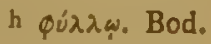

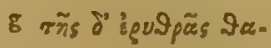




\section{MEPI TMTSN ISTOPIAS TO $\Delta^{\prime} .169$}

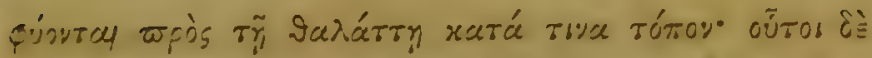

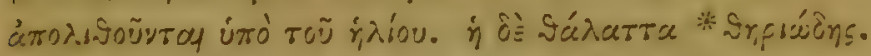

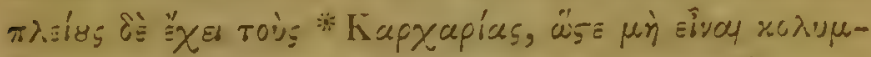

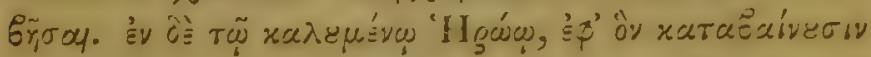

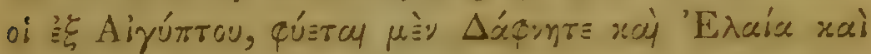

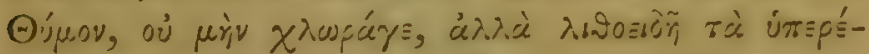

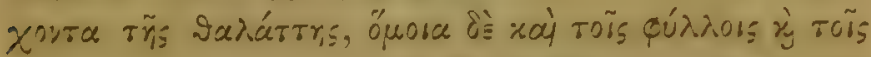

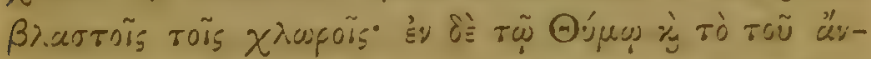

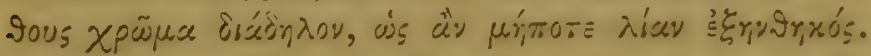

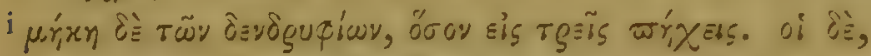

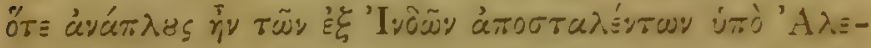

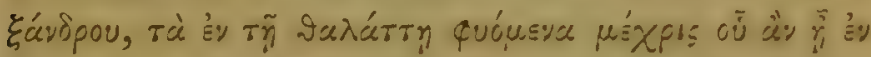

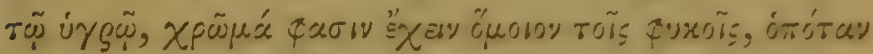

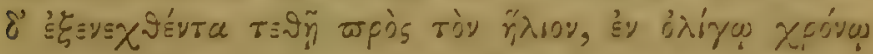

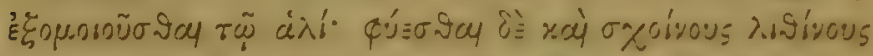

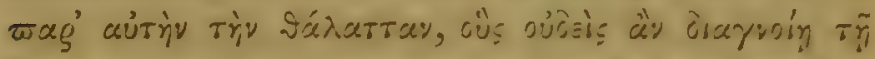

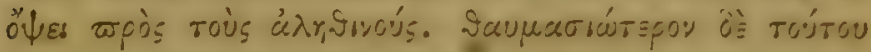

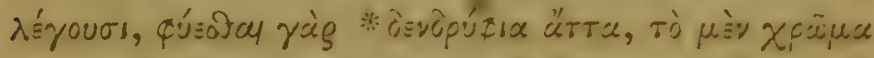

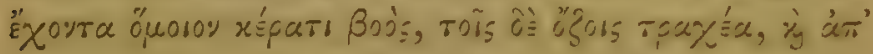

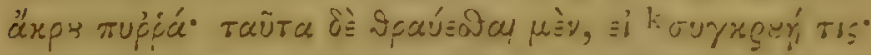

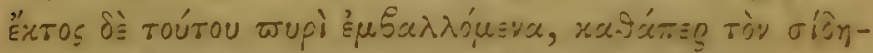

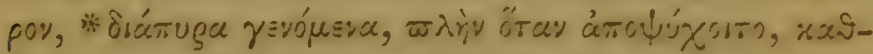

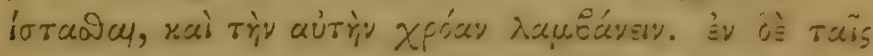

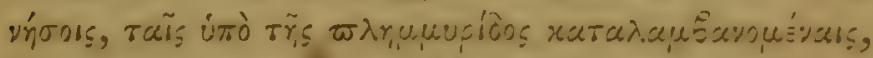

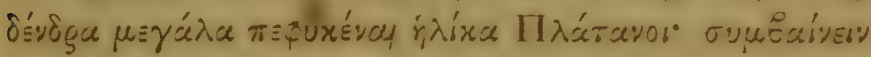

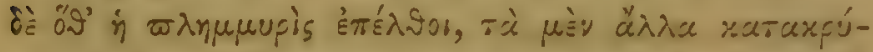

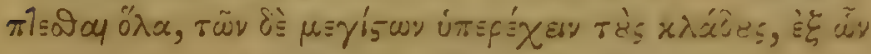

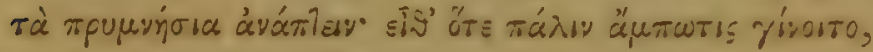

i $\mu$ ńxues Bod.

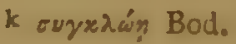




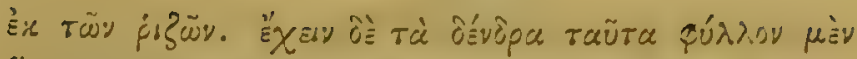

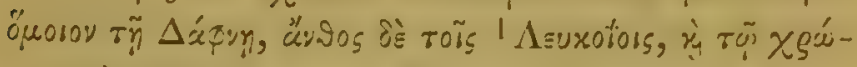

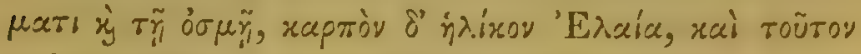

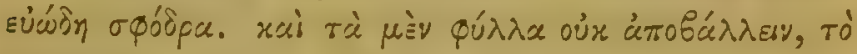

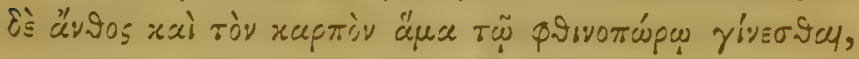

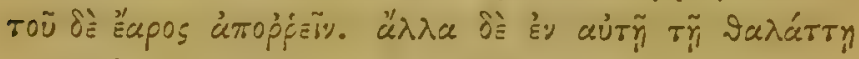

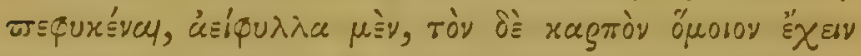

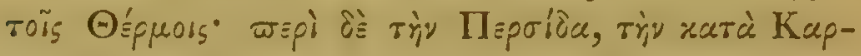

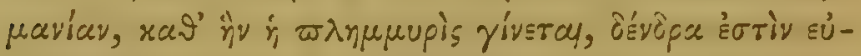

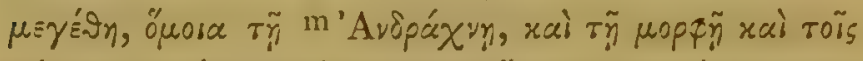

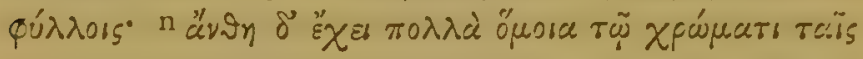

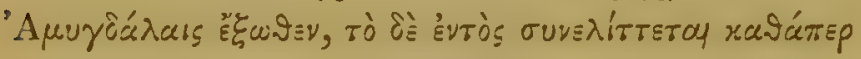
- бuท

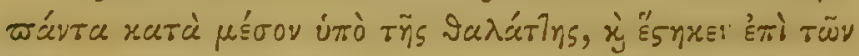

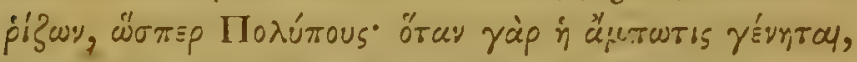

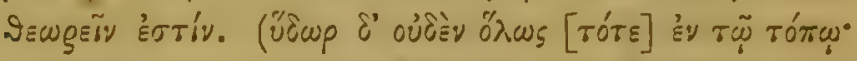

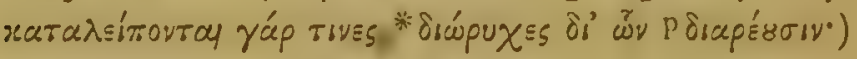

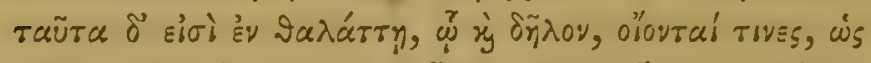

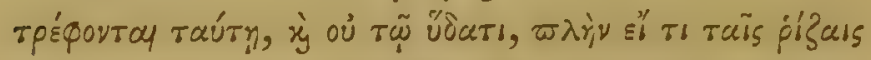

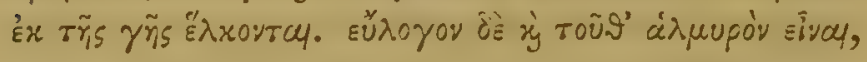

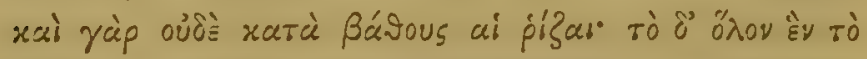

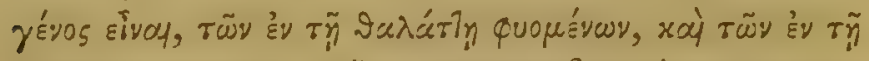

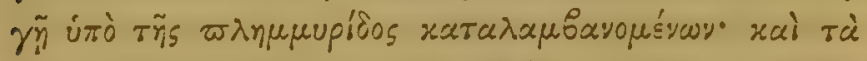

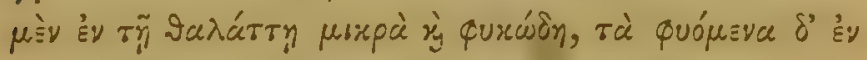

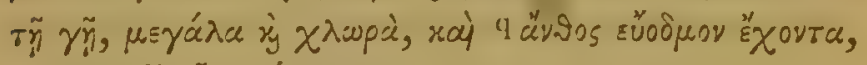

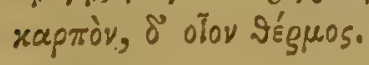

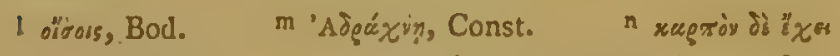

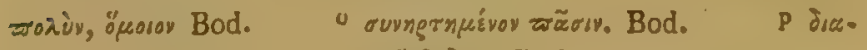

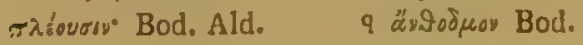




\section{MEPI WNTSN ISTOPIAS TO $\Delta^{\prime} . \quad 17 \mathrm{I}$}

\section{CAP. IX.}

Gossypium, arboreum, L. Papyrus, Nilotica, et affnes.

Plante ZEgypti et Syrie.

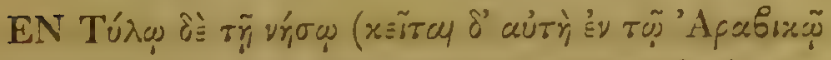

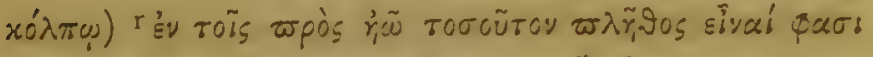

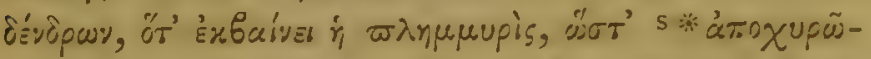

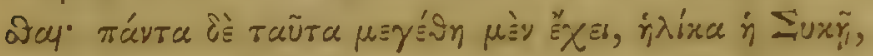

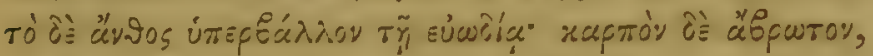

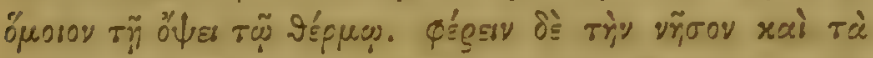

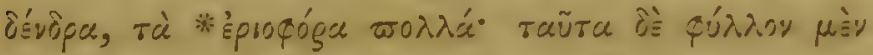

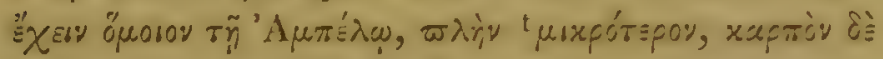

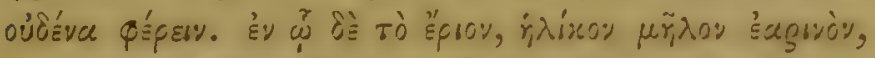

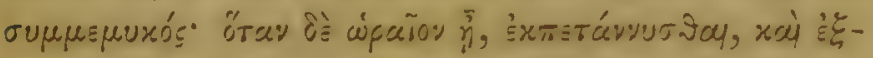

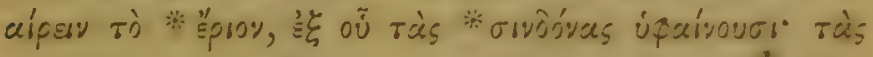

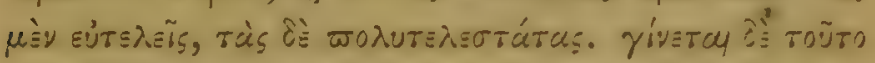

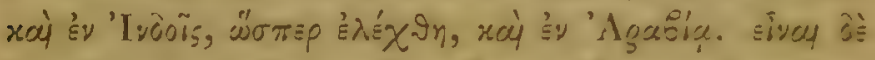

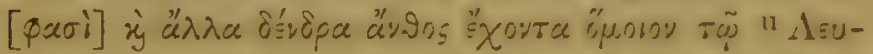

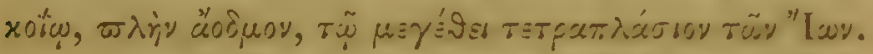

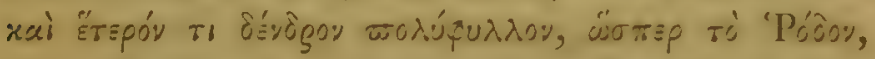

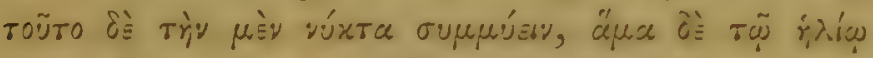

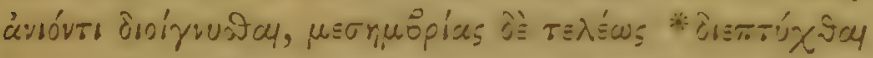

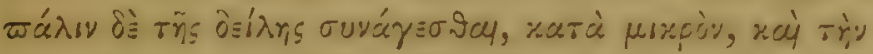

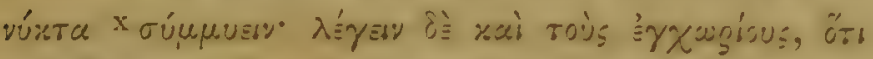

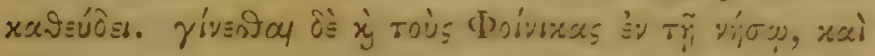

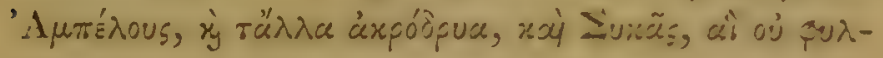

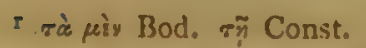

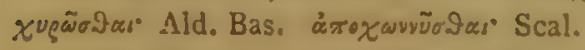

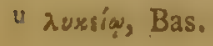

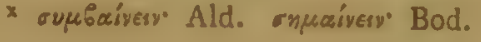

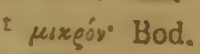




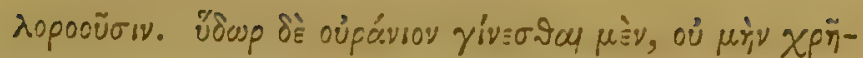

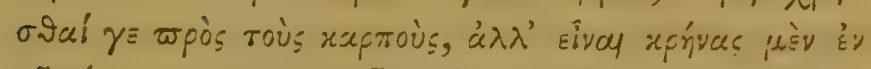

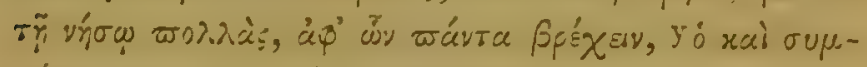

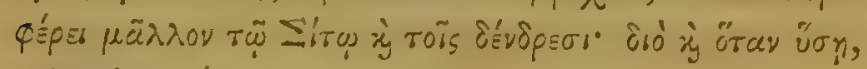

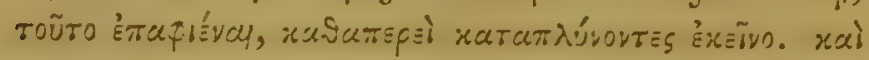

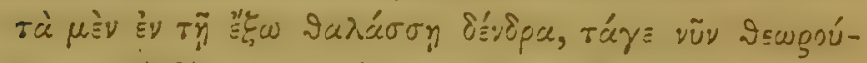

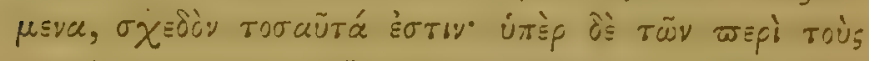

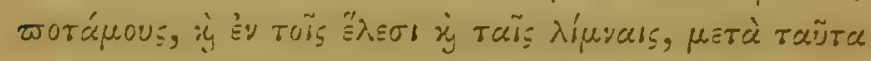

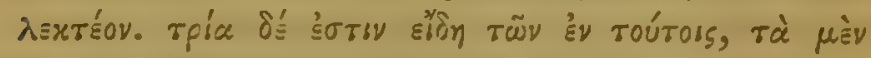

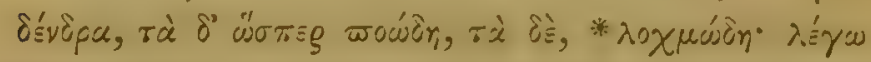

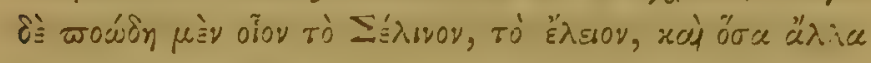

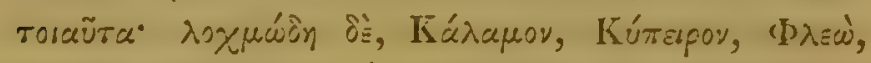

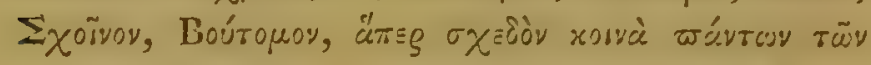

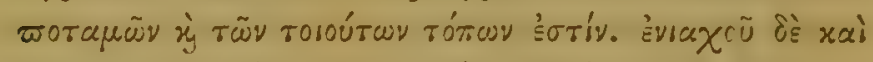

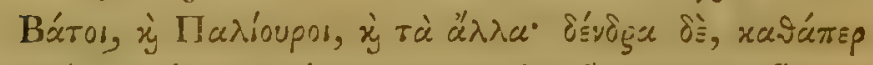

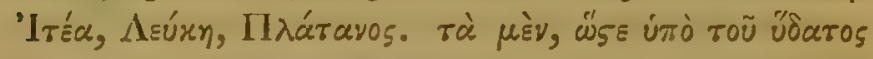

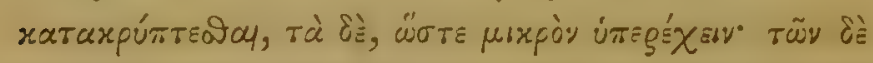

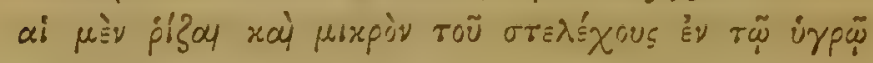

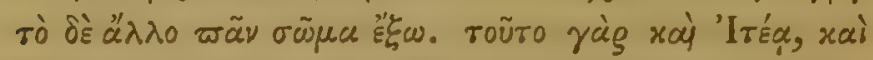

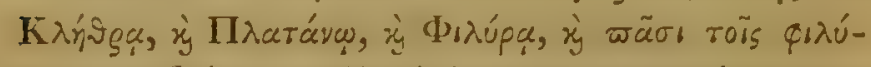

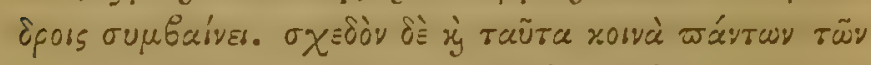

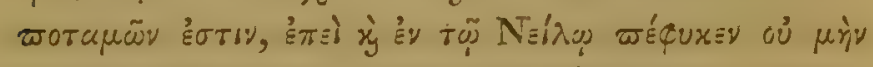

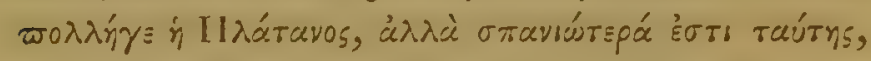

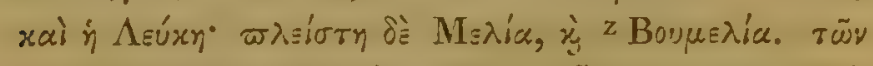

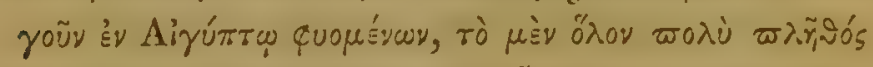

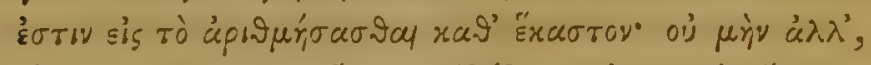

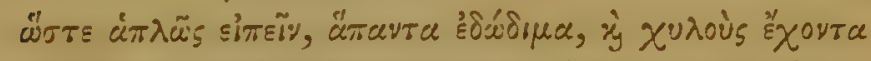

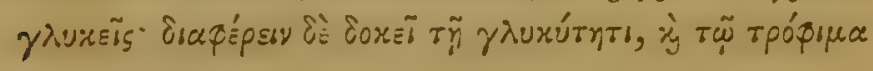

y ä rai Bod.

z Boypídıss. Bod. 


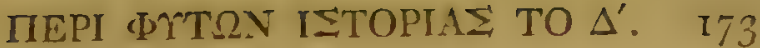

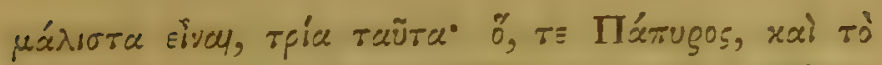

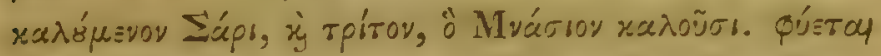

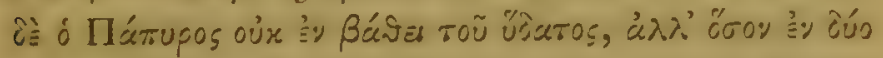

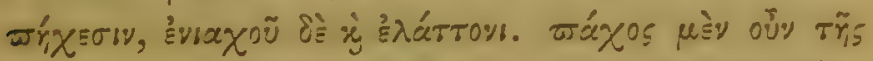

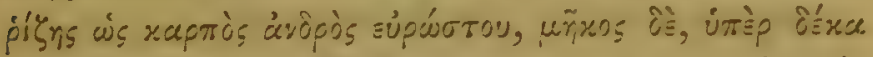

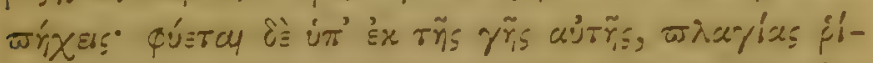

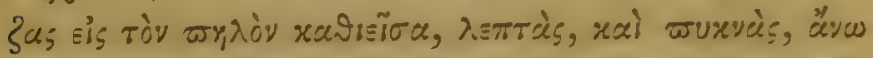

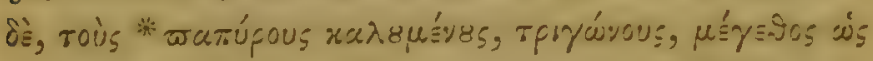

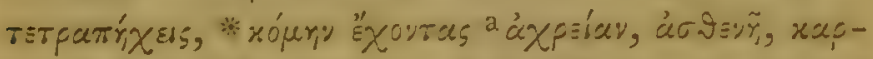

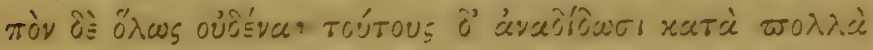

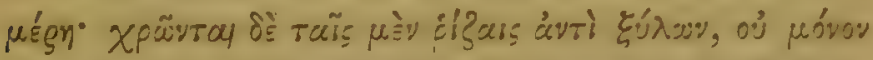

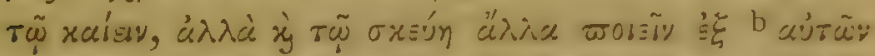

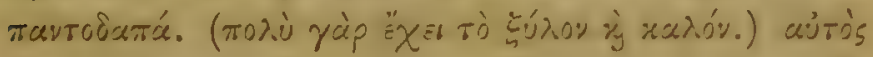

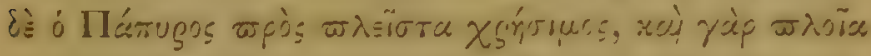

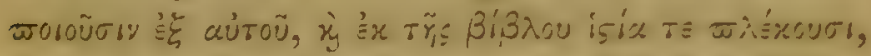

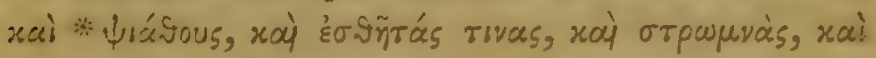

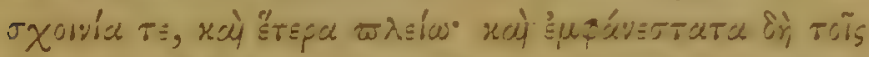
है,

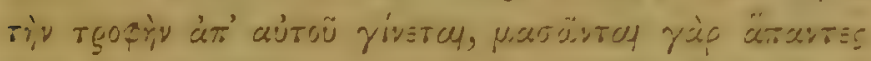

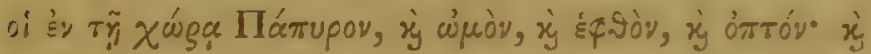

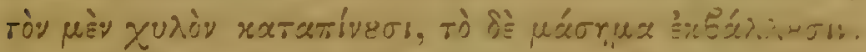

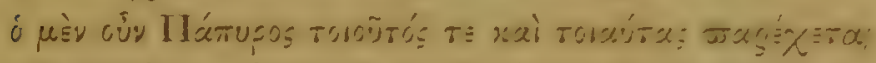

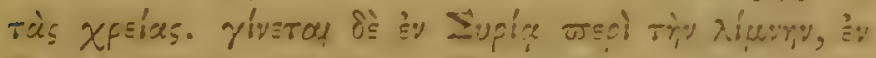

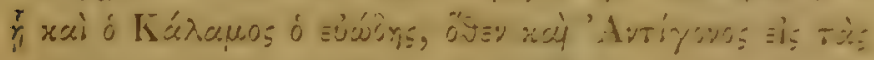

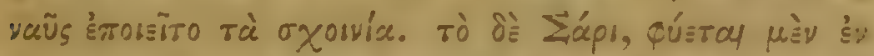

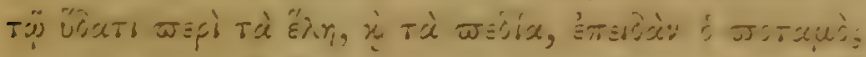

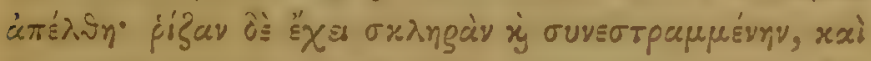

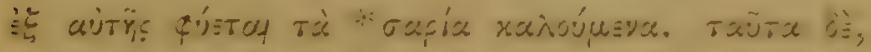

z exsoisay, i. e. Nugorirry, Const.

L $\propto \dot{u} \approx o \tilde{u}$ Bord. 


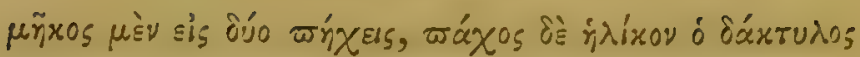

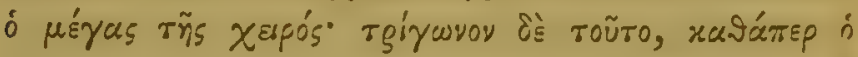

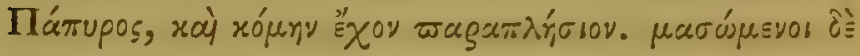

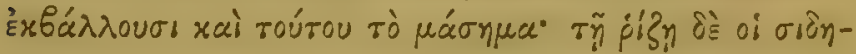

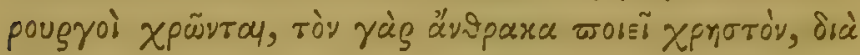

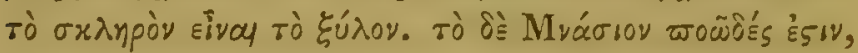

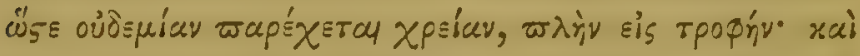

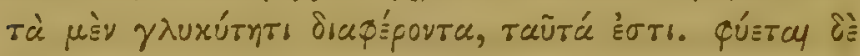

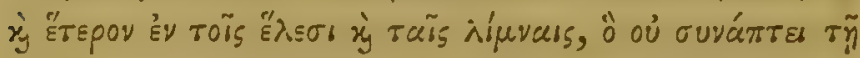

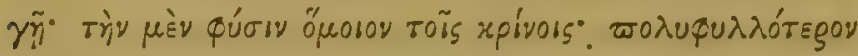

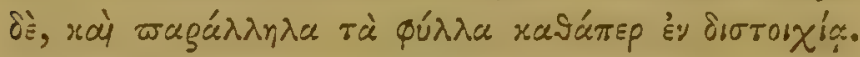

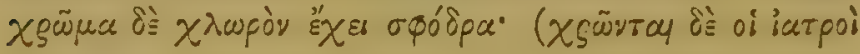

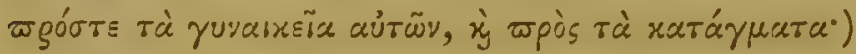

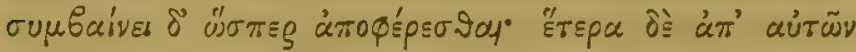

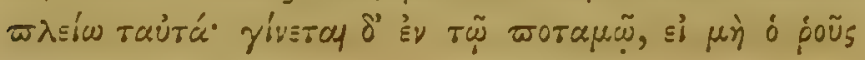

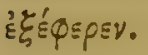

\section{CAP. X.}

Arum Colocasia L. Nymphau, Lotus: Cyperus, esculentus.

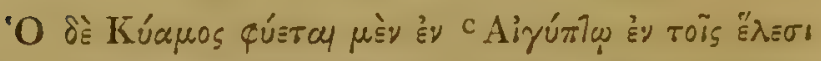

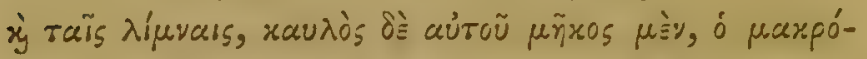

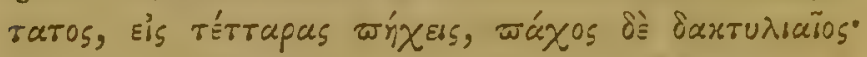

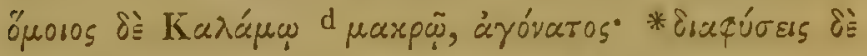

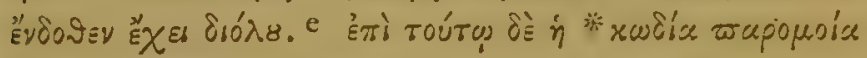
f $\sigma \phi \eta x i \omega$ б

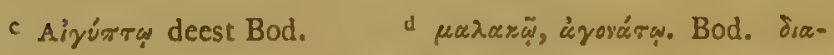
oxiosis. Scal. c Vid. not. ad fin. libri. f apoxíy Bas. Vid. not. ad fin. libri. $g$ zиráp̧ay Bas. 


\section{IIEPI $\Phi M T \Omega N$ I}

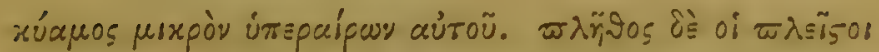

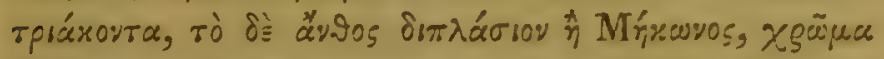
¿ミ ö

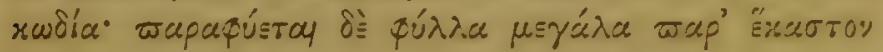

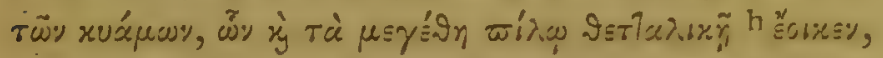

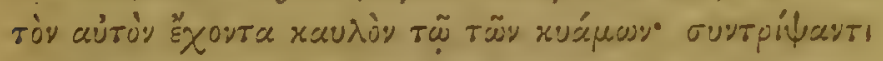

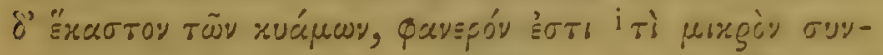

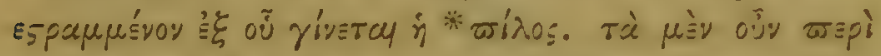

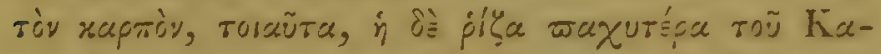

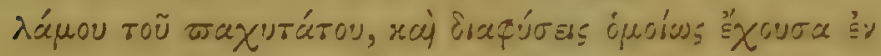

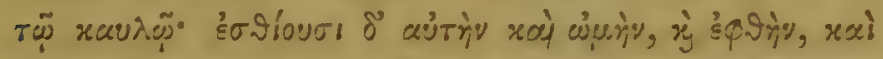

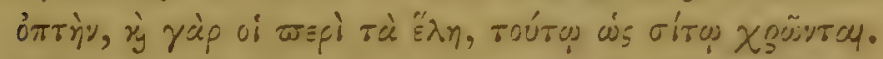

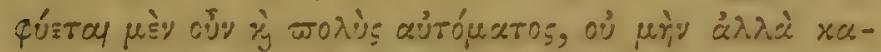

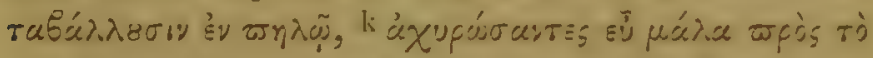

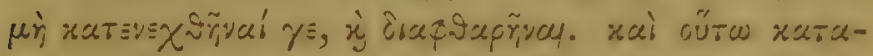

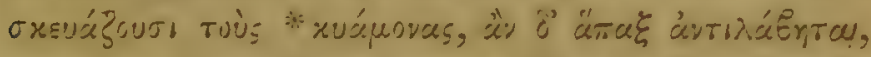

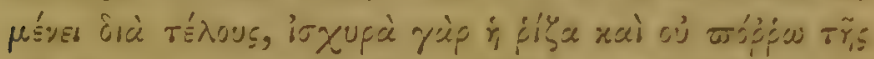

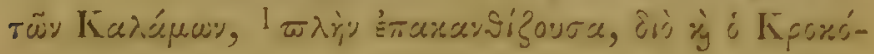

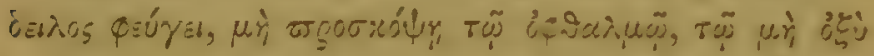

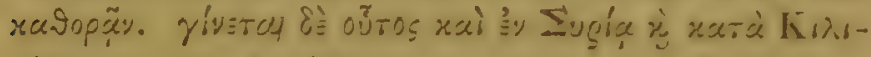

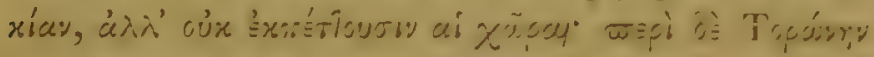

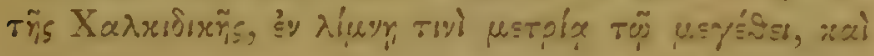

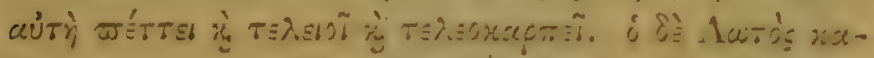

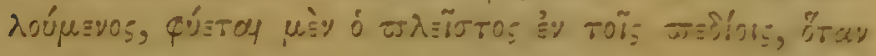

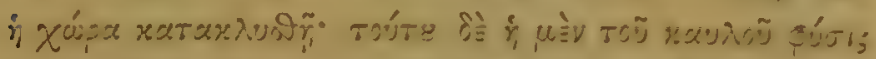

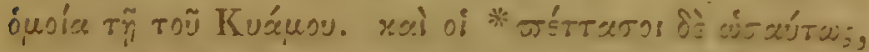

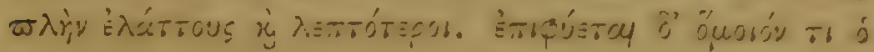

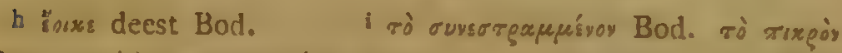

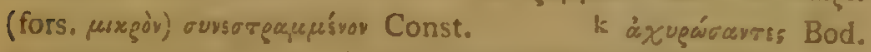

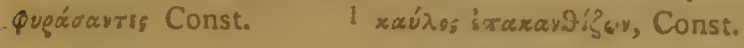




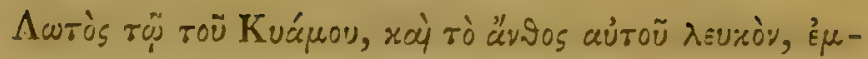

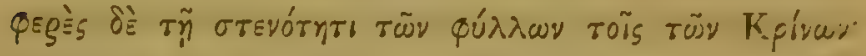

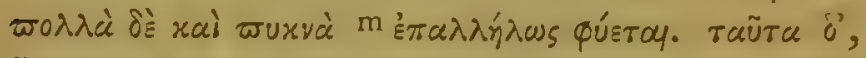

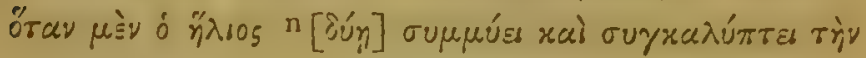

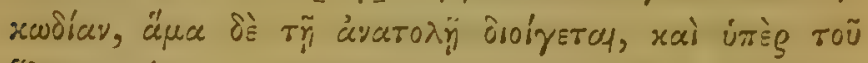

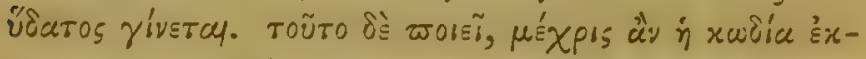

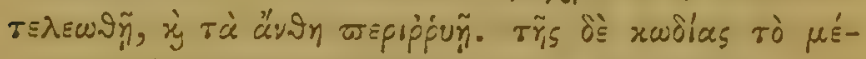

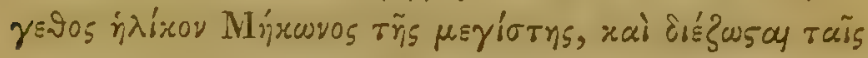

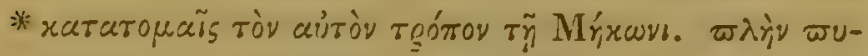

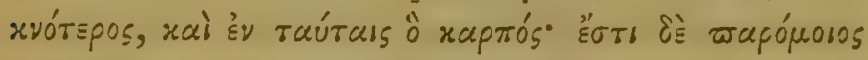

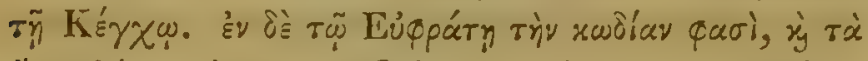

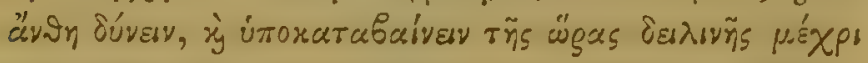

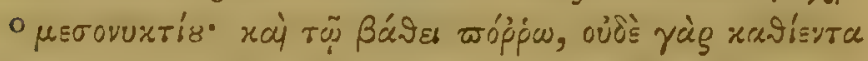

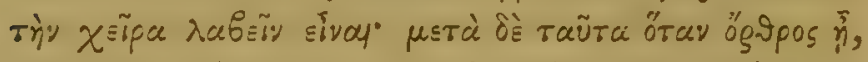

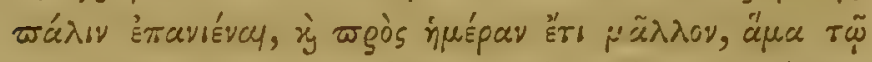

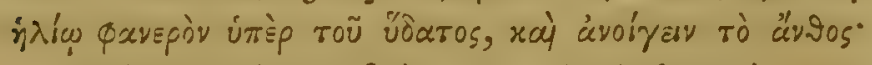

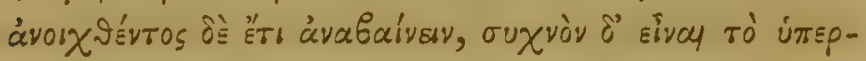

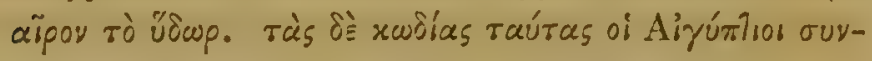

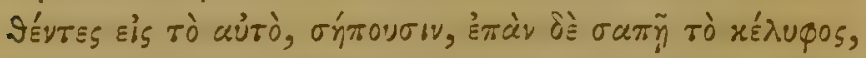

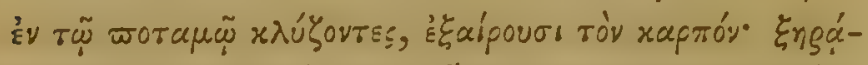

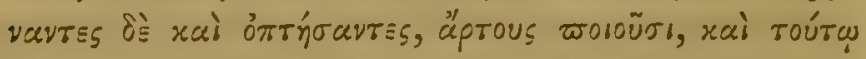

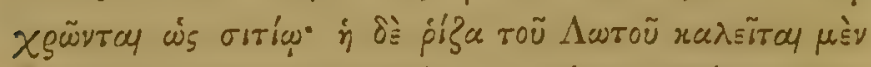

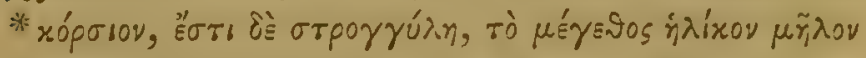

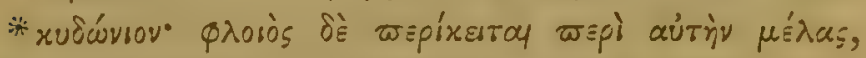

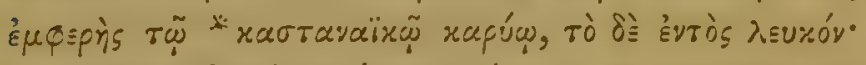

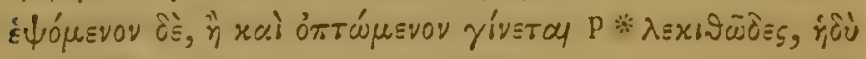

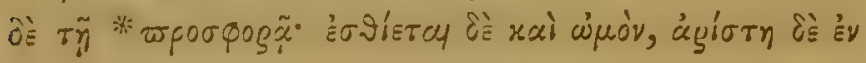

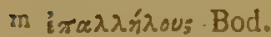

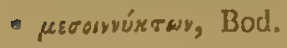

n Júszaı Const. Júgy deest Bod.

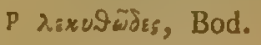




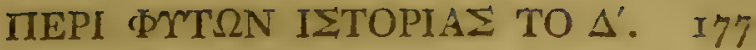

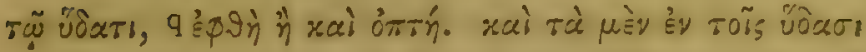

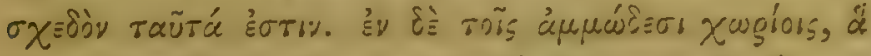

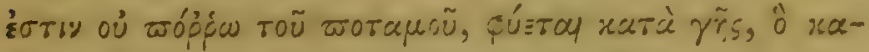

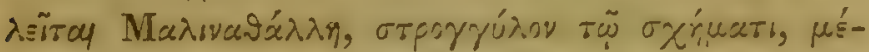

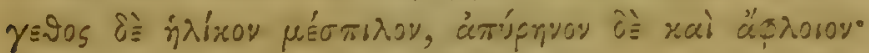

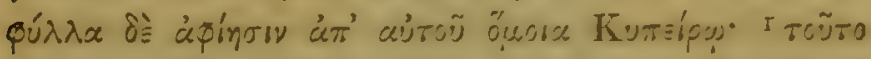

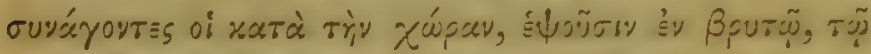

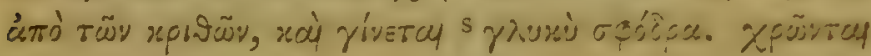

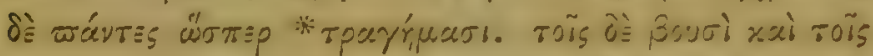

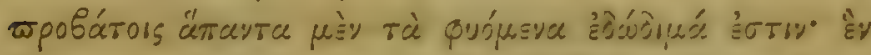

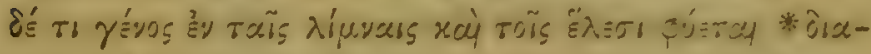

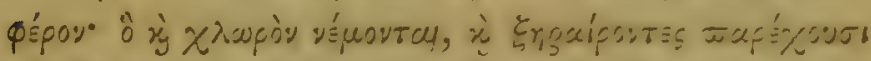

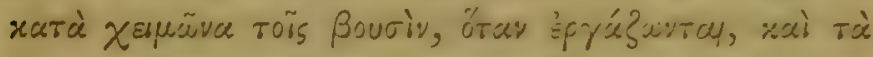

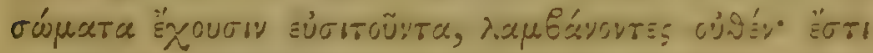

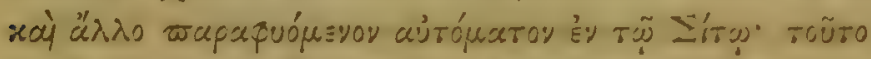

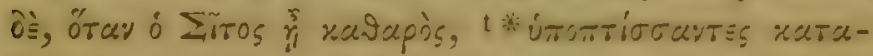

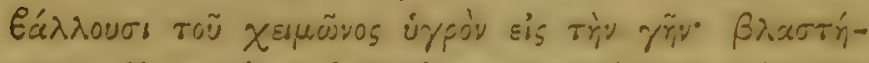

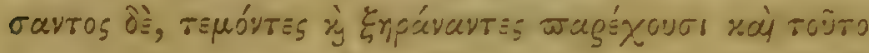

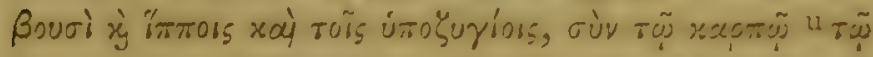

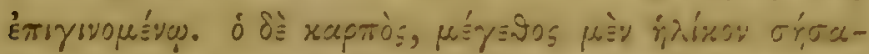

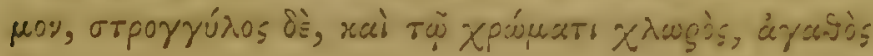

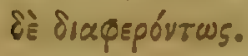

\section{CAP. XI.}

Planter fluoiatiles, et palustres Lucies Orchomenii.

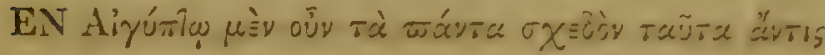

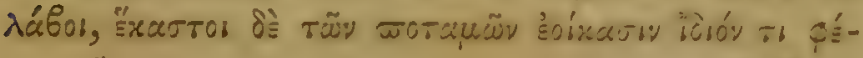

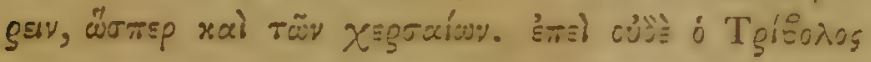

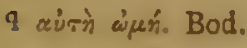

I таี่⿻ Bod.

s yruxia Bod.

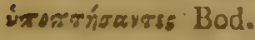

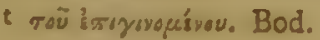




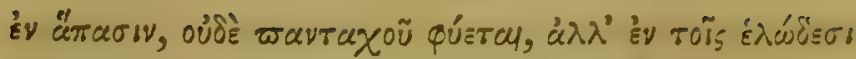

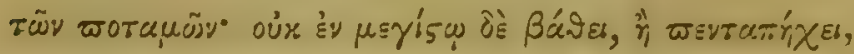

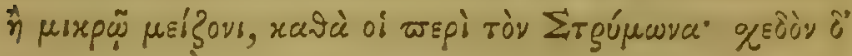

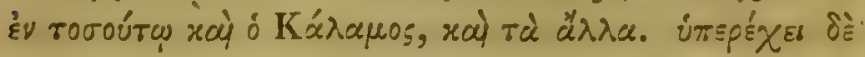

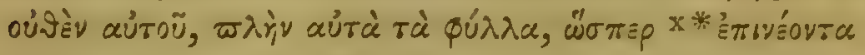

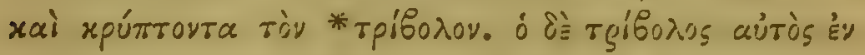

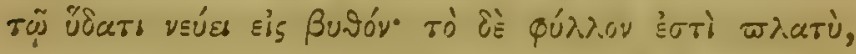

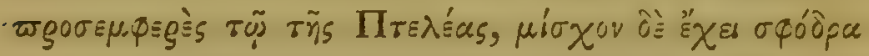

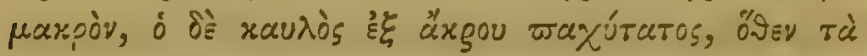

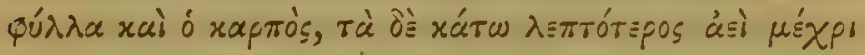

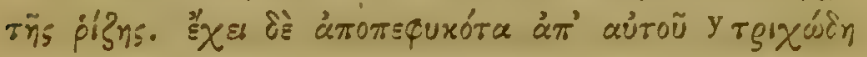

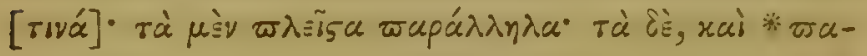

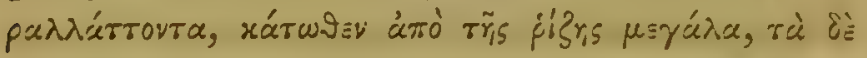

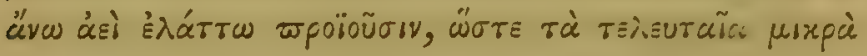

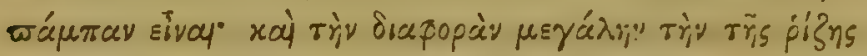

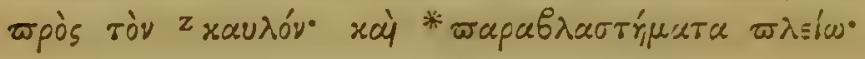

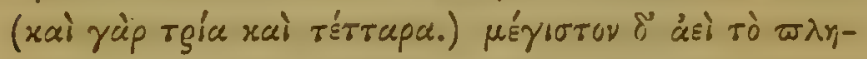

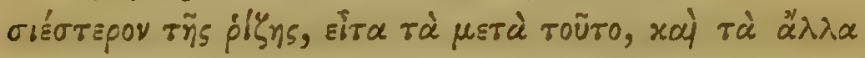

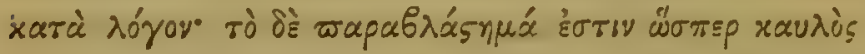

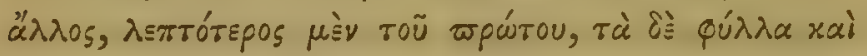

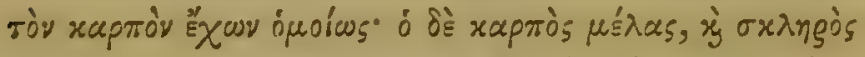

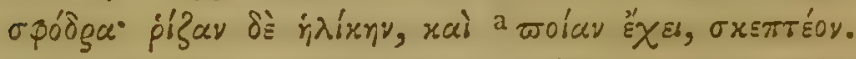

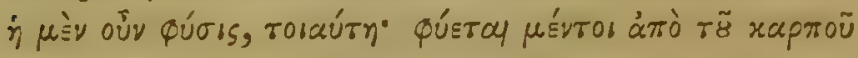

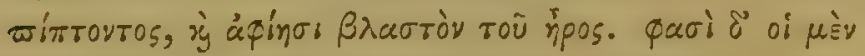

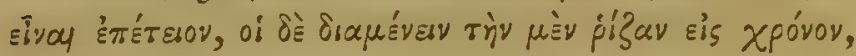

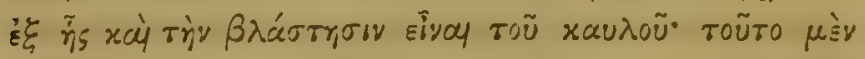

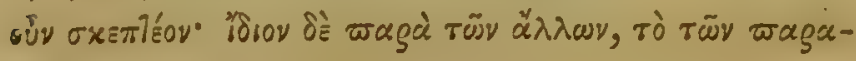

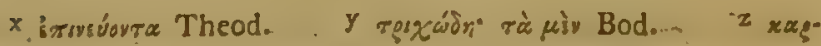
róy. Bod.

wón Bod. 


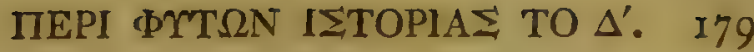

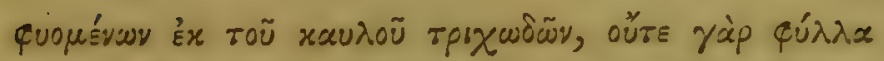

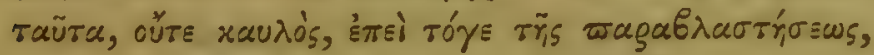

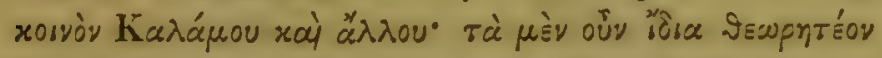

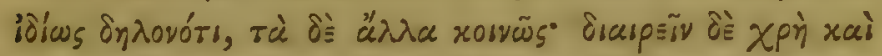

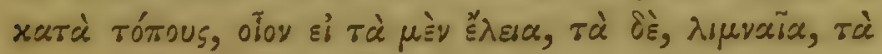

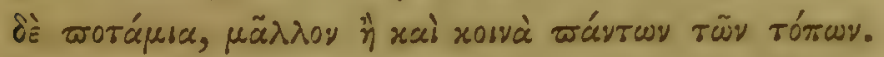

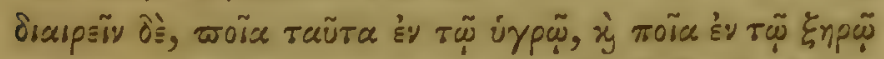

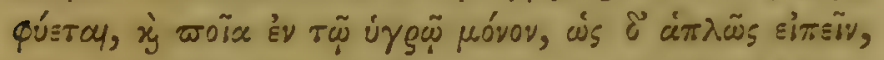

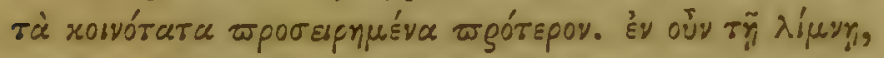

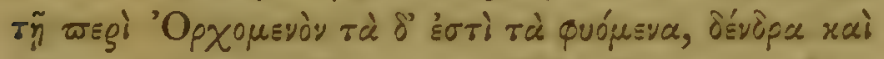

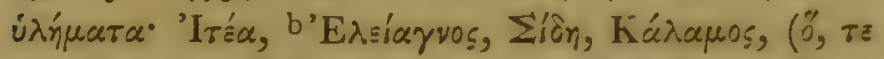

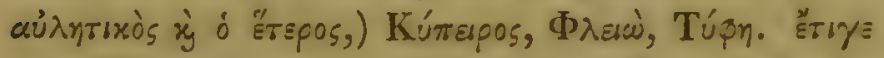

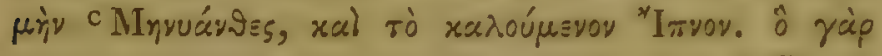

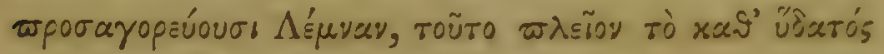

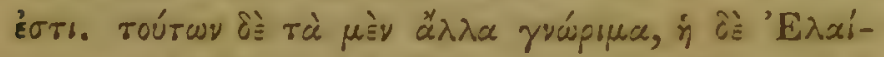

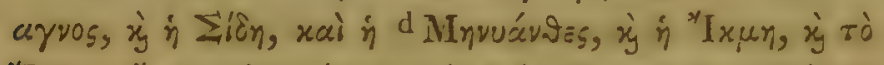

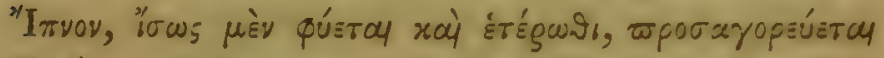

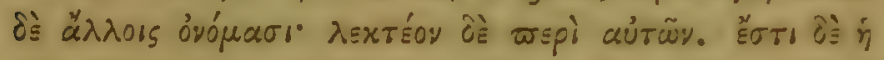

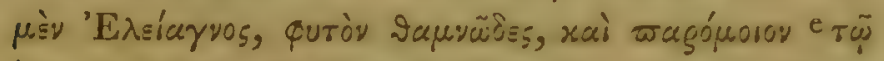

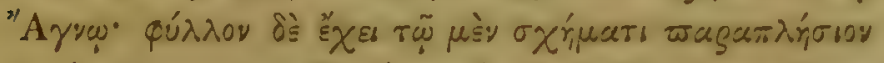

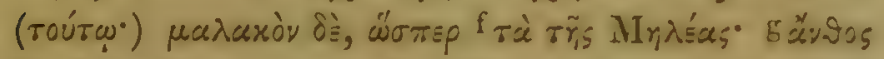

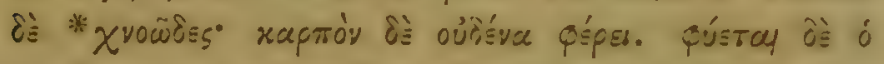

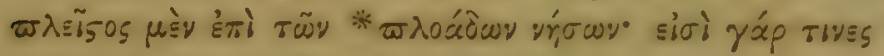

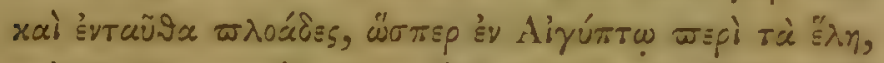

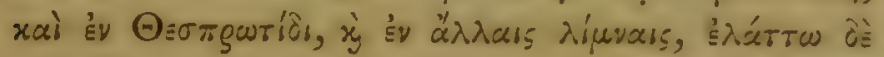

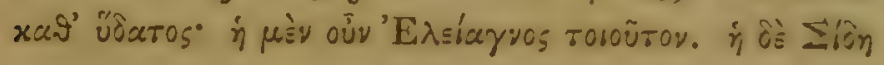

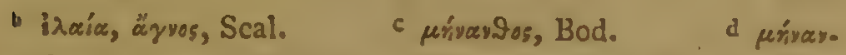

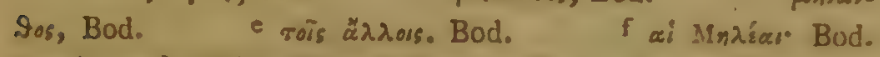

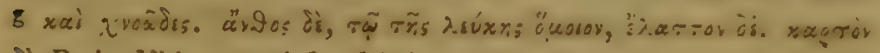
di Bod. Vid. not. ad fin, libri. 


\section{0}

\section{OEOФPASTON}

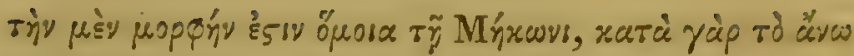

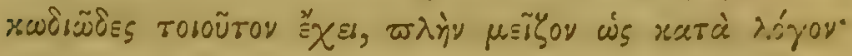

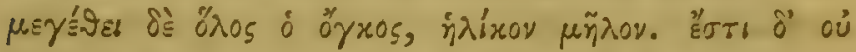

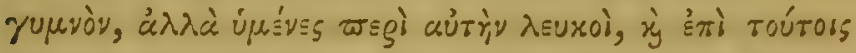

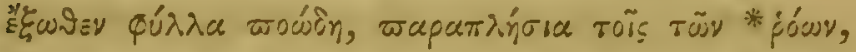

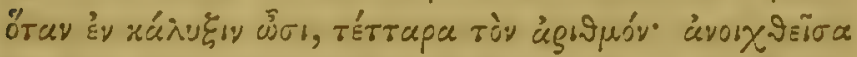

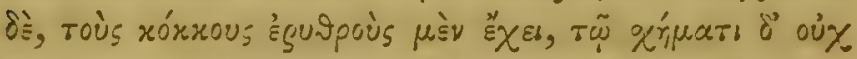

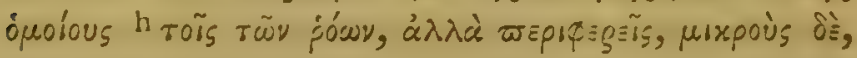
xà оن

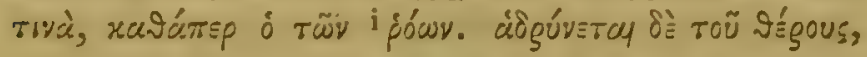

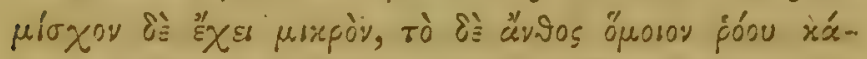

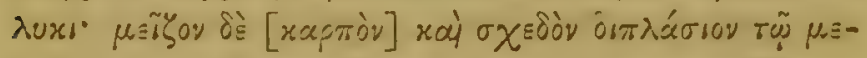

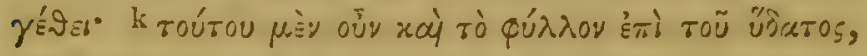

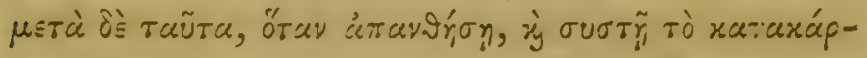

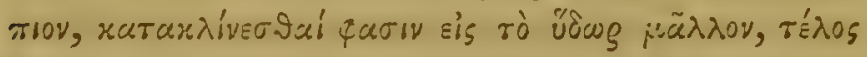

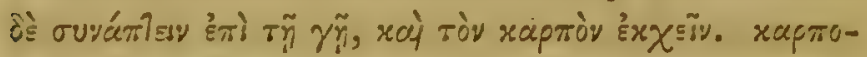

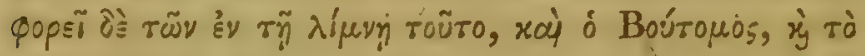

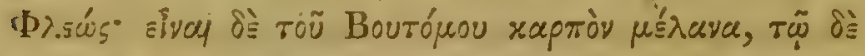

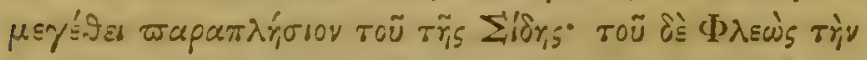

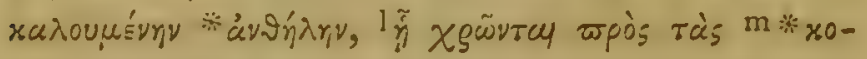

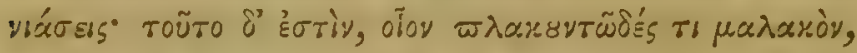

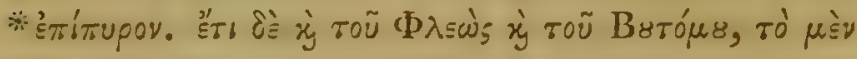

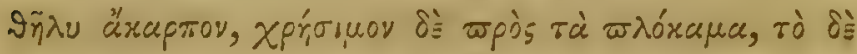

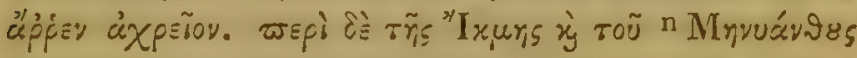

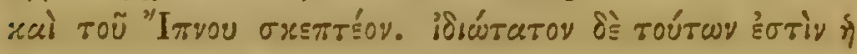

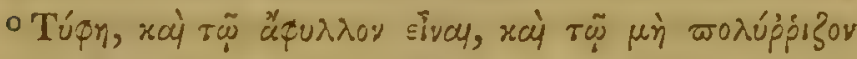

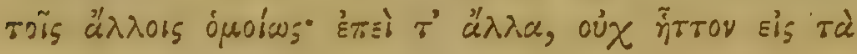

h rais pí̧al;, Bod.

1 a Bod. Bod.

$$
\text { สขอุณ̃. Bod. }
$$

$k$ roṽrs Scal. n Mrvávaิeus Bod:

- Típri, 


\section{MEPI $\Phi \Upsilon T \Omega N ~ I \Sigma T O P I A \Sigma T O \Delta^{\prime} . \quad I \delta I$}

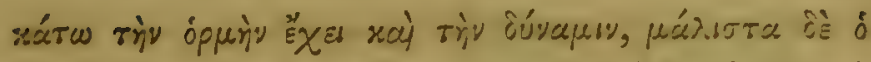

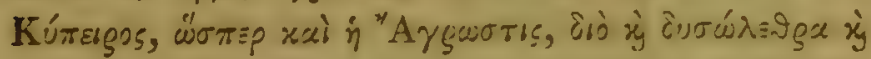
รаи̃т

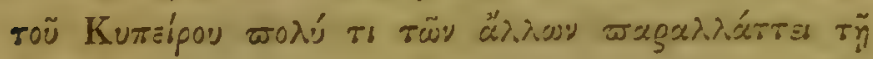

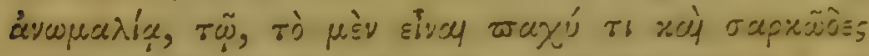

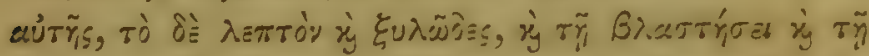

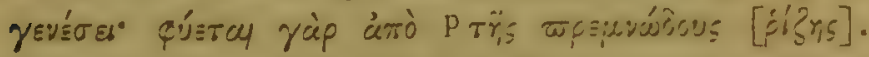

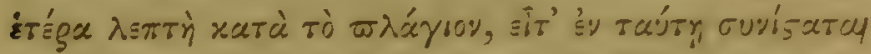

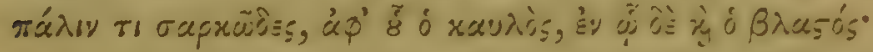
aे

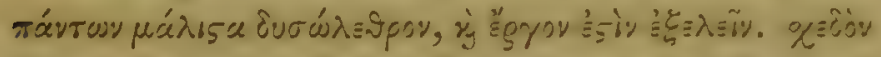

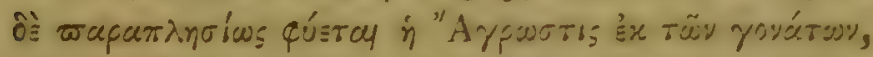

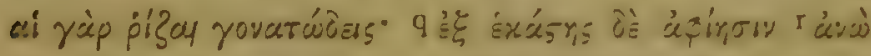

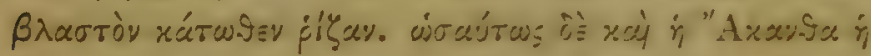

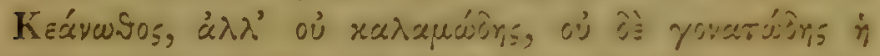
ṕl’

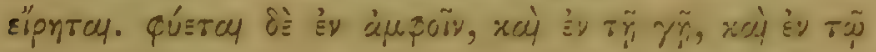

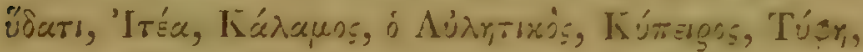

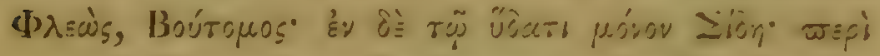

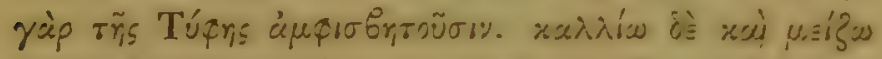

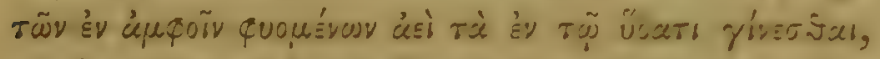

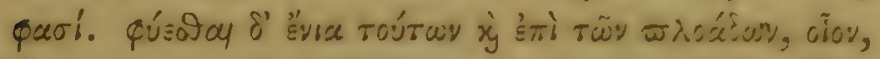

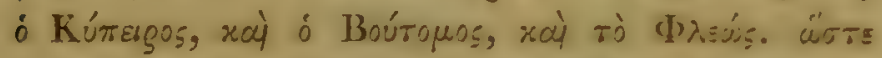

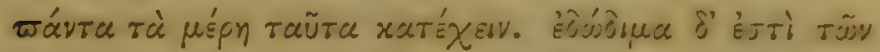

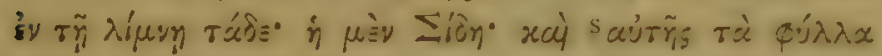

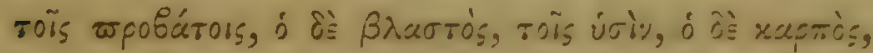

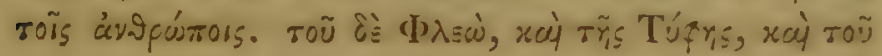

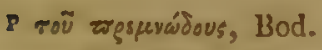

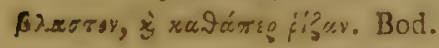

qุ irर́oray Bod. I àvá.

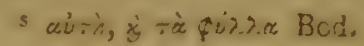




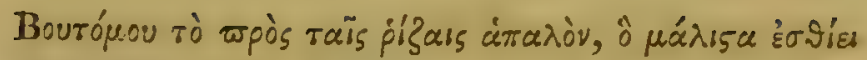

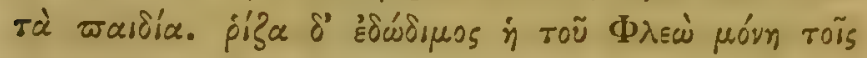

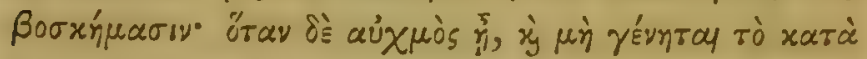

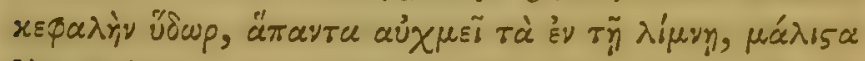

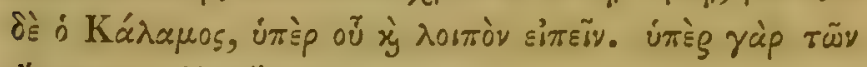

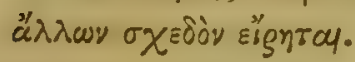

\section{CAP. XII.}

Arundinis, et Canne Species.

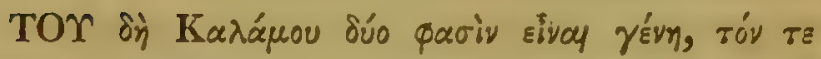

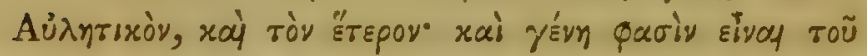

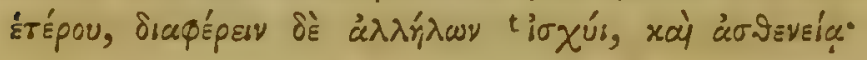

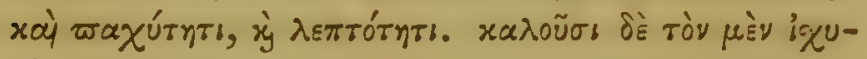

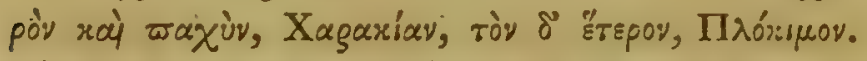

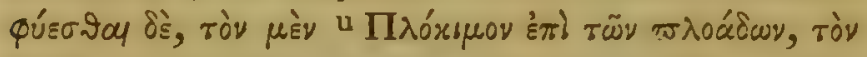

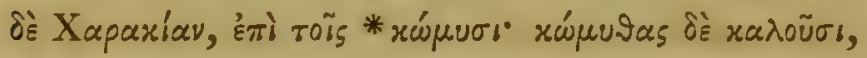

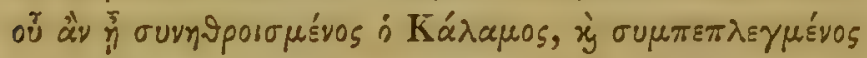

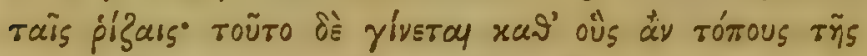

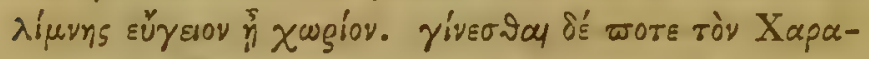

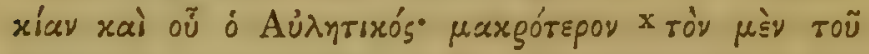

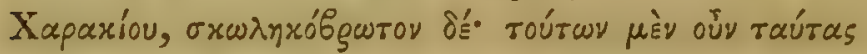

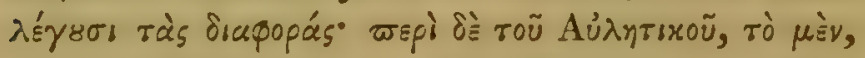

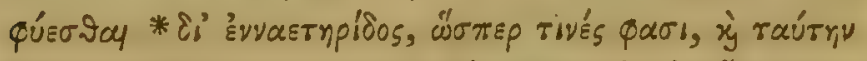

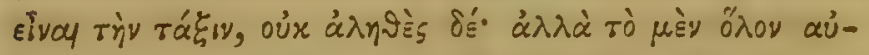

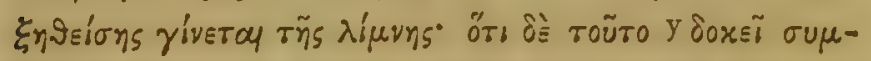

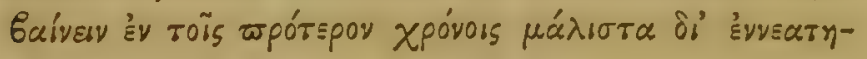

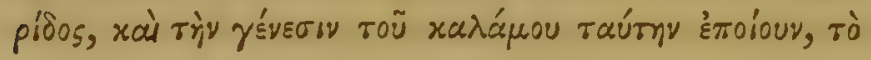

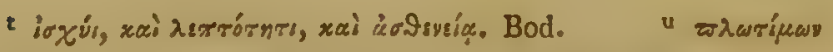

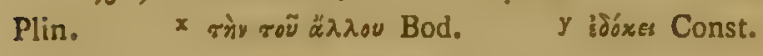




\section{ПEPI ФบT $\Omega N$ I TOPIA TO $\Delta^{\prime} . \quad$ I $\delta_{3}$}

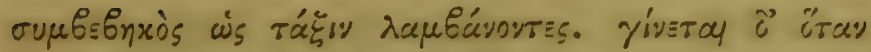

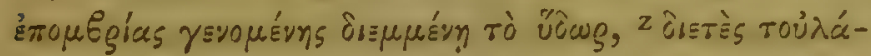
X

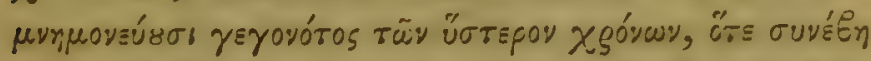

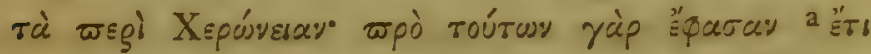


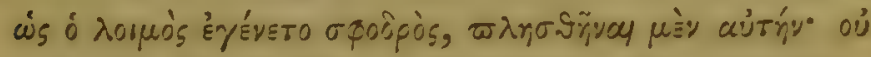

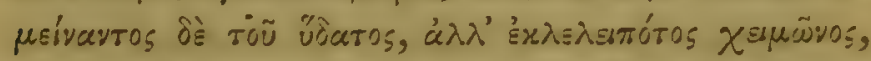

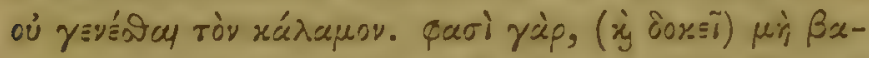

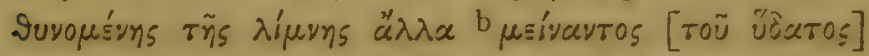

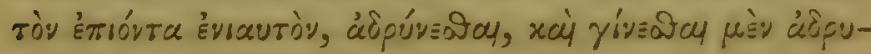

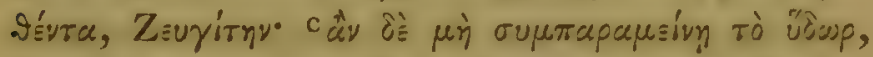

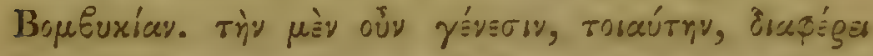

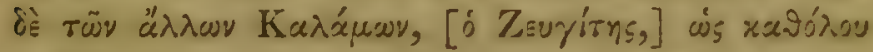

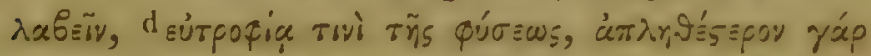

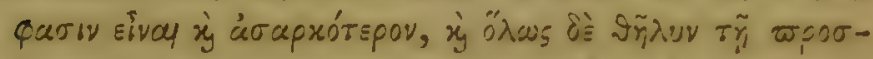

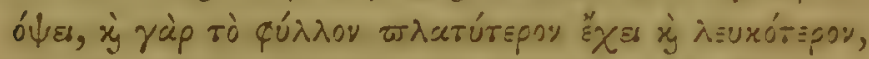

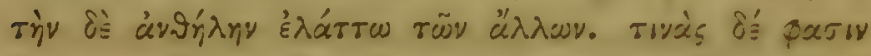

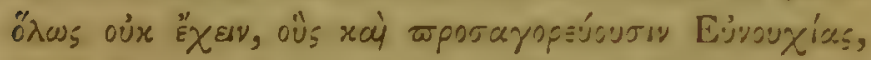

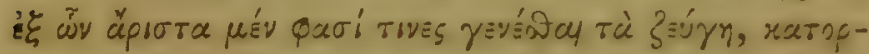

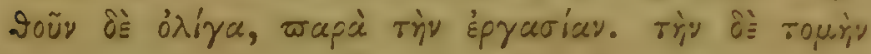

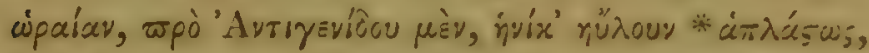
نं $\pi^{\prime}$ 'A

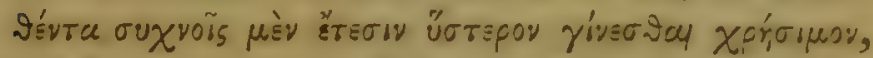

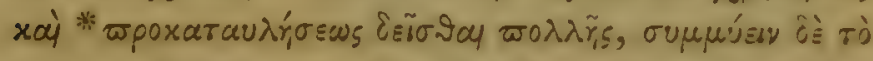

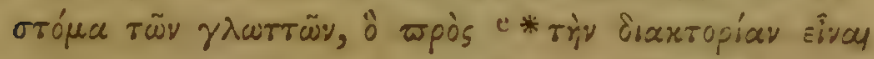

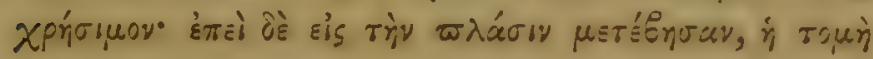

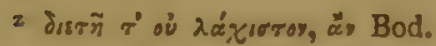

b pesivaysss Bod.

- Siarogiar Bas.
2 चxเian รัธท Theod. 1) ảrgopia Ald.

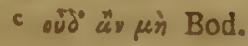




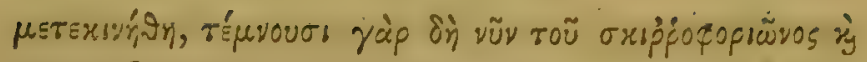

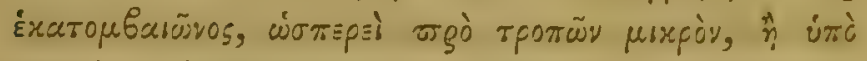

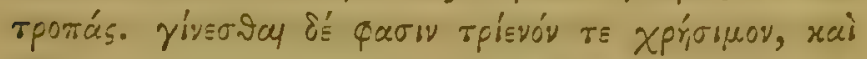

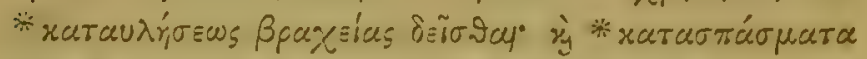

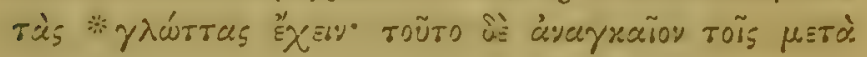

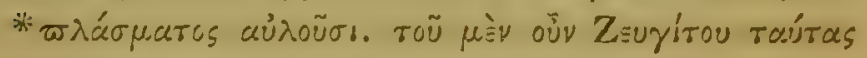

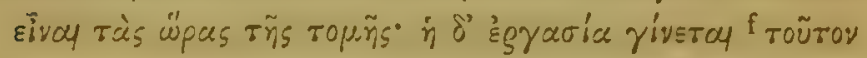

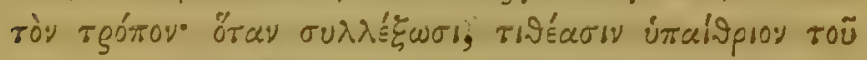

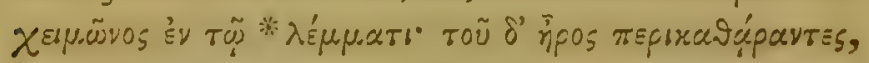

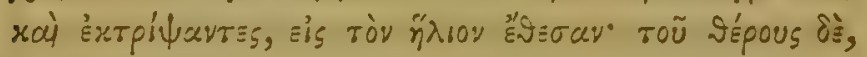

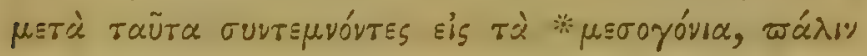

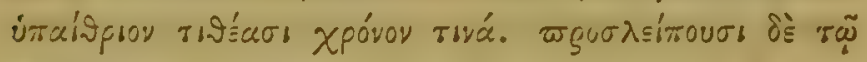

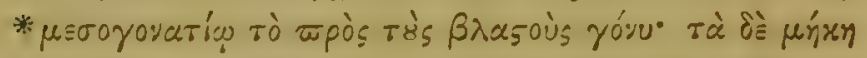

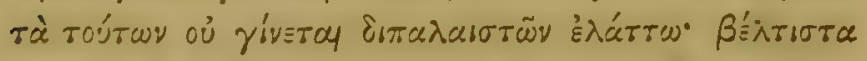

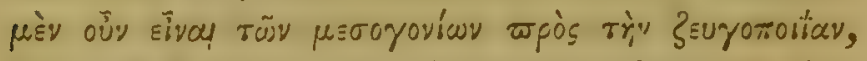

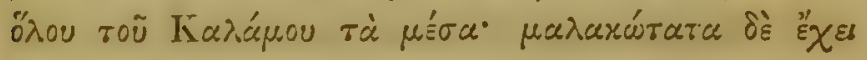

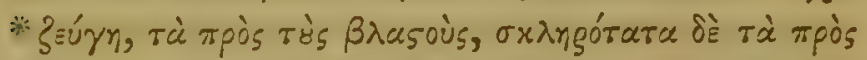

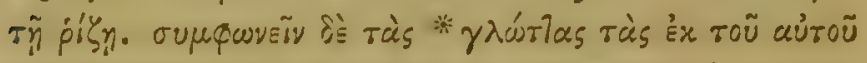

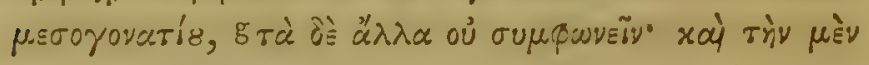

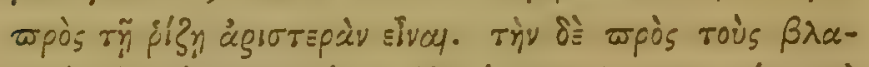

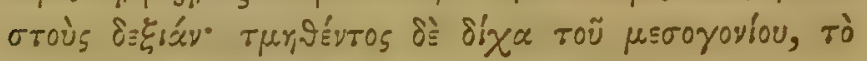

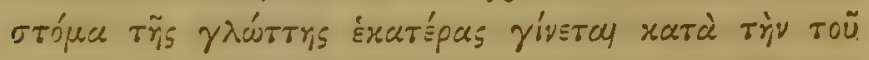

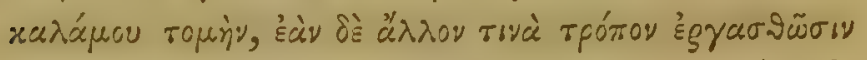

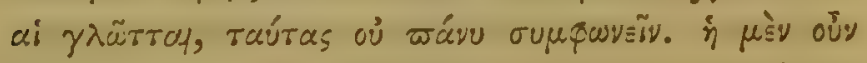

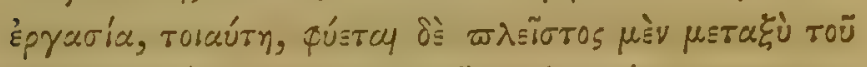

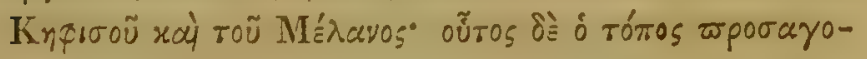

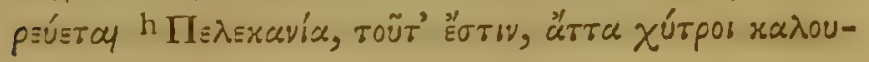

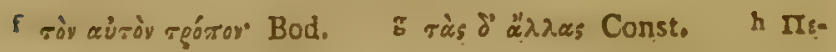
dixavixe, Ald. 


\section{ПЕPI TMT $\Omega N$ ISTOPI.A TO $\Delta^{\prime} . \quad$ I 85}

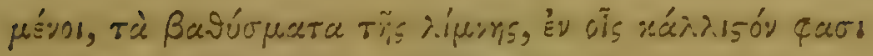

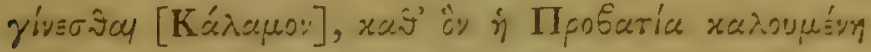

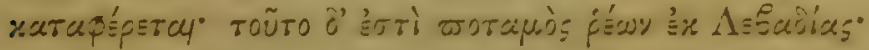

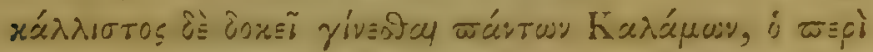

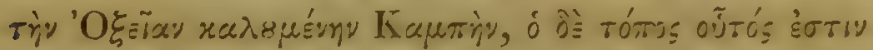

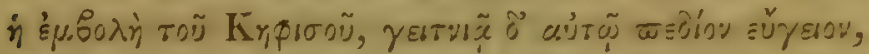

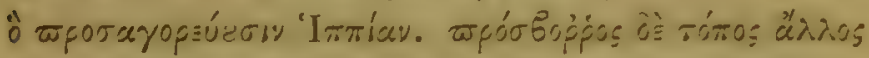

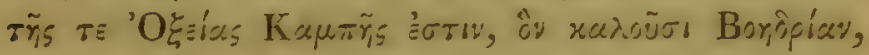

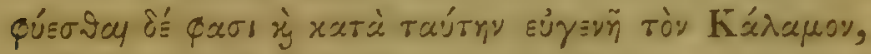

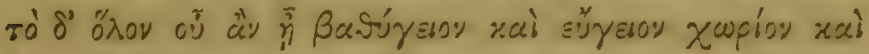

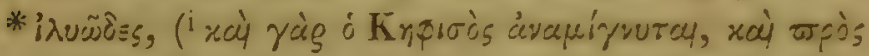

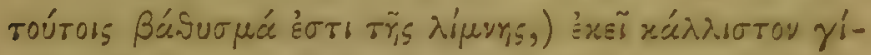

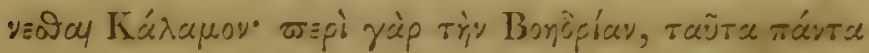

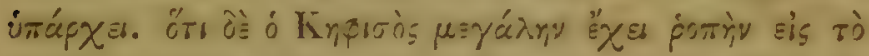

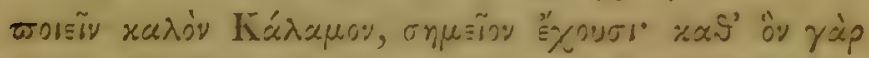

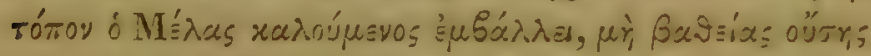

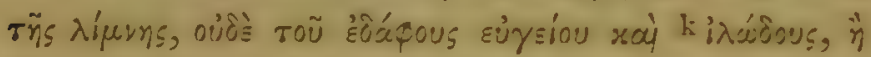

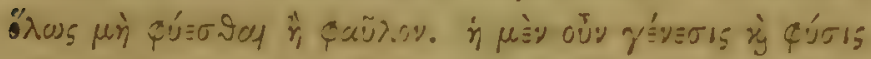

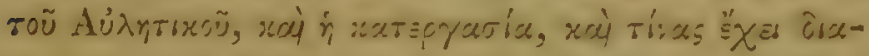

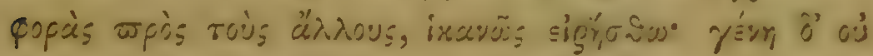

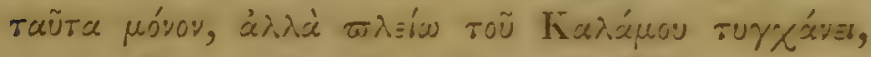

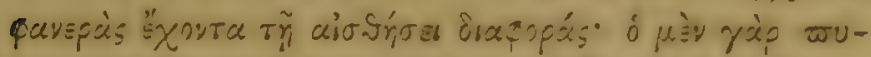

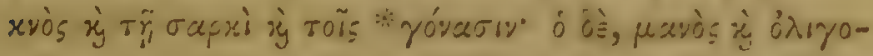

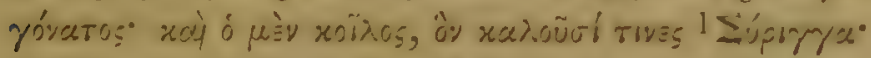

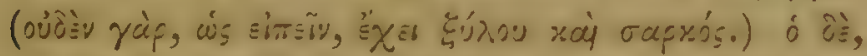

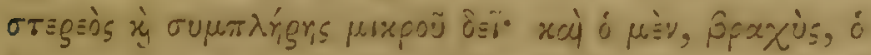

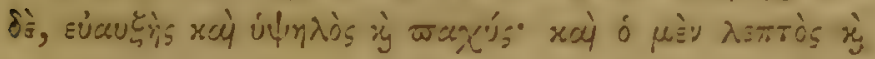

i : Ksprơòs Ald. Bas. Vid. not. ad fin. libri. \& irwônovis Bad. I Suergriav Diosc. 


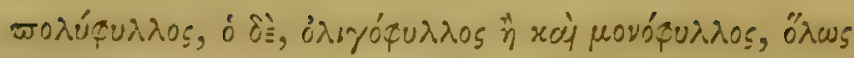

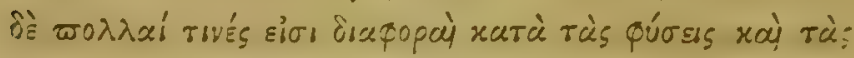

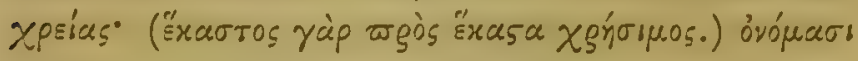

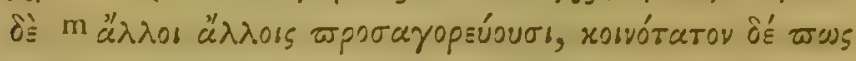

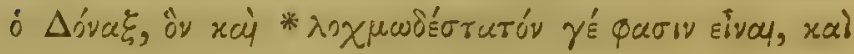

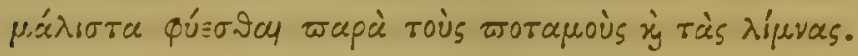

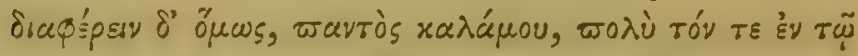

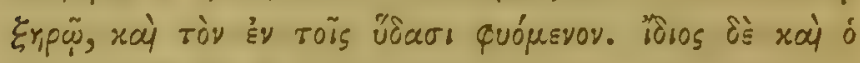

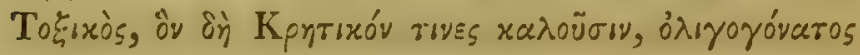

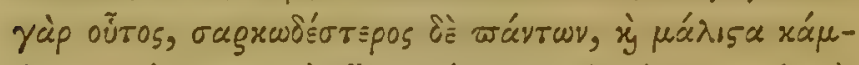

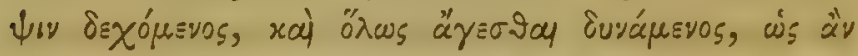

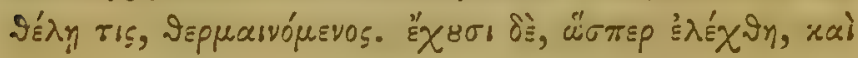

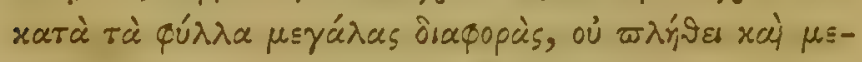

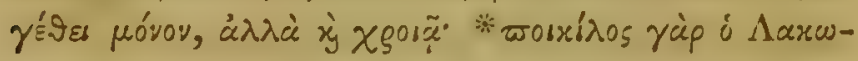

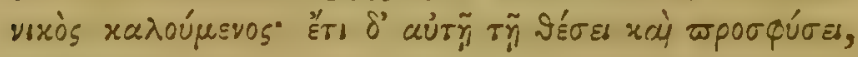

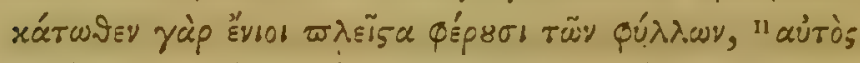

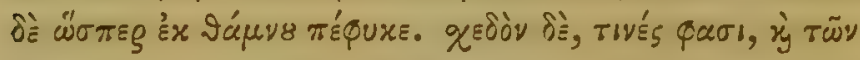

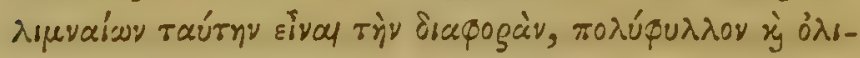

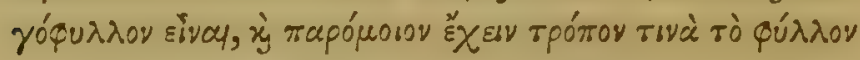

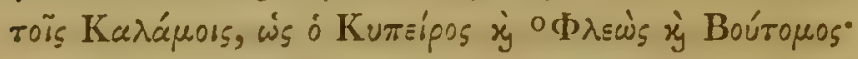

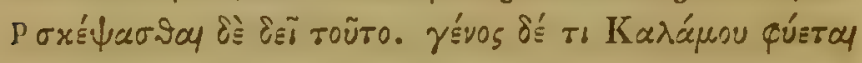

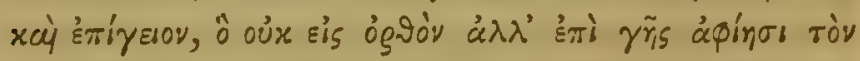

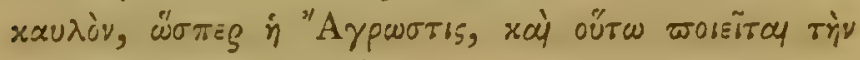

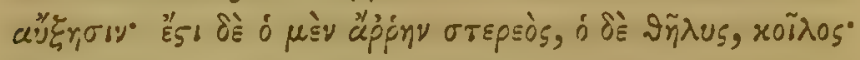

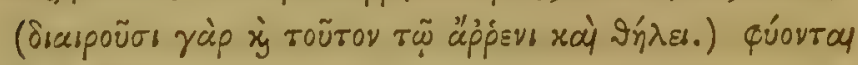

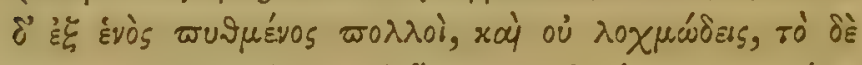

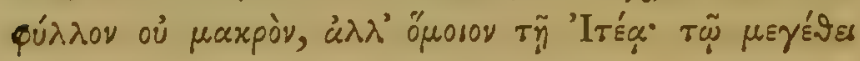

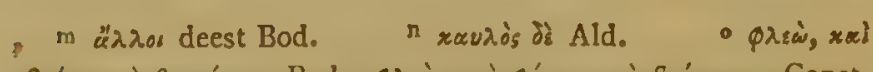

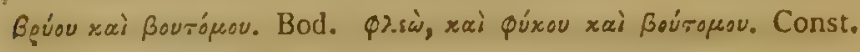

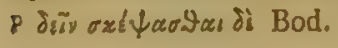




\section{MEPI ФTT $\Omega N$ ISTOPIAS TO $\Delta^{\prime} . \quad$ I87}

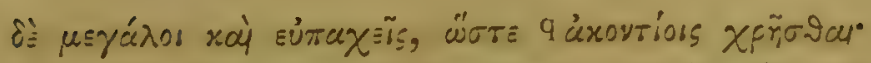

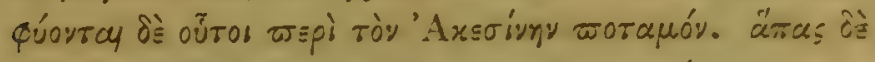

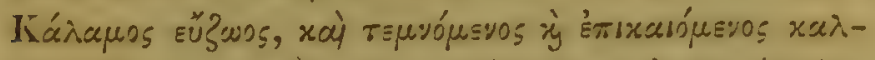

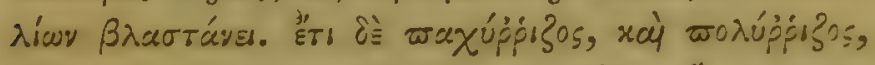

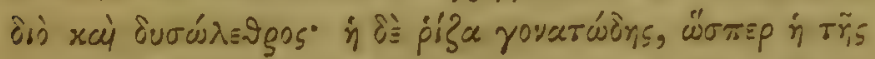

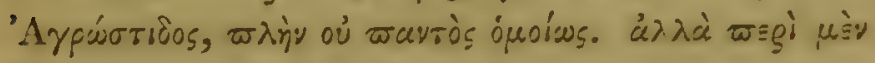

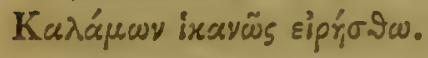

\section{CAP. XIII.}

Scheni Spec, et Scirpi, $L$.

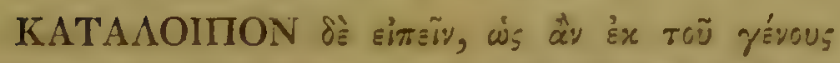

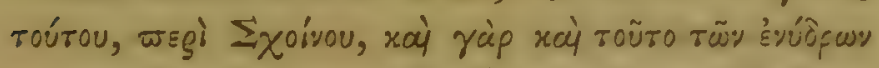

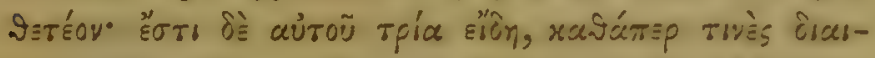

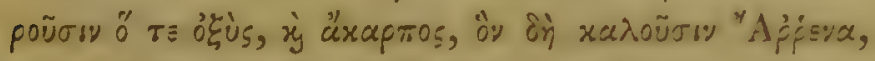

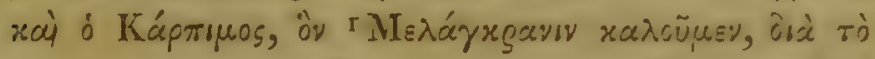

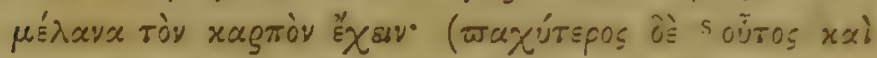

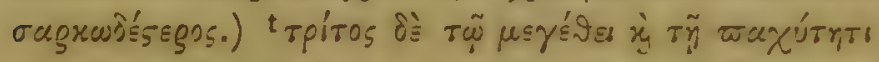

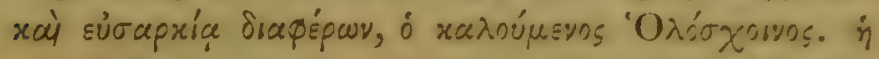

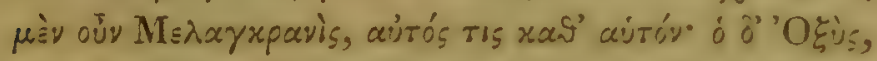

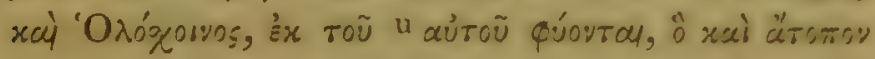

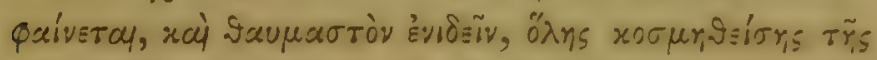

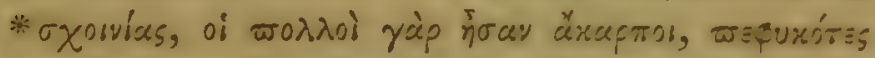

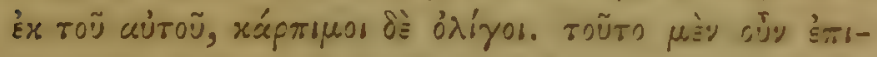

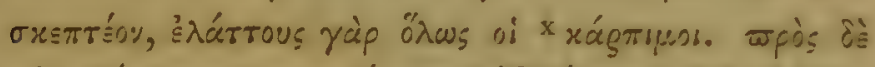

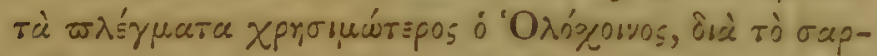

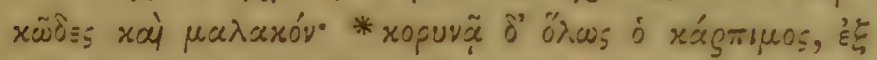

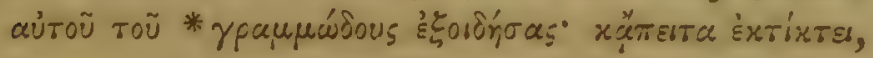

q àxarious Plinius? Vid. not. ad fin. libri. vispì Bod. - roúrou Const.

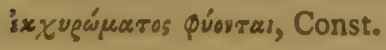




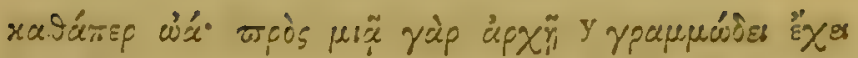

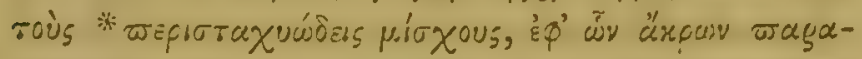

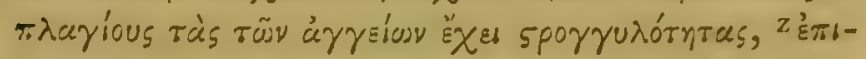

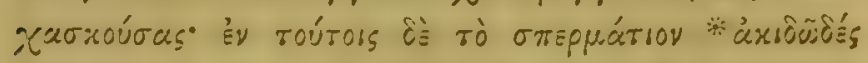

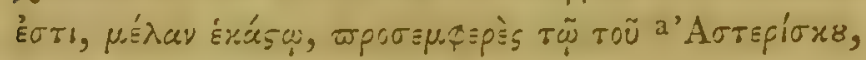

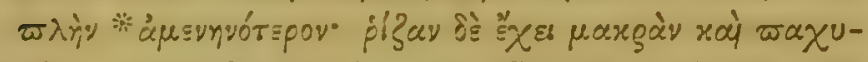

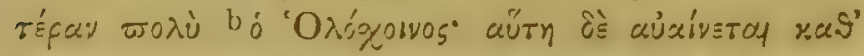

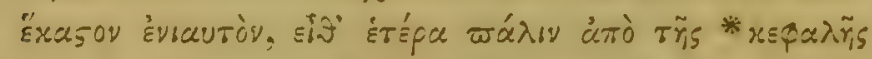

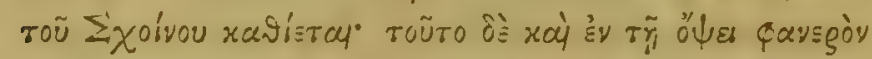

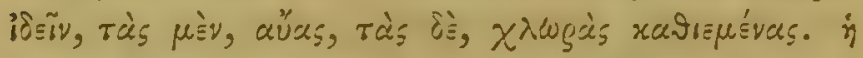

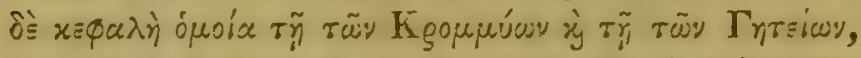

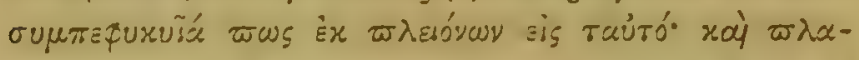

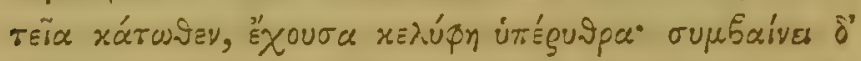

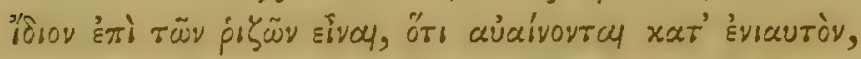

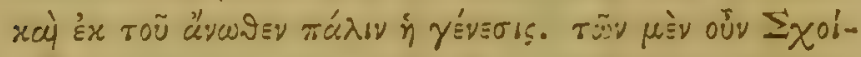

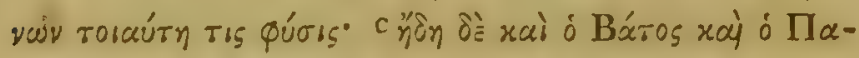

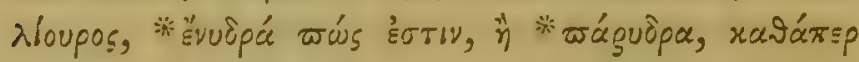

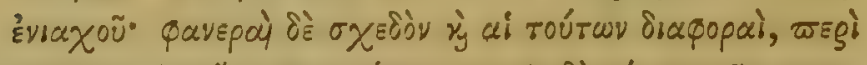

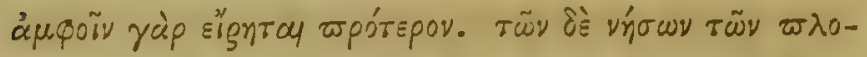

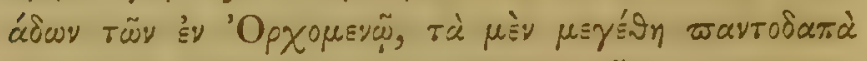

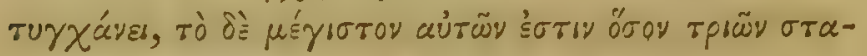

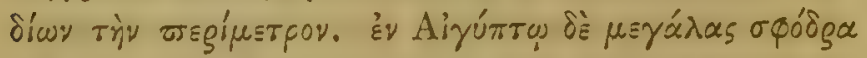

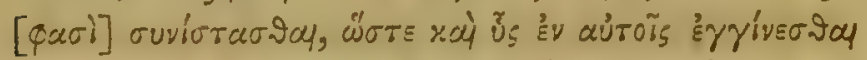

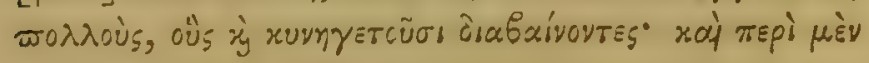

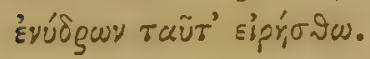

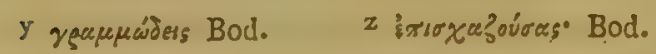

$2 \dot{\alpha} \sigma \tau t-$ éixov, Const. b roũ rxolvos. Bod.

c sisn Theod. 


\section{MEPI INTSN ISTOPIA TO $\Delta^{\prime} . \quad 189$}

\section{CAP. XIV.}

Duratio Arborum.

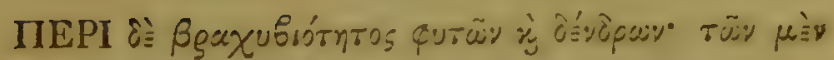

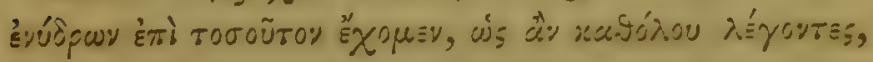

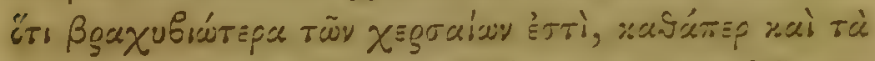

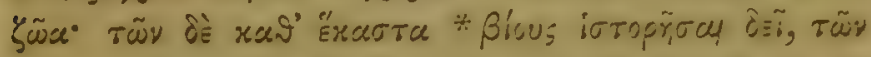

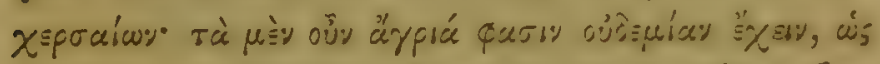

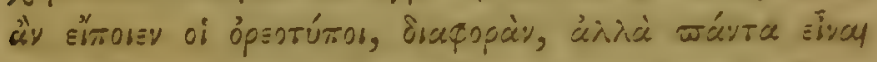

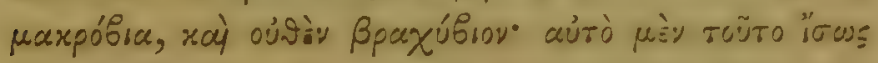

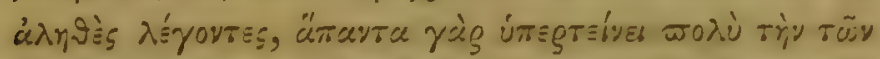

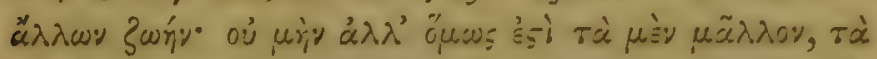

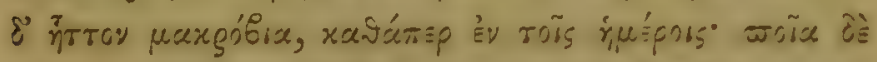

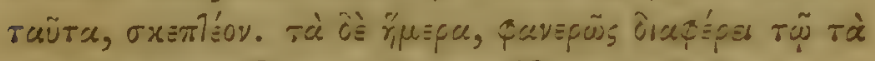

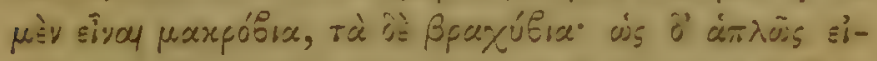

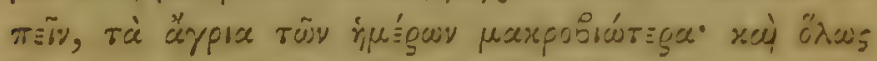

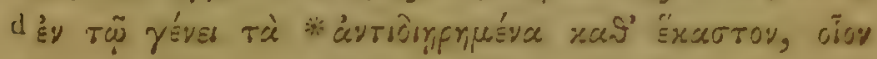

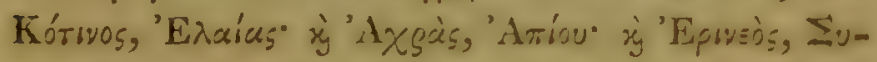

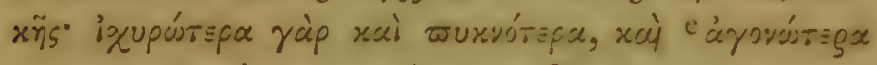

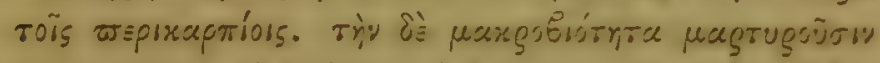

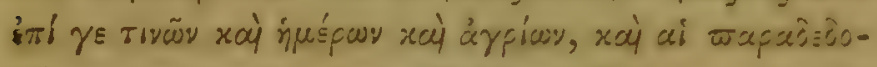

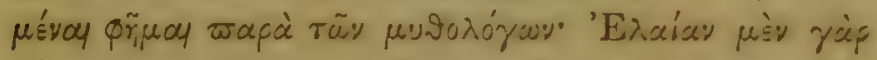

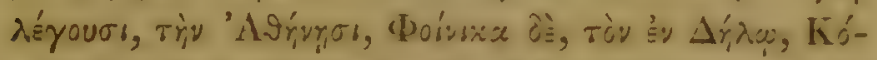

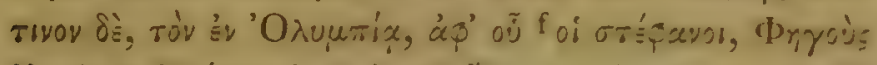

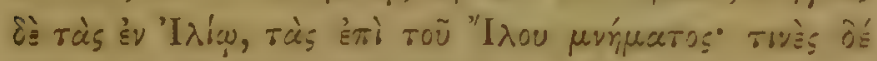

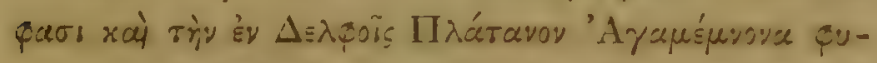

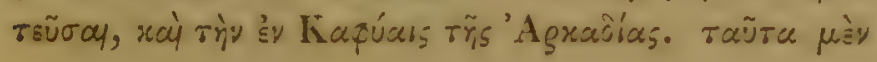

d iv deest Bod. e éyovurrsea. Vid, not, ad finem libri. if sorípavos, Bod. 


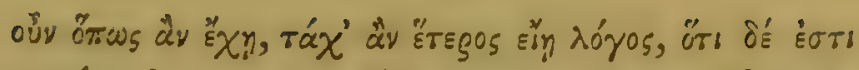

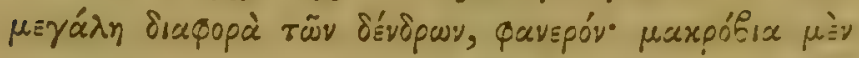

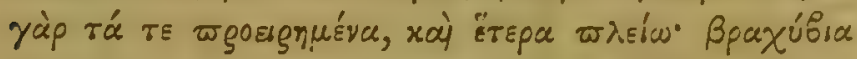

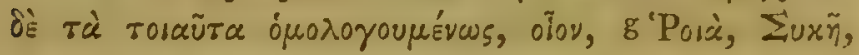
Min的

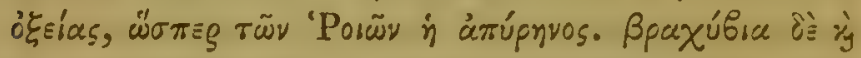

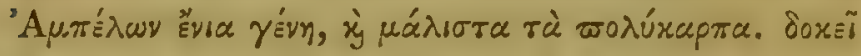

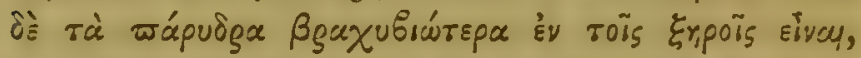

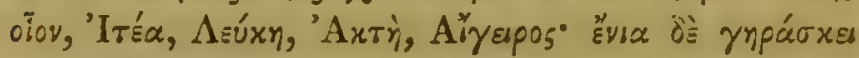

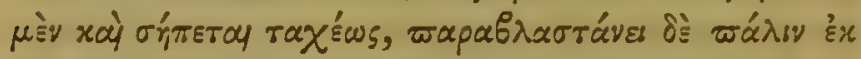

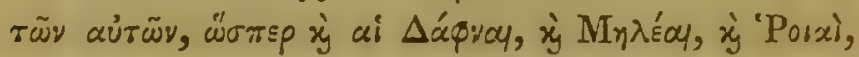

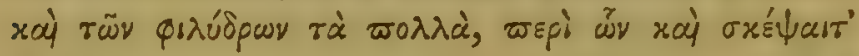

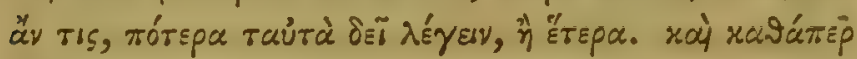

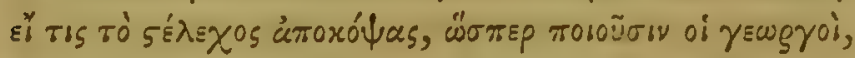

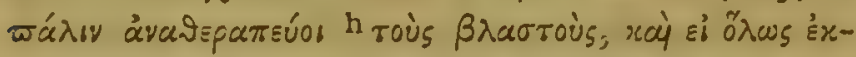

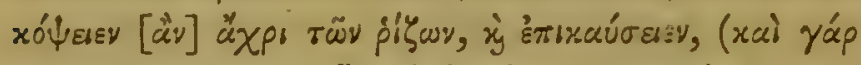

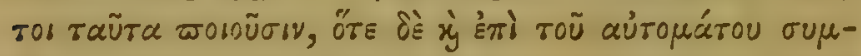

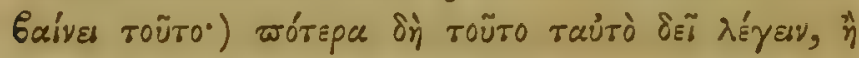

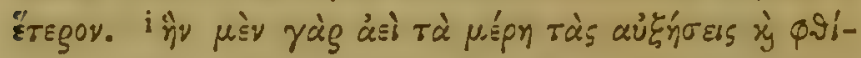

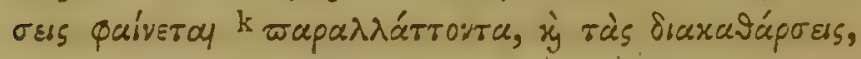

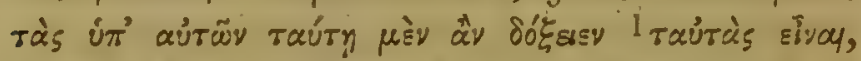

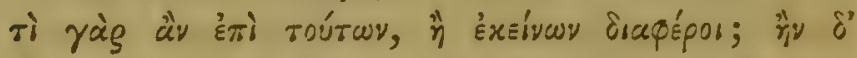

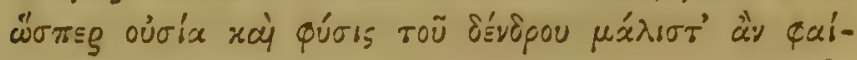

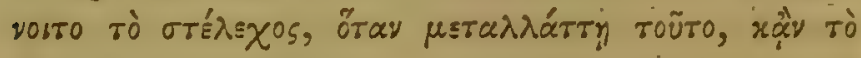

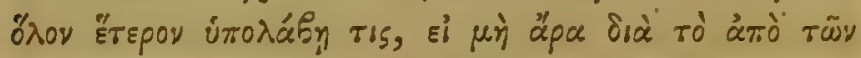

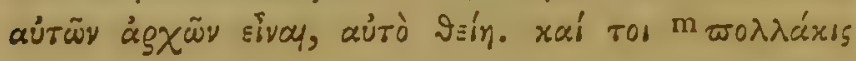

r "Pox, Ald.

h siácrarrov:, Bod.

i मे $\mu$ iे Bod,

* wapariárrousa, Bod.

1 ravirò Bod.

m च $37 . \lambda$ à

xai Bod. 


\section{IIEPI TMT $\Omega N$ ISTOPIAS TO $\Delta^{\prime} . \quad$ IgI}

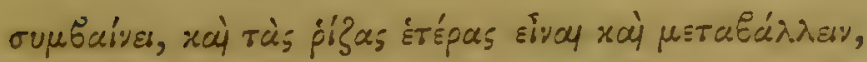

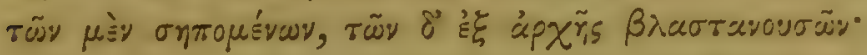

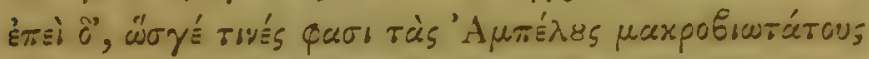

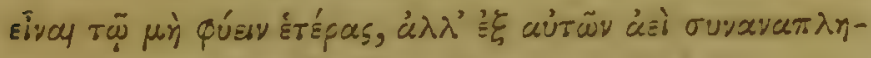

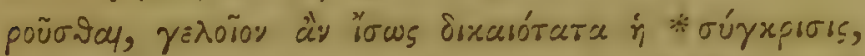

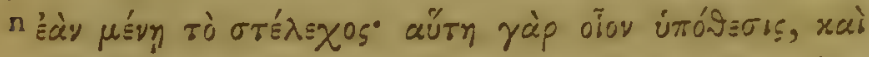

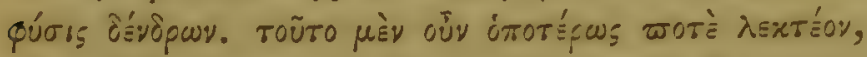

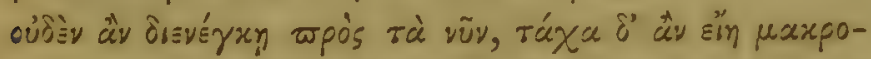

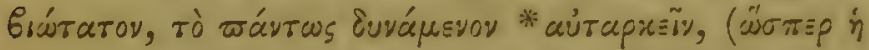

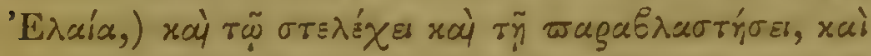

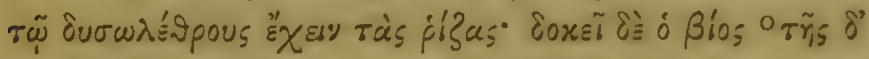

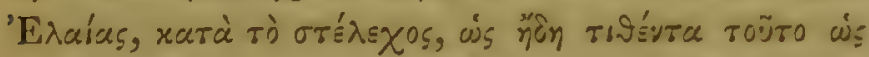

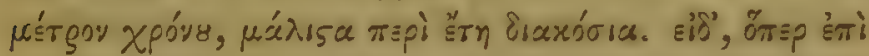

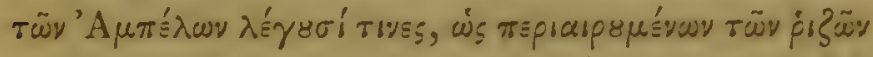

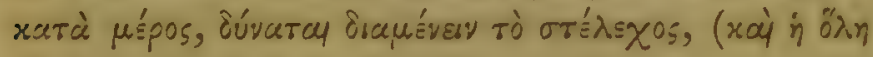

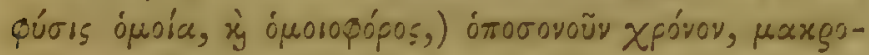

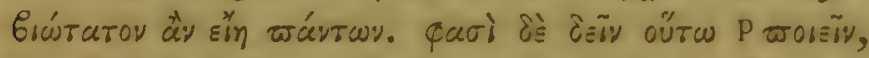

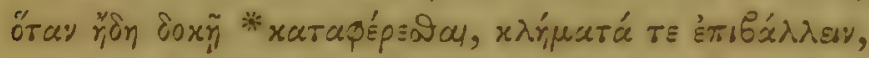

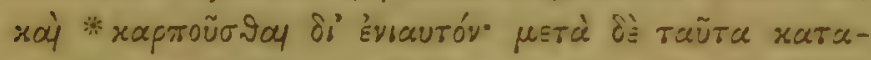

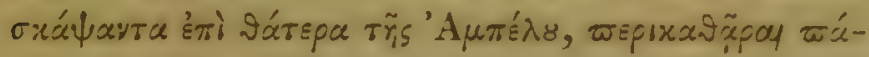

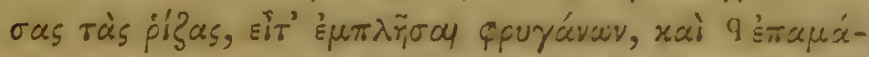

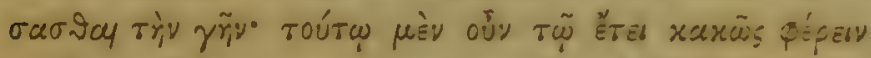

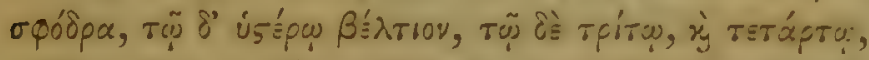

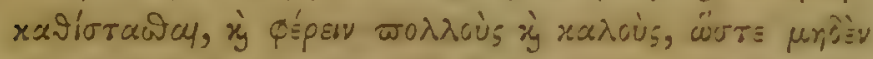

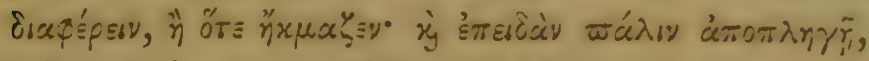

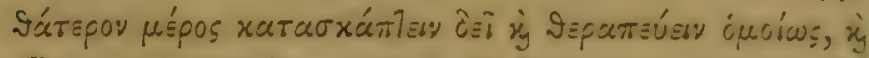

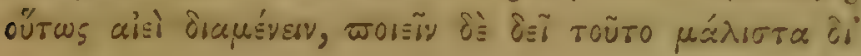

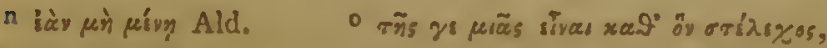

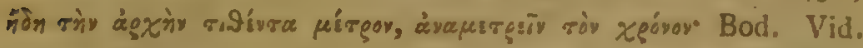

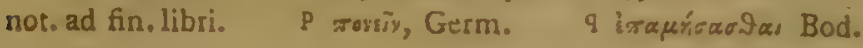




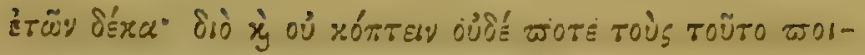

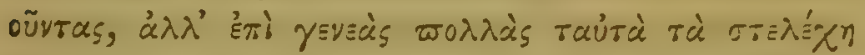

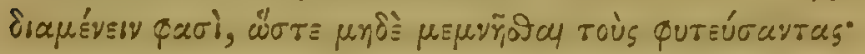

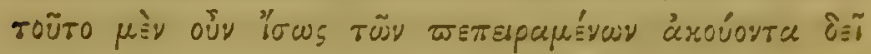

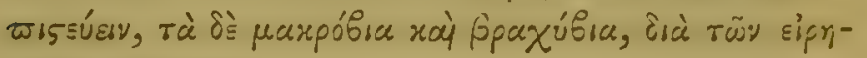

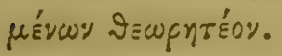

\section{CAP. XV.}

De Morbis Arborum.

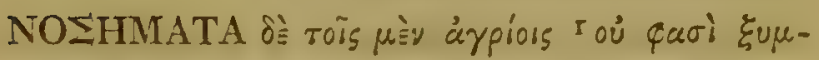

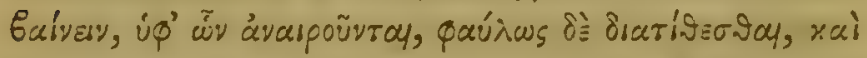

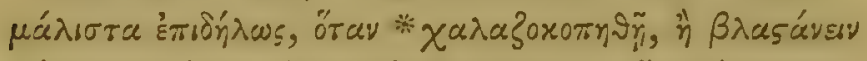

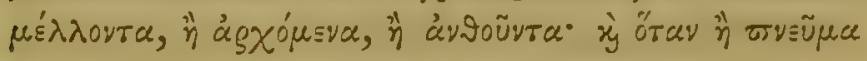

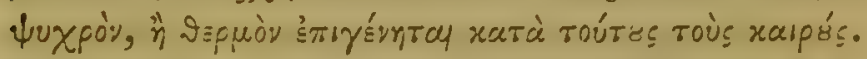

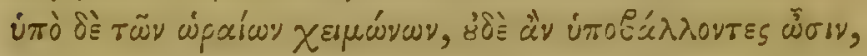

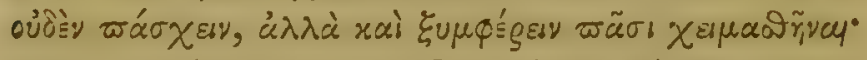

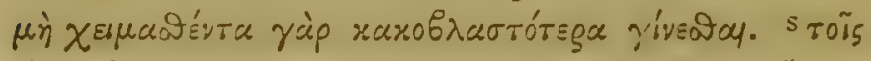

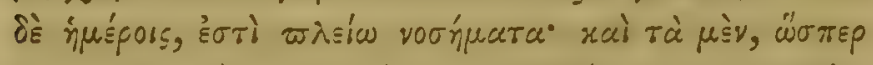

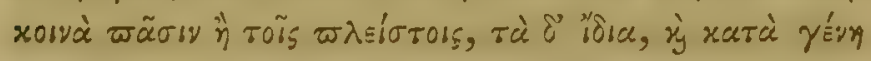

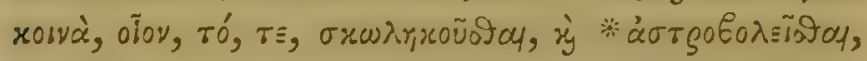
xà ó

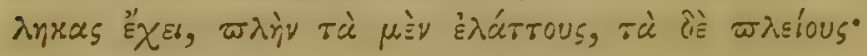

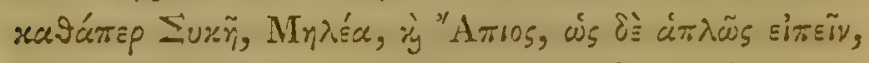

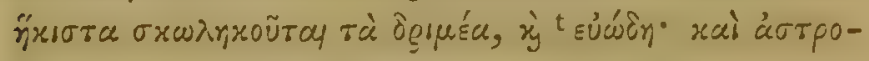

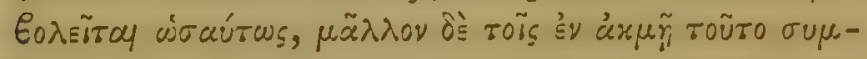

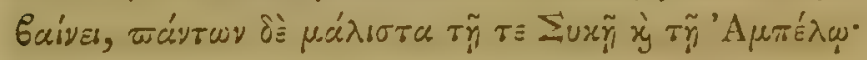

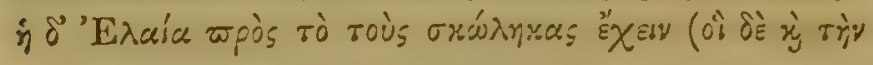

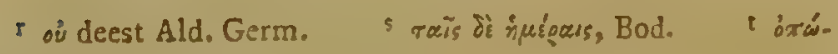
$\delta \eta^{\circ}$ Ald. 


\section{MEPI ФTTSN ISTOPIAS TO $\Delta^{\prime} . \quad 193$}

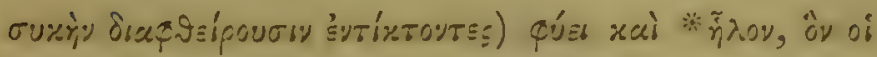

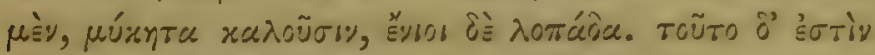

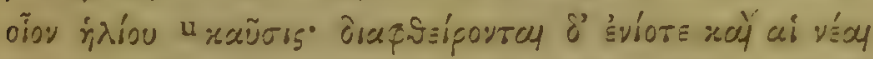

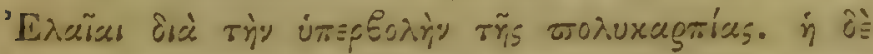

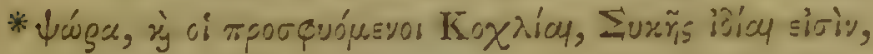

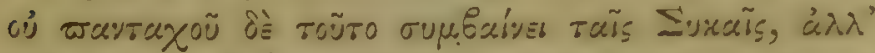

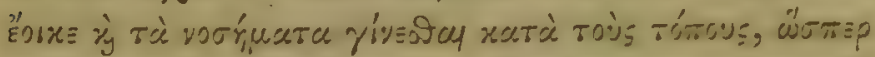

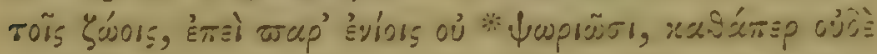

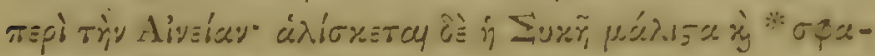

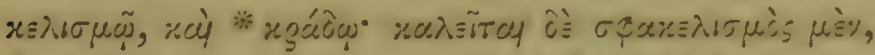

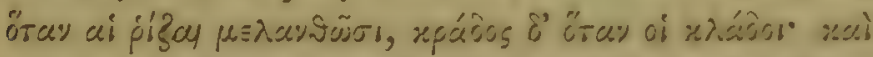

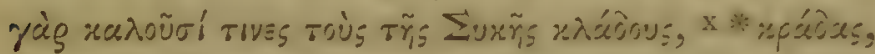

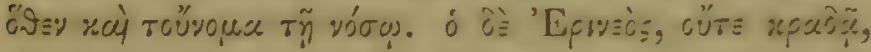

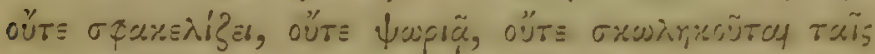

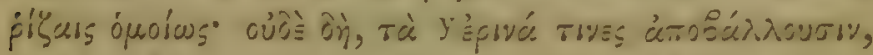

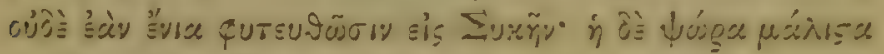

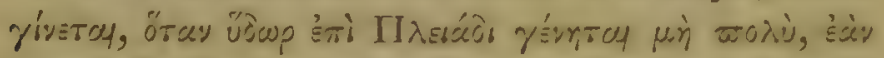

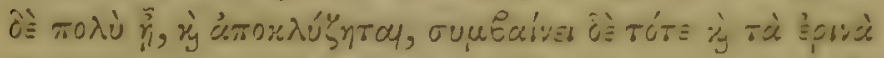

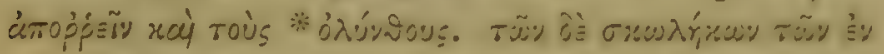

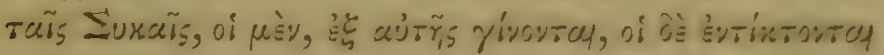

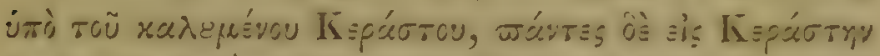

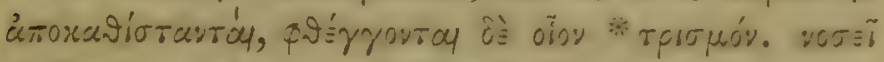

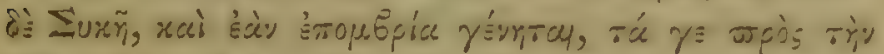

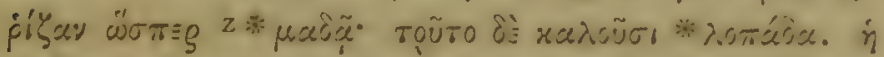

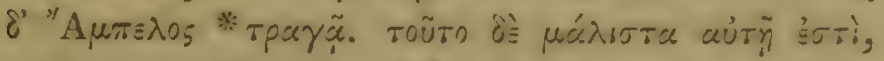

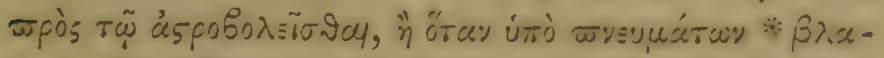

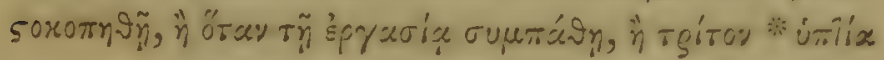

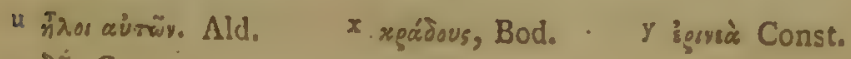
$z \mu v \delta \dot{\tilde{u}}$. Const. 


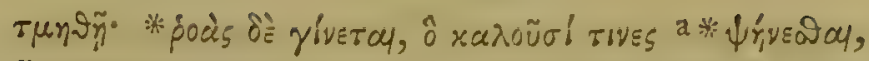

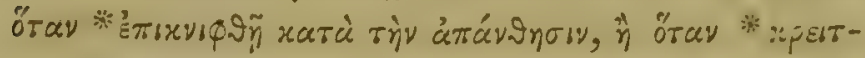

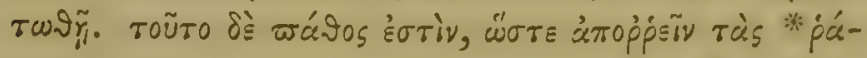

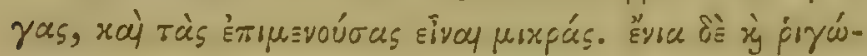

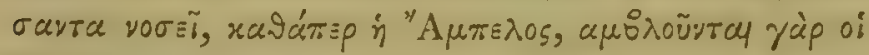

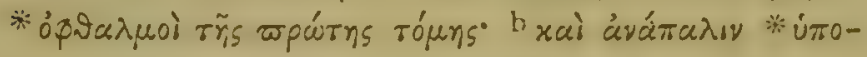

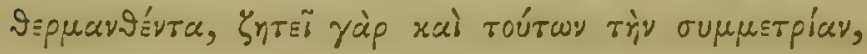

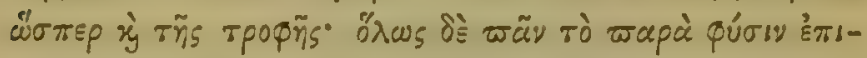

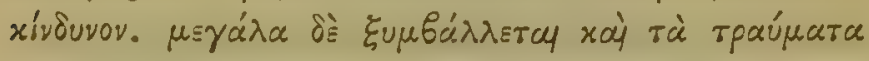

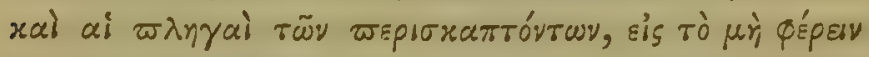

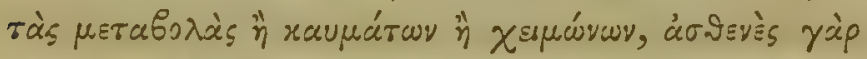

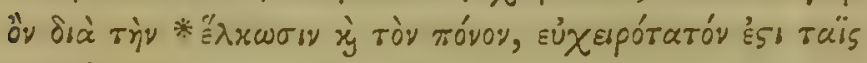

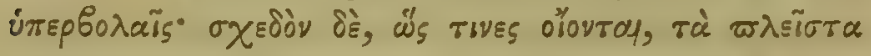

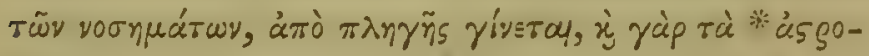

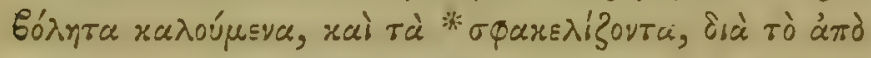

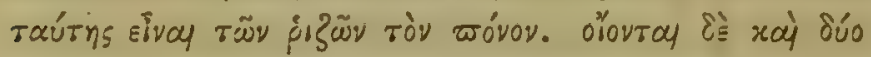

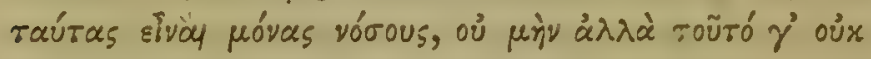

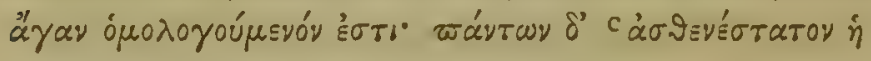

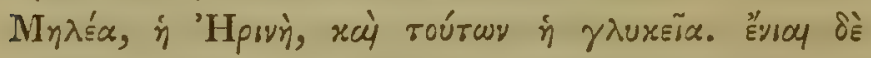

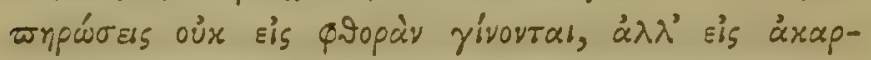

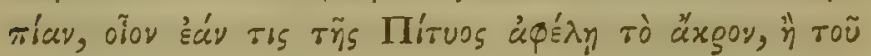

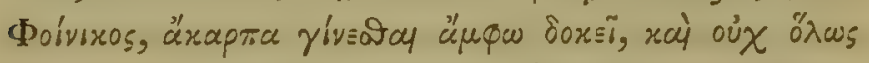

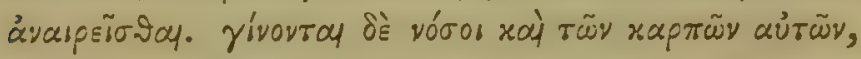

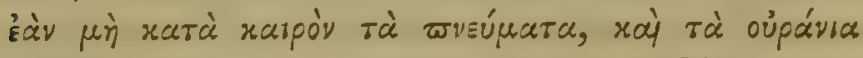

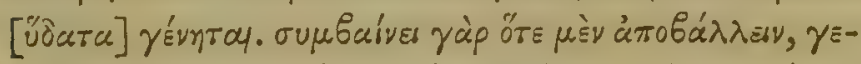

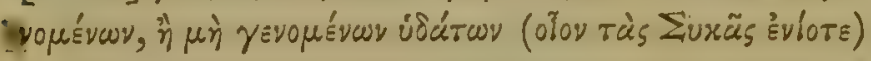

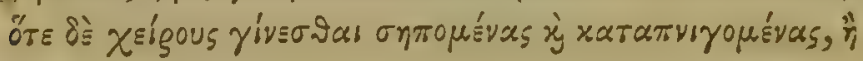

2 భivsescer, Bod.

- xai ซád,y Bod.

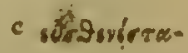

en Bod. 


\section{ПEPI $\Phi{ }^{\top} T \Omega N$ I}

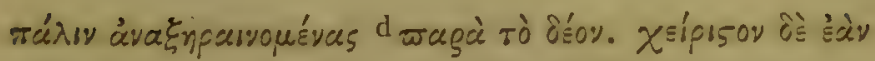

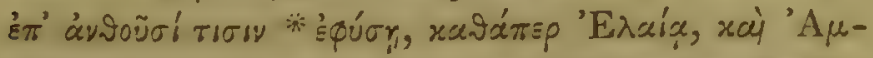

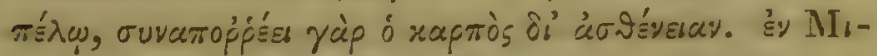

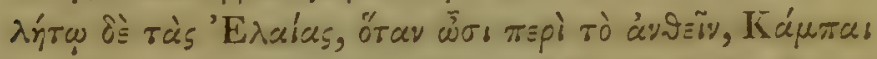

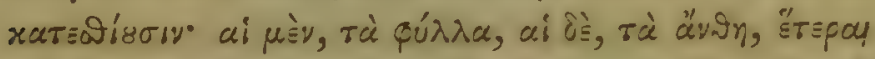

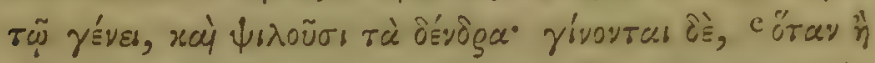

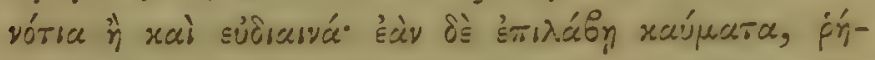

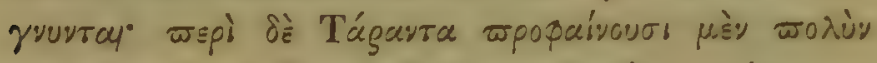

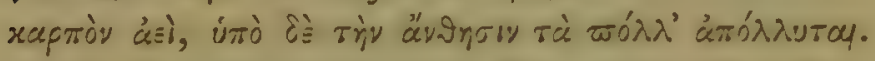

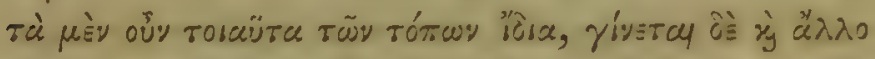

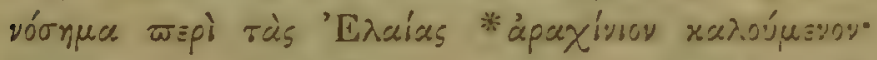

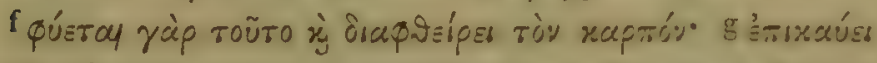

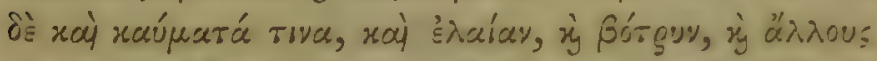

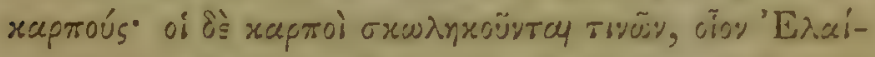

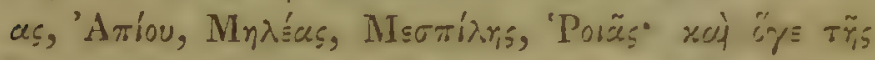

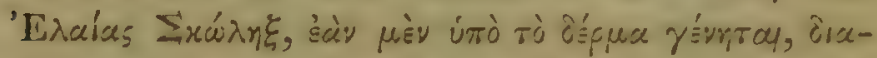
Q⿱宀⿻三丨日巾

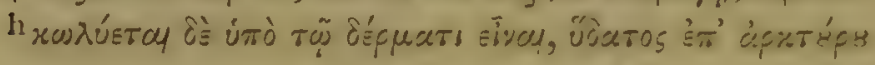

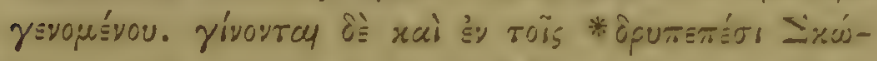

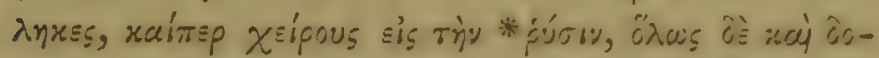

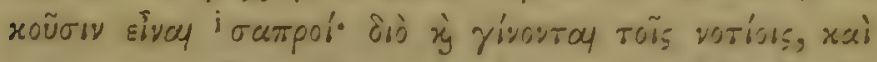

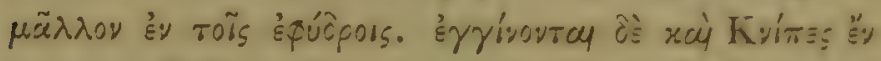

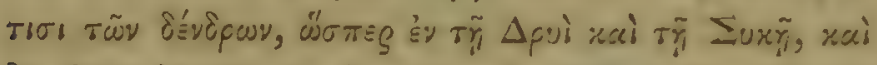

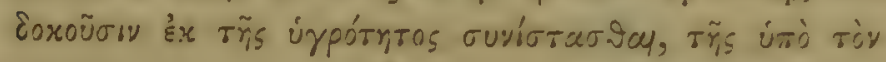

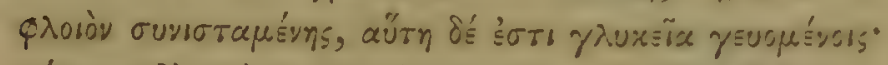

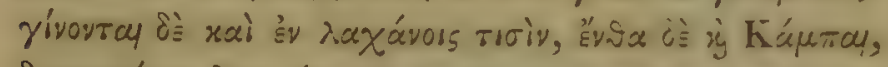

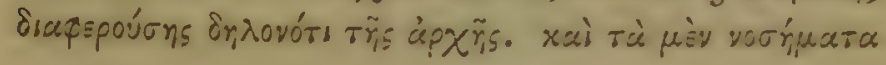

d $x a r \grave{a}$ rò Shov. Ald.

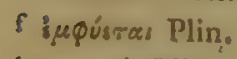

C "ัँ

it rompaí. Plin.
- ismaxáei Ald.

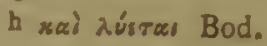




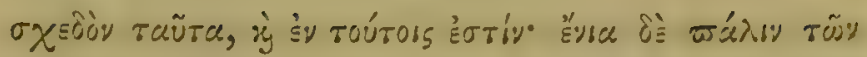

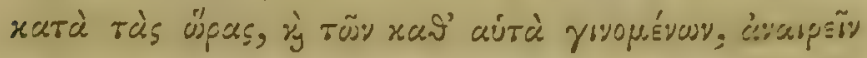

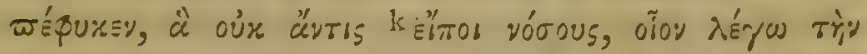

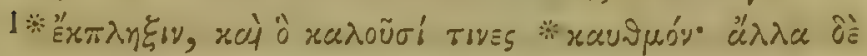

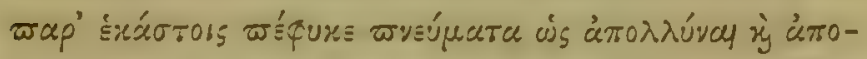

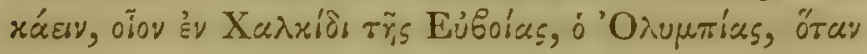

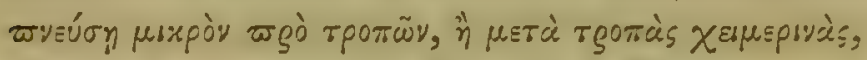

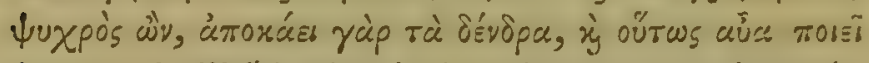

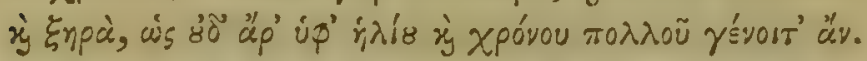

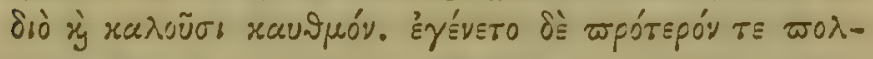

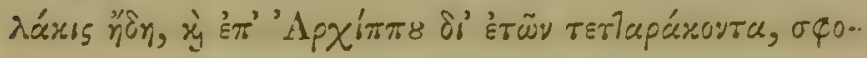

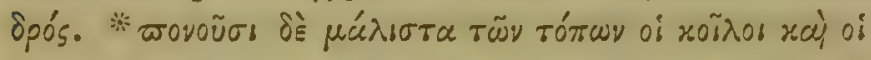

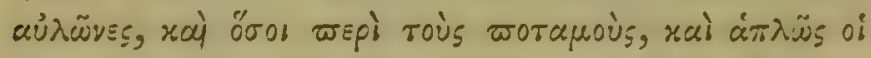

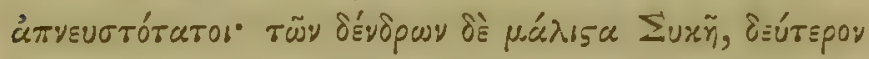

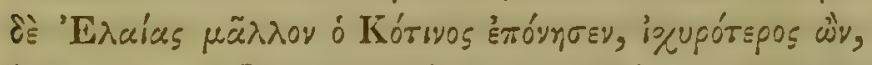

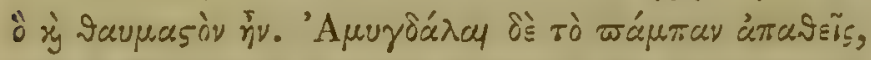

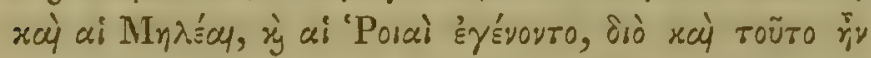

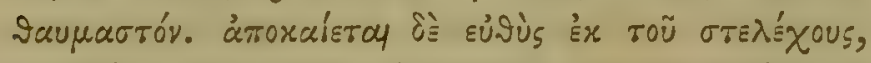

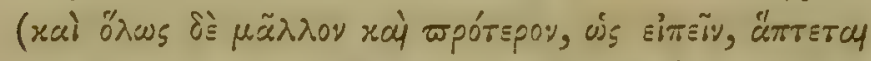

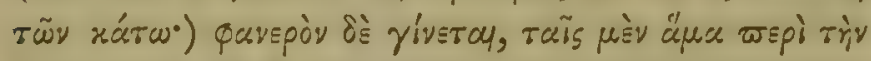

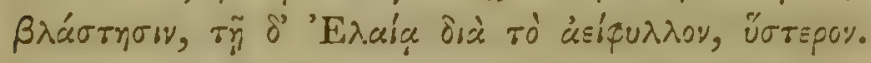

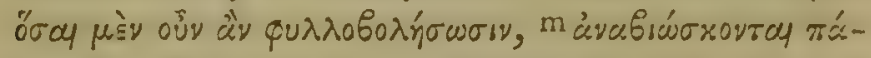

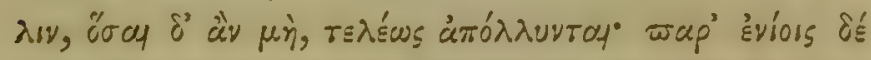

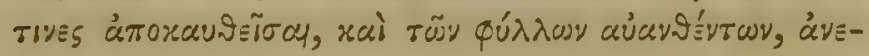

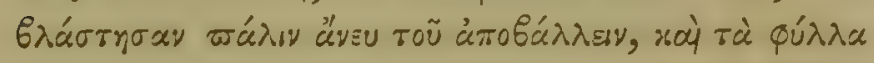

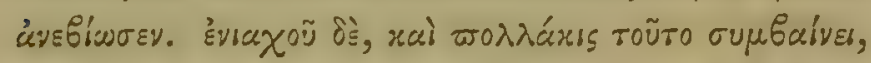

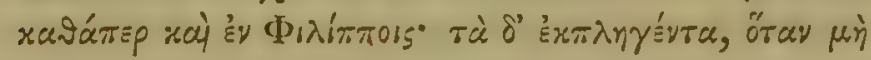

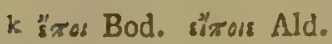
Gépúaroverar Ald.

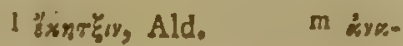




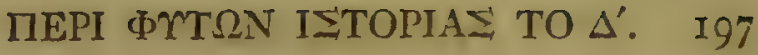

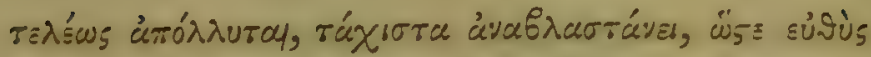

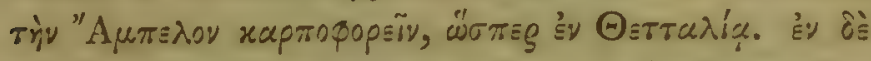

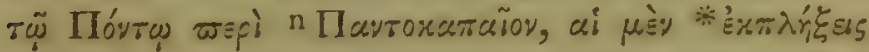

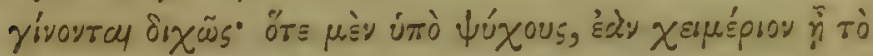

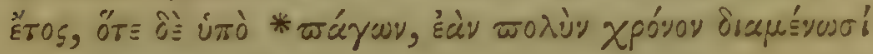

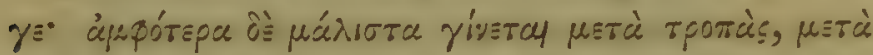

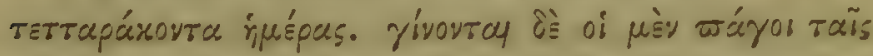

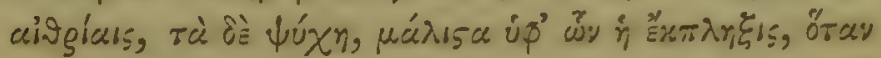

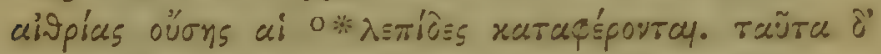

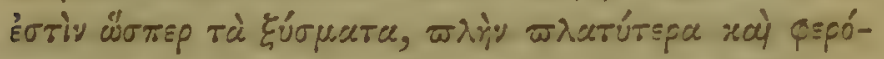

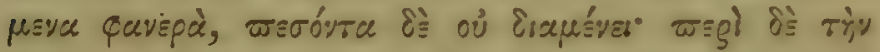

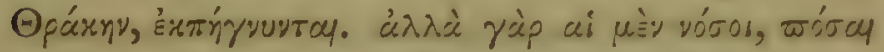

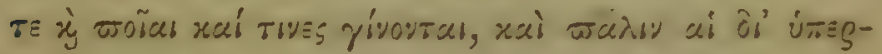

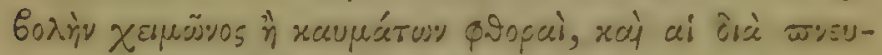

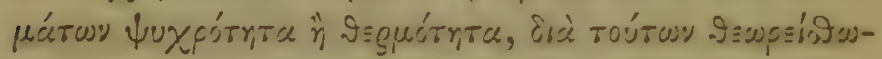

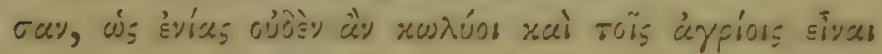

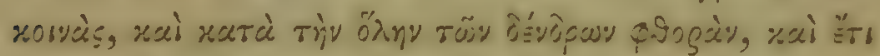

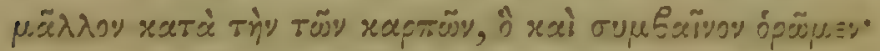

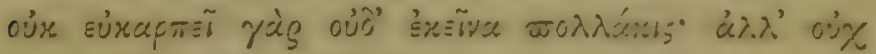

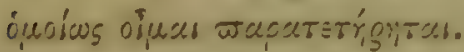

\section{CAP. XVI.}

De Vulneribus, et Amputatione Arborum.

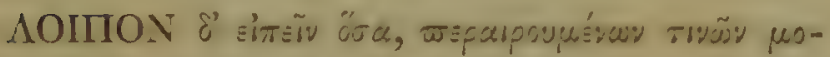

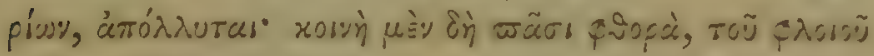

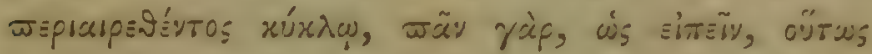

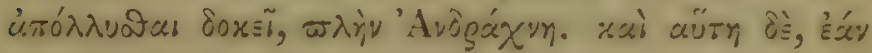

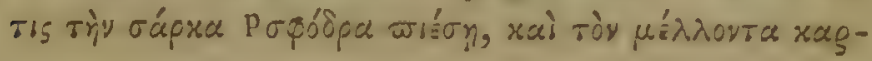

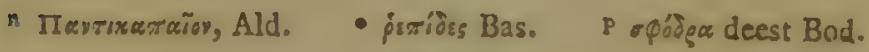




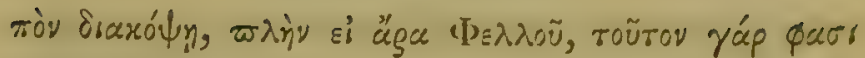

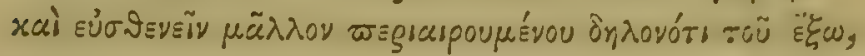

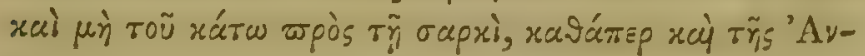

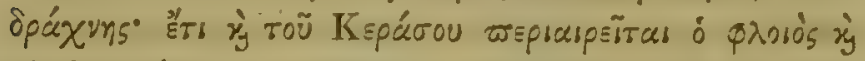

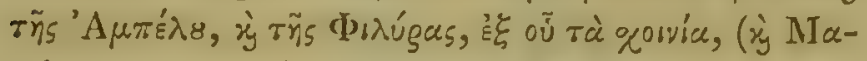

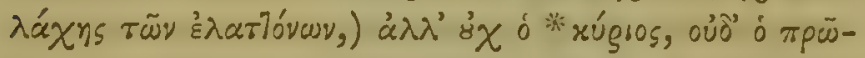

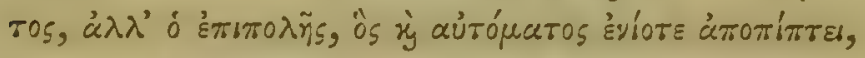

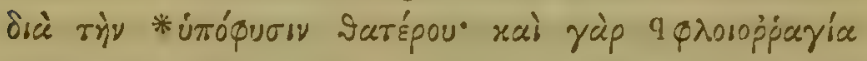

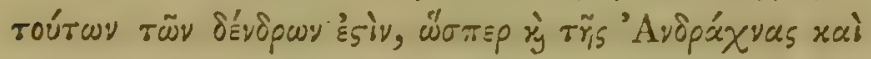

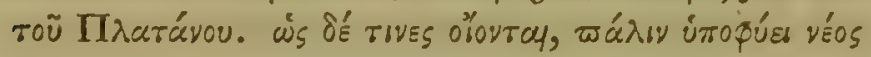

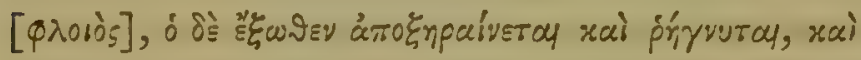

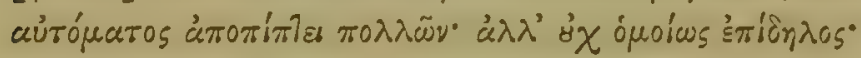

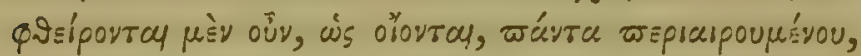

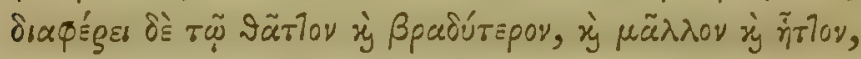

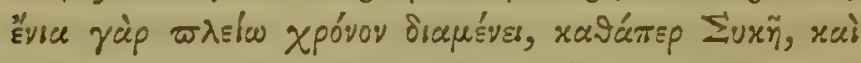

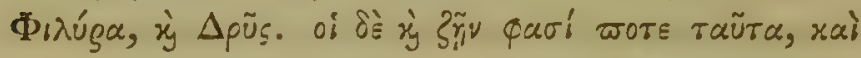

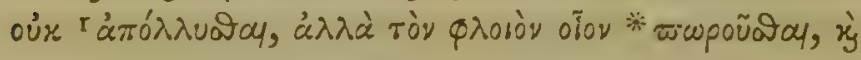

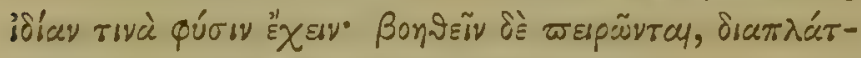

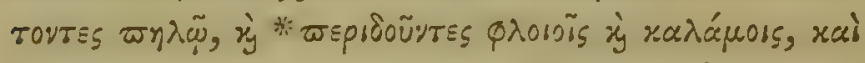

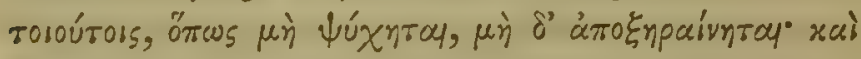

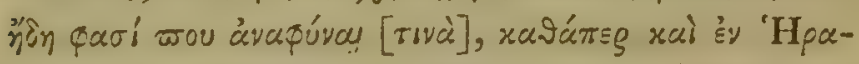

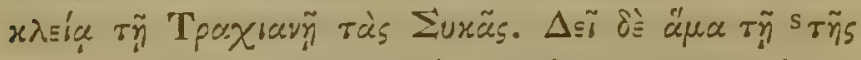

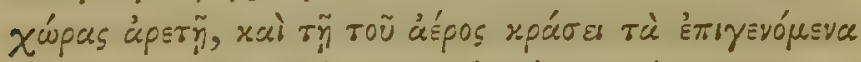

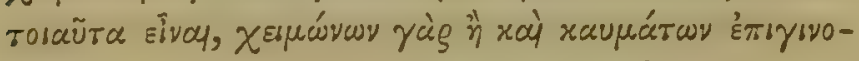

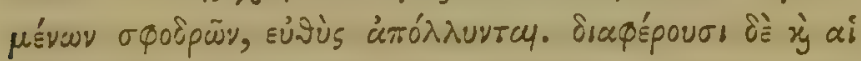

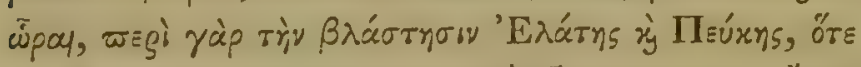

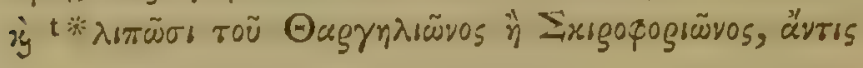

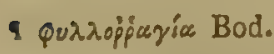
Const.

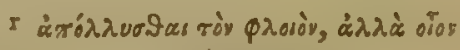

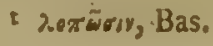




\section{MEPI $\Phi M T \Omega N ~ I \Sigma T O P I A \Sigma ~ T O ~ \Delta^{\prime} .199$}

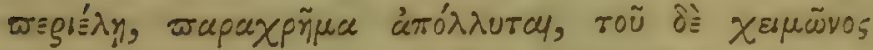

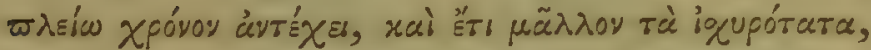

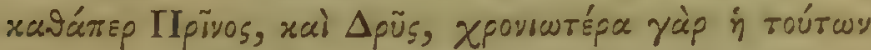

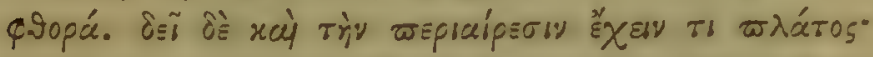

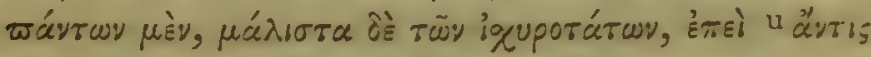

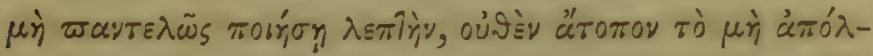

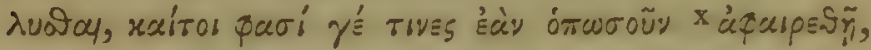

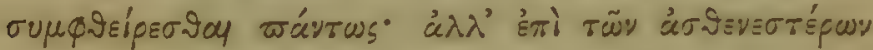

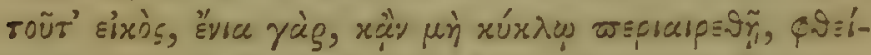

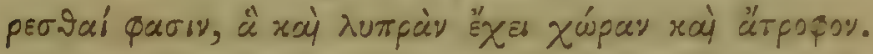

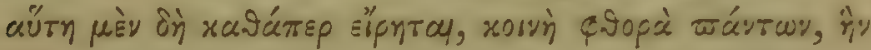

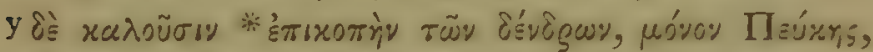

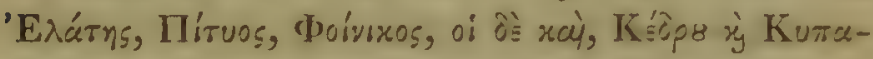

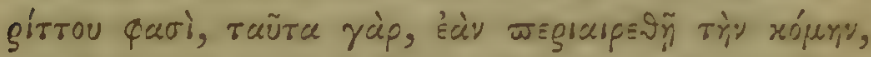

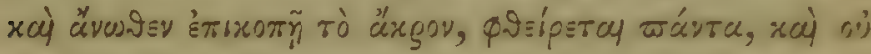

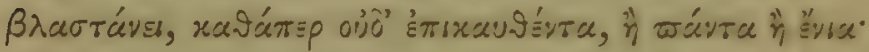

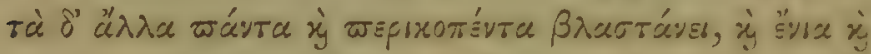

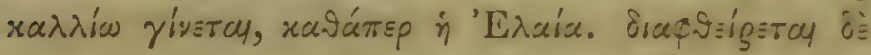

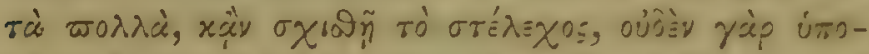

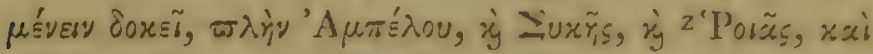

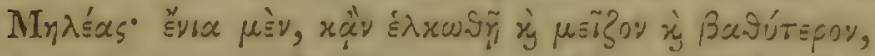

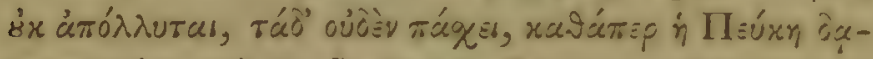

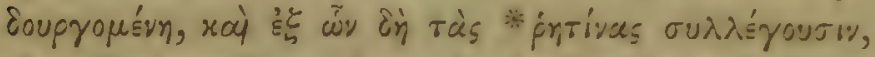

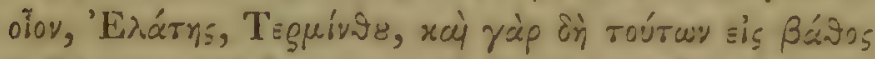

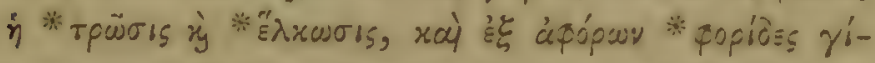

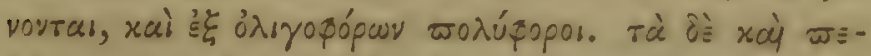

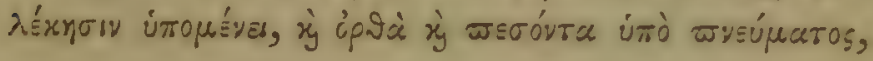

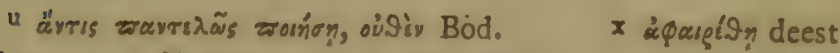
Ald. $y$ jì Bod. $z$ 'Poõs, Bod.

04 


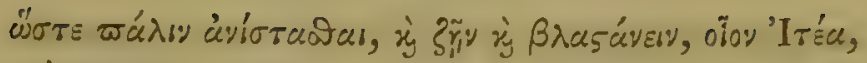

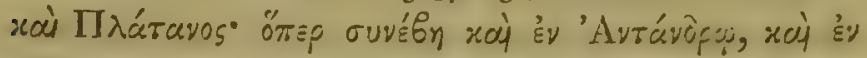

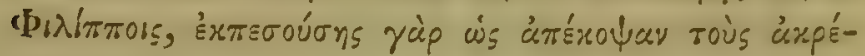

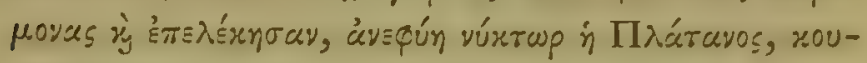

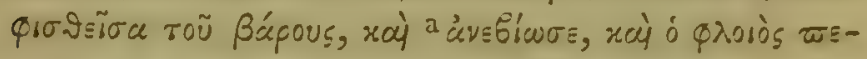

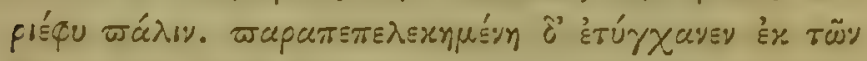

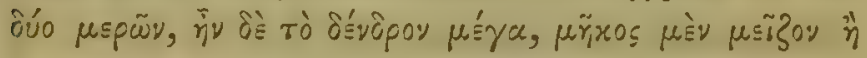

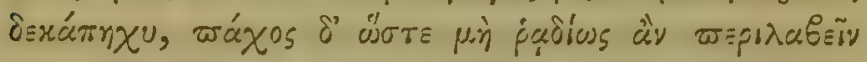

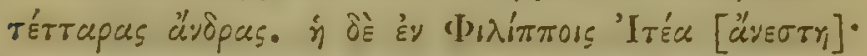

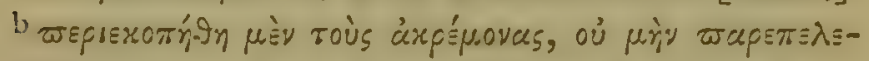

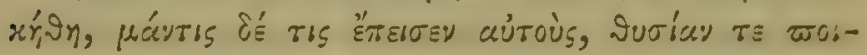

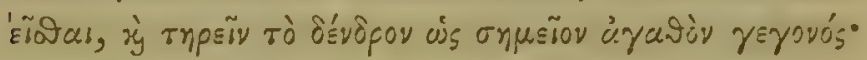

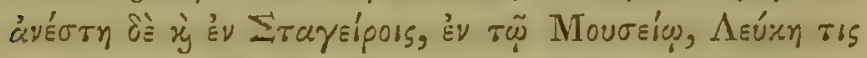

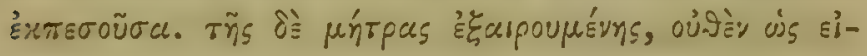

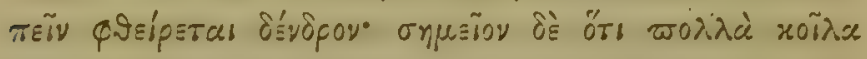

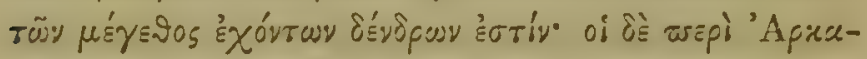

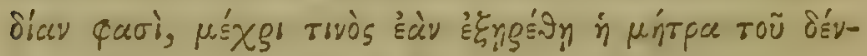

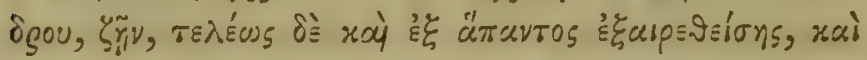

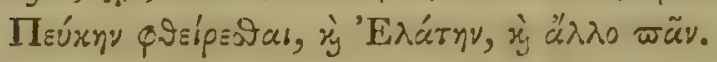

\section{CAP. XVII.}

Mors Plantarum, et Inimicitia mutuc.

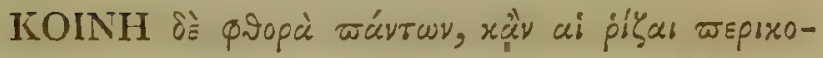

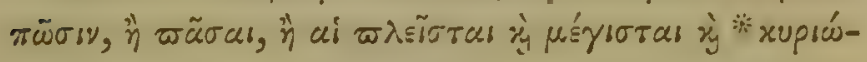

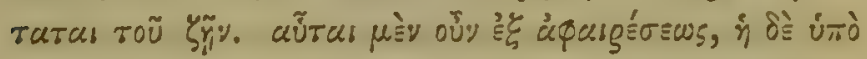

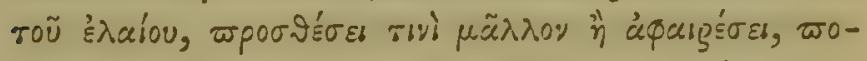

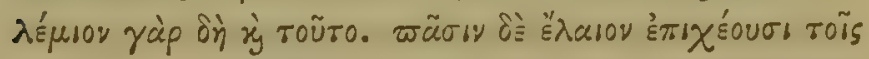

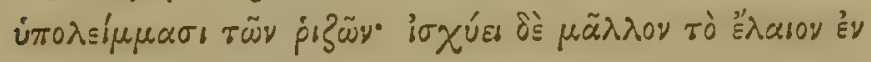

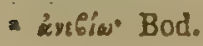

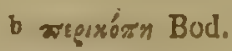




\section{ПEPI TMTRN IУTOPIAS TO $\Delta^{\prime}$. 2OI}

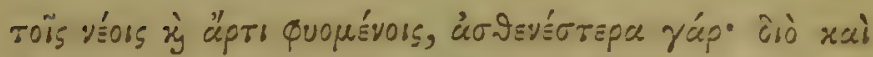

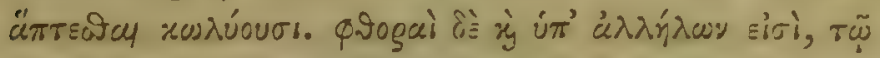

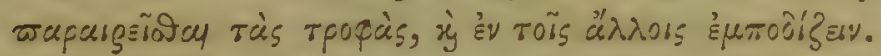

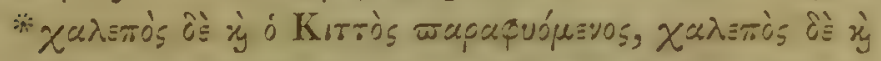

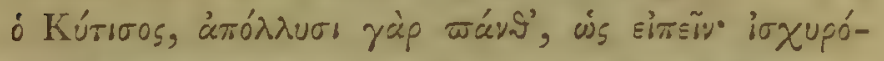

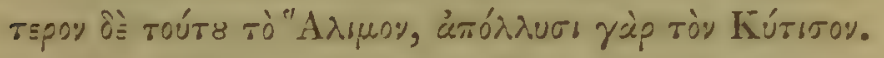

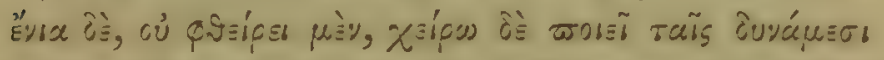

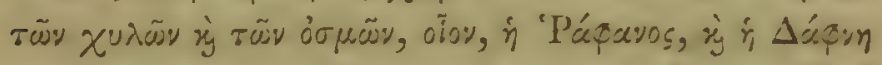

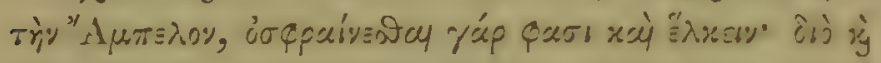

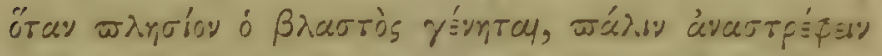

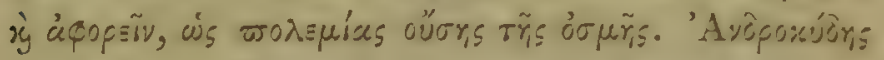

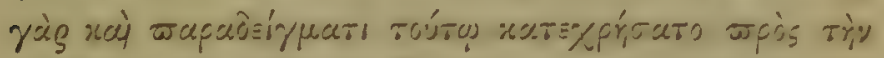

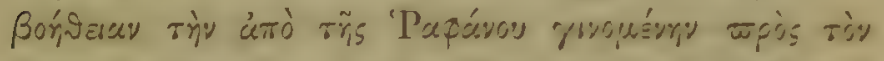

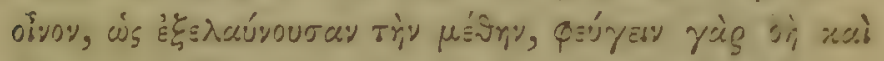

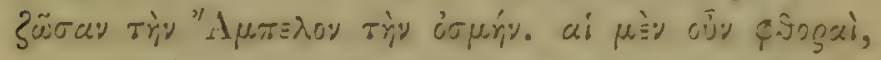

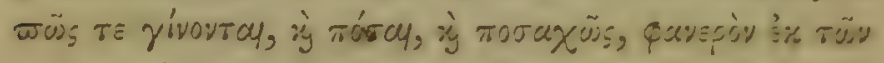
шposeprustrvo\% 


\section{NOT $A$}

\section{IN LIBRUM QUARTUM.}

\section{A P. I.}

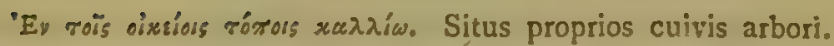

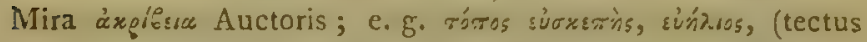
simul et apricus,). itemque in intervallis montium habitatio.

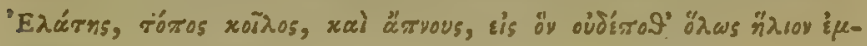

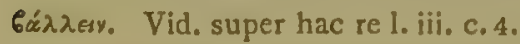

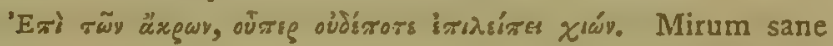
Cupressum, quæe in calidis regionibus solummodo reperitur, in Cretæ montibus nivem attingere.

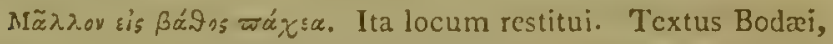
et aliorum, ut ad imum paginæ videre est, corruptissimus. De diminutione molis sursum in truncis sermo est, quæ variat multum in diversis speciebus; in deciduis ninus, in Pinu tamen maxime conspicua, presertim respectu crassitudinis juxta radicem.

$$
\text { C AP. } 11 \text {. }
$$

N. B. Plantas IEgyptiacas quasdam in hoc capite describit Auctor, non tamen omnes ex củrofía, ut videfur.

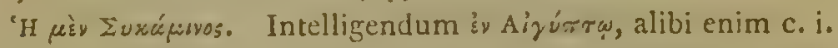
p. 9, 19, 21. Euxúutvoy Italiae et Gracix, sc. Morum nigram L. satis accurate describit. Species hæc, Ficus religiosa L. Angl. "The Banyan Tree," in India orientali, utpote et in Egypto, notissima. Icon datur apud Bod. p. 291. et Ger. cm. 1509.

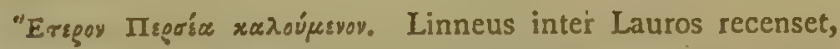
cum syn. Clusii : sed Clusius describit plantam novi orbis Hispaniam advectam; ergo L. Persea Linn. non חıgác Theophrasti. "Perseæ pomum myxis rubentibus simile," ait Plinius, ut videtur ex autopsia: inter Prunos igitur recensenda. 
Operæ pretium tamen erit inquirere de loco natali Amygdali, Persica L. an ullibi occurrat statu sylvestri : sin minus, forsan Amygdalus, Persica L. cum varietatibus innumeris, Amygdalo, communi L. ut parenti referenda. Vid. obss. in notis ad librum iii.p. 136.

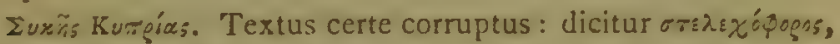

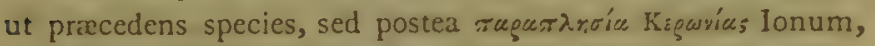
quæ tamen arbor siliquosa. Keowvín Theophr. Cassiam fistulam L. interpretatur a Bodro; sed suspicor duo gencra sub codem nomine enumerari. Ceratoniam, sc. siliquam L. $1 . i$.

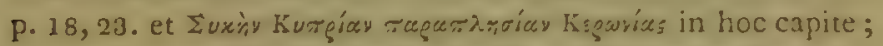
attamen descriptio hæc valde confusa. Ceratonie Hos pur-

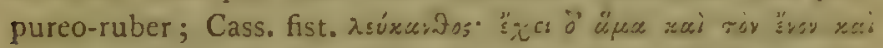

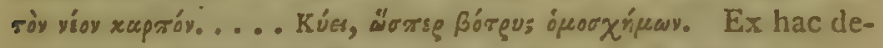
scriptione conjicerem Tamarindum Indicum L. indicari, etsi nullibi fit mentio. Ilic enim in unum coeunt characteres siliquosi fructus et pulpamentosi, necnon racemosa quadarn congeries baccarum, xoxkyuñ aw similium; videndum in successiva fructificatio obtineat.

'II Bádavos. Secundum Bodreum Myrobalanus Limblica. Bauh. Pin. 445. Phyllanthus, Emblica L. quae ex Greco-

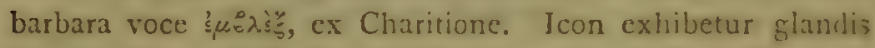
unguentarix, vel Myrobalani Bod. p. 300 . N. B. A Linn. gुenus novum sub nomine Guillandinre.

Koverí̧̧oga. De genere hoc Palme affini silet Bodreus; interpretor Palmam Thebaicam, Anģl. " The Doom Tree." Vid. "Bruce's Travels," v. 45.

Kęrò̀s rogevsúvor. Annulos Iled. sed forsan orbiculos sub axe volventcs, pedibus pulvinaris subjectos; Ang. "Castors."

\section{A P. III.}

$\Delta$ rròy dè rívos. Acacire AEgyptiacre, Mimosx Nibotiče L. non dantur species nec varietates. A, Mśraura forsan Acacia Matthioli ficta, cujus icon apud Bod. p. 306.

'Avri Kiriós. Usus coriarius corticis Quercus antiquis forsan ignotus; gallis utebantur, ut in .Egypto siliq̨uis Mimosæ.

Tã тог

Ko 


\section{NOTA IN LIBRUM QUARTUM.}

Prunus Scbestinus. Vid. Ger. em. t.i. p. 1499. Vid. de hae arbore Plin. xv. 18. "Fructus, drupa rotunda Pruno domestico "minor, pulpa molli, et pene fluido, unde nnmen púgn a " $\mu$ Ú̧̧⿻, Nulla fructus mentio apud hodiernos.

Eis rò бupbuinov rálos. Mira hæc proprietas Mimosx, sensitive Theoplurasto haud ignota. N. B. Folia M. describuntur, rupóa

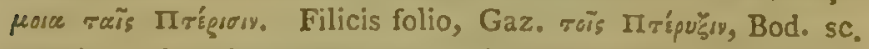
pennis in ala avis, qua utrinque plumulis densissime obsitæ: alibi folium pinnatum $\pi$ rígug comparatur, itemque surculus l'inus, Pices. iii. 10.

\section{A P. IV.}

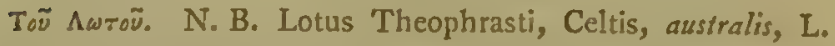
(vid. icon. Bod. p. 325. Ger. em. 1193.) fructus parvus magni Kuápusu, (pisi sc. non fabx, apud Theopt:astum et alios.) Ita

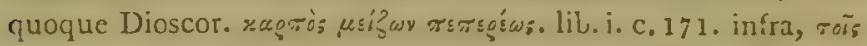
púgrous, baccis Myrti, communis, comparatur. Vid. Plin.xiii. 17.

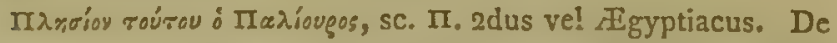
Iarsoúg: 1mo, Rhamn. Paliuro L. supra mentio fit i. 4, 8, 16. et iii. 4, 8, 17. N. B. De Paliuro Africano tractat Plin. xiii. 10. sed exscriptum ex Theophr. et parum fideliter. Apud Linn. Spec. Plant. 1478, spec. duæ occurrunt; Celtis, australis et orientalis. Vid. Athenæum, l. xiv.

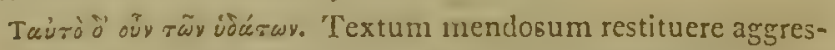
sus sum ex versione Theodori. Supra dixit mirabile esse $\approx \bar{\omega}$;

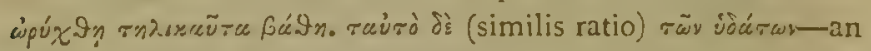
radices attingant aquas, vel subditas esse radicibus, secundum

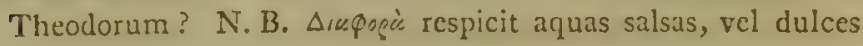
supra.

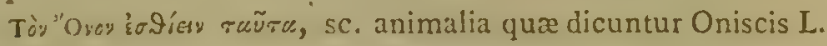
resci. "Ovos insectum multipes, contactu sese complicans, ut pillula appareat." Bod. p. 332. Sub nomine Millepedis satis cogn. Angl. " a Wood Louse." Vid. Scrib. Long. c. 39. Galen.

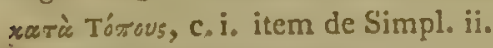

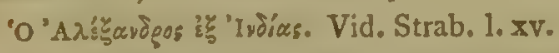

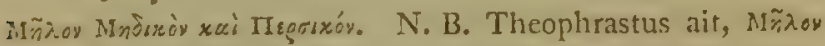
- is íâis rul, sc. sylvestri statu: ergo varietates cultæ nondum 


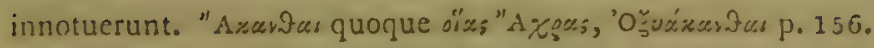
memorantur.

\section{A P. V.}

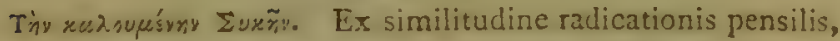
si ita dicam, suspicor Theophr. sub communi nomine Iuxñ genera duo maxime diversa confundere, sc. Ficum, religiosum L. et Rhizophoram. Vid. 1.i. c. 12. Species hæc ad Fluv. Aci-

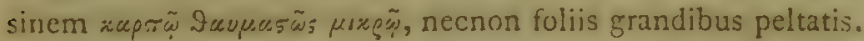

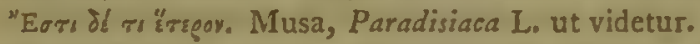

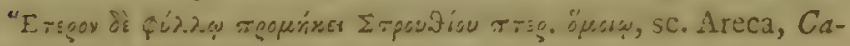
shecu, L. ex familia Palmarum.

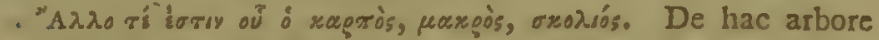
inquirendum. An Strychnos, Nux Vomica L.? cujus mira prominentia nucis ex apice promi, figuræ incurva. N. B. Specics plures cursim enumerat ex India; aitque Ceren!ea regionis istius, etsi diversa ab Europais, proxime tamen accedere, Ory-

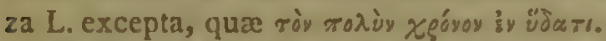

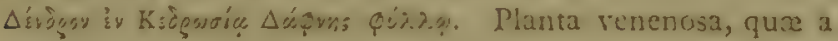
Bodao, Apocyno, L. refertur.

\section{$\mathrm{C} \Lambda \mathrm{P} . \mathrm{VI}$.}

Ṫ̀ ะü๊orex. De odoriferis Arabia et Indix hoc capitulo tractatur.

Bángupes. Arbor cujus gumma b́so ìsecus: ut apud Bod. Amyris Giladensis L. apud Proap. Mlpinum de-cribitur, ct reconter a $D$. Bruce $\Lambda$ byss. $A$ pp. sub nomine Balessian, ubi icones duxe dantur.

'Ey $\tau \tilde{y}$ 'Adgik. Regione vicina maris Hadriatici: adeo ut complectetur Galliam cis Alpes.

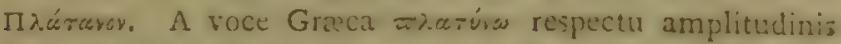
folii, unde umbra fit densissima. Vid. Platani laudes Plin. zii. 1. etiam qua de adniratione Xerxis apud Elianum, ii. 1.4.

\section{CA P. VII.}

- Ti $\ddot{0}$ ivejgz. In hoc capite de plantis marinis tractat, quz

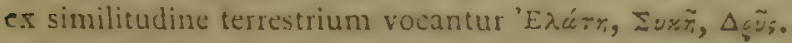

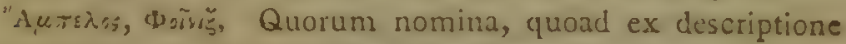
eruenda sint, in Catalogo Plant. recensentur.

Káxinov rr̃s Monfúgas. MUREX, L. cujus usus ad tingend. antiquis notus, æque ac Fucorum quorundam. 


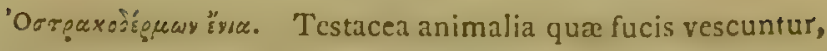
et ibi adhærent; sed F. vesiculoso L. quasi innascitur genus parvulum, sc. Serpula, spirorbis L.

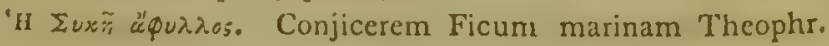
Alcyoniis referendam.

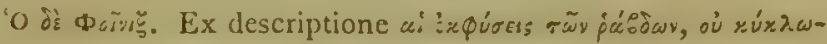
$\hat{z} \xi y-\dot{\alpha} \lambda \lambda^{\prime} \dot{\omega}_{s} l_{v} \pi \lambda \dot{c}^{\prime} r \epsilon$, Fucis plurimis convenit : sed charactere

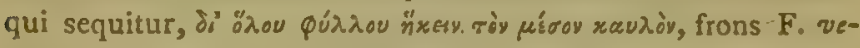
siculosi et serrati, apte describitur folio oblongo, costa intermedia, alis utrinque. Bot.

\section{A P. VIII.}

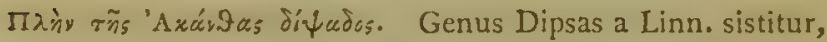
sc. Dips. Fullotum, Ang. "Teasel." Planta hæc instruitur membrana cyathiformi ad caulem, cujus ope retinetur aqua restatis tempore: sed apud nos ad aggercs vulgatissima, ideoque forsan diversa a planta Theophr. N. B. "Ax. 'A gabixns mentio fit apud Galen. de Simpl. lib. vi. ut et apud Dioscor. quæe dicitur A. $\lambda$ súx» örosa. Forsan tamen species hæe adhuc latet in arenosis Arabix.

Múxnтss, sc. Madrepora, fungites L. Corallini species notissima. N. B. Quæ de Daphne marina, Olea, ct Thymo, fabulosa admodum. Inter Corallinas reperiuntur species arborescentes; necnon in recenter inundatis a mari casu quopiam, arbores submersas videre est, quxe per secula duraverunt.

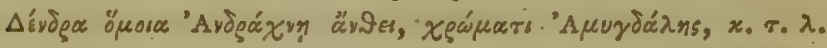
Gorgonize species reperiuntur ramosissimæ, cujus ex apicibus Polypi, ibi nidulantes (Hydri L.) in formam floris sesc expandunt. Vid. icon. tubulariæ, magnifice, Act. Linn. v. 5. Ten-

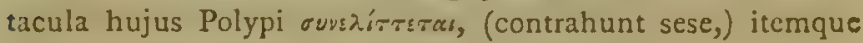

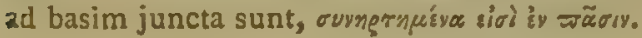

\section{A.P. IX.}

'Ey Túda. Vid. Plin. xii. 10. Hic etiam fabulosa narratio: nempe de sylvis arborum in intervallo insula a continentis æstu maris relictis : sed quænam pars Arabici sinus indicatur?

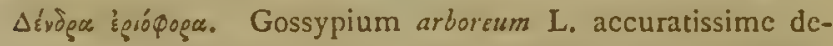
scribitur. Notandum quoqque owsóvas apud Græeos gossypinas

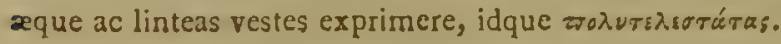




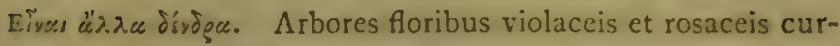
sim nominantur, adeo ut vix liceat conjicere an Hybiscus, vel alia quædam inter exotica specioso flore.

חúruess. Papyrus Nilotica L. fuse ex autopsia, ut videtur, describitur. Vid. Plin. xii. 11.

2api. Barbara vox. N. B. Planta affinis Papyri describitur sub hoc nomine: sed nulla mentio apud synonyma Linn. nec apud antiquos, quoad scio.

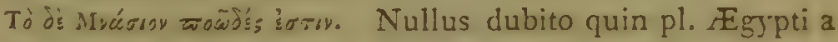
D. Bruce descripta et delineata sub nomine "Ensete," (vid. App. p. 36.) hic referenda sit. Dempta terminatione Grace oy, voces Mnasi, Ansi, haud absimiles, et usus plantæ ad victum humanum idem.

$$
\text { C A P. X. }
$$

'o di Kúuros. Lotus Colocasia L. vulgo Faba Egyptiaca. Vid. Plin, xxi. 15. Dioscor, ii. 129. Celebris planta, ex xủro భ'ó, ut videtur, descripta.

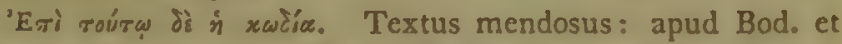

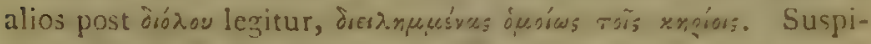
cor hac verba ex margine in textum irrepsisse, aut saltem locum obtinere post descriptionem pericarpii apud Bod. cibo-

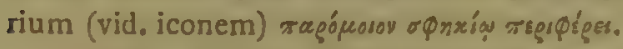

'II. arizos. Folium Galeriforme Colocasiæ.

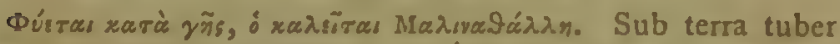
Cyperi esculemti L. reperitur in arenosis juxta Nilum. A Plin.

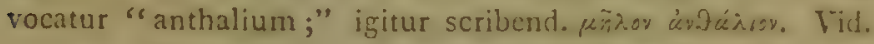
icon. apud Bod. p. 471. Hujus mentio in Flora Græec. fasc. 2.

"Oray : Eiros

$$
\text { CA P. XI. }
$$

'O Tṕóodos. Tribuli aquatici L. pericarpio excepto, descriptios

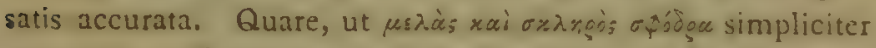
rocatur, cum forma ejus sit omnium maxime singularis, sc. undique muricata punctis acutis, muricum ad instar: Angl. "Caltrops." "

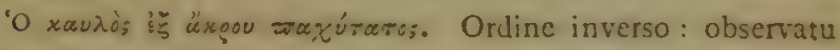
dignum hunc ordinem in aquosis quibusdam obtinere.

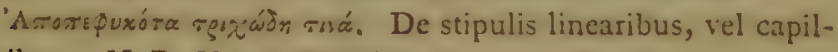
laribus. N. B. Hæ in Tribulo et Potamogeitone notissimæ. 
"As.9os ₹yoüds. Flos stamineus. Bot. Textus hoc loco corruptus, non nisi inspectione fructificationis Viticis, agni casti

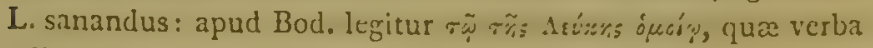
tollerida censet idem auctor.

“'H $\delta \dot{\varepsilon} \Sigma i \delta$. Planta hæc inter ignotas. Bod. p.462. Certe tamen Nymphæx affinis planta. Nomen forsan ex pericarpio, cujus forma instar pomi M. Granati (aidicu Lex. Theophr). N. B. De Butomo, Equiseto, aliisque fluviatilibus in hoc capite sermo est : vid. Cat. Plant. necnon operæ pretium erit in ipso Lacu Orchomeni plantas investigare.

\section{CAP. XII.}

- 'o $\delta \grave{~ K e ́ r a \mu e \xi . ~ A r u n d i n u m ~ a r b o r e s c e n t i u m ~ d u x ~ a p u d ~ L i n n . ~}$ Spec. Plant. A.D. 1674. Novissime tamen Bambusa, ut gerus proprium, sistitur. De usibus Arundinis et Cannæe occurrunt multa in hoc capite observatu digna.

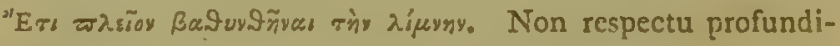
tatis aquæ, sed e contra, ut constat ex textu.

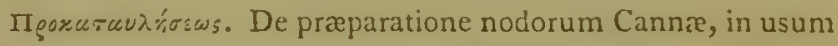
tibiarum, sc. ut pars exterior fiat quam firmissima; sermo est descriptio manipulationis accurata admodun.

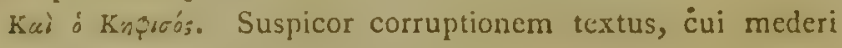
conatus sum, parenthesi interposita.

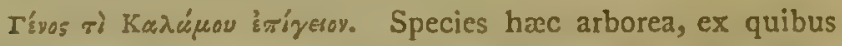
cymbula (àrárior secundum Plinium) fiebant, certe Bambusa Linn. sed mallem legere cum Bodæo üxáyrio.

\section{AP. XIII.}

Iiģi Zzoivev. Genus Schenus L. videtur indicari, etsi Bodreus interpretetur Juncus. Fortasse tria $\Sigma$ zoinay Theophrasti $\gamma^{\prime}$ mm, sub generibus diversis L. militant. Scirpi species quzedam appellatur Holoschonus a Linn. et ut ins régrepury enumeratur species Melanoschonus a Michelio: sed quare «áererpou quidam? Anne seminibus utebantur? Plin. xxi. 1\%.

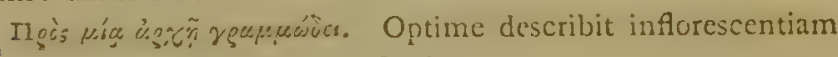
plantæ, ex qua species eruenda sit.

'O Báros. Incidenter fit mentio. Búrov, ut siccis pariter ac aquosis gaudens. Descriptio occurrit iii. 17 . 


\section{CAP. XIV.}

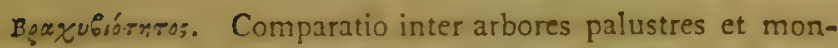
eanas instituitur hoc capite. Vid. etiam de Caus. Plant. ii. 15.

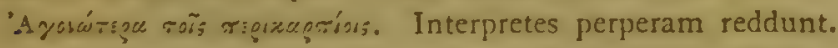
Sensus est, fructum plantas hasce edere, sed non maturare :

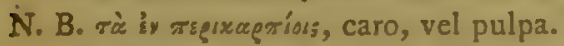

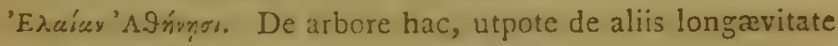
famosis, vid: Plin. xvi. 44.

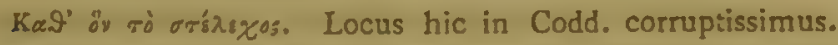
Sensus, secundum Scal. "Si metiamur vite tractum in arbo. "ribus a diuturnitate stipitis tanquam principii ejus, inibitur "ratio vite ejus, circa 200 annos." Bod. p. 493. Error textus,

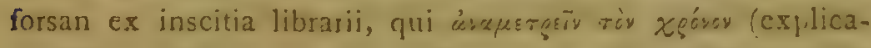

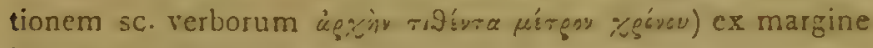
in textum recepit.

\section{CA P. XV.}

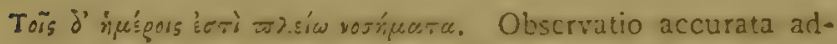
modum : cultura cnim, etsi feraciores, imbecilliores tamen funt arbores. N. B. Morbi generales et peculiares arborum

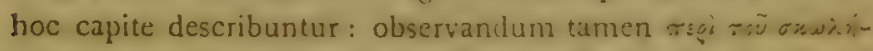
xovgart, quod non proprie morbus, sed effec:us morbi, sive radicem, seu truncum, vel fructum spectat.

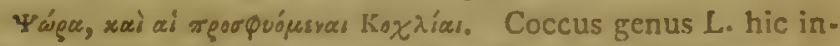
dicatur. In viridariis nostris stipites Citri Auramii infestat.

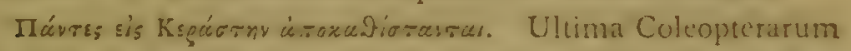
L. transformatio: vid. Linn. Syst. Nat. N. B. Mentio hujus insecti supra, ii. 9.

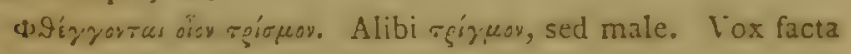
ad imitationem fremitus alarum in insectis.

'Açúxysov. Morbus Olexe; Araneus, Plin. xvii. 24. Inquirendum de hoc in loco natali. N. B. Animalcula quredam arbores infestantia, texunt sibi nidum, tela araner, quoad materiem, similen. Hujus generis videre est in Larice, et in arboribus fructiferis quibusdam; præcipue in pomiferis ex Gallia, ut ferunt, importatis.

'Egrivoyras 81 Krites. De A phide L. vid. supra, c. 7. N. B. 


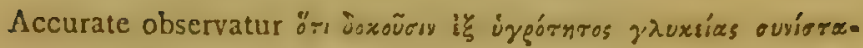
- 9 a, Aphidis enim excrementum, mel quoddam, quod folia estate illinans, appellatur Angl. "Honey Dew." Vid. Aphidis hist. Act. Linn. v, 6.

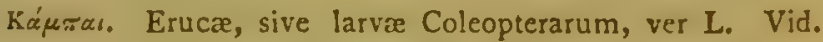

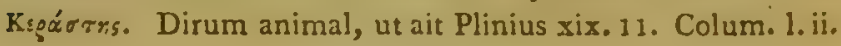

\section{A P. XVI.}

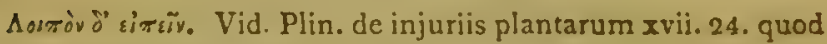

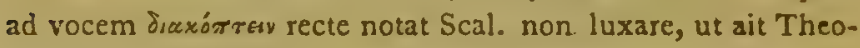
dorus, sed pertundere.

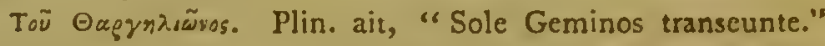
N. B. Scal. conjicit mendam inesse textui, ex comparatione cap. ix. cui mederi conatus est. Bod. p. 5 os.

\section{CA P. XVII.}

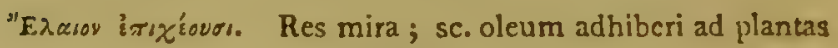
necandas; an ex nimia foecunditate? Adeps et Pix, ut æque arboribus noxiz, enumerantur Plin. xxvii. 24.

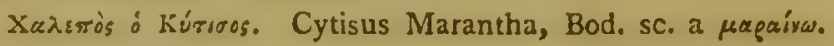
N. B. Laudes Cytisi in generando lacte apud Plin. celebrantur xiii. 24. et Colum. ix. 4. N. B. C. Marantha Bodxi (p. 508.) syn. C. cornuti Ger. em. cujus icon mutuatur. Silent ambo de viribus nocivis. Anne fruticulum a Carolo Clusio descriptum, circa sepes vinearum in Sicilia proveniens, quod, ut ait, Cytisus Latine audit? Vid. Bod. p. 508. Parasitica forsan species, vel ut Polygonum, Fagopyrus, Fumaria, amplexu enecans plantas vicinas. N.B. Kúrıos arbor describitur i. 9. iv. 20. V. 4.

"Aגıен. Salicornia species: vid. Catal. De viribus nocivis hujusce marinæ plantæ respectu terrestrium non est quod miremur. 


\title{
$\Theta \mathrm{EO} \Phi \mathrm{PA} \Sigma \mathrm{TO}$
}

\section{IEPI $\Phi \Upsilon T \Omega N$ I $\Sigma T O P I A \Sigma$}

\author{
TO $E^{\prime}$.
}

\section{CAP. I.}

De cadendo Ligno, tum rolundo, trum quadrato.

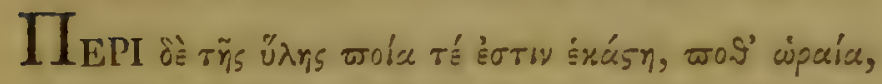
тย́

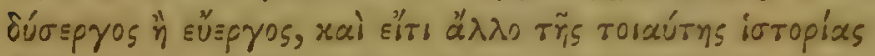

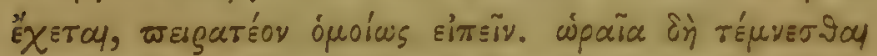

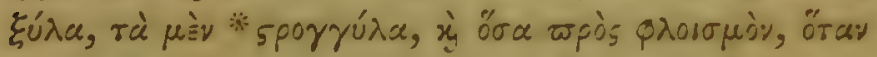

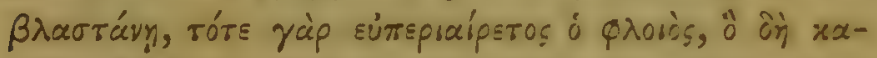

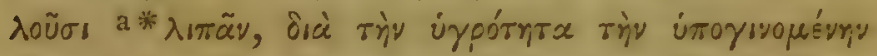

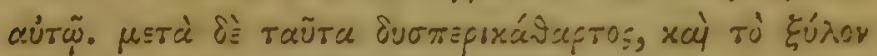

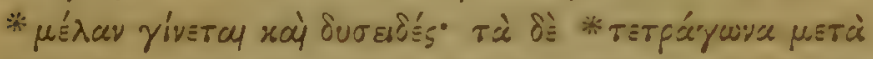

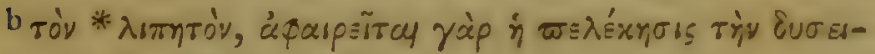

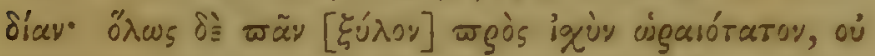

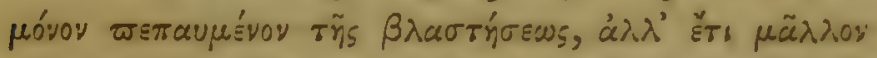

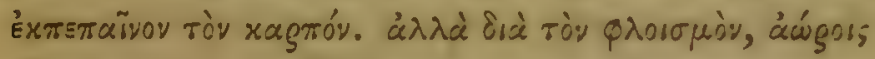
ỡ

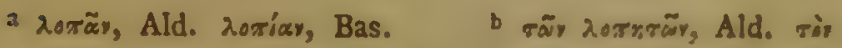
xornriv, Const. 


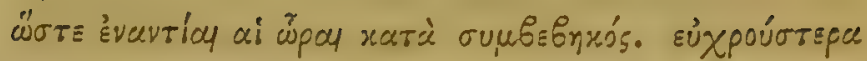

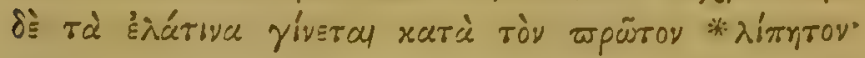

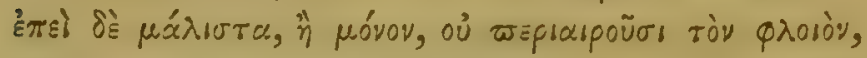

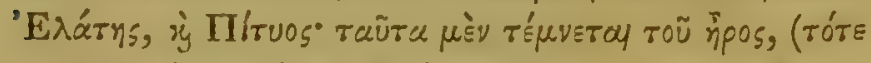

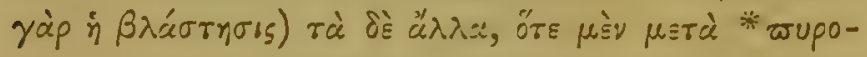

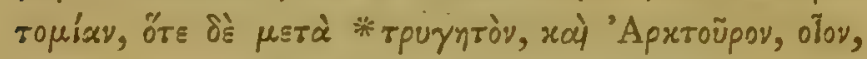

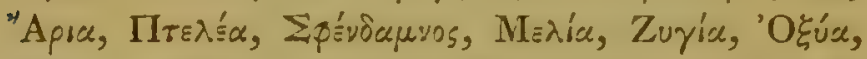

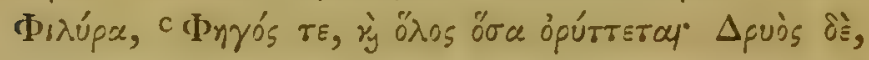

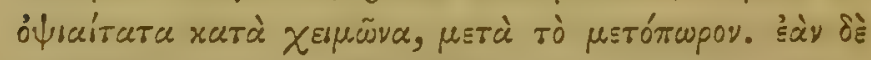

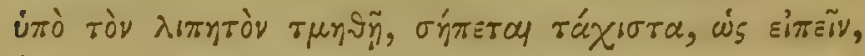

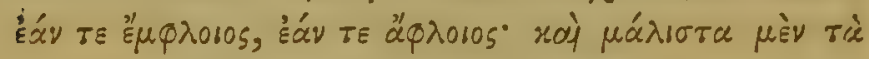

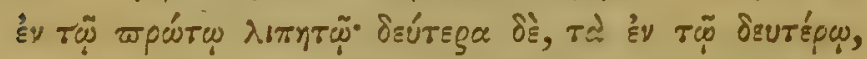

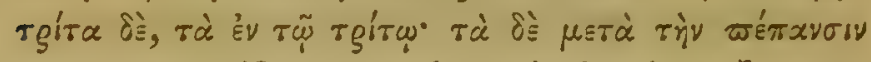

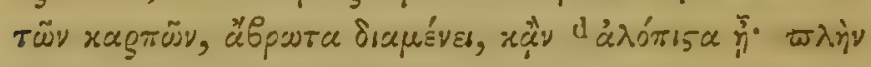

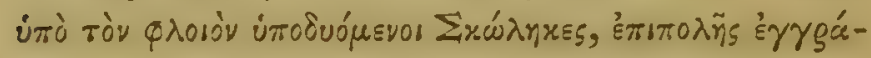

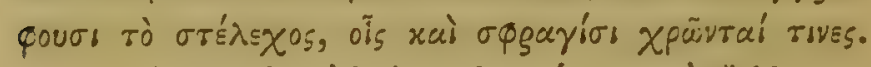

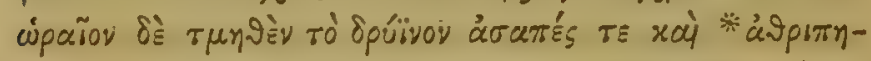

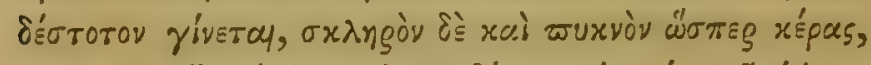

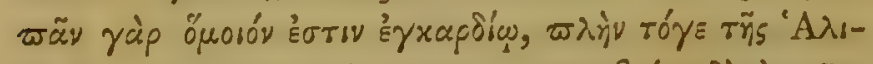

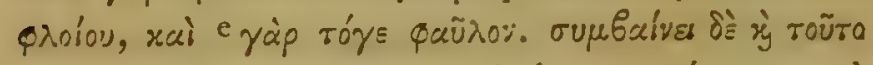

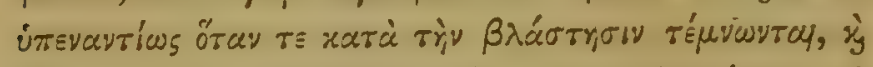

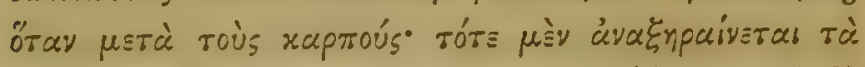

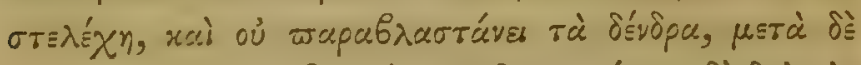

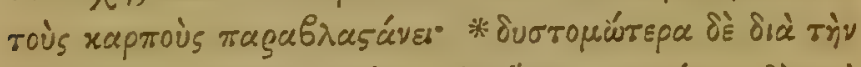

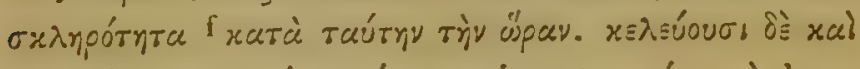

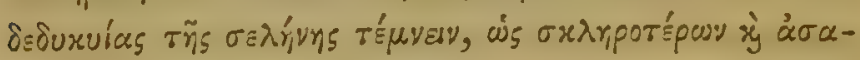

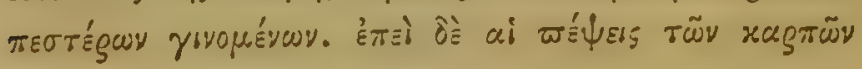

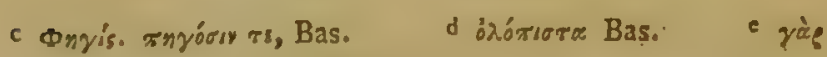
deest Bod. I xal тxú Bod. 


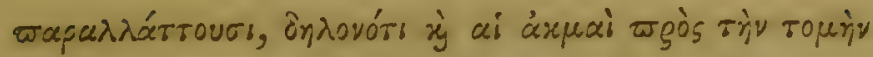

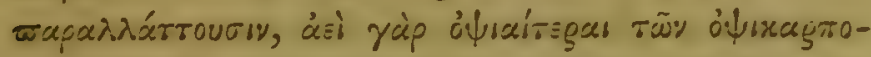

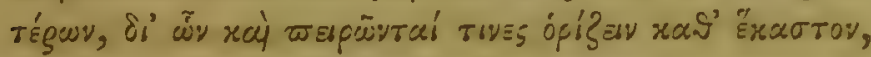

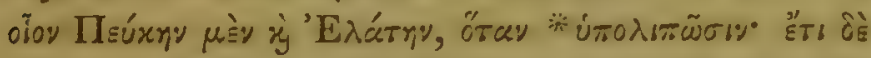

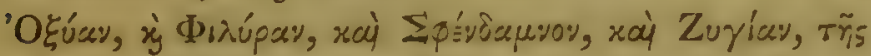

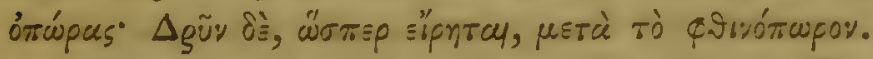

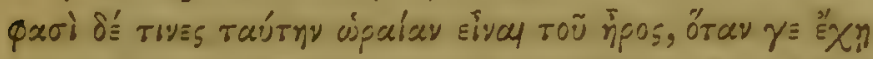

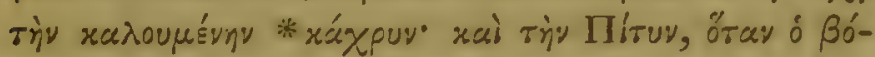

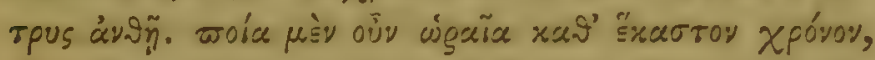

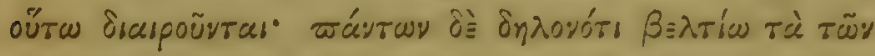

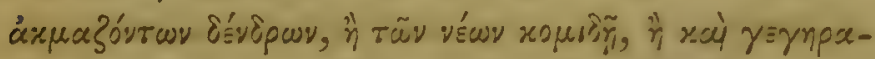
xór

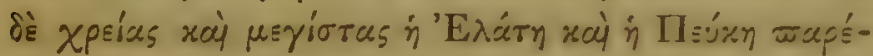

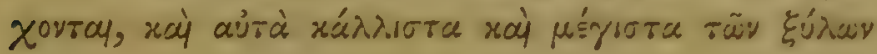
ह̉orí.

\section{CAP. II.}

Lignorum Differentic.

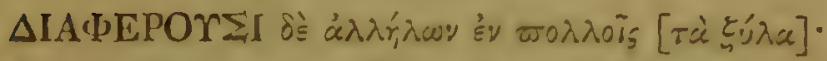

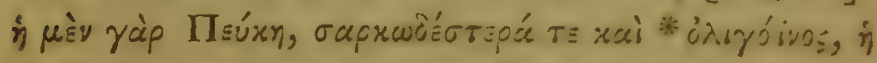

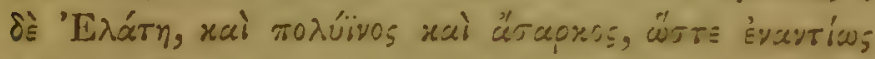

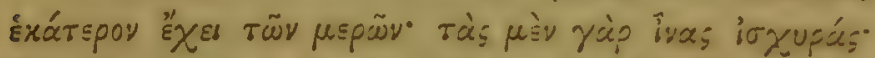

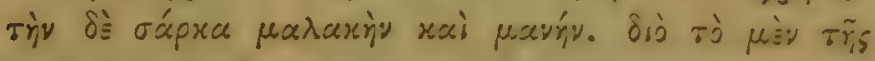

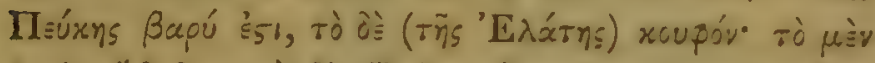

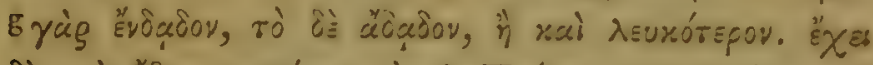

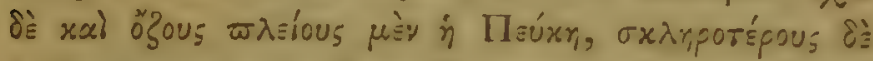

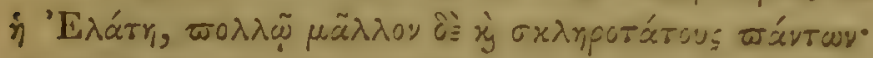

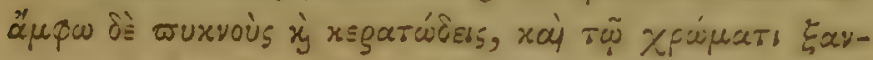

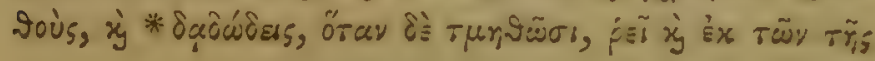

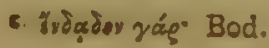

P 3 


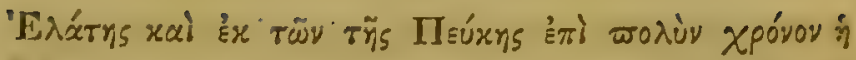

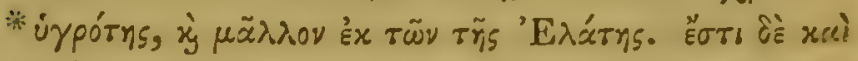

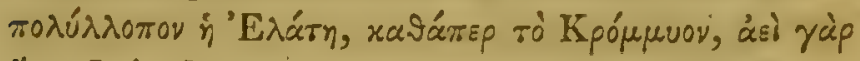

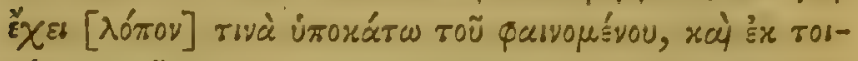

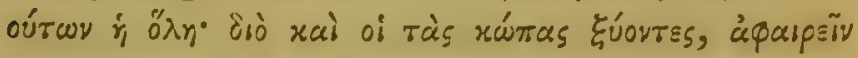

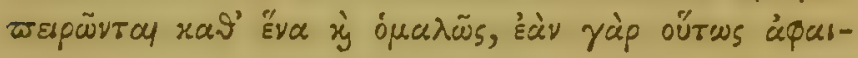
p

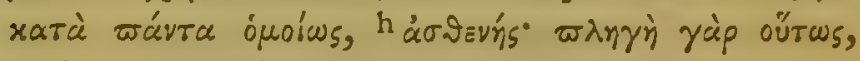

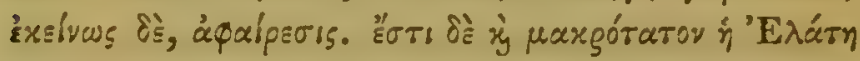

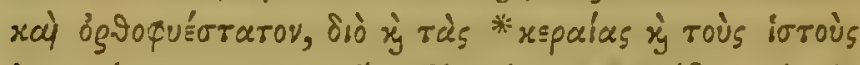

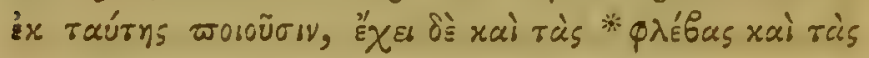

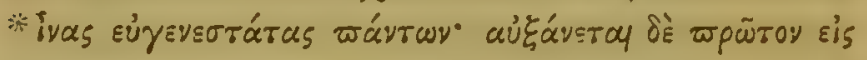

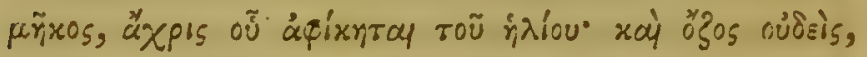

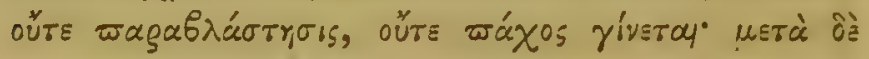

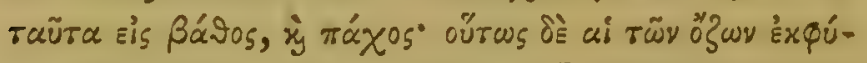

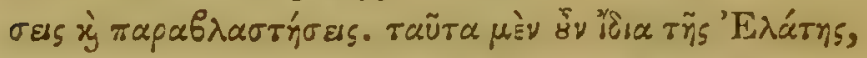

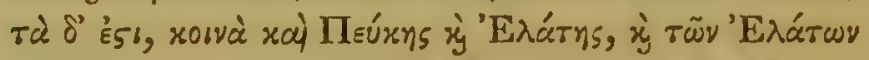

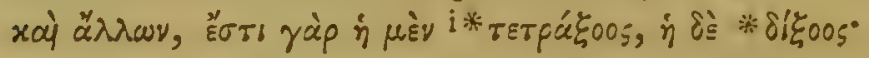

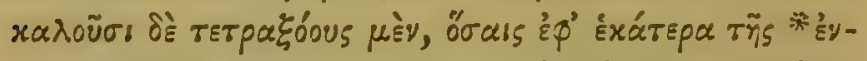

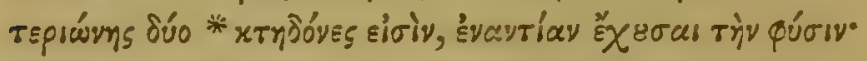

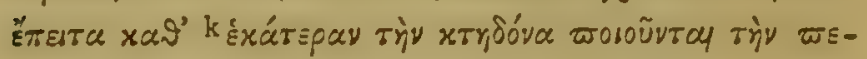

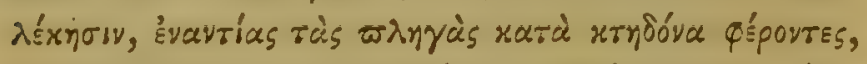

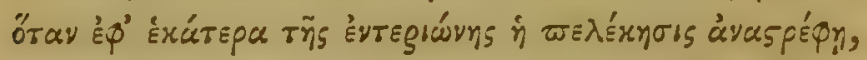

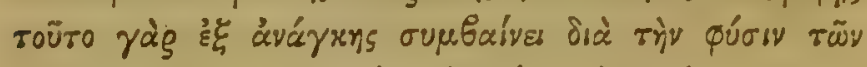

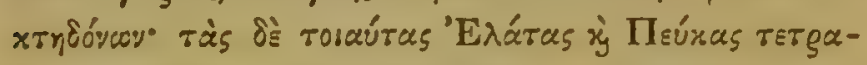

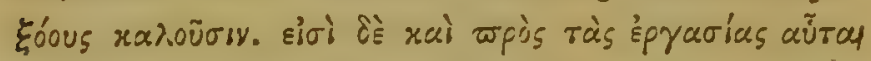

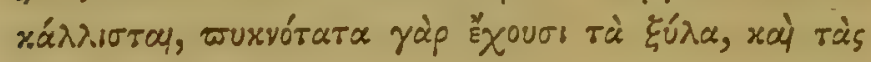

h süstrins, Bod. Yid. not. ad fin. libri. i rergásoos, Ald. Bas. rsrgappóos, Plin. k irigar Bod. 


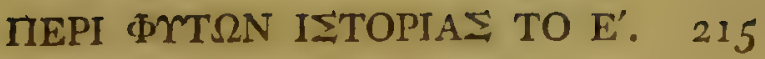

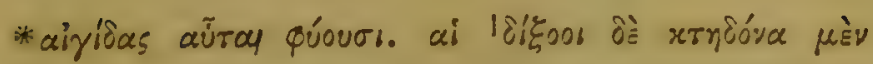

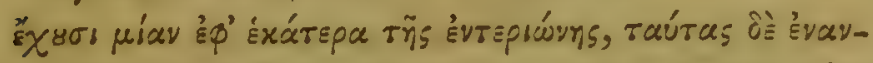

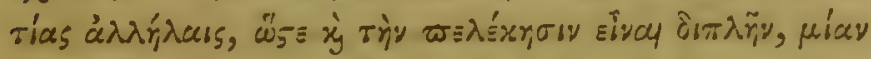

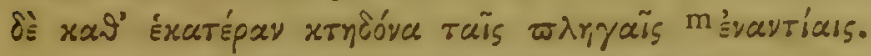

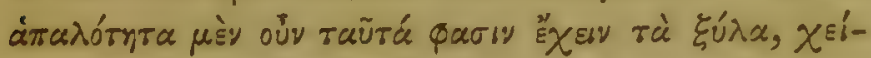

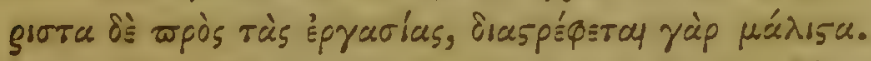

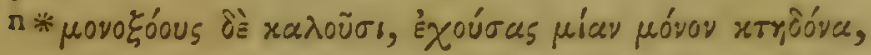

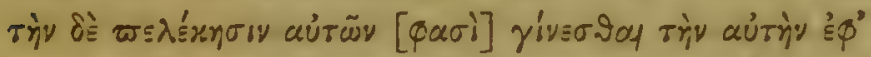
ixá́

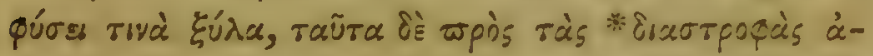

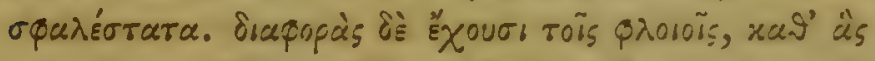

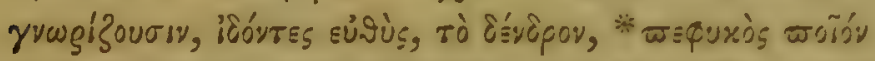

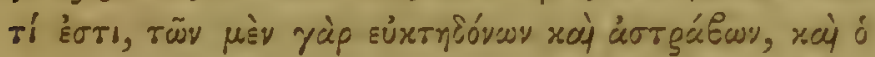

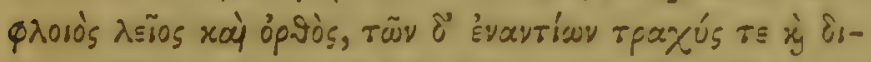

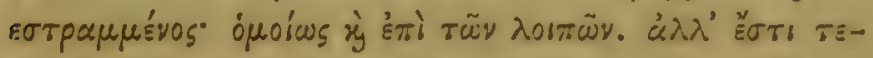

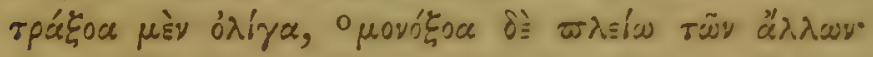

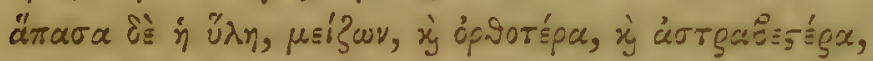
xay नтрupvor है

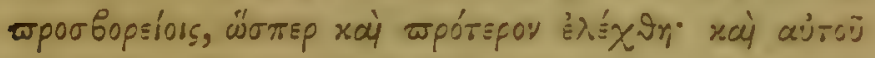

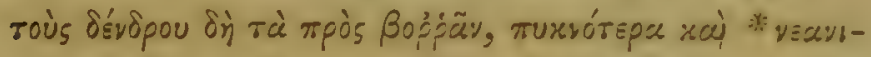
x

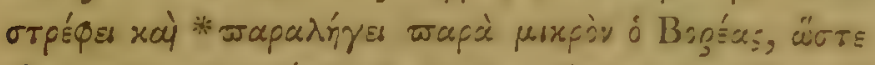

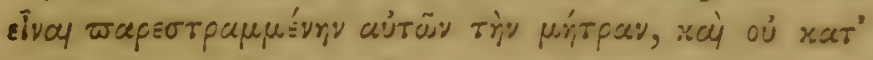

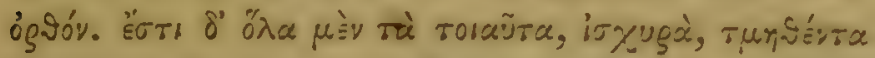

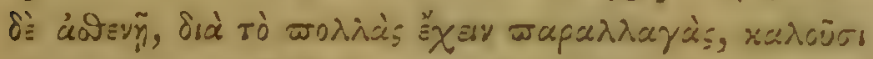

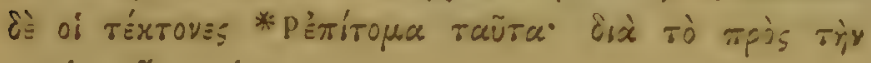
X

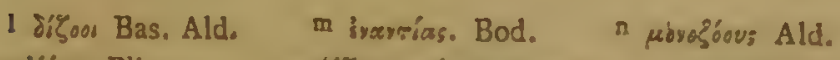

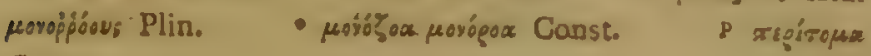
Consto 


\section{CAP. III.}

Usus Lignifabriles, et igniarii. Spirc in Ligno. Circumsepla quadam in T'runco Arboris.

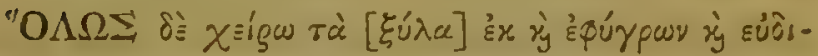

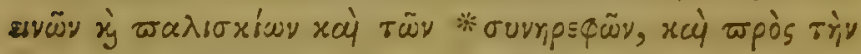

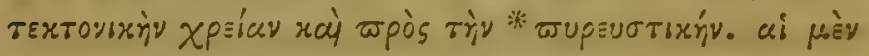

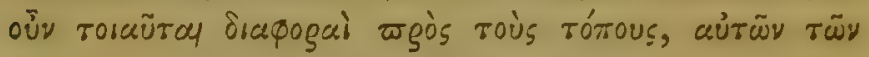

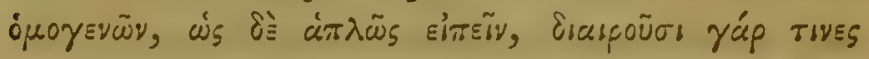

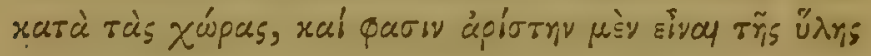

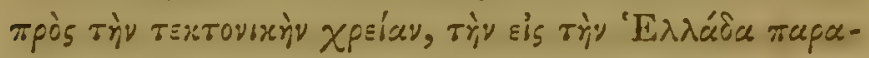

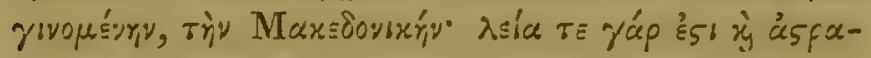

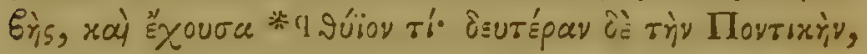

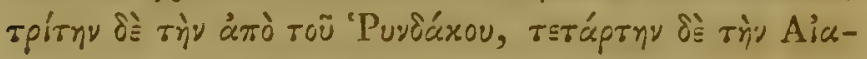

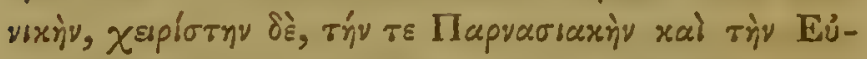

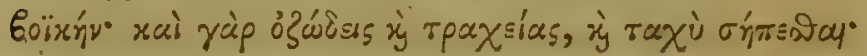

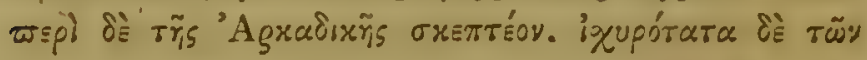

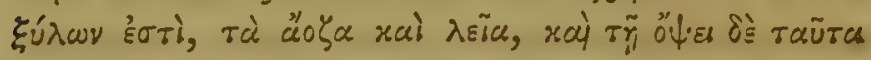

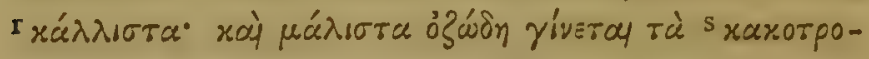

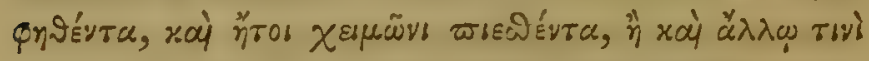

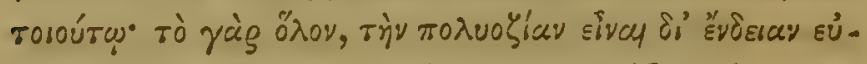

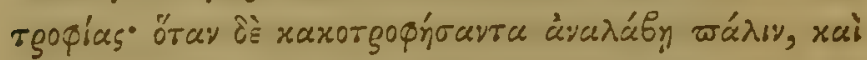

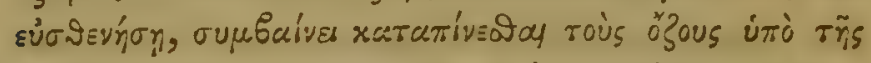

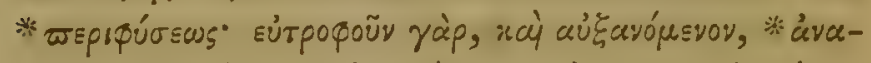

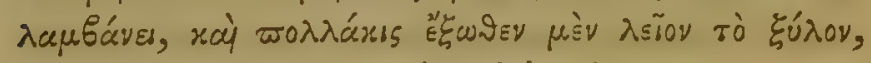

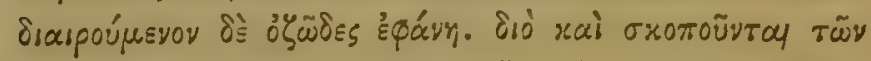

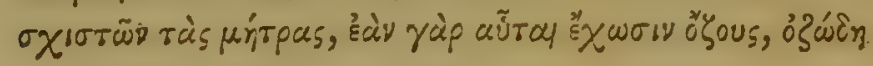

q rüior, Bod.

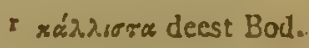
किт, $96 r \alpha$, Bod. 


\section{MEPI $\Phi T T \Omega N$ ISTOPIA TO E'. 217}

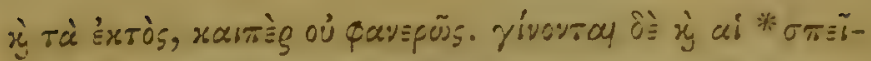

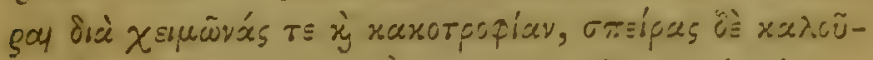

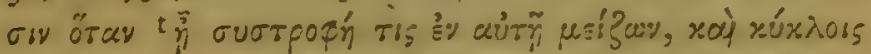

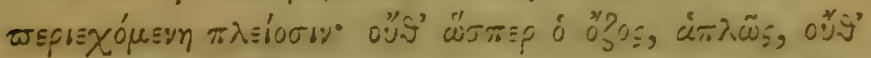

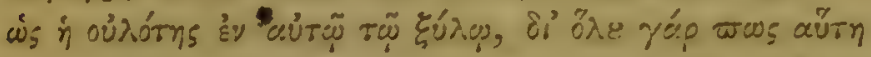

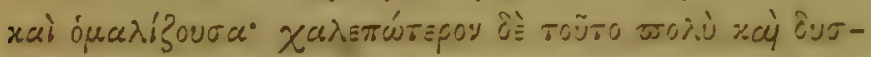

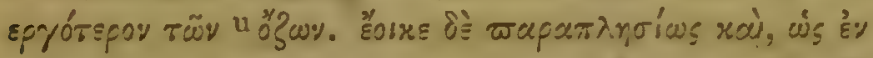

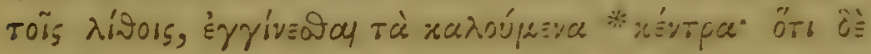

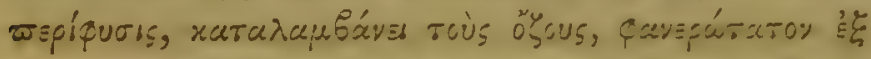

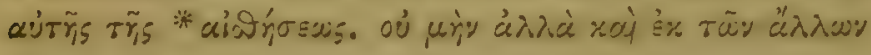

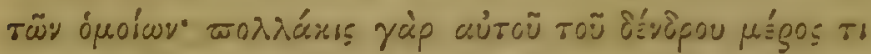

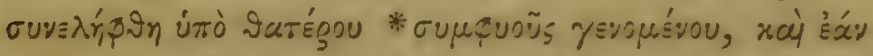

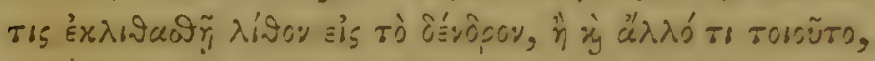

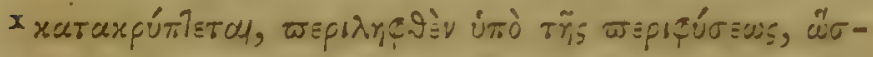

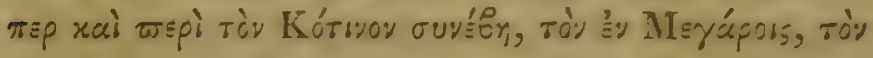

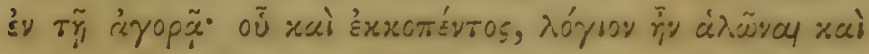

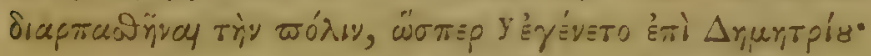

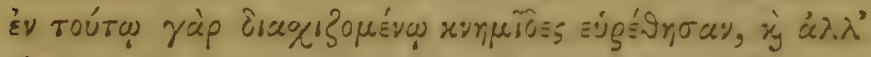

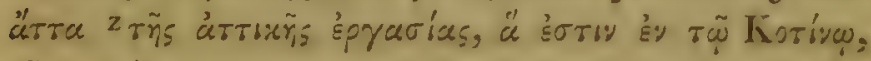

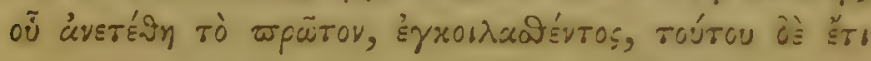

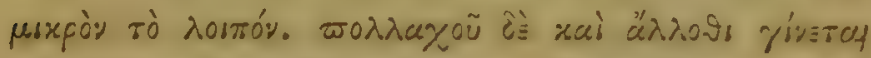

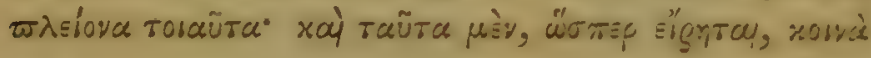

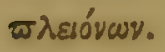

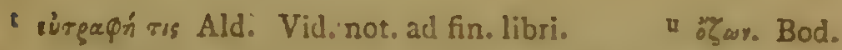

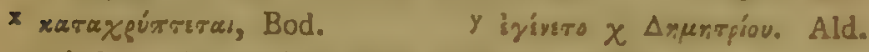
z รѐेs 'A 


\section{CAP. IV. \\ Qualitales alic Lignorum.}

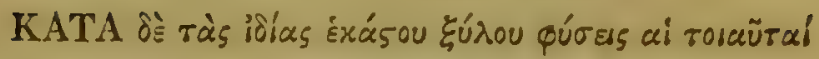

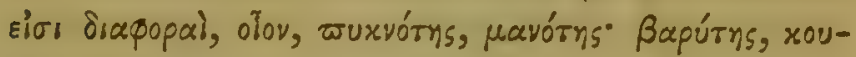

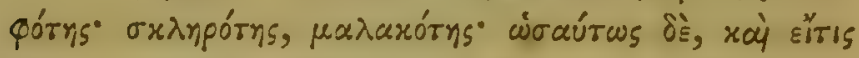

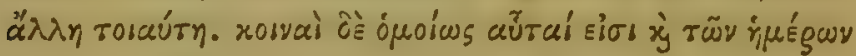

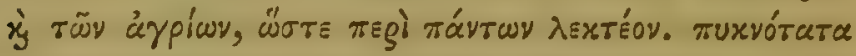

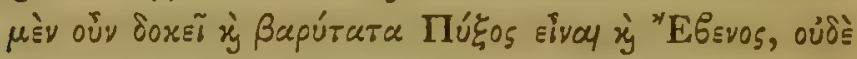

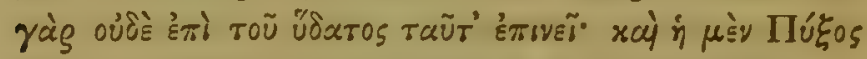

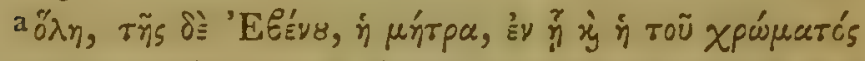

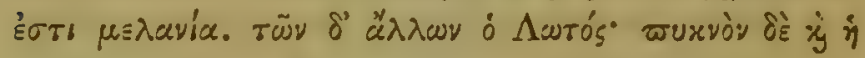

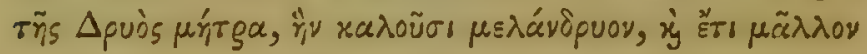

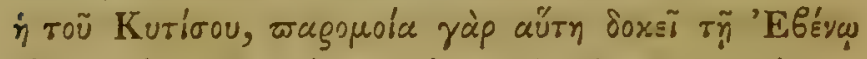

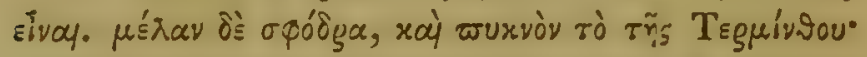

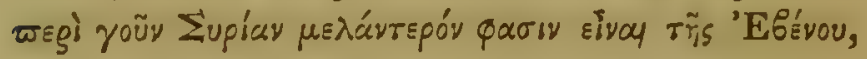

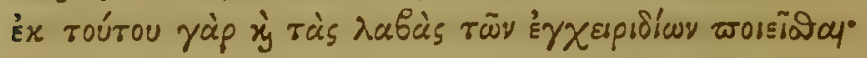

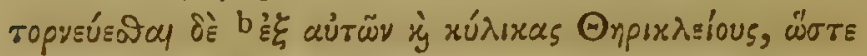

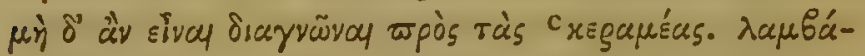

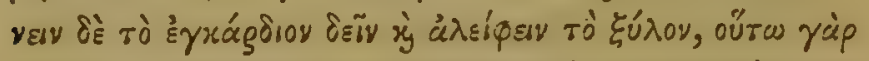

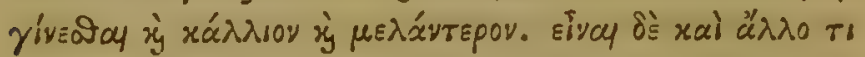

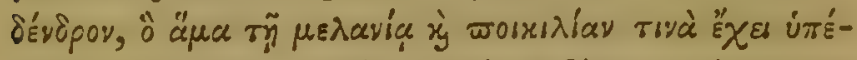

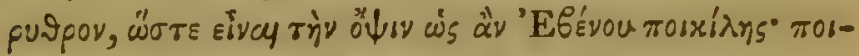

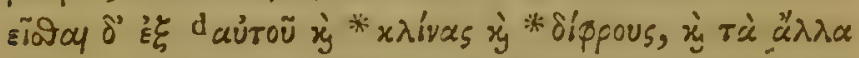

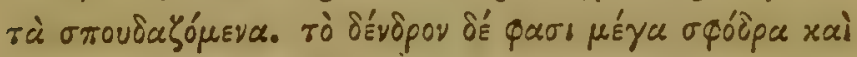

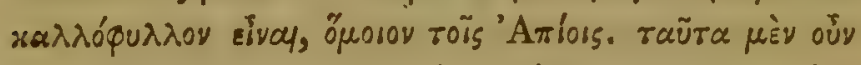

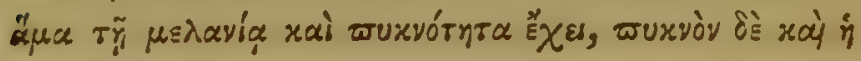

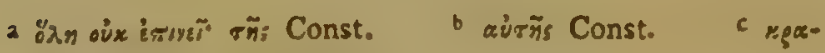

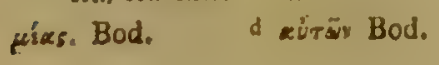




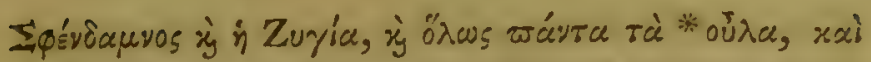

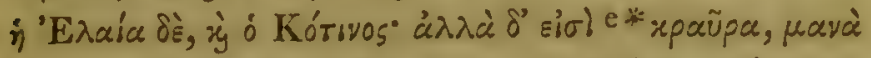

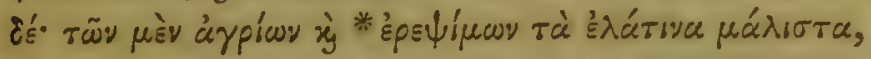

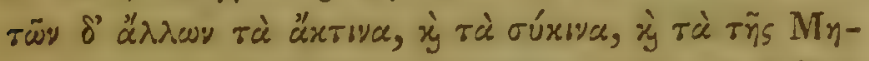

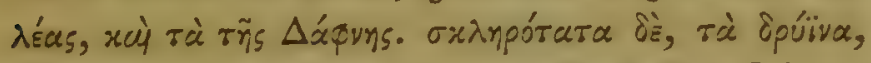

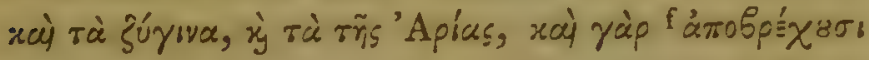

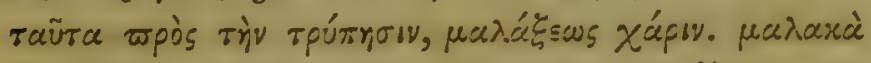

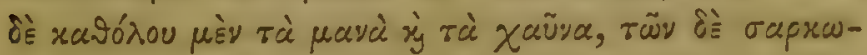

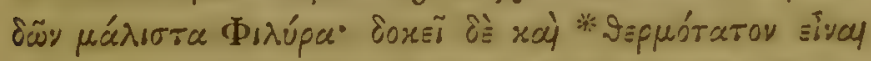

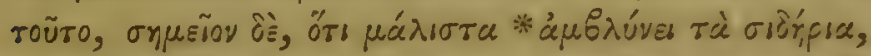

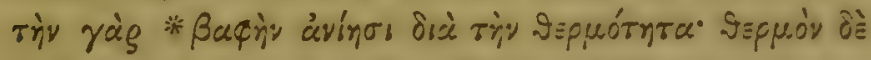

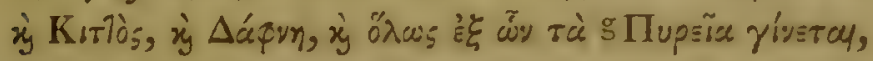

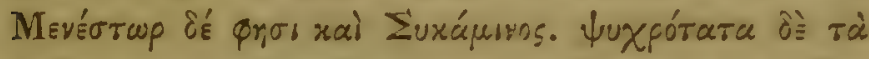

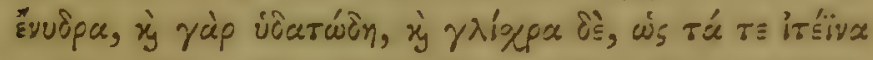

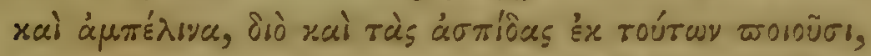

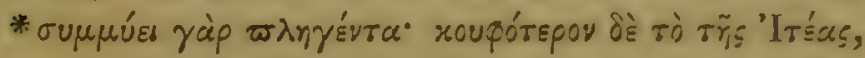

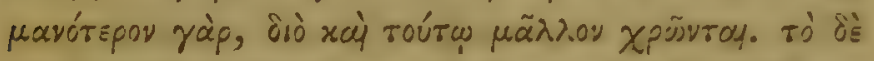

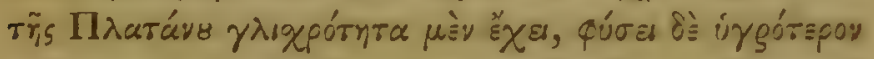

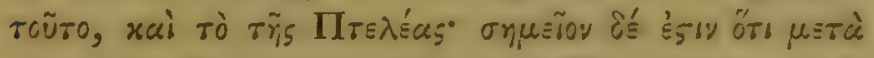

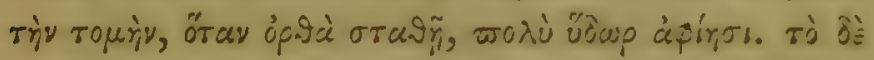

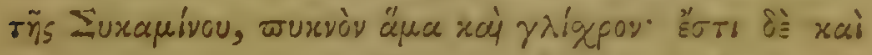

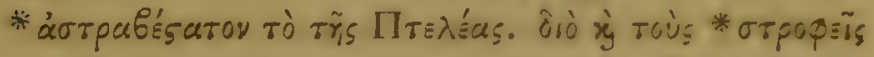

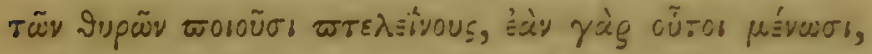

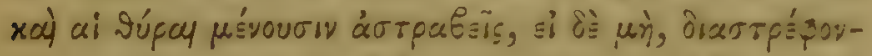

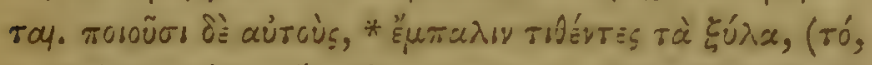

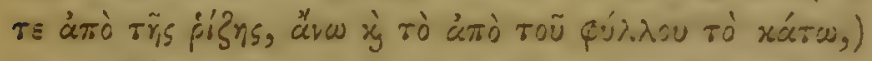

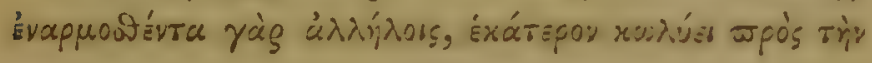

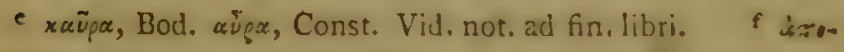
Seía aves Bod. $\mathrm{g}$ zupà Ald. 


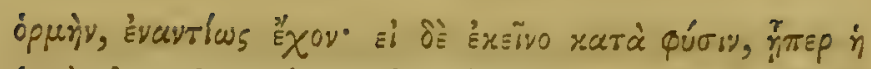

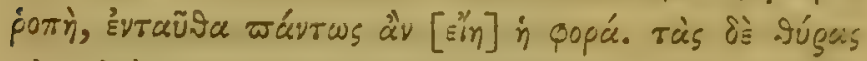

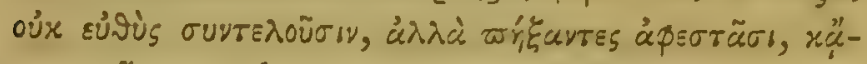

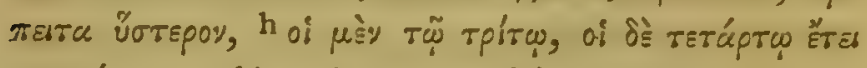

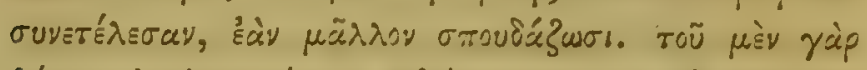

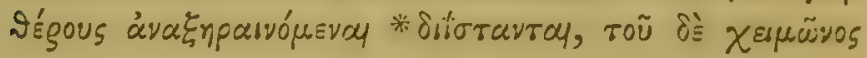

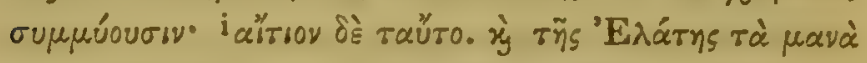

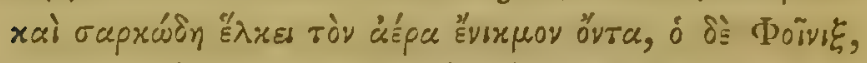

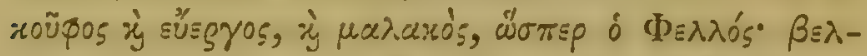

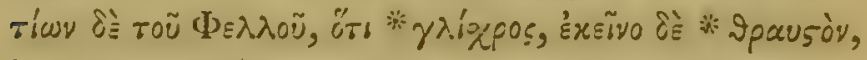

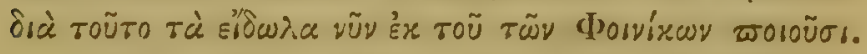

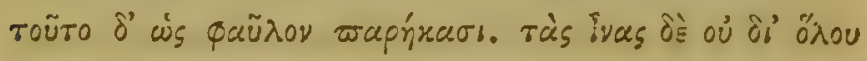

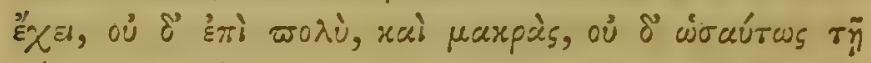

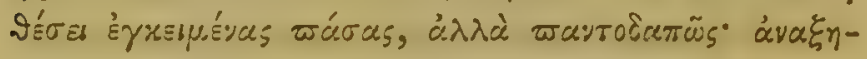

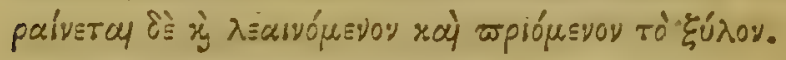

\section{CAP. V.}

De Ligno Thuyce et aliis diuturnis, ut Cupressi, Loti,

Buxi, Juglandis, \&.c. Item de Teredone:navali, L. et Vermibus aliis in Ligno.

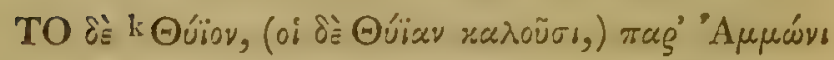

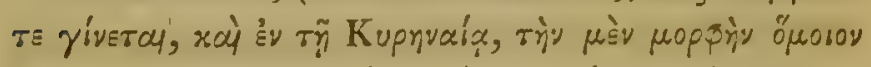

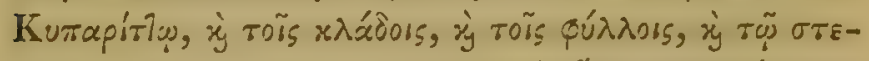

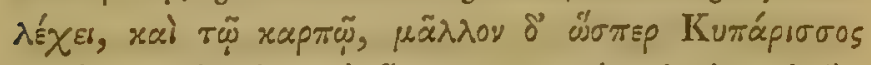

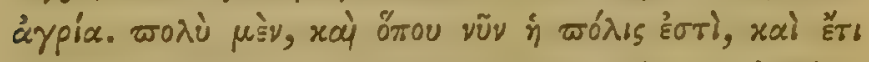

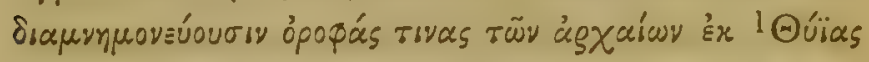

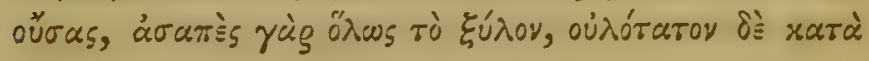

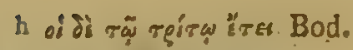
₹ Túv, oi si gúav Ald. 1 gúás. Ald. 


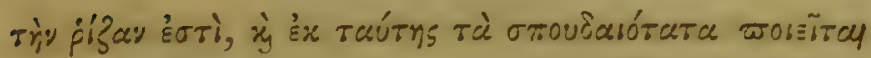

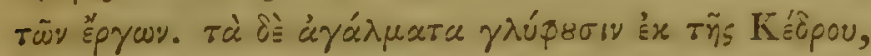

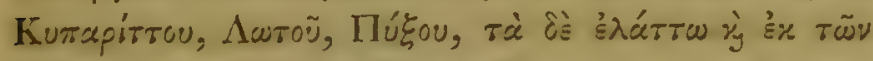

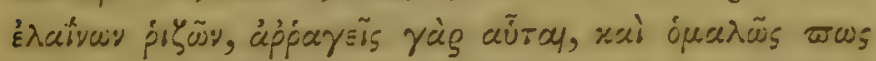

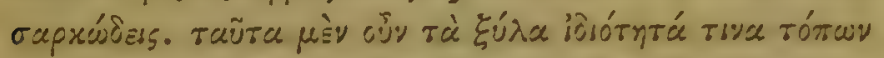
نे qú

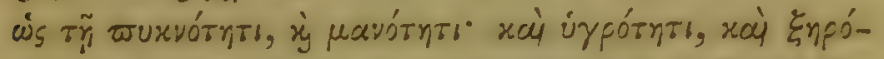

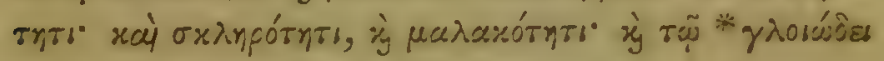

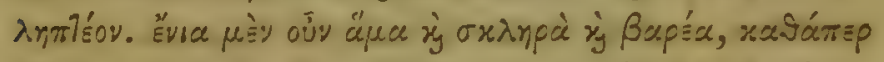

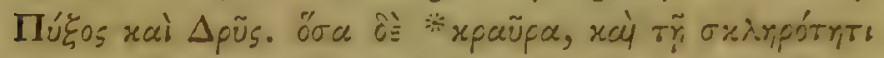

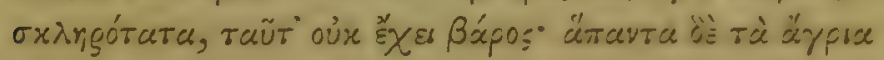

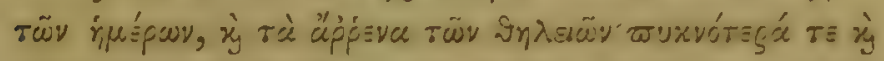

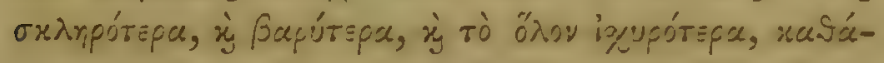
$\pi \Xi \rho$ मे ซ

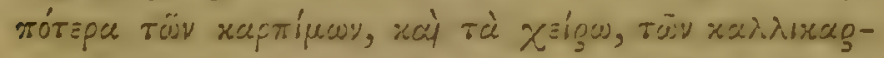

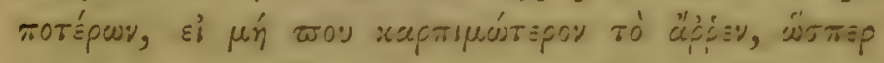

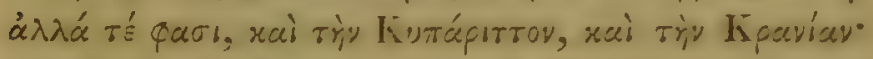

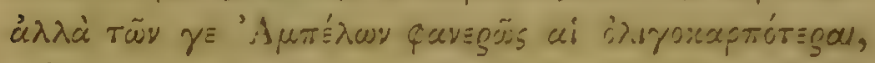

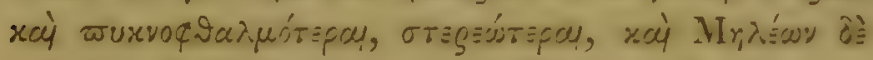

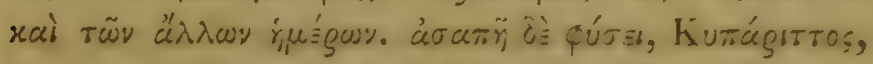

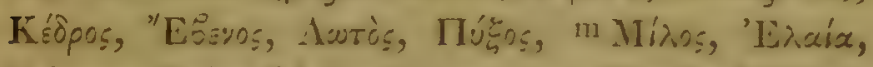

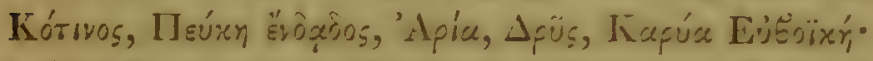

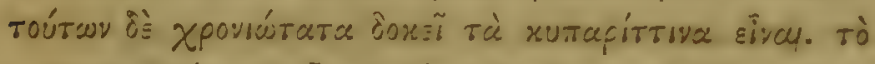

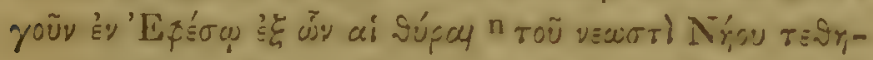

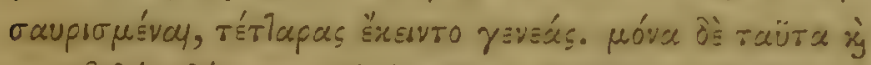

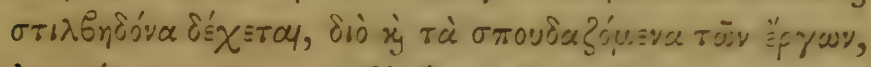

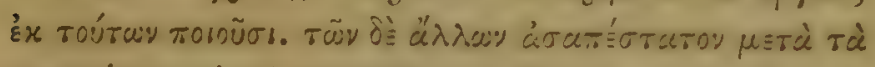

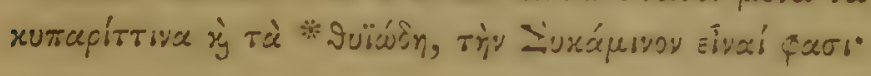

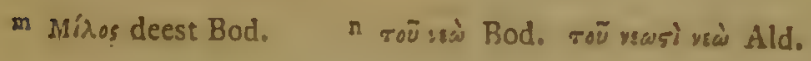




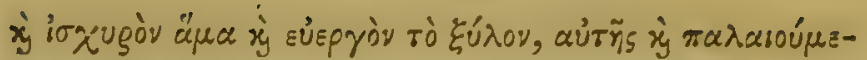

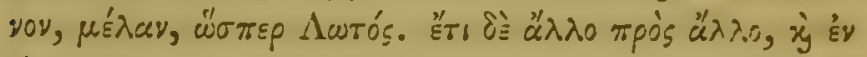

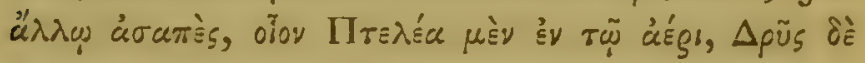

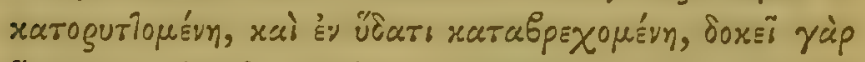

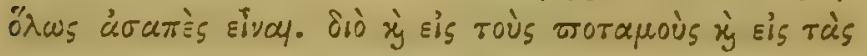

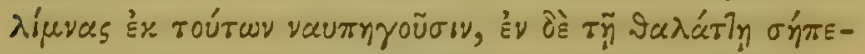

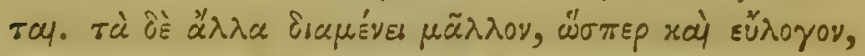

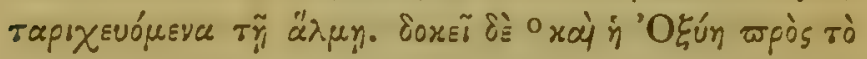

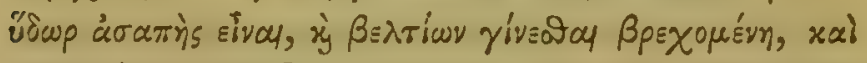

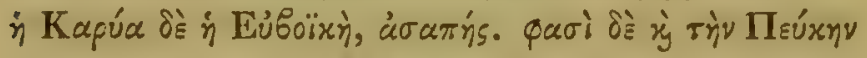
'E

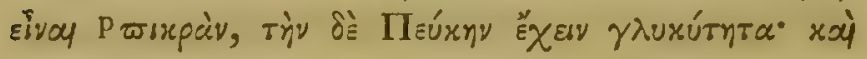
ö ${ }^{\prime}$

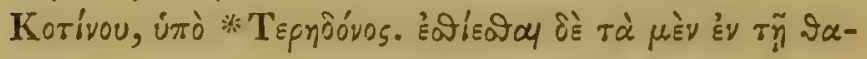

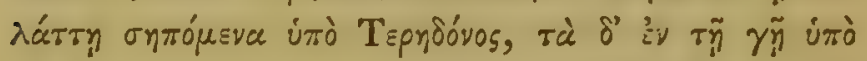

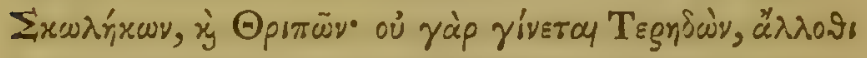

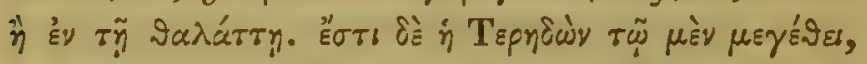

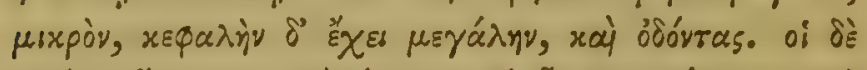

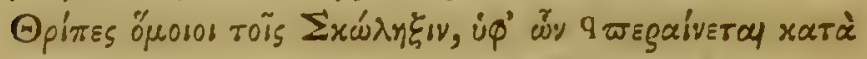

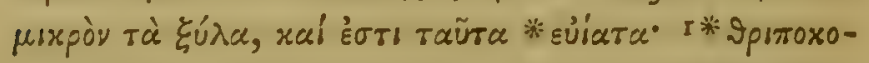

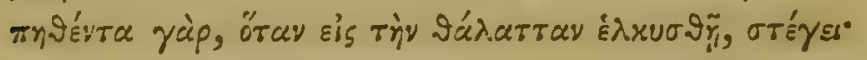

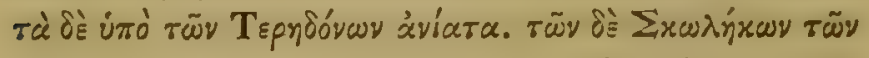

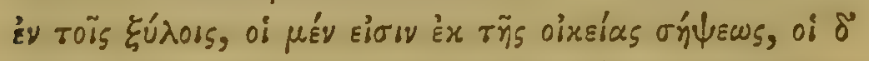

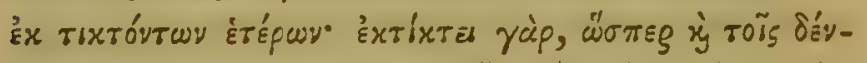

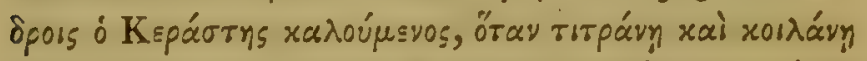

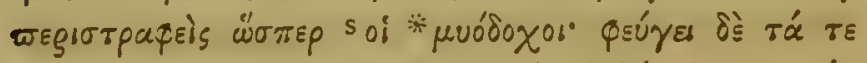

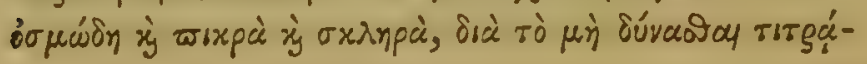

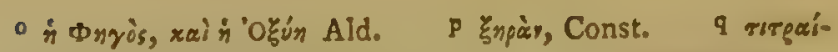

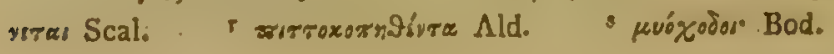




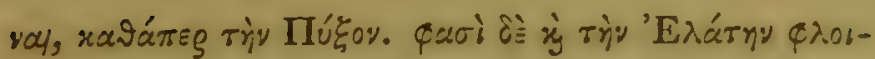

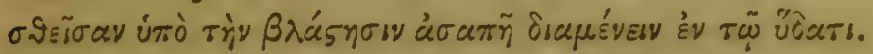

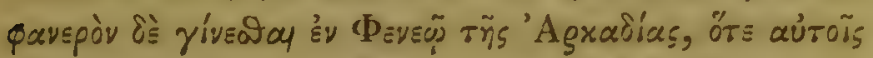

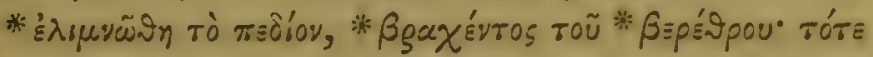

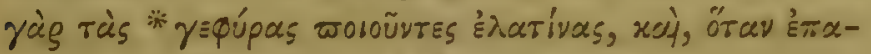
vabain rò ữ

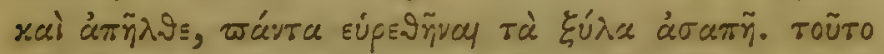

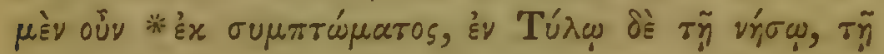

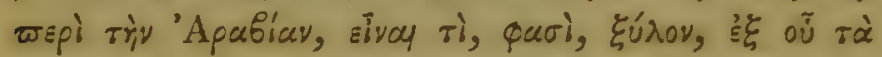

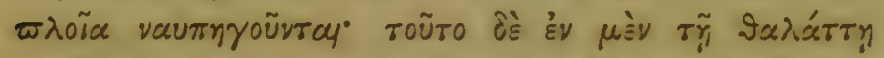

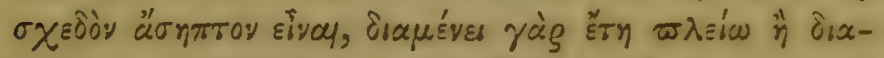

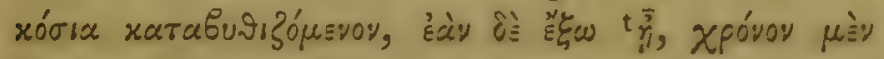

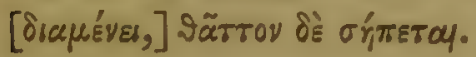

\section{CAP. VI.}

De Ligno tigrino. De condiendis Lignis duris. Quulitates et Differentice Medullac et Alburni.

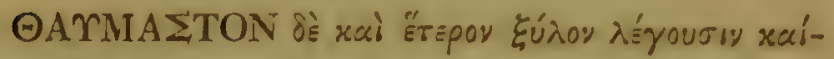

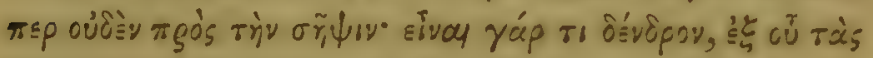

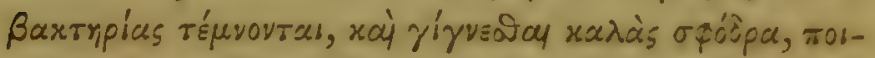

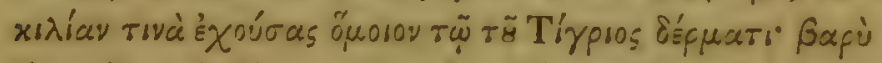

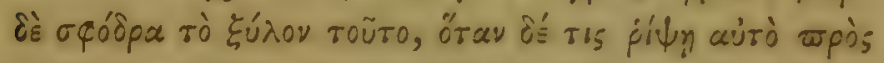

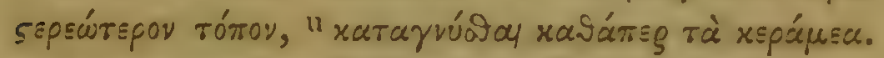

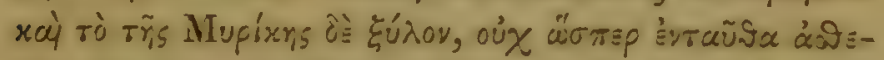

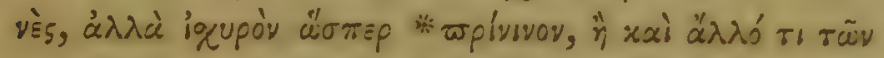

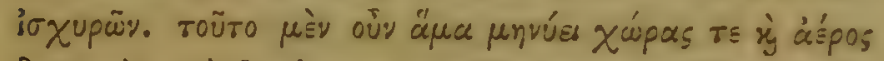

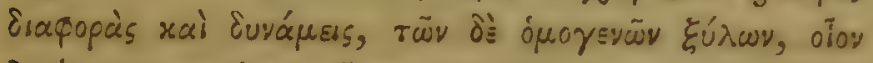

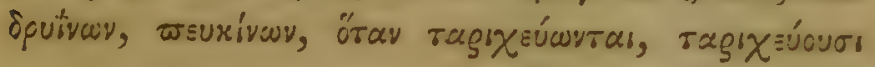

t d deest Bod.

" exrayiversar, Bod. 


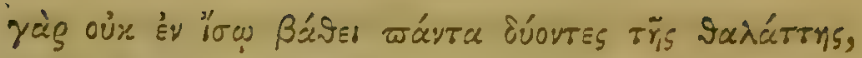

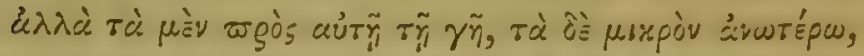

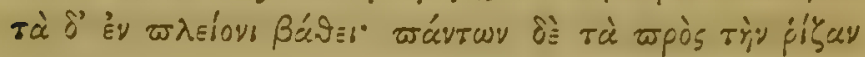

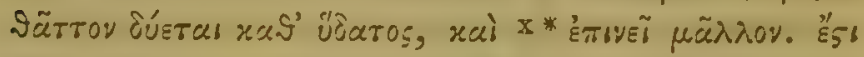

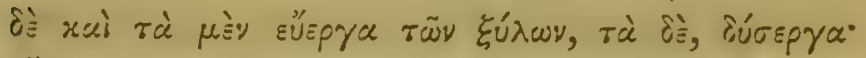

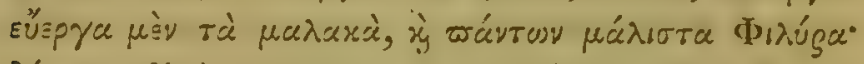

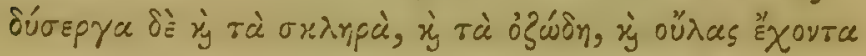

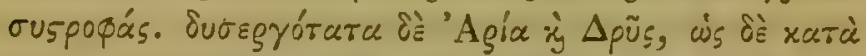

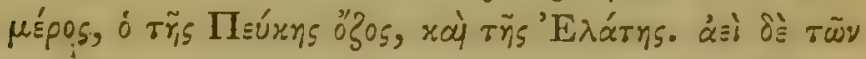

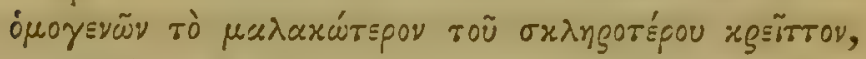

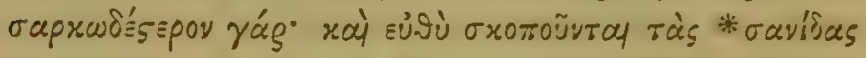

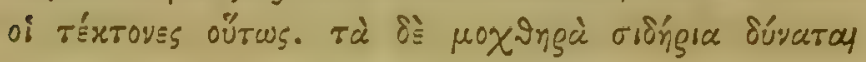

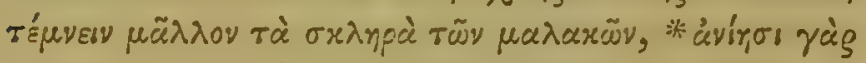

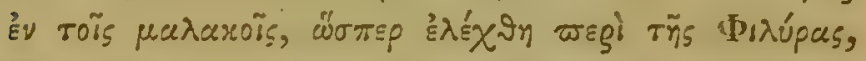

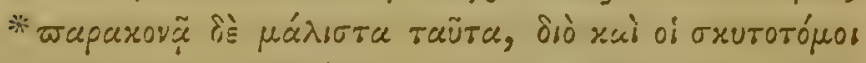

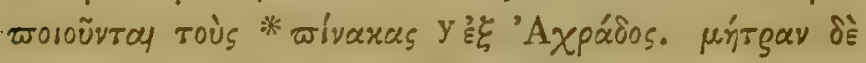

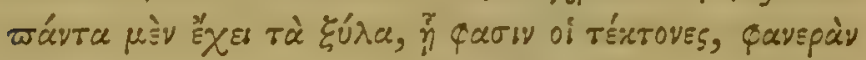

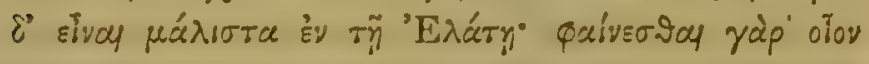

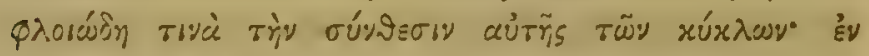

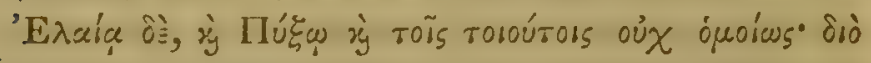

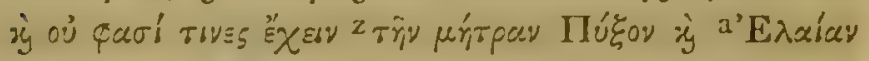

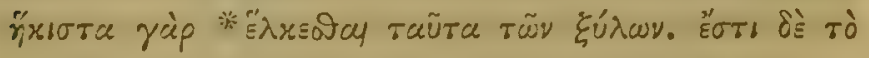

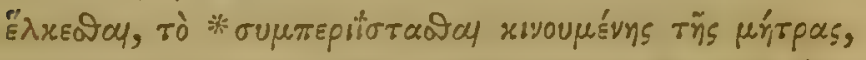

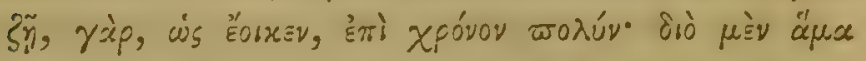

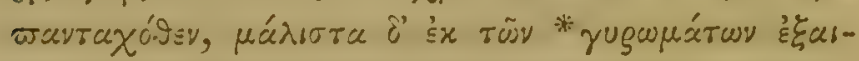

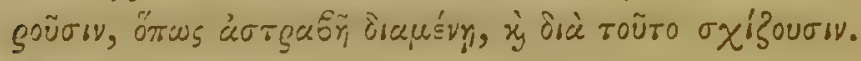

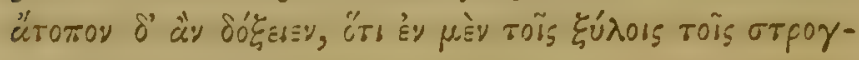

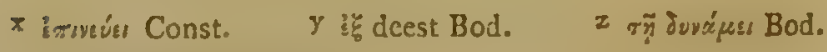

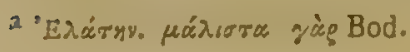




\section{MEPI $\Phi M T \Omega N$ I}

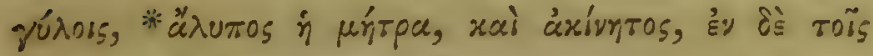

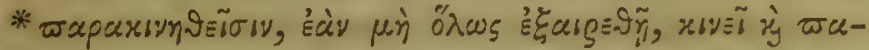

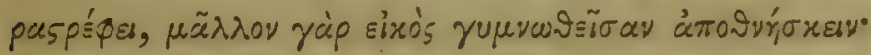

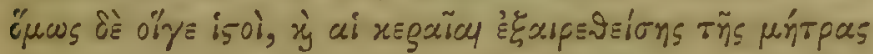

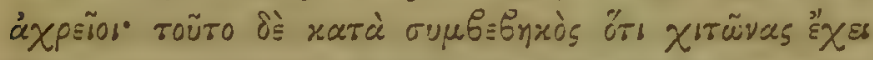

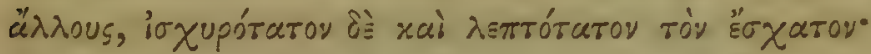

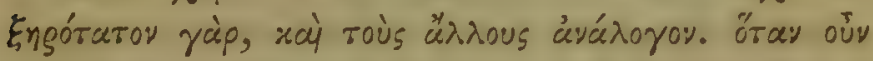

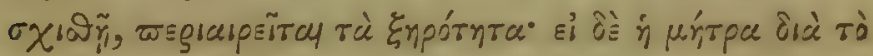

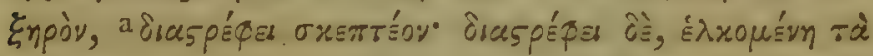

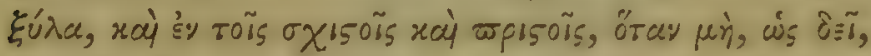

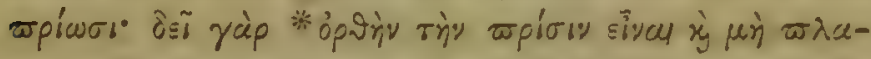

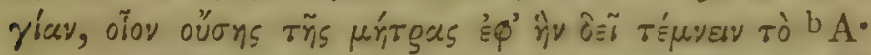

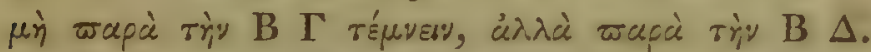

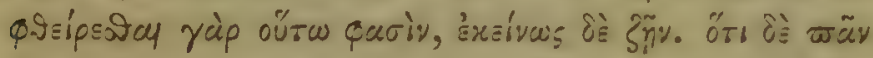

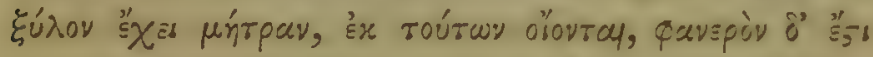

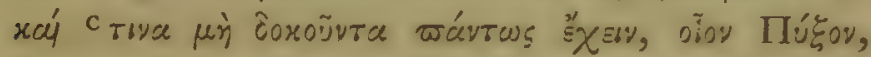

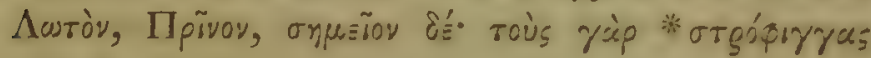

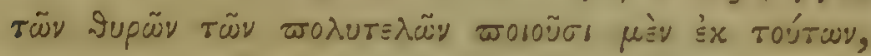

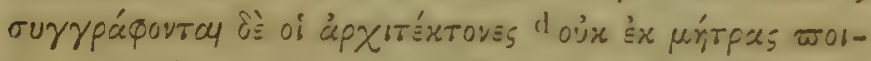

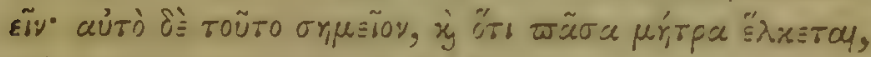

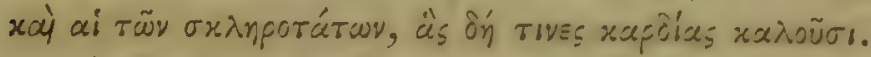

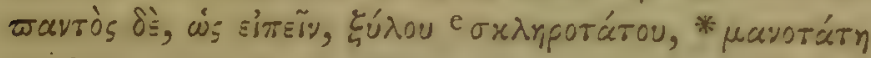

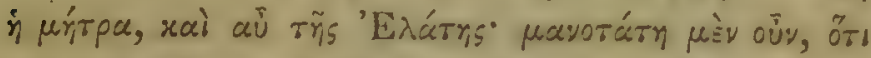

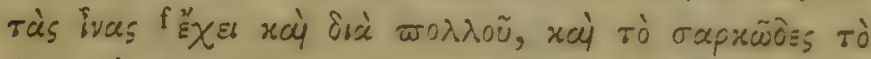

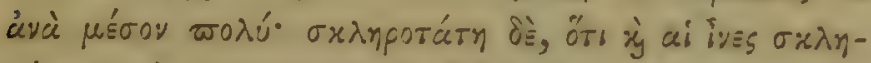

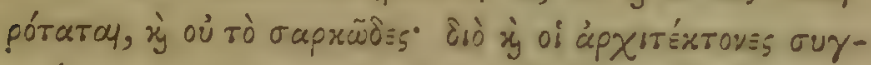

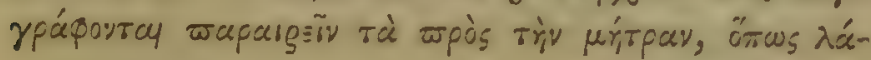

a dıarrpiper deest Bod.

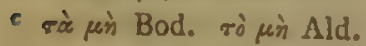

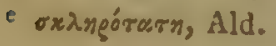

b Vid, nòt, ad finem libri.

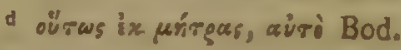
$f$ ixi $i$, Bod. 


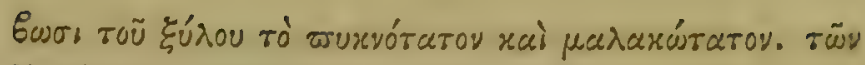

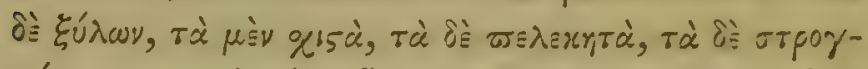

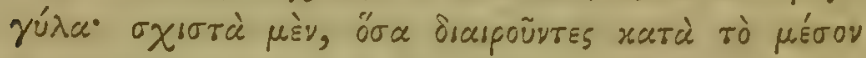

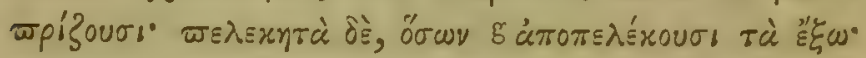

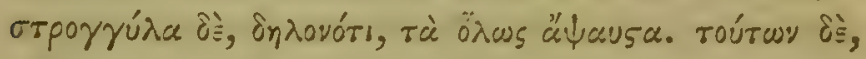

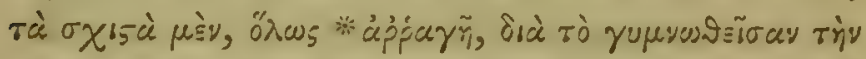

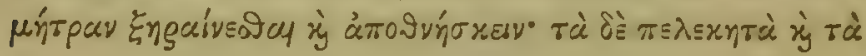

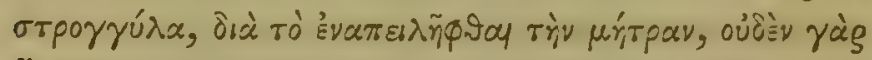

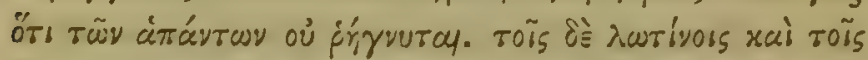

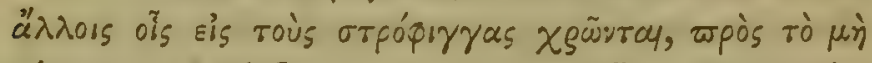

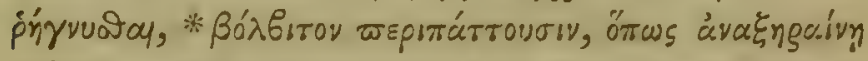

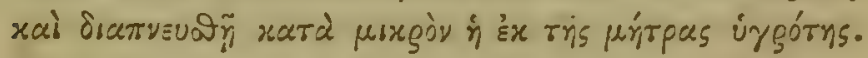

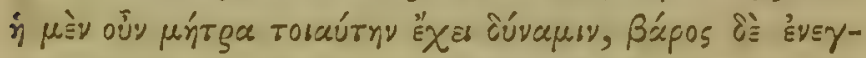

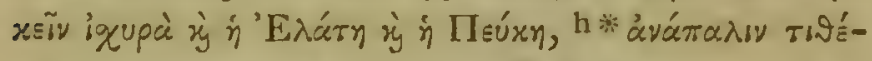

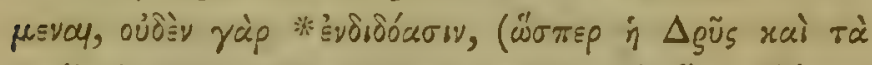

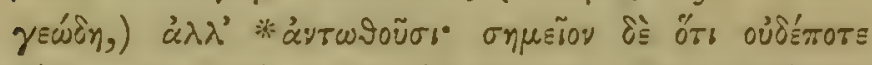
ṕry

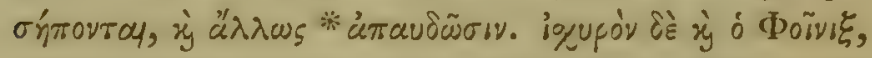

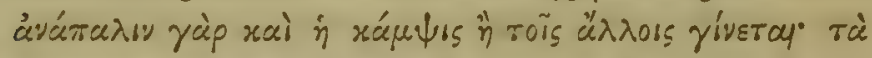

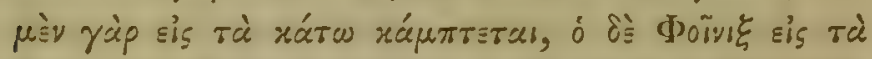

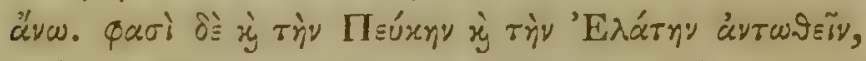

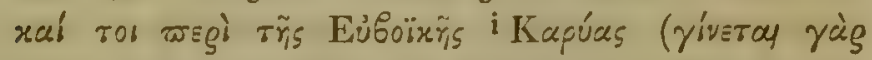

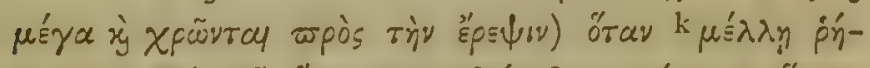

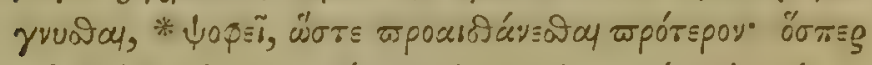

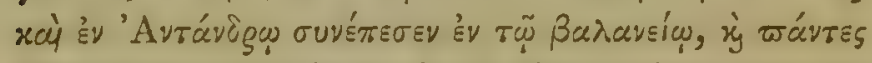

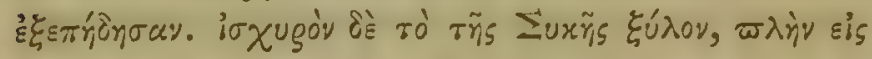

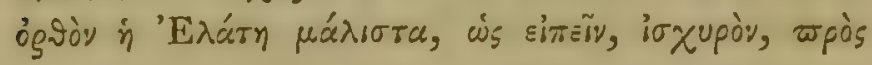

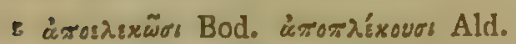
h àzara) Bod.

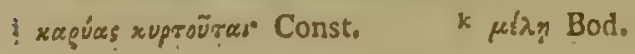




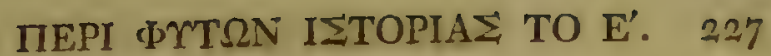

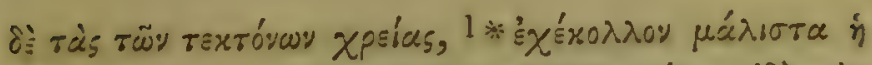

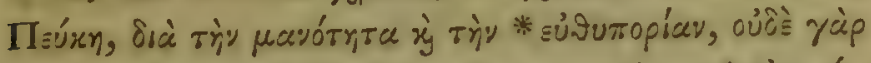

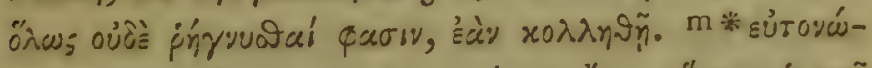

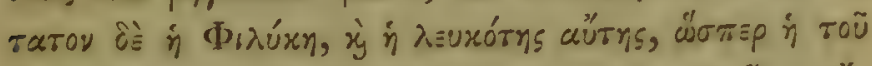

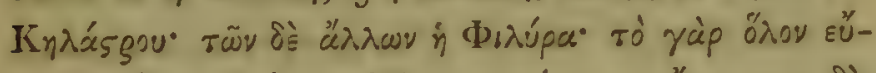

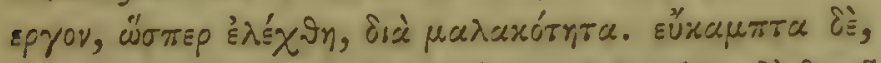

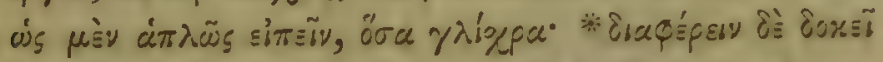

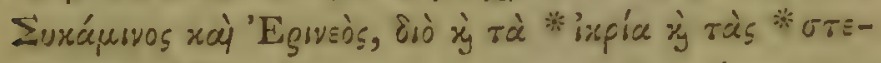
申'ávas, xờ ö̀ อั๊ธเ\%.

\section{CAP. VII.}

Fabricutiones et Usus fabriles Lignorum.

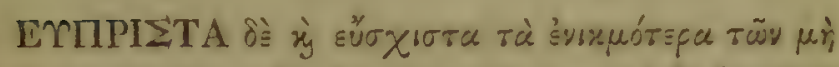

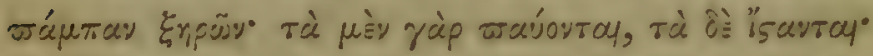

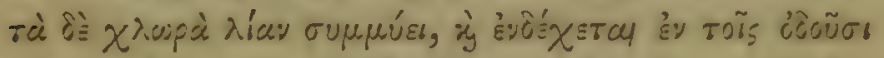

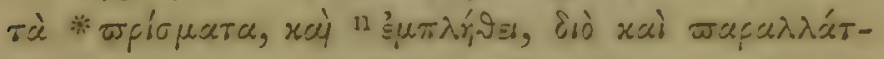

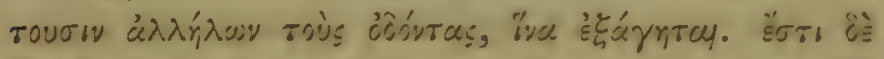

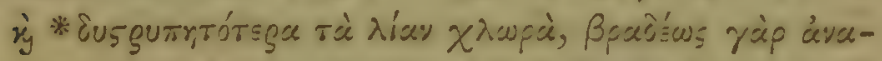

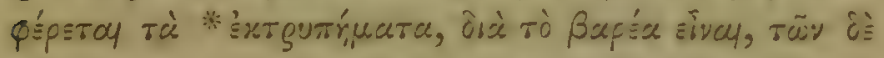

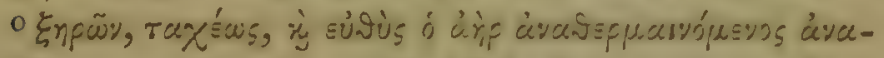

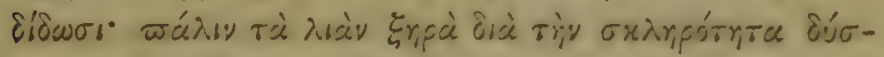

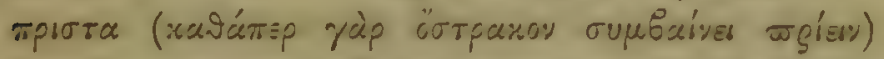

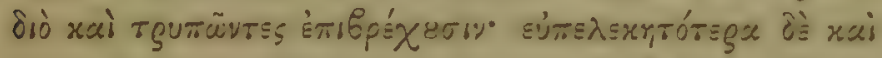

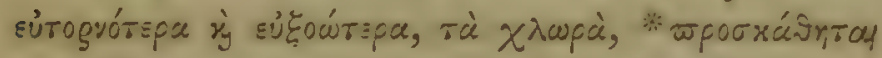

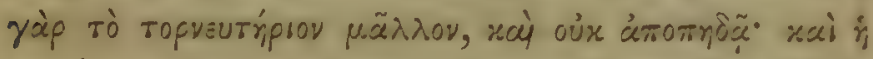

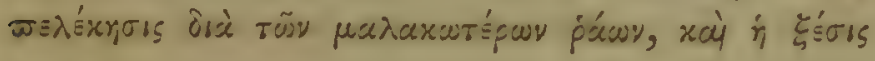

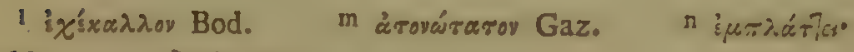
Ald. O Sevär Bod.

Q 2 


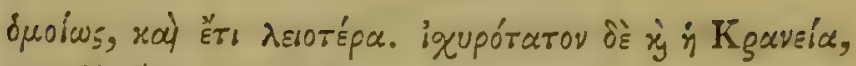

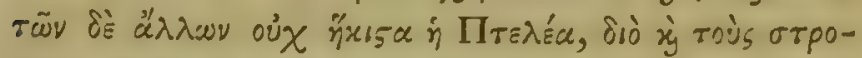

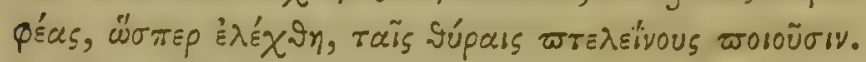

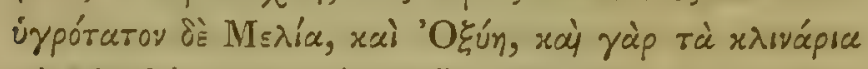

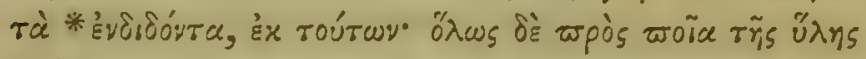

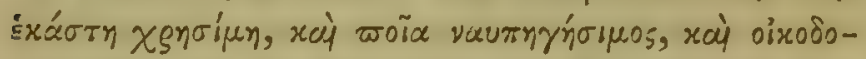
$\mu เ x \dot{y}$ (

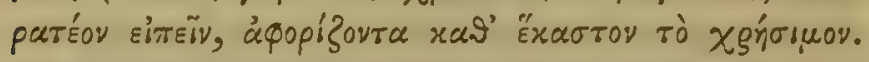

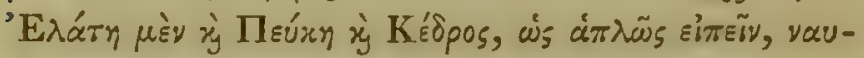

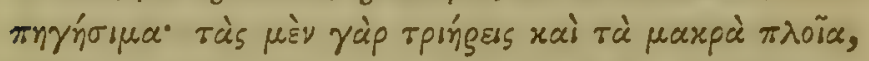

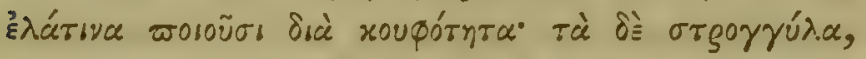

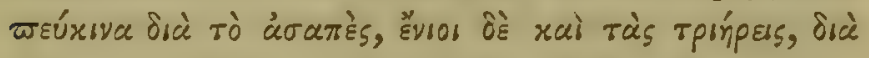

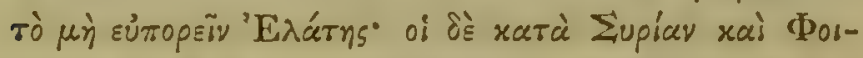

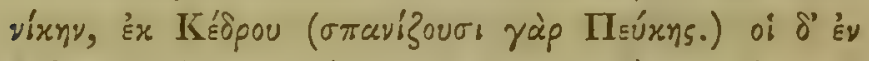

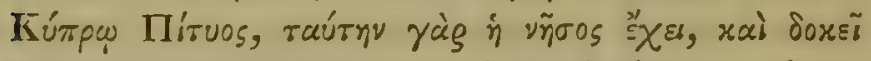

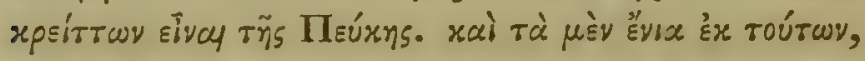

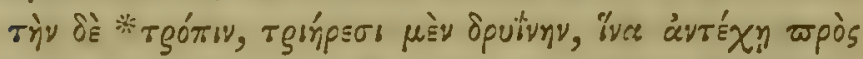

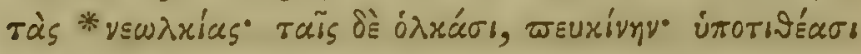

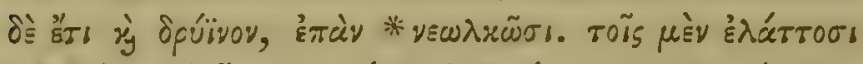

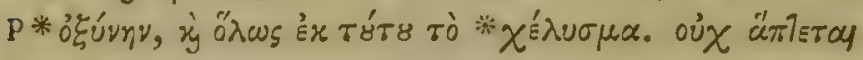

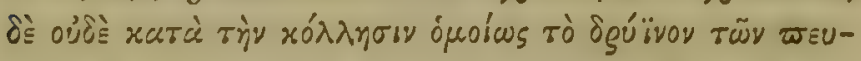

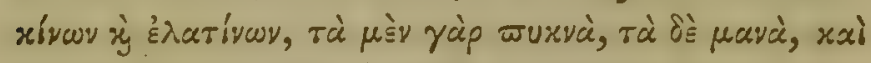

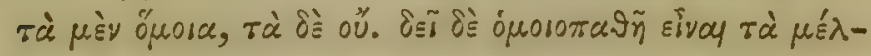

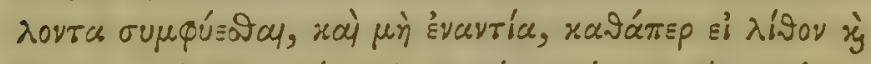

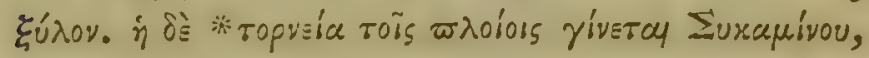

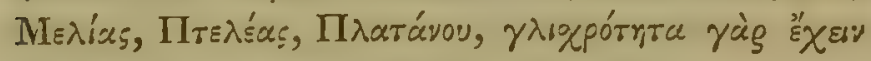

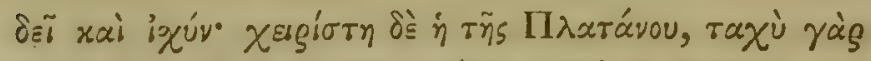

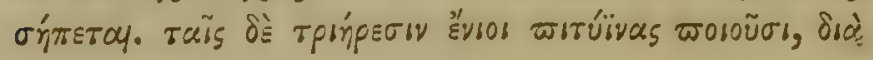

p̣ ¿̌̌únn, Bod. 


\section{MEPI $\mathscr{\text { TTT } \Omega N ~ I \Sigma T O P I A \Sigma ~ T O ~ E ' . ~}$}

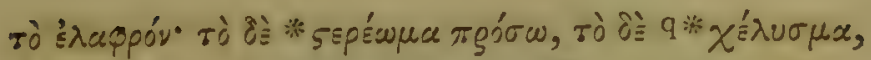

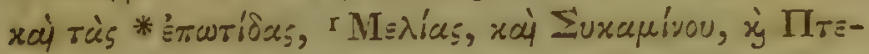

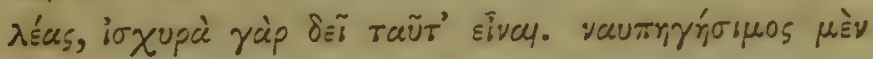

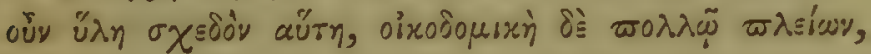

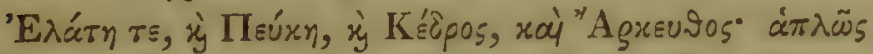

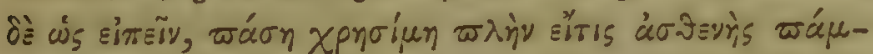

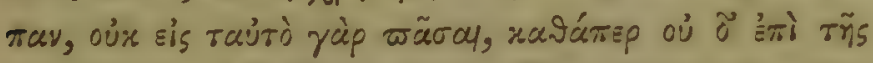

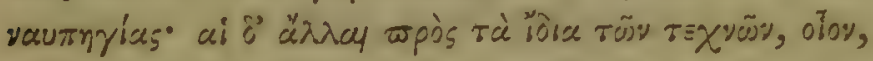

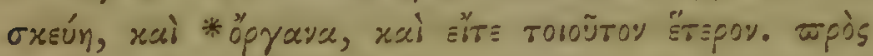

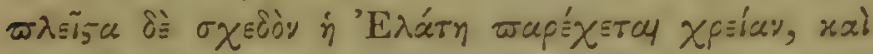

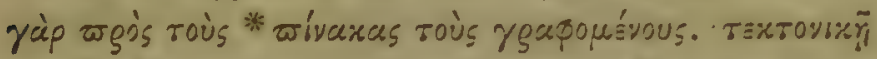

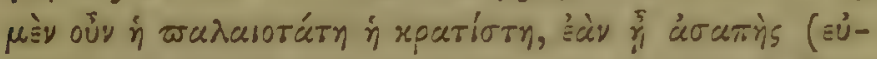

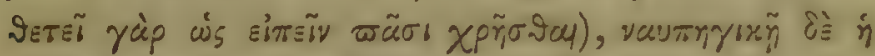

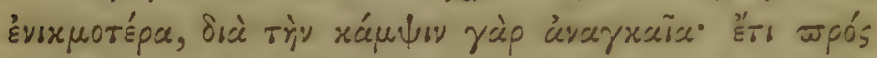

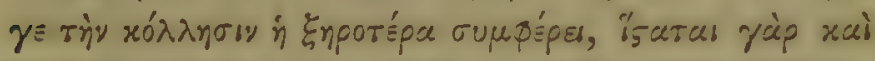

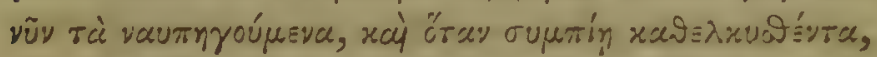

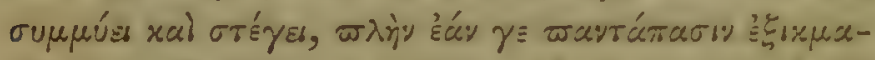

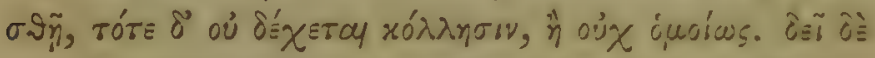

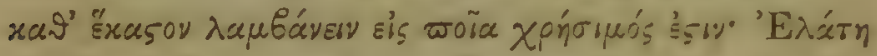

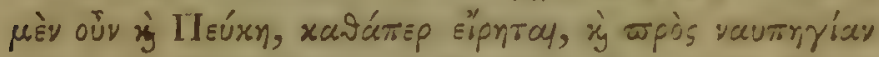

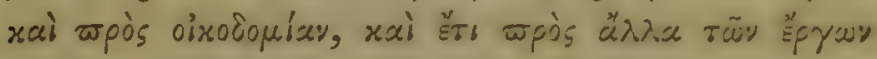

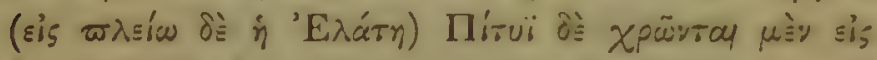

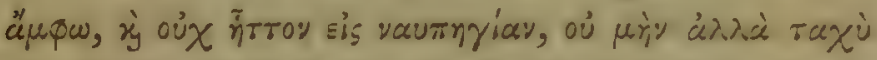

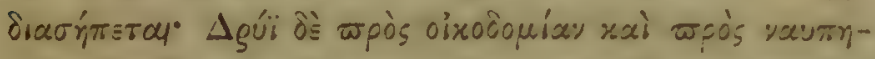

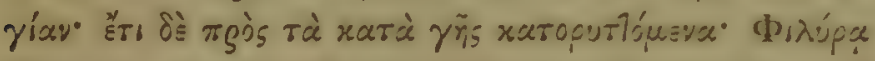

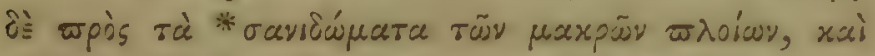

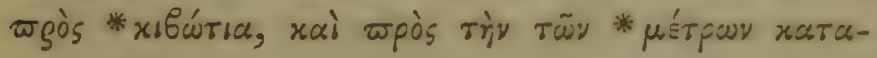

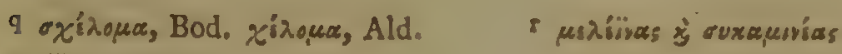
Trisives. Const. 


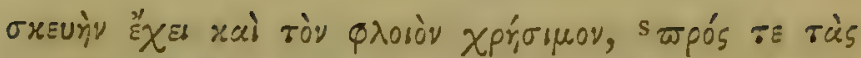

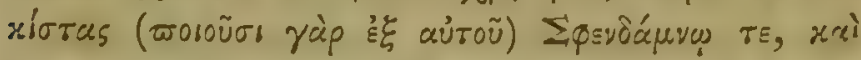

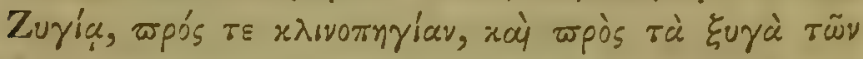

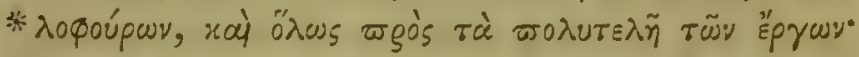

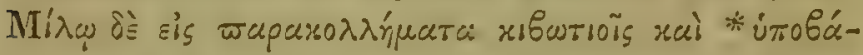

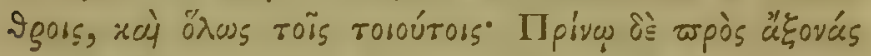

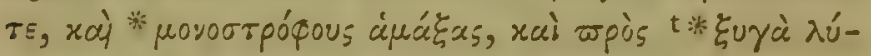

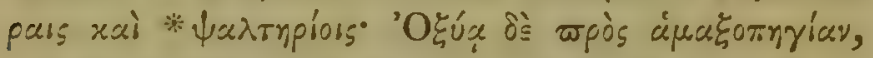

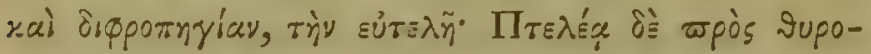

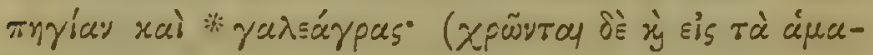

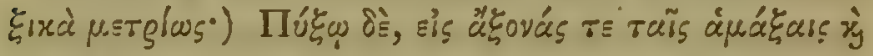

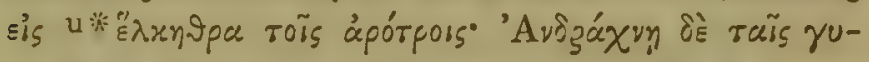

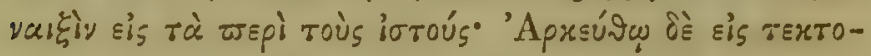

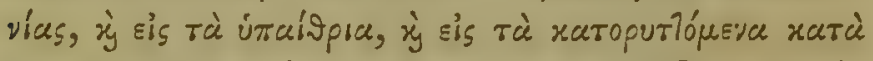

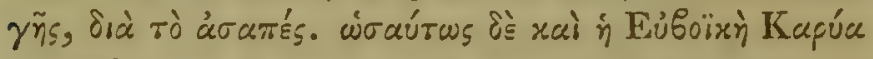

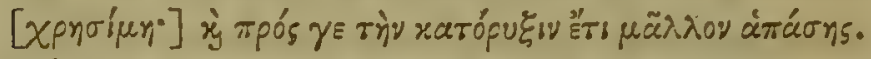

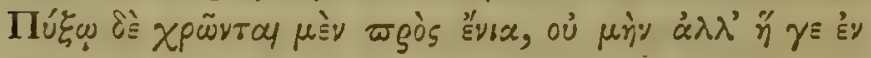

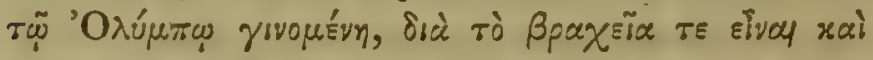

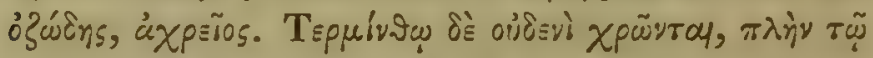

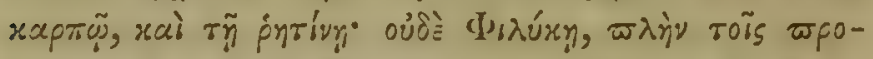

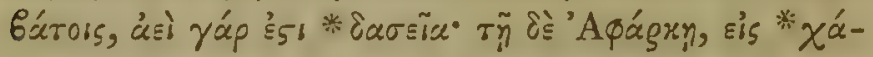

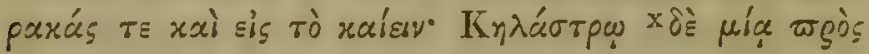

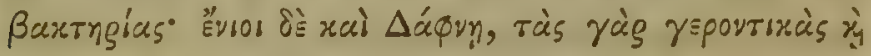

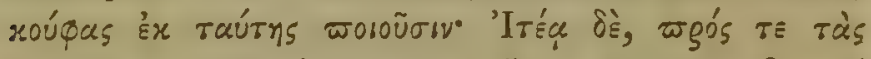

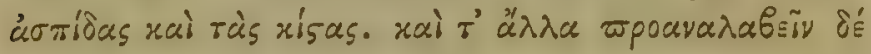

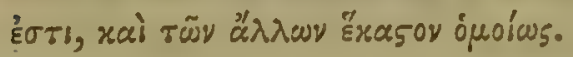

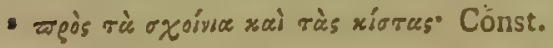

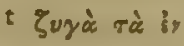

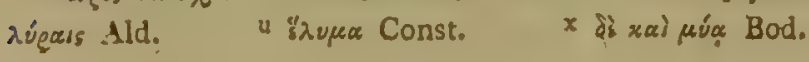




\section{MEPI TYTSN ISTOPIAS TO E'. 23 I}

\section{CAP. VIII.}

Organa ex Ligno: Usus navales.

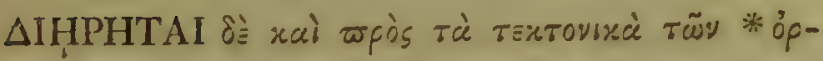

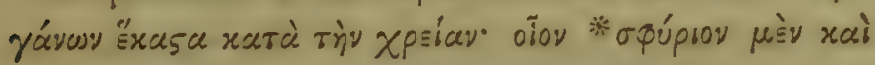

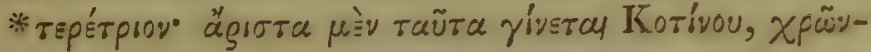

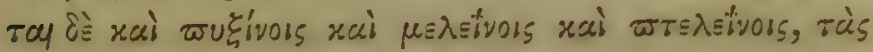

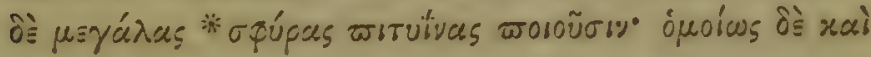

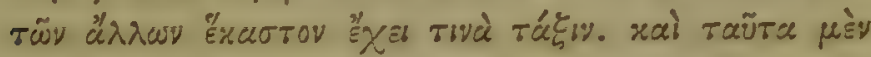

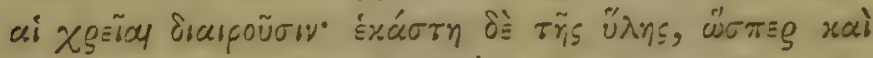

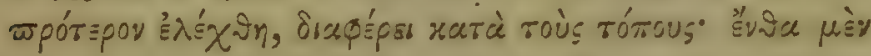

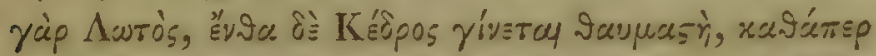

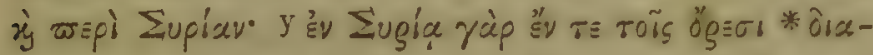

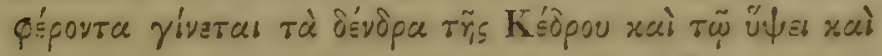

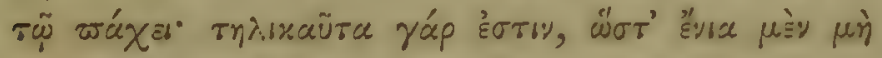

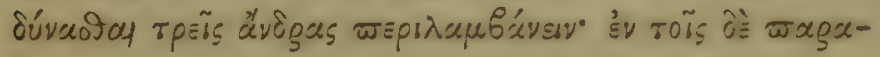

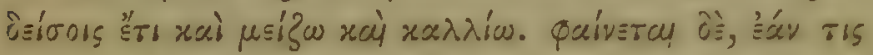

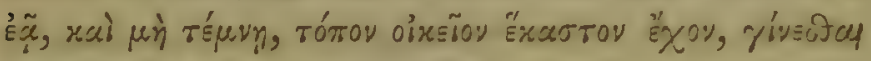

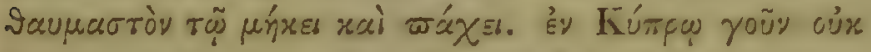

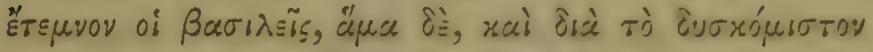

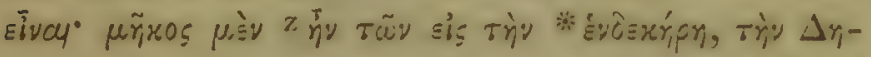

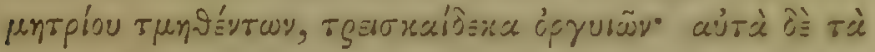

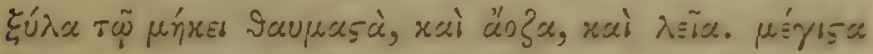

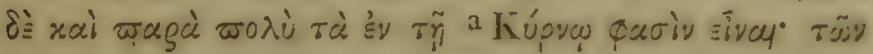

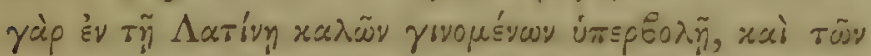

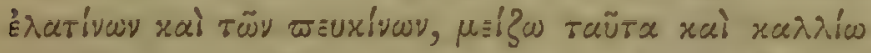

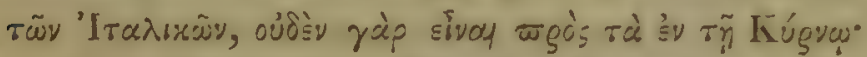

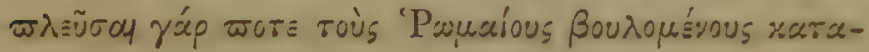

y iv deest Bod.

$$
z \text { ที่ รับิ Bod. }
$$

- Kogáixy Scal.

\section{Q 4}




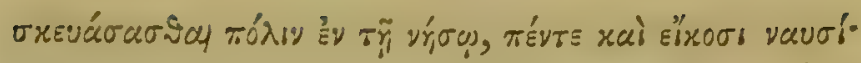

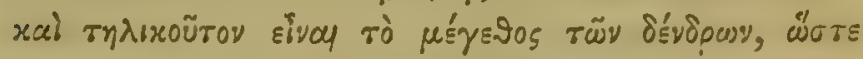

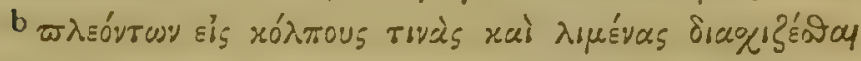

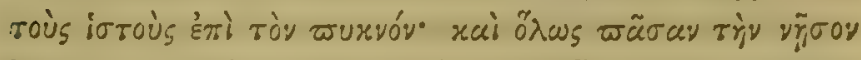

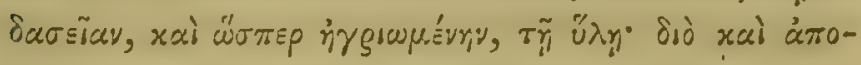

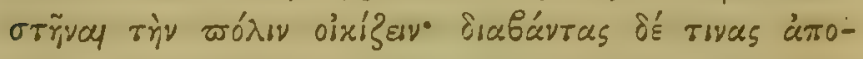
T⿱㇒㠯

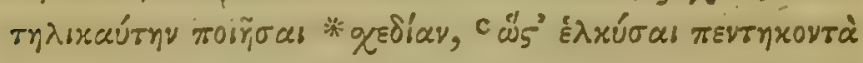

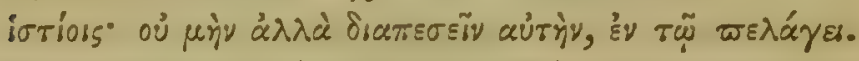

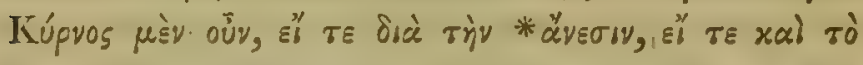

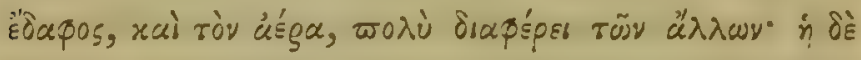

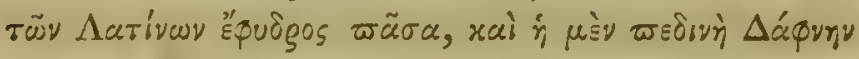

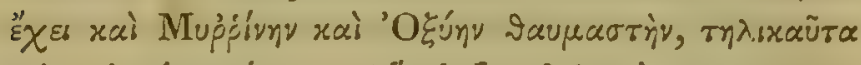

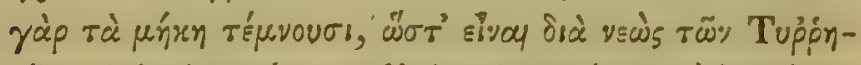

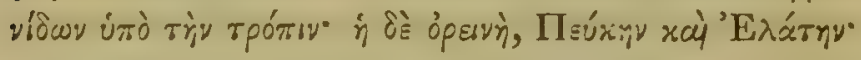

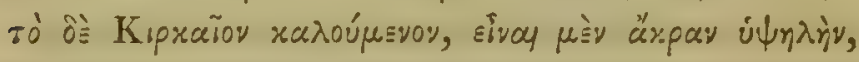

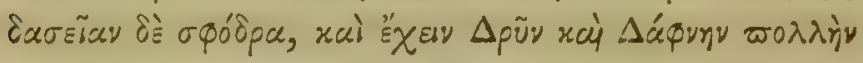

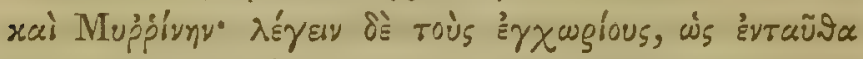

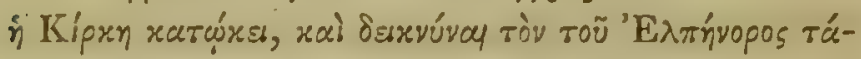

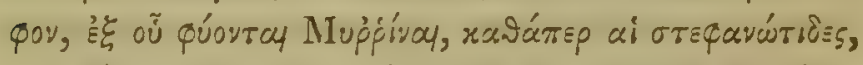

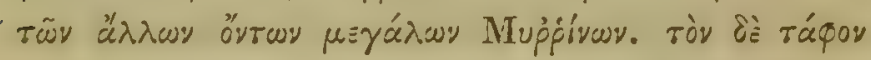

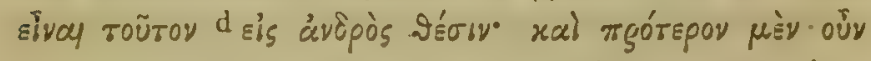

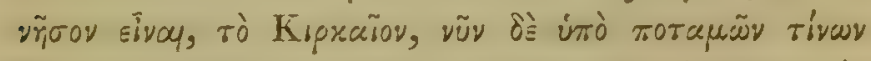

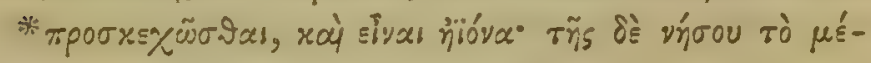

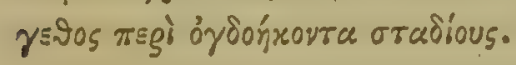

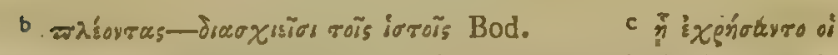

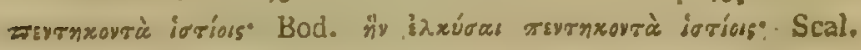

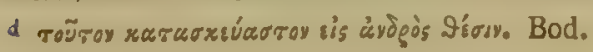




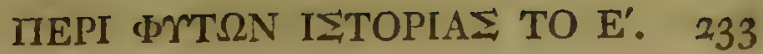

\section{CAP. IX.}

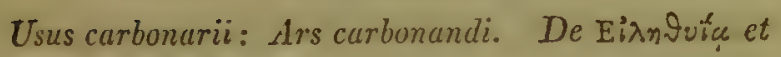

$$
\text { Mugríce. }
$$

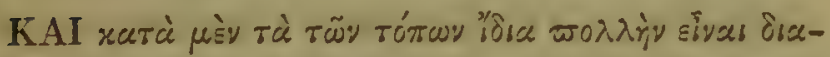

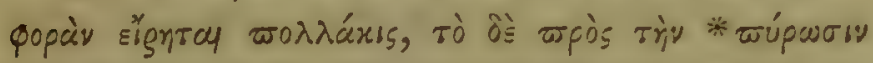

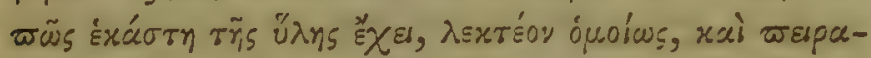

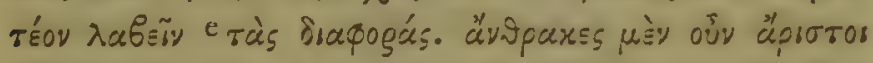

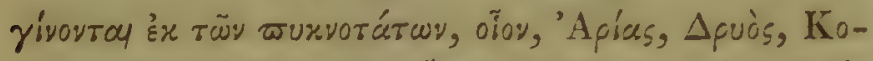

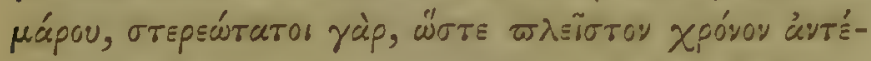

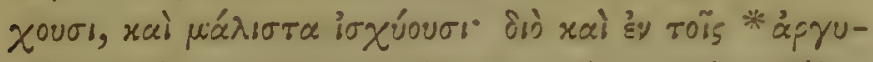

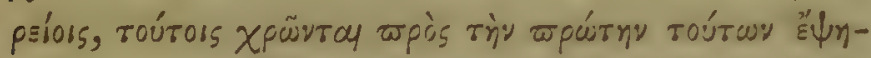

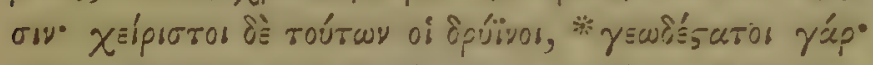

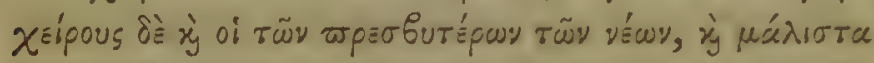

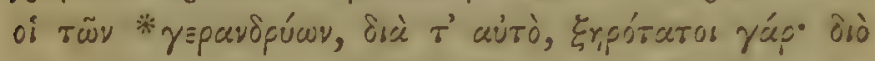

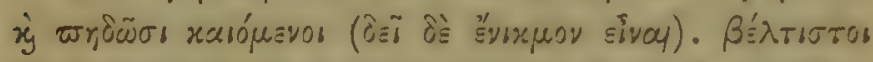

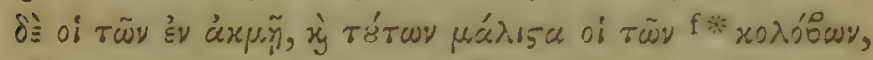

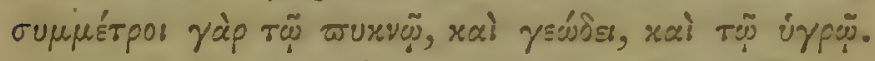

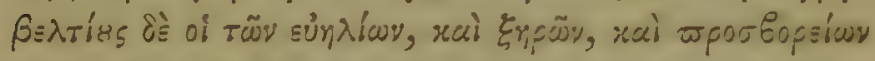

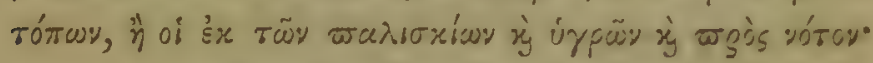

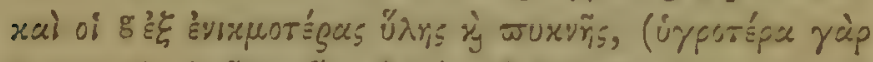

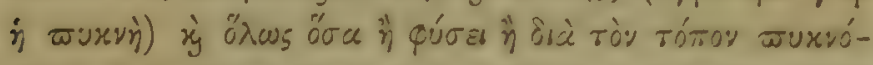

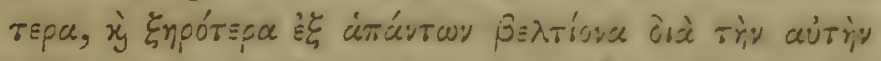

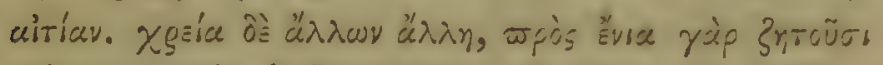

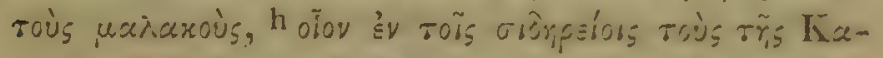

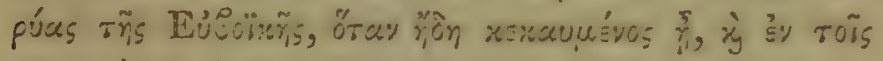

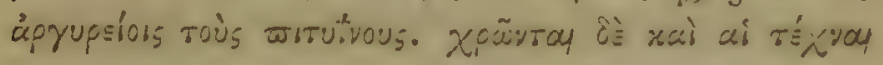

C 'ràs joxpogàs desunt Bod.

f roגá6wy. Bod.

$g i \xi$ deest Bod. b ois Ald. Bas. 


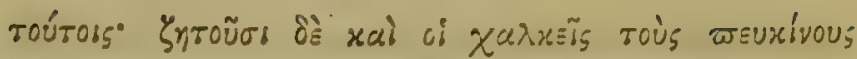

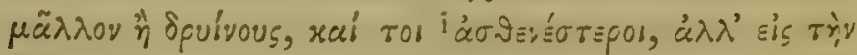

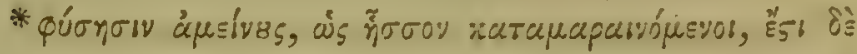

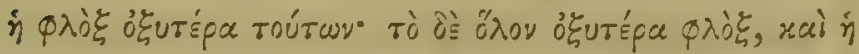

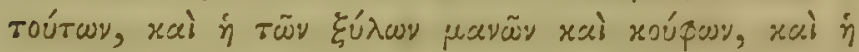

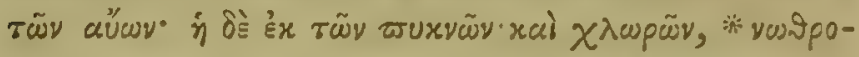

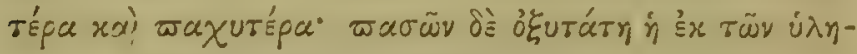

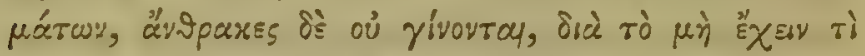

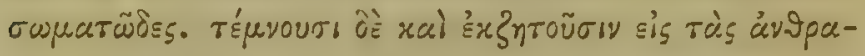

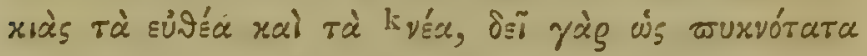

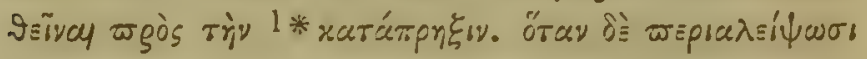

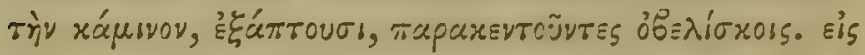

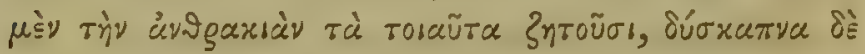

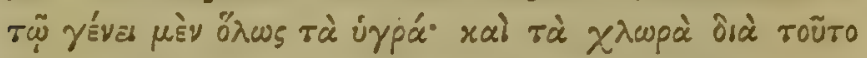

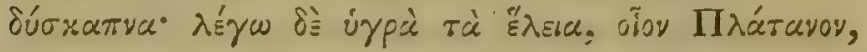

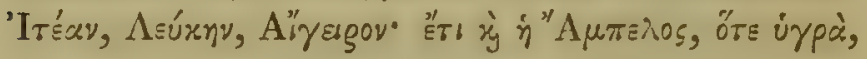

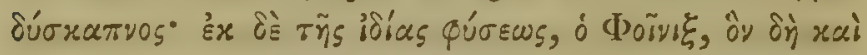

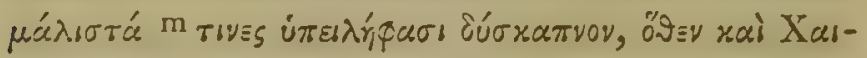

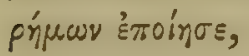

\section{Toũ $\tau \varepsilon \delta \cup \sigma x \alpha \pi \psi \omega \tau a ́ r, 0 u$}

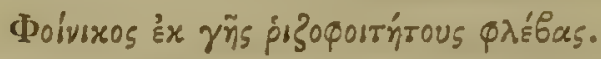

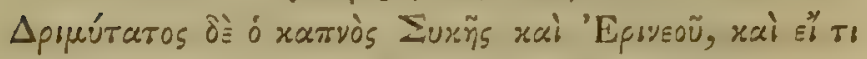

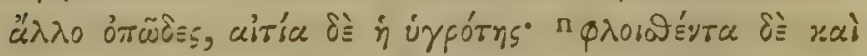

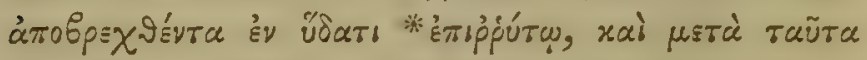

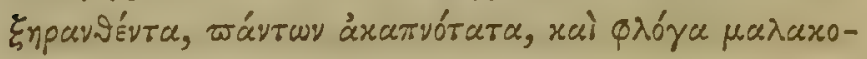

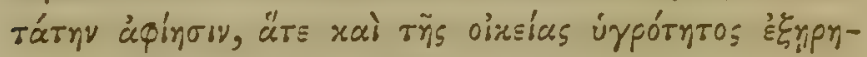

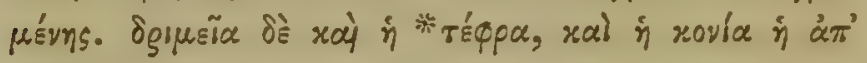

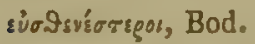

$k$ rĩa. Ald.

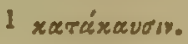

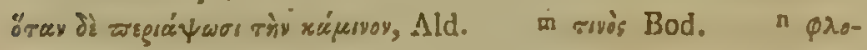
yır'ivre Bas. 


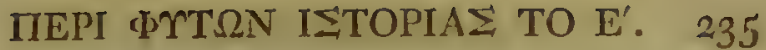

aủं

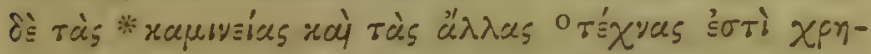

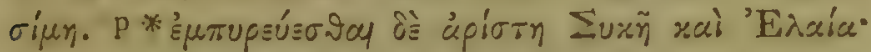

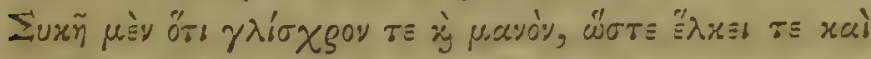

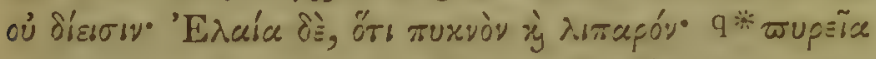

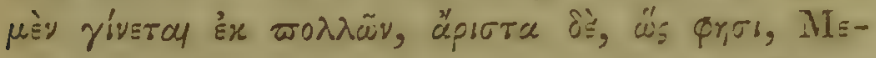

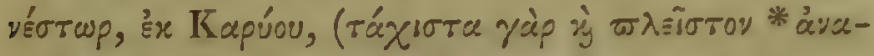

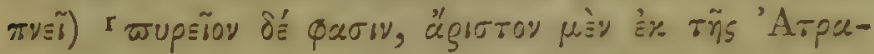

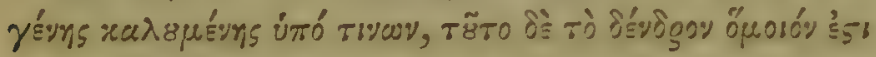

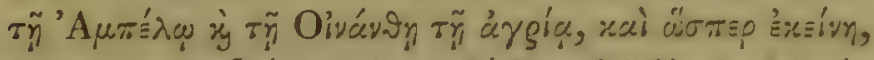

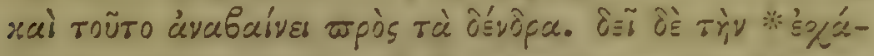

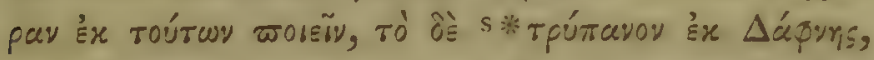

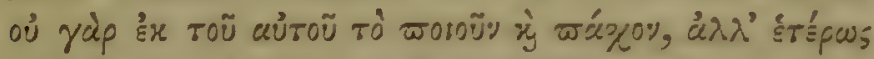

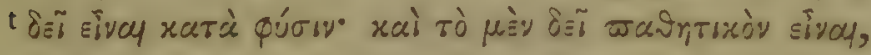

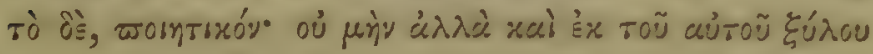

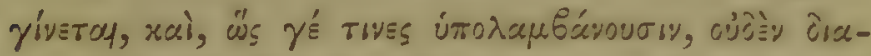

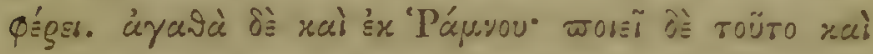

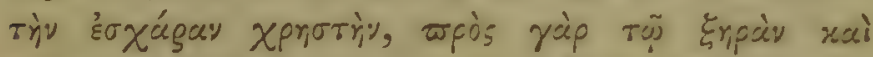

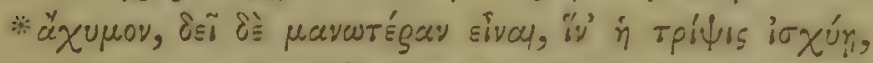

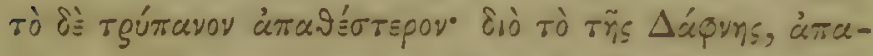

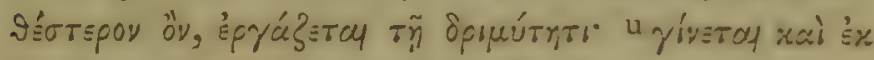

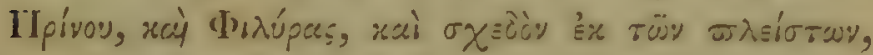

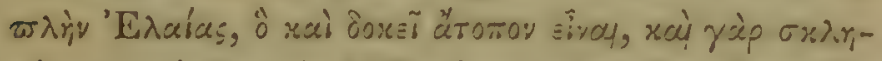

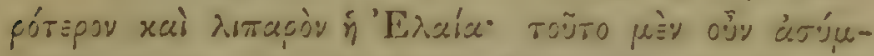

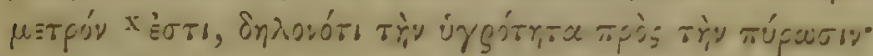

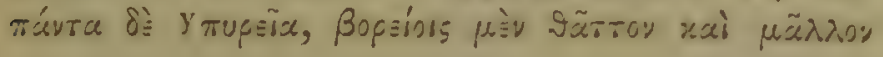

- Tíxvas ä $\lambda \lambda n^{\prime} \lambda$ as lari Bod. se 9 as Bod. q rupgè Bod.

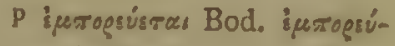

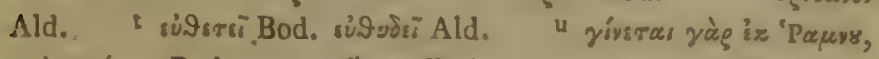

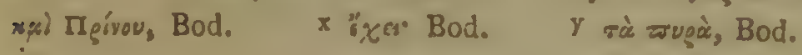




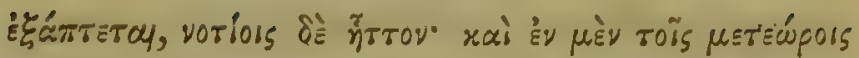

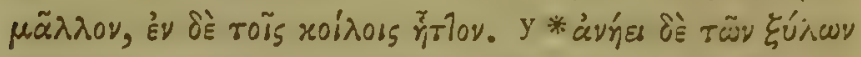

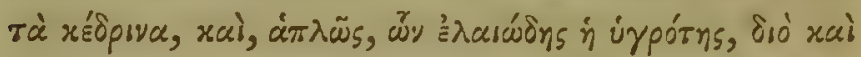

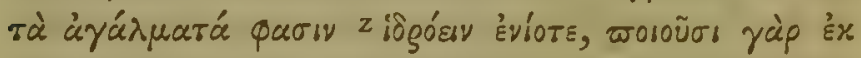

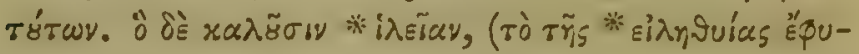

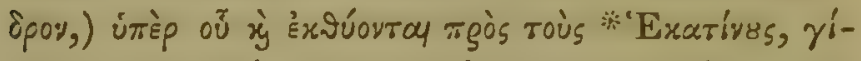

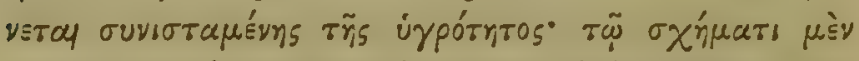

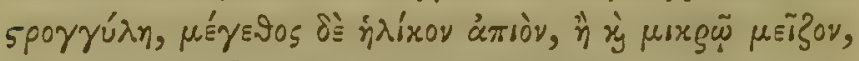

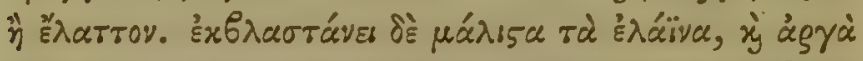

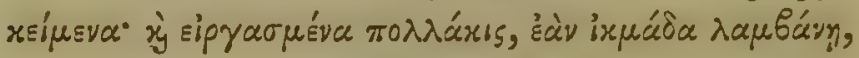

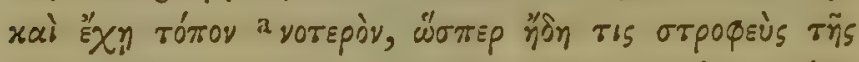

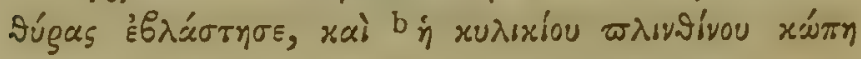

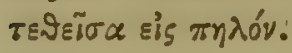

y üyres Ald. $z$ isgien Ald. BDien Bod.

a véтรgov" Ald.

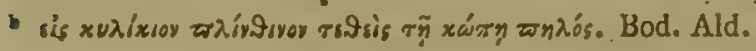




\section{NOT}

\section{IN LIBRUM QUINTUM.}

\section{CAP. I.}

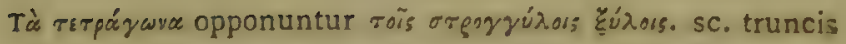
quibus in ædificando utebantur " non dolatis :" vid. Plin. xv. 2. xvi. 15, 18, Vitruv. ii. 9.

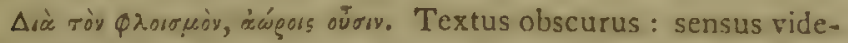

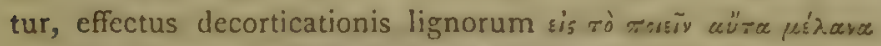
minimi momenti cffe in iis qux ad tigna vel alios usus cæ-

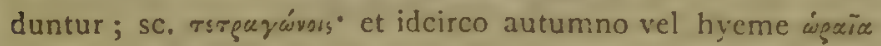

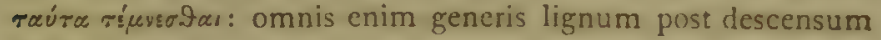

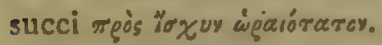

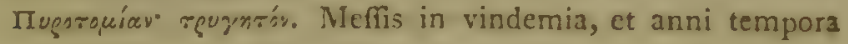
proxime sequentia, altera alteram.

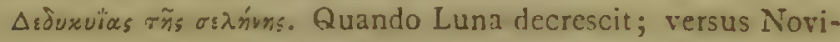
Iunium.

"Ora boúrteras. Qua subtus terram in ædificando collocantur.

\section{CA P. II.}

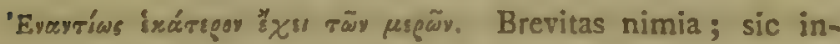
sellige, ubi caro mollis, fibræ rigidæ, et e contra.

Terpašón: d'soovs. Ubi venxe ordine quadruplici vel duplici

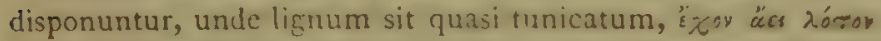

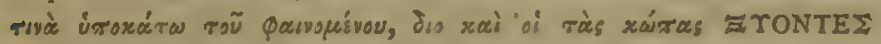

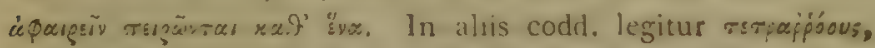
quod Plinius inter rectatur qualruplici ordine fluvintas: cursus enim venarum: Auvios vocatint Latini. xv. 39. Vitruvius ctiam Abietis lignum qudififurvium rocat. Alii ex verbe 
¿ávves interpretantus quarlruplici venarun pracinctione, $\tau$ :rgásions.

C $\Lambda$ P. III.

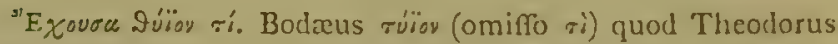
satis inepte twion, ut ignotum, vocat. Scal, ait vocem effe de qua nemo poteft conjicere. Cum tamen lignum arboris Ovice maxime omnium sempiternum sit, proprietas ifta quod plus minusve in lignis dolatis apparet, hic videtur innui.

$\Sigma$ riócas. Convolutiones venarum spirales; sic Plinius Latine "spiras" vocat, xvi. 30.

Kózıyoy í Meyágoss. Plinius in loco xxxvii. 2. vice rynpídss

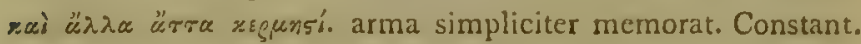

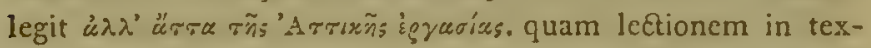
tum recepi: haud tamen placet; et mallem legere xspresrorises nulla auctoritate, ex voce xsopnori. sc. monota Atticæ parvula. De restitutione civitatis Megarensis sub Demetrio, vid. Diod. Sic. 1. 20.

\section{A P. IV.}

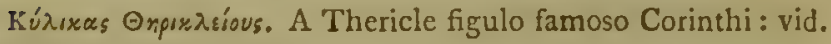
Athenæum 1. ii.

\section{A P. V.}

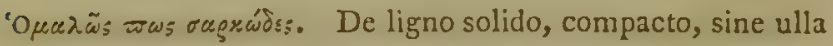
specie venarum.

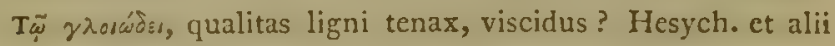
debilitas. N.B. Proprietates ceteræ enumerantur mutuo sibi invicem oppositæ; $\gamma$ roús ns simpliciter.

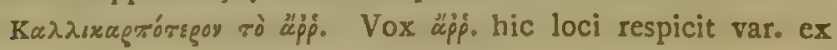
semine in arboribus, qux, quo validiores, eo fructuosiores, vel e contra.

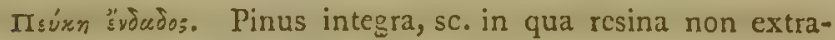
hitur terebrando.

' $\Upsilon$ zò Tsenóóvos. Accurata admodum desc. Teredonis navalis, L. De hoc, utpote de vernibus aliis lignariis Theophr. vid. Plin. xvi. 41. 


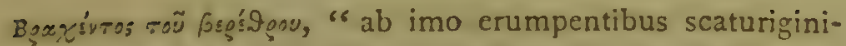
"bus." Scal. a fẹúrostw, ebullire. Subita forsan eruptio aquæ subterraneæ, ut aliquando evenit in locis montosis.

\section{C $\Lambda$ P. VI.}

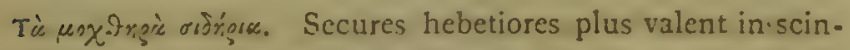
dendis lignis duris quam in mollibus. Vid. observ. de lignis Sepuoss supra.

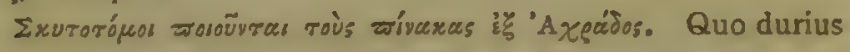

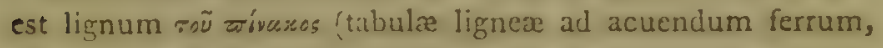
Ang. "a strop") eo efficacius.

'Og.9inv riny r giom. Serratura rectangula, non transversim. Quod ad literas A. B. $\Gamma$. sectiones indicantes, ita forsan explicandum; litere A. A. A. medullam, T. vel cor ligni indicant. B. $\Delta$. sectioncm rectang. B. $\mathrm{r}$. sectionem obliquam.

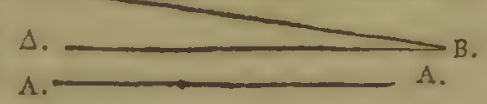

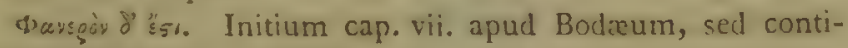
nuatio subjecti, ut notat Scal.

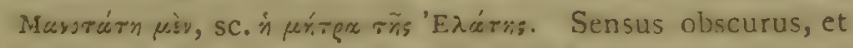
forsan textus corruptus. Durities cordis Abietini ligni adecribitur venis resiniferis quxe abundant. N. B. Corrigo us tha

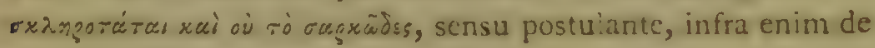

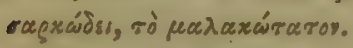

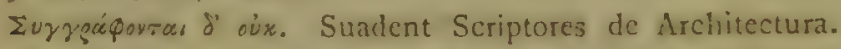
N. B. Substituo oux pro oürw; contra fidem Codt. ita enin pos-

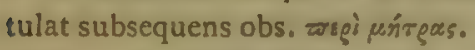

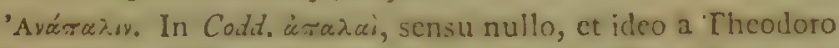
in traductione omittitur. In margine legitur Pinus in trans. versum posita. Sensus vocis àvé-sidin, est sursum, deorsum, vel ordine inverso. $v$. i. 20. et alibi.

\section{A P. VII.}

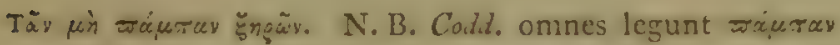
sine $\mu$. Emendavi ex Plinio, et ut sensus requirit, "quae mo-

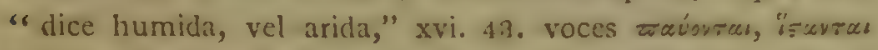
subintelligunt actionem scrra, चp̣isu ; sic Plin. ib. "serris ce"dunt, vel pertinacius resistunt." 


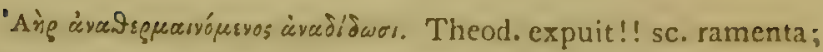

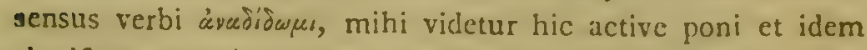
significare ac áyinu supra; intelligendum hebetat tientes serræ.

T⿳亠े dè şoryúra. Partes navis, quæe ex solido vel quadrato ligno fiebant, non ex assibus.

Tà $\mu$ ì̀ हैyir. Partes quædam particulares.

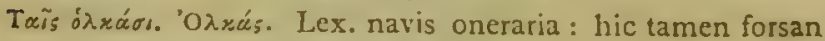
interpretandum remus, a $\mathrm{a} b$ " $\lambda$ xw.

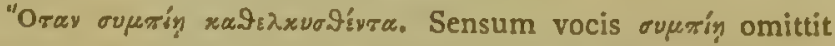
Theod. absorptionem aqua denotat, navi ex arena in mare subducta.

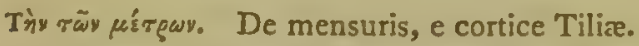

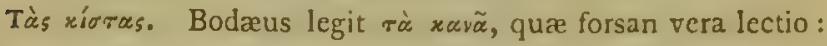
hic enim sermo est de operibus vimineis, vel textilibus.

\section{A P. VIII.}

¿qúguav, Tę̣́rę̧ay. Vid. Plin. xvi. 43.

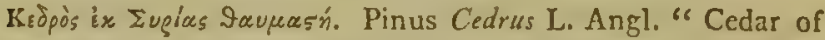
"Libanus," hoc loco certe designatur, itemque usus ligni istius prene sempiterni, etsi nulla detur habitus desc. N. B. Ex hujus ligno Templum Domini, et Arca Foderis in S.S. Itemque Templum Dianæ Ephesina secundum Plinium xvi. 40.

'Eу rй Kúpvạ. Nomen antiquum Corsicæ. Vid. Scal, Obs.

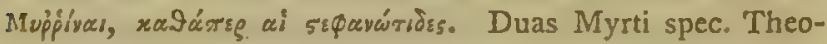
phr. hic indicat; ex quibus ì 5 sqáywrs cujus usus ad serta,

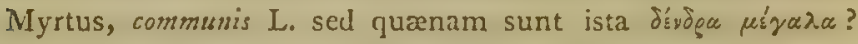
N. B. Desc. Promontorii Circæi, et tumuli Elpenoris ab ipso visi, confirmant traditiones, quae a nonnullis reputantur fabulosæ:

\section{CA P. IX.}

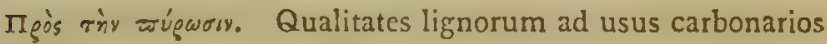
accurate tractantur in hoc capitulo.

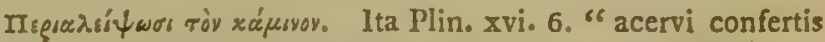
" taleis recentibus luto caminantur," $\mathrm{i}$. e. in camini modum oblinuntur. Bod. Forsan struuntur. 


\section{NOTE IN LIBRUM QUINTUM.}

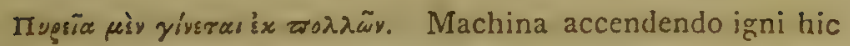
describitur. Ita etiam Plin. in loco " ad excurlendum ignem " non semper lapidis occasio est: teritur lignum ligno, ignem"que concipit attritu; excipiente materie arida..... hedera " nihil præstantius quiæ teratur; lauro quæ terat."

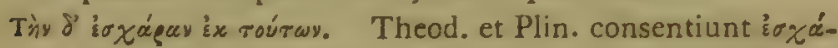
$\rho^{\alpha \nu,}$ i. e. tabulam, fovea in medio, quæ rovmávw subjiciatur fieri debere ex Hedera; Vite Indica; vel Clematide, Vitalba, quæ omnes plantæ scandentes et quarum moles trunci aptior ad reúravov. vid. 'a zága' три́ravov. Lex. Theophr. Apud Scholiaften antiquum 'oxága augeías vocatur oropivs: vid. Hesych. 



\section{By the same Author.}

I.

Illustrationes Theophrasti in usum Botanicorum pracipue peregrinantium. Oxonii, e Typographeo Clarendoniano. 1811. Prostant venales apud J. Parlier, Oxonii, et $\mathrm{T}$. Payne, Londini.

\section{II.}

Nereis Britannica, continens Species omnes Fucn rum ir Insulis Britannicis crescentium. Londini apud I. White, Fleet Street. 1801. 



\title{
THEOPHRASTI ERESII
}

\author{
$D E$
}

\section{HISTORIA PLANTARUM}

\section{LIBRI DECEM.}

PARS SECUNDA. 



\title{
THEOPHRASTI ERESII
}

\author{
$\mathrm{DE}$
}

\section{HISTORIA PLANTARUM}

\section{LIBRI DECEM,}

GRECE。

CUM

SYLLABO GENERUM ET SPECIERUM,

GLOSSARIO, ET NOTIS.

PARS SECUNDA.

CURANTE

JOH. STACKHOUSE, ARm. Soc. Livx, S.

OXONII,

EXCUDEBAT S. COLLINGWOOD.

Prostant venales apud J. Parker, Oxumi; T. Payse,

White et Cocirrane, et J. Murray, Londini;

et J. Deiciton, Cantabrigix.

MDCCCXIV. 



\section{$\Theta \mathrm{EO} \Phi \mathrm{PA} \Sigma \mathrm{TO} \Upsilon$}

\section{$\Pi$ EPI $\Phi \Upsilon T \Omega N$ I $\Sigma T O P I A \Sigma$}

TO $5^{\prime}$.

\section{CAP. I.}

Divisio Plantarum in Frutices et Herbas.

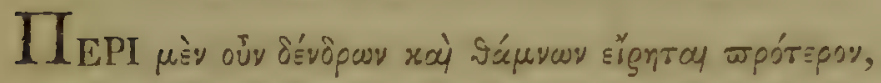

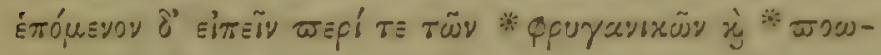

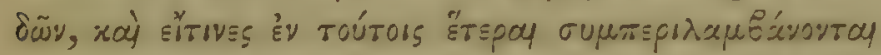

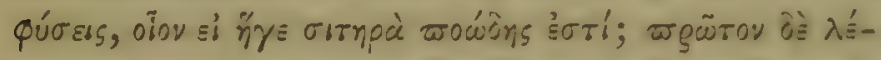

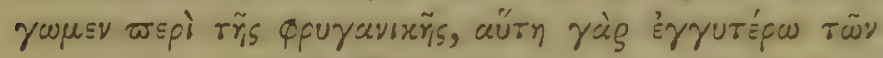

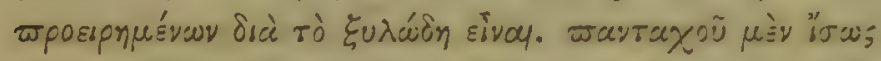

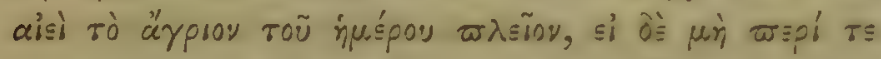

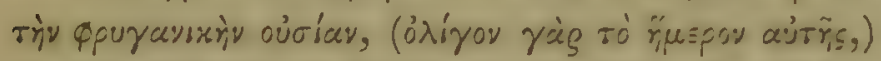

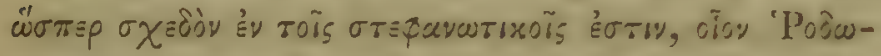
vic̀, 'I

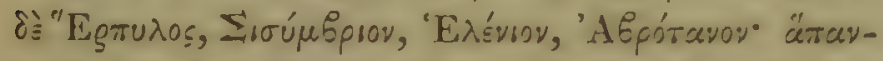

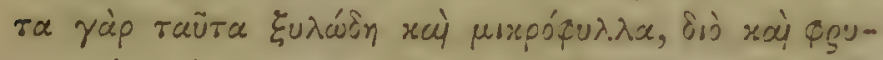

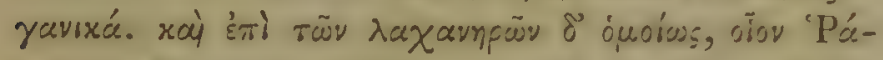

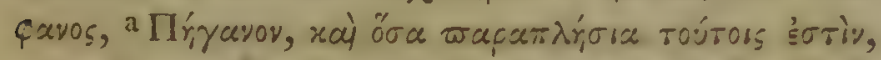

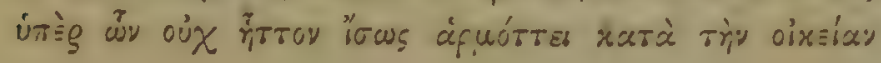

2 Tŕngevar, Bod.

PARS II. 


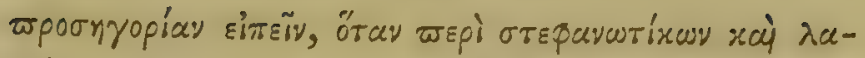

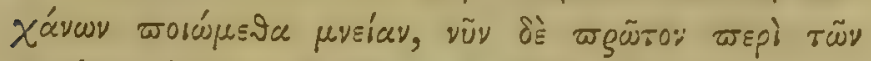

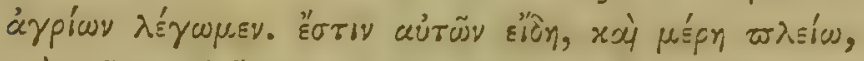

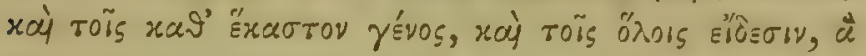

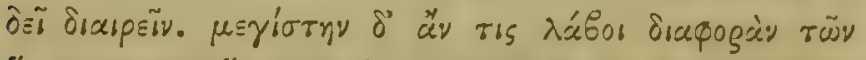

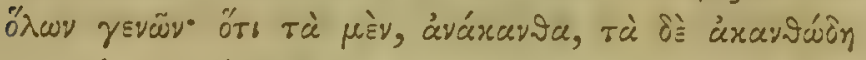

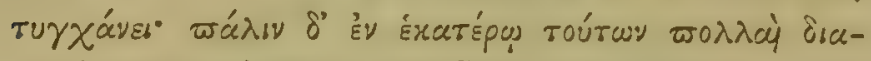

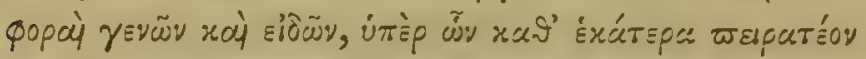

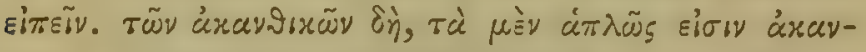

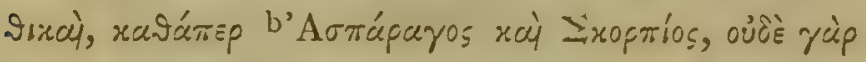

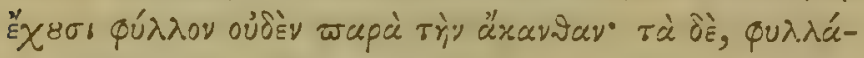

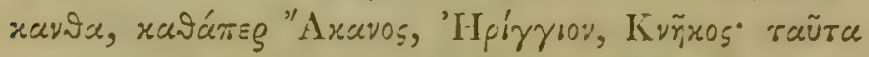

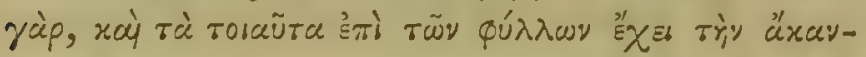

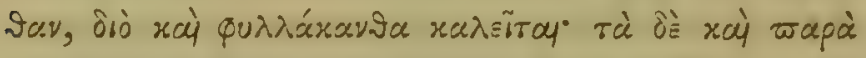

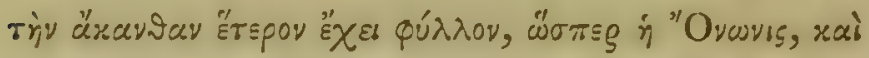

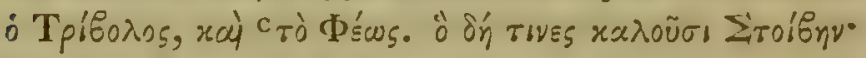

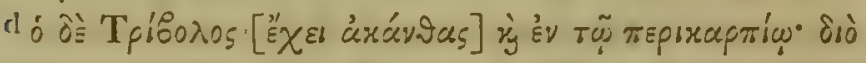

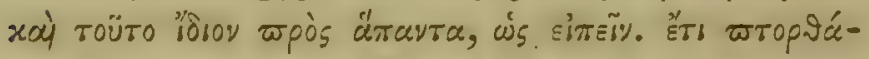

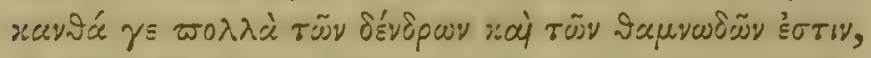

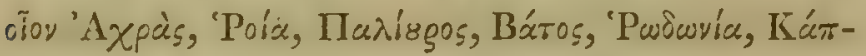

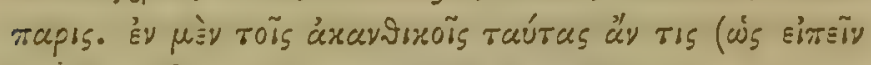

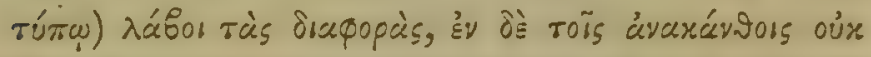

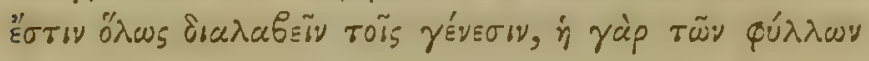

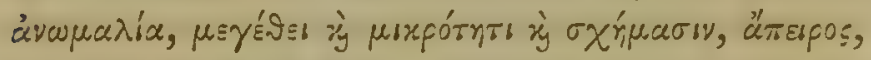

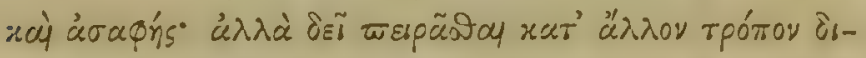

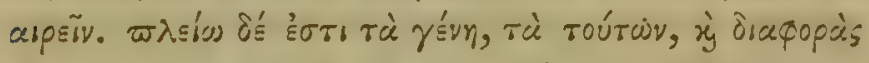

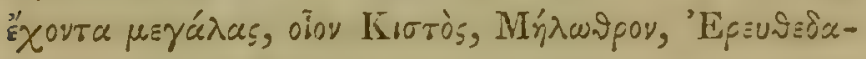

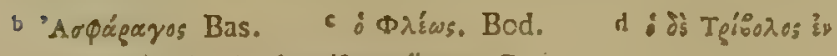

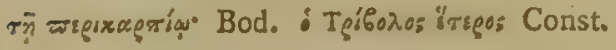




\section{MEPI INTSN ISTOPIAS TO ร́. 245}

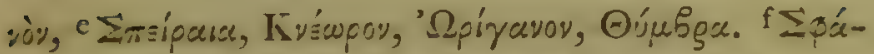

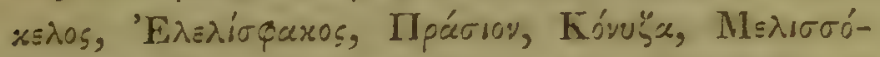

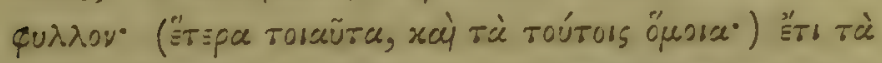

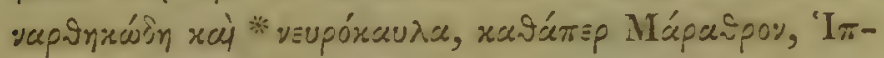

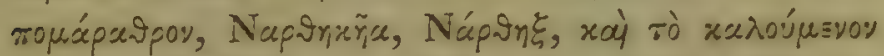

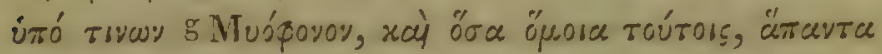

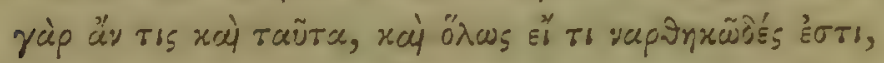

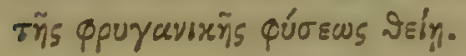

\section{CilP. II.}

Cistus. Origanum. Thymus. Salvia. Murvubizm. Ferula. Atropa. Cicuta, \&c. \&c.

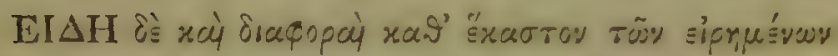

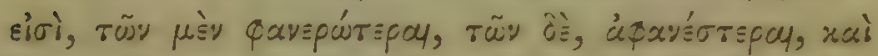

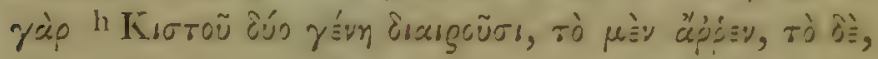

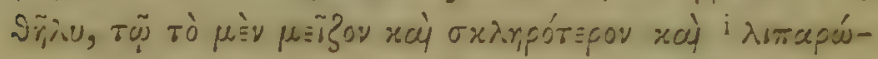

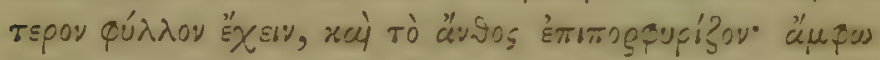

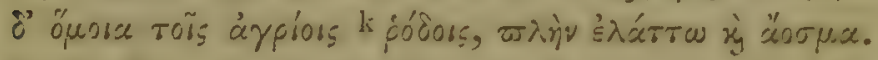

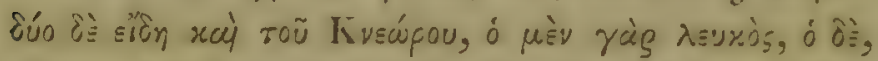

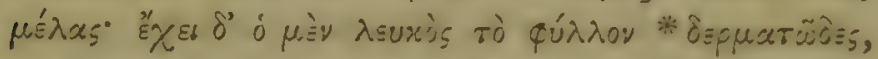

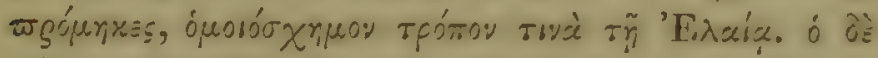

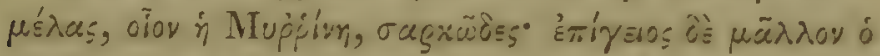
$\lambda$ suxós

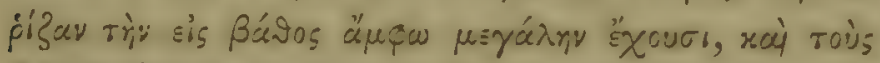

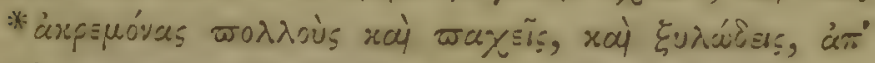

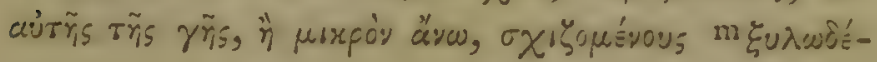

\footnotetext{
e $\Sigma \mu \eta g e ́ r a$, Bod.

Bod. h Kugroũ Bod.

if Ipaxis, Ald. Bas.

B Muóparoy,

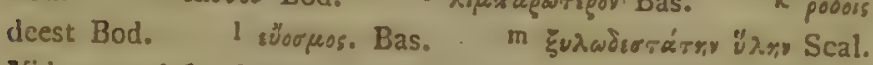
Vid, not, ad fin. libri.
} 


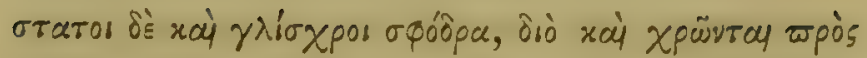

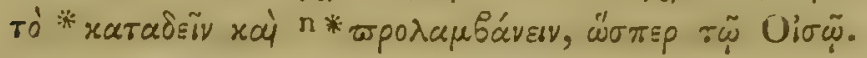

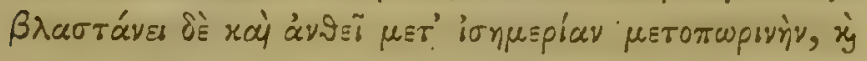
ảvง

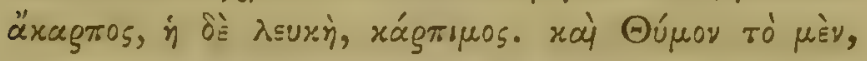

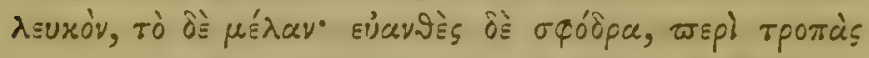

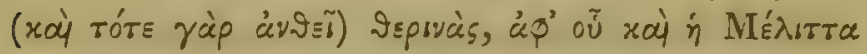

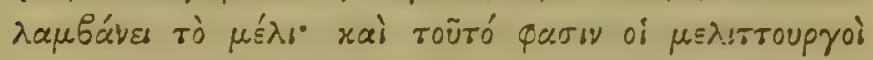

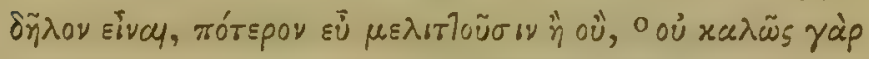

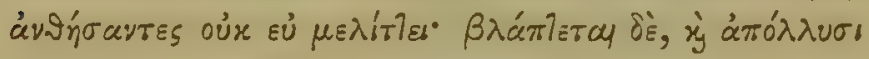

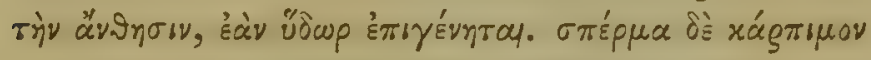

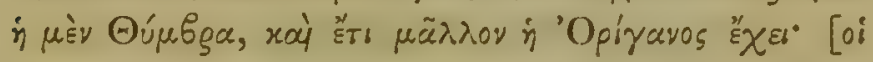

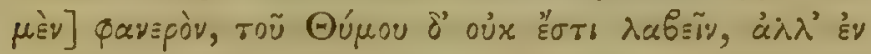

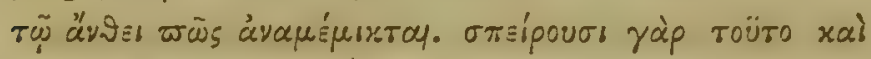

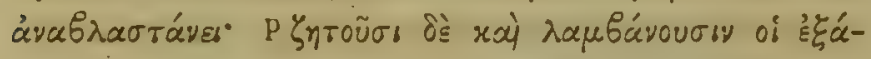

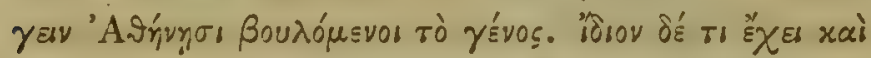

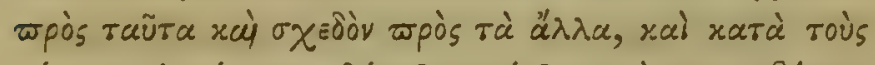

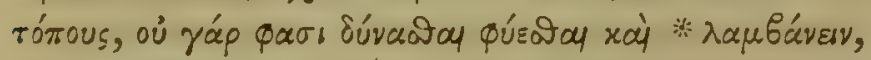

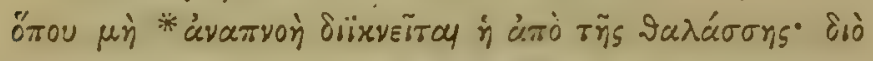

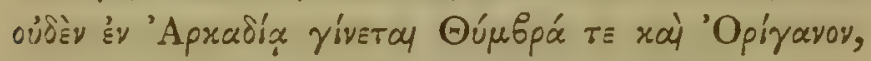

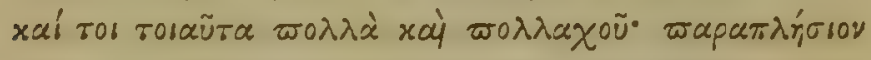

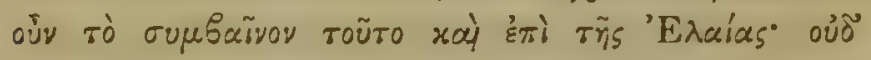

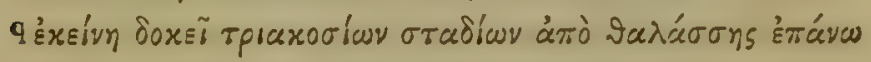

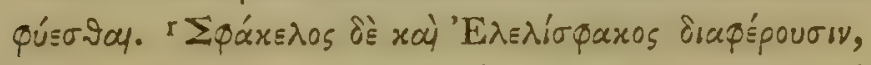

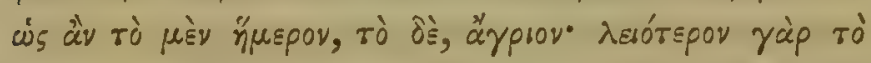

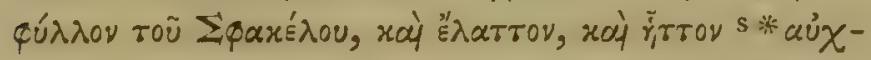

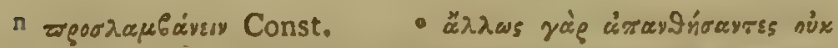

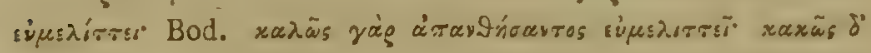
¿ix. Const. p Vid.not. ad finem libri. $q$ lxĩe Bod.

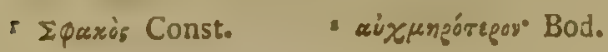




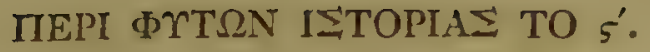

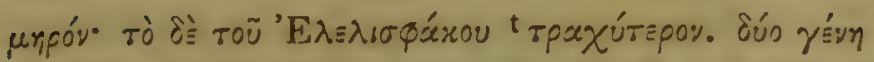

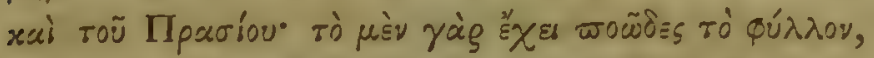

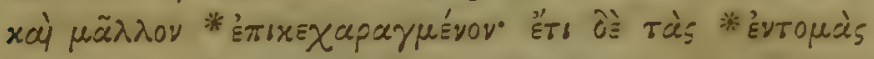

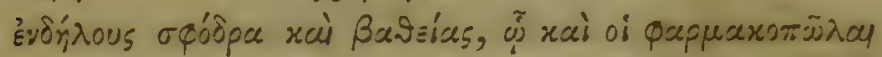

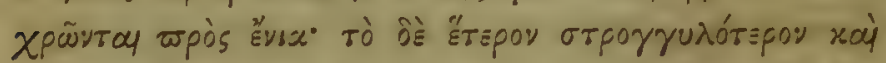

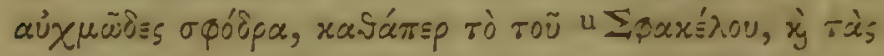

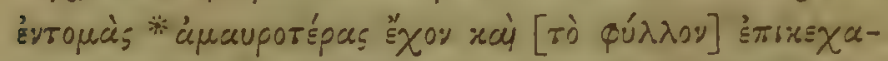

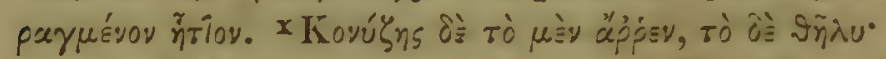

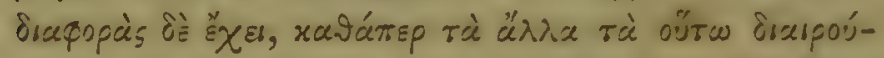

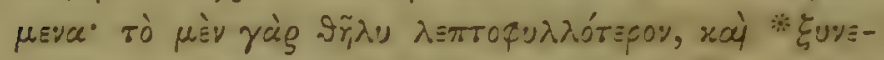

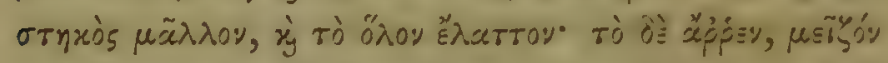

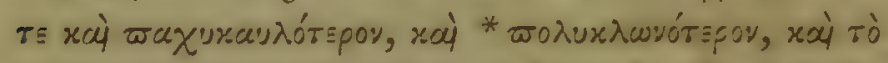

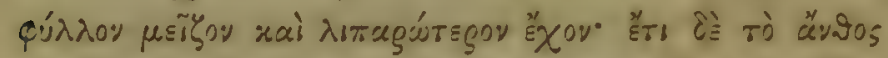

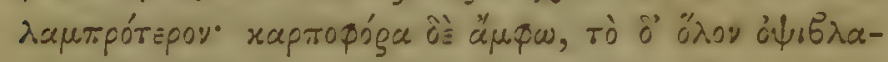

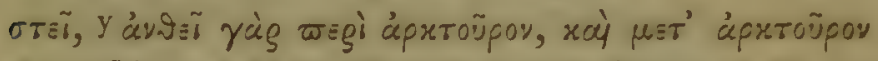

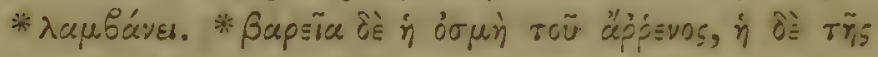

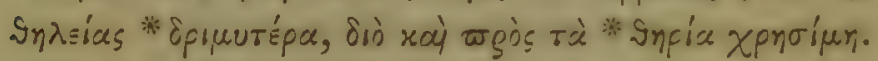

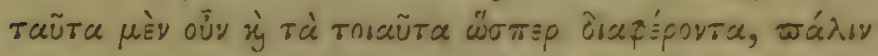

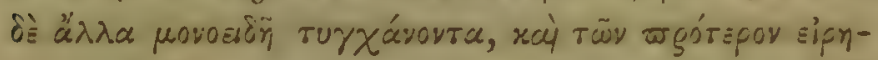

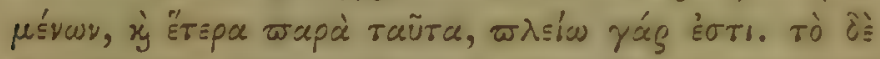

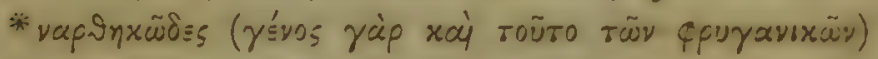

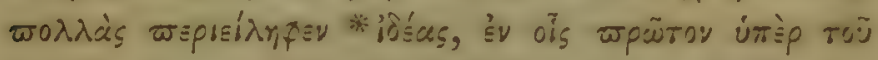

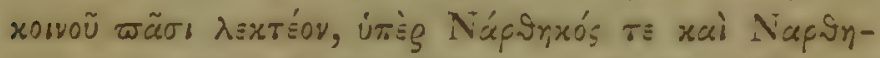

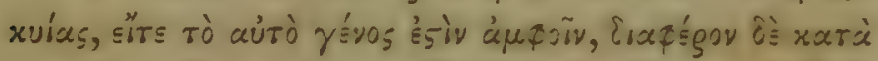

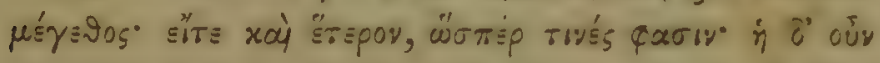

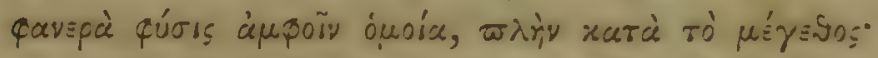

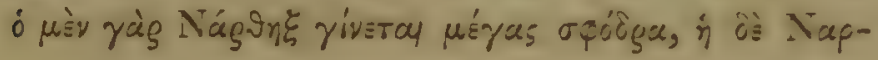

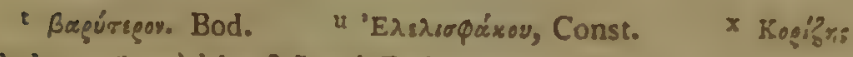

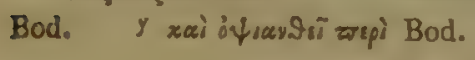




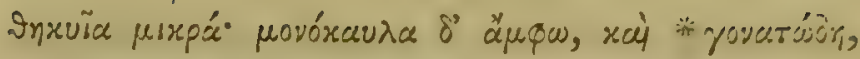

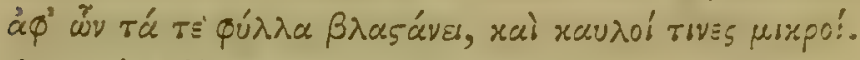

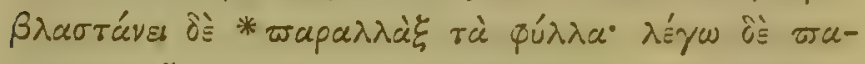

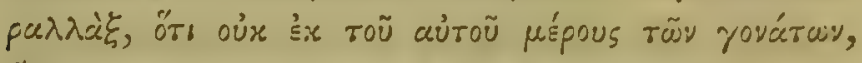

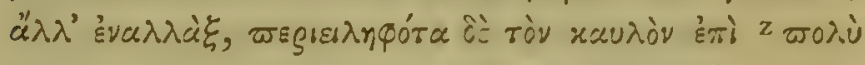

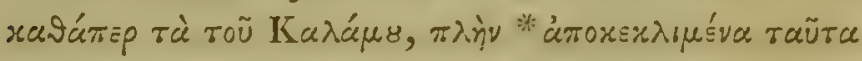

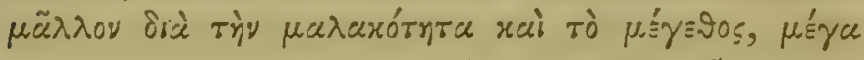

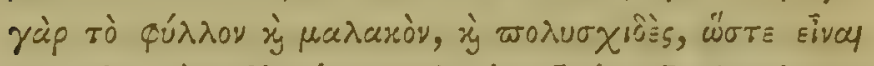

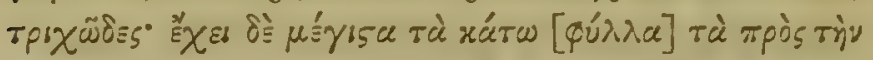

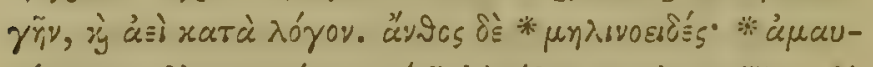

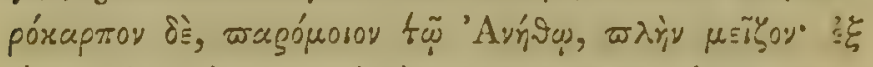

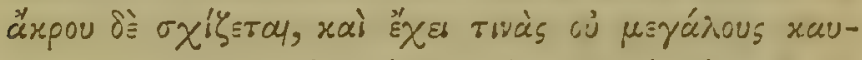

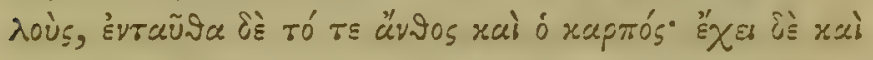

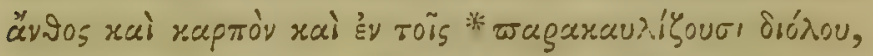

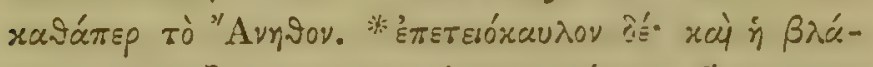

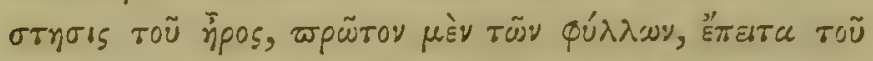

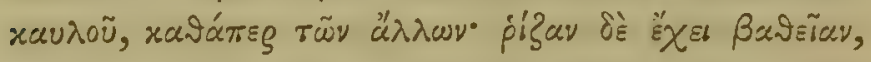

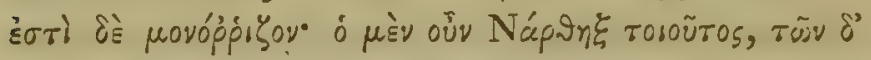

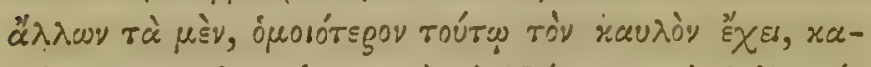

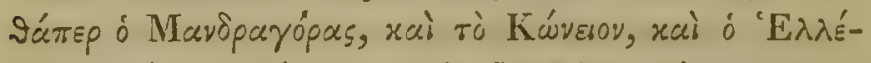

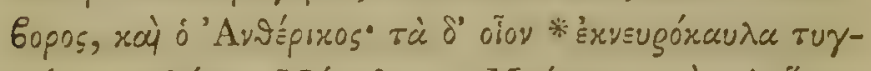

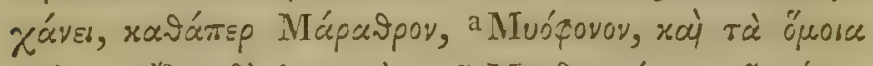

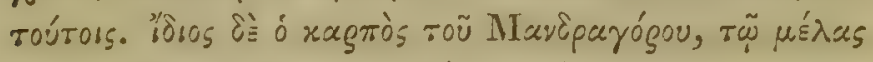

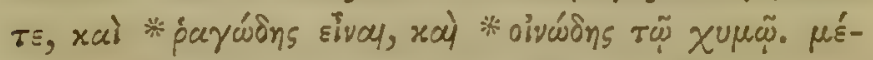

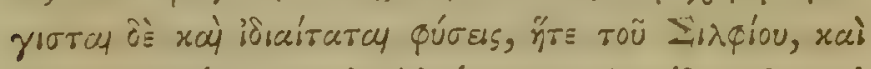

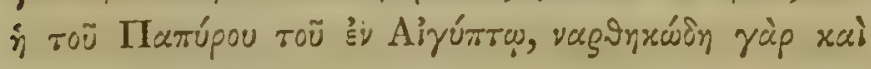

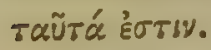
$z$ zoגi deest Bod.
a Muópuroy, Const. 


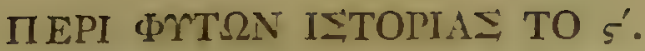

\section{CAP. III.}

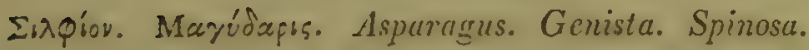

Trupa. Capparis, \&-c.\&.c.

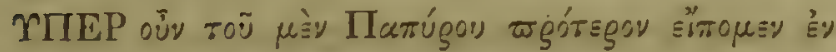

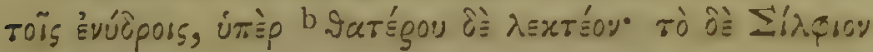

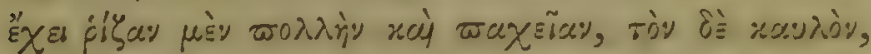

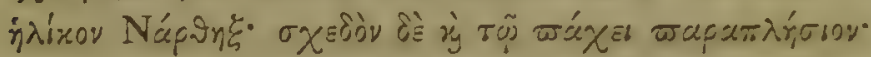

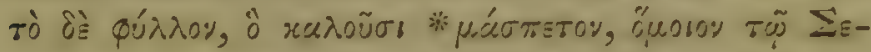

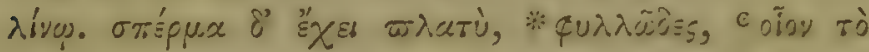

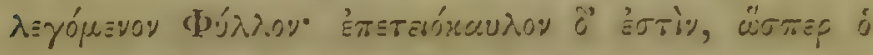

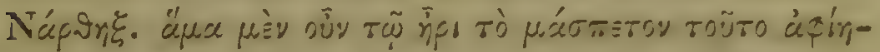

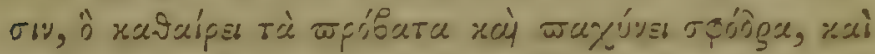

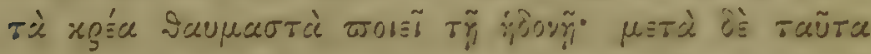

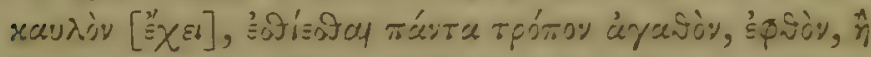

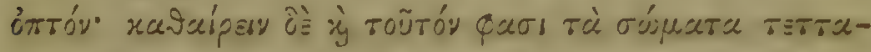

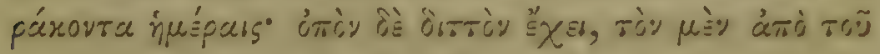

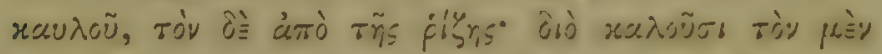

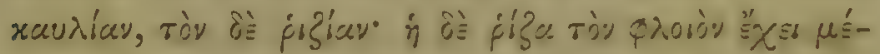

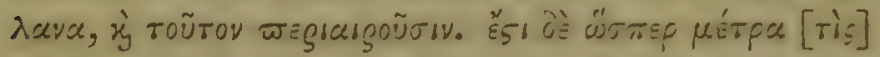

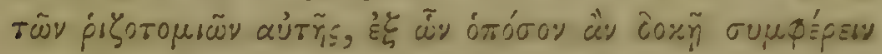

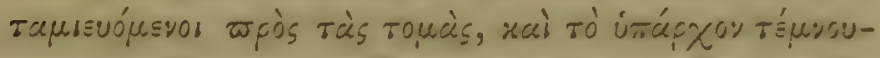
бเ\%

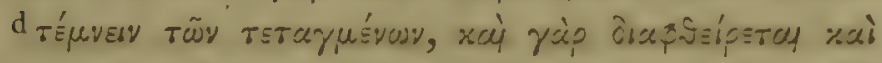

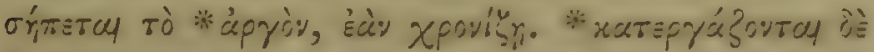

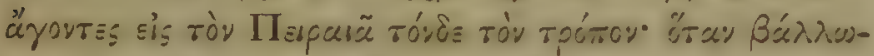

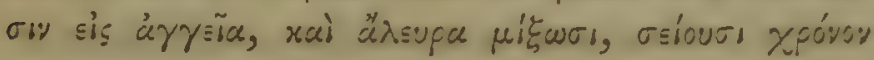

b Eirpion Gaza.

c oioy deest Const.

d $\tau i \mu v \& \mid$ deest Bod. 


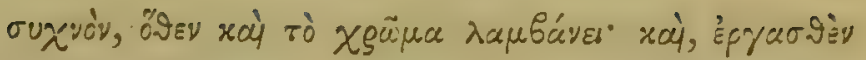

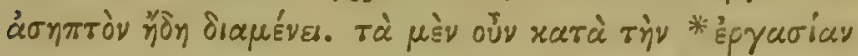

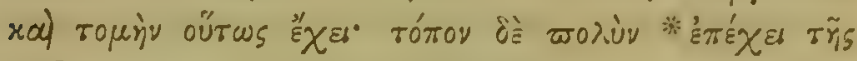

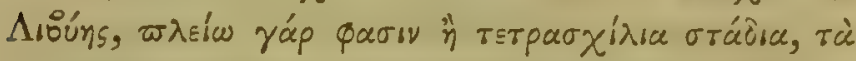

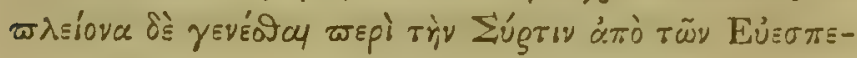

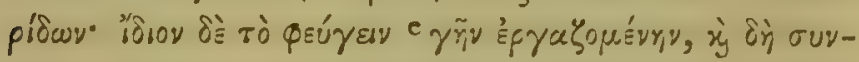

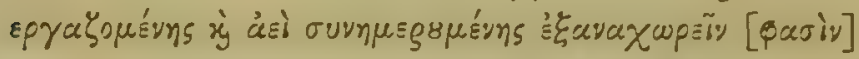

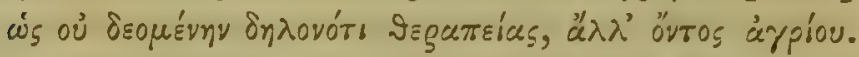

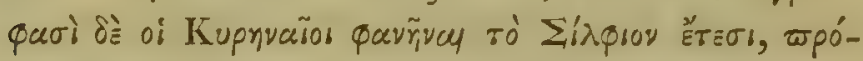

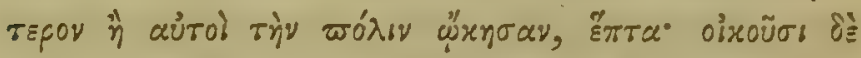

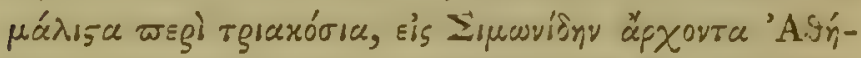

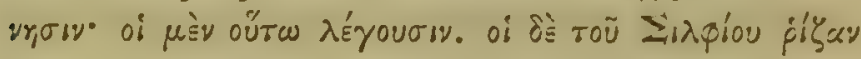

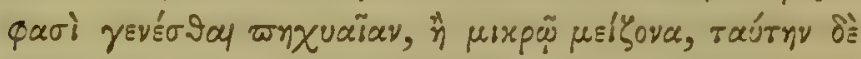

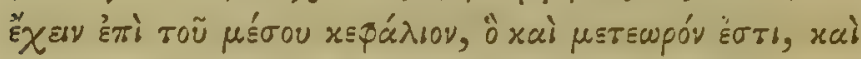

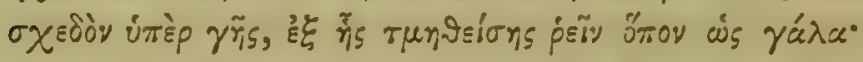

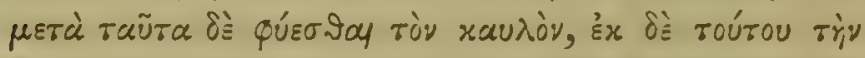

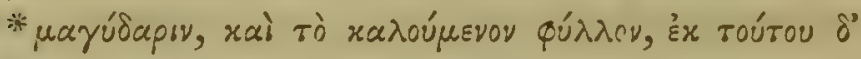

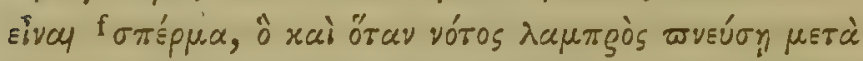

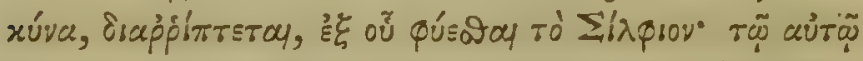

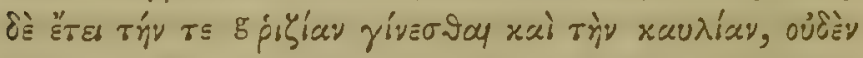

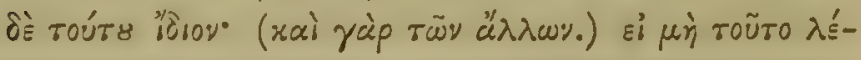

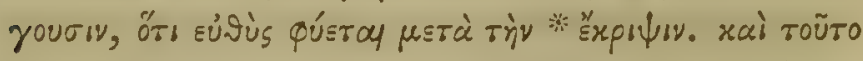

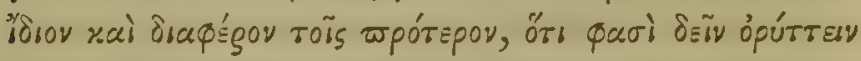

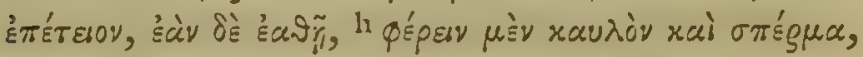

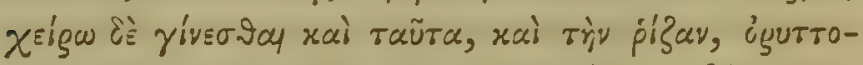

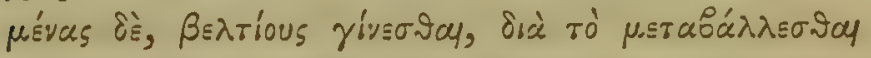

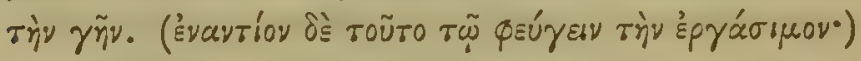

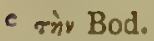

f Vid. not, ad fin. libri.

g piliav yiveratas

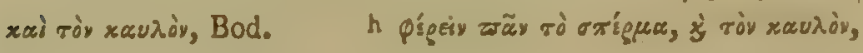
Bod. 


\section{ПEPI TYTRN ISTOPIAS TO s'. 25T}

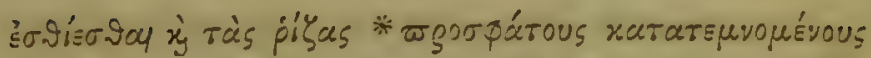

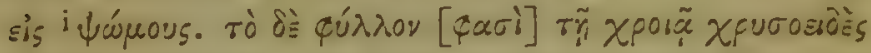

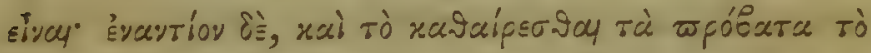

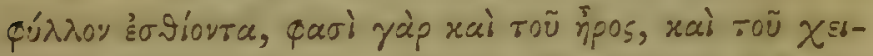

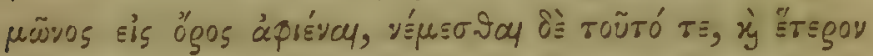

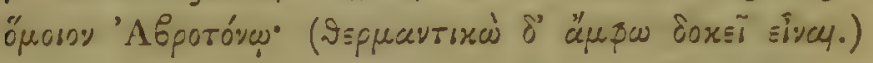

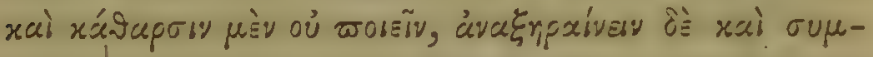

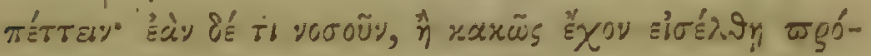

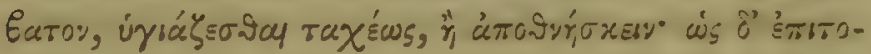

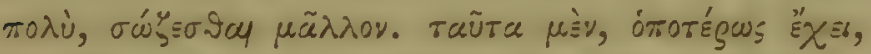

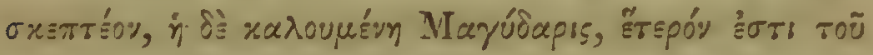

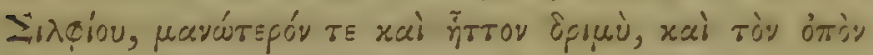

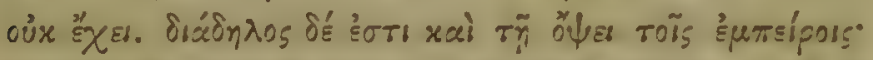

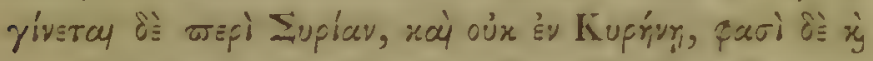

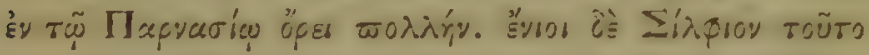

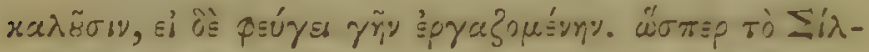

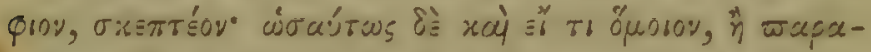

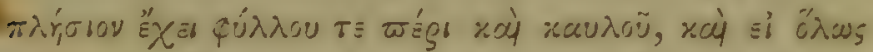

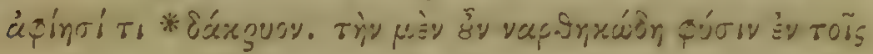

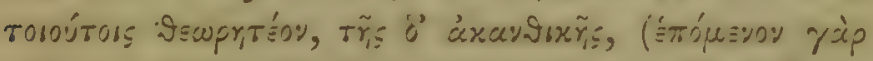

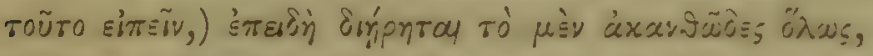

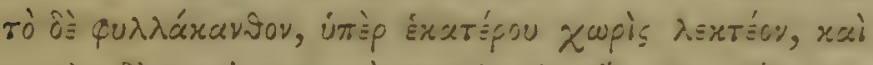

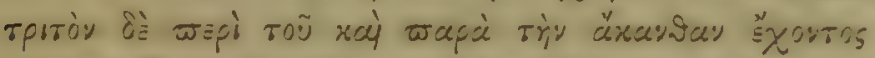

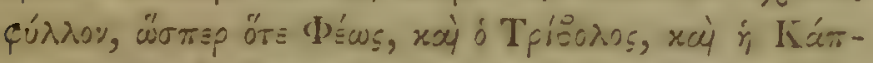

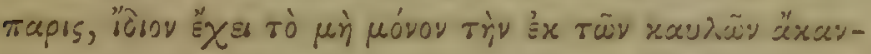
Vav E้ X

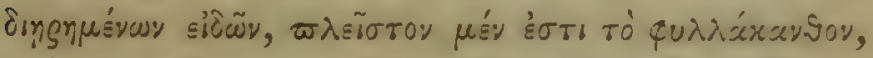

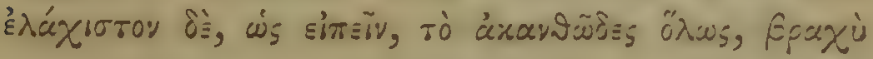

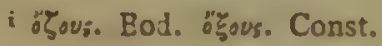




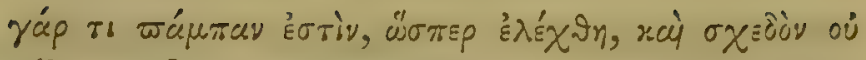

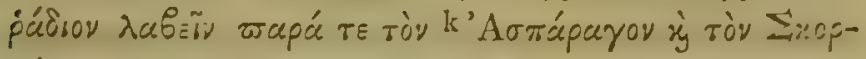

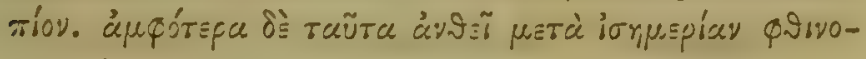

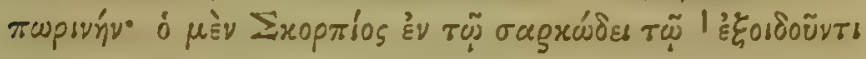

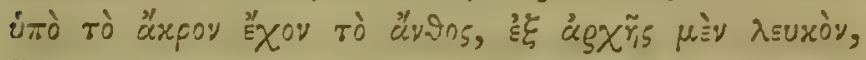

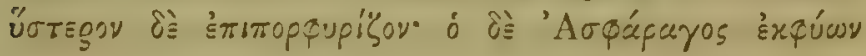

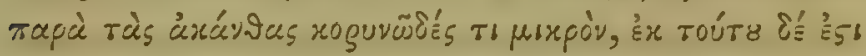

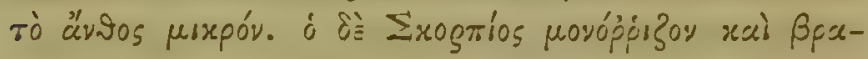

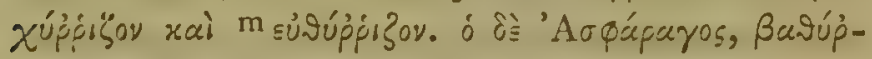

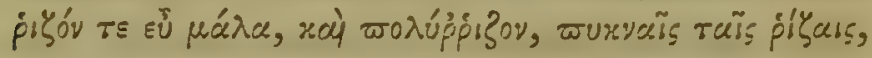

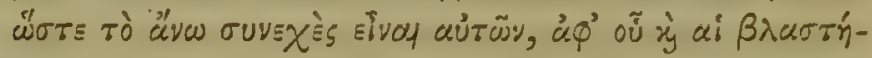

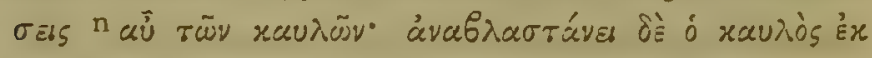

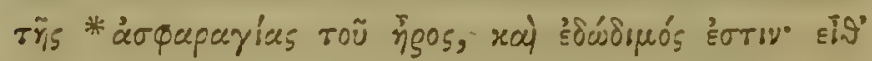

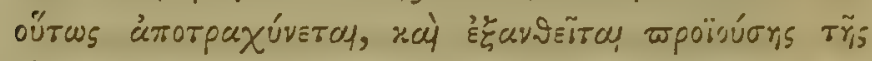

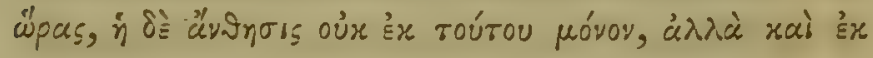

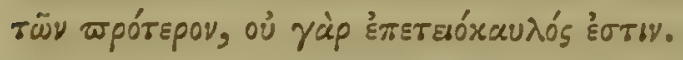

\section{CAP. IV.}

Plante Folio spinoso, \&.c. Carduns. Cnicus. Scolymus, $\& \cdot c . \& \cdot c$.

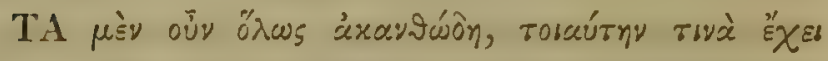

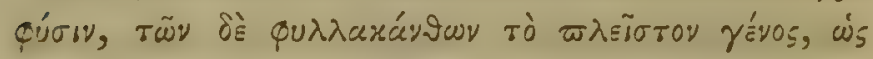

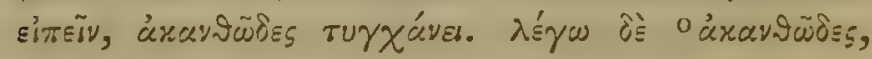

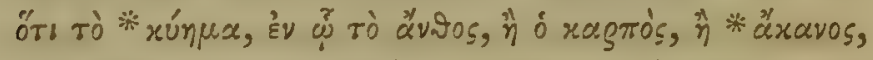

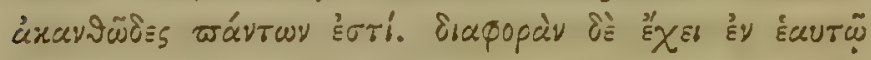

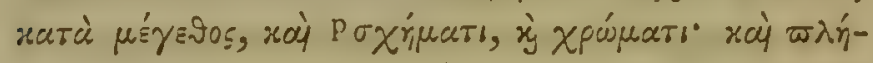

$k$ Vid. not. ad fin. libri.

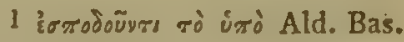

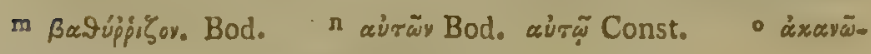
$\delta i s$, Scal.

p $x_{s}^{\text {ripex } \alpha \tau, \text { Bod. }}$ 


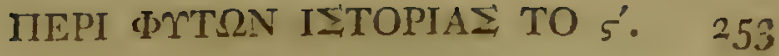

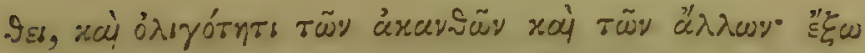

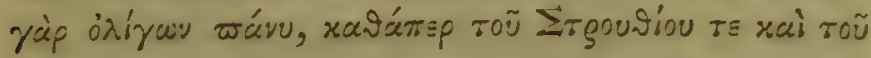

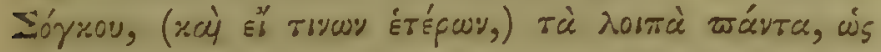

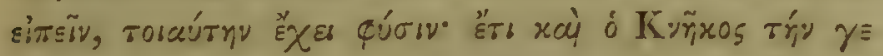

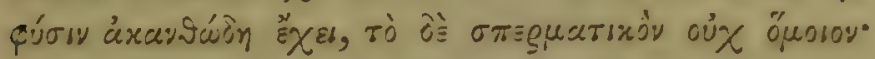

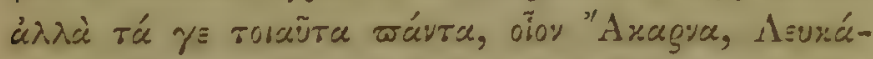

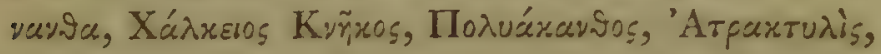
q'Ovó-

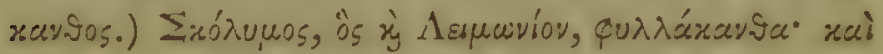

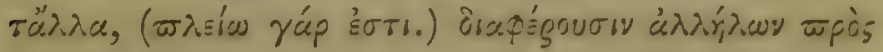

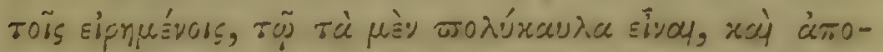

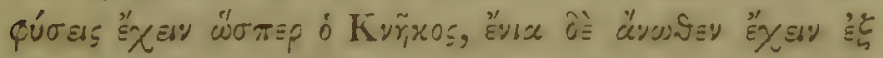

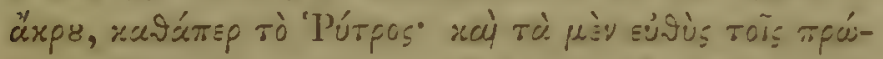

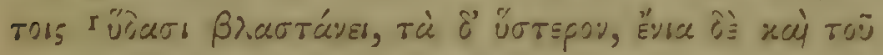

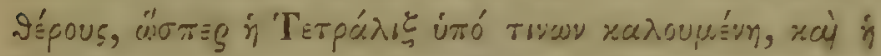

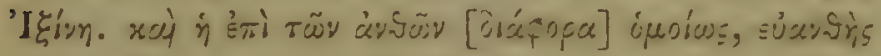

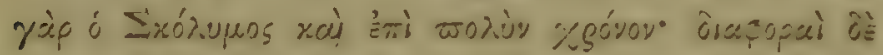

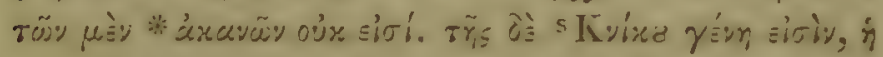

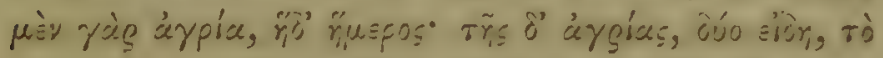

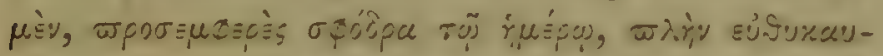

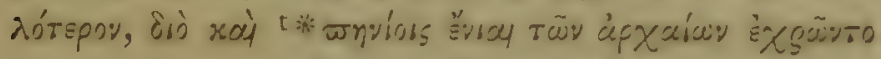

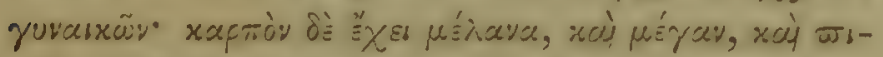

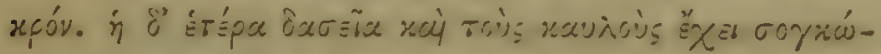

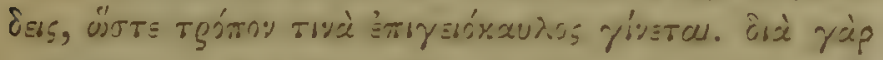

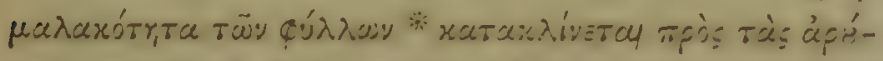

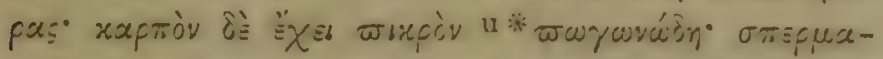

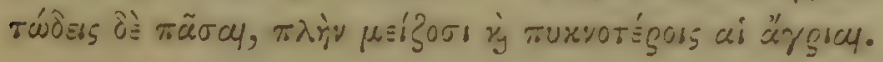

$q$ 'Ovó yueos, Const.

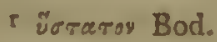

8 Kvท́xoy Bod.

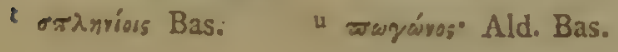




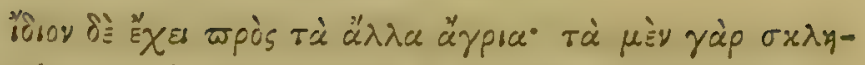

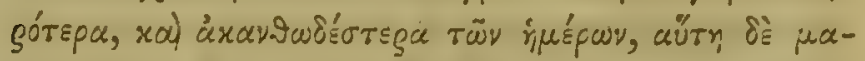

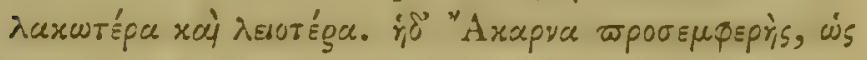

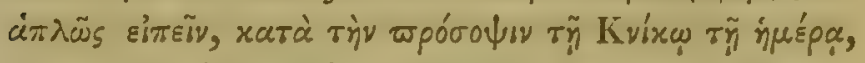

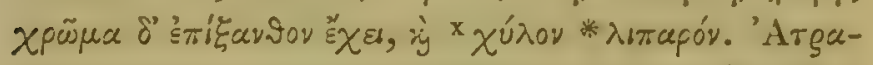

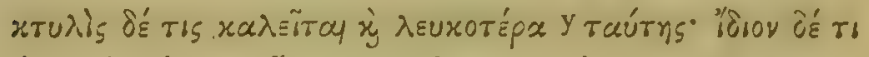

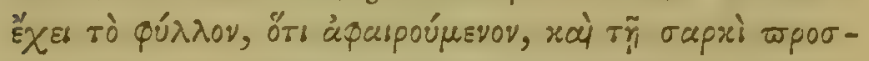

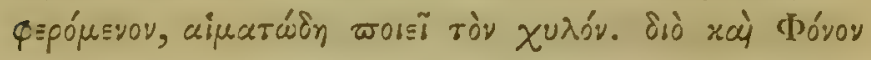

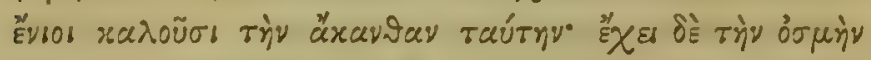

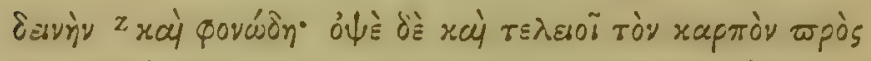

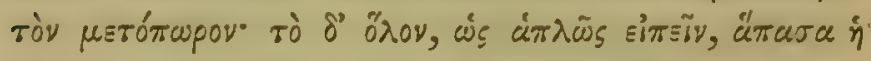

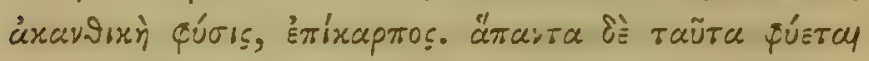

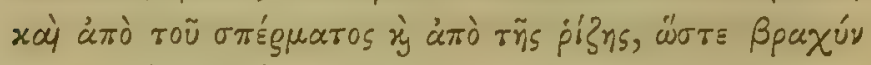

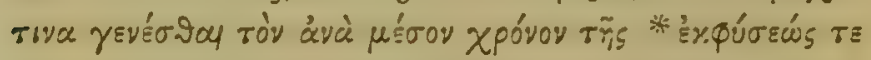

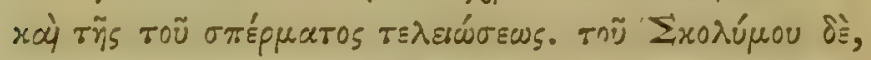

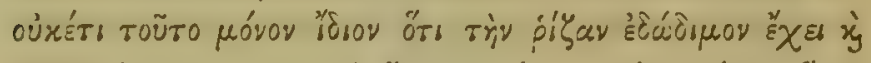

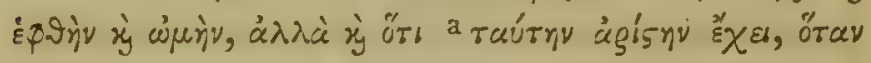

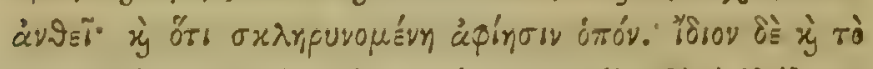

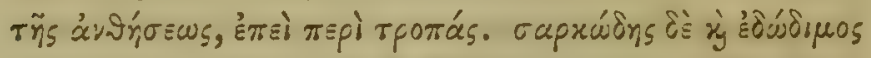

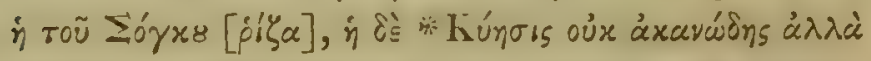

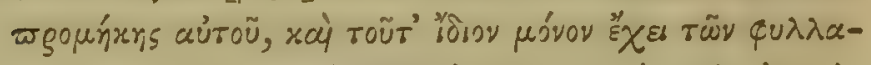

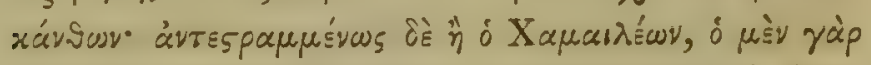

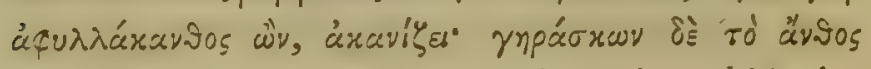

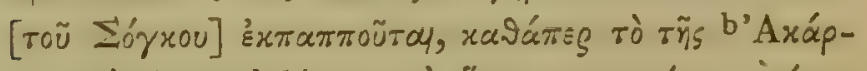

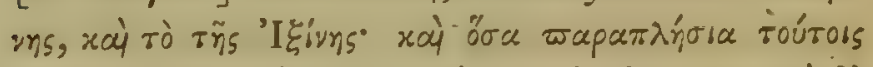

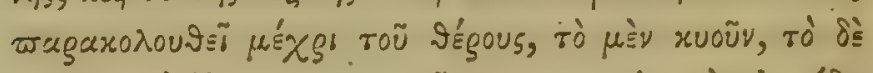

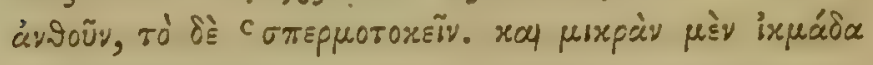

$x$ xúray deest Bod.

Y roúray Bod. $z$ xúdoy Qovád̄n,

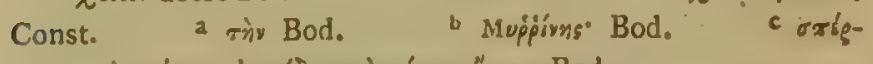

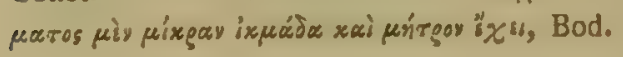




\section{MEPI ФTT $\Omega N$ ISTOPIA}

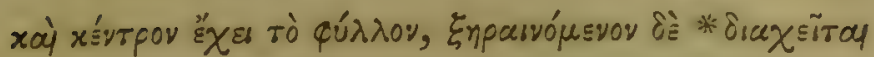

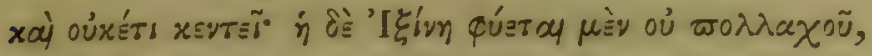

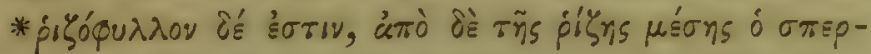

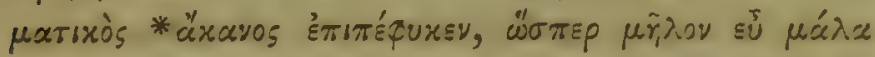

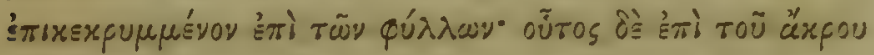

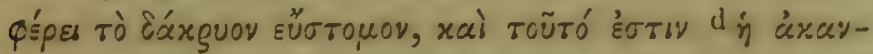

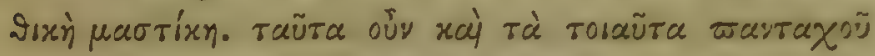

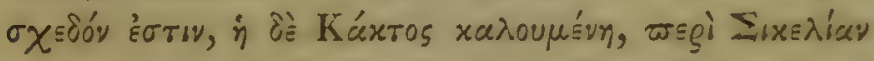

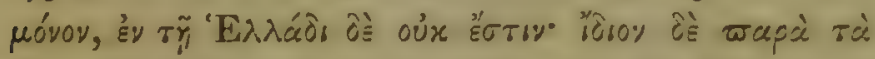

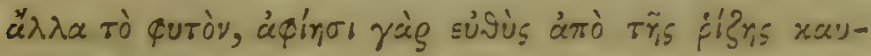

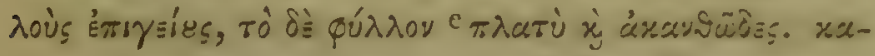

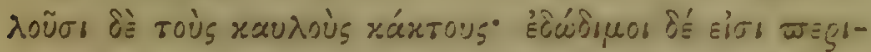

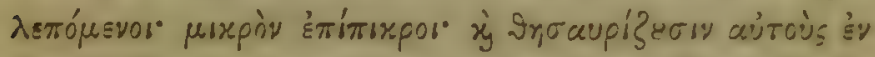

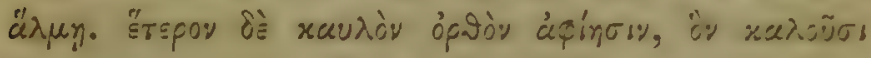

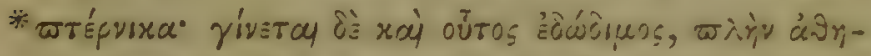

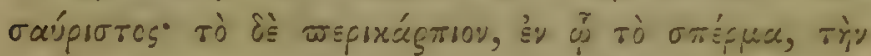

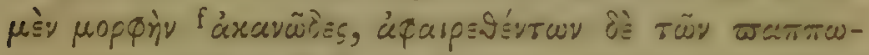

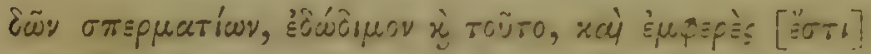

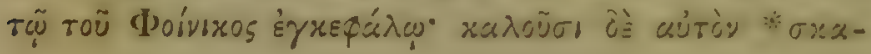
$\lambda i a v$.

\section{CAP. V.}

Potcrium, spinosum. Capparis. Tribulus, terrestris.

Ononis, \& c. \& c.

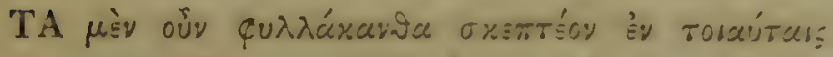

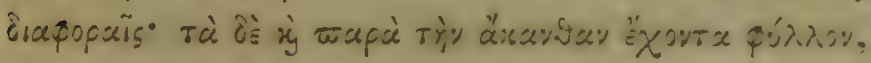

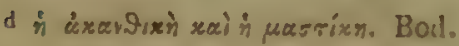
- "̈xsı xáx:ovs Bod.

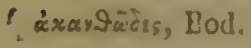




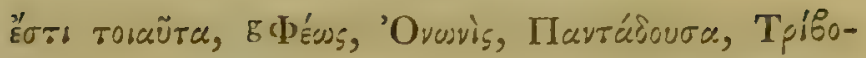

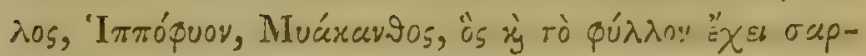

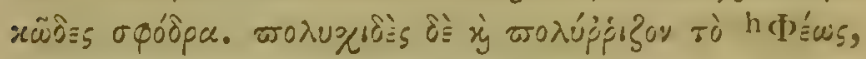

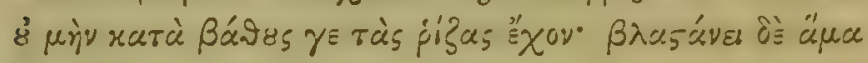

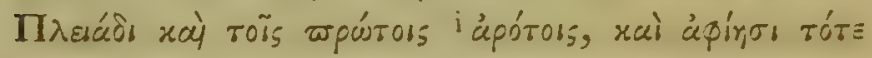

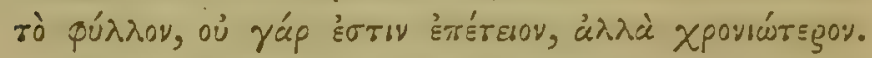

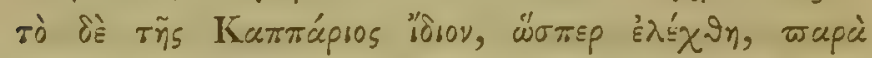

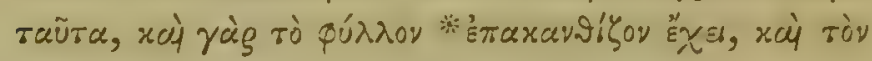

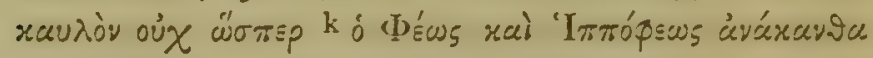

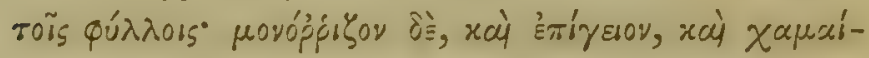

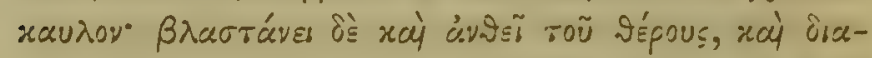

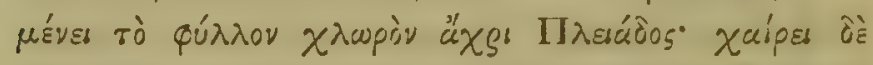

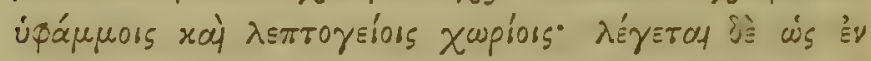

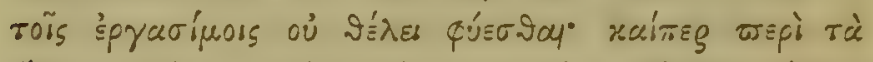

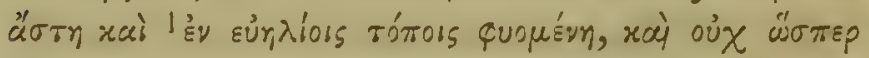

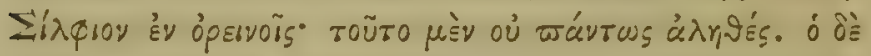

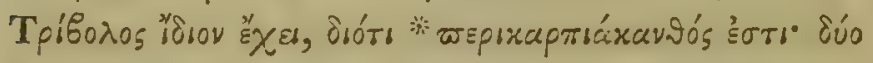

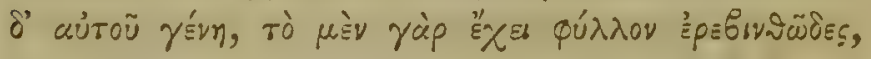

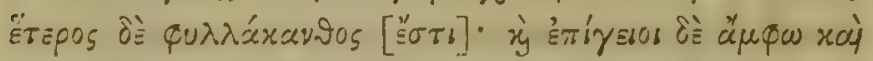

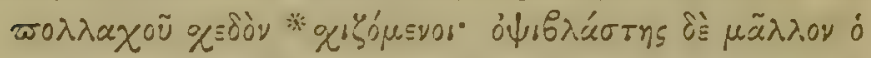

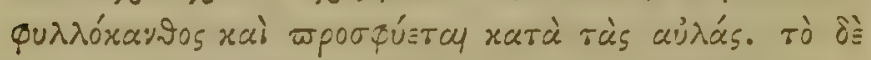

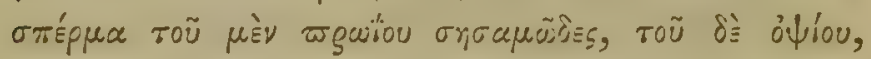

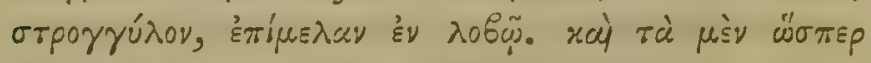

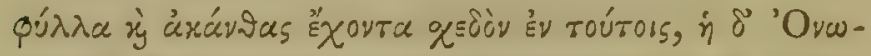

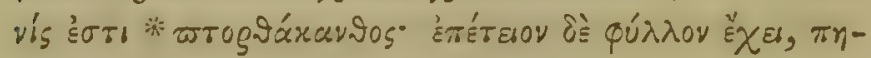

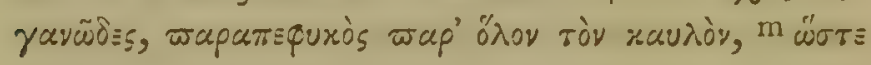
8. $\$ \lambda_{\text {śws }}$, Bod.
h Dríws, Bod.
i ágóreous, Bod.
$k$ öpsws Bod.
1 चाisvois Theod.
m ${ }_{\omega}^{\prime \sigma} \pi \xi \xi \mathrm{B}$. 


\section{MEPI WTT $\Omega N$ ISTOPIAS TO 5'. 257}

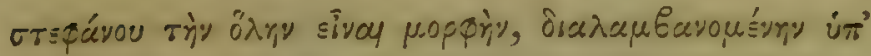

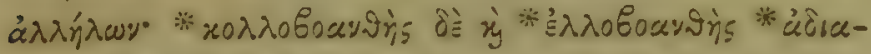

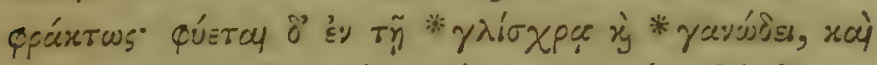

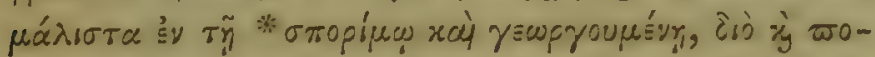

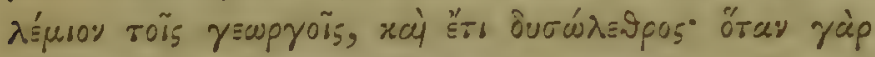

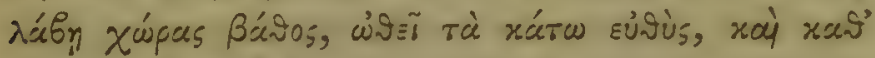

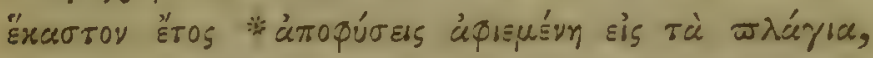

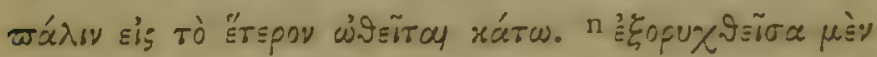

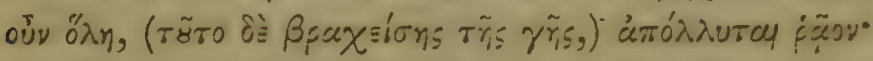

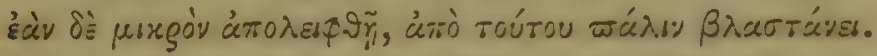

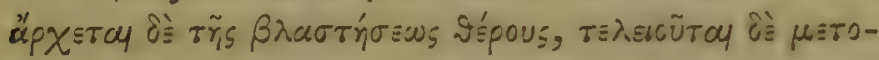

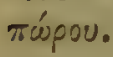

\section{CAP. VI.}

Plunta coronenice Flore speriuso. Rose. Lilium. Narcissus. Crocus. Enanthe.

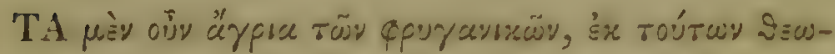
psiбจ

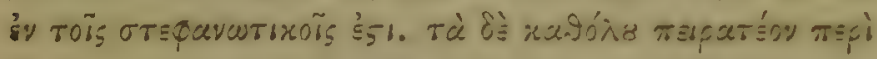

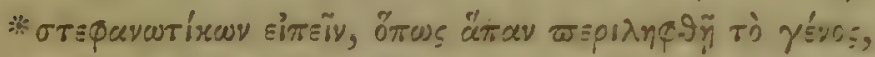

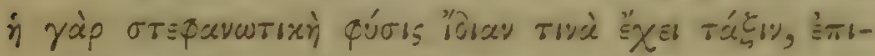

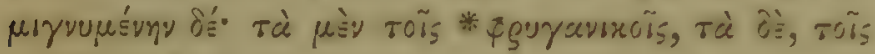

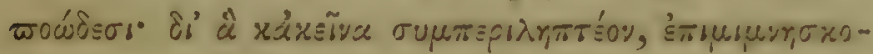

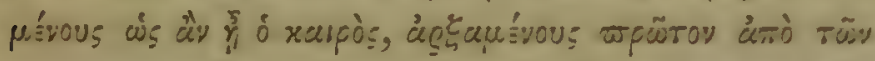

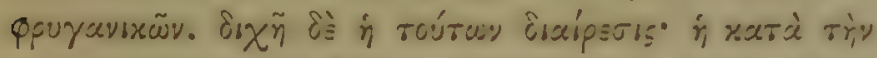

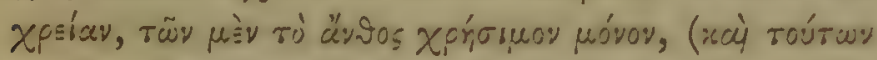

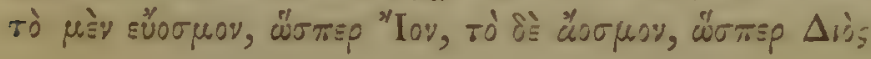

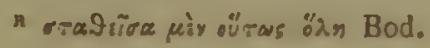




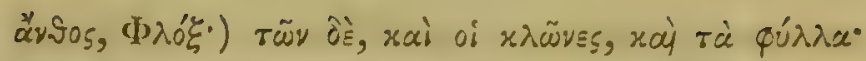

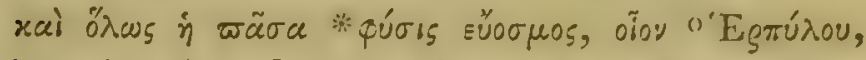

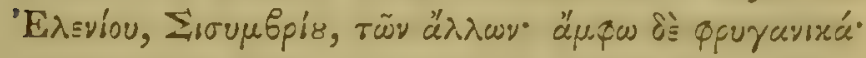
xảx

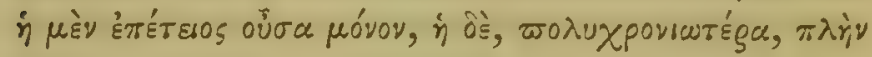

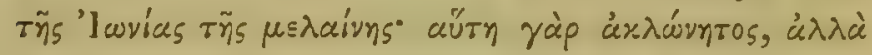

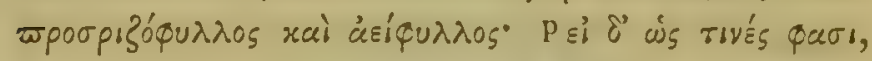

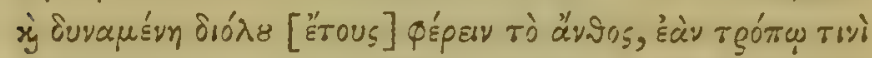

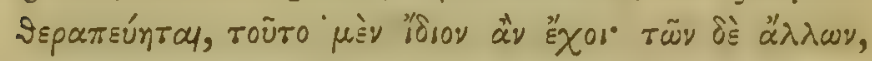

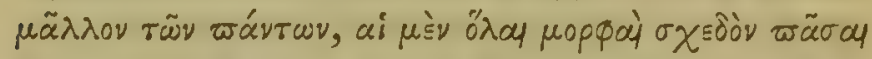

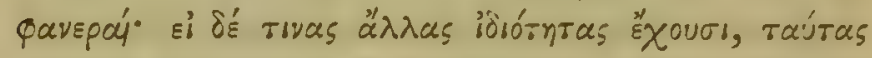

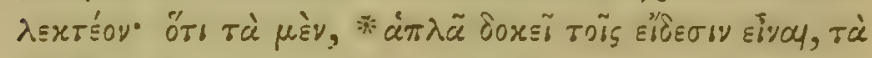

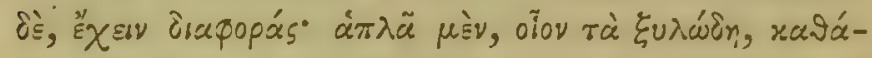

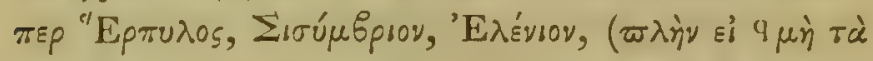

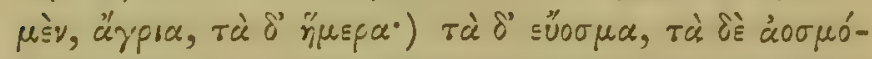

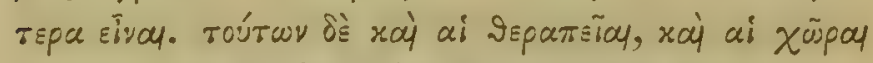

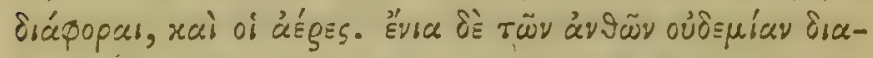

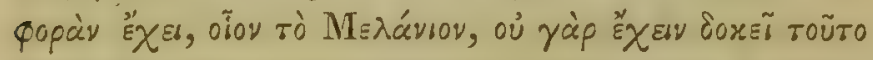

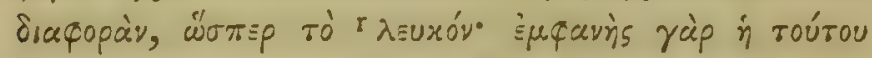

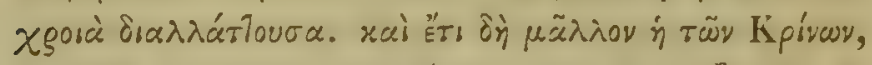

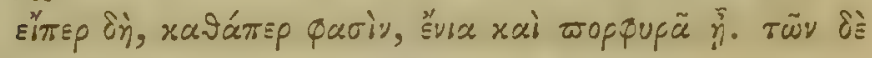

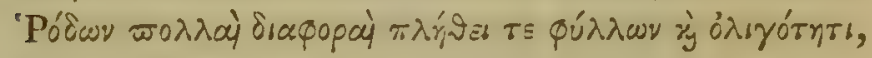

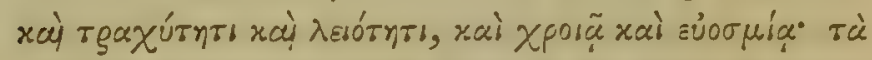

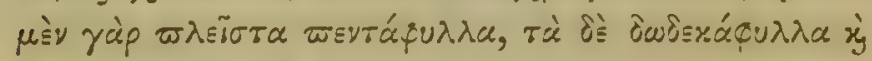

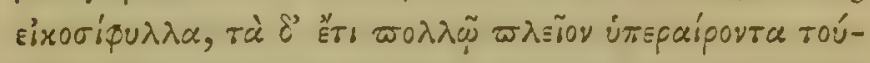

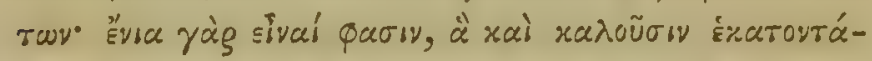

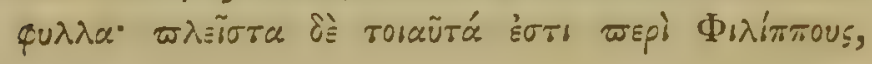

- 'E Bod. I $\lambda$ suxóì. Bod. 


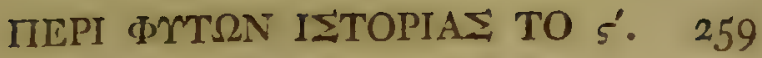

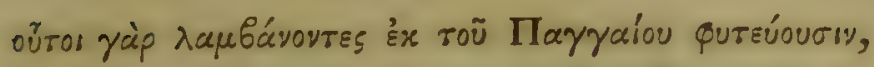

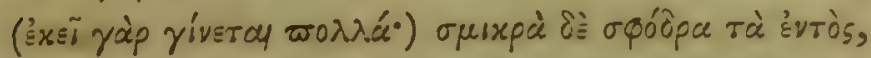

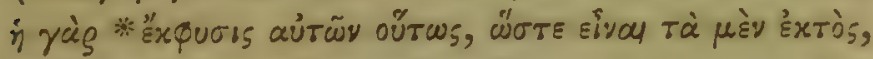

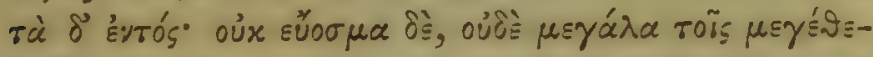

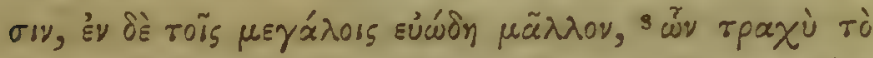

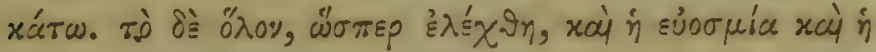

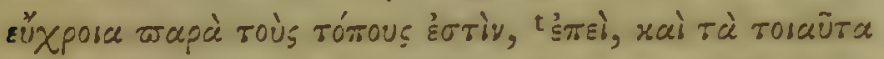

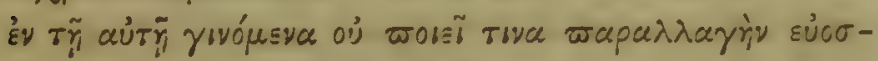

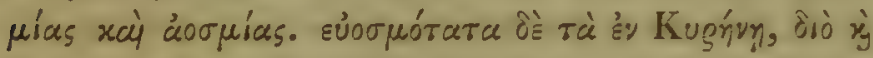

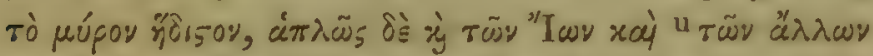

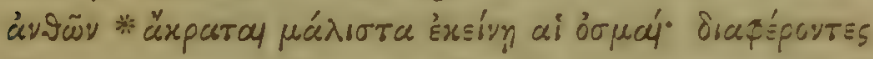

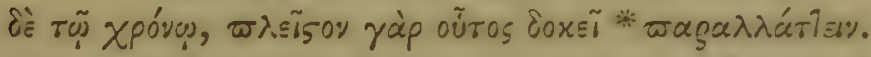

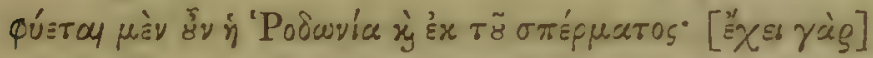

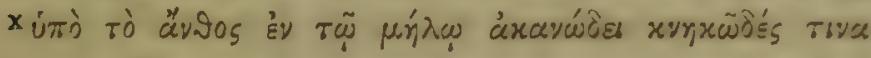

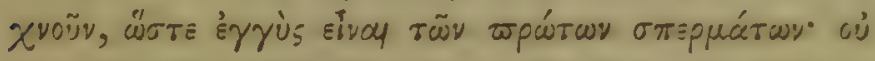

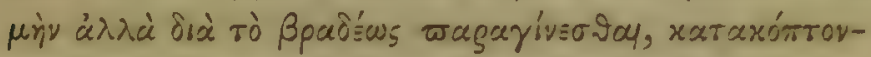

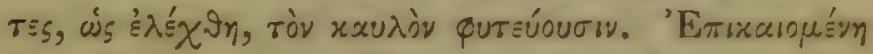

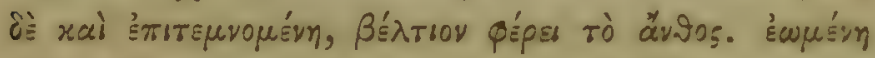

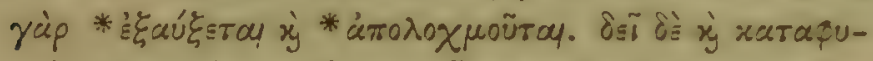

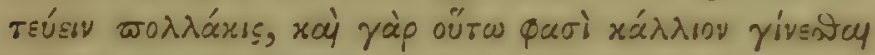

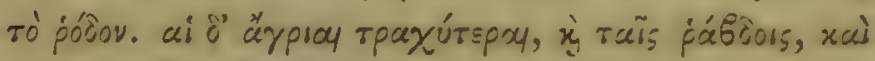

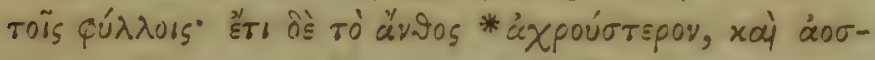

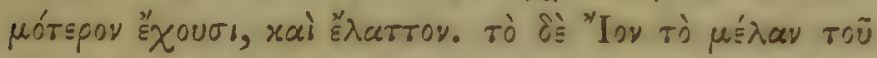

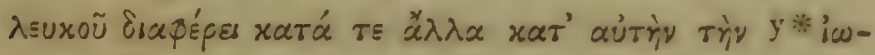

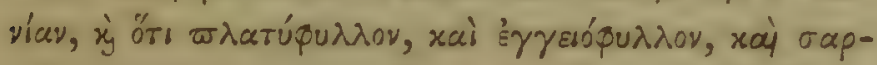

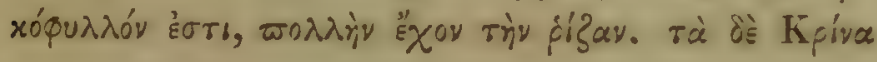

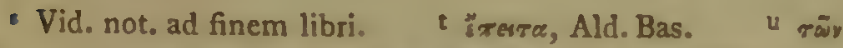

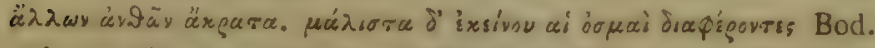

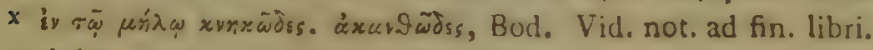
y sixóvace Const. Vid. not, ad fin. libri.

PARS II.

c 


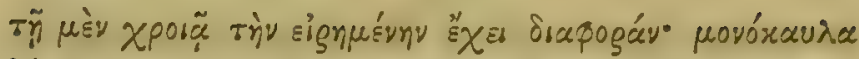

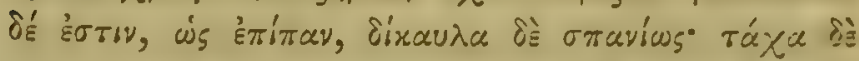

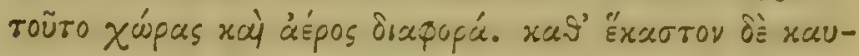

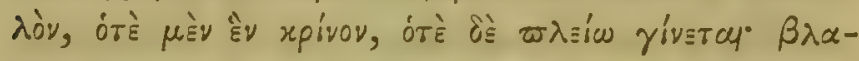

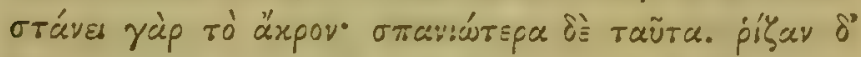

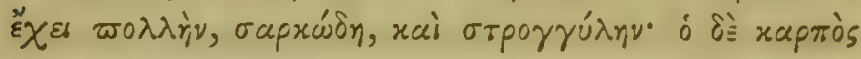

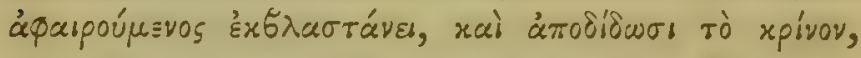

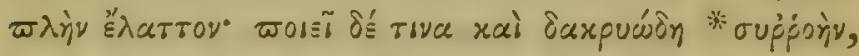

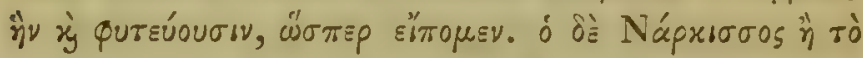

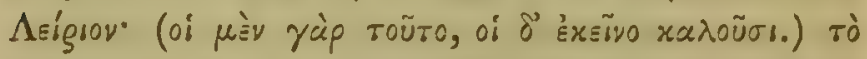

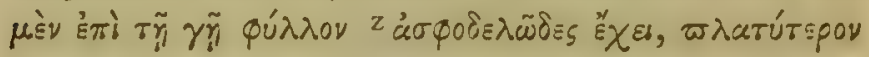

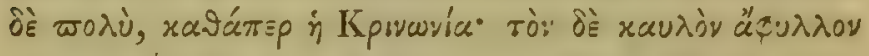

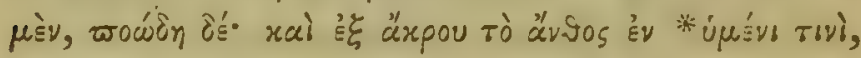

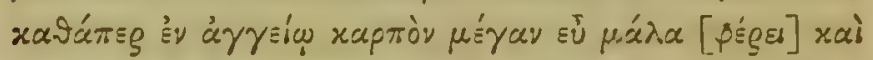

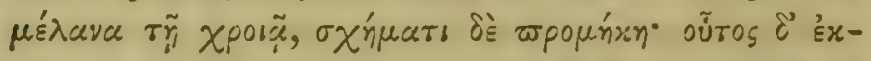

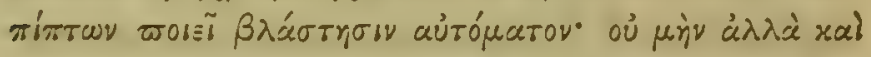

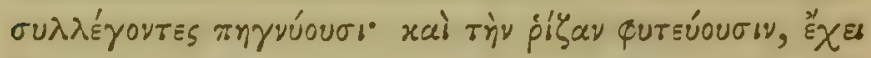

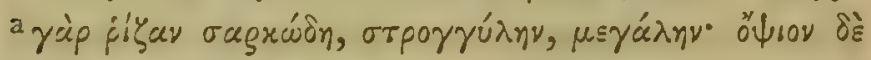

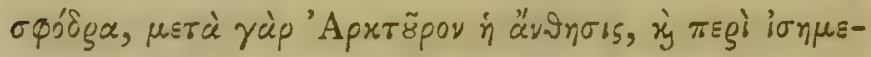

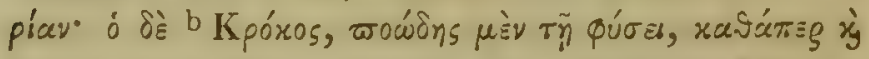

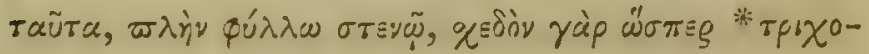

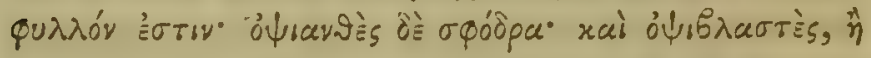

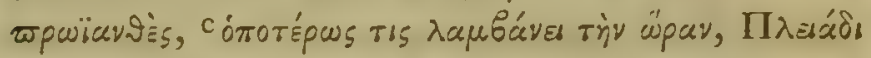

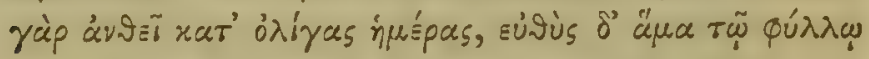

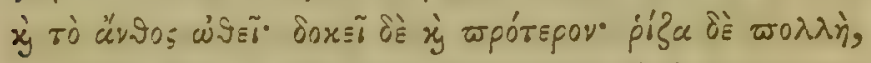

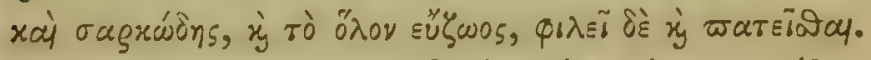

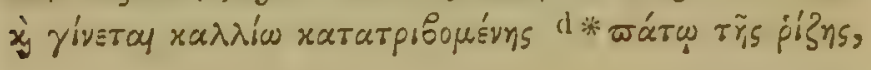

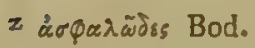

- jùg deest Bod.

- xagสòs, Bod.

e Vid. not. ad fin. libri. . d $x \alpha ́ r \omega$ Bod. 


\section{MEPI ФMTSN ISTOPIAミ TO ร'. $26 \mathrm{I}$}

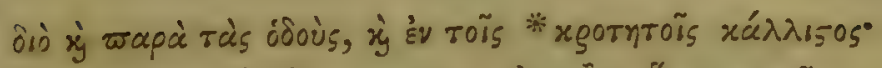

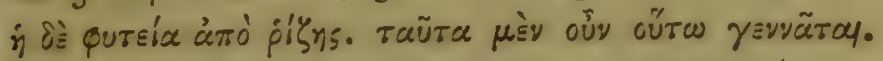

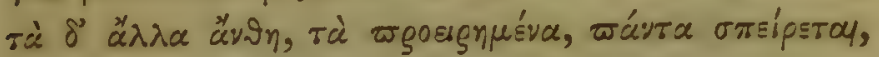

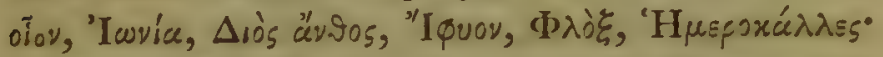

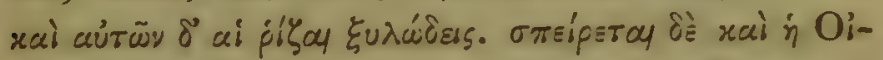

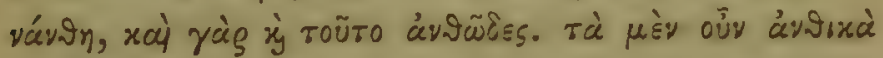

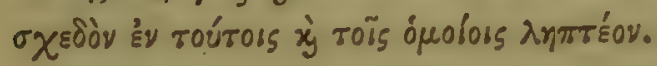

\section{CAP. VII.}

Plante coronuria Foliis et Stirpibus orloriforis. Origanum. Abrotonum. Mentha. Thymus.

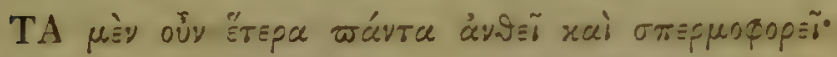

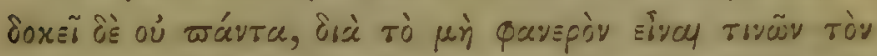

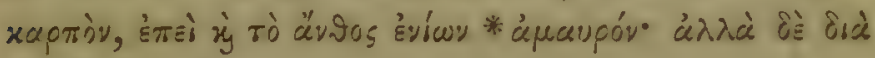

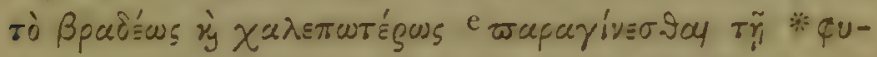

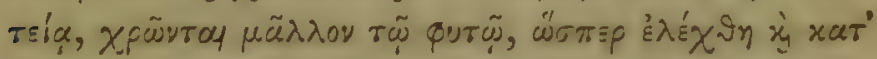

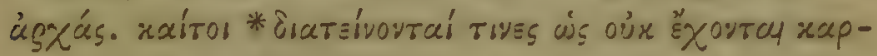

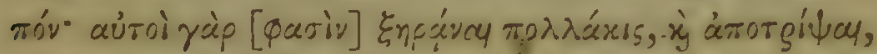

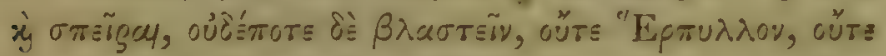

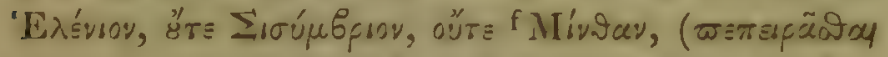

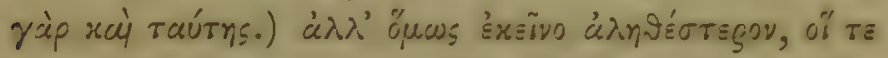

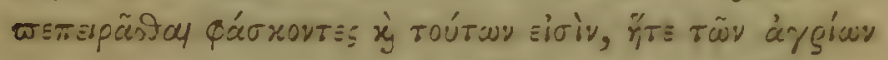

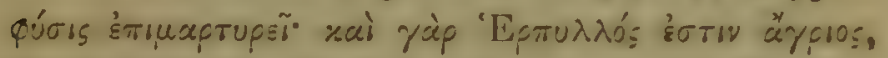

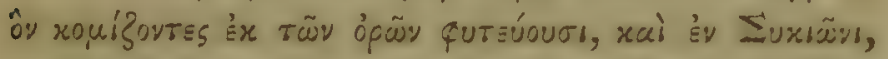

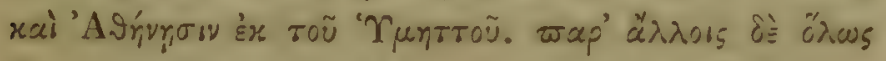

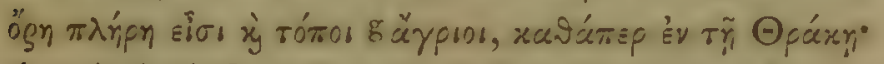

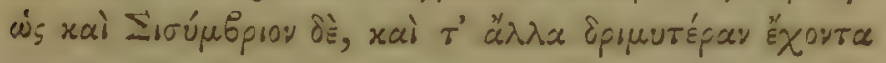

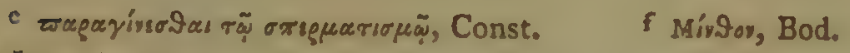
g a y gros deest Bod.

C 2 


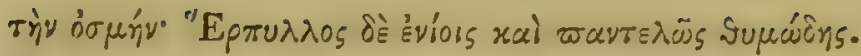

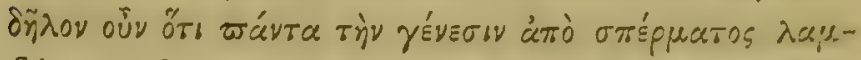

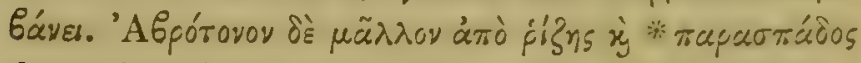

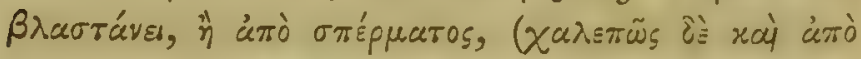

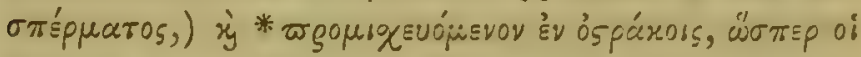

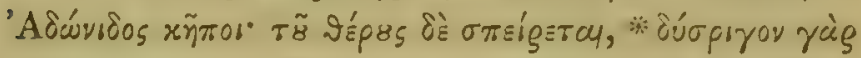

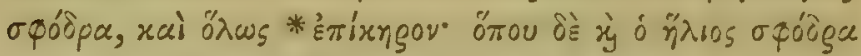

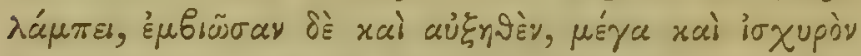

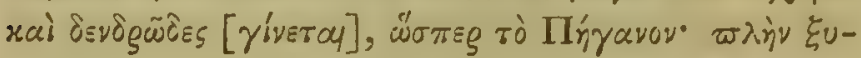

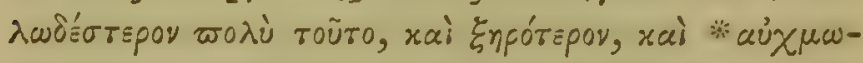

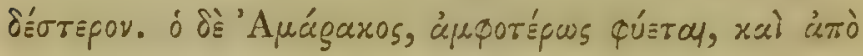

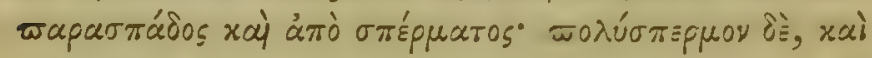

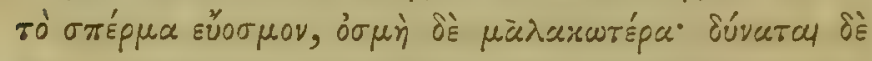

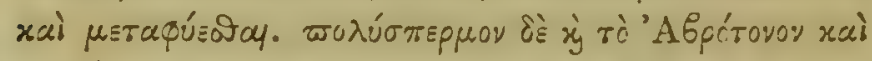

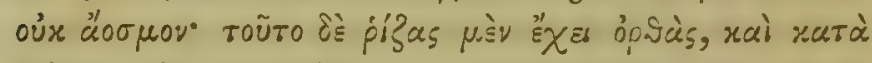

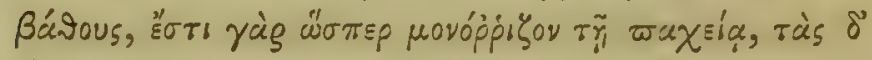

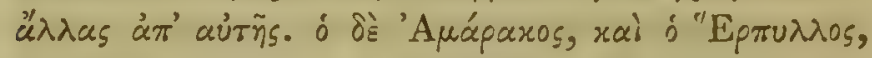

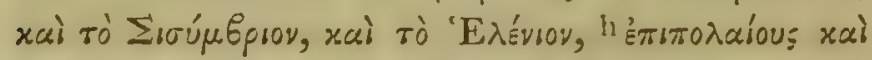

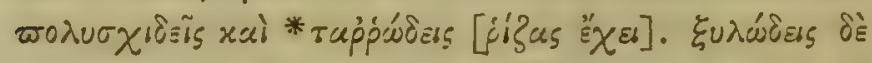

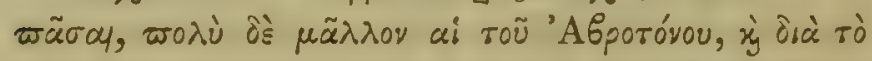

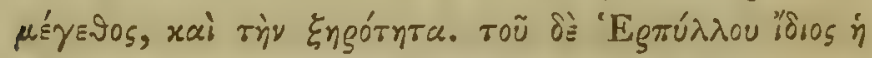

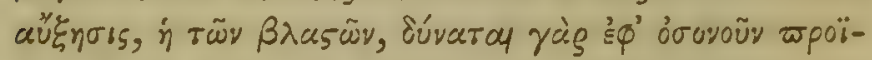

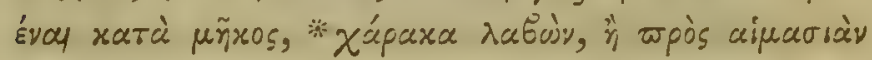

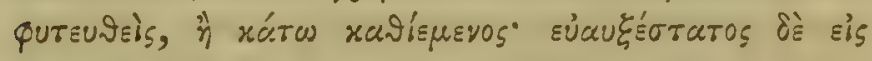

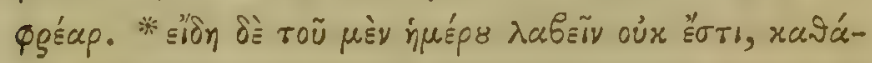

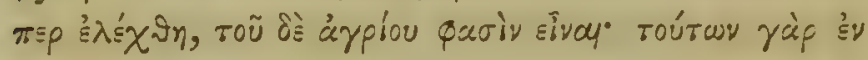

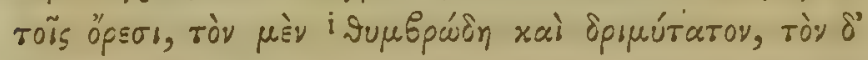

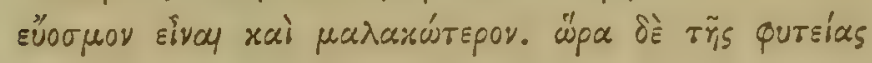

b ixi ซorroùs Ald. Bas.

i Supẹpuion ravè xai Bod. 


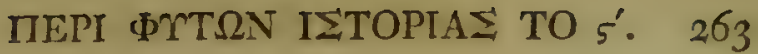

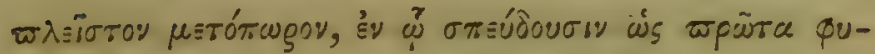

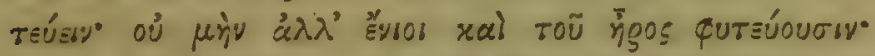

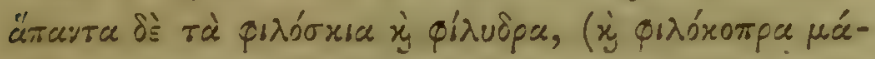

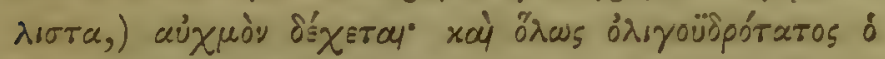

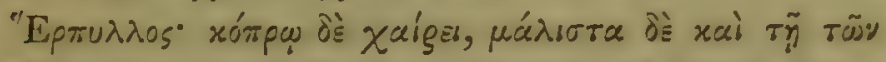

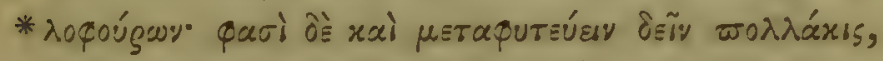

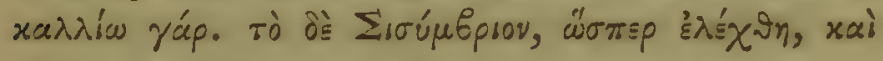

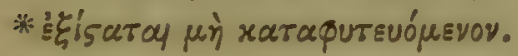

\section{CAP. VIII.}

Tempora Florescentice Plantarum supradicfarum: item

Climatum Differentic, \&c.

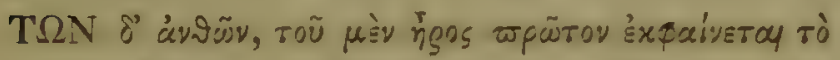

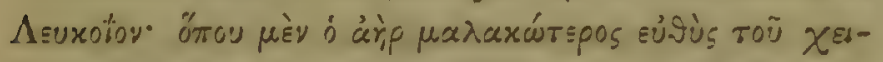

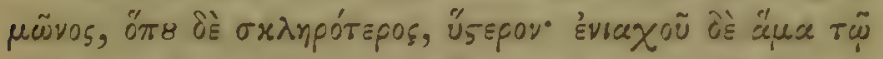

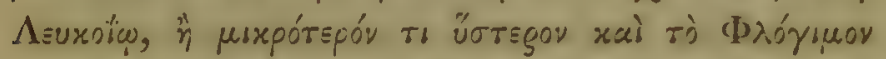

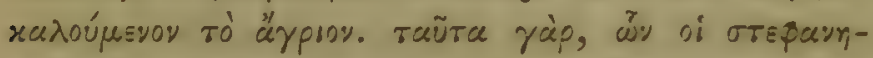

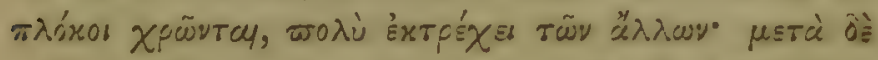

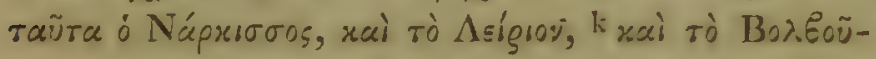

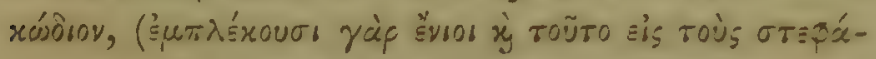

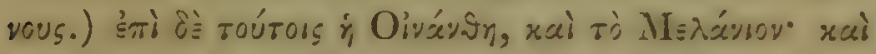

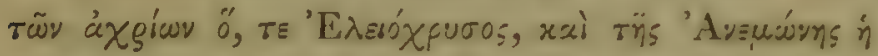

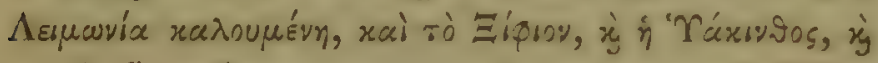

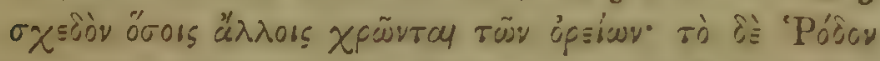

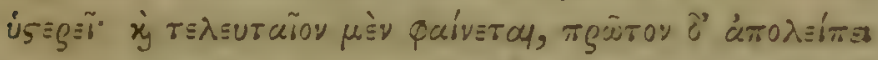

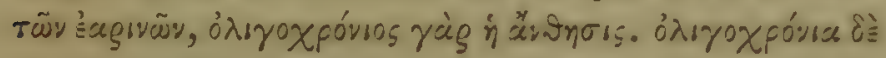

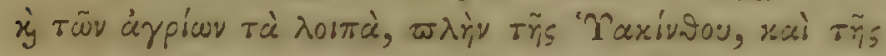

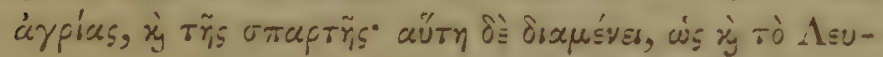

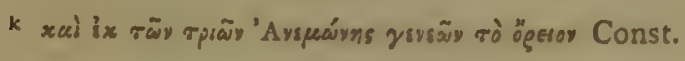

c 3 


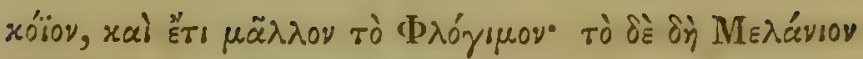

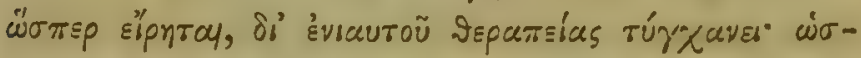

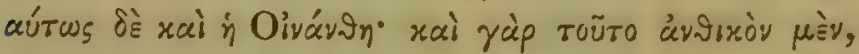

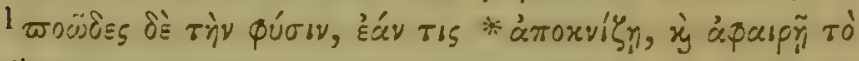

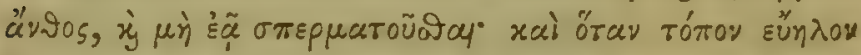

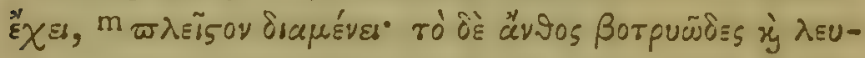

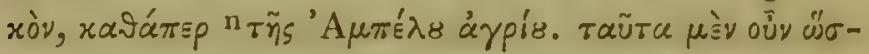

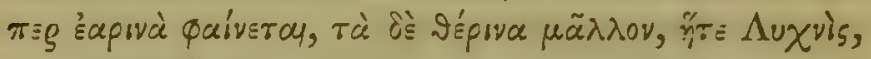

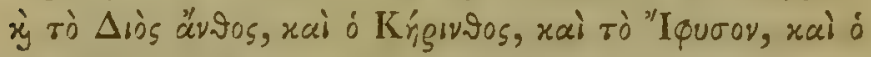

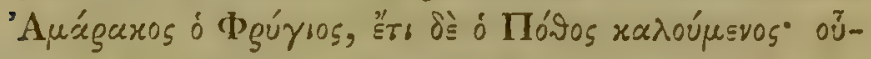

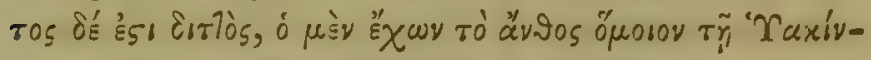

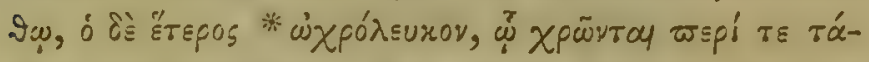

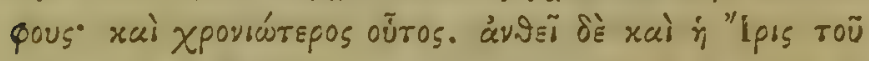

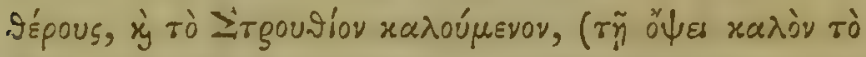

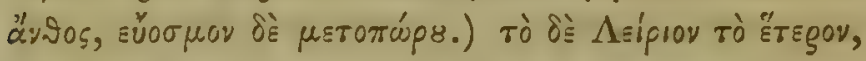

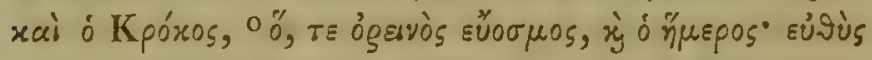

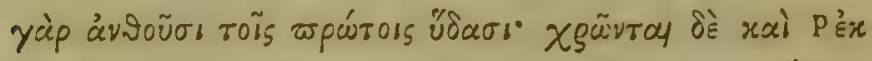

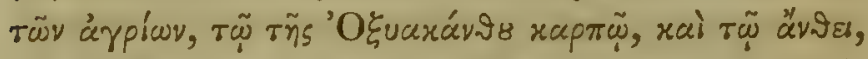

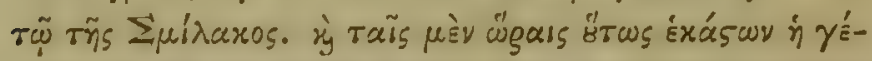

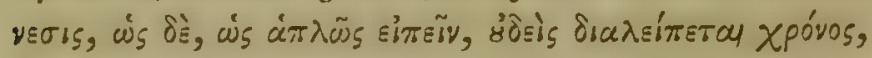

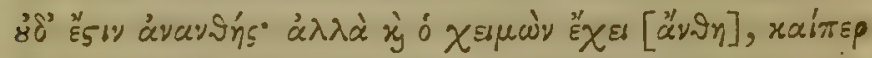

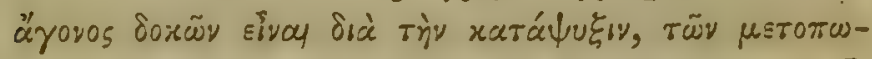

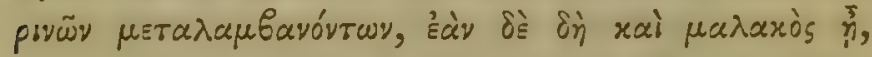

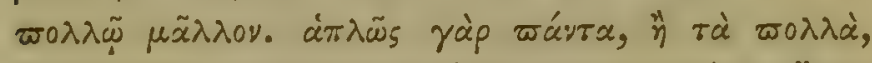

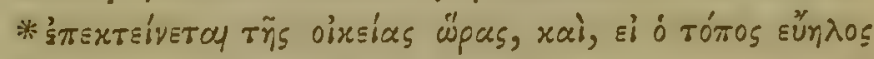

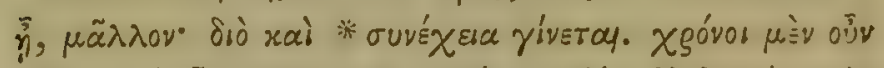

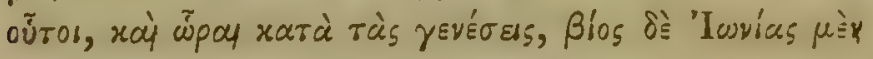

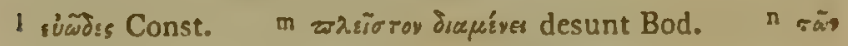
¿́yéisy. Bod.

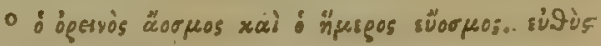
Const. P \& тส̃y áxpiay Bod. 


\section{MEPI $\Phi P T \Omega N$ ISTOPIA TO s'. 265}

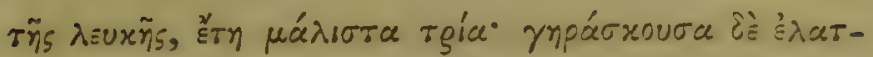

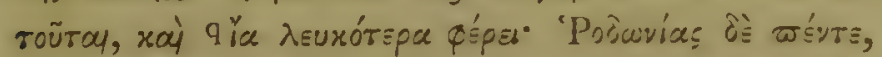

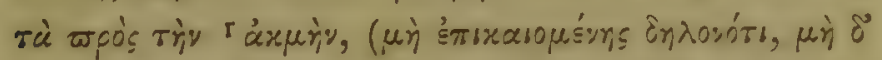

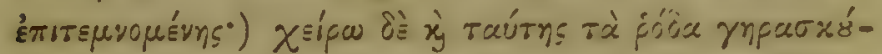

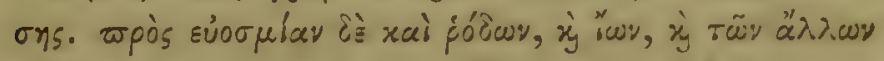

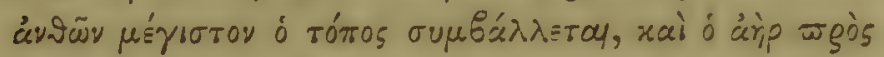

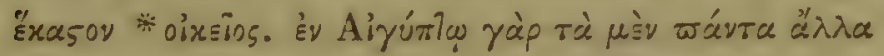

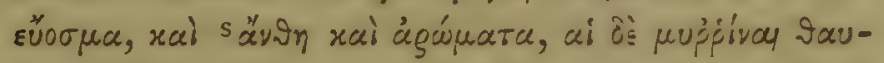

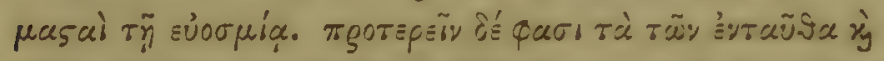

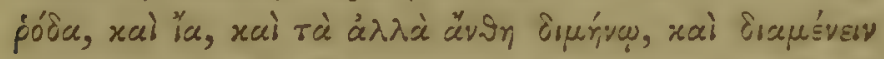

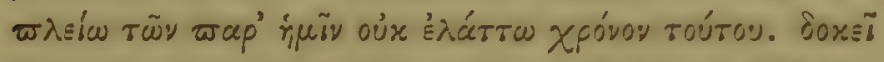

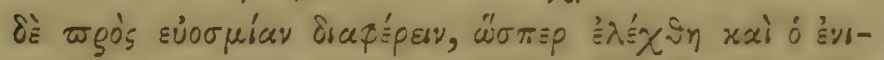

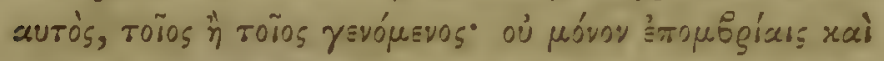

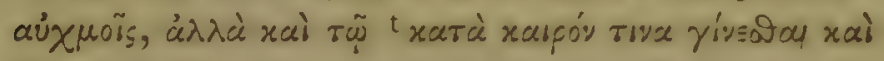

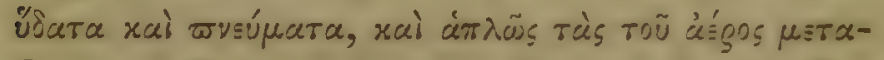

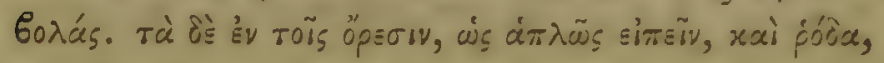

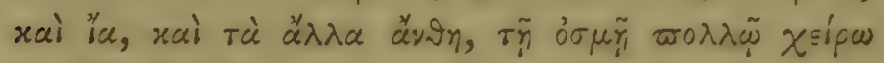

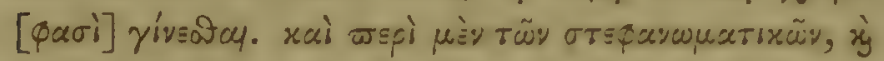

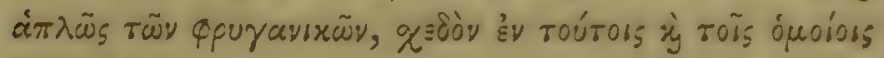
Ė $\sigma$ riv $\dot{n}$ i $\sigma$ rogía.

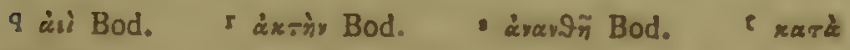
deest Bod. 


\section{NOT E}

\section{IN LIBRUM SEXTUM.}

\section{A P. I.}

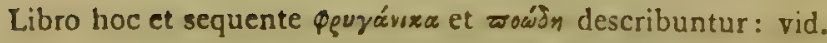
divisionem plantarum, lib.i. c. 4. et Lex. Theophr.

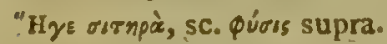

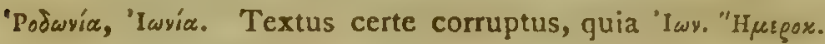

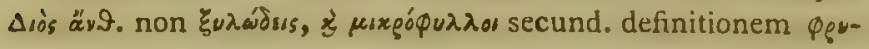
yavixwy.

'Apégaxos. In Cat. Origanum, AEgyptiacum L. Opiniones

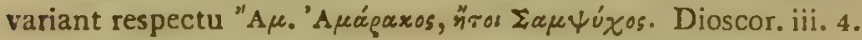
Galenus Mápov (Thymi, Mastichine L.) affinem plantam dicit.

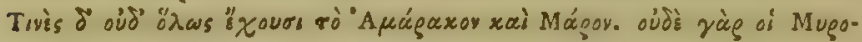

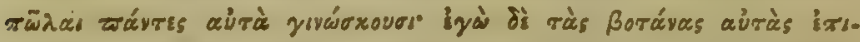

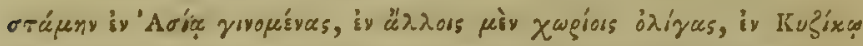

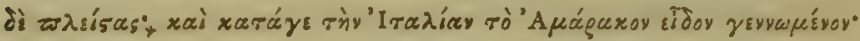

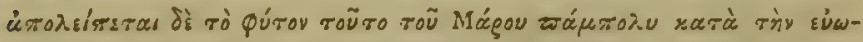

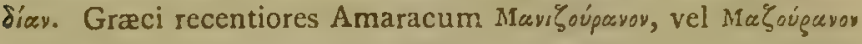
vocabant: unde vox Latina Majorana Bod.p.628. Sampsuchus Bauhin. syn. Thymi, Mastichine Linn. Planta celebris apud poetas, Virg. Catull. Ovid.

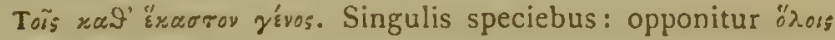
๘ँั $\delta \varepsilon \sigma$, generibus, vel familiis plantarum.

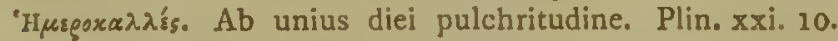

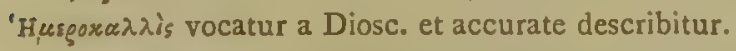

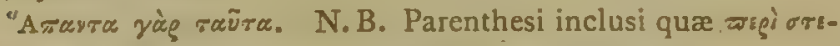
Qxvarixwy: aliter qualitas lignosa Violæ et Hemerocallidi attribuenda. 


\section{A P. II.}

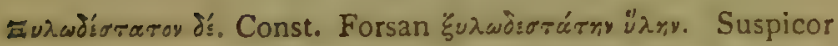
aliquod ex textu intercidisse: ait enim ó $\mu \mathrm{i} \lambda \dot{\alpha} \xi x_{0} \tau, \lambda$. sc. virgulas Cneori, rigre lignosiores esse: evidens ergo comparatio.

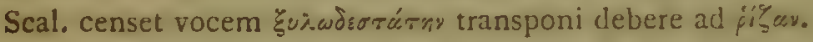

Kyéwģy. Daphne, Cneorum. Cat. Plinius vero in loco ait, " Cneori duo genera: nigri et candidi." Alibi tamen confundit cum Casia, xii. 20. Forsan Cn. Tricoceum L.

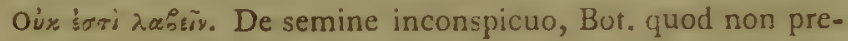
hendi vult ob parvitatem.

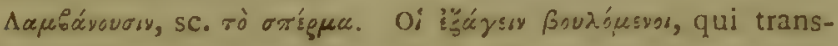
ferre cupiunt in alias regiones:

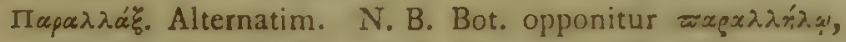
opposito.

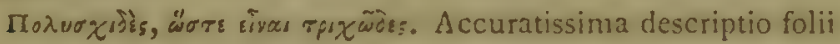
Ferula et Freniculi \&c.

'O Mavógaygóas. Atropa, Maniragoras, Cat. sed rectius Atropa, Belladonna, quia caulis dicitur subfistulosus; sed quarendum.

\section{A P. III.}

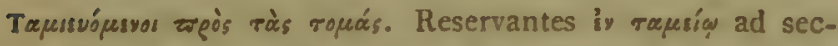
tiones futuras. Gaz. Tò üra? xov, reliquum; i. e. partem superiorem radicis.

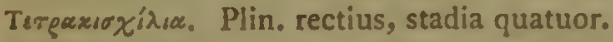

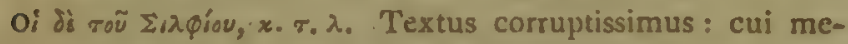
deri conatus sum ex margine, et traductione, itemque ex descriptione Plinii. N. B. Magudags; a Plinio vocatur succus caulinus Silphii : et duplex succus xaviia; et fis.as supra memoratur, et lib.ix. c. 9. Galenus c contra ait, payúdaģv esse succum quiarov. N. B. Vid. plura de Silphio Strab. ii. 173.

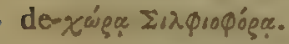

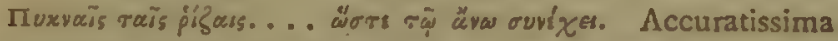
descriptio radicis Asp. sativi L. quançuam ex descriptione spinarum in caule, $\Lambda$ sp. sylvestris innui videatur. Anne anti. quam cultura exuisset spinas? 
'O x.cudìs 'Arqugáyou lóódreos. Sc. caules juniori statu, turiones rocati.

¿xógтиos. Ulex; an Genista spinosa. Cat. Scorpius secundus Clusii, apud Belgas "Gaspeldorne." Bor. p. 605. Comparent Botanici descriptionem plantæ hujus cum Genista, Lusitanica L. N. B. Ulex Europæus nostras optime convenit

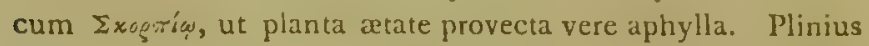
meminit Scorpii, xxi.15. Descriptio etiam apud Honor. Bellum citatur. Bod. p. 605.

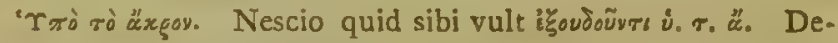
scriptio hæc convenit Carduis, vel Cnico. Forsan transpositio verborum, si non Scorpii duo.

'Púrgos. Carduus; an Echinops? Cat. Plinius, recte forsan, vocat Eryngium. Vid. etiam Dioscor. iii. 24. et Plut. Sympos. lib. vii. Duæ Cardui species occurrunt capitulis spinosis, folio lævi : C. stellatus, et C. solstitialis L.

\section{A P. IV.}

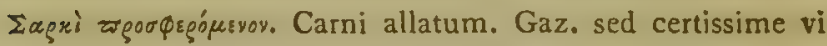
compressum, adeo ut succus effluat.

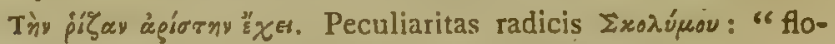
"rescentibus enim aliis radix deterior." Scal.

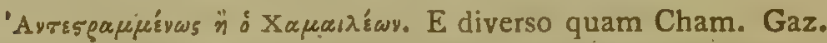
Comparat auctor plantam hanc cum Chamæleonte: idque

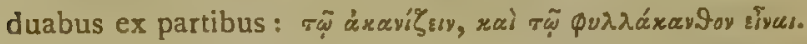

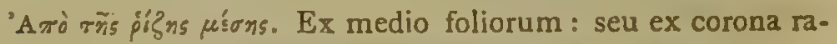
dicis, in medio foliorum.

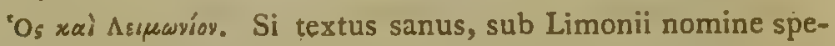

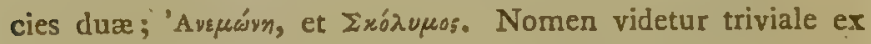
loco natali in pratis.

'x ̌̌íy. Carduus, Cat. Ixine Fabii Colonnæ citatur a Bodæo icone addita : cujus tamen nulla mentio apud syn. Linn. sed ex gummi mastichino, forsan Atractylidis species. N. B. Alia 'I 'Givn, Prosp. Alp. ibi citatur, una cum icone, sub nomine Card. Pineæ, quam tamen nusquam repperio. Forsan Carlina, acaulis $\mathrm{L}$.

Káxrovs. Cactus, opuntia, L. Cat. Ita secund. Bod. Sed Cactus genus novi orbis. Athenzeus interpretatur Cinaram; 


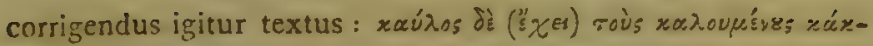
rovs, sc. pericarpium squamosum Cinaræ Scolymi ảxarüdos,

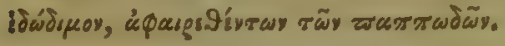

\section{CAP. V.}

(D)́ws. Dipsacus, fullonum. Cat. $\mathrm{Ab}$ aliis Centaurea, stobs L. sed mallem legere Poterium, spinosum L.

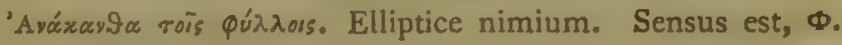
et ' $1 \pi \%$. nullas in foliis spinas gerere.

Tp̧ibonns. Duo Tribuli hic clare nominantur, diversi a $T_{g}$ Góxw Träpa natante, lib. iv. c. 11. Prior certissime Tribulus, terrestris L. posterior forsan Medicago, echinata L. Nedica, spinosa Raii, 962.

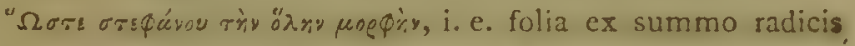
provenientia, et humi repentia, corona formam exhibent.

Eis รั่ हैं

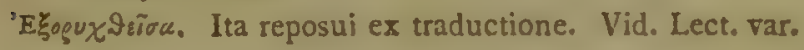

\section{CAP. VI.}

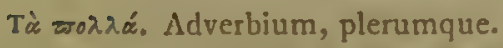

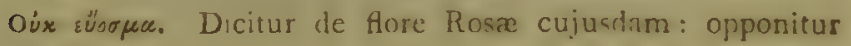

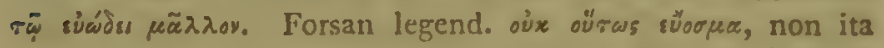
suaveolentia, per comparationem cum Rosa Pangæi.

" $\Omega$ y те̨ахѝ rò rárw. Cujus pars inferior (calyx) scabra. Descriptio Rosæ centifoliæ, varietatis " pedunculo et calyce mus. " coso." Linn. Spec. Plant. Angl. "Moss Rose."

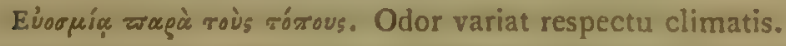

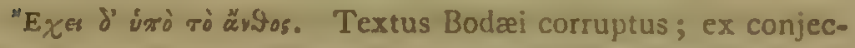
tura, tamen resarciendlus quodammodo. De seminibus in peri-

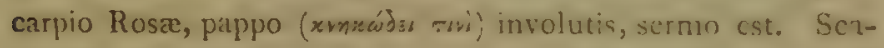

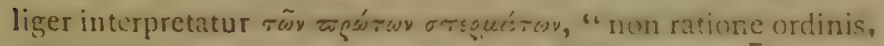
"sed loci, ut quae in imo loco sita sunt." Mihi videtur dici de incipiente, et nondum adulto semine.

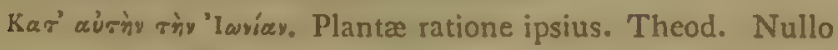
prorsus sensu. Interpretor Violas nigras et candidas in codem violeto (iavío) mixtas inter se differre.

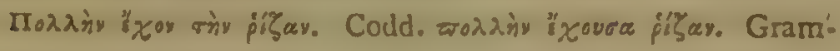


matice repugnante: sed forsan "xoura ad iwviay referenda, et

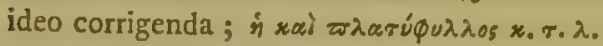

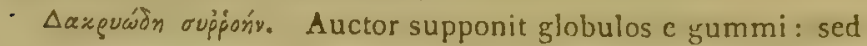
gemma fertiles, bulbis similes, hic indicari videntur; quas videre est in Lilio bulbifero L. et in Dentaria.

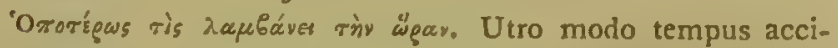
peres. Theod. Sensus est, Crocus adeo præcox, ut dubium an sero hyeme, vel initio primo veris.

Siós üyos. Dianthus Caryophylleus Agrostemma, Cat. Sed Bodæus censet D. armerium innuj.

"IQuoo\%. Lavandula spica L. Forsan L. stachas.

$\Phi \lambda o_{\text {g. }}$ Agrosternma, Cat. Nulla descriptio apud Theophr. Nicandrus in Georgicis ita describit:

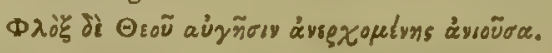

Forsan Clematis, fammula, L. Flammula Bauhin. Dodnn. et Raii.

OivávAn. Convallaria majalis L. Cat. Bodæus inteıpretatur Filipendulam. Differt ab oiváy9n Dioscor. iii. c.135. Quærendum respectu odoris, an Spiræa ulmaria $\mathrm{L}$.

\section{A P. VII.}

'Eגśvıs. Ign. Cat. Heleniun ex lachrymis Helenæe natum.

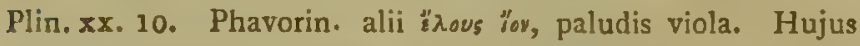

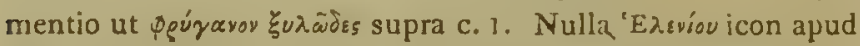
Bod. An Inula hellenium L.? Marum, mastychinum. Ger. em. Clinopodium arvense, vel Thymus acinos. Dodon. Tragoriganum rectius, seu Thymus Cephalorus L.

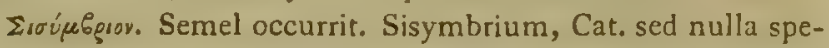

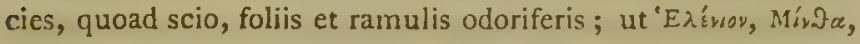
Ińryavov, 'A ré́gaxos. Bodreus ait Sisymbrium, Mentha agres-

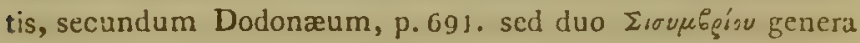
apud Theophrastum, ut videtur, quorum alterum dicitur mutari in Mentham. Bod. p.692, 771.

\section{A P. VIII.}

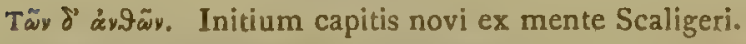

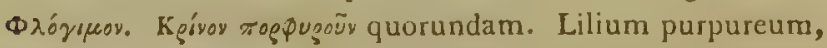
rel rubrum, Plinii, quem immediate post Leucoium florere 
scribit. "Ex violæ fit genere, floremque in quo flammei quid

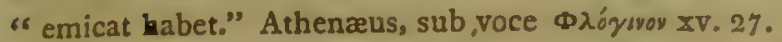

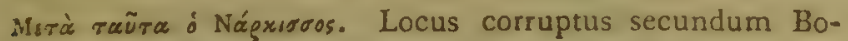
dæum : ex Athenæo restituendus. Vid. etiam Plin. xi. 11.

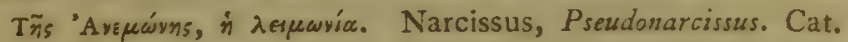

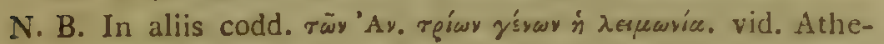
næum in loco, lib. xv. N. B. Nomen Anemonis latissime

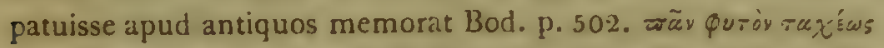

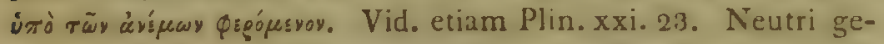
neris apud Dinscor. ii. 207. Secundum ordinem florescentia forsan A. nemorosa indicatur. Vid. etiam A. pulsatillam L.

Tò Mrzáxiov. Viola odorata L. forsan var. $\gamma$. De speciebus Violæ vid. infra lib. vii. c. 7 .

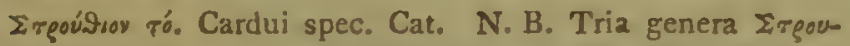
Sise occurrunt apud Theophrastum: 1. Cyclonia sylerstris,

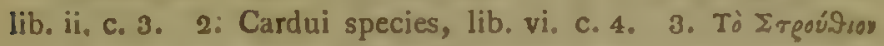
xa $a$ úusyyy, una cum Iride. Elaborata admodum dissertatio occurrit apud Bod. respectu hujus plantex, citanturque auctores vereres: inter alios Honor. Bellus et Car. Clusius de planta antiquitus vocata Kivuśre, cujus tamen nulla apud Synon. Linn. mentio, p. 722. Icon etiam occurrit Luti Cre-

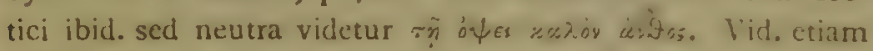
$\Lambda$ thenæurn, lib. xv. c. 24. ubi mentio fit Struthia curonep : et

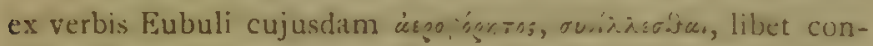
jicere plantam scandentem describi : forsan Lonicera pericly. menum L.

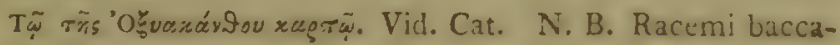
rum Cr. Pyracanthi aurantii coloris splendidissimi. 



\section{$\Theta \mathrm{EO}$ O PA $\Sigma$ TO $\Upsilon$}

\section{IIEPI $\Phi \Upsilon \mathrm{T} \Omega \mathrm{N}$ I $\Sigma \mathrm{TOPIA \Sigma}$}

\section{TO $Z^{\prime}$.}

\section{CAP. I.}

Plante perennes et herbacea. Olera. Frumentacea.

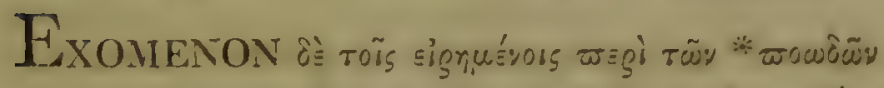

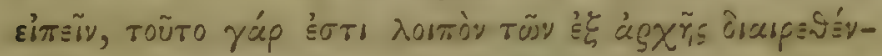

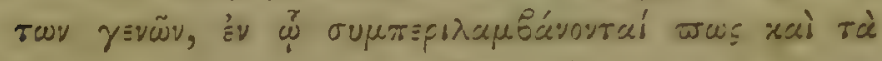

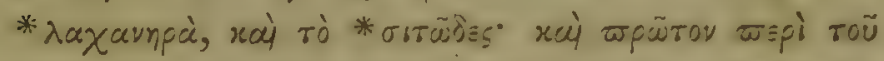

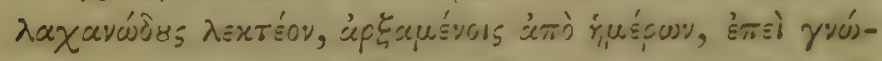

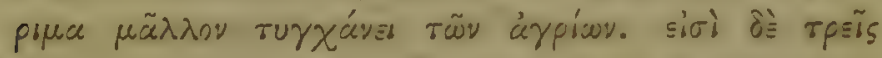

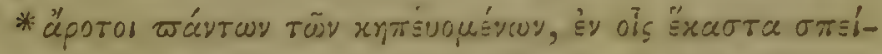

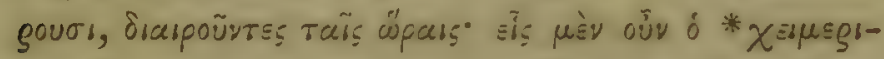

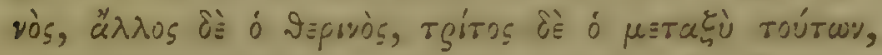

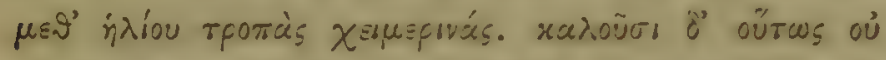

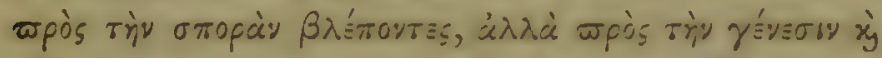

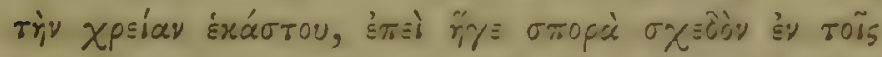

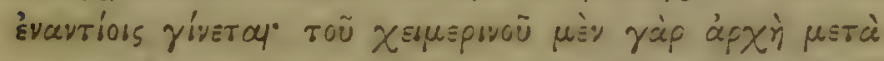

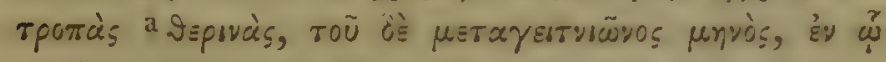

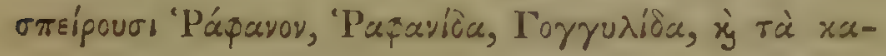

2 Xupuservàs, Ald, Bas. 


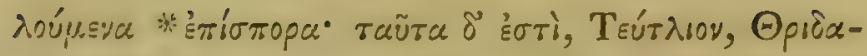

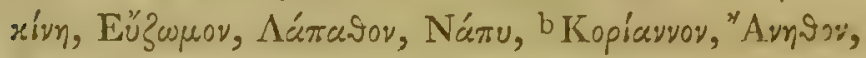

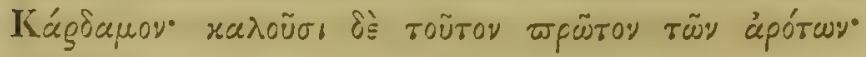

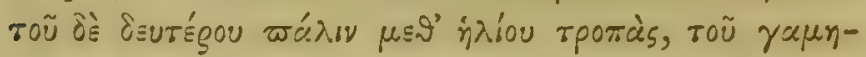

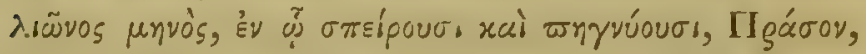

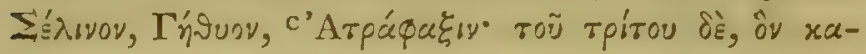

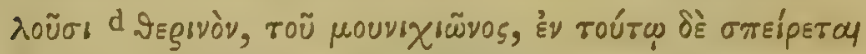

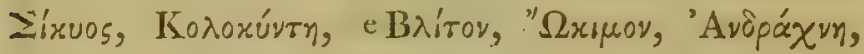
Oúre

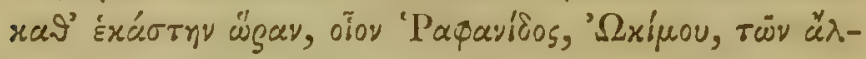

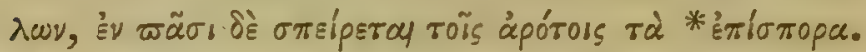

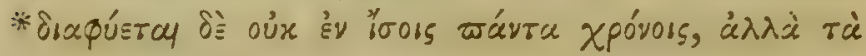

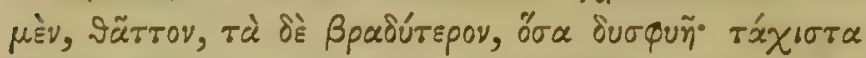

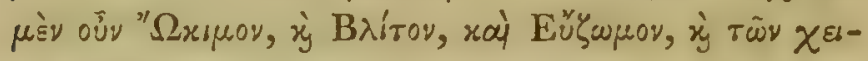

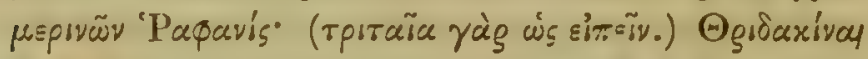

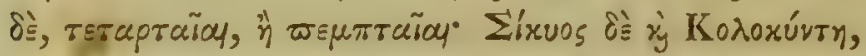
ఐЕ

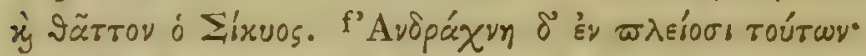

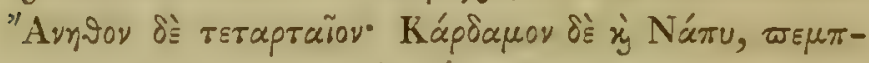

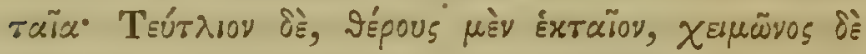

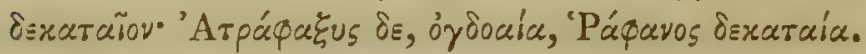

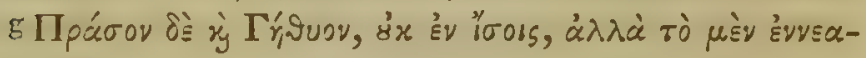

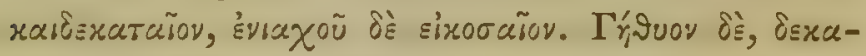

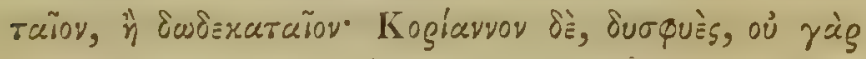

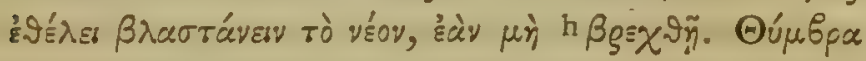

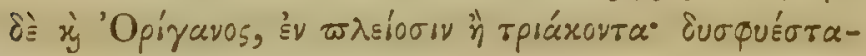

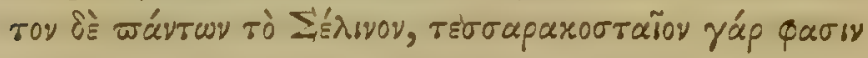

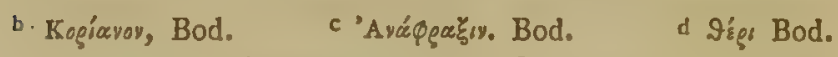

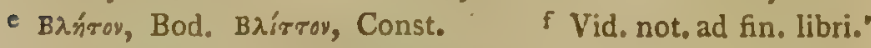

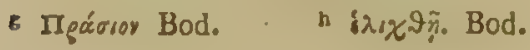




\section{MEPI TMTSN ISTOPIAS TO Z'. 275}

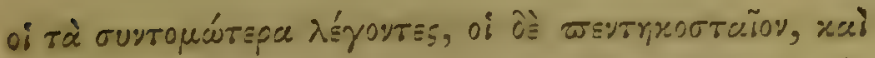

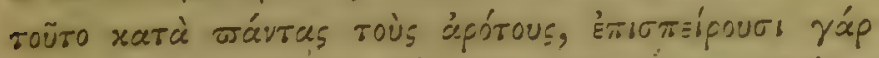

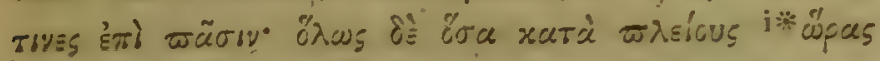

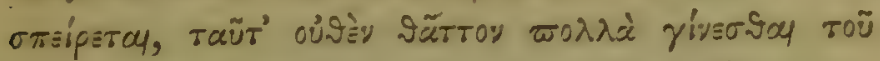

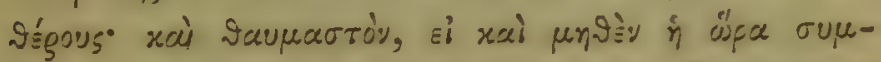

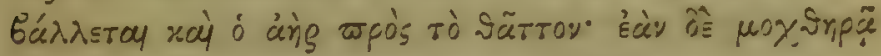

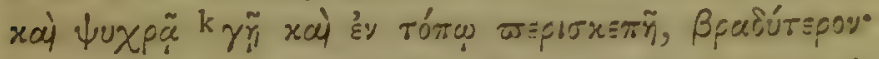

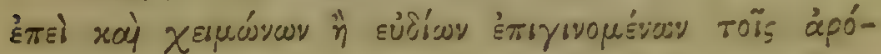

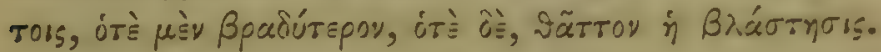

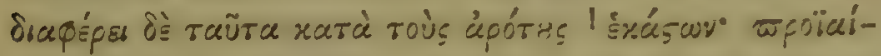

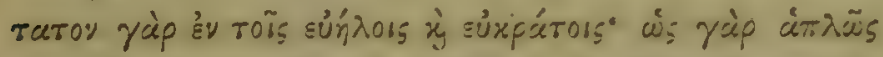

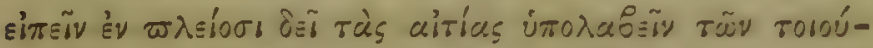

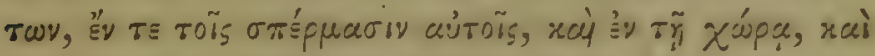

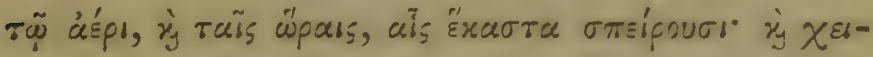

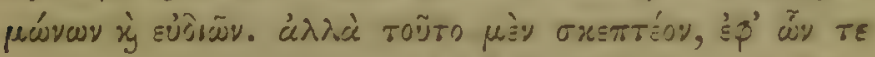

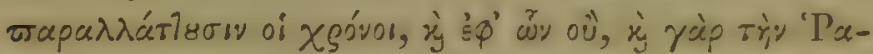

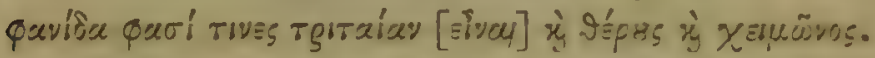

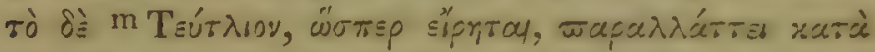

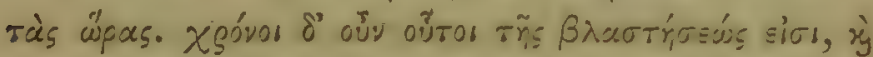

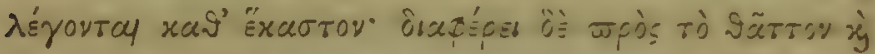

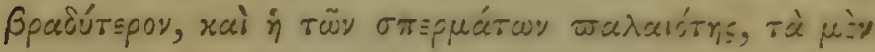

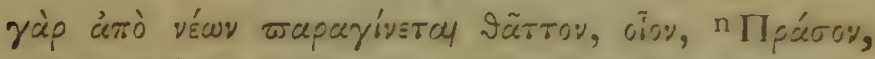

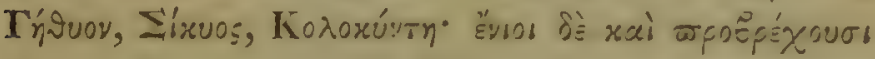

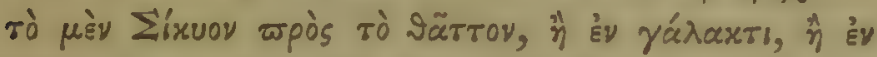

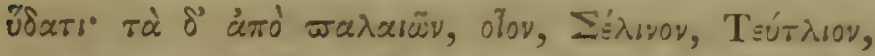

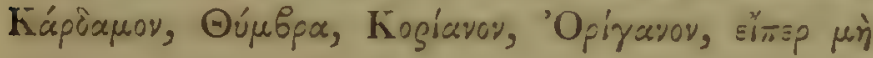

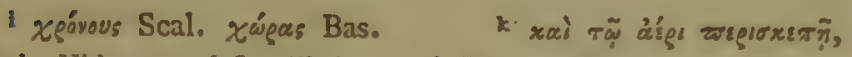

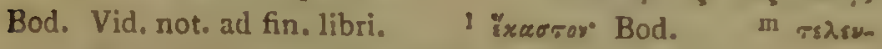
raiov, Bod. Vid. noto ad finem libri. in If párovy, Bod. 


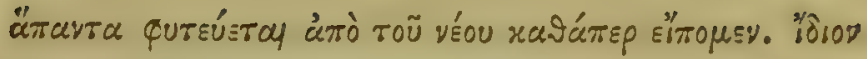

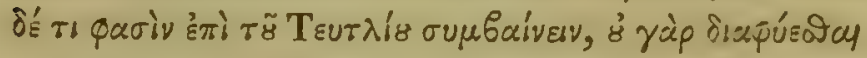

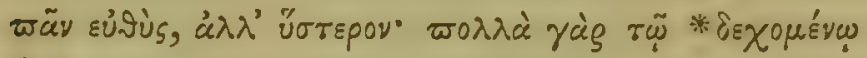

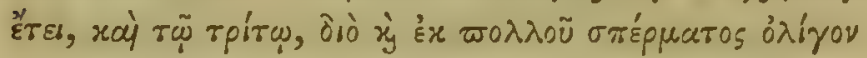

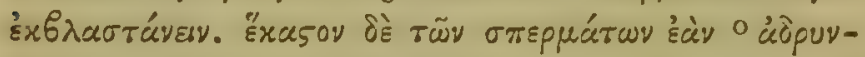

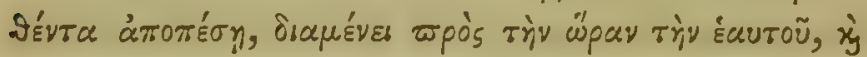

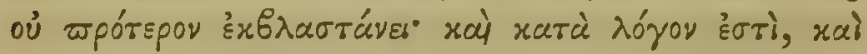

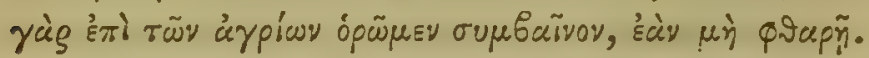

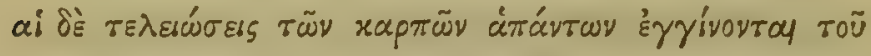

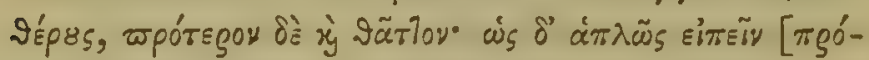

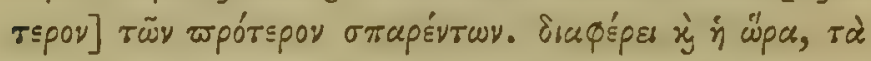

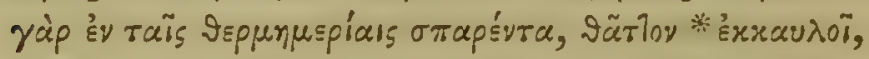

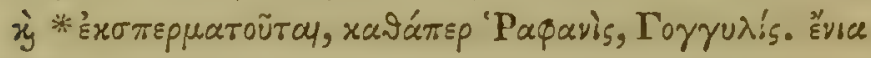

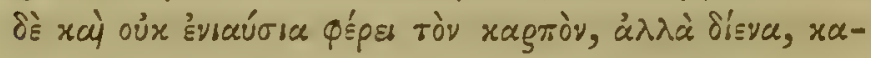

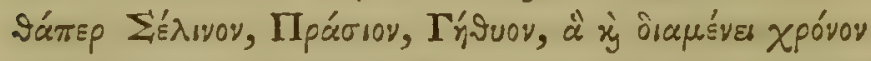

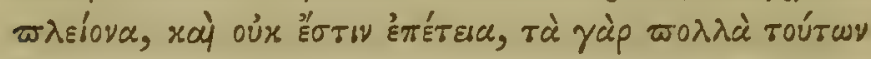

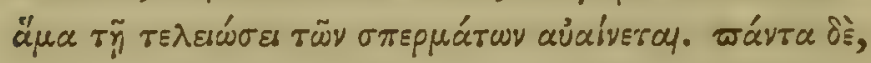

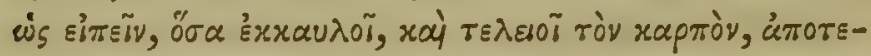

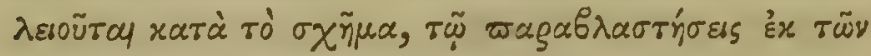

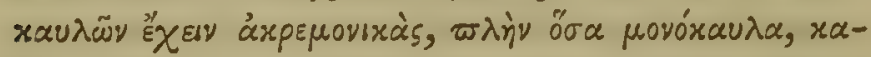

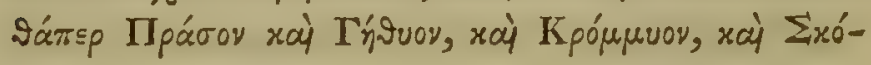
poór.

\section{CAP. II.}

Propagationes Olerum.

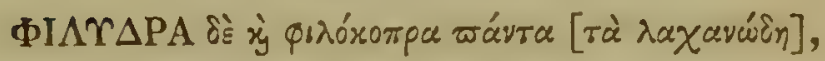

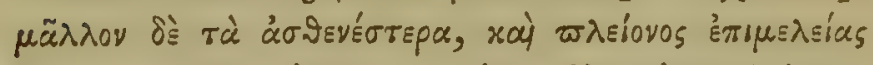

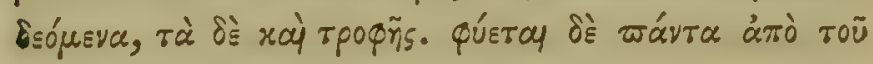

- éyรgúviseyra Ald, Bas. Vid. not. ad finem libri. 


\section{MEPI ФYTSN ISTOPIA TO Z'. 277}

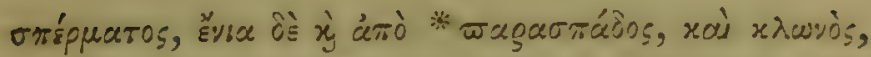

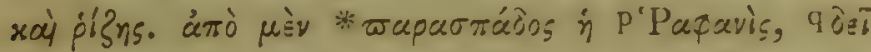

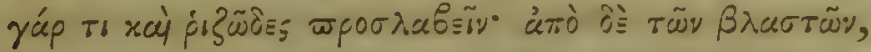

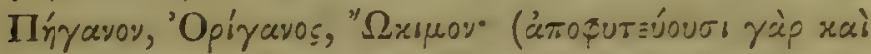

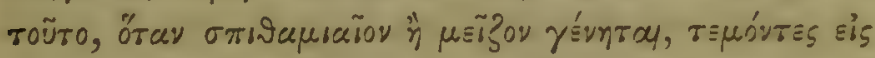

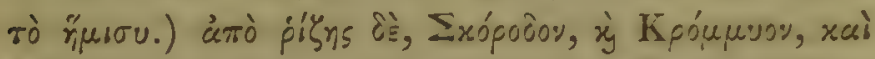

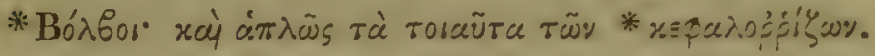

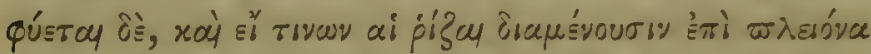

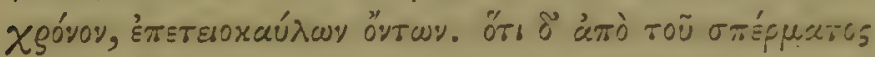

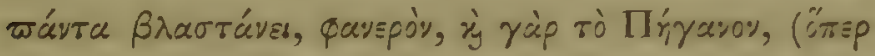

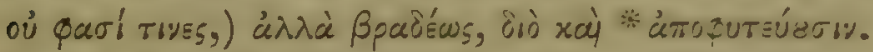

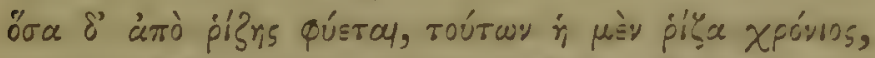

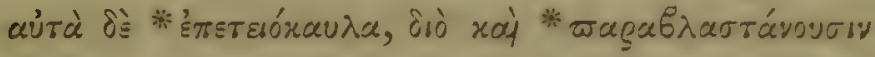

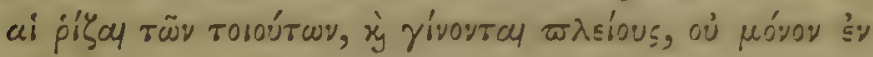

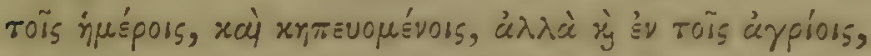

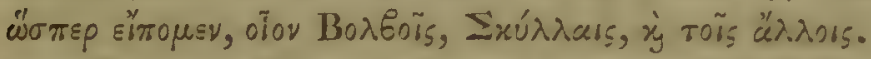

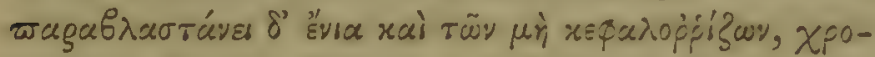

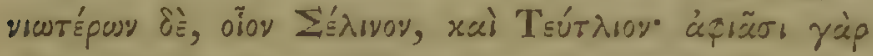

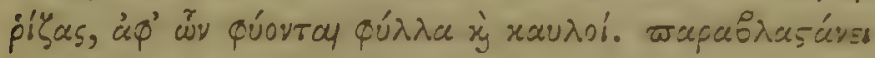

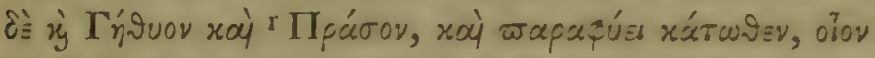

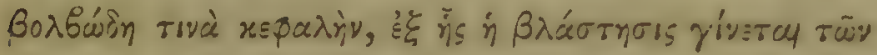

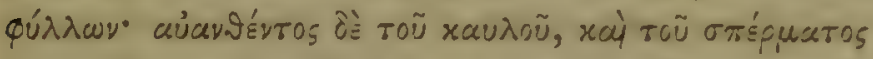

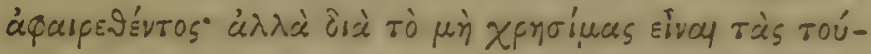

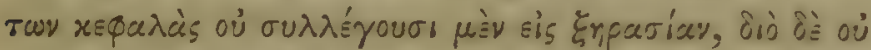

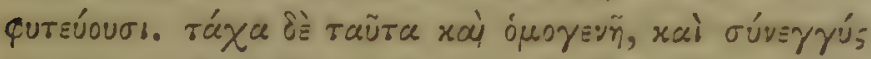

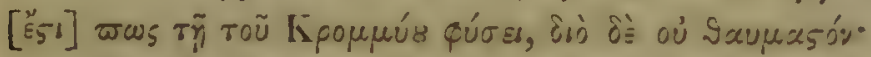

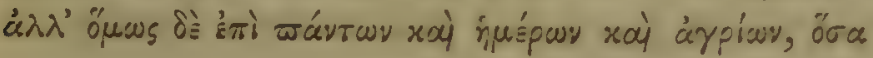

p 'Pápayos, Codd. Vid. not, ad finem libri.

\& Mৎárvoy, Bod.

$q$ ài Bod. 


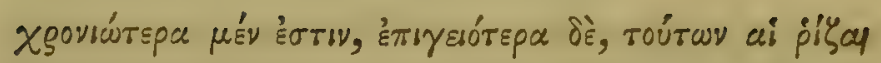

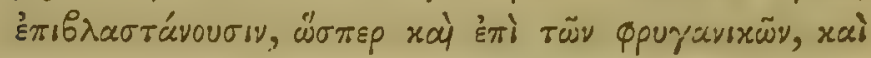

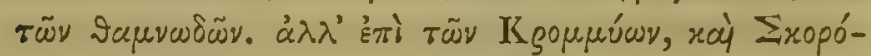

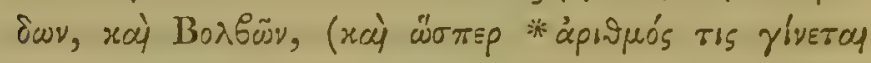

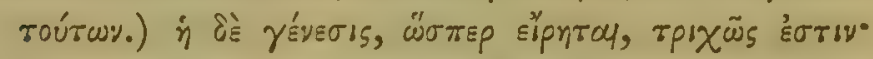

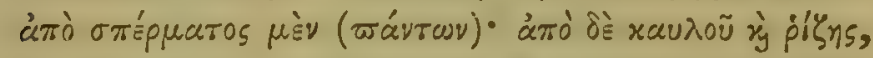

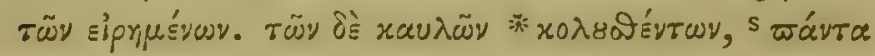

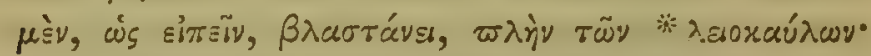

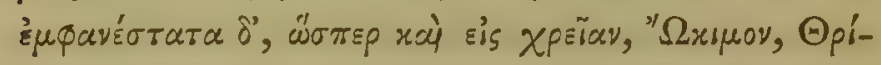

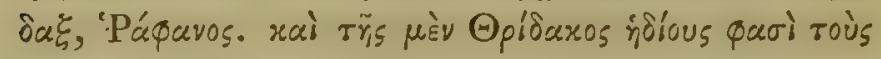
*

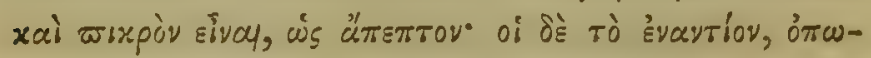

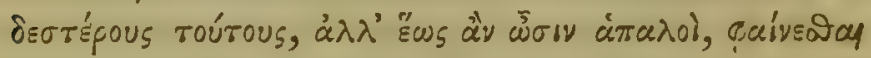

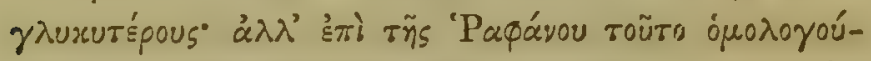

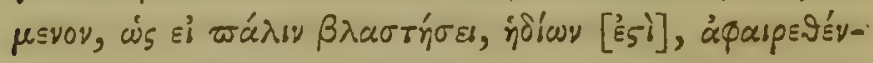

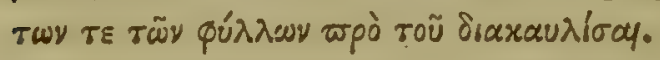

\section{CAP. III.}

\section{Qualitates Radicum.}

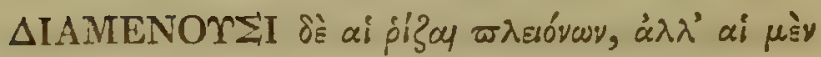

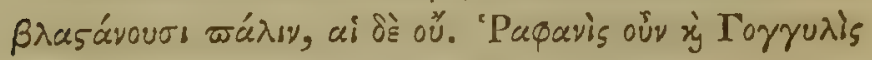

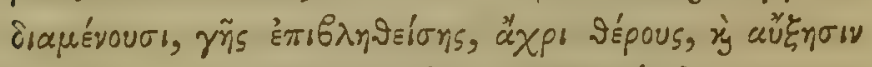

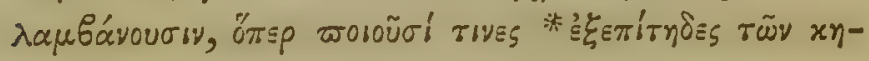

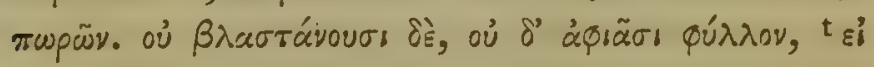

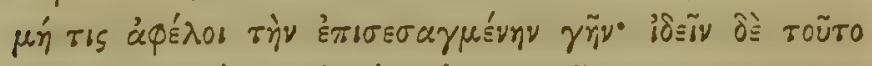

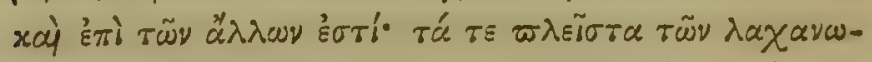

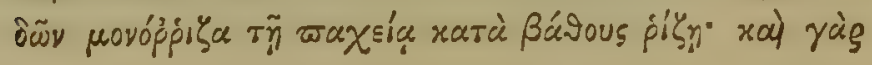

- áávrar Bod.

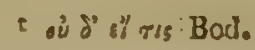




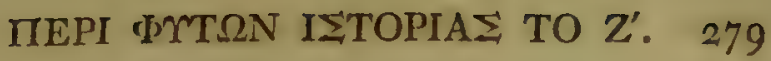

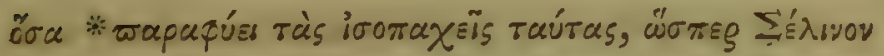

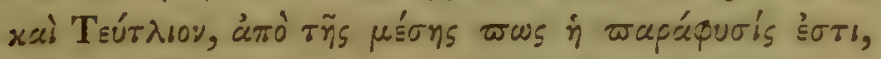

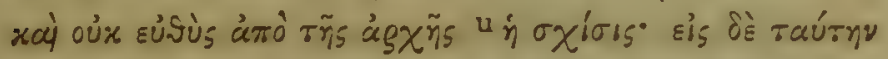

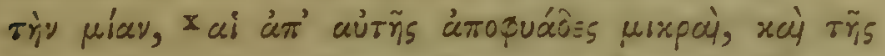

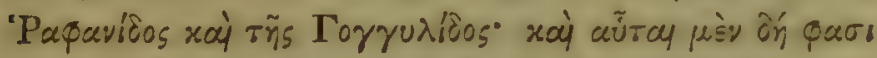

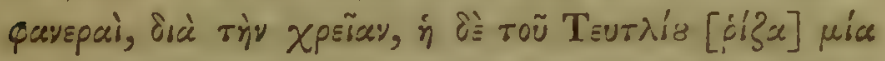

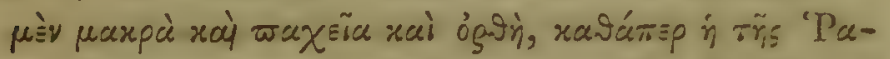

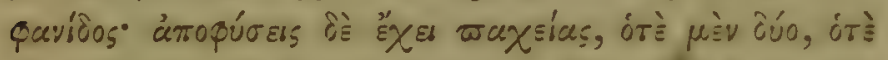

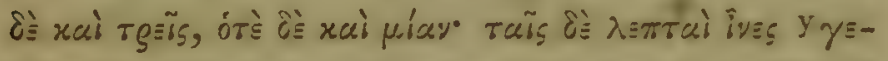

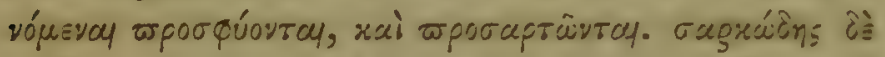

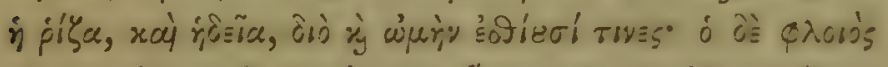

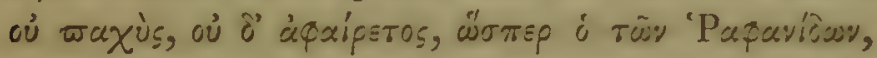

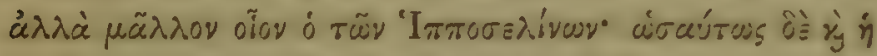

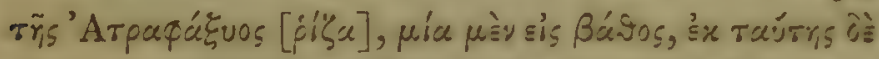

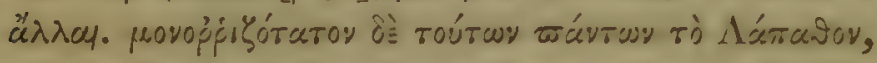

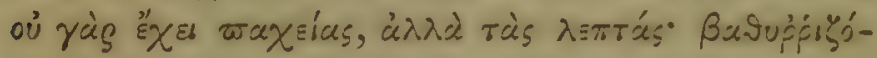

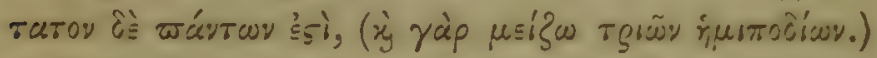

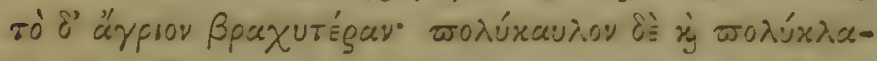

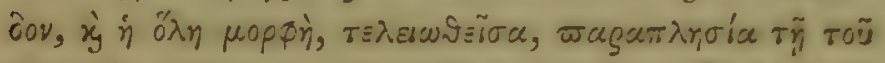

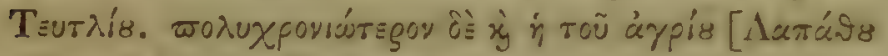

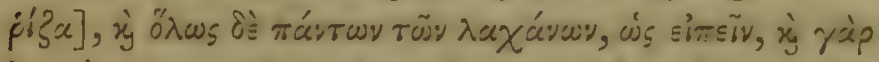

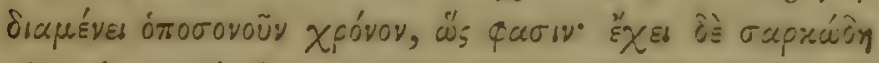

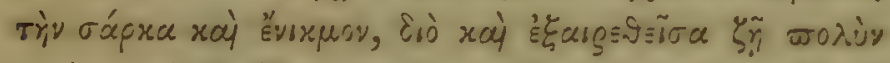

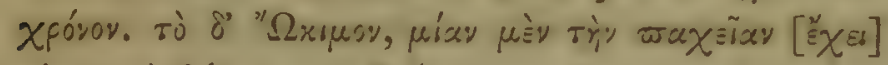

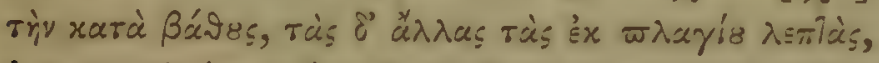

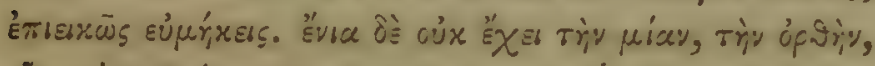

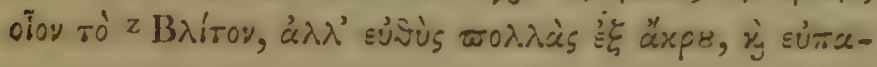

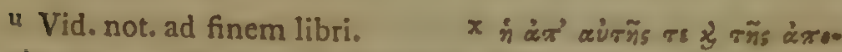

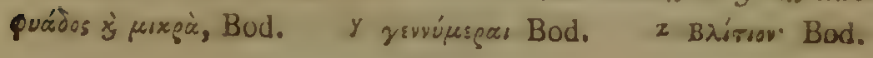

D 3 


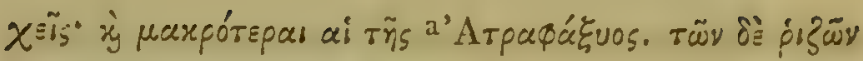

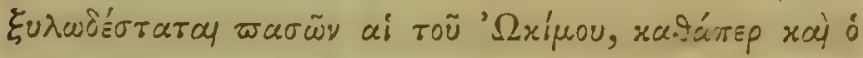

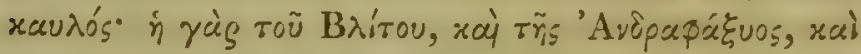

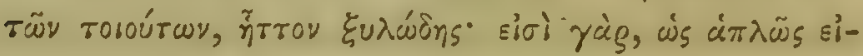

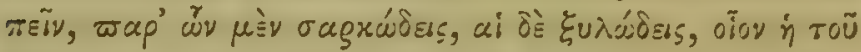

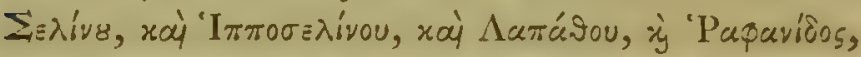

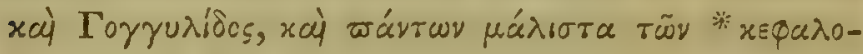

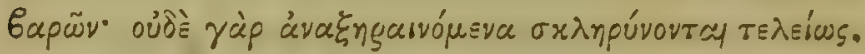

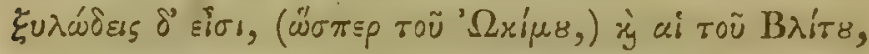

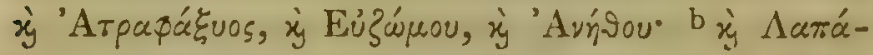

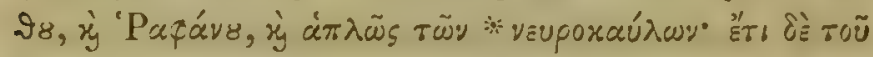

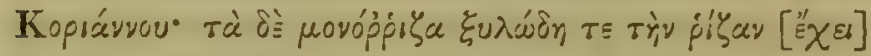

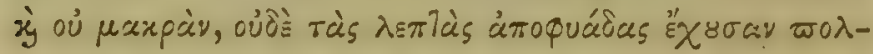

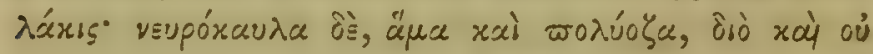

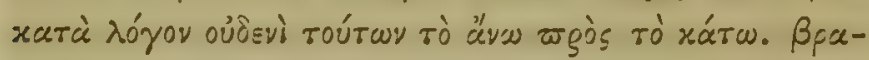

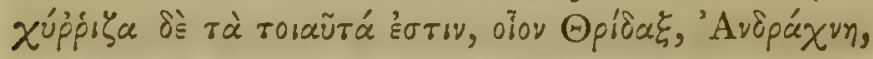

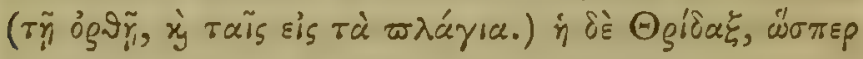

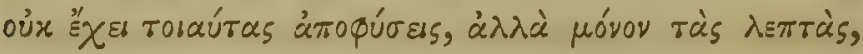

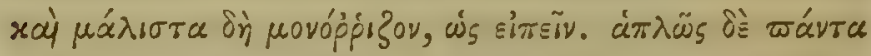

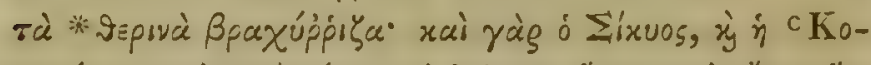

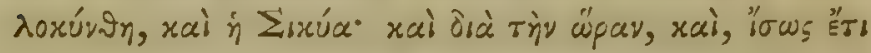

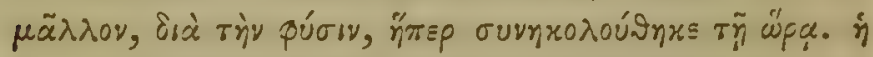

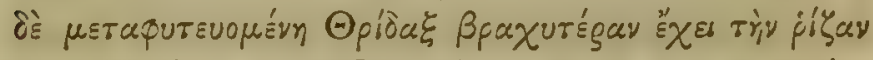

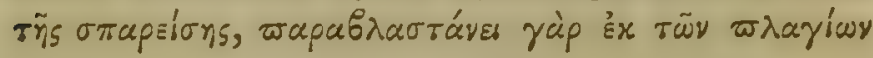

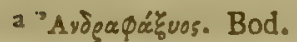

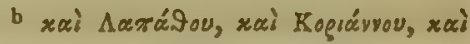

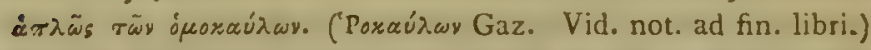

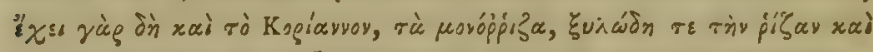

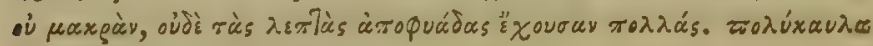

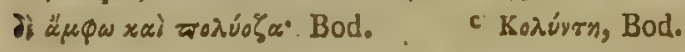




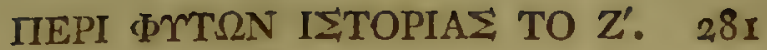

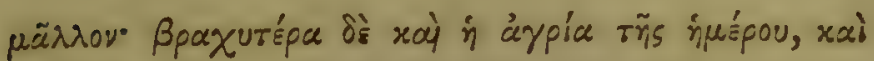

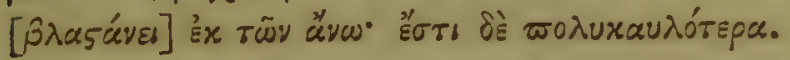

\section{- CAP. IV.}

Florum et Seminum Differentic.

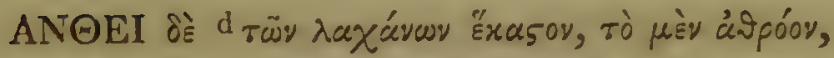

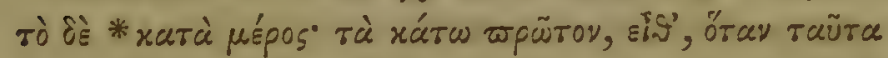

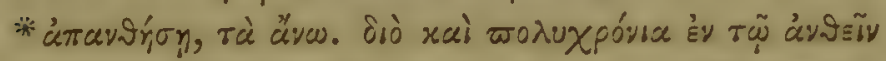

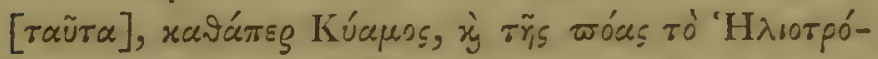

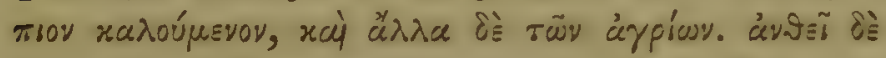

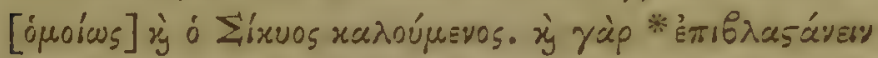

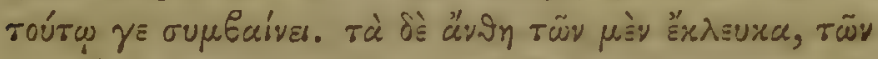

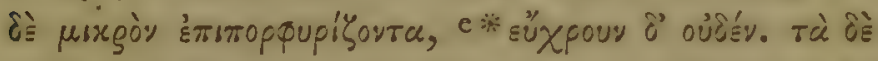

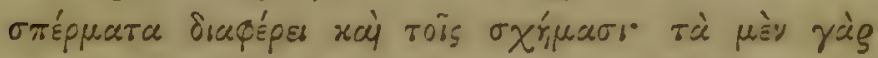

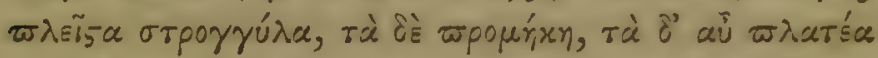

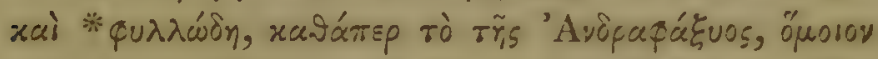

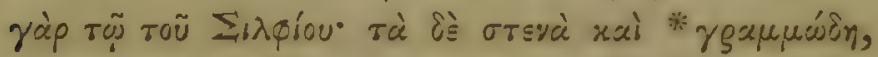

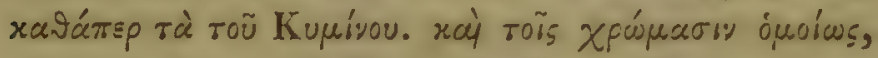

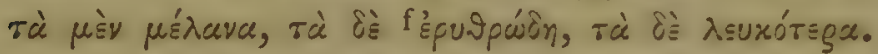

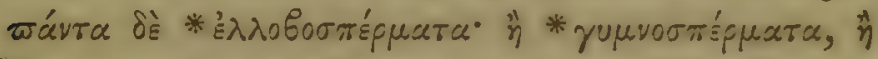

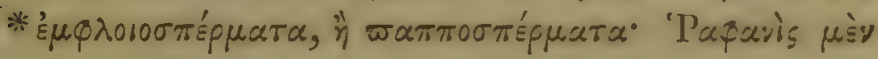

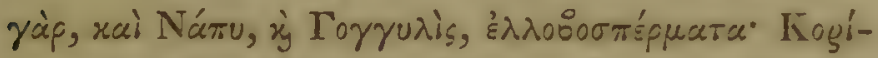

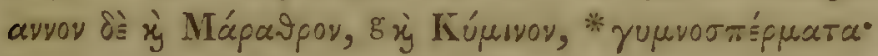

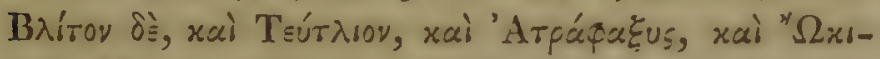

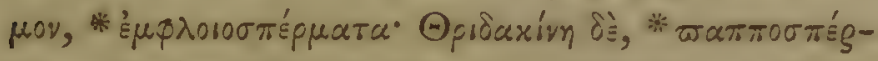

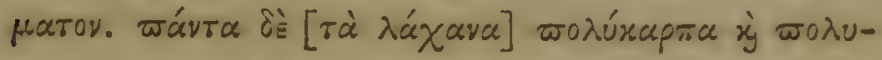

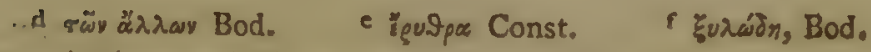

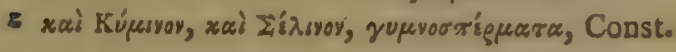

D 4 


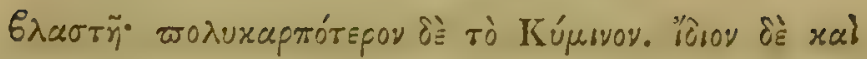

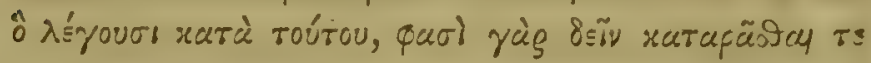

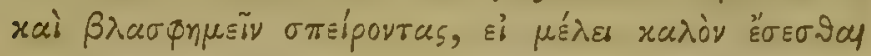

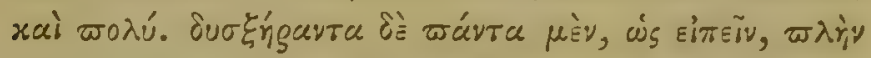

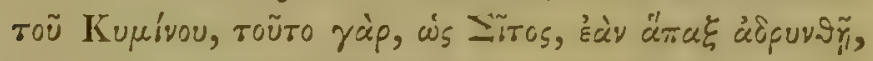

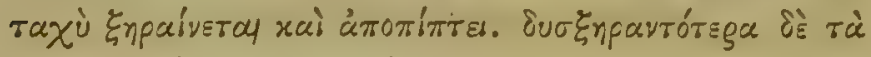

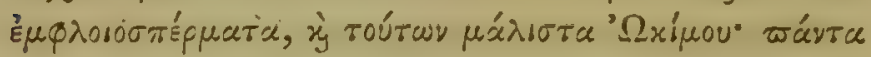

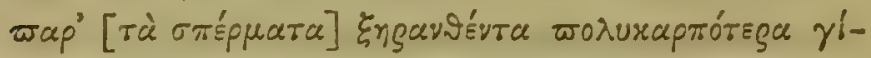

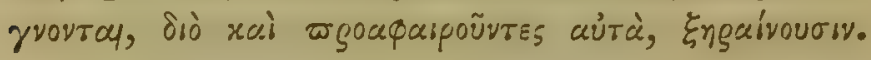

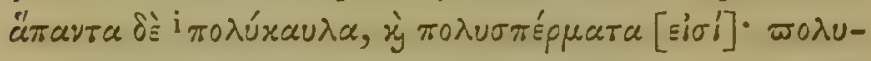

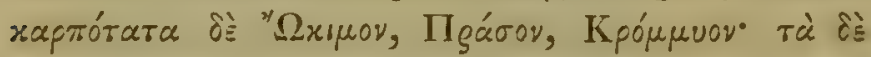

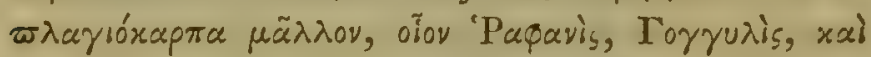

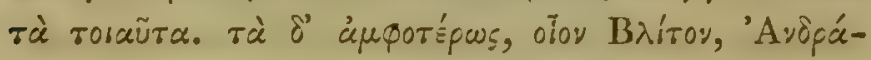

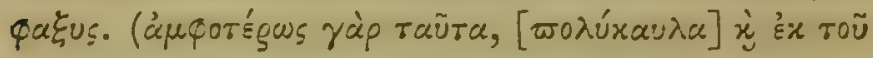

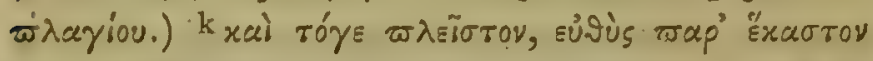

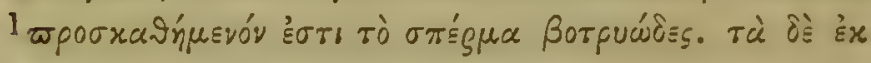

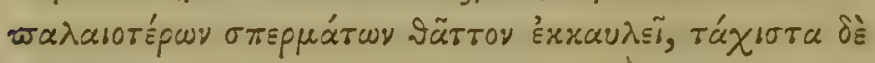

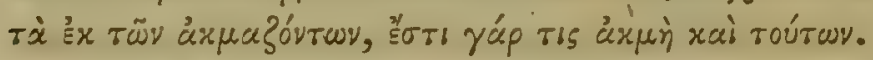

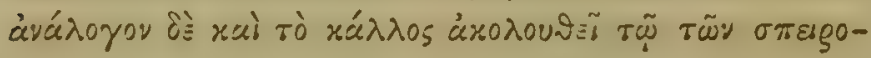

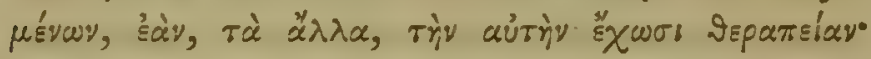

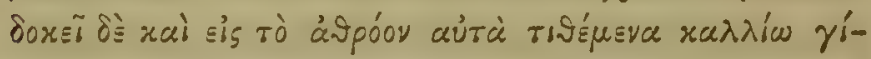

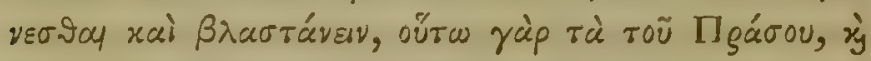

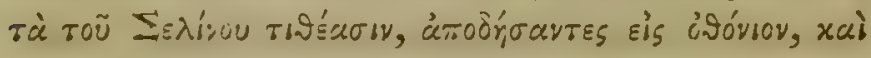

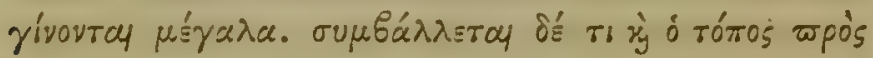

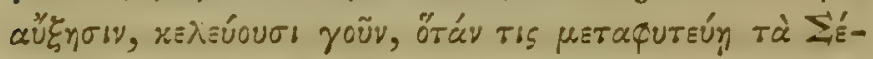

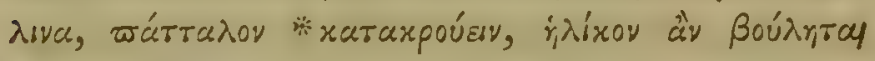

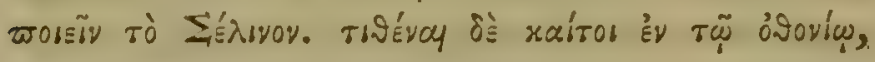

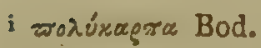

k Vid, not. ad fin. libri.

1 ซgor-

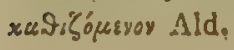




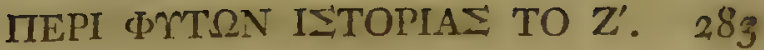

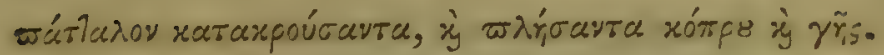

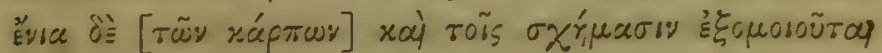

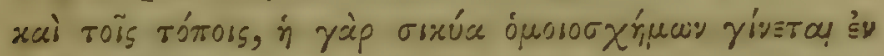

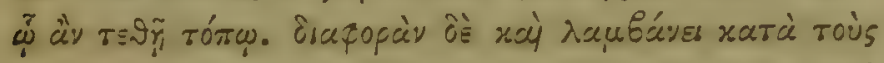

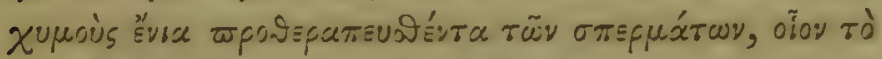

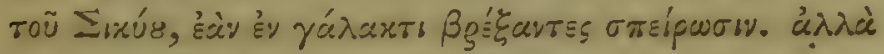

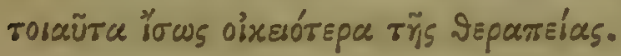

\section{CAP. V.}

Ruphunus, sutirus. Brassicu, Rapu. Beta, vulgaris. Lactuca, saliva. Cucumis. Cucurbita. Allii

Species varia.

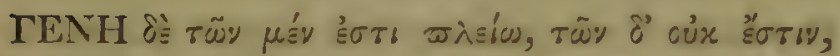

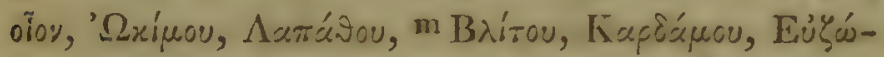

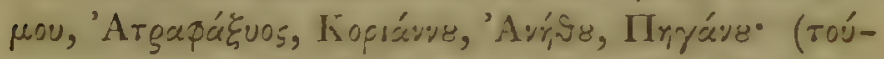

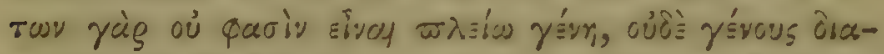

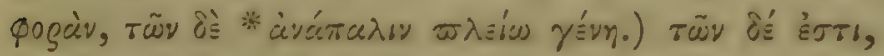

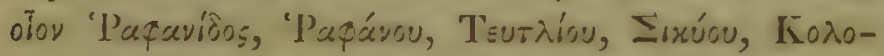

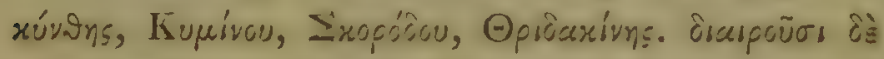

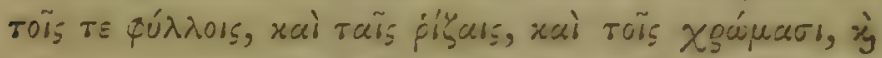

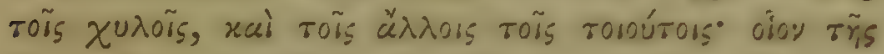

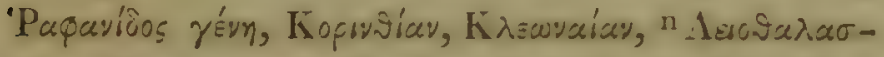

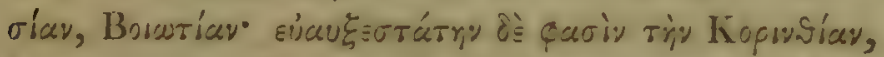

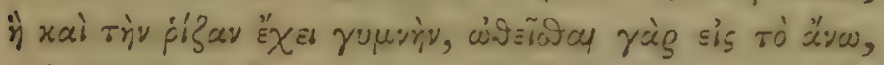

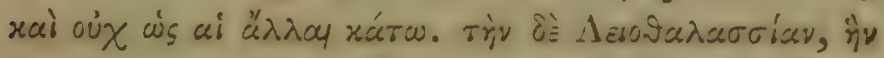
हैं

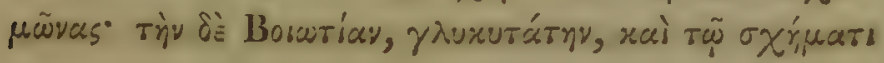
m Bגýlav, Const.

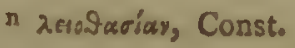
- $\theta_{\xi} \alpha-$ nian, Const. 


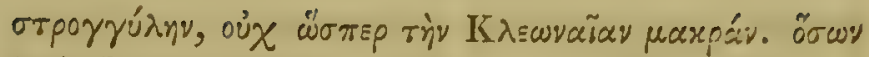

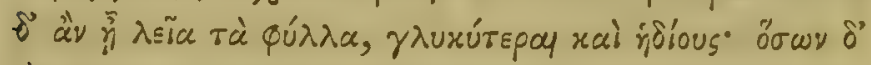

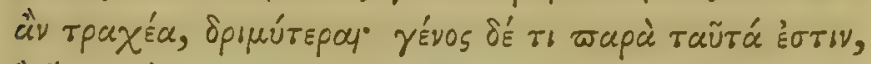

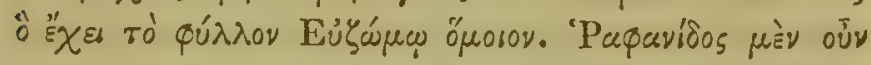

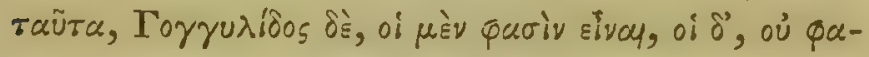

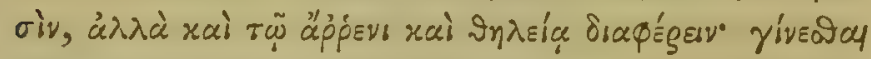

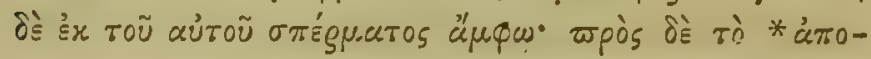

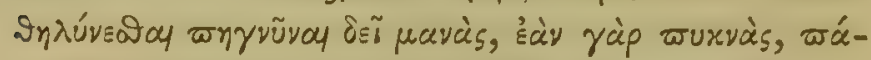

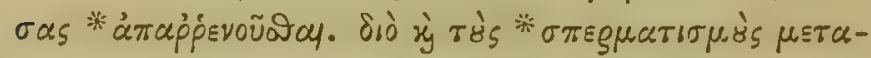

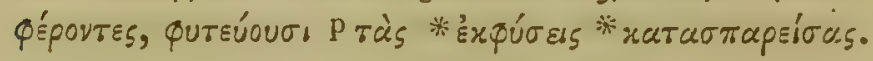

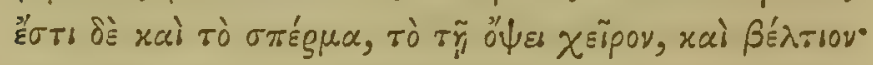

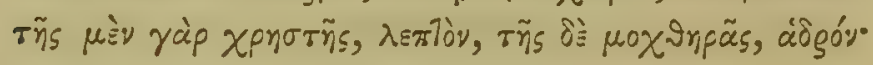

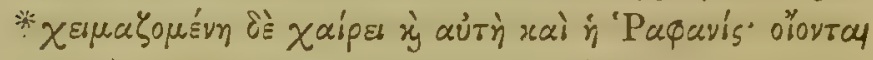

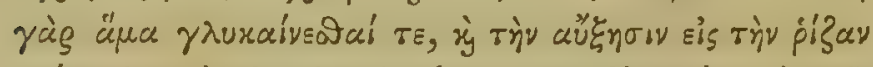

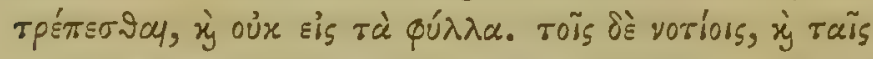

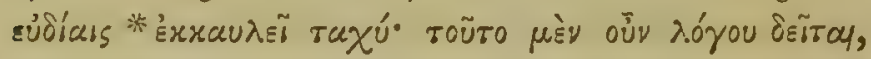

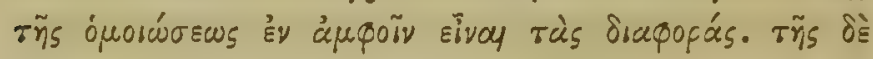

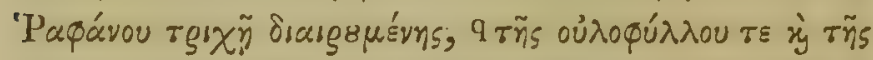

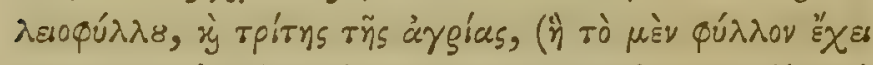

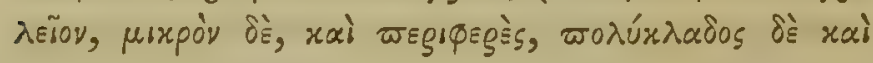

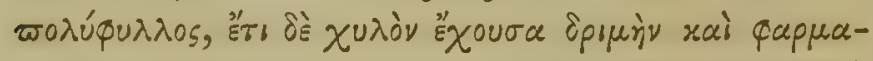

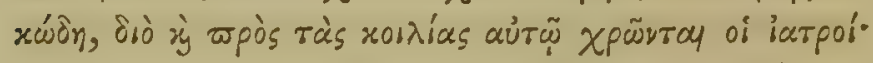

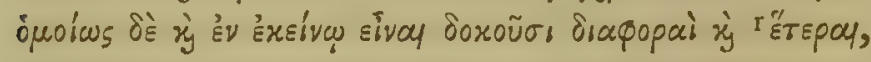

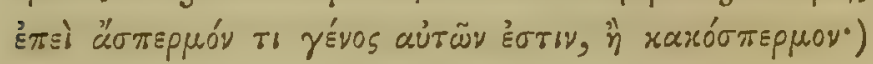

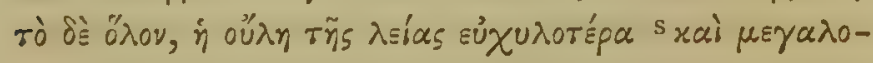

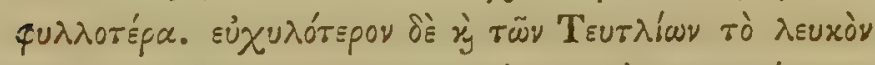

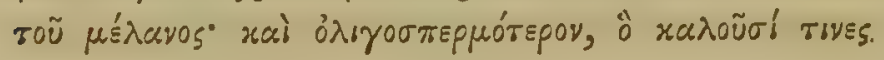

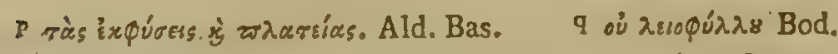

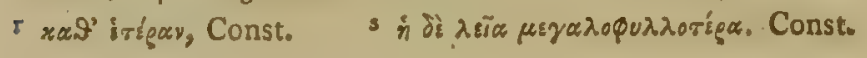




\section{MEPI TMT $\Omega N$ ISTOPIAS TO Z'. 285}

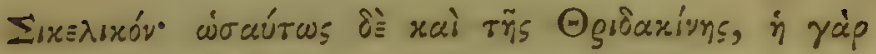

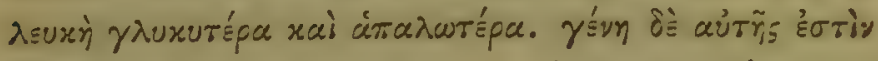

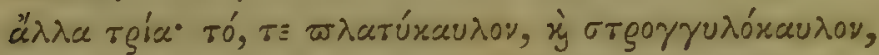

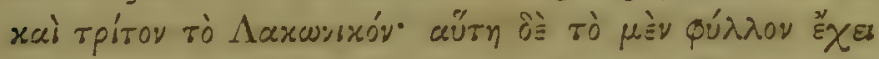

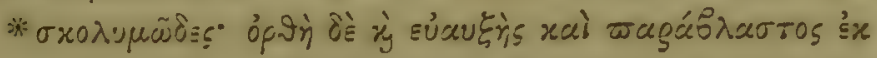

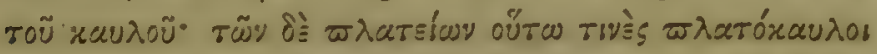

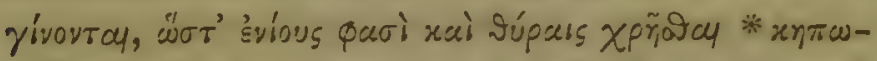

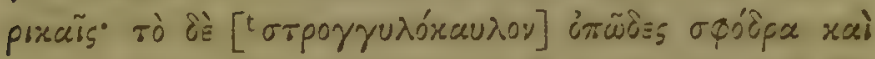

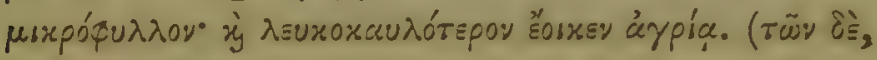

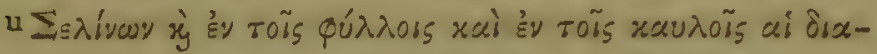

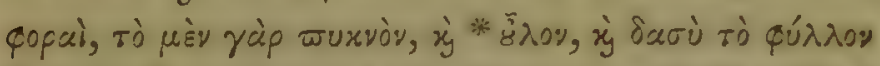

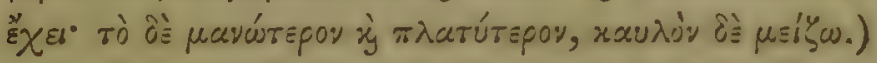

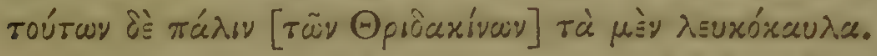

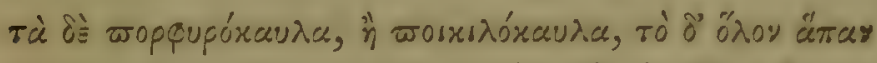

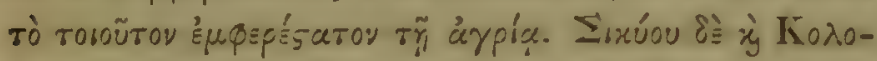

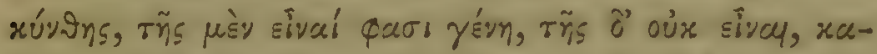

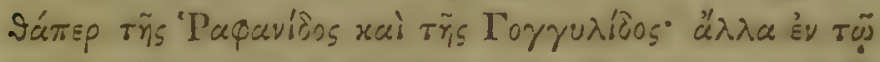

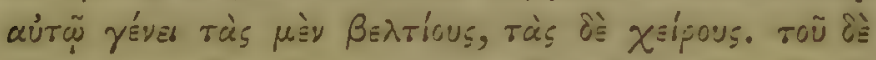
Sixúou tpia $\left[\gamma^{\prime}=\eta \eta \eta\right.$

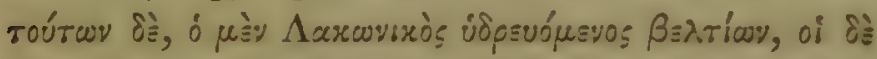

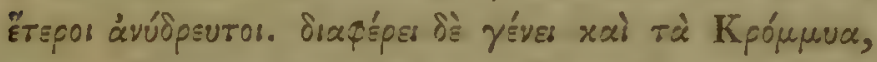

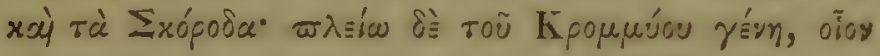

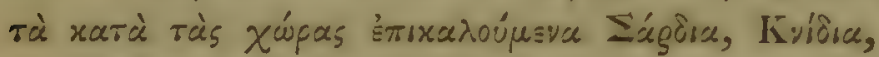

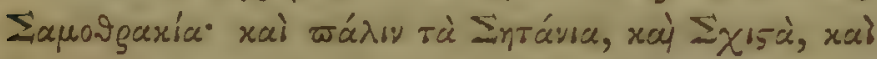

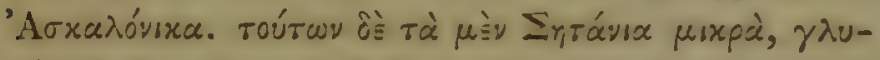

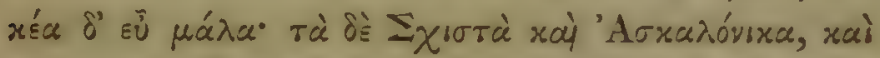

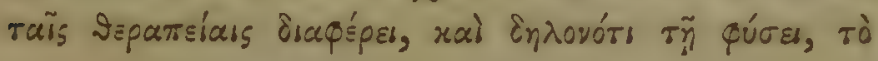

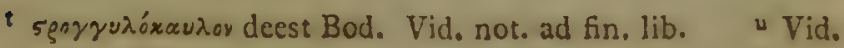
not. ad fir. libri. 


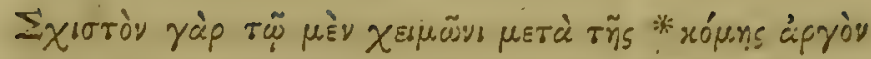

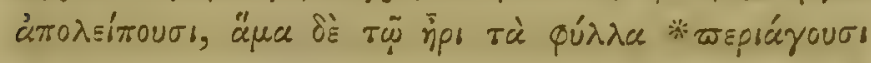

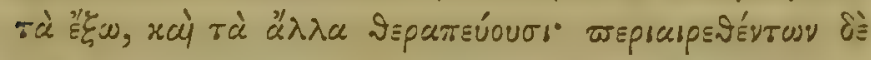

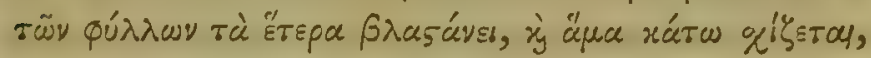

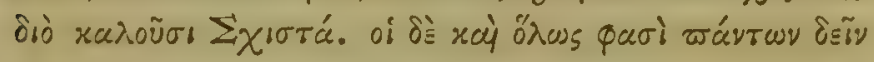

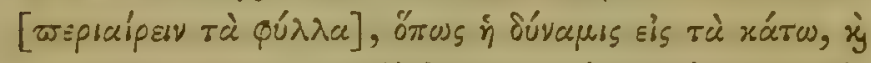

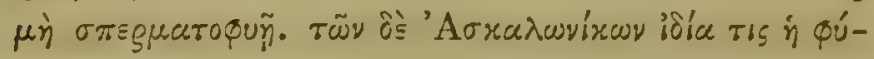

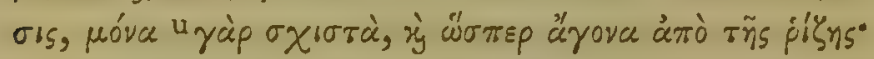

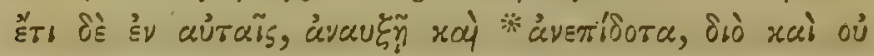

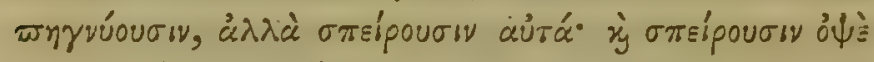

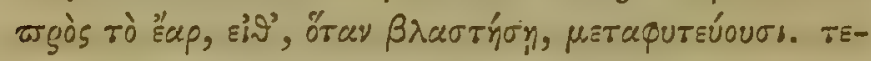

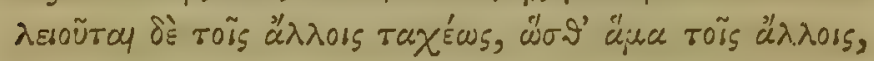

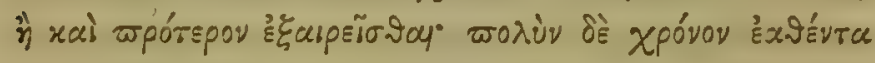

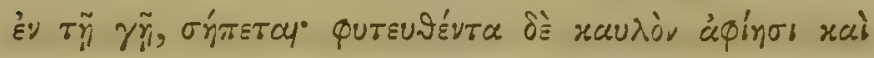

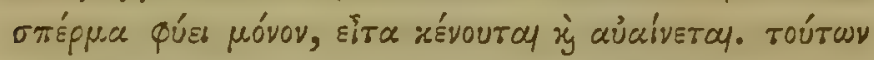

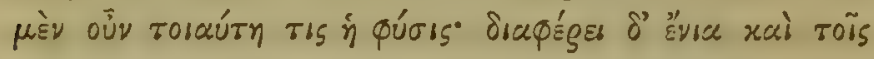

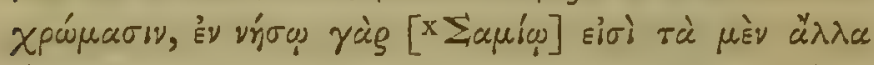

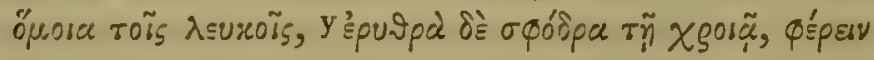

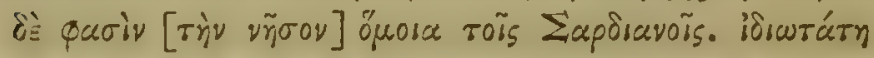

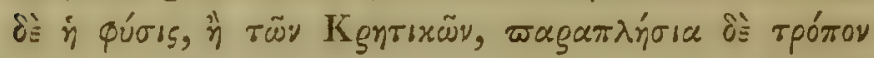

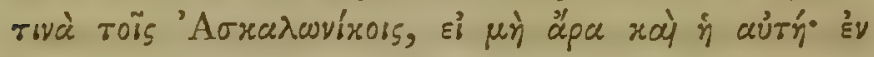

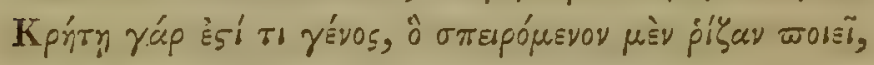

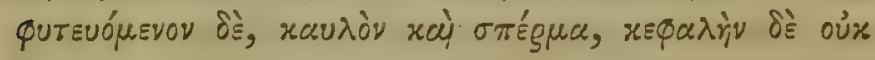

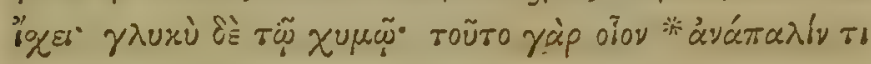

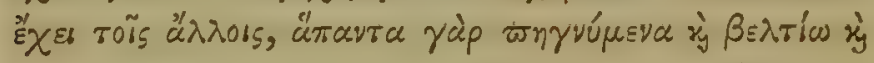
จа̃

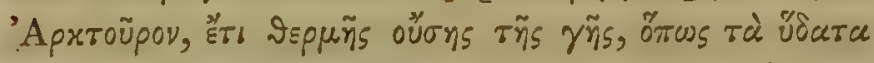

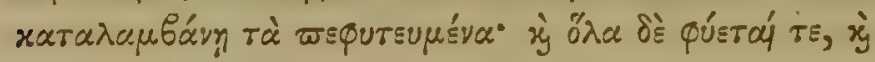

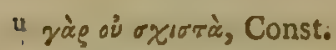
$x$ Eapím deest Bod. y. Virl. not. ad fin. libri. 


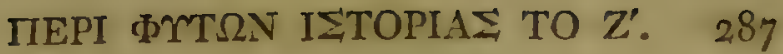

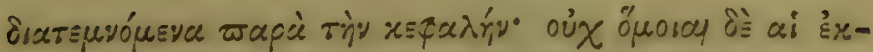

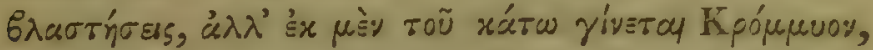

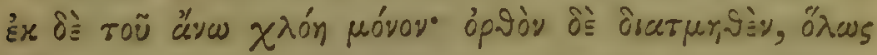

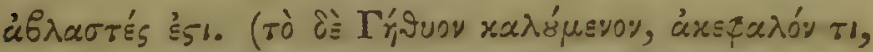

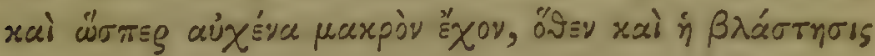

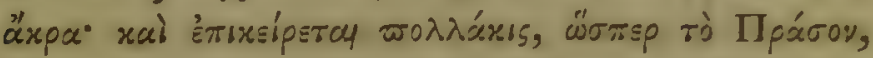

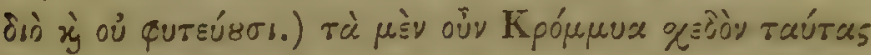

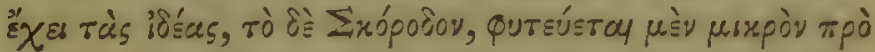

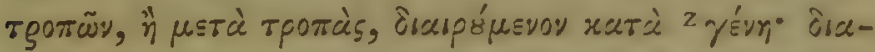

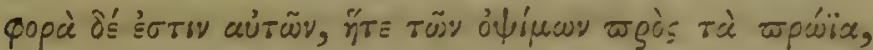

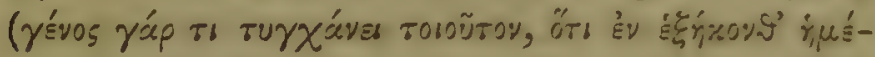

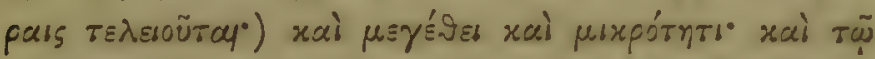

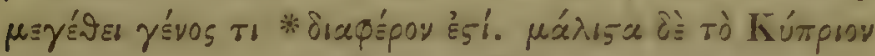

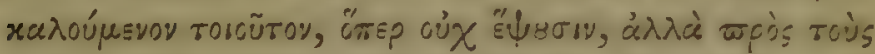

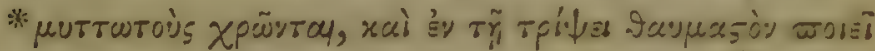

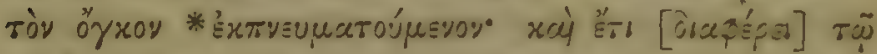

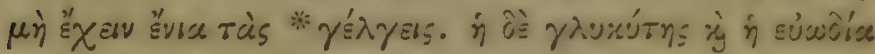

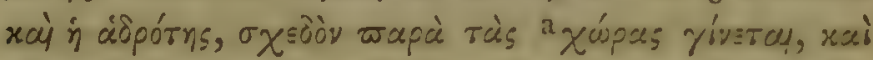

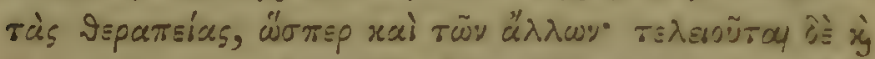

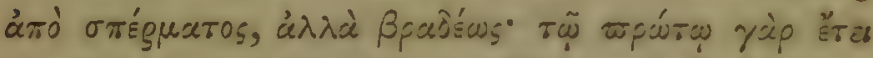

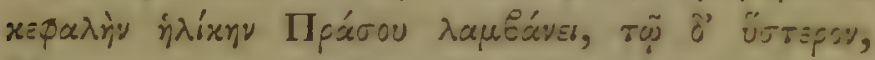

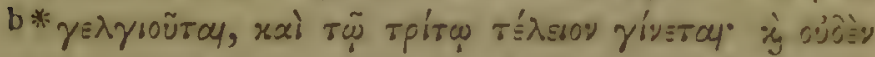

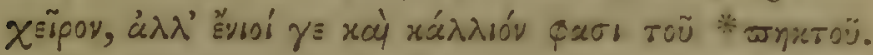

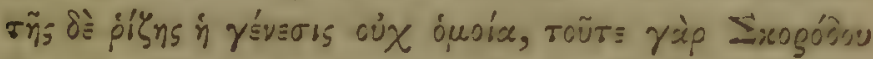

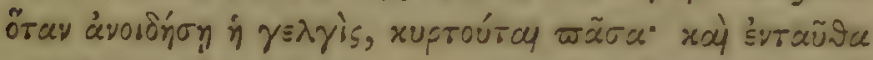

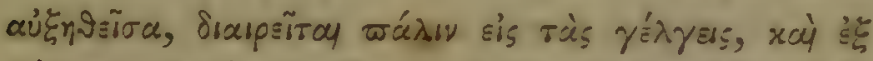

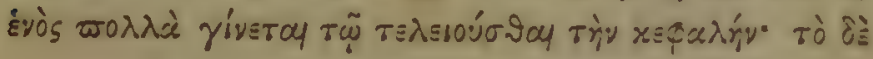
2 yirirus. Const.
2. ₹ųकेs Bod.
b gsidioúyrai,
Bod. 


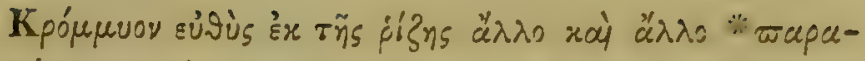

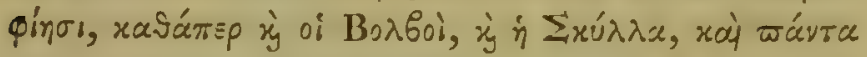

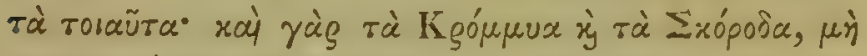

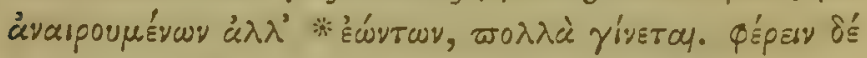

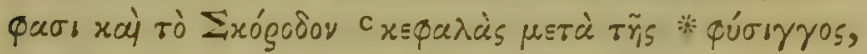

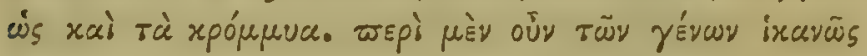

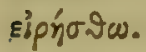

\section{CAP. VI.}

Cultura, \&c. Olerum hortensium.

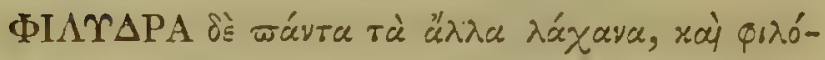

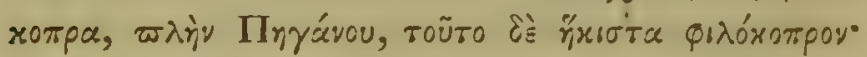

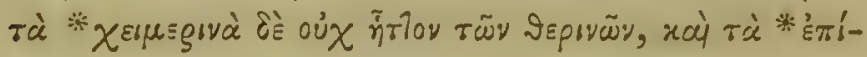

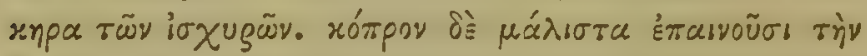

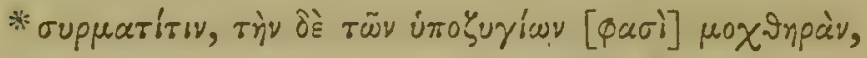

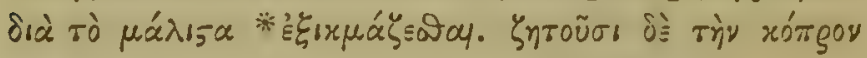

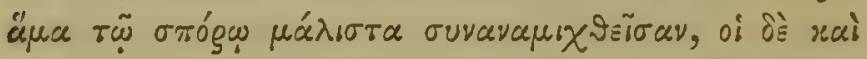

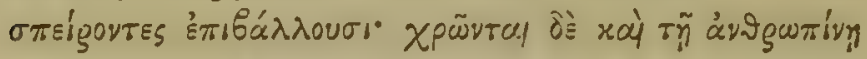

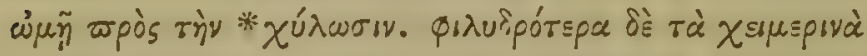
$\tau \tilde{\omega} y$ ง

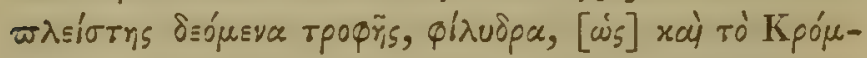

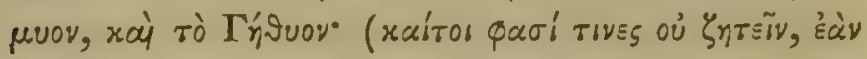

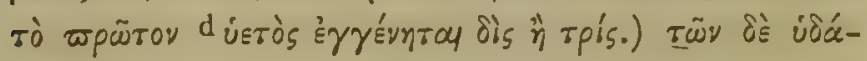

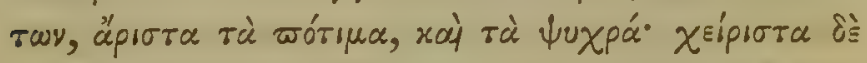

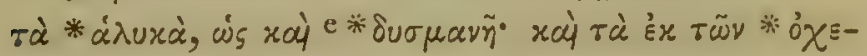

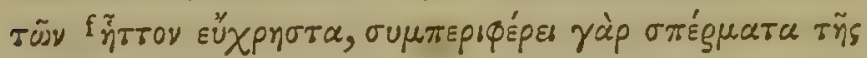

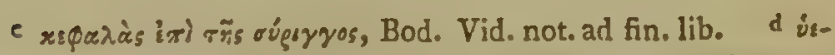

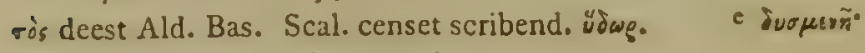

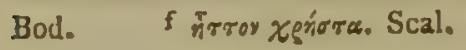




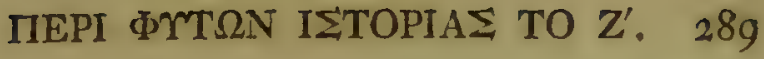

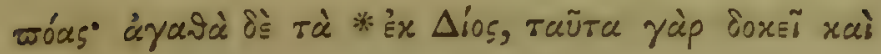

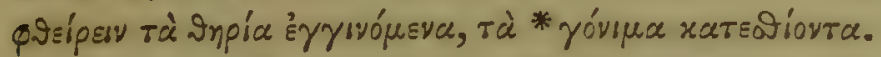

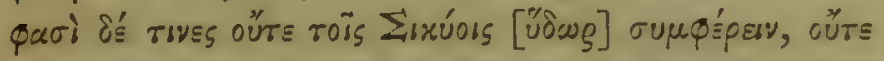

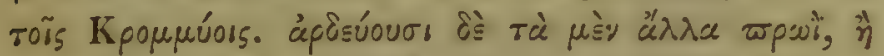

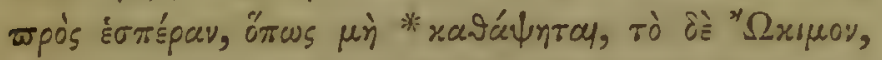

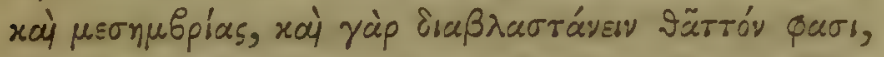

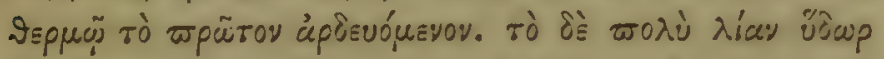

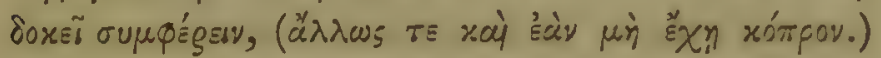

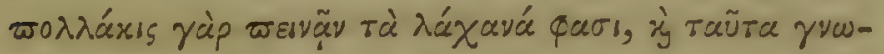

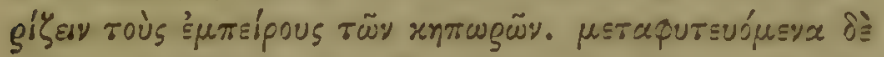

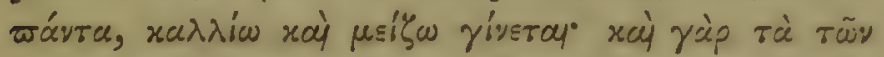

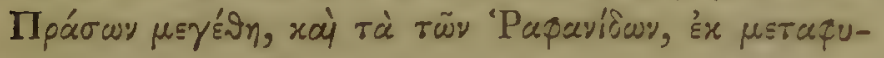

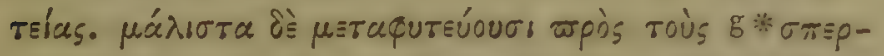

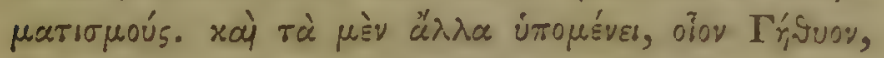

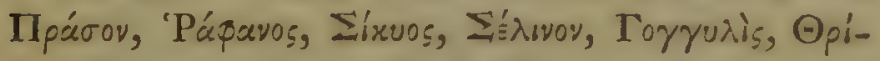

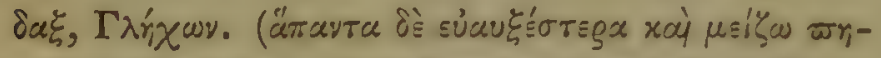

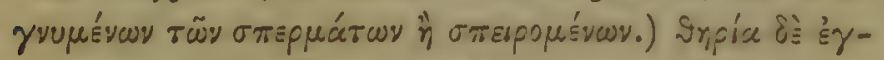

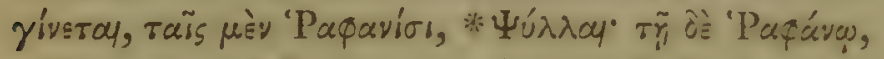

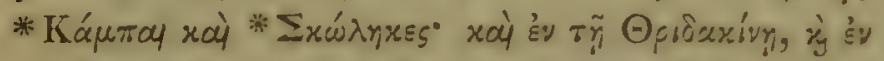

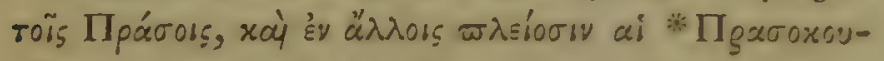

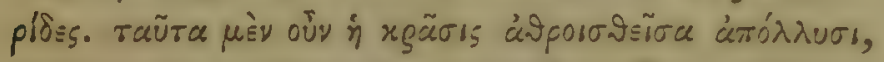

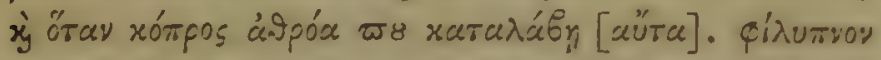

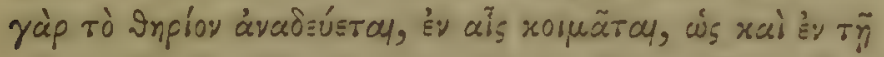

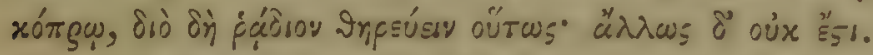

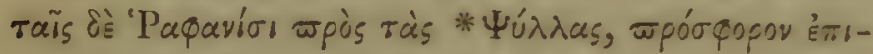

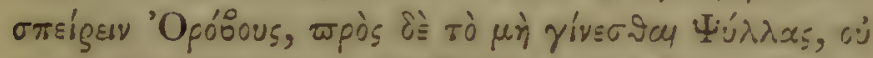

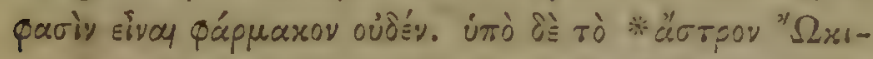

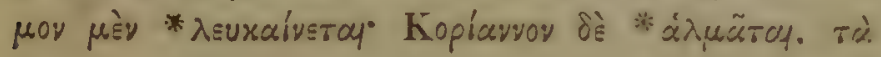

\footnotetext{
g oтlouatioús. Ald.
} 


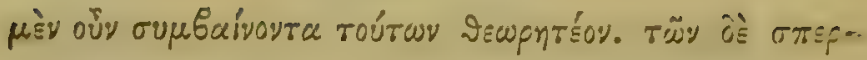

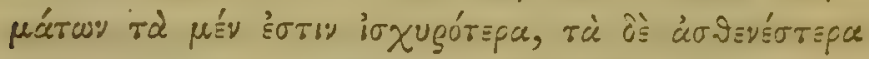

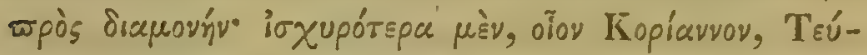

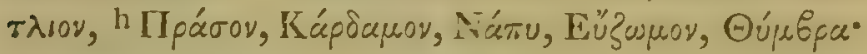

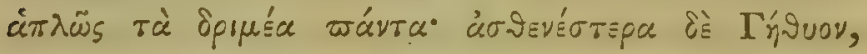

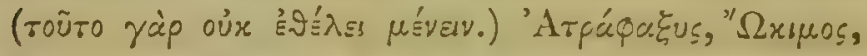

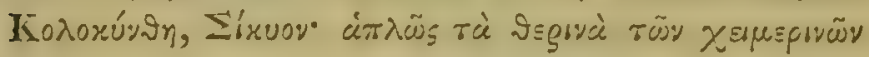

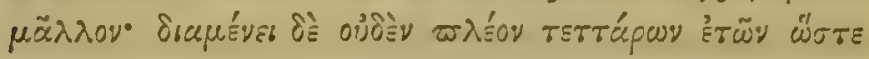

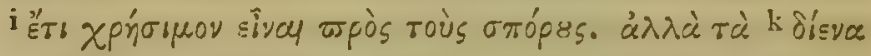

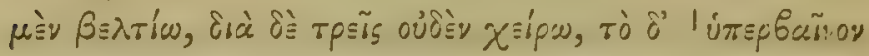

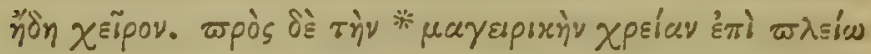

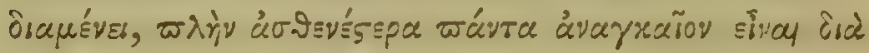

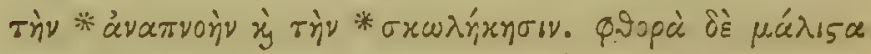

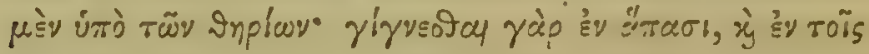

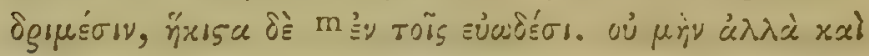

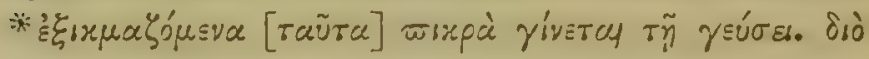

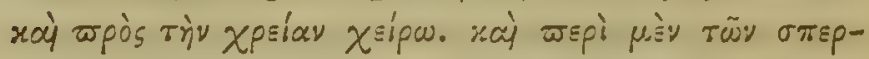

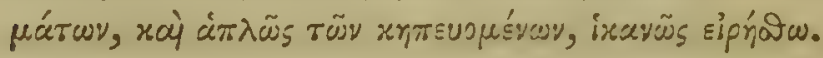

\section{CAP. VII.}

\section{Olera agrestia.}

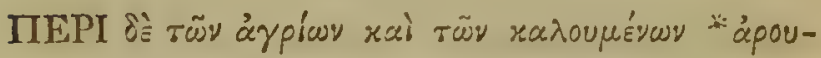

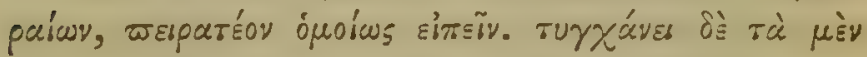

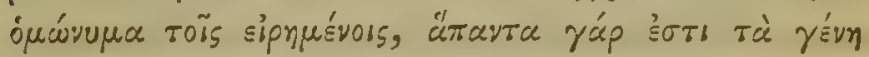

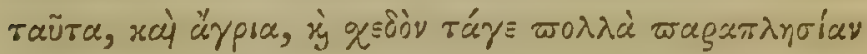

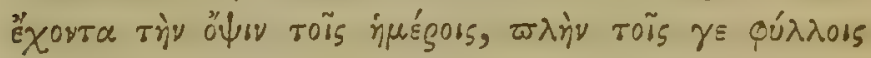

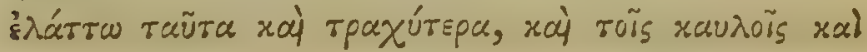

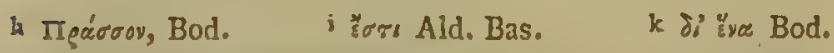

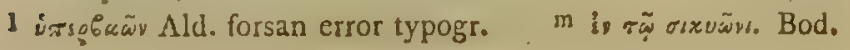




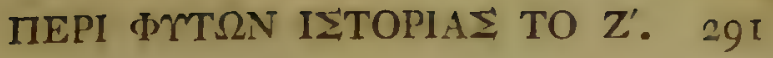

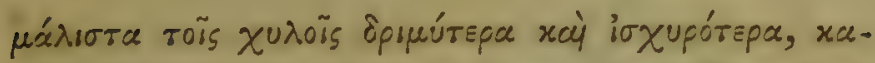

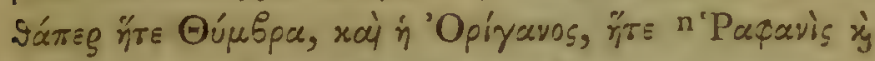

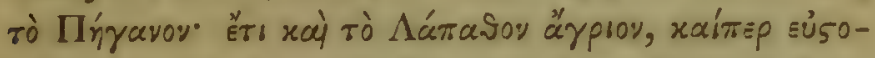

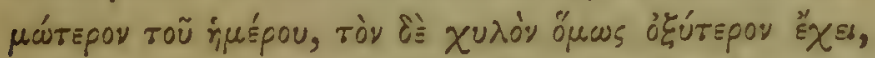

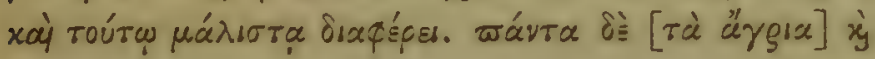

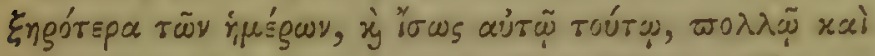

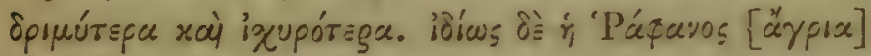

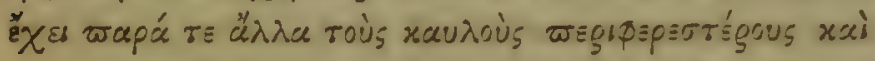

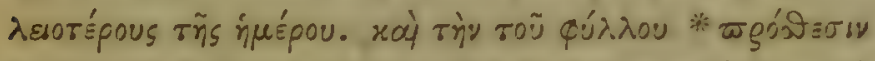

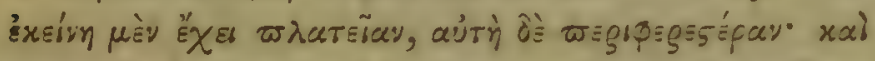

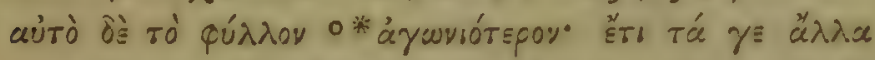

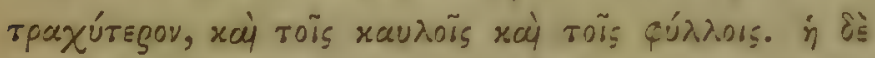

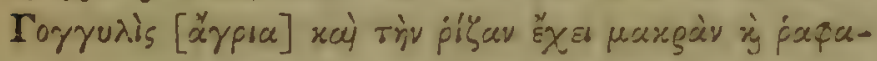

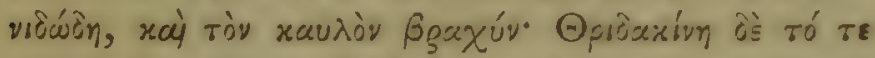

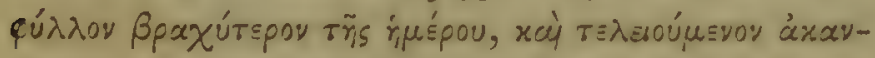

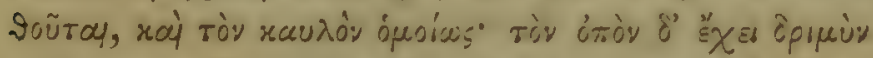

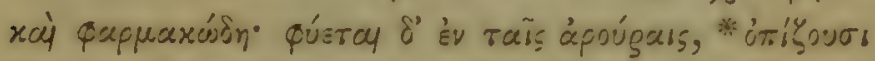

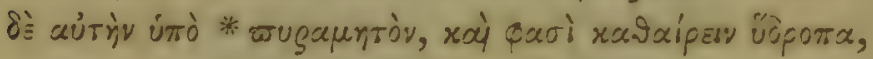

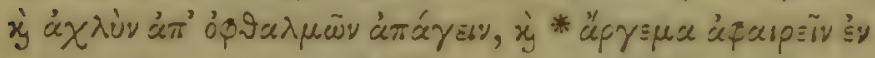

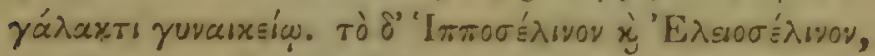

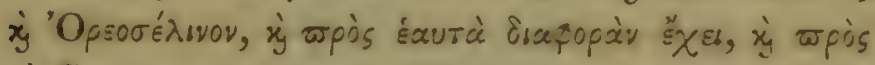

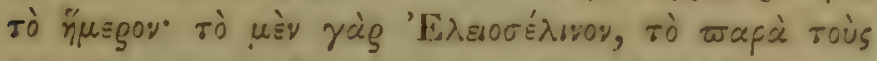

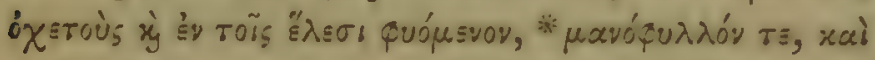

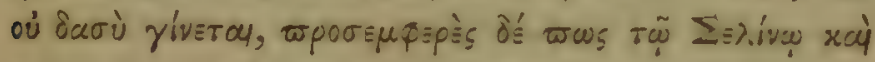

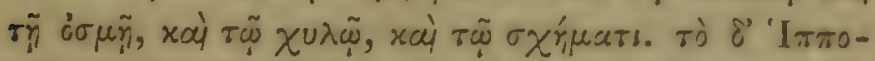

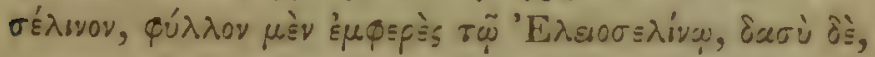

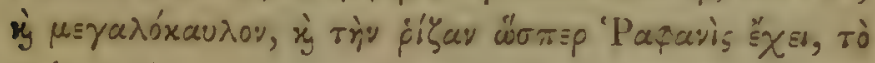

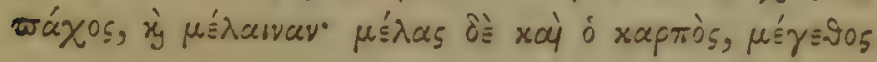

n 'Pápavos Bod.

PARS II.
- éyavórşar. Bod. 


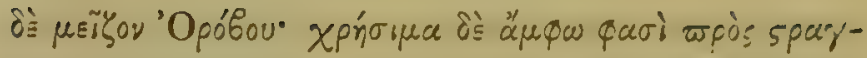

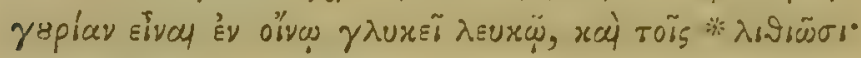

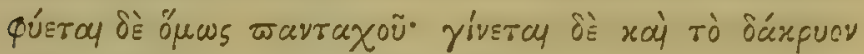

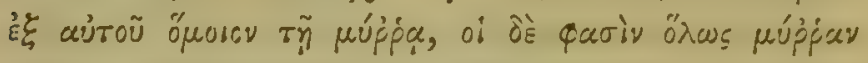

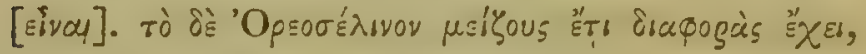

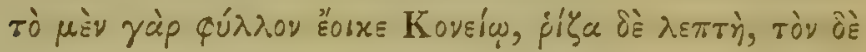

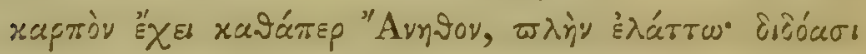

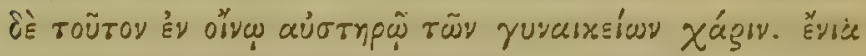

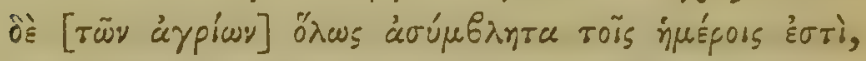

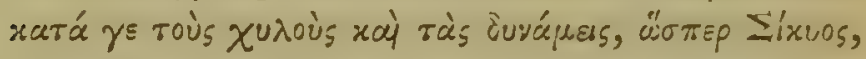

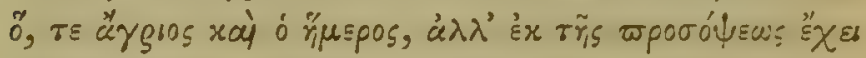

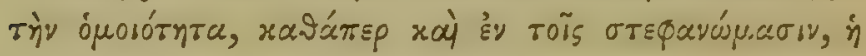

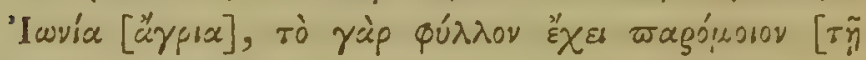

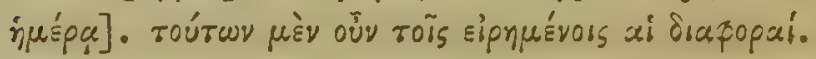

\section{CAP. VIII.}

Varia Pluntarum Genera ad Usus culinarios in Agris reperte. Cichorucia. Iragoponon, \& c. \& c. Tempora Germinationis.

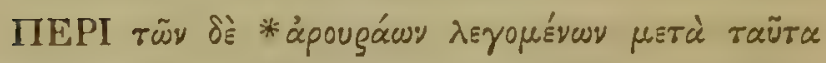

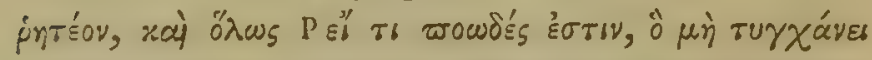

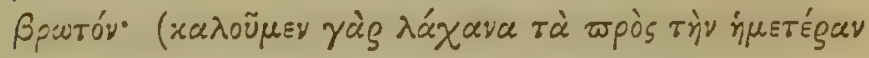

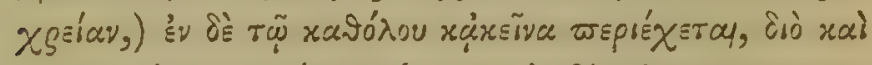

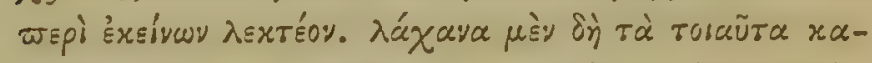

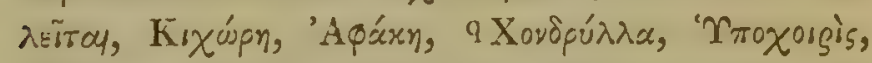

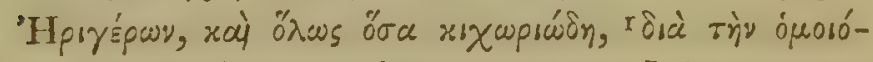

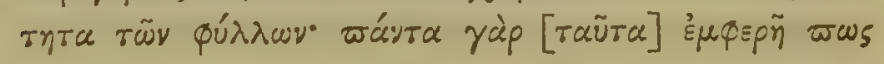

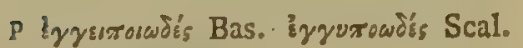

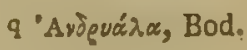

I xarç ซàेs rìy Bod: 


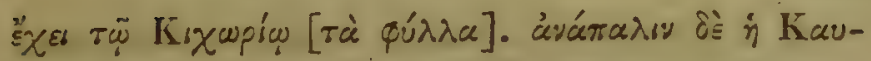

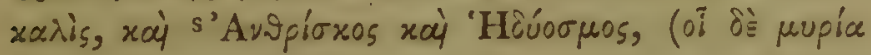

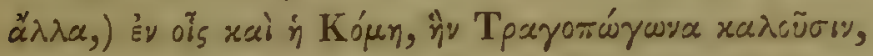

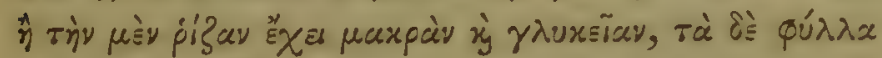

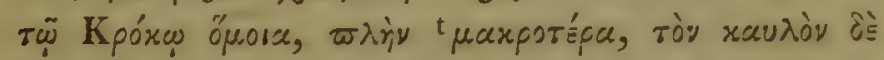

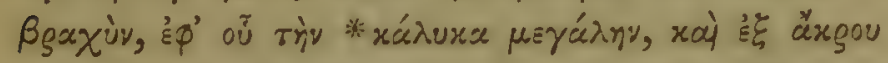

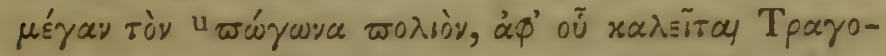

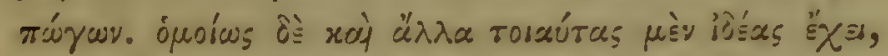

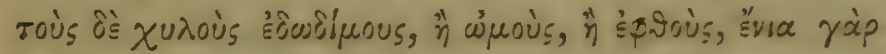

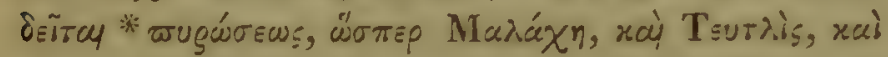

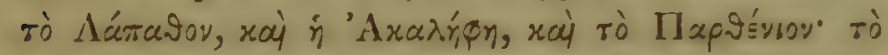

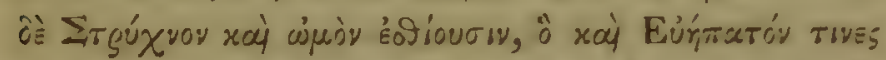
एрот

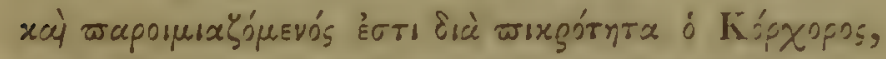

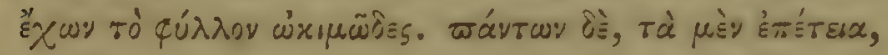

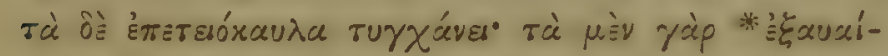

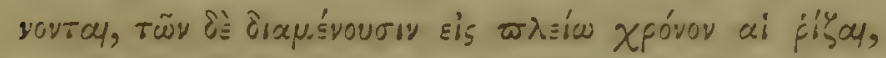

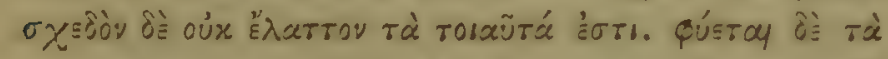

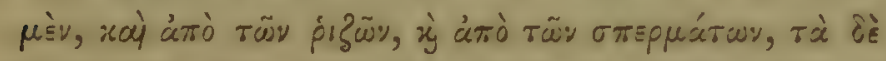

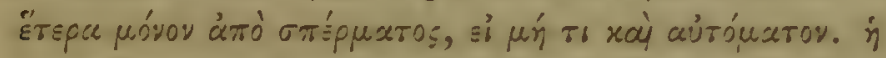

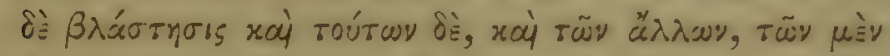

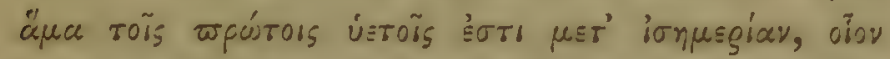

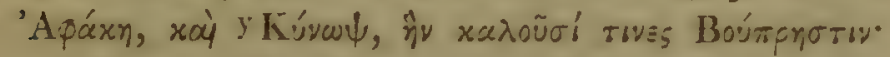

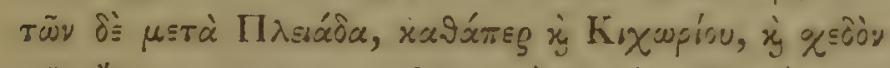

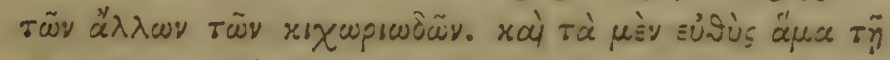

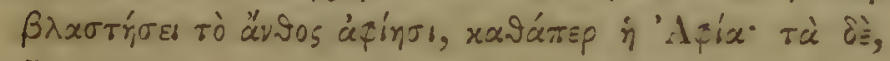

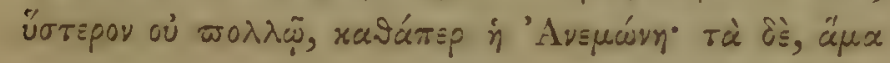

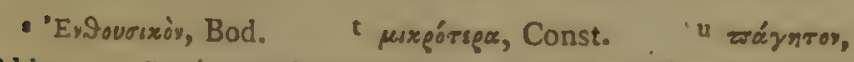

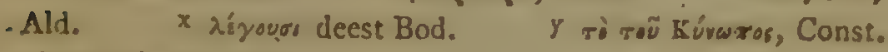
รò roũ Kúwสos, Bod. 


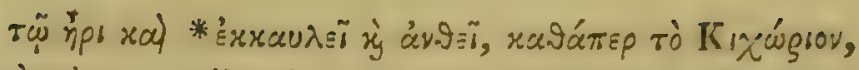

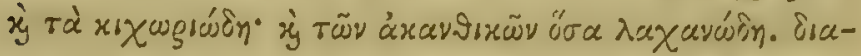

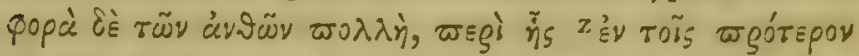

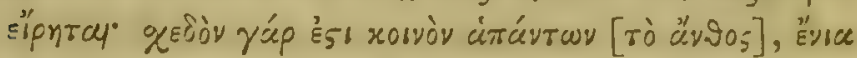

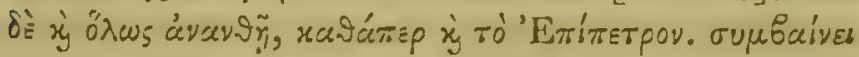

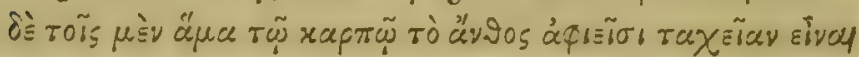

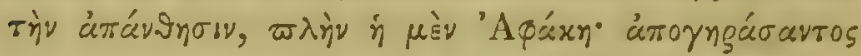

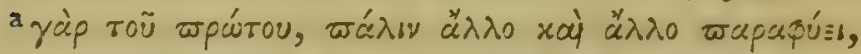

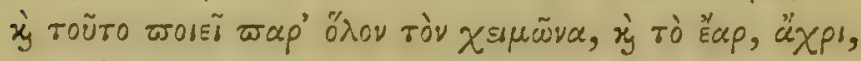

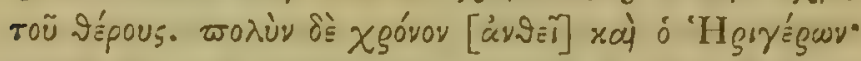

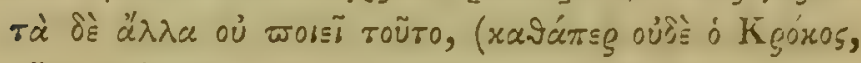

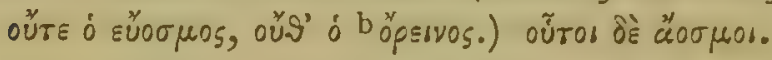

\section{CAP. IX.}

Differentic quoad Caules, Foliu, Flores, Radices.

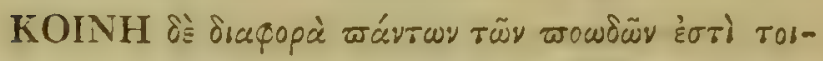

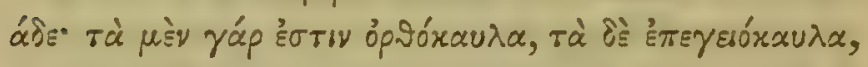

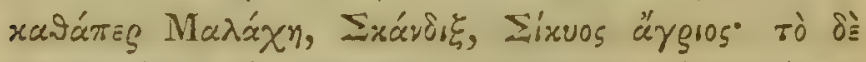

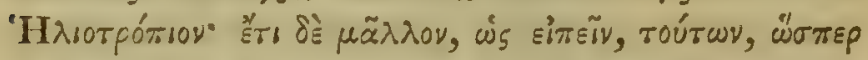

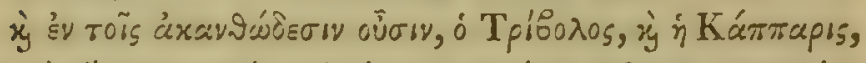

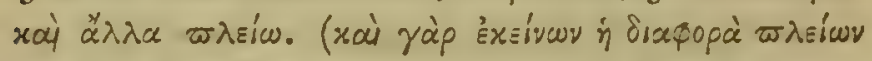

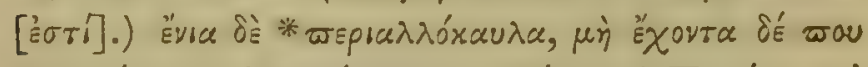

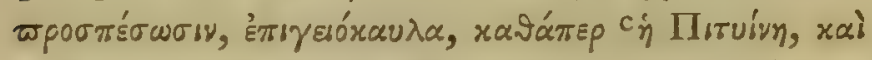
iे 'A

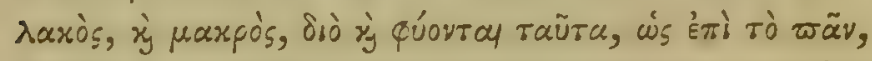

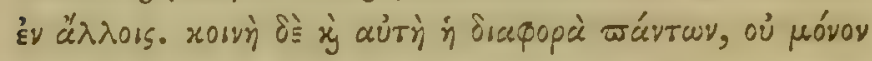

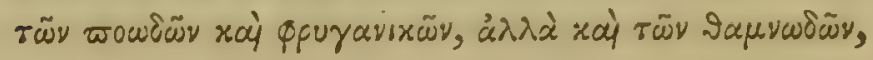

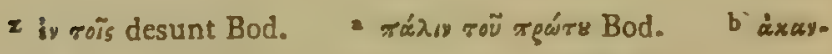

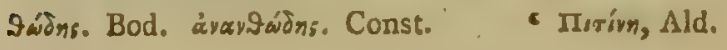




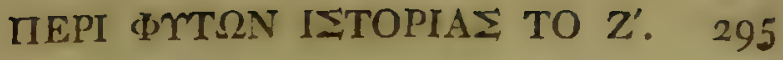

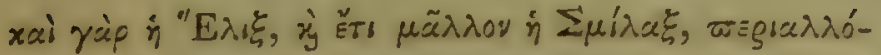

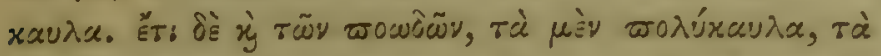

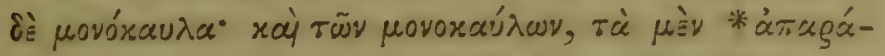

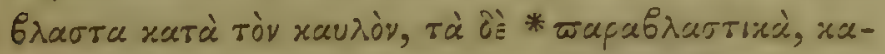

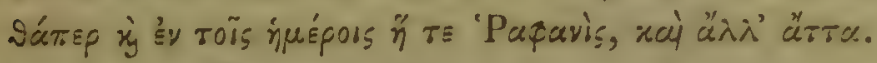

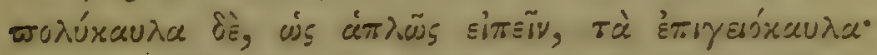

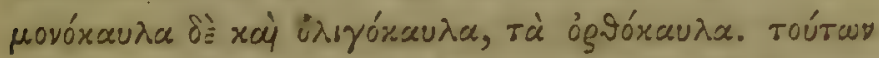

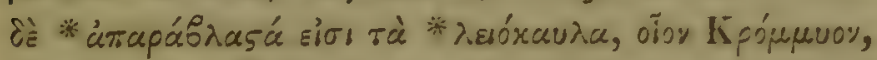

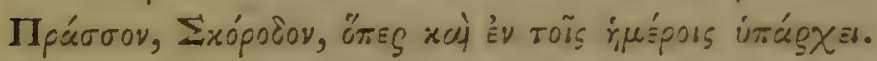

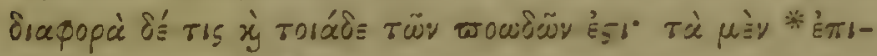

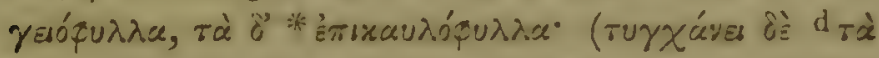
$\delta$ ' á

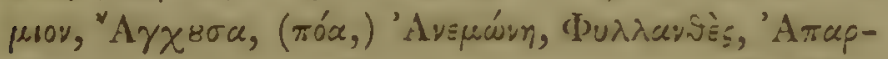

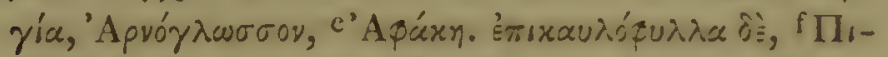

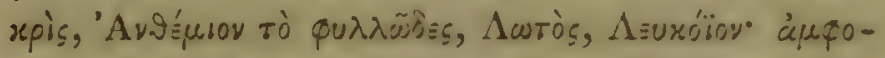

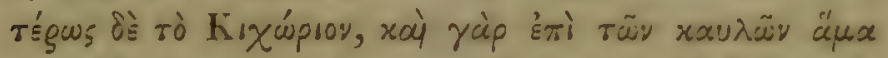

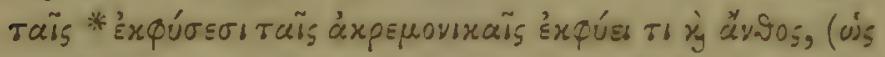

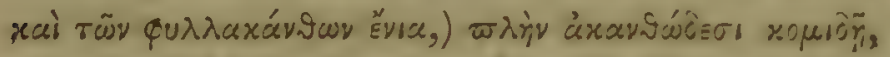

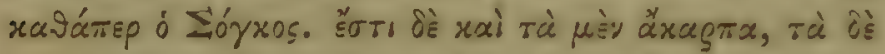

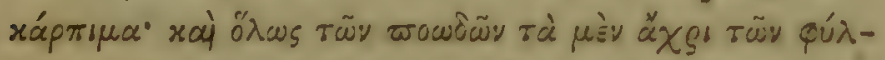

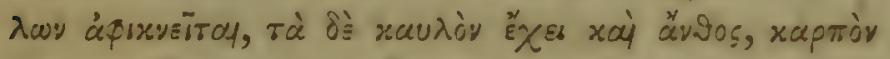

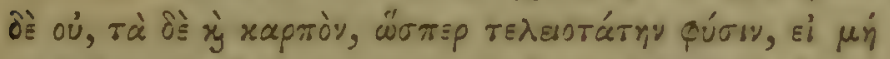

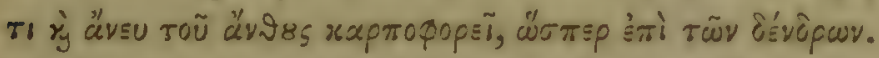

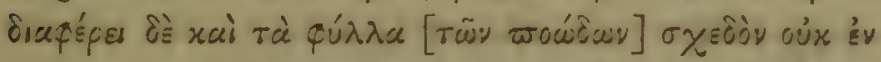

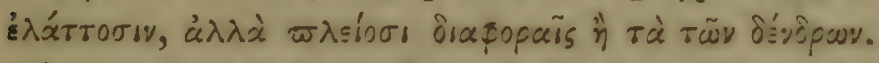

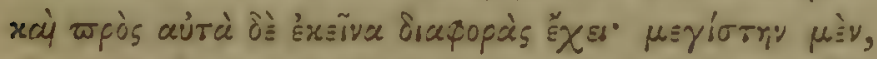

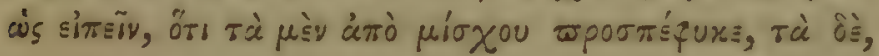

Ald. Bas.

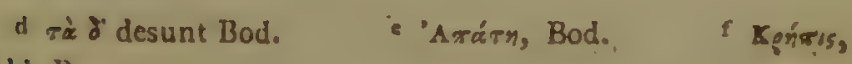




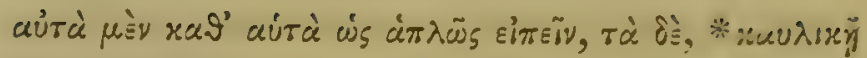

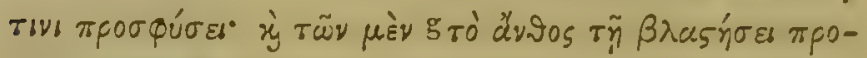

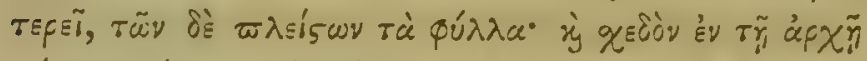

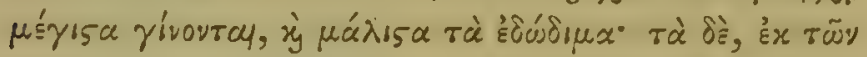

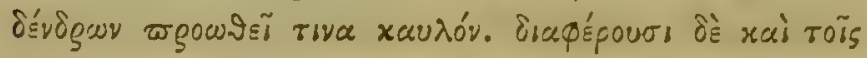

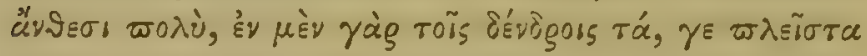

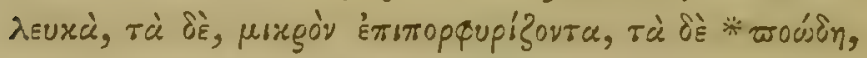

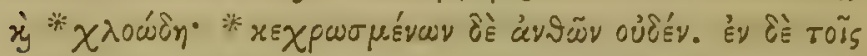

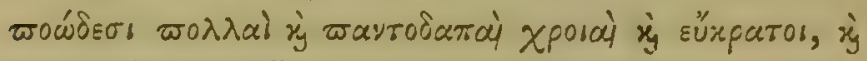

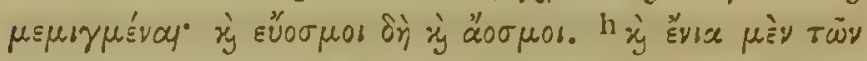

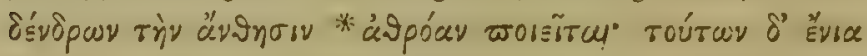

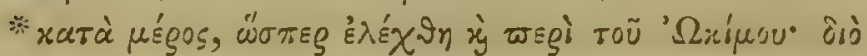

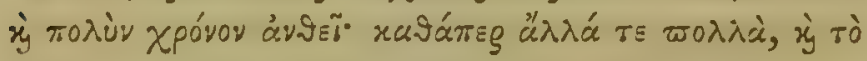

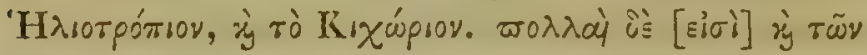

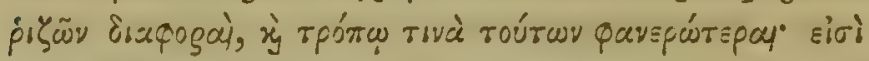

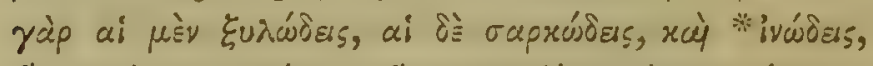

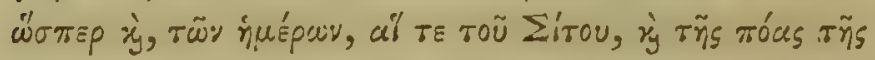

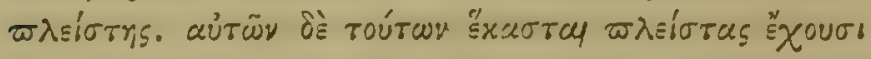

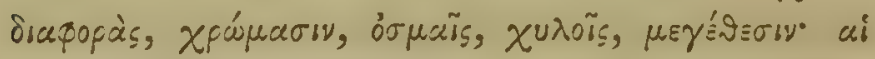

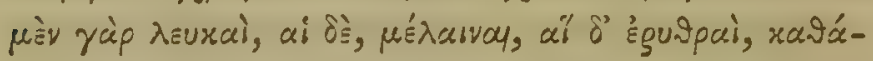

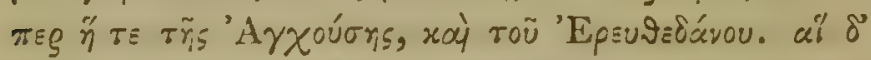

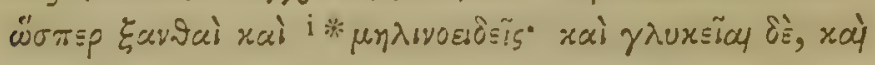

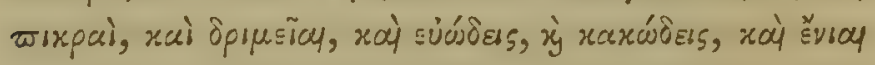

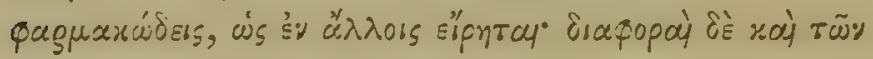

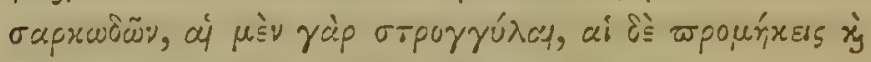

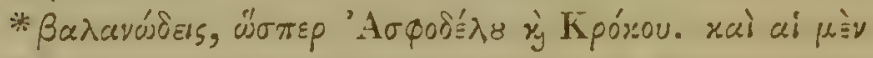

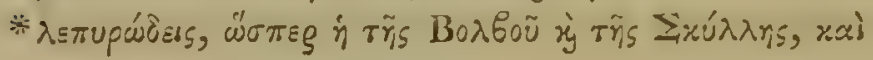

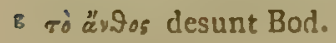

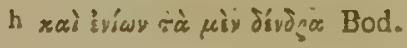

i दूँ 


\section{MEPI TYTSN ISTOPIAভ TO Z'. 297}

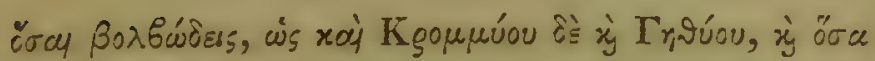

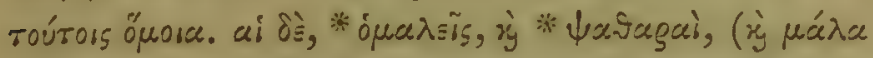

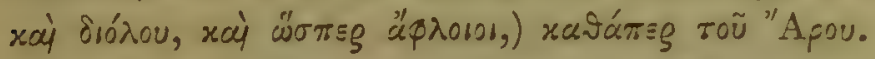

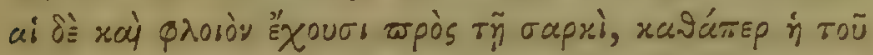

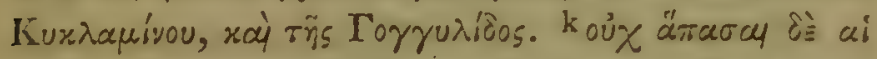

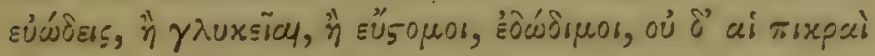

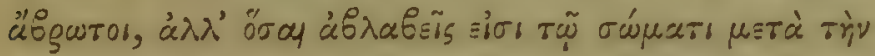

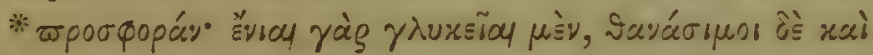

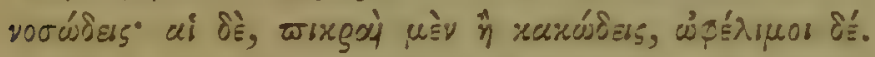

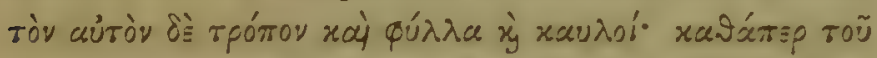

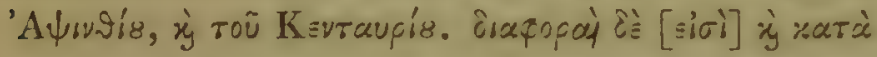

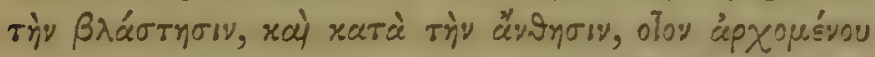

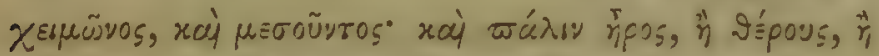

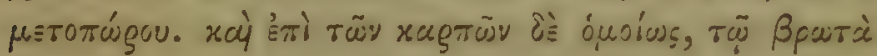

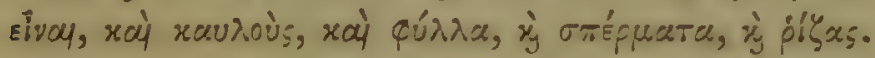

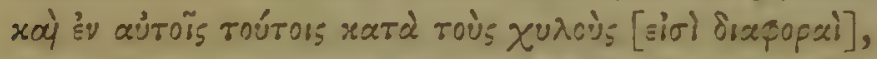

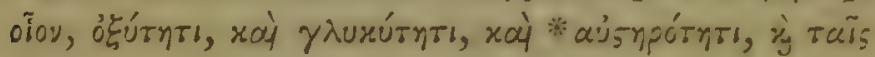

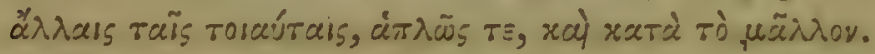

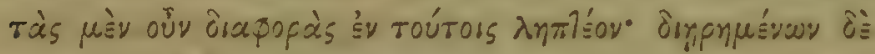

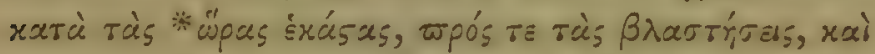

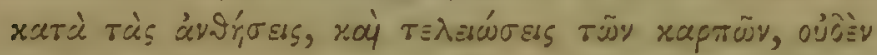

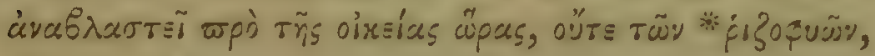

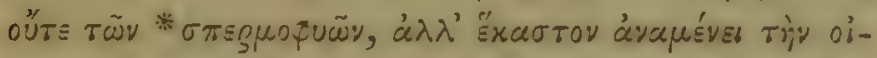

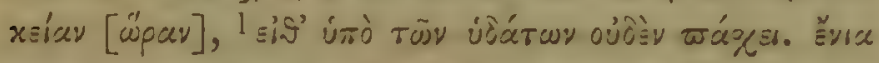

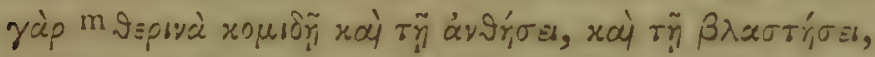

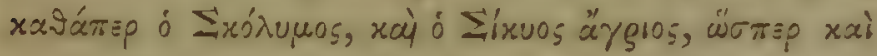

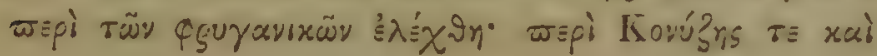

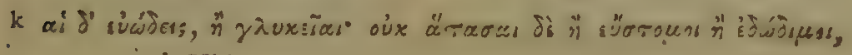
Const. I Vid.'not, ad fin. libri. In Mepes Bod.

E 4 


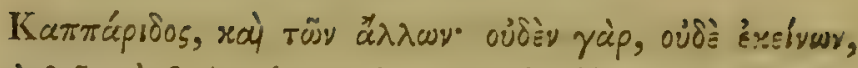

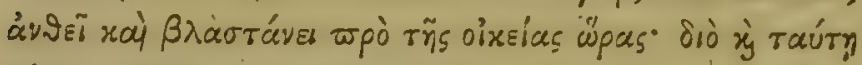

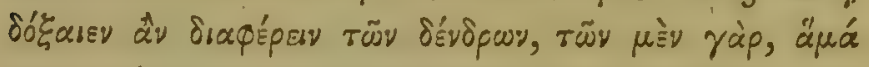

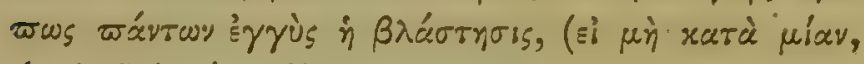

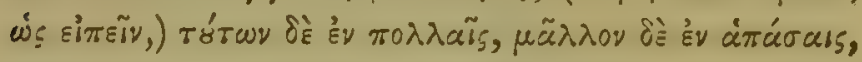

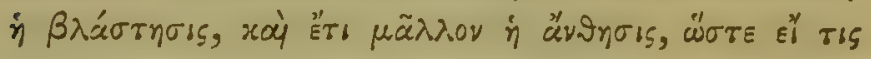

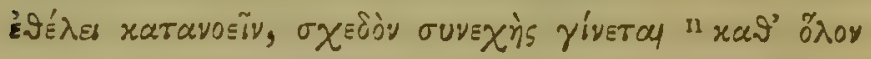

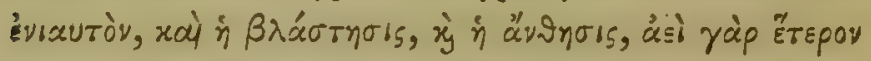

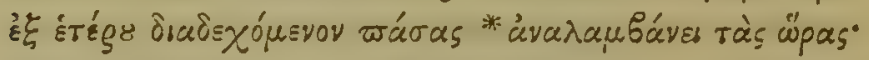

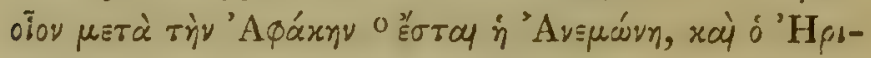

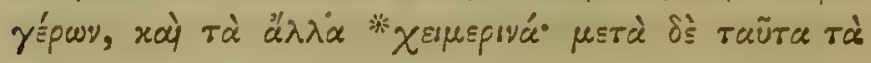

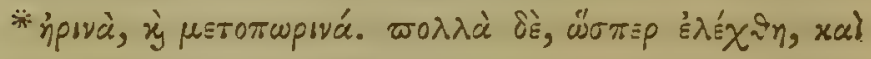

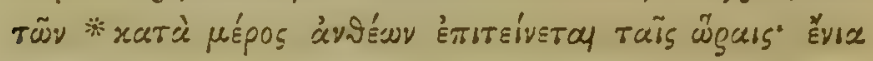

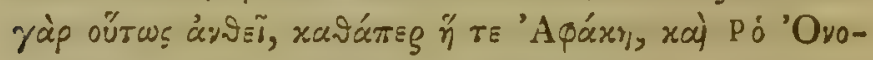

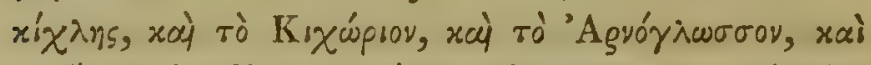

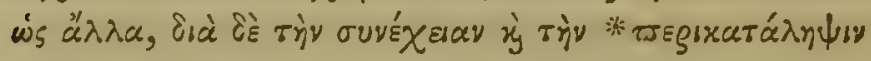

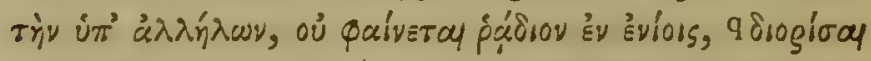

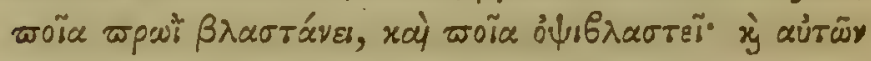

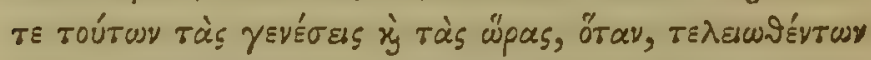

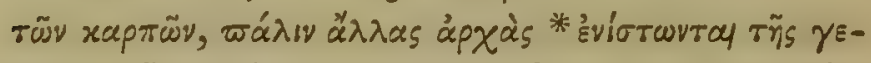

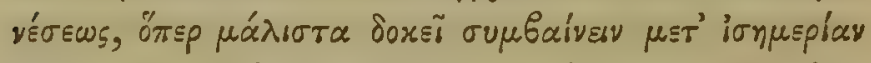

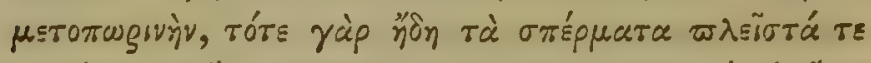

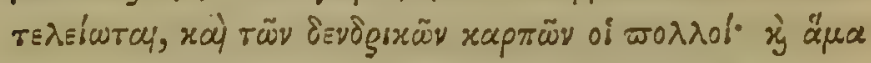

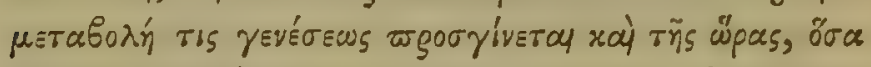

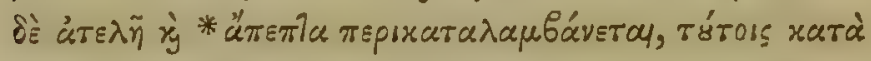

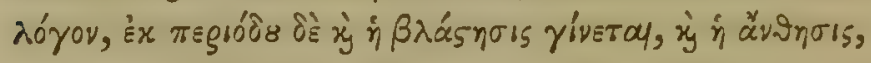

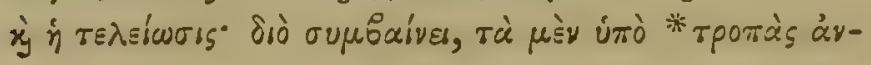

n rasór

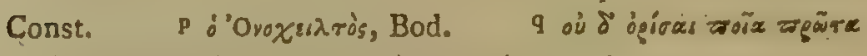

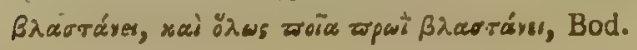




\section{MEPI IMTRN ISTOPIA TO Z'. 299}

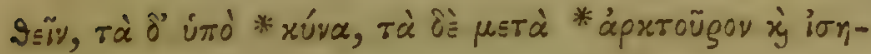

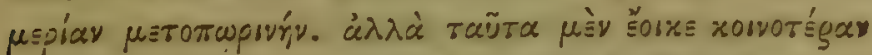

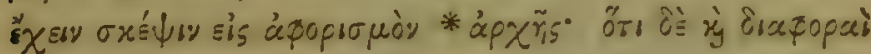

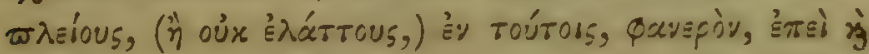

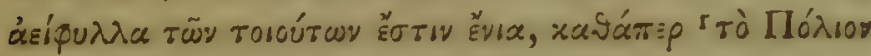

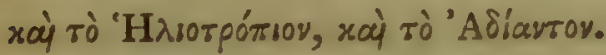

\section{CAP. X.}

Planta thyrsiflore, cichorucere; Rudices fusiformes; bulbosa, \&.c.

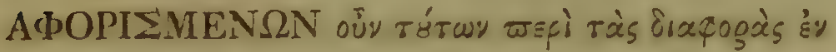

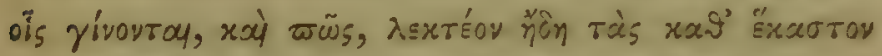

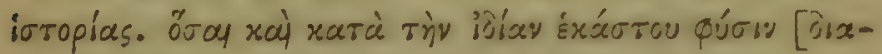

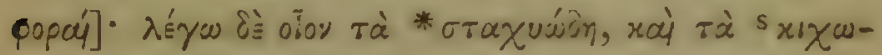

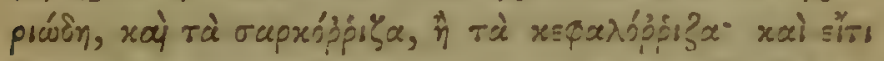

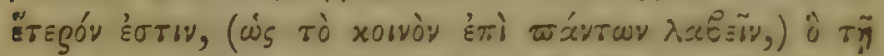

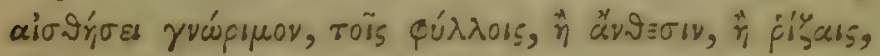

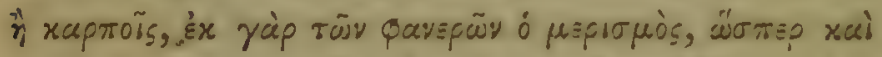

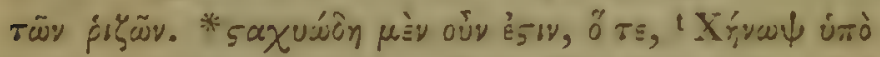

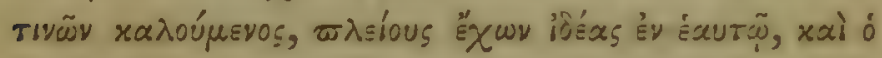

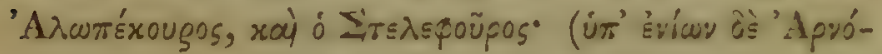

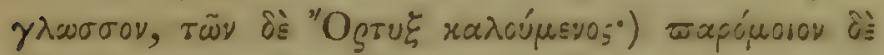

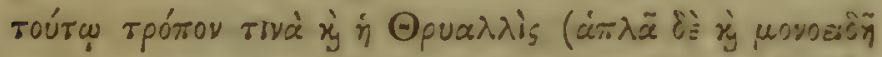

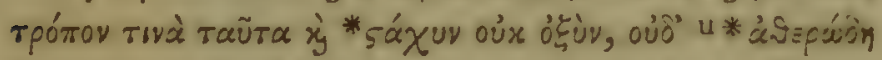

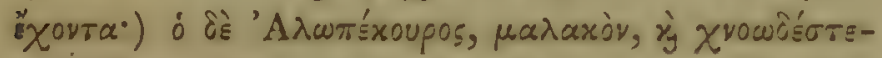

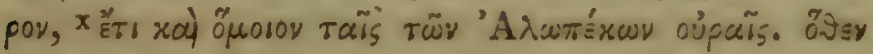

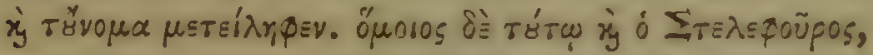

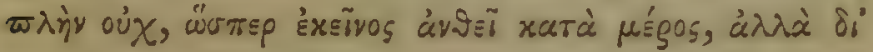
I tò Inósar mai desunt Bod.

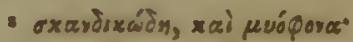

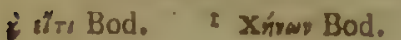
- aina 


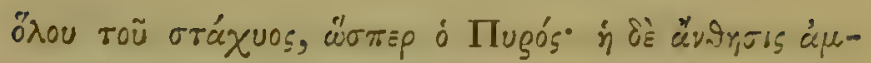

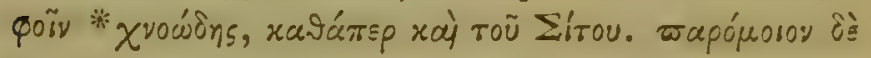

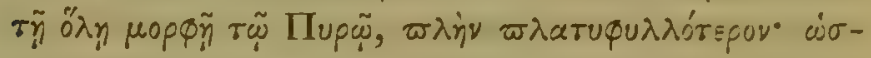

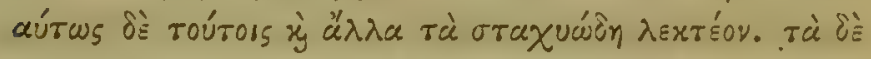

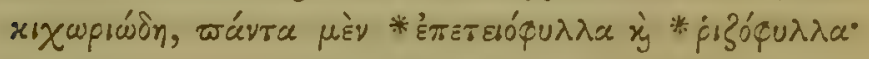

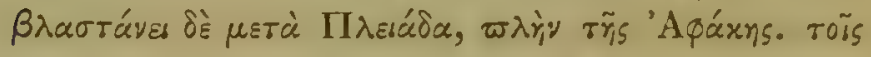

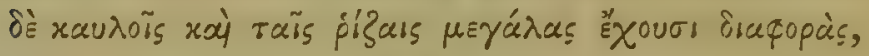

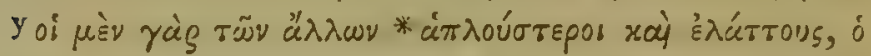

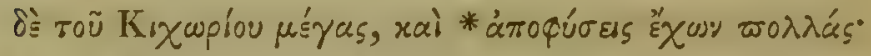

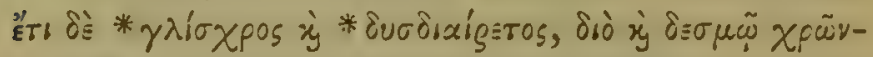

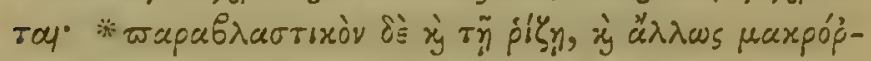

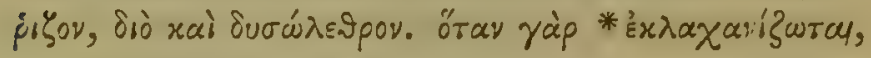

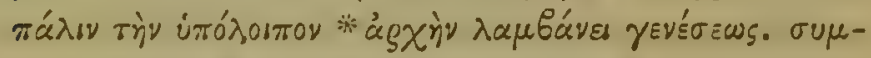

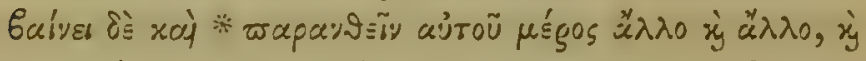

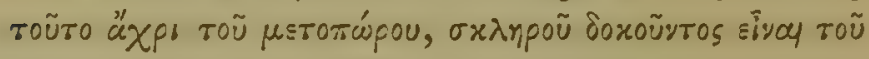

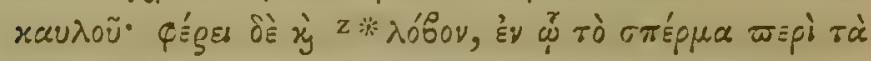

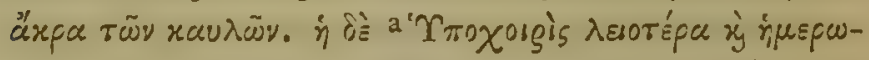

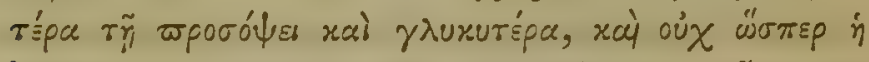

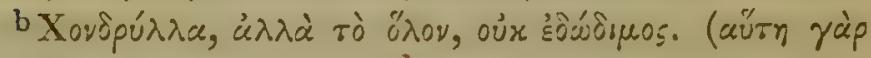

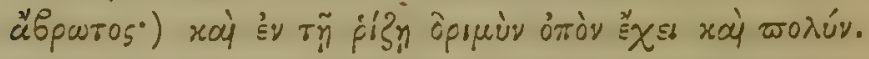
äb

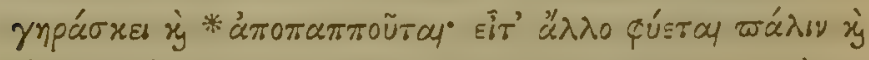

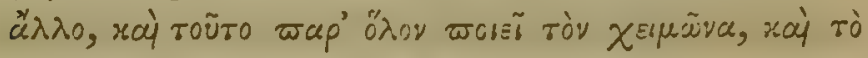

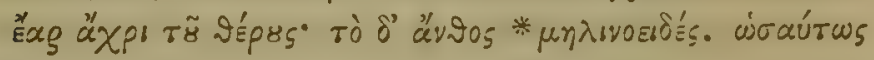

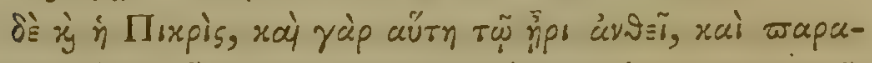

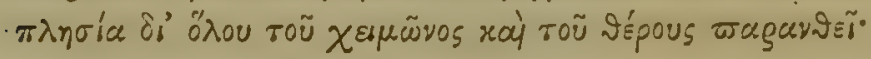

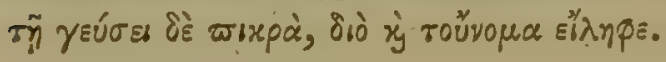

Y ai pişas Ald. Bas.

- iтoxwégrois Ald. Bas. z rópoy, Ald. Bas. An 申óboy? - xavb̧às, Bod. 


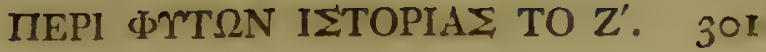

\section{CAP. XI.}

Differentia respectu Radicum, Foliorum, Cantium, ct Bulborum.

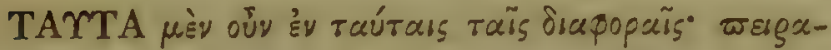

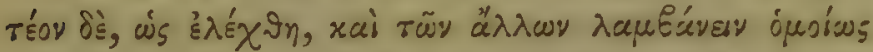

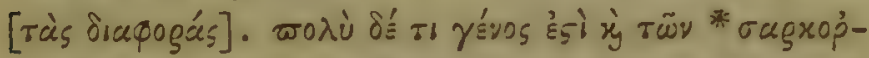

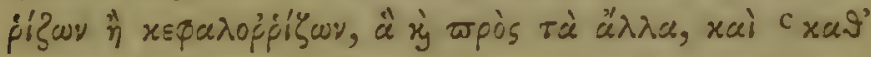

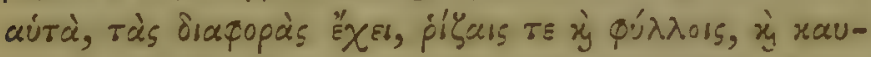

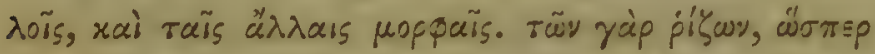

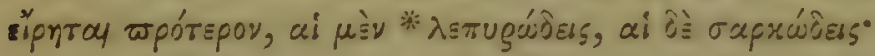

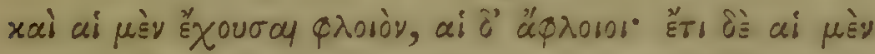

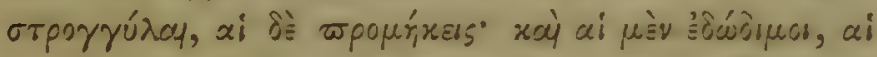

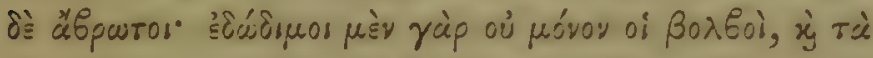

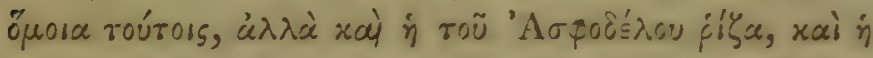

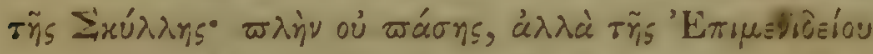

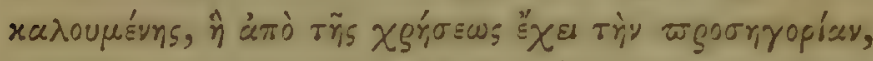

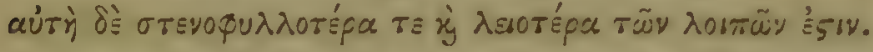

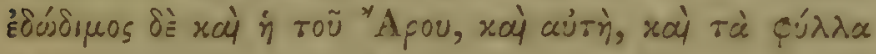
* ఐp

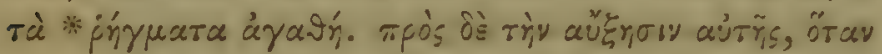

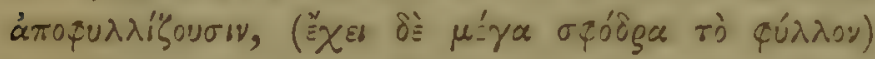

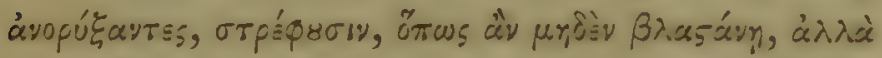

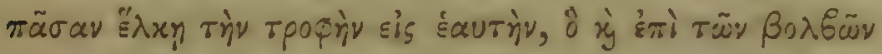

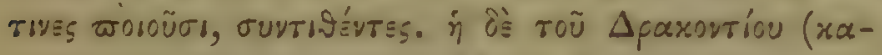

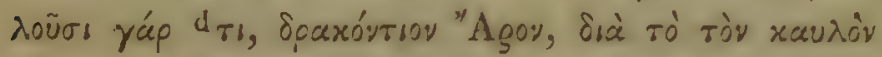

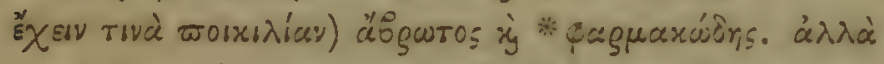

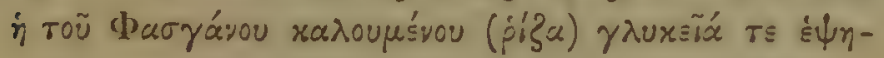

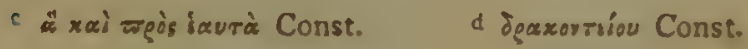




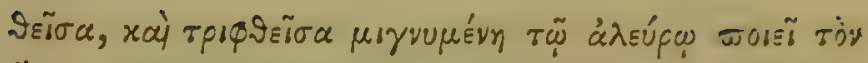

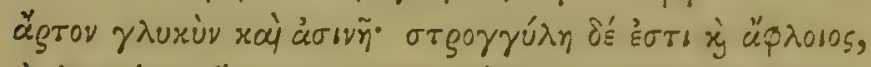

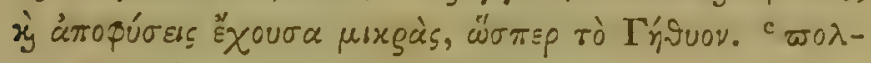

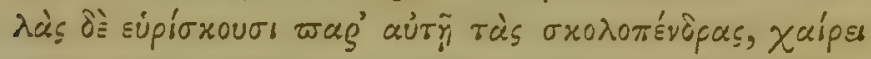

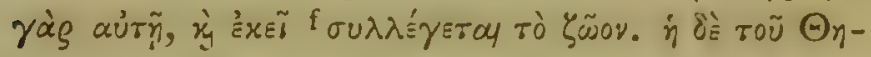

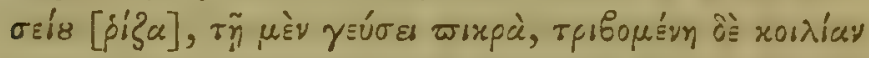

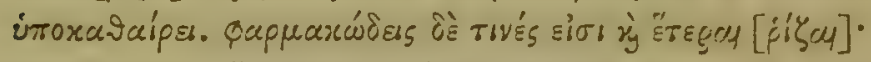

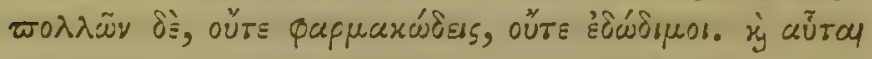

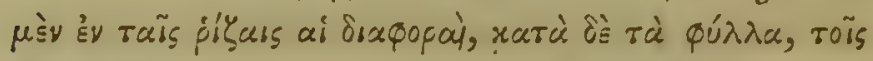

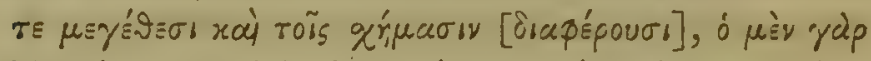

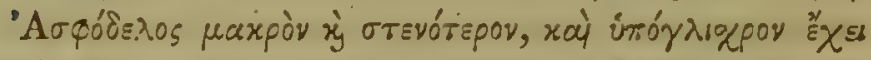

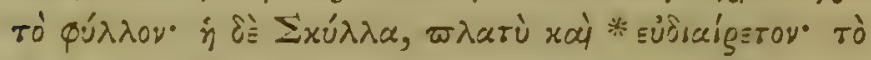

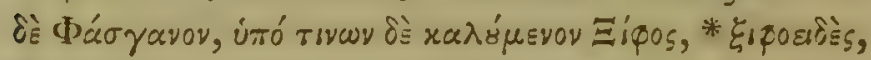

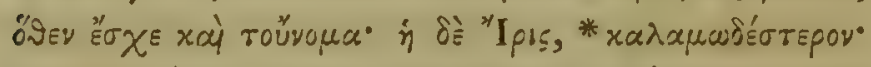
тò $\delta \tilde{\varepsilon}$ roũ "A

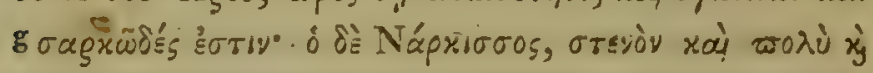

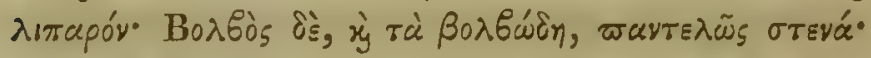

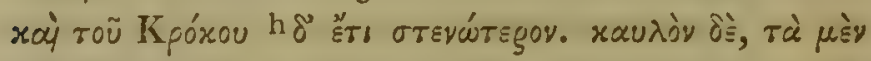

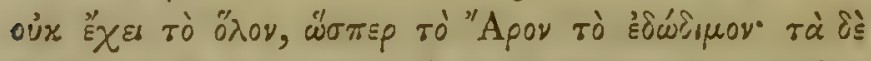

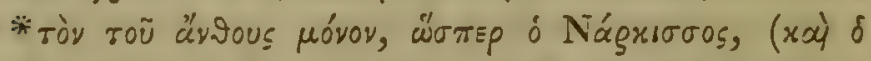

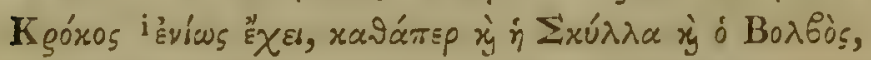

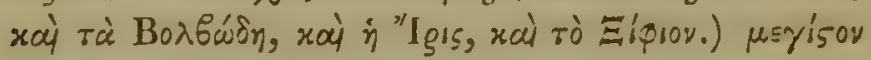

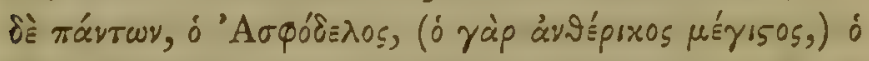

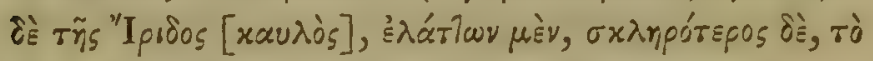

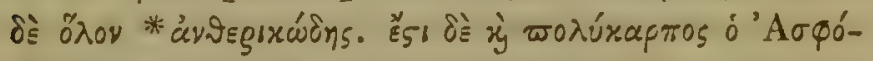

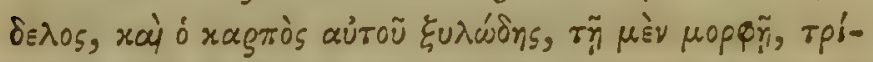

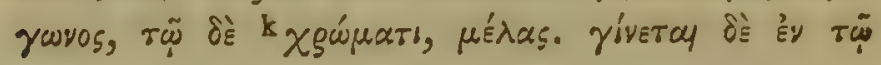

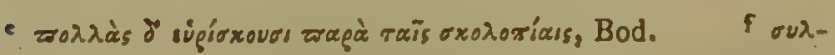

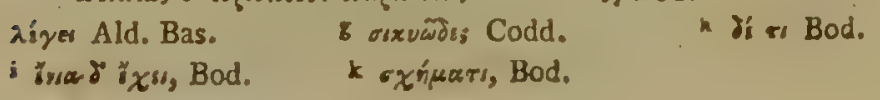




\section{MEPI $\Phi{ }^{\prime} T \Omega N$ I ITOPIAS TO Z'. 303}

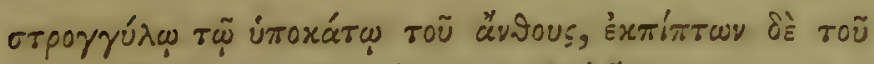

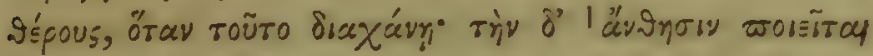

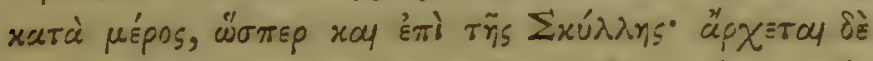

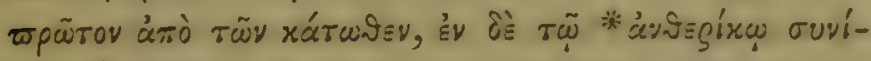

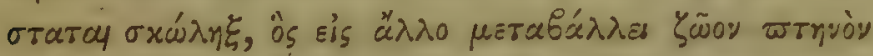
$\mathrm{m} *$ à

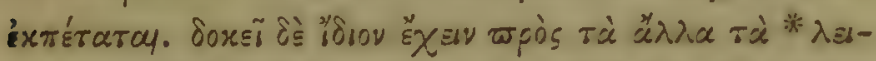

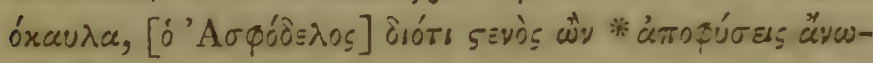

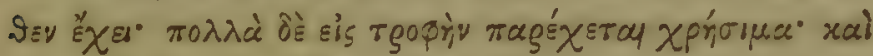

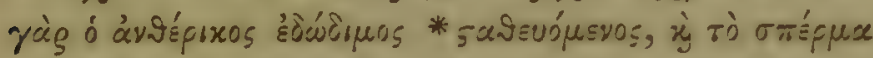

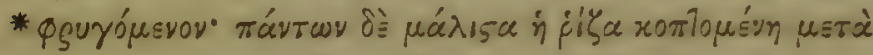

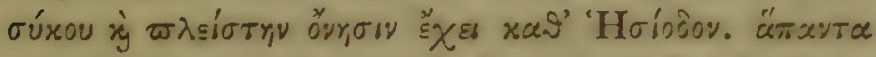
$\mu \grave{s} \nu$ ờ

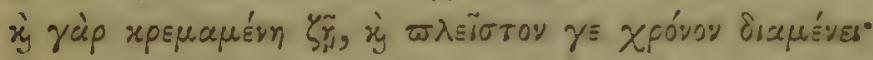

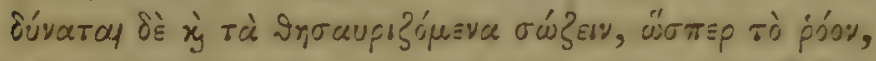

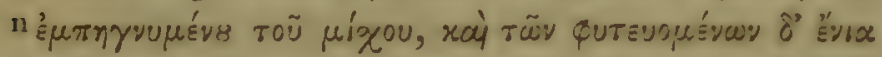

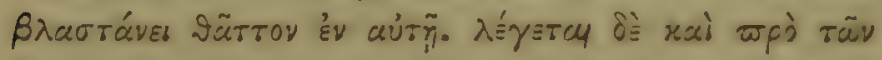

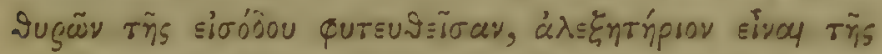

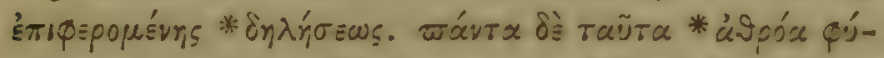

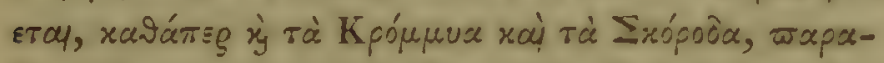

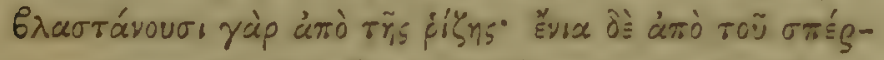

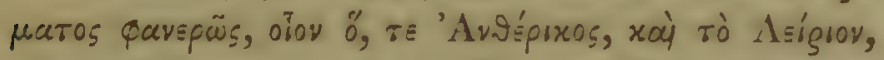

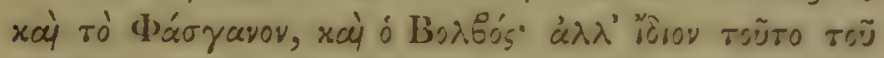

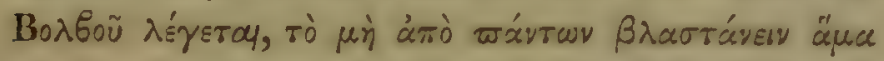

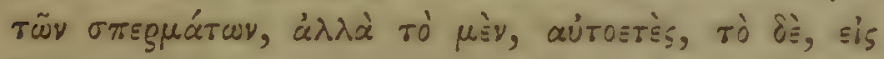

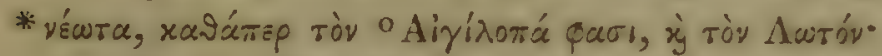

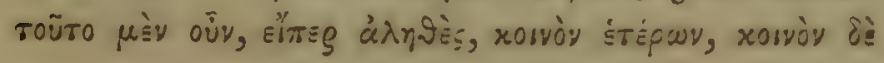

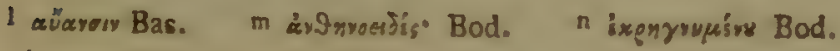
- gídwara Ald. gíziwa Bod. 


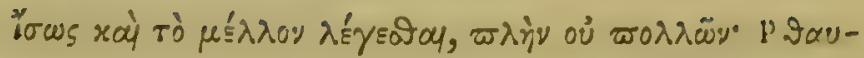

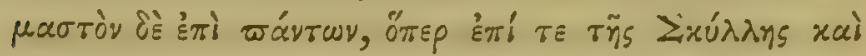

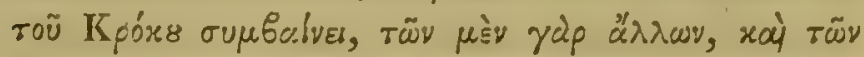

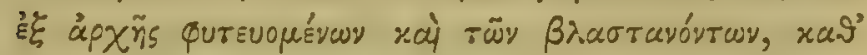

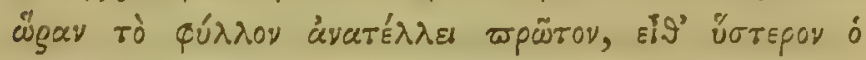

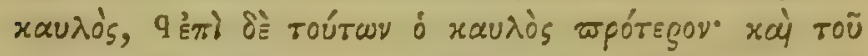

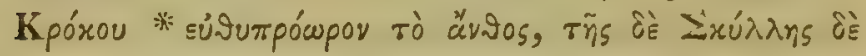

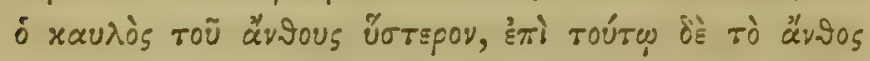

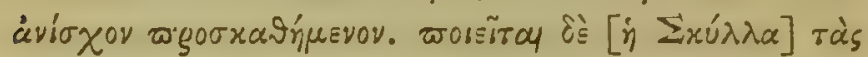

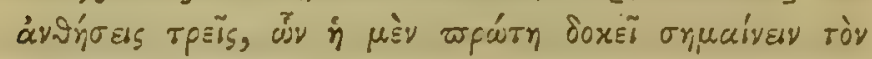

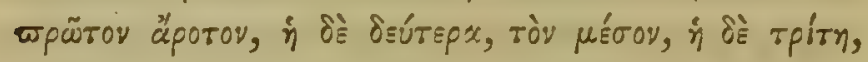

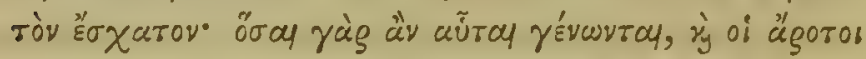

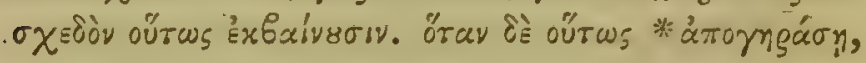

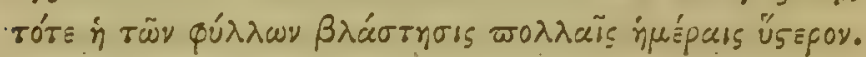

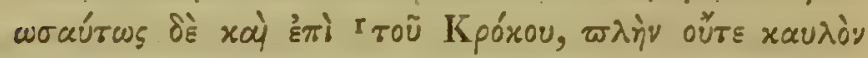

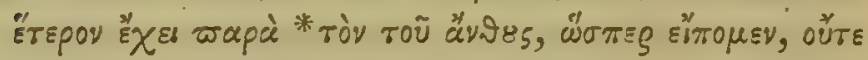

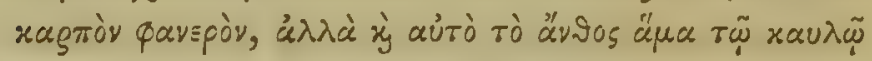

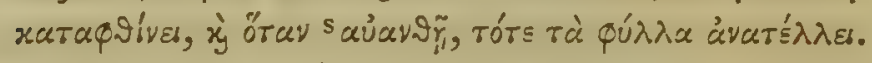

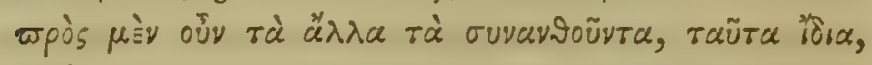

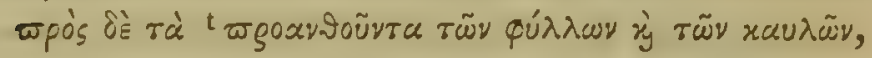

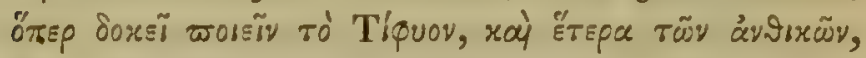

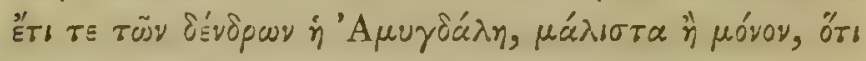

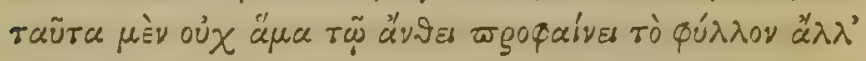

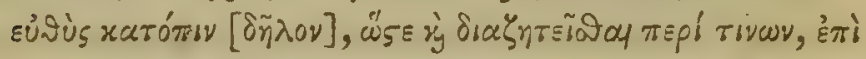

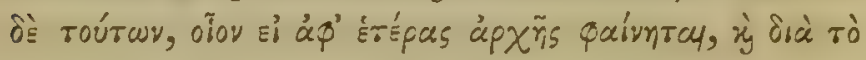

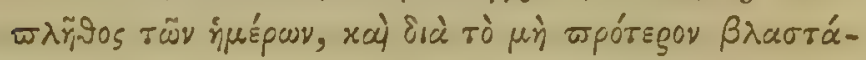

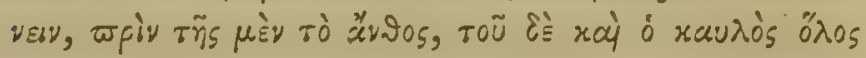

q Vid. not. ad fin. libri. r roü Nąriorou. Bod. - $\alpha \dot{\nu}-$

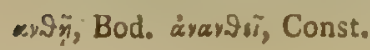

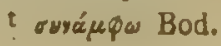




\section{MEPI $\Phi \Upsilon T \Omega N ~ I S T O P I A \Sigma T O ~ Z ' .305$}

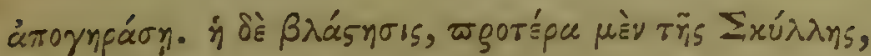

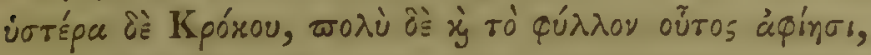

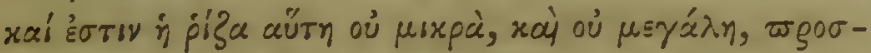

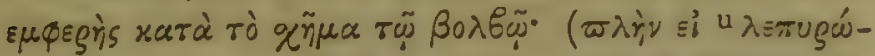

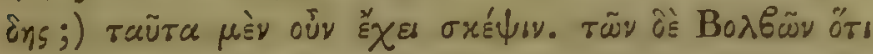

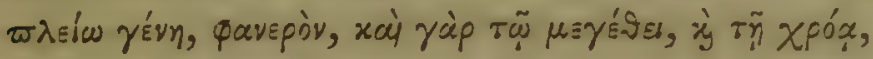

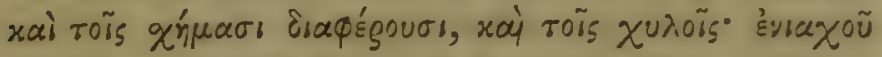

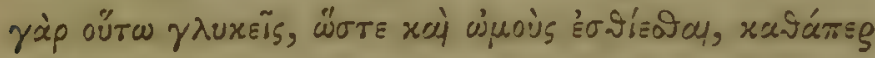

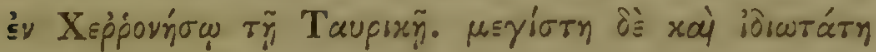

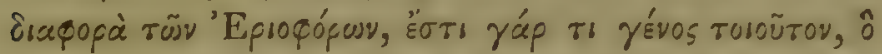

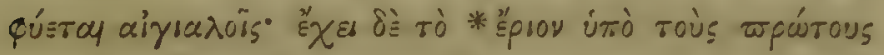

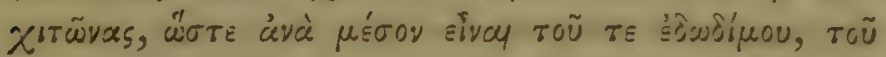

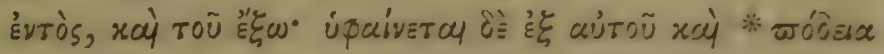

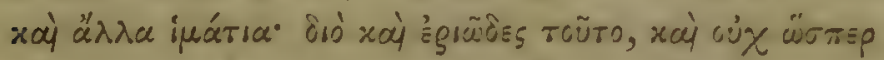

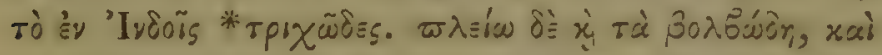

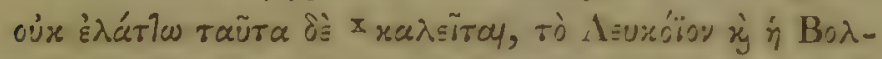

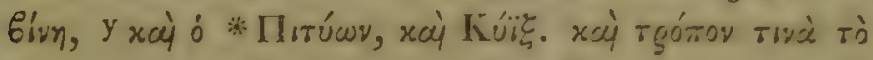

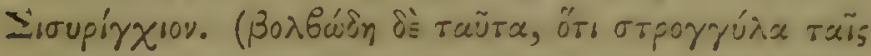

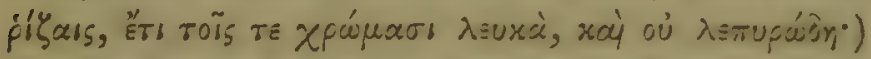

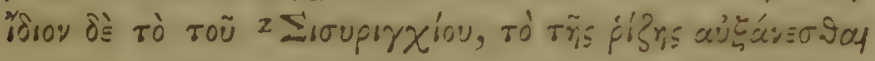

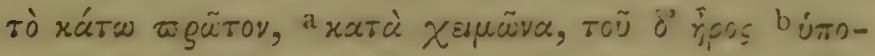

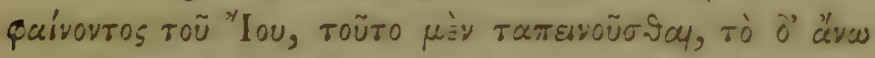

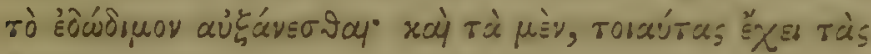
Sixpopás.
4 sopaisis,
woï. Bod.
$x$ xaจárฺ Bod.
8 :

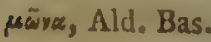
z Eıougúrxus, Const.

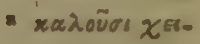
b Vid. not. ad fin. libri. 


\section{CAP. XII.}

Proprietates quadam Plantarum: Adianti, Aparines, Chelidonii, Heliotropii, Sempervivi, \&.c. \&c.

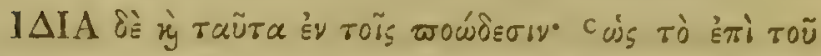

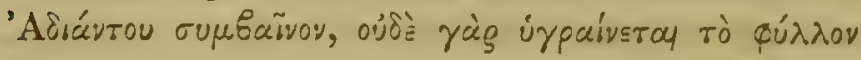

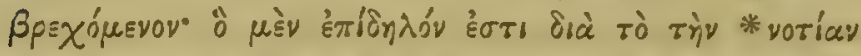

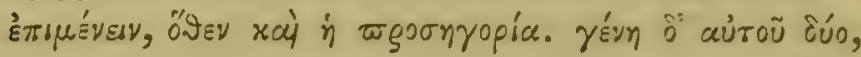

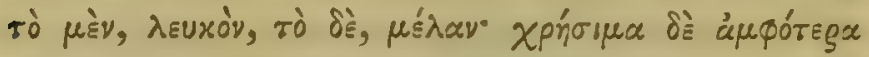

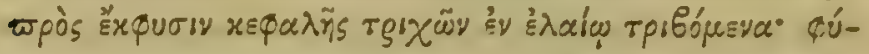

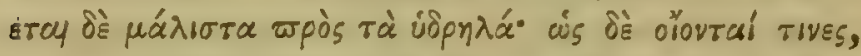

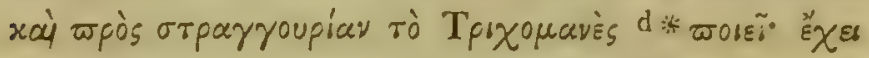

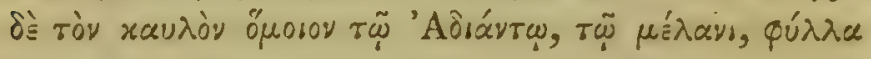

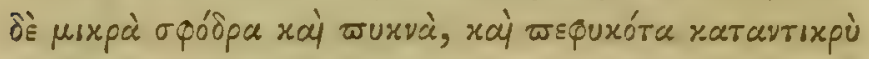

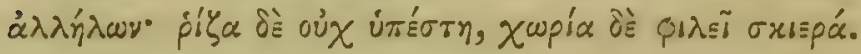

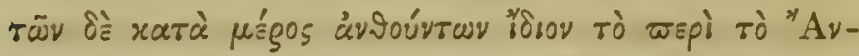

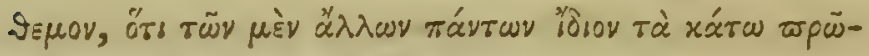

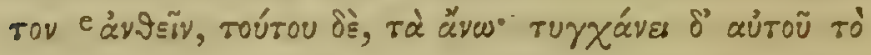

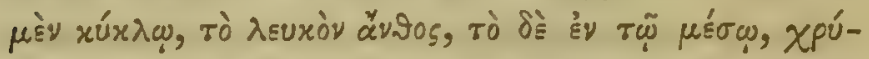

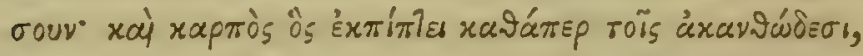

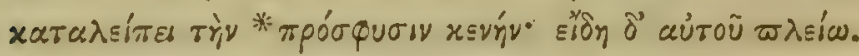

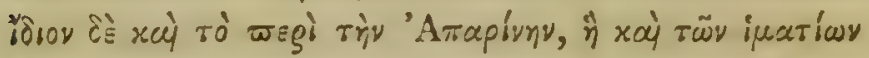

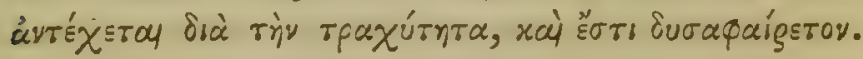

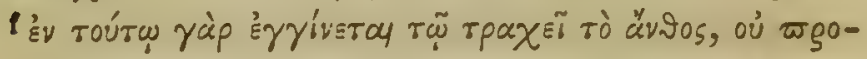

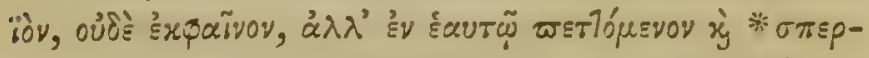

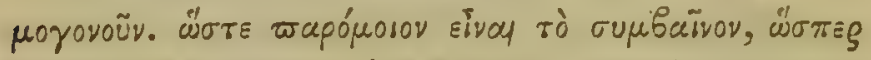

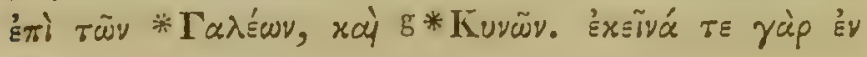

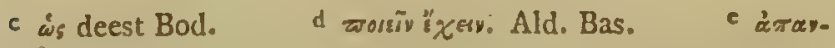

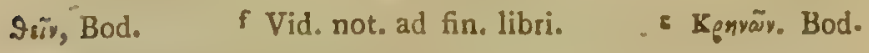
firwy. Idem notis. "zeswy. Theod. 


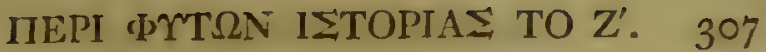

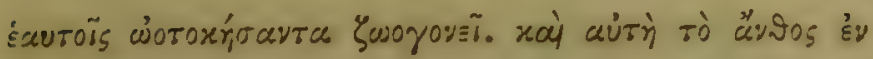

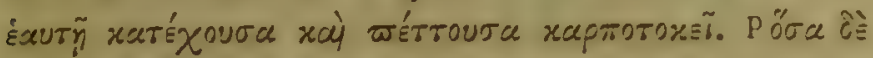

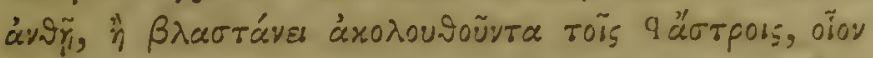

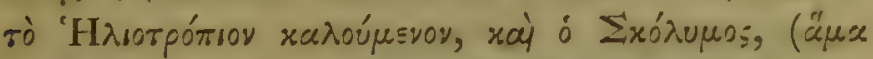

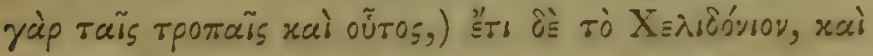

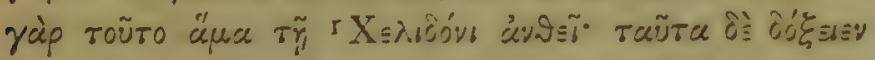

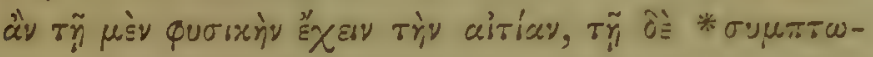

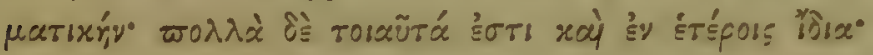

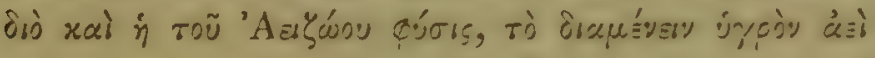

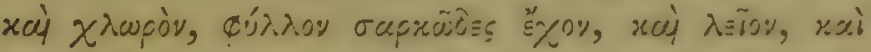

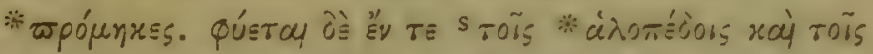

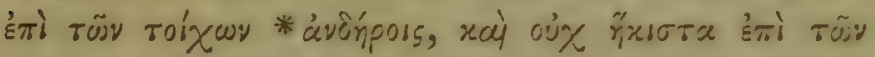

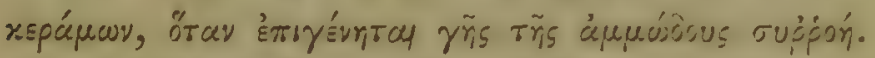

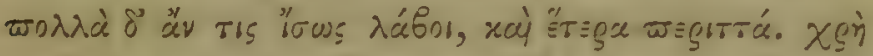

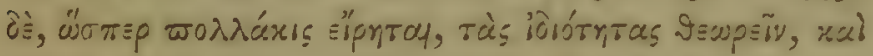

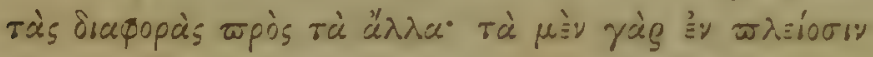

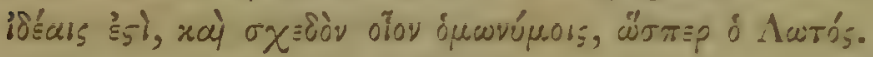

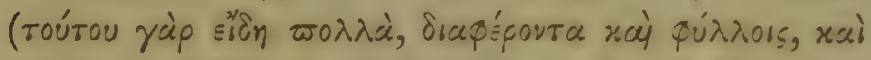

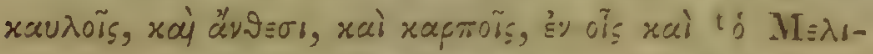

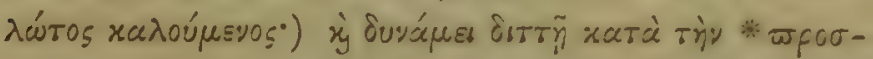

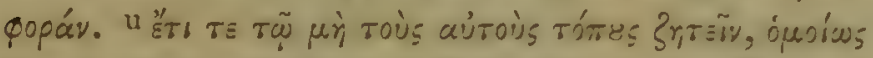

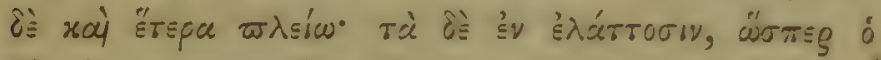

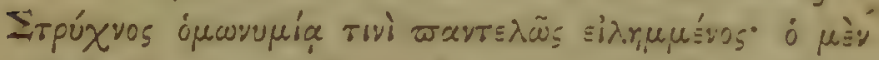

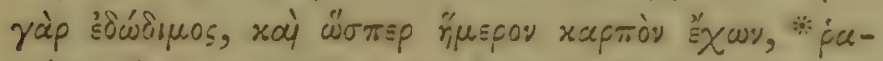

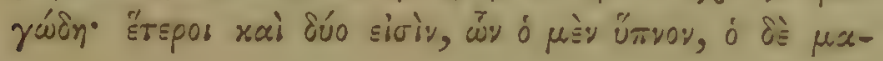

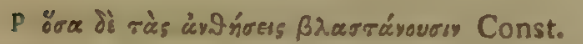

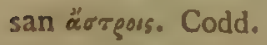
Qpous, rai zoŕrporg Const. I xisiovíz Ald. Bas.

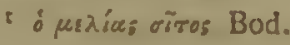

9 ảy jiors, for- тої́ ráT\& Bod.

PARS II.

\section{F}




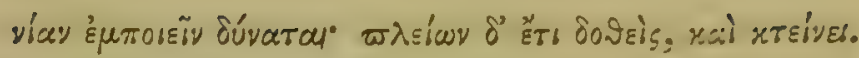

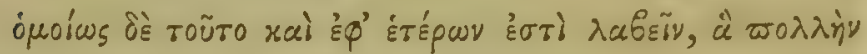

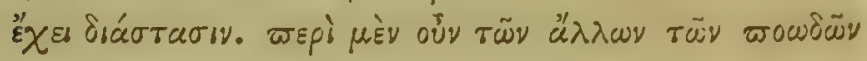

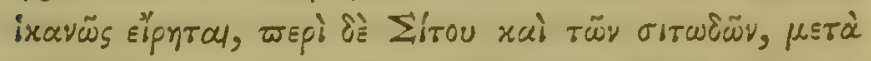

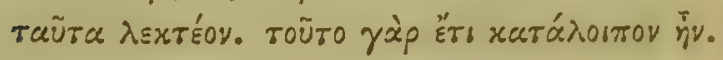




\section{NO.T $\nexists$}

\section{IN LIBRUM SEPTIMUM.}

\section{A P. I.}

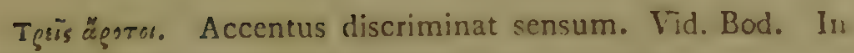
antepenultima, sementes: in penultima, arationes.

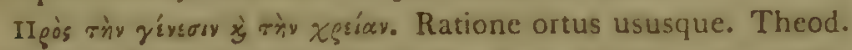

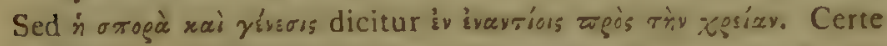
sementes et messes contrariæ; sic ergo corrigendum : oi «g gis

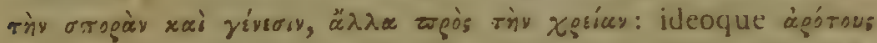
denominari non ex satione, sed ex messe. Vid. Col. xi. 3. Pallad. ii. Cassian. Bas. xii.

Merayєarviävos. Mensis Atticus incipit xxii die Julii. Bod.

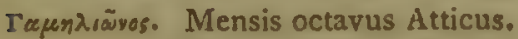

Mouvıx sãyos. Mensis Martius. Bod.

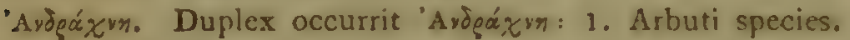

2. Portulacæ species. Ita Plinius xiii. 23. "Andrachnem "omnes fere Græci Portulacæ nomine interpretantur." E contra Helladius (Phutii Biblioth.) ait Atticos non 'Avipázy,y

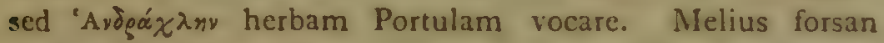

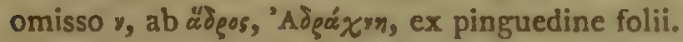

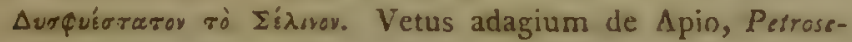
lino $\mathbf{L}$.

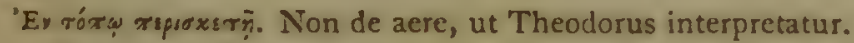

Tò di Tsúr

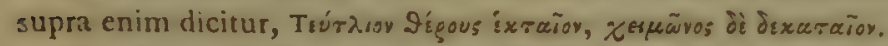

'Adevy'irra. Perfecte matura. N. B. Exemplum sumitur ex plantis sylvestribus, cujus fructus non nisi maturo decidit. Oix ivavíara: i.c. non anno quo seruntur, sed sequenti. 


\section{CAP. II.}

'It 'Paqavis. Ita emendavi secundum Bod. qui Raphanum, rusticanum Bauhini hic indicari vult. Cochleariam, armoraceam L. hoc loco describi nullus dubito. Notandum tamen 'Puфuvío duplicem apud Theophrastum inveniri: 1. Cochl. armoraceam. 2. Raph. sativum.

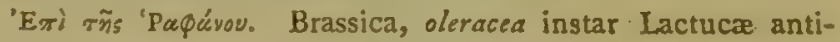

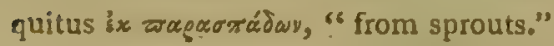

\section{C $\Lambda$ P. III.}

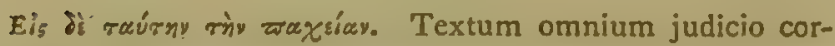
ruptissimum emendare conatus sum, adeo ut descriptio congruat cum sensu. In bulbis enim Brassicx Napa, necnon in radicibus fusiformibus Raphani sativi, radiculae exiles producuntur xarcè xesíay, sc, ad alendas radices vel bulbos: aliter enim si majores forent, detraherent de mole illorum:

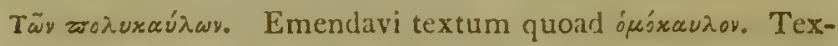

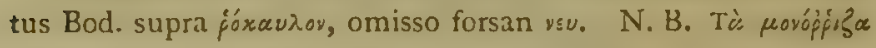

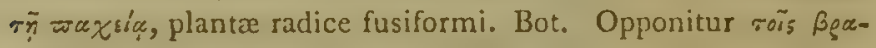
xúp̧işors.

Tò Kogíavvov. Inter $\lambda \dot{\alpha} \chi_{\alpha}$ vac recensetur, quia usus ejus ad saporem in jusculis et condimentis.

Eǘçupov. Saturcia, hortensis. Cat. sed rectius Brassica, eru-

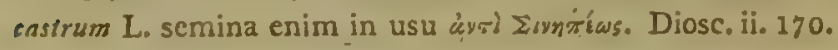

\section{A.P. IV.}

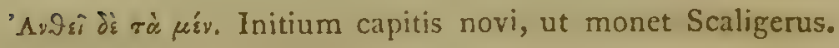

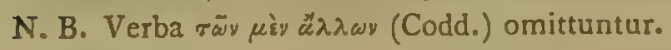

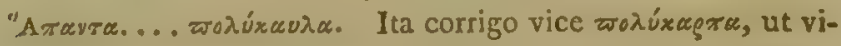
tetur tautologia.

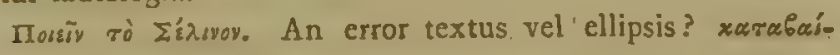
yesy?

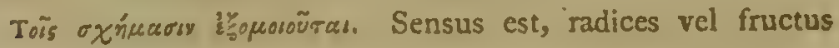
crescendo accipere formám cavitatis ubi crescunt. 


\section{CAP. V.}

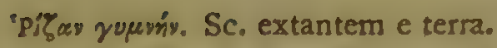

Tйs óposẃosws. Obscura lectio, si sana. Sensus est, plus vel minus similitudinis inesse.

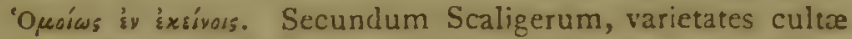

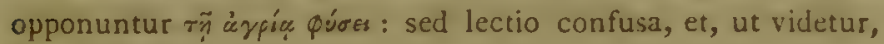
parum sana.

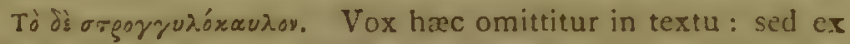
tribus Lactucæ speciebus supra memoratis dure solummodo hic describuntur, sc. Laconica, et Platyphylla; ergo characteres

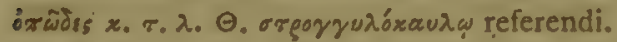

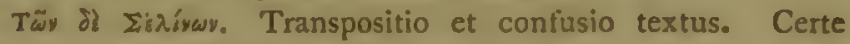

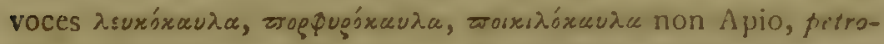
selino tribuenda, sed Lactucr. N. B. Uncis inclusi qua de sisiow.

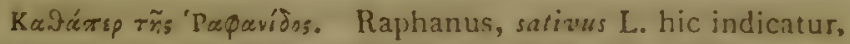
cujus varietates enumerantur. N. B. 2. "Pupasi, Cochlearia, armoracea L. suprá memoratur, cujus non dantur varietates.

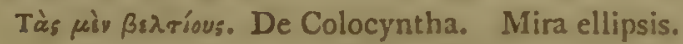

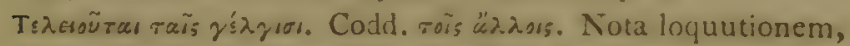
ait Scaligerus. Supra memoratur species äysvos. Fursan rö̈

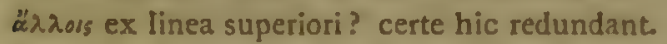

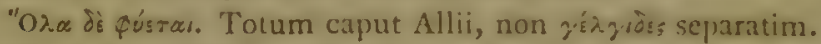

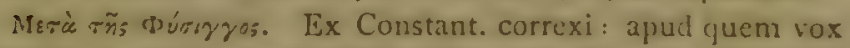

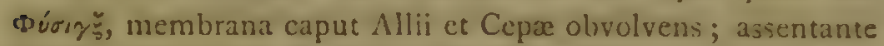

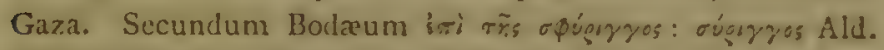
qua voces scapum fistulosum in Alliis denotare possint.

\section{C $\wedge$ P. VI.}

Tà 2rọiz ìyivópsva. Bestiolas innascentes. Plin. N. B. Qualitates aqua salsæ et stagnantis notantur voce deruávers, sc. quae ægre evaporantur.

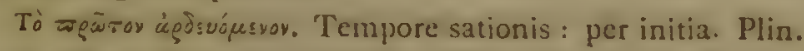

rywóscsy. An pro givwoxsay? Aliter intellige probare: hinc enim écrsıía horticultoris eminet, cognoscendo q̨uando plantæ aqua indigeant, vel non. 
$\Gamma \lambda \dot{x} \chi \omega v$. Ita repono ex conjectura Scaligeri, sed rectius $\gamma \lambda i \sigma \chi \rho \propto ⿻ \ddot{\alpha} \pi \alpha \nu \tau \alpha$. Vid. Lex. Theophr.

"Y Yjovoris. Codd. omnes, Const. excepto, habent xpãors,

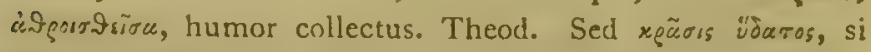
detur, turbidam et mixtam aqua infusionem denotat: et forsan vera lectio.

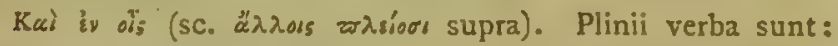
"Porro (sc. ח९̣́a $\sigma$ Theophr.) animalia innascentia facillime " stercore injecto capiuntur, condentia sese in id."

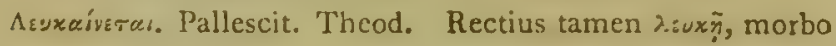
afficiuntur. Vid. Lex.

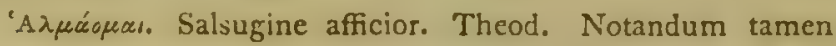
$\dot{\alpha} \lambda \mu \grave{y}$ morbum plant. quarundam secund. Theophr. Morbi hi forsan ex morsu A phidum. Vid. lib. i. not.

'Ey roĩs sủwóros. Acerbis. Theod, ex alia voce in textu. Bod.

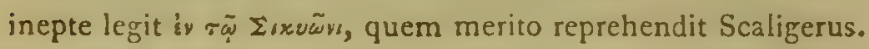
Naturæ consentaneam videtur, semina aromatica minime ver-

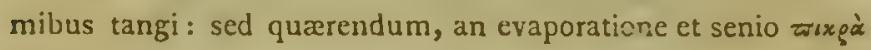
evadant?

\section{CAP. VII.}

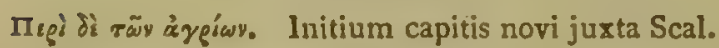

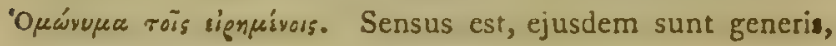
etsi habitu varii.

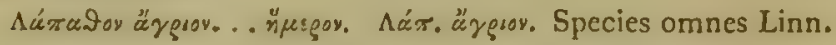
sub nominibus Patientice, crispi, pulcliri, maritimi, divaricati, acuti, obtusifolii, aquatici, continere videtur, quorum nullus ad

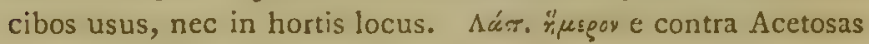
veterum et Oxalidas, ex succo acri ita vocatas designabat auctor, quæ cultura pinguiores, et magis grati saporis. Vid.

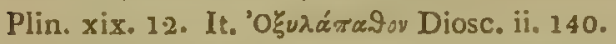

'İís ń 'Pápucyos. Brassicam oleraceam sylv, et cult. hic describit auctor. Varietates innumeræ Brassicæ L. unde præcipua materies culinaria antiq̨uitus æque ac apud nos. Notandum tamen Brassicam, campestrcm L. spec. seorsum. Bras. oleracea sylvestri statu in clivis maritimis ubique reperitur.

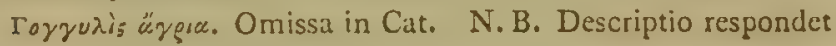
Rhaphano, Rhaphanistro, L. 


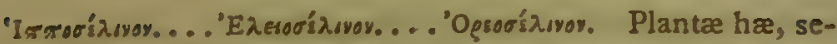
cundum Theophrastum, varietates $\Sigma \varepsilon \lambda$ ívou, Apii Petroselini, in hortis usitatissimi : longe tamen diversa Botanicorum recentiorum mens. Vid. Cat. item quæ Dioscor. de $\Sigma \mu u$ vé, \& \&c. \&c. lib. iii. c. 179 .

Kǻárs inodora vocatur? Hinc liquet Violam, caninam L. 'I wviav à $\gamma$ f̧av a Theophrasto vocari.

\section{A P. VIII.}

'Ev generali sensu plantas edules et inedules amplectere videtur. Distinctio sumitur inter $\lambda a ́ x$ ceva et aowín.

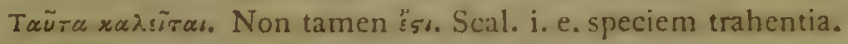

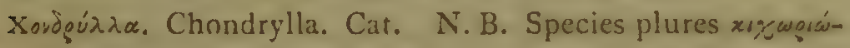
Jus ad cibos antiquitus usitatæ hic recensentur. Vid. Plin. $x x i$. 15,17 .

'Avòeuxaia. Andryala, integrifolia. Cat. minus recte tamen. Notandus error Plinii, qui Chondryllam ait inedulem esse, ubi pro 'r roxougín usurpatur.

'Avagioxos. Ita ex margine reposui pro 'Evâovoirs, qui in Catalogo, Thymus, masticlina L. Ita conjici ex pungente, et scnsus opprimente, odore. Plinius tamen Anthriscum vertit, utpote Scandicis speciem. N. B. Scandix, Anthriscus, ct Caucalis, Anthriscus apud Linneum occurrunt: apud Ger. em. Scandices 2. Caucalides, 6. p. 10.21-10\%. Planta hæc forsan Scandix, odorata L.

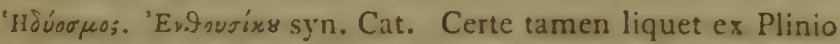
xix. 8. Menthre species innui: "Mentha nomen "súsopos an" tiquitus ex suavitate odoris."

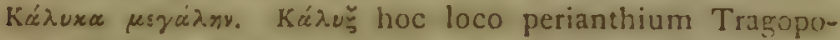

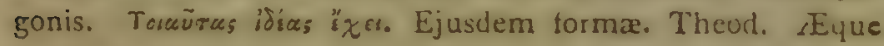
papposo semine.

¿rpúxvos sủríratos. Solanum, melangina L. Forsan efficax in morbis jecinoris. Ang. "Egg Plant."

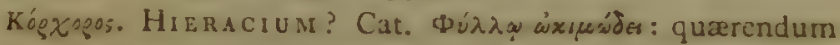
de 'Oxip..

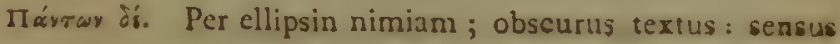




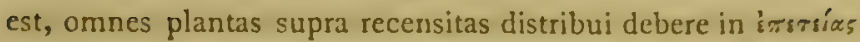
(annuas); et érsтьaxaúdous (perennes), sc. quarum caules pereunt, radix durat.

- Kúvaros. l'lantago, Cyrrops L. Cat. Plin. in loco ait Acinos, чuem tamen viri docti pro Achynops interpretantur; sed ex flore ringente canis os apertum referente, Antirrbini speciem sisto. Bodaus censet Kuvoxsфázıs plantam hanc vocari, an Antirrhinum majus? P. $820,822$.

Boúrgnoris. Bupleurum. Cat. Baúrৎ. Cantharidis species, et

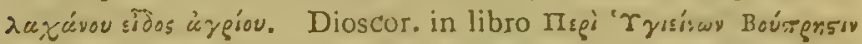
describit, qui tamen periit. Plinius ait: "caule cubitali, foliis " multis, longis; capite Anethi sımili." Vid. Nicandr. de Theriacis. B. Ptarmicæ speciem vocat Dodon. rectius vero B. folcatum L. cujus syn. B. latifolium Monspeliense, cujus icon (Ger.em.p. 608.) florem umbelliferam Ancthi similem exhibet.

'A pia. Caltha, palustris. Cat. Ita Bod. Sed genus dicitur

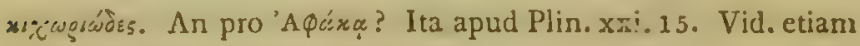

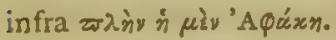

'Erizergav. Alchemilla, arvensis. Cat. Ita vocavi, quia flos cx parvitate inconspicuus, ideoque íyx́y omnium vivax. Forsan ergo ex succulentia et ex loco natali in rupibus Parnassi, Sempervivi species diversa ab 'Aes'áw, vel Sedi, L. N. B. Alii legunt 'Erruŕóny: vid. Diod. lib. iv. c. 19. et certe parvitas florum, necnon occultatio sub foliis xque descriptioni pl ¿́xáysovs favet.

"Ебть ковуоу ázúyтwy. Sc. Hores proferre.

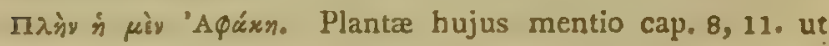
species x‘cwénóns, et amara, semine papposo. Bodæus censet Leontodon taraxicum L. indicari: sed minus recte. N.B. Hyoseris, hedypnois L. caule folioso. Planta Hieracii affinis hic intelligenda. Tragopogonis etiam species Dalecampii a Linn. vocatur, Hedypnois Bauhini. Vid. de hac planta Plin. xx. 8.

\section{CA P. IX.}

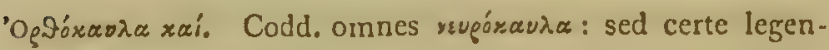

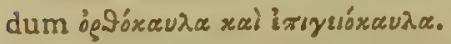

Ir úïr. Ajuga, Chamapitys. Cat. Error typogr. pro Teu- 
crium, Chamapitys. N. B. Species humifusa; non, ut apud Bod. erecta: p. 826 .

'Aragiy\%. Galiu.r. Cat. Suspicor tamen duo genera: diversa hic et c. 14. describi.

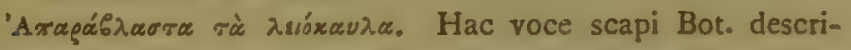
buntur, quæe nunquam ramosi.

Astipsay. Anthemis. Cat. Alii putant Nigellam describi hic.

חáu. Vox generalis, plantas herbaceas amplectens: hic tamen gramina solum.

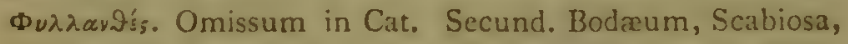
arvensis L. ex calyce folioso. "Foliosum gerit floris fluscu"lum." Bod. p. 840.

'Aragyía. Omissa in Cat. Hicracium, minus. Dodon. Hi. eracium, cymosum L. Præmorsa radice. Bod. p. 841.

Aurós. Tres Loti in Catal. occurrunt. Planta hæc, Lotus, melilotus L.

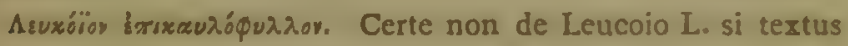
sanus. An iтsяеś́

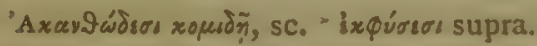

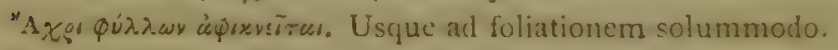

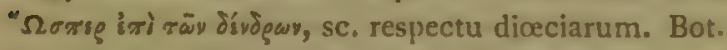

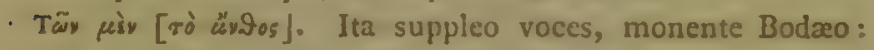

c. g. respectu Tussilaginis, Equiseti, \&c.

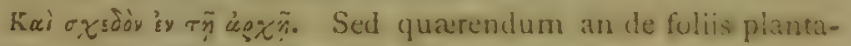

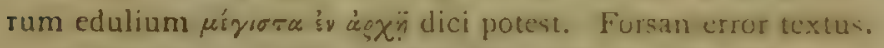

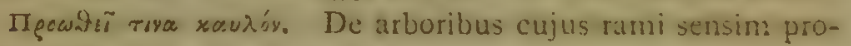
Hucuntur.

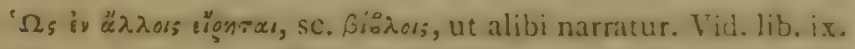

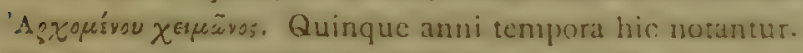

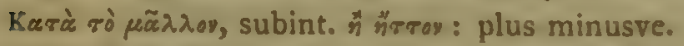

' $\Upsilon$ rò rãy ízárwy. Forsan pluvias immaturas, vel tempora anni "Monsoons" dicta.

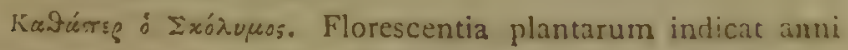
tempus, et Scolyınus juxta Hesiodum floret cun Cicada :

$$
\begin{aligned}
& \text { "O- }
\end{aligned}
$$

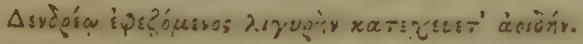

Kovílns xai Kursapídos. Vid. lib. vi. c. 5. 


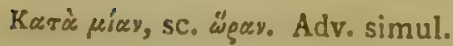

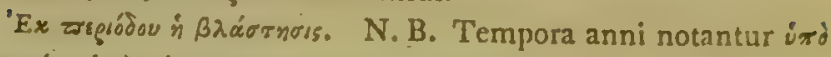

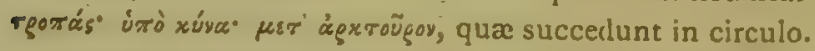

Eis «̌

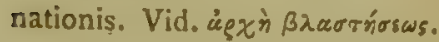

חódsoy. Teucrium, Creficum. Cat. Forsan T. monłanum vel T. Polium L. Icones exhibentur a Bodieo Polii campestris et montani. P. 844. Nomen derivatur a canitie foliorum. N. B. Planta hæc non occurrit in textu Bod.

\section{CAP. X.}

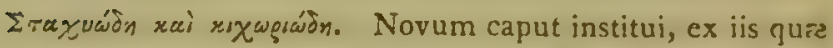

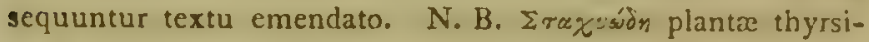
floræ. Bot.

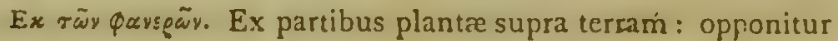
rais pígass.

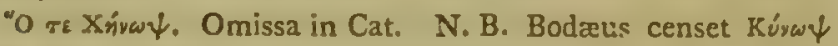
pro $\mathrm{X}$ ńwary in textu reponi, et hinc apud Linn. planta hæc $\sigma \tau a-$ xuẃons Plantagini refertur: sed Kúvwros supra mentio fit c. 9. ut Antirrhinum. Forsan X'́n๘ $\downarrow$ ex rostro anseris, ut Kúycu ex facie canis. Alibi planta Xnvoróòov vocatur ex pede anse-

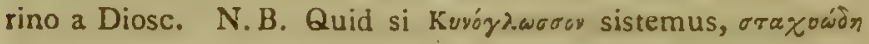
genus?

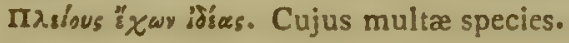

'Arwríxougos. Alopecurus. Cat. Bot. N. B. Icones duæ Alo. pec. in Flor. Græc. occurrunt nullomodo caudam vulpinam referentes; Phlei tamen criniti spica ibid. tab. 63. simillima. Nomen hodiernum Alopecuri graminis 'A versa tamen vocis orazuádous acceptatione Bodæus conjicit Trifolium quoddam, inter Lagopoda $\mathcal{L}$. indicari.

Tà di xıxwęádn. Divisio plantarum ex habitu. N. B. Hic

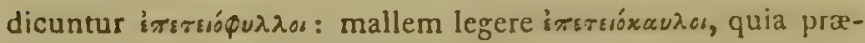
cipua plantæ perennis distinctio.

'H 'Aфа́хฑ. Vid. supra c. 8. sed quære, annon plante diversie ex habitu diverso. Supra legitur in codd. quibusdam 'A p̧iu.

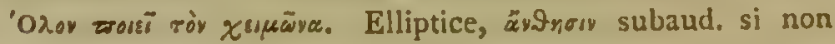
sensus vocis zuís ita acceptandus. 


\section{- CAP. XI.}

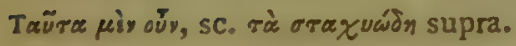

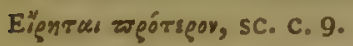

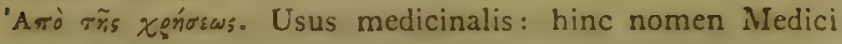
Inventoris accepit.

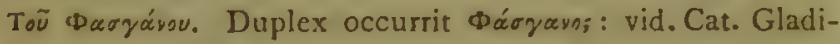
olus. Hic Ari species, cujus radix edulis.

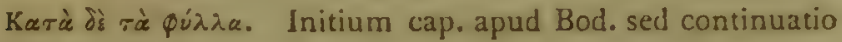
evidens subjecti.

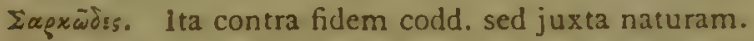

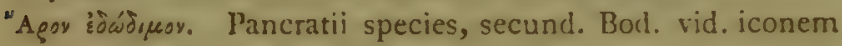
P. veri, Clus. p. 876 . N. B. Ari succus acris valde.

Kéros di" kniws " $\chi^{z} \%$. Crocus vernus, et autumnalis acaules: C. aureus tamen Flor. Gr. " tubo longissimo." Forsan apud Theophr. cauliger dictus.

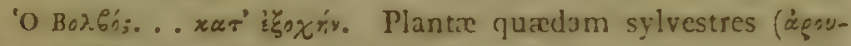
pasol) a Theophrasto et Plinio hoc nomine describuntur: vid. Plin. de bulbo vomitorio, eduli, \&c. Forsan Muscari antiqunrum Hyacintho affine. Vid. Ger. em. 120.

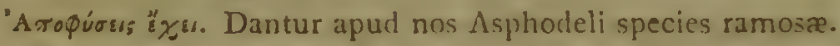

Oú ó áva? gaxos. N. B. Duplex sensus vocis hujus: 1. plantam designat: 2. pericarpium in Liliaceis, ut videcur, sic infra vermis dicitur generari in pericarpio Asphodeli.

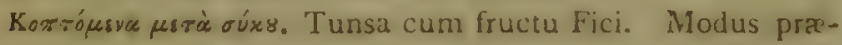
parandi medicamenta.

'A

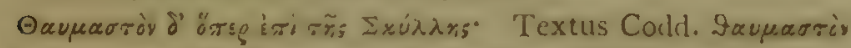

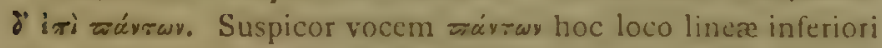
inserendam post $\ddot{\alpha} \lambda \lambda$.asy, sensu suadente; non potest enim ri

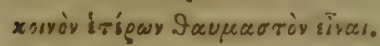

Eùsvrgówgoy gás. Ita Scal, sine commentario. Vox hæc nullibi, quoad scio, occurrit. Germinatio erecta et pracox

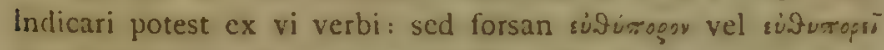
substituendam ; qua voces apud Theophrastum occurrunt.

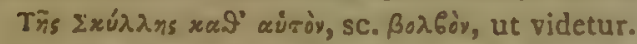

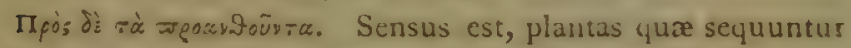
addendas numero illarum quarum flores pracedunt folia. 
Tíquav. Omittitur in Catalogo. Forsan Narcissus Persicus, Bod, sed nulla ejus mentio apud syn. Linn. Anne Colchici vel Iridis species? Secundum alios Tussilago indicatur, cujus flos precedit folia.

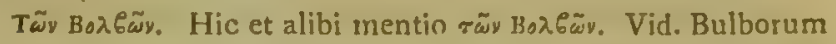
quatuor genera, Plin.xix.2. Bulbus hic dicitur edulis esse (ふứós); alius apud Plin. et Dioscor.vomitorius. Vid. etiam Ger. em. 120.

Bodbìs lerópogos. Hyacinth. Peruv. Cat. minus recte tamen, nisi orbis veteris æque ac novi incola. Usus in lanificiis antiquitus notissimi. Plin. loc. cit. "impilia," ait, "ficri ex lana "radicis hujus." Ex Girardo accepimus Medicum quendam Germanicum ex Constantinopoli Carolo Clusio bulbos quos. dam Eriophoros misisse, qui flurucre apud ipsum, et cujus iconem Girardo communicatum videre est, p.121. Bulbi tamen Girardo communicati diu manserunt sine ullo flo: is vestigio. Flos apud Ger. em. Hyacintho, botryoidi similis, spica flor. cærulea. N. B. Ex lanoso bulbo species quæedam forsan Bulbocodium appellabatur. (Boג6oxwoía, i. e. bulbus vellere cinctus.) Hinc forsan genus Bulbocodium L. 422. cujus syn. Colchicum vernum Bauhini et Clusii.

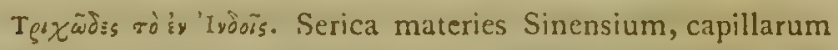
instar nitens, hic clare describitur : opponitur rạ "ẹ sypinæ.

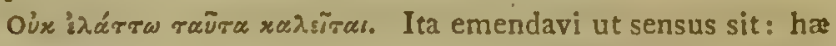
etiam non minus reputantur bulbosæ. Ser quære.

Boגeiv». Scylla, unifolia!' Cat. "Bulbincm Græci rocant "herbam porraceis foliis, rubicundo bulbo." Characteres distinctivi. Anne Hyacinthus, muscari L.?

'O IIrv́wav. Euphorbia, Pithyusa. Cat. sed quærendum de radice bulbosa : rectius forsan E. bulbosa $\mathrm{L}$.

'o Kúï̌. Omissa in Cat. N. B. Ibi reperitur Kö́z̆, cujus

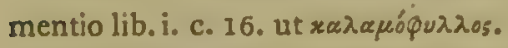

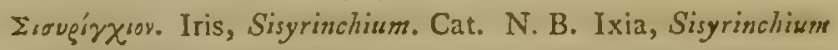
L. BoגGoxndí, Theophr. ascribitur. Flor. Græc. Sed notandum

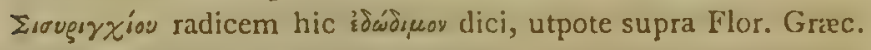
fasc. Imo. radix Ixire Sisyrinchii. Peculiaris crescendi methodus respectu bulborum notatu dignus : vid. icon. apud Bod, p. 880 . 
simile quoddam notavit Fab. Colonna: "Inanis bulbi cortex "anno proximo reperi supra vegetum bulbum."

\section{CA P. XII.}

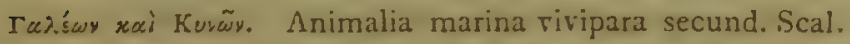
Galea et Sqquatina, Plin. in loco. N. B. Bodazus pro Kusäy legit pives, quia propius vulg. lectioni жarvav. Constant. substituit ix $\chi$ swy, quae magis arridet, animal enim manifeste viviparum xque ac squalus piscis.

'Aragivn. Galium, verrucosum: an Arctium, Lappa L. Cat. Bodreus censet de vulgata Aparine intelligendum. Libet subjicere accuratam planta hujus descriptionem ex Diosc. lib. iii.

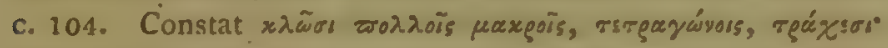

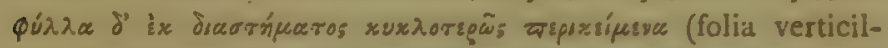

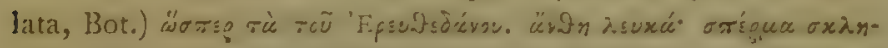

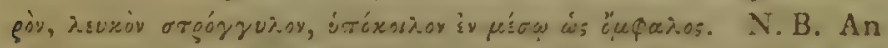
pericarpium orbiculare hic sumitur pro semine, ut apud Theophrast. Pericarpium Galii apud Linn. G. P. 125. "Baccæ " sicce dlux, globo:a, conlite." Hinc forsan cavitas in medio " $\mu \varphi \alpha \lambda$ ns dict. et similituclo ovi in animalibus.

Xènón:uv. Chelidonium majus. Succus croseus apud Diosc.

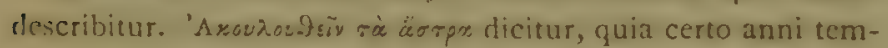
pore floret; sc. adiventu Hirundinis, unde nomen.

Tìv uiv фuбtxì̀, sc. partim naturaliter, partim ex accidente.

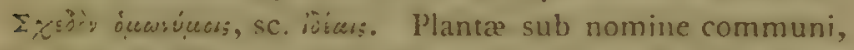
inter se tamen diversa, plus minusve: exemplis Loti Mrliloti, Strychin speciebus. 



\section{$\Theta \mathrm{EO} \Phi \mathrm{PA} \Sigma \mathrm{TO} \Upsilon$}

\section{$\Pi \mathrm{EPI} \Phi \Upsilon \mathrm{T} \Omega \mathrm{N}$ I $\Sigma \mathrm{TOPIA \Sigma}$}

\section{TO $\mathrm{H}^{\prime}$.}

\section{CAP. I.}

Frumentacea et Leguminosa: Tempora Sutionis.

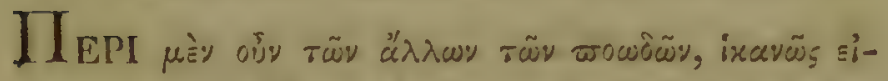

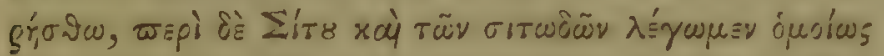

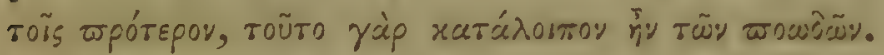

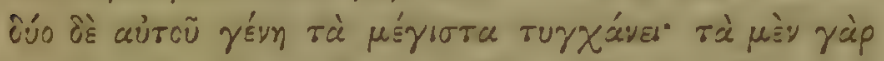

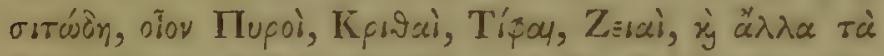

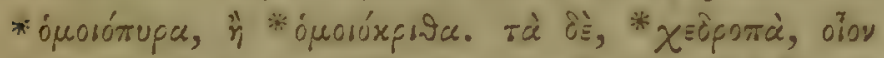

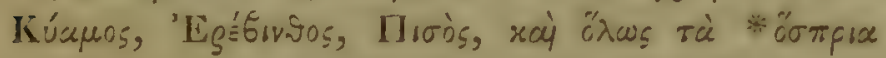

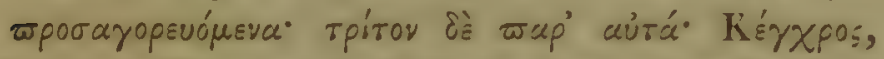

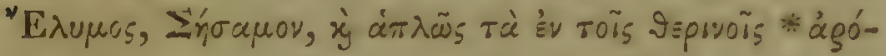

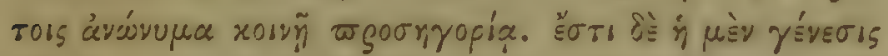

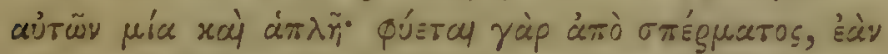

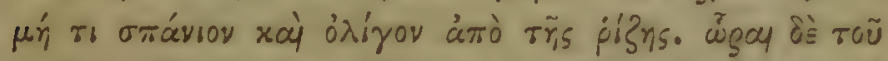

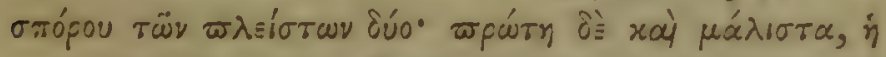

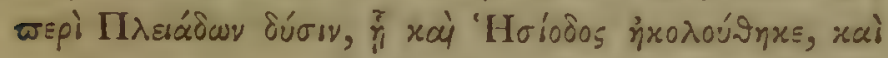
$\sigma \chi £ \delta$ oे

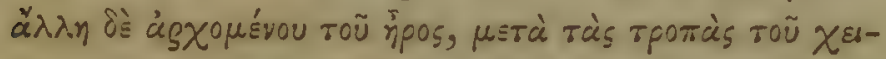

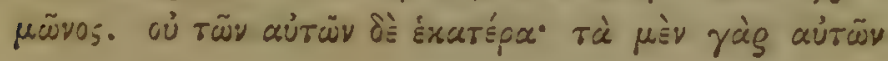




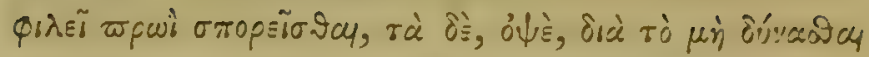

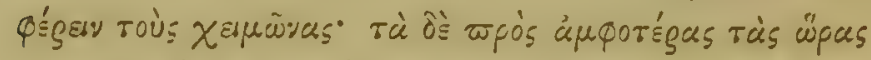

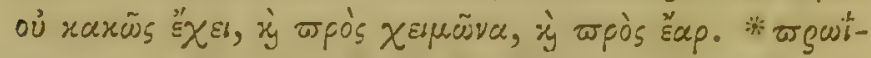

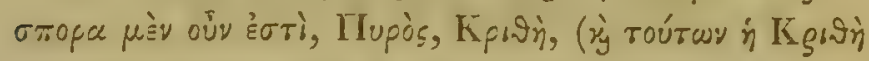

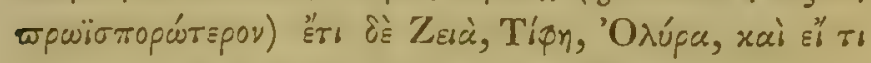

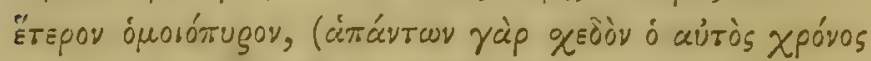

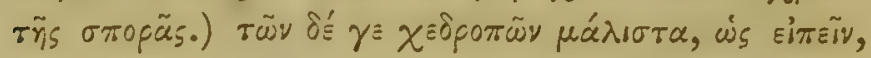

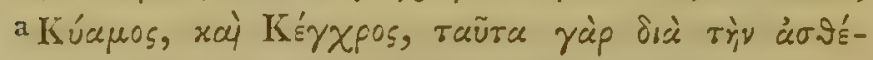
y

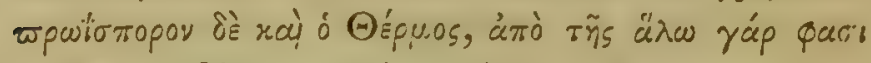

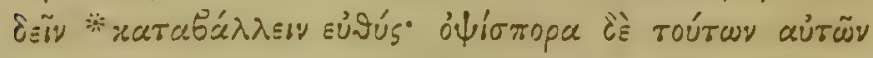

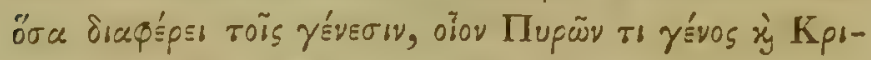

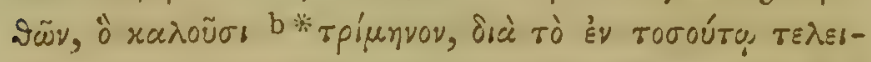

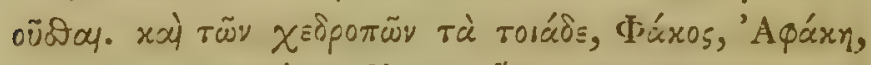

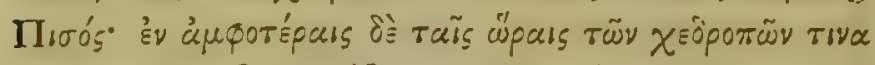

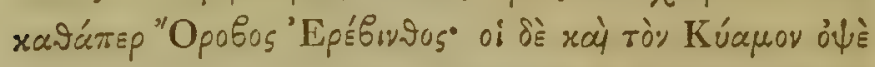

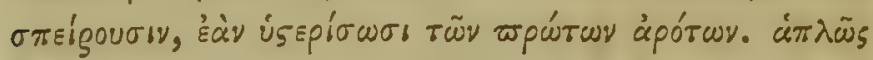

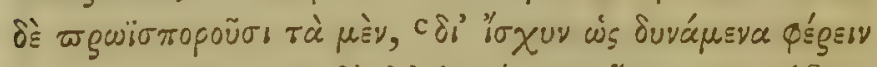

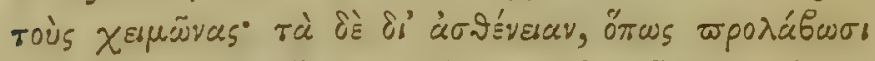

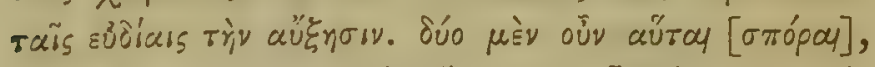

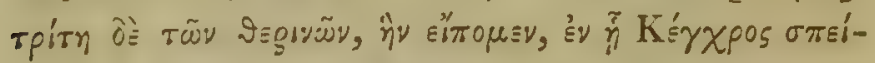

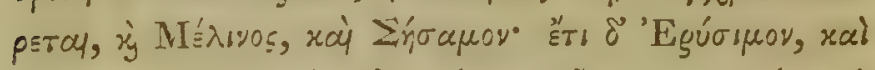

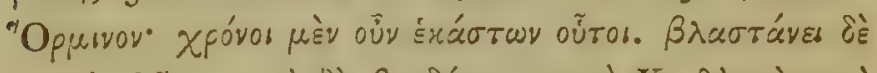

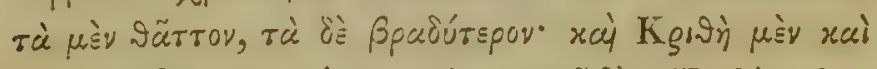

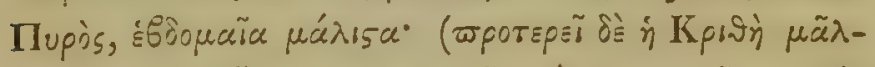

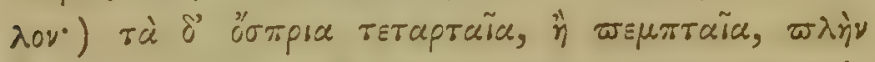

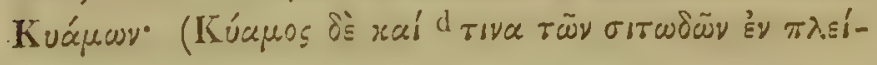

a xúapes rai ráaveos. Const. b ręiravov, Bod. e dioxuy Bod. a ruve deest Codd. 


\section{MEPI TMT $\Omega N$ ISTOPIAS TO H'. 323}

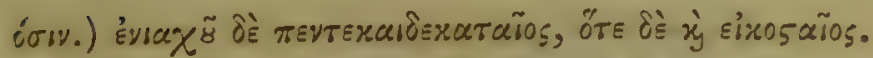

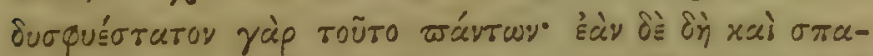

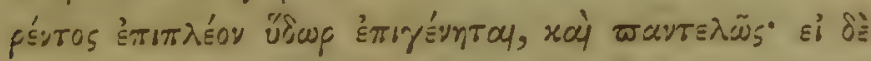

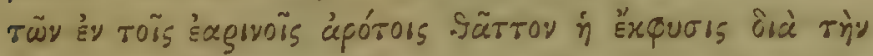

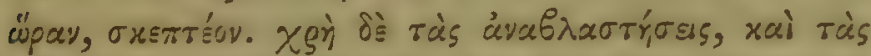

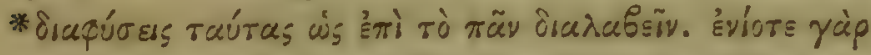

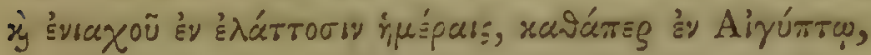

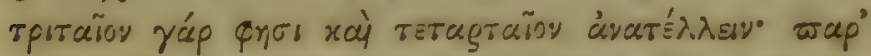

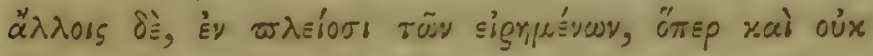

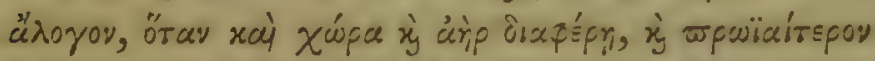

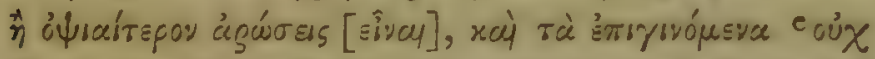

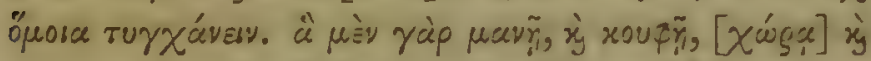

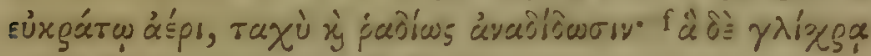

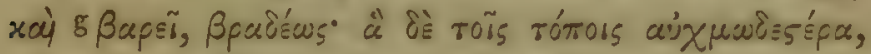

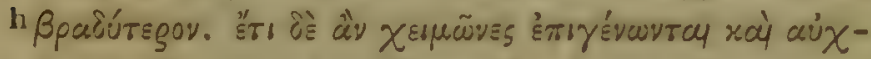

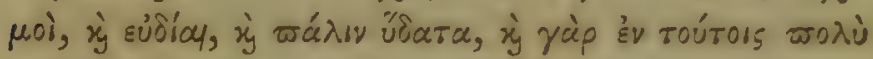

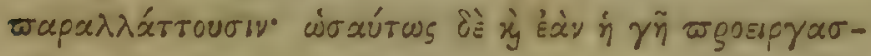

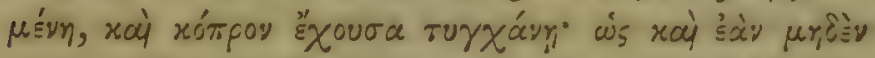

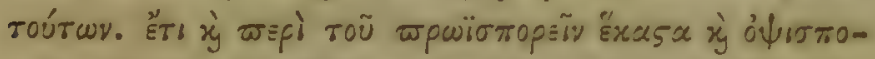

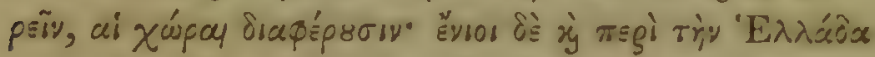

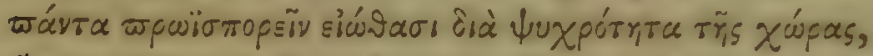

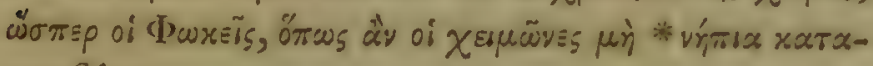

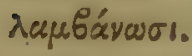

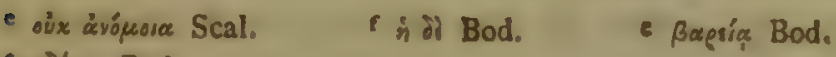

b Bgerodias. Bod.

PLISII.

a 


\section{CAP. II.}

Principia Germinationis in Frumentaccis et Leguminosis, et Tempora germinandi.

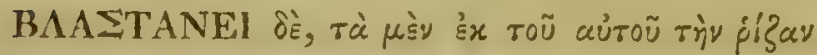

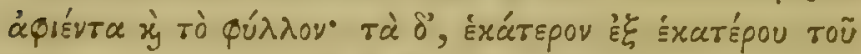

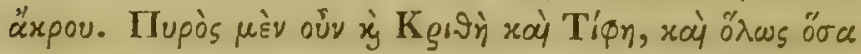

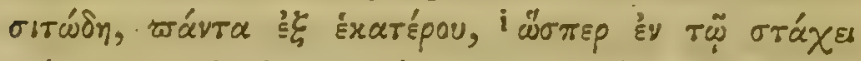

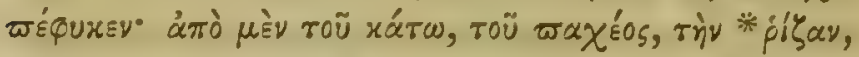

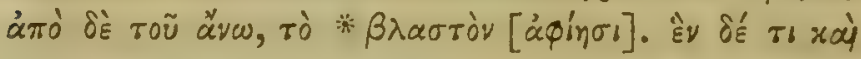

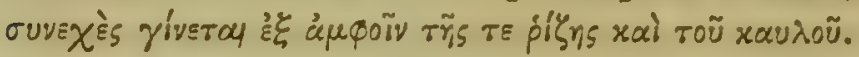

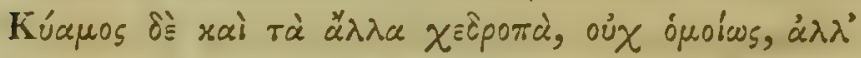

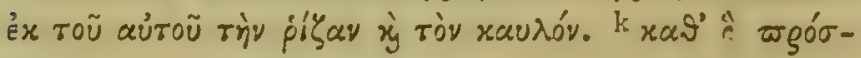

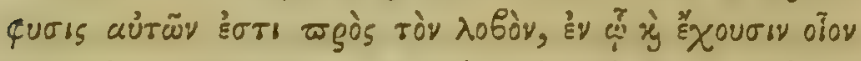

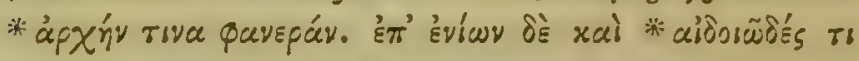

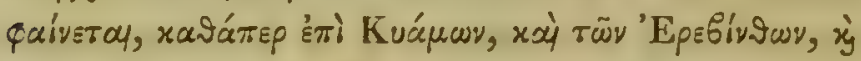

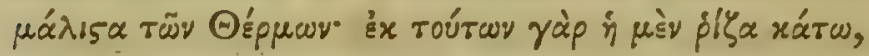
то̀ $\delta$ фú

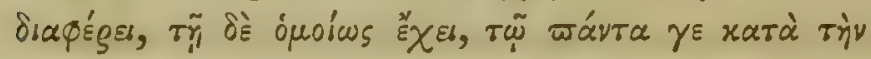

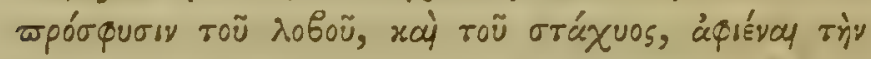

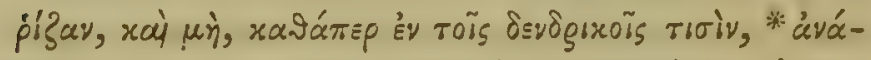

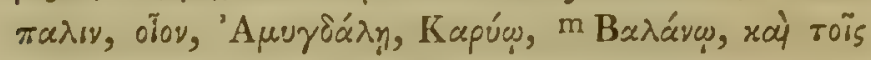

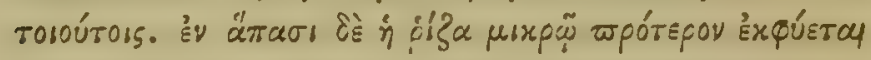

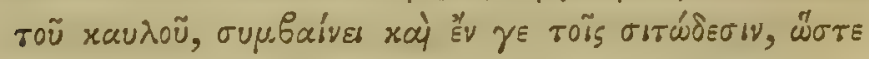

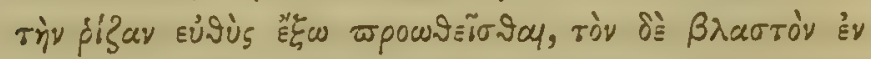

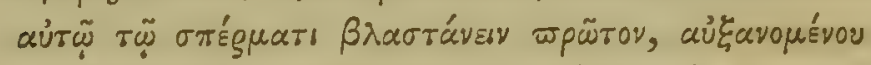

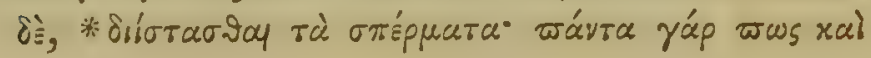

1. ซৈর́yra Bod.

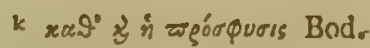

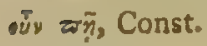

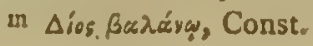

1 pis. 


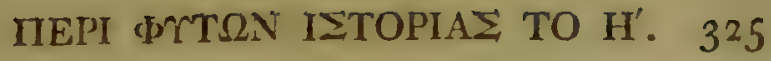

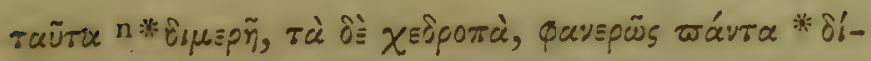

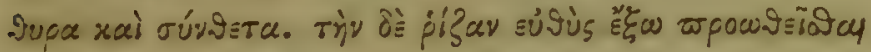

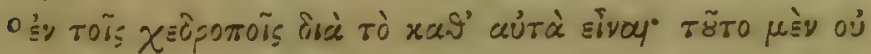

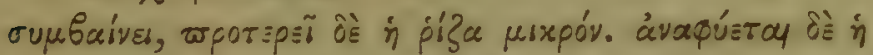

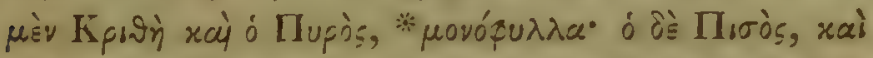

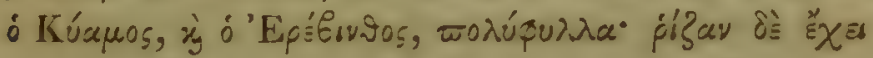

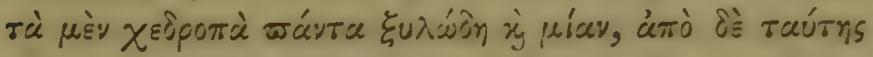

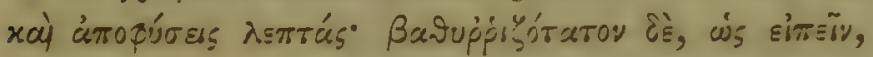

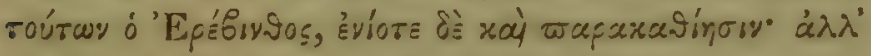

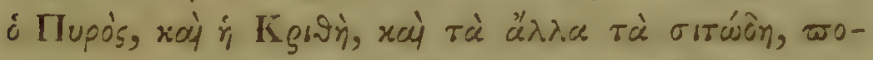

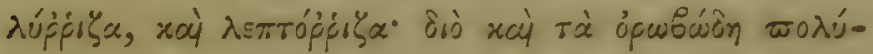

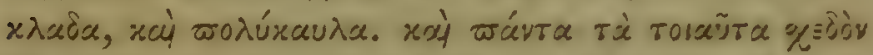

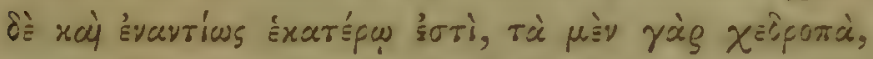

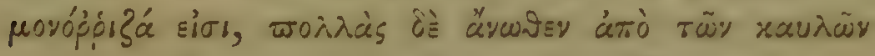

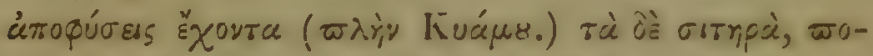

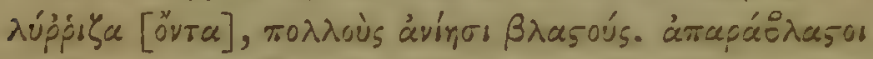

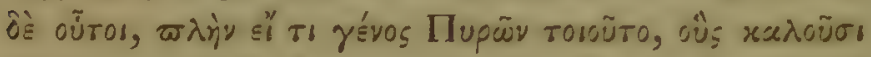

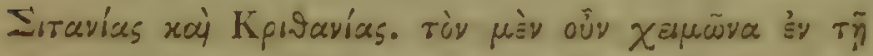

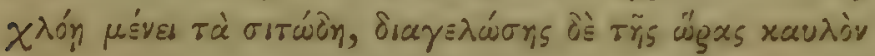

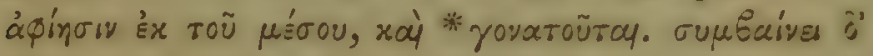

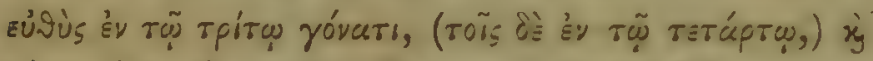

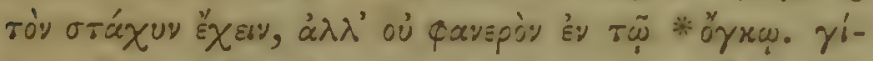

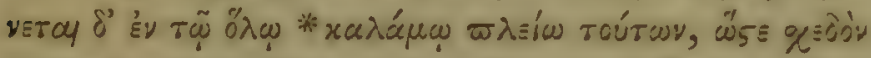

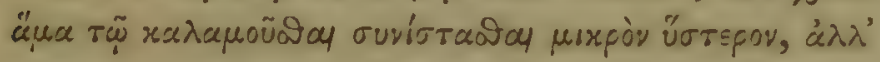

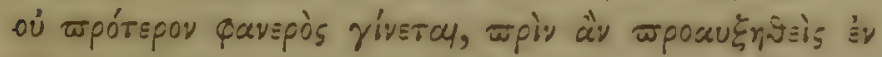

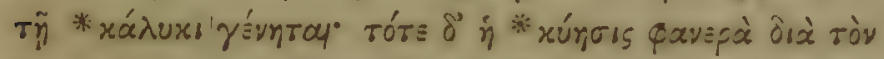

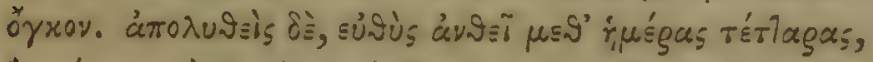

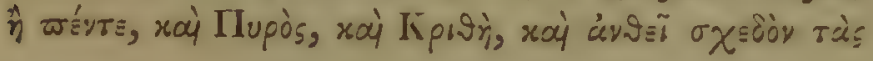

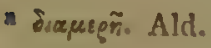

- Vid. not. ad fin. libri.

G 2 


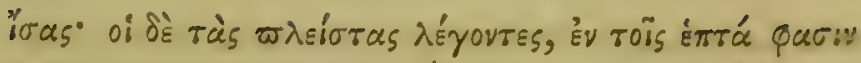

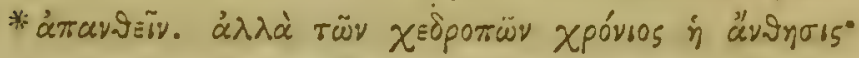

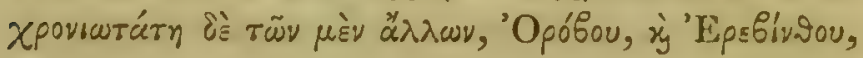

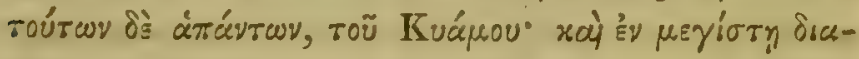

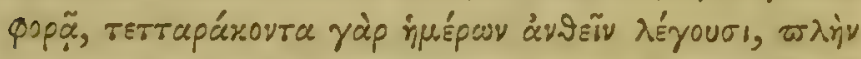

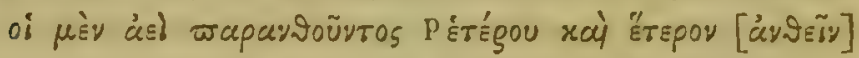

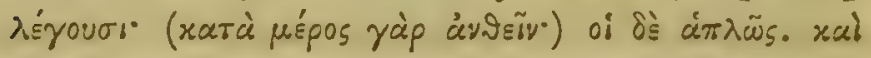

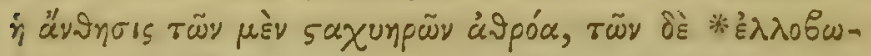

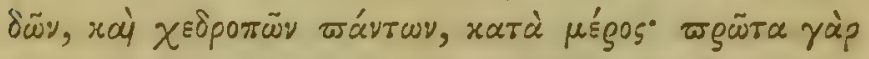

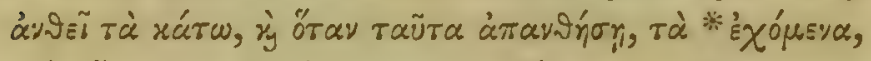

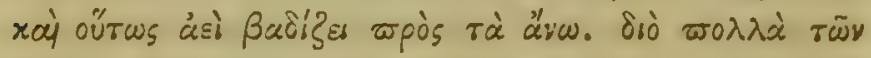

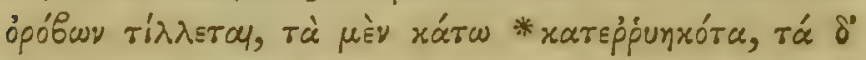

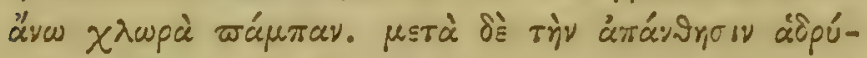

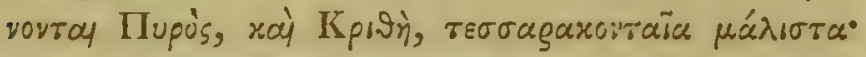

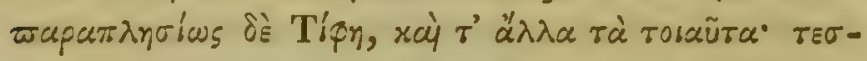

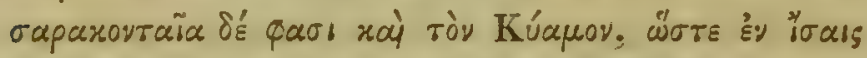

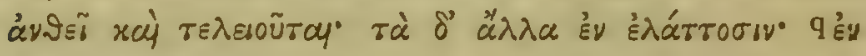

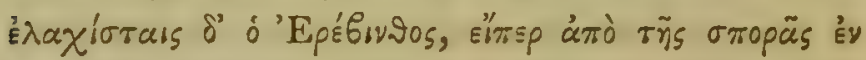

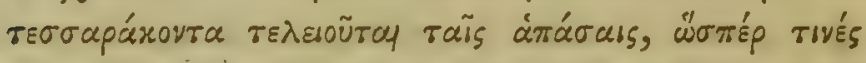

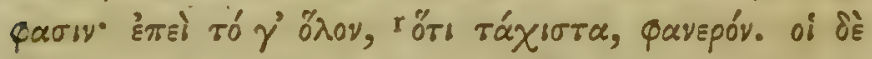

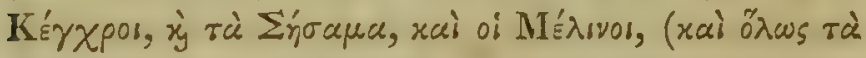

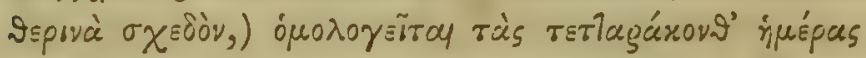

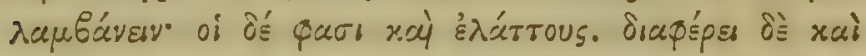

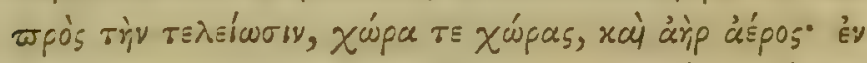

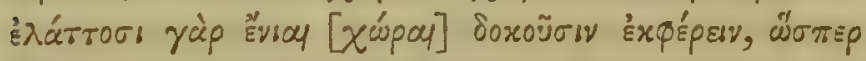

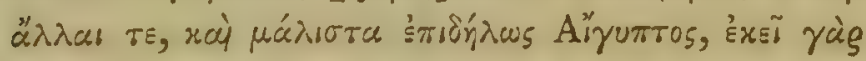

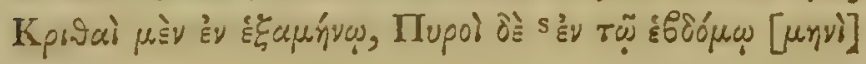

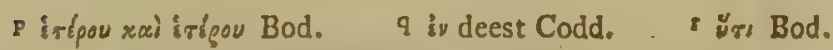

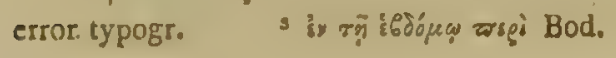




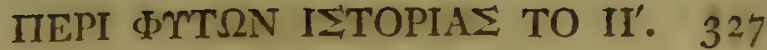

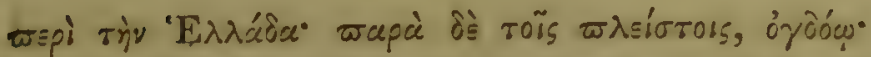

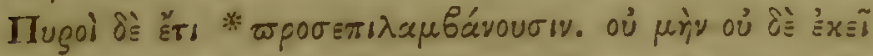

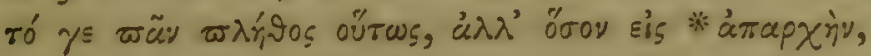

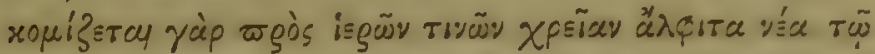

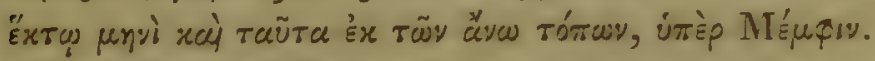

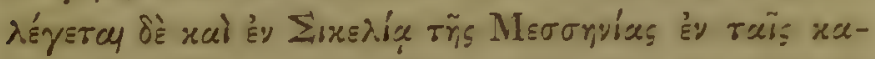

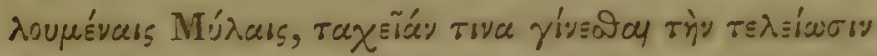

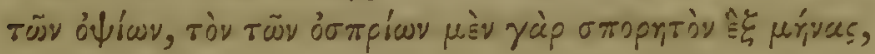

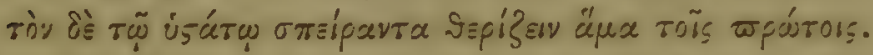

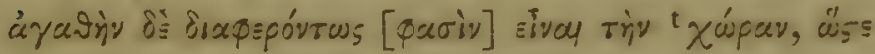

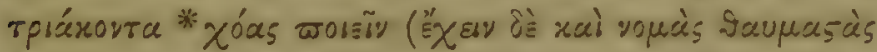

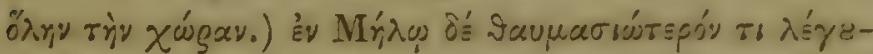

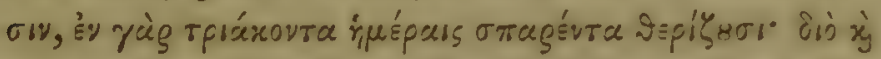

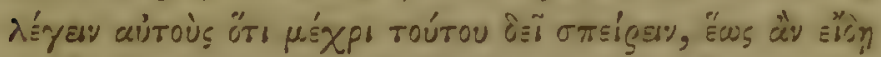

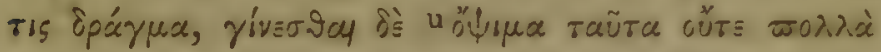

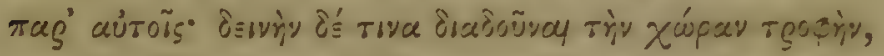

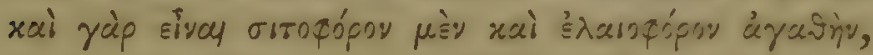

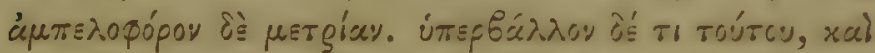

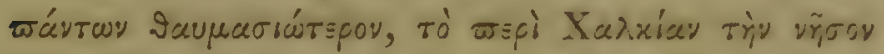

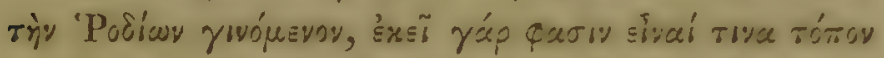

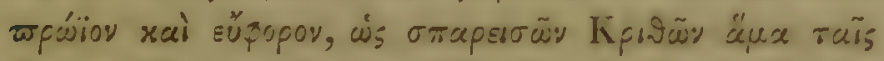

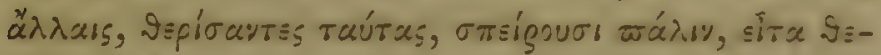

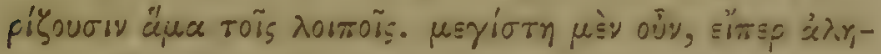

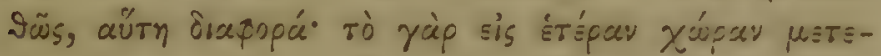

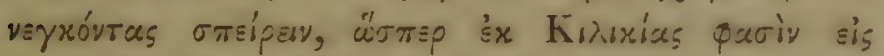

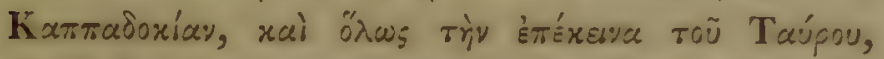

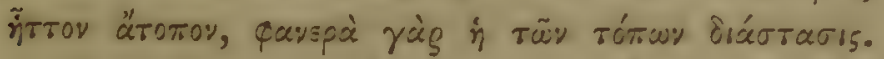

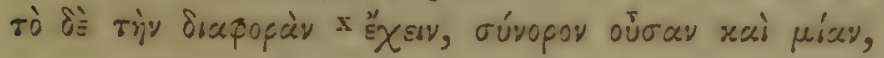

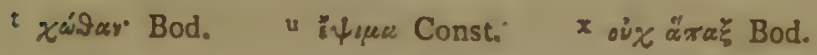

G 3 


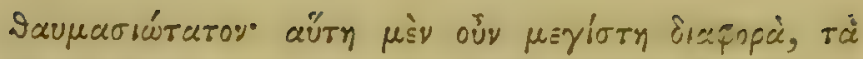

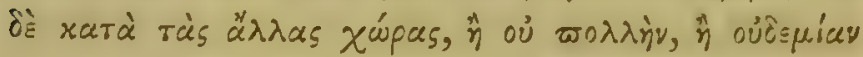

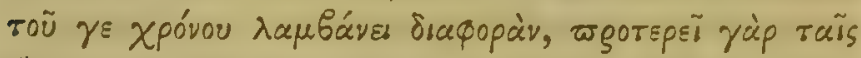

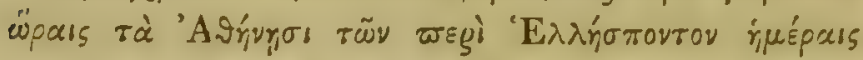

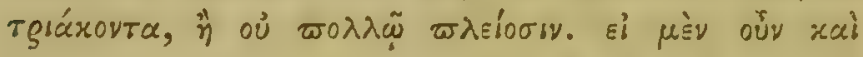

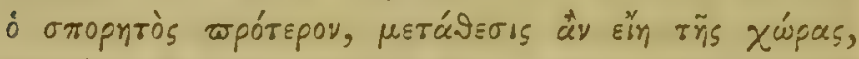

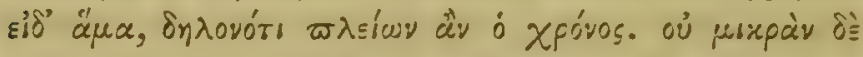

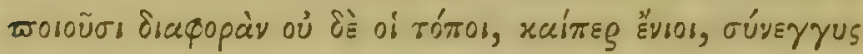

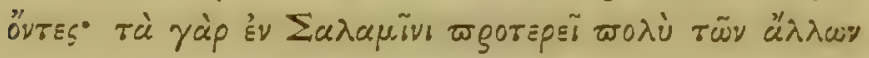

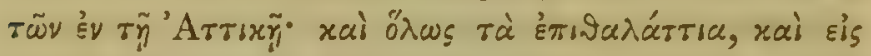

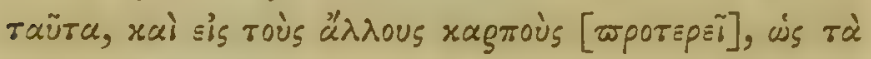

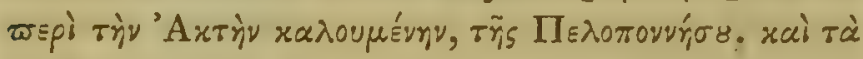

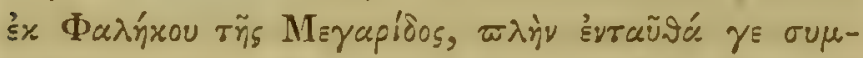

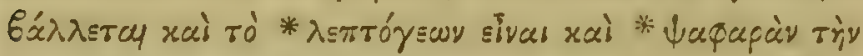

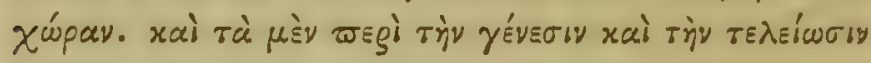

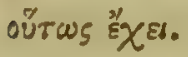

\section{CAP. III.}

Differentic Generum in Frumentaceis.

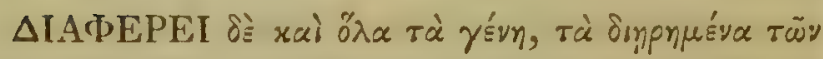

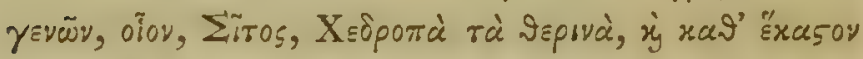

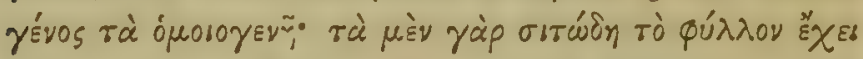

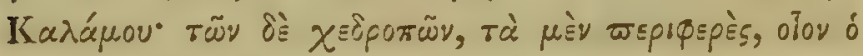

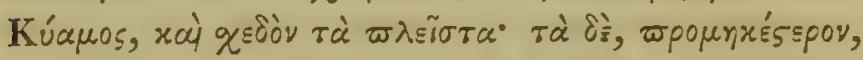

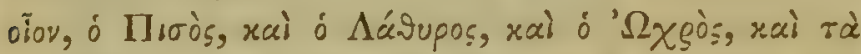

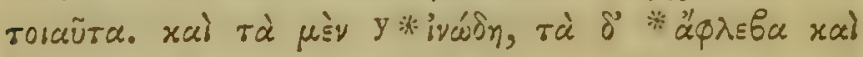

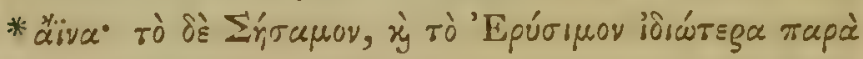

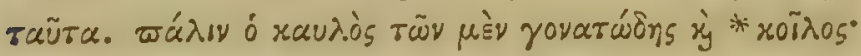




\section{MEPI $\Phi M T \Omega N$ ISTOPIA TO HO 329}

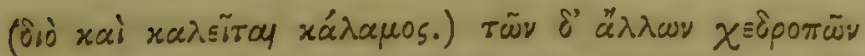
छัय

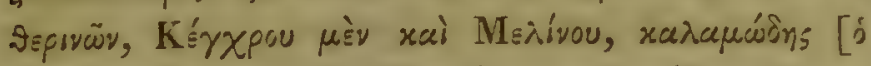

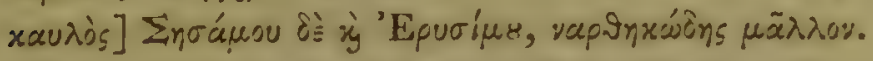

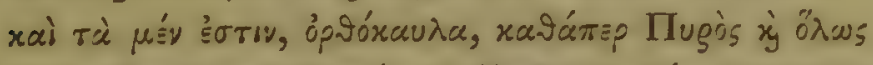

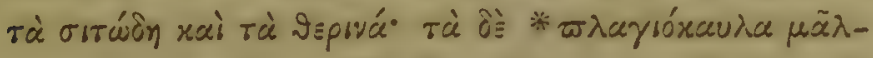

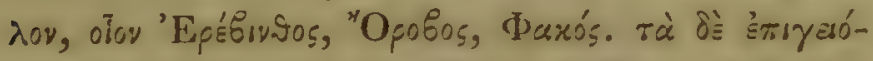

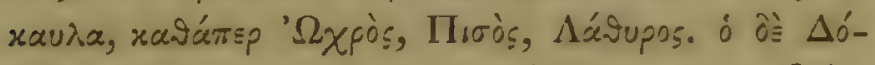

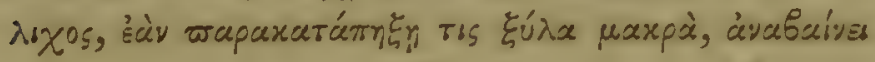

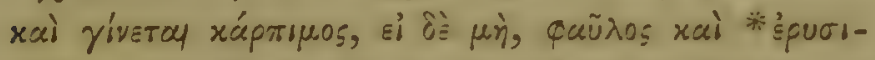

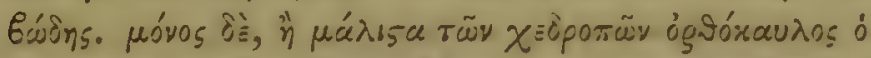

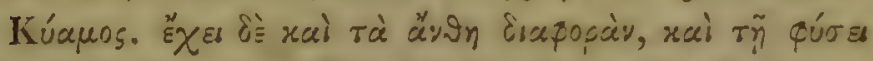

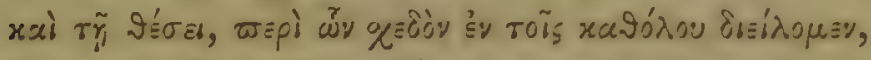

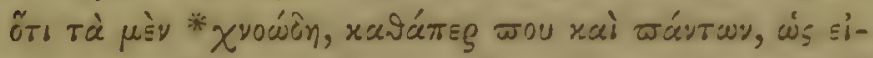

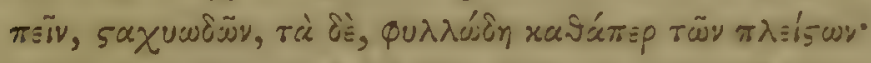

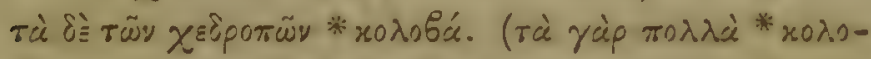

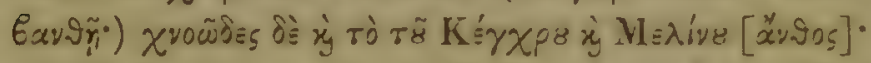

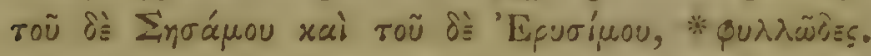
xaे है

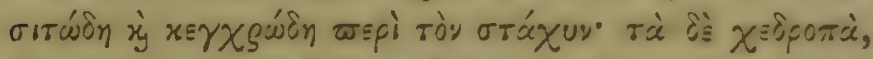
ह̇

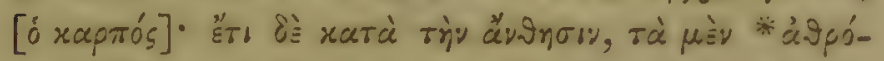

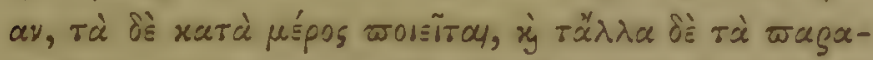

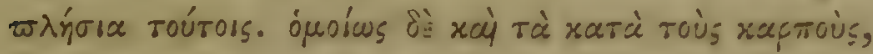

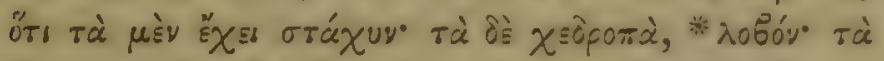

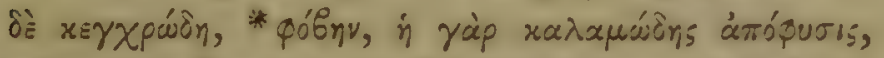

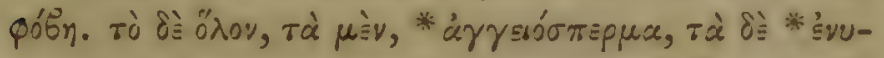

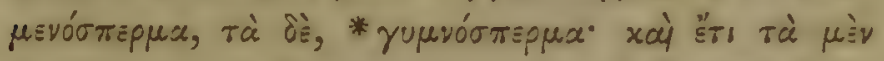

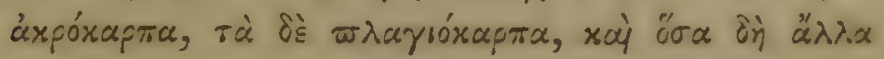

G 4 


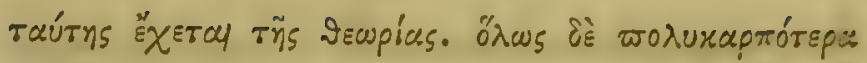

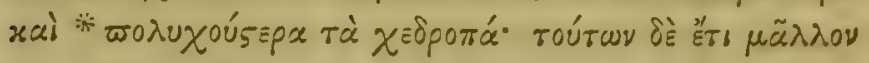

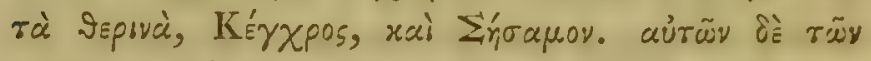

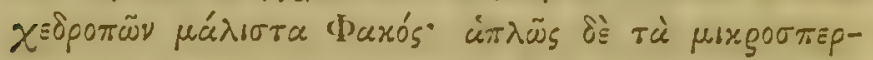

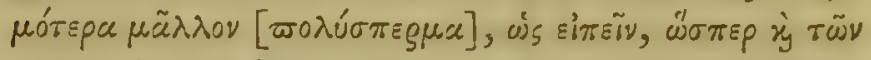

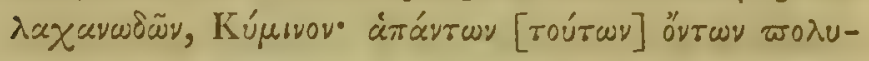

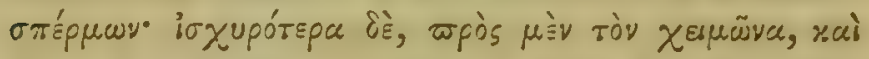

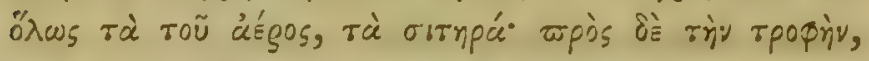

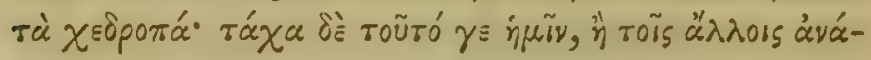
$\pi \alpha \lambda$ \%.

\section{CAP. IV.}

Differentice Specierum.

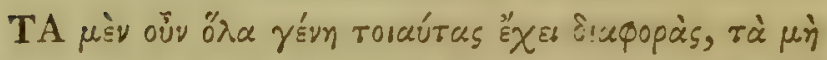

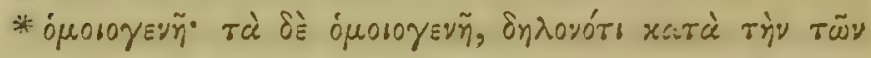

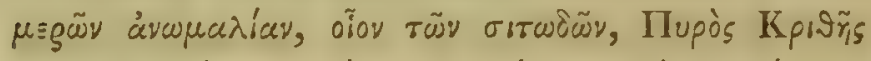

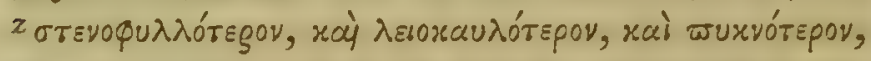

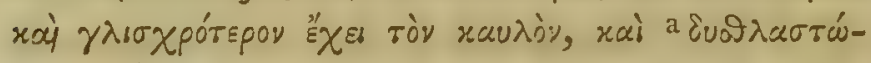

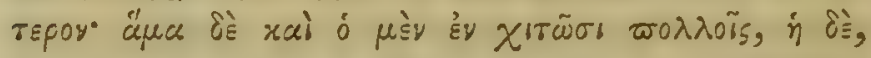

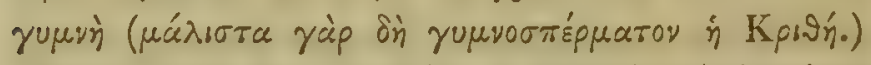

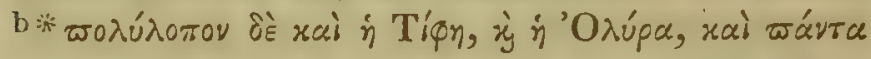

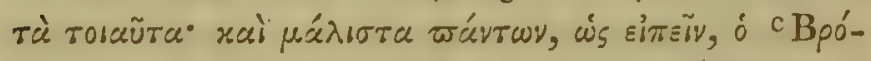

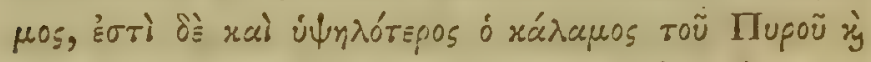

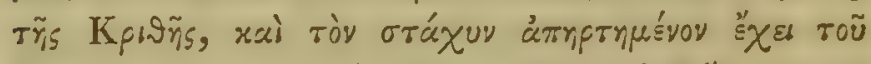

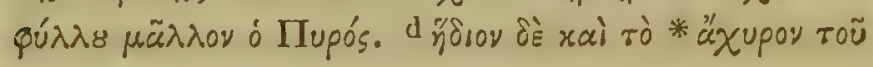

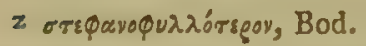

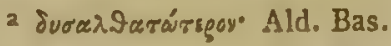
b zoגúrobay Bod.

c Kéóxos. Ald. Bas.

d Joov Ald. Bas. 


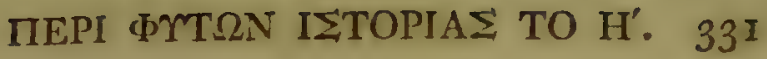

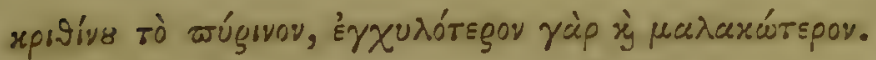

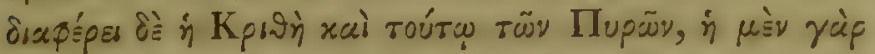

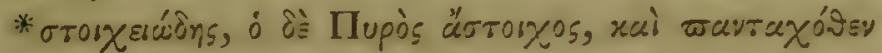

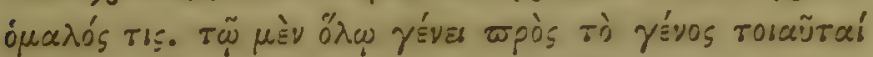

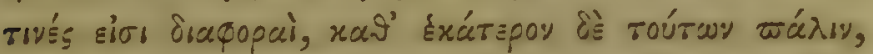

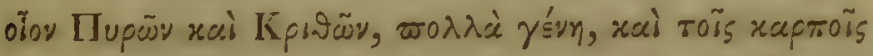

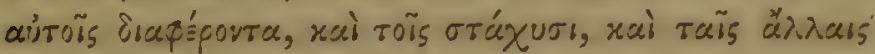

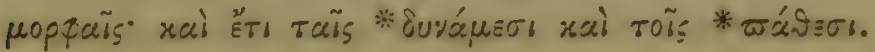

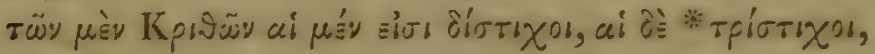

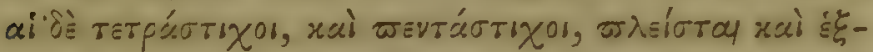

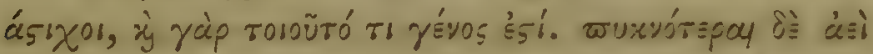

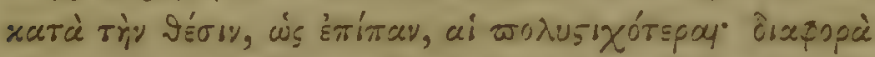

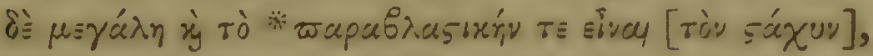

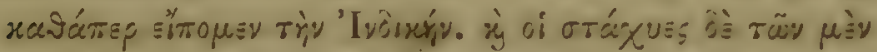

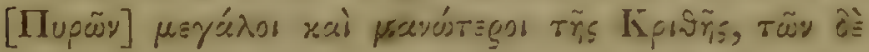

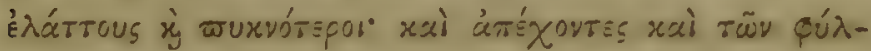

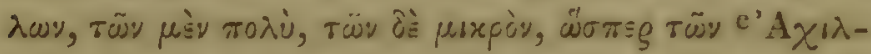

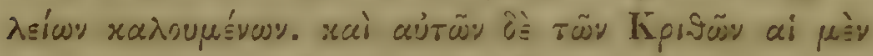

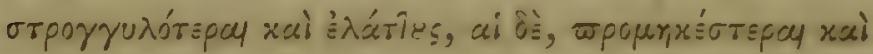

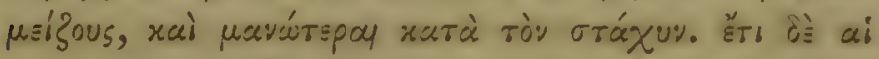

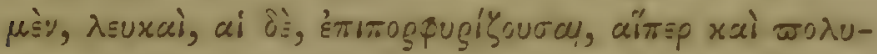

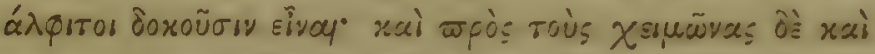

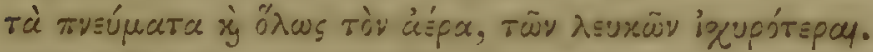

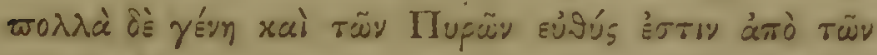

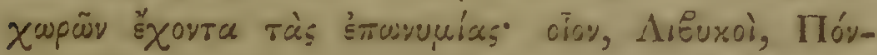

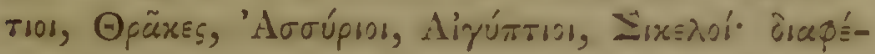

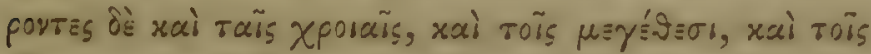

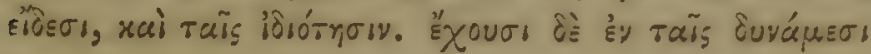

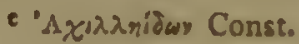




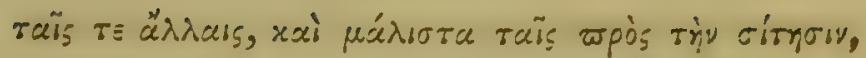

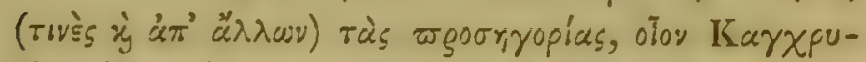

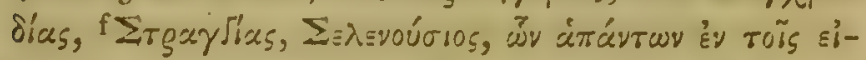

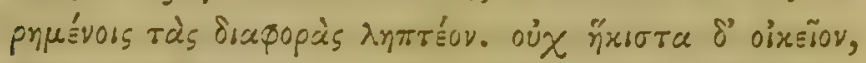

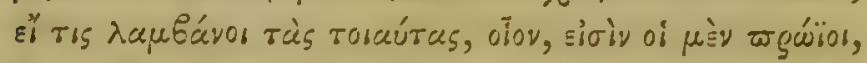

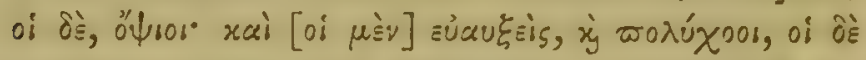

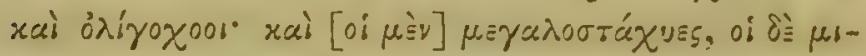

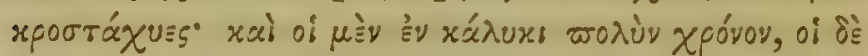

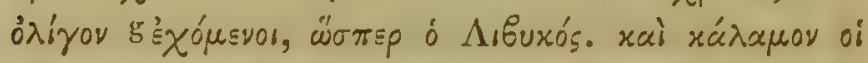

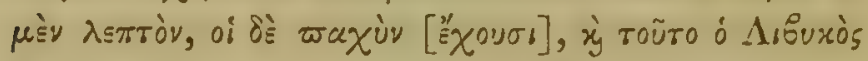

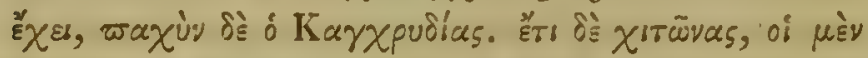

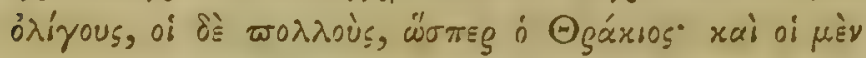

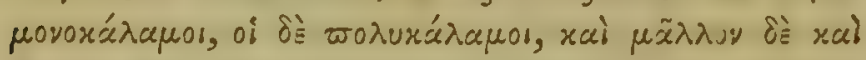

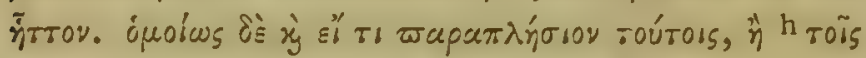

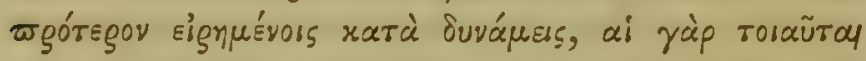

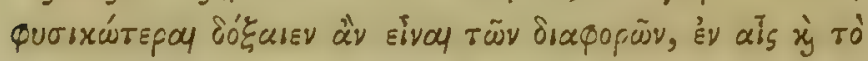

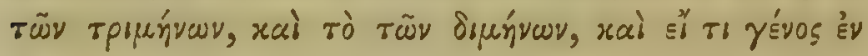

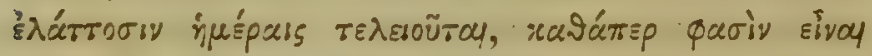

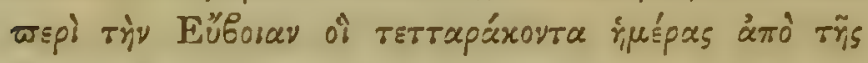

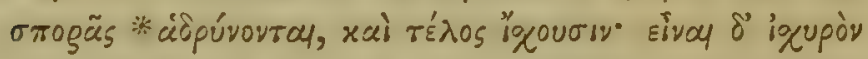

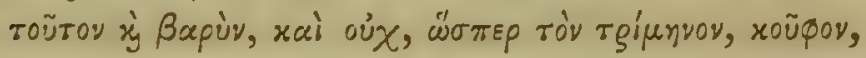

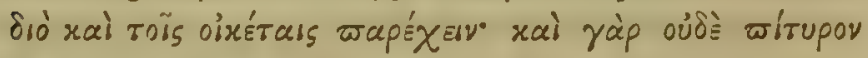

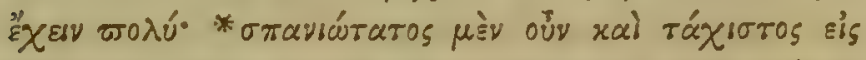

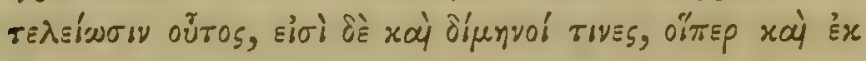

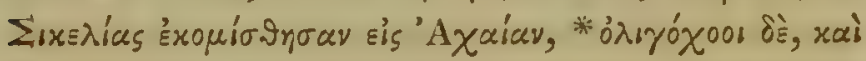

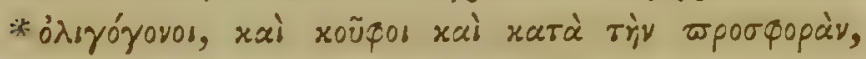

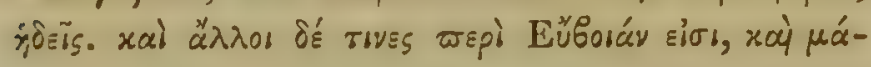

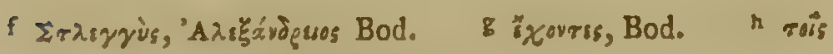
deest Bod. 


\section{MEPI ФTTSN ISTOPIA TO H'. $3: 3$}

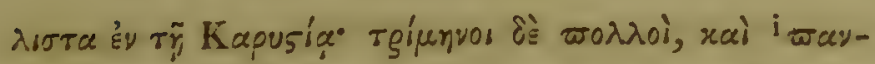

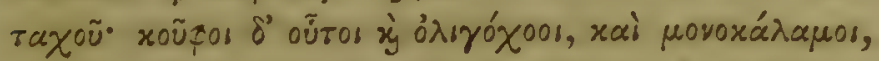

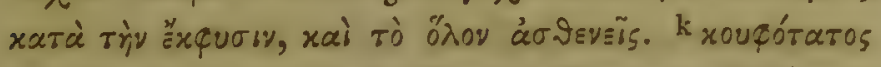

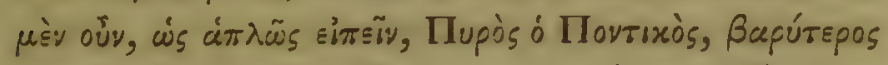

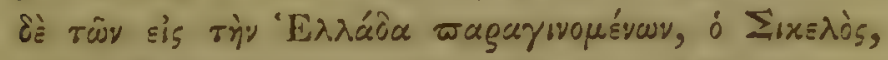

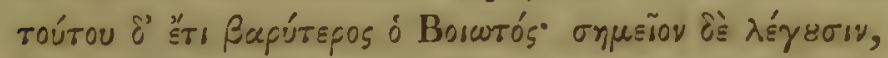

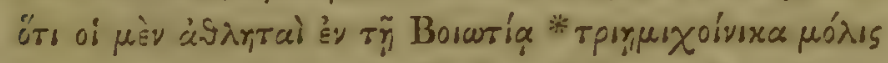

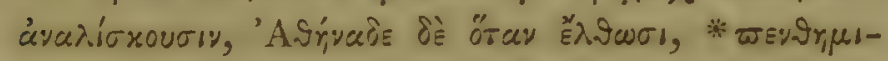

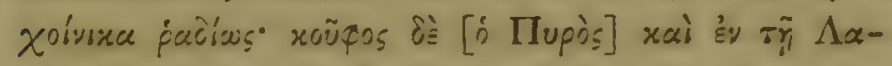

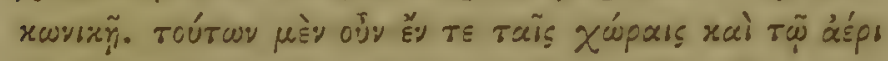

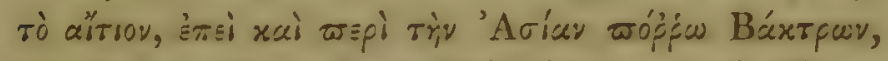

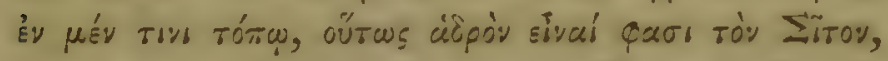

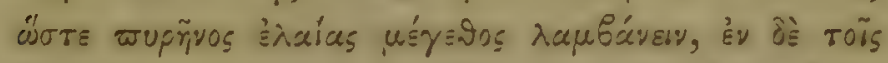

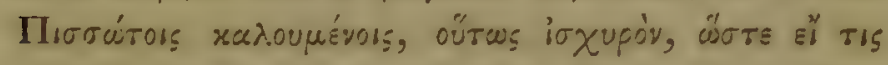

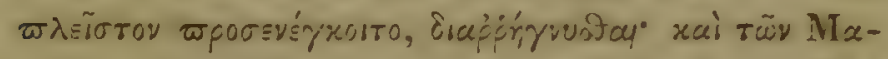

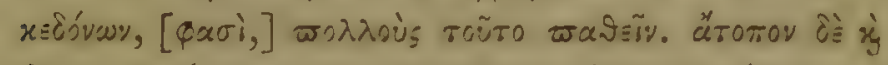

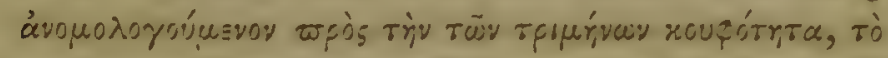

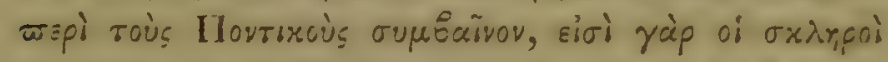

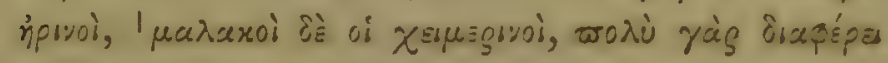

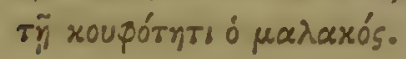

\section{CAP. V.}

Sationes. Differentia in Leguminibus.

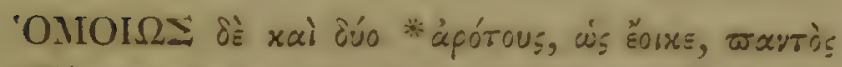

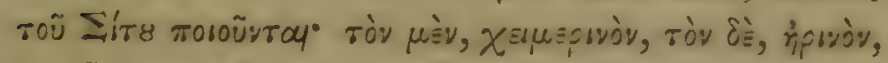

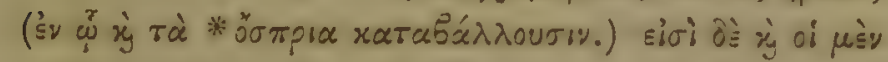

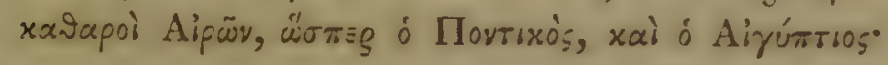

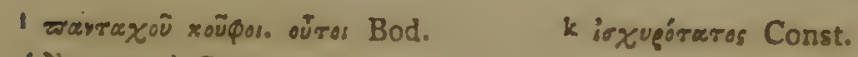
1 oi dì $\mu \alpha \lambda \alpha \times 0)$ Const. 


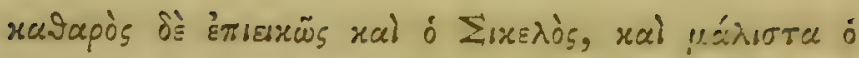

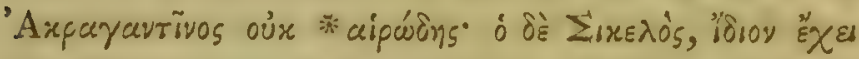

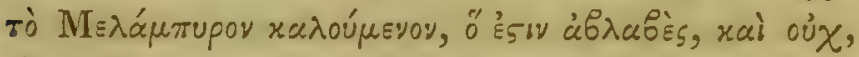

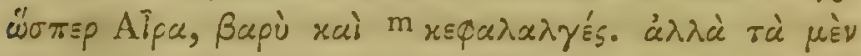

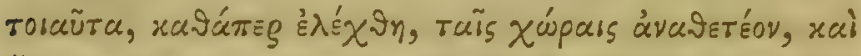

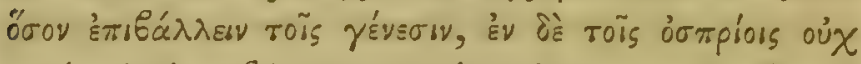

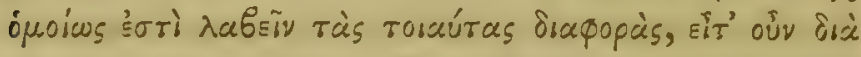

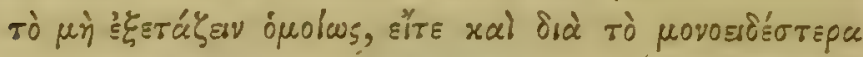

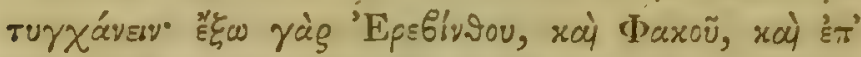

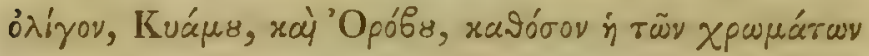

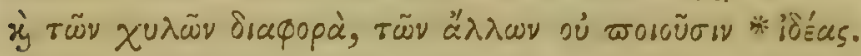

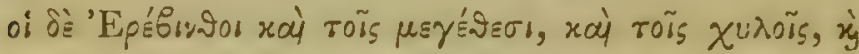

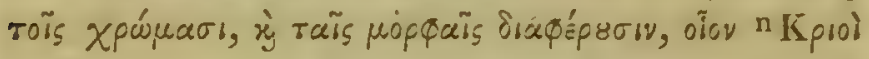

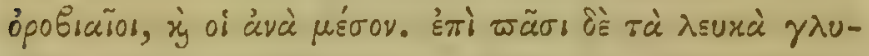

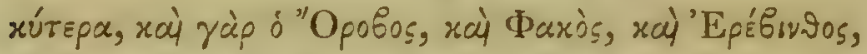

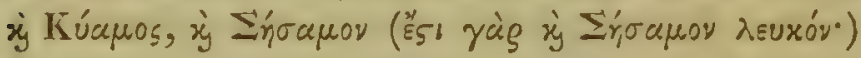

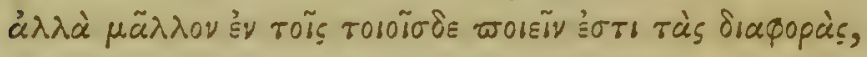

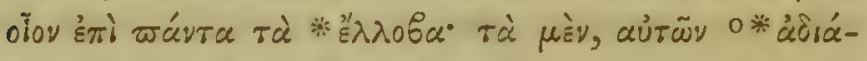

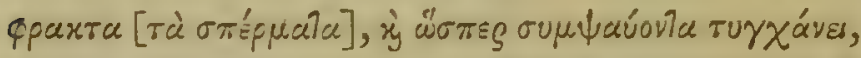

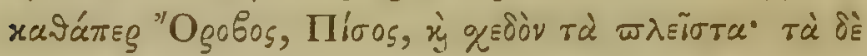

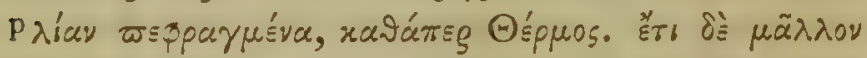

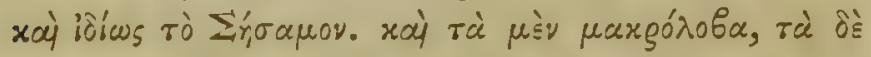

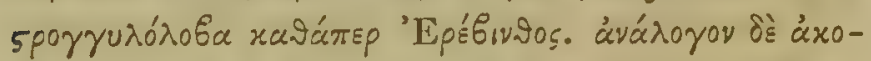

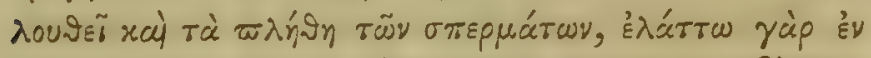

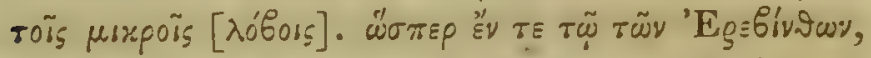

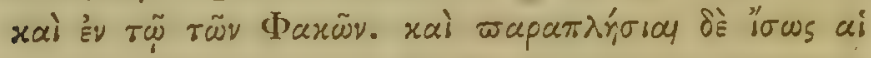

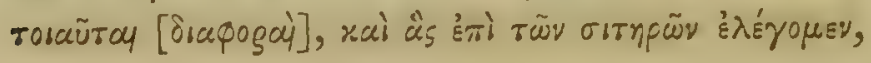

$m$ xsperar yís. Const.

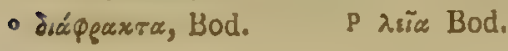




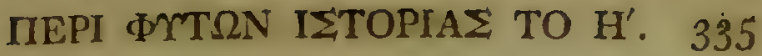

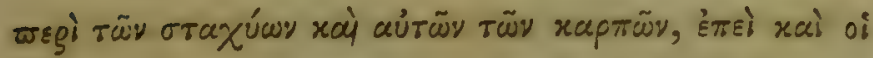

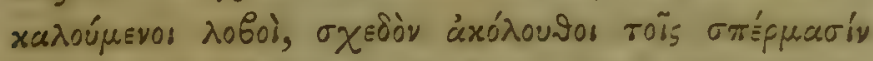

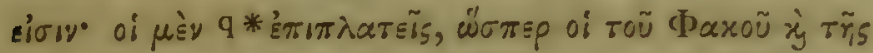

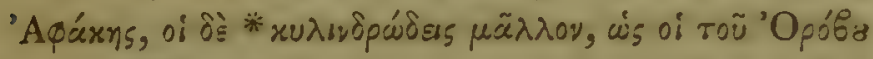

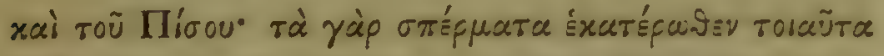

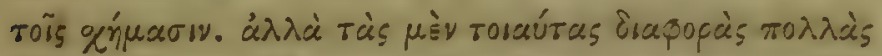

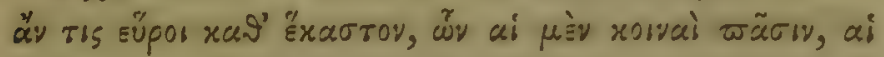

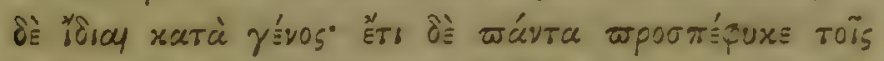

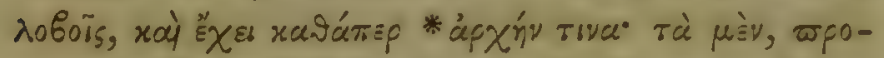

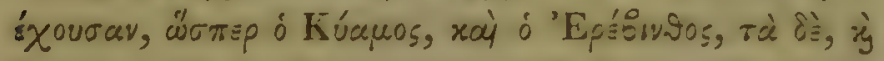

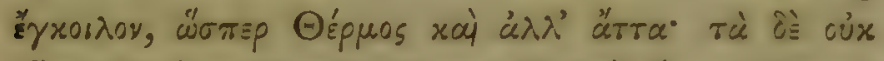

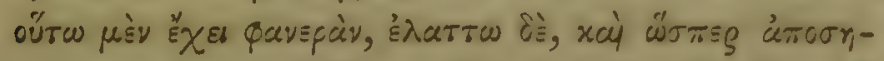

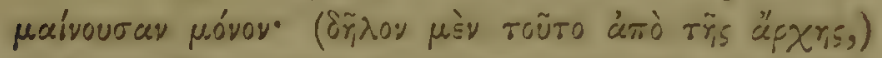

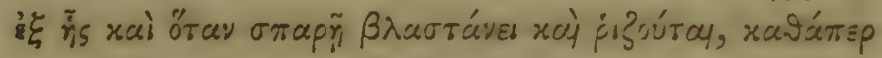

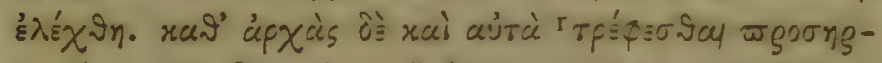

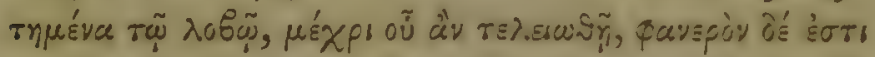

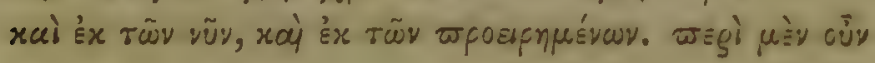

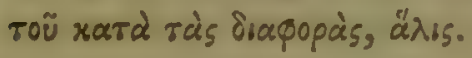

\section{CAP. VI.}

Sutiones. Stercoratio. Qualitates Soli.

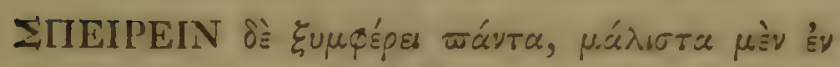

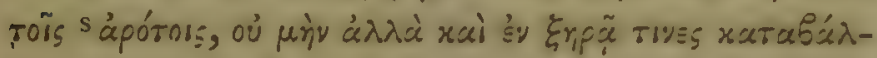

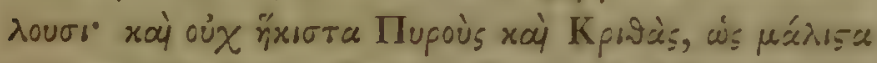

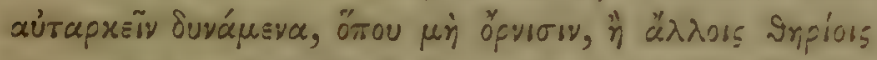

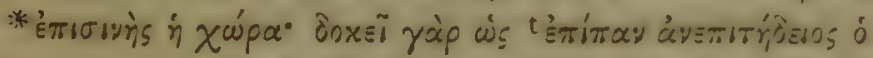

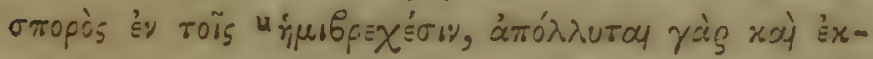

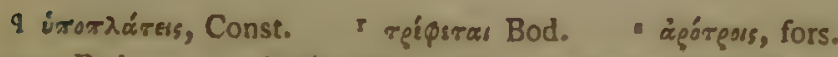

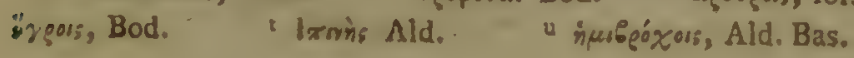




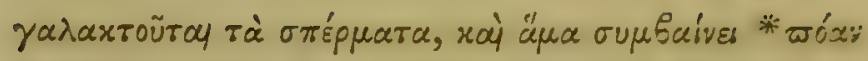

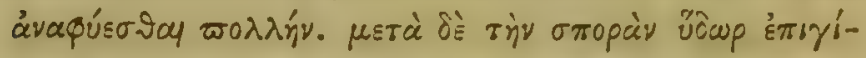

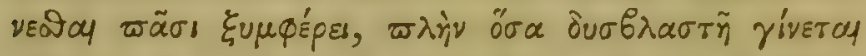

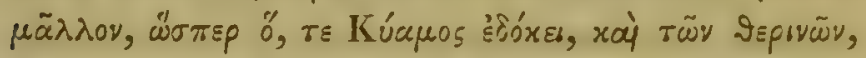

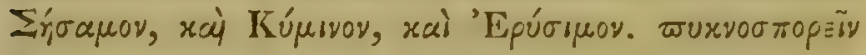

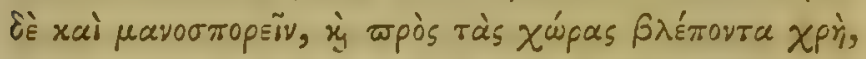

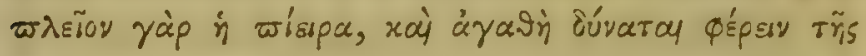

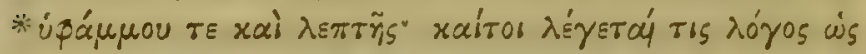

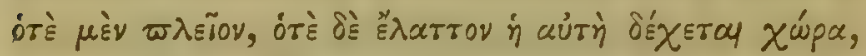

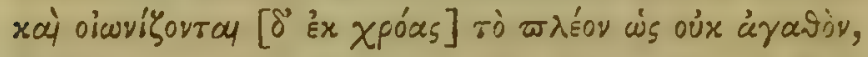

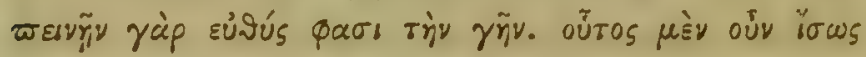

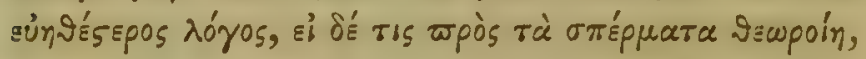

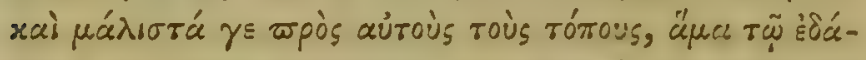

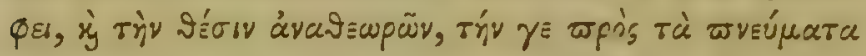

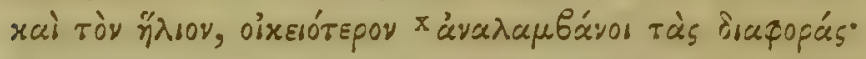

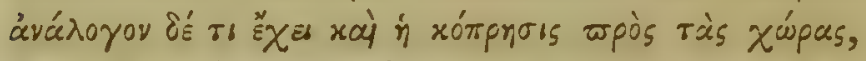

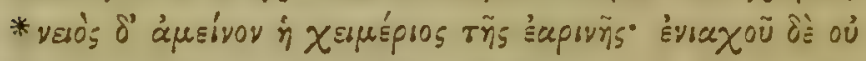

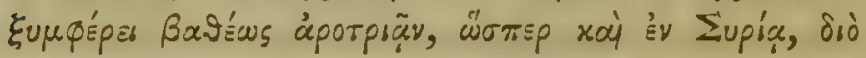

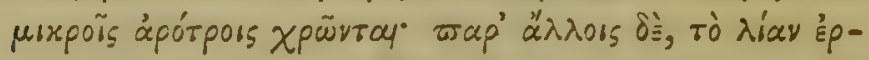

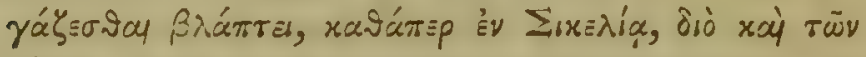

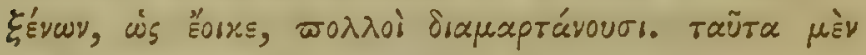

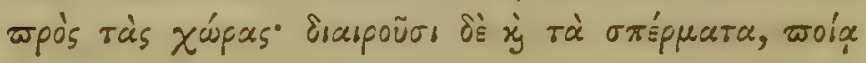

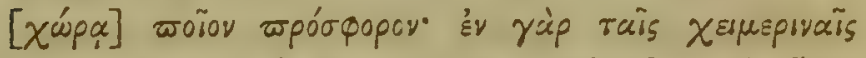

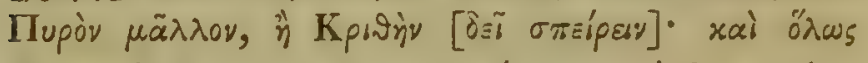

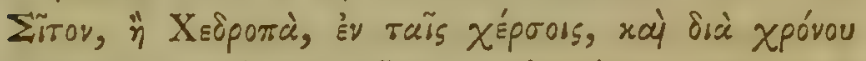

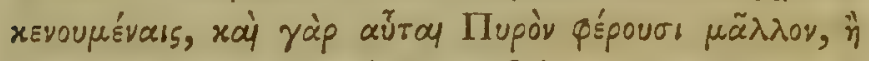

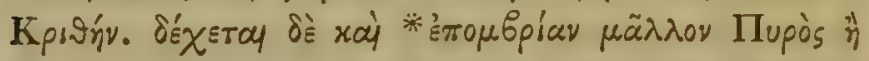

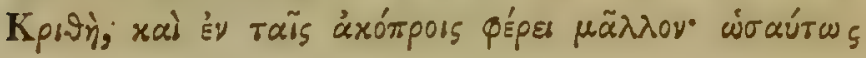

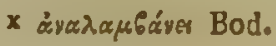




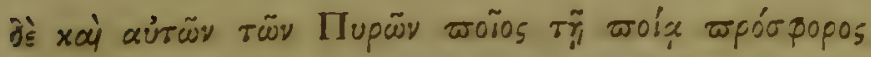

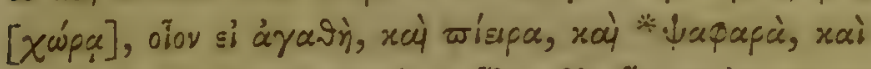

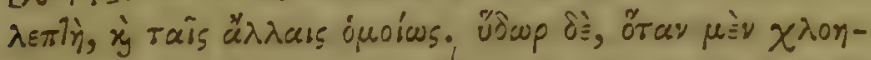

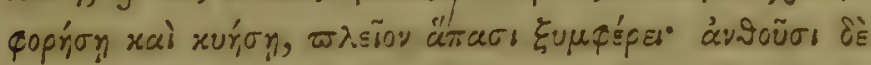

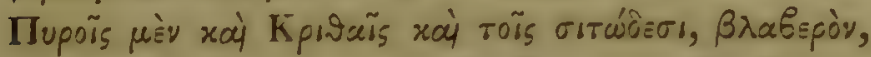

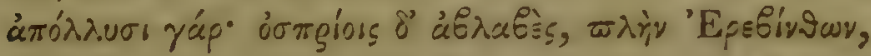
oútos $\delta$ à

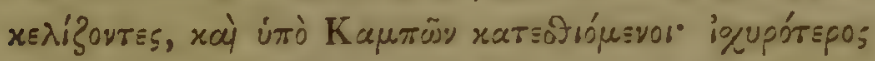

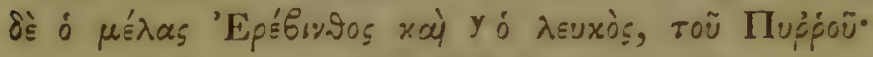

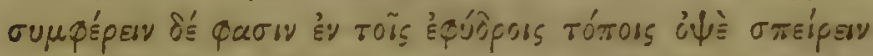

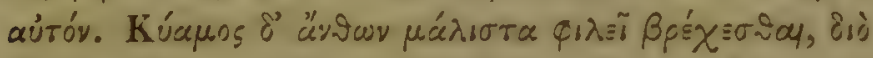

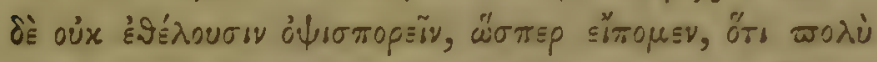

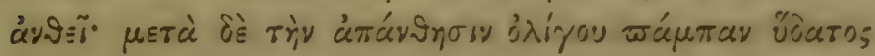

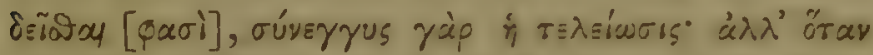

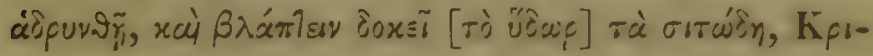

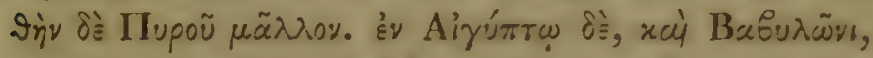

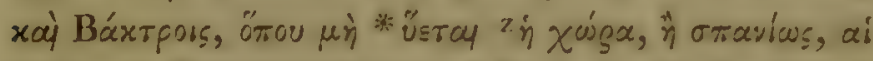

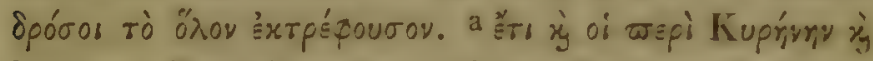

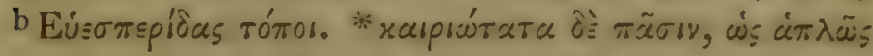

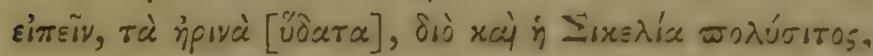

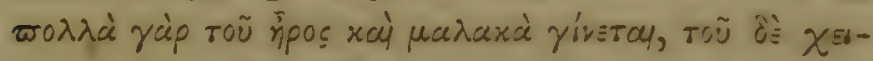

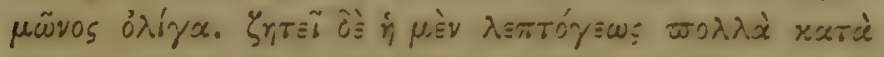

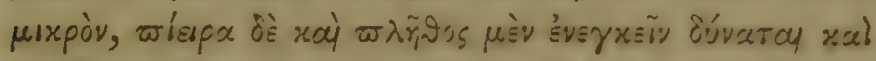

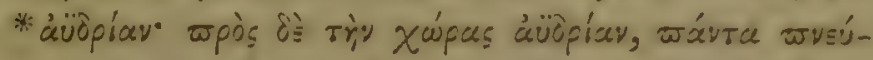

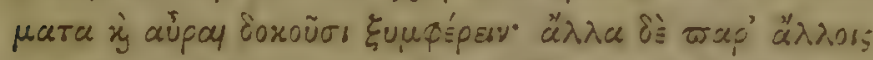

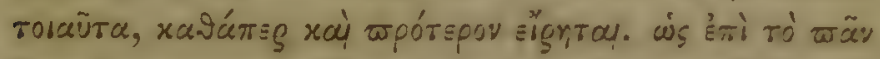

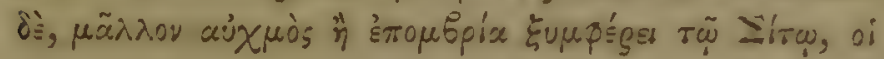

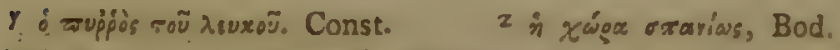
a imsi Bod.
- Evirrstióas Bod. 


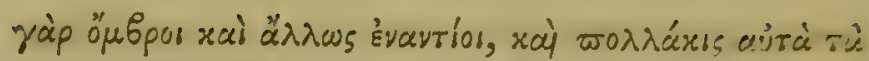

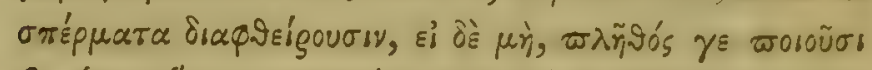

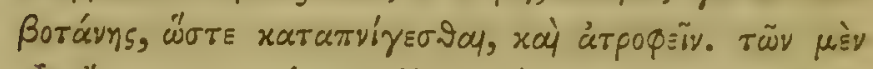

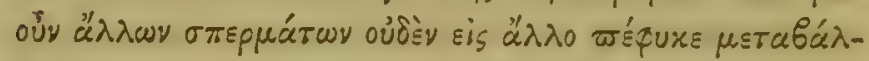

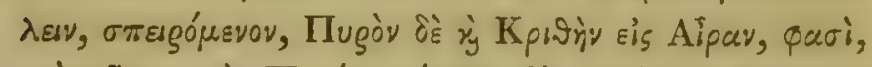

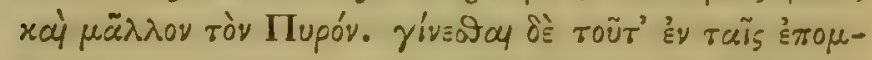

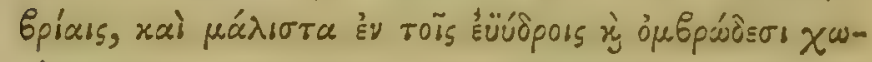
plors.

\section{CAP. VII.}

De Lolio inter Segetes: Culluru et Proprietates

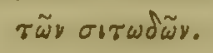

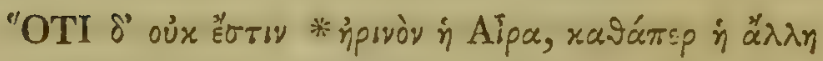

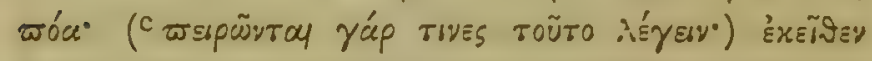

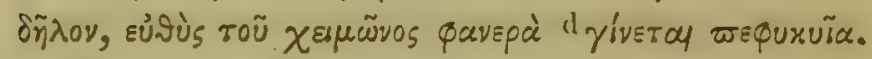

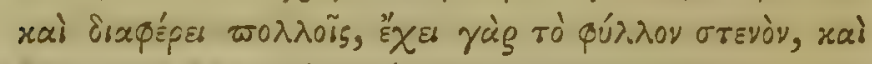

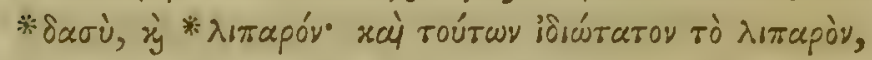

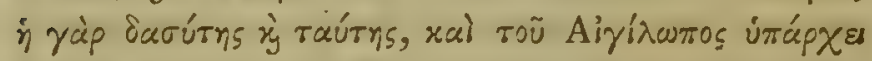

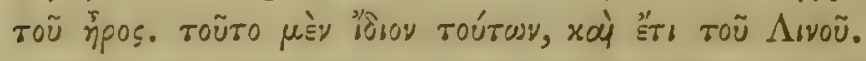

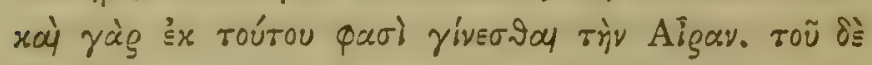

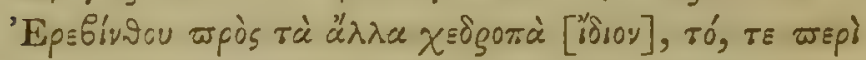

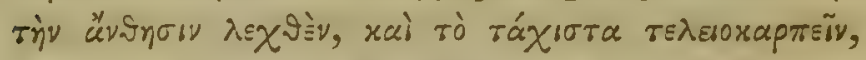

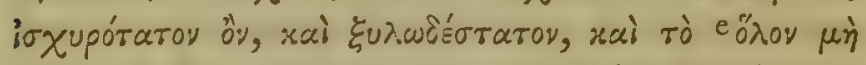

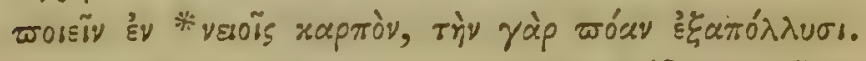

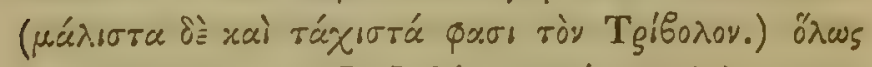

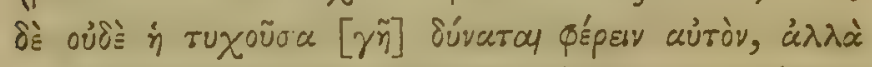

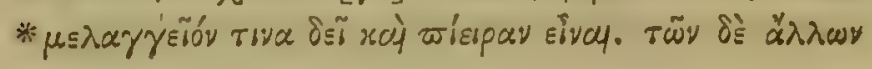

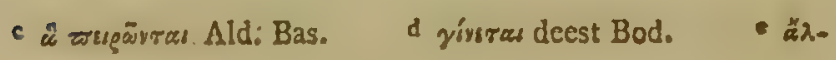
2ov $\mu$ ì Bod. 


\section{MEPI ФYTSN ISTOPIA TO H'. 339}

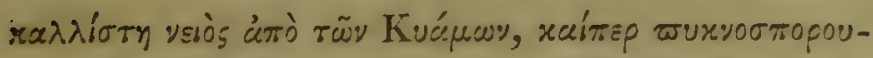

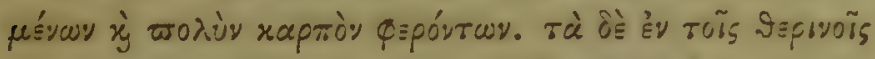

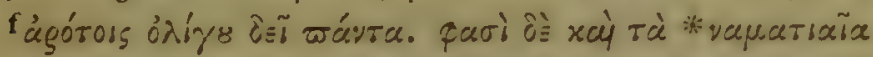

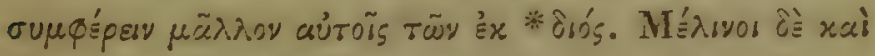

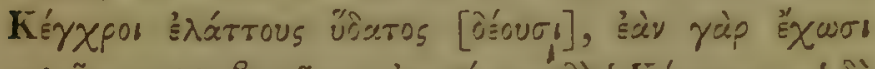

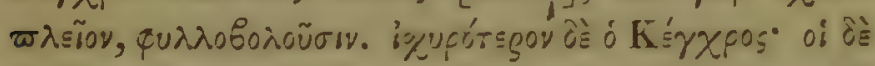

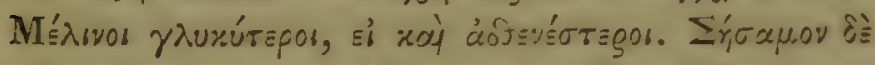

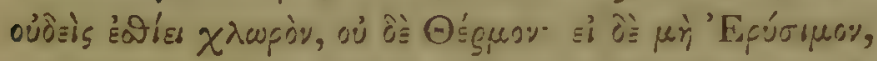

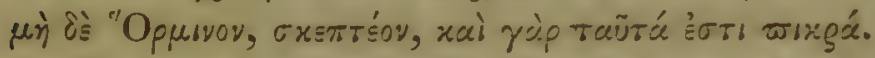

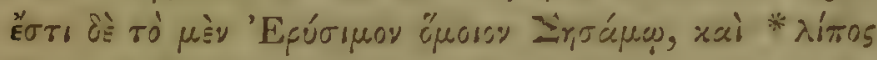

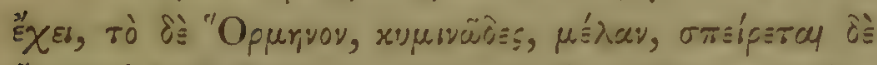

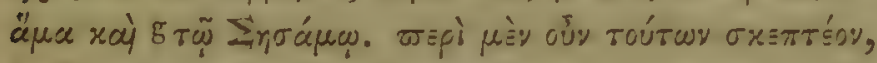

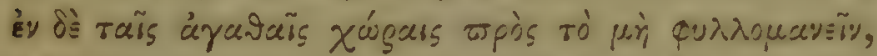

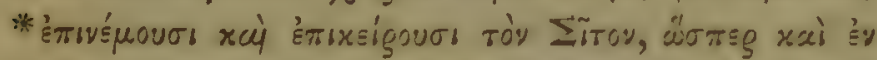

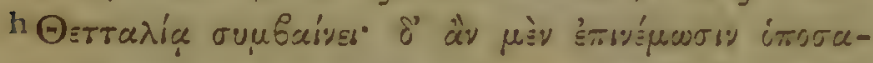

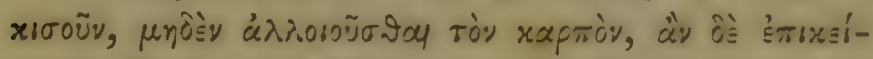

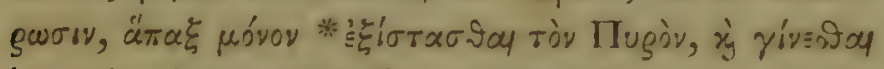

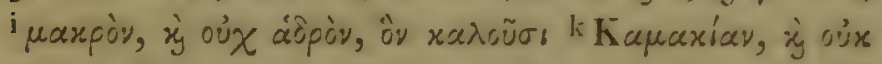

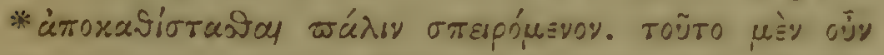

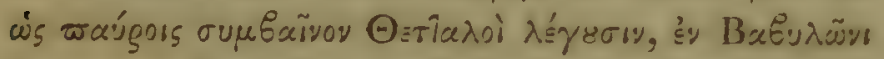

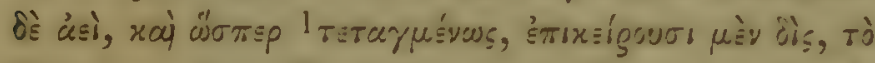

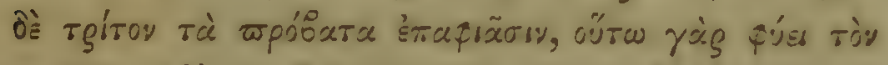

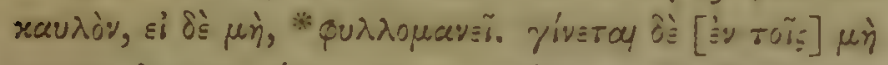

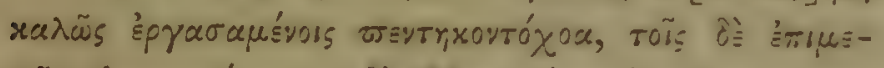

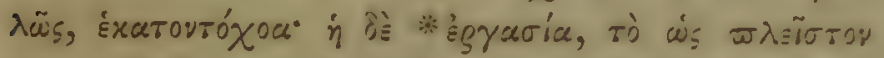

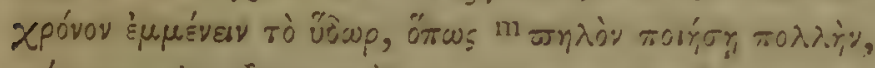

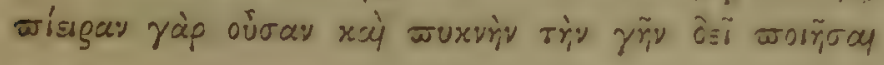
5 ąórẹous Bod.

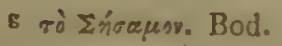
soítsas ouplaives, Const.
1 rвтаредиws, Ald. Bas.

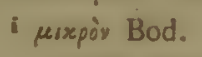
h Osтraxía m घंतy Bod.

PARSII. 


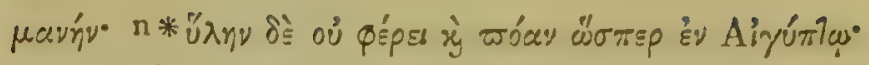

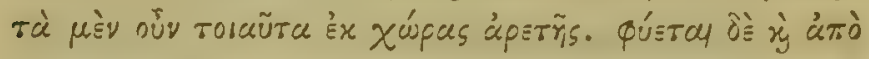

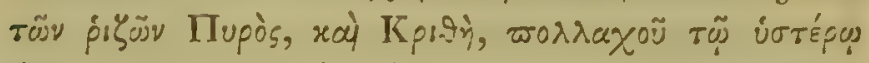

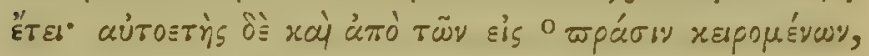

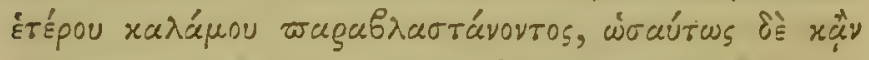

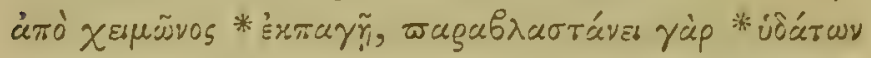

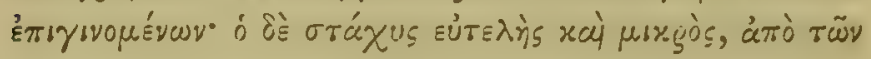

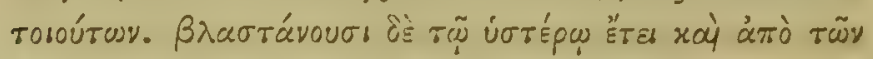

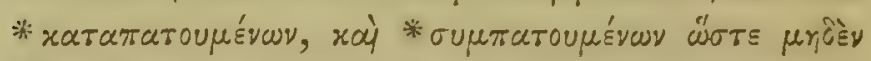

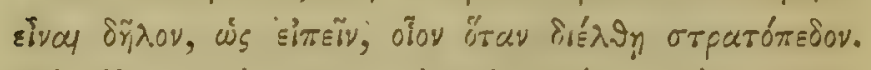

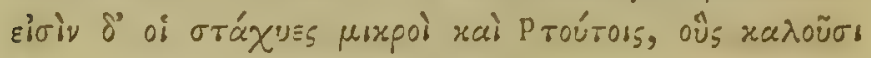

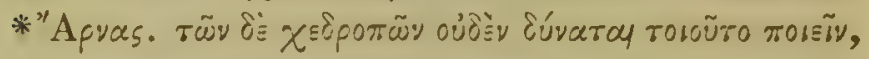

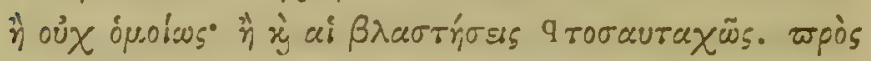

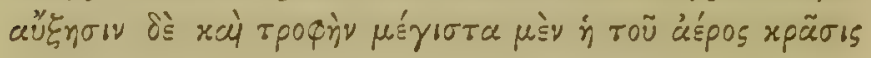

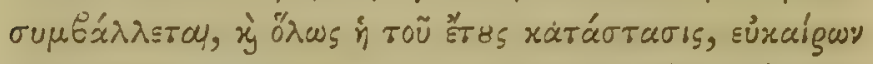

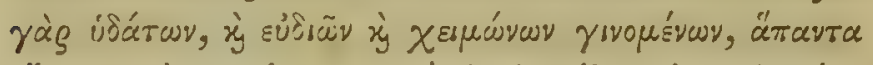

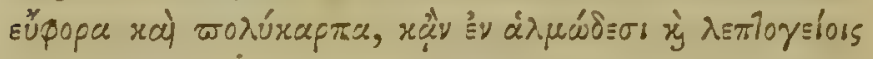

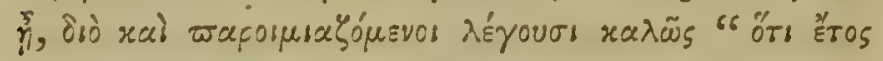

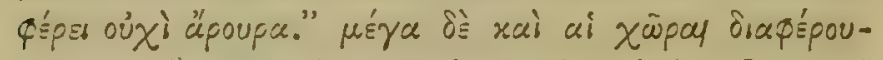

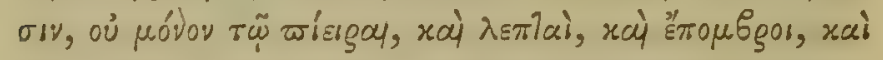

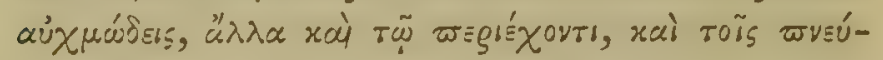
$\mu a \sigma \nu^{\circ}$ हैท

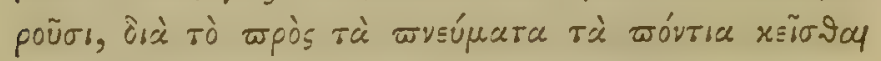

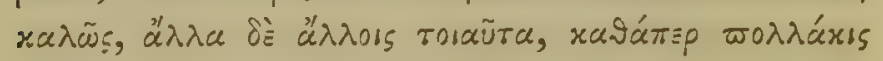

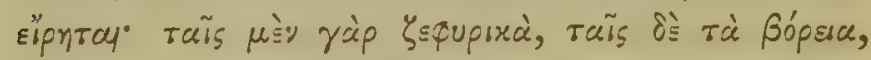

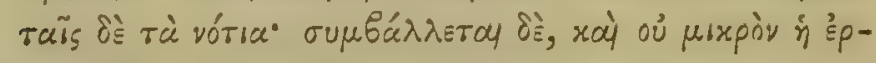

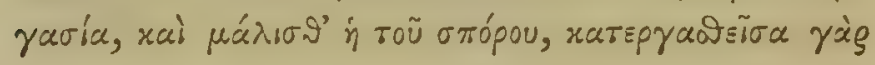

nVid, not, ad fin. libri.

- x̧áair Bod. P тоบ́zous Bod. I rosauraxüs Bod. 


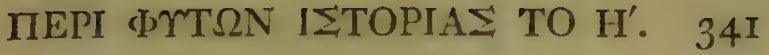

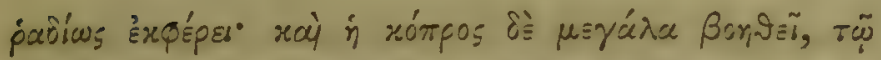

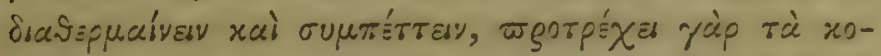

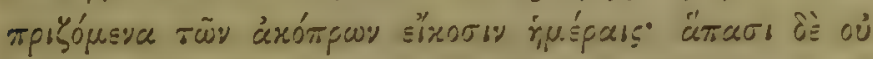

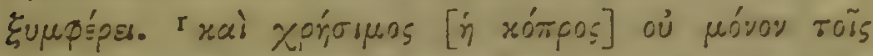

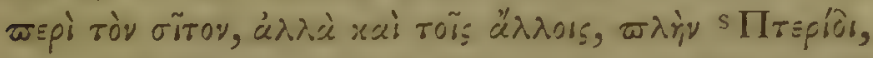

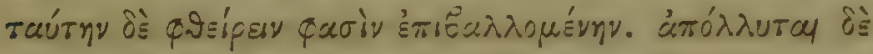

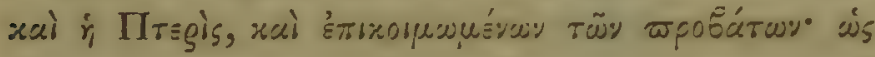

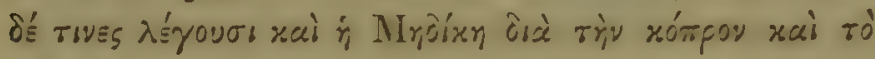
oùgov.

\section{CAP. VIII.}

Seminum Differentice: Nulationes. De Polygono, Aparine, et Orobanche.

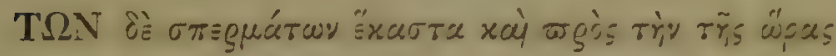

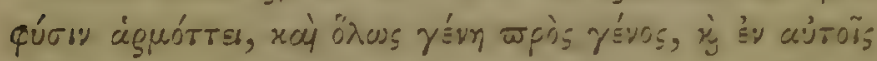

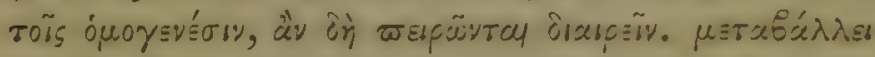

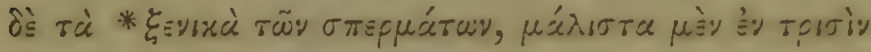

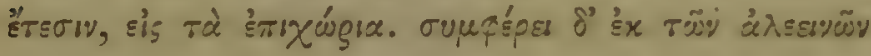

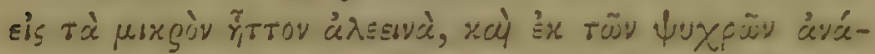

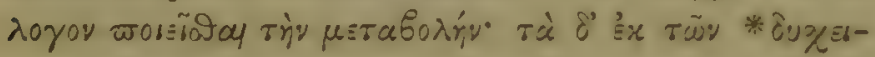

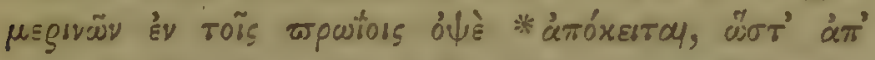

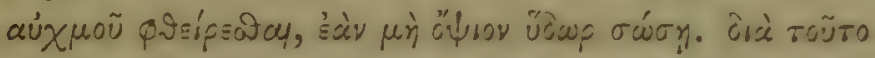

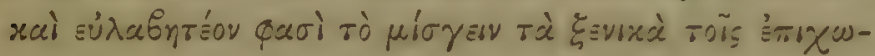

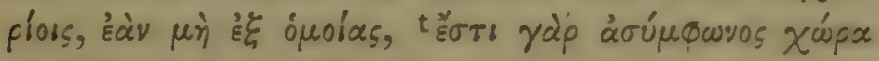

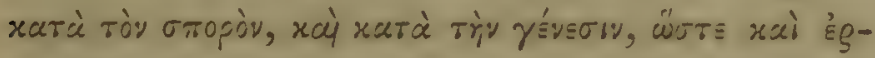

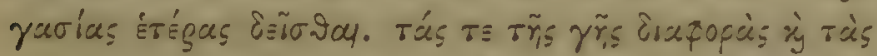

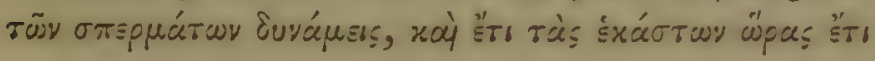

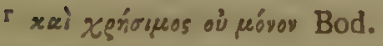
- ๘rzęir. Bod. t: 3

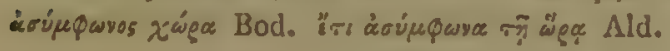

H 2 


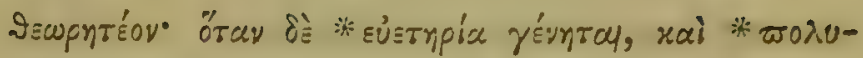

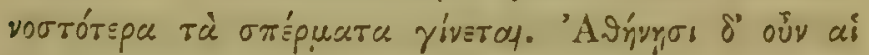

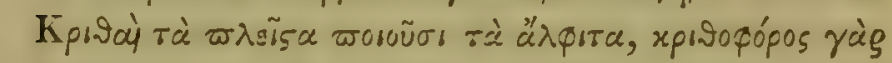

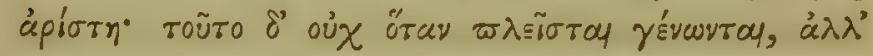

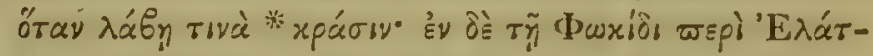

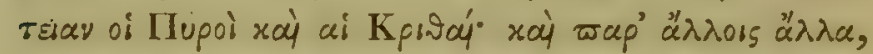

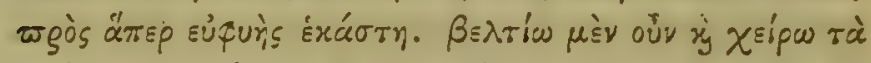

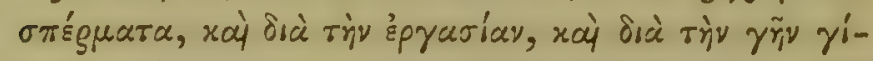

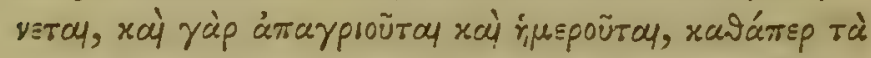
$\delta \varepsilon^{\prime} v \delta \rho a^{*} x \alpha i$ u

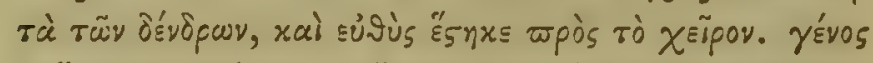

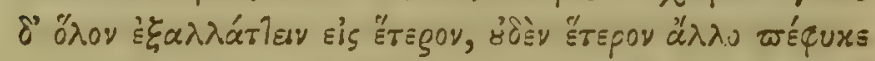

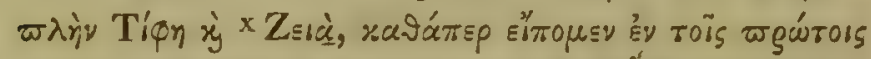

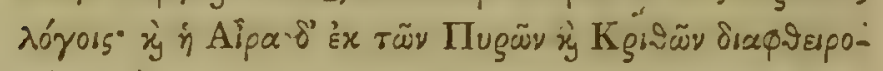

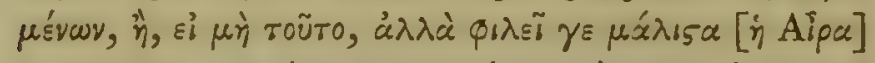

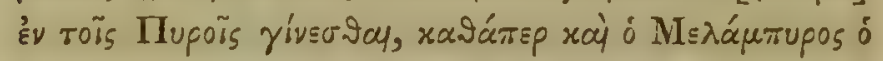

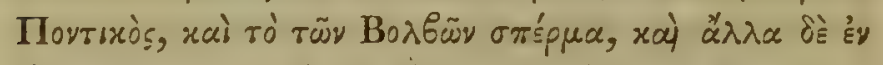

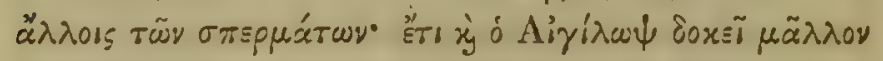

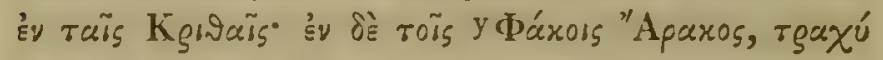

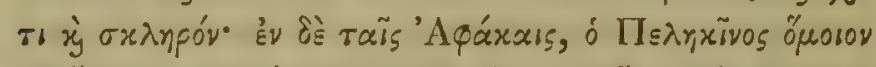

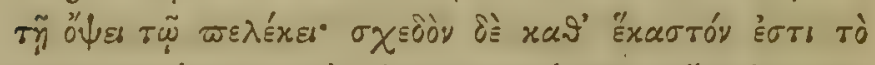

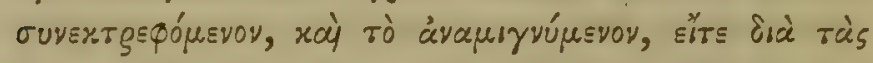

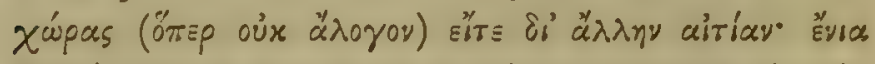

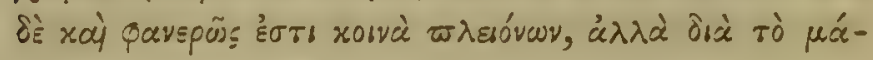

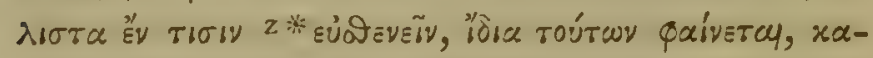

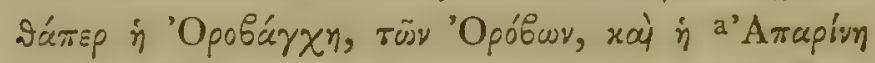

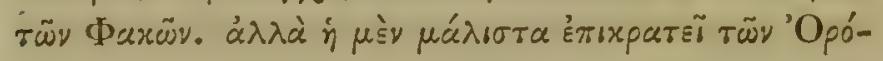

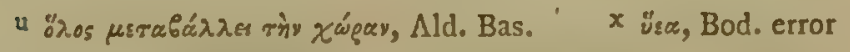

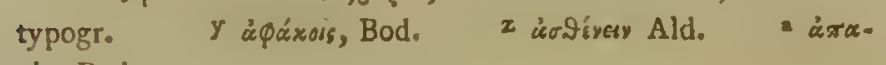
v/v» Bod. 


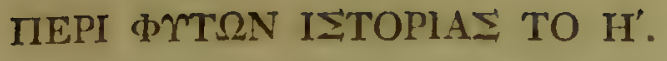

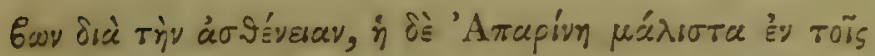

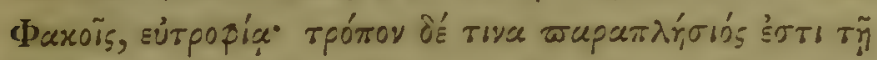

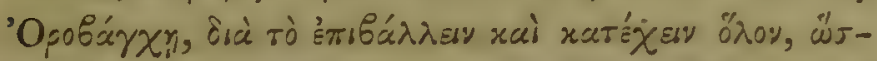

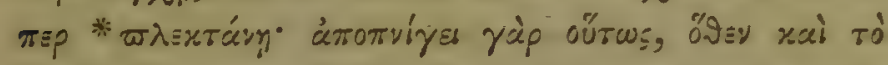

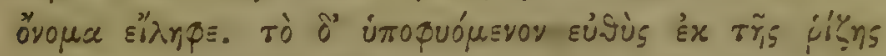

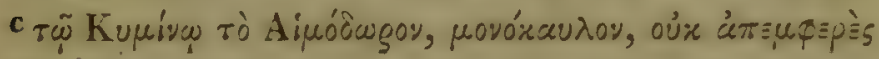

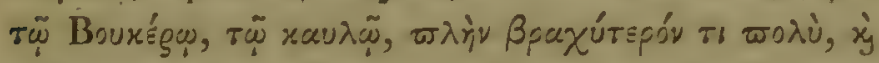

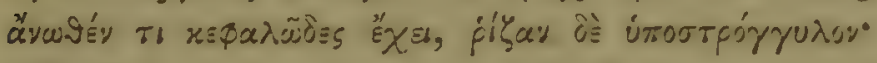

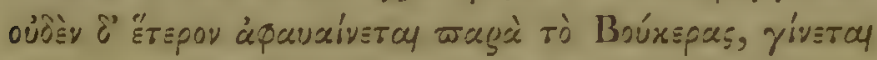

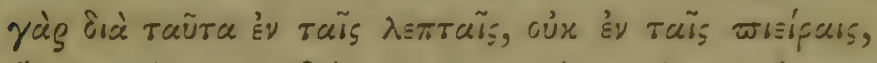

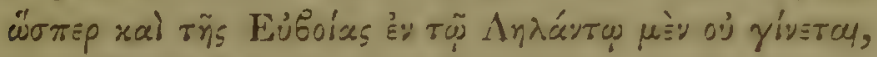

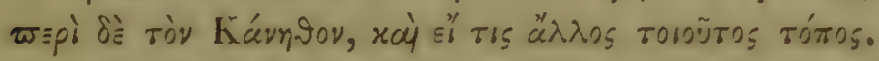

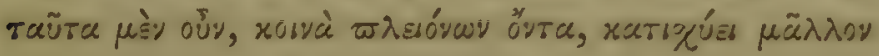

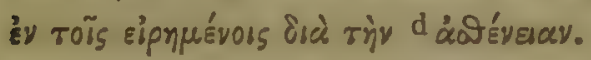

\section{CAP. IX.}

Qualitates Leguminum. Triticum monococum. Hordeun Zeocritum. Avena fatun, \& \&. \& $\&$.

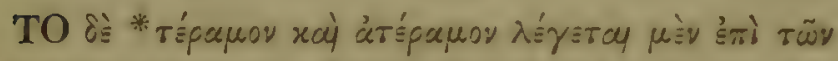

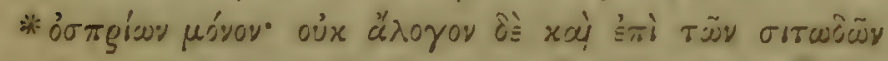

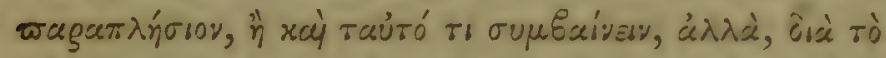

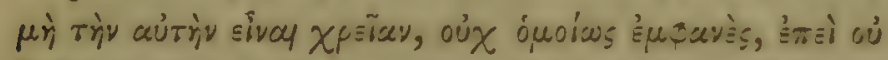

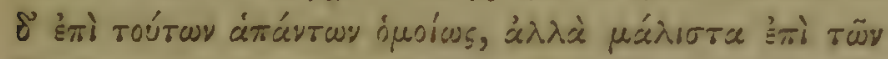

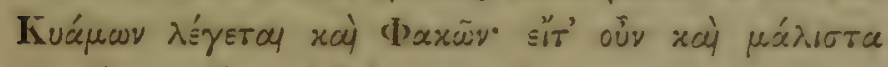

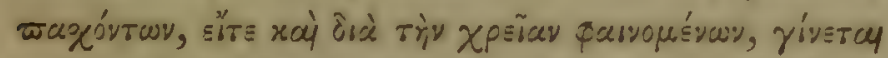

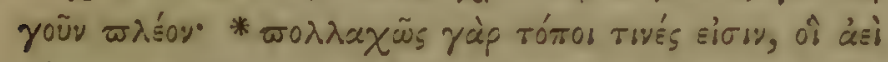

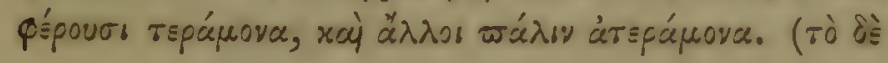

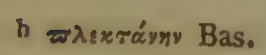
not. ad fin. libri. c Vid. not. ad fin. libri.

d Vid. 


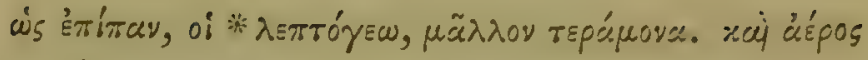

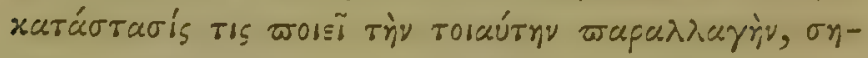

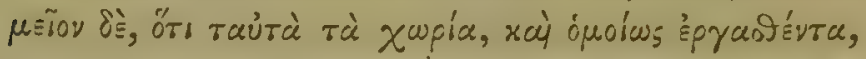

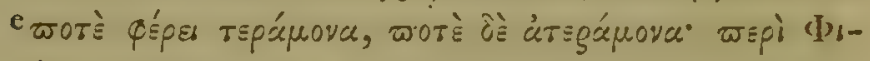

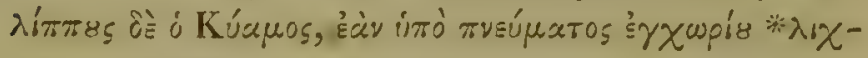

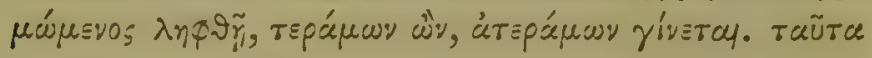

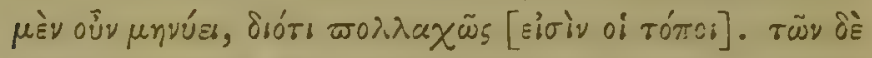

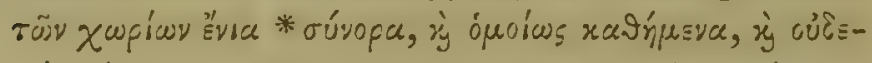

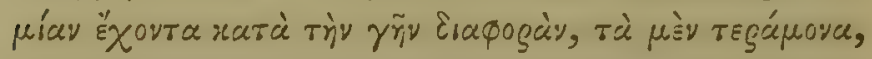

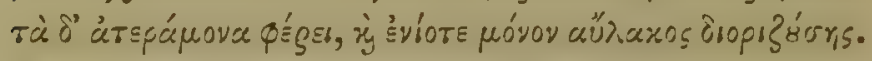

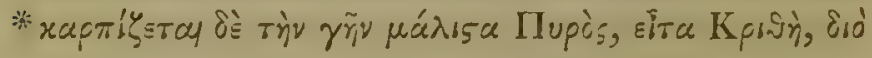

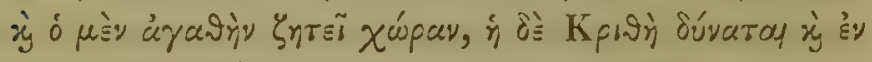

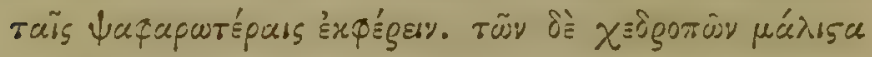

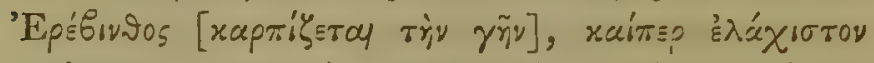

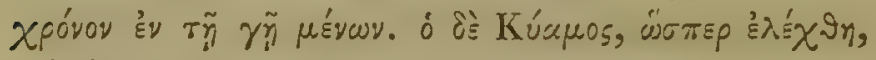

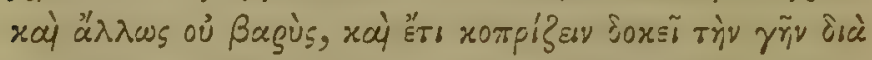

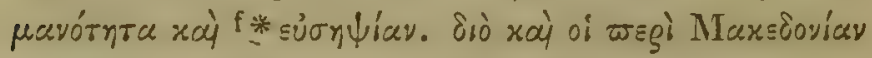

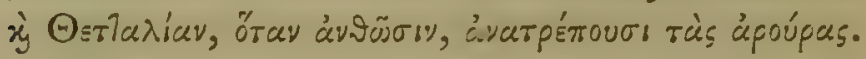

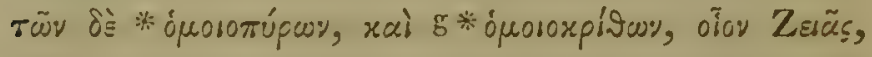

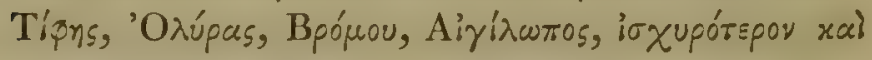

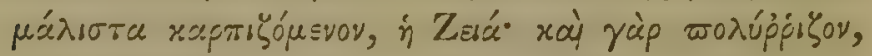

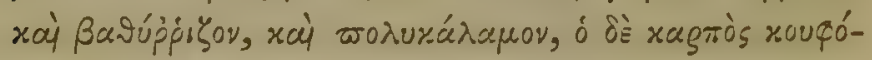

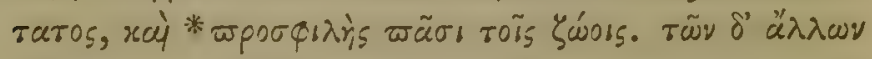

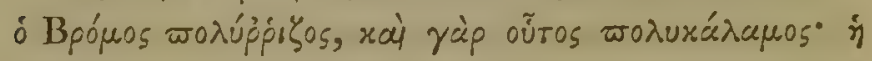

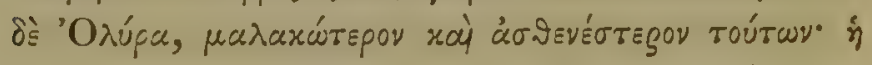

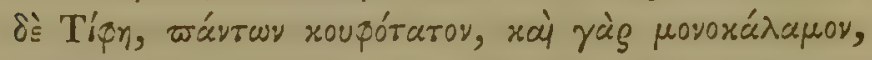

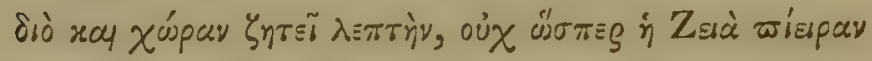

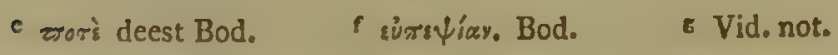
ad finem libri. 


\section{ПEPI ФYT $\Omega N$ I}

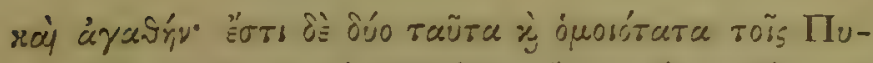

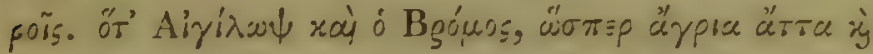

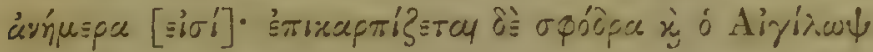

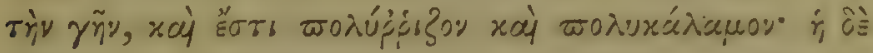

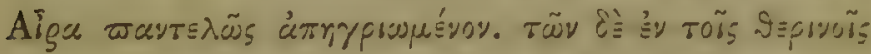

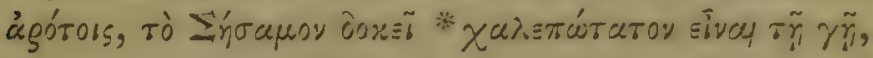

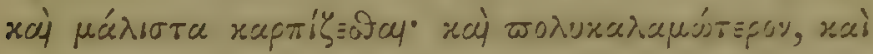

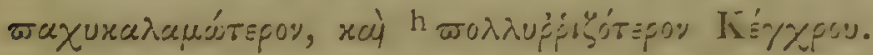

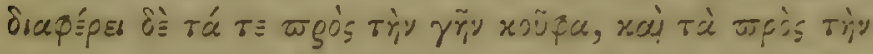

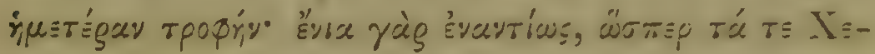

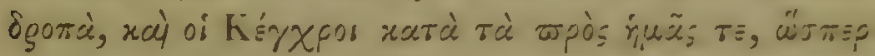

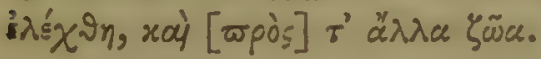

\section{CAP. X.}

Seminum Corruptiones, \& c. \&.c.

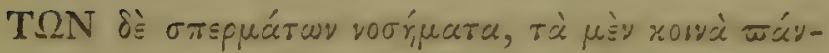

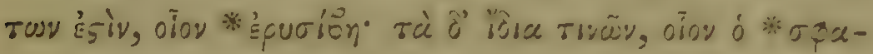

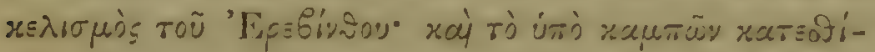

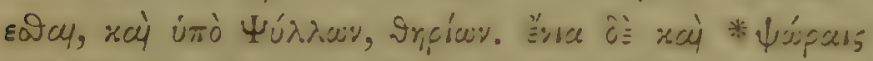

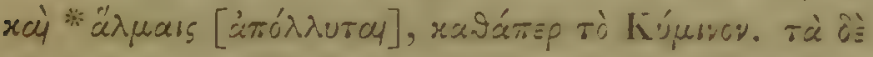

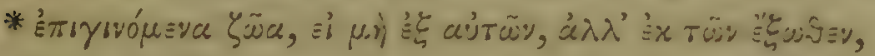

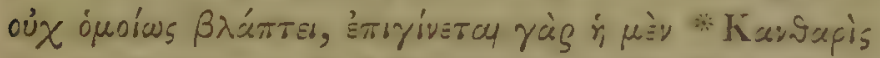

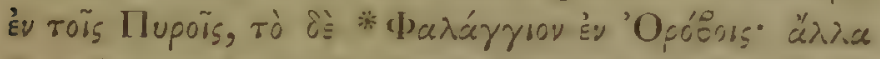

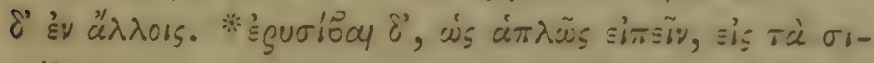

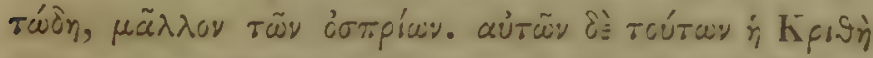

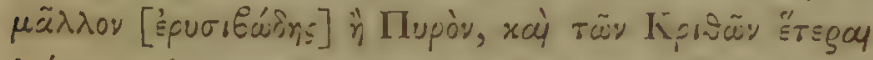

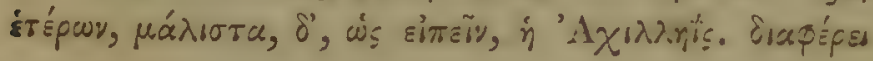

1. Ravequpešórspoy Const.

H 4 


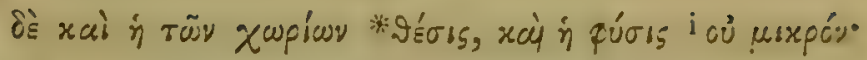

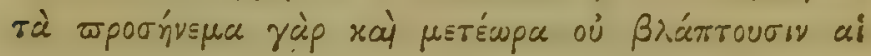

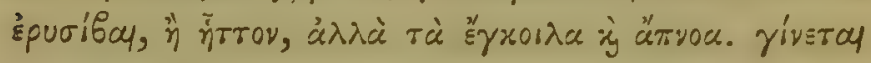
$\delta \dot{~} \dot{\eta}$ É

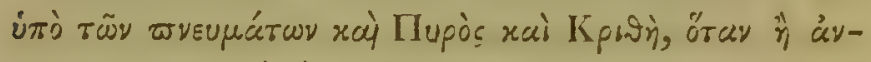

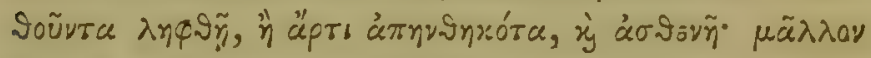

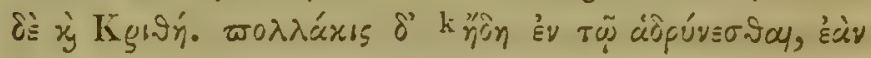

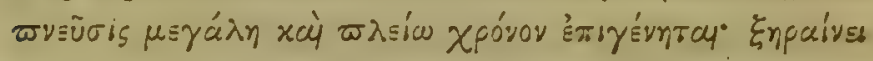

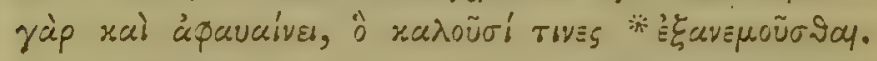

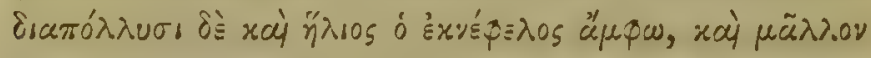

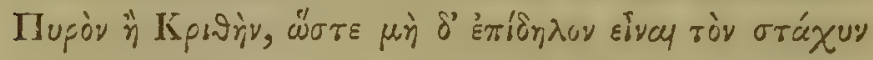

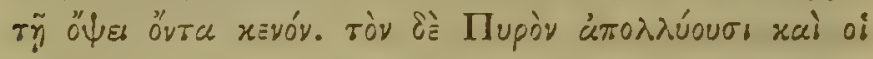

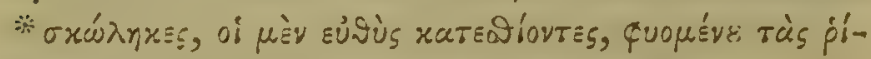

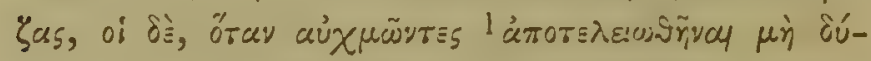

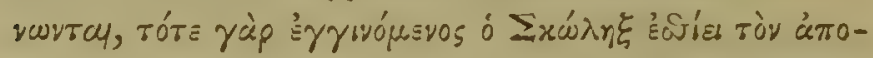

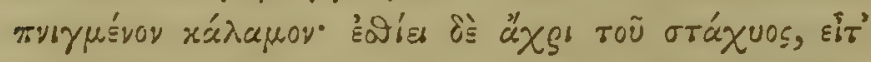

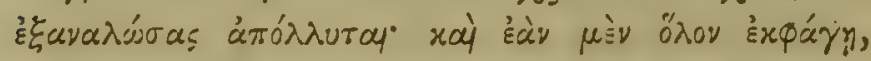

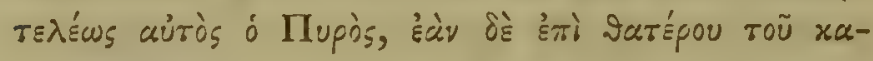

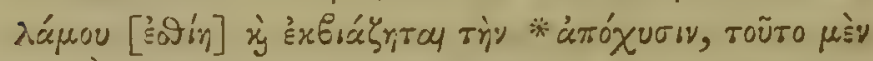

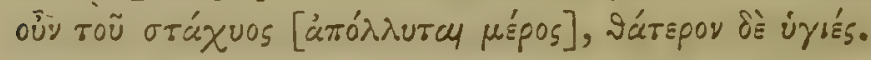

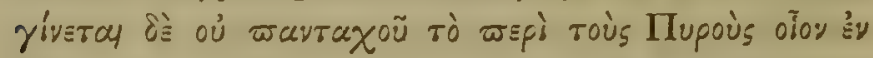

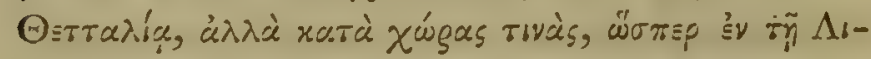

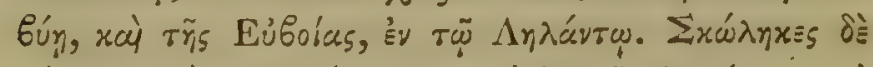

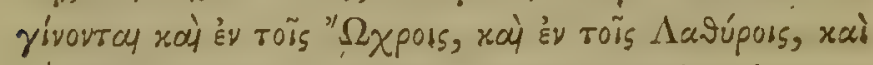

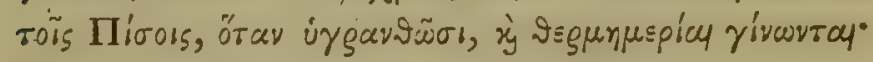

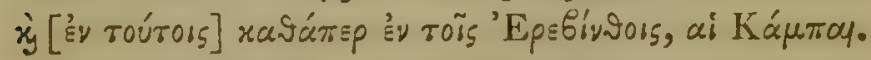

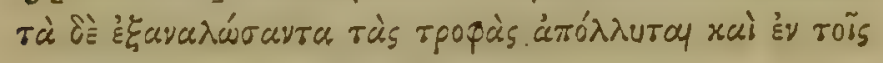

i oủ deest Bod,

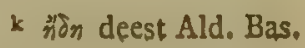

$1 \dot{\alpha} \pi 0 \lambda \mu-$ श्रัทขย Ald. 


\section{ПEPI ФMT $\Omega N$ ISTOPIA TO H'.}

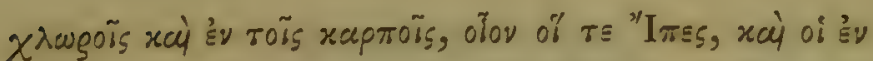

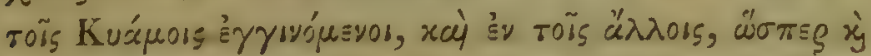

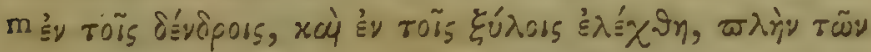

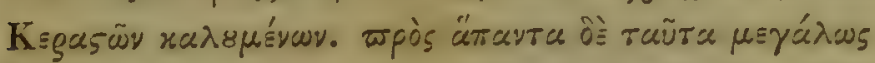

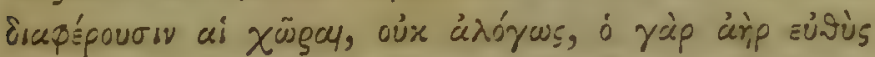

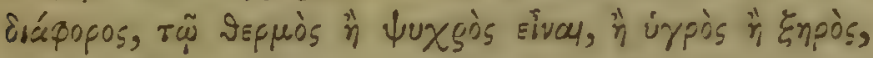
"10 ช̃

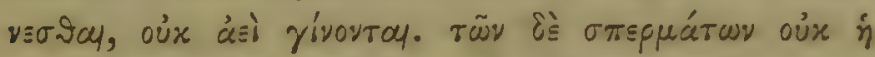

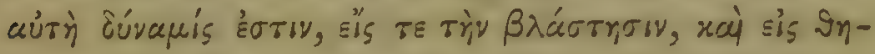

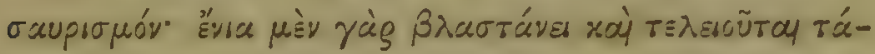
Х

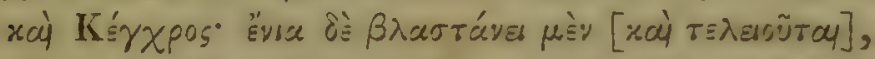

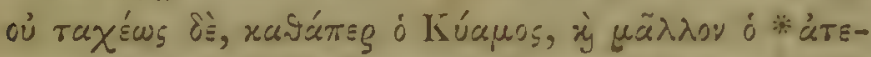

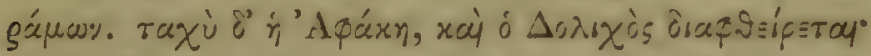

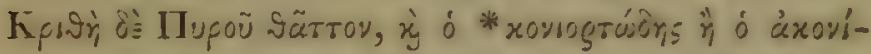

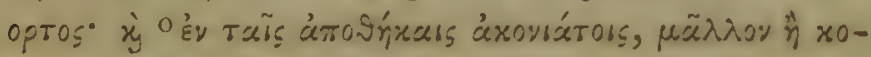

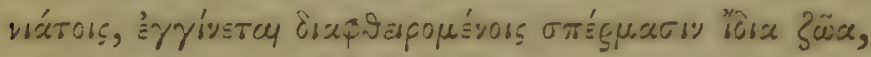

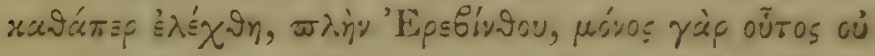

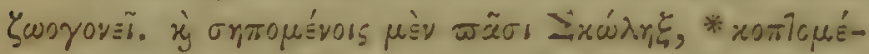

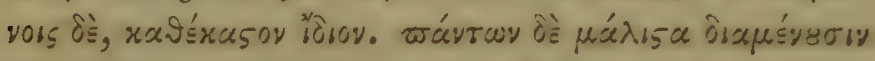

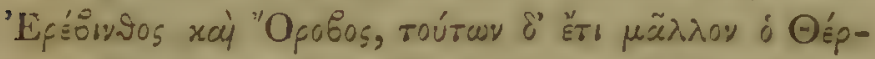

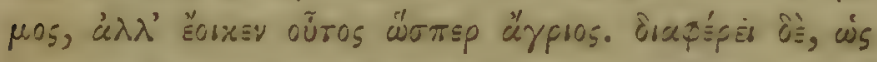

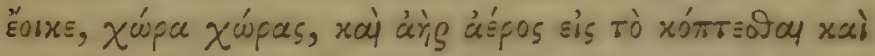

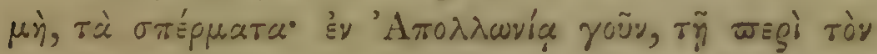

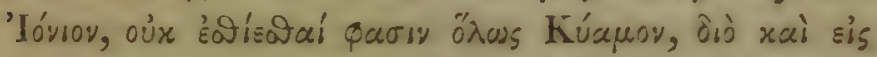

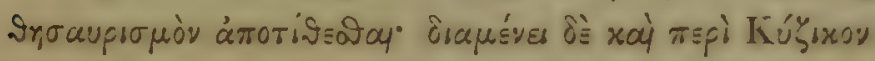

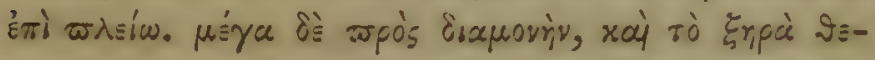

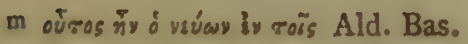

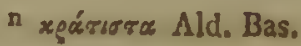
- iy roís xovrogroüs čzceav. oĩoy rayuárous Bod. 


\section{8}

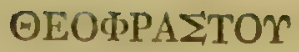

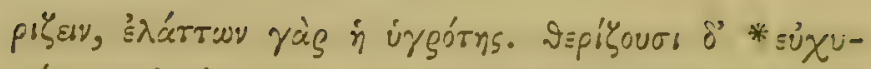

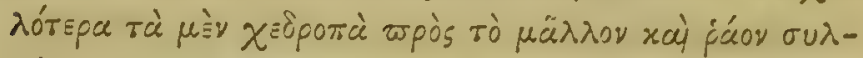

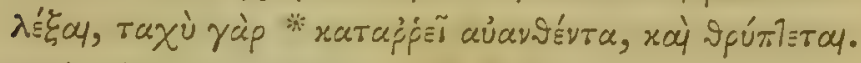

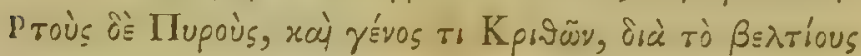

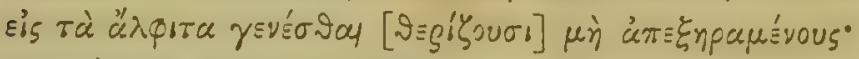

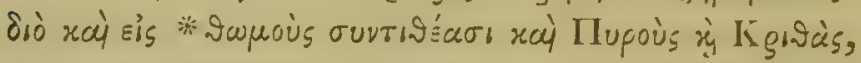

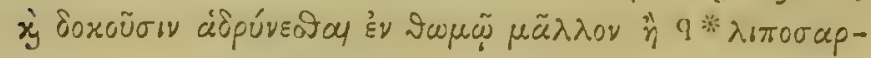

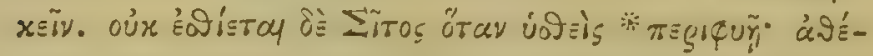

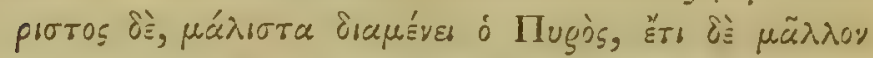

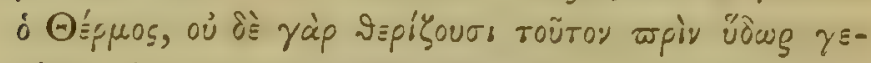

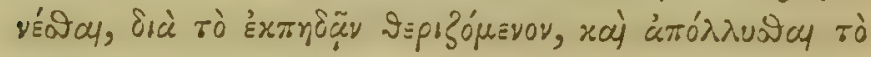

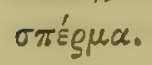

\section{CAP. XI.}

Anniculum Semen optimum ad sementem. Deque Iupino, et Avena fatua.

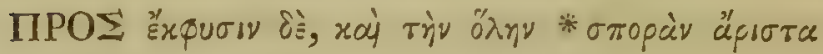

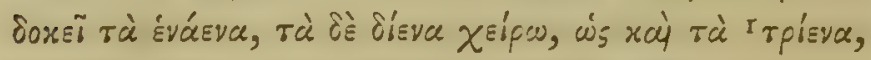

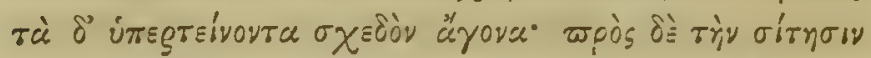

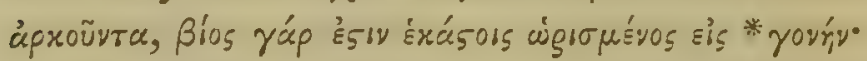

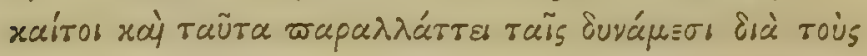

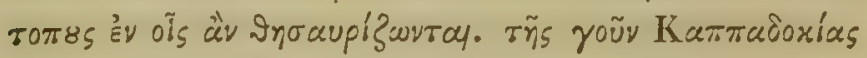

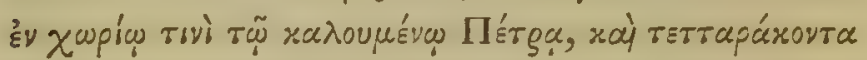

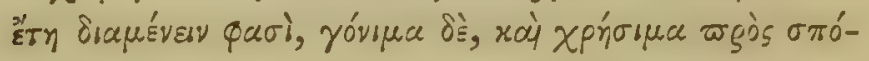

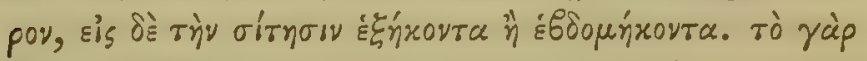

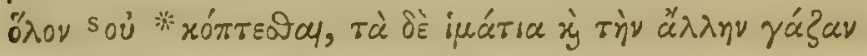

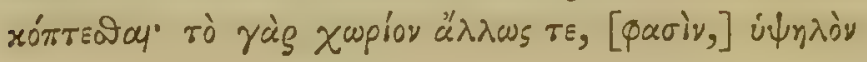

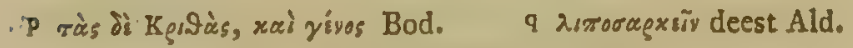
r rǵisva xúxiora, Const. - oủx ö 


\section{MEPI TYTSN ISTOPIAS TO H'.}

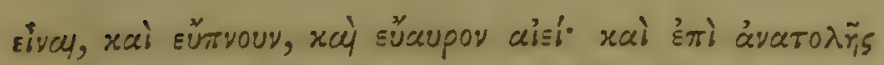

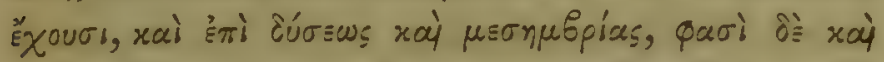

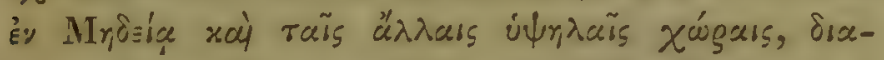

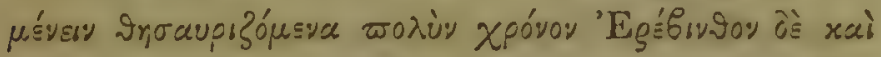

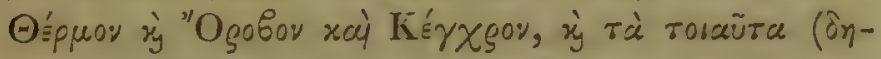

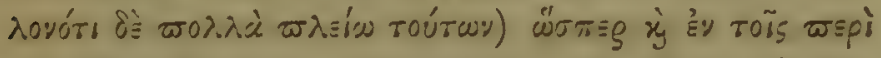

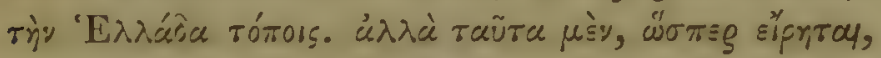

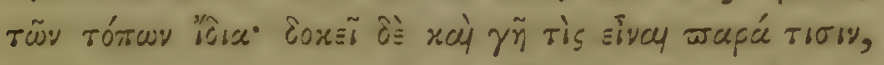

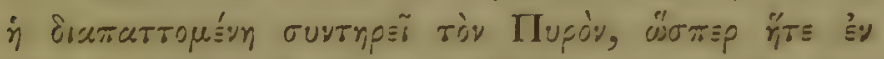

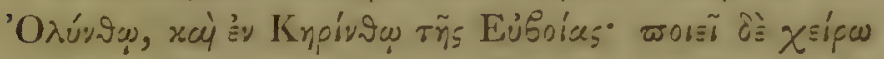

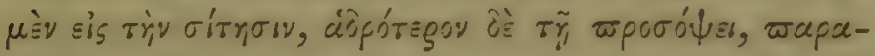

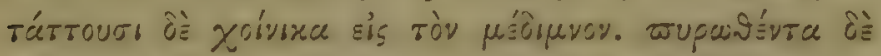

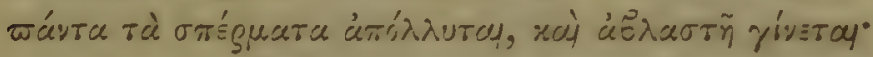

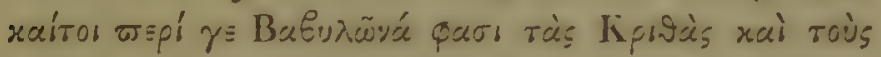

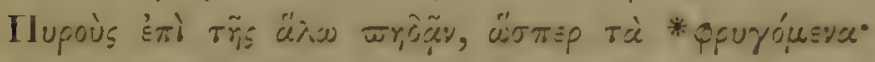

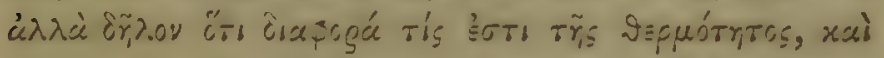

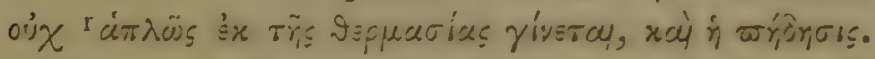

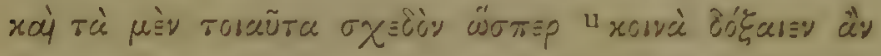

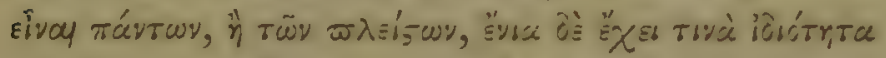

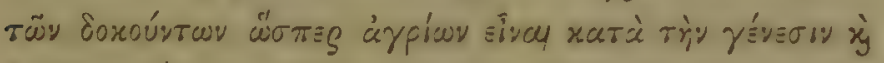

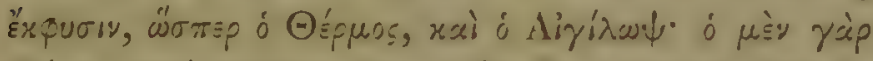

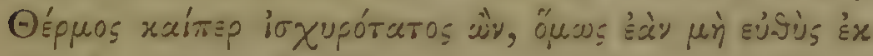

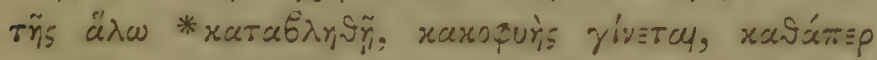

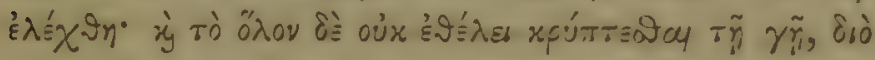

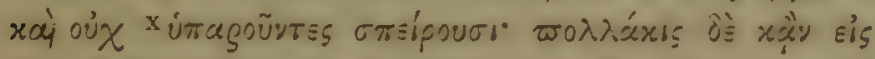

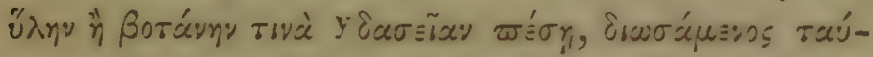

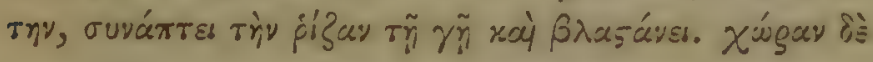

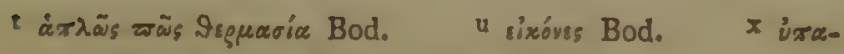

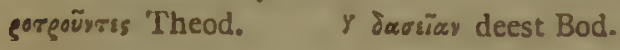




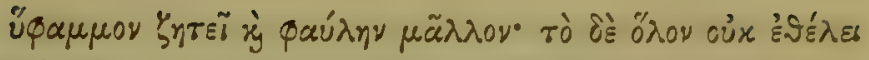

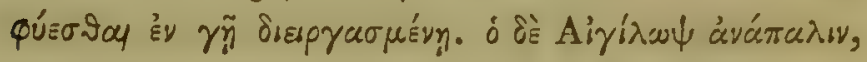

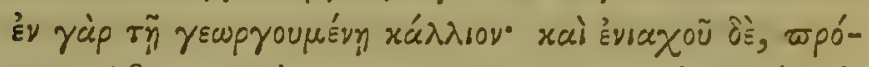

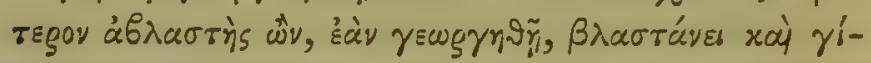

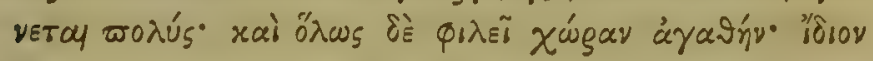

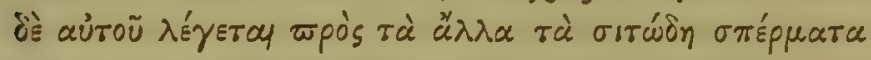

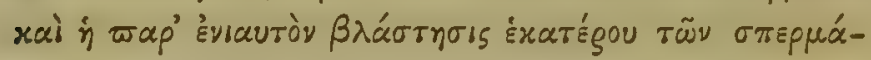

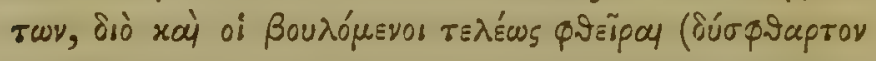

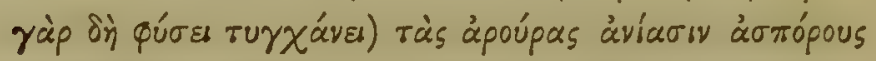

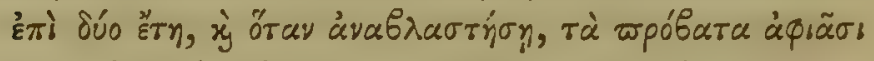

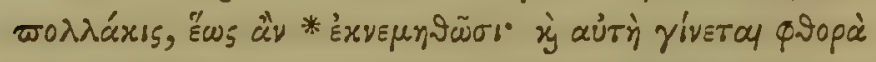

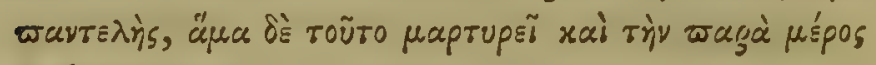
$\beta \lambda \alpha ́ \sigma \tau t h \sigma_{b} \%$ 


\section{NOT压}

\section{, IN LIBRUM OCTAVUM.}

\section{CA P. I.}

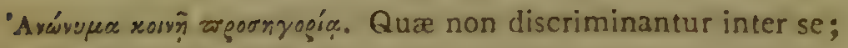
communi nomine indicata.

Zetá. Triticum, monoroccum. Cat. "Frumenta, ut Triticum, "Hordeun." Plin. lib. xviii. c. 7. Trit. Far, Hordeum, infra inter hyberna. Octobri mense serimus Triticum ct Adoreum Pallad. c. 9. Zere monococce et dicocce meminit Bauhinus, quarum prior Trit. monococcum L. Briza dicta: posterior Trit.

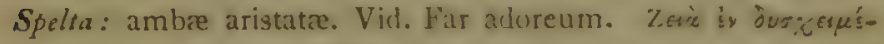
grs, Gal. Secundum Plinium etiam prapurum seges: "Qui "Zea utuntur non habent Far." Ibid. c. 8. Zsiãs y'sn dún" $\dot{\alpha} \pi \sin$ et dixoxxss. Dioscor, ita Bauhin. supra. Quatuor species enumerantur a Columella, lib. ii. c. 6. Superfluum videtur curiosius indagarc Tritici, vel Farris -pecics, quæe aleo cultura variant.

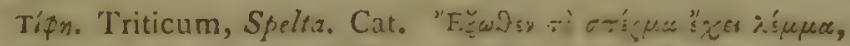

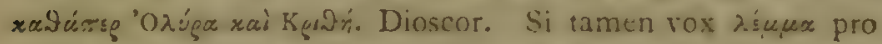
tunica vel cortice accipiatur, Theophrastum contradicit, qui

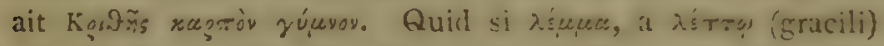
arista? alias nulla spice aristate inter frumentacea mentio. Apud Ger. em. exhibentur species ciure Tritici aristati, quarum una Triticum, Tiphinum. Num. 2, 3. p.66. Observatione dignum est nomen Teff, terminatione Graee $n$ omissa, hodie apud Ethiopas frumenti genus indicare: necnon apad Ho-

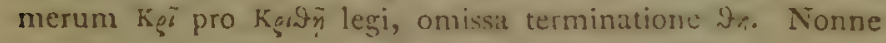
hinc probabile fit frumenta ex orionte Gracian allata?

'o úọu. Hordeum, zeocriticum L. Cat. Arinca, Plin. sed, ue 
ipse ait, species Gallica. Avenæ mentio fit apud Plinium aliu loco: sed certe Avena non ípoiónvgos. Equorum pabulum secund. Homerum.

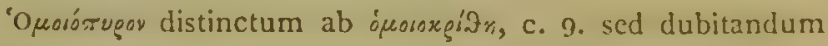
an de Spica simplici et paniculata dictum. Vid. Zssic, \&rc. supra.

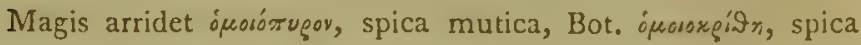
aristata.

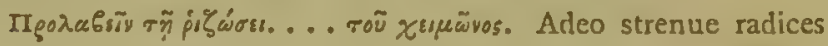
agere, ut hyemem durent.

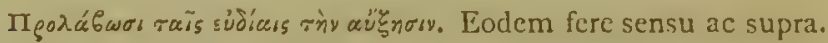

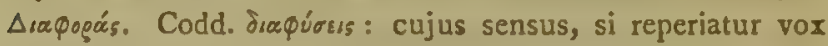
in scriptis, idem, ex vi vocis drá.

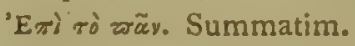

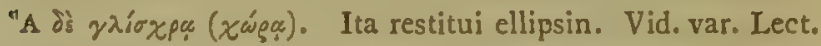

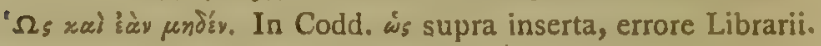

Nи́лi๔. Infantes : plantæ ex seminio.

\section{A P. II.}

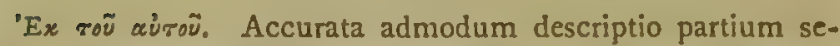
minis. In quamplurimis plantis, a Botanicis nomine Dicotyledonum donatis, corculum et plumula ex eodem puncto pro-

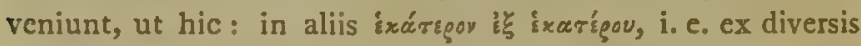
et oppositis, quæ monocotyledones, ut in granis frumenti.

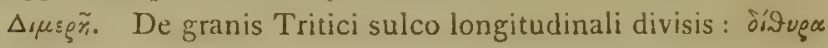
de lobis leguminosorum.

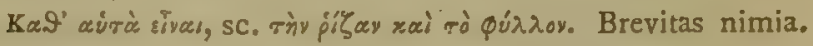

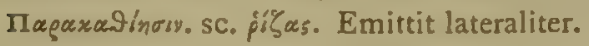

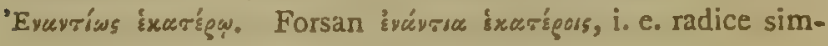
plici vel divaricata.

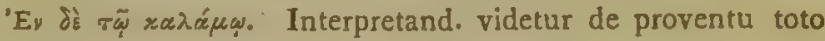
ejusdem seminis, qui aliquando culmos 30 . vel 40 . profert.

Kатхрерияво́ra. Seminibus ex siliqua in terram jactis. Observatio justa respectu órrgíwy in genere.

'Adeúvovrau. Crassantur, Theod. Crassescunt, Plin.' De luxurie plantarum.

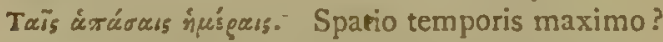

Arąxท́v. Primitias frugum Diis oblatas. 


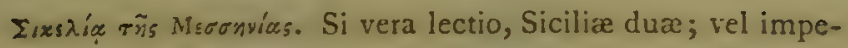
rium in Siciliam Messeniensium.

Tüy ơłiwv. Leguminum, ita dict. ex tempore serendi. Vid. "ẹorol, cap. 1.

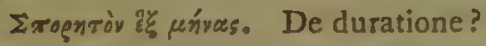

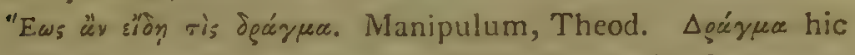
portio telluris sulco exarata : Angl. "a furrow." Sensus re-

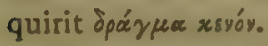

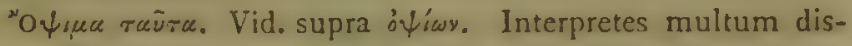
crepant inter se de sensu hujus loci. Mihi videtur, leguminosa non provenire in hac regione.

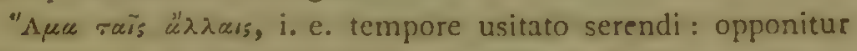

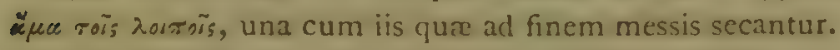

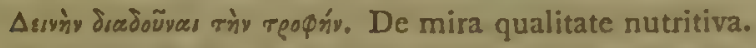

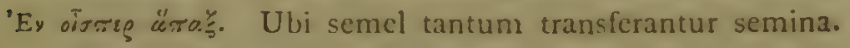
Scal. Suspicor corruptionem textus.

Toũ xgóvou. Ratione praccocitatis.

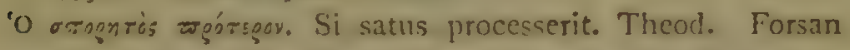

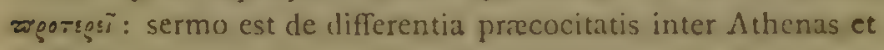
regiones Hellesponti.

\section{CAP. III.}

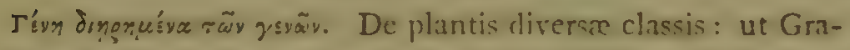

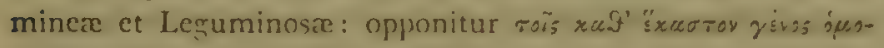
givse', speciebus ejusdem generis.

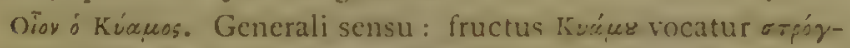
gunos alibi, fructu Loti arboris similis. Ifinc Faba sylvestris Grecorum, cujus icon exhibetur Bod. p. 919. Piso vel Lathyro similior. "Veterum Faba pusilla fuit, Terebinthi similis, vel "bacre Taxi." ibid. Forsan cultura grandior facta. Nlibi tamen Faba nostras indicari videtur caule bog भópus. Diosc. addit

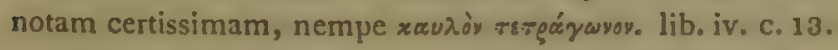

¿ńcaúcoy. Sesamum, orientale. Cat. Frequens mentio apud Theophrastum Exoruses. Apud Dioscor. et Plinium plures dantur species. Vid. etiam Culunell. ii. 10. Pericarpiun cjus peculiare, lib.i.c. 18. Ita apud Linn. "capsula oblonga, ob.

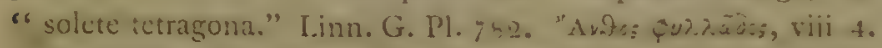
"Flos Digitalis, sed fructus diversissimus." Linn. G. Pl. In. 
ter condimentarias herbas cum papaveris semine celeberrimum. Sesami seminibus consperguntur lanes: hinc Enoapiros äpros. Athan. iv. 172. Ab Indiis profectum, Plin. xviii. 10. Frequens usus olei Sesami in placentis ex Tritico in aqua cocto, saccharo, aromaticis et seminibus Mali Granati ad nuptias sub nomine Colyva, et ubique in arvis a Turcis colitur. Hobhouse's $\mathrm{Al}$ bania, vol. i.

'E gúruss. Erysimum, officinale. Cat. minus recte. Erysimum Theophrasti et Dioscor. diversa plantæ. Prior inter nlera; posterior inter Cerealea cum Sesamo. Farina amborum sc. cum farina Tritici ad conficiendos panes. "Irio inter Segetes "Sesami similis, a Grzcis 'Eguvorpos dictus, foliis Erucre an" gustioribus, caule fruticoso, seminıbus Nasturtii." Plin. xxii. 15. "Erysimum in Asia Graciaque, nisi pinguius esset, " medicaminibus potius quam frugibus annumerandum." Ib. xviii. 10. "Folia enervia: caulis subfistúlosus, succus acris, " inter condimentarios." Bod. N. B. Sisymbrium, Irio Linn. Erysinum Bauhini. Sunt qui Myagri speciem interpretantur. Erysimum Tabernamont.

'Ệ́frvios. Ervum, Lens. Cat. Cicer, Orobæum Bod. Esca

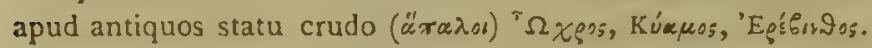

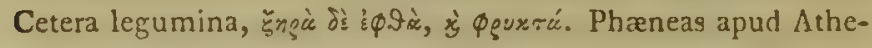

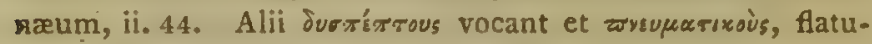

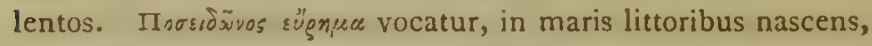
e succo setino. Nomen hodiernum 'Pśs.

'O apta specics. Hroculdubio Ervum, ervilia L. Orobus Bauhini, Orobus receptus Herbariorum. Ger. em. 1225. Varietas hujus Kęòs, 'Opotíasos, viii. 5. Cicer, arietinum L. N. B. Ervum, Ervilia Linn. hodie 'Pós.s.

Фarós. Ervum, satiwum. Cat. Rectius Ervum, Lens L.

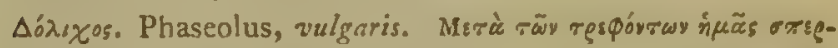

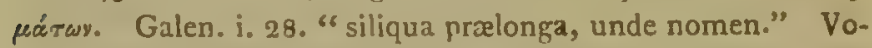
catur a Plinio Phascolus, ex siliqua lembiformi. xviii. 12. Sed. quare genus Dolichos apud Linn. cujus, una vel altera exccptis, siliquæ curtæ?

@śpuos. Lupixus, Cat. corr. Lupinus, albus L. Sola species ad cibos culta. 


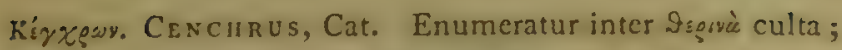
ergo minime inter Cenchros L. Certissime species hac et Míavos inter Panica Linn. enumeranda; quarum hæc P. Italicum, illa P. miliaceum.

Mśryos. Panicum, Italicum. Cat. Rectius P. miliaceum. Vid. supra. N.B. Nulla mentio usus Milii apud Athenreum, ex. cepto semel in potione quadam cum Conyza, lib. $x$. p. $44 \hat{\imath}$. Nomen ex sapore melleo granorum.

\section{C $\Lambda$ P. IV.}

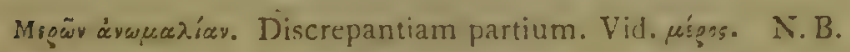
Planta habitu toto dissimiles supra describuntur: capite hoc plante similes, sive ejusdem generis, foliis tantum vel fluribus diversis.

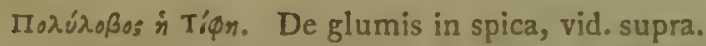

'Aтręrmpíver roũ púrrov. Distans a folio. De spatio inter spicam et folium caulinum superius sermo est.

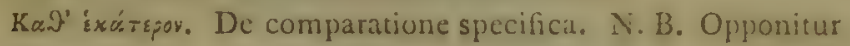
comp. genericæ.

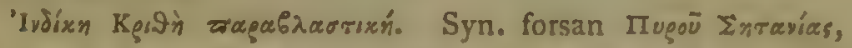
¿'bi. N. B. Species Agricultoribus hodie bene nota; vil. Triticum multiplici spica, Ger. em. 66. Species ista Tritici spicam gerit aristatam, ideoque forsan Hordeum vocatur.

Kayxevoías. Vid. Plin. in loco.

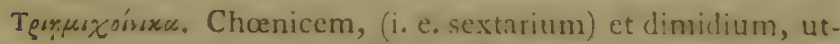

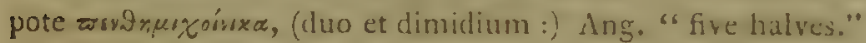

Oüras ioxugév. Quoad vires nutritivas.

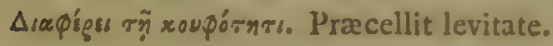

$$
\text { CA P. V. }
$$

"Aporor $\chi$ sipegrvoí. Duo sementis tempora. N. B. Omnibus regionibus commune hoc.

Ä̧̈as. Lolium, temulentum. Cat. Planta hæc ubique infestat segetes. "Infelix Lolium et steriles dominantur Arena."

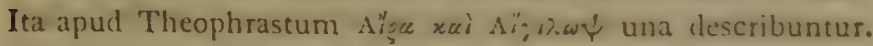

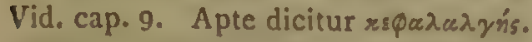

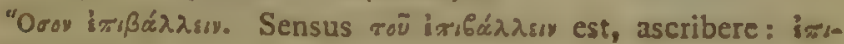

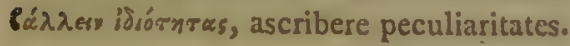

PARS II. 


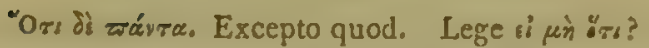

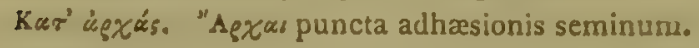

\author{
CAP, VI.
}

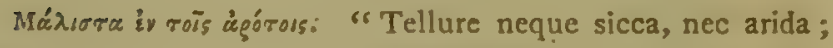
"humore enecta." Scal. N. B. "Aporas tempora opportuna ad serendum.

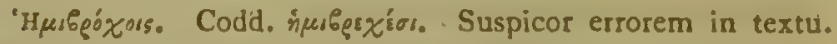
Terra enim modice humida apta ad serendum : c contra destructio fit seminum ex nimio humore vel nimia ariditate:

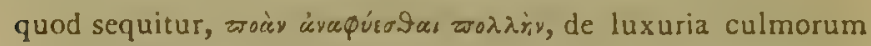
sine spicis fertilibus.

Oiwrí̧orreu. Infaustum augurium ducunt. Theod. "Religi"osum; inde primum coloris augurium." Plin. N. B. Ex verbis Plinii constat voces $\dot{\varepsilon} x$ xpoía e textu excidisse: color pallidus indicat $\tau \dot{\partial} \varpi \lambda \dot{\imath} o v$ úrpou.

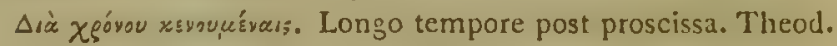
Sensus est, longum tempus inaratis.

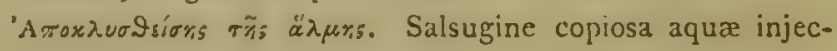
tione abluta.

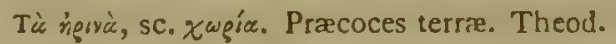

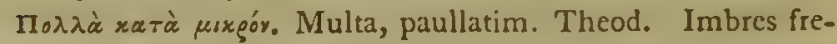
quentes, nec nimii.

\title{
CAP. VII.
}

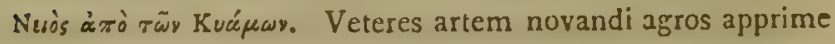
callebant, sc. satione Pisi, Fabæ, \&c. \&c.

'Exúínovo،. Depascuntur. Ita Plinius : "Luxuria segetum " castigatur dente pecorum."

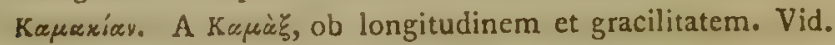

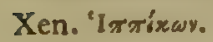

Iıvrnxovróxoog. Quinquagesimo foenore. Plin. Mira fertilitas. N. B. Plinii verba qux sequantur quinquagesimo et centesimo, ex incuria saltem. Theophrastus ait a quinquagesimo ad centesimum.

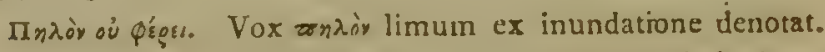
Corrigend, textus ex Plin. xviii. 17. Sensus est, Babylonicam 
terram non fuecundari limo peculiari, sicut confinia Nili in Egypto.

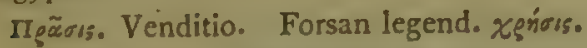

"Agras. Nomen triviale segetis imbecillæ.

IIpjs aưngw. N. B. Initium capitis hujus apud Bod. supra, Ka) ör

Eủdiây xai xuspéryar. Textus forsan corruptus.

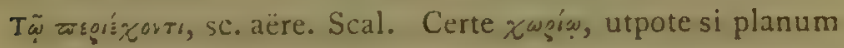
sit, vel montuosum, \&c. \&c.

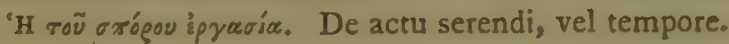

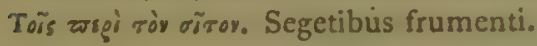

\section{CA P. VIII.}

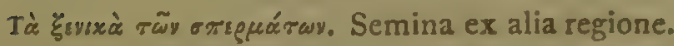

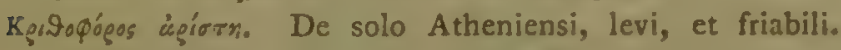
Opt. "light Barley or Rye land." Ita Miltonus noster:

"Pure the air and light the soill"

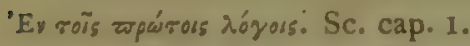

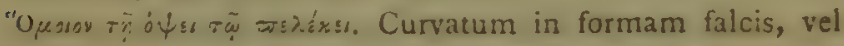
acinacis: "a scymitas."

Aipádoçov. Textus hic corruptus, levi transpositione, ut videtur, restitucndus. Sensus est, H.emadorum, Orobanchis speciem (O. major L.?) nasci ad radices Cumini, caule simplici; haud absimilem rợ Bouxípz, sed breviorem; radice buibosa. Virl. Cat. N. B. Plance ha, vere Paracite, exhauriendo succum cnecant, 'Opon'a $y x$ tamen Theophr. circumvolvendo.

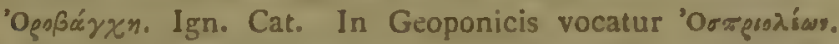
Ex descriptione Theophrasti planta amplexu alias enccans innuitur: hujusmodi sunt Galium, afurine L. Fumaria, capreolata, \&c. \&c. Nullus tamen dubito quin hic loci Polygonum, convolvulus L. planta segetibus adeo lethalis, indicetur.

Boúxsous. Ophrys, nilus arvis. Cat. Ex formu incurva, cornu bovis referente, ct caule simplicissimo: necnon habitu parasitico. Rectius forsan Lathraee vel Orobanclses L. species.

'Aragivy. Galium, verrucosum. Cat. Rectius G. aparine, ex habitu.

Mndixn. Medica, sative. Cat. N. B. Error typogr. pro Me. dicagine. Medica legitima Clusii. M. satiza, Moris. Fœnum 
Burgundicum, Lob. ic. 2. Nostratibus notissimum sub nomine "Lucerne."

\section{A P. IX.}

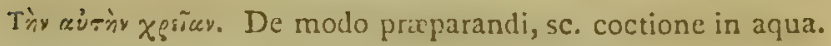

'Arşúpova. Vid. Tşápewy Lex. De qualitate leguminum in aqua coctorum, an tenera et mollia evadant, vel aliter. Alibi

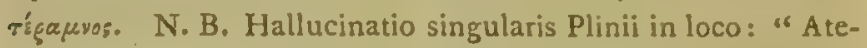
"ramnon nominant herbam in piugui solo, qua Faba ne"catur." xviii. 27.

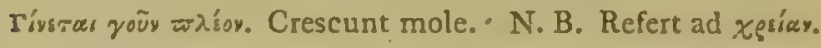

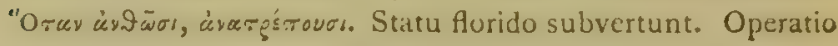
agriculturæ satis nota: "ploughing in a crop."

"Oparoxpiquv. Forsan distinctio inter Triticum et Hordeum apud Theophr. respectu spicæ muticæ, vel aristatæ: quo casu Zuc̀, Típn species Tritici spicis aristatis.

Airì $\psi$. Avena, falua, L. Cat. Secund. Bod. Avena sativa. Sed quare infensa segetibus, si inter cultas numeranda est?

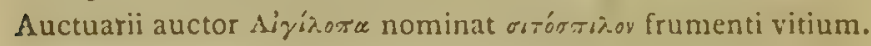
Forsan inter oı ẃdous hac de causa enumerata. Hic etiam censura notandus Linnæus, qui genus plane alienum Egilopa sistit.

Bépros. Secale, Cereale. Linn. Cat. N. B. Vox Bromus, ut Cerealis species, apud Plin. occurrit, et dicitur externæ originis, xviii. 10. Cel. Car. Sprengel e contra B̧ófuoy Avenam, fatuam, L. Airí оr $\alpha$ A. sterilem appellat, p. 80. Videndum an sit Bromus, secalinus, L. si species ista infestet segetes Græciæ.

\section{A P. X.}

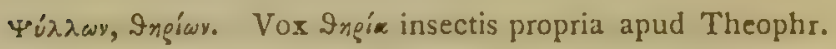

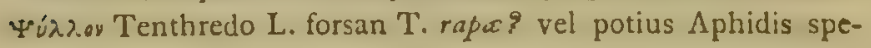
cies.

Ei $\mu$ r vel ex accidentibus, ut rore, salsugine ( $\alpha_{\lambda} \lambda \mu \eta$ ).

'Epuribar. Uredo, persoon. Cat. Vid. supra lib. iii. c. 27. et De Caus. Plant. lib.v. cap. ult. 'E Auctuarii Auctor. 


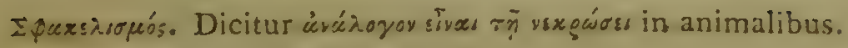
Vid. supra. Morbus trunci vel radicis.

Káura. Uricæ. Plin. in loco. Sed quo sensu? Sensus vocis

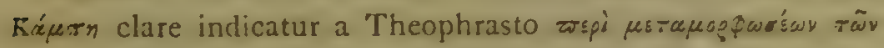
Teryayrácyzay, triplici inutatione Coleopterarum, \&c. Linn. De Caus. Plant. lib. v. N. B. Vox Kápers propr. Erucarum, Grometrarum L. a modo sese incurvandi ambulando.

Dàárysoy. Cat. Aranea. N. B. Hic loci forsan nidus animalculi cujusdam textorii infestantis plantas: alibi lib. ix. c. 12. Araneæ species morsu noxiæ ita vocatur.

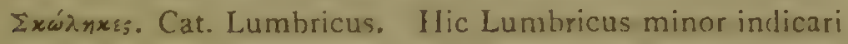
videtur; vel forsan Ascaris, vermicularis. Linn. G. Pl. 1076. Videant entomologi an sit species apud nos "Cut-worm" dicta.

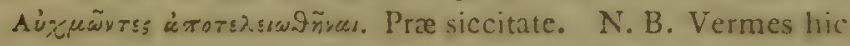
et supra descripti valde diversi.

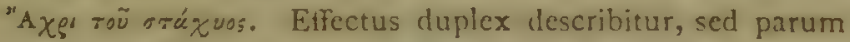

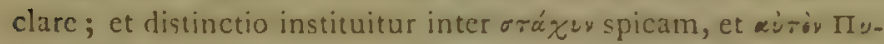
gov, plantam totam.

"Irs. Cat. Cynips L. N. B. Alibi occurrit Krił 'Aphis Cat.", sed nescio an idem animalculum, vel species dure ejusdem generis Syst. Nat. Linn. ubi numerosissimas videre est.

'Ey roïs z̧údass. Vid. ii. 9.

Eììs sáépopos. De subita mutatione?

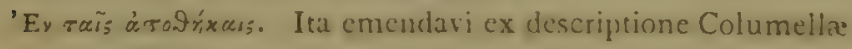
et Palladii. Vid.supra de usu roviógrav, lib.iv. c.5.

EnToú́vas $\approx \tilde{x} \sigma 1$, i. c. vermes omnes seminibus putridis vesci: sanis vero animalcula propria unicuique.

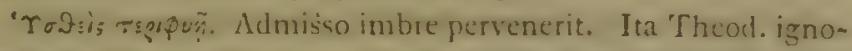
rantia rocis assupur. Sermo est de collectione in manipulos, vel in Tápuovs: Anglo "putting together wet."

\section{CA P. XI.}

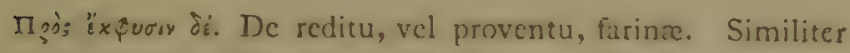
Plin. "semen optimum quod gravissimum." xviii. 24.

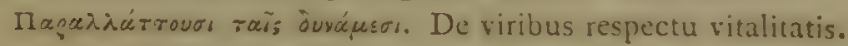
Plin. xi.

'Ey Xweín rov'. Mirum sane, si non fabulosum, quod auctor dicit de duratione frugum in quibusdam locis. Ex voce wirag 
licet conjicere, horrea ista ex saxo vivo exsculpta ad concervanda grana, aere penitus excluso, Vid. super hac re Plin. xviii. 30 .

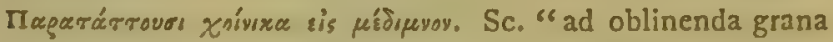
"singula, ut Saccharo Coriandrum." Scal. De parietibus horrei, ut mihi videtur, sermo est. N. B. Pavimenti rimas excludendo aeri amurca oblinebant veteres. Plin, xv. 8.

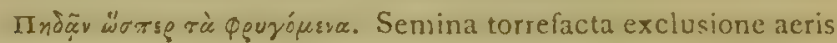
crepitant et dissiliunt: hinc adagium vetus, "to skip like a "s parched pea."

Oủx iீragoûyrs orrigove. Idcm observat Plinius respectu Lupinorum, xviii. 14.

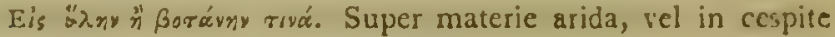
herboso. 


\section{$\Theta \mathrm{EO} \Phi \mathrm{PA} \Sigma \mathrm{TO} \Upsilon$}

\section{IIEPI $\Phi \Upsilon T \Omega N$ I $\Sigma T O P I A \Sigma$}

TO $\Theta^{\prime}$.

\section{CAP. I.}

Qualitates Succi, Resin ${ }^{2}$ Balsama, \&c.\&c.

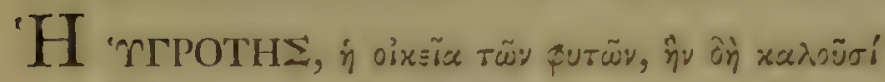

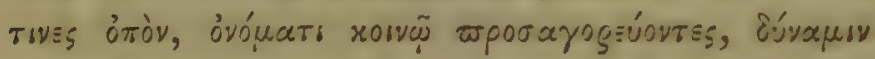

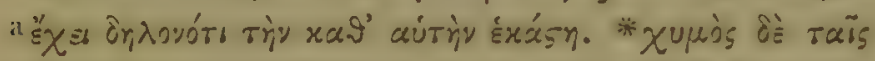

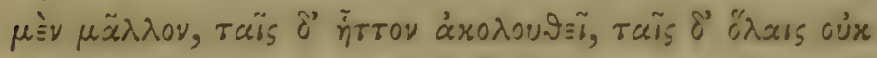

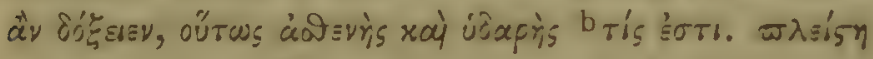

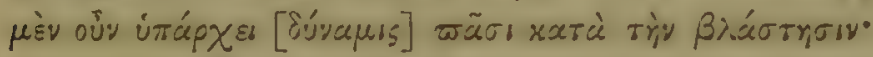

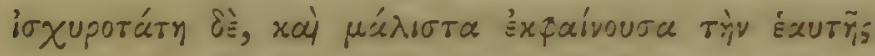

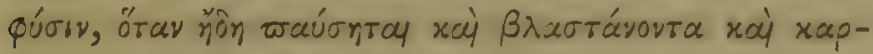

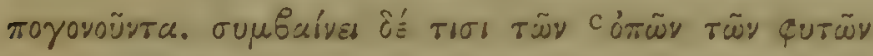

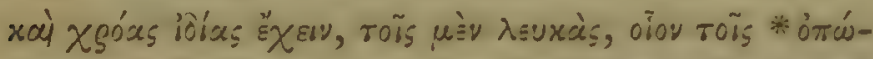

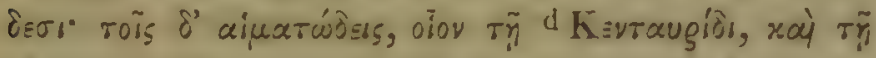

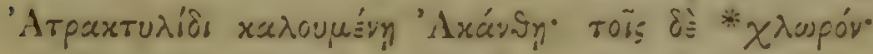

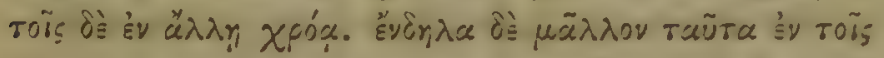

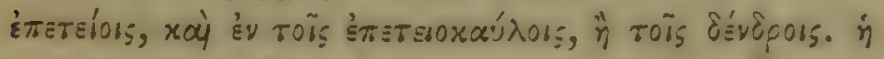

2 "ใน sunt Bod. a Ksurnela, Bod. Ksyraugia, Const. 


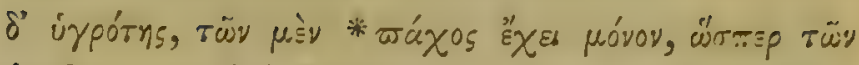

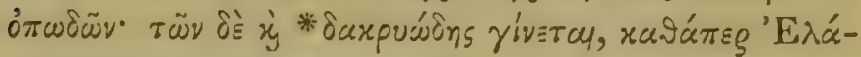

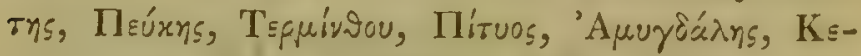

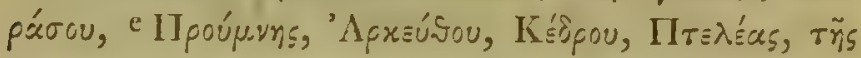

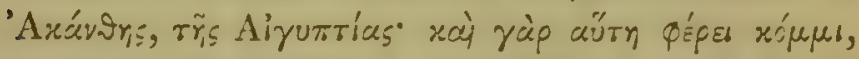

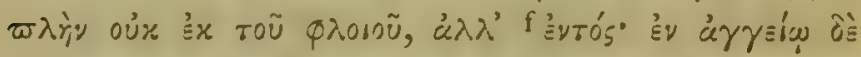

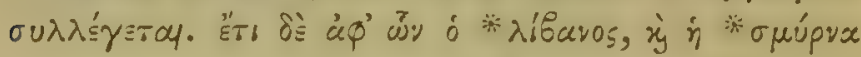

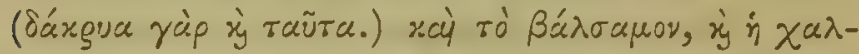

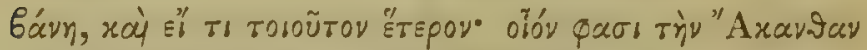

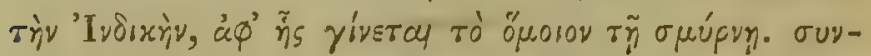

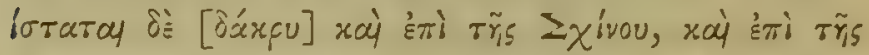

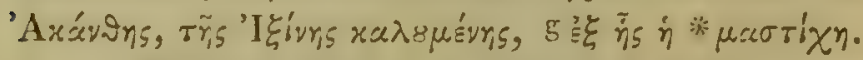

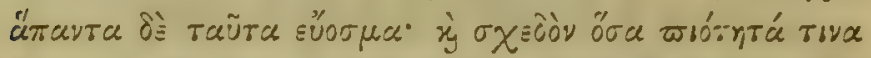

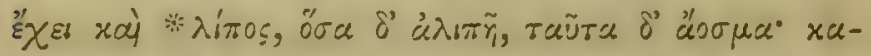

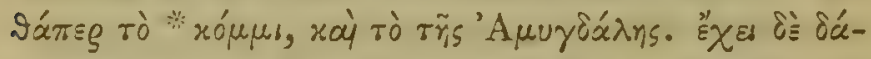

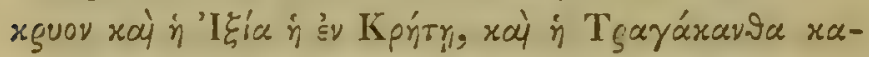

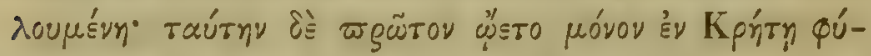

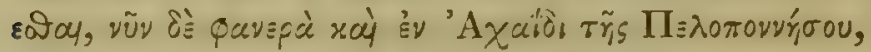

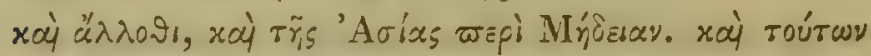

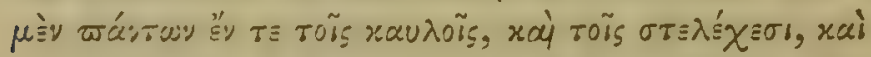

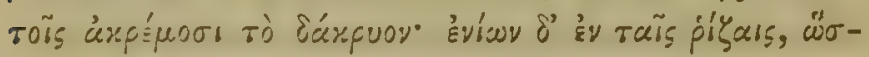

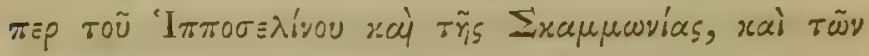

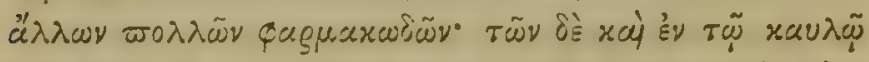

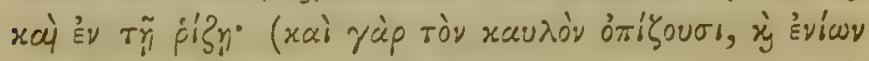

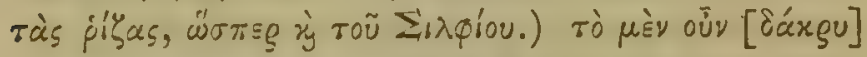

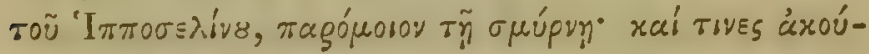

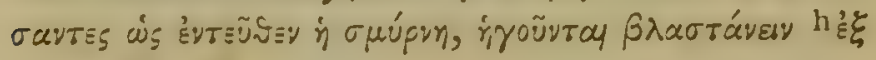

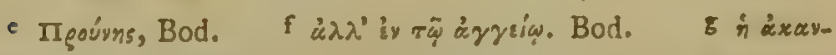

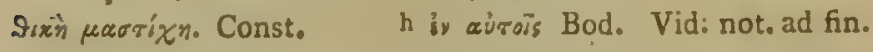
libri. 


\section{ПEPI IMT $\Omega N$ ISTOPIA TO $\Theta^{\prime} . \quad 363$}

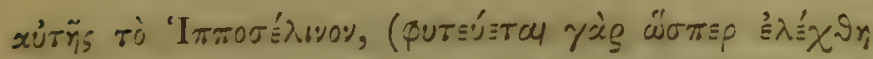

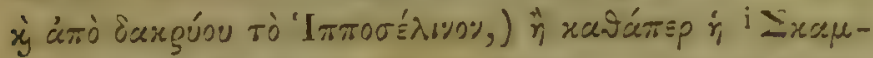

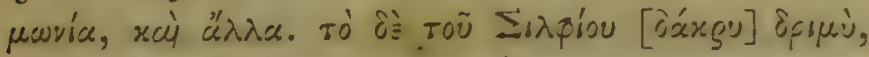

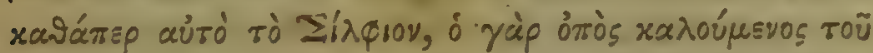

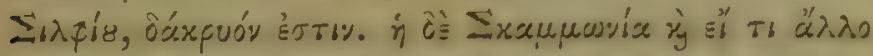

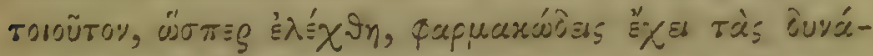

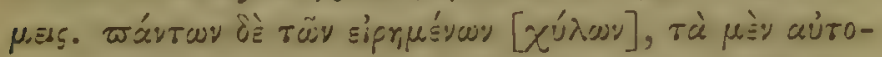

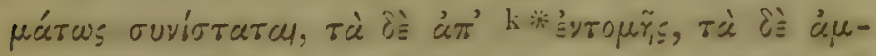

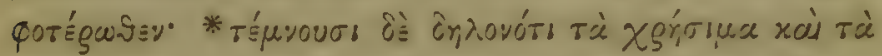

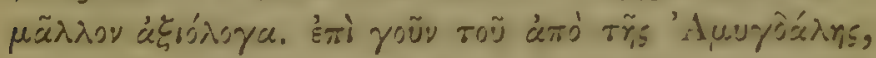

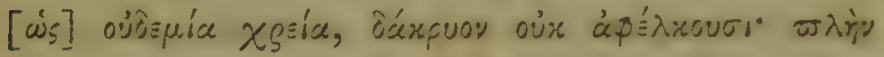

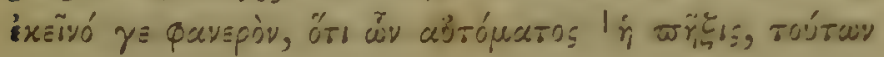

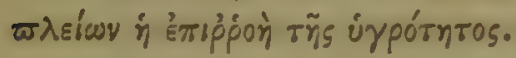

\section{CAP. II.}

Modi extrahendi Resinam et Picem.

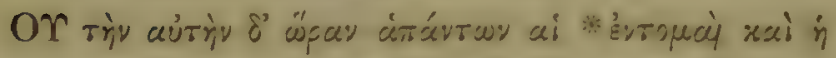

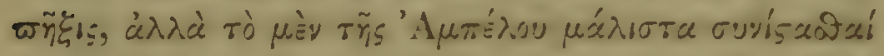

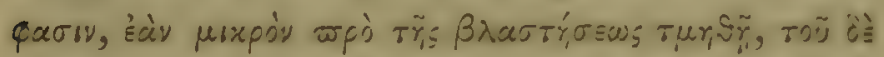

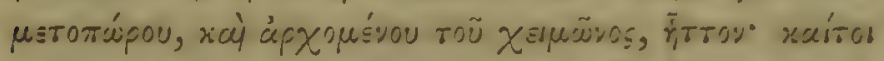

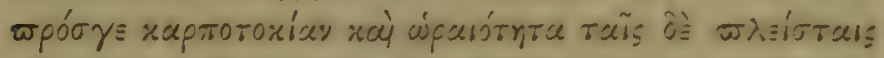

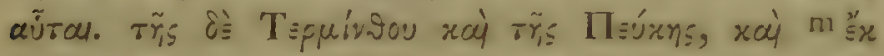

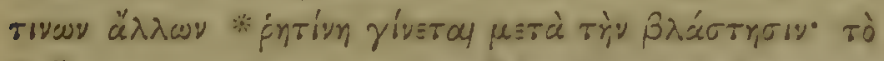

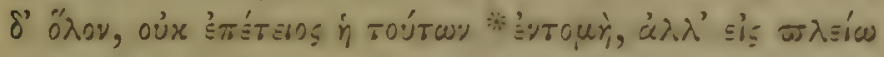

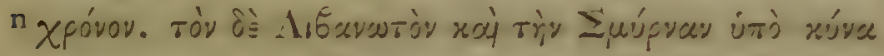

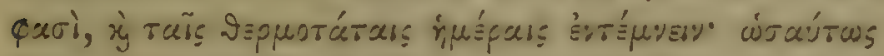

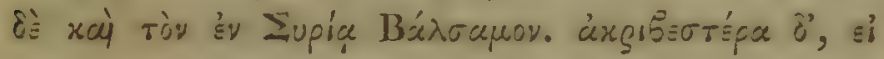

i Kequavia, Const.

1 Vid. not. ad finem libri.

n xpíray roúrov. Const. k àvaropris, Codd. Vid. cap. ii. $\mathrm{m}$ ทे ix Bod. a' ix Const. 


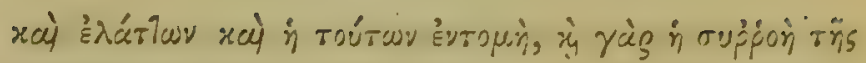

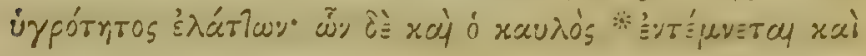

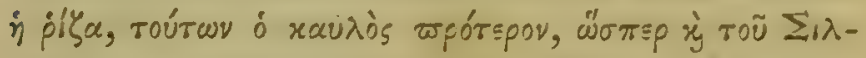

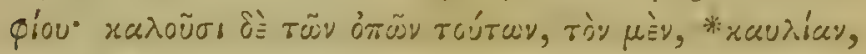

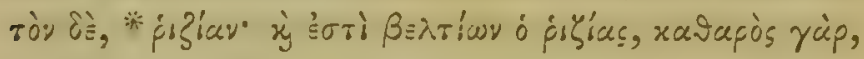

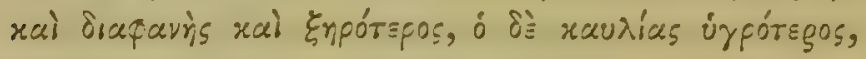

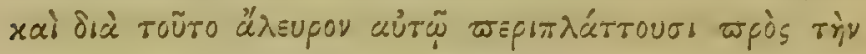

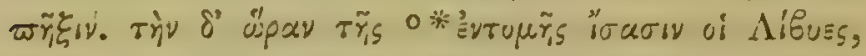

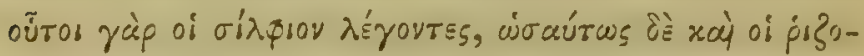

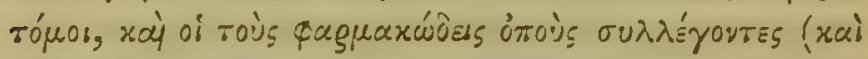

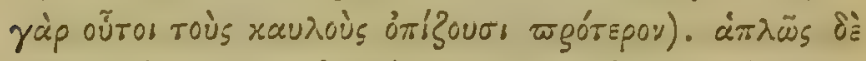
та́)

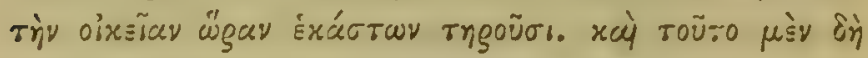

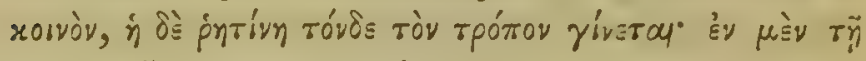

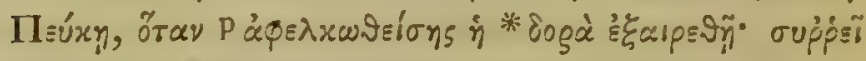

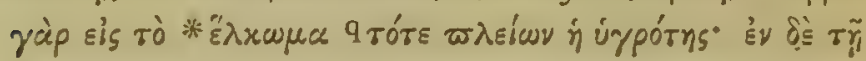

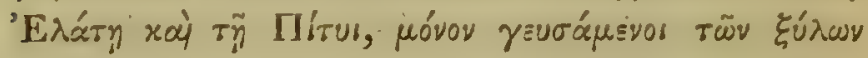

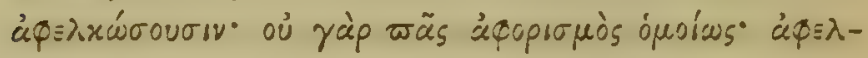

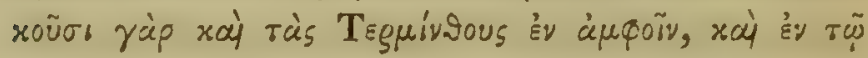

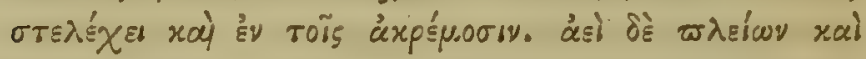

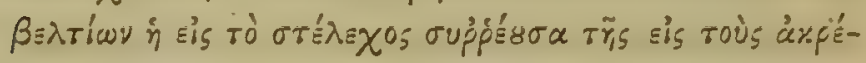

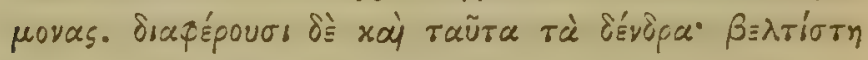

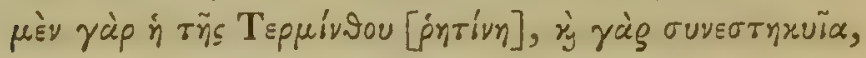

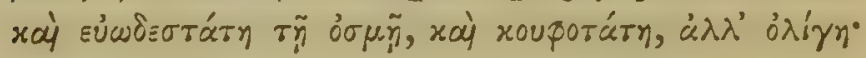

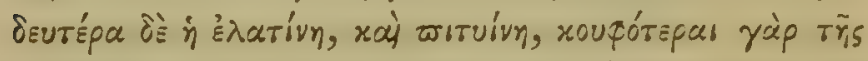

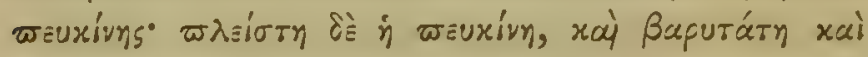

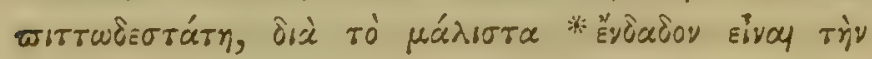

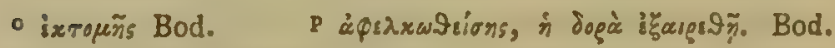

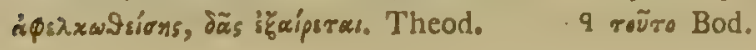




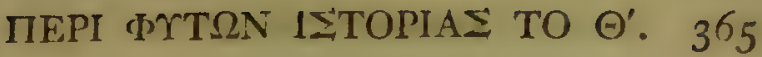

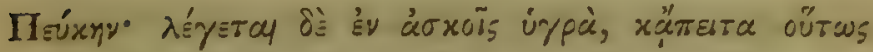

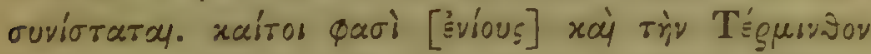

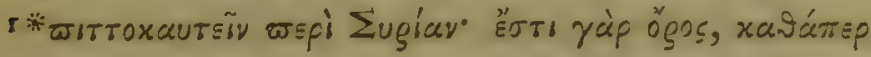

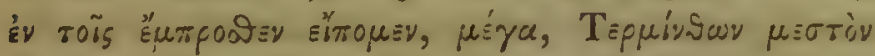

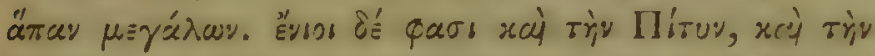

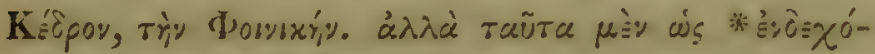

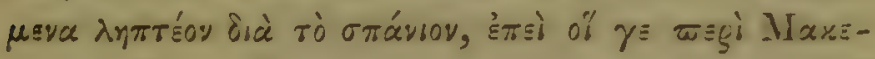

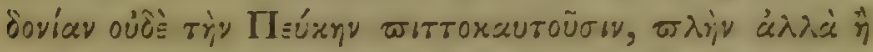

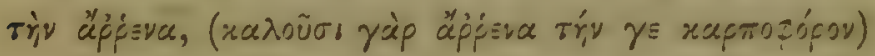

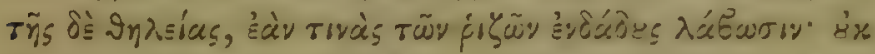

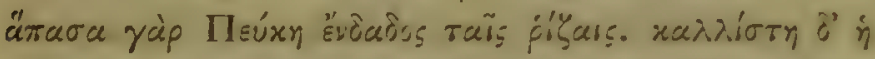

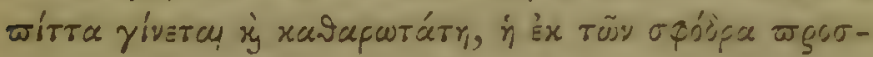

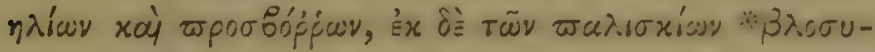

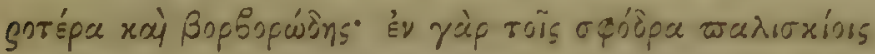

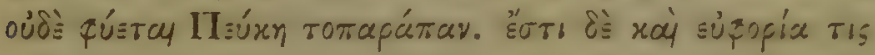

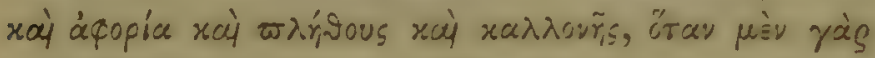

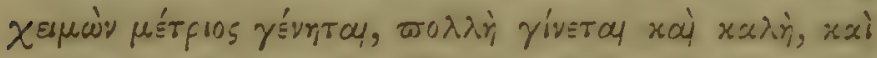

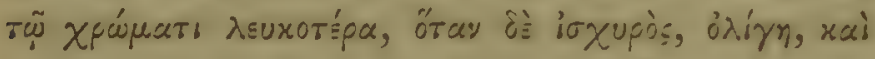

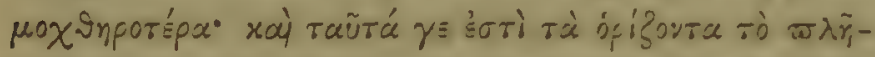

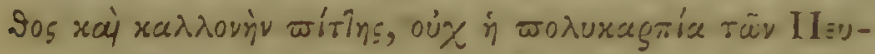

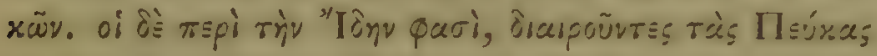

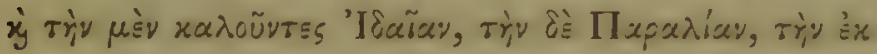

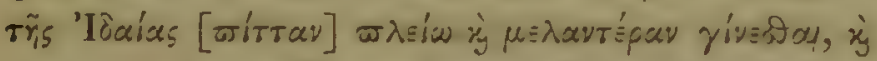

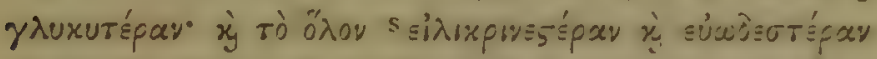

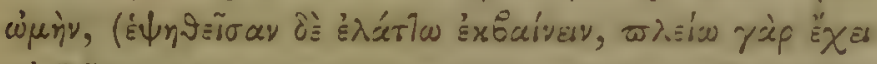

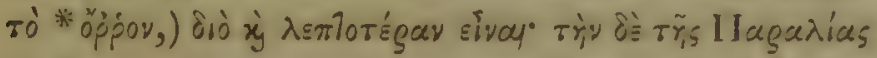

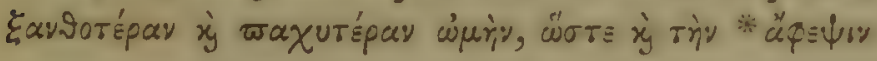

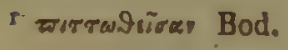

- sundisorigar Bod. 


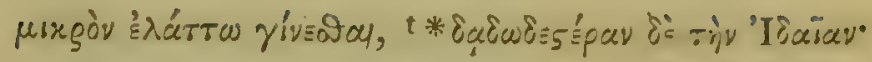

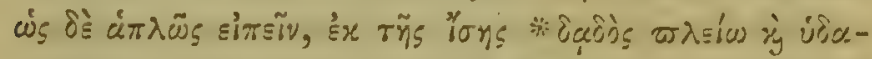

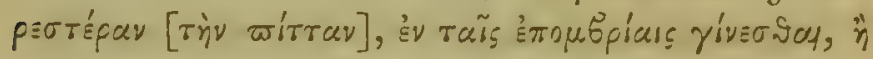

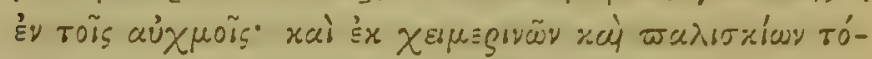

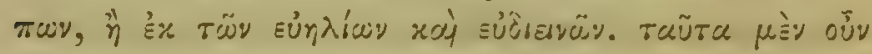

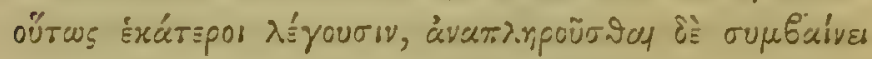

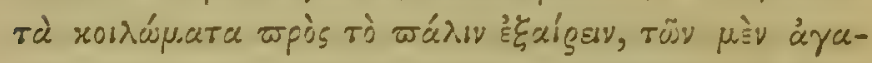

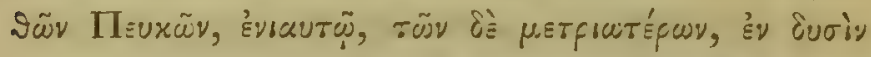

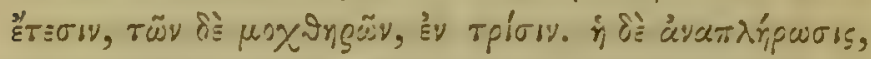

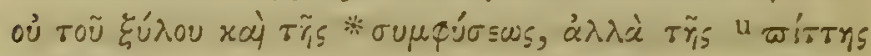

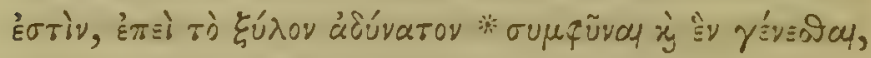

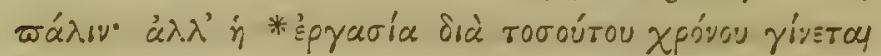

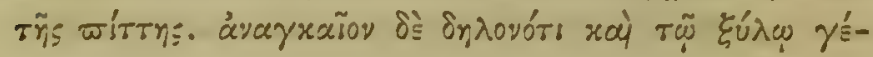

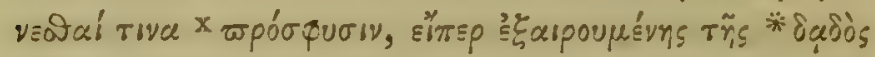

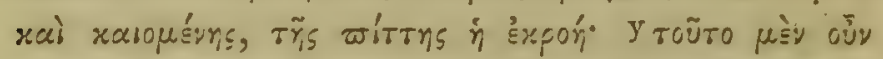
oü

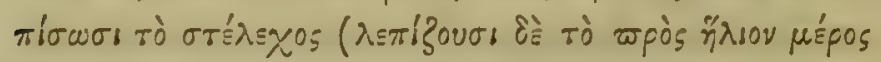

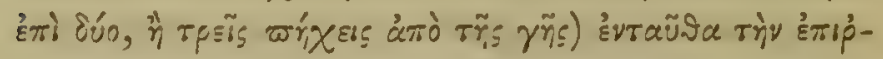

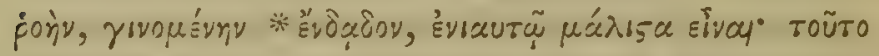

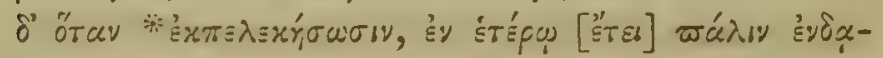

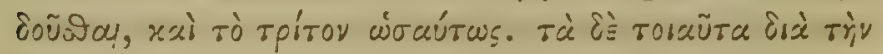

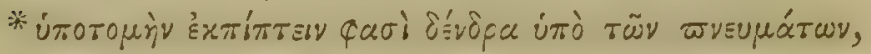

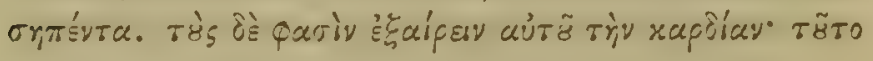

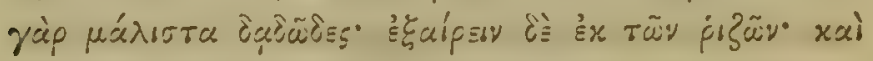

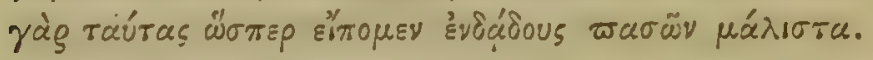

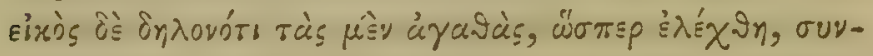

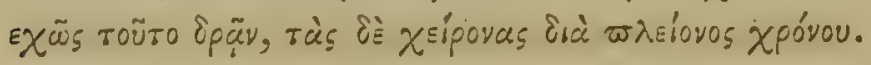

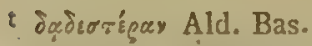
"pinrivys Const.
$x$ चॅéor-

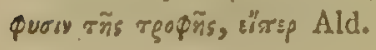
$y$ Vid. not. ad fin. libri. 


\section{MEPI TXTSN IITOPIA TO O'. 367}

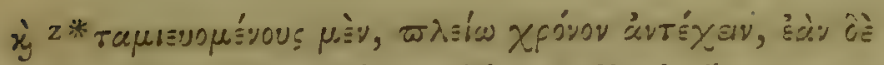

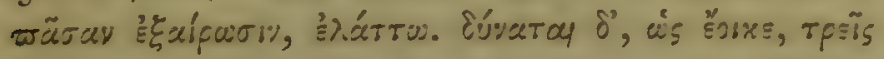

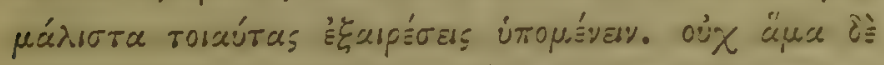

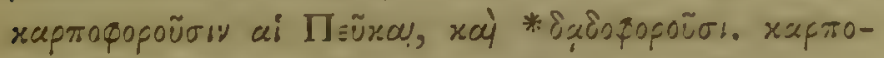

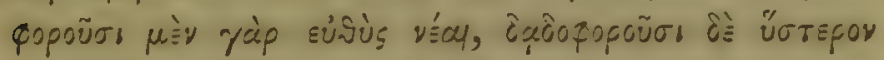

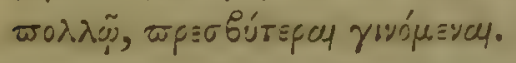

\section{CAP. III.}

Picis liquide et concrete Manipulatio.

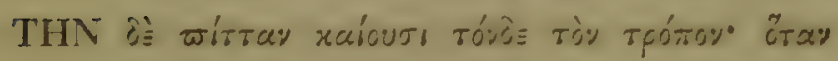

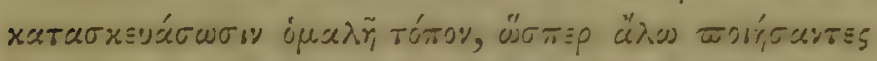

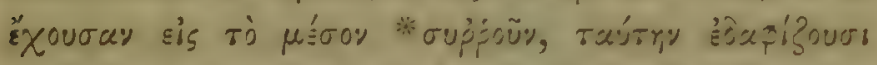

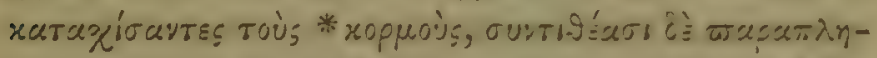

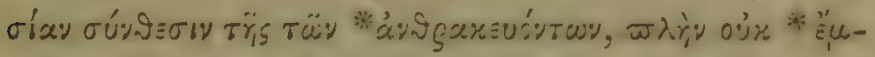

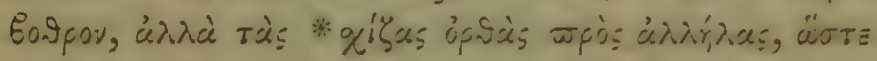

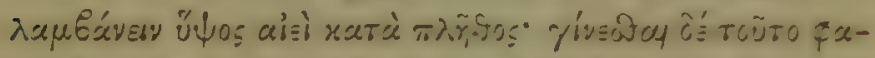

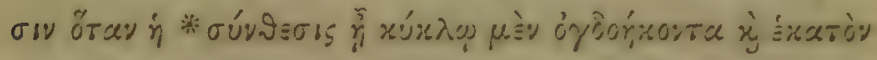

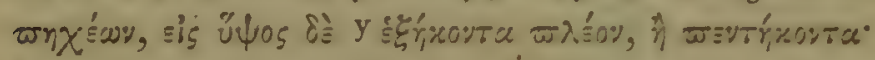

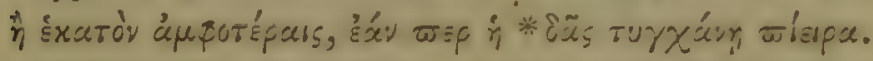

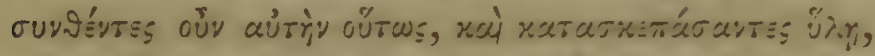

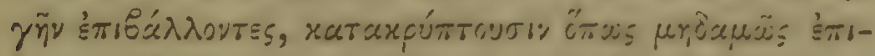

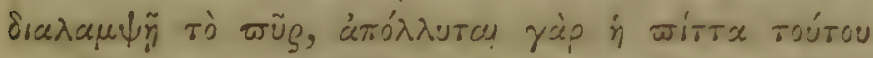

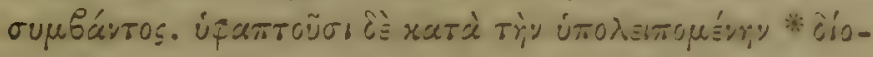

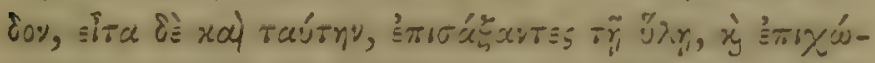

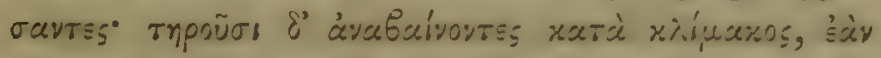

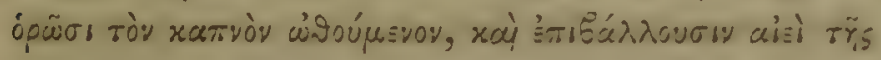

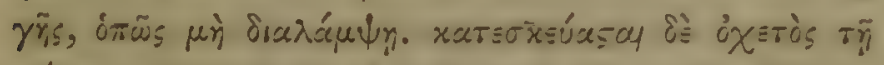

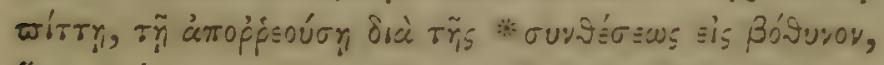

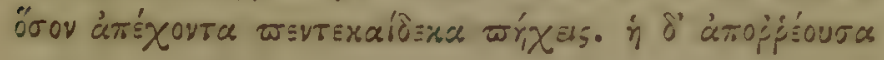

$x$ rapunuirwy Codd.

y vid. not. ad fin. libri. 


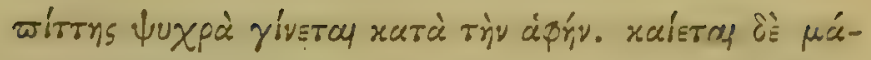

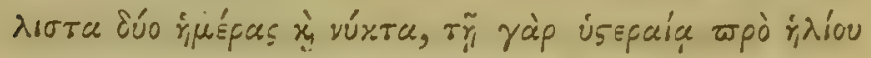

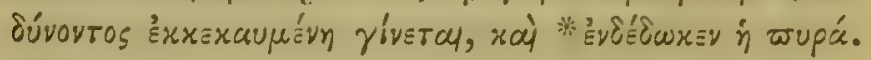

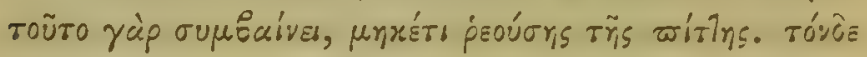

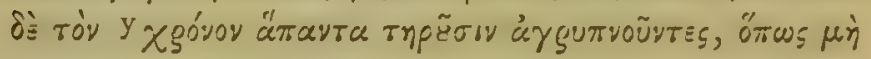

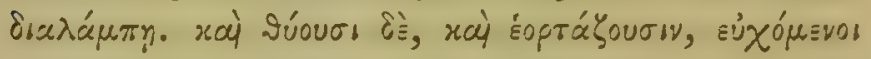

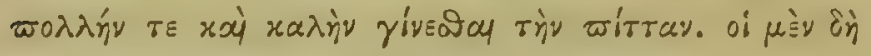

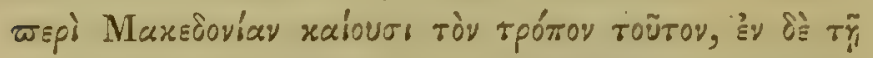

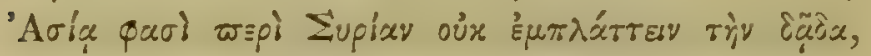

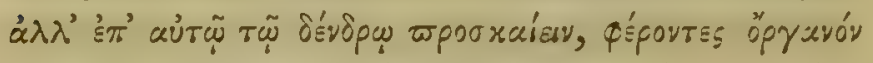

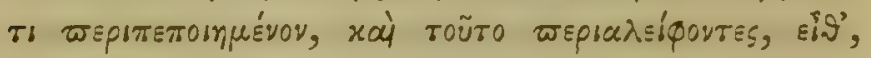

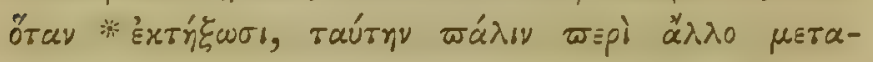

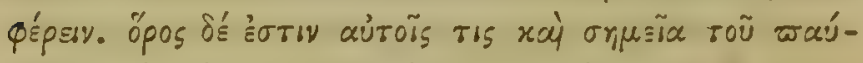

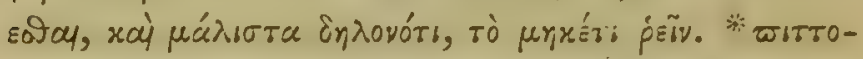

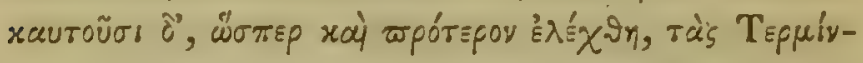

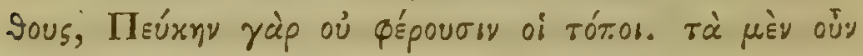

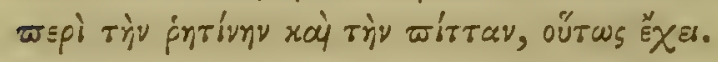

\section{CAP. IV.}

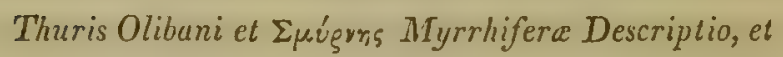

\section{Historia.}

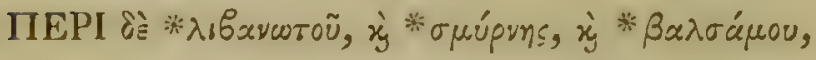

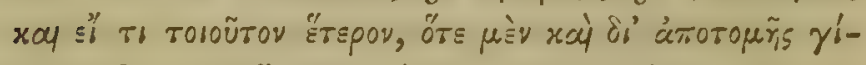

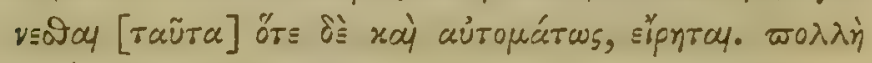

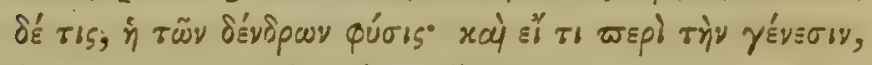

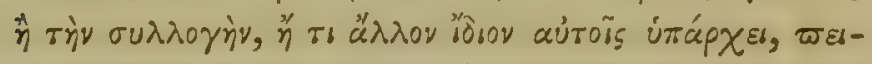

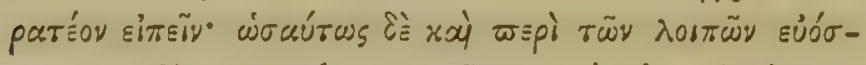

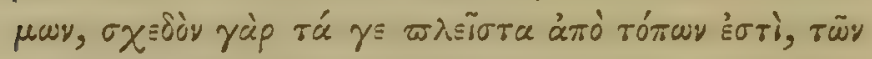

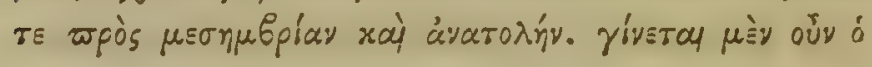

$$
y \text { réarror Codd. }
$$




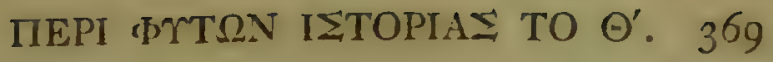

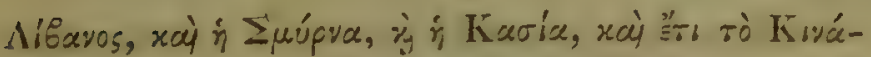

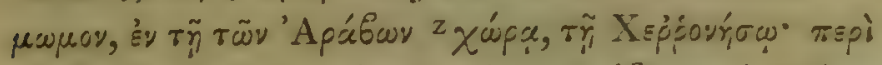

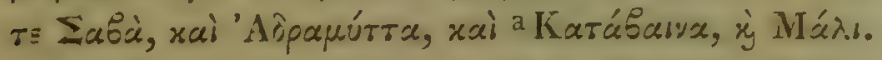

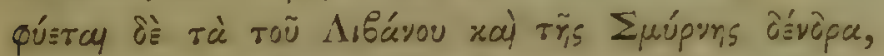

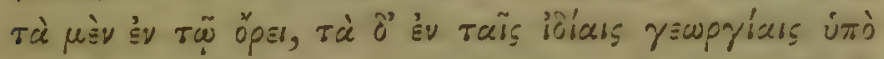

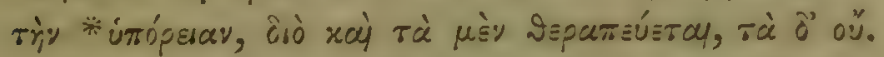

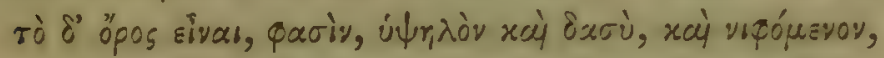

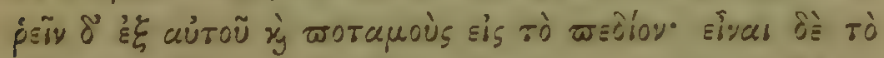

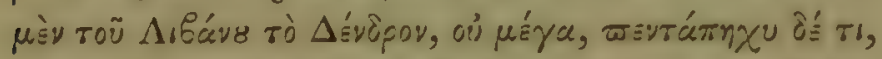

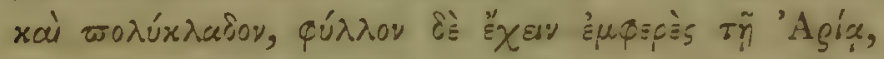

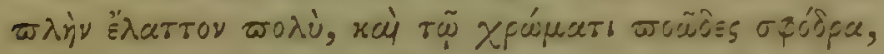

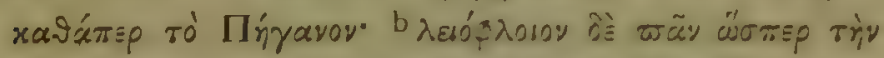

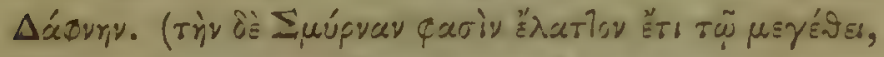

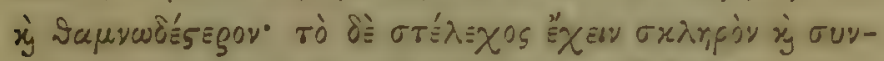

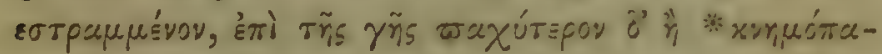

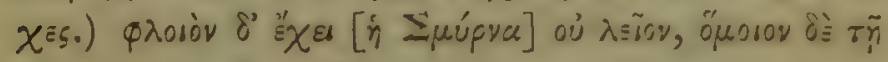

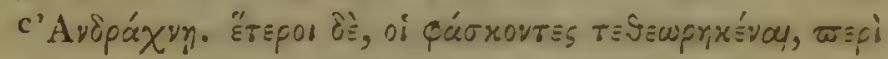

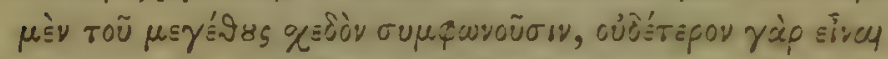

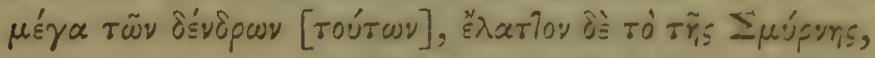

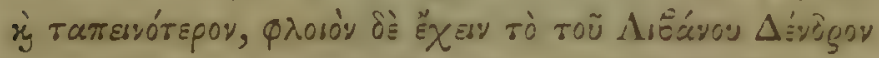

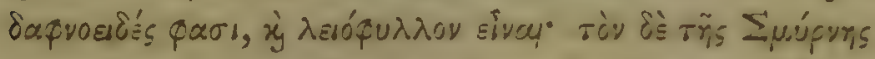

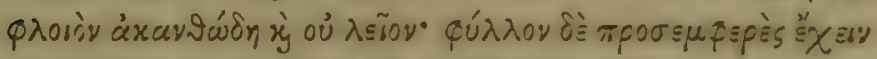
$\tau \tilde{\eta}$ "IT

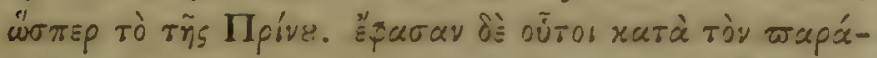

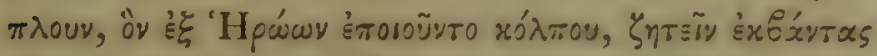

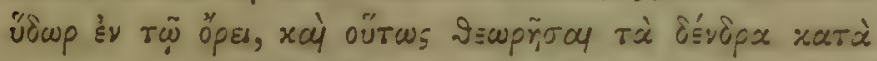

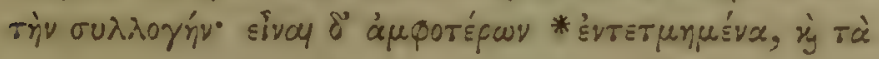

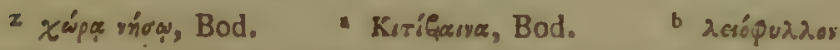
Codd. 'Aséáxy. Const. d'Ezaiá, Bod.
} 


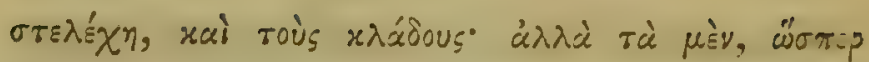

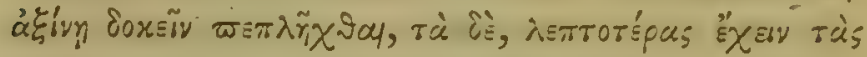

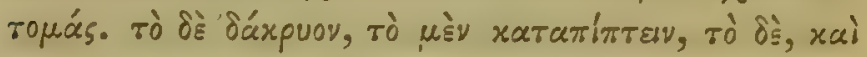

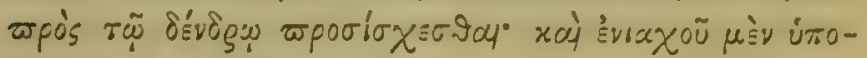

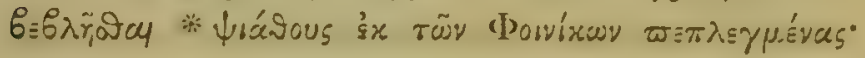

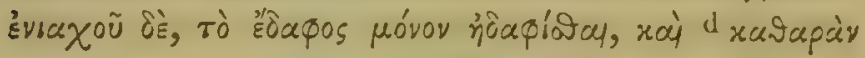

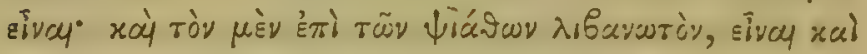

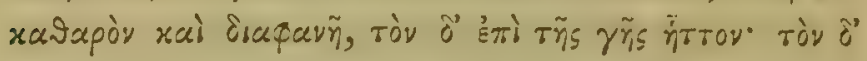

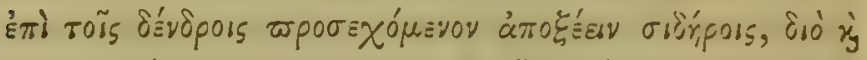

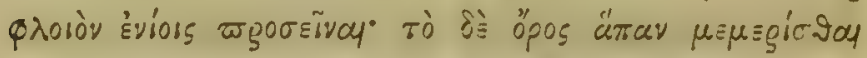

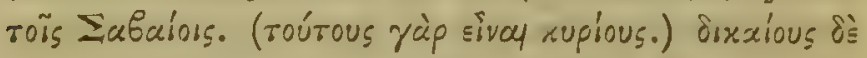

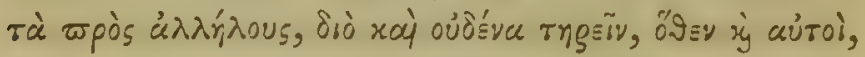

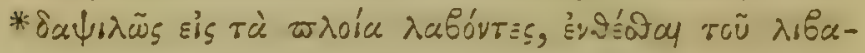

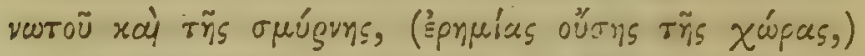

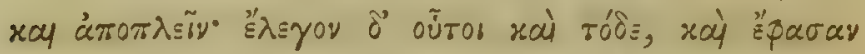

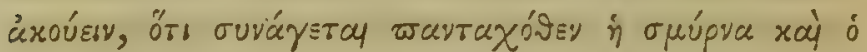

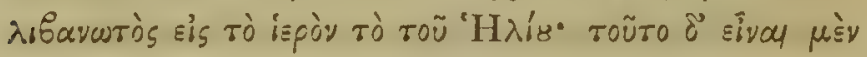

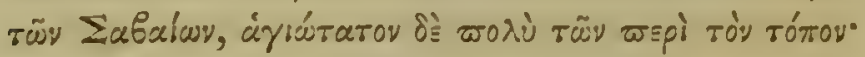

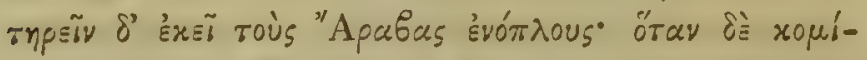

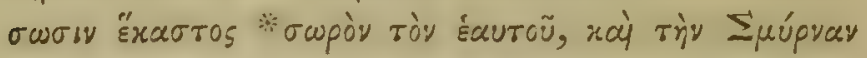

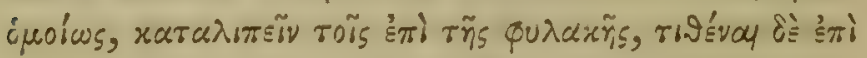

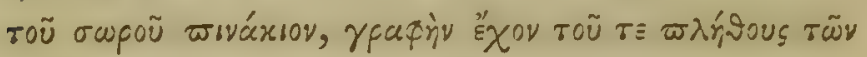

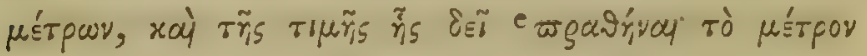

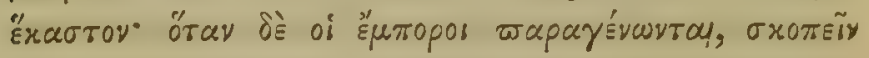

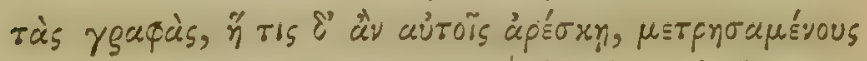

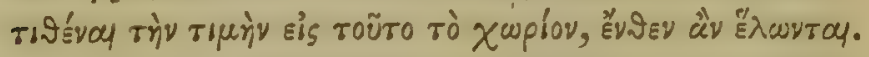

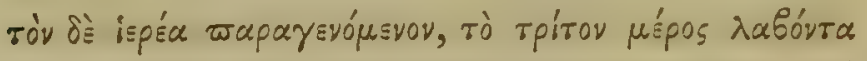

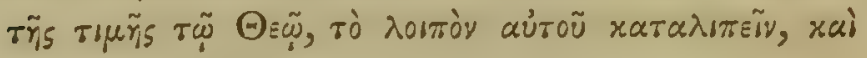




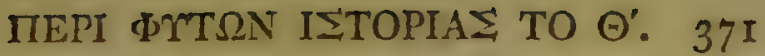

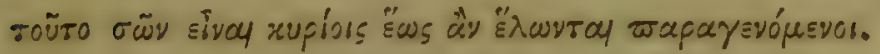

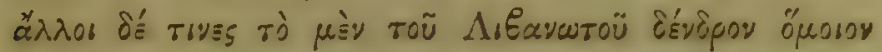

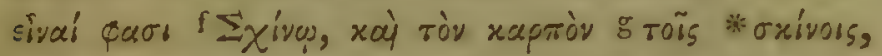

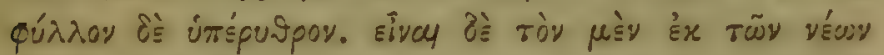

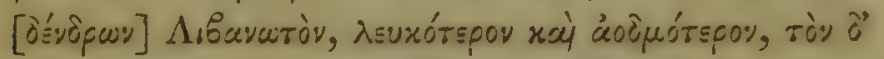

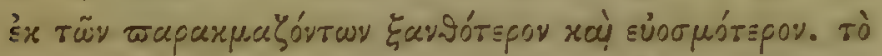

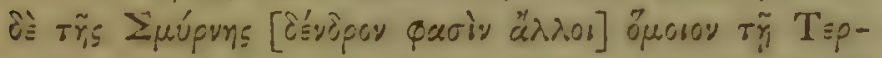

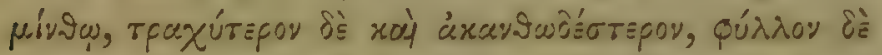

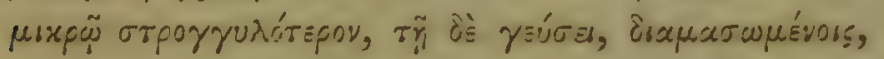

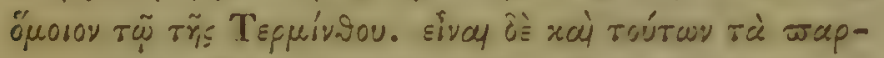

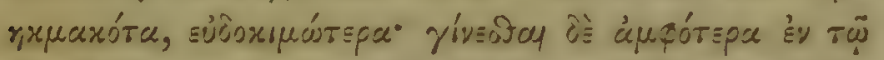

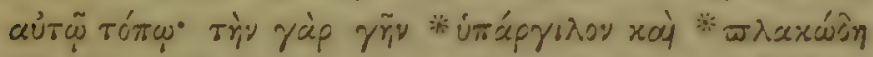

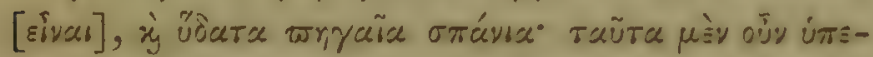

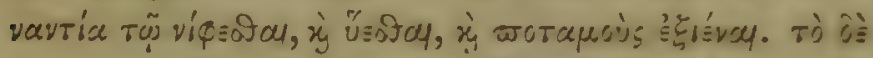

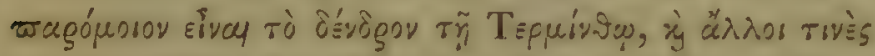

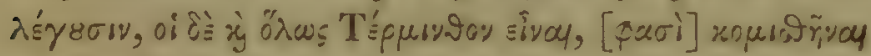

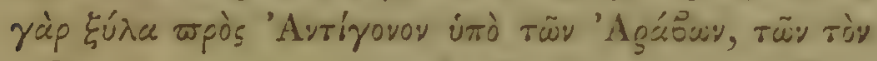

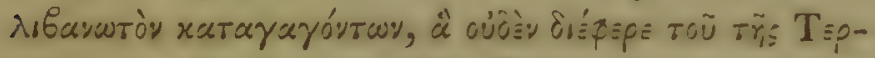

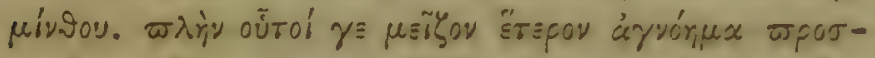

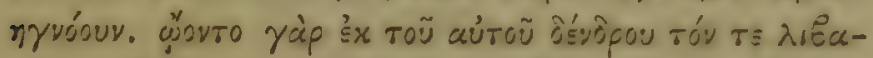

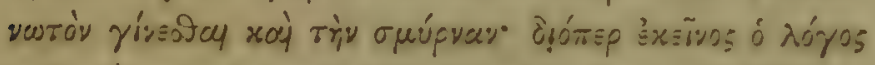

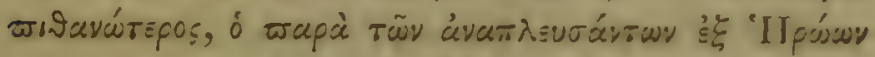

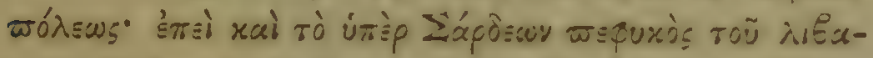

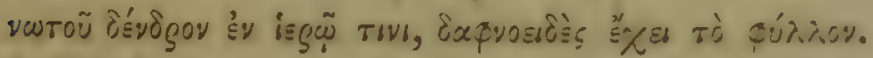

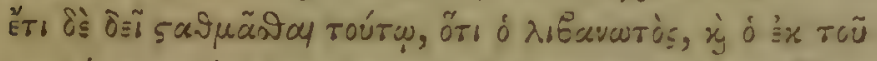

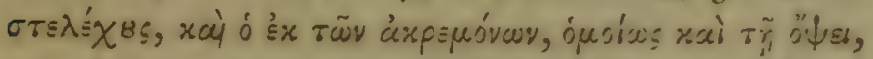

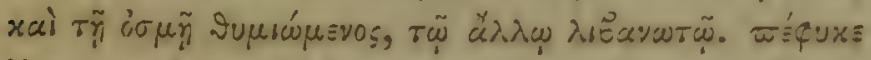

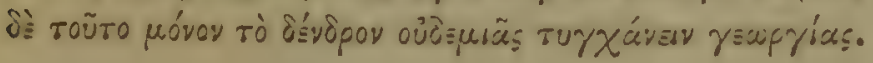

5xoiyn, Bod. $\quad$ soĩs oxives, Const. oxoivies, Bod.

PARS II.

$\mathbf{K}$ 


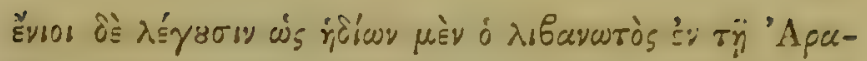

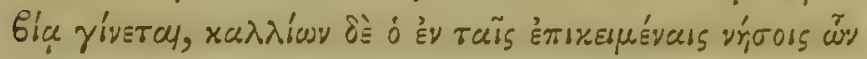

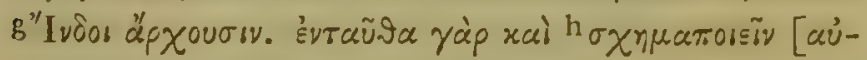

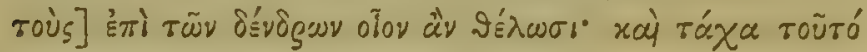

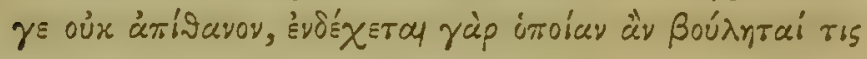

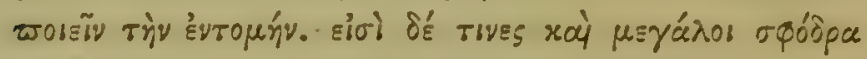

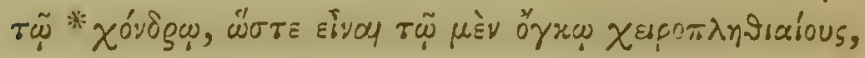

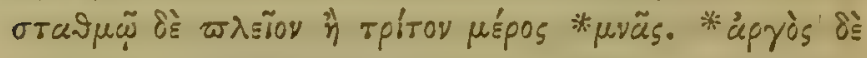

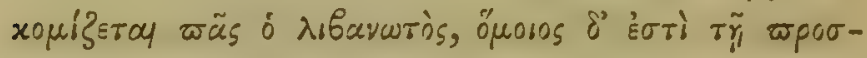

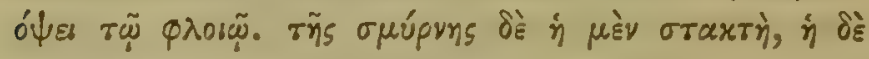

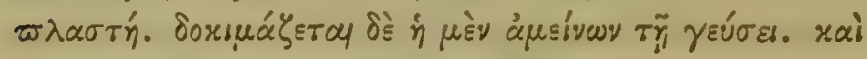

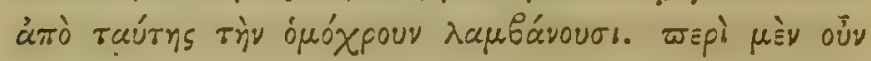

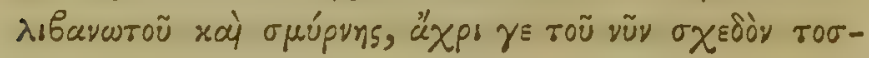

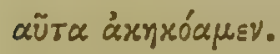

\section{CAP. V.}

Laurus Cinnamomum et Laurus Cassia, \&c.

ПIEPI $\delta$ Ė Kı

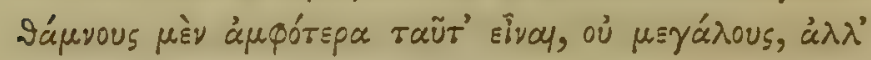

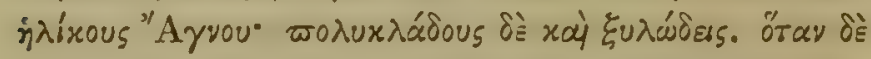

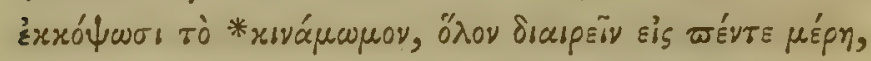

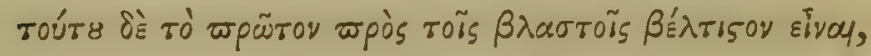

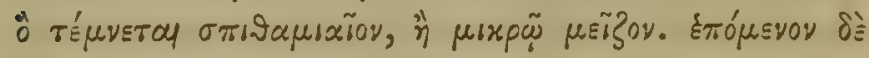

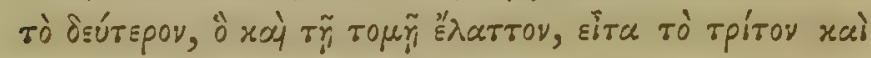

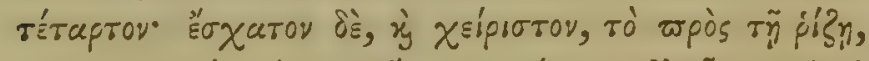

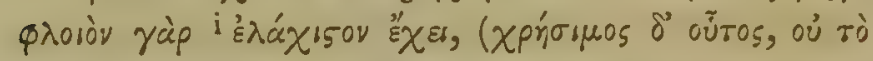

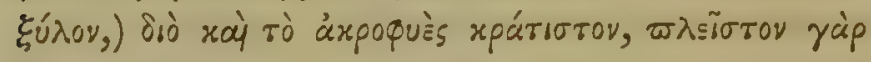

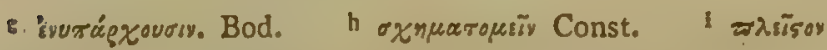

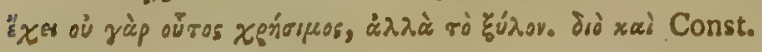




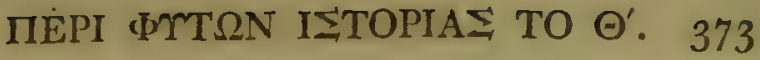

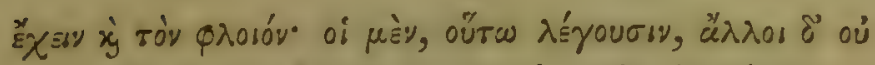

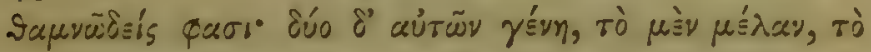

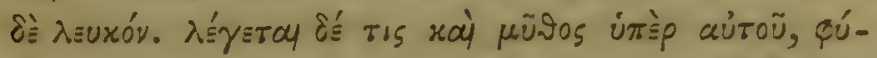

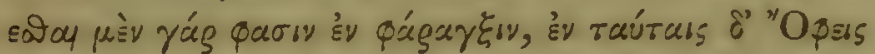

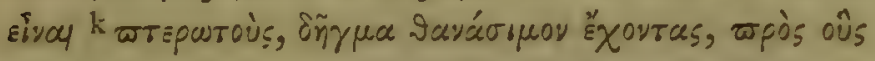

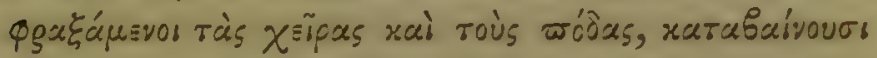

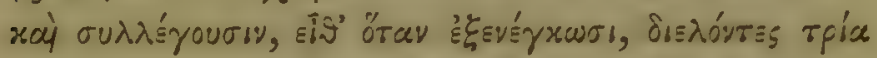

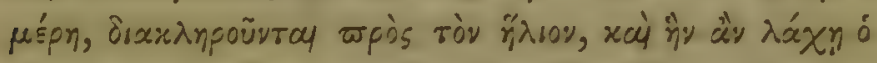

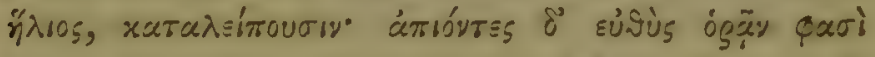

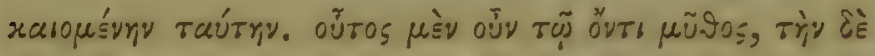

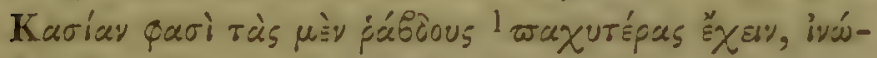

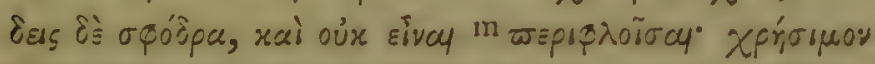

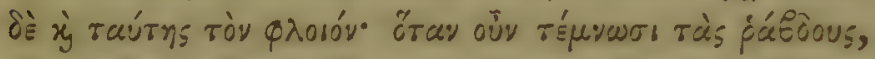

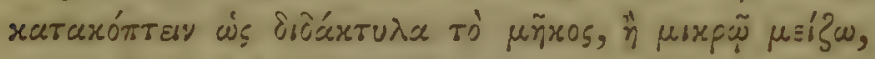

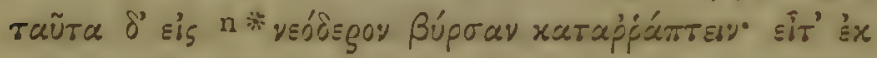

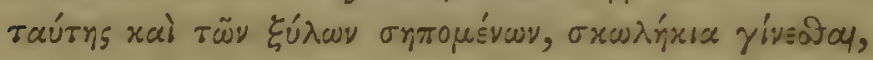

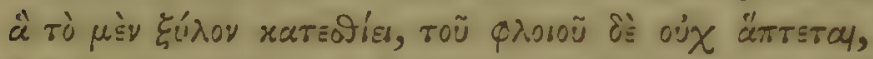

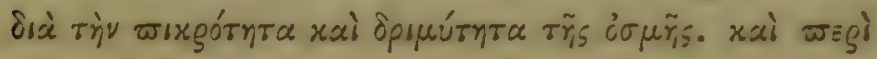

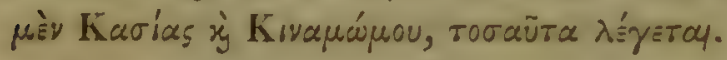

\section{CAP. VI.}

Balsami, Balessan, Historia.

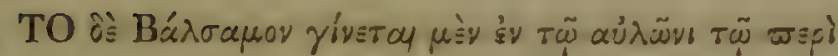

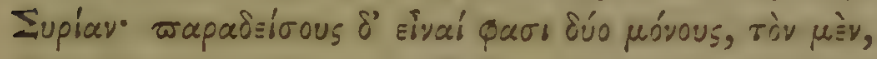

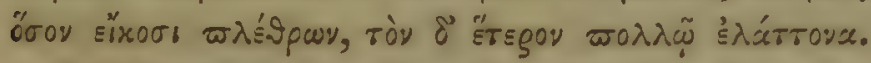

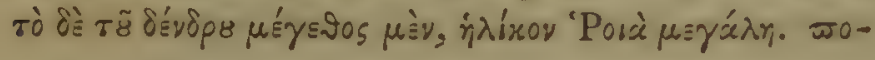

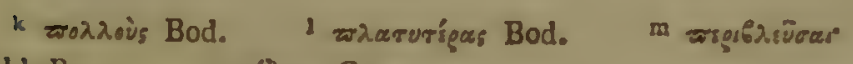
Ald. Bas. n ytódogar Const.

\section{K 2}




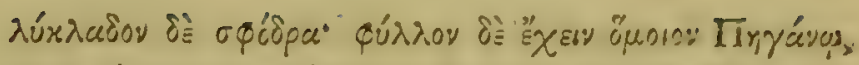

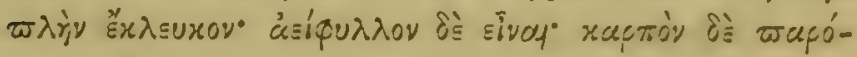

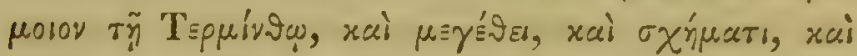

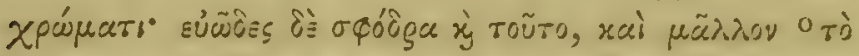

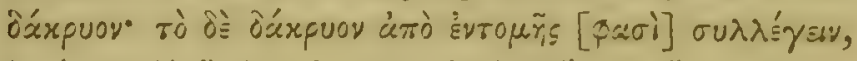

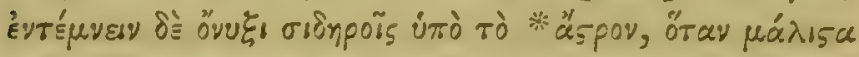

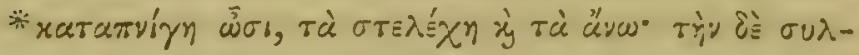

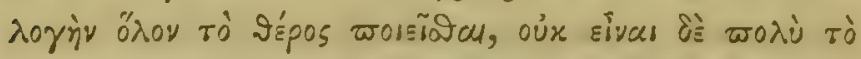

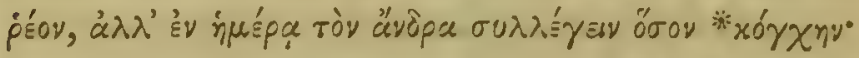

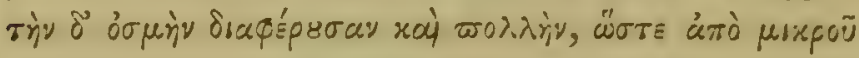

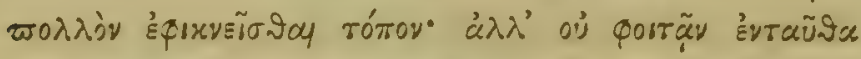

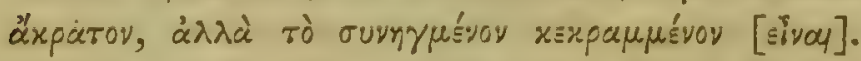

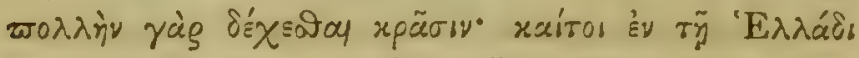

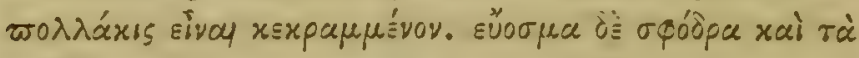

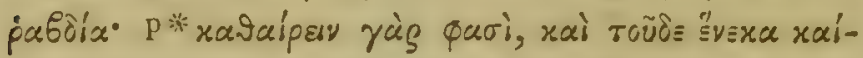

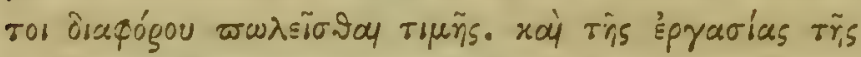

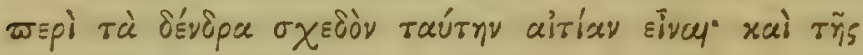

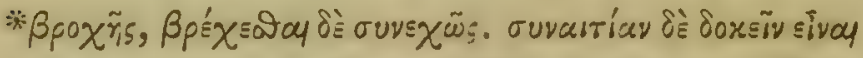

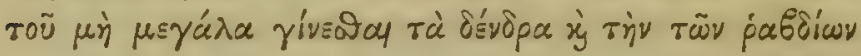

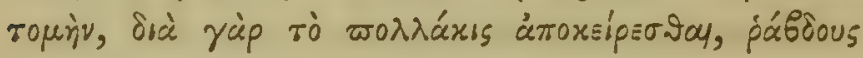

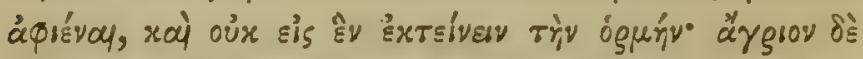

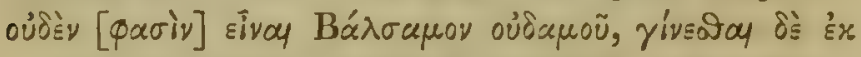

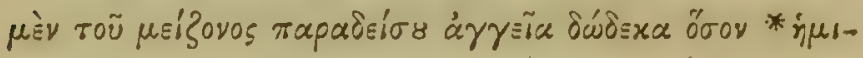

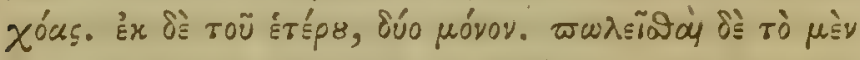

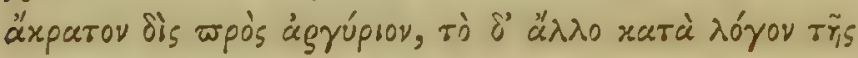

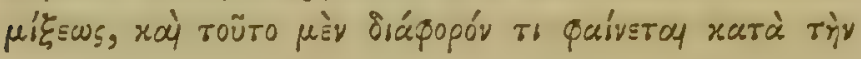
Evंo $\sigma \mu i \alpha$.

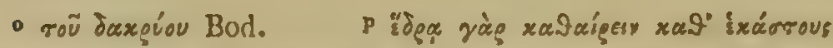

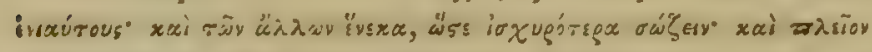

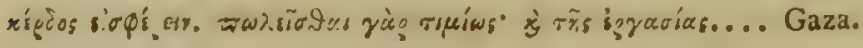




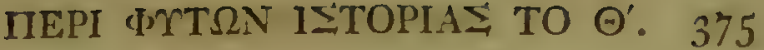

\section{CAP. VII.}

Acorus Calamus: Amomum, aliceque Balsumiferce Arbores.

Item de Unguentis Antiquorum.

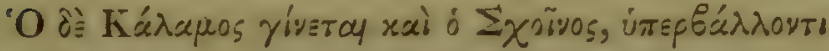

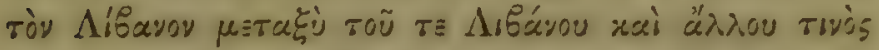

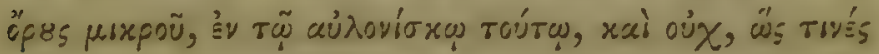

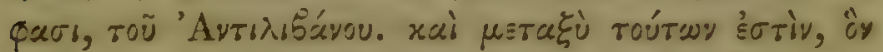

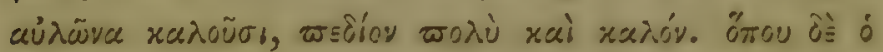

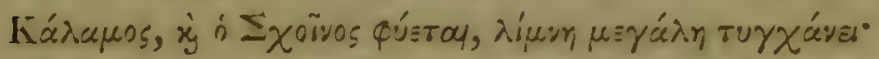

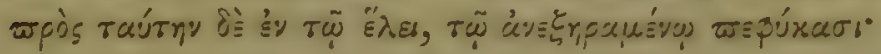

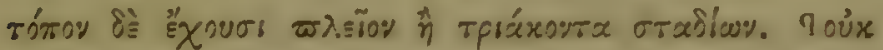

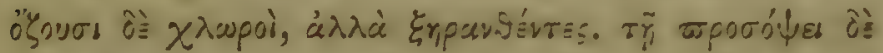

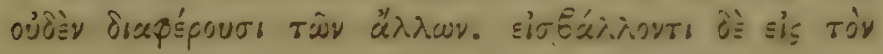

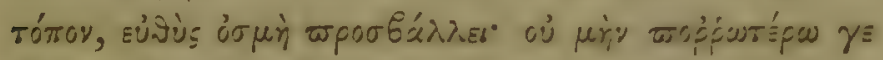

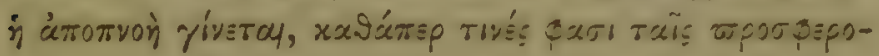

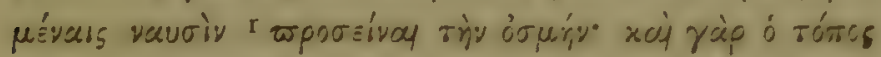
oữ

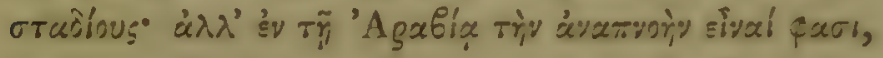

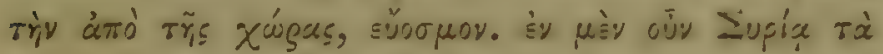

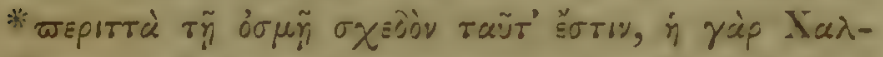

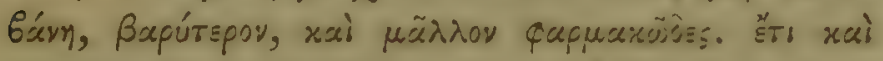

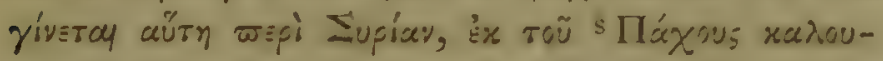

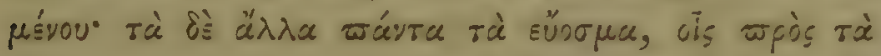

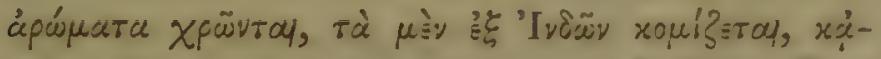

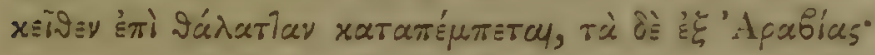

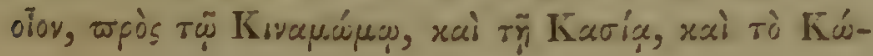

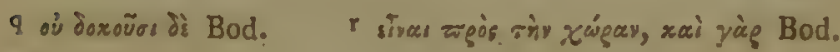
- axúxou Const.

K 3 


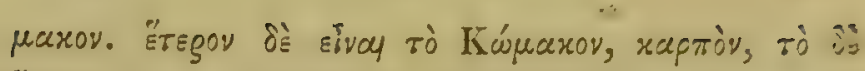

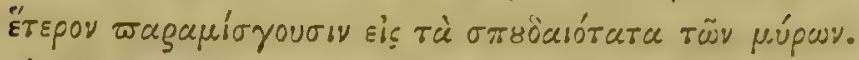

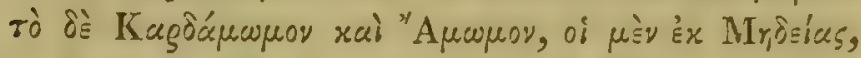

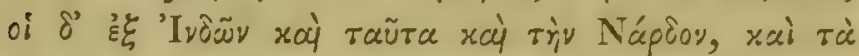

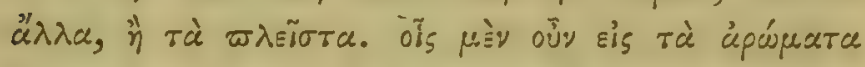

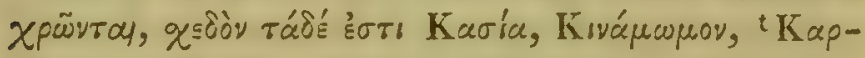

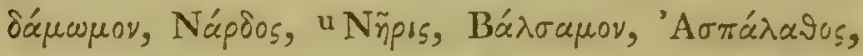

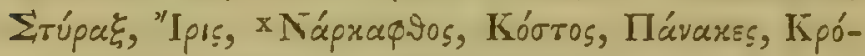

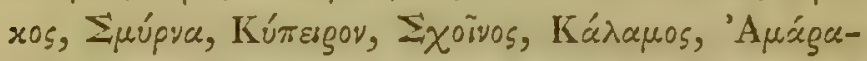

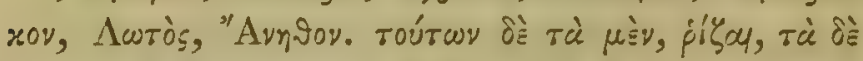

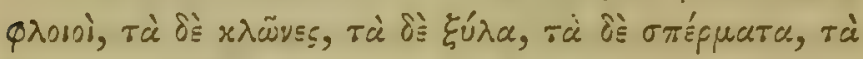

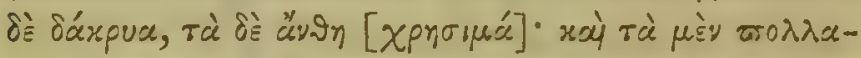

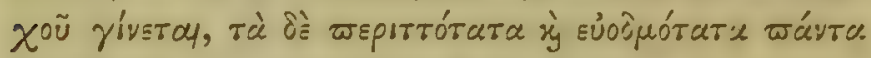

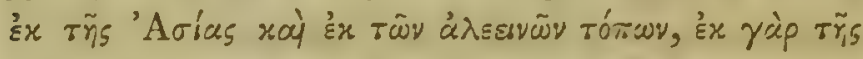

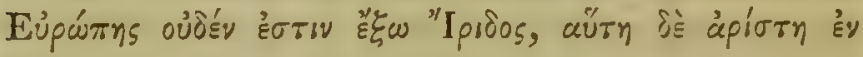

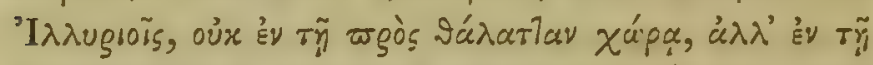

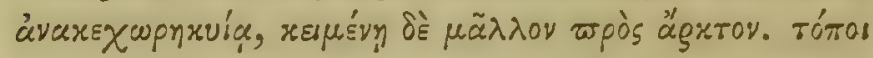

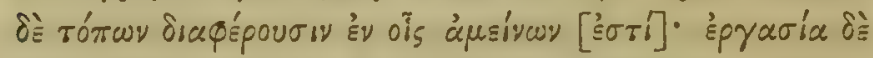

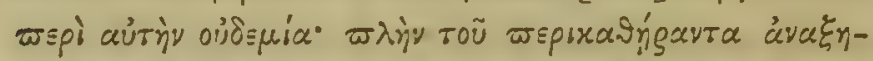

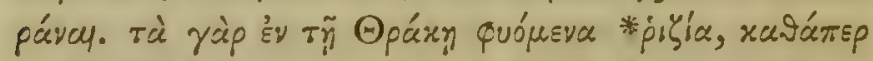

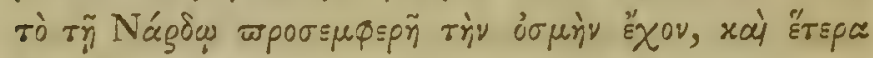

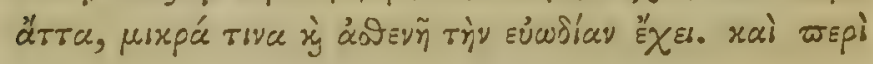

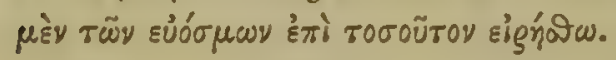

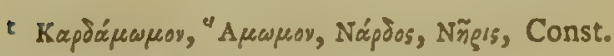

is Naigor,

Bod. $x$ Nágrr, Bod. 


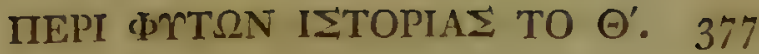

\section{CAP. VIII.}

Vires Pharmaceutica Planlarnu, et Modi extrahendi Succos.

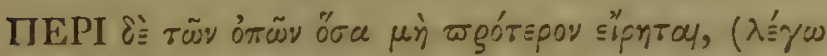

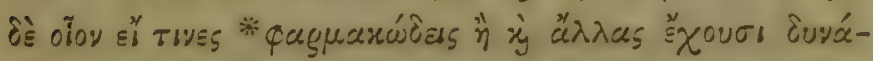

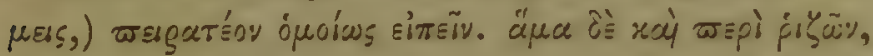

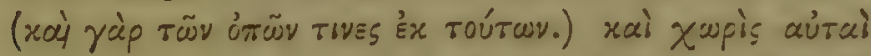

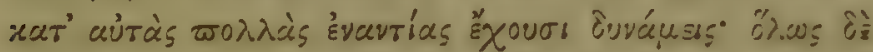

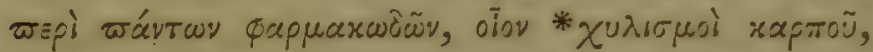

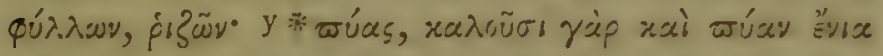

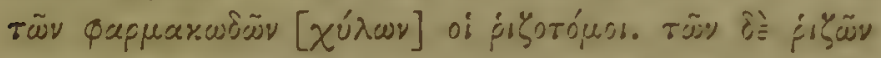

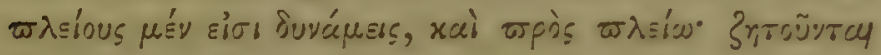

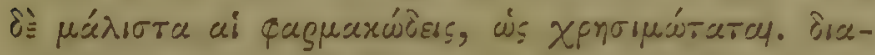

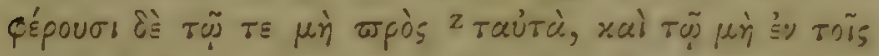

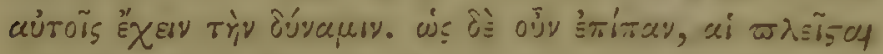

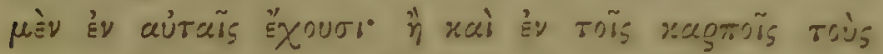

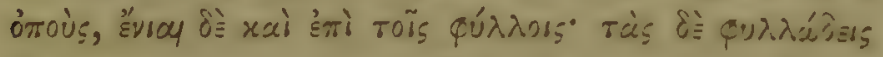

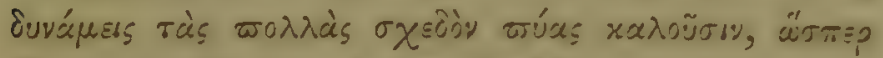

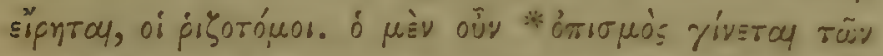

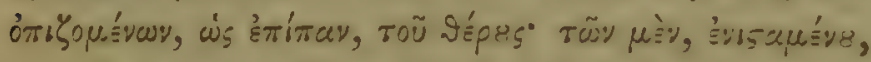

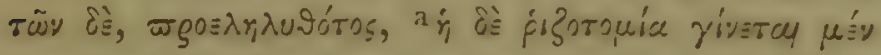

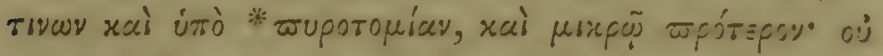

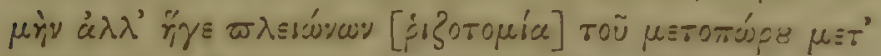

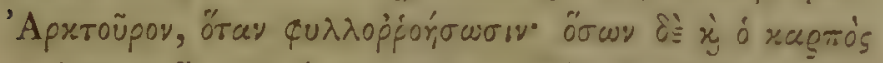

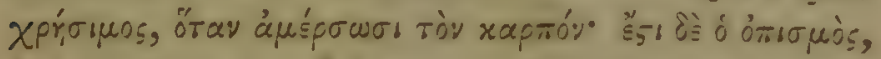

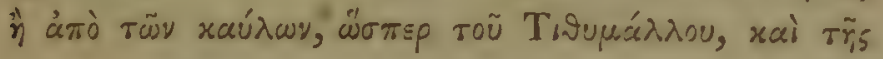

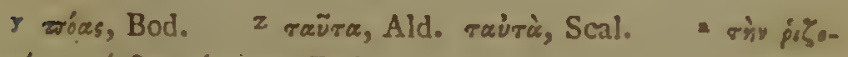

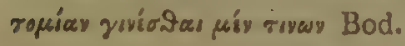

\section{K 4}




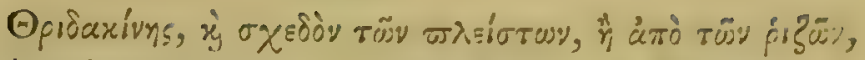

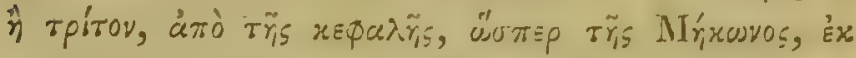

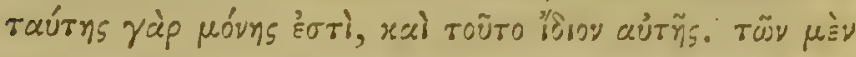

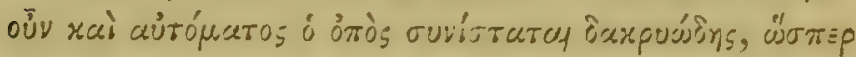

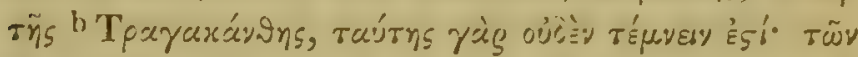

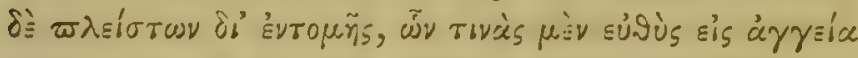

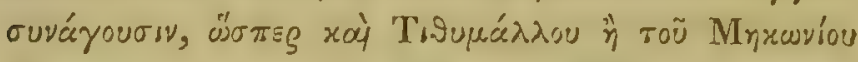

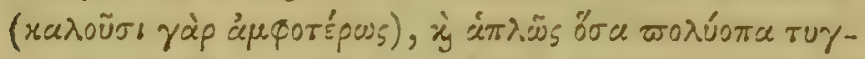

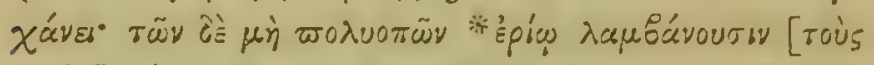

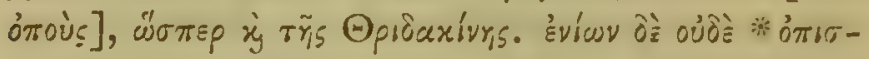

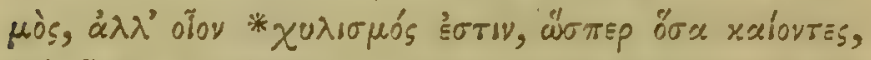

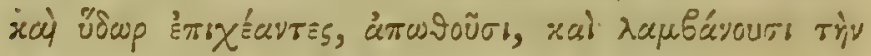

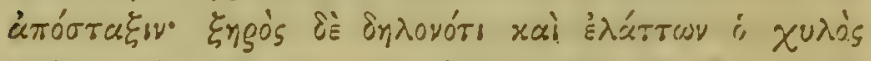

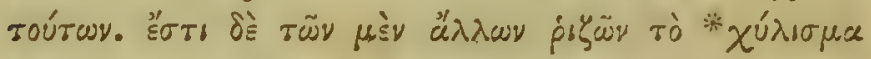

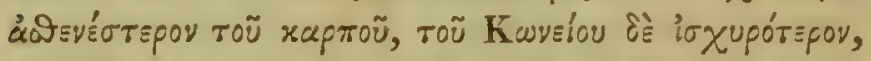

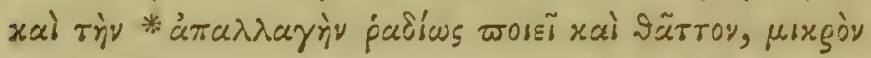

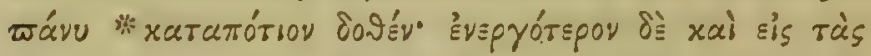

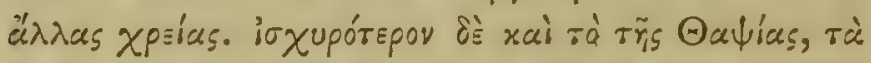

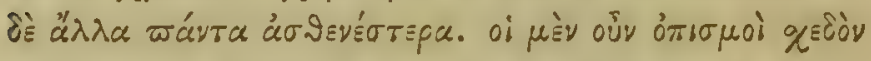

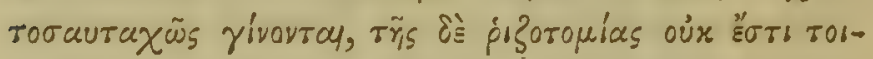

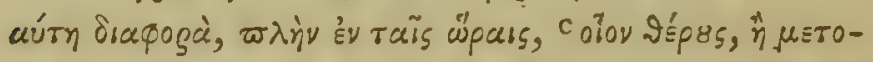

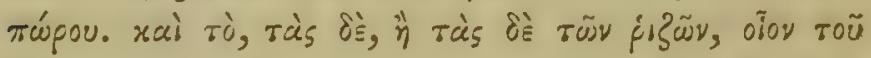

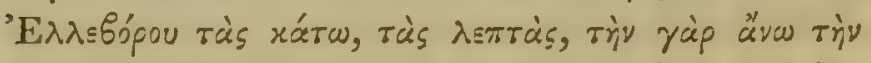

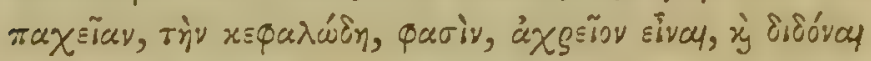

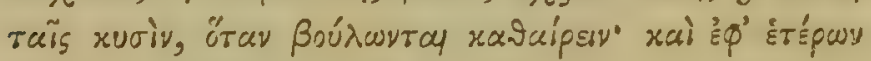

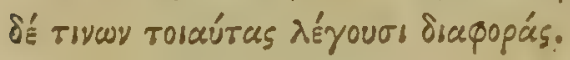

b T९raxrivans, Bod, error typogr. c Vid. not. ad finem libri. 


\section{MEPI ФYT $\Omega N$ IITOPIAS TO $\Theta^{\prime} .379$}

\section{CAP. IX.}

Modi et Tempora colligendi Succos, \&.c. medicinales.

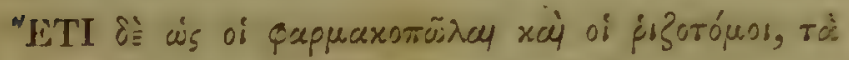

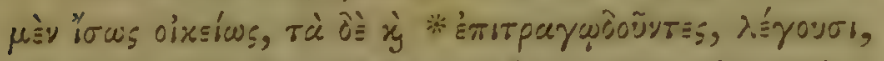

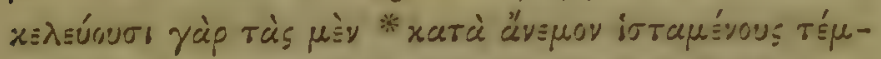

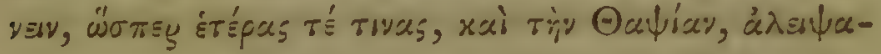

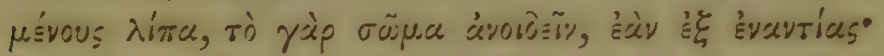

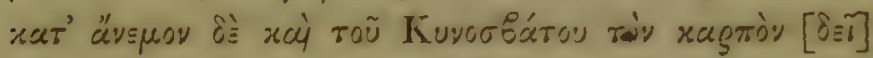

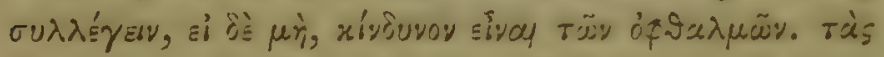

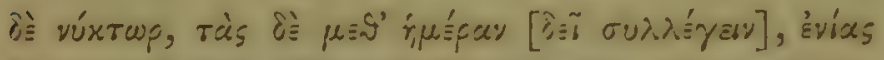

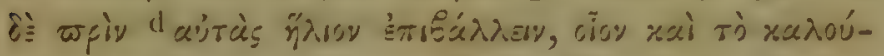

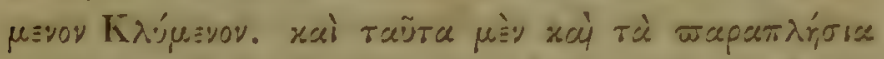

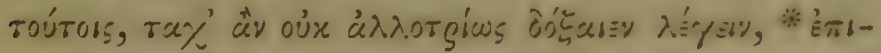

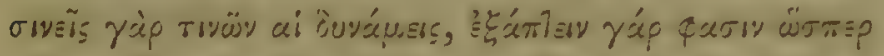

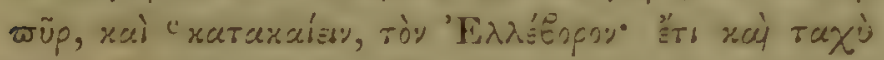

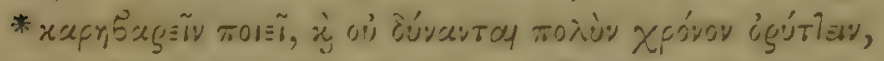

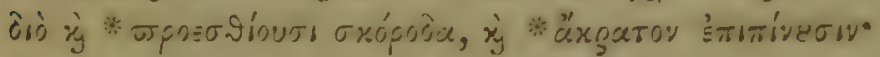

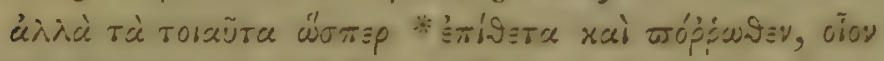

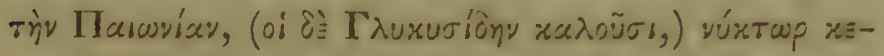

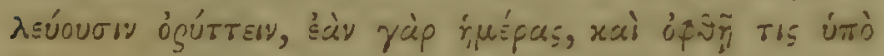

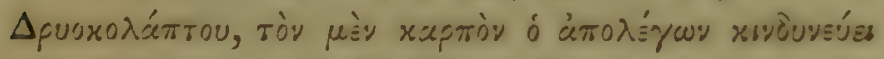

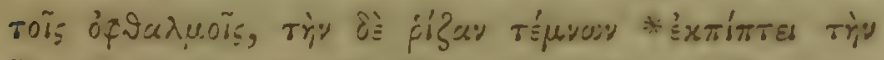

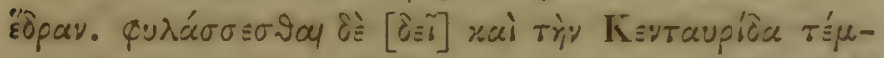

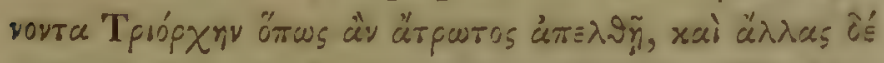

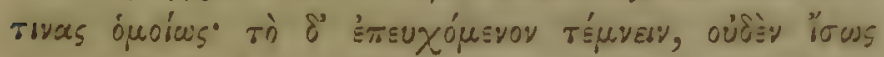

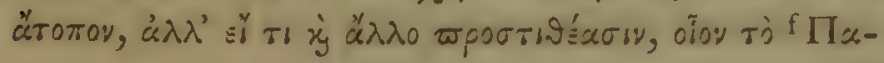

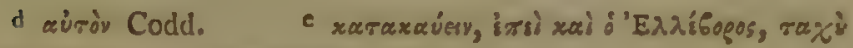
Ald. Bas. $\quad$ - 


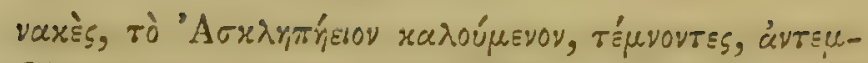

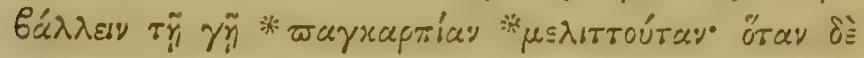

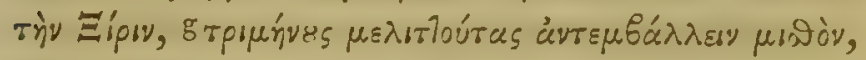

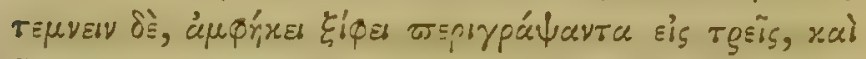

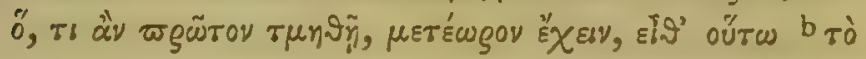

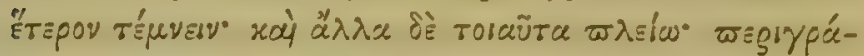

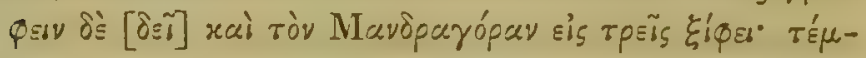

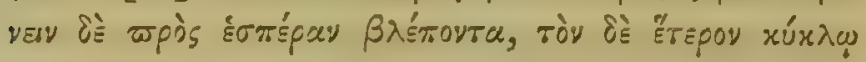

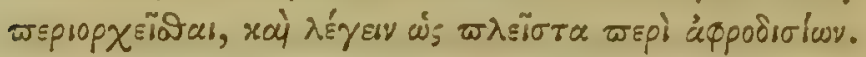

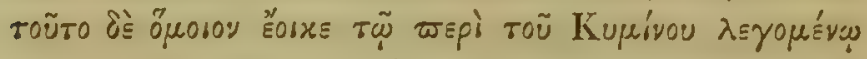

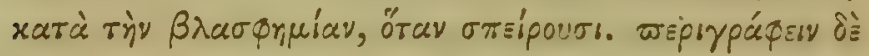

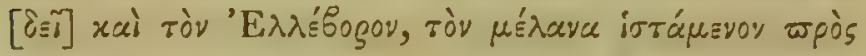

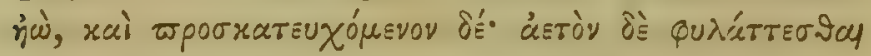

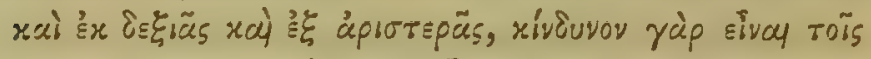

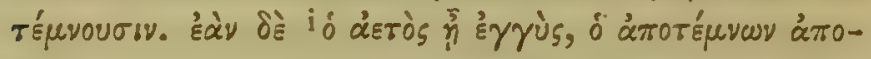

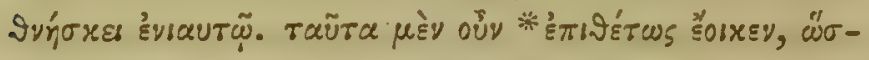

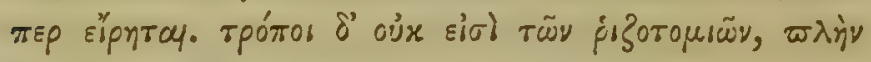

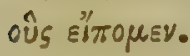

\section{CA'P. X.}

Sucii medicinales, Laserpitii, Scammonii, Thapsice, \&.c.

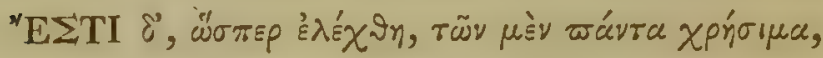
xх⿱

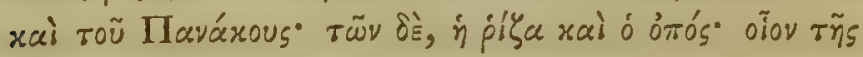

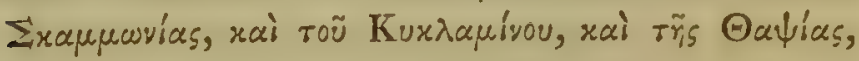

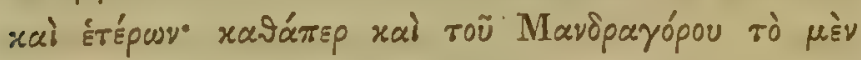

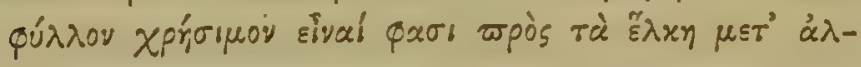

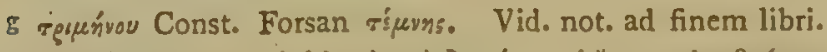

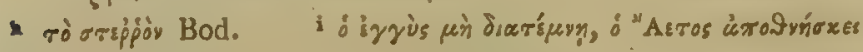

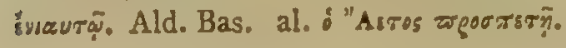




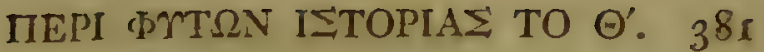

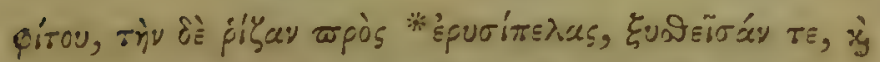

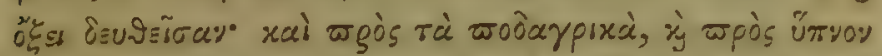

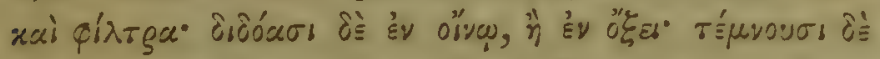

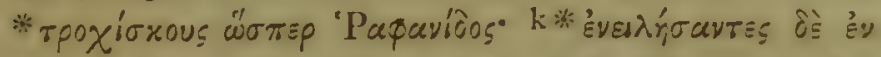

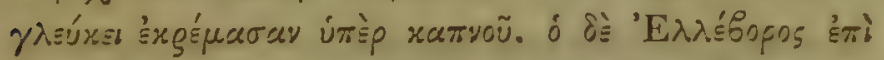

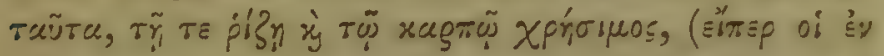

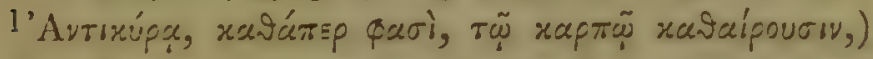

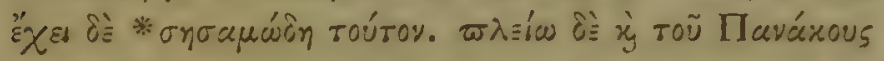

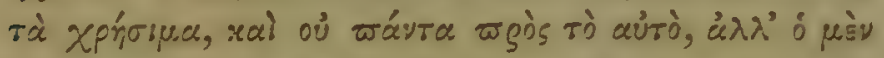

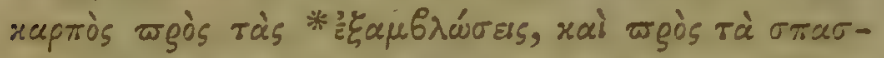

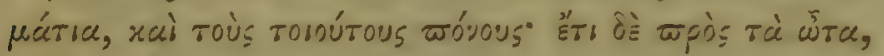

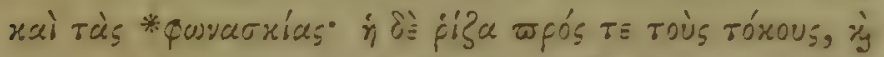

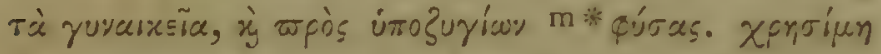

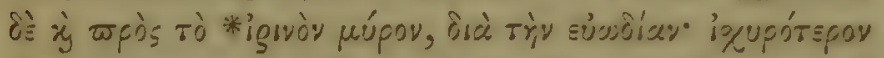

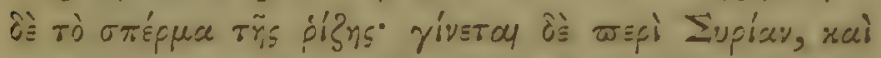

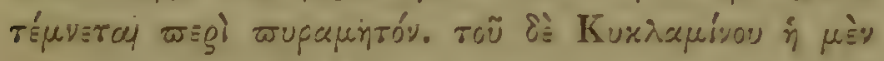

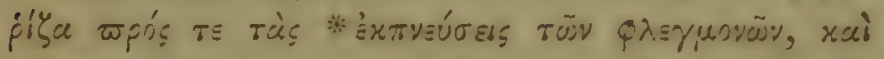

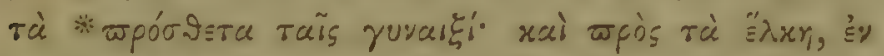

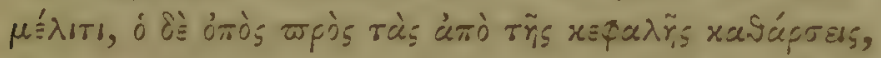

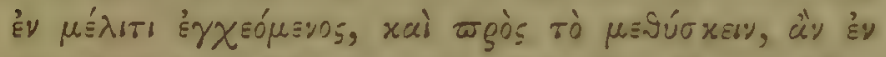

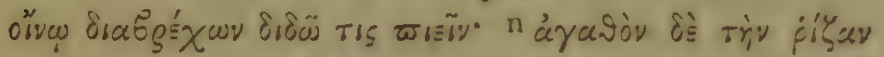

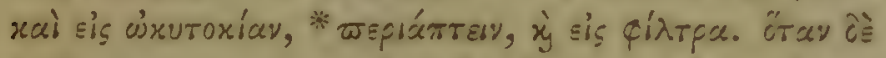

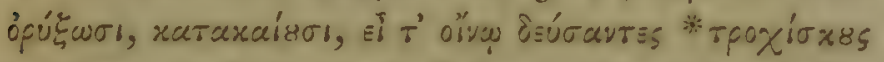

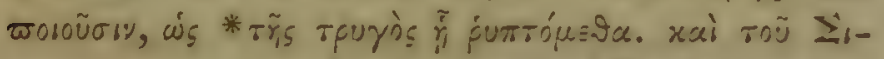

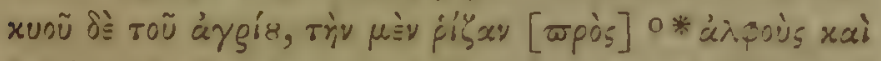

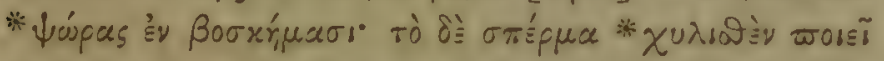

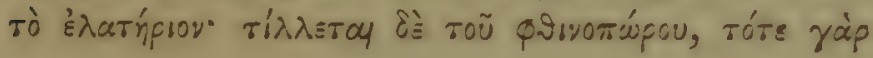

$k$ invipayrzs di Bod. res. Bod.

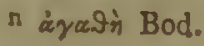

1 áyxú $\varrho x$, Ald. Bas. m Qú-

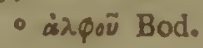




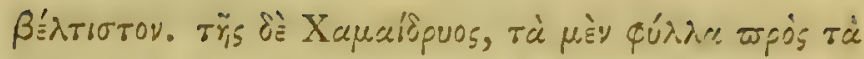

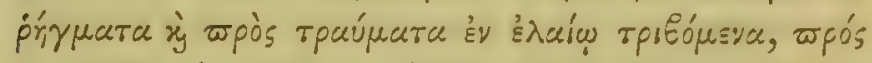
$\tau \equiv \tau \dot{\alpha}$ "

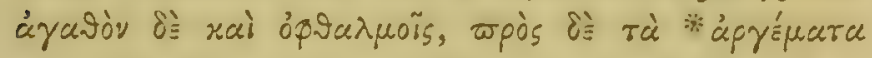

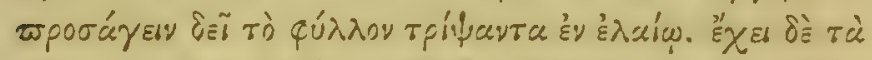

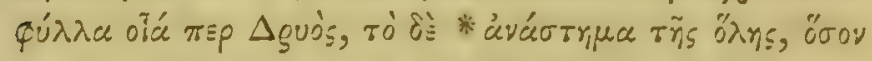

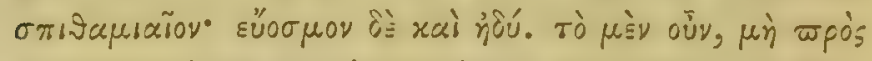

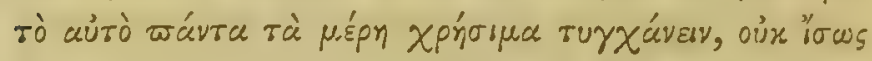

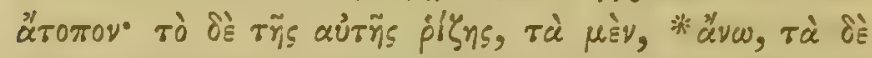

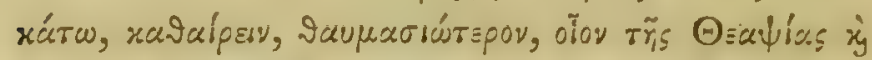

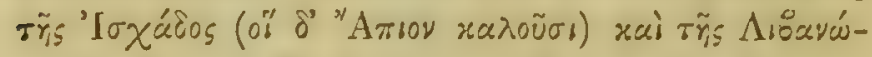

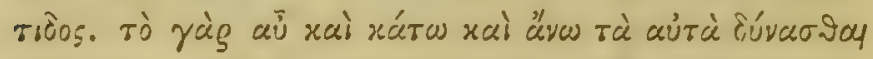

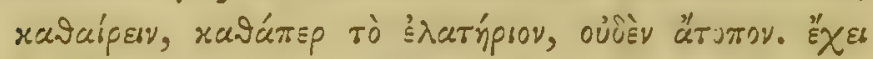

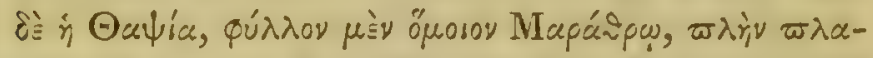

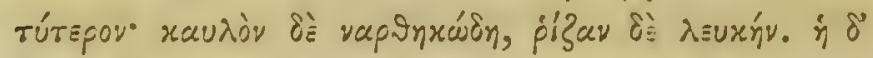

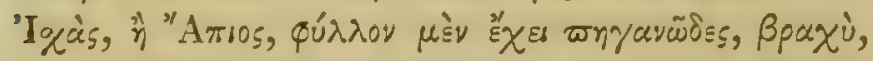

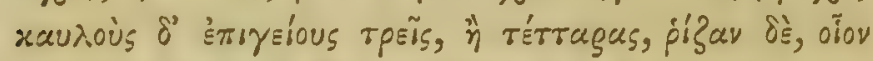

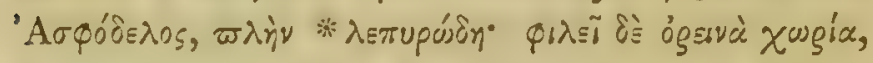

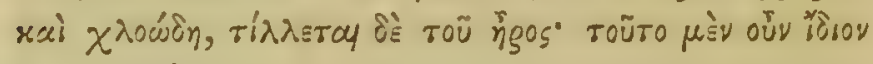

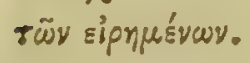

\section{CAP. XI.}

Helleborus Orientalis Tournefortii, et rarictas ejus alba.

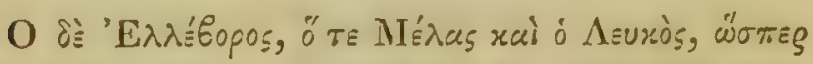

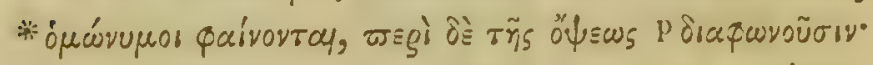

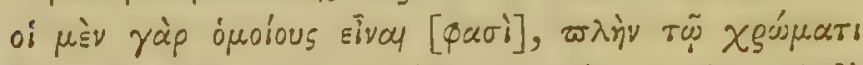

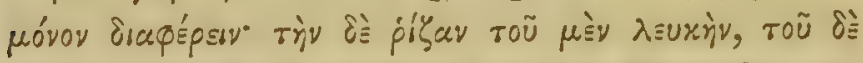

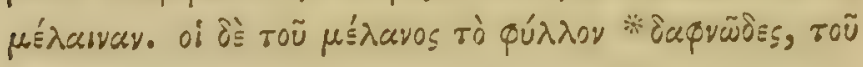

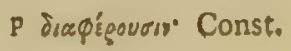




\section{ПEPI $T M T \Omega N$ IミTOPIA $\cong$ TO $\odot ' \cdot 383$}

$\partial \sum \lambda \varepsilon u r o \tilde{u}, *$ *

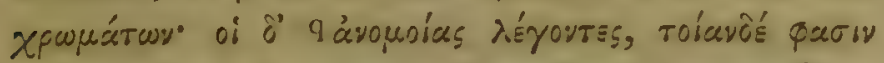

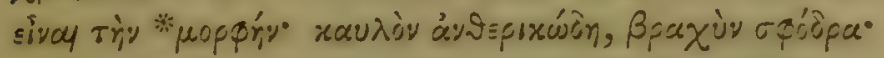

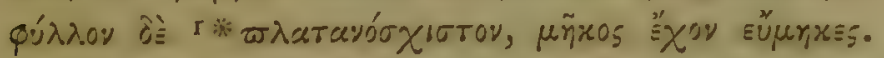

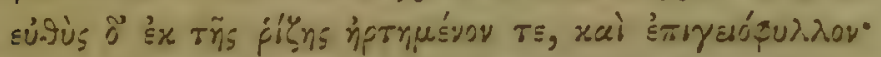

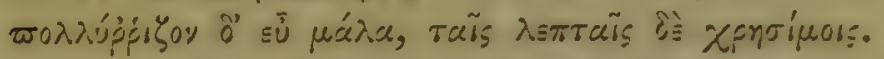

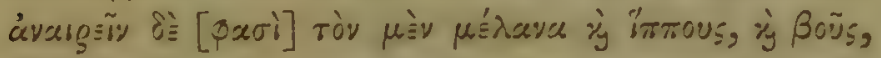

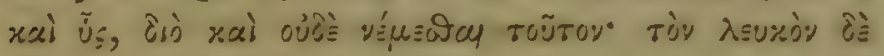

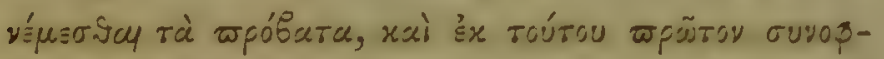

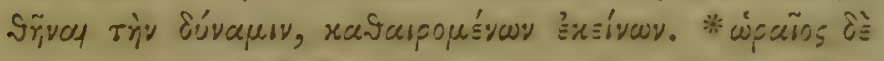

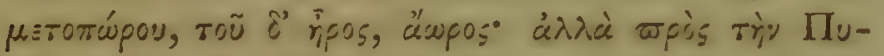

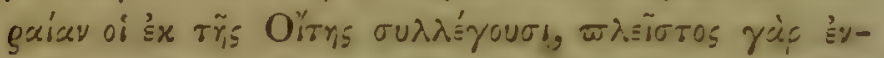

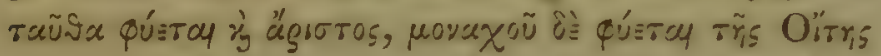

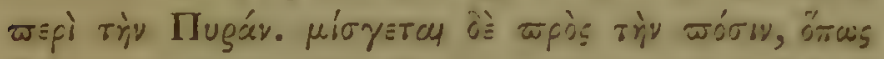

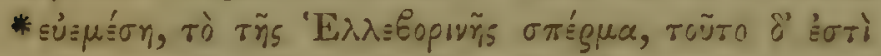

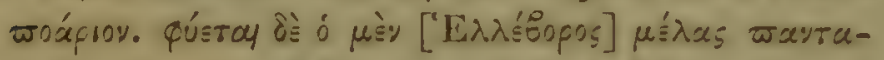

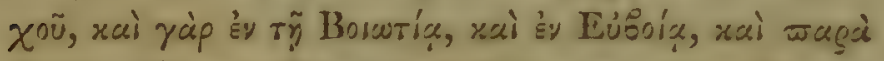

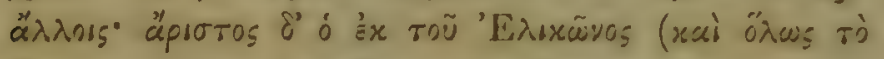

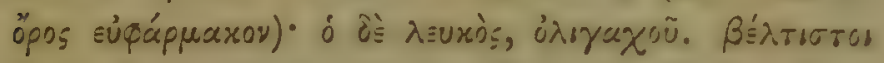

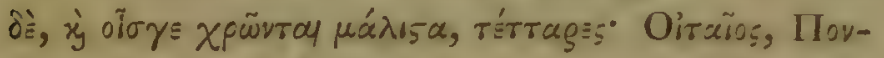

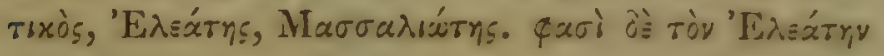

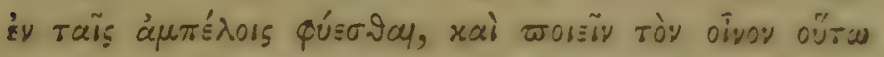

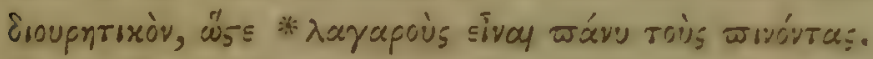

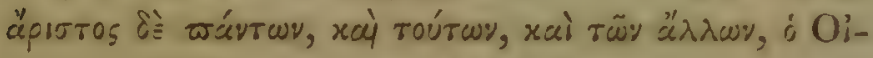

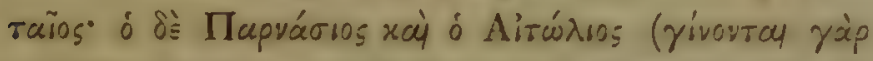

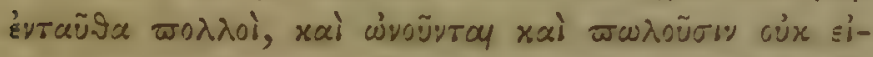

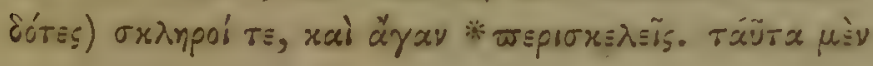

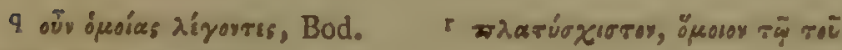

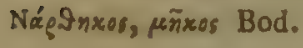




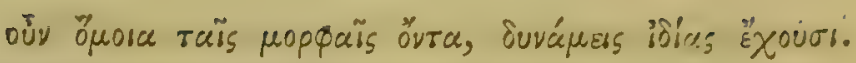

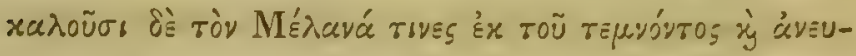

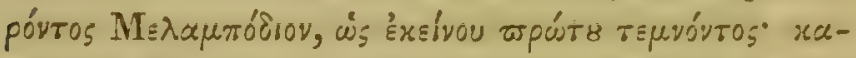

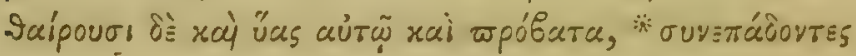

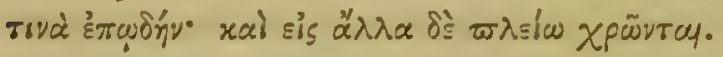

\section{CAP. XII.}

\section{Luserpitii Species.}

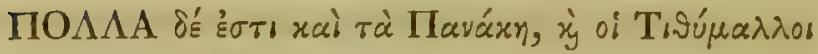

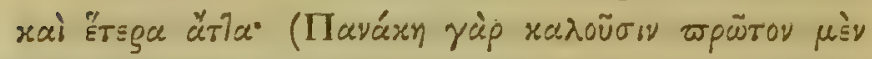

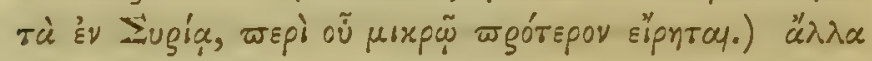

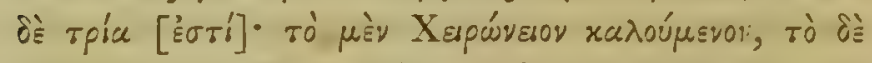
'Hрáx

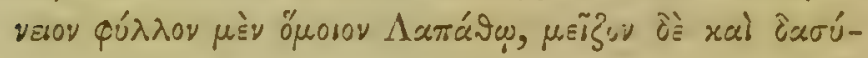

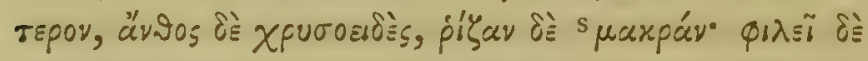

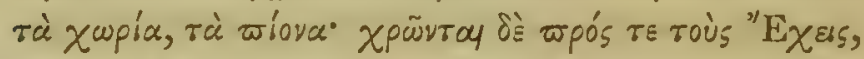

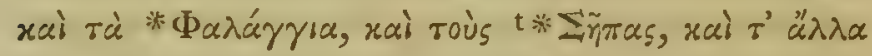

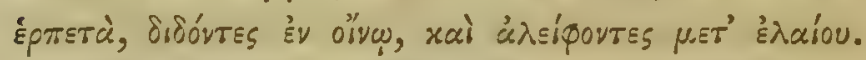

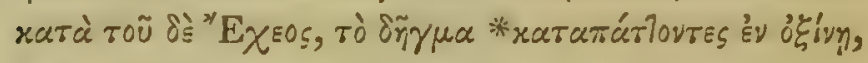

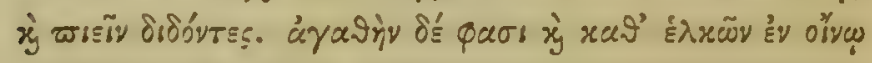

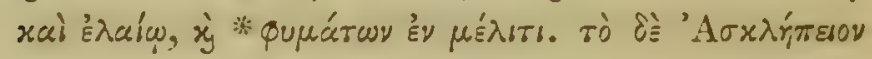

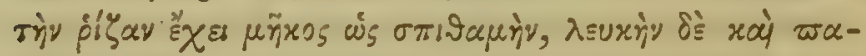

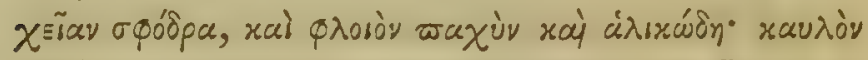

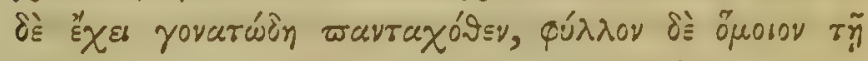

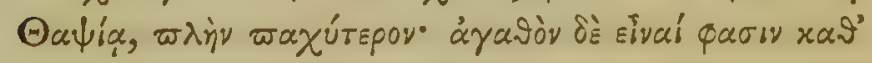

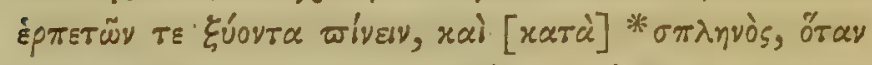

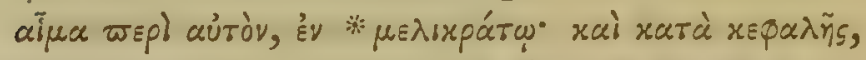

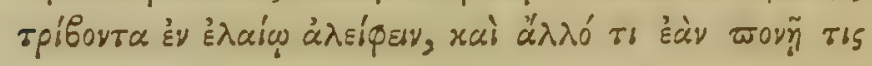

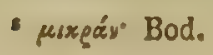

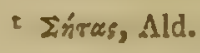




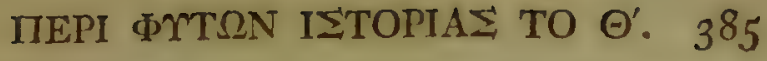

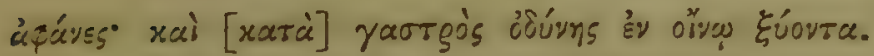

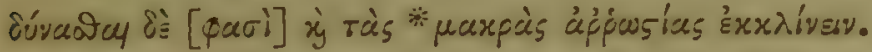

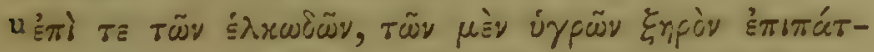

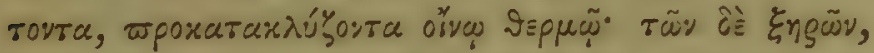

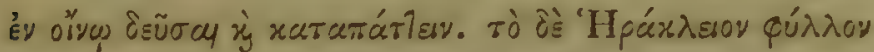

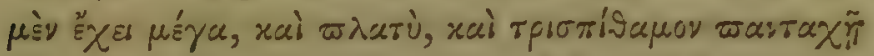

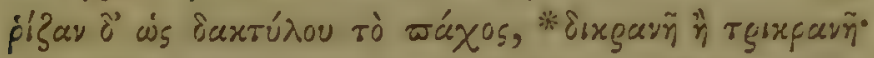

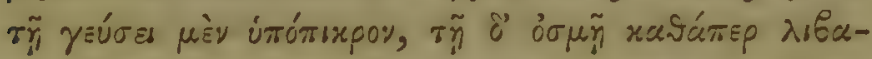

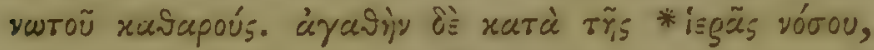

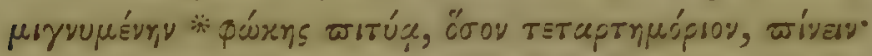

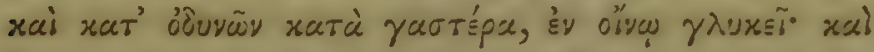

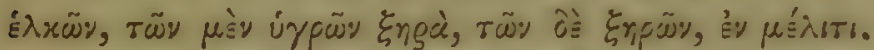

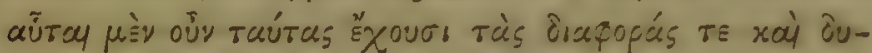

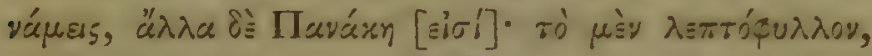

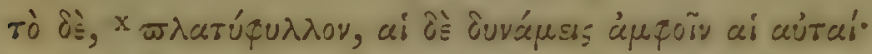

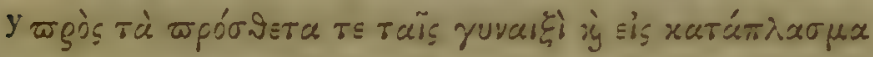

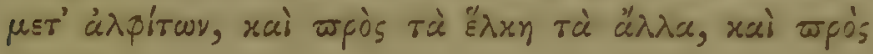

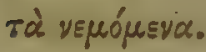

\section{CAP. XIII.}

Solani Species et Euphorbire.

INNRNTMOI Ė xaì of Itgúxyor, xai oi TiS'j-

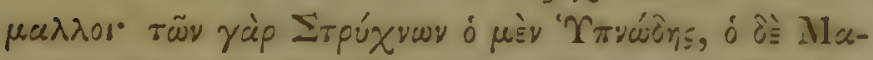

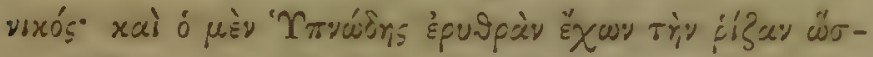

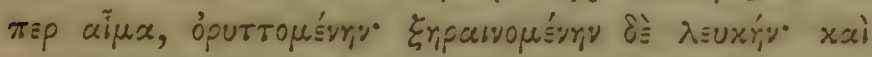

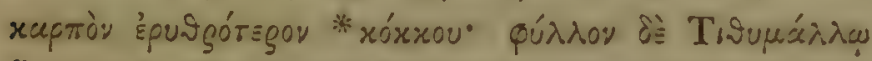

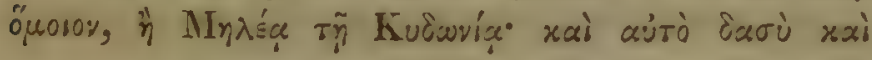

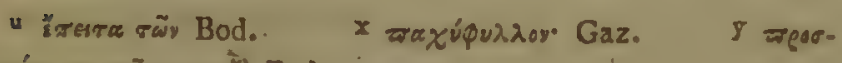

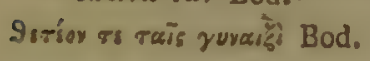




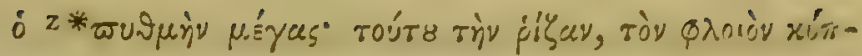

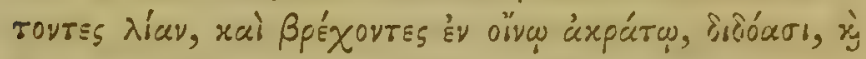

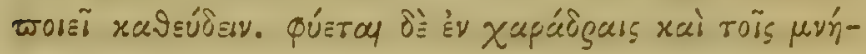

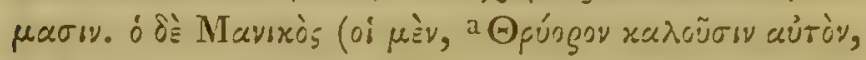

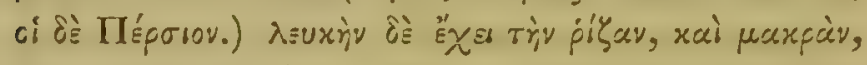

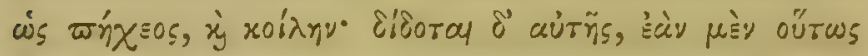

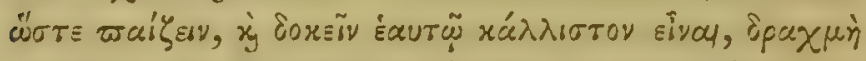

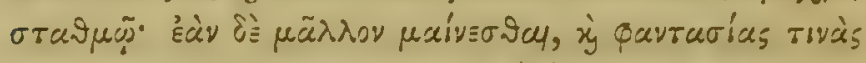

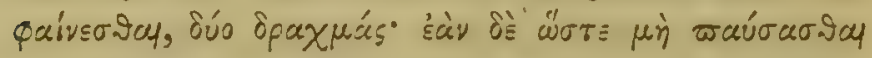

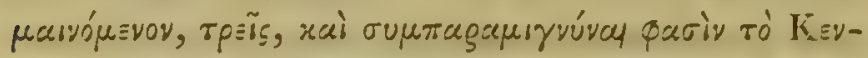

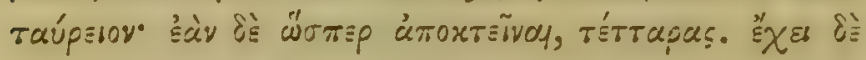

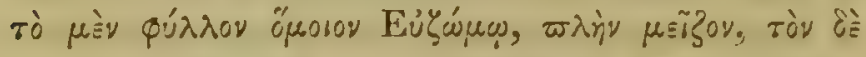

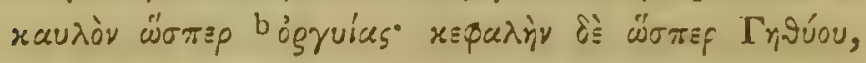

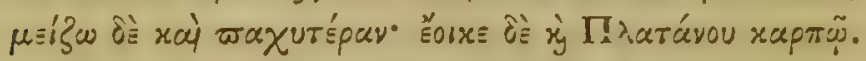

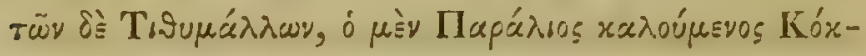

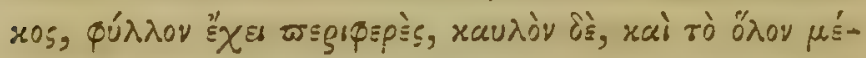

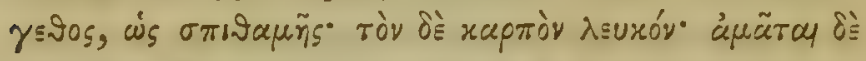

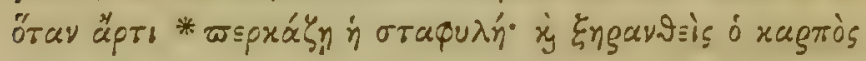

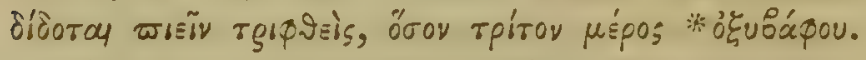

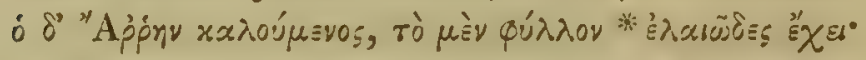

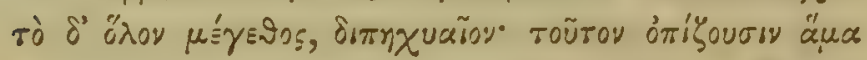

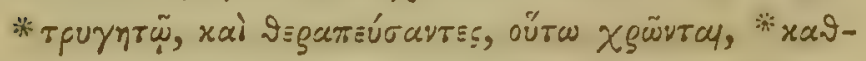

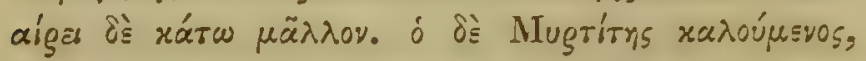

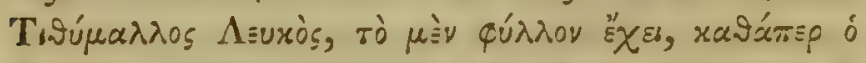

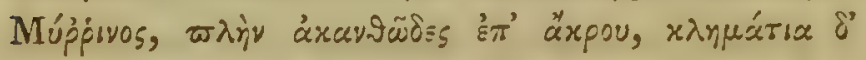
à

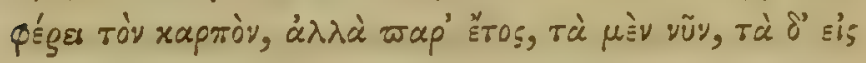

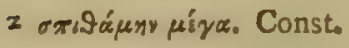

b ógruias tirragas. Const.

2 Bérogar Bod. Ogárar Const. 


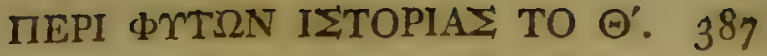

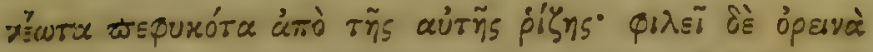

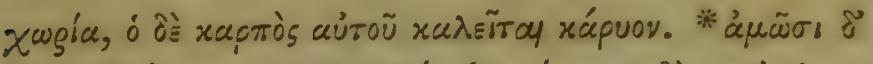

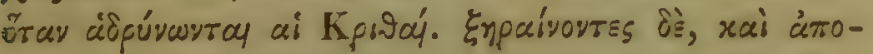

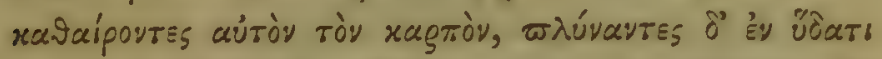

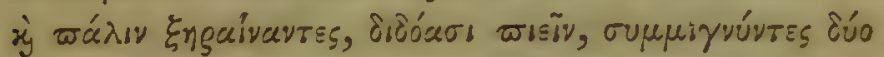

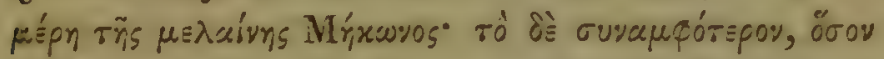

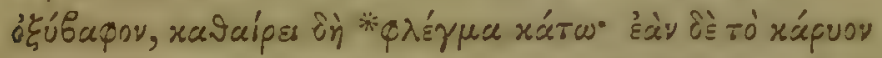

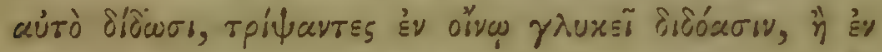

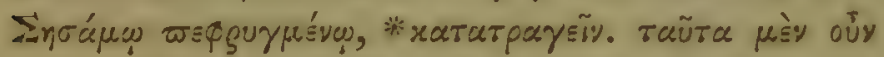

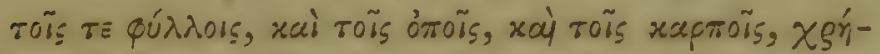

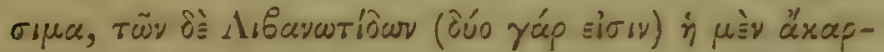

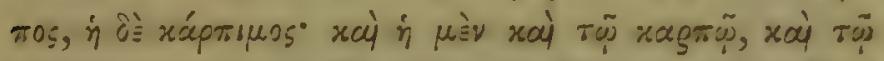

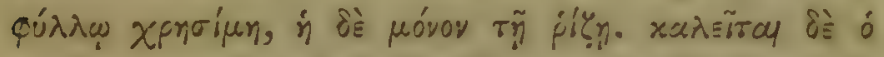

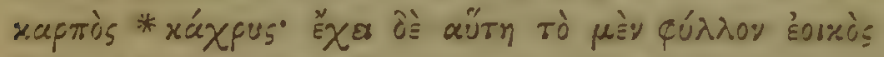

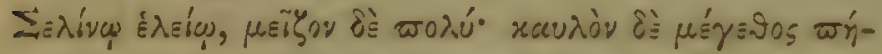

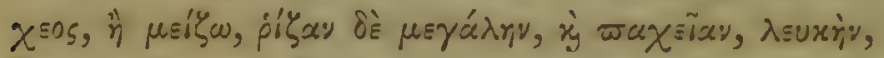

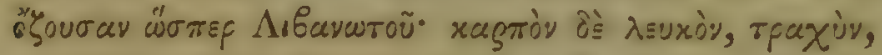

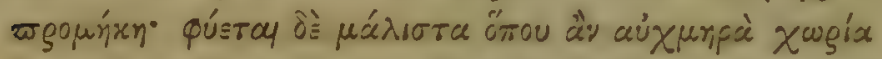

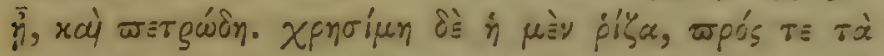

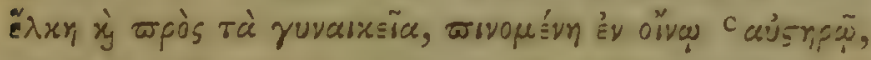

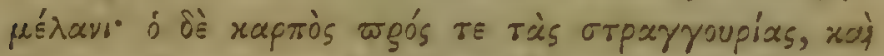

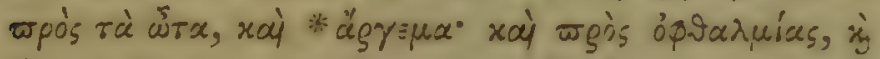

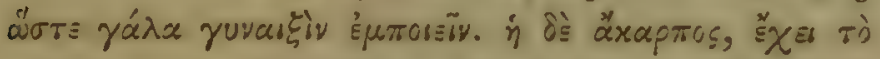

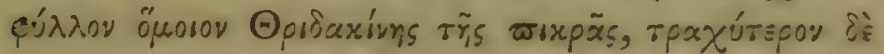

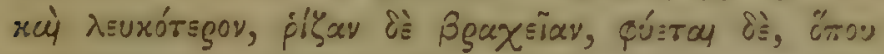

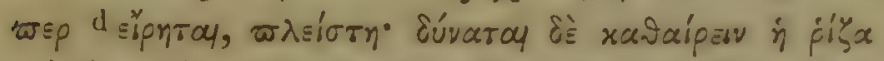

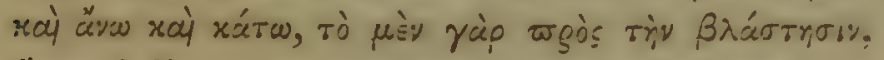

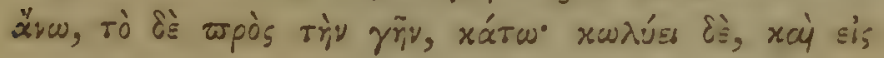

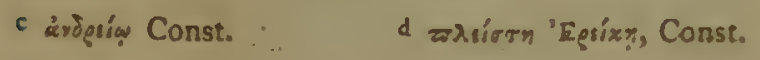

EARS II.

L. 


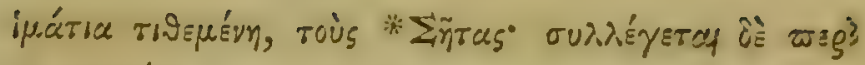
ஐuporopilas.

\section{CAP. XIV.}

\section{Carlina; Carthamus, et Papaver.}

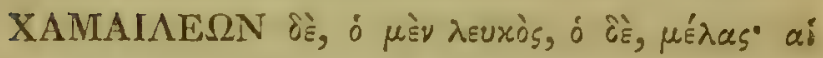

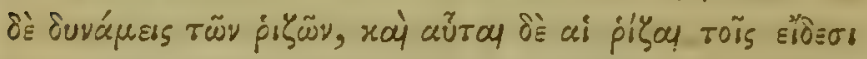

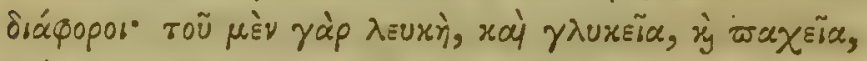

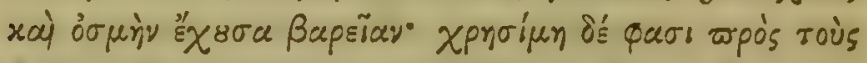
*

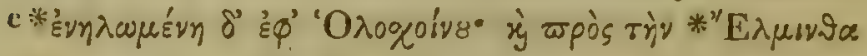

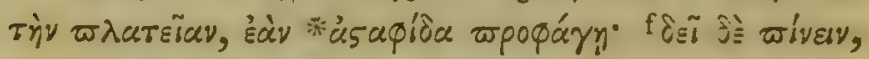

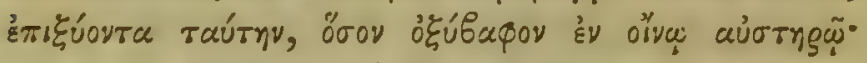

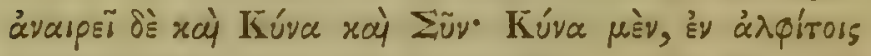

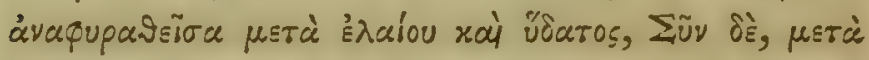

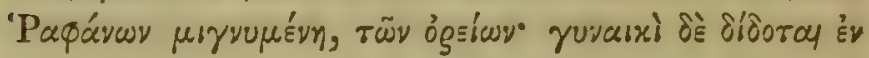

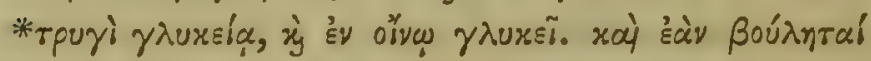

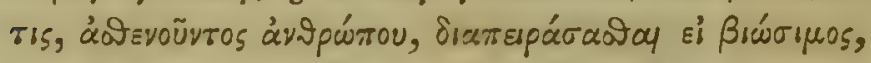

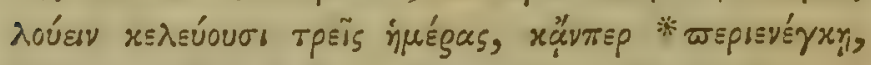

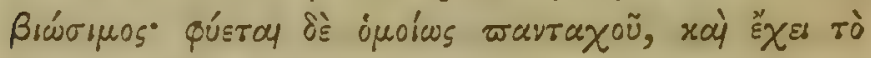

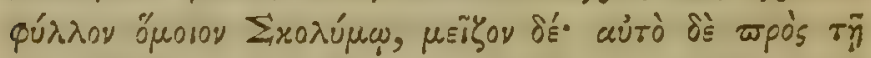

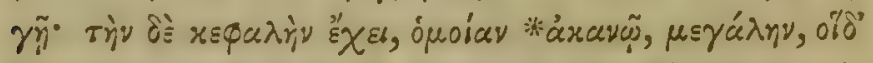

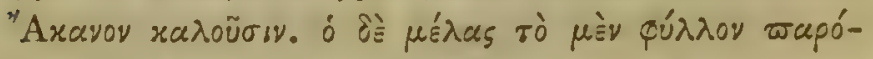

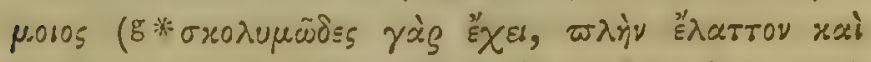

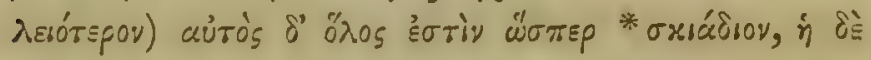

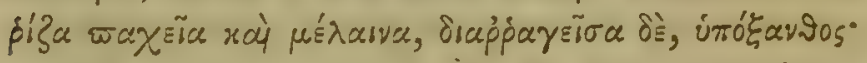

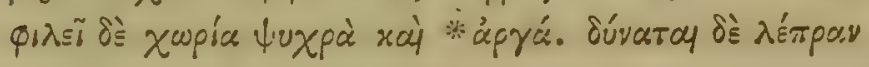

e ivstrouivn Bod. f dsĩ di desunt Bod.

e exorym

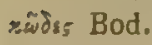




\section{TEII INTSN ISTOPIA}

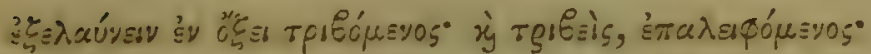

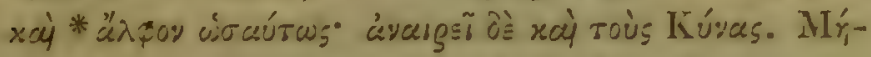

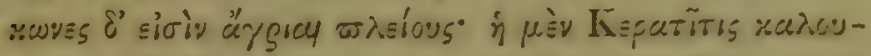

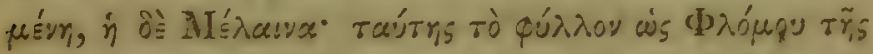

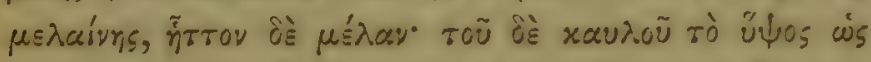

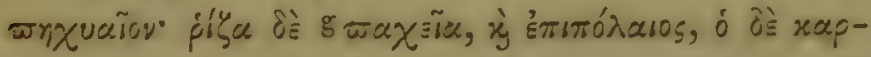

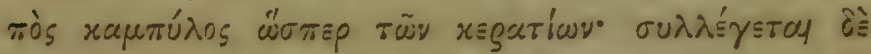

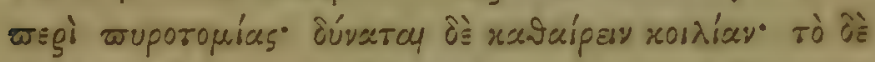

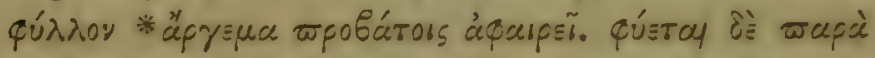

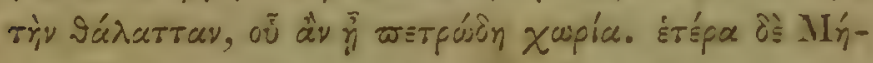

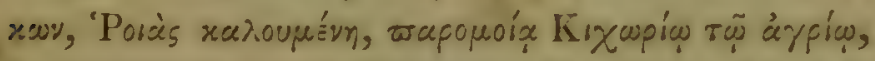

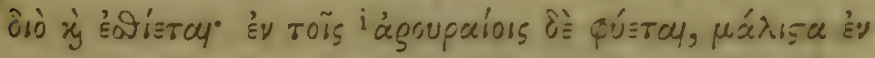

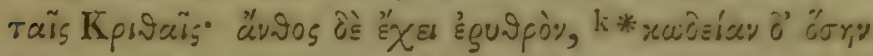

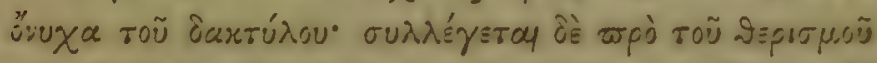

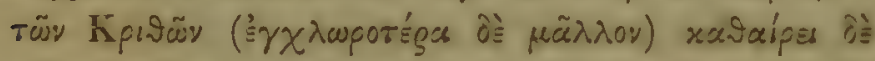

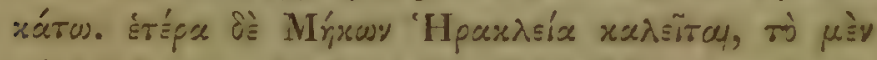

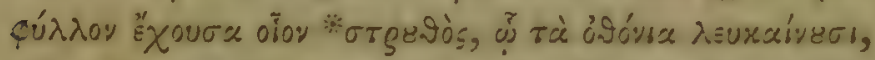

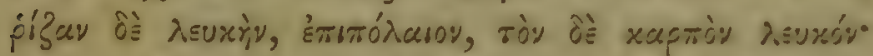

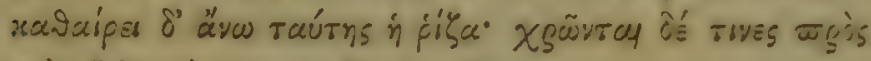

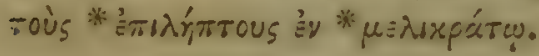

\section{CAP. XV.}

Radices quadam medicinales.

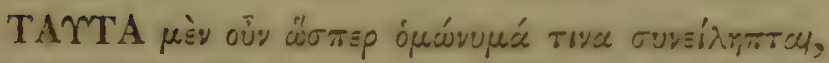

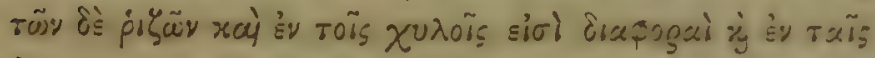

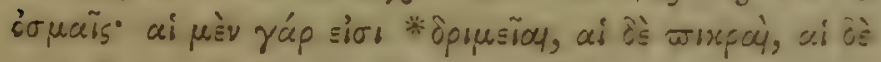

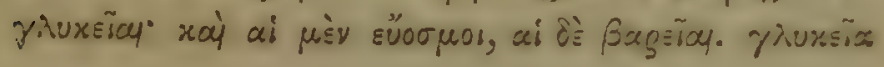

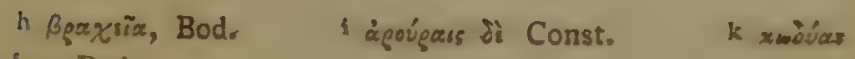
$\because$ irnv Bod.

I 2 


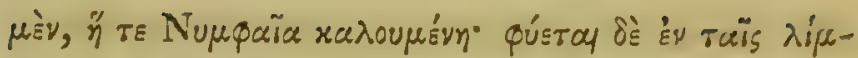

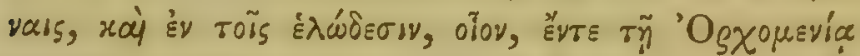

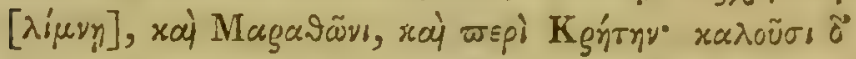

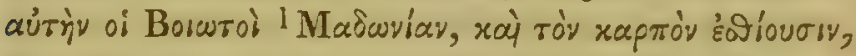

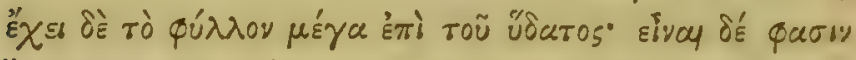

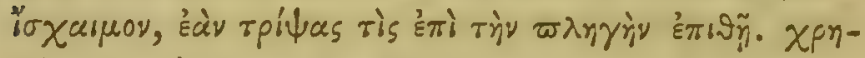

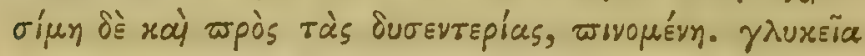

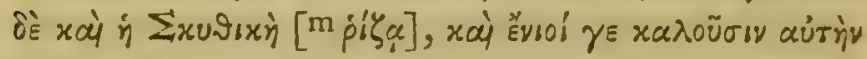

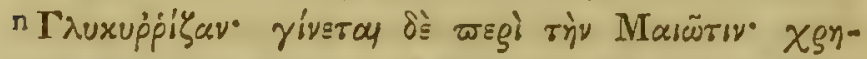

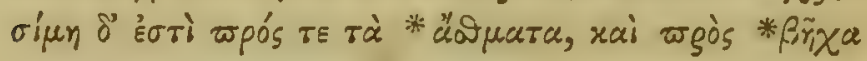

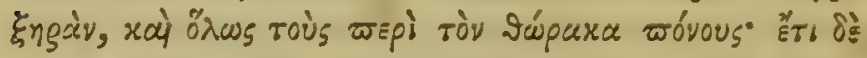
ఐ

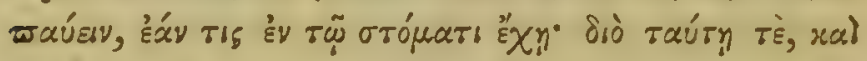

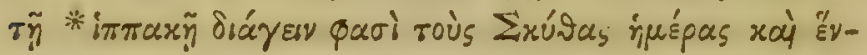

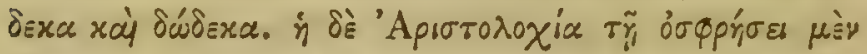

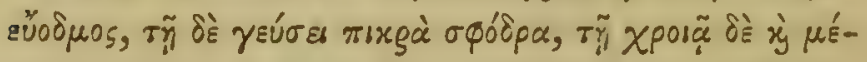

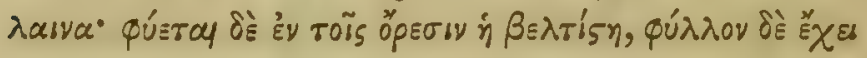

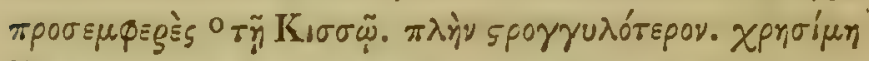

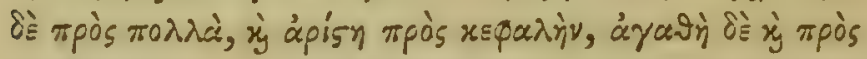

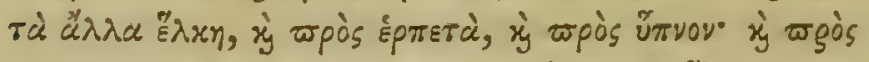

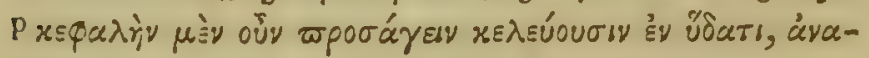

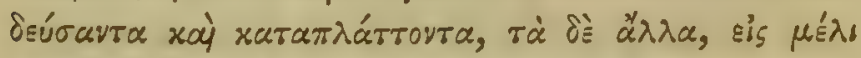

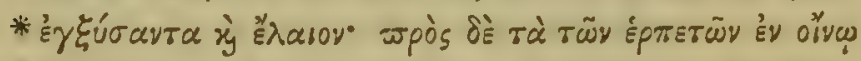

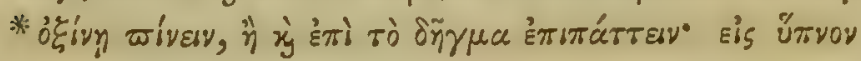

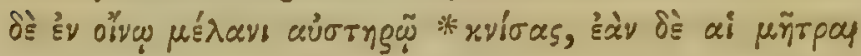

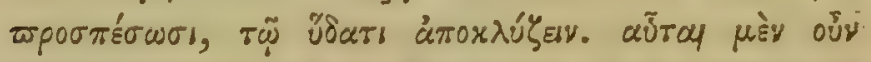

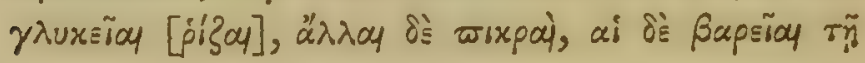

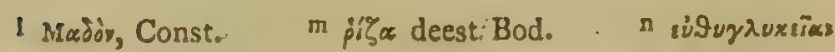

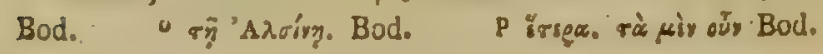




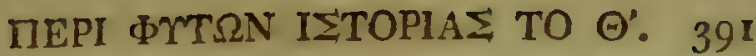

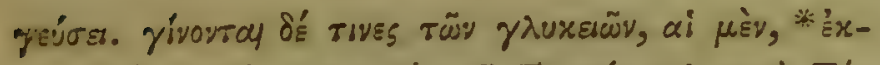

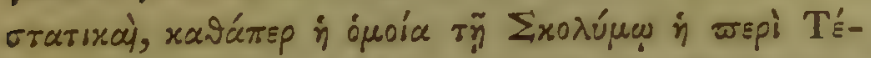

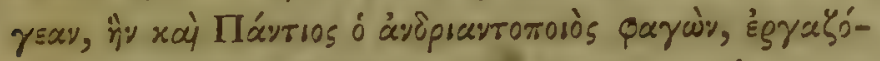

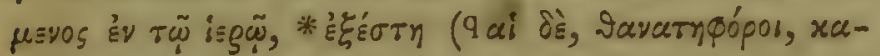

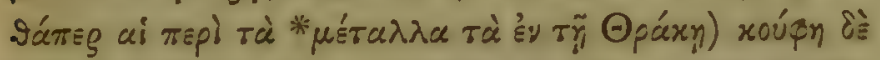

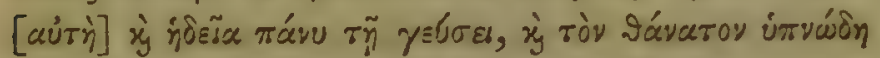

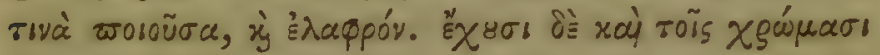

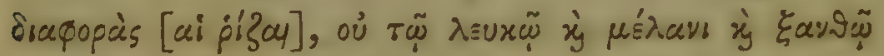

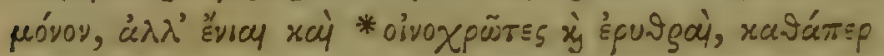
ทे тоนี 'E

\section{CAP. XVI.}

Tormentilla, Rubiu, sc. Medicamentorum Durationes,

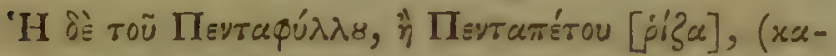

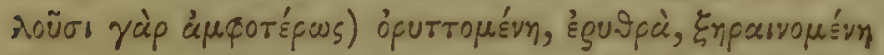

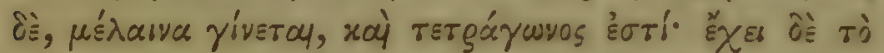

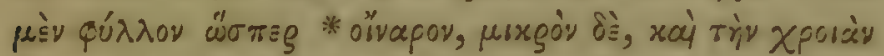

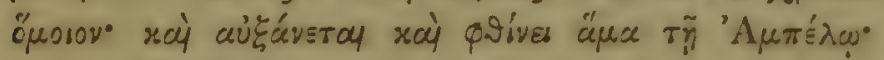

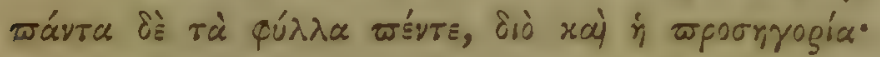
rau

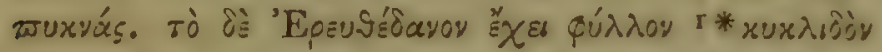

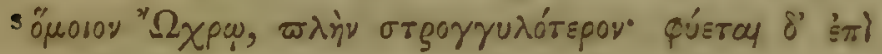

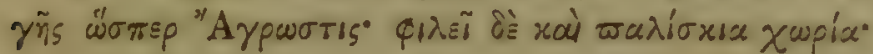

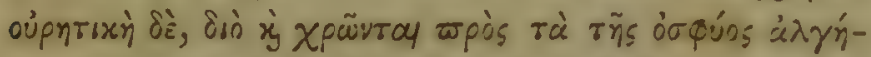

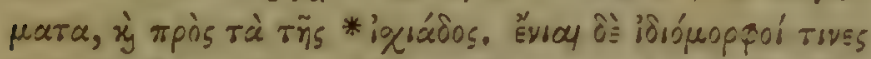

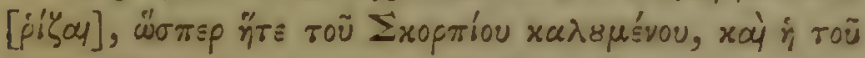

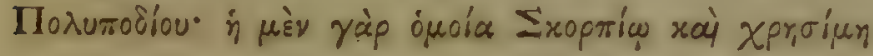

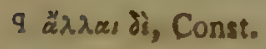

E xuxajōor deest Bod.

$="$ "\%usos Клтё, Bod.

I. 3 


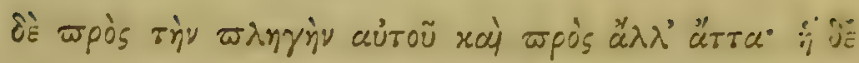

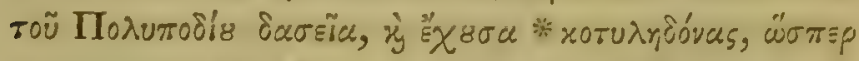

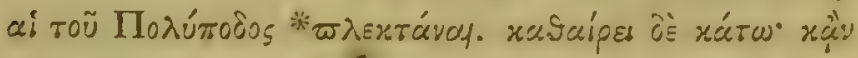

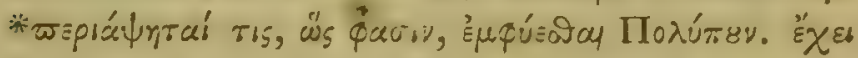

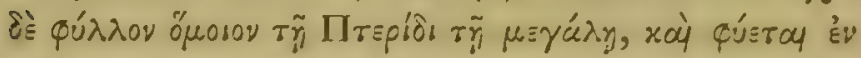

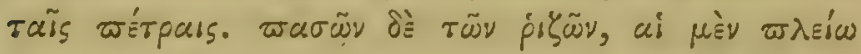

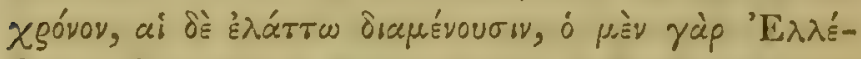

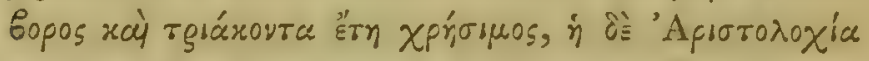

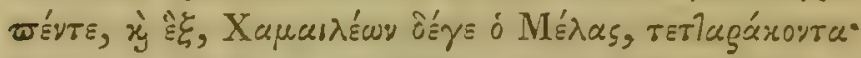

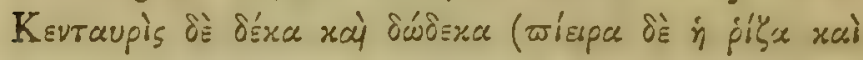

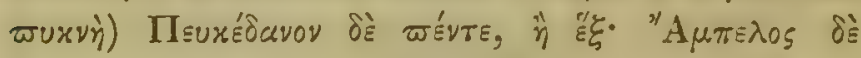

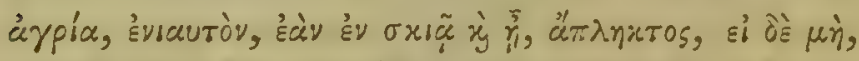

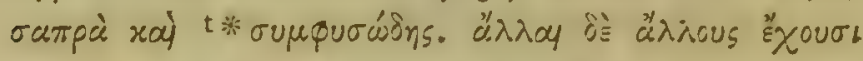

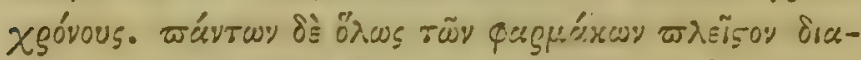

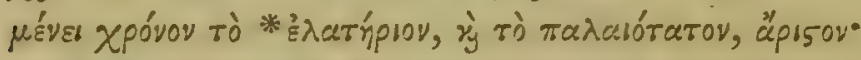

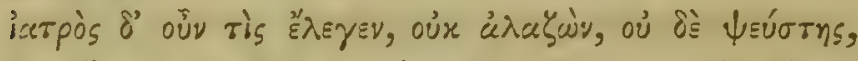

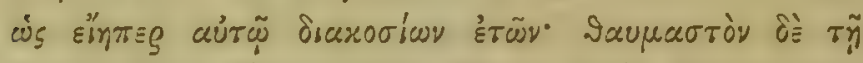

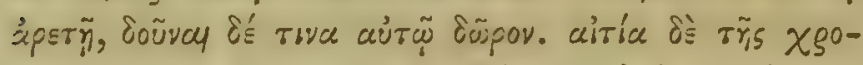
भóty

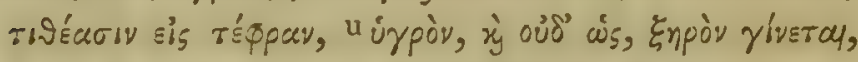

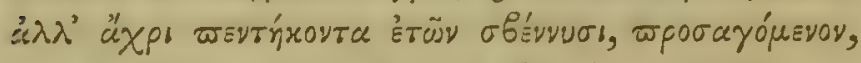

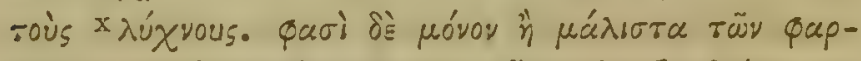

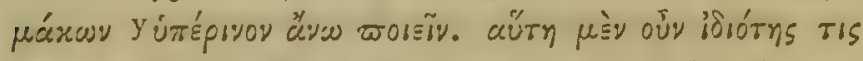

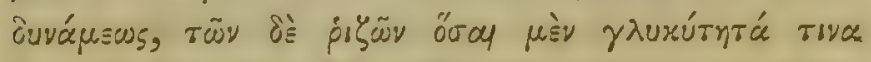

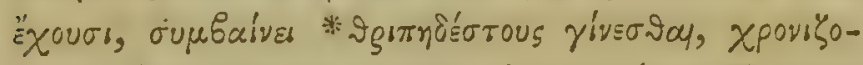

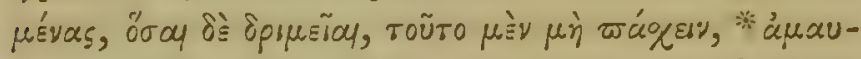

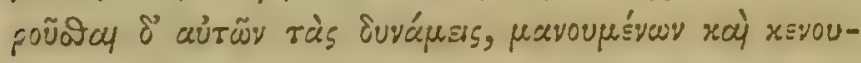

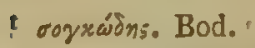

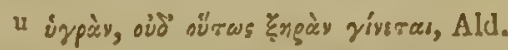

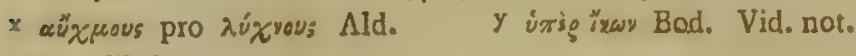
ad fin, libri. 


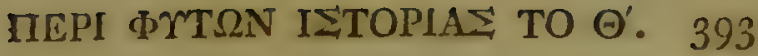

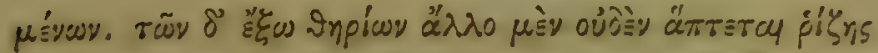

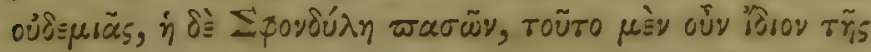

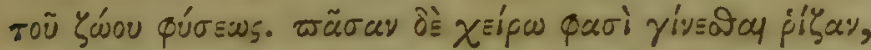

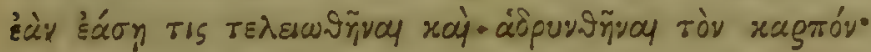

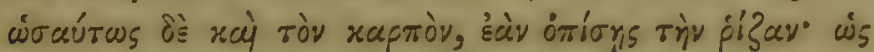

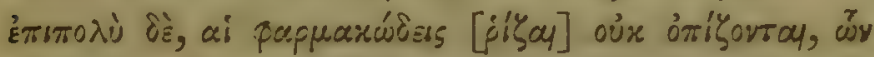

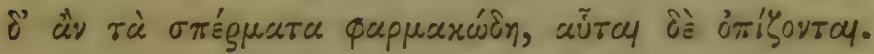

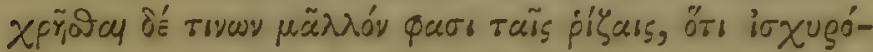

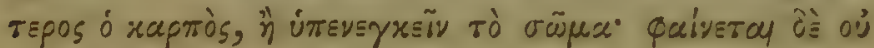

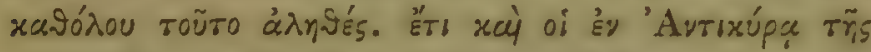

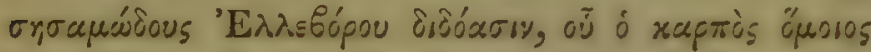

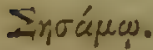

\section{CAP. XVII.}

Regiones pharmaceutica. De Moly Antiquorum, \&c. \& c.

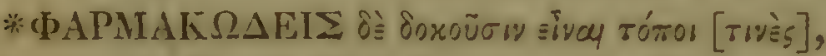

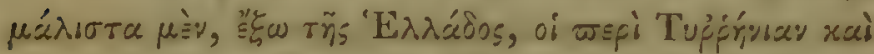

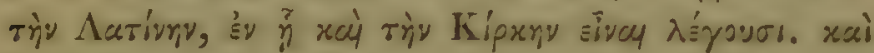

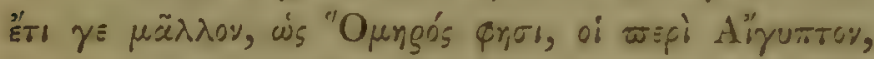

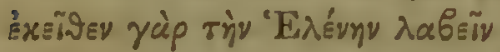

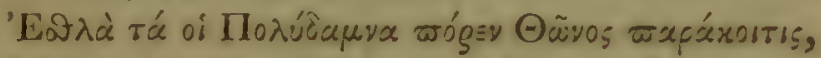

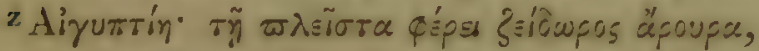

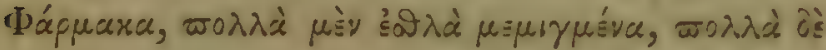

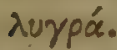

'O $\delta . \Delta .228$.

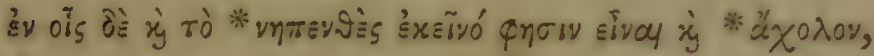

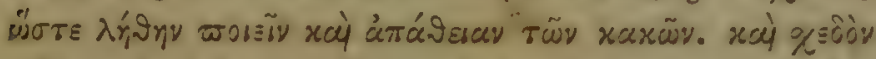

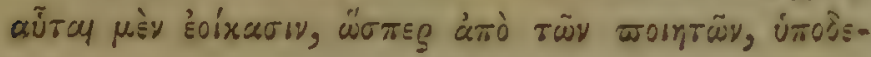

2 Airumrin Bod.

L 4 


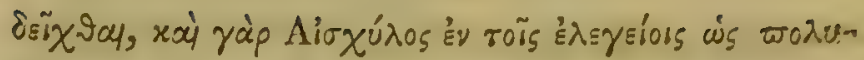

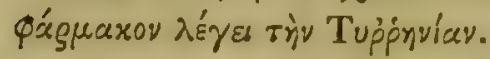

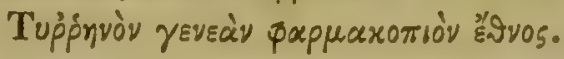

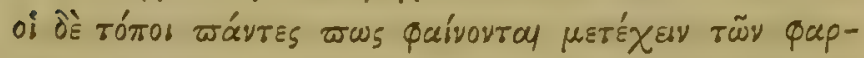

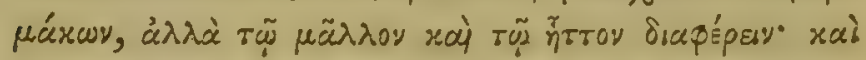

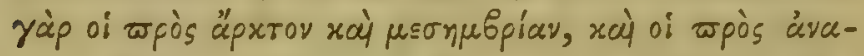

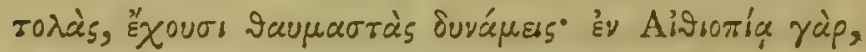

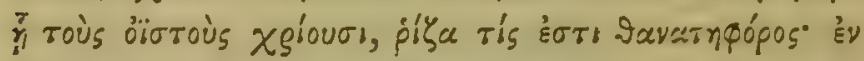

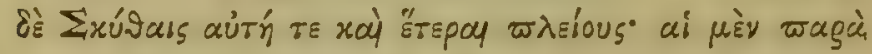

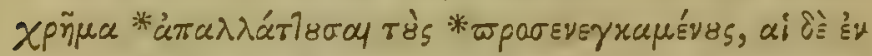

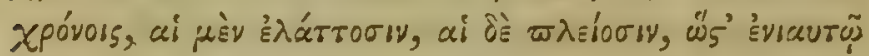

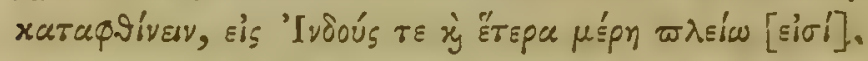

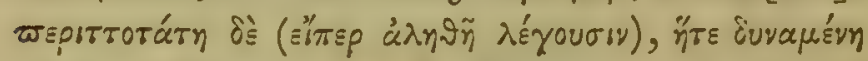

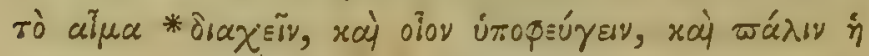

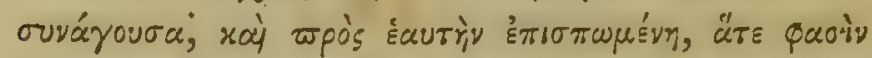

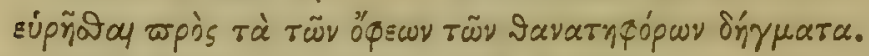

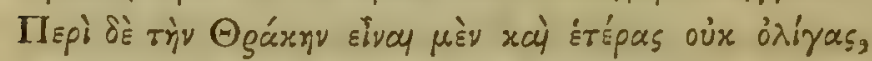

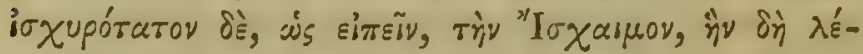

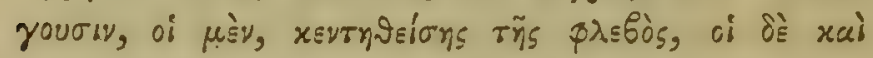

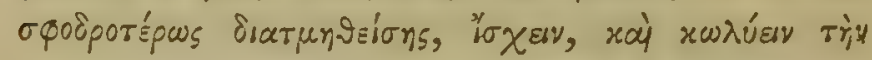

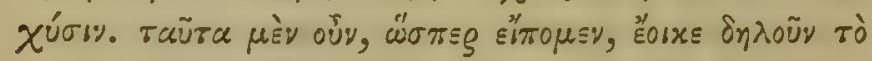

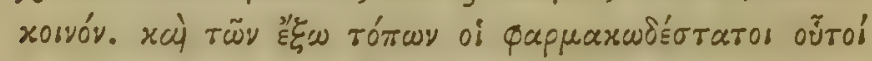

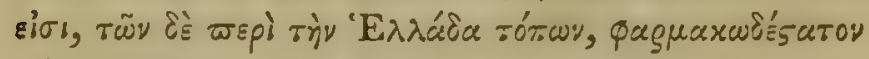

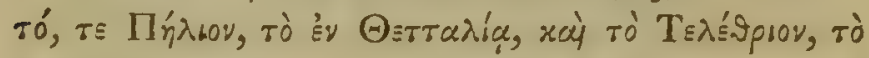

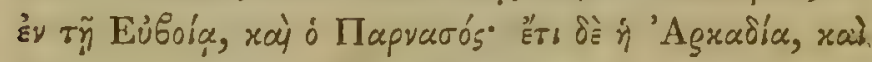

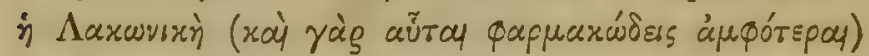

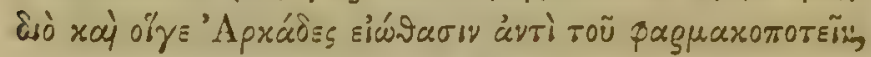

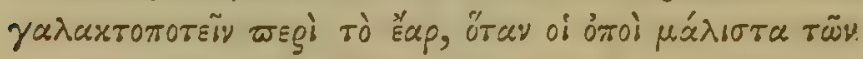

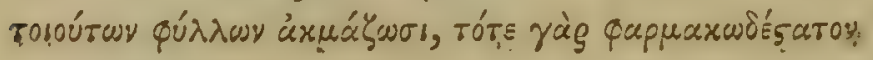




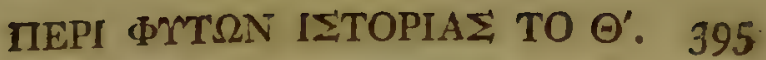

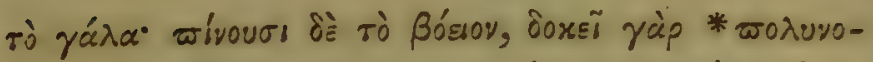

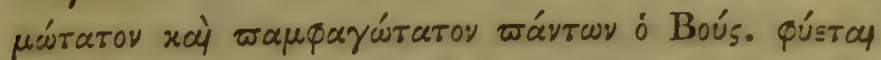

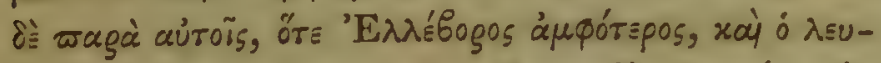

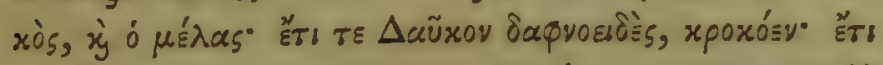

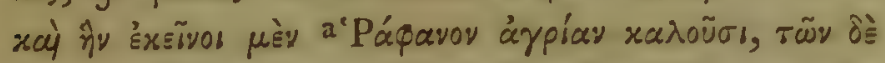

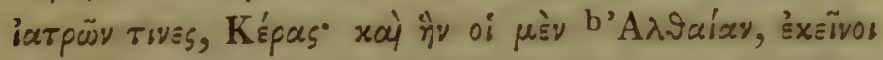

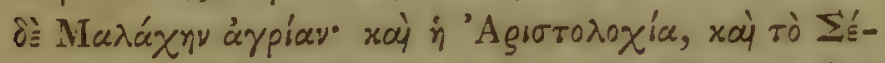

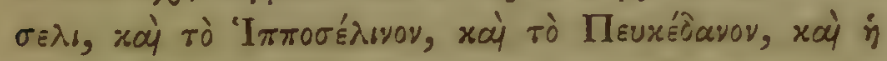

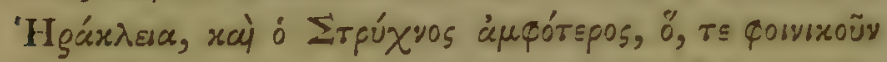

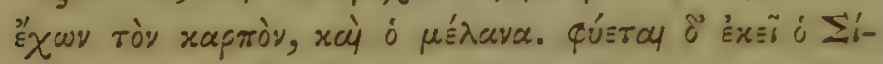

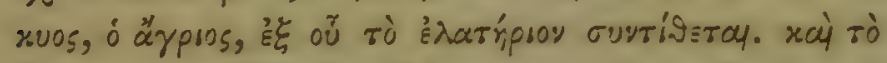

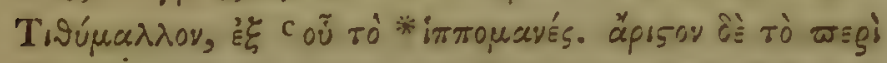

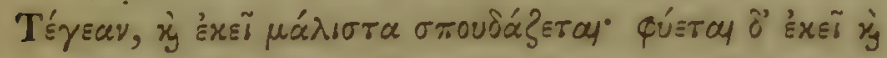

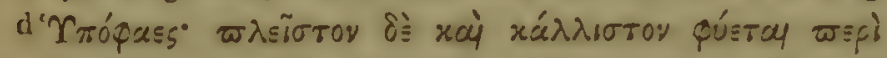

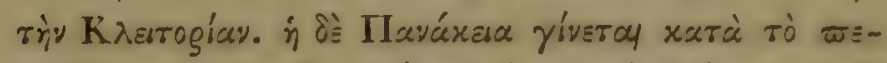

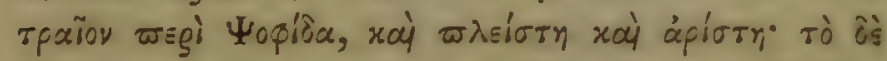

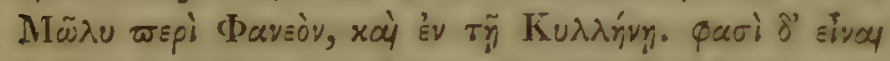

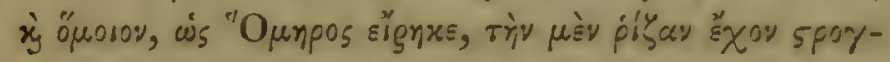

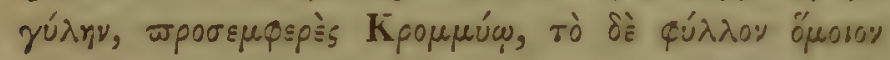

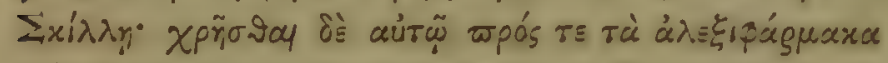

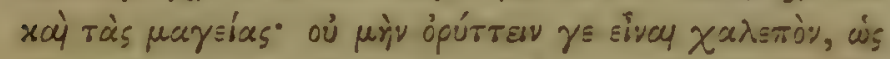

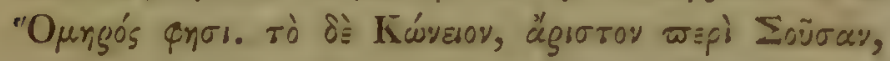

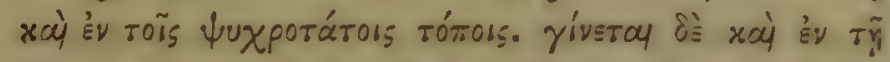

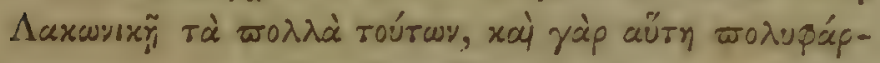

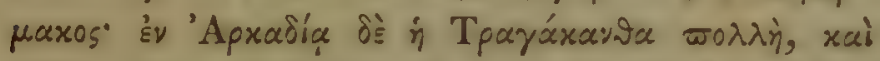

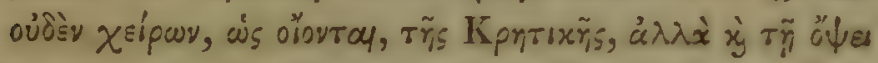

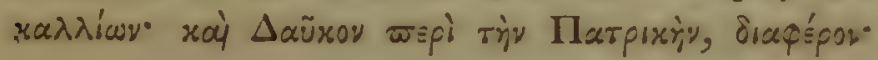

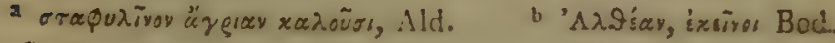

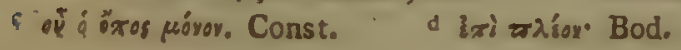




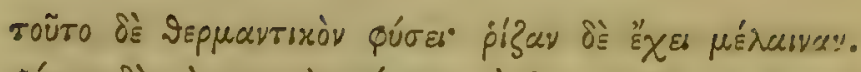

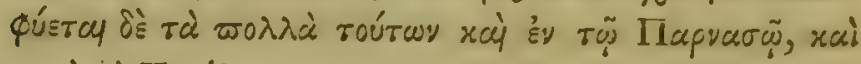

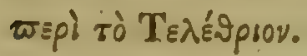

\section{CAP. XVIII.}

Origanum Dictamnus, et Pseudo-Dictammus: Aconitum Lyctoctinum, \&.c. \&.c.

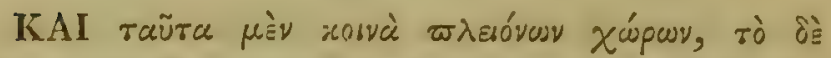

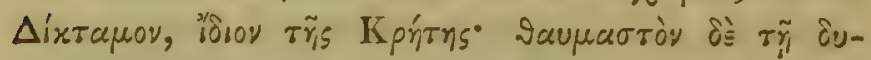

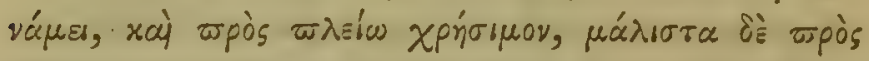

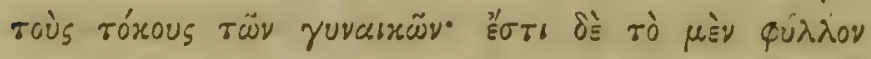

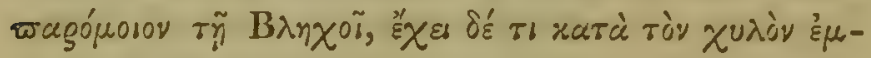

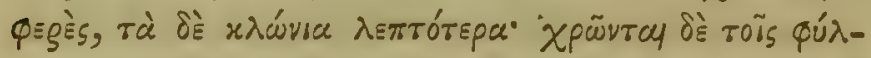

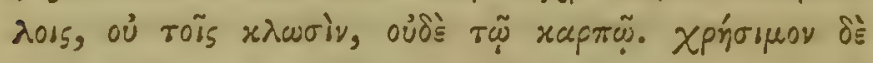

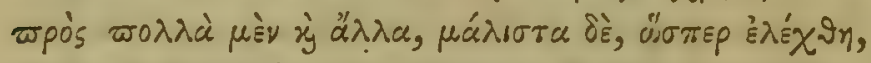

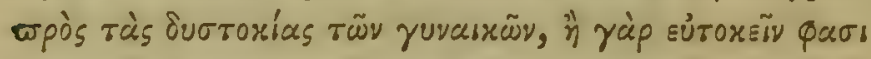

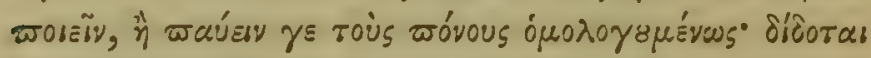

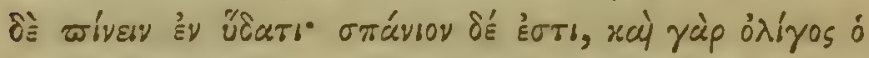

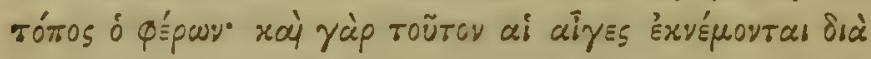

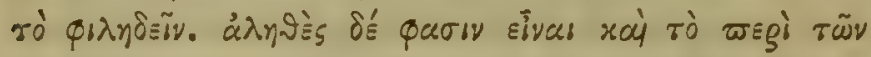

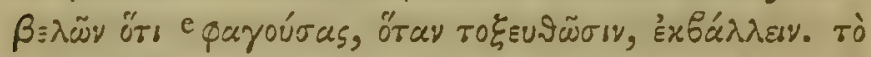

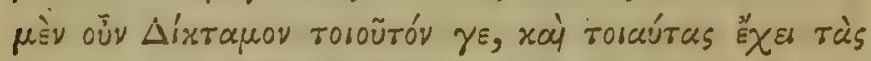

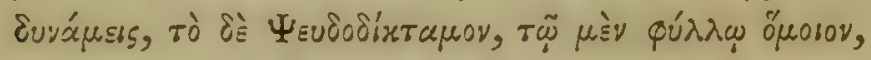

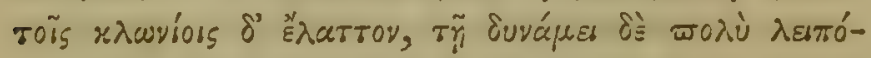

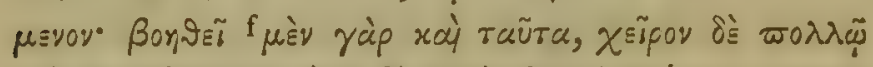

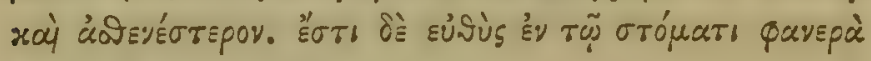

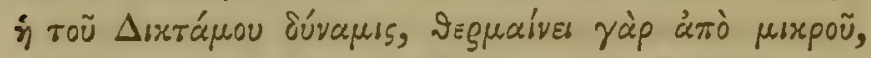

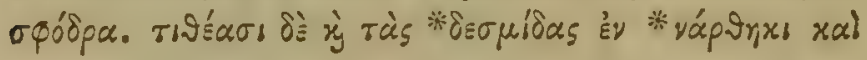

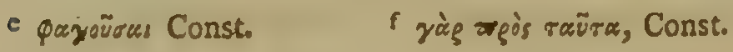




\section{MEPI TMTSN ISTOPIA TO $\Theta^{\prime}$}

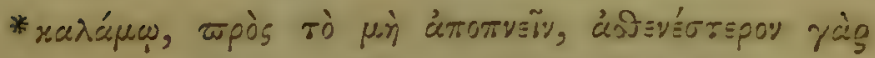

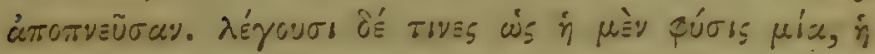

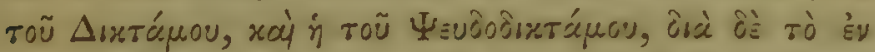

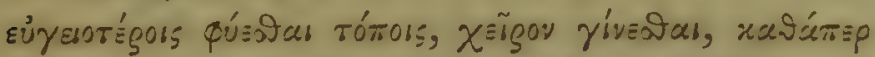

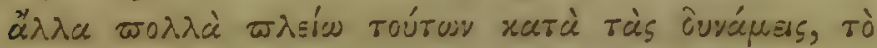

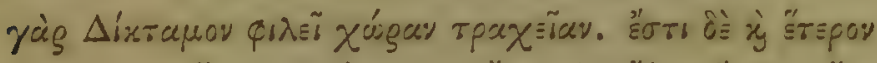

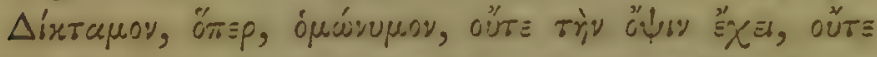

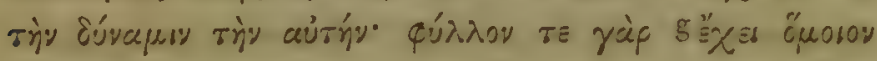

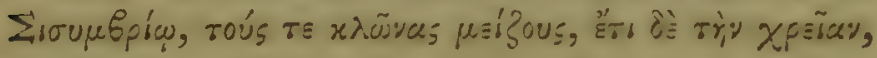

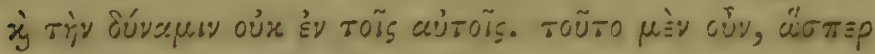

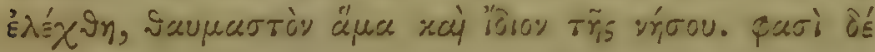

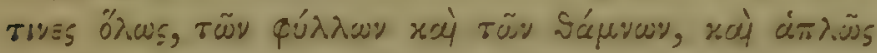

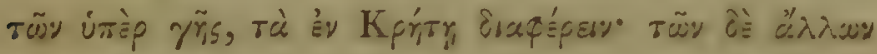

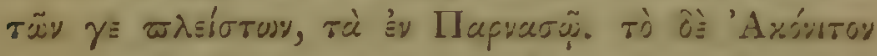

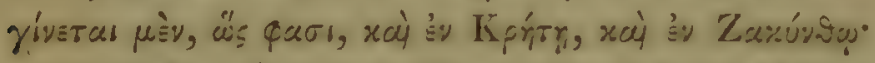

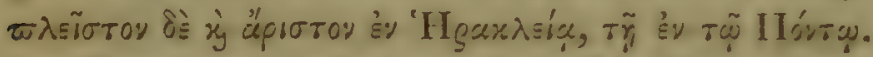

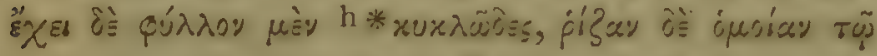

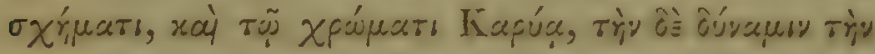

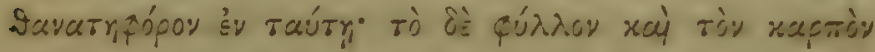

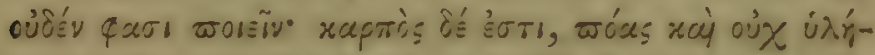

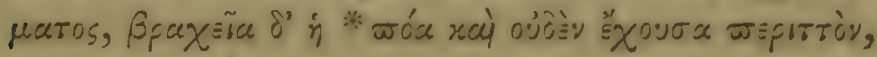

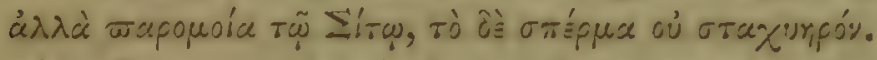

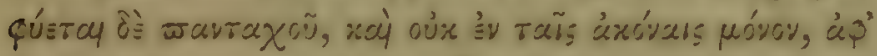

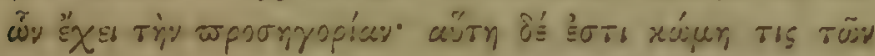

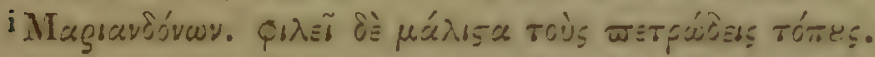

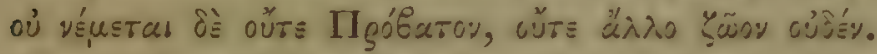

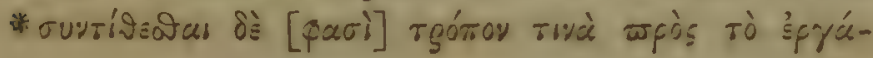

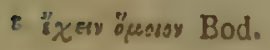
iv́var. Bod.

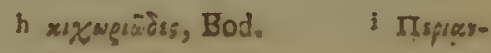




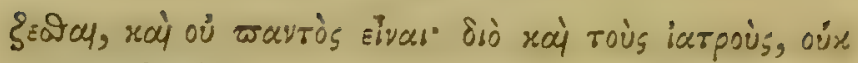

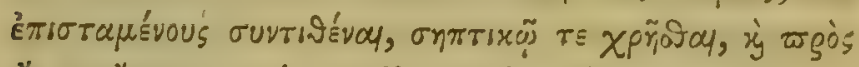

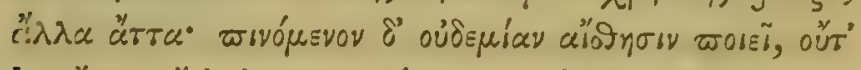

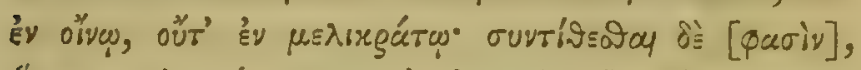

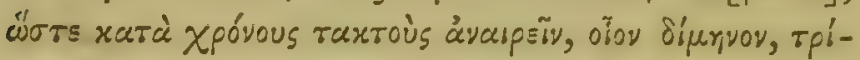

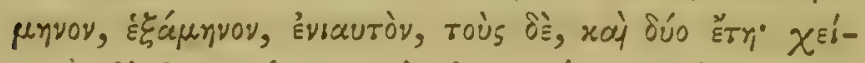

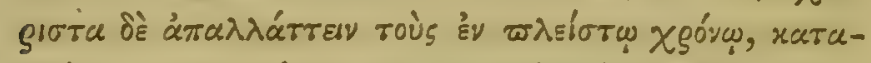

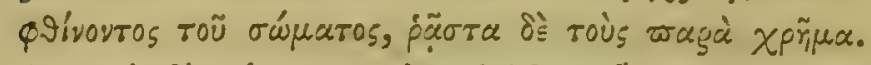

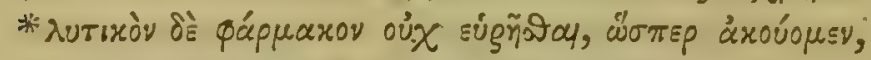

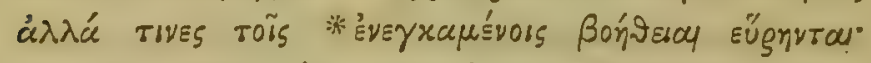

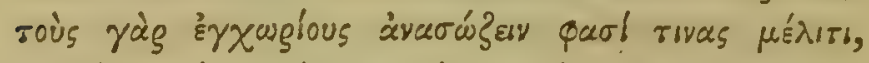

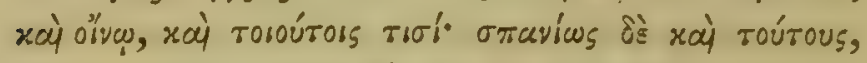

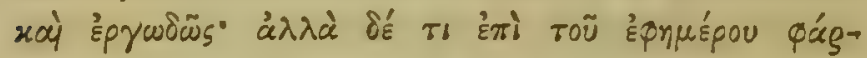

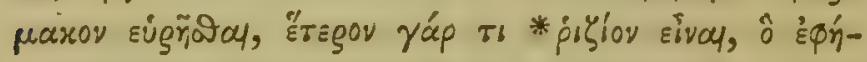

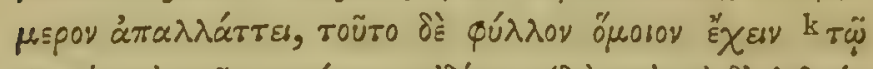

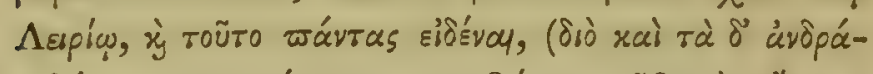

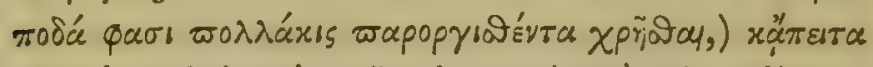

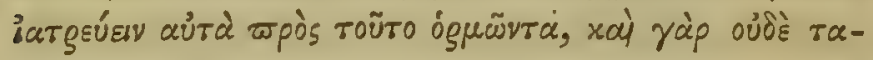

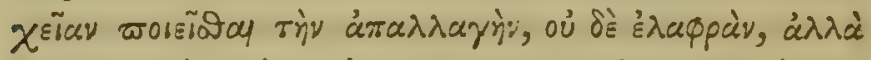

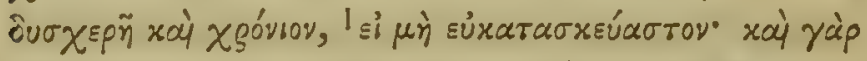
Eủaspám

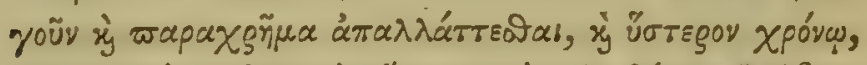

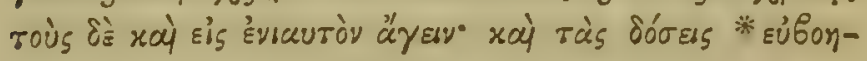

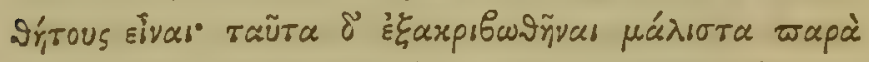

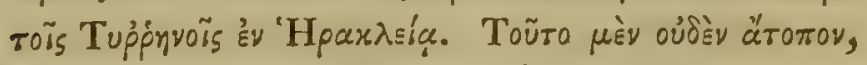

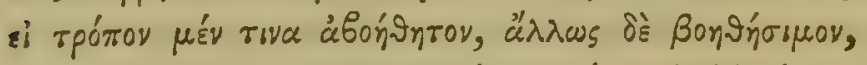

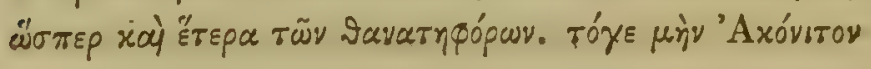

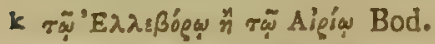

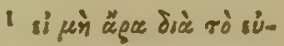

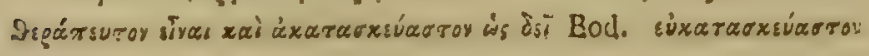
Scal. 


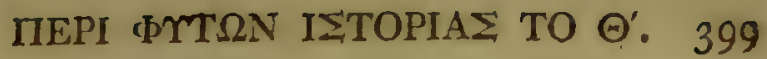

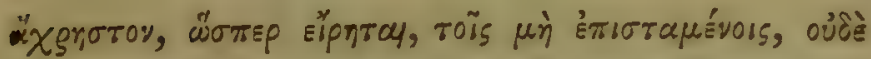

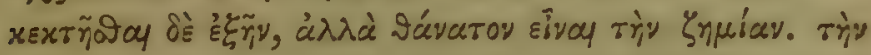

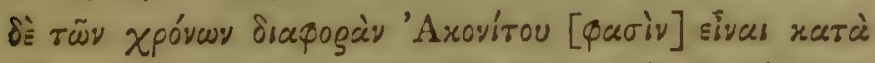

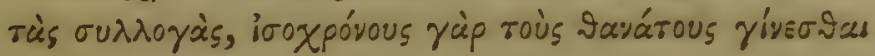

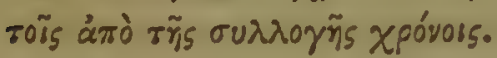

\section{CAP. XIX.}

Thrasya Veneni Compositio, et aliorum.

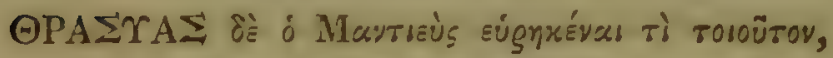

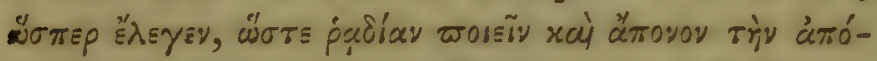

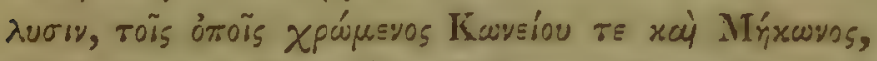

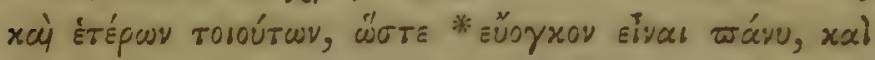

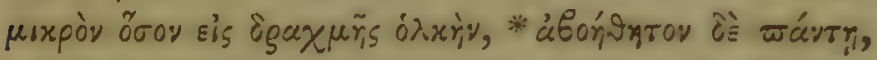

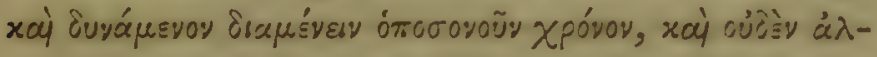

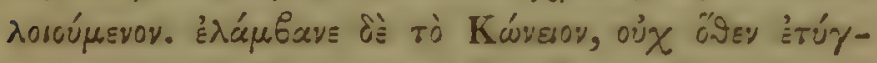

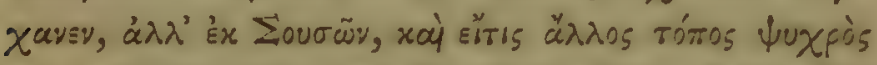

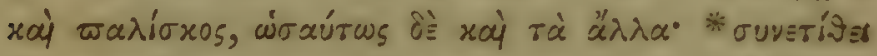

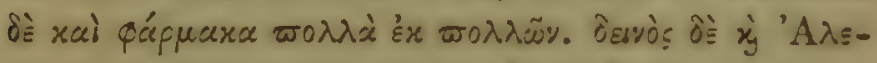

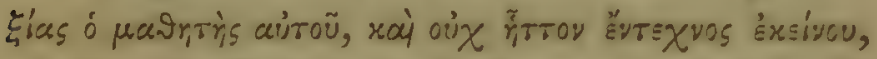

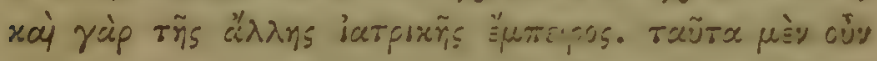

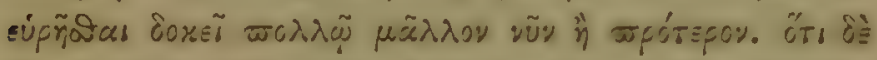

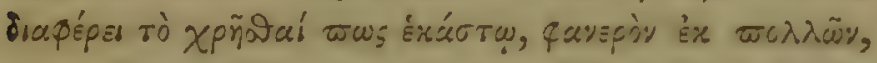

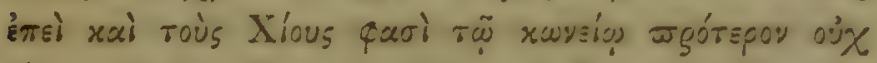

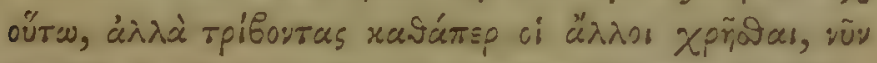

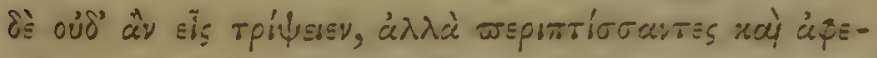

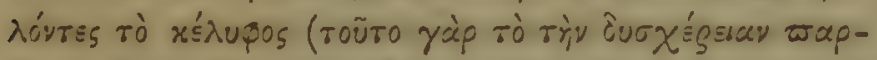

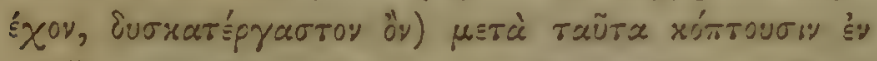

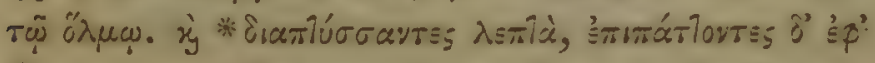

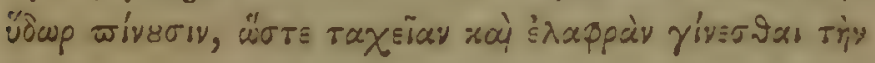

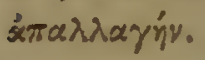




\section{CAP. XX.}

Фą̧arewdũv Vires et Remedia.

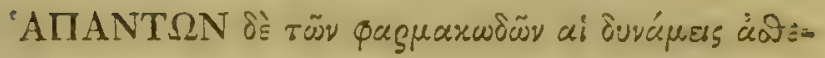
עร́์

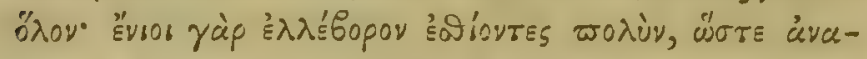

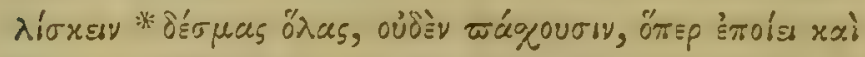

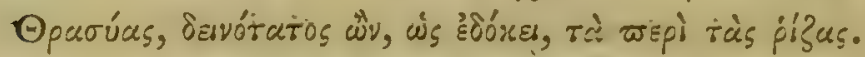

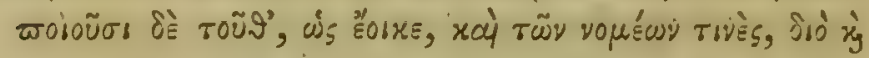

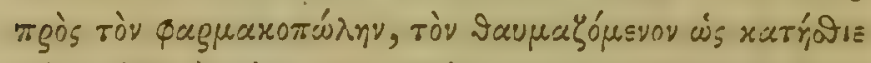

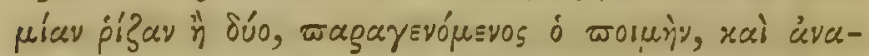

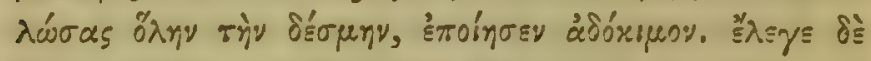

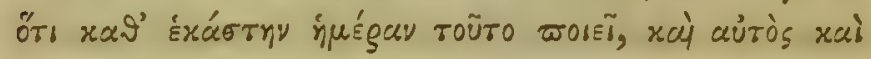

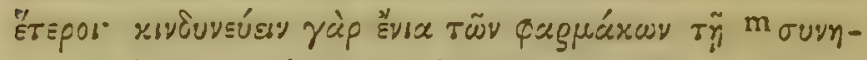

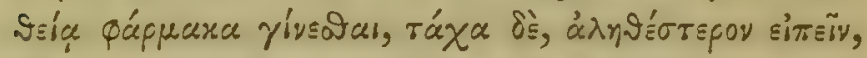

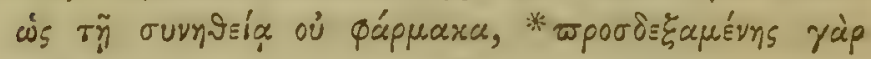

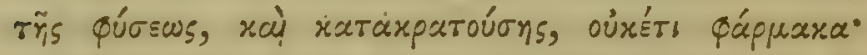

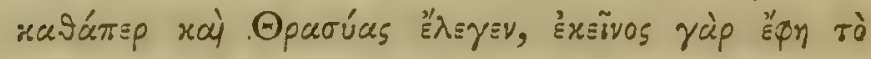

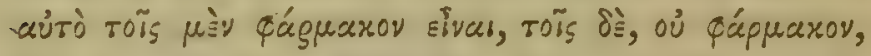

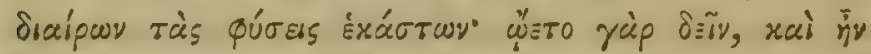

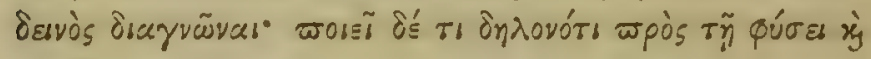

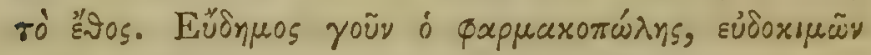

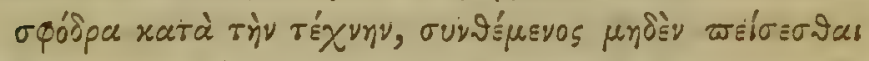

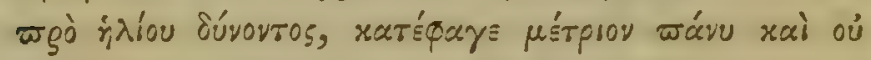

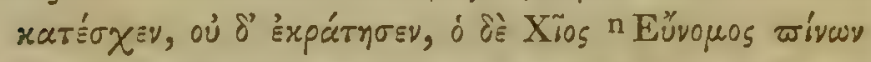

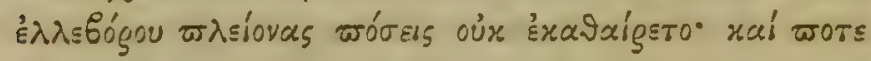

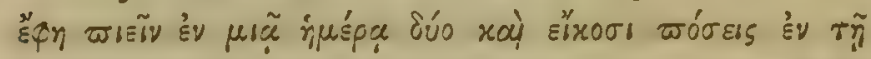

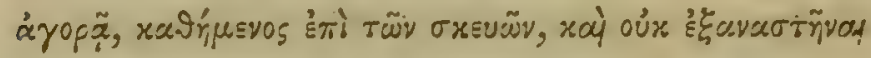

In żevymglía Const.

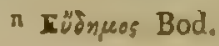




\section{MEPI $\Phi M T \Omega N ~ I S T O P I A \Sigma$ TO $\Theta^{\prime} .40 \pi$}

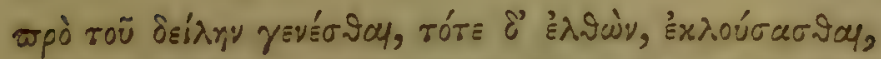

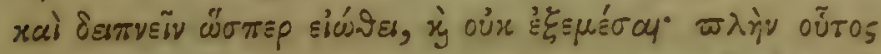

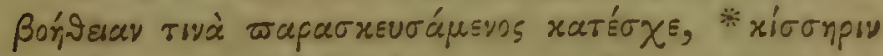

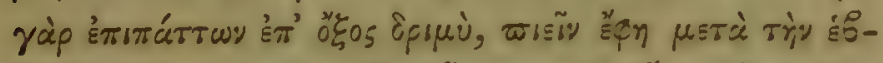

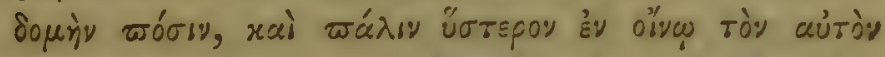

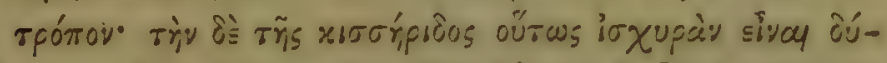

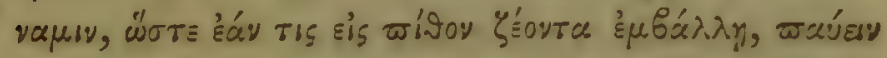

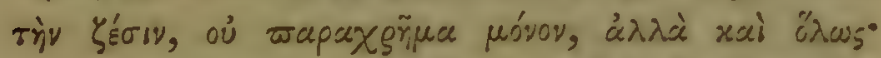

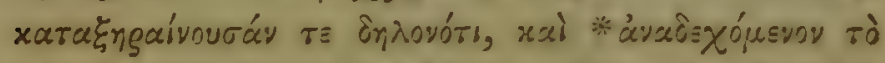

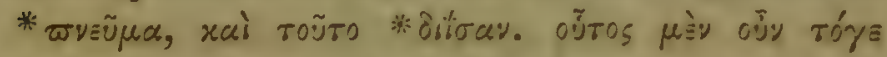

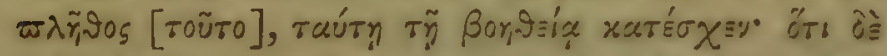

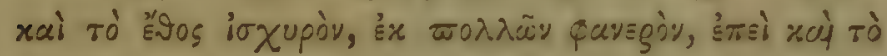

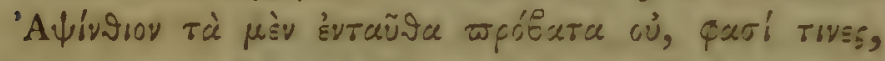

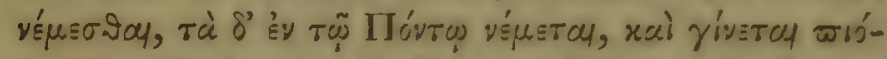

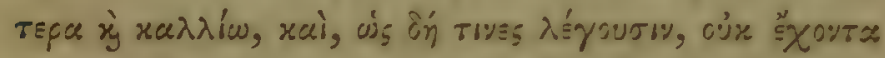

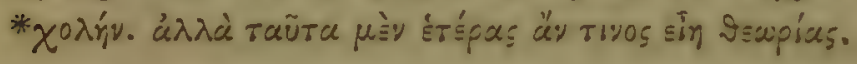

\section{CAP. XXI.}

Vires medicinales Planturum, el futulosu quadam.

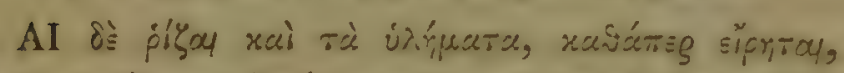

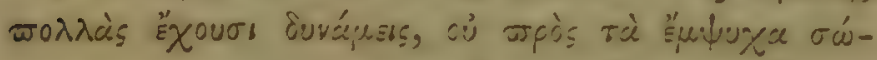

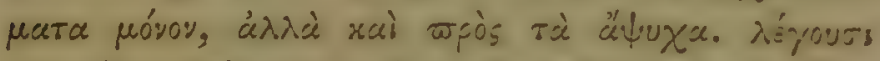

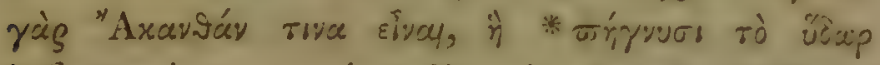

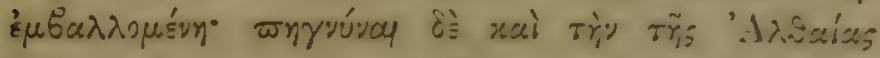

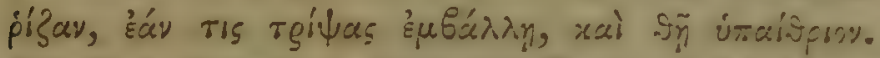

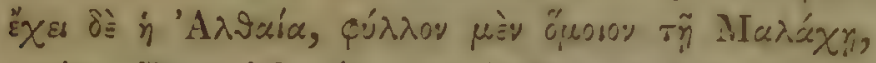

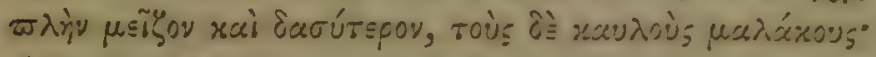

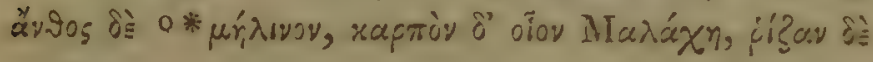

- $\mu$ íravoy, Const. 


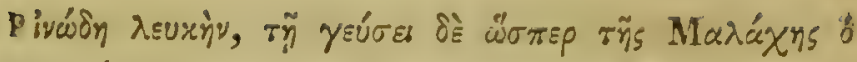

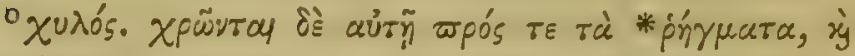

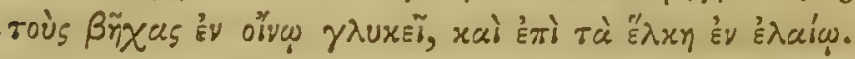

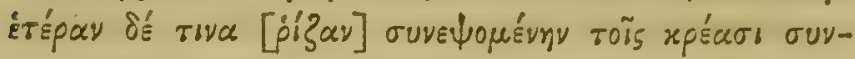

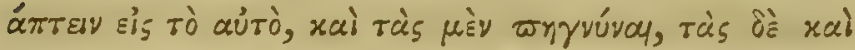

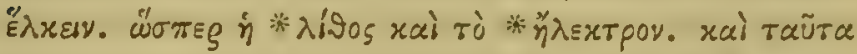

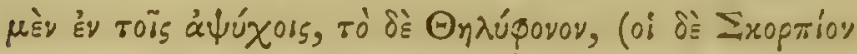

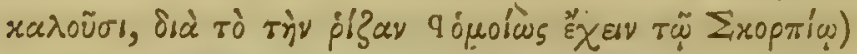

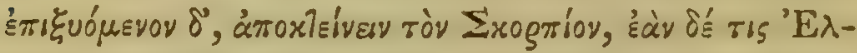

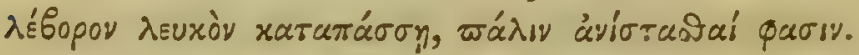

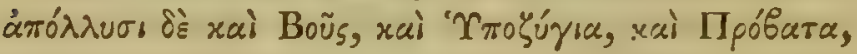

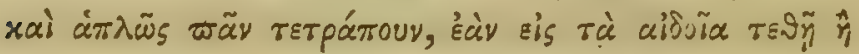

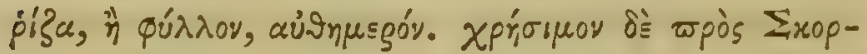

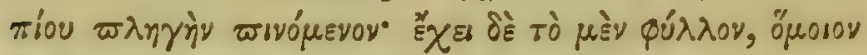

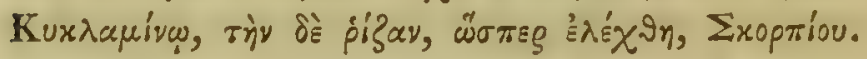

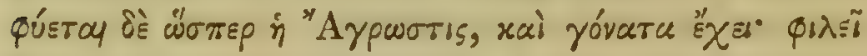

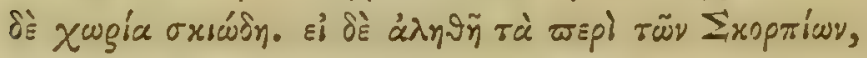

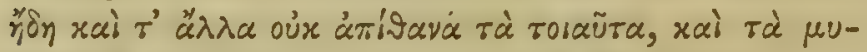

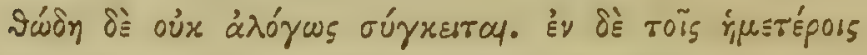

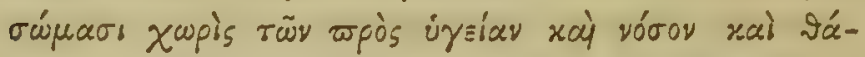

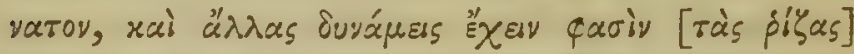

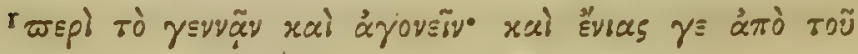

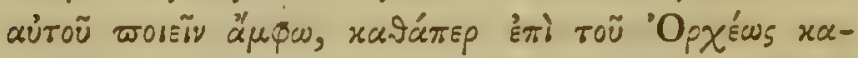

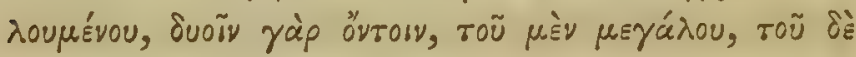

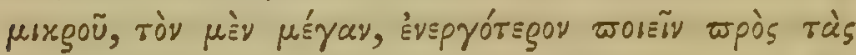

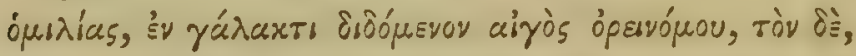

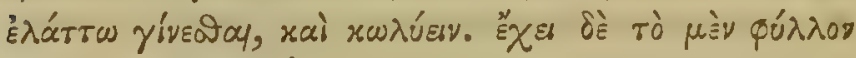

xaùós. Codd.

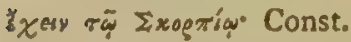

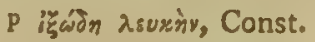

q. 8ूosoy

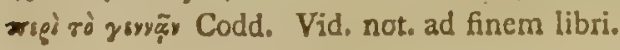




\section{MEPI TMTIN ISTOPIAI TO $\Theta^{\prime} .403$}

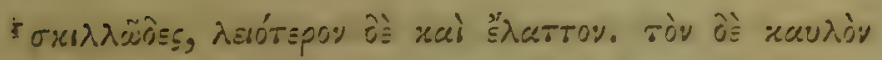

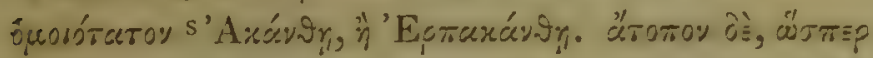

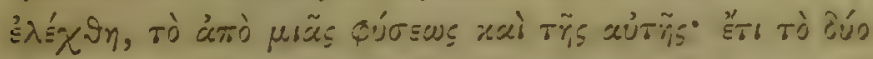

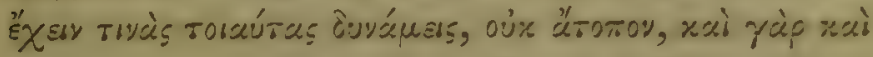

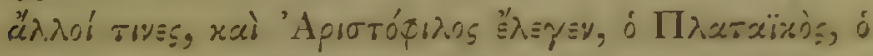

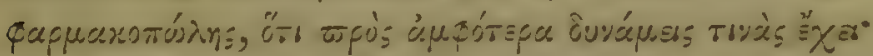

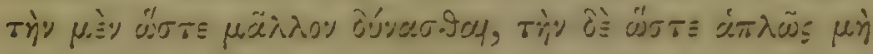

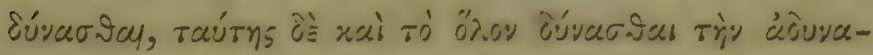

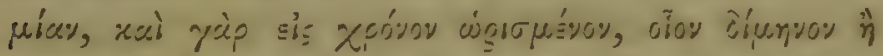

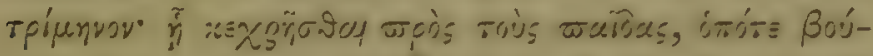

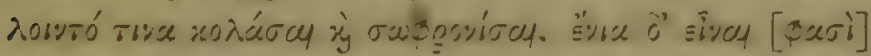

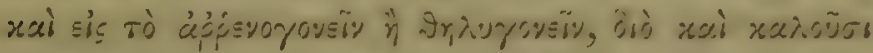

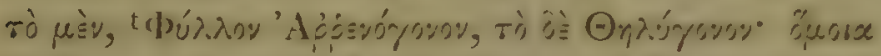

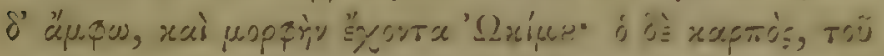

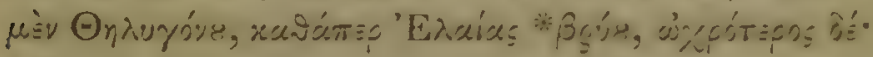

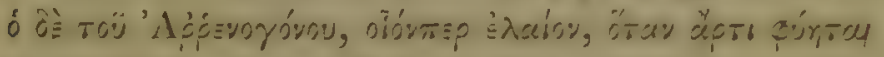

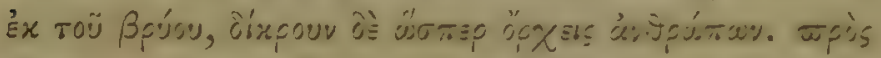

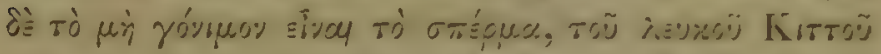

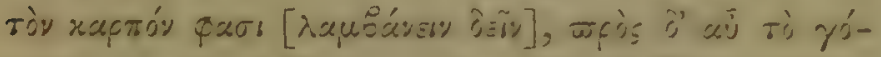

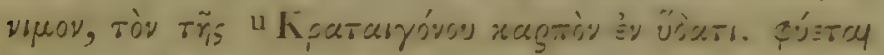

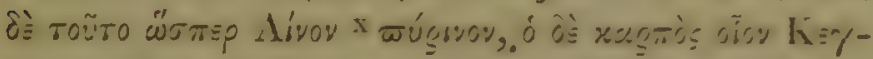

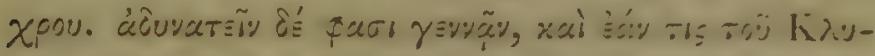

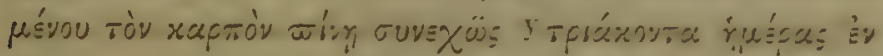

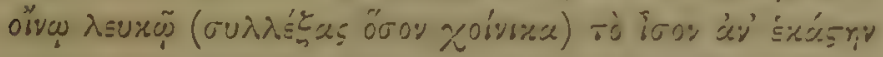

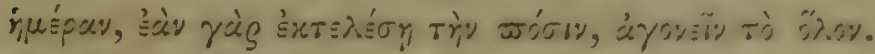

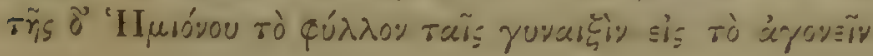

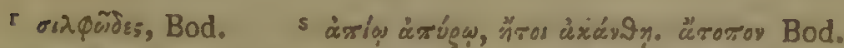

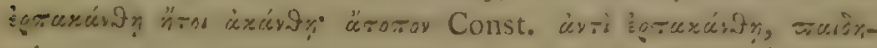

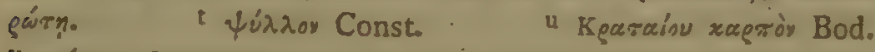

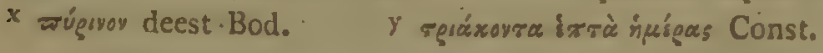

PARS II. 


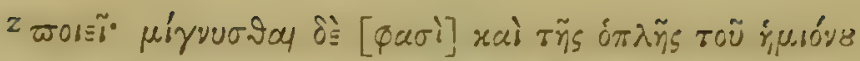

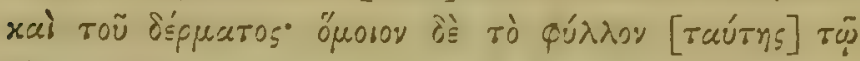

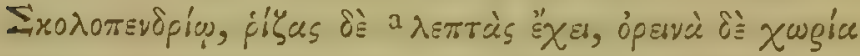


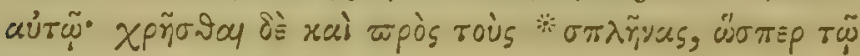

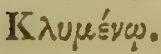

\section{CAP. XXII.}

Filices quadam, et eurum Vircs.

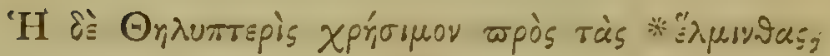

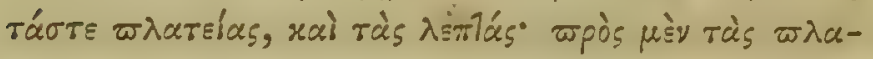

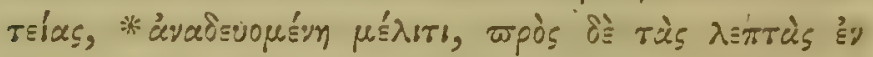

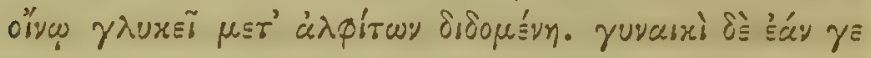

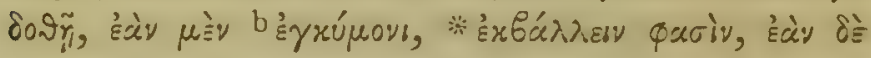

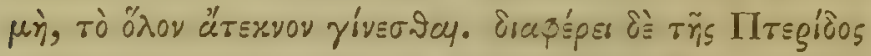

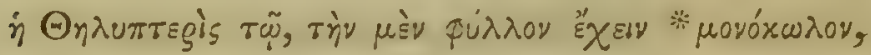

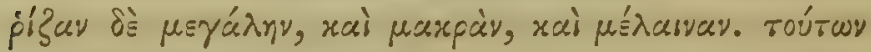

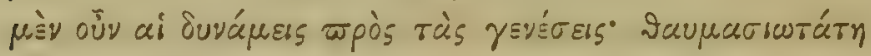

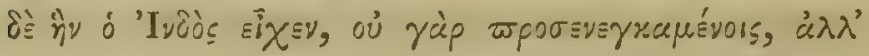

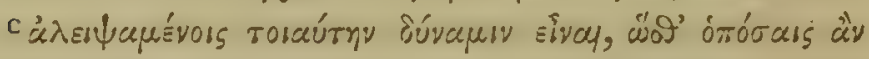

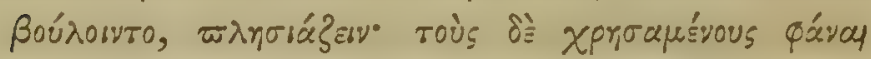

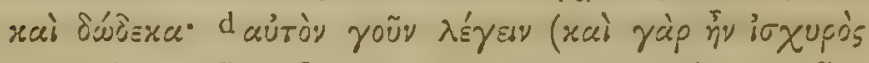

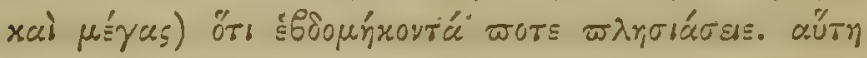

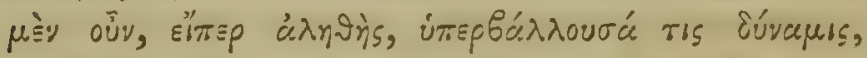

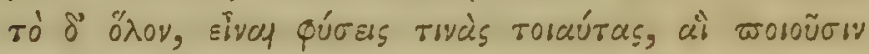

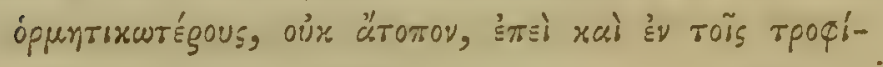

2 चorsĩ deest Bod.

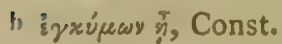
hic, et infra post $\approx \lambda$ nob́rees, pudoris causa.

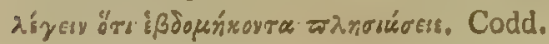

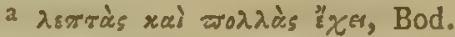
c áqaulvoss Const. Desunt quæedam

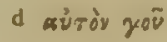




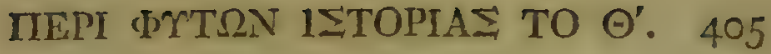

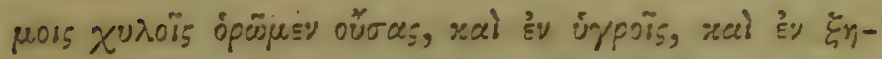

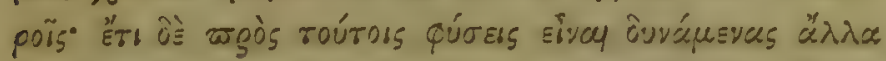

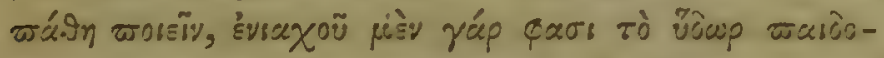

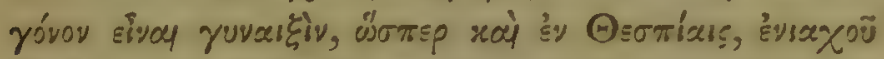

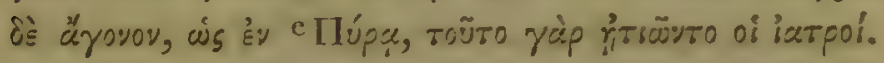

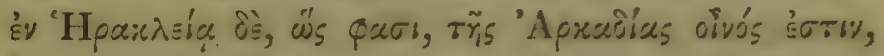

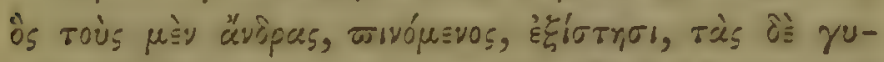

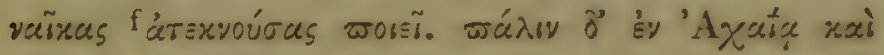

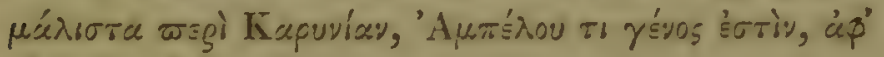

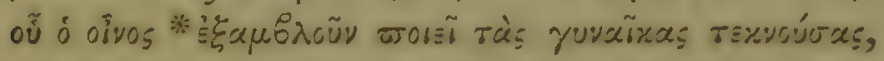

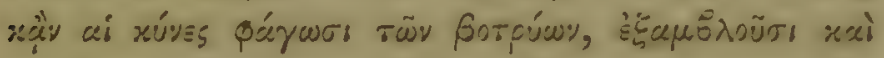

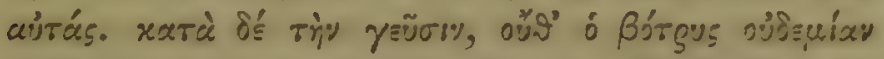

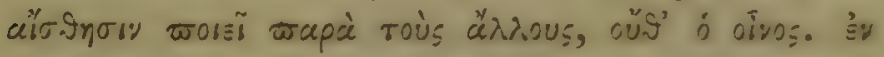

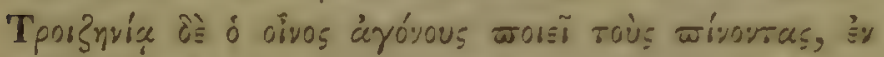

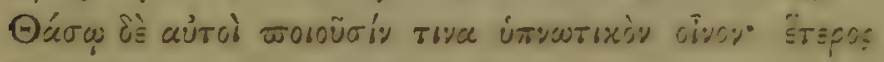

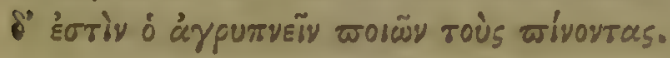

\section{CAP. XXIII.}

Plantarum Vires alexipharmace et magica.

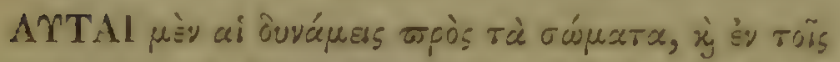

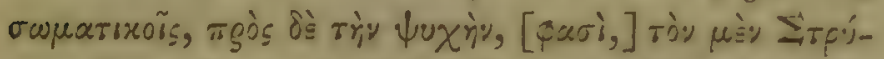

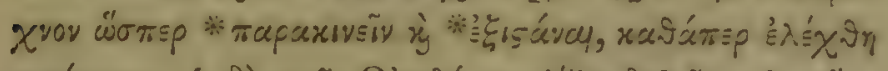

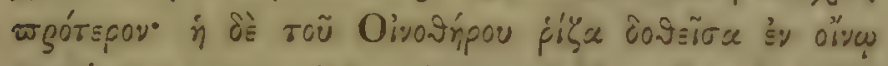

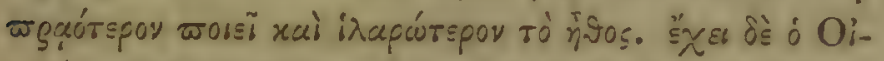

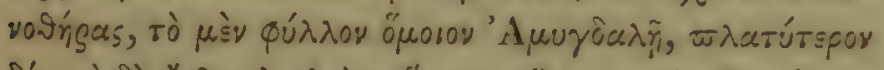

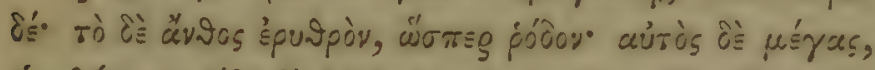

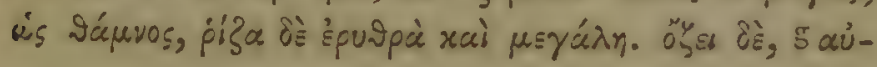
Ald.

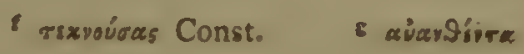




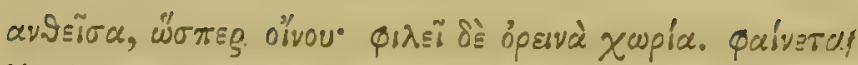

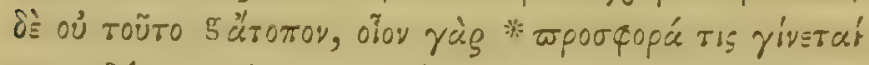

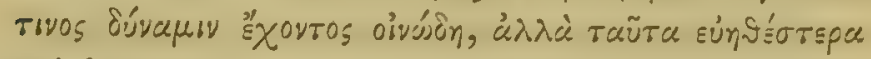

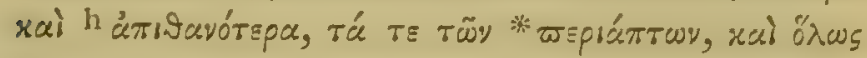

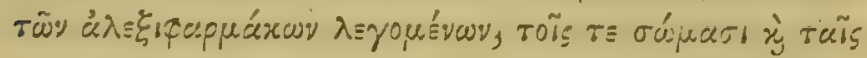

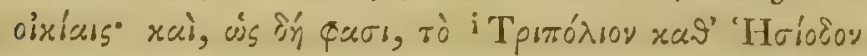

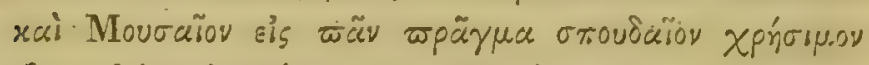

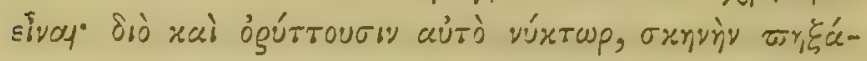

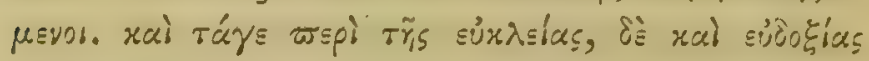

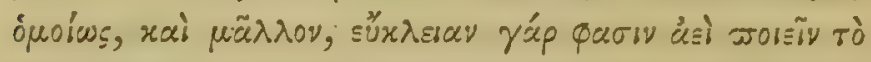

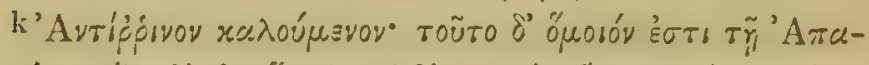

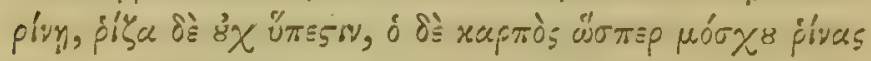

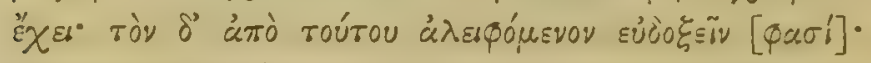

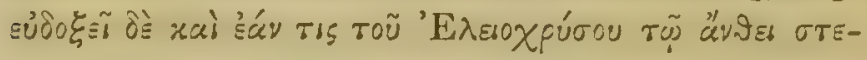

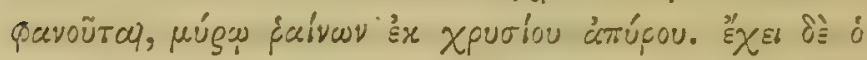

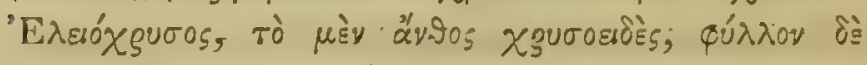

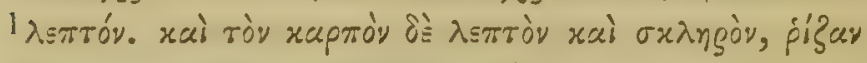

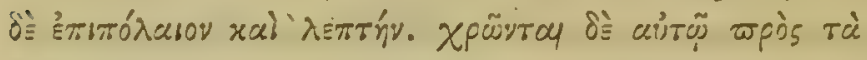

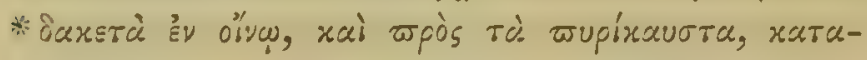

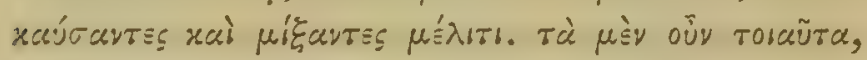

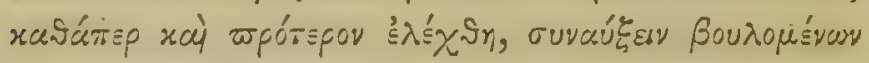

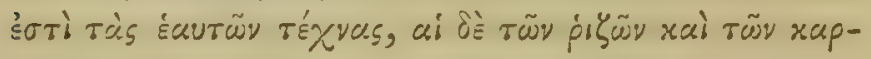

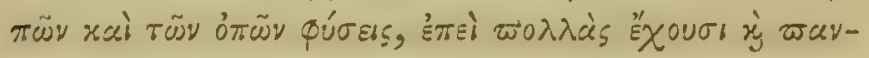

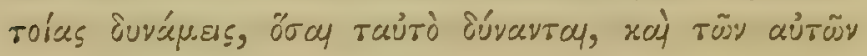

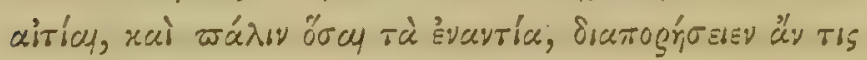

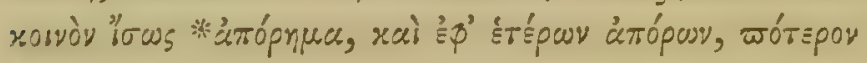

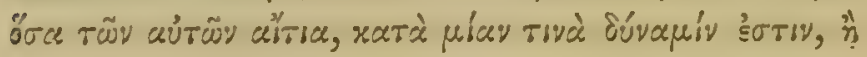

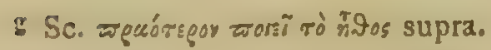
h ॠl9avórsgor, Ald.

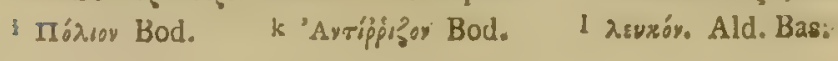




\section{IIEPI WTTSN ISTOPIAS TO $\Theta^{\prime} .407$}

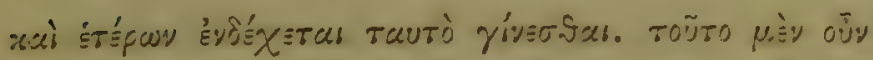

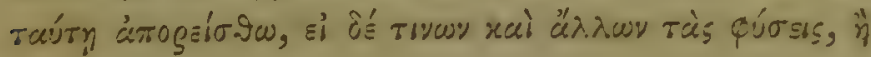

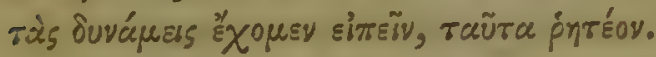

\section{CAP. XXIV.}

1) Pijeris Generibus, rariisque ad Hedicinam ufilibus

\section{Plantis.}

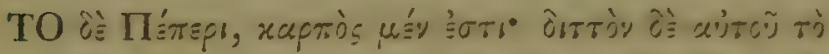

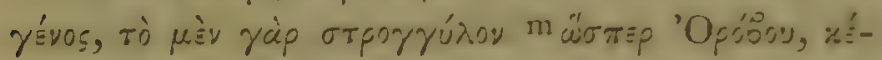

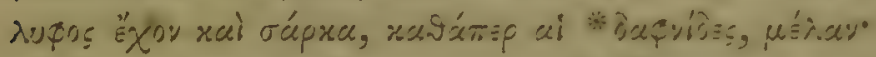

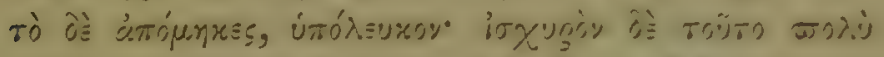

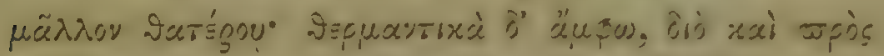

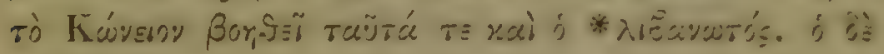

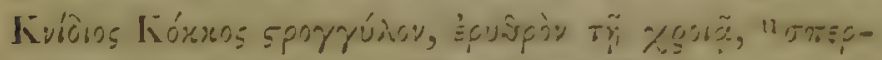

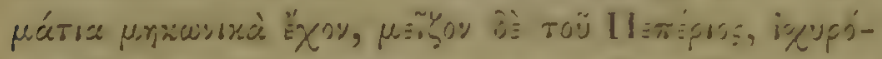

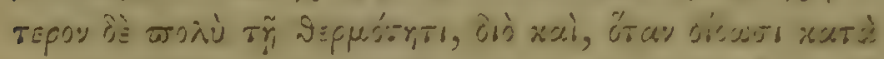

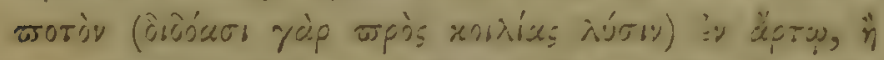

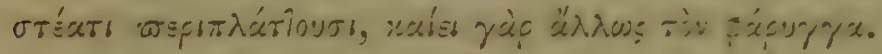

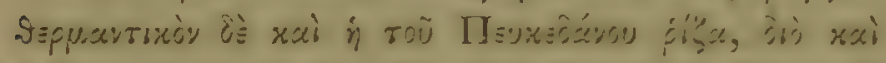

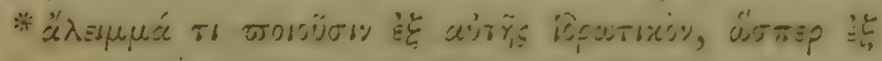

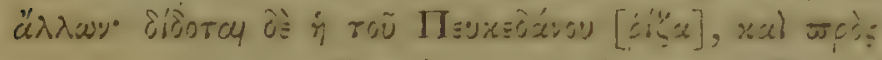

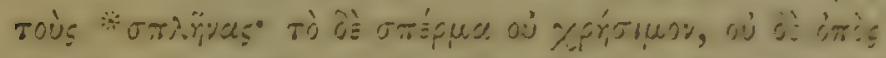

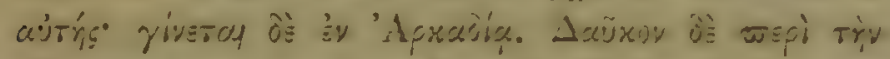

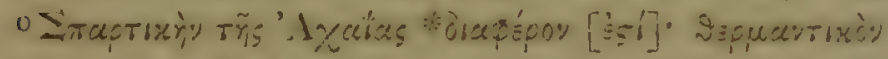

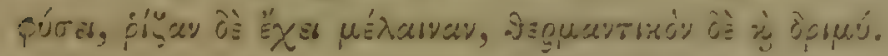

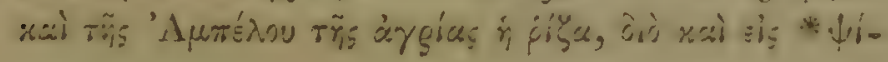

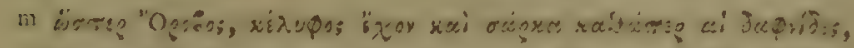

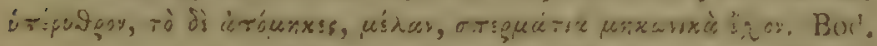

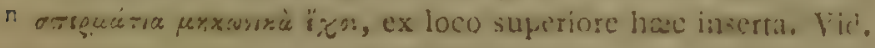
not. ad fin. libri.

- ๘argixìy Const. 


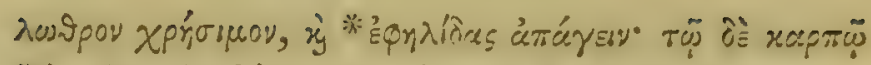

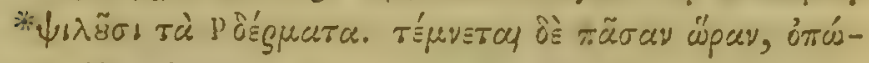

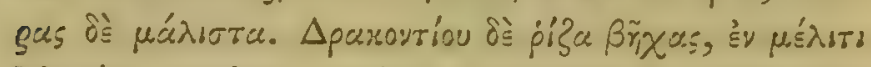

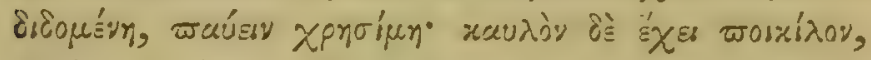
ò

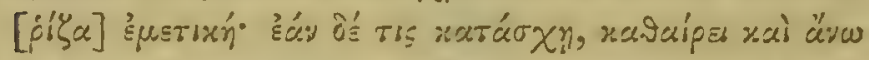

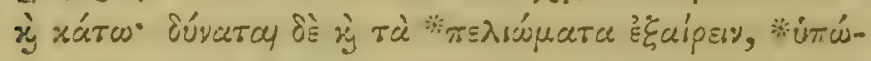

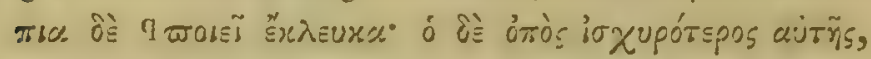

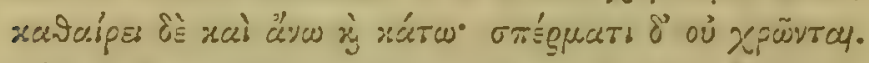

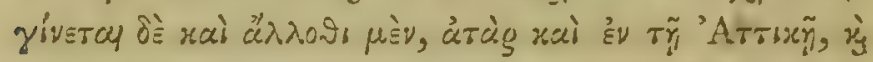

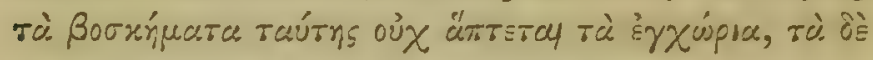

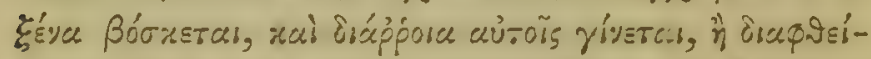

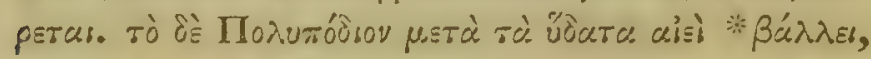

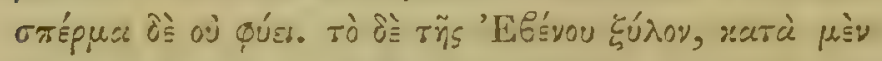

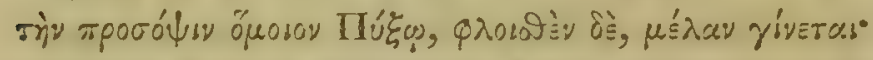

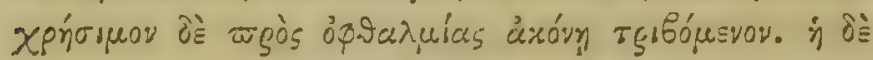

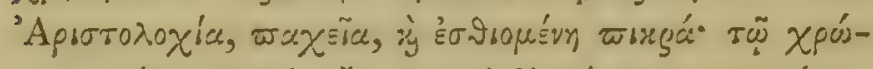

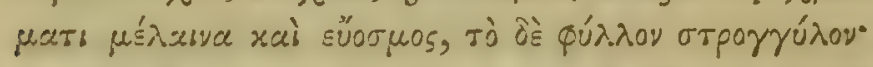

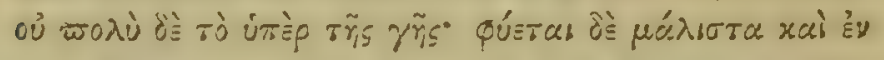

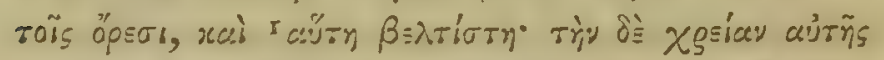

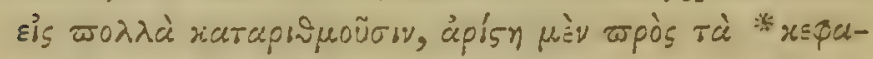

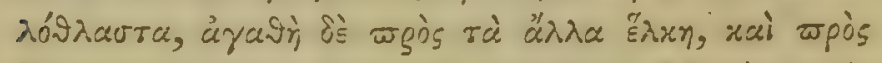

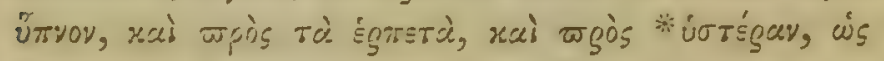

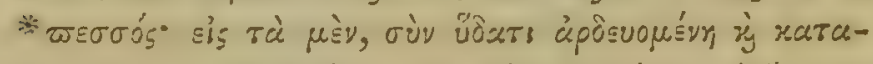

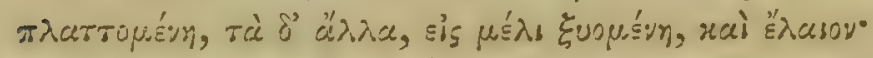

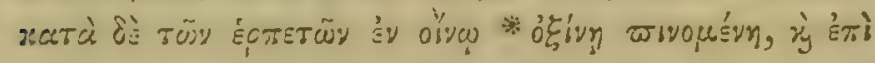

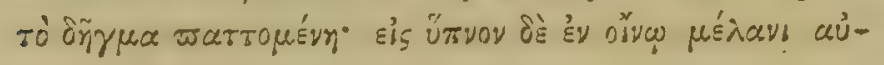

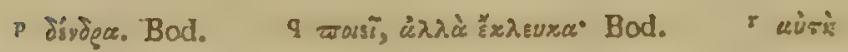

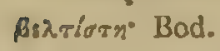




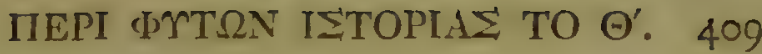

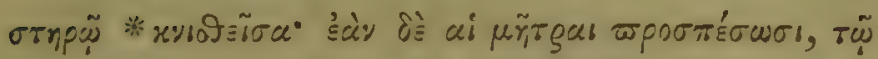

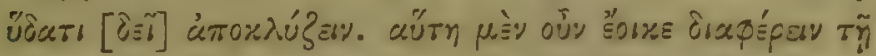

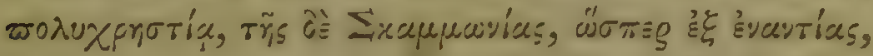

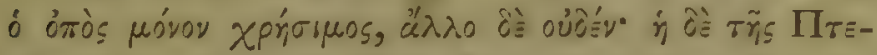

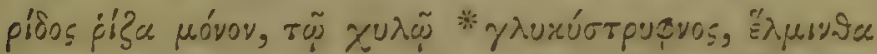

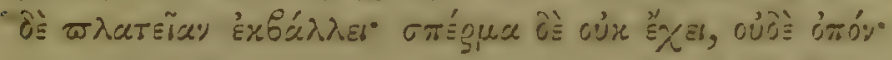

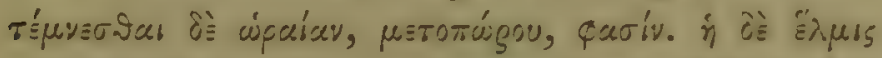

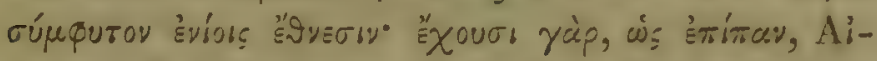

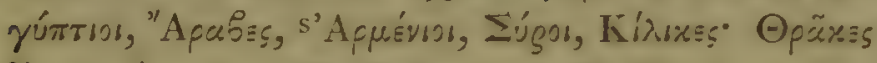

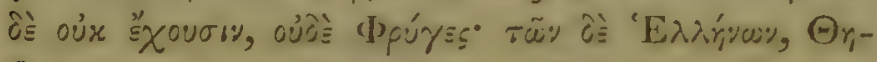

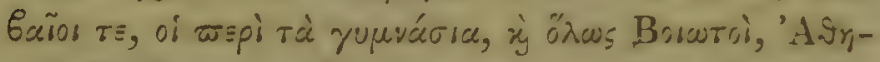

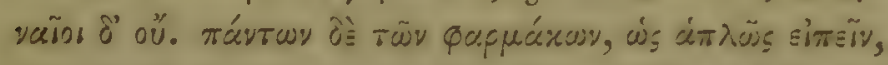

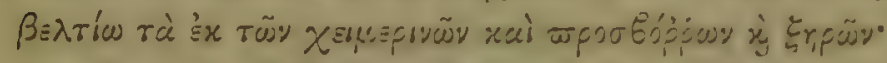

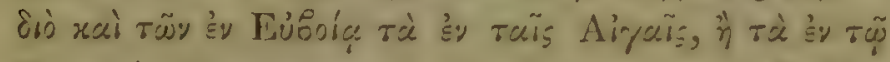

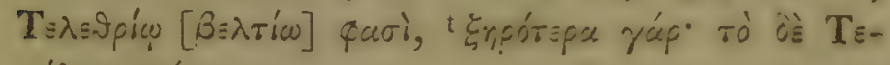

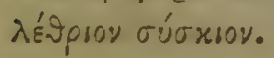

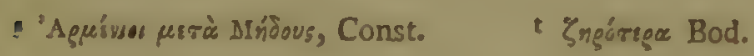




\section{NOT压}

\section{IN LIBRUM NONUM.}

\section{A P. I.}

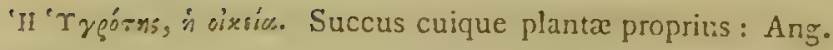
"sap."

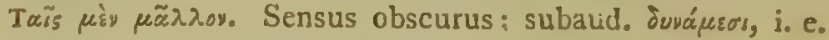
plus minusve virium habent.

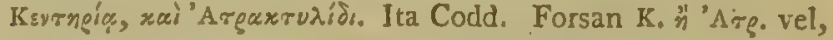
ut in margine, Kestuveí (Centaureo majori), cujus radix rubescens madido succo. Plin. xxv. 6. Succo rubro discrim:nata. Ger. em. 146.

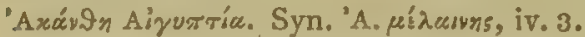

"H Xarbúrn. Gummi Bubonis, Galbani L. cujus nulla descriptio.

'Axáyงn 'Ivวเxต'. Affinis Atractylidis, si non syn.

$\Sigma$ Xivov, Lentiscus, Cat. N. B. Corr. Pistacia, Léntiscus L.

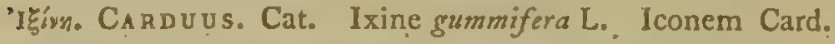

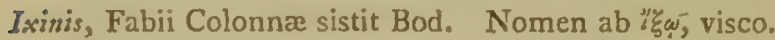

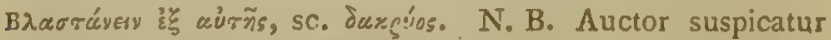

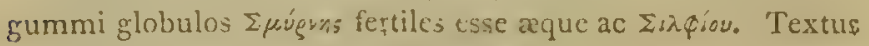
tamen videtur corruptus.

$$
\text { CA.P. II. }
$$

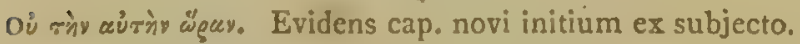

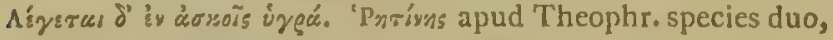
liquida et sicca. Ita juxta Plin. "Sicca e Pinu et Picea; li"quida ex 'J"erebintho, Larice, Lentisco, Cupresso." xxiv. 6. Dioscor. i. 93. Gal. simpl. iii.4.

'Exártgor, sc. Idæi, Macedones. Theod. 


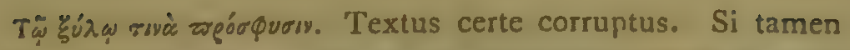
mentem $\Lambda$ uctoris perpendamus, manipulatio duplex describi videtur extralenda resine: 1 . per tercbrationen ; 2 . per excisionem ligni et lentam combustionem. Oüras gissras ri,

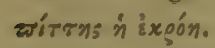

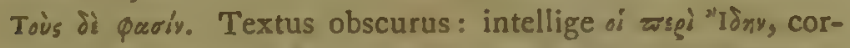
ticem detrahunt; roì; $\delta\llcorner. .$. alios autem cor ligni extrahere.

\section{C $\triangle$ P. III.}

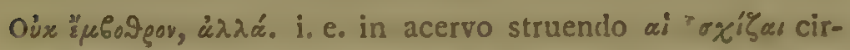
cumponuntur statu non deorsum, sed sursum spectante adeo ut progressu operis conum efticiant.

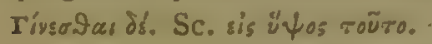

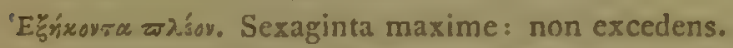

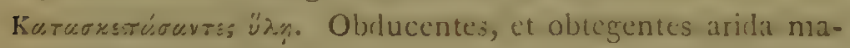
¿eria: virgultis, herba, \&c.

"Osquiós $\tau$. Macluna quiedam truncum amplectens, adeo ut ignem intus contineat.

\section{A P. IV.}

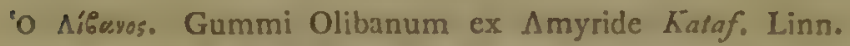
Willd. secundum Sprengel, etsi non inter synonyma Linn. Willd. N. B. In Cat. Juniperus ihurifira, sed make; descriptio cnim certe Pistaciae Ter. bintli spec. cujustam, wel Anyridis. Nucifere amber foliis pinnatis; in systemate rern sexuali Linneano remotissime. Notandum tamen Anyridem Kintaf Forskal. foliis tematis describi, Libanoum Theophrasti fulii,

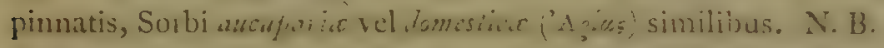
Quatuor Amyriclis specic's cnumerat cl. Forekili, sc. A. Opso

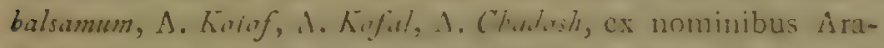
bicis, p.xc. addita Schadjact el Mhr, i.e. Aroore Myrha; de qua sub ticulo :üav.: infia: quam tamen similem prionibus ait, "ex referentium fice." Notandum tamen speciem affinem ex Oriente, sub nomine Boswellie sitrate, foliis pinnatis, l'istaciae vel Sorbi ad instar instrui pluribus loborum paribus. Gummi hujus arboris sinspin, G. Arabico longe inferius; et antiejuitus, ut constat ex testimonio Prosp. Appini, cun genuino adulteratum. Inter Linn. Spec. Pl. Willd, Berolin, 1799. 
occurrunt inter novendecim $A$ myridis species tres vere $A$ rabicæ, A. Krtaf*, A. Gilcadensis, $\Lambda$. Opobalsamum, var. Fo. additu sub nomine Balsamex Mecinnensis. Gledirsch. Berolin. Act. S. N. vol. iii. p. 127. Harum, utpote et Forskalcanarum, characteres specificos sub voce Bá $\lambda \sigma \varepsilon_{\mu} \mu s$ C. 6 . sisto, dubitatione interposita annon Olibanum antiquorum resinosis potius quam gummosis annumerandum, ideoque Aieurúrov ós̀dgov Pistacia L. speciem, non Amyridis. Ut ut se res habct Thuris, vel Olibani, duplex genus; Th. Olibanum, Th, commune vel Juniperinum. N. B. Thus

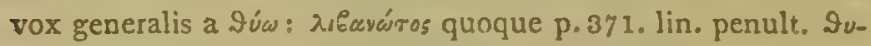

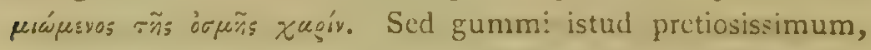
etsi antiquis bene notum; haud sufficerct diurnis Judrorum sacrificis, necnon holocaustis Romanorum, \&c. N. B. Ad arcenda miasmata victimarum casarum resinis ocioriferis utebantur; nec dubium quin abietina, junij rinx, cedrinx, terebinthinæ, \&c. \&c. materiem suppeditaverint: et cur non resina @utas arburis (vid. Cat.), cujus nomen fors. a ఫúw? Hab. Libanoti juxta Forskâl. Djöblae urbis vicino monte, Oude dict. necnon Uddein, medio itinere inter Mockham et Osthuma. P. xc.

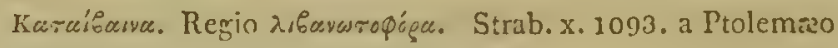
KarœBrivos vocatur populi.

Tŷ I de lobo folii pinnati; in Pistacia, Lentisco, folio oleagino simillimo. N. B. Sensus idem fúdz.ov in descriptione Mrzías, "Ахтभร, \&c. p. 3. 1. 5. p. 118. 1. 25.

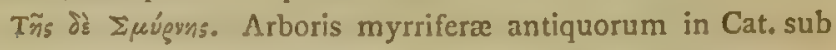
nomine Acaciæ myrrifirc, auct. Brucco, $\Lambda$ pp. Nulla arboris hujus mentio inter Synonyma Linn. nec unquam, ut videtur, sese Botanicis obtulit, etsi Gummi, myrtha dictum, ubique vulgatissimum. Theophrastus ait, in coden monte cum Balsamo repperiri juxıa Heroun portum; Strabo juxta civitatem Arsinoen. N. B. Bruceus in regione Trozloditica, qua a dextra navigantibus ex Heroum civitate conspicitur. P.1093. Mira Brucci narratio, ıui arborem, Mimosa quam simillimam,

* Vid. not. Balsamus 3. p. 416. 
sub nomine patrio "Sassa" descripsit et dclineavit. Pseudomyrhifera species hrec, et gummi, vel óáx@̨ry ejus cum vero mixtum. Resina ejus ađ̧ua insolubilis, aqque ac Olibani et Ju-

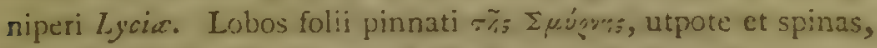
se vidisse ait Bruceus, gummi Myrrhe venalis granulis mistas; de fructu et fore silet. Theophrastus ait folia apice spinosa, vel

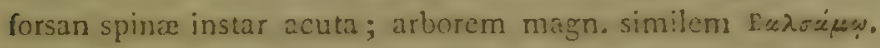
Ilic tamen errare videtur manifesto, ex narrantium culpa;

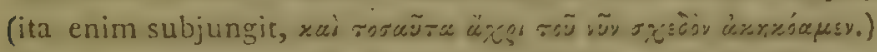
Xúrogon, i. e. molem satis magnam Olibani, non nisi ex trunco grandiori et annoso provenire probabile est. P.372.

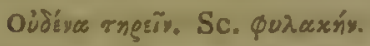

$\Sigma_{x i}$. Pistacia, Lentiscs. Species ejusdem generis cum Tequirà Strabonis, Pausaniæ, et aliorum.

¿xrusorotoreny airoús. Nos singuharis, ut videcur, formas quaslibet vacuas suspendmadi ad truncos, whi tercbratio facta fuerit, all recipiendum $\dot{a} \rightarrow \dot{2}$, qui statu concretn matricem re-

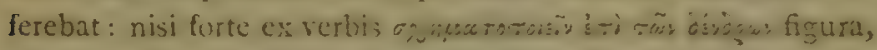
vel $\mu \circ \rho \varphi_{i}$ in ipso arboris trunco insculpta fuisset.

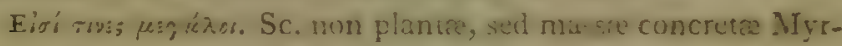

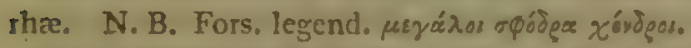

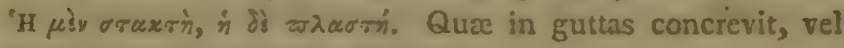
formam quandam accipit, ut supra.

\section{CAP. V.}

Kıvóáprewpos. Laurus, Cassia. Cat. Corr. L. cimnamomum. Habitat insula Tapebrana, hoslic Ceylon, ex yua Cinnamomum verum, reque ax: Pscudo-Cinn, ex arbure kusie, (non Cassia L.) Graciam deportabatur. Vicl. Lizoin infra. Commercium hoc a Strab. describitur, 10. 10. 105. ubi re siu hace w-

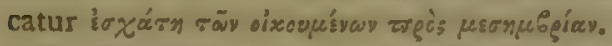

"Oтx" ¿xкiquar. Antiquitys, ut vicletur, rami ramulique arboris hujus çum ligno et medulla excisi.

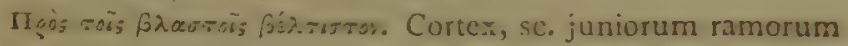
optimus.

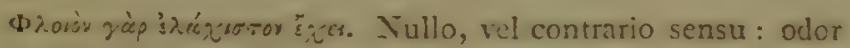

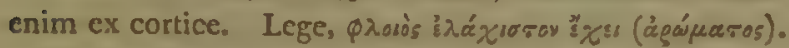

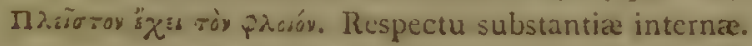


Th̀े de Kaớcev. Laurus; gracilis. Cat. Ita "apud quosdam: rectius L. Casia simplici s。, Cassia enim genus per se. L. Casia antiquitus Canella. Vox manet in compositione apud Virgilium, Colocasia, i. e. Koìro Karíc, ex forma corticis convoluta, intus cavege.

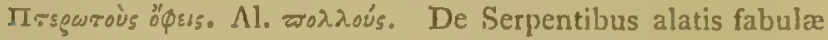
narrantur. Vid. Strab. v. p. 1000. Draco, volans I. fundamen. tum forsan: animal innocuum.

\section{A P. VI.}

Bároaros. Amyris Gileadensis, L. Balsamus Balessan, Brucei. Cat. Species novendecim $\Lambda$ myridis sistit Linn. quarum tres solum antiquis nota, omnes Arabize incola, juxta Lirn. Ethiopiae vero, ad littora Maris Rubri, prope Bab-el-Mandeb, si Bruceo fides, hodic crescunt. Secund. Thtophr, हैy «ủsär rñ s ¿uģiu; ubi Paradisi antiquitus colebantur duo qui prorsus pericre, bellis Romanorum cum Judxis et Egyptiis totam regionem vastantibus. A Forskâl. unica solum visa Balsami Arbor, etsi species quinque sub genere amplo, Amyris L. déscribantur. Notandum tamen plantam hanc non ex autopsia a Theophrasto describi. In celebri de Balsamo dialogo Prosper. Alpin. interlocutor Abdalla, Medicus Fthiopicus, ait: "Plurimas Balsami arbores in nultis Arabia locis

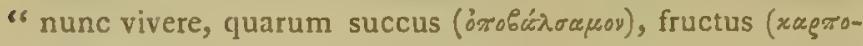

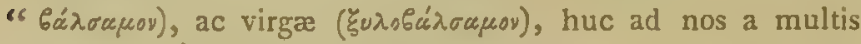
" asportantur." P. 6. Hab. monte arenoso, pergrandi juxta villam Bedruniam quindecim dies itin. ab urbe Cayri, ubi copiosissime proveniunt. Ibid. Hortos vel Paradisos ad oppidum Hierchunta Judaeorum coli, testantur Joseph. Antiquit. et Hist. Tacitus etiam, et Pausanias. Cum Theophrasto consentiunt auctores hi, et praecipue Strabo, arborem fruticosam esse, magn. Cytisi. In arenoso solo yel nihil, vel minimum succi producere affirmatur, itemyue Egyptum adrectam nec flores nec fructum ferre. P. 15. Incertæ nimis apud Prosper. Alpin. notæ Balsami arboris a se in Egypto visæ, et in horto suo Venetiis cultæ." "Folia 3, 5, 7, pinnata instar Len"tisci : flores parvi, albi, Acaciæ proximi? in umbellam "c congesti; rami rubro-virides, gemmis quasi ad apicem: 
"Grana? in molum Piperis provenientia; lac ex fissuris "trunci sponte fluit xstatis temprore; odor ejus ac levitas " mira, recens protluctum." P. 16. Theoplarastus optime describit habitum plantæe ramis tortuosis, et foliis rutaceis : vid. etiam Plin. et $\Lambda$ vicennam. Pausanias foliis Amaraci : Justinus Piceis, i.e. Terebinthinis : (vid. Libanutus.) Bruceus affirmat, se vidisse arjorem, Gambo dclatum, et in loco delineasse; (vid. tab. nostr. ubi ramus major apparet;) Ilab. Beder Hunein in littore Maris Rubri versus Bab-el-Nandeb, in regione

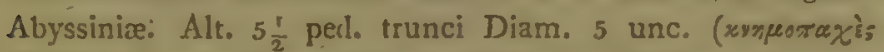
Theophr.) cortex fusco-ruber, glutinosus, digitis adhærens: Prosp. Alp. Folia sparsim, rutacea, tel triphylla. Flores ab ipso non visi. Fructus, drupa rotundiuscula, appice acuto, pericarpio basim cinsente. Harum characteres specificos infra sisto ex Linneo, Prosper. Alpino, Forskûl. aliisçue, quo fucilius a viatoribus futuris indagentur in loco natali.

\section{BALSANIUS.}

Ord. nat. Terebintaceæ.

\section{Octandria, Monogynia?}

Char. Gen. Calyx 1-dentatus: Petala 4. Stigma 4-gonum, ojtusum: Nectarium carnosum, annulare intra stamina et fermen: Anthere oblungre, diclyme, flave: Drupa oblonga, vel rotundiuscula, 2 vel 3 -capsularis, monosperma: Pulpa tenax, viscida, sæpissime abortionem inducens.

\section{Balsamus, Theophrasti.}

Bals, ramis tortuosis divaricatis : follis ternatis, rarius quirque-fobis: Whis apice rotundato-nutis, margine plano: poduncuils florum uni vel tri-floris, sparsis: drupa rotundiuscula, apice acuta: saturis 4.

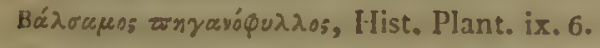

Amyris Opobalsamum. Linn. Willd. p. 755. ח. 7. sine synonymis.

Am. Opobalsamum, Forskâl. Egypt. p. 99. Vabl. Symb. i. p. 28, t, 60.

Balsamus Balessan, Brucei $\Lambda$ pp. 
Tsori, Hebr. Gen. xxxvii. 25. xliii. 11. Ezek. xxvii. 17.

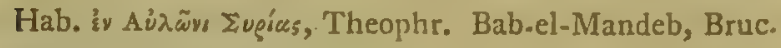

Arb. mediocr. magn. vel Frutex.

2. Balsamus, Libanotus*.

Bals. ramis rectis: foliis ternatis et 7 -lobis: lobis apice acutis, margine plano: racemis florum terminalibus: drupa oblonga, apice acuta: suturis binis.

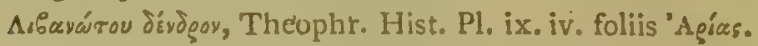

Balsamum, Prosp. Alp. Egypt. Dialog. t. p. 39.

Lebounah, Hebr. Exod. $\mathbf{x x}$. 34 , Levit. ii. I.

Hab. Arabia Fel. Prosper. Alpin. p. 8. Sabæorum montes, Theophr. Juxta Cahiram, Prosp. Alp. p. 9.

Donum Salomoni a Regina Sabæorum. Josep/. Antiquit. lib. viii.

\section{Balsamus, Kafalt?}

Bals. foliis ternatis vel pinnatis, lobis obtusis vel acutis; margine serratis : pedunculis dichotomis, ad apices ramorum : confertis, corymbosis: drupa ovalis, basi suffulta calyce 4-dentato, saturis quatuor: pericarpium osseum. Forsk. p. 80.

Amyris : foliis ternatis, \&c, apice serratis : pedunculis confertis, bifidis. Vahl..Symb. i. p. 28.

Pscudo-Carpobalsamum fructu magis oblongo? Prosp. Alp. c. 6. p. 33 .

Hab. Abu-arîsch. Forskâl. p. 80.

* 'O ÁEavos, Theophr. ix. 4. arboris nom. gummi vel resina גicavov. N. B. Latini scripserunt olibanum, masculino articulo addito terminationi neutre. Vid. tabulam Lexic. Theophrasti præfixam.

+ Spec. apud Willd. Amyris Kataf sistitur auctoritate Forskâl. n. 5. In perlegenda tamen ipsius descriptione notand. flores masculos se vidisse tantum, unde genus monocium vel dicecium; et infra: "Narrarunt $\Lambda$ rabes arborem hanc quovis " anno mensibus pluviosis intumescere, et prægnantem cva" dere pulvere rubro, fragrante (polline) quo foumina capita "aspergere solent. Notæ certissimx pl, diœcix. Fors. Schini aspecies." Ibid. p. 80. 


\section{Balsamus, Meccanensis.}

Bals. foliis bipinnatis. Linn. Willd. to ii. p. 335 .

Balsamea, Meccanensis; var. F. Amyridis, Opobalsami, Linn.

Willd. n. 755.7.

Bals. foliis bipinnatis? margine serratis. Gleditsch. Act. Soc. Nat. Berolin. vol. iii. p. 127. t. 3. f. 2.

Bals, Houttuyn. Linn. Pflanz. Syst. vol, i. p. 473.

Hab. Arabia, prope Meccam.

\section{LIBANOTUS.}

Ord. nat. Terebintaceæ.

Decandria, Monogynia?

Char. Gen. Calyx 5-fidus: Petalia 5. oblonga, cxpansa, extus pubescentia : Stigma apice 3-1obum: Nectarium carnosum annulare intra stamina et germen: Antheræ 10. longitudine alternantes: Bicca oblonga, suturis in pericarpio binis : intus tricapsularis, monosperma.

\section{Libanotus*, Asiaticus.}

Char. Spec. L. folis pinnatis : lobis alternis, utrinque 9-12. margine crenulatis. Racemis florum axillaribus, ad apices ramorum.

Boswellia, serratu. Colebrooke, Asiatic Researches, vol. ix. p. 376. t. 6. Roxburgh, Plants of Coromandel.

Hab. Nag Pur, ct alibi in montuosis Indiæ Orientalis. N. B. Genus hoc affine ex India Orientali sisto, Auctt. D. 1). RoxBURG ignotum, ut constut ex Prusp. Alp. Dialogo de Balsamo, p. 7 . ubi testimonio G. Anıati, Lusitanici Nedici, et Nicol. Monardi Hispani, affirmatur, "Syriacum et IEyptiacum Bulsanum "periisse; aliudque genus Balsani ex occidentali India parte " importari." N. B. Systema sexuale Linn. masime laborare videtur respectu Amyridis, Schini, ct Boswellia: maxima earum affinitas, excepto quoad numerum staminum. Nectarium

* Mira haec structura partium balsamo elaborando videtur inscrvire. 
annulare, basin germinis cingens idem in omnibus; necnon stigma infra, 2 vel 3-lobum. Drupa ctiam 2 vel 3-capsularis, monosperma; characteres distinctissini, adeo ut dubitet Jussicvius annon genus sit trigynum. Gen. Plant. 408. Genera hæc affinia ulteriore egent investigatione.

\section{EXPLICATIO TABULE TERTIE.}

a. Ramus major Balsami Balessan. Bruc. App.

b. Folia ejusdem triphylla et rutacea. nat. magn. lbid.

c. Drupa cum calyce, et suturis 4 . Ibid.

d. Fructificatio Amyridis Gileadensis. Vahl. Symb, t. ii.

e. Summitas Balsami arboris cum foliis et fructificatione, terminali. Prosp. Alp. tab. p. 39.

f. Folium Boswellix, serrata. Colebrooke. Dim. magri. Asiatic Researches, \&c.

g. Drupa suturis binis. Ibid.

h. Flos, cum germine, staminibus, et nectario annulari.

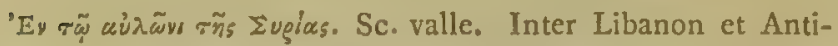
libanon, Koìo-Eupice hinc nominati Strab. vi. 1063. alibi Airovíros, lib. vii.

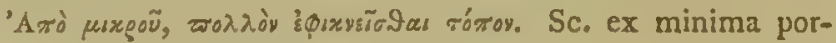
tione exhalans odor longe diffunditur.

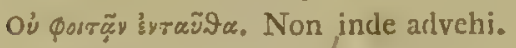

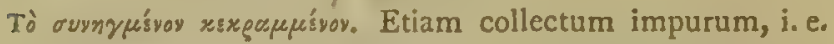
colligi nequit purum. Theod. parum intellexit sensum.

Tò paefía. 3,5-ennales virgula hujus arboris Xjlobalsamum, Pharm. Vid. Prosp. Alp.

Kastaigesv ós. Vocen medico sensu accepit Theodorus, sed de

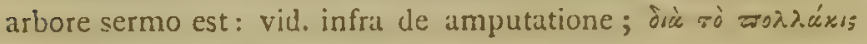

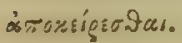

\section{CAP. ViI.}

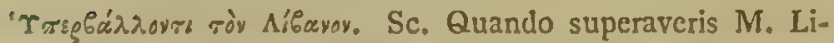
banon, in valle inter MM. Libanon et Antilibanon, in monticulo quodam. Quam accurate

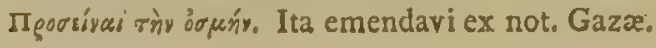




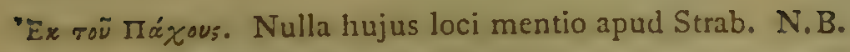
Forsan regio ita ex quálitate soli dicta?

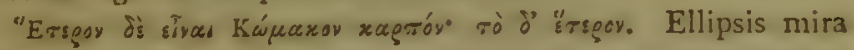
Auctoris, si non vox exciderit. N.B. Duæ species videntur arboris hujus, quarum alterius fructus, alterius succus inter unguentaria. N. B. Non Myristica, sed Myrobalanus, L. Ger: em. p. 1500.

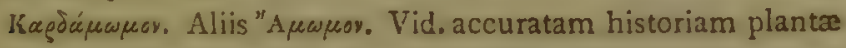
hujus; Act. Linn. vol. $x$.

Nágòos. Andropogon, Nardus. Cat. Vulg. Lect. "Spike-

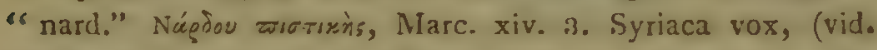
Schleusneri Lex.) præstantiam indicans; odor præcipuus in radice. Galen. Accurata descriptio gram. hujus Act. Rez. Lond. 1790. Anthoxanthi nostratis similis odor, sed evanescens.

Nĩ̧̄ıs. In Cat. Nuĩons, syn. Núpòsu. Sed species forsan ejus-

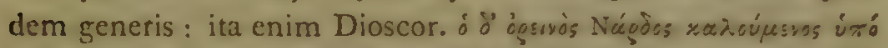

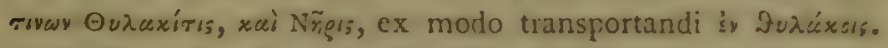
N. B. Valerianæ species, Náġos Diosc.

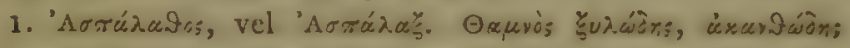
Dioscor. Spina sylvestris, Plin. xxiv. 13. Sp. candida, Ibid. c. 24. "Darsisahan Arab. ex insula Rhodo, radice crassa, "longa, dura; colore flavo-rubro." Prosp. Alp. Egypt. p. 296.

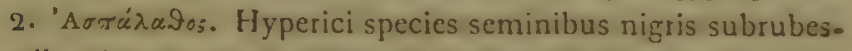
centibus in parvis folliculis; picei odoris. Ibid. p. $29 \%$.

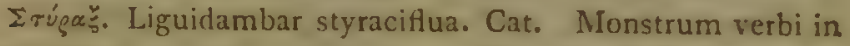
edit. 1770. corrigitur. Hodie Styr, officinalis. Mill. Ic. p. 260. Vid. Diosc. i. 79. Strab, lib. zii.

Kóoros. Costus, Arabicus. Vid. Plin. xxii, 4. Dioscor. i. 15. Inter Scytamineas Linn. Vid. Dissertationem cel. D. Roscoe, Act. Linn. $v$.

Kúrzı̧ov. Omissum in Cat. N. B. Syn. forsan Acori Calami。

$$
\text { CAP. VIII. }
$$

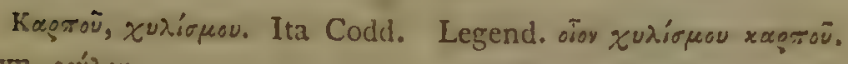
Syn. $x$ údou.

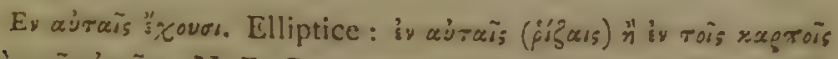
waì roís óroís. N. B. Post vocem funzois inserend. rox sy. vepuv.

PARSII. 
"Ocay dus!ngwo tòy xugróv. Priusquam fructus amiserint. Theod. Sensu contrario, ut notat Scal. sed nec ipse lucem

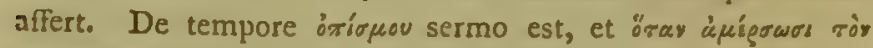
xagrò tempus indicat, quando cxprimitur succus: fors. Oliva; fæecs enim hujus proprie, amurca. Vid. Plin.

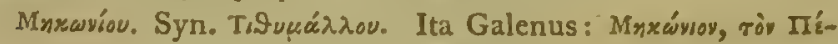

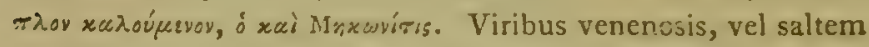
narcoticis. Sed forsan nomen a Galeno inditum ex usu succi Papaveris cum Euphorbia antiquitus. Secund. Ger. em. succus Euphorbiæ, ut purgativus valde, succo Papaveriz corrigebatur. P. 306.

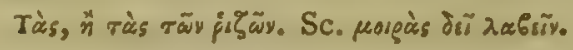

\section{CAP. IX.}

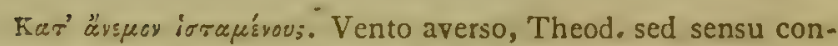
trario, ut videtur, ne odor plantæ adveniat : " to windward."

Oaque. Thapsia, Seseli. Cat. Suspicor Th. feetidam L: indicari, cujus vires venenosæ: Ang. "Deadly Carrot." Ger. em. 1030. Fabulosa hace narratio apud Plin. occurrit xiii. 22. N. B. Scal, ait se vidisse pustulos in cute ex tactu plantre; idem observavit Parens Bodæi, Pharmacopola ; vid. p. 1042.

Kuvóoßarov. Rosa, Canina, L. Vid. descriptionem fructus, lib. xvi. p. 130. Semina involvuntur materie villosa oculis et manibus infesta; sed non nisi tractentur manibus.

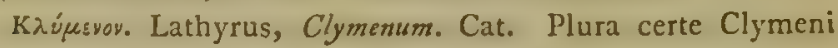
genera apud antiquos. Ita Clymena duo Tournefort. sc. Lathyrus, Clymenum L. et verticillata L. N. B. Clymenum Latinorum, Hypericum Androsamum L. Vid. Plin. xxv. 7. De viribus fructus sterilitatem inducentibus nulla apud Botanicos mentio; succus tamen foliorum calidus, et attenuans. Ger. em. 891. Constantin. inter magicas herbas enumerat Kaú $\mu$ svor. Vid. Athen.

Maswíc. Preonia, nobilis, L. Cat. Nomen a Medico Pæoni, Odyss. Glykysidam ex seminibus dulcibus, oidion 'Pories similibus. Mcdicæ vires a Dioscor. celebrantur, iii.5. Etiam apud Plin. xxvii. 10. xxv, 4. Athen. iii. Aglaophotis vocatur a Plin, xsplendore floris; de qua vid. Joseph. Bell. Jud. vii. 25. 
Apuasóratros. Picus, Martius, L. Fabula hæc de cura \ęoox. respectu Pæoniæ, vere anilis.

Ksyraugióa Tgáó $\chi$ ny. Ignot. Cat. Peculiaritas radicis satis designaret plantam hanc habitu diversam, ut videtur, a Centaurea. Plin. fabulam recitat. Alibi ait ex vi vulncraria Chironiam appellari, $x \times \mathrm{v} .6$.

\#ig̨v. Alibi vocatur "Iprs.

Téínnvov. Alii тpırx́rvous: sed nullo sensu nisi trimestri intervallo faciendum. Ex frumento trimestri. Bod. N. B. Vid. species Iúģou ręurł́rov. Ang. "Spring Wheat,"

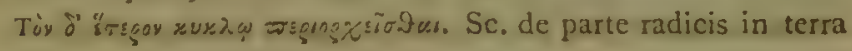
relicta : ut supra.

\section{A P. X.}

Exappewía. Vid. iv. 6. Convolvulus, Scammonia, L. Vires medicæ antiquirus notissimæ. Diosc. iv. 171. Plin. xxvi. 8. Tota planta succo turget lacteo. Bod. IEgineta, vii. A. Etius, iii. 25.

Kuz2arivos. $\Lambda$ b orbiculari forma folii et radicis. De viribus vid. Dioscor. ii. 194. Plin. xxi, 9.

Oałic. Thapsia, vel Seseli. Cat. "Diversæ, et plane dis"similes sunt plantæ Thapsia, et Thapsus." Bod. p. 1061. Thapsia genus Linn. continens quatuor species, inter quas Th.

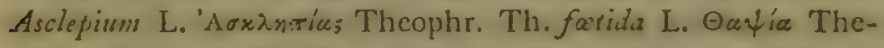
ophr. et Dioscor. Vid. Plin. xiii. 22. Vid. ctiam Lobel. et Penam in voce.

Marḑarógov. Vid. vi.2. Plin. xxvi.11. xxv. 13.

'Evsízaverts 'ì yaúxes. "Involutos musto," Scalig. et recte: sed ab aliis transfixi super calamo in fumo. Vid. Theod. in loco.

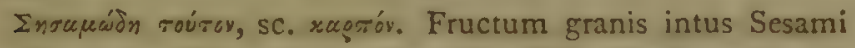
scminum similibus. Kạ̧iò paráón, alibi. De forma uram referente.

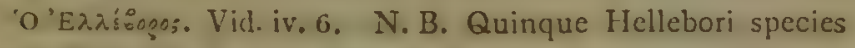
apud Linn. Sp. Pl. 793. quarum H. niger, secundum Clusium, H. legitimus. N. B. Dua species H. nigri apud Bauhinum : 1. flore roseo; 2. odore feetido. N. B. Hellebori Orientalis extat accuratissima descriptio, necnon icon ad vivum depicta, a cel. 
Tournefortio. Ann. du Mus. National, tom.xi. p. 278. Helleborum album Theophr. suspicatur Auctor speciem valde affinem esse, ab Hell. nigr. colore radicis solummodo diversam. Investigatione dignum an Theophrasti Hell, albus sit var. vel vera et distincta species.

Tàs pwrarxius. Ad vocem exercitandum, Theod, sed sensus obscurus. An ad impedimenta vocis?

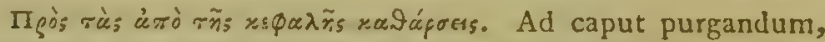
Theod. an de defluvio narium in catarrho, dict. "la Rhume," Gallis ?

Karaxaiour. Igni comburunt, et ex cineribus trochiscos efficiunt, vino madefacientes, adeo ut similes fiant fæcis vini, in.globos compactæ; quibus utebantur vice saponis.

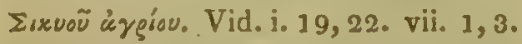

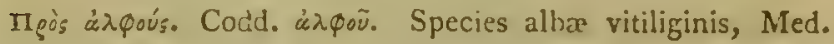
impetigo Hed. vitiliginis spec. "Morphew."

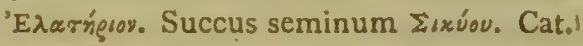

Xapuígęs. Teucrium, Chamcedrys. Cat. "Chamædrys her" ba, Latine Trissago:" Plin. xxiv. 15. E contra Rhinanthi species Trissaginis nomine occurrit in Syn. Linn. Vid. Dioscor. iii. 12. Bod. cit. Chamædryn majorem repentem, una cum icone, p. 1061. quam tamien non repperio inter syn. Linn.

"I $\sigma$ $\alpha$ s. Ign. Cat. "Lactescens hrec planta " $\sigma \chi \alpha$; dicitur a "radicis effigie, quæ exsiccatum ficum imitatur." Bod. N. B. Potius Pyrum. Planta hæc ex similitudine radicis Euphorbia, Apios, L. Apios verus Ger. em. icon. 504. Tithymalus tuberosa, pyriformi radice. Sectio transversalis bulbi apud Ger. em. $\frac{1}{2}$ unc. sect. longitud. $\frac{3}{4}$ unc.

\section{C $\Lambda$ P. XI.}

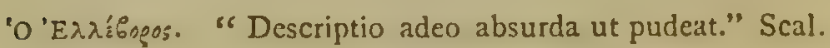
N.B. Descriptio certe valde affinium specierum, et idcirco perdifficilis: sed pace magni viri vim verborum hic loci pa-

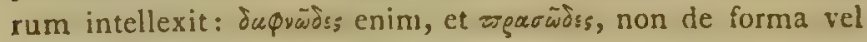
specic folii, sed de colore. Recte ergo vox $\delta a \varphi v \tilde{w} \delta \xi \xi$ nigro-viridis ${ }^{'} \mathrm{E} \lambda \lambda, \mu$ 's $\lambda$ ay attribuitur.

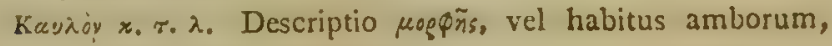
sequitur: caulis, folii, ràdicis. 


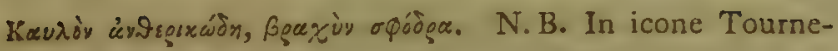
fort. supra citata, caulis assurgit e corona radicis, nudus, præ-

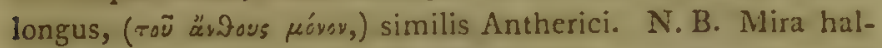
lucinatio Budæi de Veratro, albo, et nigro, L. ex ignorantia

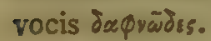

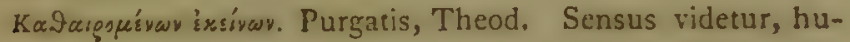
mores noxiæ purgari ante saginationem.

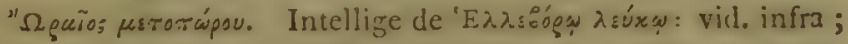

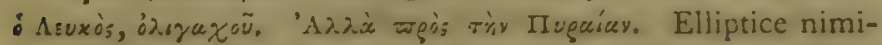

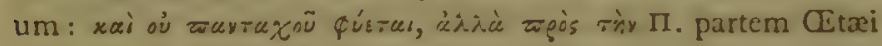
montis. Forsan supplend. $\dot{\iota} \lambda \lambda \dot{c} \dot{s} \mu$ ạvov.....

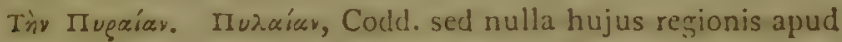

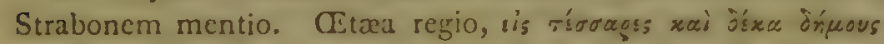
divisa. Strab. 62?. Corrigo חupuéay, ut sit regio circumjacens Pyram Herculis.

\section{CAP. XII.}

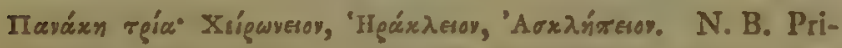
oris nulla mentio in Cat. sed ex $A$ thenæo liquet synonymum esse Ccntaureæ L. Inter medicinales frustra quæsivi : species tamen Centaurea glastifolia memoratur Spec. Pl. 1294. Roribus

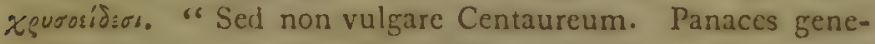
"ribus annumerandum Plin." Bod. p. 1071.

'Họ́anciov. Omittitur in Cat. N.B. Heracleum, Panaces, L.

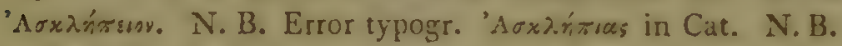
Panax, Asclepium, L. Asclepium ferulæ facie, Ger. em. icon. 1257.

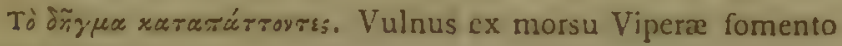
aspergentes?

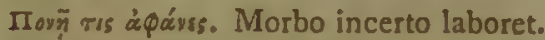

Maxjàs deppeworias. "Chronical complaints," Ang.

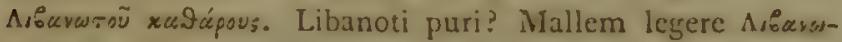
-ídos, Roris marini; vel Athamanti, Libancti, L. N. B. Mari Syriace odor, omnes omnium vires præcellit.

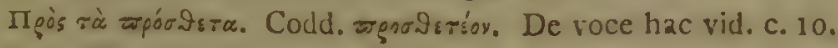
ct Lex. Theophr.

\section{CA P. XIII.}

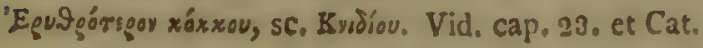




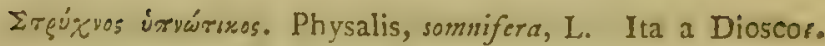
vocatur, iv. 72. Descriptio ibi accuratiscima Pericarpii : \&v

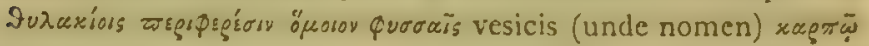

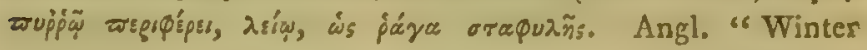
"Cherry."

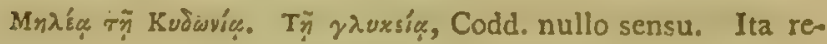
stitui ex Apuleio. Bod. 1078.1.

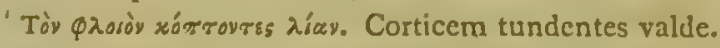

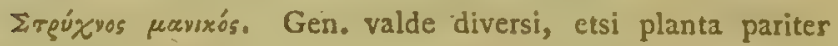
baccifera. Vid. Cat.

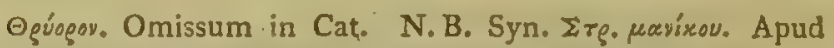
Dioscor. Epúov. Dorychnion a Plinio, ex usu venenati succi ad tela; \&c. $x x i$. 31.

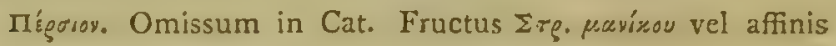
pl. Ergúxyov pavirev. Nonnulli Perissan vocant transpositione

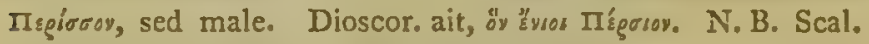
opinatur aвgirray dici a nimia vi necandi : sed absurdum.

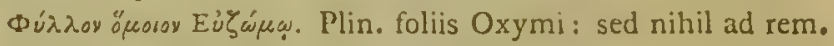
Eruca proximum, Theod.

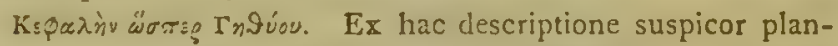
tam hanc diversam esse ab Atropa, Belladonna, L. A Bodæo Datura, Stramonium vocatur, cujus vires forsan paviay inducentes ex dosi nimia. Gaza et $\Lambda$ costæ testimonia afferuntur a Bodæo, ubi orta alienatio mentis ex infusione seminum plantæ

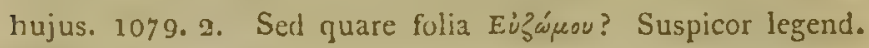
'

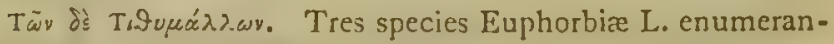
tur : vid. Cat. Sca difficile fuerit in genere tam multiplici species accurate sistere. Fuphorbiz L. 62 species. Tithymali, et Esulæ 23. apud Ger. em. N. B. Succus lacteus in omnibus; acris, et quodammodo фąpraxúdirs.

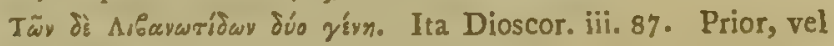

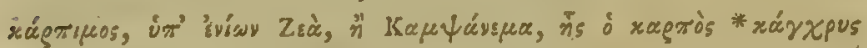

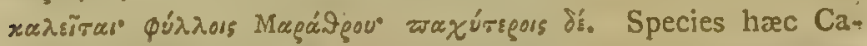
chrys, Libanotis, L. N.B. Species altera, sterilis; forsan Athã manta, Libanotis, L.

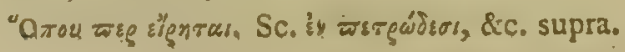


CAP. XIV.

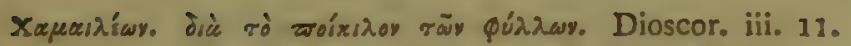
ex variegatis foliis. N. B. Varietates alba, et nigra : genera diversa a Linn. Vid. Cat.

Toùs poũs. Alvi profluvia, Thcod. Plin. in loco Rheumatismos vocat; sed alio sensu ac apud nos. N.B. A píc derivata vox humoris fluxum, defluxionem capitis forsan indicat. Unde vox Gallica "Rhume." Vid. not. p. 422.

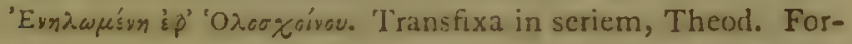
san suspensa hoc statu ad conservandum: "strung on a reed."

"Púpavos ögsiss. Planta venenosä folio atro viridi, cujus vires lethales. iv. p. 160. Vid. not. in Helleborum, p. 422.

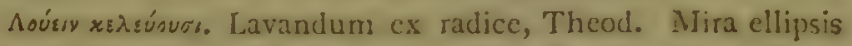
Auctoris: an in balneo planta hac medicato, an simpliciter lavandum cum decoctione plantæe ?

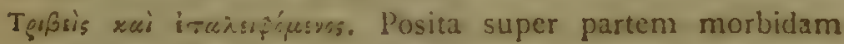
statu tunso et inuricta.

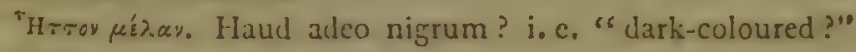
Vid. Lex. Mırás.

Toũ dì xauroj. Lectio confusa, medenda forsan parenthesi

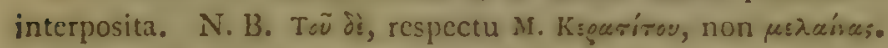

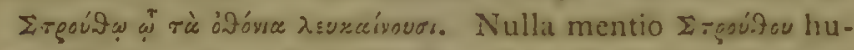

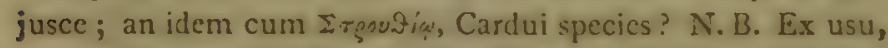
forsan Dipsacus, Fullonum, L. intelligend. Vid, 'Irropisws, Cat.

$$
\text { C'A P. XV. }
$$

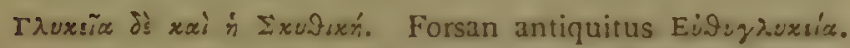

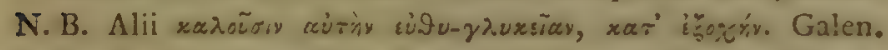
N.B. Ab Hippocrate ravxúun vocatur. Accurate describitur a Diosc. iii. 7 .

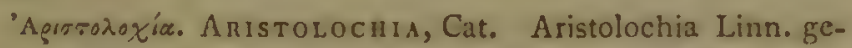
nus species 21. continet, quarum maxima pars Orbis novi incolæ. Species duas Nicander et Dioscor. citant, ubi A. Э́ñas/a A. rotunda, L. A. àppiny A. lonģa. N. B. Nomina hæc ex forma radicis. Bod. 1108.

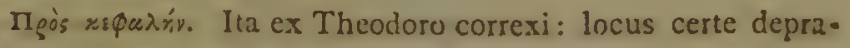
vatus. Vid. var. Lect. 
CA P. XVI.

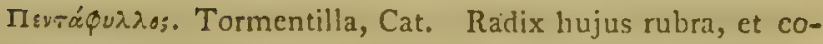
riariis in usu. N. B. Quærend. de forma radicis quadrangulari. Vid. Plin. de Quinquefolio, xxv. 9.

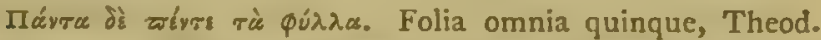

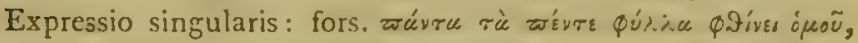
unum folium constituentia decidunt simul. Vid. de folio Sambuci, p. 119.1. 6.

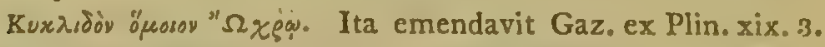

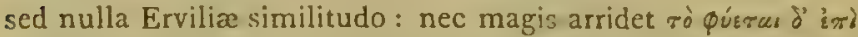

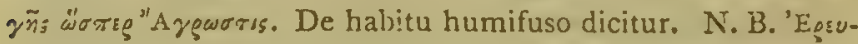

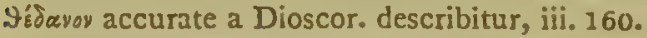

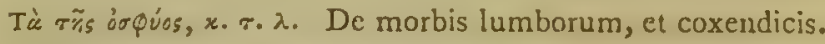
Alibi vox orgayrougía occurrit.

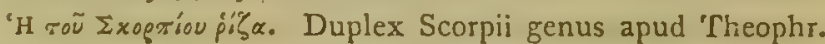
1. $\Sigma x$. Ulex, vel Genista; lib. vi. cap. 3. 2. $\Sigma x$. rádice intorta. Scorpii caudx in modum: sc. Aconitum, Scorpius, L. ix. 16. Gaz.

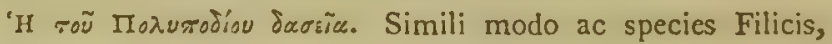
"Haresfoot Fern" dict. Polypodium stipite paleaceo, Linn.

Is gáqrras. Tetigerit, Theod. Rectius collo suspenderit, ut Amuletum. Fabulosa narratio.

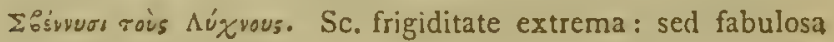
hæc quoque, ut videtur.

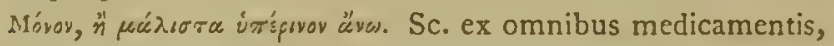
maxime purgationem immodicam per superiora efficere. Gaz.

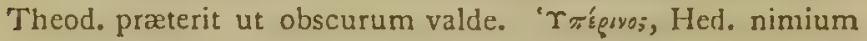

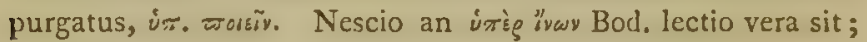

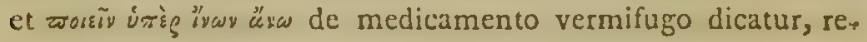
spectu stomachi.

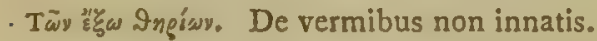

$\Sigma$ ¿оช์์่ . Larva insecti, Cat. Plin. ait, "excepta Sphon" dyle, quæ omnes persequitur." Genus id reptile ̨тร́тоug ut videtur, secund. Dalecampium : "Vermis species instar Blattæ, "flexuosa; vertebris instructa; alvo candida; parte proxima " çpiti rubescente; pedibus utrinque 1 . ore nigro; dentibus "f frrmissimis!" 
"Ort isxuǵoregos. Quæstio est, an radices magis efficaces sin fructu maturo, vel non. Bod. ait, "succus optimus, et " maxime concoctus ad superiora mittitur: contra, si ex ra"dice succum detraxeris, erunt minus prastantes, quia op" timo et elaborato privantur succo." Sed hæc nihil ad rem.

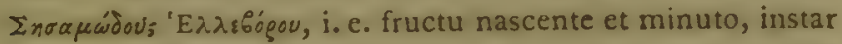
Sesami seminum; vel de mixtura Sesami granorum cum succo Ilellebori. An de bacca granis parvis Sesami instar intus? Vid. not. cap. 10. p. 421.

\section{A P. XVII.}

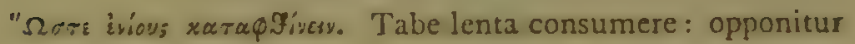
$\dot{\alpha} \tau \alpha \lambda \lambda \dot{\alpha} \tau \tau$ rousus.

Nymevấs. Cat. Papaver, Somniferum, L. sed succus solummodo memoratur. Proculdubio Nnréving syn. Mŕxwoss, cujus succus Nnrsyås. De viribus ejus, et aliorum inter narcotica, vid. Plin. xxi, 11. fuse dissertantem. De illinitione mortifera sagittarum, vid. etiam Galen.

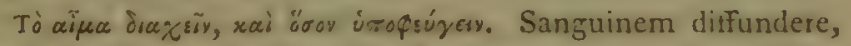
Theod. sed ex vi præpositionis dič, videtur separationem sanguinis partium significare. Hic loci opponitur rō ouxáyen, crasin sanguinis restitucre. N. B. Oïsv írop̧súgesv, i.e. aversare, retrocedere.

$\Delta \eta \lambda$ oũv тó rovvóv. Quod commune omnium, Theod. sed certe

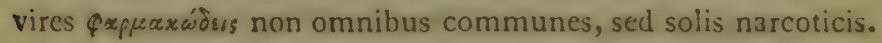
Sensus est, hac videntur illustrare opinionem communem.

$\Delta a \tilde{u}$ eoy Saquocidśs. D. Laurinis foliis, Theod. sed D. atrovirens, L. describitur, foliis atrovirentibus instar Lauri nobilis.

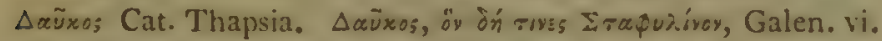
Rectius tamen Dauci lethalis species, hodie Thapsia vocata, quarum plures species apud Linn. Vid. Ger. em. 1230. c. 110. "Of stinking deadly Carrots." Daucus, niger, Bod. p. 1122. N. B. Character xpóxosy apud Dioscor. distinctivus, sc. succo croceo. De hoc quarendum.

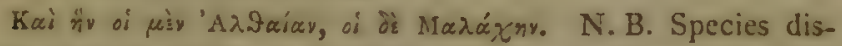
tincta hic describitur, sc. foliis Malvæ vel Althea. De hac planta inter venenosa nulla mentio: genera Althæa, Malva, plantus innocuas solummodo vel edules continet. 


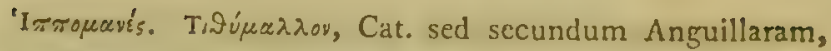
apud Ger. em. Stramonium, hirsutum. Datura, Linn. N. B. Fabulam de viribus Hippomanes respectu equarum respicit Auctor. Hippomanes vero antiquorum, tumor in fronte pulli equini. Vid. Plin. in verbo.

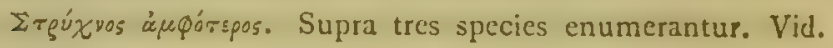
not. c. 13.

\section{CAP. XVIII.}

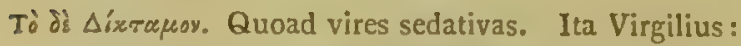

Dictamnum genetrix Cretæa carpit ab Ida, Puberibus caulem foliis, et flore comantem Purpureo.

Proculdubio verum est quod auctor memorat respectu Aigar: sed quas non laxdit plantas animal istud proobóravov. De excutione sagittarum fabulosum prorsus.

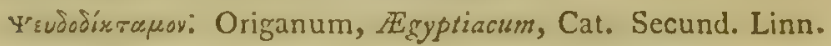
Origanum, Pseudictammum. De re dubia vidcant peregrinatores.

هix.cups" \&repos. Omissus in Cat. Fors. Origanum, Otitis, L. Gracix incola. Vid. Donn. Hort. Cant. vel O. Tournefortii, L.

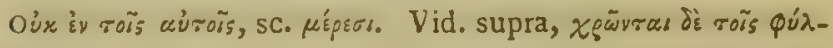
2ors.

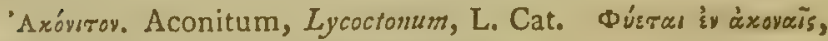
cautibus Cotis, lapidis. Ita Ovidius:

Quæ, quia nascuntur dura vivacia caute,

Agrestes Aconita vocant.

Alii ex viribus nocivis rectius legunt 'Axavrí. Plin. ex nuda caute restimat úxóvisov vocari, $\mathrm{ab} \alpha$, et rovís. xxvii. 3. Nicandr. lib. ii. Theriacis mentionem ejus facit sub nomine 9 ŕ $\lambda \varepsilon a y$ 'A $x$.

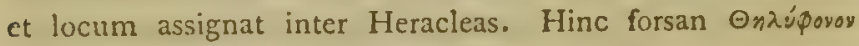

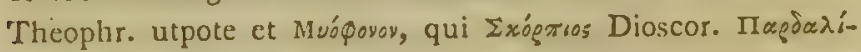
arxss Nicandri. N. B. De Aconito altero Dioscor. 'Axóvitay

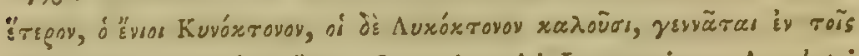

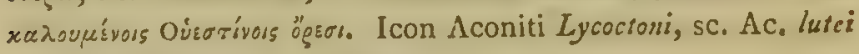
Bauhir. extat apud Bod. p.1137.

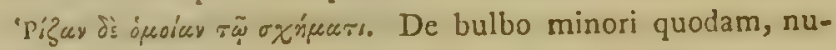
ciformi.

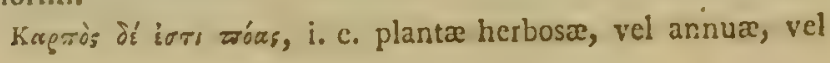


graminex. N. B. Opponitur íxńnarı, arbusto: sed duplex sensus róas in eadem sententia, ubi posterior caulem, prior her-

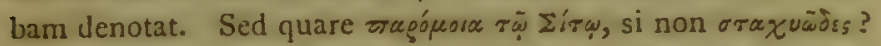
Certe textus corruptio aliter, ex radice tuberosa, xaguẃdes,

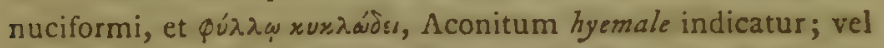
potius venenosa Dodonze planta sub nomine Thora, fors. Phthora. Vid. icon. Bod. p. 1141.

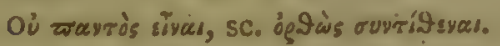

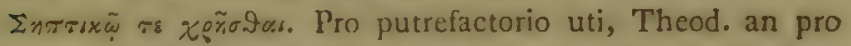
veneno tabifico? N. B. Non satis liquet quod sequitur, $x \alpha i$

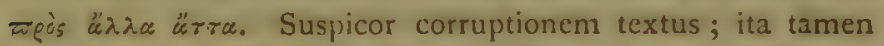

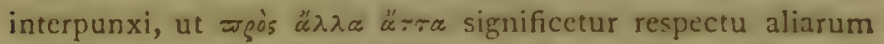
cjus proprictatum. N. B. Xs $\lambda \dot{0}$ s supra dicitur äysuscs, sed for-

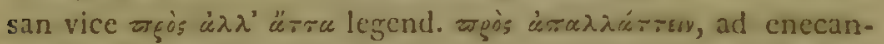
dum. Vid. infra.

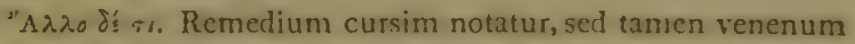
Ephenerum distincte notatur, ut fófiov, radicula, foliis liliaceis. A Dioscor.tamen fusius descriptum, unde ut Colchici species pro certe habenda. Dioscor. iv. 54. Species, ut videtur, ignota hodie, et ignota maneat!

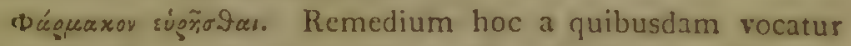
Asclepias Vincefoxicum. "Nos exploratum habemus jamdiu " saltem, aliis venenis a cane devoratis, antepharınacum fuisse, " uti Thora, Anthora, vel Paridis herba, Pardalianche dicta." Adversar auct. Vid. Ger. em. 1139.

$\Delta i o ́ x a i$ rie $\delta$ ávogároja. Confusa lectio per ellipsin nimiam.

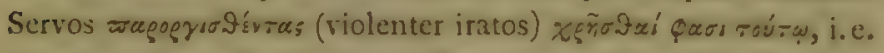
venenum hoc deglutiunt, $x \not 2+z r \alpha$ iargsús aùrè (oivaroy)

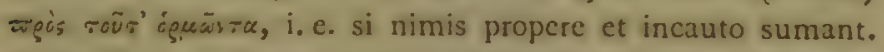
N. B. Correxi locum hunc corruptissimum, adco ut sensus eliciatur; sed forsan non verus.

\section{A P. XX.}

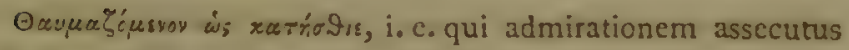
est, ita edendo.

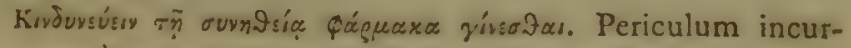
runt, ex consuctudine, vires noxias deponendi, vel amittendi. 

รัเพบ่ร.

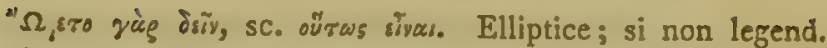

Kai 'rò घૈ. ergo tautologia, nisi textus mutetur, adco ut conclusio sit sententiæ worri oùy.

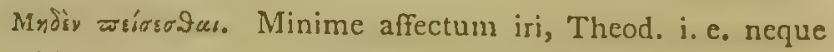
vomitione, nec purgatione.

'o ḋ Xĩos Eüropos. Bod. In textu tamen $\Lambda 1 d$. Eủdnpes: sed ita restitui ex Apollonio.

Kíonguv. Pumicem, sc. pulverem e punice, cujus usus cum aceto mixtus, absorbere videtur vires noxias.

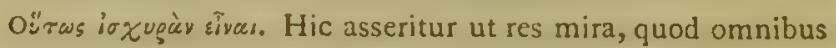
hujusce ævi notissimum : sc. Alkali quodcunque fermentationem reprimere.

'A \&ivalov. Artemisia, absynthium, L. Cat. Ita vocatur ab a

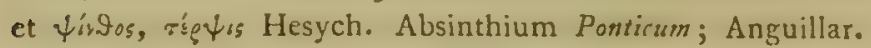

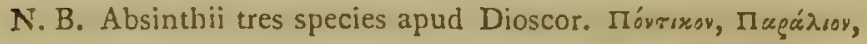

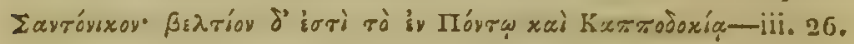

\section{CAP. XXI.}

"Ax๔y9áy rsve. De spina, quæ injecta aquæ, gelu inducit, nulla mentio ullibi; et, si margini fides, aquam solummodo densat, adeo ut fiat gelatina, atque ita ๘ŕyvuras. Idem. asseritur quoque respectu radicis Malvæ.

'Ad.9cic. Althæa, officinalis, Cat. sed ex colore floris pallide

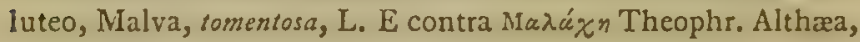
officinalis, L. Vid, Cat.

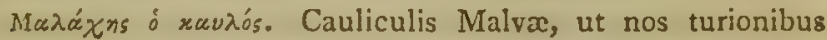
Asparagi, vescebantur antiqui. Scal.

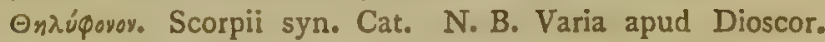

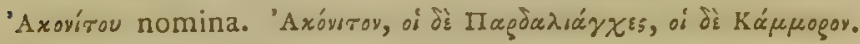

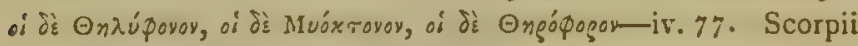
nomen ex radice curvata in modum caudre Scorpionis. De viribus ejus adi Plin. xxv. 10. xxvii. 2. peculiare virus adversus fominas, Calpurnio Bestix objectum. De Aconito vid. cap. superius. "Folia rotunda Cyclaminis, Doronico Pardalianchi " L. Doron. majori officinarum." Ger. emaicon. 759. 
Exopriog. Duplex certe Scorpii genus. 1. Genista, vel Ulex. pp. 242, 252.2. Aconitum, vel Doronicum.

Kaì yóvara "'xes. De radicatione sermo est, quæ comparatur radici repenti Tritici canini, L. vel Agrostidis stolonifera.

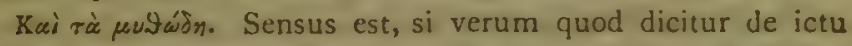
Scorpionis, alia similia credibilia; et fabulosæ narrationes non rite comparantur iis.

"Exay Qxaív. Textum corruptum emendavi ex notis marginalibus apud Bod. ita ut sensus eliciatur.

$\Delta$ voì yà ö övouv, i. e. duo bulbos singulas plantas habere, majorem et minorem; non ut Linn. aliique asserunt, plantas duas esse sc. Orchidem marem et fominam. Ex numerosissimo Orchidum genere difficile fuerit determinare speciem, nec magni interest in re adeo fabulosa: notandum tamen bulbos quorundam gelatinam maxime salutarem præbere, ut videre est in condimento, "Salep" dicto, offic.

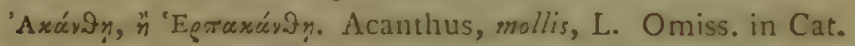
N. B. Lectionem ex corruptis cold. restitui, monente Bodro,

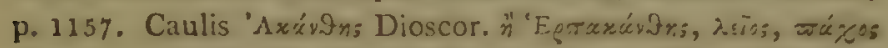
Sarrúdou, \&c. iii. 19. Species haec Acanthus Dioscoridis, secund. Linn. vel forsan Acanthus mollis, satis nota. "Ovum " ovo, ut ita dicam, vix est similius quam Acanthi et Or" chiclis caulis,nisi quod Orchidi minor, levior, lenior." Bod.

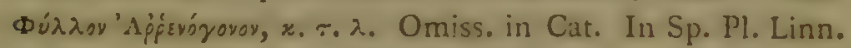
extant varietates dua, $\alpha$. et $\beta$. Mercurialis perennis $L$. sub titulo Maris, et Forminx, et apud Ger.cm. icones videre est. Baccæ

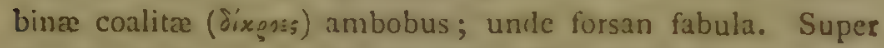
hac re vid. Dioscor. iii. 140. iv.191. Plin. xxvii. 12. xvi. 26.

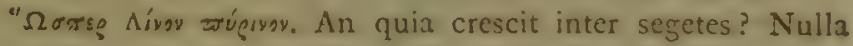
inter Linum et Mercurialem habitus similitudo. Notand, ta-

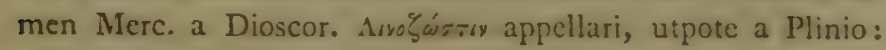
anne ex usu fibrarum?

Kearairovov. Euphrasia, odontites, Cat. Nulla hujus rocis mentio apud Linn. et forsan fabulosa planta. Apud Ger. em. refertur Crataiogono albo. "Wild Cow Wheat," differentem in

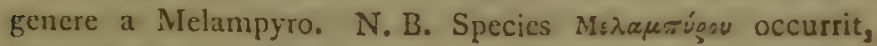
quae Mel, arvense, L. 


\section{A P. XXII.}

חrę̧is. Ptéris, Cat. Ordinis Filix L. numerosum genus, Preris. Specics forsan Pt. Aquilina L. quae passim crescit. Nomen ex similitudine $\Pi \tau s \rho \tilde{\omega} y$ avium. Frons Pteridis, bipin-

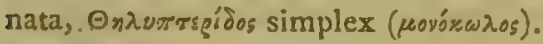

Onגuтregis. Acrosticum, Thelypreris, Cat. N. B. Apud Linn. datur species Polypodii, Filix femina dicta: sed fronde

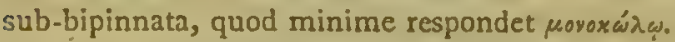

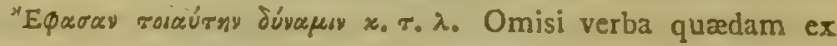
textu.

Фáves xai jássxu. Cetera fidei repugnantia qua sequuntur omisi.

$$
\text { C A P. XXIII. }
$$

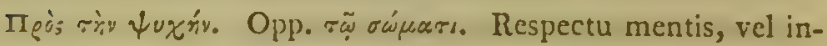
tellectus.

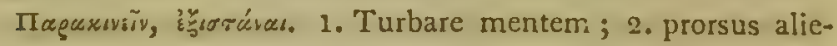
nare.

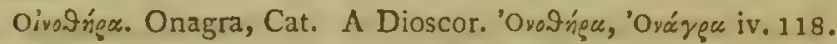
et Galen. viii. De Simpl. "Folio Amygdali floribus roseis, " magnis : radice candida, sicco statu venenum olente." Plin. xxvi. 11. Hinc nomen? Variæ Onagra apud Linn. prima exclusa. N. B. CEnothera L. species novi orbis. Cæteræ Onagra item inter recentiora. Ex descriptione forsan Epilobium augustifolium, sed quære de odore radicis.

Tоüro ๕̈roroy, sc. mores mitiores efficere. Vid. supr.

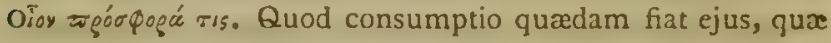
vinosam vim habet. Bod. Quod parum ad rem: sensus ta-

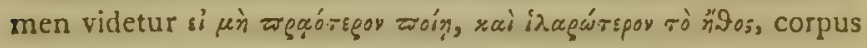

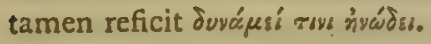

Terzóduov. Aster, Tripolium, Cat. Vid. Dioscor. iv. 135.

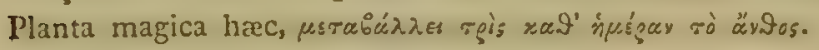

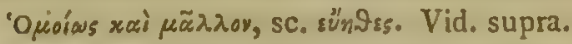

Ayróṕpivoy. Antirrhinum, majus, Cat. et forsan recte ex forma floris, ct quia pene üp’ṕs? os est, occupans interstitia laterum in muris, \&c. Vid. Dioscor. iv. 133. Galen. Simpl.viii. Quod ad folia 'Aragirns, certe diversa ab Aparine, 1. vii. 


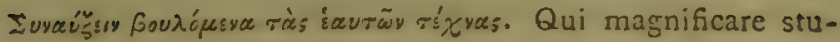
dent suas laudes: "Boasters."

\section{A P. XXIV.}

Tò $\partial \grave{s}$ níz:̨̧. "Redit ad peregrina, qux reliquebat." Scal.

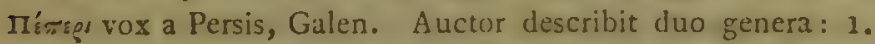
rotundum, nigrum; 2. longum. Recentiores tria : 1. nigrum; 2. longum; 3. album. N. B. Suspicor corruptionem et trans-

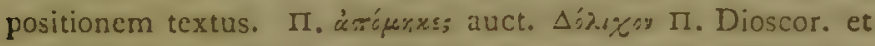
Margorírspu recentiorum. Col. cineritius : ergo substituo, auc-

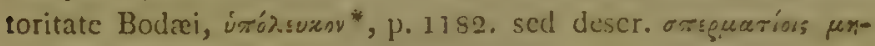
xwyixoss, videtur referre ad Kóxxoy Kýśorov, ut Capsicum L.

Kvídos Kóxros. Capsicum, frutescens, Cat. N. B. Hic trans-

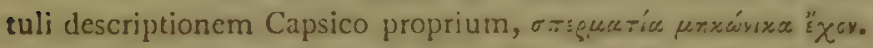

חeuxśduvoy. Peuc. officinale, Cat. Diversee plantae certe sub

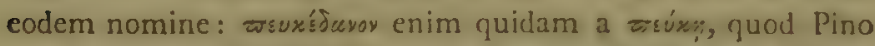
simile folium: rectius ab oclore resinoso. Dioscor. ait xaudis

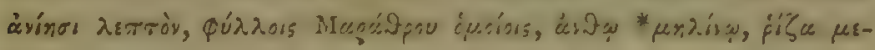
2aive.

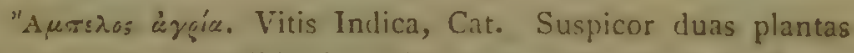
hic et p. 164. describi. Vid. Dioscor. iv. 163. Clematis forsan Vitalba L. Inquirendum de usibus coriaceis.

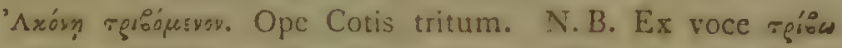
suspicor sensum esse mortario ex àzorrs facto, tunsum.

Aürn pì̀ oũv. Sc. Aristulochia, cujus nomen ab usu in partibus.

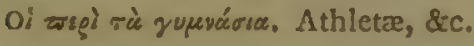

- Verior lectio forsan irrsçuagov, quod puncta et maculæ in Pipere longo subrubere videntur. N. B. Juxta Athenæum,

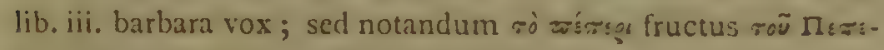

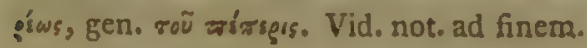





\section{$\Theta \mathrm{EO} \Phi \mathrm{PA} \Sigma \mathrm{TO} \Upsilon$}

\section{IEPI $\Phi \Upsilon T \Omega N$ I $\Sigma T O P I A \Sigma$}

TO I'.

Capitis primi Fragmentum ex Ed. Aldina. Venet. 1498.

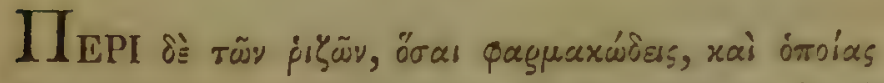

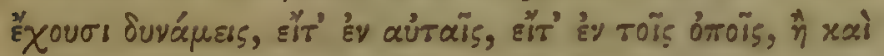

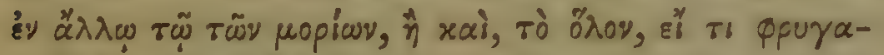

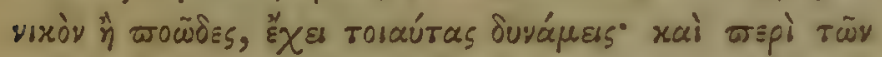

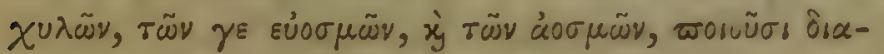

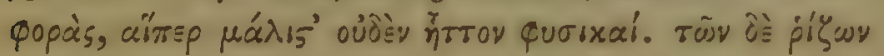

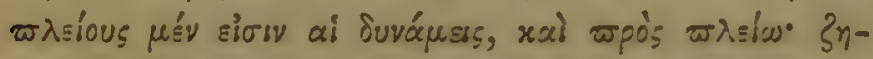

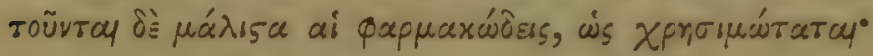

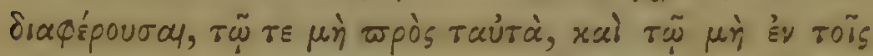

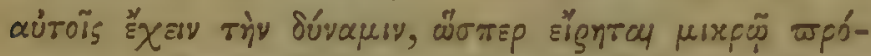

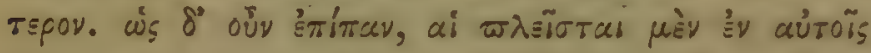

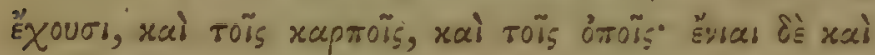

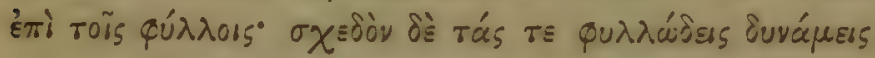

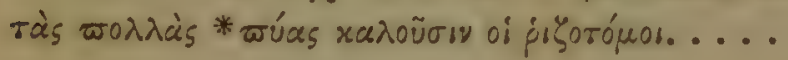

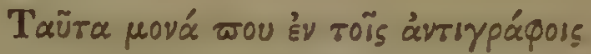

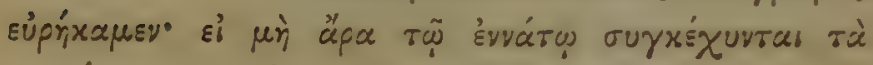

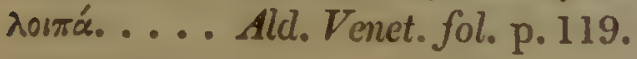

PARS II. 



\section{GLOSSARIUM THEOPHRASTI.}

A.

"A Garos. Non scansilis, ii. 8.

"A६rartos. Simplex; non ramosus, i. 3 .

'A $\gamma$ rtiov. 2. Pericarpium vasculosum, iii. 15 .

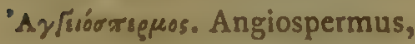
Bot. cujus semina perianthio laxo involvuntur. Vid.

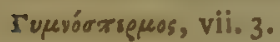

'A revin's. Ignobilis, de fructibus arboris sylvestris et incultæ, ii. 3 .

"Ayxųa. Instrumentum rusticum bi-vel tri-dentatum.

'Agruódns. Agni casti L. similis. Vid."Ayvos, Tab.Syst.p. 14.

:A yayrn. Ordinatio ramorum arboris, Angl. "training," i. 14 .

iA youncos. Vid. ravía.

'Aduá Q̧axras. Sine dissepimentis in caule, i. 8 .

'A ¿̧̇ós. Firmus, validus, cras-

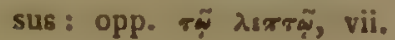
4.
'Asuvapeir. Impossibilitas, Jí

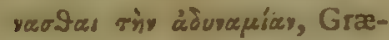
cismus, ix. I9.

'Asriaropos. Vid. 'Exị̂rogor, vii. I.

'Aগ̧ৎ̧́óns. Aristatus, Bot. vii. 10. Villosus, ibid. 18.

"Aఫpeuvaros, Tenax, Anglice "tough." De ligno, i. et pass.

'A Agéos. t. confertus. 2. simul productus. Opp. $\tau \tilde{\psi}$ xarà

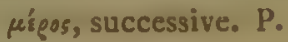

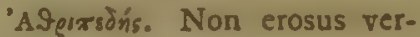
mibus, a $\Theta$ ṕiq. v.

"A Aveos. Fors. "Axveos. Paleaceus, Bot. De C. Pl. iv.

Airis. Trunci pars in pinu, ad nodus, tabulis pictoriis, vel scriptoriis usitata, iii. 10. Etiam ad clypeos, ibid. N. B. Quandoque cor totum trunci. Mold. "E"gregium pro variis operi"bus topiariis materiem "præbent tubera ad radi" ces et imas truncas Pinu. O 2 
" um subinde enata; quip"pe quæ venis pærne pel" lucidis ornantur." Pallas. Fl. Ross.

Aipreabá. Sepes ex spinis, quæ corpus vulnerant, unde nomen. pass.

"Aivos. Sine fibris (vid. 'IvEs,) de ligno. Hinc عüvivos. pass. Aipúdns. Loliaceus Bot. Lolio infestatus. De segete, v. 5 . viii. 2.

Airanrńgrov. Oris palatum. De C.Pl.vi.

Airias ai. Effectus, proprietates, vel " potestates her"barum." pass. Hinc ti-

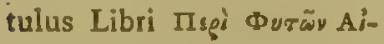
ríwv, vel, ut Varro rectius

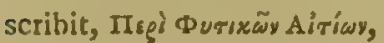
1.i. 5 .

"Arovog. Pericarpium vel capitulum in Carduis, \&c. \&c. Etiam Cardui spec, v. p. 25 .

'Axaví̧w. Supr.

'Axápdos. Vid. Kapoira, Bot.

'Axiónóns. Triangulari-acutus: similis cuspidis sagittæ; de forma seminis $\Sigma$ xoívou. Vid. iv. 13.

'Ar/s. Cuspis sagittæe.

'Axpai ai. Tempora conveni-

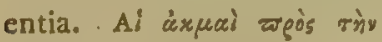
тонѝv, " the exact season." V. 1 .

"Axvreos. Scaber, non rasus. $\sum \tilde{\omega} \mu \alpha \ddot{\alpha}^{2} x$ yroov. De C: Pl.ii.
'Axóvas aí. I. Rupes calcariz; ab áxó́y, cos, "a whet"stone," ix. 16. 2. Nomen loci.

"Axor05. Vermibus intactus. De vestibus, seminibus \&c. iv. 4. De C. Yl. iii.

'Axęrtís. I. Immoderatus, $\mathrm{p}$. 2. immistus, crudus : yñ ă. x ६ати́s. De C. Pl.v.

'Axpípovis oi. Rami majores, vel superiores, i. 4.

'Axpsbonoy's. Accurate definio, i. 5 .

'Axpóoguar rá. Fructus species quæ putamine teguntur

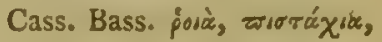

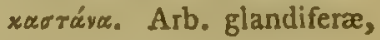
ii. $\%$.

'Axpóppišs. Radice horizontali, Bot.

'Axgooxiòn's. Apice lobatus, iii. 2.

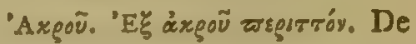
folio pinnato, impari Bot.

Axtivos. Sambucinus. Vid. 'Axrý. v. 4.

"Axuros. Ilicis glans, iii. I6.

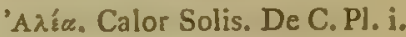

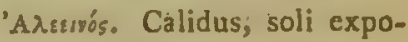

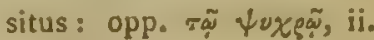
3.

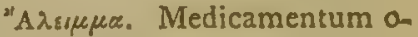
leosum.

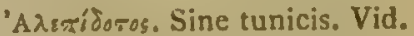
Asris; vii. 4 .

'A 4. 


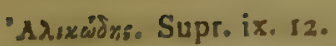

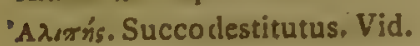
גíros, ix. 3.

'Adiproos. Cortice crasso, ab «ँגis. N. B. Spec, Quercus ita vocatur, sed fors. error textus pro à $\lambda \lambda$ ó $\phi \lambda$ osos, pro cortice duplici $Q$. Suberis L. Alii ab ä $\lambda$ rs.

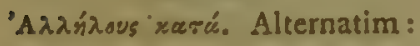
opp. xarà dós.

'Arxvavíors oi. Dies Halcyonis. Vid. Myth. Antig̨. ix.

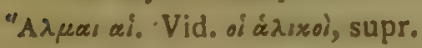
Salsugo, Gaz.

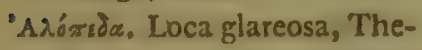

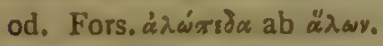

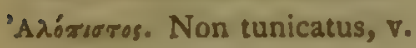
$x$.

'Arurix. Facilitas coctionis; qund stomacho convenit.

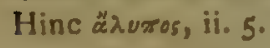

'Adpós. Scabies; morbus cutaneus in pecoribus, div. a Wúge, ix. 10. Lepræ species.

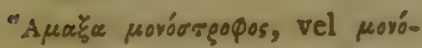
ŗoxos. Currus rota unica; an manibus accommodata, c.g. "a wheel-barrow ?" v. 8.

'Apavẹóopa. Sensim diminuor, ix. I6.

'Apexugós. Vis conspicuus, iv. 5 .

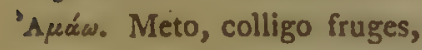
p.

'Apeziry. Hebeto; de acie ferri, v. 4.

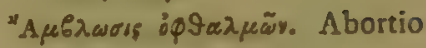
gemmarum, Bot. iv.

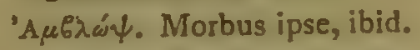

'A $\mu$ syarás. Debilis, periturus;

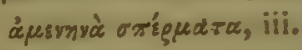

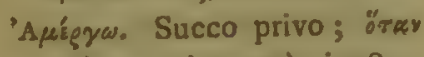
ápépowos ròy xą̧⿻े丷, ix. 8.

'Apográ. Amurca : Olei expressi recrementum. De C. Pl.vi.

"Aprs. Placenti genus. De C. Pl. vi.

"Apioxos. Vid. Míresos.

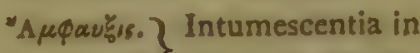

'Apqupúa.: $\}$ trunco $A$ bietis post decacuminationem. Vid. desc. accuratam, iii. 8. 'Apeíggros. Inutilis; de solo sationi inepto pre humore. De C. Pl. iii.

'Avarzaius. Egre, iv. 4.

'Avedsilyess pizwy. Hort. "the " uncovering the roots." De C. Pl. iii.

'Avadiw. Ligo, ii. 3.

'Arad̃uóprvos. Humefactus, p. 'Avasupeíasis. Exhalatio.

'Ayanowaiga. Vid. Kasaípa.

'Aváravios. Caulis ima pars intumescens in bulbum:

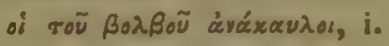
10.

'Aváxiacis. Actio circumver-

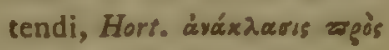

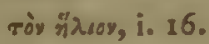

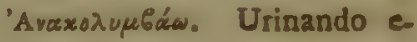
vello, iv. \%

o 3 
'Averacebáves. 1. Révivisco, v. 3. 2. Occupo, vii. 10.

-Avadíaxw. Consumo, edo, ii. 8.

'Avć́royoy. Adv. Pari ratione', viii. 5 .

'Avórroxisy. E contra, ratione contraria, p.

'Avx́r dovs. Expeditio navalis; iv. 8.

'Avะสvoń. Evaporatio, p.

'Ay⿲́丶б rnpex. Incrementum sursum, vel altitudo plantæ, ix. 10.

'Avaręirw. Agric. Solum e: verto: àvarpírtery. xuáseous, "to plough in the crop," viii. 9 .

'Avaṕśopeas, Emergo, iviz.

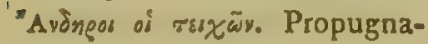
cula, "the ramparts." Summitates planæ, vii. 13 .

'Avsyseyи́s. Inefficiens, ix. 17 .'

'Aysríborog. Sine incremento. Vid.'Exíboors.

'Ay9'̣́sxov. 1. Planta. 2. Pericarpium in Liliaceis, vii: I 2.

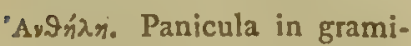
neis, Bot. de Arundine; Cypero, Papyro, \&cc. iv. II, 12.

-Ay9mp̧à rá. Tempora florendi. De C. Pl. iii.

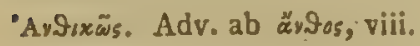
9.

"Aqv9os. Flos. Diff. botanicæ:

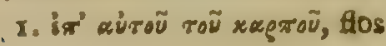

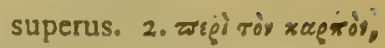
flos inferus.

'Ay Agaxíar ai. Loca vacua, vel areæ carbonandis lignis, $\nabla$. 10.

"Avą̧aร̆. Carbo lignarius, "charcoal." Antiqui artem carbonandi apprime callebant, v. ro.

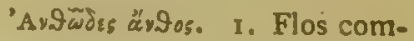
positus, i. 22. Bot. i. coloratus, Scal. apud Bod, p. $62^{\circ}$.

'Avirnes. Remitto, aciem perdo, v. 6 .

'Avsúa. Áquam e puteo haurio, ipáysi, (fune coriario,) sc. machina quadam, iv. 4 . 'Aviúdns. Gustu ingratus, vel odore.

"Avoso5. Vid."Ozos.

"Avoxoi oi. Profluvia alvi, iii. 12.

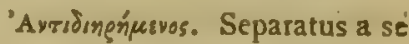

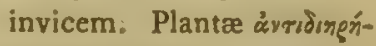

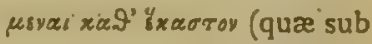
genere communi specialiter discriminantur), .10 .14$.

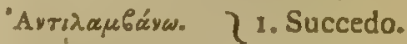

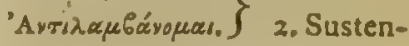
to.

'Avríniqis. Fulcrum.

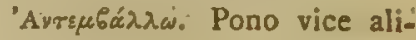
cujus, ix. 9 .

'Aytwâí. Vi elastica repello: N. B. Opp. irdidóyes, recedere, v. 6.

"Ayw reasaígsy. Vomitum excitare, ix. 10. 
'Avenearías ai äípos. Vicissitudines aeris, iii.

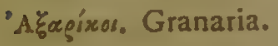

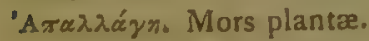

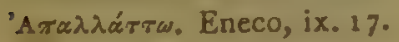

'Aray 9 is. Defloresco, $\mathrm{p}$.

'A Eicertos.

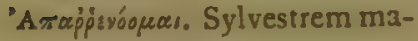
turam deponere, vii. 4 .

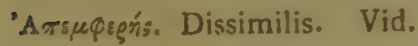

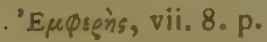

'A tígaris. Imperfectio. DeC. P.. i.

'Arsgurboso. Rubiginem genero.

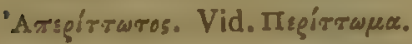

"Aтsuro5. Non resinosus, iii.

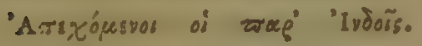
Brachmani, iv, 5.

'Armerrńrsyos. Disjunctus, divisus, $\mathrm{p}$.

'Armęrés. Non mutilatus. De ligno. De C. Pl. iii.

"Aтroy. Fructus Pyri, iv. 2.

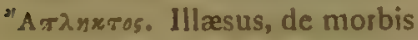
ex coeli tactu, ix. 14.

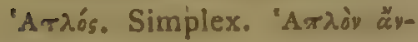
\$os, de structura monope- tala, vel de flore concolore?

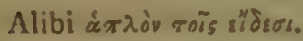

'Aтsrúw. Exsicco, humorem

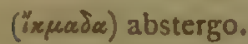

"Arvivaros. Ventis non objec. tus, iv. 17.

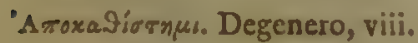
7.

'ATóxavios. Non regerminans, ut Abies, \&c.

'Aтórespaz. Vid. 'Axoxanismpes.

'Aroxsedipsvos. Deorsum tendens, divaricatus.

'A vi. 2.

'Aroxıт7oopot. Habitum in hederaceis amitto: sc, respectu formæ foliorum.

'Azoxגú̌c. Aquam copiose perfundo.

'Aтoxví̧w. Unguibus comprimo: "to nip off," vi. 8.

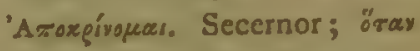

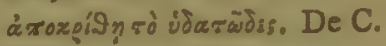
Pl. vi.

'Aródnభ1s. Absorptio. De C. Pl. ii.

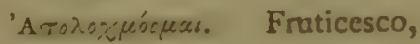
vi. 6.

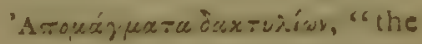
"paring of the nails." De C. PI. vi.

'Axorsíw. Evaporo, ix. 18.

'Aropías ai. Quæftiones sol. vendre: "Quere"s.".

'Axoppoǹ äyมิ "av. "A blight:"

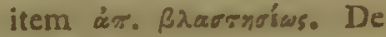
C. PI. v.

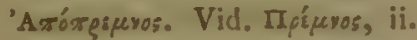
7. ramus minor, vel secundarius?

'Arrorrágers ai. Hort. Intervalla. De C.Pl. iii. Vid.

'Arrosapióón. $\}$ De uvis are'Axosa申idoopuas. $\}$ factis in arbore. De C. Pl. ii. Vid." Aerapis.

04 
'Arooripw. Condenso. De C. Pl. ii.

'Arorixrw. Demo: Fructum amitto.

"Axoris yñ. Ubi aqua deficit.

'Aro申uádı. Surculi e radice. viii. 3.

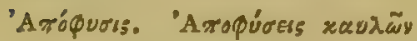
in Carduis, (pedunculi foliorum decurrentes, am. plexicaules Bot.) Vid. 'TroQúores.

'A тохиче́орех. Sepibus cingor, iv. 9 .

'Arróxuoss. Effluvium, vel jactura succirin plantis, "̈̌æay

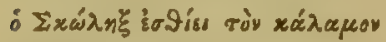

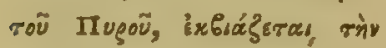
ćtróxuơv, viii. 10.

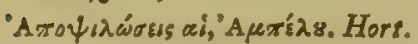
"the thinning out the "branches."

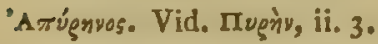

'Agáxyusv. Morbus Oleæ proprius. N. B. Nidus forsan animalculi cujusdam textorii. Coccr species.

"Agrerea. I. Álbugo oculorum : etiam हैy apolárors, ix. I4. 2. "Ey yár vauxsía.

"Aşı̇os. Argilla, gustu amara. De C. Pl. vi.

'A 'éós. I. Crudus, ix. 4. 2. de terra, incultus, "fallow"
Angl. 3. Kudis, incoctus, vi. 3 .

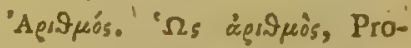
verb. de magno numero, vii. 2.

'A ęxroũęos. Arcturus. Stella primæ magn. Sideris Arctophylacis vel Bootis: sc. in cauda Ursi majoris. N. B. Tempora anni notantur ortu et occasu hujus stellæ, utpote et Caniculæ et Pleia-

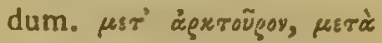
Kúve. Accuratiorem qui velit hujus' rei notitiam, adeat Gemini Observationes Astronomicas, vel Calendarium Theophrasti Hist. Plant. accommodatum in Opere miscellaneo a, cujus mentionem feci. 'Ex' 'A $\rho x-$ rép̧; sc. Ortu Heliaco, Septembri mense. ח $\rho^{a}$ ' 'A $\rho x-$ roúgov, ortu Arcturi acronyctio, vel veris initio, Martio mense.

"Ageves oi. De Tritico exinanito, viii. 7.

'A gruparios. Inter segetes crescens, sponte, vii. 7 . Opp. in $\mu$ '́soss.

"A A oros. Tempora seminandi.

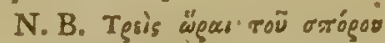
apud Theophrast.

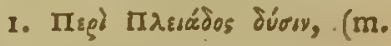
Octobri.)

- G. Falconer, M. D. Vid. Præf, operis. 
2. THeos dexpopivor, (m. Martio.)

3. "A goros Mresuàs, (m. Julio, ) viii. I.

'Apjpayńs. Compactus, tenax. De ligno, v. 5 .

"Apppv. Mas. N. B. Plantæ a Theophrasto in áp̧prýres et In sías quandoque dividuntur; núlla difierentia sexu-

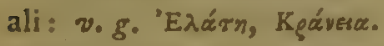
Species robustior, et qur tarde fructificat, «pppry vocatur, et contra sńरssa. Sexualis vero distinctio occurrit in Doives, et alibi, ii. 8.

"A frsos. De plantis adultis et perfectis.

"A९X". 1. Principium vitæ, ii. 8. 2. Origo plantæ, $i$. 3, 9. Hinc Bot. Corculum seminis, et plumula, viǐ. I, 2. Vid. descr. germinationis seminum diversorum, viii. 1. 3. "A. yoveriews, in. choatio germinationis, vii. I.

'A œ́puara. Catalogum aromatum antiquitus in usu iv pé-

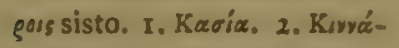

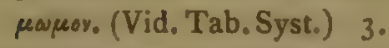
Kарда́реwper. 4. Náęos. 5.

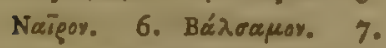

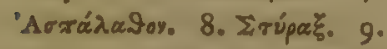
"I pus. 10. Nágrn? II. Ká- Twe 12. ILávaxss. is.

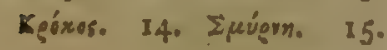

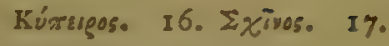

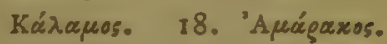
19. Awrós. 20. "Avroov, ix. 7.

'Artís. Clypeus, olim ex viminibus salignis; ut et ex ligno ejusdem arboris, $\nabla$. 8.

"Aorapis. Uva passa, "a rai" sin," ix. 14.

"Arrgábrs. Non tortuosus: ל̧ý-

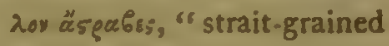
"wood," iii. Io.

'Arrgäíw. Idem.

'Aspo6ódทros. T Plantarum in-

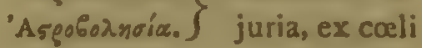
intemperie, olim sideribus attributa.

"Arrgov ró. Sirius, Canicula:

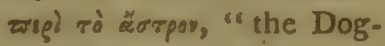
"days," ii. 7. Planta di-

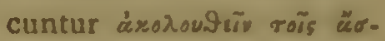
rgos, (tempora anni observare in germinando,) vii. I4. ix. 6 .

"Arpapayia. "An asparagus " bed," vi. 4.

'A тรй́s. Immaturus, ix. 9.

'Arígauvos. Vid. Tęúpary, ii. 5 .

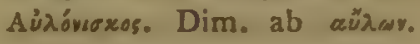
Vallis, ix. 7 .

Aùrrngós. Astringens: succi plantarum denominantur

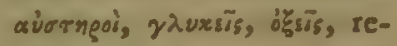
spectu gustus. Anglice, "rough."

Aúragxia. Vi propria subsisto, iv. I4. 
Av"zpas ai. "The droughts."

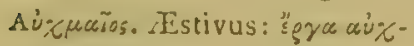
неĩa.

Aixungés. De odore? folia

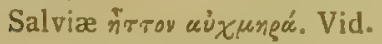
Bapús. Plin. reddit siccum, aridum, vi. 2.

'A paýs. Adverb. Occulto, ix. I2.

'Aథuvèss ró. Vapor, gas, ibid.

'A $\left.\varphi s \lambda x_{0}{ }^{\prime} \omega.\right\rangle$ Penetro, perfo-

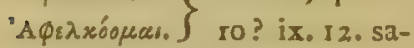
nor. De C. Pl. v.

"Apsభis. Evaporatio per coctionem, ix. 2.

"Apn. Lepra, mórbus arborum, iv. I6.

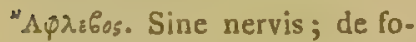
lio. Vid, $\phi \lambda s \dot{\psi} \psi$

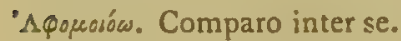

'A Qogropeoi oi. Characteres specifici, i. 5 .

"A фoeos, Sterilis,

"Apudros. Aphyllus, Bot, item de flore monopetalo ufurpatur, ut $\triangle$ rbuti, iii. 16.

¿xoros. Sine bili, i.e. tranquillus, ix. I7.

'Axpoússpos. Minus coloratus.

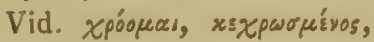
vi. 6 .

"A xurosa Insipidus.

"A zugov. 1. Palea, gluma, Bot.

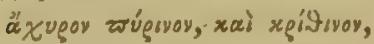
viii. I. 2. Siliqua Fabæ. De C. Pl.iv.

"Acupticis. Tempora minus propitia, "bad seasons."
B.

Búzxoyos ทे. Nux arboris $B \alpha-$

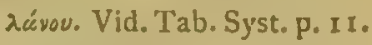
et Mueobáda vor.

Bazcuyngós. Glandifer.

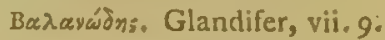

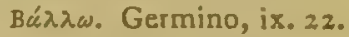

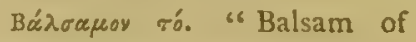
"Mecca," (vid. p. 25.) ix. 7.

Bąús. I. De odore. Graveolens, narcoticus. Opp. ¿gi$\mu \varepsilon$, vi. 2. 2. Coctu difficilis, viii. 4 .

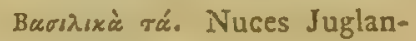
dis.

Bároy. Rubum; a "BlackBársov. $\}$ "berry."

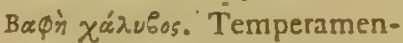
tum ferri ex immersione, cujus manipulatio antiquis haud ignota, v. 4.

B'şs:I pov. Gurges, Barathrum aquæ sub terra? v. 5 .

B'́xos: Inftrumentum rusticum. De C. Pl. iv.

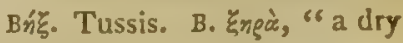
" cough," ix. 15 .

Bйeน. Mensura; passus humanus; "a pace." 3 Pedes, iv. 5 .

Bıblía rá. Cortices ad scribendum accommodati, iv. 9. Antiquitus Buthía, a Gúbros.

Bį́̌s. Z Cortex interior PaBúbz.os. $\}$ pyri..... 
Bía ழutầ. I. Vitæ, vel durationes, i. 7, 23. 2. Effectus soli, aëris, \&c. respectu sanitatis et durationis vitæe in arboribus, iv. I, I3, 14.

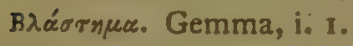

Bגáбтnos. Prima germinatio.

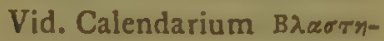
oiwy, iii. Brasoxor'sopas, "to " be blighted," iv. I5.

Brarrodoriz. Pampinatio in

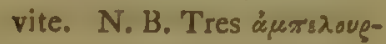

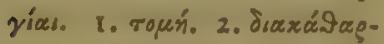

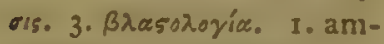
putatio generalis hyeme. 2. amputatio surculi teneri. 3. avulsio gemmarum ope manuum, \&c.

Bגaбrós. I: Surculus primus

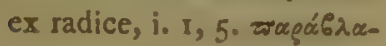
oros, surculus secundarius ex ramis. Lex. 2. Plumula. Vid. aैexy, iii. 2 .

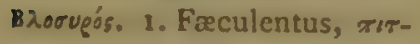

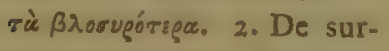
culis; turgidus, ¿\%as $\lambda 1 \mu$ -

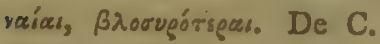
Pl. $\nabla$.

Bondeouśav. Augustus, $m$.

Bód ¿ıтos. Fimus bubulus, v. 6.

Boגeos. Bulbus plantæ.

Boגท́. Lapsus uvarum immaturus. De C. Pl. i.

Bopbogáons. Face vel terra mixtus.

Berávas ai. Herbæ noxiæ, viii. 6.
Boravíc. Herbas noxias' cvello, "to weed."

Bórpus. Racemus uvarumitem racemus quivis, vel collectio baccarum vel tho-

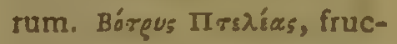
tif. iii. 6. Generatur Bórgov

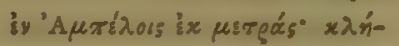

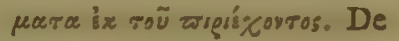
C. Pl: iii.

Bórquav. Id dim. Bórq̧u тйร ¿ápvrs, iii.

Borgúxcoy, ii. 8. dim.

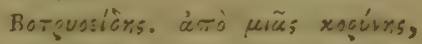

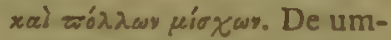
bella floris. Bot, iii. I2.

Béryxros. Branchize, "the " gills of fishes," iii. 9 .

Beadis tis requriv. Concoctu difficilis. opp. irrurięั Th:?\%:

Bqáxirs. Madefactus, a B̧́$\chi \omega$, "steeped in water," v. 5 .

Bęáxus. Bulliens, a Bgórơw, v. 5 .

B९oxń. Aquatio, ix. 6.

B̧̧úov. I. Amentum Quercûs, \&c. a ß̧úw, abundo, iii. 6. 2. Vel Thyrsus Alorum, ut Thymi Diosc. i. $\mathrm{r}$. 3. Fucus vel Alga marina, Strab.

B purodiłixn. per transp. pro Bugrodiłixn, Ars coriaria. Beqróy. Vinum hordeaceum.

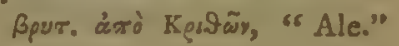
N. B. An לทंগेos spec. di- 
vers. vel statu effervescenti? Vid.

$\Gamma$

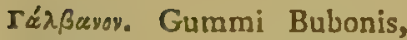
Galbani L.

Ta入śa. Mustela marina. Squalus Squatina? L.

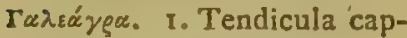
tandis feris. Ex ligno duro $\pi \pi \varepsilon \lambda_{\varepsilon} x_{5}$, \&cc. " a hutch " trap," v. 8. 2. Camera cancellata; cujus usus pro carcere Athenæus, lib. xiv. Cavea ferarum, Strab.

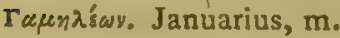

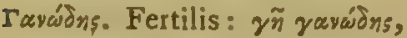
plenus, Gaza, vi. 5 .

r'́2yıs. Nucleus in capitulo Allii ; "a clove of garlick." vii. 5 .

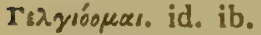

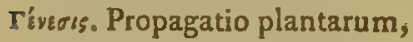
i. 4 .

revíoris ai. I. Proventus arborum. De C. PI. iv.

Tఃvхós. Genericus, i. 6.

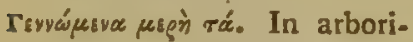
bus partes fructiferæ. Mold. i. 4 .

rivos, apud Theophr. 1. speciem, vel, 2. varietatem indicat, N. B. pass. opp. $\varsigma^{7} 8 \mathrm{~s}$. Generi.

Tęéáyęua rá, Annosæ arbores. Quercus' nodosæ ætate, ii. 8. iii. $12 ;$ ห. 9.
Is vopecs, Gustu experimentum facere, ix. 2.

Гथขั0is. id. item morbus similis äprs. iv. 16.

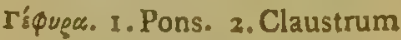
vel agger, $\nabla .5$.

rǿ์ôns. Terrenus, vel argillaceus, iii. 3. materiem terrenam continens? De ligno quercino, v. 9 .

r'yagroy. Acinus uvæ:

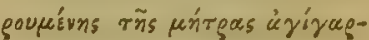
rol. De C. Pl. v.

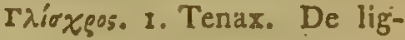

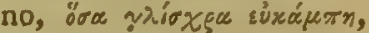
v. 6. De C. Pl. iv. 2. De

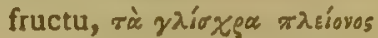

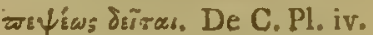
N. B. Differentia inter $\gamma \lambda i \sigma$ -

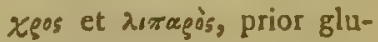
tinosus, posterior oleosus? Lign. Platani exemplum

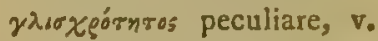
4. 3. De solo tenaci, vi. 5.

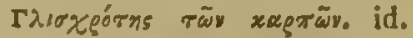
De C. Pl. iv.

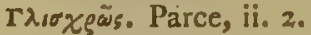

гдixомк. Vehementer cupio, i. 1.

$\Gamma$ גoós. Debilis, viscosus, tenax. De ligno, v. 5 .

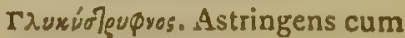
dulcedine, Vid. ¿ręúpyos, ix. 22 .

$\Gamma \lambda \tilde{\omega} \tau \tau \alpha$. Lingula in fistulis, "the tongue-piece," iv. 12. rórygos. Murbus in truncis 
et ramis majoribus: forsan cancri spec. Radix videtur ignota, i. I2, I3.

Гөy์. Vis generativa, ib.

Го́ира стірната. Semina perfecta. rò yóvupay, Principium vitæ in sem. vii. 6.

róve. Nodus in caulibus gramincis, \&c. item flexura, iii. I3.

rovarúdns. id. i. 6.8.

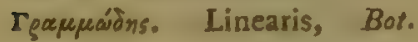

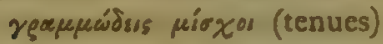

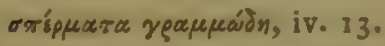

Tupvóorrepuos. Nudo semine, de seminibus umbelliferarum; minime Gymnospermus Linn.

rúpor. Fover circulares arboribus plantandis destinatæ. ii. $\%$.

rugápara. Venarum circum. volutiones, vel gyri in albumine ligni; medullam cingentes, Scal. Bod. v. 6.

Faría. I. Angulus: sic de

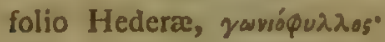

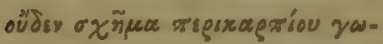
yias Iैxe? ? I. 8 . 2. Fiminentia acuta, "a ridge," folium xuxsigou descr. ws yourá

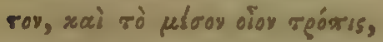
(carina,) i. 16.

Fursosions. id. vel yourcásns, angulosus, iii. 13. opp. Fsépigs, de folio Hederx, $\mathrm{i}$. I3.
$\Delta$.

$\Delta \mu$ dóopal. De pice extrahenda. De C. Pl. v. Vid. Jatis, $\delta \bar{e} \delta$, tæda.

$\Delta$ àoopogia. Picem genero, ix. 2.

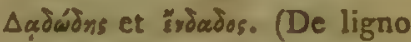
et radicibus, Gen. Pinus L.) reginosum, ib. etiam de colore rubro.

$\Delta a{ }^{*}, \delta \alpha \dot{s}$. I. Lignum fissile Pi-

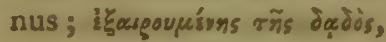
xai xasopínทs, ixgór, ix. 2. Vid. manipulationem ibi exacte descriptam. 2. Talea ligni Picei ad accendum ignem.

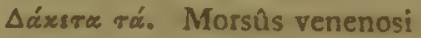
Viperarum, \&c. ix. 21 .

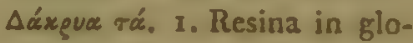
bulos concreta, ii. 16. vi. 2. Gummi ctiam sponte fluens. 3. Gemma in Liliaceis.

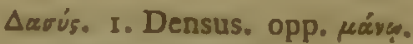
2. Pubescens de f́nlio.

$\triangle$ aquís. Lauri bacca; drupa ; Bot.

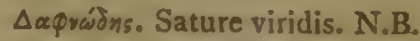
Tres occurrunt coloris viridis varietates; Angl. "shades of green." I.

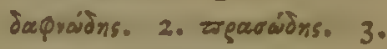

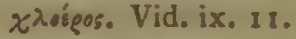

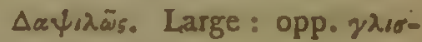
xอัตัร.

Auvjs. Efficax, "strong," if 


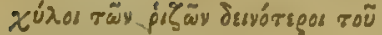

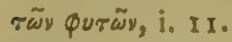

$\Delta$ ívọe rá. Vegetabilium divisio quadruplex. I. $\Delta f^{\prime} y=$

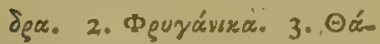
rvoi. 4. חowidus. N. B. Distinctio inter 2 dam et 3 tiam haud satis constat: an 90 pros idem quod irírsol,

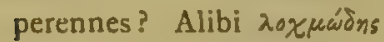
occurrit, de calamo, \&cc. An frutex paludosus? (vid.)

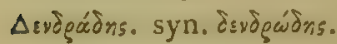

$\Delta$ เvogúpiov. Arbusculum. Dim. Corallinis applicatur, iv. 8.

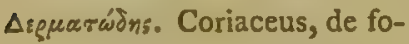
liis, vi. 2.

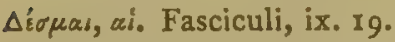

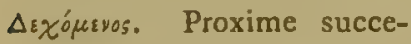

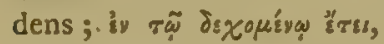

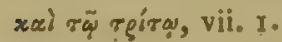

$\Delta \tilde{\eta} \gamma \mu \alpha_{0}, 1$. Morsus viperæ. 2.

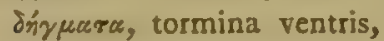
iv. 5 .

. $\Delta$ nxтіxós. Pungens: de suc$\mathrm{co}$, vi.

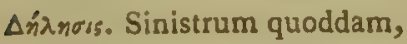
vii. 12.

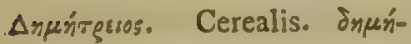
тg̨ios ragrós.

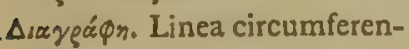
tix, i. 2 I.

$\Delta$ seóvapear. Valde efficio, iii.

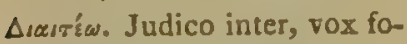
rensis, Scal. ix. 18.

Araxá9agois. Operatio horticulturæ, "Pruning" An- glice. Vid. Brasodoyia, ii. 8.

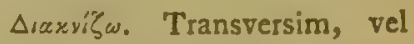
longitudinaliter, seco. Vid. rvíç, iii. 2.

Avurogńs. Saturus valde, $i$.

$\Delta$ caxrogia. Cantus vehementior, vel acutior. Hinc Mercurius apud Homerum

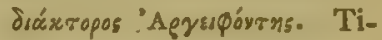
biæ $v \omega$, (per æatatem contrahitur,) et inde xeraspos rgòs

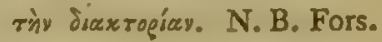

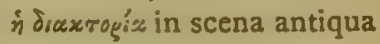
cantus præludens, Angl. " overture," iv. 12.

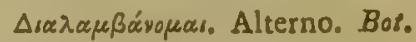
vi. 5 .

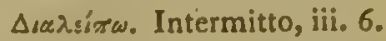

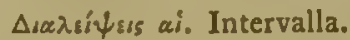

$\triangle \varepsilon \mu \alpha \sigma \alpha ́ w$. De actione manducandi, ii. 8.

$\triangle$ vargis äy 9\&: हैxoy. De flore Rosæ, i. 22.

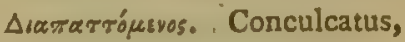
viii. II.

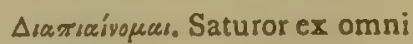
parte.

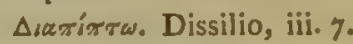

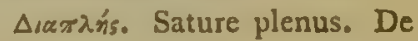
C. Pl. ii.

$\Delta$ «єтуой. Evaporatio, Vid, $\Delta l=$ aruía. De C. Pl.vi.

$\Delta$ arrírow. Tundendo comminuo, ix. 16. 2. pinso, ix. 17. ubi opp, хо́тropa. 
Diarrúvow. Illino: xúxтov-

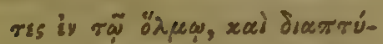

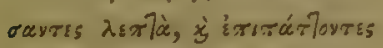
$i \varphi^{\prime}$ ข๊we. Methodus præparandi Cicutam, ix. $1 \%$.

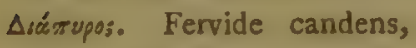
"red hot," iv. 8.

$\Delta$ sappis. Late evagor. De Nilo.

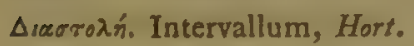

Diarsivopeaso Assevero, contendo, iii. $1 \%$

$\Delta i a \tau \mu i\left\{\omega_{0}\right.$ Evaporare facio.

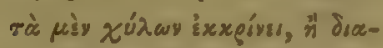

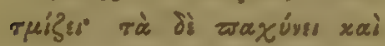
ouvisnor. De C. Pl.vi.

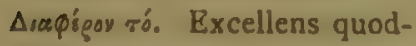
dam, ix. 14.

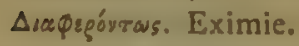

$\Delta$ rapogń. Excellentia, iv. 4 .

$\triangle$ aŕpogav. Id. si non error textus.

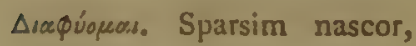
vii. 1.

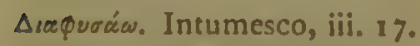

$\Delta$ uspưvis. Differentiæ germinationis, viii. 8.

Axppúrsus ai. Internodia caulina, Bor. iv. 10.

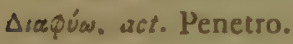

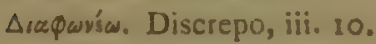

$\Delta 1 a \chi^{\prime} \omega_{0}$ 1. De separatione sanguinis partium, ix, 15 .

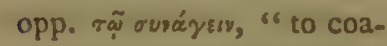
gulate." 2. Eraxionexu, flac" cesco, vi. 4 .

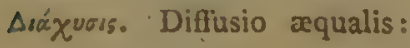

de coctione fabarum et pisorum, "when they are re. duced to a smooth paste."

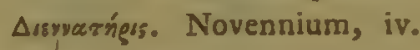
12.

$\triangle$ is yyasтmpris. Novennis.

$\Delta$ sivós. Biennis, de arboribus quarum fructus annum durat.

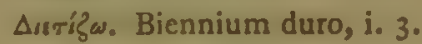
Ausugúvw. Dilato.

$\Delta$ เท́⿰习习⿱⺊s. Percolatio, ib.

هińxwy. Quod transversim

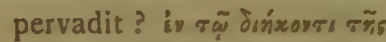

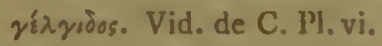

$\Delta$ inpapqúpsyos. Nodos transiens, permeans.

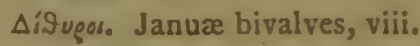
2.

$\Delta$ Aิ ข̧ós. Dicotyledonus, Bot. viii. 2.

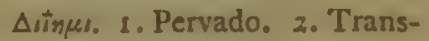
mitto, i. 10.

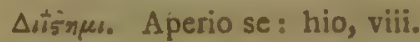
2.

Dixaptos. Fructus duorum annorum simul gerens. De arb. quibusdam, iii. 6.

$\Delta$ íxs $\lambda \lambda \alpha$. Instrumentum rusticum : ligo biceps. Angl. " a double hoe," De C. Pl. iii.

Axpayńs. Biceps, cacumine fisso, ix. 12. Sixpavos. Id. ii. 8. बixpoos. Id. iv. 2.

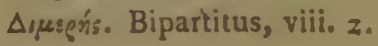


$\triangle i$ ǒs. Duplici venarum cur-

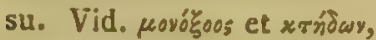
v. 2.

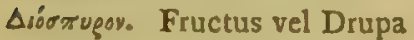
Loti, Diospyri, L. ii. 12.

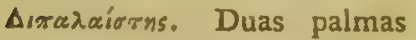
altus, iv. $I 2$.

Aipopos. Vidi díxagrios. i. 23.

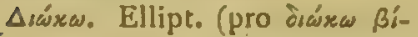

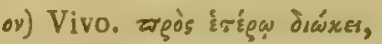
de pl. scandente, Bot. De c. Pl. ii.

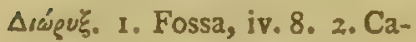
nalis.

$\triangle \Delta_{0} \alpha_{0}$ Cortex arboris, ix. 2. $\Delta \circ x^{o}$ s. Facile suscipiens: $\delta_{0}-$

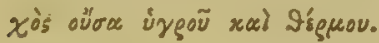
De C. Pl. ii.

$\Delta$ ģsús. Acris, pungens. De odore, vi. \%. ii. 8. opp.

$\triangle$ ģoroßó̀ios. Roridus : ubi rores abundant. $\triangle \varphi^{\circ} \sigma^{o} \beta 0 \lambda \alpha s$ xẃpos. De C. Pl. vi.

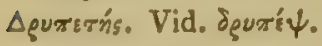

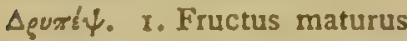
et deciduus, pass. N. $B$. $\Delta \tilde{y}^{\tilde{y}}$ pro quavis arbore. 2. Bacca Oleæ, iv. I\%.

$\triangle$ Q̧uтis. Fructus quidam. (Hinc forsan Drupa Linn.) «xavos, Sevtis.

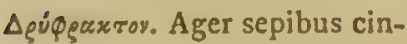
ctus? iv. 5. spatium arbo. ribus densum.

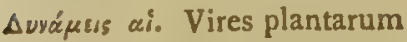
proprietates, i. II.

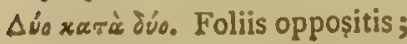

per paria, iii. 12. opp x xar"

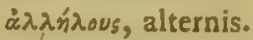

$\Delta v x^{\prime} \alpha \dot{\tau}$ raros. Frangi difficilis, iii. 8.

$\Delta$ ขoucuŕs. Spissus, non evaporens, vii. 6.

$\Delta \dot{v} \sigma \mu$ os oi. Occidens, ävz $\mu$ os

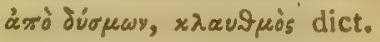

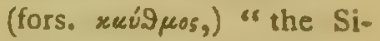
rocco." De C. PI. v.

$\Delta \dot{v o g r y o s . ~ F r i g o r i s ~ i m p a t i e n s, ~}$ vi. $\eta$.

$\Delta \dot{\sigma} \sigma \tau о \mu о s$, a rínyw. Scindi difficilis, v. $\mathbf{x}$.

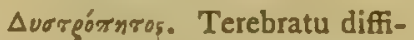
cilis, v. 8.

$\Delta$ voxbpsa. Aliquod ingratum respectu saporis. De C. Pl. vi.

$\Delta$ vordòns. Findi difficilis; de tenaci folio Fagi, iii, Io.

E.

"Erytos. De terra firma; opp.

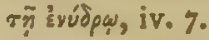

"Eyrus réós. Proxime acce.

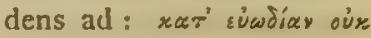

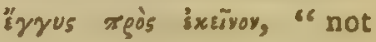
" near so fragrant as."

'Eyxzyre'́lw. Perforo: dicitur de actione succum vel resinam extrahendi e truncis arborum, ii. 3 .

'E rio. De C. Pl. iii. 


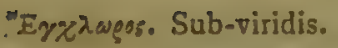

"E Exu入 os. Succulentus; opp.

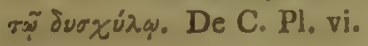

'Ejóøn rú. Varietates soli; Agricult. De C. Pl. ii.

'Edaq́isw. Solum complano, ix. 4.

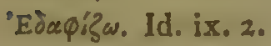

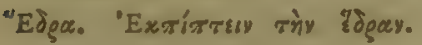
De prolapsu ani, ix. 9 .

E’d̀n rú. Genera plantarum, Bor.

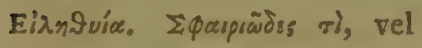
forsan pistilliforme in trunco Abietis : in magicis usitatur.

Eicoquís. Villosus.

'Exárşo\%. Utrique; (dicitur de duobus paribus.)

"Exarşúrns? Qualitas; forsan error. De C. Pl. vi. vid. supr.

'Exarívos. Sacerdotes Hecates.

'Exbráernors. Secunda germinatio; "Michaelmas "shoot," iii, 7 .

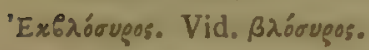

'Eryararrów. Lac exhaurio: de succo lacteo.

'Ex:9apyśspas. Fruticesco.

'Exišóv. Oblique, iii. 13.

'Exrod áxта. Tundendo eva.

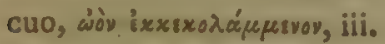
I6.

'Exxpiva. Secerno. 7 DeC.

Exxoivousu. Secernor. Pl.v.

'Exxpirtxoy ró. Id. $\int$ vi.

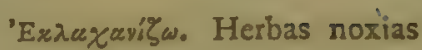
evello.

"Exגyros. Languidus : succo privatus. De C. Pl. iv.

'Expásoropas. Abstergor, aridus fio. De C. PI. v.

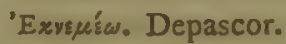

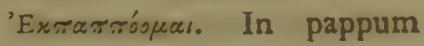
abeo. Bor. iii. 38.

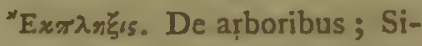

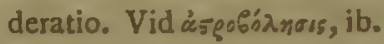
iv.

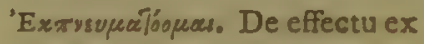
fermentatione. Vid. ซงเขี$\mu \alpha$ 。

"Еxтуยขช tiones ulcerum, i. e. ad virus extrahendum, ix. 10.

"Exsaols. Degeneratio, ab i乡g-

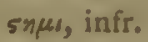

'Exти́кw. Emacero, ix. 3, 2. Maceratione stillo.

"Exzoto5. Climati proprius?

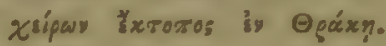
N. B. Forsan legendum "yтото\%.

'Exфuááw. Tumesco.

'Exథúon ท่. Tumor. De C. Pl. iii.

"Expuous. I. Degeneratio plantæ. 2. Proventus pl.

"Exxuros. Subtilis, tenuis : de succo.

"Erassy, N. B. Usus Olei occurrit in maturandis Ficubus. Item ad enecandas radices arborum, ib.

'Eגsxทช์óv. Adv. iii. $\times 3$.

P 
"Eגı६. Cirrhus; Bot. i. 3:

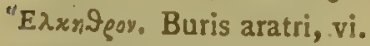

"Eגxopers. Distorqueor, "to "be warped." De ligno, v. 6.

'Eגxóopas, Perforor. N. B.

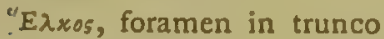
Abietis, per quod resina fluit, iv. 19. Item vulnus simplic. iv. I3.

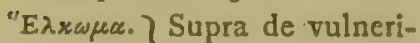
"Eגxwors. $\}$ bus ligni ex terebratione.

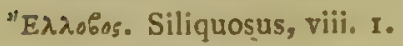

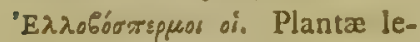
guminosæ.

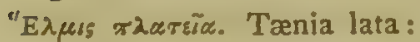
Angl. " tape-worm," ix.

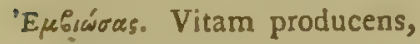
vi. $\%$.

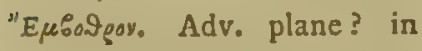

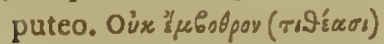

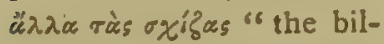

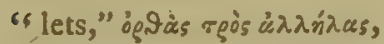
(sursum inclinantes,) ix. 3 . Sed forsan textus corruptus.

'F. $\mu$ Gódrros. Gleba involutus, ii. 5 .

"E $\mu$ bodo5. Navis rostrum æra-

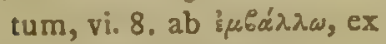
modo pugnæ navalis.

"E Eqequav, in plantis rò $\mu$ 's $\lambda \lambda a v$

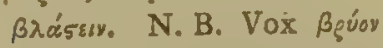
(amentum $B o t_{0}$ ) de racemo flosculorum fugacium.

"E $\mu \mu \eta \tau$ g os. Medullam habens, ז. 9 .

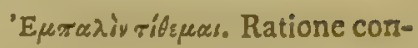
traria locare, $\nabla .5$.

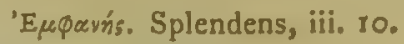

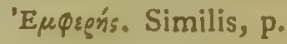

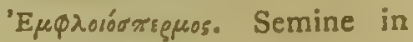
pericarpio membranaceo, vii. I, 4 .

'E $\mu$ pursíc. Insitio, horticult. " grafting." Vid. ¿̇vopá̛a. $\mu s \sigma \mu o s$.

'E $\mu$ чursúw. ii. I.

'Eváivar rá. Annua : Jísva, biennia.

"Evarpos. Stypticus, iv. 8.

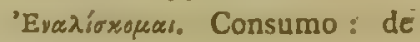
cibo, ii. 8.

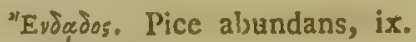
4. i. 8.

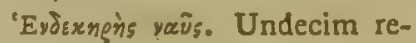
mis, v. 8.

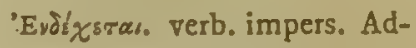

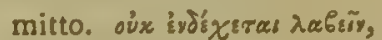
non admittit convenienter, iv. 2.

'Evঠ์ Xó $\mu \varepsilon v a v$ rò, quod convenit, ii, ib.

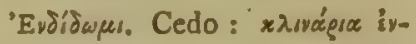
Sisovra, an lectuli elastici ?

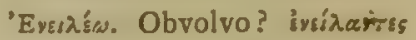

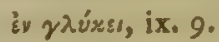

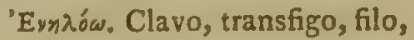
suspendo, "to string up," ix. 14 .

'Evtaúoros. Spatium anni unius, p.

'Evrauzopóogos. De arbore cujus fructus annum durat in asbore; aliter dixxąros. 


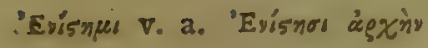
yoneriws, instituo, vii. 9 . Vid. 'A

'Evyastnọis. Novennium, iv. 12.

Eyos. Annuus, annum durans, $p$.

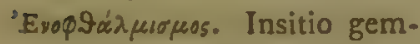
$m æ(\dot{\phi} \varphi \hat{Q} \alpha \lambda \mu \nu \tilde{v})$ in arboribus ; Ang. "6 budding?" Vid. ispursia. N. B. Ex

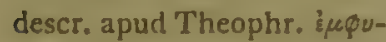
rtice videtar insitio per incisionem, zai ̌úrav oxiou, "cleft-grafting ;" švop 9 ćc $\lambda$ propes, insitio, per relaxationem corticis, "rind"grafting."

'Evox $x_{\text {it }}$. Perturbo, iv. 2.

:Evтай $9 \alpha$. Hac de causa, pass.

'Eyrípyopax. Intus seco, profunde incido, ix. 2.

'Evrsgswiyn. Pars interior, sive medulla ligni, iii. 8.

"Evropece rá. Insecta : hinc ìyTopodoría.

'Evтонй. I. Folii incisura.' 2. 'Evasur. Actio. scindendi, incisura, i. 16.

"Evudosos. Aqua coopertus, submersus, iv. $\%$

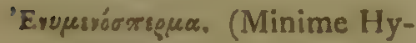
menosperma L.) Semine membrana incluso, vel pericarpio laxo, viii. $\%$.

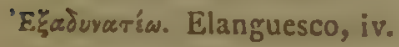

'Ě̆aıssígareas. De populo, (Aigrif $(\omega)$ habitum mutare.

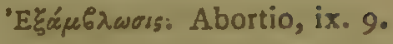

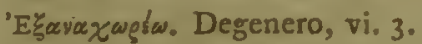

'Ě̌cuseréopest. Ventis lædor, viii, 10.

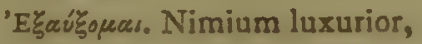
vii. 6.

'Ě̆s $\lambda$ asóopeaı。.Super-saturatus sum oleo: unde effluvium fit.

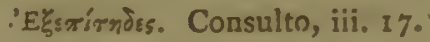
vii. 2.

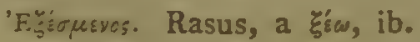
iii.

'Ě̌ıxpáw. Humorem perdo, vii. 5.

'Ě̆óóc. Evacuo.

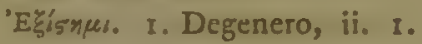
De C. Pl. v. 2. Deliro, ix. 20.

'Ě̌oposów. Similem genero, ii. I.

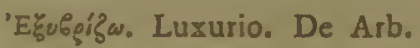
ii.

"Eל̧axgos. Pallescens, iii. 7.

'Exaxcevaí? $\omega$. Leviter spinosus sum, ix. 4.

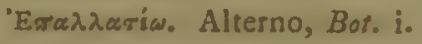
4.

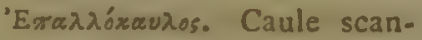
denti, Bor. iii. 8.

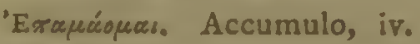
15.

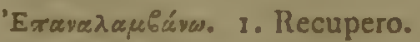
De C. Pl. iii. 2. Assequor. 'Exáфns. Tactu vel gustu sensibilis ? i. $17,19$.

'Erso:íw. Edo post aliquod, insuper edo.

P 2 
'EสEтrióxavdos. Planta caule annuo, radice perenni, Angl. "a perennial plant," vii. 7 .

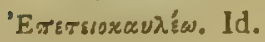

'Errí $\chi$ ẃ. I. Duro, continuo.

De C. P. iii. 2. Occupo, vi.

'E்

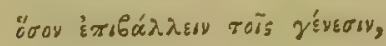
viii. 5 .

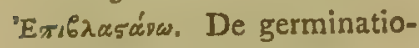
ne autumnali, vii. 2.

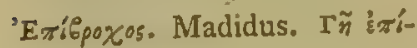
Ģoxos, vii. 6.

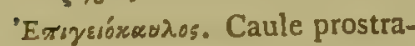
to, Bor, ix. 9.

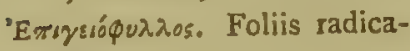
libus, Bot. vii.

'Eтí́darus. Leviter pubescens, Bot. iii. 18.

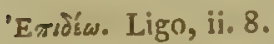

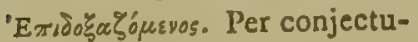
ram. De C. Pl. i.

'Exíooris. Incrementum, proventus, accrementum, i. 5 .

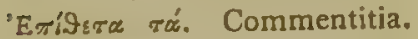

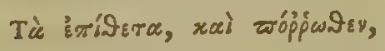
" far fetched, and with ad"ditions," ix. 9.

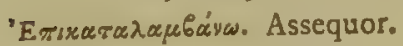

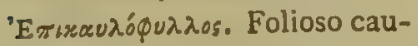
le, vii.

'Etrxáa. Inuro. N. B. Vox raíw usitatur de effectu frigoris, utpote et caloris ; . item de morsu venenoso pecorum. De C. Pl. v.
'Exirnpos, . Morbo obnoxius. Angl. " tender," vi. 7. vii. 5.

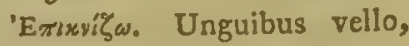
"to nip off." De C. Pl. iii.

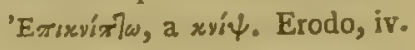
15.

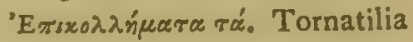
opera puppibus, ut videtur, agglutinata, iv. 4 .

'Eтเхотท́. Succisio, decacuminatio, iv. 19. De C. Pl. v.

'Eтsxvírzopas. Actus superfoetationis; utpote, in leporibus. De C. Pl. i.

'Eтtxúz]w. Declinare facio, "r to weigh down."

"Eтrúín. Depasco.

'Eสเขร์. Supernato, ut lignum, in aqua, vi. 3.

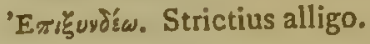

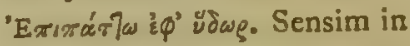
aqua tracto: manibus subigo, ix. 1\%.

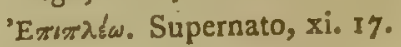

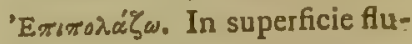
ito.

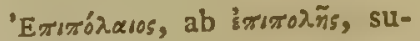
perficialis ; de radicibus оpp: $\beta$ ágิยน.

'Exípputos. Inundatus : $\gamma \tilde{n}$ "zápippuros, Agric. " flooded " ground."

'Exiтuppos. Rubescens. 'Ẽเoเท'́s. Noxius, viii. 6. 'E.riorross. Attractio. De C. PI. v. 
'zarioropa, Secunda satio. 'E.

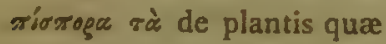
sæpius in anno seruntur, vii. $t$.

"Emiscoss. Continuatio habitûs : opp. 'ixรáreı. De C. Pl. v.

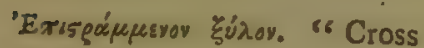
"grained," iii. 10.

'Eтưvárxas。 Valles quædam Asiæ, De C. Pl. v.

'Exsoxisay. Ab imo divisus.

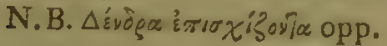

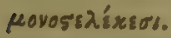

'Emircoss. Impulsus. De C. Pl. ii.

'Eтлтsóravdos. Caulibus deciduis; de pl. perennant.

'Exrpavís. Violens. 'Aǹ शిó-

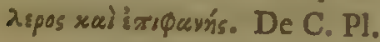

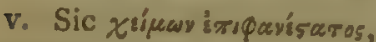
Polyb.

'Exi

'Erıpúcèss. Surculi, i. 9 .

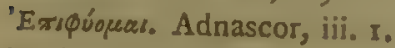

'Exívers. Supr.

'Exixgorsis. Levis coloratio, "a light staining." De C. PI. ii.

"Eтงидаg. Leviter pubescens. Vid. Oüras, iii. 10.

'Exwrídss. Prominentiæ laterales utrinque ex puppi, ubi navis nomen inscribebatur, (Poll.) v. $\%$

'Ẹfaria. 1. Manupilatio. 'Epr.

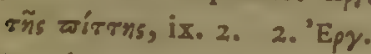
Kassis, præparatio medica. minis, vi. 3.

${ }^{2} E_{\ell} \gamma$ roores. Caprificatio, ii. g.

'Egyòs ró. Surculus: syn. "E९you.

'E

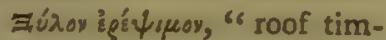

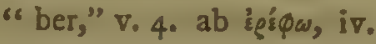
3.

"E ģyoy ró. Fructus Ficûs, sylvestris, ii. 4 .

"Eprov. 1. Lana. 2. Gossypium, iv. 9.

'Egsọ́óos. Gossypinus, iv. 9. vii. I3.

'Egrodaplex'va. Percolare ope lanz; " to strain through "wool," ix. 8.

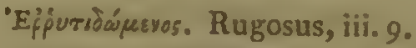
'E९vaibn. I Robigo; morb. Forsan Uredo, Persoonii. 2. Fungi species. De C. Pl. iii.

'Eoxága. Pars plana חuesías, (vid.) fovea circularis, ubi circumagitur rò rẹ́r accendendum ignem, $\nabla .10$.

'Eоxursúarra rá. Apices ra. morum, \&c.

"Eтos píps oủx ägouģa. Adagium vetus: plus cælo quam terræ tribuendum, viii. 8 .

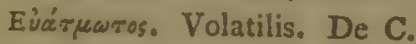
Pl. ii.

Ė̉aú̌̌nร. Libere crescens, ib.

Eürupos. Bene situs, bene ventilatus, viii. Ir.

Eưụ́ns. Tractabilis. Гñ củáens: De C. Pl. ii. 
Eübaros, Facile scansilis, ii. 8.

Eủboría. Fertilitas, i. 1, 18.

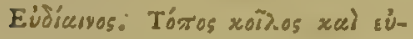
Siccivos; "a well sheltered " mild situation," iii. 3 .

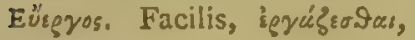
v. 6 .

Eussés $\omega$. Vomitum ciere sine dolore, ix. Ir.

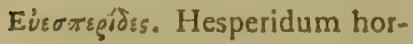
ti, iv. 4 .

Ev่ermgice. Anni prosperitas, viii. 8.

Eưŕ̛xws. Facilis, pronus. Eú-

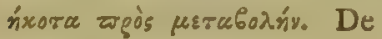
C. Pl. ii.

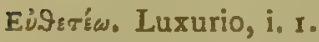

Eủง̨ẃgnros. Observatu facilis, i. 1 .

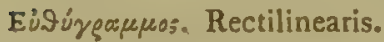

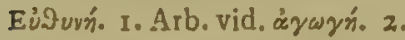
E. yoías, amelioratio soli.

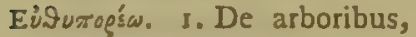
" to grow straight." 2. Lineis rectis propagor, $\vee .6$.

Eivivoxisos. Profunde lobatus, i. 16 .

Eüiaro5. Facile sanabilis, ii. 2.

Eixegarnis. Temperatus, i. 5 . Eủeráayos. Scindi facilis? ib.

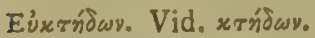

Eüvouzor oi. Pl. steriles. Mas vel foemina in Diœciis, v. 12.

Eüorros. Levis ; parvæ molis, ix. 17.
Eủodía. Luxurio, i.g. Vigeo."

Eüsopes. Gratus palato, "re" lishing."

Eürovos ๗̋ós. Aptus ad. Eüxขìos: Succulentus, viii.' IO.

Eùwoía. Gratus odor. N. B. Гúrs:s aversantur odores; apibus etiam nocivi sunt; nec datur animal, homine

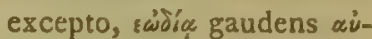
zйs xapív. De C. Pl. vi.

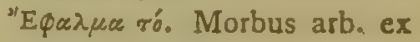
nimio sale? De C. Pl. vo

- 'Eథnríozs. Solis maculæ, " freckles," ix. 22.

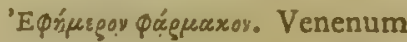
quod cito enecat (eodem die,) ix. 6, 19.

"Eழoòs Inorápov. Inundatio, iii. 2.

'Eøúw. De imbri super imbre, iv. 15.

'Exĩvos. I. Placentæ genus ex farina cruda. 2. Morbus ex ejus usu. De C. Hl. iv.

'Ex'́psva rá. I. Quæ succe-

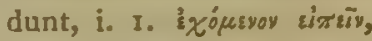
restat dicere, vii. I. 2.

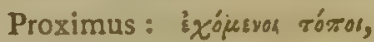
iii. 2.

'Exópzyos. Proxime adjacens, ib. Vid. Lex. '̌ớpryos tógor, iii. 2.

'Eúprvos. Derelictus; "left tos "itself," vi. 6. 
z.

2ท̃9os. Cerevisia, a ל̌s, ferveo, "to mantle." "A

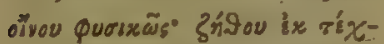
vหs. De C. Pl. vi. N, B.

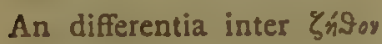
et Bgúroy?

Zuyïys: Carpineus, v. 6.

Zúyoy. Jugum. Z. 2úgos, lignum bicome-Lyræ antiquæ.

H.

"Hึเxos. Percolatus. O xor.

'Hлахиंт. 1. Pistillum Amygdali floris; item Citri, Aurantix, L. ex similitudine Fusi, i. 22. 2. Talea Calami excisa sine foliis, ii. 2 . "Haves ixvipinos (sine nubibus). Obstat aliquando asboribus, viii. 10.

"Hגol of. Agarici arborei, pusilli, iv. 15 .

TH.o5. 1. Clavus. 2. Fungus arboreus.

'Iluspoürrss oi. Qui terras incultas subigant. De C. Pl. v.

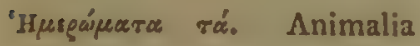
mansuefacta, pecora, ib.

'Husb̧áxrs. Sub-madidus. De C. Pl. iii.
'Hpíbgexar oi. Terra sub-madidx, iii. 2.

'H $\mu$ isxlas. Semisextarius. Theod.

"Huindos. Sub-solanus, De C. Pl. iii.

"Hesvos. Id. q, iesvos, ab ig/s, Iris, viii. $\%$.

'HouXฑ̃. Adv. leviter, p.

๑.

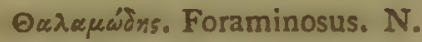

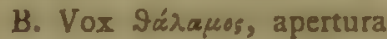

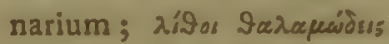
(porosi). De C. Pl. vi.

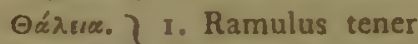

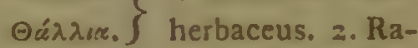
mus arboris frondibus vestitus.

Qúpros. Frutices. Plantarum divisio. Vid. $\Delta$ évogar.

Orerndiav. Aprilis mensis.

Osprvà rá. Planta annux. Opp. rois $x$ supesirvos, vii. 3 .

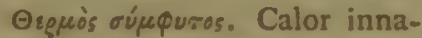

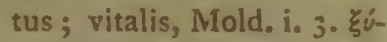

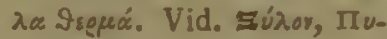
eria.

Oír то́тоv. Aspectus, setus, p.

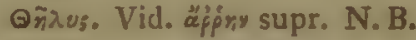
Non semper de sexu in Diceciis pl. N. B. Hinc 'E.

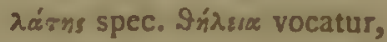
sc. Pinus, Picea, L. 'E. ฉ̈p. 
¡rv, P. abies, L. Alibi vox

- ut distinctio sexualis occurrit.

Ońpsa.icl. q.? Anęiórec. Animalcula; vermes pl. vi. 2.

Onsífse. Animalcula.

Oresúsing. Insecta generans, iv. 8.

๑ódşos. Turbidus. De differentia inter animalia et

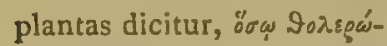

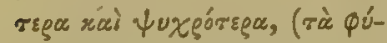

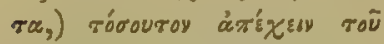
¿'ंa Eivys: forsan minus cocti, iii. 2 .

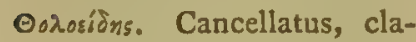
thratus. (Vid. Præfat, opjeris.) iii. Io. Vox occurrit apud Strabonem in describendis ferarum caveis. in ludis publicis Romæ.

Oópos. Piscis masculi lac seminale; "the milt." "o

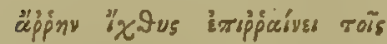

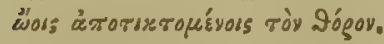
De C. Pl. ii.

Qgáúpus, Lacero: de effectu salis in enecandis plantis.

Opausós. Fragilis, v. 5.

Oploy. Folium ficulneum.

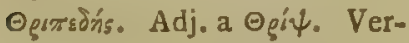
mibus erasus, iv. 16.

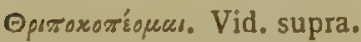

๑úravo. Fimbriæ; filamentorum fasciculi, "a fringed "edge," "6s tassels."

Qvacuídry. Fimbriatus.

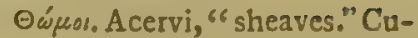
muli grandiores, "mows" Angl: viii. 10.

I.

'I $\delta \varepsilon \alpha t \alpha i$. Species plantarum, p.

"Iosos. Peculiaris, extraordinarius, pass.

'Isiórns. Supra.

'Ispò vóros. Comitialis morbus. Epilepsia, ix. 12.

"Iจ $\mu$ os. Fors. diversus ab 7\% $/ \mu \alpha-$

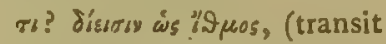
per aquam ut atomus?) \&่x हैx unde suspendatur). De C. Pl. vi.

'Ixpés. Succus seminalis, vel simpliciter humor, vi. 4 .

"Ixprec rá. Opera sculptilia in navibus; ornamenta lig-

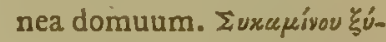

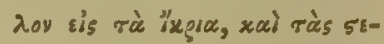

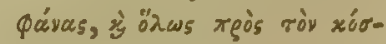
$\mu o y$, v. 6. Vid. Hesych.

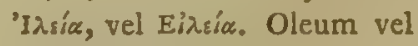

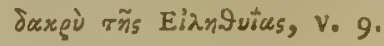
Vid. supra.

'I 2 vádns. Limosus, iv. 12.

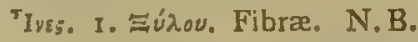
Libro primo c. 3 , 4. comparatio instituitur inter animalia et vegetabilia : ut in

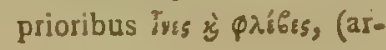


terix et venæ,) sic in posterioribus, wัoxş ivss, \&zc. 'Ivts describuntur ouví $\chi^{s / 5}$,

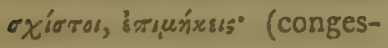
$t i$, vel fasciculati ; divisibiles; in longitudinem pro-

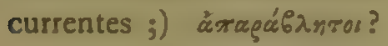
(non confusi inter sese, ) «Exac5ol (non ramosị). Congruunt hi cum canalibus capillaceis, vel lymphæductibus Grewii, Lewenhoek, aliorumquue. Quod ad $\varphi \lambda[$ leas, vel vasa spiralia, vid. 申גíł. 2. Vermes, Ascarides in corp. humano, ix. 14.?

'Ivâôns. Supra viii. 4 .

"Ios ró. Gas, vapor ex fermentatione. Tórouray los í $\phi i s \alpha-$

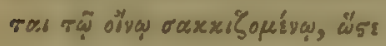

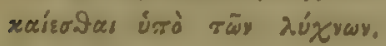
De C. PI. vi.

"Iovros. I. Iulus, amentum, Bos. iii. 6. 2. Cirrhus, iii. 17. 3. Receptaculum, vel sedes, Scolopendræe parvæ maxinæ, iii. 7 .

'1 $1 \pi \pi \dot{x} z \eta \varkappa_{n}$. Lac equarum coagulatum, ix. 15.

'Iтторехи́s. Succus lethalis $\tau \tilde{8}$

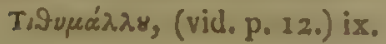
I5.

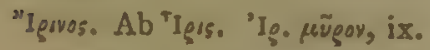
10.

'Irorodiaioy. De triangulo æquilaterali. De C. PI. vi.

"Ioxus. Fructus 'Atriov, ix. IO.
'Iwsía. I. Violetum. 2. Violæ planta; utpote boy flos ejus, vi. $G$.

K.

Kastaigu, Pharm, 1. Purgo. K. xárw, per alvum. K. ๕̈vw, vomitum cieo. 2. Amputo, "to prune."

Ka9áx7онаs. Frigore lædo, vii. 6.

Ka9áorws ¿. Oppositum aliquod. De C. PI. iii.

Káây gos. Sub-madidus, i. 6,

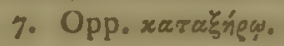

Káizapos oi. Internodia Arundinum, antiquitus in usu vice Phialarum. Vid. NágInxes.

Karapeádns. Folio vel caule Karápuov. Vid. Cat.

Kád ข气̌. I. Calyx, Bot. 2. Involucrum fructus.

Kó $\mu \pi \eta$ Larva, Linn. vid. Tab. Systematicam; ubi transformationes insectorum accurate notantur a Theophrasto, sc. I. Kó $\mu$ -

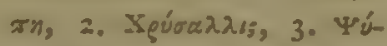
$\chi \eta$, Larva, Pupa, Imago L.

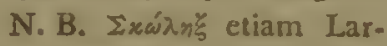
va quandoque, ös sis ä $\lambda \lambda$ 。

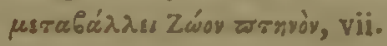
12.

Kã ya? pro xúvmร. Canistrum vimineum, v. 7. Diff. a xisa, ib. (vid.) 
Káysoy. Id. iii. I3.

Kav9agis. Curculio granarius L. "Weavil."

Kám7nฺ. Corbis spec. vàs ex Kápur?ng.\} ligno flexili. De C. Pl.v.

Kúrzyos. "Smoaky colour" ed;" "grey." " $\Delta \mu \pi \varepsilon \lambda_{0}$ s xс́тsios, vitis helvola, Columella. Varro de Re Rustica. Apud nos extat spec. "grey Frontignac" dictā, ii. 4 .

Kaęoía Gúnou. Pars interna trunci dura: "the heart of

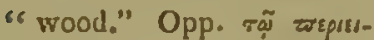
2rípors, "the Alburnum," Bot.

Ǩąxuvóopar. De ramis, et ra. dicibus; implicor instar pedum cancri ? "to tiller." (Agric.) i. 9. De C. Pl. i.z. Káérvos. I. Cancer animal. 2. Calathus vimineus, cujus usus in caprificatione, ii. 9. 3. Cancer, morbus arb. De, C. Pl. i.

Kapveíos. Pila lanæ? iii. 16.

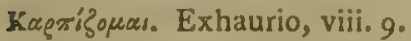
Kugróopias. Fructu spolior? iv. I3.

Kagrós. Carpus manus, "the "wrist," iv. 9.

Kapurgós. Nucifer, i. 16.

Ká́guov. Simpl. nux avellana, iii. 4 .

Kaoxagias. Squalus Carcharias, L. " the shark." iv. 8.
Kagavaixòy xúgvay. Nux Castance, iv. Io.

Kásos? Occurrit inter arómata, ix. \%. Fors. legend. Kósas, Tab. Syst. p. 3.

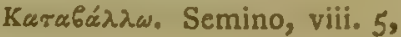
II.

Karábogos. Edax: de sterili solo, "hungry land." $\mathrm{De}$ C. Pl. $\mathrm{v}$.

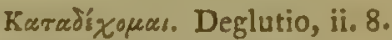
KaradÉw. Incanto, vi. 2.

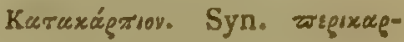
ríov, iv. Ix.

Karaxopris. Saturus; de colore, iv. 10.

Karádeyo5, Adj, Congruens.

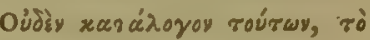

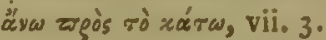

Kararar's. Pedibus concul-

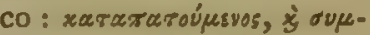
zuroúesvos, (N. B. Vox posterior conculcationem plurimorum indicat, ut exercitus.) viii. \%.

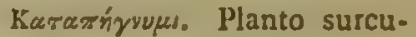
los, iii. 18.

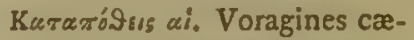
nosi: a катктiva. De C. Pl. v.

Kaтaróriov. Haustus medicus, ix. 8.

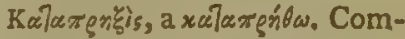
bustio, V. 9.

KüTą»yvúpesvos. Laceratus, iii. I.

Karappopopíw. Sorbillo, iv. 4 .

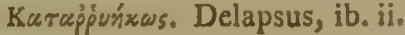




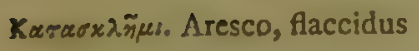

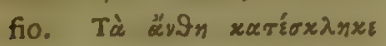

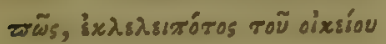

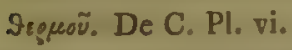

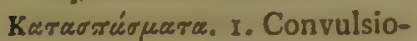
nes. 2. Vibrationes? De præparatione internodiorum Cannæ ad lingulas fistularum, iv. I 2.

Karaorsíg. Sparsim sero, vii. 5.

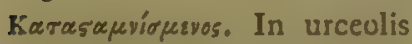
servatus: de vino; vid. súpuyroxos. De C. Pl. ii.

Kuтx́søas. Temperamentum. Karásaris ไtrovs, viii. 8.

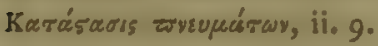

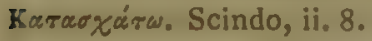

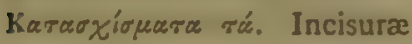
in foliis, vel lobi, Bot.iii. $1 \%$.

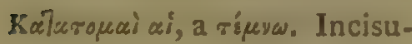
re, lobi, iv. 10. An squamæe?

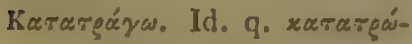
ga. Comedo, ix. I2.

Karaфísopar. Deorsum feror, deterior fio, iv. 15 .

Karaxкuоне́peryos. Hians, rin. gens, Bot.

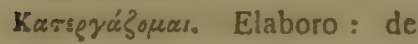
praparatione medica, ii. 3 .

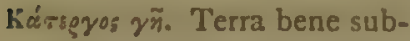
acta : opp. $\gamma \tilde{\text { ñ }} \varrho \gamma_{\eta}$. De C. Pl. v.

Karíxw. Cohibeo: restringo, ii. 5 .

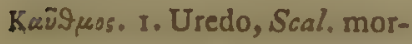
bus arborum ex nimio ca. lore. 2. Ventus calidus, "Sirocco," iv. $1 \%$.

Kaudias. Succus ex caule Silphii, ix. 2.

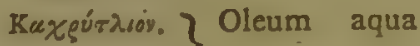
Kaхgúdıov. $\}$ mistum. De C. Pl.v. Forsan fæces olei. Káx $\rho^{u s_{0}}$ Amentum, Bot。 "Cat" kin," vi. I. ix. I2.

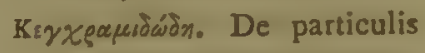
salis induratis. Vid. infra.

Kเ yxęuis. Semen Ficûs, ii. $3,9$.

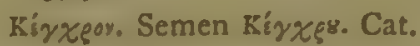
Keogẹis. Juniperis, Cedri, L bacca. De C. Pl.vi.

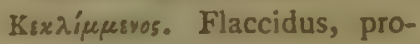
cumbens ; te foliis, iii. 10.

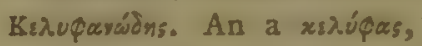

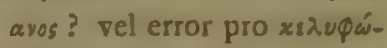
¿ns? De C. Pl. i.

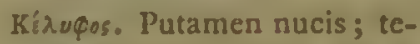
gumentum siliquæ, iii. et pass.

Kívręa rá. Nuclei in lapillis, v. 3 .

Kipaía ai. Antennæ navium minores, $v_{0} 2$. Vid. $\tau \alpha v i \alpha$. Ksqápiray. Amphora figulina. De C. Pl. vi.

Kíguerov. Fructus Kęárov, iii. 12.

Ksppenรi. Minutatim, จ. 3.

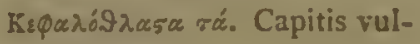
nera.

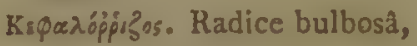
vii. 2. vel fors. fusiformi, Bof. Vid. infra. 
Freparáôns. Radice sub-bulbo-

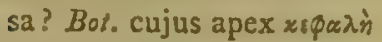
vocatur, ix. 8.

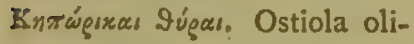
toria, Plin. "garden wick. "ets," vii.

Kņฺıúdys. Alveolatus; ex similitudine alveolarum favi. N. B. Dicitur de situ florum, urpote in plana superficie pl. umbelliferarum, iii. 12.

Kį́ error textûs, iv: 9 .

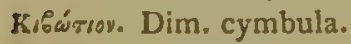

Kuvis. De ascensu succus. De C. Pl. i.

Kiocnges. Pumex; lapidis genus, ix. I9.

Keoongoídes. Id. iii, 6.

Kisa. Corbis e cortice Tilix, iii. II.

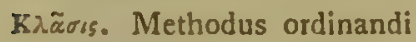

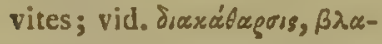
soroyix.

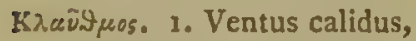

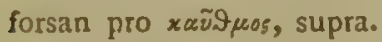
2. Olympias ventus. N. B. Ex ambiguo sensu vocis zais forsan ventus frigidus ex monte nivoso, "Vent " de Bise." Fr.

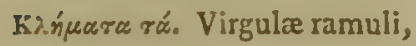
i. 7.

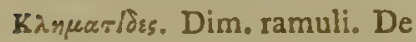
C. PI. iii.

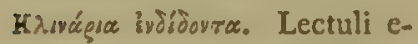
lastici ex ligno flexili ? v. 8 .

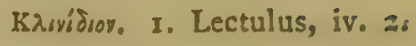
2. Tabula mensaria singulis apposita?

Kגıvń. Receptaculum in floribus compositis, Bot. ii. 8. Kגıv's. Pronus, declivis. Opp. ő९̣. De C. Pl.

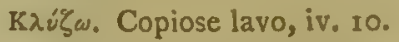

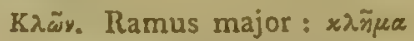
ramus secundarius? i. I.

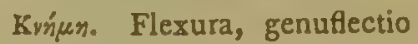
in caule, ix. $14,16$.

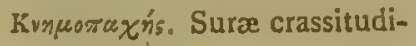
ne, ix. 4.

Куเтยุis. Folliculus, Bot. a Kvi $\psi$, vermis spec. qui ibi nidulatur, ii. 9 .

Kvízw. Rado, " to rasp, or "grate."

Kó $\gamma \chi \eta_{0}$ 1. Cochlea. Species testaceæ bivalvis. 2. Mensura antiquitus liquidorum, ix. 6 .

Kos maxillas rami, vel de flexura rami versus basin, iii. 9 .

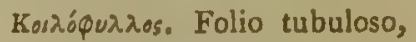
ut Allium, i. 16.

Kóxxos. I. Granum. 2. Semen Mali Punici. De C. Pl. v. 3. Fructus Kóxzov Króiou. Vid. Cat.

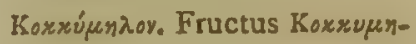
híxs.

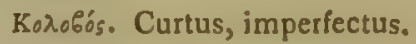

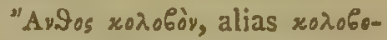
áy จns, flos papilionaccus, Bot. viii. 3 . 
Kor.o:ow. Trunco, iii. 6.

Koגoũors. Amputatio : $x_{0} \lambda$.

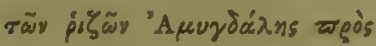
rò gruxaítysy.

Kókn ท. I. Planta herbacea, vii. 8. 2. Caput frondosum arboris. De C. Pl. iii. 3. Frondes in genere, ii. 8 . vii. 5 .

Корені то́. Gummi, ix. I.

Kovíaois rsixys. Dealbatio muris calce soluta, "white"washing," iv. Ir.

Koviogros. 1. Pollen, Bor, ii. 8. ubi foecundatio Palmæ foe. minæe accurate describitur. 2. Collectio staminum in flore; hinc rayıǫrúds \&̈yTos, de flore stamineo. Vid. Xvoũs.

Köradıg ai. "Coppices of "wood," voce fere retenta.

Korţrois. Stercoratio, viii. 6.

Kóręas. Fimus, Agric. Qualitates et genera xórę accurate discriminantur a Theophrasto.

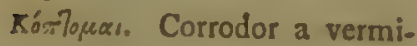
bus, viii. 10.

Kogpeós. Truncus ligni : xogerei oi, " billets."

Kóporav. Radix Loti, sic dicta, iv. 10. Vox Egyptiaca.

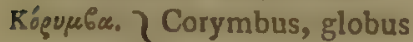

Kóguk6os.\} sphrericus semi-

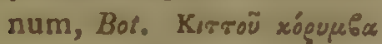

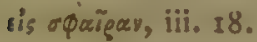

Kogérn. I. Inflorescentia thyr- siformis; ut Pruni, Lauro cerasi, L. 2. Bráss Kopúyn, Apex claviformis, vel intumescens rami, iii. 4. Hine

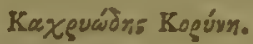

Koguvás. Id.

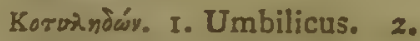
Cavitates in radice Polypodii, ix. 84 3. Tentacula,

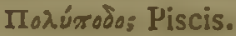

Kovęó. Z De tonsura arboKovpí̧⿻. $\}$ rum, ii. 9. 'H K\&$\varrho^{\grave{\alpha}}$, cresura, Gaz. ib.

Koüфos. De succo. Mitis? Opp. Sospes, ii. 8.

Kax גaxwíty. Terra cochleis abundans; de stratis terra, testaceis fossilibus inspersis, ix. 10.

Kpádxs ai. Verrucosæ intumescentia magnæ molis, in truncis arborum, $i$. 13 .

$\mathbf{K}_{\ell} \alpha \delta \delta^{\alpha} \omega$. Id.

Kpádn. Ramus major. Vid.

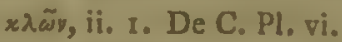

$K_{\rho} \dot{x} \delta$ s. Morbus in truncis vel

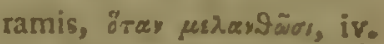

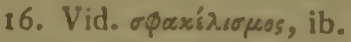

Kৎ̊́phos. Morbus Oleæ. Vid. desc. De C. PI. v.

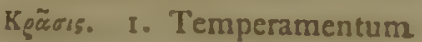

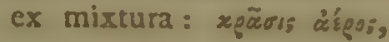
temperamentum aeris. De C. Pl. vi. Succi, i. 19 . Kpoūous. Siccus. Opp. тё yníxes, i. 8. Hešych.

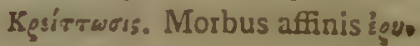
oîñis. 


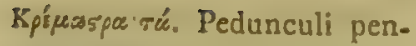
siles fiorum Arbuti, iii. 16. - Kesaqai ai, Hordei grana, p.

Kérixos. Annulus affixus pulvinari, iv. 10. Forsan "cas" tors" Angl.

Legriós. Liliaceus, a xgivov, iv. IO.

Kpevyvía. I. Lilium, candidum, L. 2. Lilietum, ii. 2.

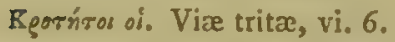

Krovía? Pectinis species? (vid. Præf.) iii. 10.

Kรndáv. Cursus venarum in ligno, v. 2. Vid. Movógoos.

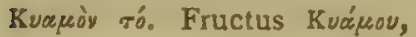
iv. 4 , 10. Pisum, non faba.

Kuapeír. Locus Kvápeors plantatus. Vid. Cat.

Kudúyov. Malum Cydonium, iv. 10.

Kuśw. Fructifico, "to set "fruit," i. 23.

Kínua. Pericarpium, Bot. vi. 4.

Kúmซss. Vid. Kúnpe, iii. 6. viii. 2.

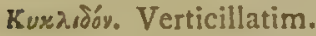

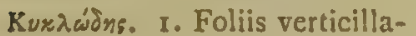
tis. 2. Descriptio folii orbicularis, lobati, ix. 18.

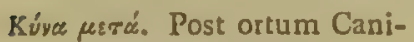
culæ æstate media.

Kúgroy ró. Principium: hinc

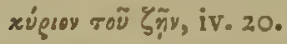

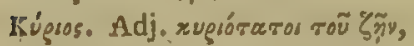
de arboribus maxime viva- cibus, iv, I 6.

Kuerós. Gibbosus, ii. 8.

Kúruvos. Pericarpium globo. sum Punicæ; iข rwี หขríy

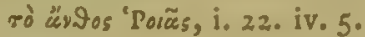

Kúrragoy, 1. Strobilus in P'inu. 2. Cavea in receptaculo Loti, Nymphææ, \&c. iii. 6. iv. 10. Bod.

1. Kuẁy ¿. Canis major, sidus, i. 15 .

2. Kù̀y ó. Canis marinus Squali Carchariæ spec. minor, vi. I3.

Kwoíc. Papaveris pericarpium, ix. 13.

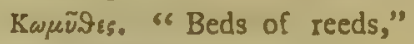
vox Igypt. iv. I2.

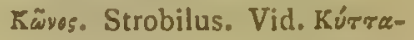
goy, i. 18.

Kw̧úxy. Folliculus. De floribus Ulmi, iii. 14,15 .

$\Lambda$.

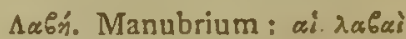

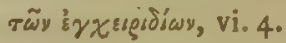

Axyapós. Laxus. Pharm. de alvo, ix. 11.

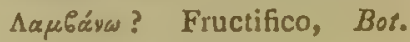
"To take up fruit," vi. $2 \mathrm{I}$.

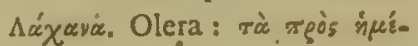
regur xgriar, vii. 8.

Aaxayríos. Z Divisio planta-

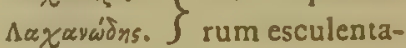

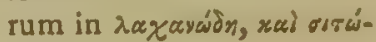
$\delta n$, vii. I. 


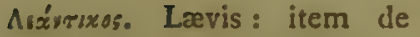
succo molli, oleoso. Xípos

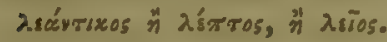
De C. Pl. vi.

Aupáysos. Pratensis? Distinguitur solum in $\lambda$ sıpúvioy, pratense; हैं $\dot{\lambda}$ sov, palustre;

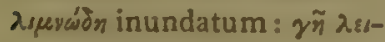
rúwa. De C. Pl, ii.

Asióxauдаs. Caule lavi : opp.

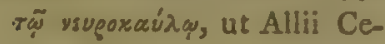
px, vii. 2.

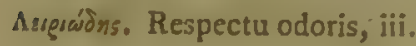
12.

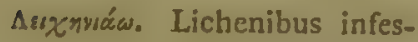
tor; de truncis arborum; "to grow mossy."

A.riádins. Instar pulpamen-

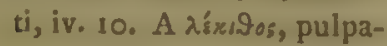
mentum; vitellus ovi.

Aípues. I. Cortex arundinis, iv. 12. 'Eу รัฒ $\lambda$, una cum cortice, 2. Arista in spica Hordei et Avenæ? viii. 3.

Asridss ai. Ramenta: particulæ minuta in aëre, $\mathrm{Angl}$. "motes," iv. 19. "Oray aíIfias อย้ซ\%s (hyemis tempo-

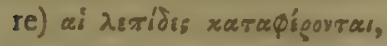

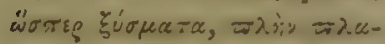
rย́rspe. N. B. Fors. particula glaciales, ib.

Asтroyśnv. Terra levis: de qualitate soli. Angl. "a "light soil," viii. 9 .

Aเтröivos. Fibris tenuibus, de ligno, "fine grained." Vid.

"Iyss, iii. 10.

A\&zropesqús. De particulis primordis. Aqua pura sic dicta. De C. Pl. vi.

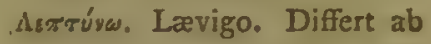
ล์วทงะย์ผ, molo. De C. Pl. iv. .

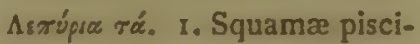
um. 2. Squamæ in corticibus et frondibus Fuca rum, iv. 7 .

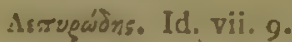

Asũxa rá. In ligno; alburnum, Bot, iii. 10 .

Asuxóyasos. Inter soli varieta-

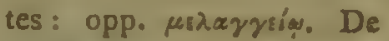
C. Pl. ii.

Asuxòy ró. Alburnum, vid.

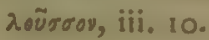

Asuxós. Unicolor, Bot. vi. 8. Vid. $\mu$ '́zas.

Aibadıs ai. Paludes; stagna, Theod. ii. 6.

sibavos o. Ylibanum, Thus,

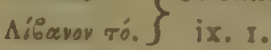

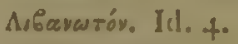

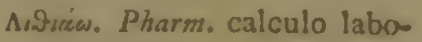
ro, vii. 6.

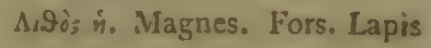
Lydius, "touch-stone." ix. 19.

Aнevidy: xáge. Aquis inundata, stagna, Theod, iii. 3 .

мragós. Oleosus, nitens: de folio Lolii, viii. 7. Vid.

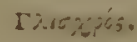


- М⿻ŕ์ succi in arboribus: $\varpi \tilde{\alpha} y$ rò

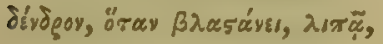

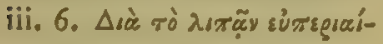
esros ì Qroíos, ib.

Airnrós. Tempus anni quo succus fluit, $V_{0} I$.

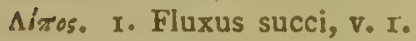
2. Pinguedo, ix. $\mathrm{x}$.

Aıтоварxís. Tabesco, viii. 10.

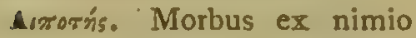
fluxu. De C. Pl. v.

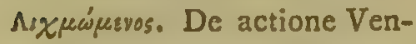
tilabri ad purganda semina, viii. 9 .

- Aobós. r. Siliqux spec, in Cichoraceis : hinc "indobos lo-

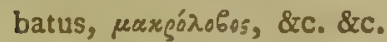
2. Capsula, vii. 10.

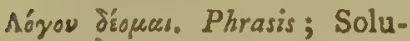
tione egeo.

Aoğos. Tortuosus, i. 7 .

Aot’ás. Morbus in radicibus ex nimio humore; ỡoy $\mu$ ó

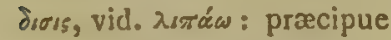
in Ficu. De C. Pl. iv. 16. v.

^oтás. Fungi spec. arborea Oleæ propria, iv. 15.

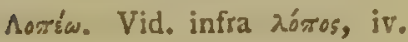
18.

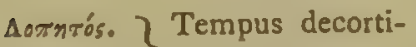

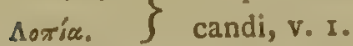

Aóros. Tunica corticis : hine

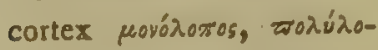
$\pi 05$, i. 8.

Aoṽroay ró. In trunco Abietis, nodus similis aiyides: (vid.)

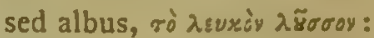

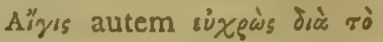

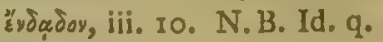
Alyss in Pinu.

Aópoupar oi. Equi, Asini? Vox dóørgos, crista-caudatus, ex usu caudæ equinæ ad galearum cristas: opp. roĩs

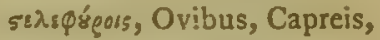
Damis, \&c. quorum cauda cylindrico-æqualis, instar stipitis, $5 \varepsilon \lambda \varepsilon \varphi \tilde{\varphi} \xi^{\circ}$, iii. 10.' p. Ir.

Aoxeír. Parturitio, item met. in arboribus. De C. Pl. iii.

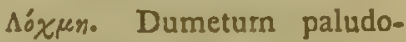
sum : "a jungle."

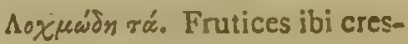
centes, iv. 9.

Aurǵ́rns. Ariditas, macies : forsan a $\lambda \dot{v} \pi n \rho o s$, tristis.

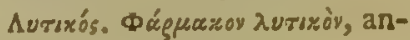
tidotum, ix. 16.

M.

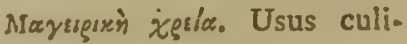
narii, vii. 7.

Mayúdaęs. Succus inspissatus caulis $\Sigma i \lambda \varphi \varphi^{\prime} \in$, Cat. vii. 3.

Masáa. Infr.

Mádrots. Morbus Ficûs ad radices, ex nimio humore, iv. I6. 
Maxidoría. Montes hujus regionis arhoribus variis sca-

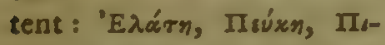

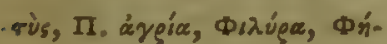

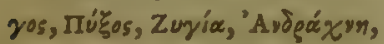

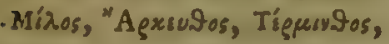

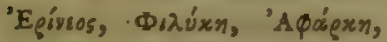

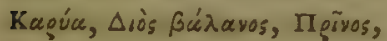
iii. 4 .

Mranax's. Respectu temperiei

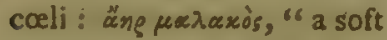
"air," vi. 7. respectu sapo. ris vini : opp. aúsท́弓. De C. Pl. ii.

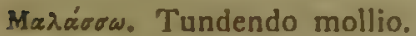
Mavós. I. Rarus respectu si-

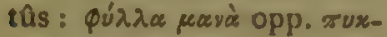
voís, v. 3. 2. Laxus, poro-

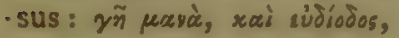

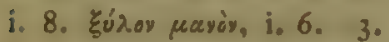
- Respectu fibrarum ligni ; adeo ut idem lignum fiat fibrosum et durum, v. 6 .

Mavórทs. Id.

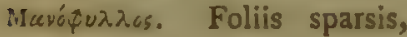
viii. 2.

Muaća. De actione manMáonux. Sducandi : "chewMéronats. "ing," iv. 9.

Máørstrav. Folium Silphii, vi. 3. N. B. Vox Syriaca ?

M⿻iorixus. iii. 8.

Marrixं" ทं. Gummi "Mas"tick" dict. vi. 5. ix. 1.

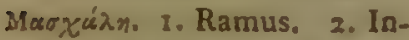
sertio rami forsan, vel axilla rami vel folii.

Meersaios. Per contractionem

PARS II.

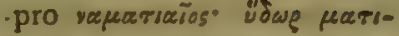
xioy, aqua fontinalis, ii. 8.

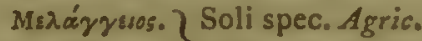

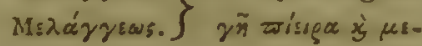

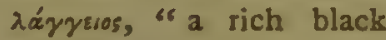
" mould," viii. $\%$.

Merávōevav. Cor ligni quercûs, vel generaliter; $\Delta \rho^{\tilde{s}}$ enim vox generalis : opp. roĩs

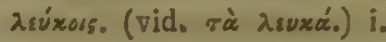

9.

Miras. T Dé colore ; obscuM: $\lambda$ avía. $\}$ ritatem quandam indicat ; ita apud nos, " dark coloured," i. 8. v. 4. et pass.

M/ $\lambda$. Methodus edulcorandi species quasdam plantarum infusione seminum in mel. le. De C. Pl. v.

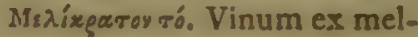
le.

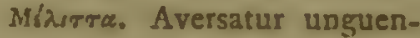
ta pretiosa. De C. Pl. vi.

Mìirroũra. Placenta farrea melle condita : áryxąros

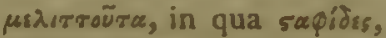
aliique fructus passi : "a "plum cake."

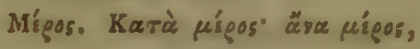
successive, vii. 3. et pass.

Misoyovárscv. Internodium, Mecoyóvor. $\}$ iv. $x 2$.

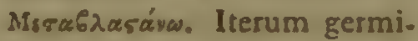

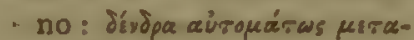

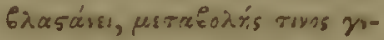

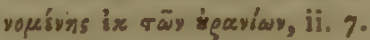
Mıraysıryáy. Julius mensis.

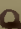




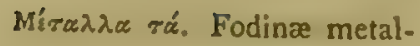
lica, ix. 13.

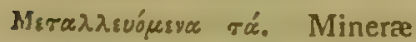
cruda ; "Ores." De C. PI. vi.

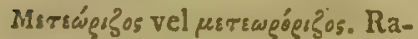
dicibus horizontalibus, iv. 2.

Mıréwosos. Superficialis; de radicibus, iii. $\mathbf{1}$.

Mírgor oi. Mensuræ ligneæ, vel fictiles ad metriendum aliquando ex cortice Tiliz, v. 7 .

Mทдırósı. Subflavus, iii. II.

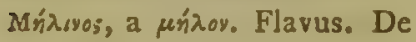
colore mali maturi.

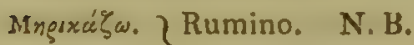

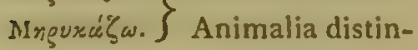

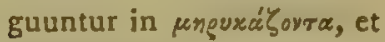

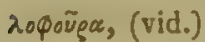

Mŕrę. I. Medulla, pars cava, vasculosa in truncis et

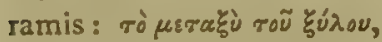
ręrà åtrò Qroíav, i. 3. 2. Interior pars trunci in adultis, aliter xagdía, в́yxágঠıy, iทrepióyr. N. B. Evanescit

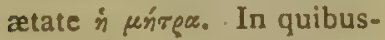
dam, ut observat Theoph.

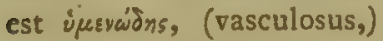

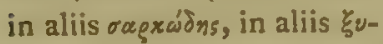

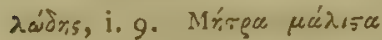

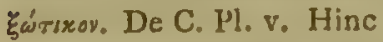
cel.Linn. in Amcnit. "vita "plantarum in substantia "medullari consistit;" fors. in junioribus: sed de hoc inquirendum.

Mirús. Morbus in Fabis, Pisis, \&zc. Forsan Puccinea, Phaseolorum Hedw. fil. Fungus ined, t. 19. vel Uredo, appendiculata var. $\beta$. Persoon, Syn. 222. N. B. Fun. gi hi minutissimi folia et plantas totas quandoque cooperiunt crusta aurei coloris, unde nomen forsan a fabula inditum.

Msxporéryos. Per contract. a rug̣̀̀y, nucleo parvo. De C. Pl. i.

Mióxos. x. Petiolus, Bot.p. \&

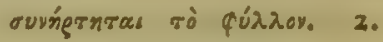
Ligonis spec. fors. tridens

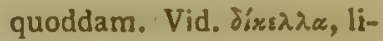
go bidentata, "6 a fork."

Mód uyous. Tarda concoctio. De C. Pl. iv.

Moyaxoũ. Uno in loco, ix. 10. Movóxwdos. Simplex, Bot. non lobatus, de folio, ix. 20.

Movódoros. Tunica simplici. Vid. толи́длото5. De structura interna ligni et radicum, \&z. i. 7 .

Movó̌̆os. De cursu venarum in ligno; "the grain。" N. B. Haud facile intelligendus sensus auctoris respectu xrydovvay in ligno; (vid.)

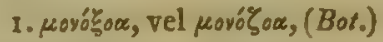

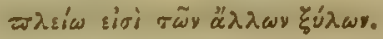

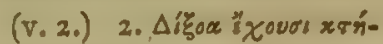

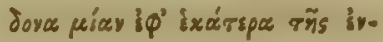




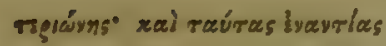

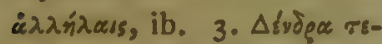

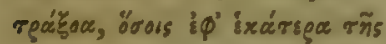

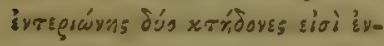

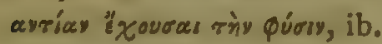
N. B. Lign. Pinûs exemplum prabet posterioris, ex singulari modo crescendi, sc. quatuor ramis horizontalibus; hinc xrydóvay, vel cursuum venarum in ligno dispositio.

Movóppos?og tỹ שaxsiá, Radix fusiformis, Bot. vi. $\%$.

Movóspoøos. Rota simplici; $\mu 0$.

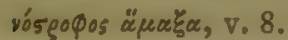

Movoధuńs. Homogeneus.

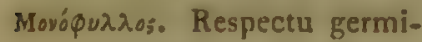
nationis seminum; Monocotyledonus, Bot. viii. 2.

Movóxpess. Unicolor, i. 21 .

Mopфŕ. Habitus pl, Bot.

Moơ Хúperre rå. Surculi: opp. furiv́uar, plantis ex semine. De C. PI. vi.

Mooxsúw. Propago per surculos. I. Simpl. " to plant " curttings or suckers." 2. Mooxtútay vel areoreorzsúus

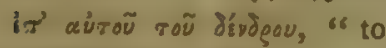
"graff," $\mathrm{i}$. $\%$. et $p$.

Novesiov. Area arb. consita porticu adjacenti. $\Lambda \pi$ Academi inst. Athen. N. B. Populus vento obruta in Movoríw Stagyris sponte surrexit, iv. I6.

Móx Snọos. Met. sterilis; $\gamma \tilde{n}$ $\mu_{0}^{\prime} x$ จุ

Múrns. Fungus. Agaricus.

Mv v̌suidns. Pituitaceus, Theod. viscidus; iii. 13.

Muóxờor. Rectius Muódoxos. I. Cavitates murium. 2. Terebrellum, "a gimlet ;" cujus actio denotatur jic̀ rò

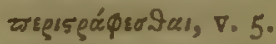

Muęxúdns. Mugeirn, Cat, iii. 7.

Mupiórsous? .Leg. áurevéárous, de Triangulo inæqquilaterali. Opp. iastadsaíe. De C. PI. vi.

Mugis. Vas unguentarium : "a perfume pot."

Múpper. Myrrha, Pharm. Jaxpù $\Sigma$ «úgøns, Cat. vii. 7 .

Mugrór. Bacca Mysti, iv. 4.

N.

Naīov. Unguenti pretiosi spec. ix. 7 .

Napúrzios. Fontinalis. Vid. Nauarixios. $\}$ per contractionem parraĩos, supr. N. B.

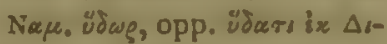
is, "rain water," viii. 7. Náèos. Ung. Vid. Nágicos, Tab. Syst. p. 22. "spike"nard," ib. N. B. Andropogon Schonanthus L. accurate delineatur ef describitur in opere egregio apud Gallos "Jardin de Cels" dicto, Tab. 89.

Q 2 


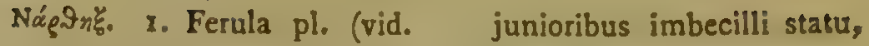
Syst.) 2. Internodium caulinum. N. B. Tò̀ roù̀̀y vóéInros, vice phialæ apud antiquos in usu, ix. 16.

Néépraplos. Forsan Nóorxaplos. Cortex externus nucis Mos. chatæ: Angl. " mace."

Nágrn. Forsan præparatio diversa váę̧y, supr. N. B. Separatim enumeratur in Cat. ix. 7 .

Nix́c. De actione novandi agros : " to fallow."

Nuós. Wovale. Neòs "áx érvos" Nsióv. $\}$ y\&sòs Xsurégesvos, viii. 6 , 7.

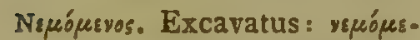
ye $" \lambda x \eta$, ulcera profunda, inveterata, ix. 12.

Nsódsgos. Recens excoriatus, ix. 15 . met. de cortice in arboribus.

Níos pro "'vos. Ejusdem anni, i. 23 .

Nìยุóxauros. Caule striato, vi. I.

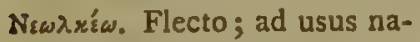
vales, $\mathrm{ib}$.

Nsádxsse rá. Ligna navium curvata ad proram, \&cc ? v. I.

Niwre. Eis vilara, in annum proximum.

Nทंтsyàs ró. Papaveris somniferi succus : fabulosa narratio, ix. I5.

Nýrsog. I. Metaph. de plantis

Nทัбos $\pi \lambda$ ○ó́dsร. Fluitantes. Frequens mentio in lacubus et fluviis. L. Orchomeni, ix. 13.

Nirgov. Sal nitrum: singularis usus ejus ad edulcorandos Raphanos. De C. PI. iii.

Nósıpos. Gustu dulcis, a yoรós. Phav. orípuara sixy

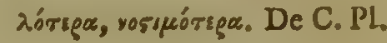
iv.

Nơí ท́. 1. Humor roridus. 2. Glans in basi folii Smilacis, vii. 13.

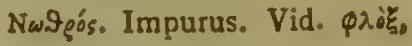
v. 9 .

3.

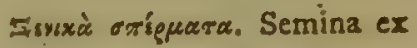
alia regione: opp. roís î. xwęioss, viii. 8.

Gúrov. Pars solida trunci et ramorum, constans ex par-

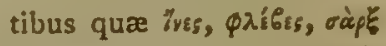
vocantur. (vid.) N:B. इú$\lambda \propto$ antiquitus in Típex xat

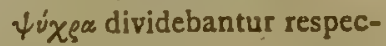
tu usûs in ซugsiars. Đúra T'̨̧́⿻大 frictione, calida evadunt, et hebetant aciem telorum; hujus generis Kir-

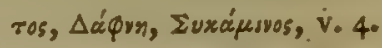

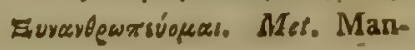


suefactus sum, de plantis cultura amelioratis. De C. P1. i.

Zuvisńxws. Compressus, vi. 2. Eupós? An error pro żngós?

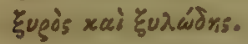

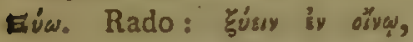
"scraping a root into "wine," ix. Iz.

o.

"O yxos. I. Tumor. 2. Pericarpium globosum rosæ, i. 22. "Oร̌s. Nodus in arbore, ubi ramus oritur.- N. B. Fibræ ("vos) ibi deflectuntur, et in orbem circumferuntur:

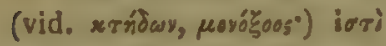
yà

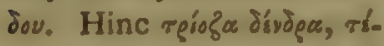

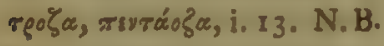
"Oל० præcipue conspiciuntur in Pinu et Abiete L.

Oixsios. Conveniens, modera. tus, consentaneus.

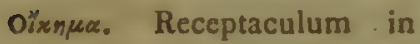
Compositis, Bot. De C. Pl. iv.

Oîvegor. Vitis folium, ix. 16 .

Oivos. Vinum. N. B. Potestates variæ in diversis vini generibus. Oìns ä́yovos, (sterilitatatem inducens,) ix. I2. o\%-

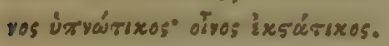
N. B. Vini usus ad arcendos vermes ex seminibus.
De C. PI. iii.

Oiváôns. I. Purpureo-ruber respectu coloris; ìygaria oi-

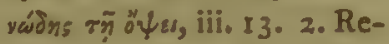
spectu saporis, $\chi u \lambda$ oi oivá-

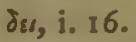

Oivoxgás. ? Id. N. B. Lignum

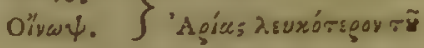

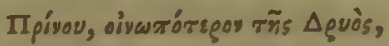
" darker coloured," iii. 16.

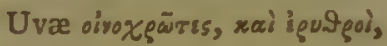
ix. 3 .

'Odíbavav. Fructus vel gummi -01,6ávev. Vid. Tab. Syst. p.

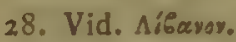

'Oxıróyovos. Parcius fructificans, $p$.

'Orsyóxoos. Parcius fructum

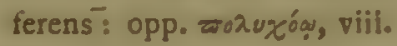
4.

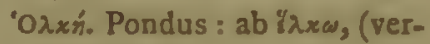
go,) ix. 17.

'Oдxòy ró. Vis attractiva, ab

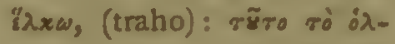
xò รทั่s тpópns. De C. Pl. iv.

"oxpos. Mortarium : xóтroyrss iv " $\lambda \mu \alpha$, " pounding in " a mortar," ix. 16.

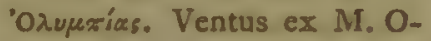
lympo, iv. 17. Vid. raṽaros.

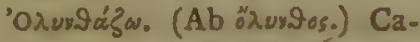
prifico. N. B. Caprificationis methodus, et notitia sexus plantarum Theo. phrasto cognitæ. Investigatione instiruta de influ. 
entia aëris respectu fructificationis, de C. Pl. ii. Ita

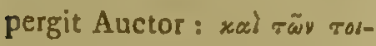

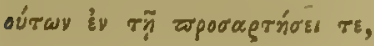

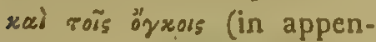
dice florali et pericarpiis) in airice (causa vel modus

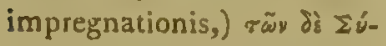

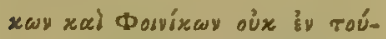

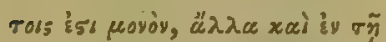

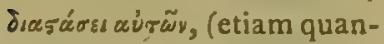
do arbores ipsæ situ sepa-

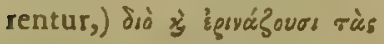

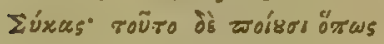
of $\Psi$ ทัขย (Cynips Psenes) of

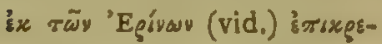

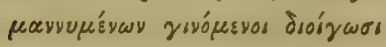

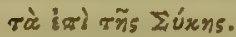

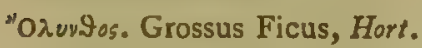
Forsan fructus mas, vid. Linn. i,'r6. iii. 9 .

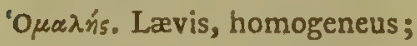
texturæ simplicis ; opp. $\lambda_{\varepsilon-}$ rvęéds, tunicato, viii. 9 .

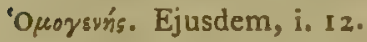

'Oposoyevńs. Similis generis. Vid. $\gamma^{\text {śvos. }}$

'Oposoxpians. De spica hordeacea aristata? ib.

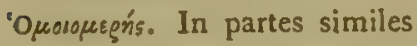
divisibilis, ut aqua, \&cc. N. B. Opp. ג̇vopeosнígr, ut truncus arboris in corticem, lignum, fibras, succum, i. 2.

'Okoíángos. De spica triticea mutica? Bot. viii. I.

Opós‘xos. Serie simplici: vid.
Jisuxos, \&c. De C. Pl. vi.

'Opழaxáóns. Color griseo-purpureus: hinc bacca Sambuci, nigri, L. ita vocatur, iii. 12. quando rséxá $\{\%$

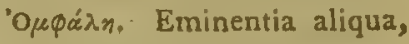
vel punctum, iii. 8.

' $0 \mu \varphi \dot{x} \xi$. Succus uvæ inspissatus.

'Opcarveía. Synonymia.

'Opáyupes. Synonymus, Boto vii. 14. id. Spec. ejus generis, ix. 16.

'OĔivms ỗvas. Vinum acetatum, vel acetum ex vino, ix. I 5 . 'ož́́baqov. Acetabulum, mensura, ix. I2.

"Oov. "תov. $\}$ Fructus Sorbi, ii. 3.

"O folii, iii. 16 .

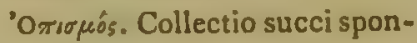
te fluentis : opp. $\chi^{\nu \lambda s \sigma \mu \bar{y}}$, succo expresso. vid.

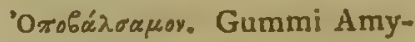
ridis, Giliadensis, L. Vid. Tab. Syst.

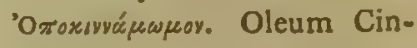
namomi, iv.

'Orós. Succus sponte fluens: opp. $\chi u \lambda \tilde{y}$, succo expresso. N. B. "Отos coagulatus aliquando Sáxpeov vocatur, i. 3.

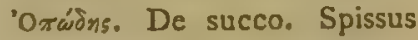
densus, ut lac. Opp. Jaxৎuẃds concreto, ix. I.

"Ogravas rá. Instrumenta fa- 
brilia. Opp. ซxเย́s๘, utensilibus, $\nabla .7$.

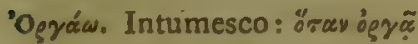

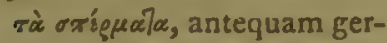

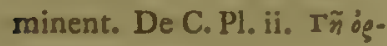

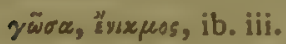

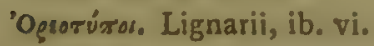

'Ogtós. Perpendicularis de angulis rectis, opp. चrargin, v. 6.

'Oęoquins. De trunco erecto arboris, $\mathrm{i}_{2} \%$.

'Oe'šs. Definio.

'O९िú́. Excitatio, tendentia : opp. $\tau \tilde{y} \varphi$ Q ópa, respectu odorum. De C. Pl. vi.

"Op̧visss. AEtate progrediente dissimiles sibi, plumarum colore mutato. De C. Pl. v.

'Ocobóv. Fructus 'O ģócov, Cat. iii. 12.

"Ogos. Z 1. Serum lactis, "Oppos. $\}$ "whey." 2. Serum sanguinis. 3. Succus tenuis, serosus, iii. 10. ix. 2. In pice, iii. 8 .

'Oppádrns. Serosus.

'Ogǔ̌́v. Semen 'Ogú̧̌ov, Cat.

"Oৎxos. Ordo plantandi xar "exous, "in rows," iv. 5 . Hinc "Oexaras, plantatio rectilinearis, "orchard."

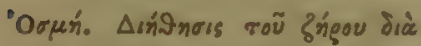
roũ ü Yge. De C. Pl.vi. Ubi subtilis admodum Demetrii l'hilosophi occurrit disquisitio de differentiis odo. rum ex forma particula. rum.

"Orragra rá. Legumina. An idera ac Xíşora? vid.

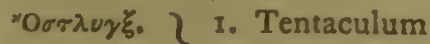

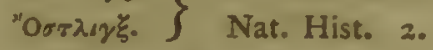
Cirshus, Bot.

"Osтраха га́. Ollæ fictiles.

Or̃nos. 1. Crispus, cirrhatus; de coma capitis apud Afros. 2. Fibrarum distorsiones in

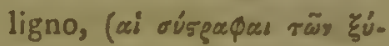

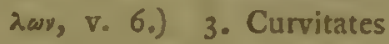
ramorum, iii. 1\%. 4. De rugoso Brassicæ folio. (Vid. póç̣avos, Tab. Syst. p. 15.)

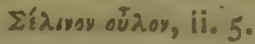

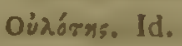

Oúgov. Usus urinæ respectu Amygdalorum. De. C. Pl. iii.

Oüov, Vid. "Oov.

'OpParpós. Gemma, Bot.

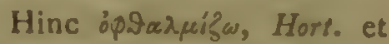

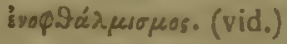

'oxsrós. Canales ad cymbas transportandas, vel ad agros irrigandos.

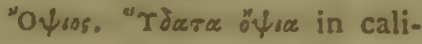
dis regionibus, "Tropical "rains"

$\pi$.

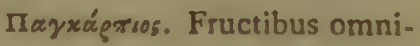
genis farctus. $\Pi a \gamma x_{0} \mu \varepsilon \lambda_{l} \tau_{-}$

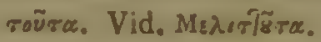

Q 4 
Táyor ai. Frigora glacialia, iv. 17.

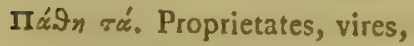
respectu plantarum; sic apud Virg. "Scire potesta" tes herbarum," i. 1. viii. 4.

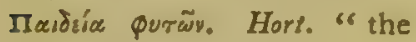
" training of trees."

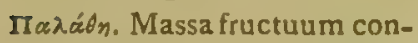
ditorum, precipue Ficuum; hoc modo facta;

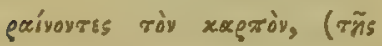

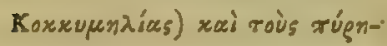

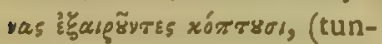

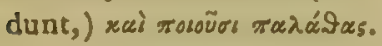
Angl. "Marmalade," iv. 3.

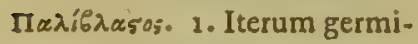
תans: de germ. autumnali, "the autumn shoots,"

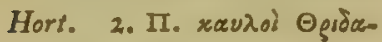
xivns, post sectionem.

Iarínosos. Reciprocus; sibi invicem succedens.

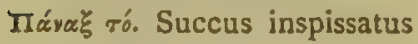
Mayaxsias.

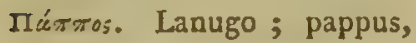
Bot.

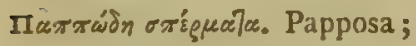
pappo coronata, Bor. vi. 4 .

IIáxugou oi. Caules Papyri præparati ad scribendum, iv. 9.

$\Pi \propto \rho \alpha 6 \lambda \alpha \alpha^{\alpha} \nu \omega$. Germino ex radice: $i$. e. "by the side of "the trunk." "To pro. "duce, or grow out."

Iragabrasixós. Emittens sur- culos, i. 9 .

Паһúbraros. Ut surculus ex radice: Ang. " a sucker," i. 9. vii. 2 .

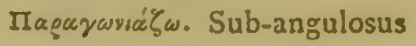
fio. Vid. Tavía, i. 16.

Magúburos. Apud Orientes. Septa spatiosa arboribus consita, feris omnigenis servandis. Vid.descr. v. 9. ix. 6.

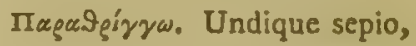
iii. 17 .

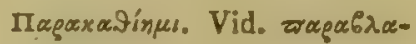
รณ́vw, viii. 2.

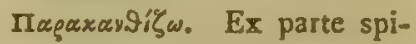
nosus sum: vel forsan spinulis, ex margine vel rachi folii, i. 17 .

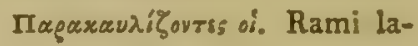
terales, vi. 2.

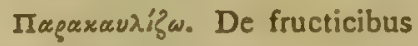
ab imo caulescentibus : opp.

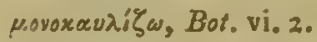

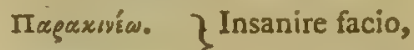

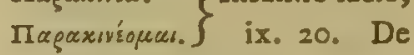
ligno, contorto, v. 6.

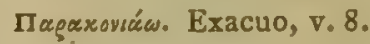

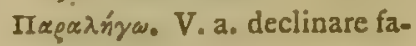
cio, vi. 6.

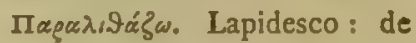
concretione in fructu Pyri, iii. 10.

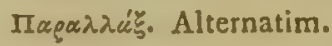

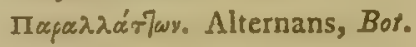

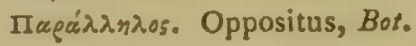
IIxperv'ś. Successive floreo, vii. 10. 


\section{GLOSSARIUM THEOPHRASTI.}

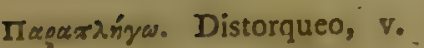

3.

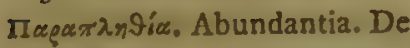

C. Pl. iii.

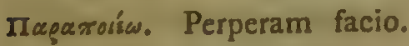
De C. Pl. iii.

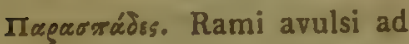
propagandum : "sets." $\mathrm{N}$.

B. Rami abscissi apud nos vocantur "cuttings," ii. 2 . iii. 2 .

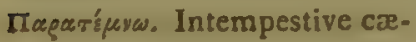
do, vi. 3 .

Iregạinpes. Emitto juxta, vii. 5.

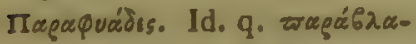
501.

חараффúa. Pullulo eodem tempore; vel act. emitto radices, surculos, \&zc. vii. z.

Maginpe, Debilitor. De C. Pl. iii.

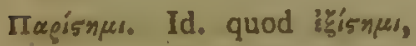
de vino. De C. Pl. vi. "s to "turn sour." Oi $\lambda$ เ Jai orvas

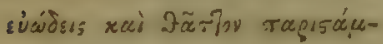
esvar, ib.

$\Pi$ חápujpos. Juxta aquas cres. cens : z้vedess, in aquis, iv. 13.

$\Pi$ İ́wos.s. Intempestivus.

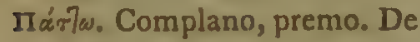
C. Pl. vi. Calco pedibus. Hinc

חáros. Via calcata, vel potius conculcatio. Angl. voce fere retenta, "a path," vi. 6 .
Márтaros. Paxillum : " a " peg." ח. oíngos, ii. 3 .

Iręáivw. Perforo, ii. 9 .

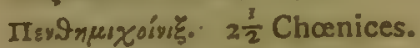
Vid. Xoĩs है. Vid. not. viii. 8.

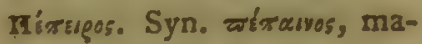
turus. De C. Pl. iii.

İpıáry. Circumago. Forsan pro चs graıgw, vii. 5 .

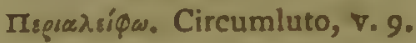

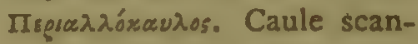
dente, Bor. viii. 8.

חigiárifo. Collo suspendo, ut amuletum, ix. 21.

Iigubodpésezvos. Hort. "trench. "s ed round." De C. PI. v.

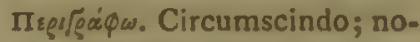
tas circum incido, ix. 9 .

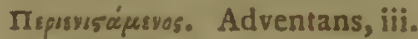
6.

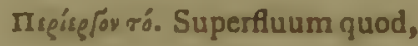
ii. $x$.

Irgsxalaigw. Hort. vid. ses Iaígs.

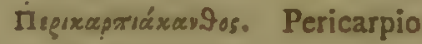
spinoso, vi. 5 .

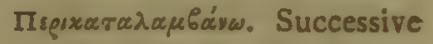
fero. Succedo, iii. 15 .

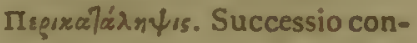
tinuata florum vel fructuuin.

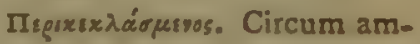
plexus, iv. $\%$

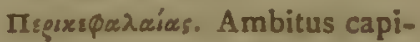
tis ; mensura, iii. 13 .

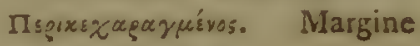
serrato, iii. I4. 
Mę̧iropes. Frondosus valde, iii.

İeppńrpesos. De ligno. Vid.

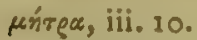

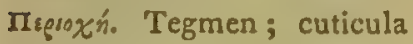
pericarpii, Bot. De C. Pl。 i.

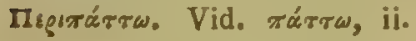
8.

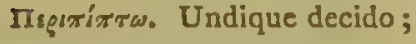
de cortice Arbuti, i. 8.

IIspirves. "An eddy of wind," V. 2 .

Mręеяуийesvos. Circumlaceratus, iii. 15.

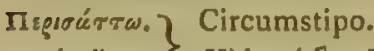

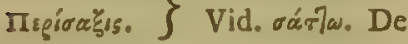
C. P1.v.

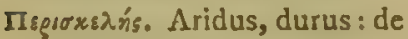

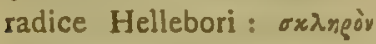

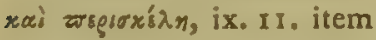
de vento, Angl. "a dry "parching wind." De C. Pl. ii. a $\sigma x^{\prime} \lambda \lambda \omega \omega$, exsicco.

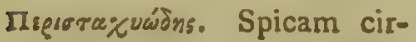
cumdans, v. 3 .

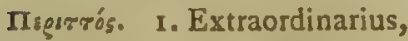
excellens, iii. 4. ix. 7. 2 .

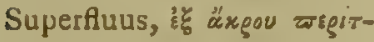
zòs, de folio pinnato, extremo impari, Bot, iii. 15.

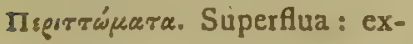
crementa. N. B. Animalia

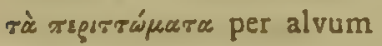
ejiciunt, non tamen plan-

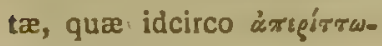
รol, i. 4 .

Ireppépa. Sustineo: de viri- bus stomachi ad digeren. dum, ix. 13.

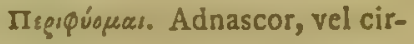
cumnascor, vo 3.

Ispíuris. Quod circum crescit, v. 3 .

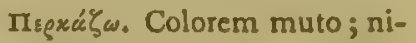
gresco, ii. 8.

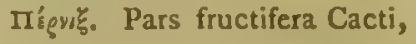
opuntia, L. vi. 4.

חвpurivós. Prioris anni; de fructu. \& xagròs (Juniperi)

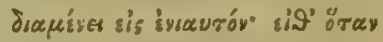

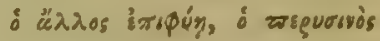

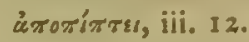

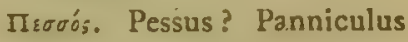
convolutus. Pharm. "a "pledget," ix. 21. " a tent "for a wound," ix. 22.

Míracos oi. Folia Ari, colocasic, ex similitudine galeri, iv. 10.

IÍpux os ró. Quod naturæ consentaneum est, iii. 9.

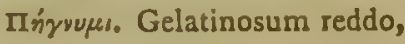
ix. 20.

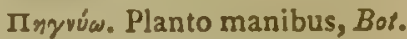
vii. I.

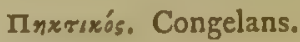

Irqvía. Fusus : "spindle." fors. ex voc. Græc, vii. 3.

Пก๊้ร. 1. Concretio gummo-

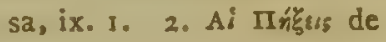
tempore pruinoso.

Пй arboribus, "a blight," iv. 16. 
Iusǻryas. 7 Anginæ pecto-

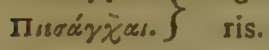

Iíryols. Constipatio. De C. Pl. ii.

חĩนos ท่. I. Folium Colocasiæ. Vid. Míraros.

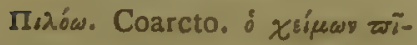
$\lambda_{01}$ xaì xáęriyos (vid.) та̀s piscus. De C. Pl. iii. 4.

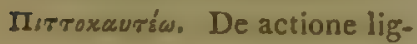
na Abietina comburendi ad extrahendanı picem. Vid. descr. ix. 2.

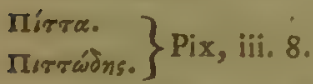

חıтúa. Coagulum, gelatina. Фwrys $\pi$. "Calves' Jelly."

Irayióraegros. Fructu laterali, i. 22. vii. 3 .

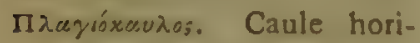
zontali: opp. ¿̨saoxaúdy, viii. 3 .

חraxovyráḋns. Placentaceus, iv.

In $\lambda$ axwónns. Schistosus. Geo-

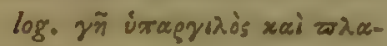
réôns, ix. 4 .

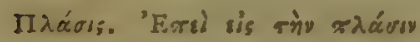

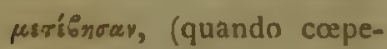
runt fistulas formare, ) oiv $\pi \dot{\alpha} \alpha \mu \alpha \pi r$, iv. 12.

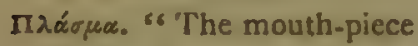

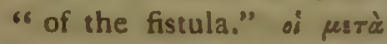
$\pi \lambda \dot{\alpha} \sigma \mu x \tau$ os aủ̉ovres. Vid. etiam

$\Pi \lambda\}^{\prime} \mu_{\mu}$. Opus plicatile? viminium? iv. 2.

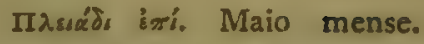

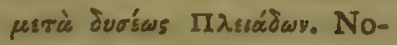
vembri mense.

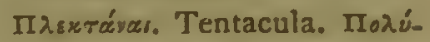

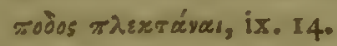

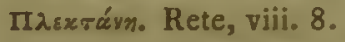

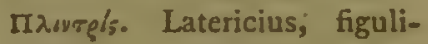

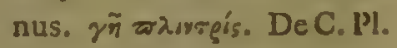
iii.

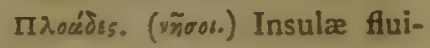
tantes, iv. II.

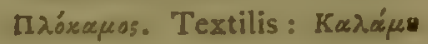
spec. iv. 11.

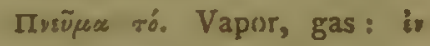

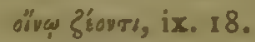

గrígท тx́. Calores æstivi, ix. 5.

חóo. 1. Pars herbacea plantæ, ix. 16. 2. Vires vel

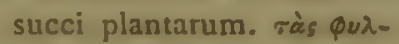

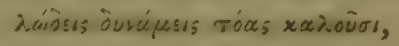
ix. 8 .

Пocorpós. Sarculatio; actus averruncandi : "weeding." De C. Pl. iii. Vid. oxádsois.

חIodvía rá. Cothurni agrestes. Impilia Plin.

Mojicios. Vid. irotrodiaños.

חosxíros. Variegatus. Bot.

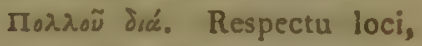
longo intervallo.

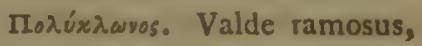
vi. 2.

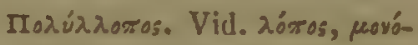
2oros, iv. 9. viii. 4. De glumis spicæ. 


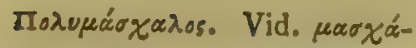
$\lambda_{n}$, iii. 17 ramosus valde.

Moגúvorros. Focundus valde, viii. 8.

IIorúxoos. Id. De C. Pl, ii.

חоy์́w. Marcesco, debilis sum.

Mógos oi. Venæ, canales; tubuli, i. I6.

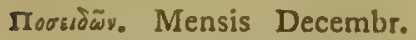
iii. 17.

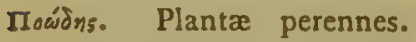
N. B. Divisio plantarum $4^{\text {ta, vi. I. }}$

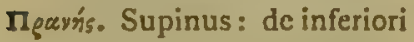
folii superficie: opp. $\tau \tilde{u} \dot{u} x-$ ries, i. $14, \mathrm{~s} 6$.

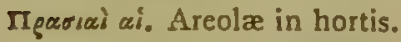

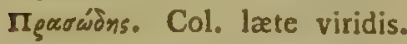

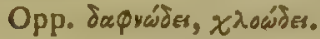

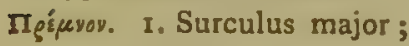
stipes, ii. I. 2. Morbus, seu intumescentia in ramo, $i$. 13.

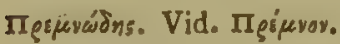

Méryvos. Vid. II pivos, Cat.

II grovádns. Serratus, Bot. iii. 14. ut fol. Pin. Abietis, i. 13 .

I pírss. Actio serræ, $\nabla .6$.

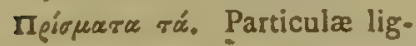
neæ ex serratura: "saw"dust," v. 8.

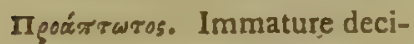

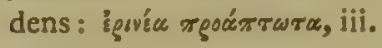
5.

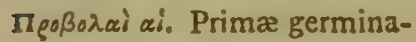
tiones, De C. Pl. v.
Ipodpopexi ai. Fructus præcox Ficûs.

Igosogia. Ante edo.

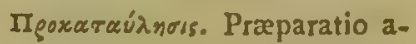
rundinum ad fistulas faciendas.

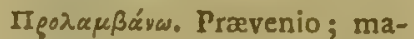

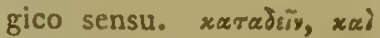

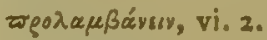

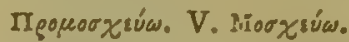

$\Pi_{\text {çoór }} \omega$. Applico remedium, ix. 13.

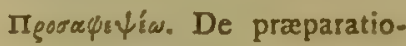
ne culinaria : -

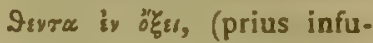
sa et cocta in aceto,) vii. It.

Mporysios. Litteralis, iii. $\%$.

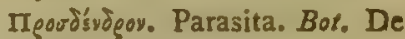
C. Pl. ii.

İoodixopes. Admitto ad cibum.

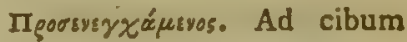
sumptus, ix. 15 .

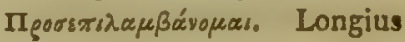
tempus requiro, viii. 3 .

Iporývipos. Vento expositus, iii. 3 .

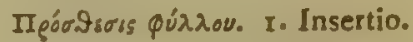
2. Incrementum. 3. Receptaculum, Bot. vii. I2. Vid. IIpóopuors.

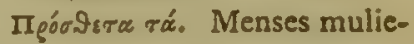
bres, ix. 10.

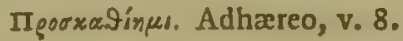

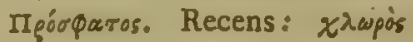

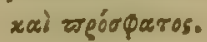


Ifporфogà xará. De cibo idoneo ad sumendum. De C.

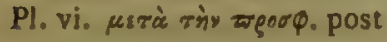
esum, vii. 9 .

Ị̇́rópogos. Conveniens, ii. 7. viii. 6.

ח९́óquors. 1. Insertio, i. 16, 18. 2. Adhæsio, viii. 2, 9. 3. Receptaculum in compositis, Bot. vii. I3.

Mporxárvups. Aggerem struo, v. 8 .

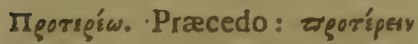

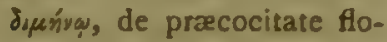
rum in Egypto, vi.7.

Ipórgera. Adv. tertio. De C. Pl. iii.

ח gowatopas. Sursum impello, iii. 7 .

İ gów p̧os. Præcox, vii. I2.

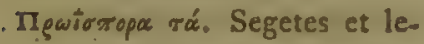
gumina quae primo vere se. runtur, viii. $I$.

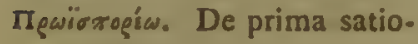
ne. Vid. "A poros.

İৎ̄̄ga. Bot. Ima pars rami, \&c. ii. I.

Iripvǐ. Caulis Cacti, opuntic, L.? vel potius Cardui species.

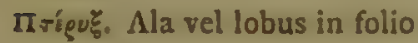
pinnato, iii. ro.

חrţádns. Pinnatus, Bot. ii.

Rríra. 1. Tundo. 2. Decortico, ii. 5. 3. Pinso, ii. Scaliger.

חropจáxayฎos. Kamis spino. sis, vi. $\mathrm{x}$.
Пúa. Lac primum, quod densum et grumosum est: hinc humores spissi, expressi, ix. 9 .

חuaysqiáy. Octobris m.

חuyúv. Cubitus; mensura, iv. 6.

$\Pi$ กินท์ข. Corona radicis fusiformis, Bot. iv. 12: ix. 13 . IIvxvós. De ligno; solidus, densus: opp. parä. vid.

Iugsia. \} I. Instrumentum

II upsiov. $\}$ igni accendendo vi frictionis: partes sunt, $x$. xapo, (lignum planum cum fovea in medio ;) 2. чgúrayoy, (terebra ; pistillum obtusum ex ligno duro,) $v$. 10. N. B. Mos adhuc obtinet in India occidentali. 2. Camini.

IITPHN, 1. Bacca, vel drupa, Bor. 2. Nucleus in medio lapilli, vel calculi. 3. Granum in baccis.

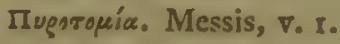

Mugiów. Torreo: igni coquo.

Iúpowors (a Mugós.) 1. Panificilim. De C. Pl. iv. 2. A IIüg, combustio ad carbonem igniarium, v. 9 .

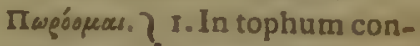
Mágwars. $\int$ vertor: de cortice arboris, iv. 18. 2. Combustio ad carbonandum, $v$. 9. 3. Coctio per ignem, vii. 8 . 
p.

'Pábjos oi. Venæe minerales, pábjor $\mu s \tau \alpha ́ \lambda \lambda \omega \omega \nu$.

'Páldos Фaryixos. Spatha, Bot. ii. 8.

'Paxádns.\} A ’̊à乡, uva: de 'Payádins. $\}$ fructu Mandragoræ, vi. 3. De cellulis mali Punici. De C. Pl.v. 5 .

'Pá́̆. I. Uva. 2. Acinus uvæ.

'Paxiov. Dim. a paxós, pannus lacerus, iii. 9 .

'Páxis. Rachis, Bot. 1. Nervus intermedius folii. 2. Pedunculi continuatio, iii. 8.

'Psìy ró. Morbus vitis, ex nimio succo.

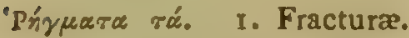
Med. vii. 11. ix. 20. 2. Hernia, morbus.

'Pnтínn. $)$ Propr. Terebinthina "Puriyn: $\}$ fluido statu: hinc vox Angl. " resin," de concreto, iii. I5. iv. 18.

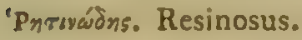

'piçias. Succus e radice Silphii, (vid. sír $\varphi_{6} y_{9}$ ) ix. 2. 'PiY̧iov, a písa. Radicula, iv. 2.

'Pi Gotopíx. Anni tempus herborisando proprium, ix. 8 .

'PıLorópes. Herbarius, iv. 5.

'Pı'sopuńs. Pl. ex surculo propaga: орp. бrequeфúss.

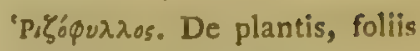
radicalibus, Bot. vii. IO.

'Poćés ai. Grana vel semina Mali Punici, iv. 11.

'poós. Yorbus vitis. Syn. $\approx \tilde{8}$ "Poscés. $\}$ ṕriv: "couleur" Fr. De C. PI, ii. 8.v.

'Podwvice. I. Rosa planta. 2. Rosetum, ii. 2.

'Poö oi. Profluvia alvi. Diar. rhcea, ix. 2.

'Poóv. Fructus 'Poiãs. Cat.

'Ретŕ. I. Inclinatio, propensio, iv. 4. 2. Vis insita. De C. Pl. iv.

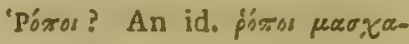

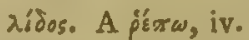

¿Poũs ท่. 1. Succus fruticis. 'Póos, (vid. Tab. Systo) in. spissatus, iii. 18. iv. 15. 2. Roratio, Plin. morbus?

'Powions. Irriguus, ỹ̃ powiôns. De C. Pl. iii.

'Puтrıxós. Alustergens. De C. Pl. v.

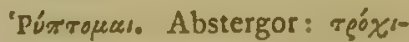

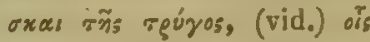

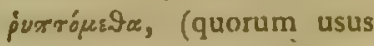
in abstergendis sordibus, ut hodie saponis, ix. 10.

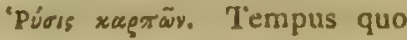
fructus decidunt, iv. 16 .

'Puтòy v̇uep. Aquia rivularis : occurrunt etiam 2. ข้ ע. ขee-

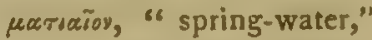

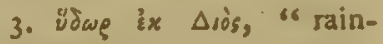
"water," ii. 3. 
$\Sigma$

Eaxri̧óprvar. In sacco, vel utri servatus : ôvos carxilóa

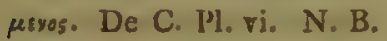
"Afxor mentio fit vinis servandis apud Homerum, Il. T. 247. item apud Herod. lib. ii.c. 121. sæpius apud LXX. in V.T. etiam in N. T. Matth. ix, 17. Luc. v. 37,38 .

Earidis. Asses: tabella ligneae, " 6 lanks," v. 6.

¿ápuer rá. Caules vel surculi roũ $\Sigma \alpha \dot{\rho} \beta$, Cat.

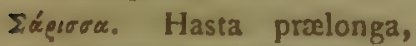
Macedonica. N. B. Altitudo Corni, famine, L.com-

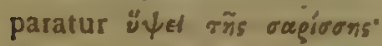

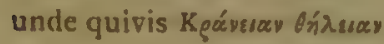
statu naturali investigans longitudinem celebris istius teli assequetur.

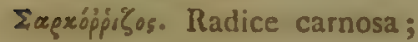
distinctio inter plantas, vii. 11.

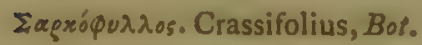
" Plantes grasses," Gall.

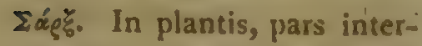
media inter "vas et pribas. (vid.) Constat laminulis flexilibus in cellulas orbiculares vel ovales dispositis, i.iv. Qui accuratiorem hujus rei velit scientiam, consulat Grewium, Mal: pighium, Duhamel. inter antiquos, et celeberr. hodiern. T. A. Knight. N. B. Caro fructús Citri Aurantii, monente illo, nudo oculo vascula exhibet, alibi ope Microscopii xgre conspicienda. Linn. c. 4. p. 24. Vid. etiam Hillium de structura ligni, 1. ii. c. 4 .

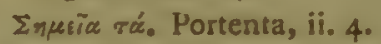

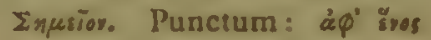
orpesion oi reírzes, iii. 28.

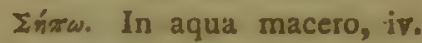
10.

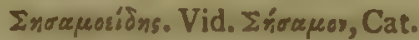
iii. II.

Irrávens. $\}$ Ex roce Dor. oá-

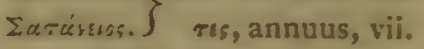
4. N. B. Apud Romanos vox synon. hornus, ab ho. ra.

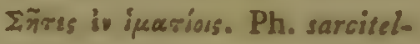
la, L.

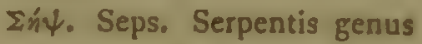
lethale. Diosc. ii. \%. Plin. $\mathrm{x} \times \mathrm{xii} .5$.

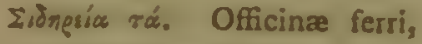
"Iron forges," v. 9.

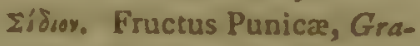
nati, L. etiam pericarpium pl. aquaticæ Nymphaæ affinis. De C. Pl. v.

Sixuov. Fruct. Sixúve, Cat.

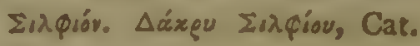
ix. 2.

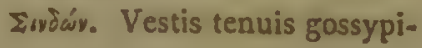


na, " muslin," æque ac lintea. N. B. Vox "eguy apud Theophr. gossypium æque ac lanam amplectitur. " $E$ -

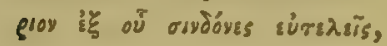

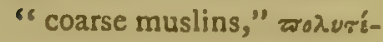
גsis, "fine muslins," (vid. 'Egroథópac, Tab. Syst. p. 15.) iv. 9 .

乏ivos. Detrimentum, injuria. De C. Pl. ii.

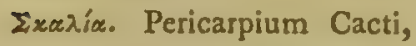
opuntice, L. De C. Pl.v.

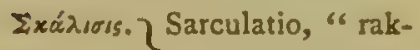

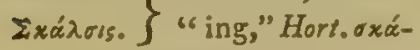

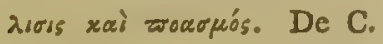
Pl. iii.

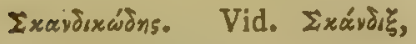
Tab. Syst. p. 9.

$\sum x a \pi \dot{v} v$. Fossio ope ligonis, "spading," ii. 8.

¿xıódıoy, Umbella, ix. 4.

$\sum x i ́ \lambda \lambda \alpha_{0}$ Bulbùs Scillæ, Cat. ii. $\%$.

Exivàos. Urinator, "a diver," iv. 6.

Exsppopossiúv. Maius m.

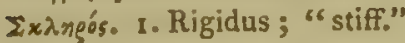

Opp. เủxá $\mu \pi \tau$ : dicitur de ligno Arbuti, iii. 10. ix. 4. 2. De qualitate vini annosi. Angl. "dry." De C. Pl. vi. 3. De fructu.

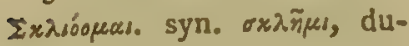
resco, i. ix.

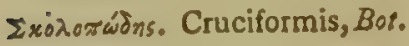

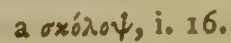

Exurádsov. Scutica: "a thong " "whip," iv. 5 .

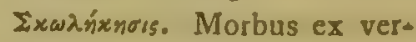
mibus, vi. 5 .

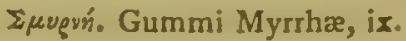
4.

$\Sigma \pi a^{9}$. Palmes fructui inserviens; Spatha, Bot. ii. 8.

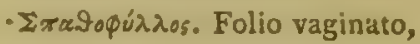
Bot. i. 16.

乏̇ávios. Parcius fructificans, p.

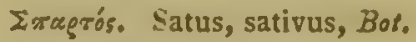
opp. árgis, vi. $\%$.

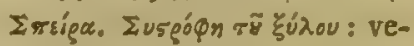
$n æ$ in ligno in orbem circumactre ad nodos, v. 3 .

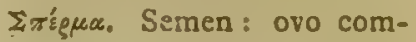

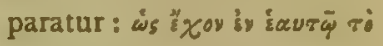

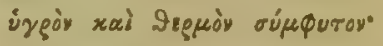

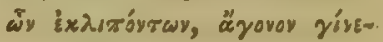
Tar, $i_{i}$ I 8 .

$\Sigma$ твреатлнео оi. Seminia.

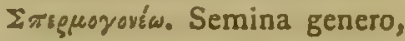
vii. 13 .

$\Sigma \pi i \lambda \alpha \dot{s}$, adj. $\gamma \tilde{\eta} \sigma \pi \Delta \lambda \dot{\alpha} s$, terra glareosa.

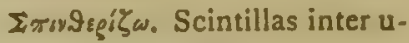
rendum emitto, iii. 10.

$\Sigma \pi \lambda$ yvai ai. Morbus lienum, ix. 20.

¿roygrús. Qui urinando colligit Spongias. 2. Urinator in genere, iii. 7 .

$\Sigma$ rodios. Cinereus de colore.

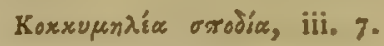

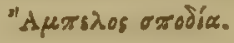




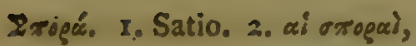
sementes.

Erognroi di. Sementes, vel "tempora serendi : Anglice, " seed-times," viii. 3 .

Xxópeses oi. Arva in genere, vi. 5 .

Ixópes oi. id. ii. 5 .

Exúgrs. Corbis, Calathus, ii. 8.

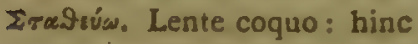
derivata forsan vox Angl. " to stew," vii. 12 .

Erapvioxos. Urceolus vinis servandis: oìvev íรapríapesyoy, ex verb. sapuíropasi. De C. Pl。ii。

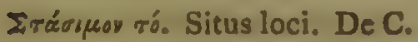
PI. v.

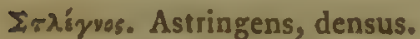
De C. Pl. vi.

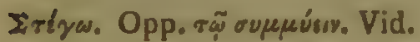
v. 5. .vi. 8 .

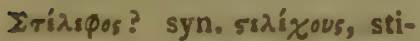
pes.

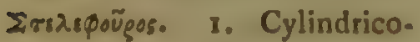
caudatus, ut Bos : opp. $\lambda_{0}$ Qoúes, cristæ-caudato, ut Equus. 2. De spica Phlei L. aliorumque, et thyrso Plantaginis, viì. 10.

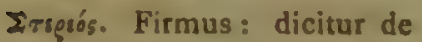
qualitate uvarum: Anglice, "firm, fleshy."

Eripiwex. Rostrum navis, cum ligneis firmamentis, ad imperum faciendum, vi. 8 .

Irspaivn, i. q. Erripayos. Irr-

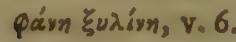

PARS IT.
Erspavwparzixós. De plantis

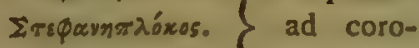

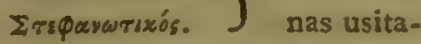
tis ; "garland flowers," vi. 7. et alibi.

$\Sigma \tau$ т́n 17.

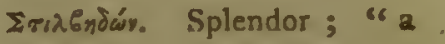
"glossy polish," vi. 5 .

$\Sigma \tau \lambda \iota r \gamma \dot{s}$ ? Spec. Tritici. N.B. In Catalogo Specierum inserenda. Vox Egyptiaca? viii. 4 .

¿roixtow. Ordinatim, vel in serie (รoix w) dispono, iii. 16.

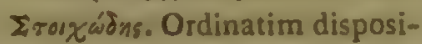
tus, ut in spica hordei, viii. 4.

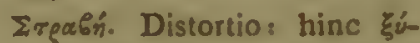

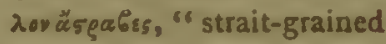
"timber," vi. 2.

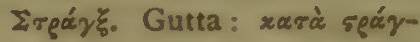
yo, guttatim, ix. 19.

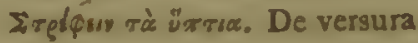
foliorum in quibusdam arboribus autumni tempore. Sæpius occurrit mentio apud Theophrastum : sic quoque M. T. Varro de Re Rustica, 1. i. c. 46. "Ad" miranda discrimina sune " naturalia, quod ex qui" busdam foliis, propter eo. "rum versuram, quod sit " anni tempus, dici possit, " ut Olea, et Populus alba, "et Salix."

İęsqvés. Strigosus, macilen-

$\mathbf{R}$ 
tus; hinc meraph. de ligno dicitur kúriov üspabes, splQvìv, vi، 2.

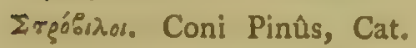
iii. 6 .

¿̧̇oryúros. Cylindricus, vi. 7. de ligno trunci non quadrato. Vid. Tiт̧е́yavov.

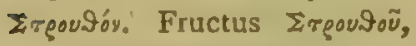
Dipsaci, Fullonum, L.

Srgóøry̌. Cardo: antiquitus ex ligno duro, vi. 7 .

İøuquós. Austero-acerbus, astringens: uva dicitur অpā-

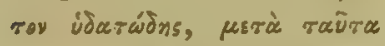

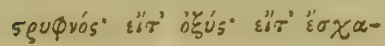
roy givxús. De C. Pl. vi.

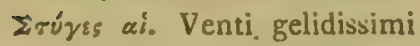
ex antris montium: aैs oủx Iร

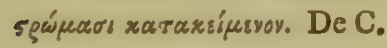
$\mathrm{Pl}$. $\mathrm{v}$.

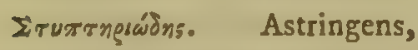
stypticus. De aquis aluminosis.

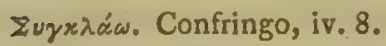

Iúyxorras. Judicium ex comparatione, iv. 14.

Zurxgoúw. Collido, iv. 8.

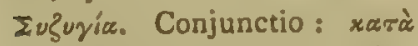
ous?uyiay, de paribus loborum folii pinnati ex opposito, Bot. Bii. 15 .

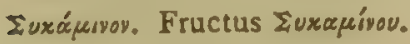

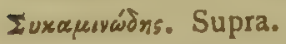

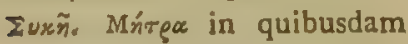
resiniferis. Vid. Ä̌ris, iii. 8.

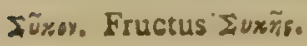

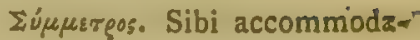
tus, gratus.

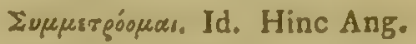
vox "symmetry."

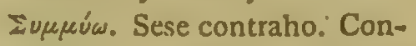

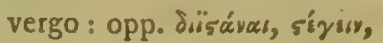
v. 4 .

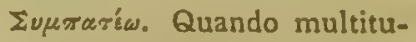
do vel exercitus coneulcat: opp. rararareñy, viii. $\%$

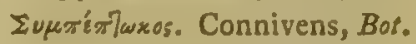

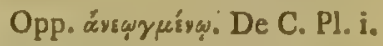

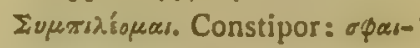

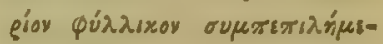

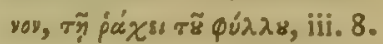

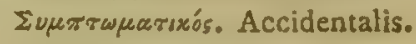

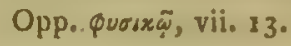

$\Sigma \dot{\nu} \mu \tau \omega \mu \alpha$. Accidens, $\mathbf{v} \cdot 6$.

¿úppurıs. Generatio novi ligni, ix. 1.

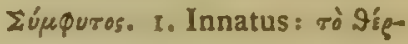

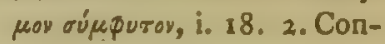
suetus, vulgaris : $\eta^{\circ} E \lambda \mu$ s

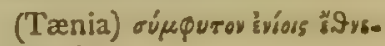
$\sigma i$, ix. 22.

suváyxus. Vallis continuaı. De C. Pl. ii.

Eurairía. Causa insuper. Vid. Airia, ix. 6.

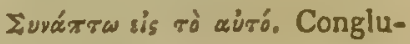
tino, ix. 19.

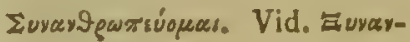

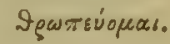

Euysxpaivw. Sensim spargo, iii. 13. vel effluere facio.

Evysxrsxós. Compactus. De C. Pl. iv.

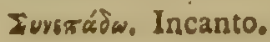


Xivrséṕw. Una tectum efficio: de tecto frondoso sylvæ, iii. 2. ab işi $\phi \omega$.

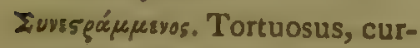
vatus, "warped," iii. 9 .

Eurixua. Continuatio, continuata successio, vi. \%.

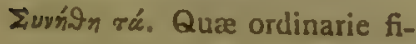
unt, ii. 4 .

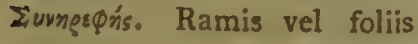
densis coopertus, instar tecti. Vid. auvę́s $\omega_{\text {. }}$

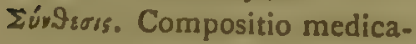
menti, ix. 16.

Iuvaráw. Comprimendo uni-

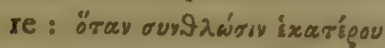

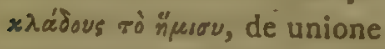
duorum surculorum post sectionem longitudinalem. De C. PI.

súvogos. Confinis, iii. 5 .

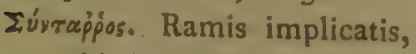
corbis in modum, vid. $r \alpha \dot{\alpha} p$ pos. De C. Pl。 iii.

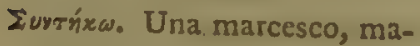
ceror. De C. PI, vi.

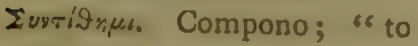
" make up a prescription," ix. I6.

Eveperits. In acervum congestus, undique attractus,

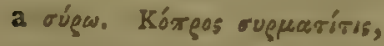
Quisquiliæ, Scal. ii. 8. vii. 5. "A compost dunghill."

- Zup̉poon jaxpucuions. Coagmentatio resinosa, iv. 6 . globulus gummosus.

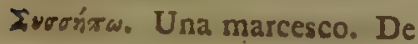

C. Pl. iii.

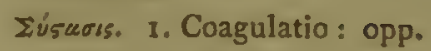

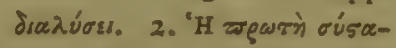
ots, embryon plantæ. De C. Pl. v.

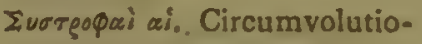

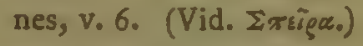

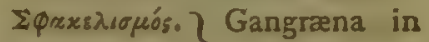
$\left.\Sigma \oint \alpha x^{\prime} \lambda \eta_{0}\right\}$ arboribus, iv. 16. prope radicem.

$\Sigma \varphi n x i o y . F a v u s$ Vesparum, iv. 10.

$\Sigma$ Qnyosid̀ns. Cuneiformis. De C. Pl, i.

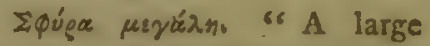
" wooden mallet," จ. 8 .

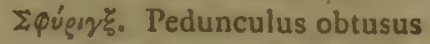
malleiformis? Bor. vii. 4 .

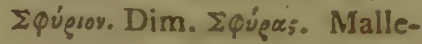
olus, v. 8. ¿qúuar plerumque ir Korivov: sc. ligno præeduro, ib.

Exioia. Navis tumultuarie facta ex lignis vel trabibus, " a raft." Mentio fit ox"-

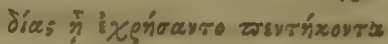
tsois, vi. 9 .

$\Sigma \chi^{\prime}$ i $\lambda$ yex. Pars navis juxta

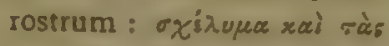
izwrióas, (vid.) v. 8. N. B. Theod. inter Testudines.

$\Sigma \chi \tilde{n} \mu \alpha_{*}$ Habitus plantæ, vii. 6 . $\Sigma \chi \eta \mu а т а \pi)$ otw. Nutas inuro, ix. 4.

$\Sigma x i \xi a \dot{\eta}_{0}$ "A billet of wood," ix. 3 . , X $_{\text {ivov. Fructus } \Sigma} \Sigma_{\text {Xivov, Cat. }}$ Exivis. Id.

I 2 


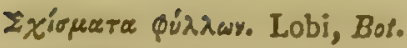
iii. Ir.

"zouvic ท่-Juncetum: "a bed " of rushes," iv. I3.

$\Sigma \tilde{\mu} \mu \alpha$. Respectu pl, totalitas partium, i. Ir.

Eaprérwors. Induratio humidi : reductio in solidum. De C. Pl. vi.

Swgós. Cumulus. Dicitur de acervo aromatum, ix. 4 .

\section{T.}

Táragos. 8. Calathus. 2. Vas figulinum? N. B. Antiqui semina Cucumeris, aliorumque id genus, iy $\tau \alpha-$ rágous (vasibus fictilibus, an corbibus?) durante hyeme, locis apricis, tectis, serebant: "garden-pots?" De C. Pl. v.

Tаривгоран. Reservo, in horreo colloco, ix. 2.

Taysia. Antenna navis, a roivw, " the yard of a ship " on which the sails are "spread," iv. I. Differt a xepoía, sed quomodo? An curvatura posterioris instar cornu? Ambo simul occurrunt, ib. Vid. Lex. Crispini, voc. таvĩa.

Tręresíe rá. Radiculæ vel fibrillæ caulinæ, Hederæ proprix. N. B. Succidia Gloss. ret. sed quare : an radices succedaneæ? Mallem scribere duplici $\varrho$, utpote ex rápippo derivatum.

Tappós. 1. Crates ex ligno textili, unde oúyrappós im. plicatus. N. B. Antiquitus occurrit vox ragrò̀s a rígow, quia casei superimpositi exsiccabantur. 2. Implicatio ramorum, vel fibrarum radicis, oủx ivox

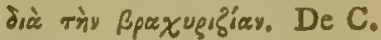
Pl. iii.

Tappóésns. Implicatus. "E

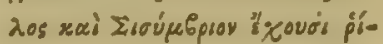

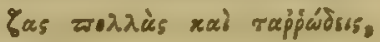
vi. 7 .

T'ísıos. Maturus, iii. 12. TElsopogis. Probe fructifico, viii. 8.

T'́ros. Perfectio ; iv rís.s yívioser. De C. Pl. vi.

T'śvw. Incido, ad extrahendam succum, ix. I.

Tвеариórns. Mollities.

Tşárew. Tener; de qualitate Pisorum, \&c. post coctio-

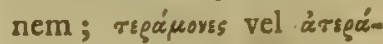
reves, (" they boil hard or "soft,") viii. 9.

Tséiтgioy. Terebellum. Pars arvęsias. (vid.) ex duro ligno, sc. Korívou, v. 8, 9 .

Tвendáv. Teredo, navalis, V. 5 .

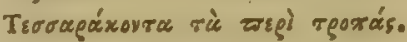
Dies antiquitus insignes, $\mathfrak{x}$ que ac Halcyonii, etsi numero impares. De C. Pl, r. 
Tiravós. Rigidus, tensus : de folio, iii. 10, 18.

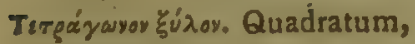

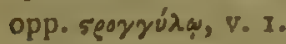

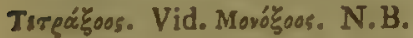

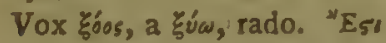

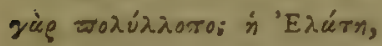

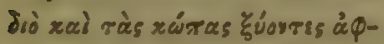

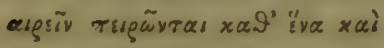
iradaws, ("they work with "the grain of the wood," v. 2 .

Tergixúpesvos ซndós. Lutum capillis mixtum ad opera cæmentitia, ut apud nos. De C. Pl. i.

TiFroia. Mansuefactio, iii. 3 .

Tenrsxós. Acie acuta : dicitur

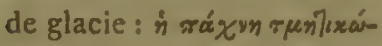
твре Tóros. Situs loci.

Toẹsioc $\dot{\eta}^{\circ}$ Opus tornatile; "carved work, or turnery," v. 8.

Ţaráa. Luxurio, mer. ex li-

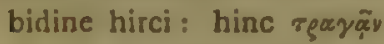
dicitur de morbo vitis ex nimia luxurie; articulatio, Plin. xvii. 24. "a swelling " of the joints." De C. Pl.v.

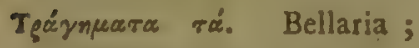
"sweet-meats." N. B. Hinc vox Gallica "dragées."

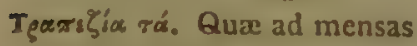
construendas pertinent, iii. 11.

Tecrpess. Stridor alarum insecti; "buzzing:" $\varphi$ sir - rovras vià resypúv. De C. Pl. v. Vid. Terapeòs, iv. 15.

Ţ̧rovíw. De triplici metamorphosi insectorum, $\tau \rho$ to

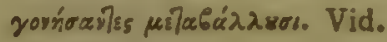

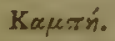

Tprnpıxoiviç. Congiarium et dimidium. N. B. Modus lo.

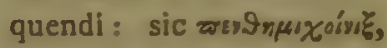
$2 \frac{i}{2}$.

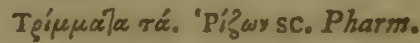
"powders of roots in medi" cine?" ix. 9, 12.

Ţ́ió̧os. Ramis terna serie, iv. 5.

Téiogxis. Radicibus bulbosis ternis, ix. 9.

Teropós. Alarum stridor in insectis, iv. 15.

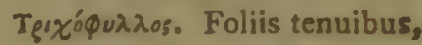
linearibus, ut Pinas, $\& x c$. iii. 10.

Tęrxádes tó. Serica materies. N. B. Ex nitore, instar capillarum, ita dicta. Opp. iẹıúdz, gossypinæ, vii. $\times 3$.

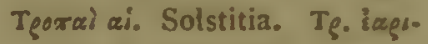
vai, re. Xespesersai.

Ţ́⿱㇒⿻二丿亅八. Gubernaculum navis, i. 16.

Ţ́⿱㇒⿻丷木⿸丆o丨丶og. Trochiscus. Angl. "s lozenge :" antiquitus ra. dicis medicinalis frustulum ita appellabatur, ix. 9.

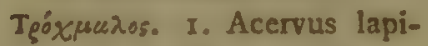
dum. 2. Adj. lapideus, cal. culis plenus, $\gamma \tilde{n}$ r $\varrho^{\circ} x \mu \alpha \lambda$ os. De C. Pl. iii.

\section{R 3}




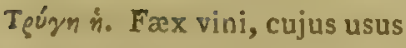
vice saponis, ix. 10.

Tequrrós. Vindemiæ tempus, v. $r$.

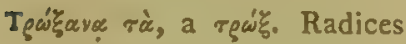
fibrosæ? surculi juniores semesi a vermibus? De C. Pl. iii.

Té์тavav. Id.q. Tegírguv, (vid.) V. 10 .

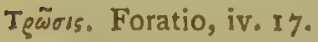

Túrw \&. Quodammodo: iv

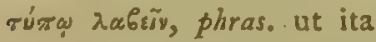
loquar.

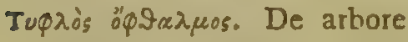
læso; " blighted:" vid. " $\phi$ -

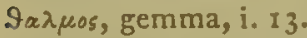

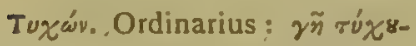
$\sigma \alpha$, communis, viii. $\eta$.

$$
r
$$

'Tręu' ทे. Tempus pluviale. De C. Pl. iv.

' $\Upsilon$ ręroía. Humiditas, succus, iii. 13.

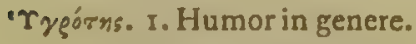
2. Succus pl. "sap" dictus, ix. I.

'rdagńs. Aquosus tenuis: opp. Túxyw, in succis, ix. I.

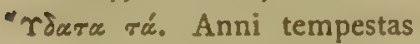
pluviosa in calidis regioni-

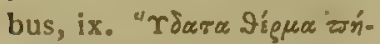
gvvars \$ã 7 Tov, optime. De C. $\mathrm{v}$.

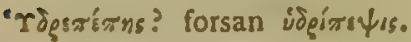

Succus aquosus. De C. Pl: vi.

" $\Upsilon \lambda$. Materies primaria, i: 19.

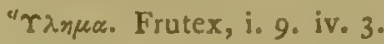
' $r$ suxoi of. Foramina. Vasa fibrosa succum haurientia; " sap vessels." De C. Pl.vi. ' $\Upsilon \lambda$ soruis. Percolatio, ib.

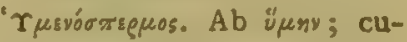
jus semen capsula mem. branacea tectum. Hymenospermus, Bot.

' $\Upsilon \mu \varepsilon v \omega ́ \delta$ ñ. Membranaceus. N. B. Mŕr @̧a vasculosa Sambuci ita vocatur, sc, vasculis membranaceis, i. 3,8 .

' $\Upsilon \mu$ ŕv. I. Membrana, i. I8. 2. Spatha Narcissi.

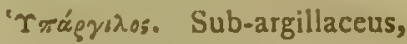
de solo, ix. 3.

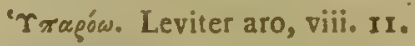
" to skim the ground."

' $\Upsilon \pi$ r'gropoppos. Calidus valde. De C. Pl. i.

' $T$ reṕpicuv. Valde radicatus. De C. Pl. iii.

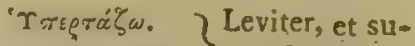

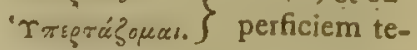

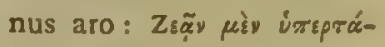

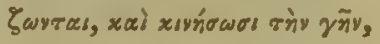
iii. 2.

'Tríguąos. Pallide rubens, i. $2 \mathrm{I}$.

"rtrvos. Met. Somnus plantarum; hinc dicuntur, $x \alpha 9$ sivSouv vuxtós.

' $\Upsilon$ то́b 7. 


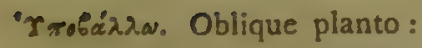

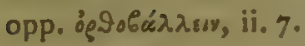

' $r$ ro? 2 yia. Ex usu antiquitus distinguebantur boves aratorii a lactariis. Boũot $x \alpha \grave{3}$

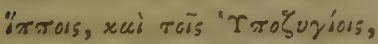
(" cows, horses, and work" ing cattle,") iv. 4.

"Trostspexivopas. Nimium calescere. An ixspąppeciyo-

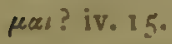

' $r$ tó.9806s. Materia subjecta; origo alicujus rei, iv. 14.

' $\Upsilon$ Toxar wguxia. Sursum, deorsum fossio: "trenching "ground." De C. Pl.v.

"Troxaviaers.\} Methodus ma-

'Troxóviois. $\}$ turandi uvas et cucumeres pulvere superinjecto, ii. 8. De C Pl. iii.

' $\Upsilon$ Troxoyiów. Id. ii. 8.

' $\Upsilon$ 'xó iii. 14.

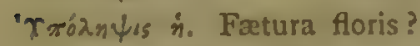

"the setting of blossoms."

De C. II. v.

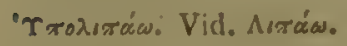

'Trovsáa. Vid. Neáw, iii. 2.

' $\Upsilon$ тоrтidjos. Leviter cinereus, iii. 10. De colore uvæ, et pruni cujusdam.

' $\Upsilon$ róræępesos. Surculus cum perna sua, Plin. "with "part of the old wood," ii. I.

'rx́óxispos. Volatilis: de odo. re. De C. PI. vi.

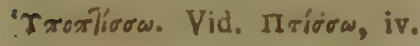

10. leviter tundo.

'Trógua. Pars subjacens monti, ix. 1.

' rróppossos. Radicibus ex una parte, ii. I.

'rxóśḉ̀s. Intervallum, ii. $\%$

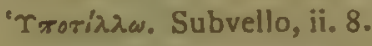

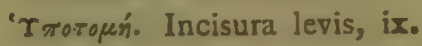

2.

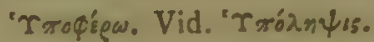

'Troфı́́ yw. Devito, quasi abhorreo, ix. 15.

' $T$ rópuoss. Quod subtus cres-

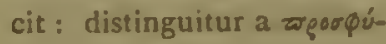
ou proío, vi. 3.

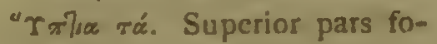

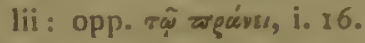

"roflioy rípen. Hort. "to prune "with the cus upwards." Dc C. PI. V.

' $\gamma$ та́тıа. Cavitates sub ocu.

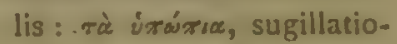
nes, " a black eye," vulgo, ix. 22.

' $T$ xágsue rá. Loca sita ad radices montium: acclivia? ii. 7 .

" Tรęe rá. Secundinæ, ix. 20. ' $\Upsilon$ รsegí. De plantis Serotinis :

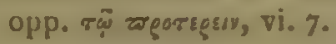
" $\Upsilon_{5} \lambda \iota \xi_{\xi} .1$. Tentaculum in Molluscis. Linn. 2. Cirrhus in arboribus, iii. 18.

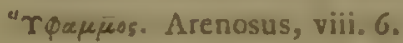
'Tpisnes. Subsido; de flus. idis. De C. Pl. iv. 
$\Phi$.

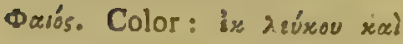

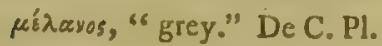
vi.

Фaxóv. 1. Legumen Фaxษั, viii. 5. 2. Фaxòv, semen.

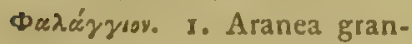
dis. 2. Animalculum texcorium.

Фagaryádns. Vallibus et praruptis locis proprius, iii. II.

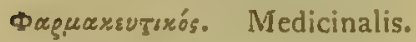
De C. Pl. iii. Opp. фарнаxẃss, lethali.

- Q́ęuarar Evvarpar. Medicamentum stypticum, iv. 8.

Фagparádns. Venenosus: ధą-

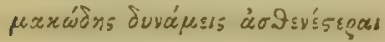
тої sialopulvous. Ita Poeta, " Effecit poto Mithridates " sæpe Veneno, Toxica ne " poterint sæva nocera si" bi."

Фavdia? rá. Oliva minutæ inutiles, ii. 3 .

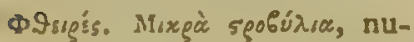
clei minimi. Plin. Hinc

\$S Suóóloga IIírvs. De Larice? ii. 3 .

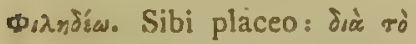
ధıวи́dยı, (voluptatis causa,) ix. 16.

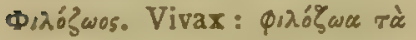

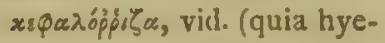
mem durant,) vii. 12.

$\Phi$ дร́:๕ร. Apud Theophrastum vasa spiralia. Vide Grewi- um, ii. c. 4. iii. 3. Hillium de structura ligni, ii.c. 2,3 . ubi multa de lactiferis, resiniferis, et gummosis enumerantur; etiam Malpighii Anat. t. 7. f. 30 . Et cel. Mirbel, Ann. du Museum national.

$\Phi \lambda_{\varepsilon}$ ixà rá. Superficies papillosa cutis. De C. Pl. vi.

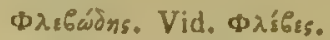

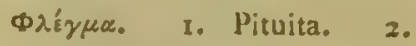
"plegm," voce retenta, ix. 13.

$\Phi \lambda \varepsilon \gamma \mu o r \dot{.}$ Inflammatio : vid.

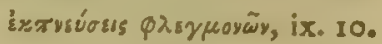
$\Phi$ גosós. Cortex plantæ. $\mathbf{x} . \Phi \lambda$.

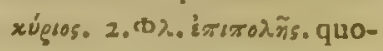
rum posterior sæpius, ut in Arbuto, et Platano, жüropé-

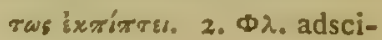
titius, utpote $\$$ i $\lambda \lambda$, , iv. 18. p.

Фóón. Loculus, capsula minuta; Bot. viii. 3. hinc Angl. "a fob," iv. 5.

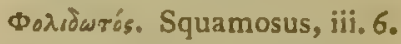
Dopá. Proventus, seges, iii. 14.

Фogis. adj. Ferax, fructifer, iv. 17.

Фoppeoí, Calathi, ii. 8:

Фevyavixós. Fruticosus. N. B.

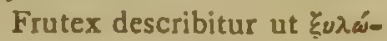

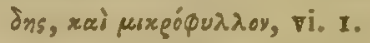
Фgúyavov. I. Frutex. 2. PI. perennis. Divisio genera-

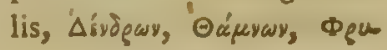


yousecen, Mowdeny, vi. x. - gégare dividuntur in \&váxava (inermia, Bot.) xai ¿xaxa riora etiam in áxaviád

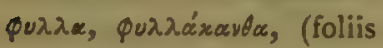

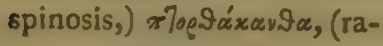
mis spinosis,) ib.

Фequópzyos. Torrefactus, vii. 12.

Déxos. Fucus, iv. 7

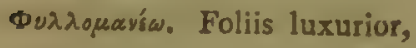
viii. 7.

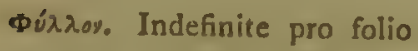
et petalo, Bot. Lobi ctiam

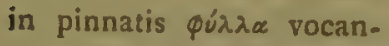
tur. Ita semel dicitur rò

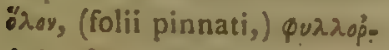

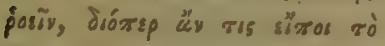

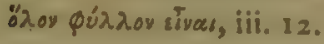

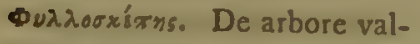
de frondosa, adeo ut solis radios arceat.

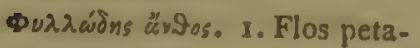
lis expansis. 2. Flos plenus, i. 21.

Фи́para. Tumores, pustulæ, ix. 12.

Фvers. Id.? An inflatio totius corporis, in pecoribus, "be. " ing hoved," ix. 10.

Qvírus. Generativus, generando aptus. De C. Pl. iv.

Oursia. Propagatio pl.

Dursúpara rá. Planta ex se-

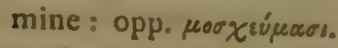

Dursvópesvos. Opp. -xagríog, vii. 3 .
Фư7เยrńgı rá. Seminia, "seed " beds," ii. 2. Pl. ex semi. nio, ii. 7 .

$\Phi \omega \lambda \varepsilon v ́ w v$. Nidificans : $\tau \grave{\alpha} \phi_{\omega-}$ $\lambda$ súoyro, aves in genere: sed rectius, ut videtur, quando plumas exuunt, a фwisúw, quia tunc temporis late. bras quarunt: " moulting " birds."

$\mathbf{x .}$

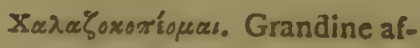
ficior, iv. 15.

$\mathrm{Xa \lambda}$ ¿rós. Inimicus, iii. 17 .

Xagaypós. Serratura folii, Bor. iii. 10.

Xágǔ. Sudes, vallum, ii. $x$. xaĩyos. Laxus, porosus, iii. 6.

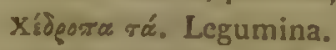

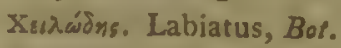

Xupearoúprvos. Frigori expositus, vii. 5 .

Xipeworrogín. Hyeme sero. De C. $\mathrm{Pl}$. iv.

Xะดотภทดท่ร. Manipulus, manipuli instar, ii. 7. Mensura molis, iv. 2.

Xísvorex. Statumen navis,

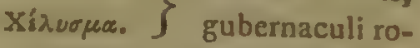
borandi gratia. (Jul. Poll.) v. 7 .

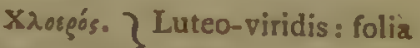

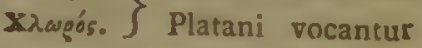

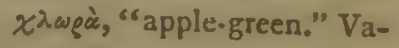
rietates coloris viridis alibi occurrunt; e.g. I. rowions. 


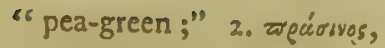 "green as a leek;" 3 . du $\varphi$ - vwóns, "dark-green."}

Xxón. Vox generalis, pars herbacea : ix roũ xárw, х⿻̧ó $\mu=$

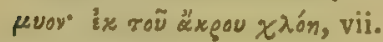
4. viii. 2.

Xvoüs. I. Pollen, Bot. 2. VilXovs. $\}$ li in pericarpio Rosæe, vi. 6. 3. Staminum congeries in floribus.

Xivoúdns. De floribus stamineis, apetalis, ut Vitis, Hedera, \&c. i. 21 . viii. 4 .

Xór. Mensura, viii. 3 .

Xórxy. Eadem; ex Concha testacea. N. B. Duo cochlearia continet, ix. 6. Concha spec. bivalvis, $\mathrm{L}$.

Xorń. Fel.

Xóvdes. I. Far, Phav. sed rectius Tritici vel Hordei cujusdam massa farinacea. De C. Pl.iv. 2. Aqua cocta ad cibum, iv. 5. 3. Massa gummosa, ix. 4 .

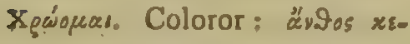
Xgúpesvos ảvǻxus : opp. äy-

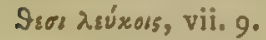

X $น \lambda เ \omega_{\omega}$. Viridi herba pasco: "to soil cattle." De C. PI. ii.

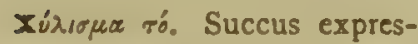
sus, ix. 8.

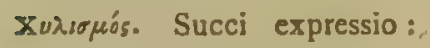
differt ab ó

xurés. $\}$ Succus plantæ exXupós. $\}$ pressus. Vide öros, succus sponte fluens, i. 3 . sapor, i. 19. ix. 1.

$\mathrm{X} u \lambda$ ów. Succo abundo.

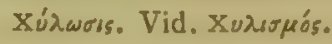

Xäpк. Tumulus, agger, ii. $\eta$.

$\Psi$

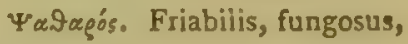
vii. 9 .

$\Psi$ « musicum lyræforme, cui Súroy (pars curvata instar cornu) proprium, v. 8.

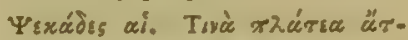

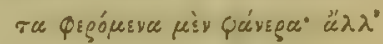

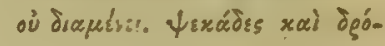

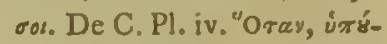

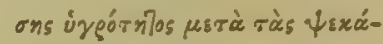

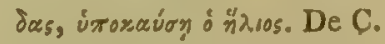
$\mathrm{Pl}$. v. Oủ yive

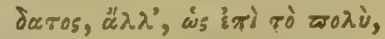
భixa5: Pruinæ particula

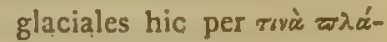

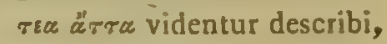
nisi textus sit corruptus.

$\Psi$ भ́v. Cynips Psenes, Linn.

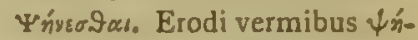
vis vocatis. N. B. Tò భríveo9a, morbus Punicæ, Grawate, L. iv. 16.

Yianos. Storea, "c a mat," iv. 9.

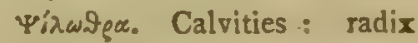

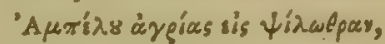
(le vi depilatoria,) ix. 22.

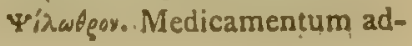




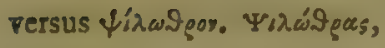
ix. $2 \pi$.

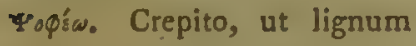
durum, $\nabla .6$.

Yúxy. Papilio, vel Imago, L. Vid. Metamorphoses Insectorum, et Káprn.

צux̧ós. Qualitas lignorum quorundam : opp. Isøpü.

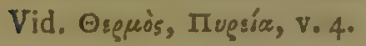

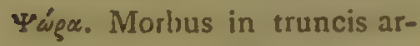
borum scabiei similis, pracipue in Ficubus, iv. 15.

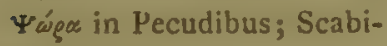
es, ix. Io.

Yuģáa. Scabiosus fio. De C. Pl.v.

$\Omega$.

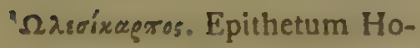
meri 'Iría (Salici L.) pro-

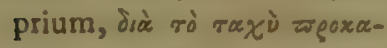

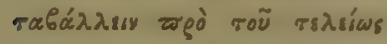
¿̇́úvar, xa) riqua ròy xaptòy, iii. 2. N. B. Sensum Homeri haud plane intellexisse videtur Theophras- tus, qui verbo hoc immensam substantia papposæ diffusionem solummodo indicat. Botanicis satis notum est flores masculos et fomineos in Salicibus ca. lyce papposo instructos esse. Nature saltem incongruum est immatura semina. spargere, nisi morbo, vel aëris vitio. Cuivis autem,

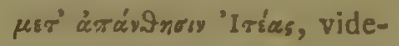
re licet aërem totum naterie papposa repletum; amentis sc, utriusque sexus dilabentibus, et undequa que circumfusis.

" $\Omega$ ga. . Tempus anni; "the "season of the ycar:" " w soxyirwox, "the smiling "spring." De C. Pl. i.

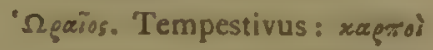

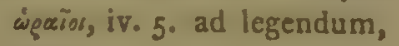
ix. II.

' $\Omega x \rho^{\circ}$ isuxos. Pallide colora. tus, de flore Amaraci $\Pi$ ós dicti, vi. 8. 



\section{N D E X.}

\section{A.}

'AGpótayor, 27, 243, 251, 262.

"Ayvos, 10, 12, 112, 113, 179, 373.

'A yeríraios, 54.

"Arewsts, 19, 21, 53, 181.

"A yowsis тоyтí, 166.

"Arxovor, 295, 296.

"Adiayroy, 299, 306.

'Así?war, 30, 307.

Aifrugos, 9, 14, 79, 80, 85, 86, $89,94,118,120,145,190$, 234.

Aïysigos in Kgทrrr, 57.

1. Airirw $\psi, 303,338 ; 342$, $344,345,349,350$.

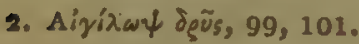

Aigiruges, 73.

Äyss in trunco Abietis, 106.

Aifuábworor, 343.

Aigo, 15, 33, 59, 333, 334, $338,345$.

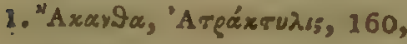
361.

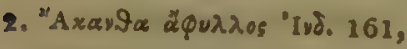
162.

3. "A raysa Siłas, 168.

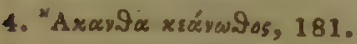

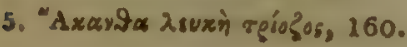

6. "Axavta' Hewería, syn. 160

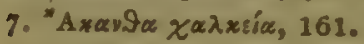

8. "Axuy9a 芕ivn, 362.

9. "Axaria Aizurila, syn. 'Axáv9ov, 362.

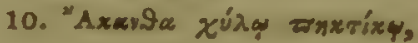
401.

"Axceyos, 148, 151.

"Axavo5, 244, 388.

Axagye, 31, $253,254$.

'Axóyroy, 397, 398.

"Axogos, 40.

"Axogos xárapes, 375.

:Axrn, 15, 16, 23, 89, 118, 190.

Algæ marinæ, 164 .

"Aגsara äre. 395, 401.

-Adupar ró, 201.

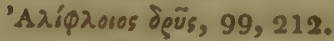

"Aגeas. Morbus, 345.

'A

1. 'Aprépaxo5, 27, 243, 26\%, $264,376$.

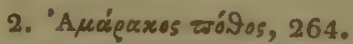

Amenta in arboribus, 88 .

Amomum Syriæ, 375.

"Aнтsरo5, 7, 9, 10, 11, 14, 16,

$17,18,25,26,30,31,32$, $35,36,37,38,40,41,43$, $52,62,63,69,71,92,122$, 
$127,171,190,191,192$, 198, 199, 221, 234, 235.

"Aнtrios àrgía, 264, 392, 407.

"A $\mu \pi \varepsilon \lambda_{05}$ 'I $\alpha$ aía, 128.

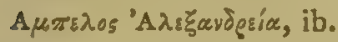

"A

'Apuydúinn, 17, 28, 34, 36, 38, $89,41,52,54,55,57,63$,

$64,71,72,111,114,196$, $235,304,324,362,363$, 405.

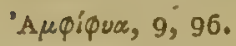

"Apwers, 376.

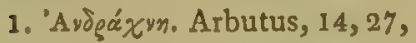
85,$86 ; 89,90,91,94,126$, 136.

2. 'Avơúxum. Portulaci, 274, 281.

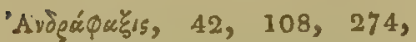
$279,280,281,282,290$.

Androtion Medicus, 70.

Angiospermæ pl. 328.

'Aveqúvn, 293, 295, 298.

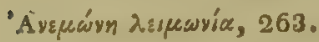

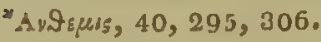

'Ayśęures, 13, 248, 303.

'Av9nóny. Mespilus, 114.

Animalia å $\pi \circ \sigma \alpha$. In arenosis deserti, 155.

'Avequaría, 144.

'Ayríppossur, 406.

'A таруік, 295.

'Aтrapirn, 294, 306, 342.

'Arárr. Vid. 'A ب́xin.

'Aт105, 9, 10, 24, 35, 37, 38, $39,41,42,43,52,54,55$, $5 \%, 62,63,71,72,83,89$,
94, 107, 112, 116, 1:8, $120,131,149,153,189$, $192,195$.

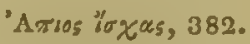

1. "A

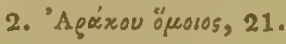

'A paxî̀u, 4, 21.

Arbores cultae et sylvestres; $11,79$.

Arbores fructiferæ, 83.

Arbores campestres Macedow niæ, 85.

Arbores odoriferæ, gummiferæ, 161.

1. 'A p̧í $\delta \rho \tilde{u} s, 125,126,219$, $221,225,233$.

2. 'A pia, Cratægus, 89, 90, 212.

Aristophilus Philosophus, 403.

'Apl50roxia, 390, 392, 395, 407.

"A gxsu905, 26, 84, 85, 86, 88, $90,94,96,114,146,229$, $230 ; 362$.

Agves. Tritici, 340.

"A gorat oi, 333.

Aromatum spec. 36.

'Agvér rworov, 295, 298.

1. "A 302.

2. "A 302.

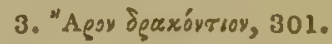

"Aoriov, 20.

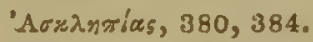

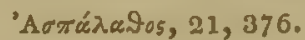

'Artrígeryos, 31, 244, 252.

Arígiaxos, 188. 
'Áp̧ósros, 19, 31, 296, 301, 302, 303.

"A rexalun, 235.

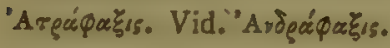

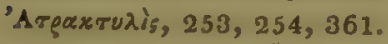

Aìmтixís Kádapos, 179, 181, $182,185$.

Aulon Syriæ, 86.

1. 'A páxn. Lathyrus, 322, 335 , $3.12,347$.

2. 'Aథúxn. Syng. 292, 293, 295, 298, 299.

'A фia, 293.

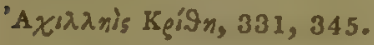

'Axpas, 12, 24, 28, 42, 55, $57,83,85,89,90,94,112$, 116, $131,244$.

"Axgess "Aт105, 157, 189.

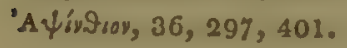

B.

Bagox horti, 67.

Báravos, Vid. Diòs Báravos.

Bádacuos भ่, 147, 150.

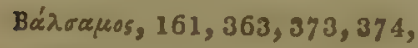
376.

Báto5, 10, 13, 27, 31, 32, $129,133,172,188,244$.

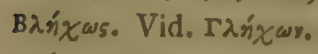

Bגíтоу, 42, 274, 279, 280, 281, 282.

BoגGivn, 305.

Boגboi oi, $277,278,288,342$.

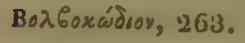

Boג6òs, 19, 20, 31, 277, 296, $302,303,305$.

Boג Ès igrópoeos, 305.

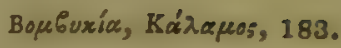

Boúxspus, 160, 343.

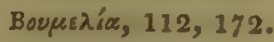

Boúтрпรเs; 293.

Boúтopes, 15, 30, 172, 180,

$181,182,186$.

B̊ópos, 330, 344, 345.

Bęuogos. Vid. Ǫúuegos.

Bulbosæ pl. 19, 301.

$\Gamma$.

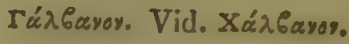

Gangrena arb. 345.

Generationes arborum, 51 .

Generationes fruticum, 53 .

Germinatio prima et secunda, 92.

Germinatio particularis seminis Tritici, 321.

rท่́งอง, 20, 274, 275, 276, $277,287,288,290,296$, $302,386$.

Ги่งยเงท, 32, 188.

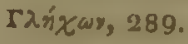

Гגสับขร, 85, 110.

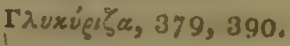

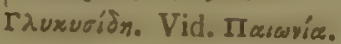

Гorguids, 18, 19, 273, 276, $278,279,280,281,282$, $284,289,297$.

Гoyrudis àrgia, 291.

Gymnospermæ pl. 329.

$\Delta$.

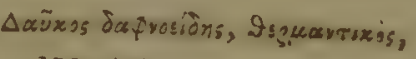
$395,407$. 
1. $\Delta$ áфvท, 14, 17, 18, 23, 26, $36,43,52,55,63,86,89$, $97,120,170,190,201$, $219,230,232,235,369$.

2. $\triangle \alpha \dot{\varphi}$ ที áręla, 27.

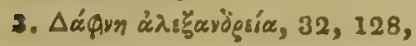
229.

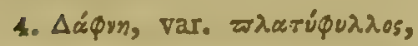

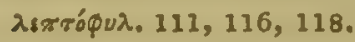

5. $\Delta \alpha \dot{\varphi v n ~ \varpi о ห т i ́, ~ 160, ~} 169$.

$\Delta \alpha \dot{\varphi}$ vrs "̈povos, 160.

Degenerationes arb. 54 .

Degenerationes frumentacearum, 341.

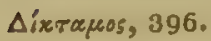

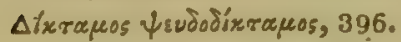

$\Delta$ iòs «ँจัง $243,257,261$, 264.

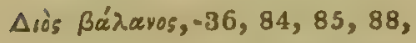
$89,90,93,107,147$.

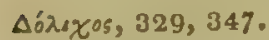

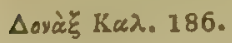

$\triangle$ ¿̨axánrioy, 301, 407.

$\triangle$ Фи́тl\%, 31.

$\Delta \rho \tilde{u} 5,4,6,9,14,16,17,25$, $27,31,54,55,85,86,88$, $89,90,91,93,94,97,99$, $124,198,199,213,221$, $222,224,226,229,232$, 233.

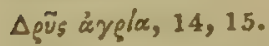

$\Delta \rho \tilde{u}$ s тоутік, 165, 166.

Durationes arb. 189.

E.

1. $\left\{\begin{array}{l}{ }^{2} E \text { bryos, } \\ \text { 'Efiry, }\end{array}\right\} \begin{aligned} & 15,16,218, \\ & 221,407 .\end{aligned}$
2. "E6ะyos, 159.

Eirnguta, q.? 236.

'Edxia, 10, 12, 15, 16, 17, $18,23,24,25,26,29,30$, $31,34,35,38,39,41,42$, $57,58,62,63,70,83,113$, $123,170,188,191,196$, $199,219,221,224,226$, $235,245$.

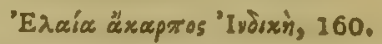

'Eגaía rovтí, 168.

'Eגaíxyvos, 179.

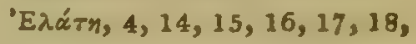
$23,24,25,26,30,36,37$, $39,53,80,85,86,90,91$, $92,93,94,95,96,97,305$, $145,156,198,199,212$, $213,214,220,226,228$, $232,362,364$.

'Ела์тท тоутік, 165.

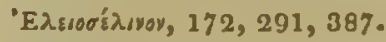

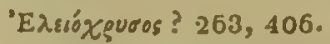

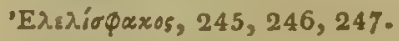

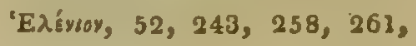
262.

'Eג|xทे, 119.

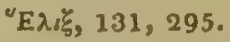

'Eגíxguros, 263, 406.

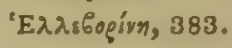

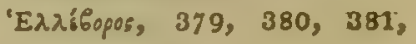
$382,383,395$.

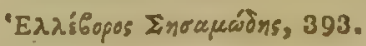

'Eג Girn, 120.

"Eגupes, 160, 321, 34\%.

'Evgov́osrav,

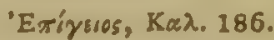

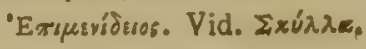

'Exixireor, 293. 
"Exwభ. Avis, plumas mutat, 61.

'Epitwos, 60, 321; 322, 324, $325,326,329,334,335$, $337,338,345,346,34 \%$, 349.

'Essixy, 42.

'E Esysòs, 24, 42, 54, 57, 58, 85, $88,89,189,193,227,234$.

'Ẹ́̆ópoęa, 159, 171.

"E E $261,262$.

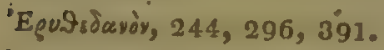

'Equoien. Morbus, 345.

'E Eqúotreov, 322, 328, 328, 336, 339.

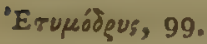

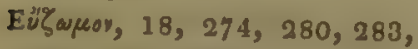
$284,290,386$.

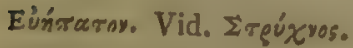

Eủúvujeoy, 134.

$z$.

Zssì, 60, 321, 322, 342, 344.

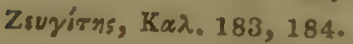

Zuyia, 85, 89, 120, 212, 213, $219,230$.

Zusing, 165.

II.

\section{'H8ن́oopos, 293.}

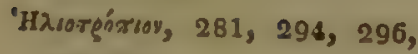
$298,30 \%$.
"H H.o5, 193.

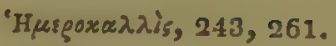

'Huiovos,

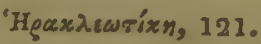

'H paxiriov. Vid. Mávą.

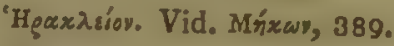

'Heiryrov, 244.

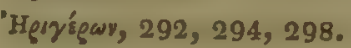

$\Theta$.

Oafice, 378, 379, 381, 382, 407.

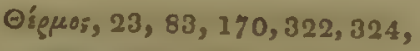
$334,335,339,347,348$, 349.

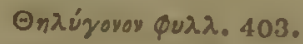

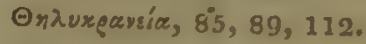

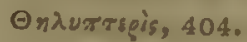

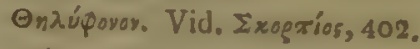

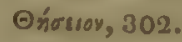

Opáxicos IIupòs, var. 332.

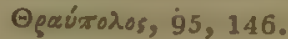

Ofioaxív, 32, 37, 274, 278 , $280,281,283,285,289$, 378.

Opidaxirm åyg̣ix, 387.

Opidaxivm rovria, 166.

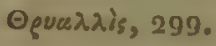

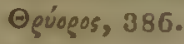

@vita, 26, 89, 91, 146, 220.

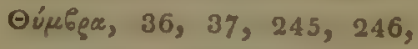
$274,275,290,291$.

1. Oúpes, 37, 81, 155, 246.

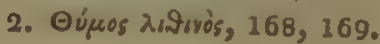

PARS II. 
I.

'1coscíny, 39.

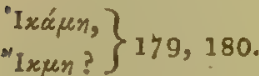

Inosculationes, 67, 75 .

Insitiones, ib.

'1乡̈ix, 98, 124, 362.

'1 ऊ̌ivn, 253, 254, 255, 362.

"Iov. Vid. 'I wrio.

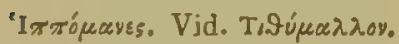

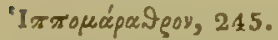

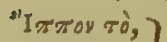

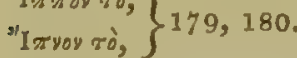

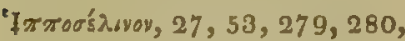

$291,362,363,395$.

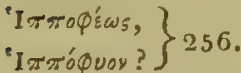

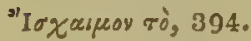

"1

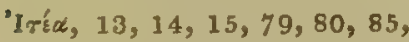
$86,89,94,119,145,164$, $172,179,181$.

1. "I Q vor, 261.

2. "1 Quov, an "1 purov? 264.

${ }^{3} \mathbf{\Psi} \psi \circ 5,89$.

$\left.\begin{array}{c}\text { 'I wrix, } \\ \text { vel }\end{array}\right\} 27,39,52,257,258$,

'Iòv, $\} 259,260,264,305$.

'Iuvia àrģía. Viola canina, inodora, 292.

K.

Kayxęuías Irúos, var. 332.

Cacti folia edulia, 255.

Káxzos, 255.

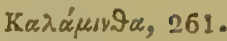

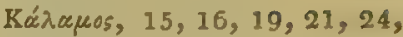
$25,27,30,32,33,53$, $172,178,179,182,-248$, $338,375$.

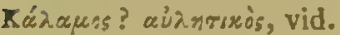

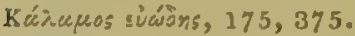

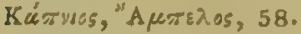

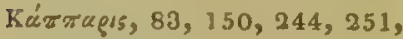
$256,294,298$.

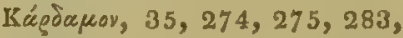
290.

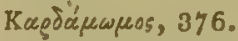

Ка gúx, 34, 36, 84, 85, 89, $93,235,324$.

Kagúa Eüböxì, 34, 221, 222, $226,230,233$.

Кари́х Пвебเхทे, 34.

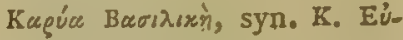
ธäxทั5, ib.

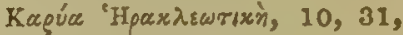
$88,93,94,95,97,120$, 121.

Karí, 161, 369, 372, 373, $375,376$.

Cassia Laurus, Pseudo-Cassia, 373.

Kauraxis, 293.

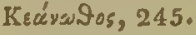

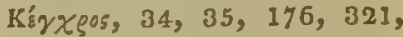
$322,326,329,330,339$, $345,347,349,403$.

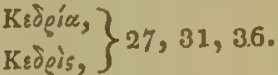

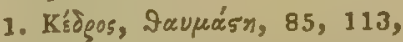
$154,221,228,231,362$.

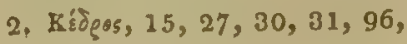
$107,113,114,119,199$. 


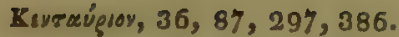

Kвитео-Мup̉pirin, 128.

Kigas; syn. 'Paфaviósos àyeíau, 395.

Kigáabarav, vid. Фáxos.

Kígaros, 117, 198, 362.

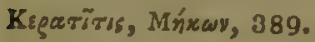

Kigxis, 34, 120.

1. Ksparía Ionum, 149.

2. Kiparla, 149.

Kй аร९०5, 27, 85, 86, 90, 146, 230.

Kห́ğvงิos, 264.

Cinnamomi commercium, 373.

Kьучх́реснео, 161, 369, 370, $372,373,375,376$.

Kísos, 28, 344, 345 .

1. Kょтrìs, $10,27,28,29,40$, $90,101,129,130,201$, 219. Var. Xúguxa, 130, 156.

2. Kurròs $\lambda$ suxòs, $292,403$.

1. Kıxápiov, 31, 293, 294, 295, $296,298$.

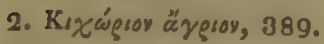

Cichoraceæ plantæ, 299.

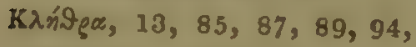
$96,120,122,172$.

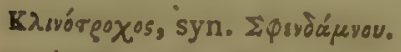

K入ข́pesyos, 379,404 .

Kyścsey, 30, 245.

Kyidios xóxxos, $40 \%$.

1. Kvíxo5, 40, 244, 253, 254.

2. Kvixos xádxs6s, 233.

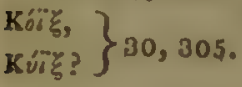

Koxxúygse, 126.

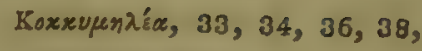
$39,95,152$.

Koגoxúyatn, 35, 37, 40, 71, $274,275,282,283,285$, 290.

1. Koגouria, 34, 127 .

2. Koגourta, 121.

3. Koגouría, ib.

Kópąos, \} 14, 27, 125, 126,

Kúpagos, $\} 233$.

Kó

Kóyscoy. Vid. Kávìcoy.

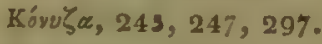

Kogícuyor, 34, 274, 280, 281, $282,283,289,290$.

Coronariæ plantæ, 216.

Kogovórtous, 295.

Kógxogos, 293.

Kós05, 376.

Cotyledonum distinctio, 325 .

Kótivos, $12,23,24,25,42$, $57,58,83,189,196,219$, $222,231$.

Kovxiọ́̆ogos, 150.

Kóฟipos, 124.

Koavía, 16, 83, 85, 89, $94,112,113,128,221$, 228.

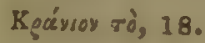

K.

Keqraiyà, $\} 123$.

K弓araióyovov, 403.

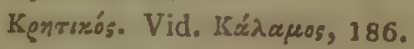

Kegticyuos Trugòs, 325.

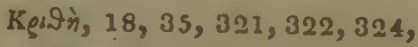

$325,327,330,331,335$, $337,340,342,344,346$, $348,387$.

S 2 


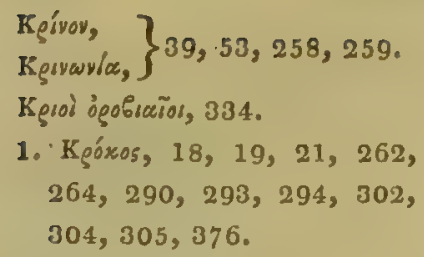

2. K 'óros, 264.

Кํ́ниноу, 15, 19, 20, 31, 32, $188,276,277,282,283$, $287,283,295$.

Керениауи́твเо, 165.

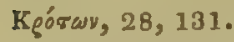

1. Kúaros. Nelumb. 174.

2. Kúarog. $\mathrm{Faba}, 321,322$, $324,325,326,328,329$, $334,335,336,339,344$, 347.

1. Kudúv105, 55 .

2. Kuชัúviog, 385.

Kúxas, 68.

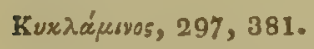

Kи́ревуо, 34, 281, 282, 283, $330,336,343,345,380$.

Kuvógodoy, (vid. Búros,) 379.

Kuvó́батау, 379.

Кथขผे廿, 293.

Kuта́gıтто, 14, 15, 18, 26; $30,53,54,55,69,82,84$, $85,114,146,153,199$, $220,221$.

Kи́тยฺุ०5, 15, 19, 23, 24, 30, $172,177,179,181,186$, 376.

1. Kúríos. Laburnum, 16, 218.

2. Kúrıos. Medicago, 201.

3. Kúrıos. Cytisus Marantha, 201.
Kápaxos, 375, 376.

Kávesov; 15, 248, 292, 378, $395,399,407$.

\section{$\Lambda$.}

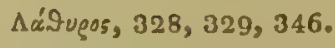

^axáan, 83 .

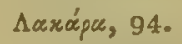

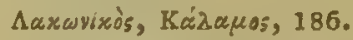

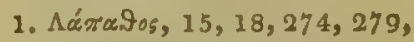
$280,283,291,293$.

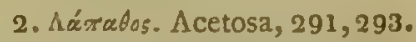

Leguminosæ pl. 322, 333.

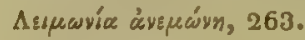

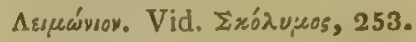

1. 'Asigoy, 260, 263, 303.

2. Ariplay, 204.

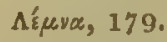

$\Lambda \varepsilon u x a ́ x c \dot{y} \propto 2,253$.

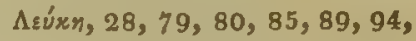
$110,124,131,145,172$, $190,200$.

Asuróiov, 134, 170, 263, 295, 305.

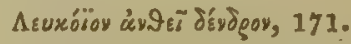

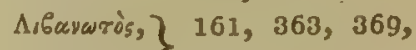

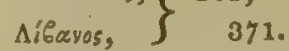

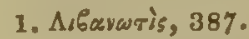

2. Mr6avwrís. Athamanta, 382.

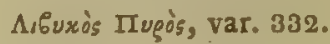

Lignorum qualitates, 211, 213.

Lignorum carbonatio, 216.

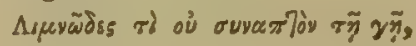
174.

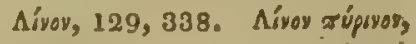
syn. 408 ; 
Avócraptov, 15.

Lolium segetibus infestum, 338.

Lupini proprietates, 384.

Auxyis, 264.

1. Awròs, Celtis, 15, 16, 24, $150,153,218,221,222$, $225,231$.

2. Aarìs, Nymph, 175.

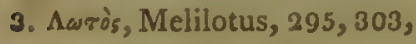
307.

M.

Maðowia, 390.

Mayúdaģıs, 21, 251.

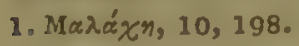

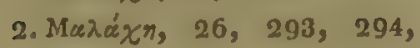
395.

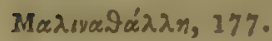

Maviparýge, 248, 380.

Mágatpov, 34, 37, 215, 248, $281,382$.

Mája9 9̧oy róyrsoy, 165.

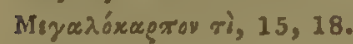

Medullam pl. 16.

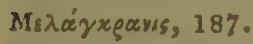

Mะдаंнтиро5, 334, 342.

Mirávioy, 258, 263.

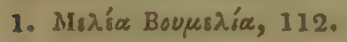

2. $\mathrm{M} \varepsilon \lambda i \alpha, 85,89,94,95,96$, $110,112,127,172,212$.

Msдidwros, 295, 303.

Míluyou oi, 322, 326, 329, 339.

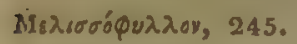

Menestor Pharmacopola, 44. Мะศтілท, 114, 116, 118, 123,
$124,123,195$.

Mrঠixr, 341.

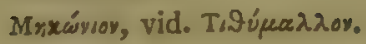

Mท́xผy, 27, 34, 37, 174, 176, $180,378,387,388$.

Mndร́a, 10, 14, 16, 1\%, 18, $24,26,30,35,37,38,39$, $41,43,51,52,54,55,63$, $72,85,89,90,112,189$, $192,195,196,199,221$.

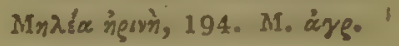

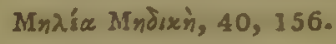

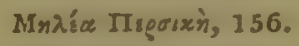

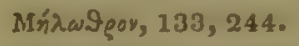

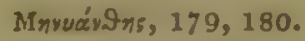

Mí̀os, 85, 86, 89, 90, 91, 94, $146,221,230$.

Mivara, 59, 261.

Myécioy, 173, 174.

Morbi arborum, 193.

Mućxz:ẫo, 256.

Mreíos, syn. $\triangle$ guós.

Múxทร, $5,15,18,98$.

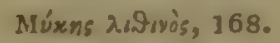

Muóqoyoy, 245, 248.

Mugixin, 27, 30, 85, 86, 125 , $164,224$.

Mup̉pirn, $\} 10,13,26,29,30$, Múgro5, $\}$ 32, 36, 39, 41, $43,52,55,63,70,94$, $123,126,150,232,245$.

Mutatio II ugoñ sis Aigav, 338, 340.

Myrrha et arbor myrrifera, 362.

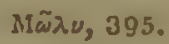

s 3 
N.

Nalgos, vid. Nágòos.

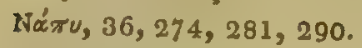

Nágdos, 376.

Ná 9 ทร้, 9, 16, 245, 247, 249.

Nop९⿱nxvite, 245, 247.

Nágxaф905, 376.

Náexuoros, 260, 302.

Nหт64.

Nņ̃̄ง, 376.

Nuнфагіх, 390.

ב.

Eigis, 380.

Eípiov, 263, 302.

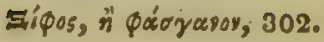

\section{o.}

"On, $\} 57,71,83,96,111$, O $\left.{ }^{\prime} n,\right\} 115,123$.

Oivx์ท9ท, 261, 263, 264.

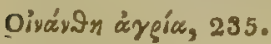

Oivolńga, 405.

1. OtFo5, 129, 246. Ribes?

2. Oloos, 246. Salix viminalis.

"Oxspos, vel" $\Omega$ xiнss infra.

Olera, divisio pl. 274, 283, $288,290,294$.

Olibanum, vel Myrrhifera arb. 362.

'Odíßavos, 362, 369, 370.

'OAórxoiros, 187.
'Oxข́ga, 322, 330, 844 .

'Ovoxixג 1 s, 298.

'Ov'́ruร̌०s, 253.

"Ovaris, 244, 286.

'Oद̧ú, 88, 96, 10\%, 108, 112, $212,213,222,228,230$, 232.

'Оद̆ча́хку $9 \propto, 85,86,89,90$, 157, 264.

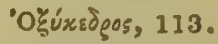

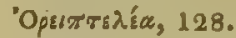

'Oesoc'́rıvoy, 291, 292.

'Ogírayoy, 27, 36, 246, 274, $275,277,291$.

1. "O९fus ov,

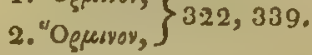

'OpoßárXY, 242, 243.

"Oẹoßos, 60, 289, 292, 322, $326,329,334,335,312$,

$345,347,349,407$.

'Opoßscior Korol, 334.

"O९ru乡, 299.

"O६u५̌ar, 160.

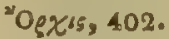

Ostenta in arboribus, $58,217$.

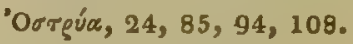

Oǘrýos, 4, 20, 21.

"Ох"ท, 63.

II.

IIádos, 145.

חxusvíce, 379.

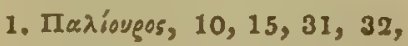
$85,89,90,110,129,153$, 172.

2. Mexiougos, 254. 
Palmæ foecundatio, 74 .

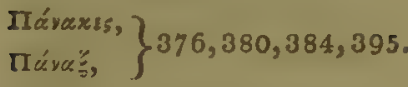

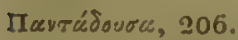

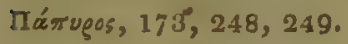

Ixpå'viv, 293.

IE $\lambda$ srĩvos, 342.

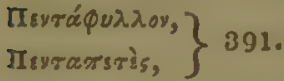

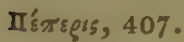

IIEs⿱ixiov, 21.

Irfola, $37,87,147,149,152$.

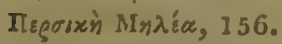

Iврбізй Kąúu, 94.

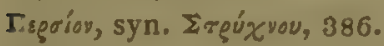

Thuxśdavoy, 392, 395, 40\%.

Пะúxท, 14, 16, 17, 18, 23, 26, $30,31,36,37,53,62,82$, $84,85,86,88,90,92,93$, $94,95,100,145,198,199$, $213,221,222,226,227$, $228,362,363,364,365$, 368 .

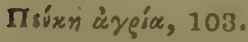

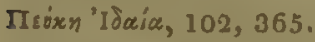

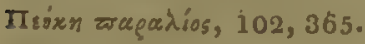

II sixn xwró

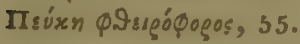

Пrýavoy, $11,27,52,243$, $262,277,283,288,291$, 374.

Perennes pl. 273.

Phonix Judæorum, 65.

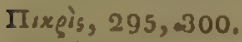

$\Pi$ חídos, $9 \%$.

గivòs, 321, 322, 32.5, 328, $329,334,335,346$.

חіти5, 26, 27, 30, 31, 36, 53,
$80,88,90,93,94,105$, 108.

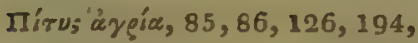
199, 212, 213, 229, 362, 364.

חirviทn, 294.

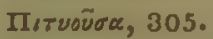

Pix et resina, 363 .

Plantarum divisio in terrestres et aquaticas, $12,14$.

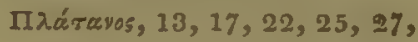
$30,31,79,81,86,89,94$, $110,111,164,172,188$, $200,219,228,234,386$.

Platanus Cretæ singularis, 27.

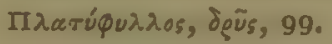

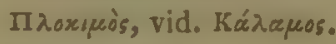

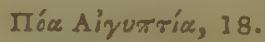

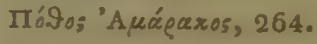

ก'́d.uov, 30, 73, 298.

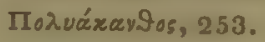

Политт́́̊ioy, 391, 407.

$\Pi_{\varphi} \alpha^{\prime} \sigma$ isov, $245,247$.

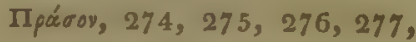
$282,287,289,292,295$.

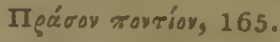

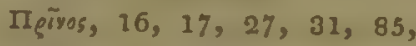
$86,88,90,95,97,124$, $199,225,330,335,369$.

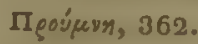

$\Pi \pi \varepsilon \lambda \varepsilon a, 25,29,31,73,79$, $85,86,94,97,112,120$, $123,130,149,164,178$, $212,219,221,228,230$, 362,369 .

IIrşis, 30, 152, 341, 392, 404, 408.

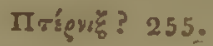

s 4 
1. Iúğ०5, 15, 16, 17, 24, 27 , $85,86,90,94,123,156$, $218,221,223,224,225$ 230,407 .

2. $\Pi$ úğos, Fungus, 18.

IIvgsias descriptio, 235.

Ivegò, 15, 18, 34, 35, 59, 60, $300,321,322,324,325$, $327,329,330,331,335$, $336,337,340,342,344$, $345,346,348,349$.

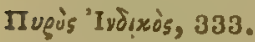

P.

"Pápvos, 27, 129, 133, 235.

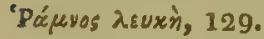

'Papavis, 9, 11, 18, 19, 273, $274,275,277,278,279$, $280,281,282,283,289$, $290,295,381$.

1. 'Pá фavos, Brassica, 201,243, $273,278,280,283,284$, 289.

2. 'Páфayos, Cochlearea Arm. $18,30,42,291$ ?

3. 'Pápàyos óguròs, 27, 160, 291 ? 395.

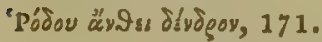

'Podwvía, 27, 39, 53, 243, 238 , 259, 263, 265.

'Poíce, 10, 14, 16, 17, 18, 26, $30,33,35,39,40,41,43$, $51,52,54,55,56,57,58$, $63,69,70,72,92,94,134$, $154,189,195,196,199$, 244.
'Poíc Mýxwy, 389.

'Poथ̃s, 129, 130.

'Púrgos, 253.

$\Sigma$.

Sabæorum commercium oli: bani, 370.

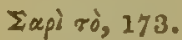

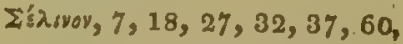
$115,249,274,276,277$, $279,280,282,289,291$.

Sementis tempora, $321,32 \%$, 333.

Seminum distinctio, 341,346 . Serpentes volantes, 373 .

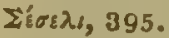

Sexualis distinctio, 87 .

$\Sigma \dot{n} \mu \nu \delta \alpha, 120$.

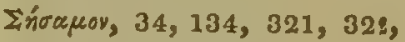
$326,328,329,330,334$, $339,345,387$.

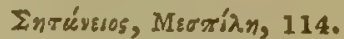

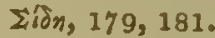

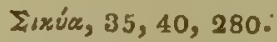

1. Níxvo5, 33,40,71, 214, $275,281,283,285,239$, 290, 296.

2. Eixvos ärgsos, 294, 297, $381,395$.

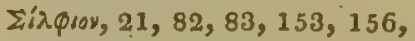
$248,249,250,256,281$, $362,363,364$.

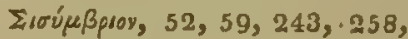
$261,262,263$.

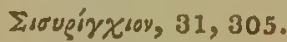

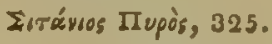


Siros, 10, 32, 33, 95, 281, $296,300,308,321,328$, $333,338,339$.

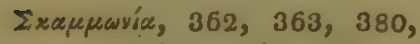
408.

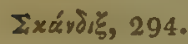

$\left.\sum x / \lambda \lambda \alpha,\right\} 13,19,20,31,277$,

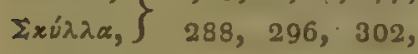
303, 304.

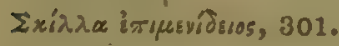

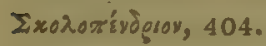

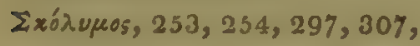
388, 391:

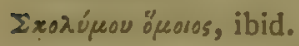

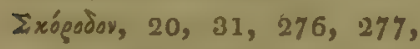
$278,283,285,287,288$, 295, 303.

Exogrios, 244, 252, 391.

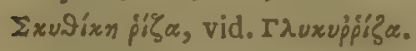

1. $\Sigma \mu^{\prime} \lambda \alpha \alpha_{\xi}, 20,30,31,39$, 133, 264, 995.

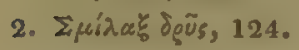

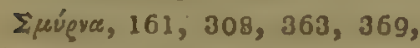
$370,371,376$.

Síyxos, 167, 254, 295.

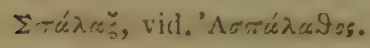

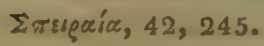

Spiræ in lignis, 217.

¿rodias, 95.

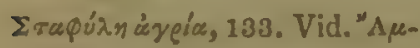

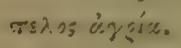

$\Sigma \tau i \lambda \dot{\varphi}$ poveos, 299.

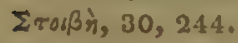

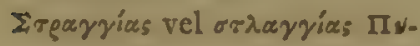
देंร, 332.

1. Erẹúgsos, Cydonia, 55.

2. Erẹoús 105, Carduus? 253, 289.

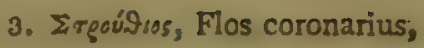
264.

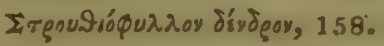

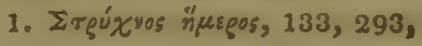
$307,385$.

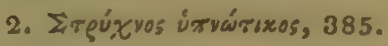

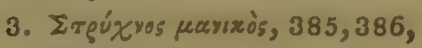
395,405 .

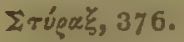

Evxс́рнето, 16, 28, 33, 36, 38, $40,219,221,227,228$, 229.

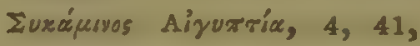
$147,148,149$.

$\Sigma_{u \times \tilde{n}}, 10,11,14,15,18,22$, $23,24,25,28,30,31,32$, $35,36,37,41,42,43,51$, $57,58,59,63,6 \mathrm{R}, 69,71$, $72,73,88,89,92,94,97$, $189,193,196,198,199$, $234,235$.

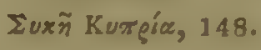

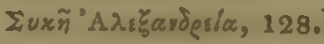

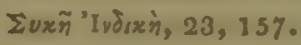

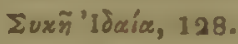

$\Sigma$ ขะก̃ สवขтí, 165, 166.

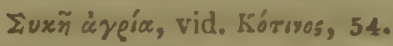

Succi melicinales, \&z. 380.

Succi proprii pl. 361.

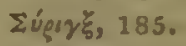

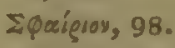

$\Sigma \phi \dot{x} x$ \&205, 245, 246.

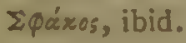

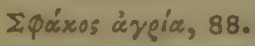

$\Sigma$ pívdapvos, 85, 88, 89, 94, 95, $108,110,212,213,219$, 230.

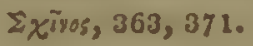





\section{ERRATA IN PARTE PRIMA.}

\section{In Prafat.}

Pag. iii. 1. 11. Pro ducentum lege ducenta.

viii. 24. Pro tradit lege tradiderit.

\section{In Textu.}

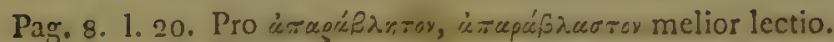

10. 8. Pro rúrs legc rúré.

14. 1.5. Pro

15. 23. Pro xouфñ lege xoú $\phi a$.

21. 1. Pro ஷ̉o

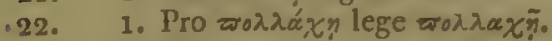

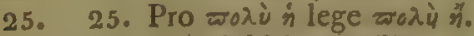

31. 7. Pro rì di lege rád.

34. 8. Pro Rsparia lege Kigavía.

38. 25. Dele $\mu$ हो post тoúrwy.

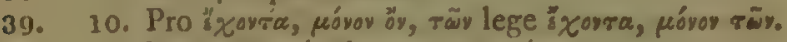

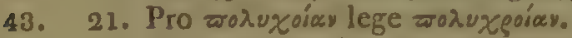

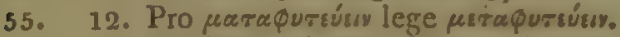

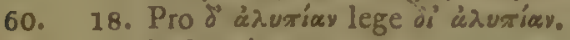

68. 15. Dele $\mu$ ńx.

79. 9. Pro ทे xù lege ทै xaí.

82. 7. Pro xiуoupúvn lege xivoupíng.

84. 27. Dele $\left[r \tilde{\omega} y\right.$ i $\left.\oint^{\prime} \omega \nu\right]$.

92. 5. Dele [raúrns].

103. 10. Dele [таи́rทv].

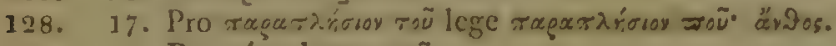

134. 13. Pro тúxท lege тขхฑิ.

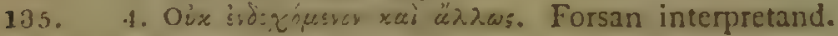

Non tamen ut fieri possit.

145. 3. Pro sủatเva lege sข̉a 9 เvit.

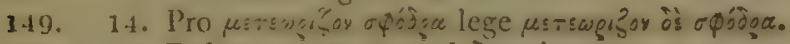

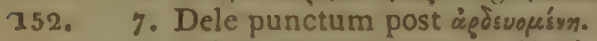

157. 9. Dele punctum post xaraṕpoprír.

161. 1. Dele punctum post pá yob.

182. 12. Pro rą̧ay lege äv\$os.

183. 5. Pro Xşávure lege Xaı̣árua.

197. 3. Pro Паутохатаїо lege Паитихатаї.

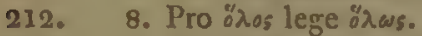

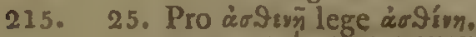

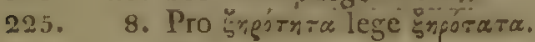

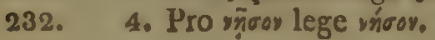




\section{ERRATA IN PARTE SECUNDA.}

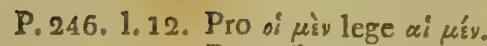

248. 21. Pro rád lege ruйra $\delta$.

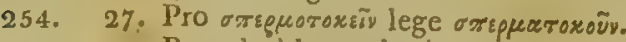

261. 17. Pro củroì lege aủroús.

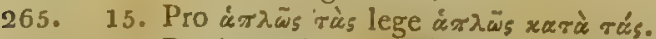

277. 2. Pro 'Paфavis lege 'Pá́quyo. Vid. not.

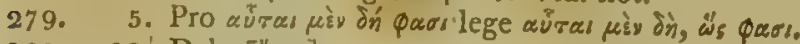

280. 12.' Dele [" $\left.\chi^{\varepsilon} \mathrm{s}\right]$.

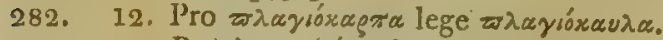

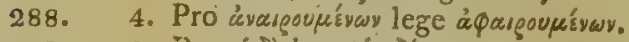

293. 2. Pro oi di lege $\omega^{\prime} \delta \dot{\delta}$.

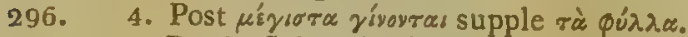

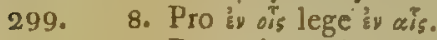

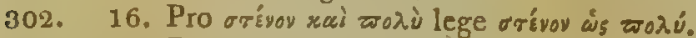

313. 27. Pro species lege speciem.

Ibid. 31. Pro Melangina lege Melongena.

319. 2. Pro reperi lege reperitur.

Ibid. 36. Pro Sirychin lege Sirychni.

326. 5. Pro ínúpay lege inulécas.

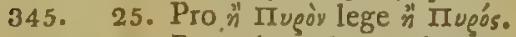

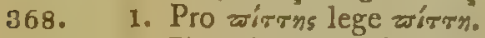

370. 10. Pro Èyíos lege syíus.

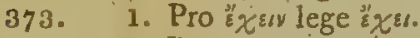

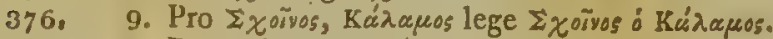

377. 7. Pro Irúas lege חúar.

381. 22. P'ro $\varepsilon i \tau^{\prime}$ lege $\varepsilon " r^{\prime}$ '.

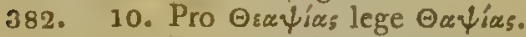

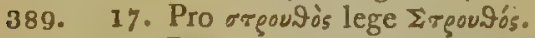

396. 5. Pro Lycoctinum lege Lycoctonum.

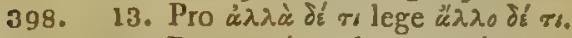

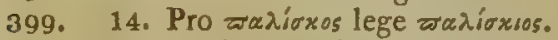

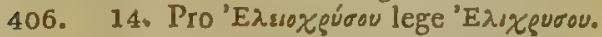

Ibid. 16. Pro 'E $\lambda$ is

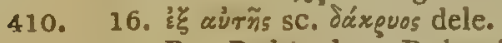

429. 6. Pro Dodona lege Dodonai.

Ibid. 14. Pro xaròs lege xudós. 

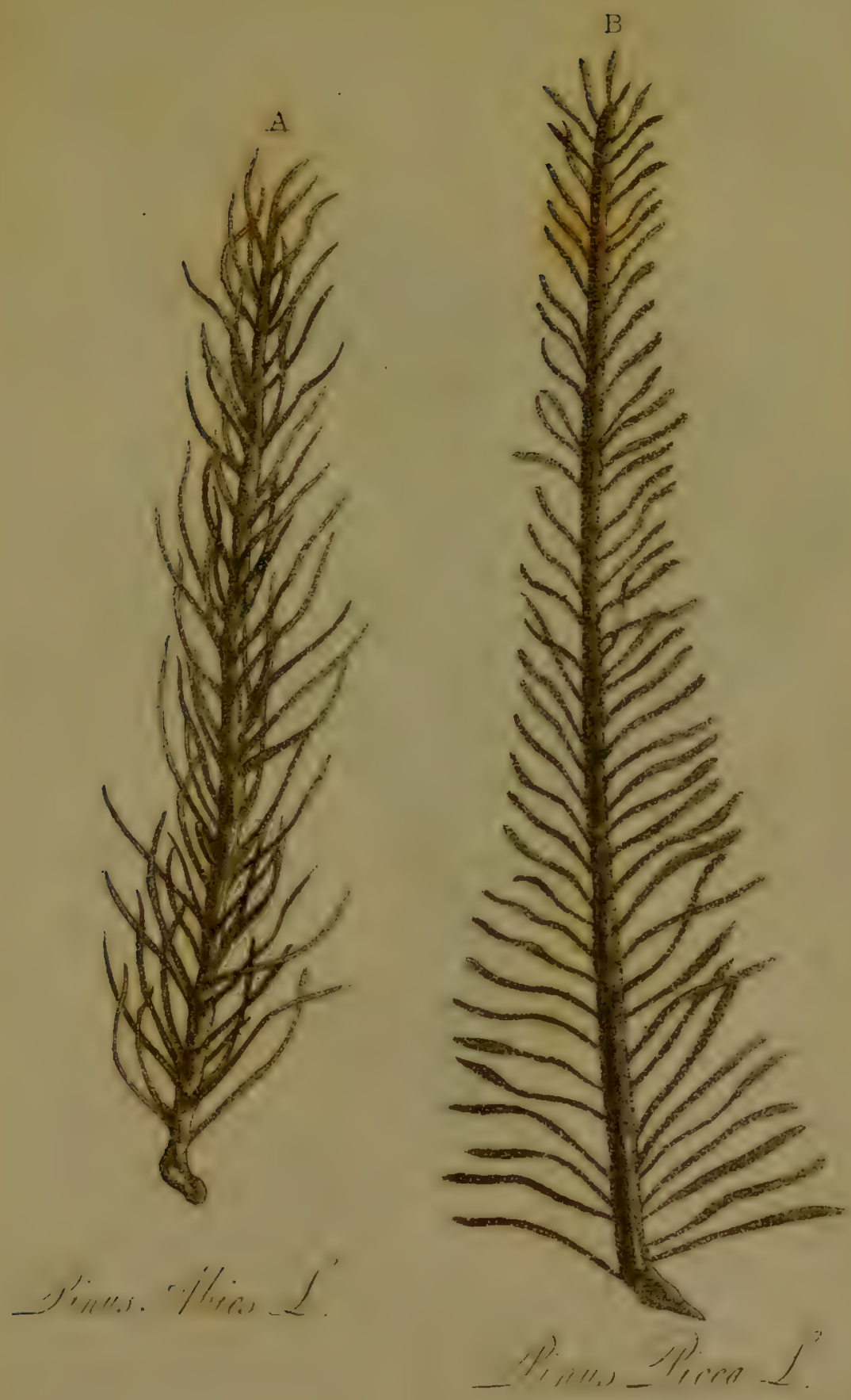



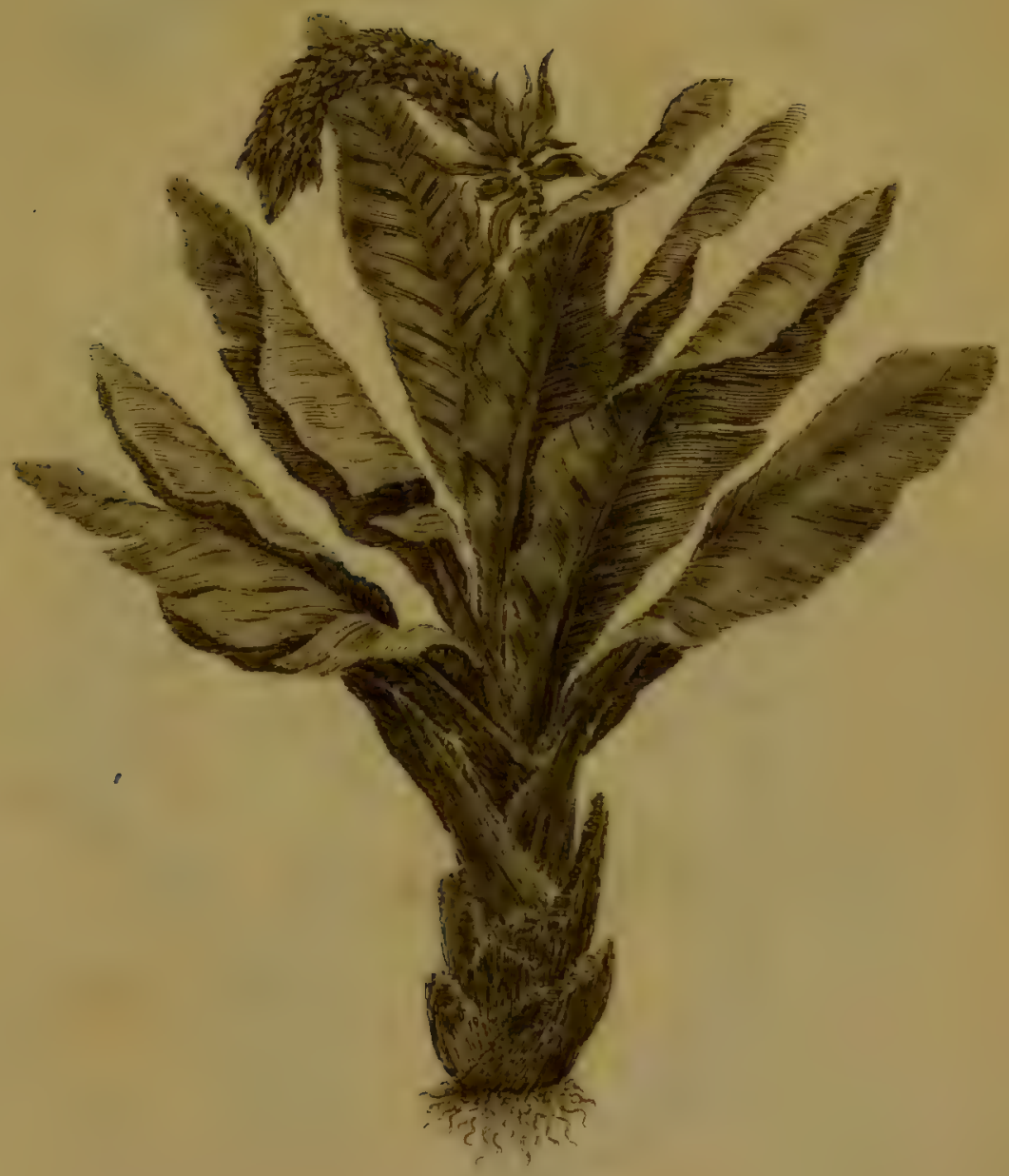




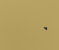

$\sqrt{2}+2$
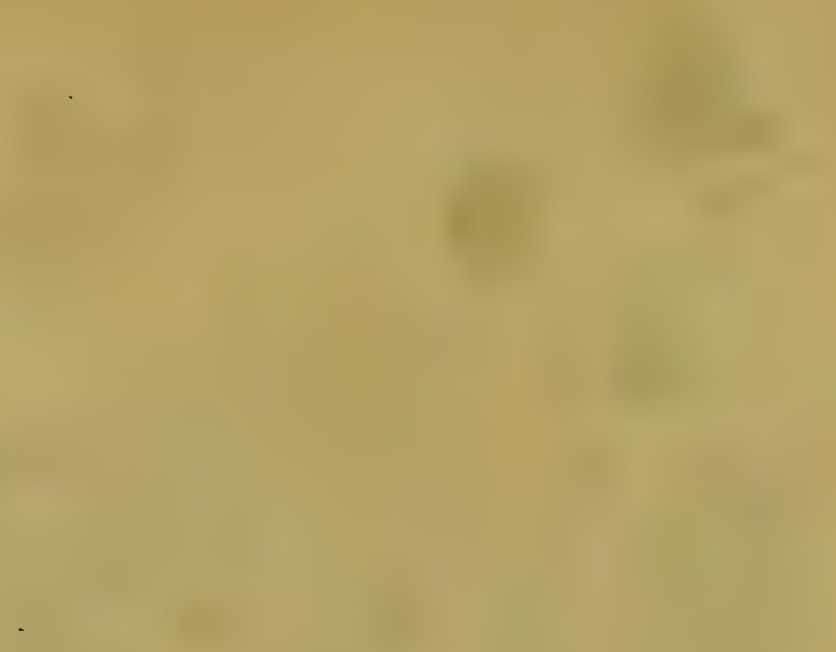

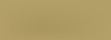

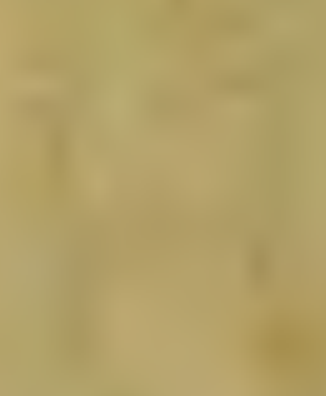

(n)

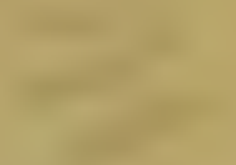

.

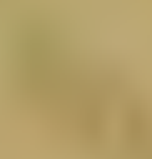

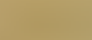


Wifie $\mathrm{B}$.

P.NT.
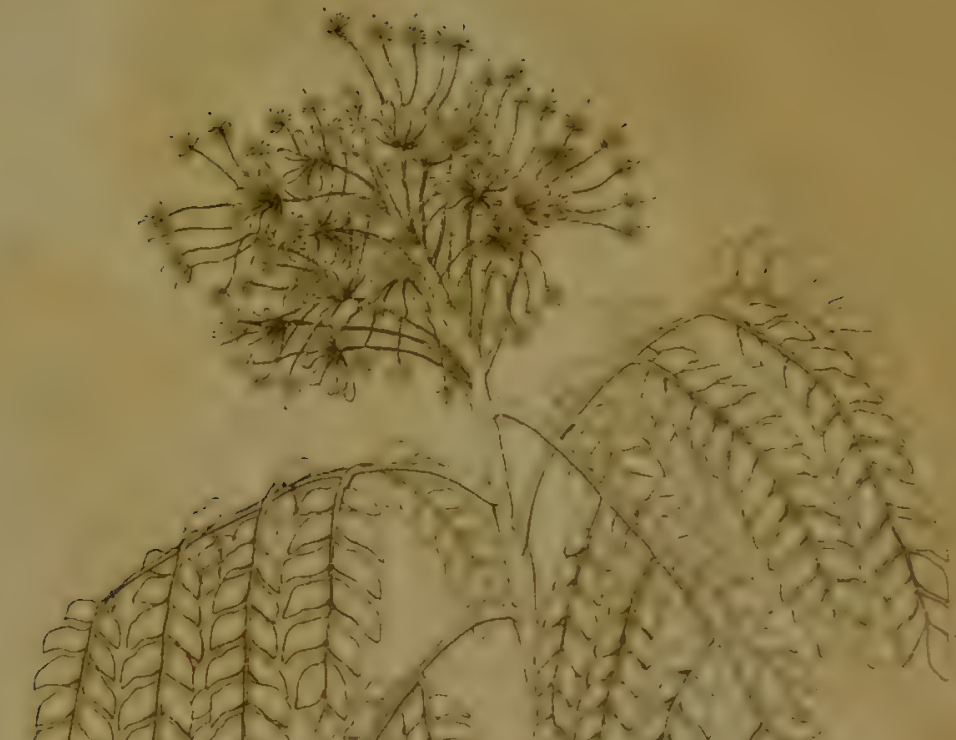

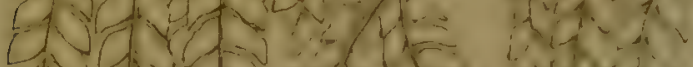

(1)

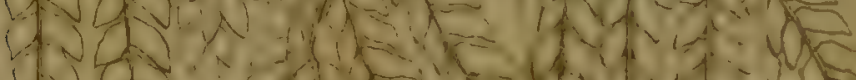

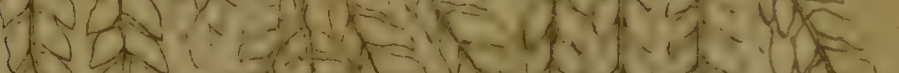

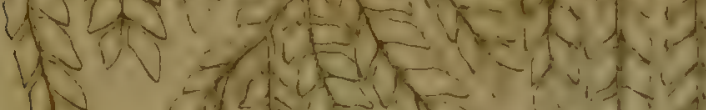
$x=\sqrt{1}$

gù

Sila

$4 x+y=5$ in:

Af

a

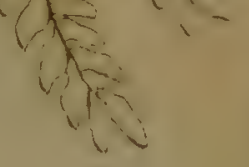

tofixce $P \leqslant 12$
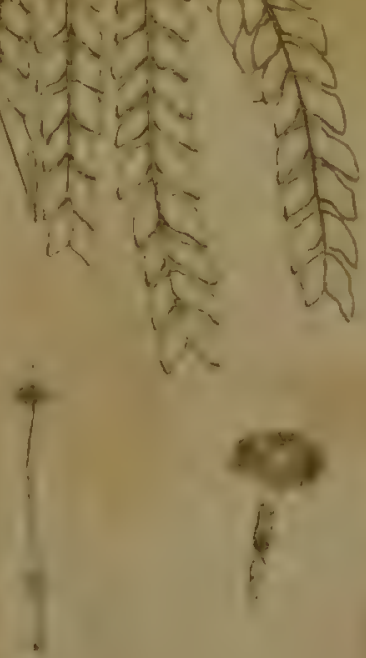






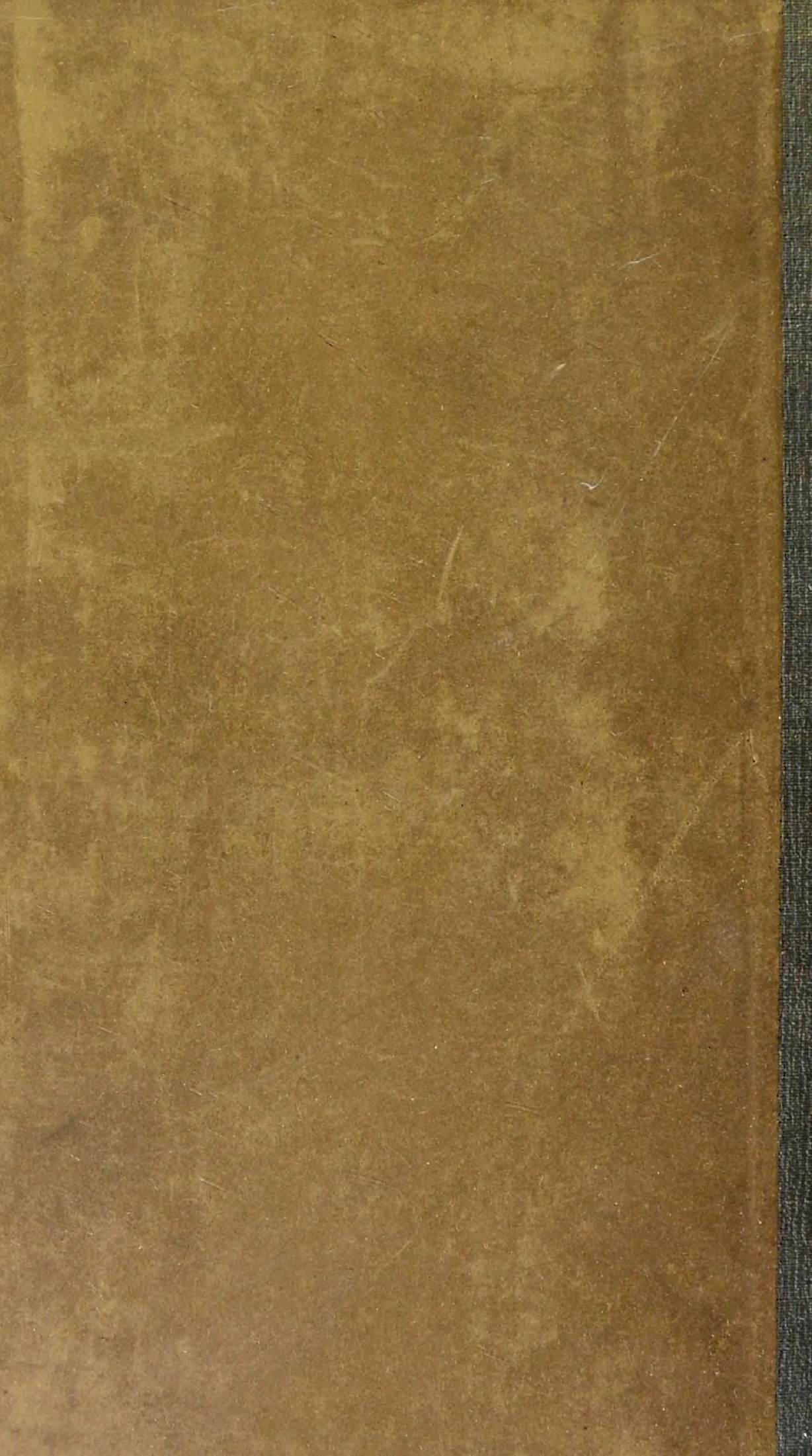

